\title{
GEOLOGY OF THE \\ SOURCE PHYSICS EXPERIMENT SITE \\ CLIMAX STOCK \\ NEVADA NATIONAL SECURITY SITE
}

March 2012

Prepared for:

U.S. Department of Energy

National Nuclear Security Administration

National Center for Nuclear Security

Prepared by:

Margaret Townsend, Lance B. Prothro, and Curtis Obi

Underground Test Area and Boreholes Programs and Operations

Environmental Restoration

National Security Technologies, LLC

Las Vegas, Nevada 


\section{DISCLAIMER}

Reference herein to any specific commercial product, process, or service by trade name, trademark, manufacturer, or otherwise, does not necessarily constitute or imply its endorsement, recommendation, or favoring by the U.S. Government or any agency thereof. 


\section{GEOLOGY OF THE \\ SOURCE PHYSICS EXPERIMENT SITE \\ CLIMAX STOCK \\ NEVADA NATIONAL SECURITY SITE}

March 2012

Prepared by:

Margaret Townsend, Lance B. Prothro, and Curtis Obi

Underground Test Area and Boreholes Programs and Operations

Environmental Restoration

National Security Technologies, LLC

Las Vegas, Nevada 
This page intentionally left blank. 


\section{Abstract}

A test bed for a series of chemical explosives tests known as Source Physics Experiments (SPE) was constructed in granitic rock of the Climax stock, in northern Yucca Flat at the Nevada National Security Site in 2010-2011. These tests are sponsored by the U.S. Department of Energy, National Nuclear Security Administration's National Center for Nuclear Security. The test series is designed to study the generation and propagation of seismic waves, and will provide data that will improve the predictive capability of calculational models for detecting and characterizing underground explosions. Abundant geologic data are available for the area, primarily as a result of studies performed in conjunction with the three underground nuclear tests conducted in the Climax granite in the 1960s and a few later studies of various types.

The SPE test bed was constructed at an elevation of approximately 1,524 meters (m), and consists of a 91.4-centimeter $(\mathrm{cm})$ diameter source hole at its center, surrounded by two rings of three 20.3-cm diameter instrument holes. The inner ring of holes is positioned $10 \mathrm{~m}$ away from the source hole, and the outer ring of holes is positioned $20 \mathrm{~m}$ from the source hole. An initial 160-m deep core hole was drilled at the location of the source hole that provided information on the geology of the site and rock samples for later laboratory testing. A suite of geophysical logs was run in the core hole and all six instruments holes to obtain matrix and fracture properties.

Detailed information on the character and density of fractures encountered was obtained from the borehole image logs run in the holes. A total of 2,488 fractures were identified in the seven boreholes, and these were ranked into six categories (0 through 5 ) on the basis of their degree of openness and continuity. The analysis presented here considered only the higher-ranked fractures (ranks 2 through 5), of which there were 1,215 (approximately 49 percent of all fractures identified from borehole image logs). The fractures were grouped into sets based on their orientation. The most ubiquitous fracture set (50 percent of all higher-ranked fractures) is a group of low-angle fractures (dips 0 to 30 degrees). Fractures with dips of 60 to 90 degrees account for 38 percent of high-ranked fractures, and the remaining 12 percent are fractures with moderate dips (30 to 60 degrees). The higher-angle fractures are further subdivided into three sets based on their dip direction: fractures of Set 1 dip to the north-northeast, fractures of Set 2 dip to the south-southwest, and Set 3 consists of high-angle fractures that dip to the southeast and strike northeast. The low-angle fractures (Set 4) dip eastward. Fracture frequency does not appear to change substantially with depth. True fracture spacing averages 0.9 to $1.2 \mathrm{~m}$ for high-angle Sets 1, 2, and 3, and $0.6 \mathrm{~m}$ for Set 4 . Two significant faults were observed in the core, centered at the depths of 25.3 and $32.3 \mathrm{~m}$. The upper of these two faults dips 80 degrees to the north-northeast and, thus, is related to the Set- 1 fractures. The lower fault dips 79 degrees to the south-southwest and is related to SPE Set-2 fractures. Neither fault has an identifiable surface trace.

Groundwater was encountered in all holes drilled on the SPE test bed, and the fluid level averaged about 15.2 to $18.3 \mathrm{~m}$ below ground surface. An informal study of variations in the fluid level in the holes conducted during various phases of construction of the test bed concluded that groundwater flow through the fractured granitic rocks is not uniform, and appears to be controlled by variations in the orientation and degree of interconnectedness of the fractures. It may also be possible that an aplite dike or quartz vein may be present in the test bed, which could act as a barrier to groundwater flow and, thus, could account for anisotropy seen in the groundwater recovery measurements. 
This page intentionally left blank. 


\section{Table of Contents}

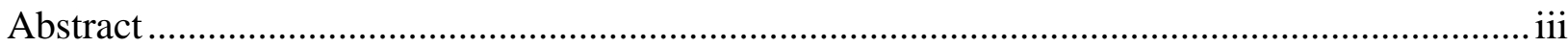

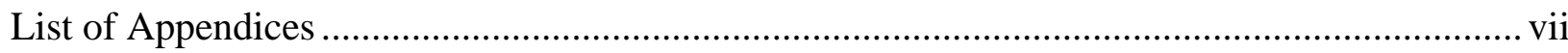

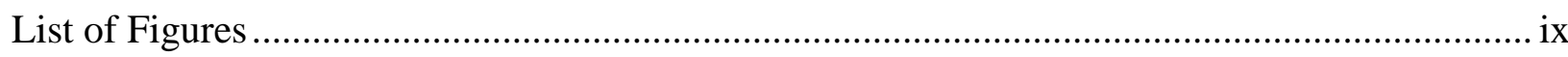

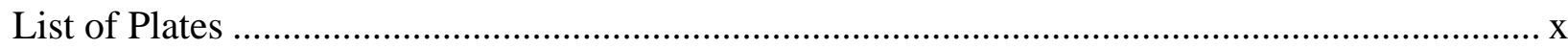

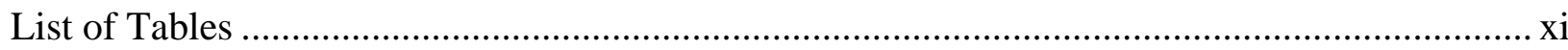

List of Acronyms and Abbreviations .......................................................................................

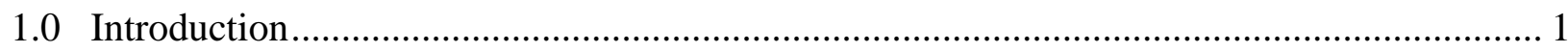

1.1 Site Selection................................................................................................... 1

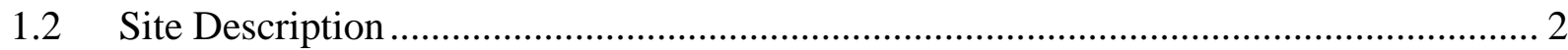

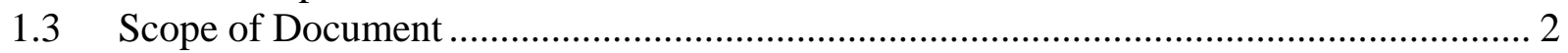

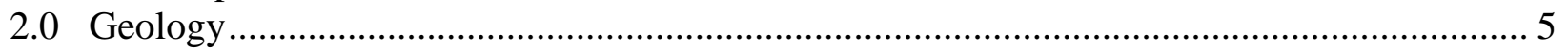

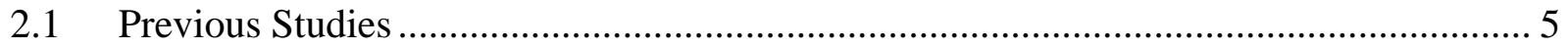

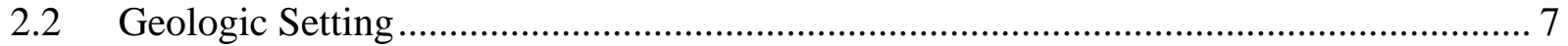

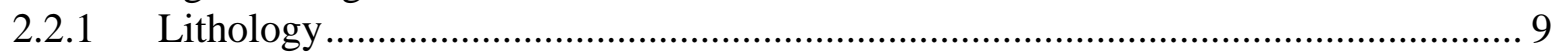

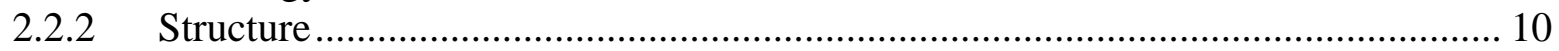

2.2.3 Weathering ............................................................................................................. 12

3.0 Geologic Characterization Data for the SPE ………………….................................... 17

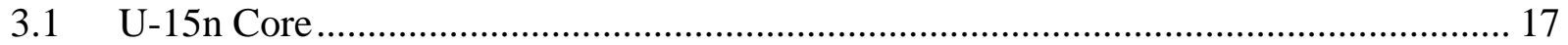

3.2 Borehole Geophysical Logs ............................................................................... 17

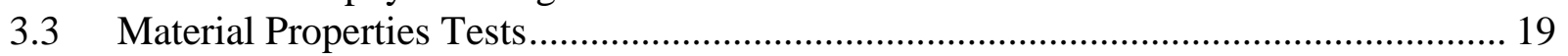

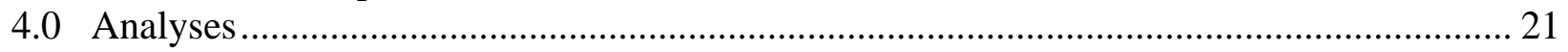

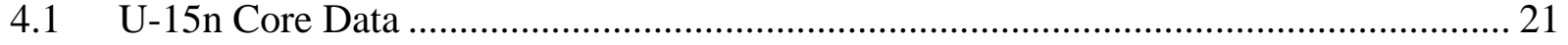

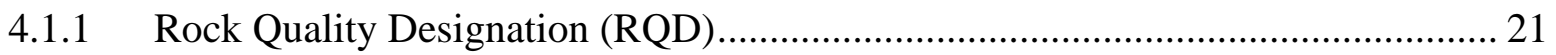

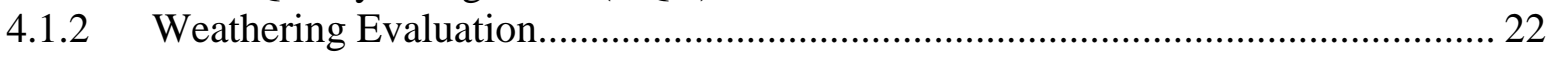

4.1.3 Evaluation of Velocity Data from the U-15n Core Hole ....................................... 26

4.1.4 Fracture Logging......................................................................................... 28

4.2 Fracture Data from Borehole Image Logs................................................................ 30

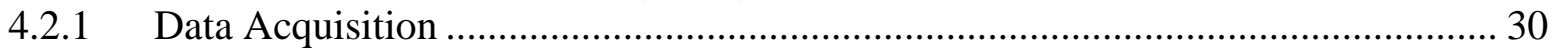

4.2.2 Fracture Analysis ............................................................................................ 34

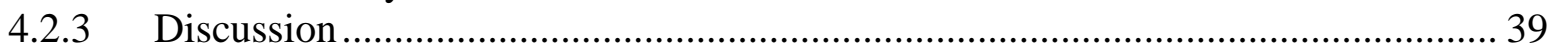

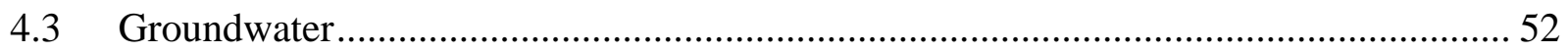

4.3.1 Information about Groundwater at the SPE Site.................................................... 52

4.3.2 Description of Investigation.................................................................................. 53

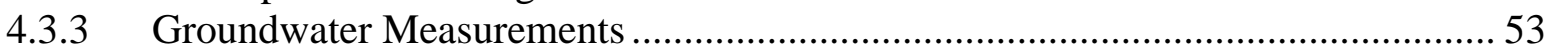

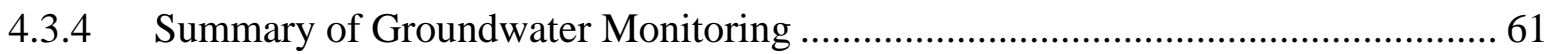

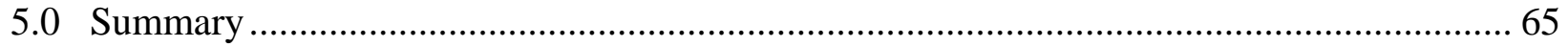

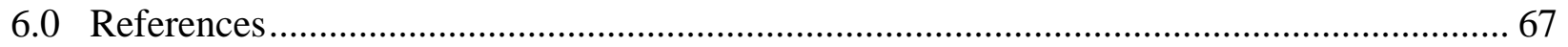


This page intentionally left blank. 


\section{List of Appendices}

A Site Selection for Source Physics Experiment in Granite at the Nevada Test Site (NSTec, 2010)

B Drilling Narratives for the U15n Source Physics Experiment

C Daily Rig Operations Reports for U15n Source Physics Experiment (provided on accompanying compact disk (CD) only [not printed])

C-1: Core Hole

C-2: 36-Inch-Diameter Source Hole

C-3: 8-Inch-Diameter Instrument Holes

D Survey Data and Borehole Deviation Data for Source Physics Experiment Holes

E Data for U-15n Core Hole

E-1: Rock Quality Designation (RQD) Data for the U-15n Core Hole

E-2: List of Preserved Samples from the U-15n Core Hole

E-3: Fracture Log for the U-15n Core Hole (from visual examination)

F Borehole Geophysical Log Plots by Colog, Inc., Source Physics Experiment Holes (provided on accompanying CD only [not printed])

F-1: U-15n Core Hole

F-2: Instrument Hole U-15n\#1

F-3: Instrument Hole U-15n\#2

F-4: Instrument Hole U-15n\#3

F-5: Instrument Hole U-15n\#4

F-6: Instrument Hole U-15n\#5

F-7: Instrument Hole U-15n\#6

G Phase 1 Mechanical Testing Results on Core from Borehole U-15n, Nevada National Security Site, in Support of NCNS Source Physics Experiment (Broome and Pfeifle, 2011)

$\mathrm{H}$ Measurements of Compressional Velocity Made on Behalf of the Defense Threat Reduction Agency Interagency Geotechnical Assessment Team (IGAT) on Samples from the U-15n Core Hole

I Projected Extent of Two Faults Encountered in Core Hole U-15n (NSTec, 2011a)

J Fracture Data Tabulated from Borehole Image Logs by Colog, Inc., U-15n Source Physics Experiment Holes(provided on accompanying CD only [not printed])

J-1: U-15n Core Hole

J-2: Instrument Hole U-15n\#1

J-3: Instrument Hole U-15n\#2

J-4: Instrument Hole U-15n\#3

J-5: Instrument Hole U-15n\#4

J-6: Instrument Hole U-15n\#5

J-7: Instrument Hole U-15n\#6

K Information Regarding Weathering at the U15n Source Physics Experiment Site

L Water in the SPE Holes (Townsend, 2010) 
This page intentionally left blank. 


\section{List of Figures}

1 Map of Climax Stock Area Showing Three Potential Sites Considered for Location of

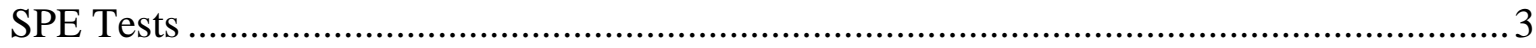

2 Map of Source Physics Experiment Site in Southern Portion of Climax Stock 4

3 Map Showing Layout of Drifts Constructed for the Three Nuclear Tests Conducted at

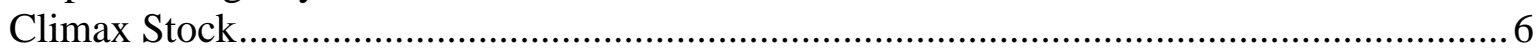

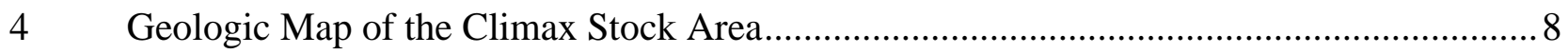

5 Geologic Map of the Climax Stock Showing Locations of Drill Holes for which

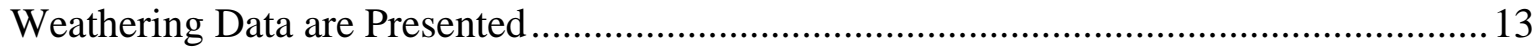

6 Photographs of Selected Intervals from the U-15n Core Hole ....................................... 18

$7 \quad$ Plot of RQD Data versus Depth for the U-15n Core Hole ..............................................21

8 Examples of Resistivity and Velocity Logs from the U-15n Core Hole ..........................23

9a Plots of Gamma, Caliper, and Density Logs Obtained by Colog in Instrument Holes

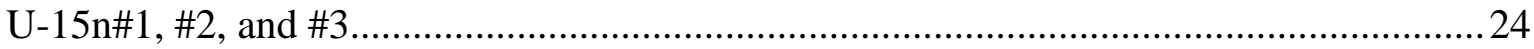

9b Plots of Gamma, Caliper, and Density Logs Obtained by Colog in Instrument Holes U-15n\#4, \#5, and \#6.

10 Plots of Shear Velocity (left) and Compressional Velocity (right) for the U-15n Core Hole

11 Plots of Shear Velocity (left) and Compressional Velocty (right) Measured in Instrument Holes U-15n\#1, \#2, \#3, \#4, \#5, and \#6 by Colog ........................................................ 29

12 Photographs of Core from U-15n Showing the Two Main Fault Zones.............................30

13 Example of Colog's Interpreted Image Log Data from Instrument Hole U-15n\#6............32

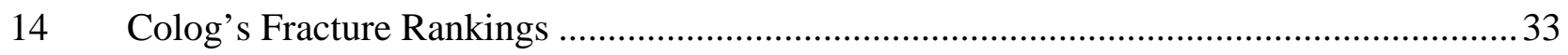

15 Stereonet Plot of All Fractures Identifed in SPE Drill Holes ..........................................35

16 Dip Magnitude Histogram (top) and Stereonet Plot of Fractures with Rankings 2 through 5 Identified by Colog in the SPE Drill Holes.... .36

17 Dip Direction Histogram (top) and Rose Diagram (bottom) of High-Angle Fractures in All SPE Drill Holes, Showing the Three Main High-Angle Fracture Sets Identified by Dip Direction

18 Dip Direction Rose Diagram of Low-Angle Fractures in All SPE Drill Holes ..................38

19 Plots of Cumulative Number of Fractures versus Depth for the SPE Site.........................38

20 Rose Diagram Map of the SPE Site Showing Dip Directions of the Three Main HighAngle Fracture Sets (Rankings 2-5) in each of the Seven Holes

21 Rose Diagram Map of the SPE Site Showing the Dip Directions of Set 4 (Low-Angle) Fractures in each of the Seven Holes

22 Photographs of Fractures Exposed West of the SPE Drill Pad. 


\section{List of Figures (continued)}

23 Photograph of Quartz Monzonite Exposure West of the SPE Site Showing Fracture Sets.43

24 Portion of the Surface Geologic Map of the Climax Stock (Houser and Poole, 1960) Showing Locations of the SPE Site and Nearby Fracture Set Measurements.....

25 Dip Magnitude Histograms Comparing Fractures Observed in SPE Drill Holes with Fracture Sets Observed in Outcrop

26 Dip Direction Rose Diagrams Comparing Low-Angle Fractures Identified at the SPE Site with Low-Angle Fracture Sets Observed in Outcrop 46

27 Bi-Directional Rose Diagrams Comparing the Strikes of High-Angle Fractures Observed within SPE Holes with High-Angle Fracture Sets Observed in Outcrop

28 Bi-Directional Rose Diagram of the Strikes of Fractures Observed in the Tunnel Workings at Climax Stock

29 Stereonet Diagram of the Orientations of Surface Fracture Sets Plotted with Respect to Lithology

30 Plot of Number of High-Angle Fractures per Foot in Core Hole U-15n ....

31 Portion of Geologic Map of Climax Stock (Houser and Poole, 1960) Showing Location of SPE Site

32 Groundwater Elevation Contour Maps for December 23 and 28, 2010, and January 6, 2011

33 Groundwater Elevation Contour Maps for January 19 and 26, 2011, and February 3 and 9, 2011.

34 Groundwater Elevation Contour Maps for February 11, 17, and 24, 2011.

35 Groundwater Elevation Contour Maps for March 21, April 7, and April 14, 2011

\section{List of Plates}

1 Houser, F. N., and F. G. Poole, 1960. "Preliminary Geologic Map of the Climax Stock and Vicinity, Nye County, Nevada.” U.S. Geological Survey, Miscellaneous Geologic Investigations Map I-328. Washington, D.C. (provided on accompanying CD only [not printed])

2 Barnes, H., F. N. Houser, and F. G. Poole, 1963. “Geologic Map of the Oak Spring Quadrangle, Nye County, Nevada.” U.S. Geological Survey Map GQ-214. Scale: 1:24,000. Washington, D.C. (provided on accompanying CD only [not printed]) 


\section{List of Tables}

1 Average Chemical Composition of Quartz Monzonite and Granodiorite from Climax

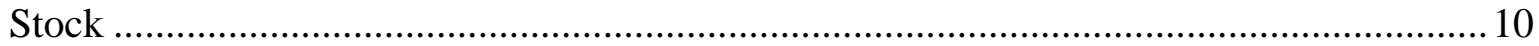

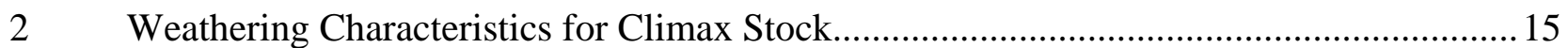

3 List of Samples from the U-15n Core Hole Selected for Material Property Testing by SNL, and Petrographic Characterization by LANL .............................................................2 20

$4 \quad$ Fluid-Level Measurements Made in SPE Drill Holes from December 2010 through April 2011 ............................................................................................................ 55 
This page intentionally left blank. 


\section{List of Acronyms and Abbreviations}

CD compact disk

cm centimeter(s)

DTRA Defense Threat Reduction Agency

$\mathrm{ft} \quad$ foot (feet)

IGAT Interagency Geotechnical Assessment Team

in. inch(es)

ISRM International Society of Rock Mechanics

Kgd granodiorite

$\mathrm{km} / \mathrm{s} \quad$ kilometer(s) per second

Kqm quartz monzonite

LANL Los Alamos National Laboratory

LLNL Lawrence Livermore National Laboratory

m meter(s)

$\mathrm{mm} \quad$ millimeter(s)

$\mathrm{MzPg} \quad$ Mesozoic granodiorite

$\mathrm{MzPq} \quad$ Mesozoic quartz monzonite

NCNS National Center for Nuclear Security

NSTec National Security Technologies, LLC

P-wave Compressional wave

RQD Rock Quality Designation

SGZ surface ground zero

SME subject matter expert

SNL Sandia National Laboratories

SPE Source Physics Experiment

S-wave Shear wave

TD total depth

Tkg Tertiary granodiorite

Tkq Tertiary quartz monzonite

UGT underground nuclear test

UGTA Underground Test Area

USBR U.S. Bureau of Reclamation

USGS U.S. Geological Survey

WP working point 
This page intentionally left blank. 


\section{Geology of the Source Physics Experiment Site, Climax Stock Nevada National Security Site}

\subsection{Introduction}

The National Center for Nuclear Security (NCNS) has been established at the Nevada National Security Site (NNSS; formerly Nevada Test Site) by the U.S. Department of Energy, National Nuclear Security Administration. The NCNS is conducting a variety of studies that are designed to increase the understanding of certain basic physical phenomena associated with underground explosions and to develop technologies that might be used detect underground nuclear explosions in support of verification activities for the Comprehensive Test Ban Treaty.

The initial NCNS project consists of conducting a series of explosive tests, known collectively as the Source Physics Experiment (SPE), in granitic rocks at the Climax stock in northern Yucca Flat at the NNSS. The SPE test series is specifically designed to study the generation and propagation of seismic waves. Los Alamos National Laboratory (LANL), Lawrence Livermore National Laboratory (LLNL), Sandia National Laboratories, (SNL), and the Defense Threat Reduction Agency (DTRA), in conjunction with National Security Technologies, LLC (NSTec), the Management and Operations contractor at the NNSS, are designing and conducting these tests, and will use the data obtained to improve the predictive capability of their calculational models for detecting and characterizing underground explosions. The first SPE test was conducted in May 2011, and a second was conducted in October 2011; additional tests at this site are planned.

A variety of geologic data, described in this report, were acquired from the site by NSTec to provide input to the calculational modelers. This report was prepared by geologists of the NSTec Underground Test Area (UGTA)/Boreholes Programs and Operations group.

\subsection{Site Selection}

In February 2010, subject matter experts (SMEs; representatives from NSTec, LANL, LLNL, and SNL) for the proposed SPE tests developed preliminary criteria for selecting a site in the Climax granitic body, pending further development of the experiment design. These preliminary requirements included:

- "Homogeneous” granite, with surface weathered zone as thin as possible

- No obvious faults in the area, though it was recognized that there would be fractures, even in the unweathered granite at depth

- Avoid lithologic contacts, including the contact between the quartz monzonite (Kqm; also Tkq or MzPq on various maps) and the granodiorite (Kgd; also Tkg or MzPg) that make up the Climax stock (preference for quartz monzonite or granodiorite was not specified)

- Position as close as feasible to existing roads and other infrastructure

- Keep appropriate distance from the surface ground zeros of the three underground nuclear tests (UGTs) conducted in the Climax stock 
- Other criteria were based on expected hole depth and distance to instrument holes, as determining factors in the size of the site.

NSTec geologists selected three locations as potential sites at the Climax stock for the SPE. The report prepared to present information about these locations is provided in Appendix A (NSTec, 2010). The SME group selected the southernmost site (Site \#1 on Figure 1), which is closest to the access road, and at which there was already a graded area and a pit that could serve as a mudpit for drilling.

\subsection{Site Description}

The SPE test bed was constructed on a drill pad that is located approximately 347 meters (m) $(1,140$ feet [ft]) south-southwest of the U15a headframe. The pad is located on a southeastdipping slope, at an elevation of approximately 1,524 $\mathrm{m}(5,000 \mathrm{ft})$. The test bed was designed to consist of a 36-inch (in.) diameter source hole at its center, surrounded by six 8-in. diameter instrument holes arranged in two rings of three (Figure 2). The drilling plan included an initial core hole at the location of the Source Hole that would provide information on the geology of the site and rock samples for later laboratory testing.

All holes were drilled to depths ranging from 57.9 to $60.7 \mathrm{~m}$ (190 to $199 \mathrm{ft}$ ). The instrument

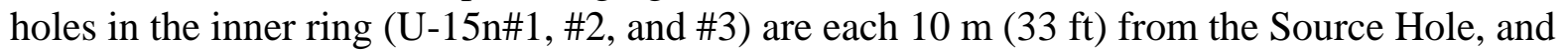
positioned 120 degrees apart. The instrument holes in the outer ring (U-15n\#4, \#5, and \#6) are each $20 \mathrm{~m}$ (66 ft) from the Source Hole and staggered so that they are 60 degrees off the positions of the holes in the inner ring. The placement of the instrument holes was determined from the position of a hole in the outer ring (U-15n\#4), whose location was selected to be on a line from the U-15n Source Hole to U16b Tunnel, approximately 24.6 kilometers (15.3 miles) away (coincident with one of the planned geophone lines). Instrument Hole U-15n\#1 was

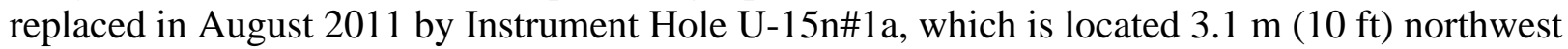
of hole U-15n\#1. U-15n\#1a and other holes planned for the site will be described in a future report.

See Appendix B for detailed information about the construction of the holes at the SPE site.

\subsection{Scope of Document}

This document presents geologic data collected in support of the first two SPE tests. Much of this information, mainly concerning the fracture characteristics, was provided to the calculational modelers in preliminary form as it was acquired, but it is compiled here in one source document for easy reference. Also included here is a discussion of information obtained about the perched groundwater encountered at the SPE site. This document also includes additional background geologic information for the Climax stock area summarized from previous work conducted at the stock in support of historical underground nuclear testing and other projects.

Appendices A through L are included to provide detailed information on the construction of the SPE test bed, data obtained from logging of core and geophysical borehole logging, and various supporting information relevant to the understanding of the geologic characteristics of the SPE site. Appendices C, F, and J were not printed, but are included on the compact disk (CD) attached to this report. 


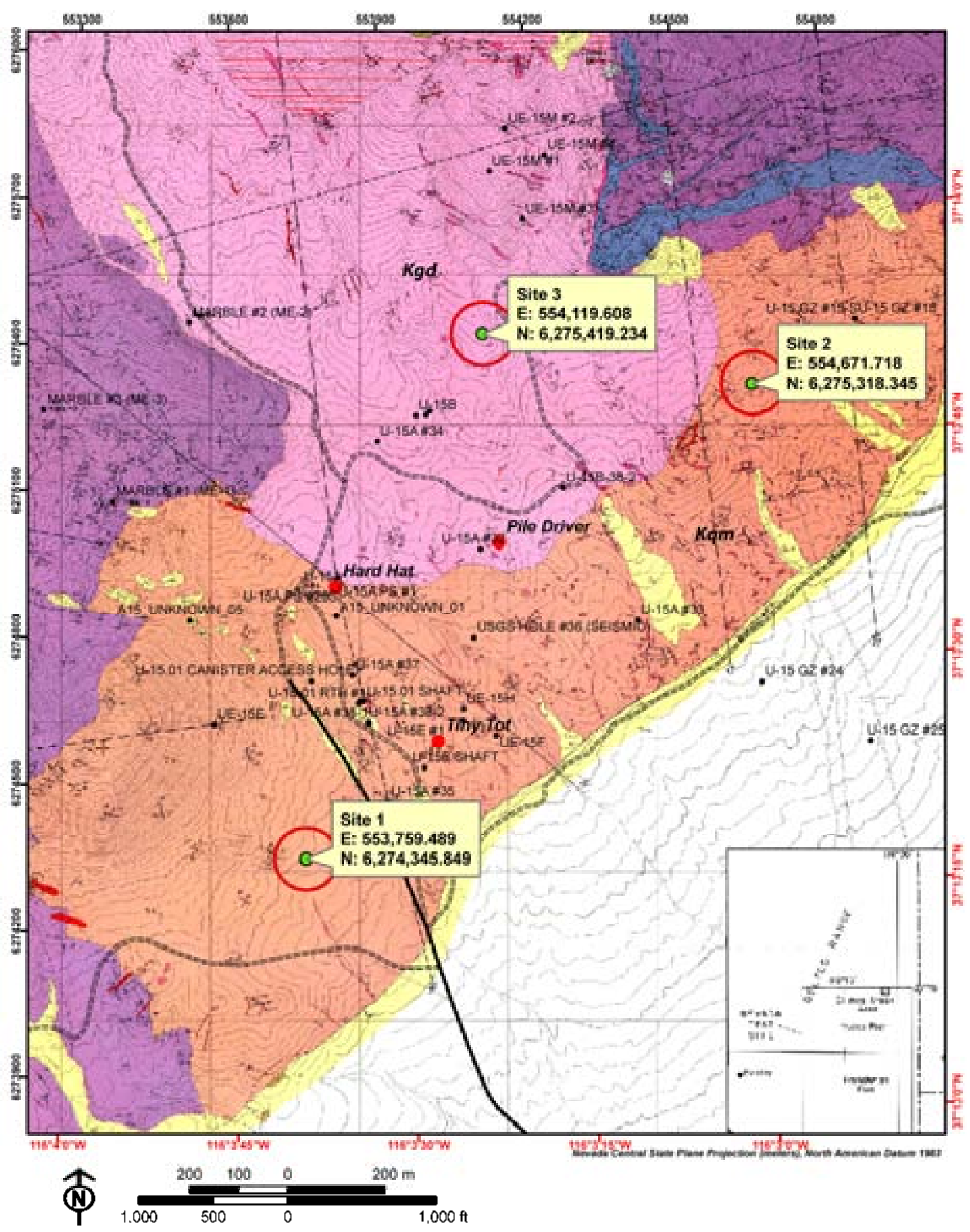

Figure 1

Map of Climax Stock Area Showing Three Potential Sites Considered for Location of SPE Tests

Red dots mark locations of underground nuclear tests.

Geology is from Houser and Poole, 1960, See full map with legend in Plate 1. 


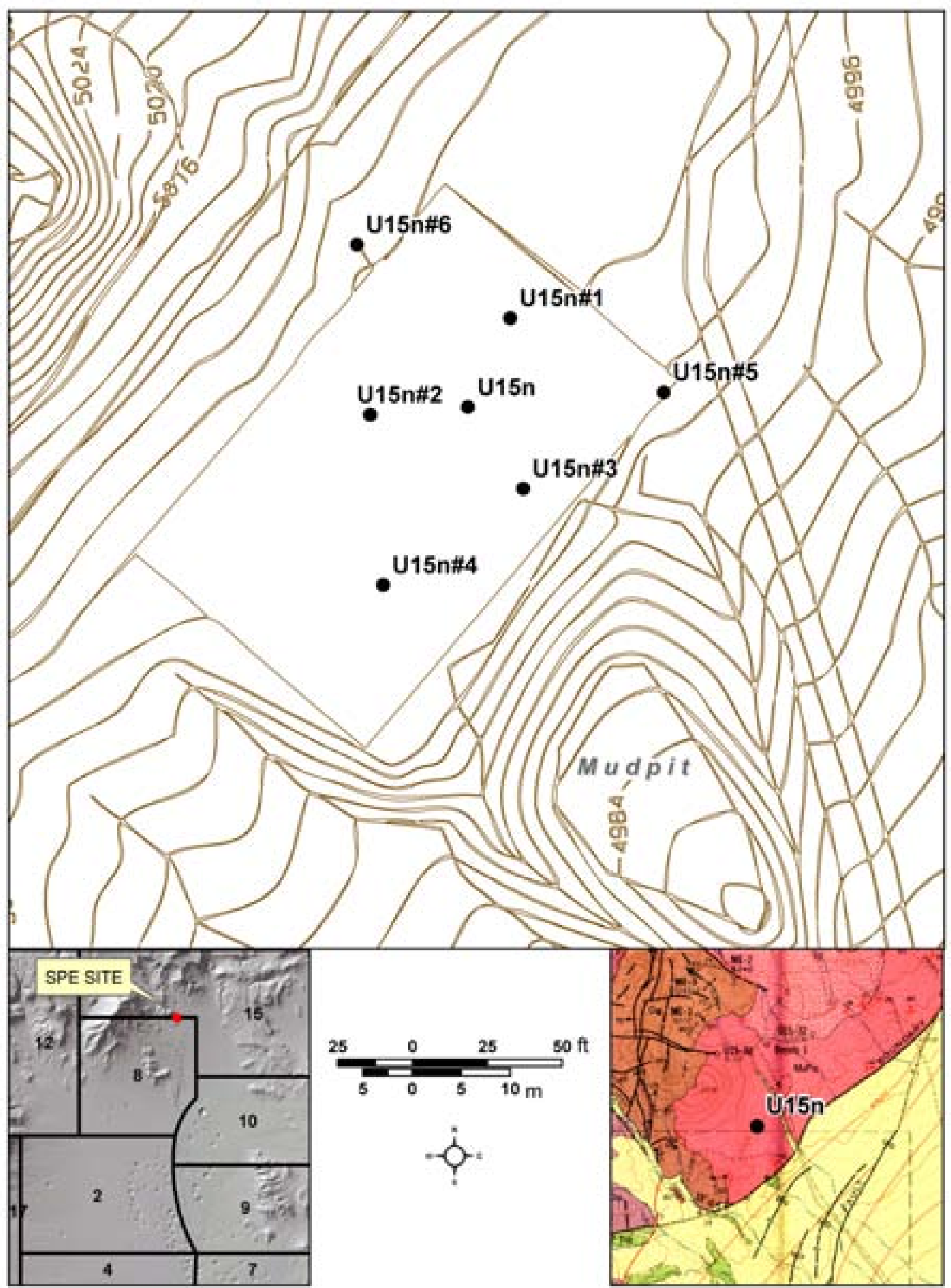

Figure 2

Map of Source Physics Experiment Site in Southern Portion of Climax Stock (Inset at lower right shows geology from Barnes et al., 1963. See full map with legend in Plate 2) 


\subsection{Geology}

The Climax stock was selected as the site of the first set of SPE tests because its granite lithology provides a relatively "homogenous" medium and because, as the site of three historical UGTs, abundant geologic, seismic, and ground shock data are available for comparison to expected SPE test data.

The Climax stock, located in the northeast corner of the NNSS, in Area 15, is largest of three exposed granitic masses at the NNSS (Slate et al., 1999). The U.S. Geological Survey (USGS) has published three geologic maps that include the area of the stock (Houser and Poole, 1960; Barnes et al., 1963; Sargent and Orkild, 1973). The stock has been extensively characterized in support of the three UGTs conducted there, the LLNL Spent Fuel Test, and several proposed projects. At least three summary reports have been written, in which basic physical and geologic properties, including fracture data, are provided (Maldonado, 1977; Orkild, et al., 1983; Blouin et al., 2003).

\subsection{Previous Studies}

Most earlier geologic studies at Climax stock were concerned primarily with the character of the granite body at the depths of the nuclear test working points, which ranged from $110.9 \mathrm{~m} \mathrm{(364 \textrm {ft } )}$ (U15e, TINY TOT) to $293.5 \mathrm{~m}$ (963 ft) (U15a, HARD HAT) to $416.7 \mathrm{~m}$ (1,367 ft) (U15a.01, PILE DRIVER) (Figure 3). The earliest geologic studies were conducted by the USGS and the Lawrence Radiation Laboratory (now LLNL) in support of these tests; SNL and the U.S. Army Corps of Engineers Waterways Experiment Station also conducted numerous supporting studies.

Characterization, ground motion, and structural response data for HARD HAT and PILE DRIVER, conducted in 1962 and 1966, respectively, were compiled in support of the DTRA Hard Rock Data Review in 2002 (DTRA, 2003). As part of that effort, all existing geotechnical, seismic, and response data were reviewed and evaluated in the attempt to develop a database of granite properties and response regarding nuclear explosions.

The earliest studies were conducted on the "Granite" exploratory hole (also known as U-15a\#31), which was drilled from the surface at the site of the U-15a HARD HAT emplacement hole. Other studies included surface geologic mapping (Houser and Poole, 1960; Barnes et al., 1963), chemical and petrographic studies (e.g., Houser and Poole, 1959; McArthur and Misz, 1960), measurements of material properties on samples from drill holes and tunnel workings (Houser and Poole, 1959), aeromagnetic surveys to determine the general configuration of the stock (Allingham and Zietz, 1962), and determination of the age relations of the two lithologies (granodiorite and quartz monzonite) that make up the body (Houser and Poole, 1961). Naiser and Maldonado (1981) reported fission-track dating on samples from Climax stock.

Most of the HARD HAT, PILE DRIVER, and TINY TOT drifts were mapped in detail (discussed in various papers compiled in DTRA [2003] and in Cording [1967]), and numerous core holes were drilled and sampled to characterize the granite test beds before and after the tests (chimney delineation, etc.). 


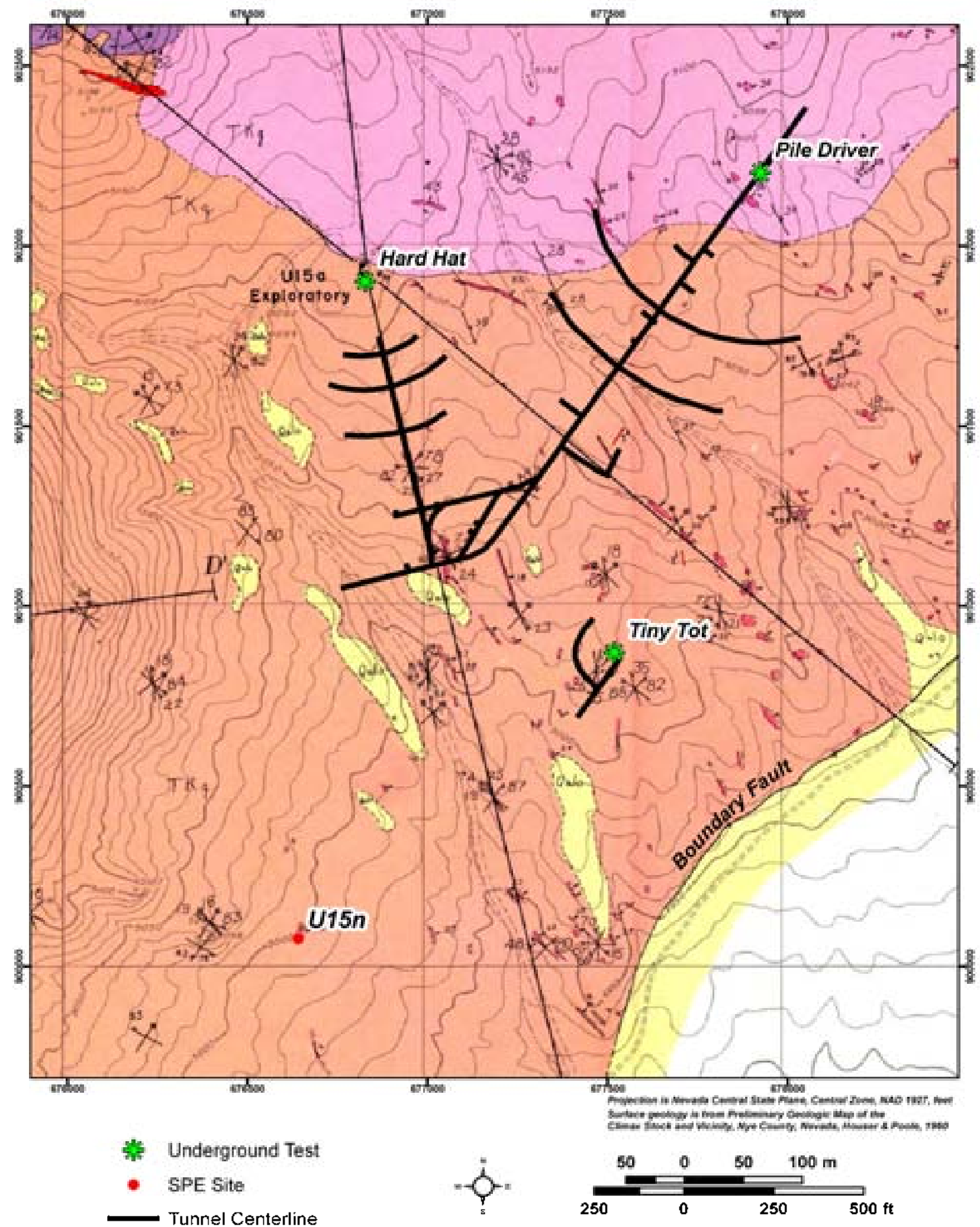

Figure 3

Map Showing Layout of Drifts Constructed for the Three Nuclear Tests Conducted at Climax Stock

All drifts not at same elevation. See Houser and Poole (1960), presented as Plate 1, for explanation of surface geology notations. 
To explore the feasibility of using granitic rock for the underground storage of spent nuclear reactor fuel, in the late 1970s, LLNL constructed a test bed near the shaft station at the PILE DRIVER level, which consisted of three parallel drifts and several core holes. LLNL mapped the geologic structure of the drifts, logged the core in detail, and conducted many physical and chemical studies on samples. A large body of data from this effort is available in the literature, including a report on the structural geology of the site (Wilder and Yow, 1984).

In the early 1980s, the USGS conducted studies at the request of the Defense Nuclear Agency (now DTRA) to update the understanding of the geometry of the Climax stock. They conducted comprehensive magnetic and gravity measurements, including a new aerial magnetic survey. In addition, they conducted field mapping and trenching to improve the understanding of the three main faults that define the stock structurally. A comprehensive report of these studies, which includes a summary of previous work, was published by the USGS (Orkild et al., 1983). In 2004, the USGS (Phelps et al., 2004) reevaluated the body of gravity and magnetic data for the region using more modern analytical tools to update again the understanding of the configuration of the stock for groundwater modeling studies.

In 1996, four core holes were drilled for the Defense Special Weapons Agency (now DTRA) at a

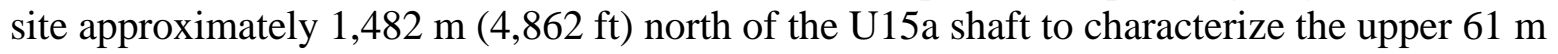
(200 ft) of the granodiorite for a proposed tunneling project. The degree and depth of weathering at this site and other locations at the Climax stock were evaluated by Shellum (1996) as part of this investigation, as described in Section 2.2.3.

The U.S. Department of Energy, National Nuclear Security Administration Nevada Site Office UGTA Sub-Project constructed a three-dimensional hydrostratigraphic framework model for the Yucca Flat-Climax Mine Corrective Action Unit in support of the Nevada Environmental Restoration Project at the NNSS. All available geologic and geophysical data from drill holes and surface geophysical surveys were incorporated into the model, using EarthVision as the platform. The construction of this model, which includes all of Yucca Flat as well as Climax stock, is documented in Bechtel Nevada (2006), and an electronic version of the model has been made available to various entities that are tasked with modeling data from the SPE. In addition, the Desert Research Institute developed a hydrogeologic flow model for the Climax stock in support of the UGTA Sub-Project (Pohlmann et al., 2007) that includes an appendix in which are compiled all fracture data available for the underground workings at the stock.

\subsection{Geologic Setting}

This section provides a summary of the geology of the Climax stock, taken primarily from the sources mentioned above.

The Climax stock is a composite granitic intrusive of Cretaceous age, composed of quartz monzonite and granodiorite, which intrudes sedimentary rocks of Paleozoic and Precambrian age (Figure 4). The granite body is exposed at the base of Oak Spring Butte, in extreme northern Yucca Flat. The surface exposure of the stock is approximately 2.4 square kilometers (0.93 square miles) in area, and large areas are eroded pediment surface with scattered outcrops protruding above it. Tertiary volcanic rocks, consisting of ash-flow and ash-fall tuffs, overlie portions of the pre-Tertiary sedimentary rocks and the stock. 


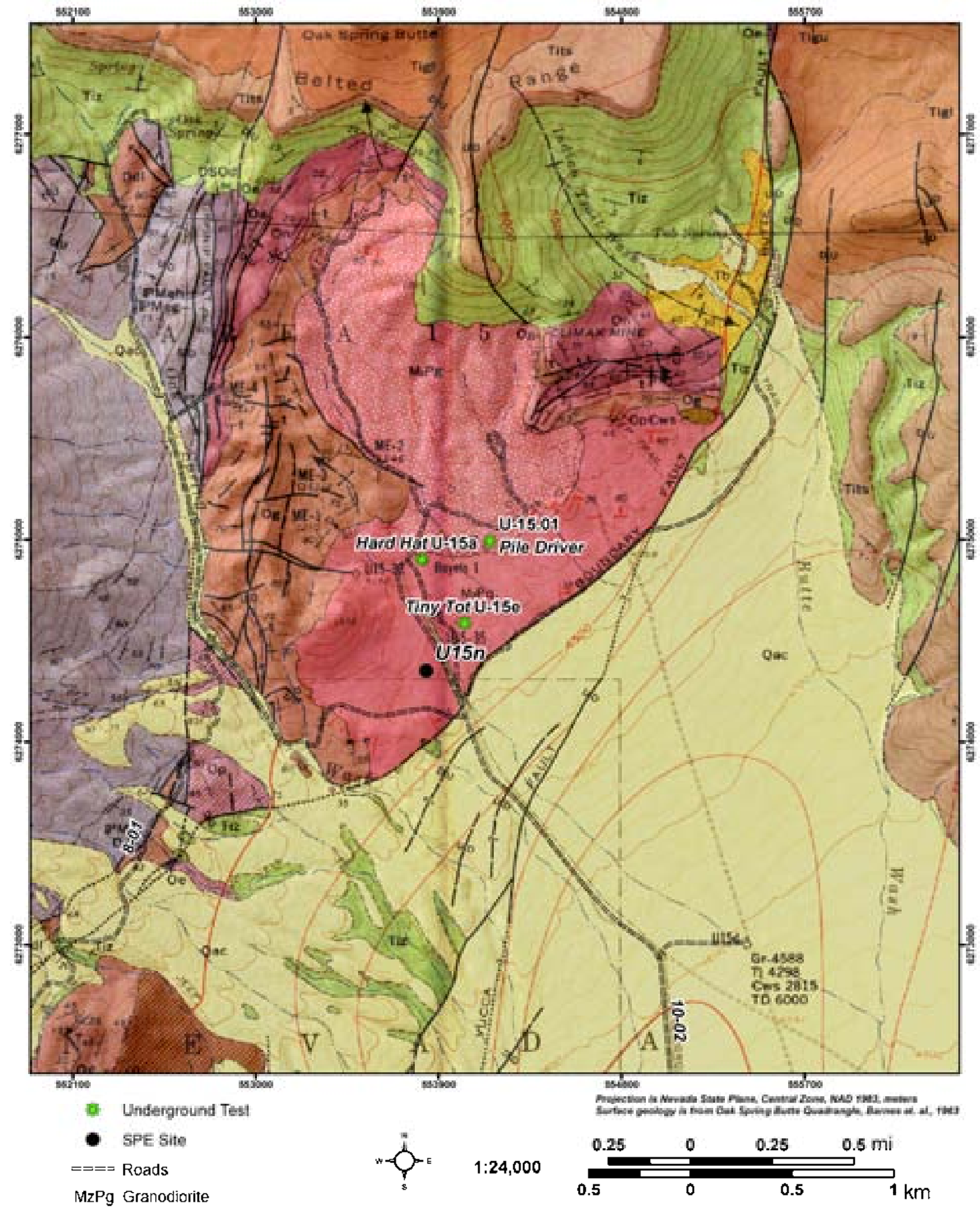

Figure 4

Geologic Map of the Climax Stock Area

Geology is from Barnes et al. (1963). See full map with legend in Plate 2. 
Three major faults define the structure of the Climax area, the Tippinip fault on the west and the Boundary and Yucca faults on the east and south. The SPE site is located approximately $245 \mathrm{~m}$ (800 ft) northwest, at closest approach, from the Boundary fault, which separates the surface exposure of the granitic rocks from the alluvium of the Yucca Flat basin. The Boundary fault dips steeply to the southeast, and offset on it is inferred from gravity data to be approximately $245 \mathrm{~m}$ (800 ft) down to the east near the SPE site. The offset apparently decreases to the northeast along the fault trace, as it approaches the junction with the Yucca fault to become the Butte fault (Orkild et al., 1983). The last movement is thought to have occurred approximately 10,000 years ago (Orkild et al., 1983).

The granitic rocks at Climax stock produce a strong magnetic anomaly that has been measured by ground and aerial magnetic surveys to help to define the gross configuration of the buried intrusive body. In addition, gravity studies have improved the understanding of the three-dimensional character of the site. However, little or no density contrast is discernible between Paleozoic sedimentary rocks that surround the stock and the intrusive igneous rocks of the stock itself, making interpretation of gravity data difficult. Detailed discussions of some of these geophysical studies at the Climax site can be found in Orkild et al. (1983) and Phelps et al. (2004), among others.

\subsubsection{Lithology}

As described by Orkild et al. (1983), the stock is composed of an older, medium-grained, equigranular granodiorite and a slightly younger, medium-grained, coarsely porphyritic quartz monzonite. Various age-dating studies have yielded ages of approximately 100 million years. Orkild et al. (1983) describe the granodiorite as light-gray to medium greenish-gray, and consisting of 28 percent quartz, 16 percent potassium feldspar, 45 percent plagioclase feldspar, and 9 percent biotite. The average grain size is about 2 millimeters $(\mathrm{mm})$, but the phenocrysts can range from 0.5 to $4.0 \mathrm{~mm}$. Accessory minerals, mainly apatite, sphene, opaque iron oxides and zircon, constitute 1 to 2 percent of the rock. The quartz monzonite is porphyritic, light- to medium-gray, and consists of approximately 28 percent quartz, 25 percent potassium feldspar, 40 percent plagioclase, and 6 percent biotite. The potassium feldspar phenocrysts are as large as 15 centimeters $(\mathrm{cm})$ in length and average $5 \mathrm{~cm}$ in length. The chemical compositions of the two granitic rock types are similar, as shown in Table 1.

The contact between the granodiorite and the quartz monzonite is generally near vertical, but it is highly irregular, with mutually penetrating fingers of each rock type. There is no glassy, chilled zone in either rock type. At one exposure of the interface in the U15a.01 PILE DRIVER workings, an isolated pocket of altered, clayey material was encountered (Merritt, 2003).

Dikes and sills, ranging in texture from aplitic (fine grained) to pegmatitic (coarsely crystalline), were mapped by Houser and Poole (1960) throughout the exposure. Extensive areas of silicification were also mapped, primarily in the granodiorite north of the SPE site. The surface exposures of both types of granite are weathered to depths ranging from about 7.6 to $38.1 \mathrm{~m}$ (25 to $125 \mathrm{ft}$ ). 
Table 1

Average Chemical Composition of Quartz Monzonite and Granodiorite from Climax Stock

\begin{tabular}{|l|c|c||}
\hline & $\begin{array}{c}\text { Quartz Monzonite } \\
\text { (24 samples) }\end{array}$ & $\begin{array}{c}\text { Granodiorite } \\
\text { (24 samples) }\end{array}$ \\
\hline \hline $\mathrm{SiO}_{2}$ & 69.1 & 67.6 \\
\hline $\mathrm{Al}_{2} \mathrm{O}_{3}$ & 15.8 & 15.8 \\
\hline $\mathrm{Fe}_{2} \mathrm{O}_{3}$ & 1.5 & 1.8 \\
\hline $\mathrm{FeO}$ & 1.3 & 1.6 \\
\hline $\mathrm{MgO}$ & 0.6 & 0.82 \\
\hline $\mathrm{CaO}$ & 3.2 & 3.7 \\
\hline $\mathrm{Na} \mathrm{O}_{2}$ & 3.0 & 3.1 \\
\hline $\mathrm{K}_{2} \mathrm{O}$ & 3.9 & 3.5 \\
\hline $\mathrm{H}_{2} \mathrm{O}$ & 0.89 & 1.0 \\
\hline $\mathrm{TiO}_{2}$ & 0.40 & 0.39 \\
\hline $\mathrm{P}_{2} \mathrm{O}_{5}$ & 0.21 & 0.18 \\
\hline $\mathrm{MnO}$ & 0.04 & 0.07 \\
\hline $\mathrm{CO}_{2}$ & 0.10 & 0.20 \\
\hline
\end{tabular}

From Maldonado (1977).

All values given in weight percent.

Orkild et al. (1983) note that hydrothermal alteration of the granitic rocks produced widespread but localized argillic alteration of the plagioclase feldspar and chloritic alteration of biotite. They also state that quartz and secondary minerals, such as clay minerals, sericite, feldspar, and calcite can occur in veinlets, while pyrite, chalcopyrite, limonite, and manganese, are present as fillings along joints. Most joints display some degree of mineralization and/or alteration. Quartz veinlets are widespread throughout the stock and in the surrounding Paleozoic sedimentary rocks.

The Paleozoic limestone and dolomite adjacent to the stock have been thermally and metasomatically altered to marble and tactite as much as $457 \mathrm{~m}(1,500 \mathrm{ft})$ from the contact, and minor discontinuous metasomatic effects are noted in all rocks out to a distance of $914 \mathrm{~m}$ $(3,000 \mathrm{ft})$ from the contact. Tactite mineralogy consists of garnet, quartz, epidote, chlorite, limonite, calcite, and idocrase. Small amounts of the tungsten minerals sheelite and powellite were mined on the northeast edge of the stock (the original “Climax Mine”) in 1941.

\subsubsection{Structure}

The Climax stock can be said to be moderately to highly fractured, but no faults are shown on surface geologic maps of the stock. Various sources of information about fractures mapped in the workings of drifts constructed for the U15a (HARD HAT) and U15a.01 (PILE DRIVER) tests (summarized by Borg [1970] and by Wilder and Yow [1984]) and in the U15e TINY TOT workings (reported by Cording [1967]) indicate that most of the individual fractures do not persist more than a few meters, though a few more continuous faults with significant damage zones were encountered. Some of the larger faults encountered in the underground workings of the Climax stock are described here. Brief descriptions of fracture sets described in various early 
sources are also provided. See Section 4.2 of this report for more discussion of fractures encountered at the SPE site.

\subsubsection{Faults}

Reference has been found to only one fault encountered in the U15.01 HARD HAT drifts. This fault was parallel to the planned location of one of the radial test drifts in the HARD HAT workings, and the damage zone associated with the fault caused that drift to be abandoned for the purpose of the test (Merritt, 2003).

The U15a.01 PILE DRIVER main drift was purposely constructed along a bearing of 035 degrees azimuth, so that it was approximately parallel to one of the main high-angle fracture sets in the Climax stock and perpendicular to the other. This was unlike the U15a HARD HAT workings, which bisected the main fracture sets, encountering both at about a 45-degree angle. Only one major normal fault ("the horsetail fault") was mapped in the PILE DRIVER workings, and was intersected in several locations. It had a strike of 020 degrees azimuth and dipped 65 degrees southeast. Another fault was encountered near the end of the main drift, and produced water for approximately 24 hours. The orientation of this fault was determined from drilling (data not found), and the decision was made to move the planned working point (WP) back

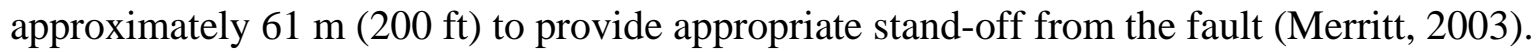

One of the larger faults found in the LLNL Spent Fuel Test Facility has a strike of about 045 degrees azimuth, and dip of 60-65 degrees southeast, with a clay gouge zone 30.5 to $40.6 \mathrm{~cm}$ (12 to 16 in.) thick (Wilder and Yow, 1984). This fault projects to the surface close to the contact of the quartz monzonite and granodiorite, and appears to be one of a series of parallel faults within the stock, though none are shown on published surface geologic maps.

Two major faults were encountered in the U15e TINY TOT drifts (Cording, 1967), constructed in quartz monzonite at the depth of $122 \mathrm{~m}$ (400 ft) below ground surface, approximately $360 \mathrm{~m}$ $(1,180 \mathrm{ft})$ northeast of the SPE site. One of these has a strike of 043 degrees azimuth and dip of 65 to 70 degrees southeast. Its damage zone varied in width from 0.3 to $2.1 \mathrm{~m}$ ( 1 to $7 \mathrm{ft}$ ) in the U15e drifts, and consisted of closely sheared and "weathered" rock with soft clay gouge 2.5 to $7.6 \mathrm{~cm}$ ( 1 to 3 in.) thick. The other fault was oriented at 330 degrees azimuth and dipped 43 degrees northeast where encountered in the drifts. This structure had a gouge zone $15.2 \mathrm{~cm}$ (6 in.) thick, consisting of soft clay and 1.3 to $2.5 \mathrm{~cm}$ (0.5 to 1 in.) of hard slickensided clay (the slicks indicated that strike-slip movement had occurred).

\subsubsection{Joints}

Maldonado (1977) compiled previously unpublished information about joints mapped by the USGS in the U15.01 PILE DRIVER main drift. This drift was driven on a bearing of approximately 035 degrees azimuth through approximately $402 \mathrm{~m}(1,320 \mathrm{ft})$ of quartz

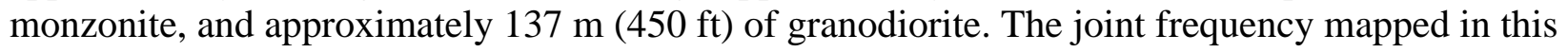
drift was approximately 0.89 joints per foot in the quartz monzonite and 0.52 joints per foot in the granodiorite. However, including joints mapped in side drifts of other orientations driven in granodiorite, little difference was noted in joint orientation or density between the two lithologies. 
As documented on the surface geologic map by Houser and Poole (1960), and described by Maldonado (1977) and by Orkild et al. (1983), three main joint sets are present at Climax stock. These have the following average orientations: a low-angle (22 degrees) set oriented 328 degrees azimuth, and two vertical sets, one oriented 296 degrees azimuth, and the other 035 degrees azimuth. In outcrop, joints are weathered and generally open. Borg (1970) notes that as many as eleven joint sets were identified in the HARD HAT drifts and nine sets were identified in the PILE DRIVER drifts, though three were considered to be the major sets. Wilder and Yow (1984) describe eight joint sets based on very detailed mapping in the three parallel drifts mined for workings of the Spent Fuel Test Facility, at the same level as the PILE DRIVER test. Of these, the three most numerous sets correspond to the three identified by Maldonado (1977) and Orkild et al. (1983). Merritt (2003) summarized the fracture data for HARD HAT and PILE DRIVER as three sets of natural joints: two with nearly vertical dips and strikes of about 306 degrees and 036 degrees azimuth, and the third with a dip of 14 to 18 degrees and (coincidentally) a strike of about 036 degrees azimuth. All of these sources note that the lowangle joint set is the most pervasive.

Cording (1967) also noted the presence of a low-angle joint system in the U15e TINY TOT drifts, with a strike of approximately 030 degrees azimuth and dip of 15 to 20 degrees to the east. Cording (1967) stated that jointing in the U15e test bed cut the rock into blocks approximately 0.15 to $0.6 \mathrm{~m}$ (6 in. to $2 \mathrm{ft}$ ) in width, and noted that limonite stains, sericite, and pyrite were present on many of the joint surfaces.

(Interesting notes: (1) Borg [1970] describes how one of the main vertical fracture sets influenced the shape of the PILE DRIVER chimney. (2) The chamber excavated for TINY TOT was designed so that the flat face of the chamber was parallel to the main northeast-trending high-angle fracture set to obtain a relatively smooth planar surface without resorting to smooth-wall or pre-split blasting techniques [Cording, 1976]).

\subsubsection{Weathering}

The depth of weathering was not well documented in the early geologic studies at the Climax stock, and few holes were cored in the upper weathered portion of the granite body that might provide this information.

During the site selection process for the U15e TINY TOT test, the degree of weathering was described for core hole UE-15f (Ege and Davis, 1965). This hole was drilled from the surface to the proposed WP location at a downward angle of approximately 43 degrees from horizontal along an azimuth designed to intersect the primary fracture sets at as high an angle as possible (Ege and Davis, 1965). In 1996, DTRA conducted some preliminary characterization studies in an area under consideration for construction of a tunnel complex. As part of this effort, Shellum (1996) and Shellum and Fisher (1996) evaluated the depth of weathering for granodiorite in an area approximately 1,482 m (4,862 ft) north of the SPE site, where four core holes (UE-15m\#1 through \#4) were drilled (Figure 5).

This section discusses methods of quantifying the degree of weathering in granite and summarizes the variability in depth of weathering in various areas of the Climax stock. 


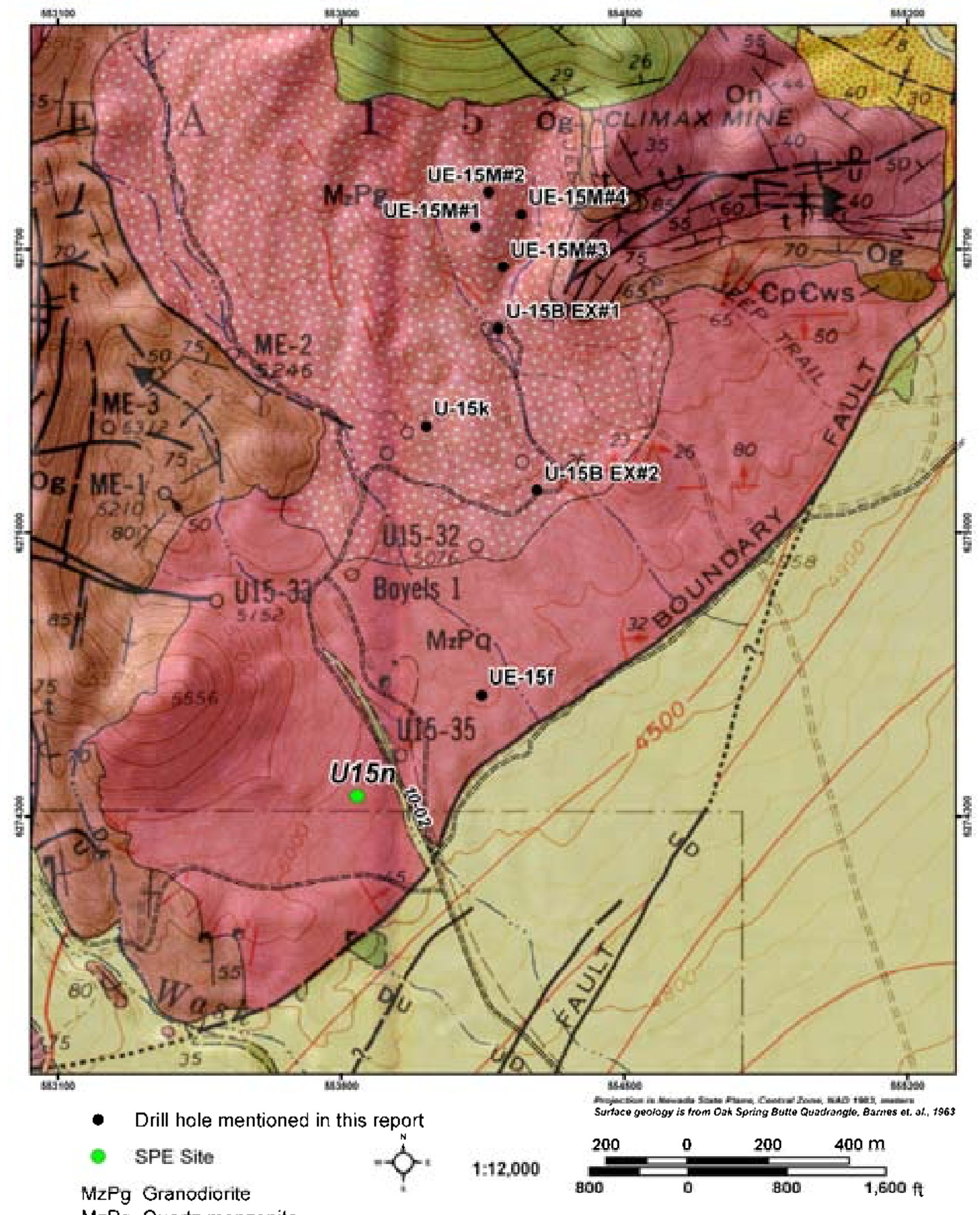

Figure 5

Geologic Map of the Climax Stock Showing Locations of Drill Holes for which Weathering Data are Presented

Open circles are other drill holes; see full map with legend in Plate 2. 


\subsubsection{General Discussion of Weathering}

The state of weathering of a rock body is an important determinant in the rock's geotechnical behavior, but weathering processes are rarely uniform enough to produce gradual or predictable alterations in the geotechnical characteristics of a rock body. Thus, weathering profiles are frequently heterogeneous, mainly due to variations in weathering rates that depend on the character of the original mass, including matrix properties, jointing, topography, and groundwater conditions. Weathering has been widely studied in a variety of rock types and terrains in support of tunneling and other construction projects and, more uniquely, in support of target-defeat efforts. The depth of weathering is also an important parameter in seismic studies.

One of the most widely accepted systems for categorizing weathering of rocks is that of the International Society of Rock Mechanics (ISRM, 1981), which defines five degrees of weathering based on visual evaluation of weakening of the matrix; fracture characteristics are not explicitly considered in the ISRM weathering categories.

The U.S. Bureau of Reclamation (USBR, 2007) also developed a system for describing weathering that is similar to the ISRM system, but it incorporates fracture characteristics. See Appendix K for more information about these two systems of describing rock weathering.

It should be noted that these systems are mainly applied to obtain estimates of geotechnical characteristics necessary for construction designs. However, they may be useful for characterizing weathering variations that affect ground shock propagation because they are so widely applied.

\subsubsection{Variability in Weathering Depth at Climax Stock}

Shellum (1996) noted that the extent of highly weathered granite at Climax stock varies from about 12 to $18 \mathrm{~m}$ ( 40 to $60 \mathrm{ft}$ ) deep in the low-lying areas of the stock, and may only be 1 to $6 \mathrm{~m}$ ( 3 to $20 \mathrm{ft}$ ) deep in the hilly portions of the area. The thickness of the highly weathered zone in the area where DTRA drilled the four UE-15m core holes varied as much as $6 \mathrm{~m}$ (20 ft) in holes located approximately $183 \mathrm{~m}$ (600 ft) apart (Shellum, 1996). Shellum (1996) also examined core from three nearby holes, U-15b Exploratory \#1, U-15b Exploratory \#2, and U-15b-GZ, as summarized in Table 2 (Figure 5). Table 2 also includes weathering estimates for the UE-15f core hole, described by NSTec geologists for comparison to the earlier studies and with the weathering observed in U-15n core. No rock consistent with definitions of highly or moderately weathered rock was seen in the UE-15f or U-15n core. See Section 4.1.2 for more discussion of weathering observed in the U-15n core. 
Table 2

Weathering Characteristics for Climax Stock

\begin{tabular}{|c|c|c|c|c|c|}
\hline $\begin{array}{c}\text { Degree of } \\
\text { Weathering }\end{array}$ & $U E-15 m \# 3^{a}$ & $\begin{array}{c}\text { U-15b } \\
\text { Expl\#1 }^{a}\end{array}$ & $\begin{array}{c}\text { U-15b } \\
\text { Expl\#2 }^{a}\end{array}$ & U-15b-Gz ${ }^{a}$ & UE-15f ${ }^{b}$ \\
\hline $\mathrm{HW}$ & $0-20$ & $0-40 ?$ & $0-50$ & $0-100$ & \\
\hline MW & $20-35$ & $40-80$ & $50-65$ & $>100$ & \\
\hline SW & $35-40$ & 80-100 & $65-80$ & & $0-100$ \\
\hline SW-F & $40-50$ & $>100$ & $80-100$ & & $>100$ \\
\hline $\mathrm{F}$ & $>50$ & & & & \\
\hline
\end{tabular}

Notes: Depths given in feet below ground surface.

$\mathrm{HW}=$ highly weathered

$\mathrm{MW}=$ moderately weathered

SW = slightly weathered

$F=$ fresh

a Source: Shellum (1996); codes refer to ISRM classification. See Appendix K for more information on the ISRM and USBR weathering categories.

b After Ege and Davis (1965), and verified by NSTec geologists; corrected to depth below ground

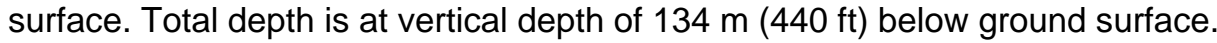


This page intentionally left blank. 


\subsection{Geologic Characterization Data for the SPE}

The SPE SME group considered it a high priority to obtain geologic data for site models being developed to improve the understanding of how ground shock travels through the medium from the explosive source to close-in and outlying accelerometers and geophones. Properties that control ground shock propagation include characteristics of the medium such as density and velocity (matrix properties), but these properties are modified in the rock mass by discontinuities, which are more difficult to characterize. It is necessary to obtain material properties of the rock mass that can be parameterized for use in ground shock propagation models.

The primary sources of geologic characterization data for the SPE site are fracture data from the U-15n core hole, material properties measurements (matrix properties and fracture properties) made on selected core samples, and borehole geophysical log data, including more detailed fracture data, from the core hole and the instrument holes.

\section{$3.1 \mathrm{U}-15 n$ Core}

The entire U-15n core hole was drilled in quartz monzonite from the bottom of the surface casing at $2.2 \mathrm{~m}(7.3 \mathrm{ft})$ to the depth of $59.9 \mathrm{~m}(196.5 \mathrm{ft})$. A total of $57.7 \mathrm{~m}(189.2 \mathrm{ft})$ was cored, and total core recovery was $57.2 \mathrm{~m}$ (187.6 ft), or 99.2 percent. The core diameter was $6.34 \mathrm{~cm}$ (2.5 in.) (“HQ” size).

Preservation of the natural water content of rock samples is important for measurement of certain material properties. Granite has low matrix porosity and thus is unlikely to lose enough moisture to affect most types of measurements. However, it was considered likely that some healed fractures could contain materials that are susceptible to drying and thus affect some planned laboratory tests, so some core samples were preserved to prevent moisture loss. The standard NNSS preservation method is to wrap fresh samples tightly in several layers of aluminum foil and coat them with unpurified beeswax (NSTec, 2011b). Geologists at the rig selected suitable samples from each drill run (minimum sound length of $15.2 \mathrm{~cm}$ [0.5 ft]; approximately 20 percent from each run), wrapped them in foil at the rig site, then sealed them in plastic. The aluminum-wrapped samples were given wax coatings at the end of each day, after they were delivered to Mercury. A list of the preserved samples is provided in Appendix E. Figure 6 shows photographs of some of the core from U-15n.

All core from the U-15n core hole was delivered to the USGS Data Center and Core Library in Mercury, Nevada. USGS personnel photographed each core box, and these photos can be found on their website at:

http://nevada.usgs.gov/imagefolio/cgi-bin/ImageFolio43/imagefolio.cgi?direct=NTS_Area15/U$\underline{15 n \& i m g=0}$

\subsection{Borehole Geophysical Logs}

Geophysical borehole logs can provide quantitative data on fundamental matrix properties such as density and velocity, and properties of discontinuities. In addition, borehole logs are used to determine hole conditions such as straightness (deviation) and rugosity. 


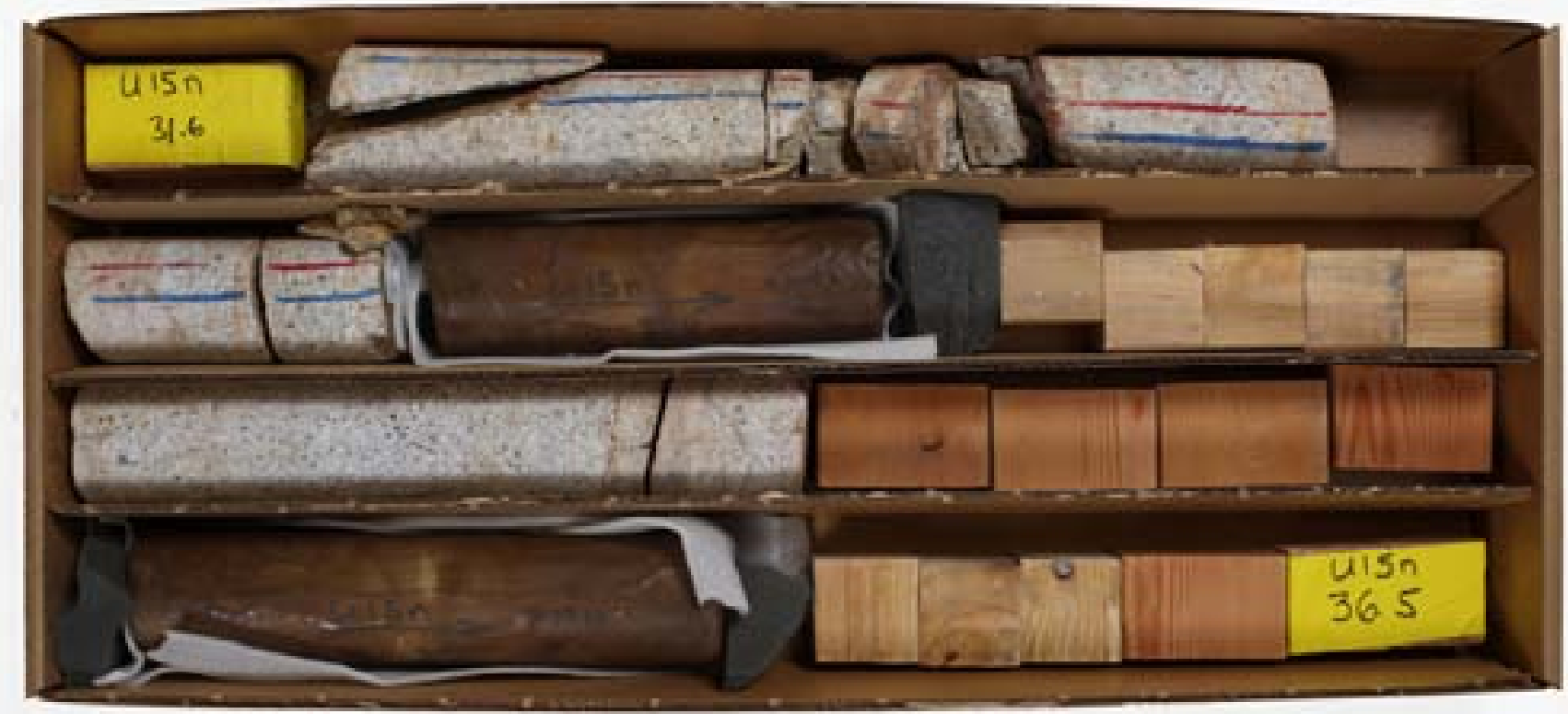

Depth interval 9.6 to $11.1 \mathrm{~m}$ (31.6 to $36.5 \mathrm{ft}$ ) below ground surface.

Brown samples are preserved in beeswax.

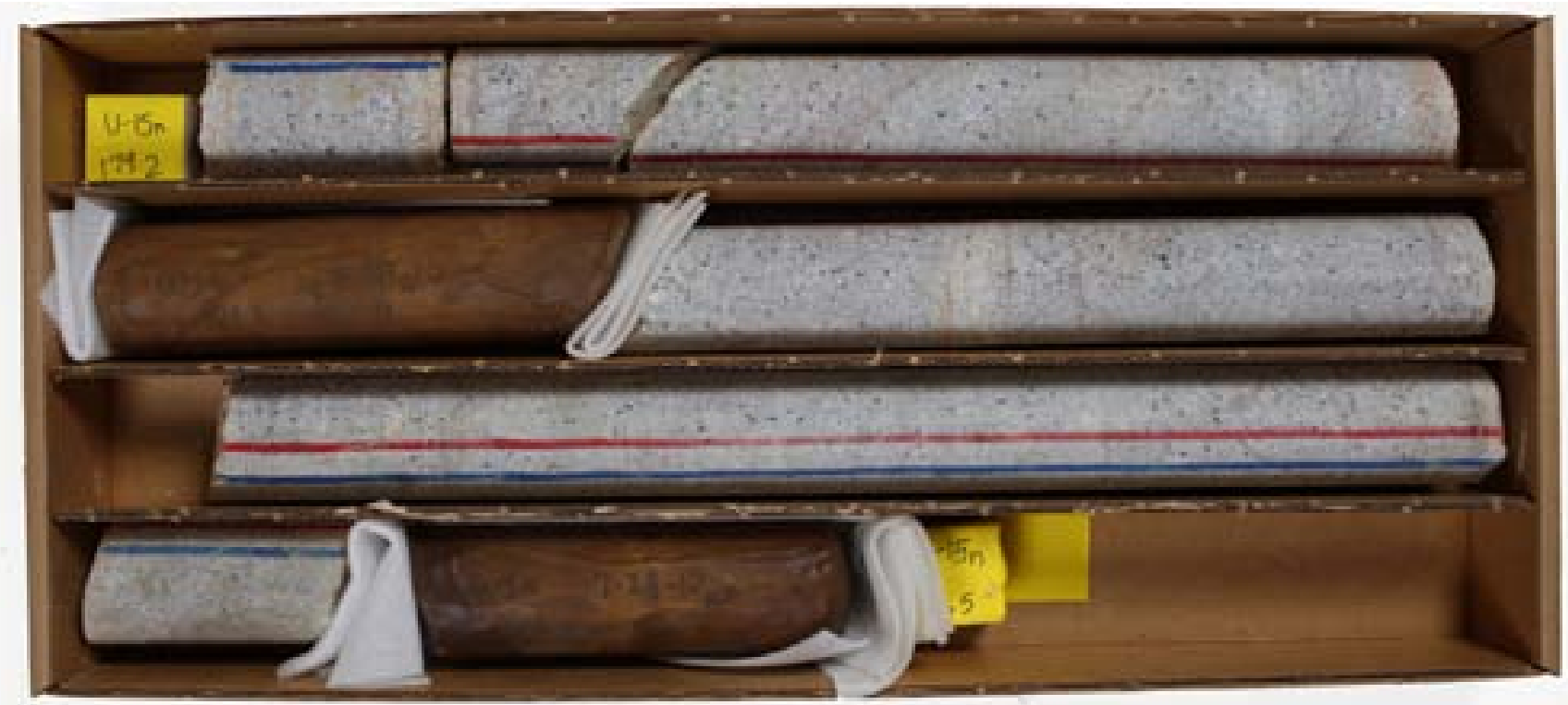

\section{initin}

Depth interval 54.6 to $56.8 \mathrm{~m}$ (179.2 to $186.5 \mathrm{ft}$ ) below ground surface

Figure 6

Photographs of Selected Intervals from the U-15n Core Hole

(Photos by U.S. Geological Survey, September 13, 2010) 
The SME group selected the following logs to be run in the U-15n core hole:

- Caliper

- Deviation

- Density

- Natural Gamma

- Resistivity

- Full-wave Sonic/Travel Time

- Televiewer

The NSTec subcontractor Colog (a division of Layne Christensen Company) ran the logs listed below (some logging tools are run simultaneously because they are connected together on the same string). The geophysical log plots from the core hole are illustrated in Appendix F (on accompanying $\mathrm{CD}$ ); paper plots and the digital log data were provided to the modelers.

- Caliper

- Deviation

- Density

- Natural Gamma/Caliper

- Natural Gamma/Caliper/Long-Space and Short-Space Density

- Natural Gamma/Spontaneous Potential/Single-Point Resistance/16" and 64" Resistivity

- Full-wave Sonic/Travel Time

- Acoustic Televiewer

- Optical Televiewer

Based on evaluation of the log data from the core hole, the decision was made to remove the resistivity log from the suite of logs run in the instrument holes, as it did not seem to provide relevant data for site characterization.

See the detailed discussion of fracture data from borehole logs in Section 4.2.

\subsection{Material Properties Tests}

Samples from the U-15n core hole were selected in April 2011 by personnel from SNL, LANL, and NSTec for laboratory testing. Phase 1 testing consisted of measurements of density, velocity, and unconfined compressive strength by SNL on ten samples (Broome and Pfeifle, 2011;

reproduced in Appendix G); direct shear tests on selected fracture surfaces by SNL and LANL at the laboratory of Call and Nicholas, Inc. (Tucson, Arizona); and optical microscopy studies by LANL (the latter two studies are both in progress). SNL, LANL, and NSTec personnel selected a second group of samples from the U-15n core in September 2011, to supply material for Phase 2 tests, which will consist of triaxial testing of damaged material from the fault zones and of intact granite, as well as additional tests on fracture surfaces under both dry and saturated conditions. See Table 3 for a list of samples selected for testing. 
Table 3

List of Samples from the U-15n Core Hole Selected for Material Property Testing by SNL
and Petrographic Characterization by LANL

\begin{tabular}{|c|c|c|c|c|}
\hline $\begin{array}{l}\text { Sample Top } \\
\text { (feet) }\end{array}$ & $\begin{array}{l}\text { Sample Bottom } \\
\text { (feet) }\end{array}$ & $\begin{array}{c}\text { Sample Length } \\
\text { (feet) }\end{array}$ & \multicolumn{2}{|c|}{ Proposed Tests } \\
\hline \multicolumn{5}{|c|}{ Phase 1: General Characterization (UCS completed June 2011; see Appendix G for SNL report) } \\
\hline 13.5 & 14.5 & 1.0 & \multirow{12}{*}{\multicolumn{2}{|c|}{$\begin{array}{l}\text { - } \text { Density } \\
\text { - Ultrasonic Velocity (Compressional and Shear) } \\
\text { - Unconfined Compressive Strength (UCS) } \\
\text { o (Young's Modulus, Poisson's Ratio) } \\
\text { - Thin sections }\end{array}$}} \\
\hline 29.2 & 30.0 & 0.8 & & \\
\hline 49.3 & 50.2 & 0.9 & & \\
\hline 50.2 & 51.1 & 0.9 & & \\
\hline 70.0 & 70.9 & 0.9 & & \\
\hline 86.5 & 87.4 & 0.9 & & \\
\hline 107.6 & 108.8 & 1.2 & & \\
\hline 131.5 & 132.4 & 0.9 & & \\
\hline 153.6 & 154.4 & 0.8 & & \\
\hline 156.5 & 157.7 & 1.2 & & \\
\hline 176.5 & 177.2 & 0.7 & & \\
\hline 192.2 & 192.9 & 0.7 & & \\
\hline 23.7 & 24.7 & 1.0 & \multirow{13}{*}{\multicolumn{2}{|c|}{$\begin{array}{l}\text { Other tests, including: } \\
\text { - } \quad \text { Direct shear on fracture surfaces } \\
\text { - } \quad \text { Direct tension on fracture surfaces } \\
\text { - } \quad \text { Split Hopkinson Bar } \\
\text { - } \quad \text { Thin sections }\end{array}$}} \\
\hline 30.3 & 31.2 & 0.9 & & \\
\hline 33.2 & 33.7 & 0.5 & & \\
\hline 39.4 & 40.1 & 0.7 & & \\
\hline 81.4 & 82.0 & 0.6 & & \\
\hline 104.0 & 105.1 & 1.1 & & \\
\hline 121.8 & 122.4 & 0.6 & & \\
\hline 154.9 & 155.5 & 0.6 & & \\
\hline 162.7 & 163.5 & 0.8 & & \\
\hline 165.4 & 166.2 & 0.8 & & \\
\hline 172.2 & 173.3 & 1.1 & & \\
\hline 177.2 & 178.2 & 1.0 & & \\
\hline 179.2 & 179.9 & 0.7 & & \\
\hline \multicolumn{5}{|c|}{ Phase 2: Characterization of fractures and fault zones (in progress) } \\
\hline 72.1 & 72.6 & $\begin{array}{c}0.5 \\
\end{array}$ & \multirow{2}{*}{ Low-angle fracture pair } & \multirow{2}{*}{ Triaxial shear } \\
\hline 72.6 & 72.8 & 0.2 & & \\
\hline 75.1 & 76.5 & 1.4 & Fault zone & Triaxial compression \\
\hline 76.5 & 77.7 & 1.2 & Fault zone / preserved & Triaxial compression \\
\hline 83.9 & 85.1 & 1.2 & Fault zone / preserved & Triaxial compression \\
\hline 85.1 & 85.8 & 0.7 & Fault zone & Triaxial compression \\
\hline 85.8 & 86.5 & 0.7 & Fault zone / preserved & Triaxial compression \\
\hline 87.4 & 88.2 & 0.8 & Fault zone & Triaxial compression \\
\hline 125.2 & 125.6 & 0.4 & \multirow{2}{*}{ Low-angle fracture pair } & \multirow{2}{*}{ Triaxial shear } \\
\hline 125.6 & 125.8 & 0.2 & & \\
\hline 136.7 & 137.3 & 0.6 & \multirow{2}{*}{$\begin{array}{l}\text { 45-degree angle fracture } \\
\text { pair }\end{array}$} & \multirow{2}{*}{ Triaxial shear } \\
\hline 137.3 & 137.8 & 0.5 & & \\
\hline 140.3 & 140.8 & 0.5 & \multirow{2}{*}{ Low-angle fracture pair } & \multirow{2}{*}{ Triaxial shear } \\
\hline 140.8 & 141.0 & 0.2 & & \\
\hline 147.3 & 148.1 & 0.8 & Intact & Triaxial compression \\
\hline 149.8 & 150.5 & 0.7 & \multirow{2}{*}{ High-angle fracture pair } & \multirow{2}{*}{$\begin{array}{l}\text { Triaxial shear and triaxial } \\
\text { compression }\end{array}$} \\
\hline 150.5 & 151.8 & 1.3 & & \\
\hline 151.8 & 152.4 & 0.6 & Intact & Triaxial compression \\
\hline 152.4 & 153.1 & 0.7 & Intact / preserved & Triaxial compression \\
\hline 153.1 & 153.7 & 0.6 & Intact & Triaxial compression \\
\hline 173.2 & 174.2 & 1.0 & \multirow{2}{*}{ Low-angle fracture pair } & \multirow{2}{*}{$\begin{array}{l}\text { Direct shear and triaxial } \\
\text { compression }\end{array}$} \\
\hline 174.2 & 174.5 & 0.3 & & \\
\hline
\end{tabular}




\subsection{Analyses}

This section includes discussions of weathering, fracturing, and groundwater as characterized at the SPE site by evaluating the core data, laboratory properties data, geophysical log data, and tags of water levels in the instrument holes and Source Hole prior to conducting the first SPE test in May 2011. In this report we use the term "fracture" to include all discontinuities, whether they are planes of offset (faults) or not (joints).

\section{$4.1 U$-15n Core Data}

As described in Section 3.0, core was obtained from Hole U-15n from the depth of 2.2 to $59.9 \mathrm{~m}$ (7.3 to $196.5 \mathrm{ft}$ ) below ground surface. This section describes studies conducted by NSTec geologists on the core. It also includes a discussion of velocity data obtained from borehole logs and measured on core samples.

\subsubsection{Rock Quality Designation (RQD)}

NSTec geologists recorded data required for calculation of Rock Quality Designation (RQD), which is a standard, internationally accepted means of estimating rock quality for engineering purposes (Deere and Deere, 1988; 1989). The RQD is a modified core-recovery percentage in which all sound core pieces more than 4 in. $(100 \mathrm{~mm})$ long are summed and divided by the length of the core run. Thus, RQD logging is basically a measurement of the percentage of "good" rock recovered from an interval of a borehole (see more information about RQD determination in Appendix E).

The RQD for the U-15n core hole ranges from 52 near the top of the hole to 100, generally increasing with depth, and averages greater than 80. RQD data by run are presented in Figure 7, and tabulated in Appendix E.

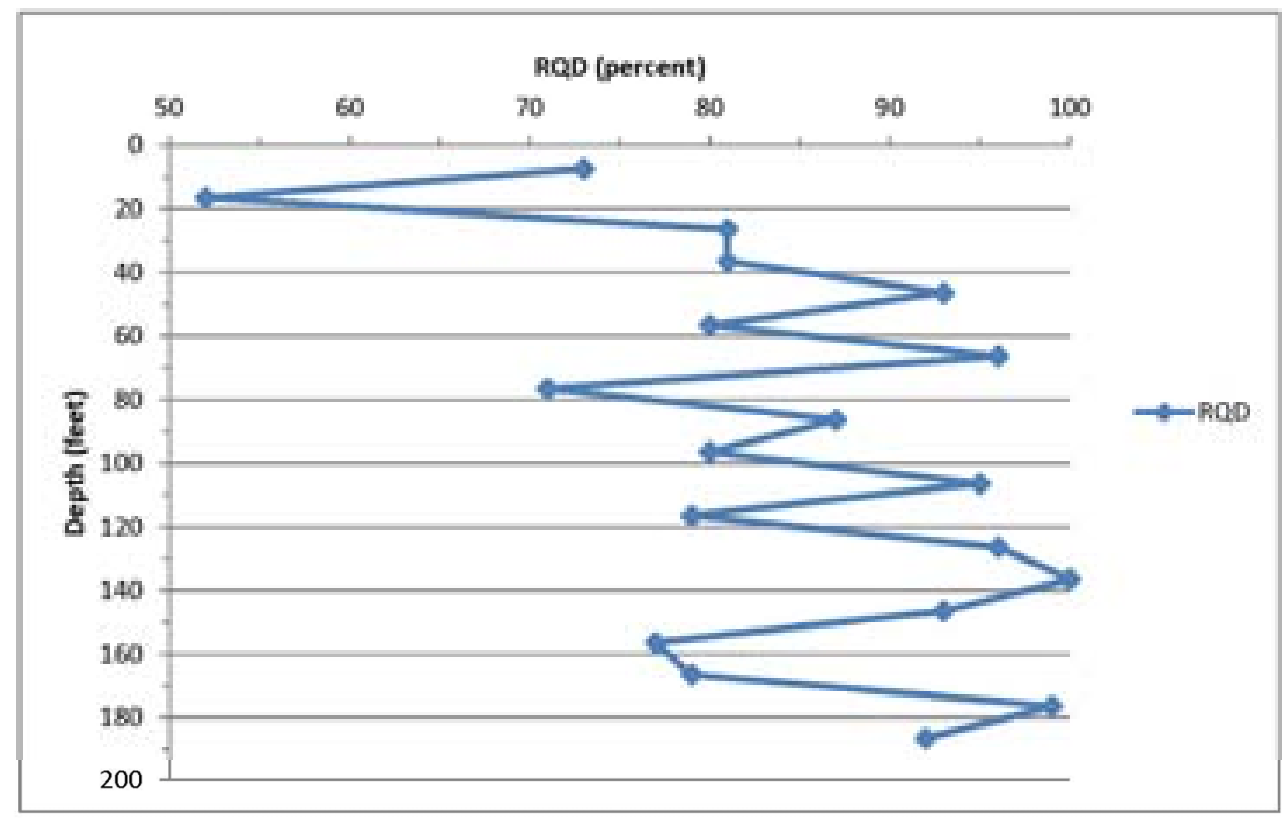

Figure 7

Plot of RQD Data versus Depth for the U-15n Core Hole 


\subsubsection{Weathering Evaluation}

A simple gradational weathering profile, progressing from highly weathered surface rock to fresh rock at depth, was not seen in the core from U-15n, based on visual evaluation (see Appendix K for a log of weathering characteristics of the U-15n core). Zones of alteration and weathering are sporadic and appear to be controlled more by fractures than by depth. Some of the color change and mineral alteration associated with fractures described at various Climax stock locations are undoubtedly attributable to the action of groundwater, including hydrothermal processes millions of years ago when the rock was more deeply buried; therefore, a progression from highly weathered at the surface to fresh rock at depth is not typically found. The term "weathering and alteration" might be more accurate.

Most rock in the U-15n core hole was categorized using the USBR system as "slightly weathered.” The slightly weathered rock in the U-15n core hole varies from largely unaltered gray quartz monzonite with iron-oxide-stained zones up to $0.63 \mathrm{~cm}(0.25 \mathrm{in}$.) wide along fractures, to rock that, although still very hard, is significantly stained throughout by iron oxides. Minor amounts of rock could be classified as "moderately to slightly weathered." These zones show some alteration of feldspar phenocrysts and some overall softening of the rock. Most of these moderately to slightly weathered zones occur above the depth of about $12 \mathrm{~m}$ (40 ft). The plot of RQD in Figure 7 illustrates the variability in this upper weathered portion of the hole.

The sporadic nature of weathering with depth in the U-15n core hole contrasts with core from UE-15f, where rock above the vertical depth of $30 \mathrm{~m}(100 \mathrm{ft})$ is pervasively moderately to slightly weathered, and rock below that is slightly weathered (Ege and Davis, 1965). The

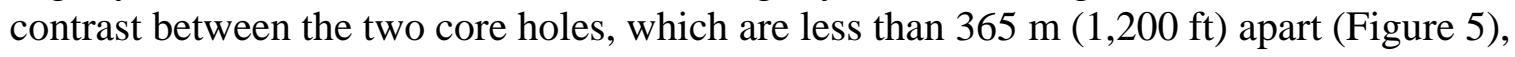
demonstrates the variability in weathering and alteration across the stock.

The borehole geophysical logs also provide some indications of weathering at the SPE site. Figure 8 shows plots of the Colog electric log and compressional wave (P-wave) and shear wave (S-wave) velocities from the Colog full-waveform sonic log, both from the U-15n core hole. On the electric log, especially the single-point resistance curve, an area of high but quite variable resistivity is observed in the upper $6.1 \mathrm{~m}(20 \mathrm{ft})$ of the U-15n core hole. It is difficult to pick the transition to less weathered rocks from the electric log, though the fault zones also show up well as areas of low resistivity. Areas with the highest resistivity correspond to areas described as relatively unweathered quartz monzonite (such as in the depth intervals 2.1-6.1 and 43.0-44.8 m (7-20 and 141-147 ft). The resistivity of hard, stained quartz monzonite is intermediate between that of the relatively unweathered zones and the fault zones, and is variable.

The velocity data (Figure 8 ) also seem to reflect weathering and alteration in the core hole. The

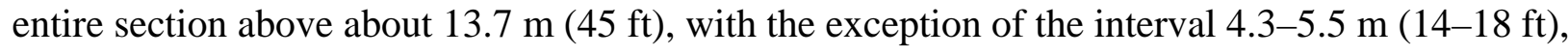
has significantly lower P-wave and S-wave velocities than the section below. Borehole density and gamma logs in five of the six instrument holes show a variable zone in the upper 15.2 to $18.3 \mathrm{~m}$ ( 50 to $60 \mathrm{ft}$ ) that appears to correlate with the weathered zone (Figures 9a and 9b). This zone is not easily identified in U-15n\#3, or it is much shallower than in the other holes. 

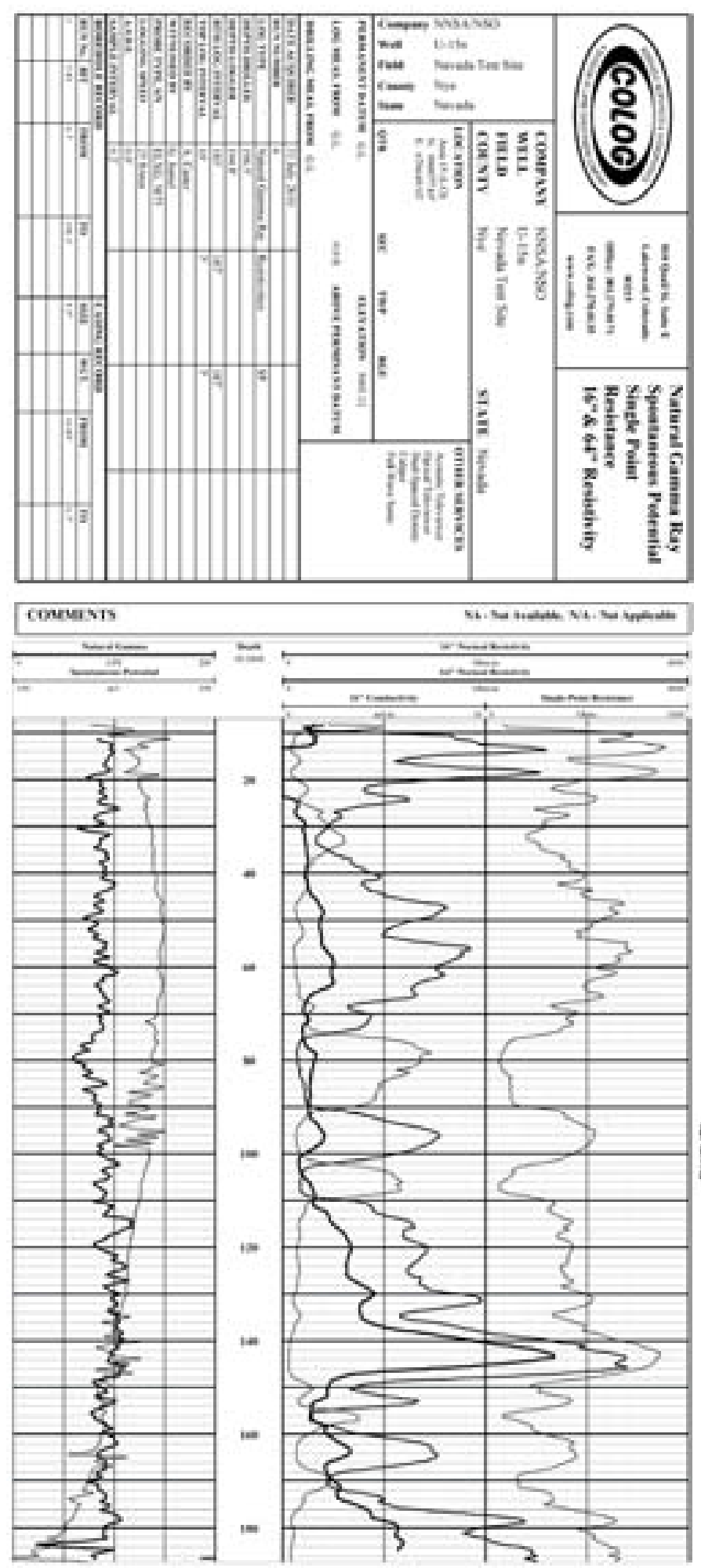

Left: Reproduction of Colog's Electrical Log run in the U-15n Core Hole. Note high but variable resistivity in the upper $6.1 \mathrm{~m}(20 \mathrm{ft})$, low-resistivity sections near the primary fault zones at 25.3 and $32.3 \mathrm{~m} \mathrm{(83} \mathrm{and} 106 \mathrm{ft}$ ), and a high-resistivity zone at 43.0 to $44.8 \mathrm{~m}$ (141 to $147 \mathrm{ft})$.

Below: Plot of compressional and shear velocity obtained from Colog's Full-Waveform Sonic Log run in the U-15n Core Hole. Note low-velocity segment at 6.1 to $15.2 \mathrm{~m}$ (20 to $50 \mathrm{ft}$ ), which may reflect surface weathering, and low-velocity segments near the depths of 25.3 and $32.3 \mathrm{~m}$ (83 and $106 \mathrm{ft}$ ), which correlate with the two primary fault zones observed in the borehole.

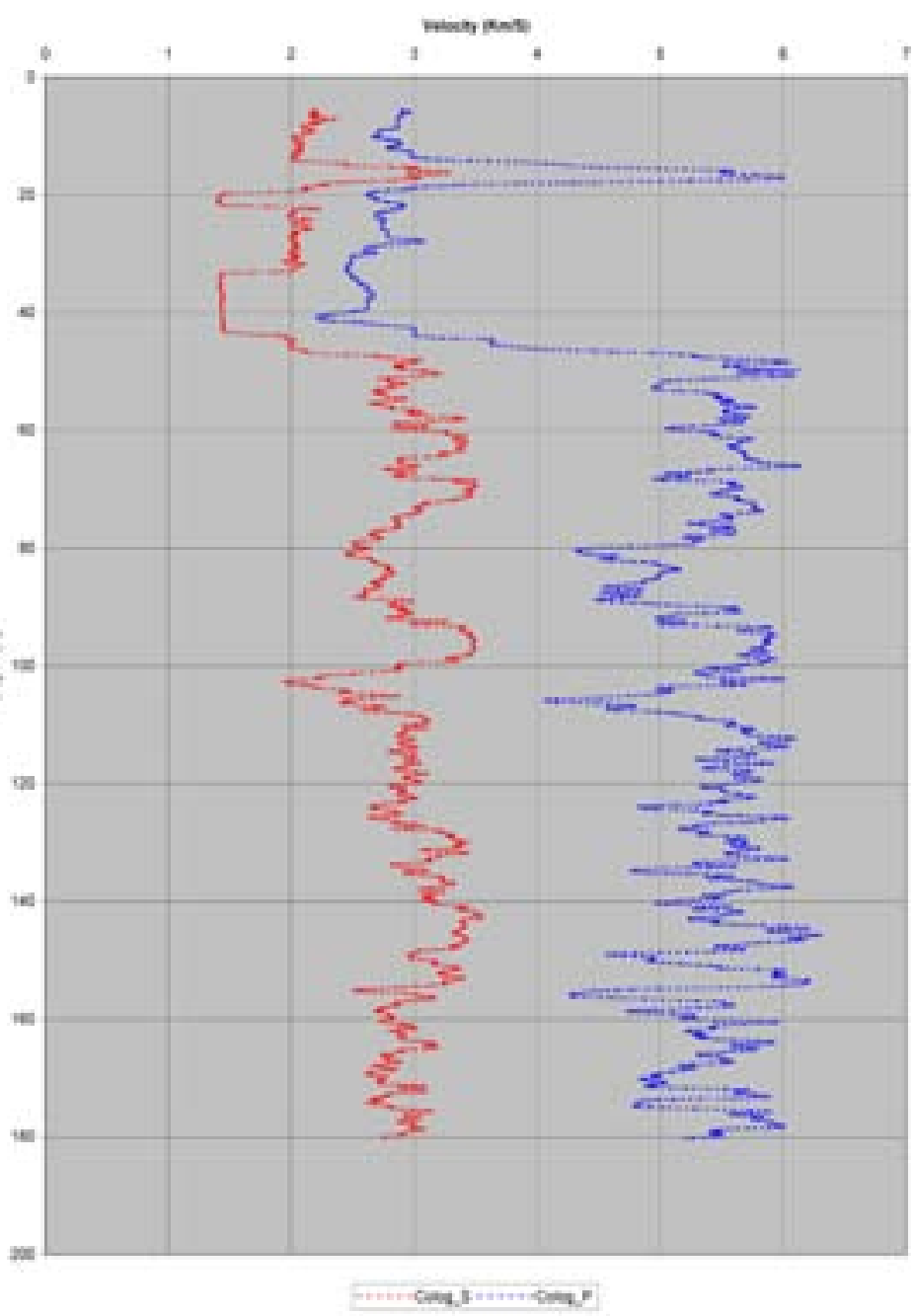

Figure 8

Examples of Resistivity and Velocity Logs from the U-15n Core Hole 


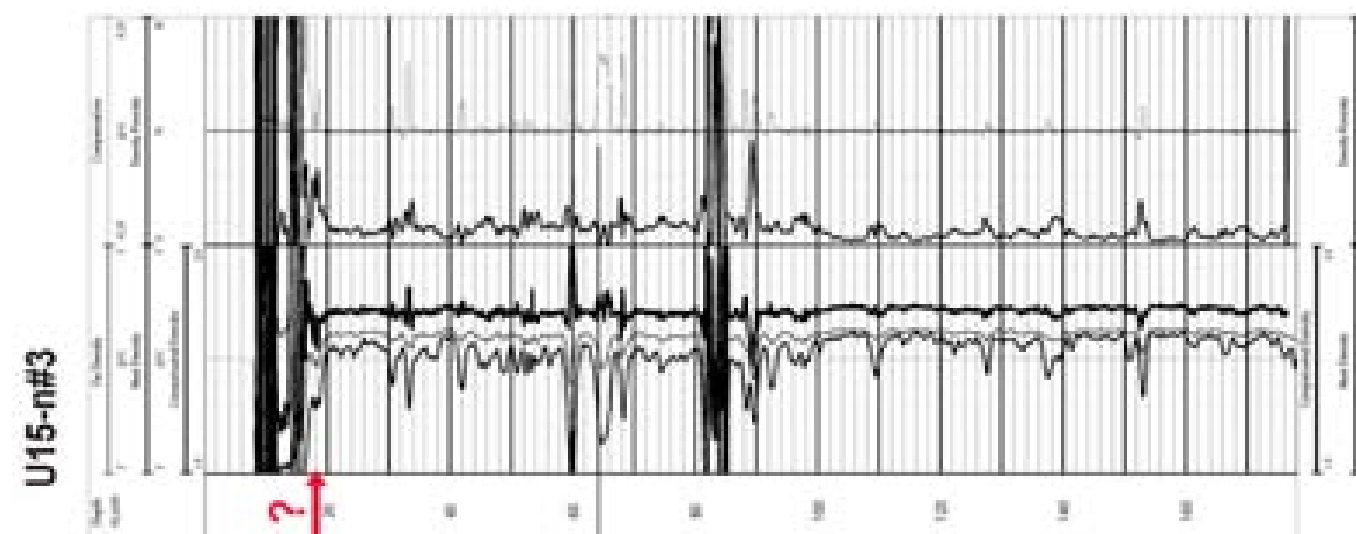

1. 1.

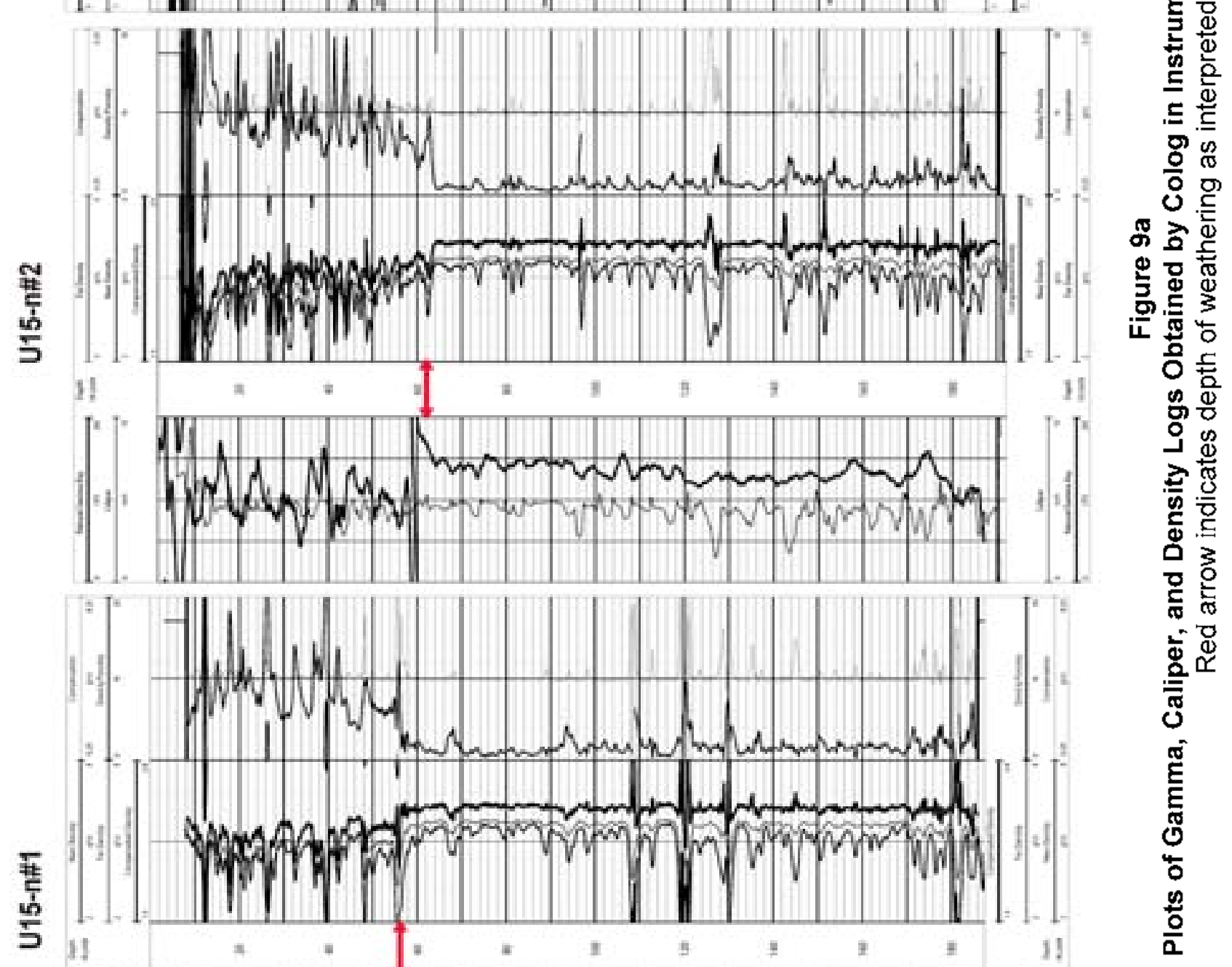

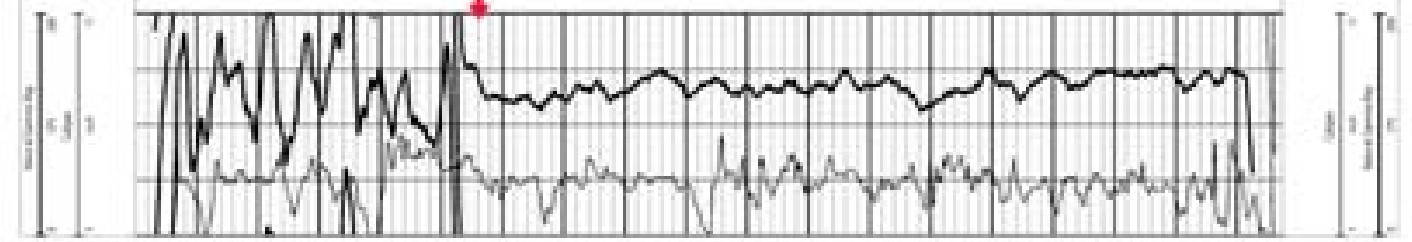




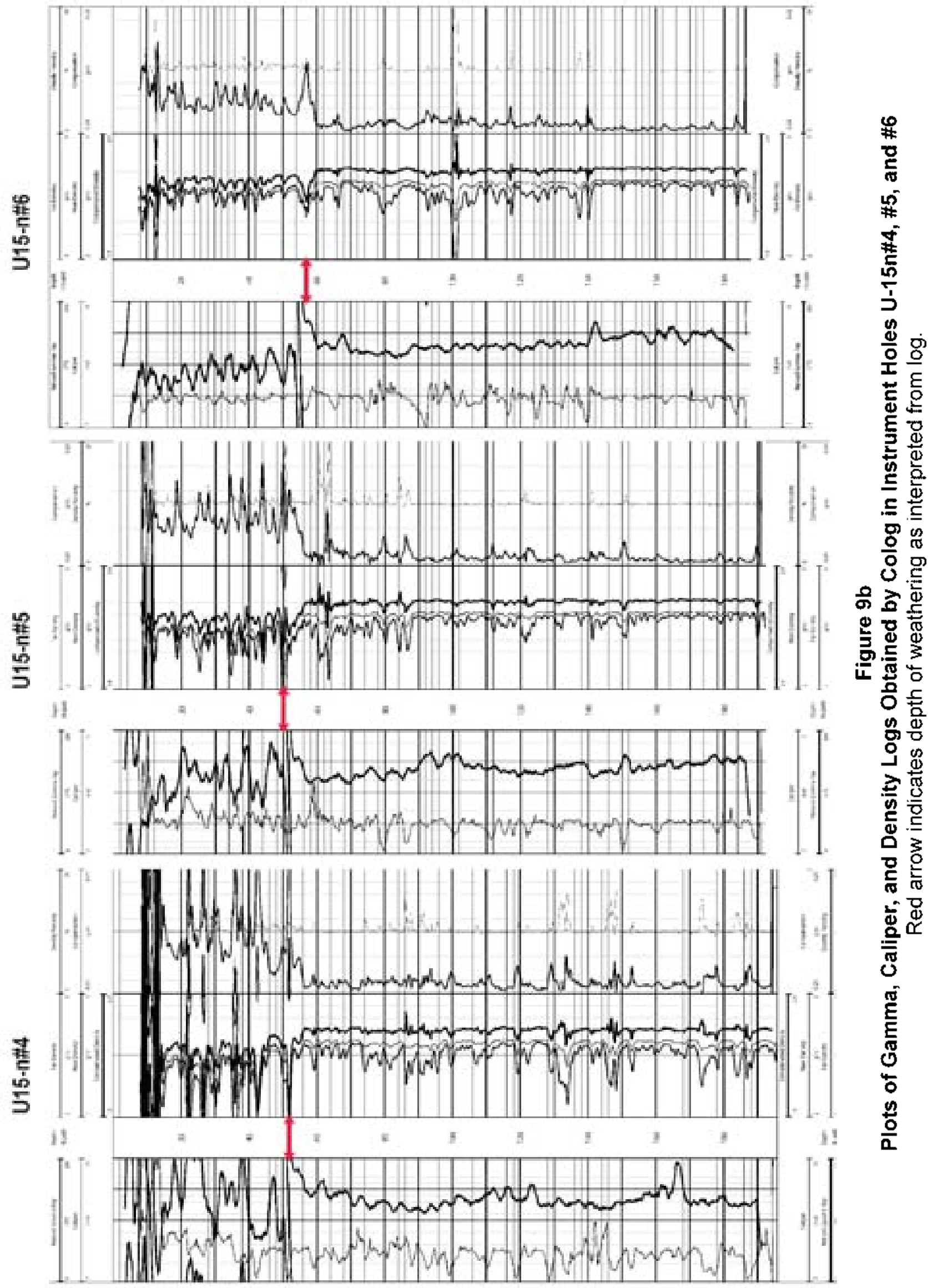




\subsubsection{Evaluation of Velocity Data from the U-15n Core Hole}

Medium velocity data from different scales of surveys (from higher-frequency ultrasonic measurements on discrete core samples, to lower-frequency continuous sonic logs in boreholes, to even lower-frequency surface seismic surveys) can provide useful information for characterizing a rock mass. Measurements on cores sample a small volume that likely does not contain many discontinuities, and may correlate mainly with matrix properties such as density, porosity, saturation, etc. However the borehole logs sample a larger volume that may contain numerous discontinuities that can further affect the medium velocity. The U-15n SPE site affords an opportunity to compare these different scales of velocity measurements in an environment with fewer variables than many other sites: the medium is a relatively homogenous granitic rock with only minor local weathering, though it contains numerous discontinuities.

In this section we compare data from three sets of velocity measurements: (1) borehole velocity logs obtained by Colog, (2) laboratory velocity data from core samples obtained by SNL, and (3) velocity data obtained on cores under less controlled conditions by a DTRA subcontractor on behalf of the DTRA Interagency Geotechnical Assessment Team (IGAT). Larger-scale seismic surveys such as those conducted at the SPE site by SNL are not discussed here.

\subsubsection{Analytical Methods and Data Presentation}

Colog performed a continuous full-waveform sonic survey in the fluid-filled portion of the U-15n core hole after completion of drilling activities, and obtained in-situ compressional and shear velocities (Figure 8). Of the three sets of velocity data, the Colog borehole data, derived from a continuous log of sonic velocities through the greater rock mass, are the most representative of actual field conditions, and are not dependent on availability of coherent samples.

SNL prepared and analyzed ten U-15n core samples in their laboratory (Broome and Pfeifle, 2011, reproduced in Appendix G). For each sample, SNL measured ultrasonic P-wave and $\mathrm{S}$-wave velocities in the axial (parallel to core axis) direction and in two radial (orthogonal to core axis) directions, 90 degrees apart. The SNL data set is likely the most accurate though least populated of the three, but provides a comparison to the sonic velocities at specific points in the Colog surveys. The SNL sonic velocities tend to trend along the upper range of those of Colog. Additional samples were later selected for further testing, which is currently in progress (see Table 3).

Ultrasonic P-wave velocities (but not S-wave velocities) were measured on behalf of IGAT on unprepared samples from the U-15n core hole. Measurements were made in both radial (136 measurements) and axial (16 measurements) directions using a portable method at the NNSS (see data listed in Appendix H). The IGAT radial and axial velocities are not directly comparable to each other because the two readings were not necessarily measured on the same sample (as was done by SNL). However they are useful for comparing to the other data sets. The IGAT sonic velocities are mostly slower than those from the Colog borehole survey.

Figure 10 shows plots comparing P- and S-wave velocities from all three data sets from the U-15n core hole.. 

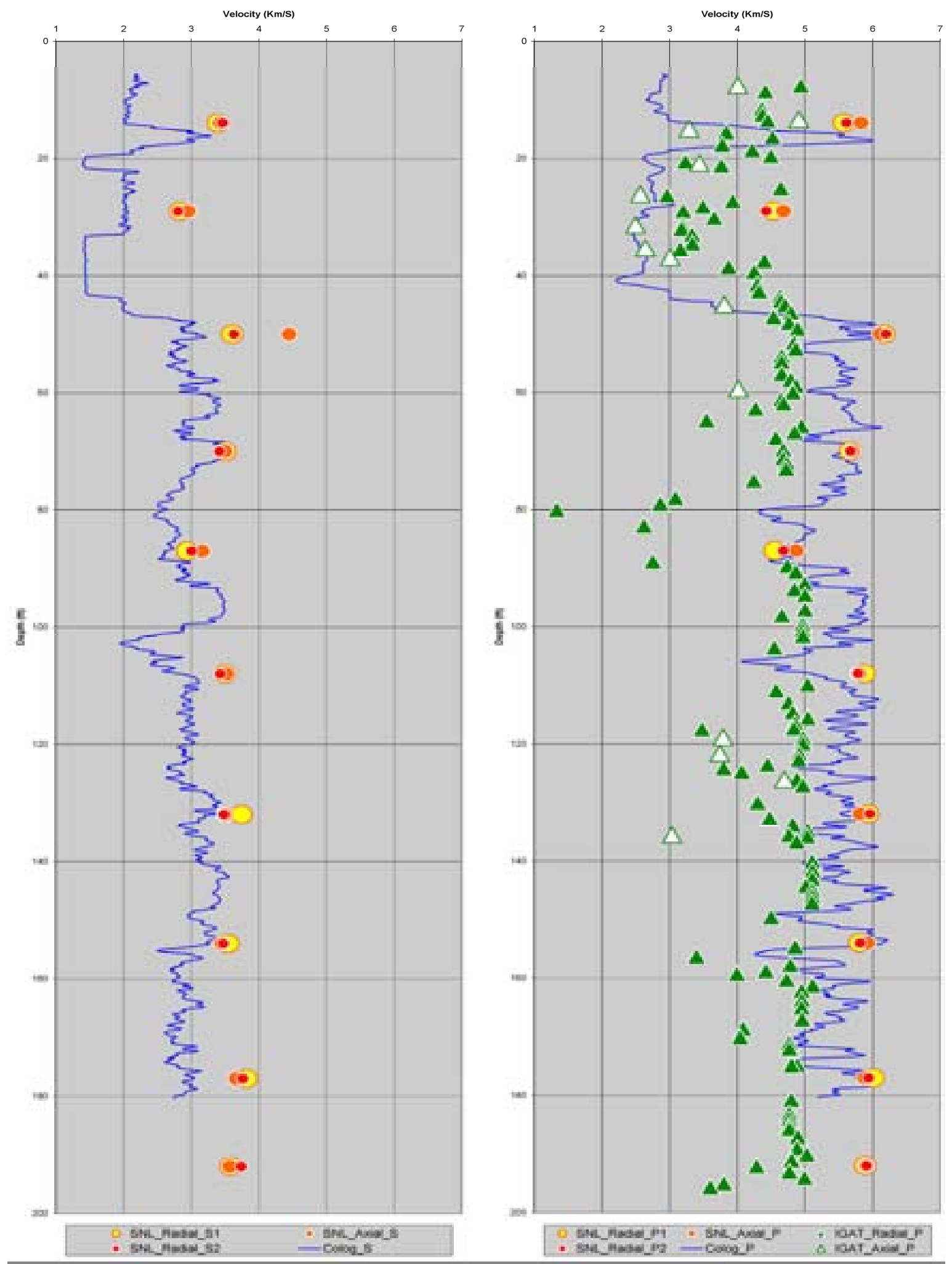

Figure 10

Plots of Shear Velocity (left) and Compressional Velocity (right) for the U-15n Core Hole

Continuous blue lines are Colog borehole data, yellow and red points are SNL data, and green triangles are IGAT data. $\mathrm{Km} / \mathrm{s}=$ kilometers per second. 


\subsubsection{Discussion of Velocity from the U-15n Core Hole}

A few observations can be made about these three sets of velocity data from the U-15n core hole.

- For a given Colog depth or SNL sample, P-wave velocities (3 to 6 kilometers per second $[\mathrm{km} / \mathrm{s}]$ ) are roughly half again faster than S-wave velocities (2 to $4 \mathrm{~km} / \mathrm{s}$ ).

- For a given SNL sample, axial and radial velocities are closely similar for P-waves and for S-waves.

- The continuous sampling by Colog appears to best characterize zones of faulting and alteration because of finer resolution.

- Weathered zone to the depth of $13.7 \mathrm{~m}$ (45 ft): The Colog and IGAT data exhibit major reductions of P- and S-wave velocities. The SNL data exhibit only minor reductions, which may be a function of the smaller number of samples tested and the variability in degree of weathering through the interval.

- Fault zone at the depth of $25.3 \mathrm{~m}$ (83 ft): The IGAT data exhibit major reductions of P-wave velocities, while the Colog and SNL data exhibit minor reductions. Again, the smaller number of samples tested by SNL may be a factor (several additional samples from this zone are currently being tested).

- Fault zone at the depth of $32.3 \mathrm{~m}$ (106 ft): The Colog data exhibit moderate to major reduction of P- and S-wave velocities, and the SNL and IGAT data exhibit minor to no reduction. Both IGAT and SNL tested fewer samples in this interval, mainly due to the poor condition of the core.

\subsubsection{Discussion of Velocity from Instrument Holes U-15n \#1 through \#6}

Colog also measured in situ P- and S-wave sonic velocities in nearby instrument holes U-15n \#1 through \#6. These data are plotted in Figure 11, and a few observations are noted below.

- The U-15n core hole and U-15n \#3 were the only two boreholes with fluid levels high enough to allow sonic logging near the surface. Lower sonic velocities (indicative of weathered/altered rock) were measured in U-15n core hole down to a depth of about

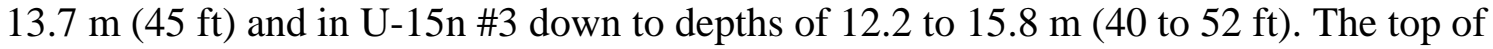
the sonic velocity log for U-15n \#5 suggests weathered/altered rock down to a depth of about $18.6 \mathrm{~m}(61 \mathrm{ft})$.

- Several isolated intervals of anomalously low velocity rock were measured in U-15n \#2, with the most severe at approximately 48.8 to $56.4 \mathrm{~m}$ (160 to $185 \mathrm{ft}$ ).

\subsubsection{Fracture Logging}

NSTec geologists logged the core to record fracture data. The core was not oriented, so it was not possible to determine fracture orientations (these data were obtained from the borehole televiewer logs; see Section 4.2). Three main fracture sets were identified in the core, based on fracture dip magnitude. A preliminary evaluation of the core indicated that the most abundant fractures (77 percent) had very low dips (generally less than 25 degrees), a secondary set (17 percent) had dips generally less than 45 degrees, and the third set (6 percent) had dips greater than 75 degrees. A more quantitative analysis was done using borehole image logs, as discussed in Section 4.2. The core fracture log is provided in Appendix E. 

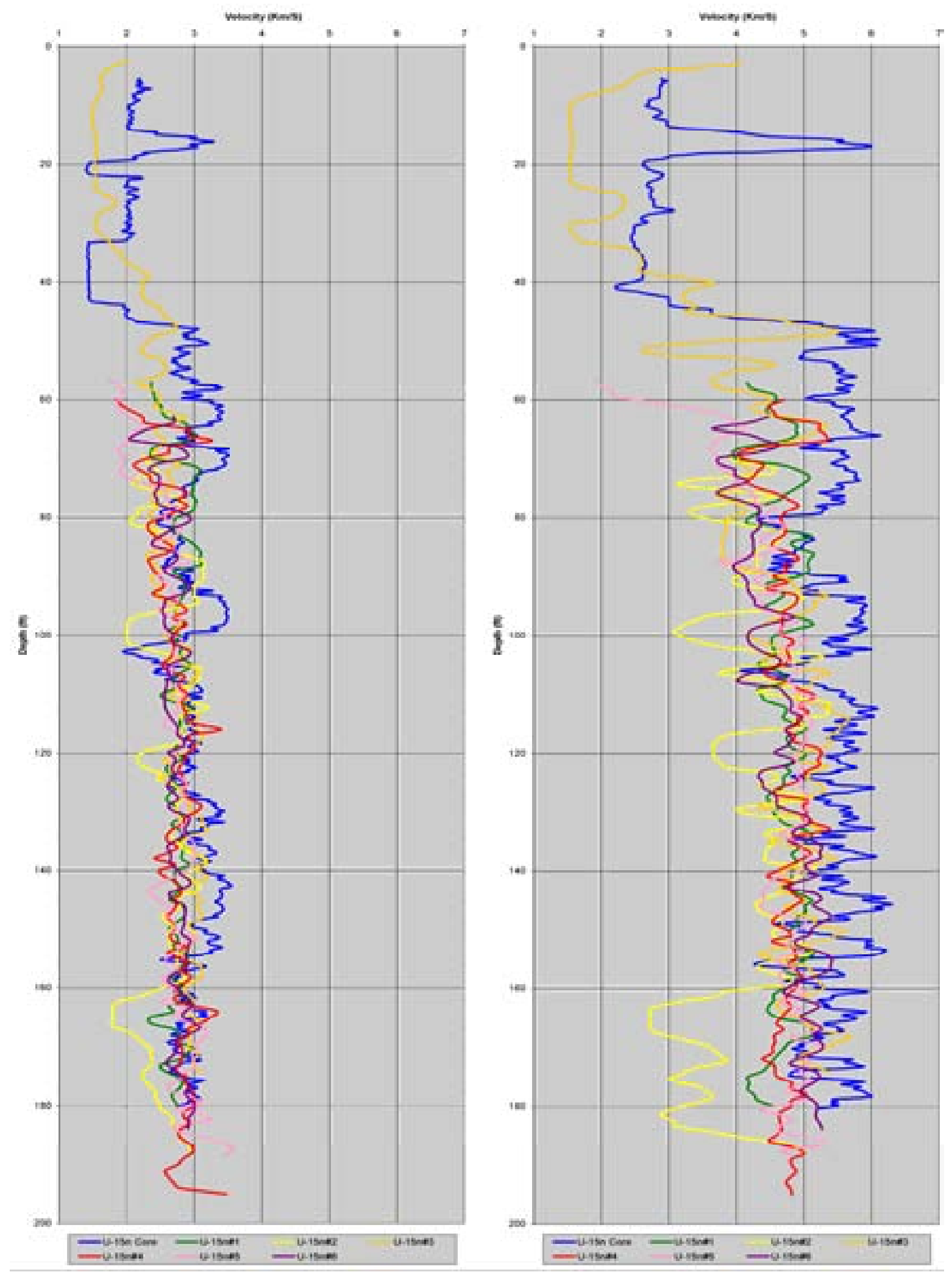

Figure 11

Plots of Shear Velocity (left) and Compressional Velocity (right) Measured in Instrument Holes U-15n\#1, \#2, \#3, \#4, \#5, and \#6 by Colog 
Two fault zones were observed in the core, both dipping at a high angle, and crossing the midpoint of the core hole at the depths of 25.3 and $32.3 \mathrm{~m}$ (83 and $106 \mathrm{ft}$ ). Both fault zones can be seen distinctly on the caliper, density, sonic velocity, and resistivity logs. Photos of the core intervals where the fault zones were encountered are shown in Figure 12. See the preliminary report (NSTec, 2011a) on possible projections of these two fault zones in Appendix I. Neither fault has an identifiable surface trace.

The fault at $25.3 \mathrm{~m}(83 \mathrm{ft})$ in the core hole (Figure 12, upper photo) is associated with an argillized zone that extends from 23.6 to $25.8 \mathrm{~m}$ (77.5 to $84.5 \mathrm{ft}$ ) (true width approximately $0.4 \mathrm{~m}$ [1.2 ft]). Based on its orientation (obtained from the borehole image log), it belongs to Fracture Set 1 (see Section 4.2.2). This fault is likely the one observed in camera runs in the 36-in. diameter hole extending from 17.7 to $24.4 \mathrm{~m}$ (58 to $80 \mathrm{ft}$ ) below ground surface. (The depths do not match, even though the core hole and the Source Hole were collared at the same point, because of the difference in diameter of the two holes and because both holes deviated in different directions from vertical. The core hole deviated to the northeast, and the Source Hole deviated to the south.)

The fault at $32.3 \mathrm{~m} \mathrm{(106} \mathrm{ft)} \mathrm{in} \mathrm{the} \mathrm{core} \mathrm{hole} \mathrm{(Figure} \mathrm{12,} \mathrm{lower} \mathrm{photo)} \mathrm{is} \mathrm{associated} \mathrm{with} \mathrm{an}$ argillized zone that extends from 31.9 to $32.6 \mathrm{~m}$ (104.7 to $106.8 \mathrm{ft}$ ) (true width approximately $0.2 \mathrm{~m}[0.6 \mathrm{ft}]$ ), and which is bounded by two fracture planes. Based on its orientation (from the borehole image log), it belongs to Fracture Set 2. This fault is likely the one observed in camera runs in the 36-in. hole extending from approximately 32.0 to $37.8 \mathrm{~m}$ (105 to $124 \mathrm{ft}$ ).

\subsection{Fracture Data from Borehole Image Logs}

Oriented fracture data were obtained primarily from acoustic and optical televiewer (image) logs run in the core hole and all six instrument holes (data from the replacement Instrument Hole \#1A are not included here). As described in Section 4.1.3, data for fractures observed in the core from U-15n were also compiled (see Appendix E), but because the core was not oriented, these data are not as useful as those from the televiewer logs.

\subsubsection{Data Acquisition}

Colog ran acoustic borehole image logs within the fluid-filled portions of all seven holes. Optical borehole image logs were run in the six instrument holes to provide image log coverage of the dry upper portions of the instrument holes, although log coverage of all the optical image logs also included the fluid-filled portions of the boreholes. Only the acoustic image log was run in

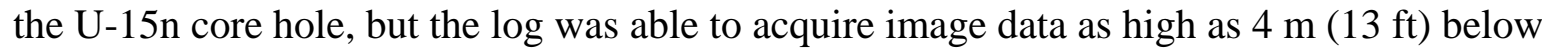
ground surface because of the high borehole fluid level at time of logging. On average, 93 percent of the drilled portions of the holes are covered by image logs.

Colog used the image log data to identify and record the orientations of all planar features observed crossing the boreholes (Figure 13). Because all the holes were drilled within granite, which has no bedding planes, all planar features identified in the boreholes are interpreted by NSTec to be fractures. Colog identified a total of 2,488 fractures, and recorded the depth and orientation (i.e., dip magnitude and direction) of each fracture. Colog assigned each fracture a ranking from 0 to 5 based on degree of openness and continuity (Figure 14). Colog corrected all fracture orientations for magnetic declination and borehole deviation, and provided in spreadsheet format the depth, orientation, and ranking for every fracture observed in each of the seven SPE drill holes (Appendix J). 

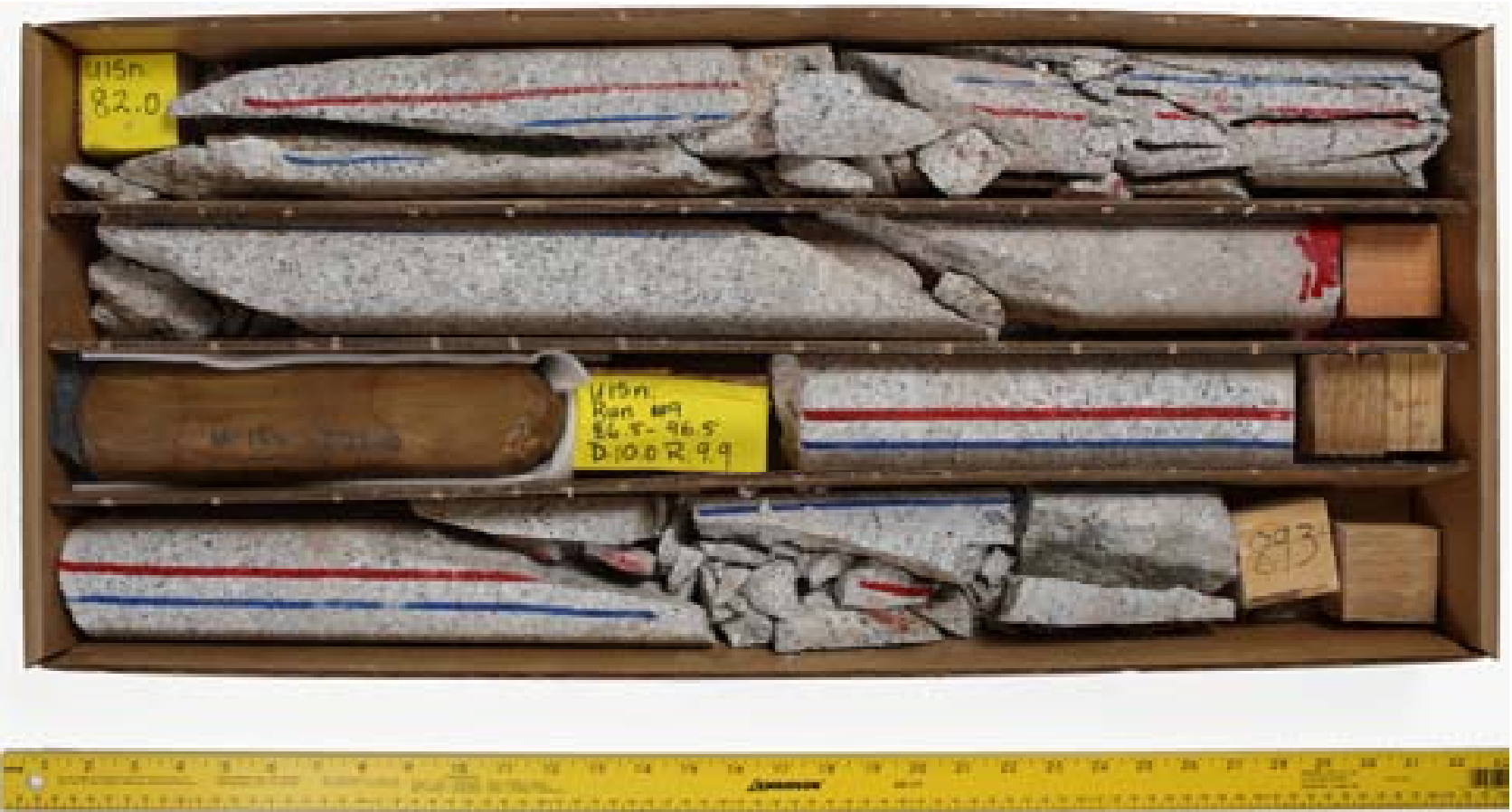

Depth interval 25.0 to $27.2 \mathrm{~m}$ (82.0 to $89.3 \mathrm{ft}$ ) below ground surface. Includes part of the upper fault zone.

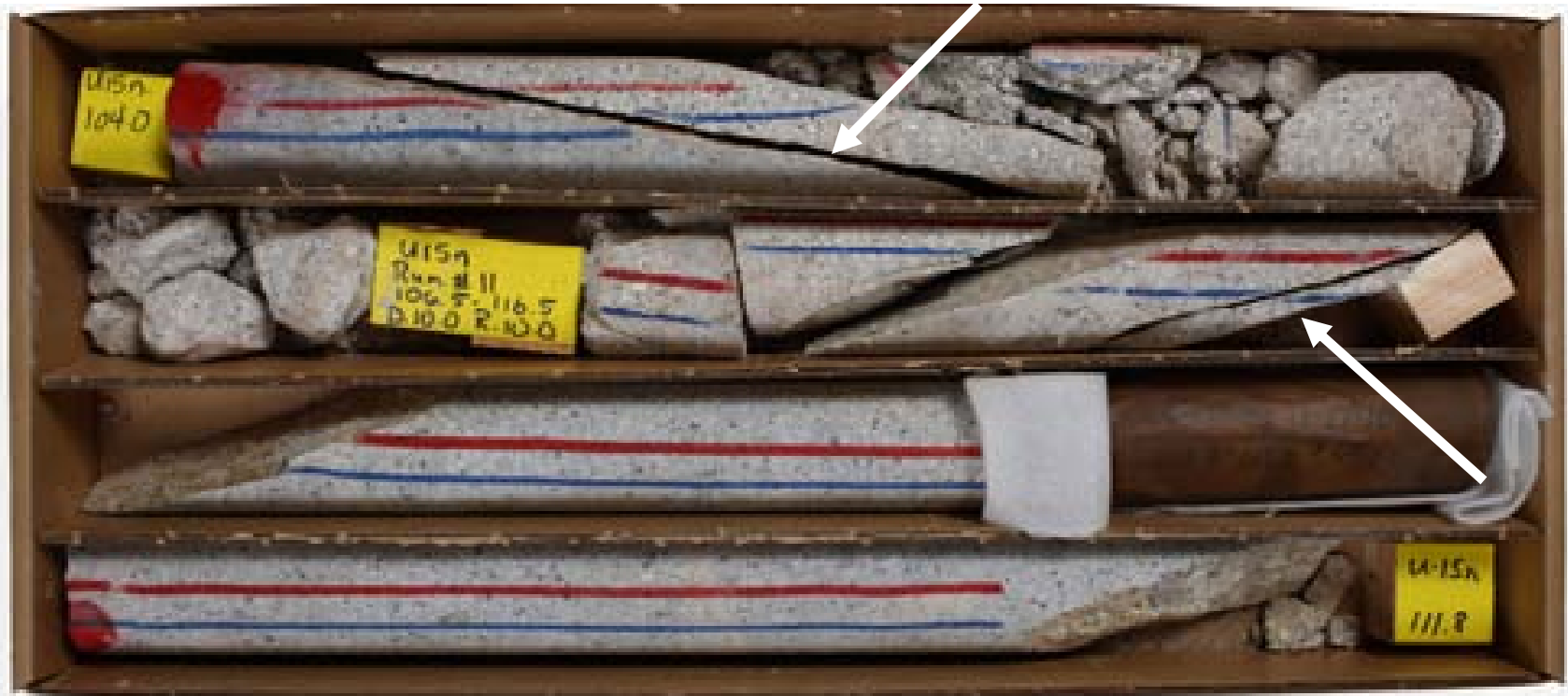

Minitit

Depth interval 31.7 to $34.1 \mathrm{~m}$ (104.0 to $111.8 \mathrm{ft}$ ) below ground surface. Includes the lower fault zone (indicated by arrows)

Figure 12

Photographs of Core from U-15n Showing the Two Main Fault Zones

(Photos by U.S. Geological Survey, September 13, 2010) 


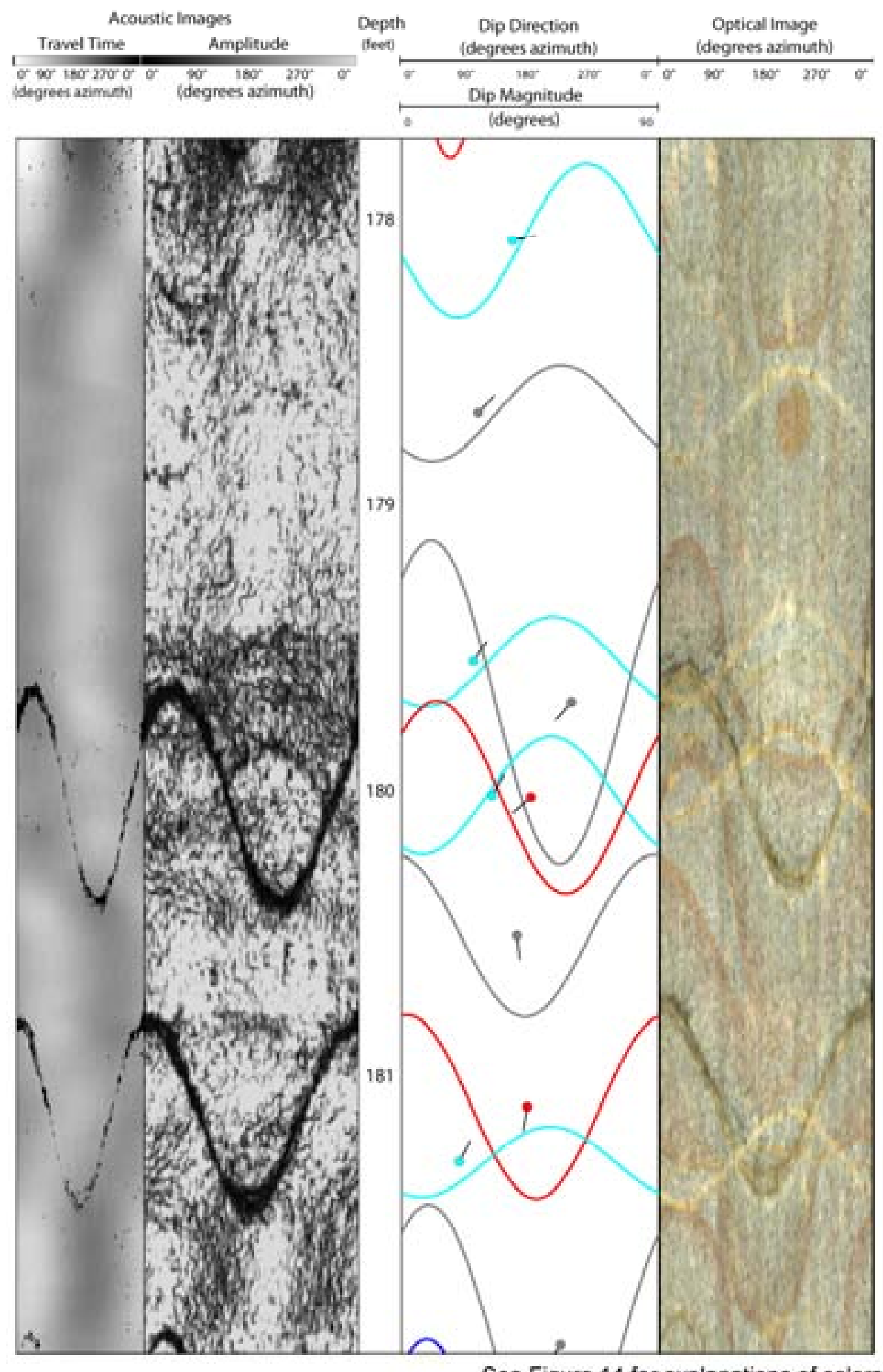

See Figure 14 for explanations of colors.

Figure 13

Example of Colog's Interpreted Image Log Data from Instrument Hole U-15n\#6 


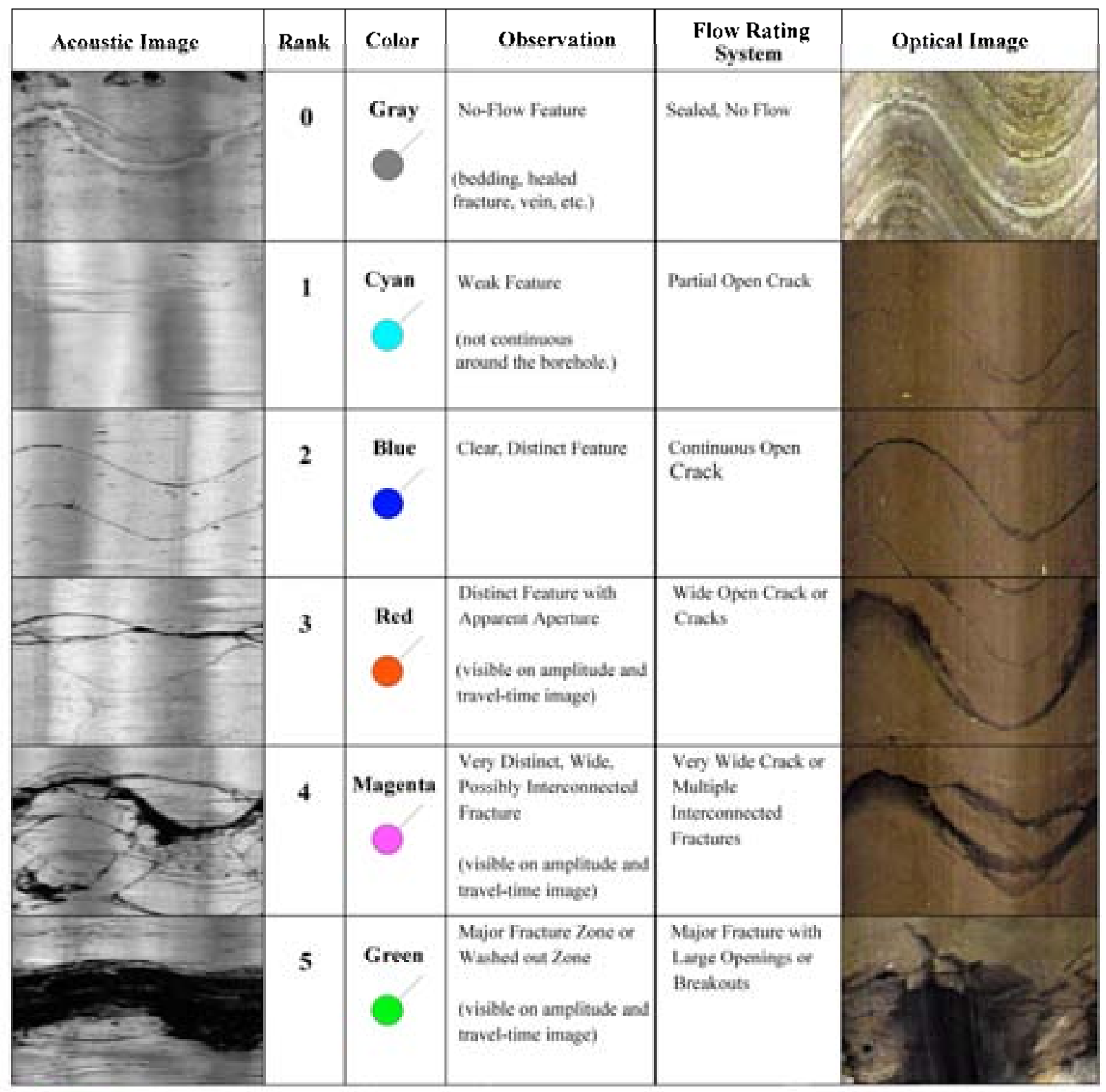

Figure 14

Colog's Fracture Rankings 


\subsubsection{Fracture Analysis}

All fractures observed on the image logs are interpreted to be natural fractures because the optical image logs show that secondary alteration rinds are associated with the vast majority of the fractures. Because Colog's feature rankings 0 and 1 include healed, discontinuous, and partially open fractures, subsequent analyses focused mainly on fractures ranked 2 through 5 , which include distinct, continuous, and open fractures. Of the 2,488 fractures identified, 1,215, or 49 percent, are assigned rankings of 2 or higher (Figure 15). Consequently, 51 percent all of the observed features are eliminated from the analyses described here by limiting the analyses to fractures with rankings 2 or higher. Although features ranked 0 and 1 are, individually, clearly minor features, they may still be significant considering their abundance. Also, subsequent analyses do not account for sampling bias related to the tendency of approximately vertical drill holes to intercept low-angle fractures more often than high-angle fractures.

Another consideration about the fracture rankings is that rankings are applied to individual fracture planes. Thus, the rankings may not reflect the overall character of fault zones that consist of a series of closely spaced fracture planes and/or intervals of altered rock. This is particularly true of the two fault zones encountered near 25.3 and $32.3 \mathrm{~m}$ (83 and $106 \mathrm{ft}$ ) in the core hole, where closely spaced fractures and argillized rock caused severe breakouts in the 36-in. diameter Source Hole. One way to compensate for this is to look for clusters of fractures, which is discussed in Section 4.2.3.

Analysis of dip magnitudes from the Colog data indicates that the majority (88 percent) of the fractures ranked 2-5 fall into two main groups based on dip magnitude: a low-angle group that dips from 0 to 30 degrees and accounts for 50 percent of all fractures ranked 2-5, and a highangle group that dips from 60 to 90 degrees and accounts for 38 percent of all fractures ranked $2-5$ (Figure 16). The remaining 12 percent of fractures ranked $2-5$ have moderate dips, between 30 and 60 degrees.

Analysis of dip directions indicates that the high-angle group of fractures consists of three main and distinct fracture sets based on dip direction (Figure 17). Set 1 fractures dip to the northnortheast between 015 and 040 degrees azimuth. Fractures of Set 2 dip to the south-southwest between 190 and 235 degrees azimuth. Sets 1 and 2 could be considered a single high-angle set with dip directions varying northeastward and southwestward off the vertical. Set 3 includes high-angle fractures that dip to the east-southeast between 110 and 145 degrees azimuth. The low-angle fractures (ranked 2-5) dip eastward and are designated Set 4 (Figure 18). Fracture frequency does not appear to change substantially with depth (Figure 19). True fracture spacing

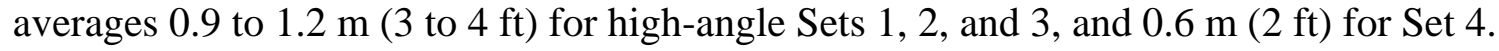




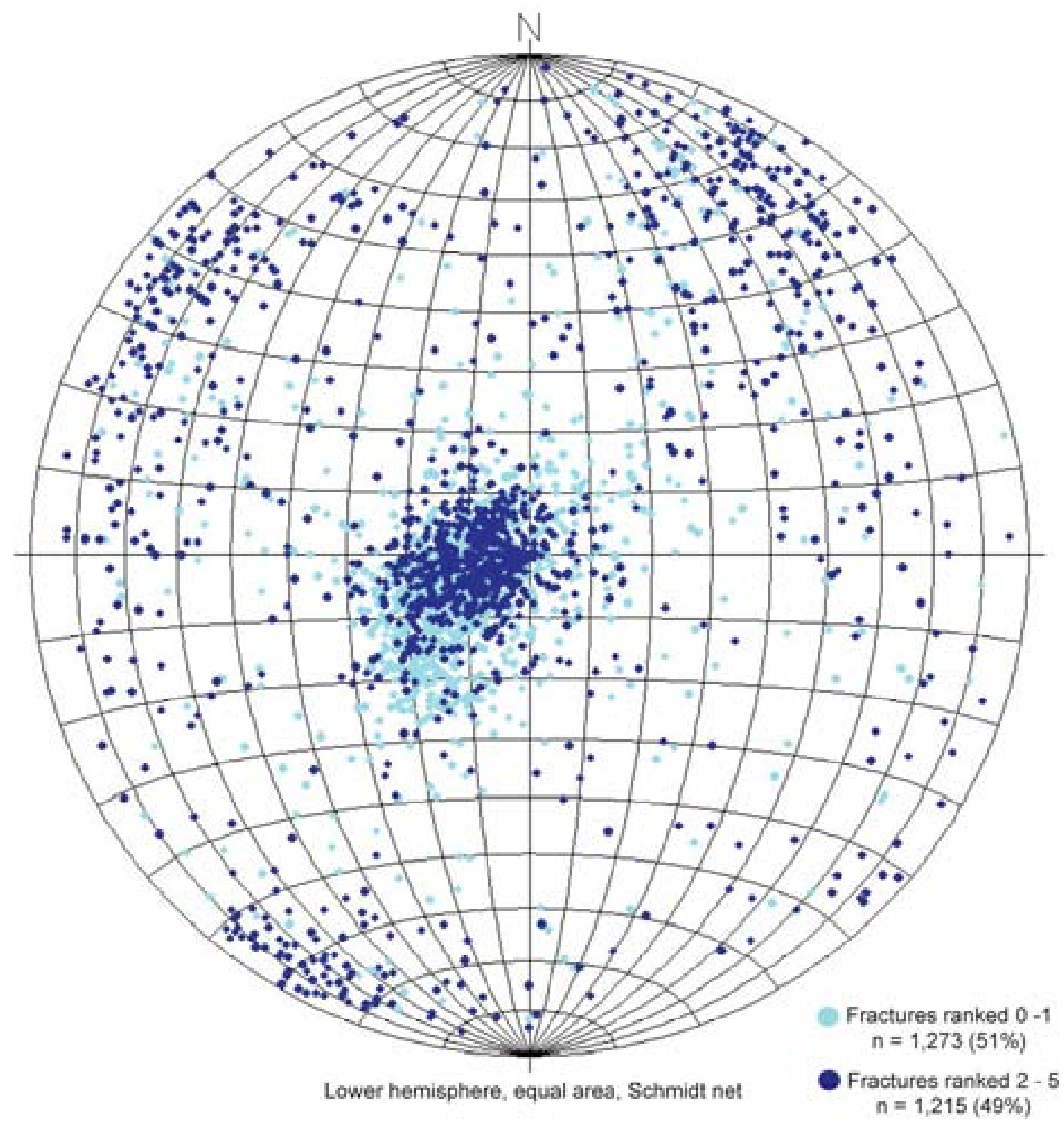

Figure 15

Stereonet Plot of All Fractures Identifed in SPE Drill Holes 

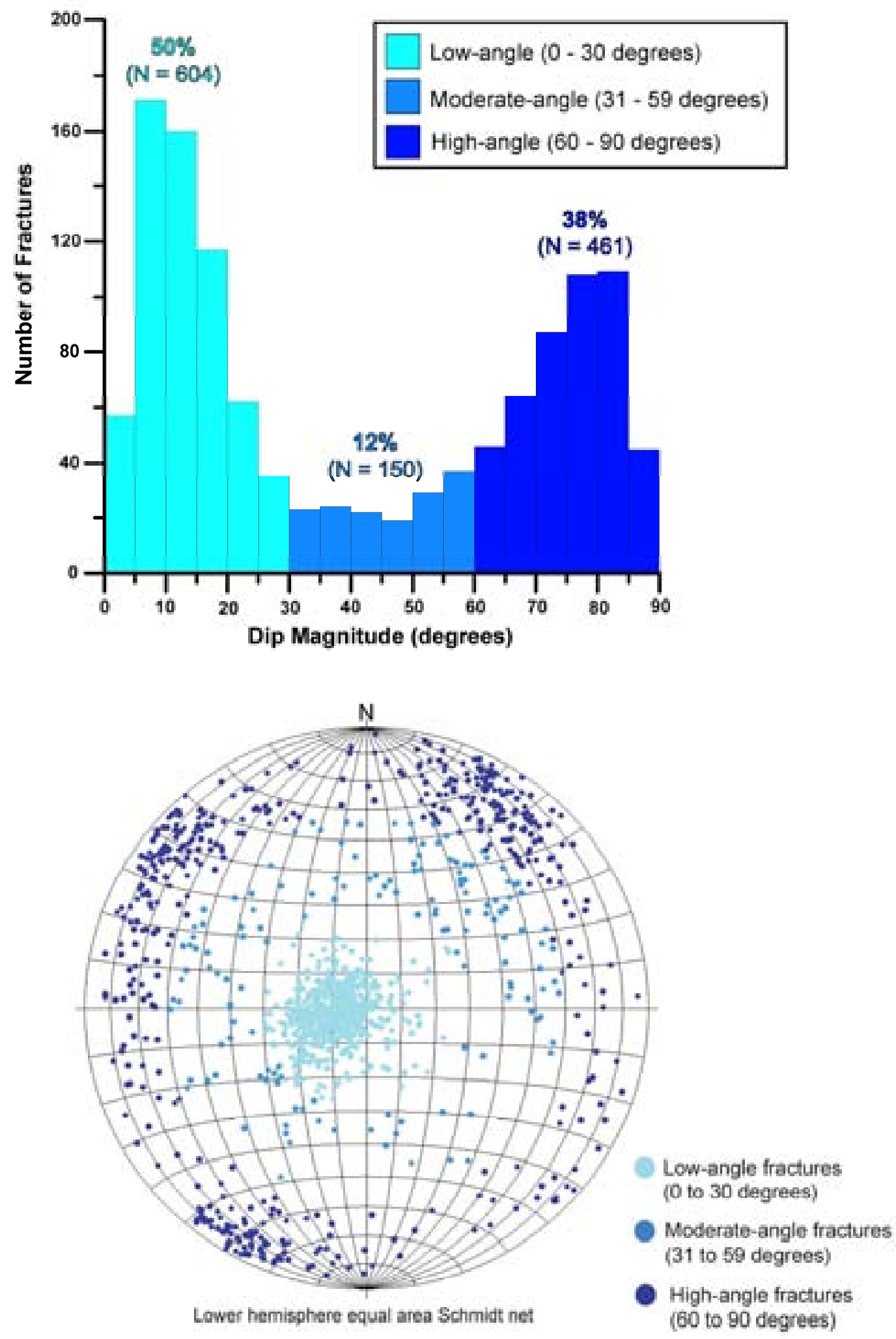

Figure 16

Dip Magnitude Histogram (top) and Stereonet Plot of Fractures with Rankings 2 through 5 Identified by Colog in the SPE Drill Holes 

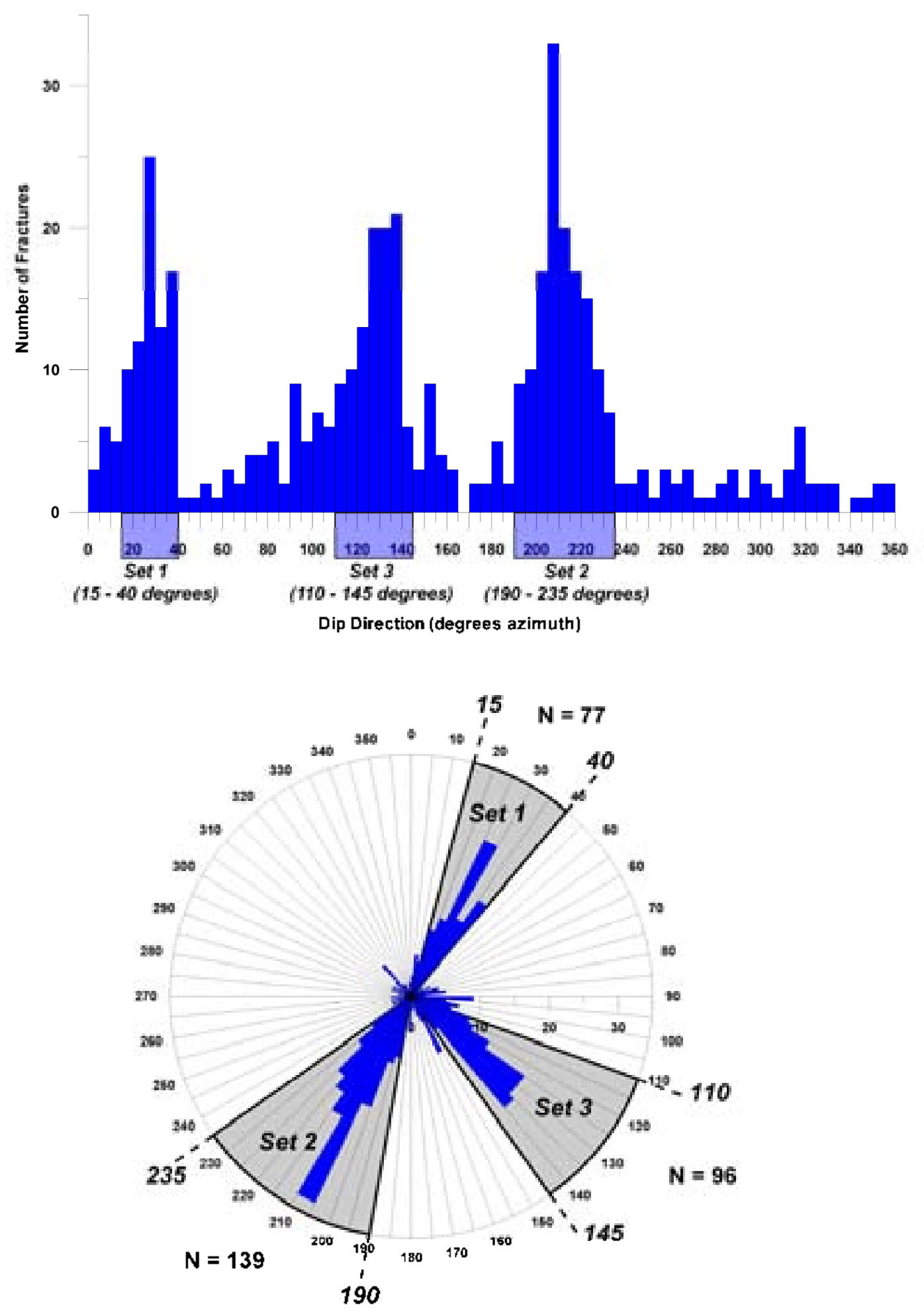

Figure 17

Dip Direction Histogram (top) and Rose Diagram (bottom) of High-Angle Fractures in All SPE Drill Holes, Showing the Three Main High-Angle Fracture Sets Identified by Dip Direction

(from the collection of fractures with dip >60 degrees and rankings 2-5 identified by Colog) 


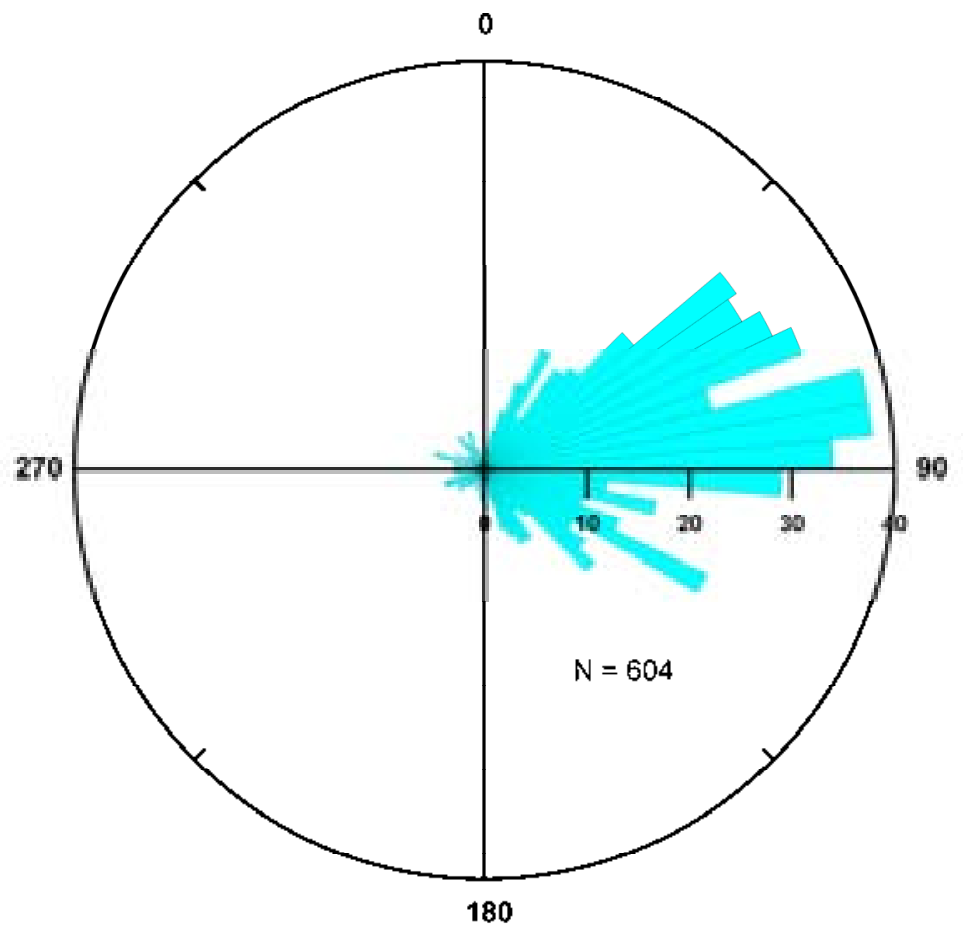

Figure 18

Dip Direction Rose Diagram of Low-Angle Fractures in All SPE Drill Holes

(from the collection of fractures with dips of $0-30$ degrees and rankings $2-5$ identified by Colog)

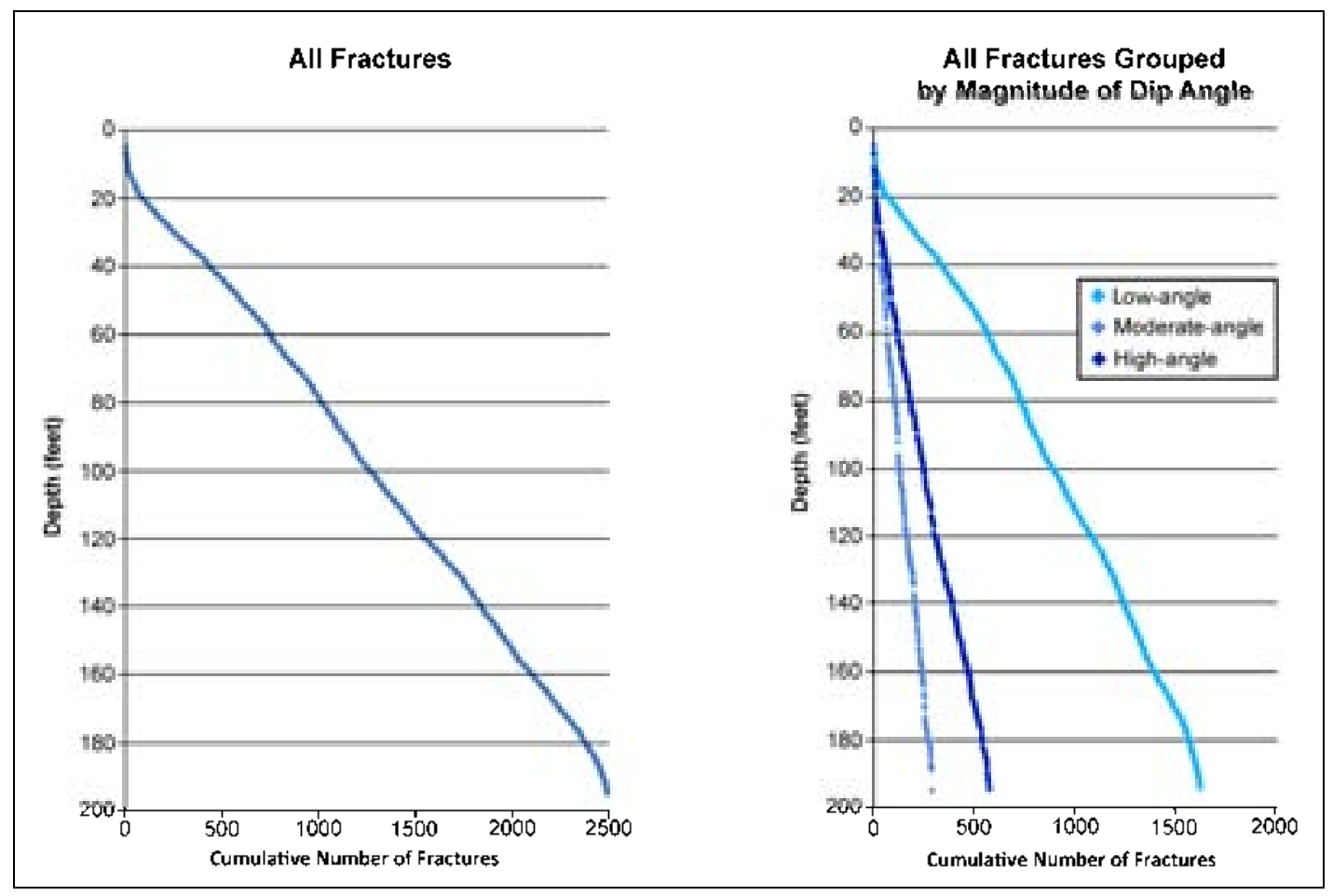

Figure 19

Plots of Cumulative Number of Fractures versus Depth for the SPE Site (all fractures, all holes) 


\subsubsection{Discussion}

The four main fracture sets described above are observed in all holes across the SPE site (Figures 20 and 21). These same fracture sets are also observed in outcrops near the SPE site (Figures 22 and 23). Houser and Poole (1960) produced a detailed surface geologic map of the Climax stock area including locations and orientations of prominent fracture sets observed in granitic outcrops (Figure 24). Houser and Poole (1960) recorded the orientations of 365 sets of fractures at 135 outcrops. These outcrops are located throughout the exposed portions of the stock, and include exposures of both granodiorite and quartz monzonite. It is important to note that Houser and Poole (1960) recorded the orientations of fracture sets at each outcrop location, and thus, each fracture set orientation likely represents the average orientation of multiple fractures with similar orientations. NSTec digitized each fracture set symbol on the map of Houser and Poole (1960) and recorded the strike, dip magnitude and direction, and associated lithology for each mapped fracture set.

Analysis of the surface fracture set data from Houser and Poole (1960) indicates some general similarities with fracture orientations observed in SPE drill holes. Like the fractures observed in the SPE holes, more than 80 percent of the surface fracture sets fall into either a low-angle group dipping from 0 to 30 degrees, or a high-angle group dipping from 60 to 90 degrees (Figure 25). The low-angle group is dominated by northeast-dipping fracture sets similar to the low-angle fractures observed in the SPE holes (Figure 26). The high-angle surface fracture sets show considerably more variability in orientation than the high-angle fractures observed in the SPE holes. However, both data sets show a similar approximately orthogonal pattern defined by northwest-southeast-striking and northeast-southwest-striking fractures (Figure 27). This same orthogonal pattern is observed in fractures from tunnels within the granite (Borg, 1970; Maldonado, 1977; Merritt, 2003; Appendix F in Pohlmann et al., 2007) (Figure 28). This fracture pattern appears to be independent of lithology (Figure 29).

In an effort to determine if one of the identified high-angle fracture sets is more prominent than the rest, we compared the number of fractures tabulated per set (from borehole image logs) and compared the percentage of higher-ranked features among the sets. Sets 1 and 2 (which might be considered part of one east-west-striking set with opposite dip directions) each have more higher-ranked features than Set 3. Sets 1 and 2 also include the two faults encountered in the core hole and Source Hole. However, based on the present-day minimum horizontal stress direction

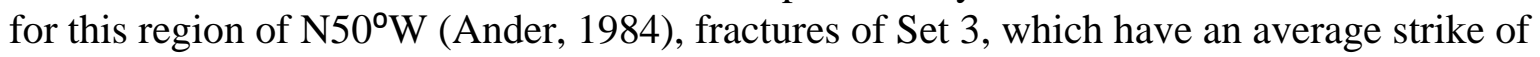
northeast-southwest (parallel to the Boundary fault), are likely in a state of tension compared to fractures with northwest-southeast strikes, which may be in compression. It should be noted, however, that this discussion refers to regional stress regimes, and does not consider local stress conditions at the SPE site.

Two prominent fault zones were observed in the core samples from U-15n. The fault encountered at a depth of $25.3 \mathrm{~m}$ (83 ft) dips 80 degrees to the north-northeast (15 degrees azimuth), and thus is related to SPE Set- 1 fractures. The fault encountered at $32.3 \mathrm{~m}(106 \mathrm{ft})$ dips 79 degrees to the south-southwest (205 degrees azimuth) and is related to SPE Set-2 fractures. Additional information regarding these faults is provided in Section 4.1.3 and in NSTec (2011a,) reproduced in Appendix I. 


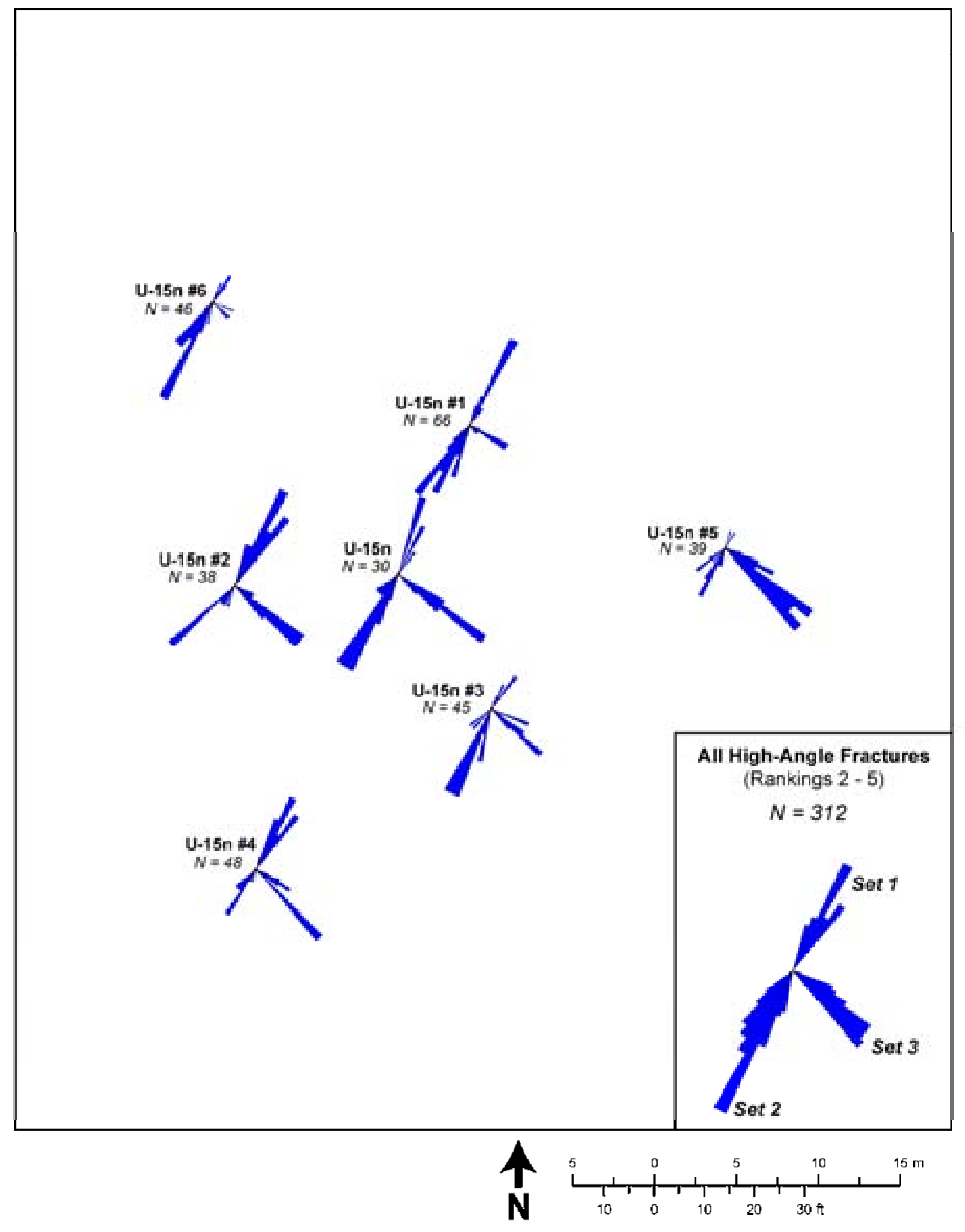

Figure 20

Rose Diagram Map of the SPE Site Showing Dip Directions of the Three Main High-Angle Fracture Sets (Rankings 2-5) in each of the Seven Holes 


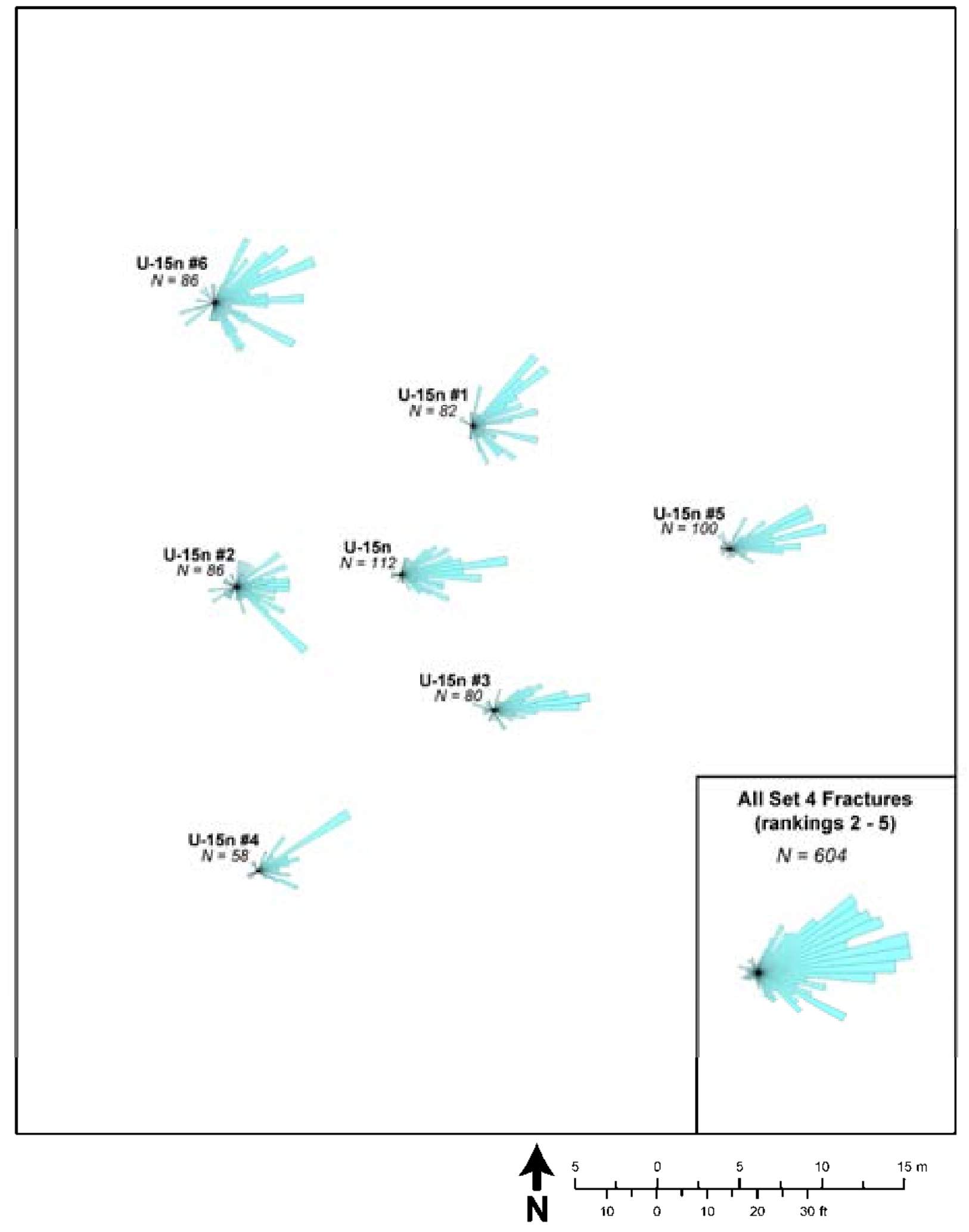

Figure 21

Rose Diagram Map of the SPE Site Showing the Dip Directions of Set 4 (Low-Angle) Fractures in each of the Seven Holes 


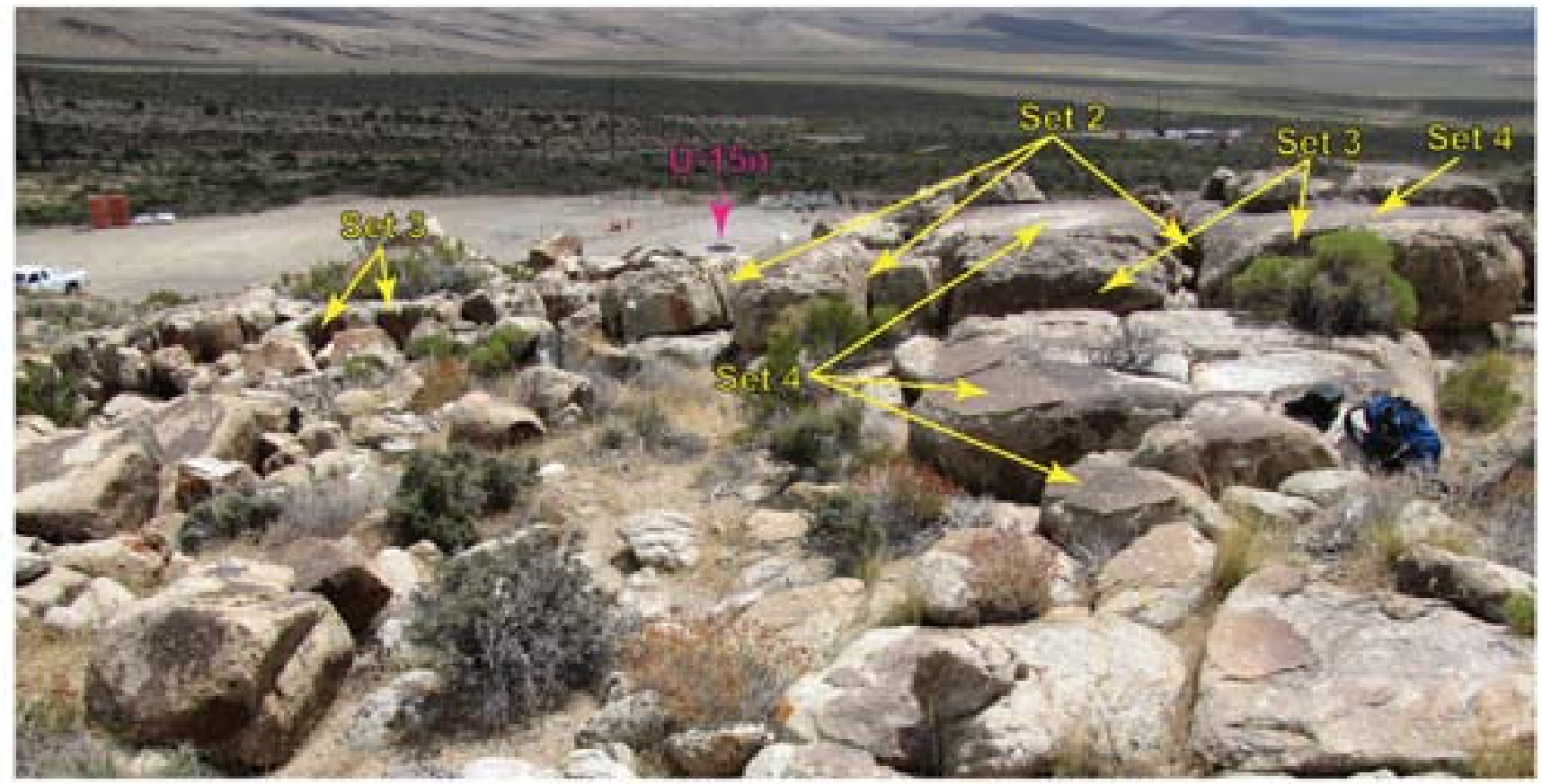

View is southeast across the SPE site and along the strike of fracture sets 1 and 2.

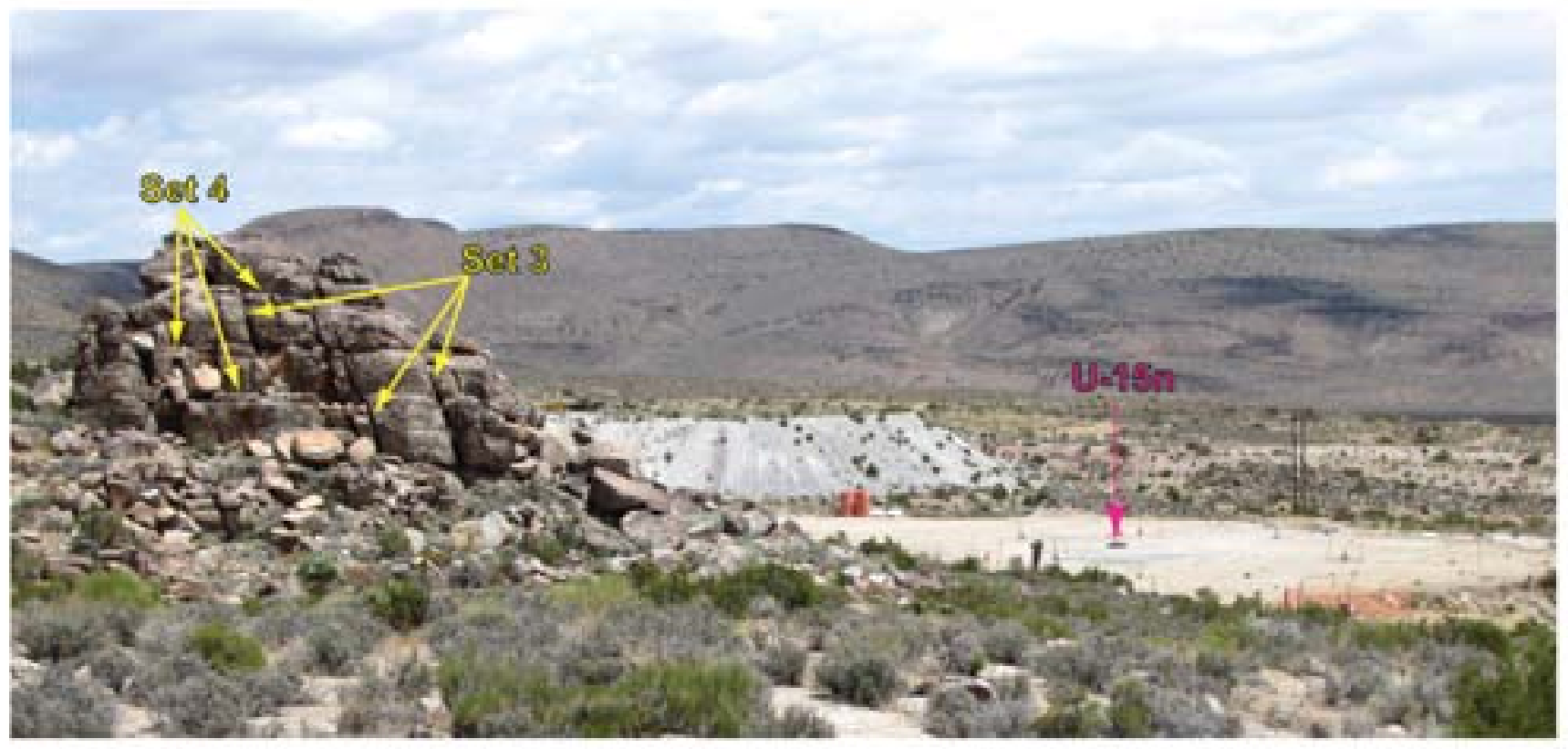

View is northeast and approximately along the strike of fracture set 3.

Figure 22

Photographs of Fractures Exposed West of the SPE Drill Pad 

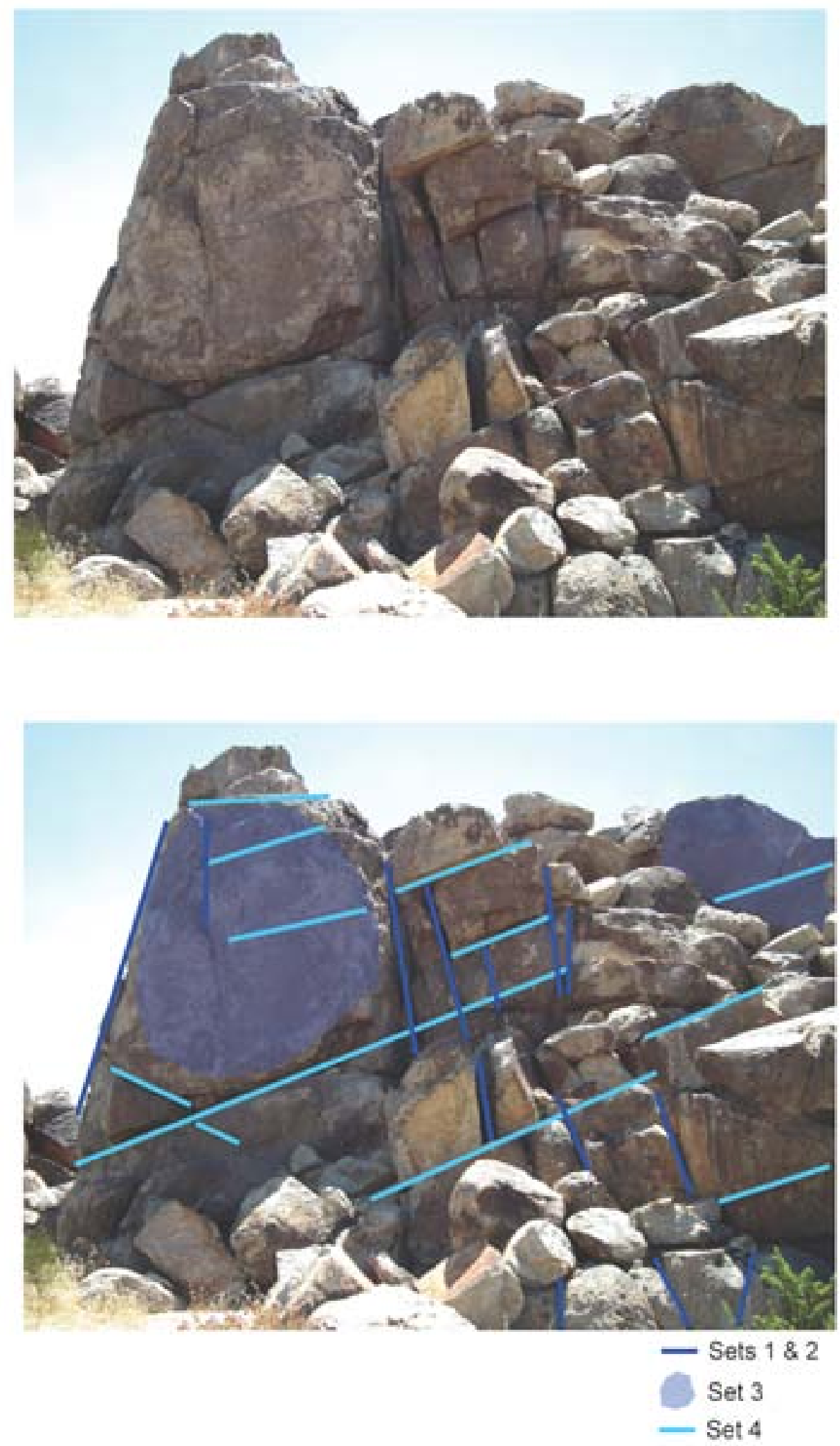

Figure 23

Photograph of Quartz Monzonite Exposure West of the SPE Site Showing Fracture Sets 


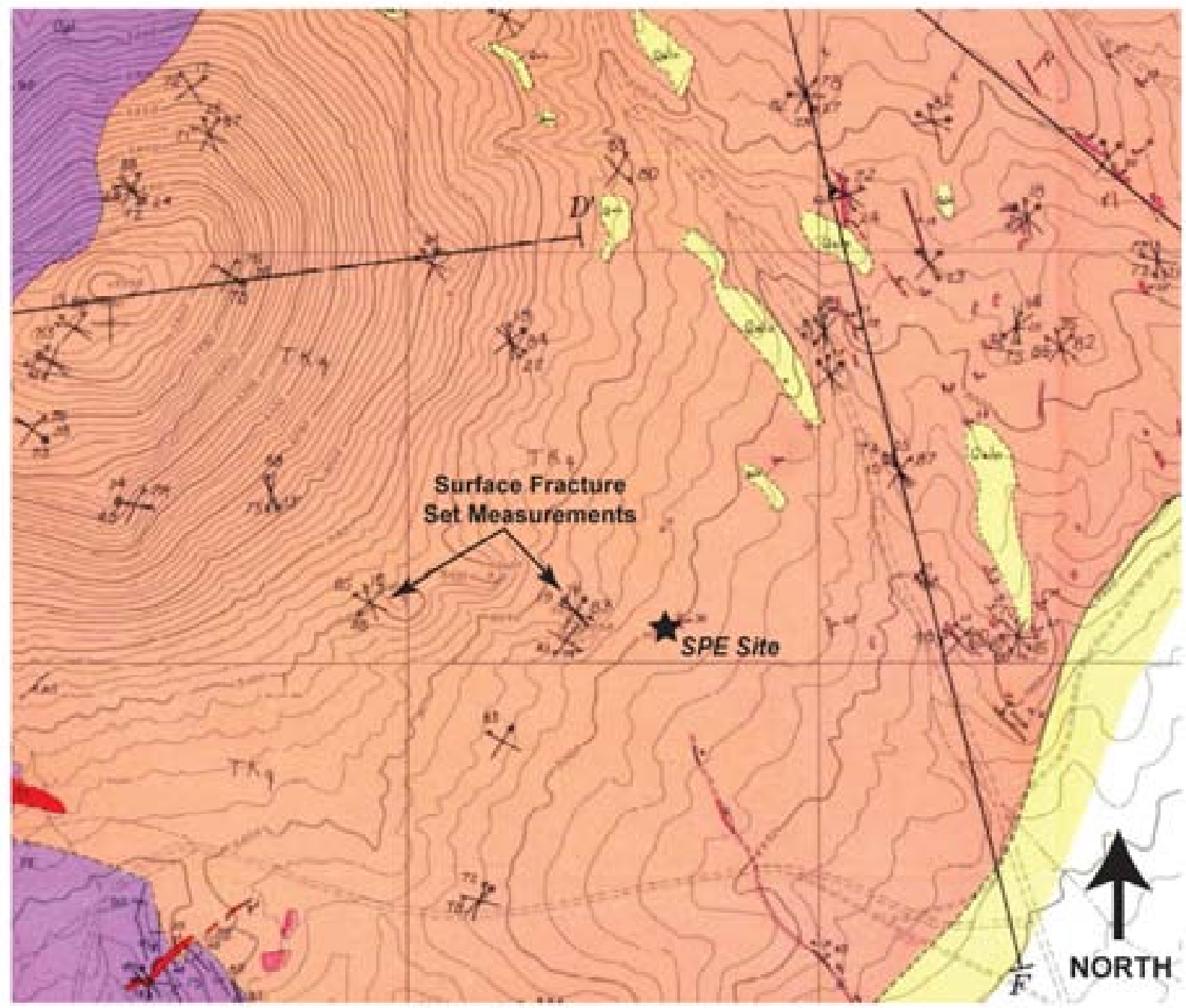

Figure 24

Portion of the Surface Geologic Map of the Climax Stock (Houser and Poole, 1960)

Showing Locations of the SPE Site and Nearby Fracture Set Measurements

See full Houser and Poole (1969) map with legend in Plate 1. 


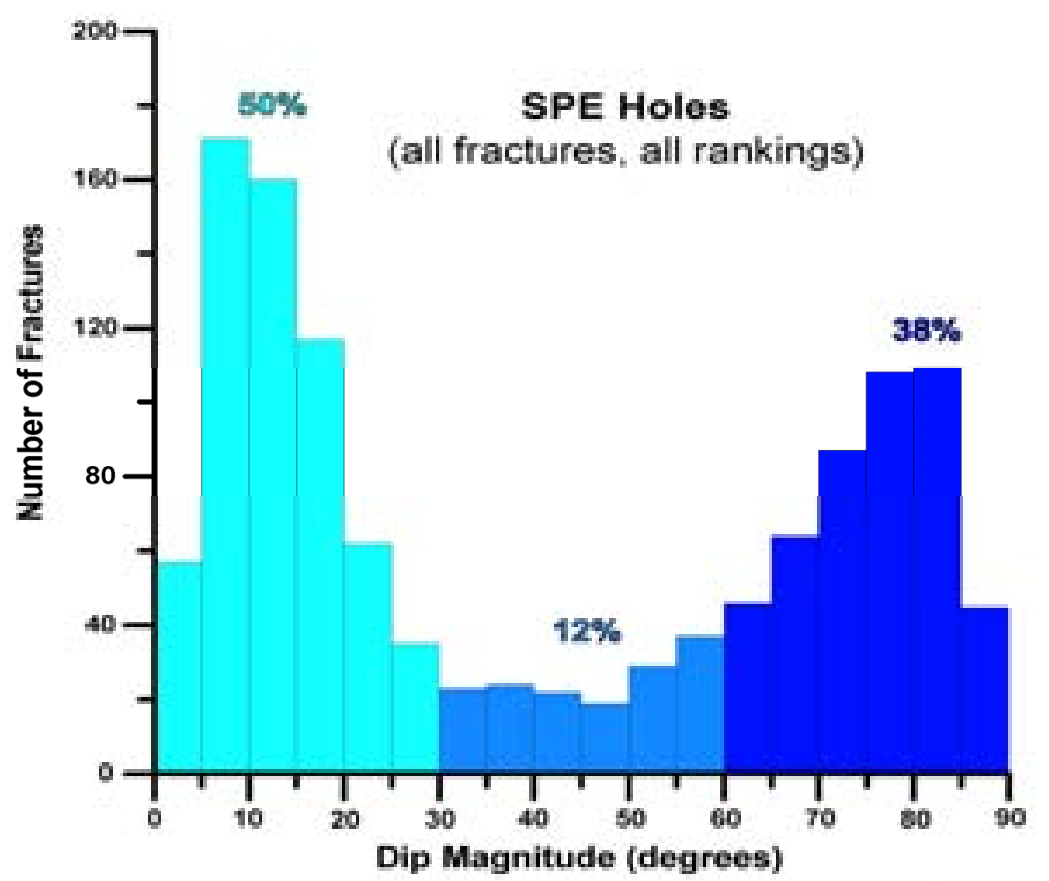

Low-angle $(0-30$ degrees $)$

Moderate-angle (31 - 59 degrees)

High-angle (60 - 90 degrees)

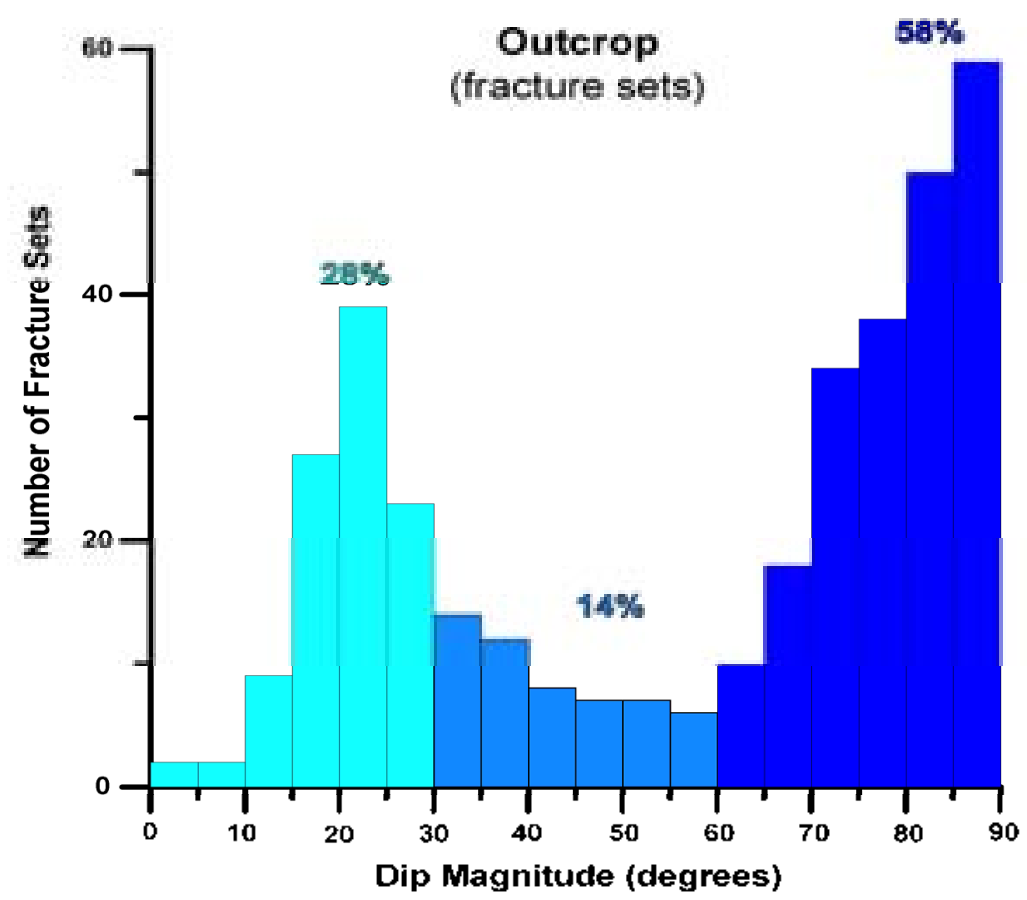

Figure 25

Dip Magnitude Histograms Comparing Fractures Observed in SPE Drill Holes with Fracture Sets Observed in Outcrop 

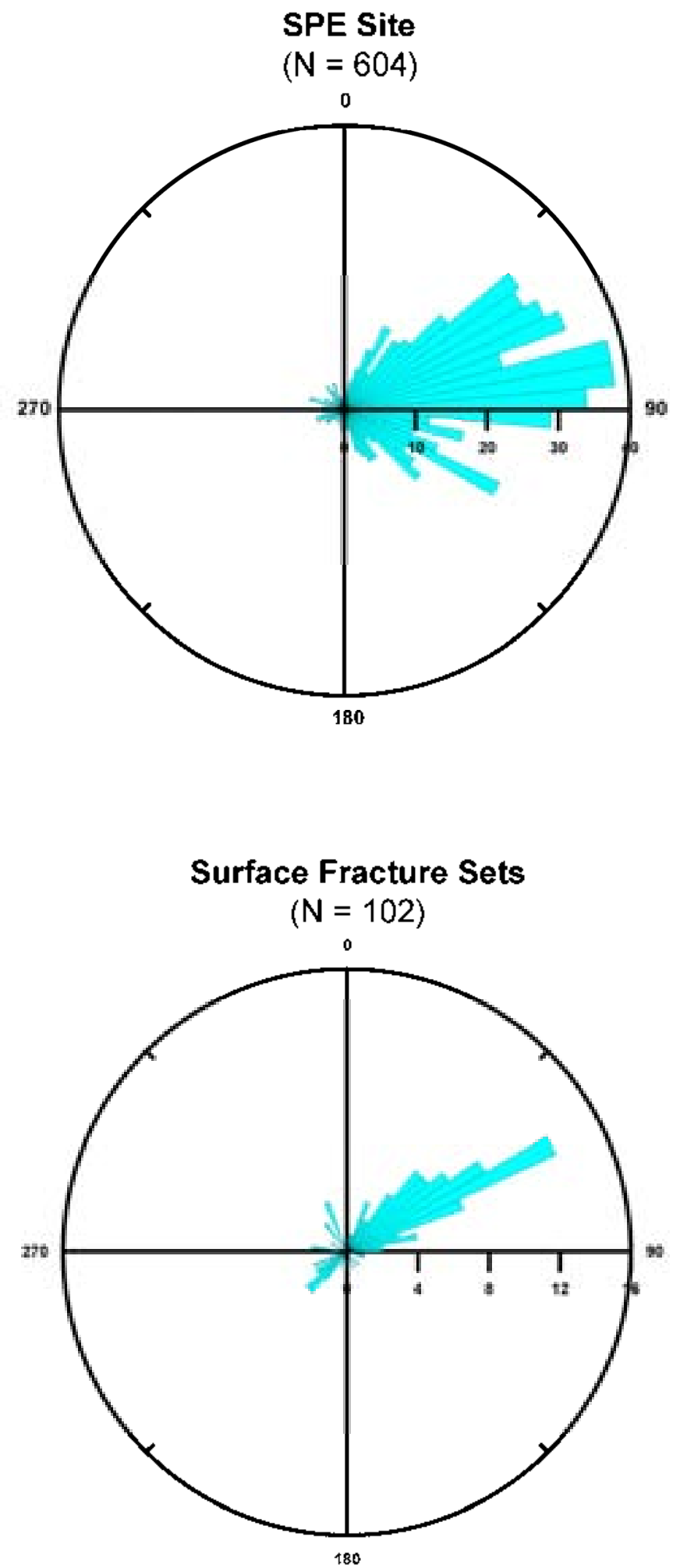

Figure 26

Dip Direction Rose Diagrams Comparing Low-Angle Fractures Identified at the SPE Site with Low-Angle Fracture Sets Observed in Outcrop

(0-30 degrees dip, rankings 2-5) 


\section{SPE Holes}

(all high-angle fractures ranked 2 - 5)

0

315

$$
N=461
$$

45

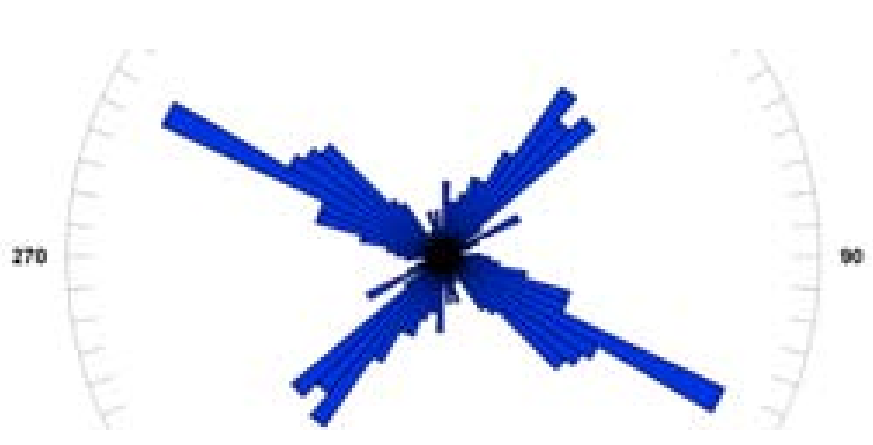

225

135

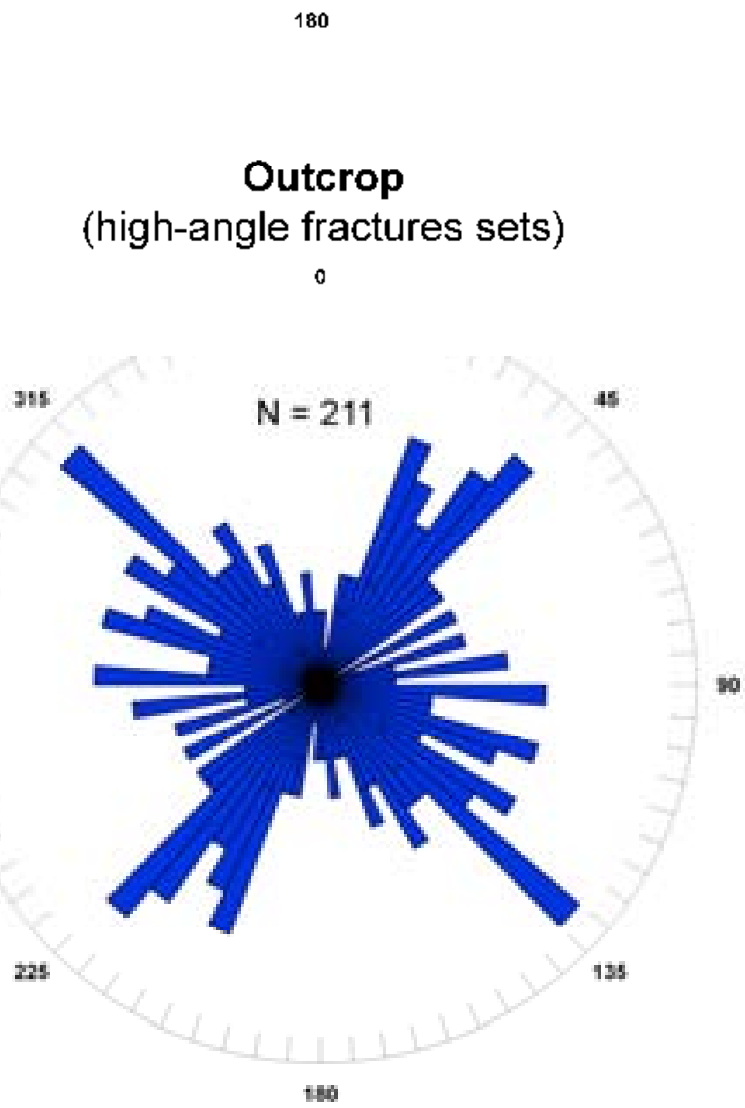

Figure 27

Bi-Directional Rose Diagrams Comparing the Strikes of High-Angle Fractures Observed within SPE Holes with High-Angle Fracture Sets Observed in Outcrop 


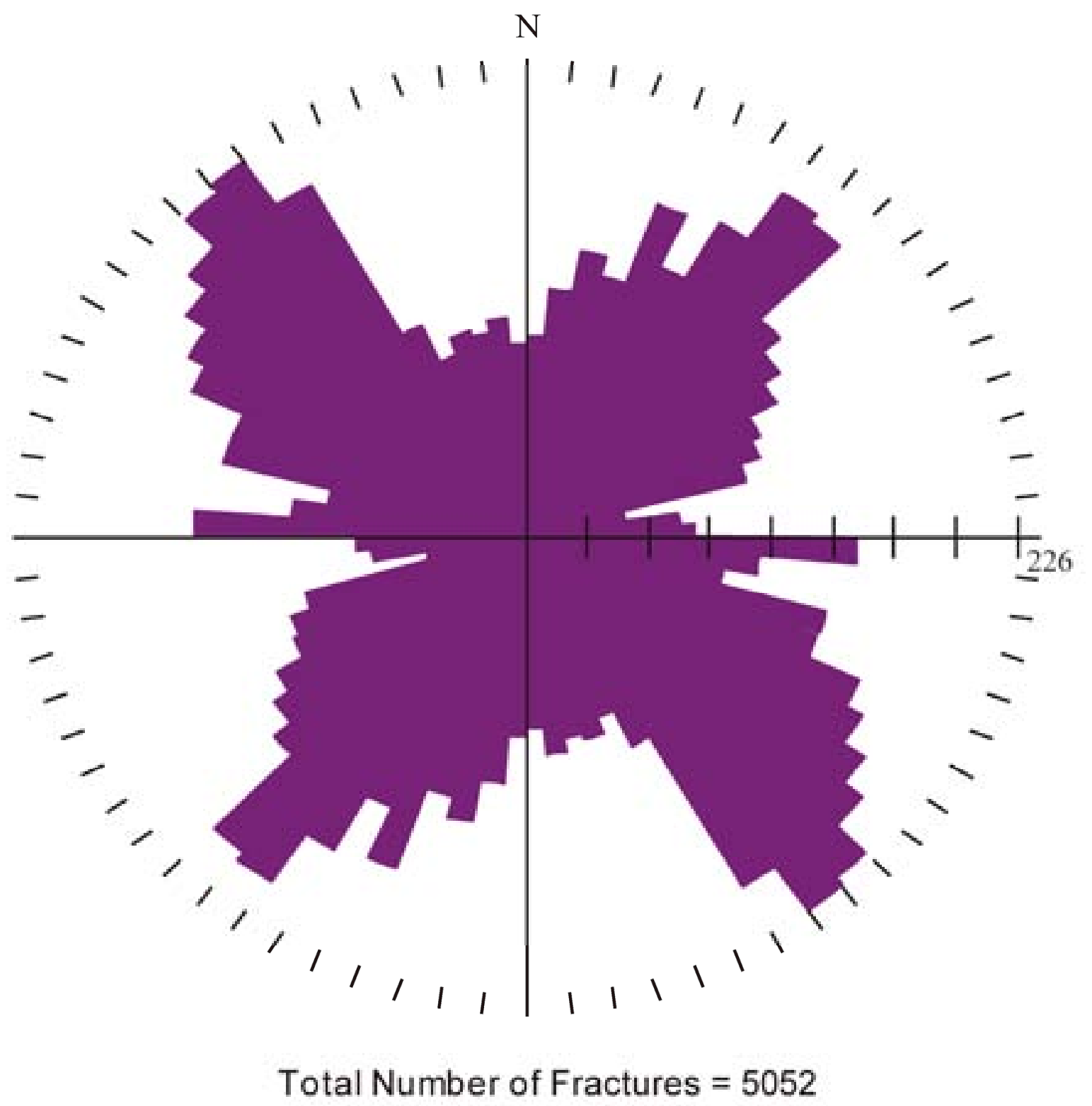

Figure 28

Bi-Directional Rose Diagram of the Strikes of Fractures Observed in the Tunnel Workings at Climax Stock

(data from Pohlmann et al., 2007) 


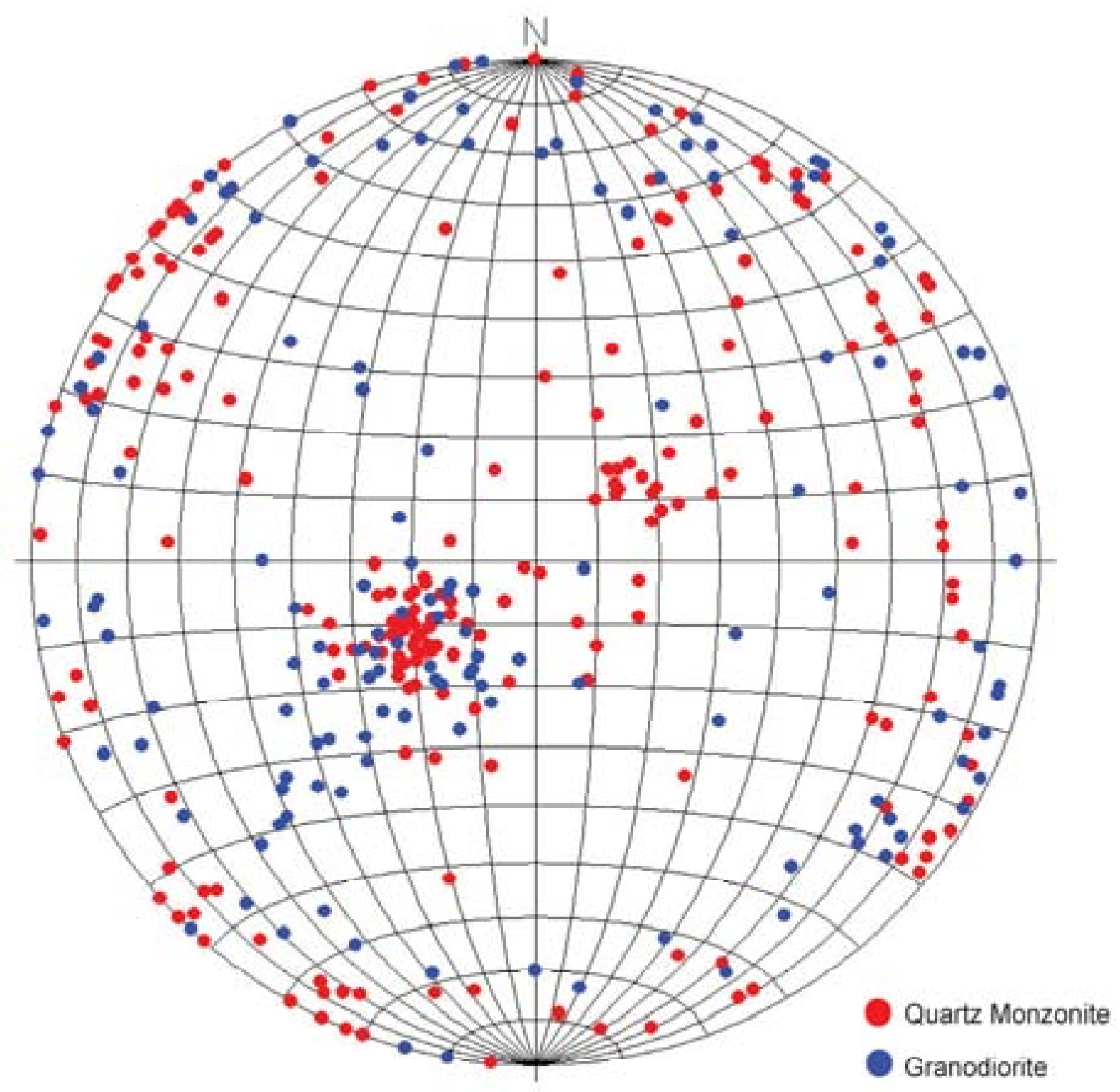

Lower hemisphere, equal area Schmidt net

Figure 29

Stereonet Diagram of the Orientations of Surface Fracture Sets Plotted with Respect to Lithology 
As mentioned previously, evaluation of fracture ranks alone may not indicate the presence of significant fault zones, but such zones might be indicated by clusters of fractures. Figure 30 shows a histogram of high-angle fractures (all ranks) per 1-ft interval in the U-15n Core Hole, based on the Colog image log data. Higher numbers of fractures are associated with both of the fault zones at 25.3 and $32.3 \mathrm{~m}$ (83 and $106 \mathrm{ft}$ ), and both zones have conspicuous intervals of lower density and velocity on borehole geophysical logs. An interval around the depth of $51.5 \mathrm{~m}$ (169 ft) also stands out on Figure 26, though the core in this zone does not appear to be as significantly altered as the two main fault zones. Two of the fractures in this interval, at the depths of 51.1 and $51.5 \mathrm{~m}$ (167.6 and $168.9 \mathrm{ft}$ ), have ranks of 4; all the rest are ranked 3 or less. This zone is not strongly indicated on the density log; however, the sonic log does show an area of slightly lower velocity in the interval compared to the rocks above and below the interval. A

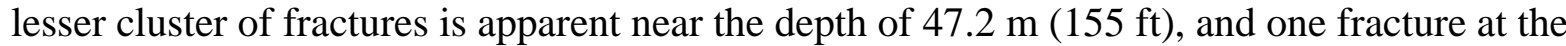
depth of $47.3 \mathrm{~m}$ (155.3 ft) has a rank of 5 (but no others have ranks greater than 3). In this interval the density log shows a short but distinctive interval of lower density, and the sonic log shows a short interval of lower velocity. The fractures in both of these intervals belong mainly to Fracture Set 2. 


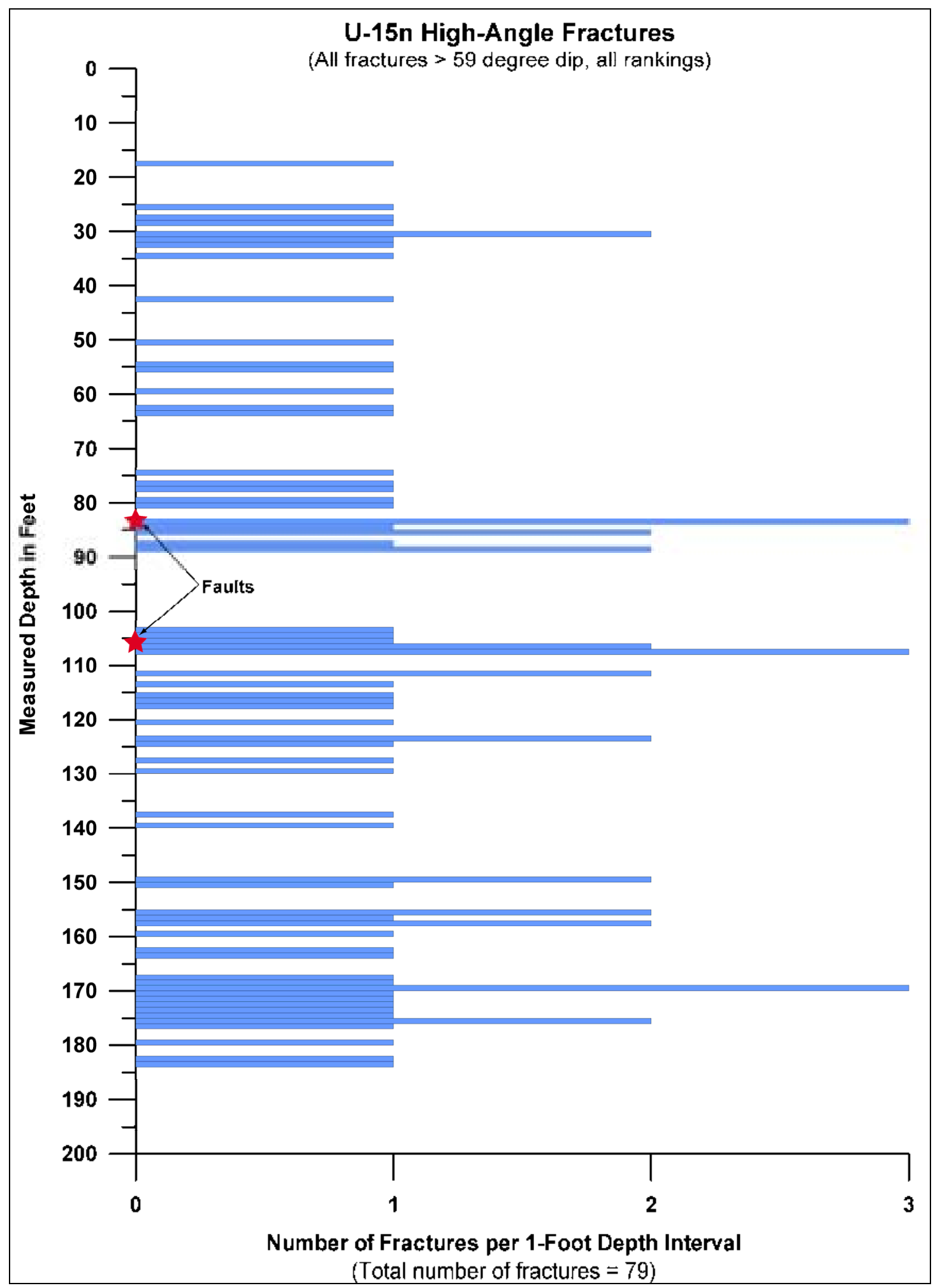

Figure 30

Plot of Number of High-Angle Fractures per Foot in Core Hole U-15n 


\subsection{Groundwater}

The granitic rock matrix at the Climax stock is essentially impervious to groundwater, so the presence and movement of groundwater in the Climax stock is controlled by fractures, faults, topography, and local recharge. The hydrology of the Climax stock area is discussed in Murray (1981).

Occurrences of groundwater were discussed in Orkild et al. (1983), with the conclusion that shallow depths (less than about $305 \mathrm{~m}$ [1,000 ft]) are "almost devoid of groundwater," and that groundwater occurs only locally in perched small volumes. Some holes drilled in support of the UGTs conducted at Climax stock are reported to have perched water at depths ranging from 25.0 to $207.9 \mathrm{~m}$ (82 to $682 \mathrm{ft}$ ), while others were dry (Orkild et al., 1983). Cording (1967) noted that dripping water was observed in only one location in the workings for the U15e TINY TOT test. This water dripped from one of the high-angle fault systems encountered in the drifts, located approximately $122 \mathrm{~m}(400 \mathrm{ft})$ below ground surface. In the present investigation, at least a moderate amount of groundwater was found in boreholes drilled at the SPE site, where the maximum depth of the first seven holes was $60.6 \mathrm{~m}$ (199 ft).

The presence of large amounts of water in the SPE test bed was not expected, and caused complications during drilling and installation of instrumentation. Measurements of groundwater levels in the open holes at the SPE site were made starting in December 2010, and continuing through April 14, 2011. This section provides information and discussion about the groundwater at the SPE site.

Only one deep borehole remains open in the Climax stock in which water level tags are routinely made. The USGS measures water levels quarterly in Well U-15k, located approximately $975 \mathrm{~m}$ $(3,200 \mathrm{ft})$ northeast of the SPE site (Figure 5). The well was pumped nearly dry in 2000, and the water level has been steadily rising from the depth of $239.9 \mathrm{~m}(787 \mathrm{ft})$ on October 26, 2000, to the most recent level of $215.8 \mathrm{~m}$ (708 ft) below ground surface, measured on June 27, 2011 (USGS, 2011).

\subsubsection{Information about Groundwater at the SPE Site}

Information relevant to the discussion of groundwater at the SPE site is listed below.

- When water was first encountered in the boreholes, samples were taken for chemical analysis to try to determine whether the fluid was from natural groundwater sources or was derived from the drilling fluid. The results indicated that the chemistry of the fluid in the boreholes was significantly different from that of the drilling fluid, and thus was likely natural groundwater (Townsend, 2010; attached as Appendix L).

- $\quad$ The four fracture sets present at the SPE site are described in Section 4.2.

- The geology mapped by Houser and Poole (1960) predates ground disturbances from the three UGTs conducted in the stock, and depicts numerous fractures, fracture sets, aplite dikes, and quartz veins. A northward-trending aplite dike/quartz vein was mapped as close as $30 \mathrm{~m}(100 \mathrm{ft})$ south of the drill pad and can be projected to pass through the drill pad (Figure 24). This dike/vein was not identified in the boreholes of the present study, but its presence could influence local fracture patterns and therefore the presence and movement of groundwater. 
- The regional topography dips toward the southeast. Underlying groundwater gradients are typically similar to the overlying topography but can be altered by changes in groundwater recharge and by differential hydrologic permeability caused by faults and fractures.

- The physical process of rotary drilling while circulating an air-foam medium expels formation water and dewaters the borehole as effectively as a pump. The response of groundwater to dewatering, and its recovery when dewatering ceases, can reveal characteristics of the aquifer. In addition, the drill sump may be recharging the local groundwater with purged formation water.

- The groundwater behavior described in this section reflects observations made in open boreholes drilled for the present investigation. It is difficult to determine the nature and movement of local groundwater that existed prior to drilling, and after stemming, because the physical act of drilling and subsequent stemming has altered the groundwater environment.

\subsubsection{Description of Investigation}

As described in Section 1.2 and Appendix B, the SPE test bed consists of seven boreholes approximately $58 \mathrm{~m}$ (190 ft) deep. The holes are located on a single drill pad that had been constructed on a gently southeast-dipping slope, at an elevation of about 1,524 m (5,000 ft) (Figure 31). The central 36-in. diameter Source Hole was drilled intermittently between August 5, 2010, and March 25, 2011. The six 8-in. diameter instrument holes were drilled in two rings around the Source Hole at 10 and $20 \mathrm{~m}$ (33 and $66 \mathrm{ft}$ ) from the Source Hole in August and September 2010. Instrument Hole U-15n\#6 was not available for inspection after instruments were installed, and the hole was stemmed on September 28, 2010. Depth to water was measured intermittently in the remaining five instrument holes and Source Hole, beginning on December 23, 2010, and ending on April 14, 2011 (Table 4).

Depth to water was measured using an electric water level sounding tape. Groundwater elevations reported by NSTec previous to this report were measured from preliminary construction layout ground level elevations. Groundwater elevations presented in this report are measured from as-built survey elevations obtained from NSTec surveyors on May 26, 2011. For this reason, groundwater elevations for particular dates and times reported here may vary slightly from those previously reported.

\subsubsection{Groundwater Measurements}

In this section we describe a series of water-level measurements made in the SPE holes at various times during construction of the test bed. Each subsection includes a description of the site activities as relevant to water levels.

\subsubsection{Prior to December 23, 2010-Site Idle and Rising Water}

The original core hole reached a total depth (TD) of $59.7 \mathrm{~m}$ (196 ft) on July 28, 2010. The fluid level was measured the following day at a depth of $14.3 \mathrm{~m}(47 \mathrm{ft})$. The core hole was enlarged to a 36-in. diameter Source Hole to a temporary bottom depth of $34.1 \mathrm{~m}$ (112 ft) beginning on August 5, 2010, and ending on October 21, 2010. The 36-in. drill bit was left in the hole when the drill string was pulled out on October 27, 2010, and was retrieved on November 3, 2010. 


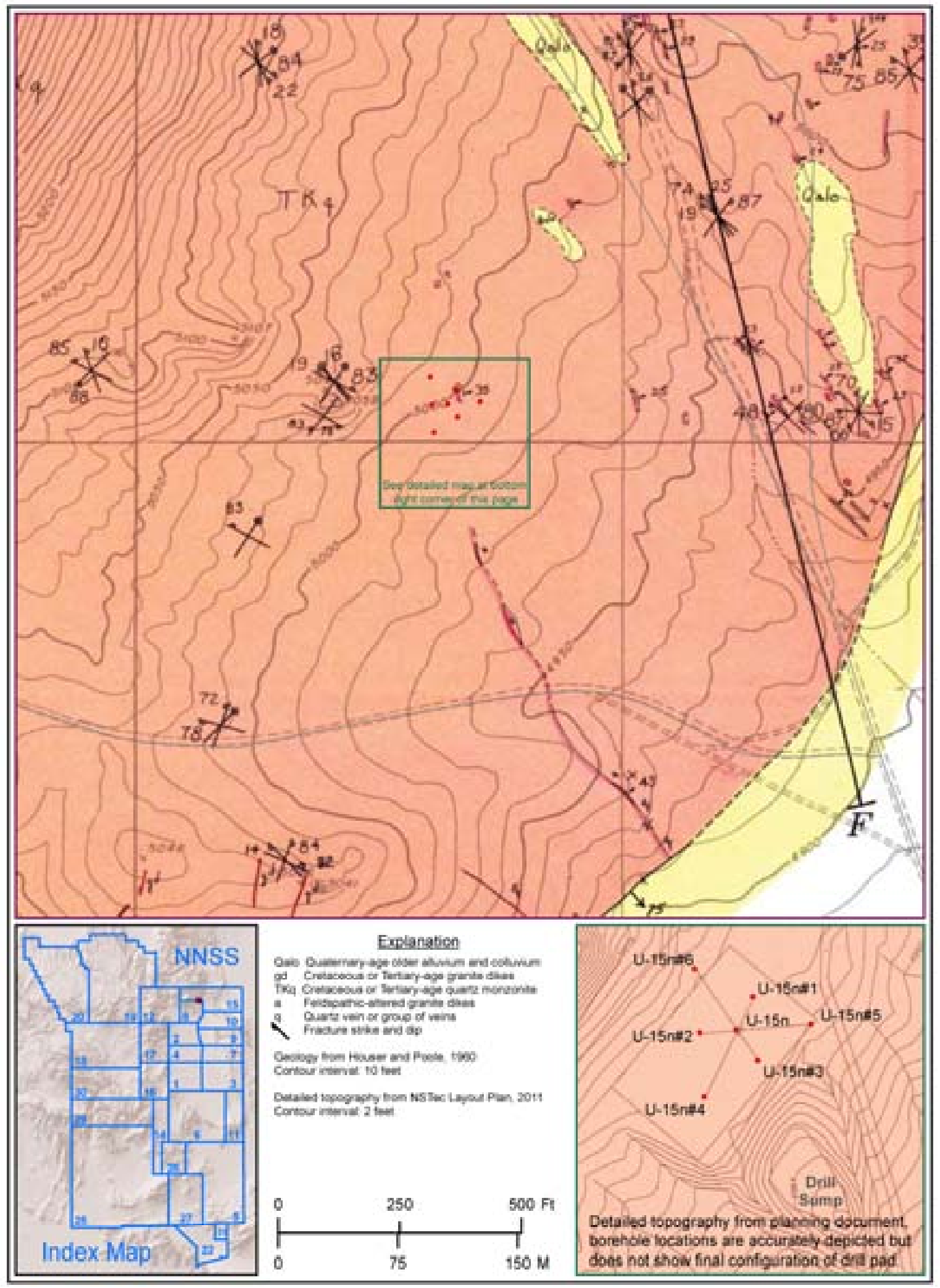

Figure 31

Portion of Geologic Map of Climax Stock (Houser and Poole, 1960) Showing Location of SPE Site 
Table 4

Fluid-Level Measurements Made in SPE Drill Holes from December 2010 through April 2011

\begin{tabular}{|c|c|c|c|c|c|c|c|c|c|c|c|c|c|c|c|c|c|c|c|c|}
\hline \multirow{3}{*}{ Dase } & \multirow{3}{*}{$\operatorname{nim}$} & \multirow{3}{*}{$\begin{array}{l}8000 \\
\text { Pros } \\
\text { mb }\end{array}$} & \multicolumn{3}{|c|}{$0.150[267$} & \multicolumn{3}{|c|}{$4-15 n=1$} & \multicolumn{3}{|c|}{$4-15 n \pi 2$} & \multicolumn{3}{|c|}{ U.15nes } & \multicolumn{3}{|c|}{ U.15n 24} & \multicolumn{3}{|c|}{ U-15nes } \\
\hline & & & 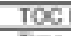 & vation & 600937 & $T \times C$ & velion & 500260 & $T O C$ & waten & 500251 & $T O C$ & Nomben & $502+17$ & $T \times C$ & vovion & $\operatorname{sen} 20$ & $T \times C$ & & $\operatorname{sxo194}$ \\
\hline & & & Time & DTW & GWither & $\pi=6$ & DTw & cWl the & Time & DTW & CWIIN & Tmen & DTW & GWilles & Tes & DTW & CWL her & Time & DTW & CWILE \\
\hline 12:3510 & 7.15 & 887.6 & 9.70 & 5050 & $8 \longdiv { 4 4 5 6 }$ & 500 & \$8.05 & 4044.55 & 900 & 5760 & $4 \sqrt{45.12}$ & 850 & 65.57 & 424461 & 8.55 & Ba.7 & 404352 & 8.41 & 57.35 & $4 \sqrt{4565}$ \\
\hline $1282 a 10$ & & & 1528 & $\operatorname{sen}$ & sa4s st & 1520 & $\operatorname{sen}$ & 49448 & 1519 & 5772 & $\operatorname{ses} 00$ & 15.15 & 5700 & sods sa & $15+17$ & $\operatorname{san}$ & 49049 & $15: 10$ & 57.37 & 4ees 57 \\
\hline $122 \pi=10$ & & & 820 & 5000 & 524454 & 8.17 & 57.78 & 4048.82 & 827 & 5760 & 4MSS.12 & 822 & 57.42 & 20476 & 8.24 & 39.76 & 406350 & 800 & 57.17 & $\operatorname{sen} 77$ \\
\hline 1282016 & 15.45 & 8029 & 1606 & $\operatorname{sos} 8 \mathrm{~s}$ & 424456 & 15.45 & 57.76 & 4044.84 & 15.50 & 57.78 & 404503 & 15.54 & 67.36 & 424480 & 15.57 & 59.75 & 404354 & 1530 & 57.10 & 4044.84 \\
\hline लक्या & $7 \% 0$ & 8744 & क्र० & 59.30 & 24505 & 0.45 & 58.54 & 494606 & 8.54 & 5661 & $4 \operatorname{sen} 20$ & 650 & 36.24 & 45.94 & 8.53 & 57.5 & 4044.4 & 8.47 & 55.92 & 456502 \\
\hline orowin & & & 15.19 & sols & cous on & 1507 & 5847 & 4065.13 & 15.17 & 56.57 & $4 \cos 24$ & 15:13 & $\$ \times 19$ & $\operatorname{sensin}$ & 15.15 & 57.41 & 404468 & is:10 & Sol Bs & $4 \sec 00$ \\
\hline जतथा & 1100 & 8649 & 11.12 & 88.30 & 5.48 .13 & 1050 & 53.33 & 4000227 & 11.10 & 5583 & 40493 & 11106 & 51.6 & 45053 & 1107 & 5525 & 4047.04 & $11 \bar{\alpha}$ & 527 & 40023 \\
\hline लाक्या & 13.30 & 8740 & 13.35 & 5400 & $5950<4$ & 13.23 & 35.65 & 405015 & 1328 & 5230 & $4 B 20.54$ & 13.28 & 49.93 & 4962.28 & 13.30 & 53.93 & 4940.36 & 93.5 & $5+.04$ & $4 B E 0.90$ \\
\hline o1 & 1430 & ด7a.7 & 1437 & 50.96 & 20so as & 1424 & 5100 & 4050.97 & $14: 38$ & 5228 & 4500.53 & 1430 & 40.96 & $\operatorname{sen} 2 x$ & 143 & $5 x$ & 40s: 38 & 1420 & 5102 & 456092 \\
\hline $6122 \pi 11$ & 13.45 & 8727 & 135 & $53 \%$ & 5.503 & 133.37 & 51.35 & 405125 & 1347 & 5207 & 450074 & 13.42 & 4060 & $4 \times 5252$ & 13.45 & 5368 & 404561 & 1340 & 5014 & $401: 20$ \\
\hline कocosil & 945 & 8774 & 940 & 6181 & .80262 & 940 & 65 & $4052 \times 5$ & 947 & 50 & 48233 & 94 & 45.34 & DSEd & 945 & 6234 & 40053 & 942 & 4927 & $4 \times 267$ \\
\hline $600 / 11$ & 900 & 8727 & 8.18 & 5000 & 6253 & 821 & $6 \infty$ & 405360 & 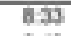 & 4912 & $4 D 500$ & 820 & 47.62 & 69456 & 820 & 5120 & 405109 & 1824 & 465 & 45555 \\
\hline 6000211 & & & & & & 230 & 497 & 405363 & 0.43 & 40.11 & 4163.70 & 237 & 47.52 & 425466 & 2.40 & 51.24 & 4051.06 & 934 & 48.37 & 400.57 \\
\hline क्या1/11 & 8.30 & 8744 & 8.25 & 60.30 & 494413 & 8.29 & 51.50 & 4051.50 & 8.22 & 5065 & 4502.16 & 8.37 & 51.85 & 495033 & 8.41 & 51.80 & 4000049 & 8.32 & 50.47 & 4051.47 \\
\hline อ & 9.45 & 6750 & 9.53 & Noes & 4939 та & 9.45 & 51.58 & 4051,42 & 956 & 5065 & 4002.16 & 1006 & 5219 & 20469 & 10.02 & 51.92 & 4050.47 & 10.07 & 5002 & 406132 \\
\hline $6011 / 11$ & 10.45 & 874.7 & 10.48 & 78.80 & $\sin 25.54$ & 10.57 & 51.47 & 4051.13 & 10.43 & son & 4162 . o2 & 10.57 & 5420 & 4247.80 & 10.54 & 51.35 & 4050.44 & $11: 00$ & $50.8 \mathrm{~s}$ & 4161.06 \\
\hline eשvit/11 & 11.45 & 8744 & 11.80 & 8400 & 471634 & $11: 54$ & 51.89 & 4000.71 & 11.45 & 5089 & 4561.92 & 1200 & 55.56 & 494660 & 11.57 & 51.89 & 4000.40 & 1204 & 51.30 & 4560.64 \\
\hline corr1/41 & 13.00 & 673 & 1314 & 100100 & 80016 & 1254 & 52.42 & 4050.16 & 1245 & 5109 & ABS1:BO & 1253 & 56.50 & 204560 & 12.49 & 51.99 & 4080,36 & 1258 & 5172 & 486022 \\
\hline owil1/11 & 1400 & 875 & 1425 & 10030 & 4064.13 & 1400 & 52.97 & 4045603 & 1348 & 51.18 & 4651.63 & 13.53 & 57.60 & 4244.58 & 1350 & 5201 & 400028 & 1350 & 5223 & $4 \operatorname{sen} .71$ \\
\hline $0611 / 11$ & 15.00 & 873.4 & & & & 15.02 & 80.35 & 4049.25 & 14.48 & 51.30 & 4561.51 & 14.55 & So. 12 & 494405 & 14.52 & 62.10 & 4050.19 & 14.58 & 5265 & 406929 \\
\hline ตรIVIII & 1600 & nzas & & & & $15 \% 9$ & 506 & Aosters & 15.45 & 51.50 & 458131 & 15.8 & 506 & $\sec 50$ & 1580 & 5220 & 400009 & 15.56 & 5997 & 4eeta 97 \\
\hline काषा। & 800 & 8876 & 730 & 8500 & 57043 & 850 & 54.73 & 404787 & 903 & 4.81 & $4+500$ & 211 & 5041 & $\$ 24277$ & gर्ष & 5347 & 405882 & 215 & 5406 & $4 A 78 B$ \\
\hline काषा1 & $\bar{x} 0$ & 8652 & 90 & $7 x$ & 42711 & 848 & 62.55 & 40056 & $8 B$ & 918 & $4 \times 293$ & 852 & 89.13 & 42405 & 84 & 629 & 400535 & 850 & 588 & $4(4) 08$ \\
\hline कrantI & 11245 & NA5 & 112 & $0 \%$ & 6254 & 112 & 5220 & 400031 & 114 & 20 & $490 / 2$ & 1140 & 528 & $\operatorname{seng}$ & $11 \times 2$ & 52.5 & $499 \mathrm{SA}$ & 1120 & 510 & $420 \times 4$ \\
\hline कळzay) & & & 800 & 7100 & 203043 & & & & & & & & & & & & & & & \\
\hline $8624 / 1$ & 8.50 & 8652 & $8 \times$ & 91.56 & $4=1287$ & 822 & 8505 & 4047.57 & 831 & 3405 & dised.75 & 827 & 61.52 & 4) 4066 & 829 & 8007 & 406522 & 8224 & 5433 & 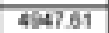 \\
\hline cereis & 1200 & Net9 & $11: 54$ & 913.34 & 4991 09 & 11.55 & 56.45 & 4947.15 & 1200 & SA 20 & tees 50 & 1204 & 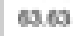 & sase 58 & 1206 & 50.20 & 490909 & 1200 & 5402 & $\operatorname{4an} 7.12$ \\
\hline ceratil & 12.15 & $8 e 4.5$ & 1211 & 11325 & 4961.18 & & & & & & & & & & & & & & & \\
\hline eorat11 & 1300 & 869 & 1255 & 11298 & 4901.45 & & & & & & & & & & & & & & & \\
\hline cersin & & & 120 & 1050 & 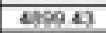 & & & & & & & & & & & & & & & \\
\hline क्षात्रा & & & 800 & 7700 & $52 \pi 0$ & & & & & & & & & & & & & & & \\
\hline $00001 / 1$ & & & & & & 850 & B2.8Y & 404.73 & 904 & 34.16 & 4.ESTES & 8356 & 8.13 & $4 \longdiv { 4 6 0 5 }$ & $2 \pi 0$ & 62.70 & 406150 & 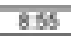 & 5220 & $4(5) \times 1 / 4$ \\
\hline 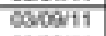 & 900 & 875.7 & & & & $100 \mathrm{~d}$ & 869 & 4945.74 & $90+19$ & $50 \mathrm{Am}$ & 405.83 & 10.14 & 6461 & $4 \$ 37.57$ & 10.66 & 84.12 & 4946.17 & $90+1$ & 86.17 & 4065.77 \\
\hline covonil & 1545 & 0780 & & & & 1560 & 80.73 & 4587 & 1549 & 3707 & 400574 & 15. & & $\cos 710$ & 15.47 & 34 & sostion & 1542 & $\sin 7$ & sess int \\
\hline $\cos 1 / 11$ & 1530 & 8660 & & & & 1528 & 16982 & 4838.76 & 1540 & 735 & $4 W 2.45$ & 15.42 & 13861 & 256557 & 1537 & 12058 & $48 \pi 1.72$ & 15300 & 161.81 & 440.13 \\
\hline 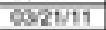 & 1075 & 8561 & 955 & 7031 & 472512 & 1000 & 77.40 & 402520 & 1007 & 6831 & $45 \times 150$ & 18.15 & $76 \times$ & 4258 & $10 \pi 11$ & 73.50 & 400100 & 1020 & 7682 & $4 \operatorname{lis} 42$ \\
\hline com/11 & 1445 & 245 & 1428 & 15000 & 5150 & 1872 & 1090 & $40 \times 67$ & 1620 & 610 & 40029 & 1447 & 116.13 & 510605 & 1860 & 1000 & $4 \times 39$ & 1651 & 14577 & 8150.17 \\
\hline किखsonा1 & 1030 & 8734 & 1010 & 1200 & 401543 & 1022 & 10010 & 483550 & 1020 & 3047 & 4100034 & & & & 1031 & 151.10 & 4851.19 & 10.42 & $106 \%$ & 4503.76 \\
\hline कeण्या1 & 915 & 8747 & 92 & 91.18 & 47328 & 9.15 & 84.05 & 491855 & 928 & 1286 & $4 \sqrt{1025}$ & 920 & 81.76 & $4720<3$ & 923 & 7820 & 402400 & 9.18 & 63.16 & $4 \pi 8.78$ \\
\hline कालड़ाI & 100 & 259 & 753 & 11575 & 5065 & 759 & 11431 & 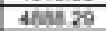 & nod & 491 & 41790 & $\overline{n \infty}$ & 11500 & 247.18 & 806 & 1000 & 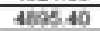 & 100 & 11310 & STHAM \\
\hline का & 800 & 845 & 731 & 13010 & 456127 & 756 & 13933 & 450022 & 800 & 9127 & 451134 & 80 & 13454 & $4 \times 1764$ & 800 & 12278 & 487851 & 730 & 13206 & 450085 \\
\hline कevil11 & 800 & 8341 & 732 & 15045 & 298597 & 7.85 & 15067 & 4551.12 & 800 & 628 & 410061 & 801 & $162 \mathrm{R}$ & 25986 & 800 & 1000 & 400200 & 784 & 14866 & 4828 \\
\hline कासा & 9.5 & 6723 & 977 & 18111 & 555 & 944 & 1652 & $\triangle B 50$ & 981 & 1000 & सका & 986 & 1600 & 150 & 951 & 1802 & 4775.37 & 950 & 1420 & SWos \\
\hline का/2/11 & 500 & 842 & 800 & 1000 & 21357 & 851 & 1002 & 480637 & 835 & 111.30 & 400145 & & & & 900 & 15177 & 485058 & 920 & 10411 & 469783 \\
\hline कe 13911 & 8.0 & 6512 & 800 & 16900 & 435137 & 8.20 & 14405 & 4656.58 & 8224 & 11460 & $48 \times .18$ & 633 & 147.80 & 43543 & 8.26 & 137.18 & 465.11 & 837 & 14228 & $4 B 963$ \\
\hline क्समाI & 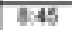 & 8737 & 900 & 11500 & 407.37 & 9.18 & 1156 & 400697 & 8.22 & 15412 & 4006 & 8.59 & 115.43 & 216675 & 8.50 & 972 & 400257 & 8.37 & 114.20 & 40704 \\
\hline
\end{tabular}

Barometric pressure in millibars (mb) recorded from the NWSS Area 2 MEDA02 NOAA weather slation.

Groundwater (GW) elevalion in feet calculated by sublacaling depth to waler (DTW) from lop of casing (TOC) elevation. 
Associated drill bit retainer half-rings, however, were not retrieved until February 2011. On November 4, 2010, a 30-in. diameter mandrel was successfully lowered to the bottom of the 34.1-m (112-ft) deep, 36-in. diameter Source Hole (see Appendix B for more information on drilling of the Source Hole).

\subsubsection{December 23, 2010, to February 9, 2011-Site Idle and Rising Water}

As of December 23, 2010, the site had been idle for 7 weeks with the Source Hole open to its temporary bottom depth of $34.1 \mathrm{~m}$ (112 ft). The site was idle for another 7 weeks, during which water levels in all open boreholes were monitored and found to be slowly recovering from previous dewatering activities (drilling and pumping), rising from depths of about $18.3 \mathrm{~m} \mathrm{(60 \textrm {ft } )}$ to about $15.2 \mathrm{~m}(50 \mathrm{ft})$.

Groundwater elevations for December 23 and 28, 2010, and January 6, 2011, reveal the following characteristics (Figure 32):

- Groundwater elevations in all boreholes were slowly rising (recovering from prior dewatering).

- Instrument Hole \#2 had the highest groundwater elevation.

- The centrally located Source Hole U-15n and eastern Instrument Holes \#1, \#3, and \#5 had similar intermediate groundwater elevations.

- Instrument Hole \#4 had the lowest groundwater elevation.

The groundwater elevation contour maps shown for this time interval do not reveal a southeastdipping water table surface, as was expected given the site topography. Instead, relatively high groundwater elevations in Instrument Holes \#3 and \#5 suggest a possible groundwater mound in the east half of the drill pad.

Groundwater elevations for January 19 and 26, and February 3 and 9, 2011, reveal the following characteristics (Figure 33):

- Groundwater elevations in all boreholes continued to slowly rise.

- Groundwater elevations in the central and eastern boreholes rose above the others, with groundwater elevation in Instrument Hole \#3 being the highest despite being located on the southeast edge of the well field where groundwater elevations were expected to be the lowest.

- Instrument Hole \#4 continued to exhibit the lowest groundwater elevation.

The groundwater elevation contour maps shown for this time interval reveal a groundwater mound forming in the middle of the southeastern edge of the well field. A possible source of the groundwater high is artificial groundwater recharge from the shallow trench and drill sump used for disposal of drill mud and purged formation water (Figure 31). 


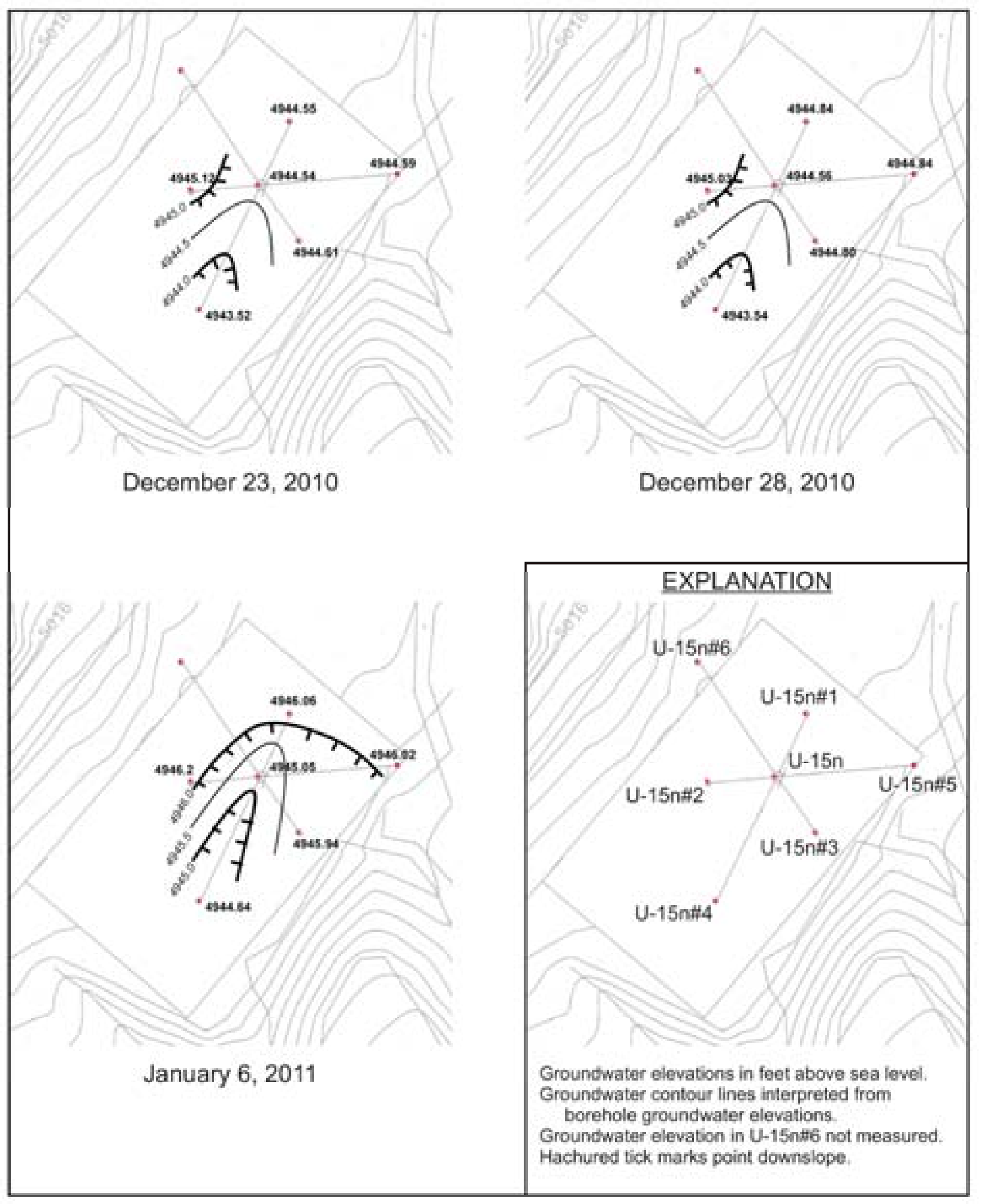

Figure 32

Groundwater Elevation Contour Maps for December 23 and 28, 2010, and January 6, 2011 


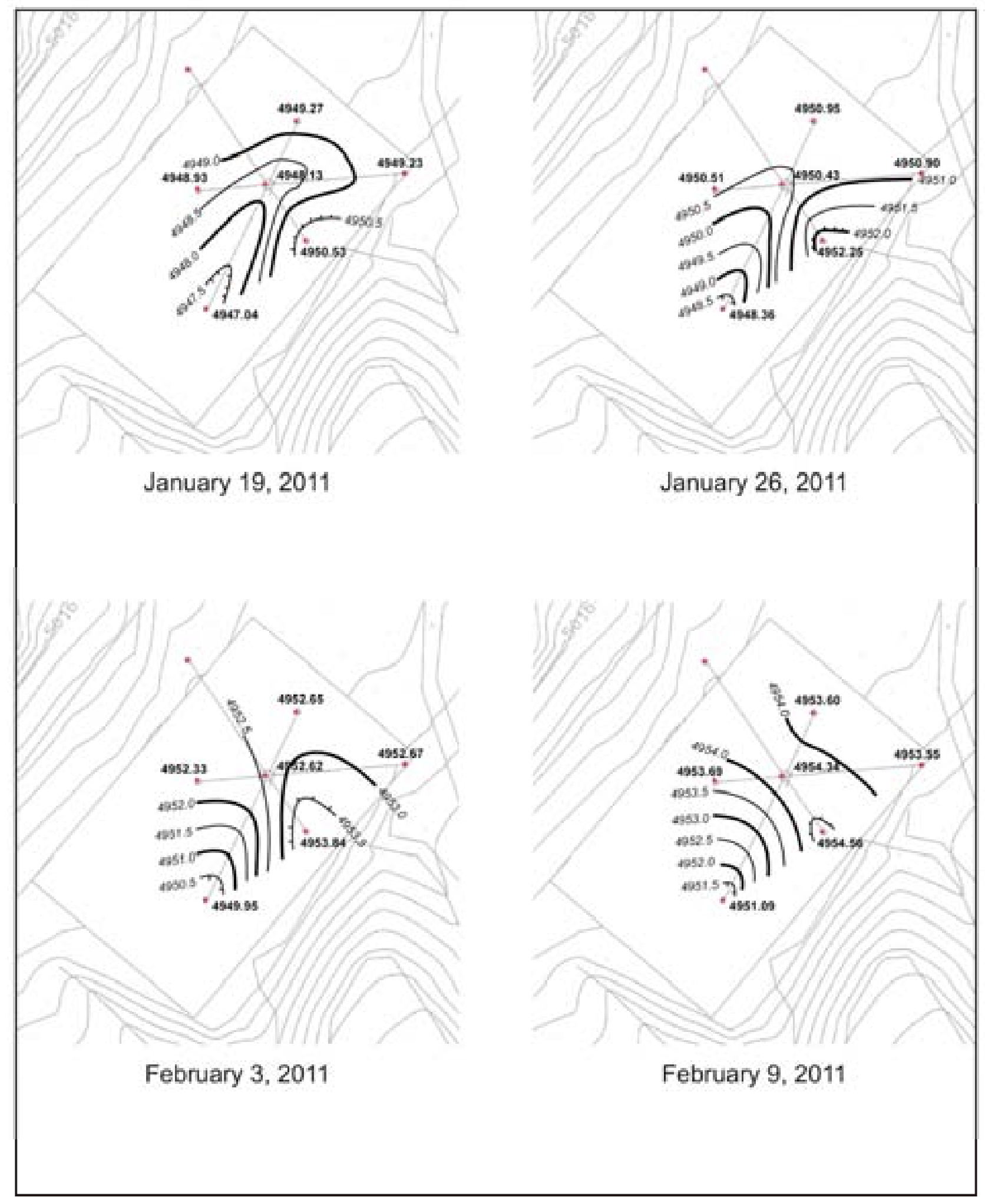

Figure 33

Groundwater Elevation Contour Maps for January 19 and 26, 2011, and February 3 and 9, 2011 


\subsubsection{February 10, 2011, to March 3, 2011-Dewater Source Hole}

In mid-February 2011, efforts resumed to remove fill and to retrieve the lost retainer ring from the bottom of the Source Hole. By the end of February 2011, at least half the ring was recovered before cement was placed in the bottom of the hole. During this month, the Source Hole was dewatered twice for video logging and retrieval of the lost ring, first on February 11, 2011, then again on February 24, 2011.

Groundwater elevation contour maps for February 11, 17, and 24, 2011, reveal the following characteristics (Figure 34):

- The instrument holes were relatively slow to respond to the dewatering of the Source Hole, causing a cone of depression in the water levels centered on the Source Hole.

- Other than the Source Hole, Instrument Hole \#3 consistently exhibited the lowest groundwater elevation during this time interval.

- No single instrument hole consistently exhibited the highest groundwater elevation during this time interval.

- By the end of this time interval, Instrument Hole \#4 exhibited the highest groundwater elevation.

When the Source Hole, open to a depth of $34.1 \mathrm{~m}$ (112 ft), was dewatered, groundwater levels in the instrument holes displayed relatively minor responses. Instrument Hole \#3, which, prior to this time interval had exhibited relatively high groundwater elevations, responded the fastest to dewatering of the Source Hole and now exhibited the lowest groundwater elevation of the instrument holes. Instrument Hole \#4, which prior to this time interval had exhibited the lowest groundwater elevations, responded the slowest to dewatering of the Source Hole and now exhibited the highest groundwater elevation. These observations suggest that, open to a depth of $34.1 \mathrm{~m}$ (112 ft), the Source Hole had relatively poor hydrologic connectivity to the surrounding instrument holes, with Instrument Hole \#3 having more relatively more connectivity to the Source Hole (perhaps due to favorable fracture conditions), and Instrument Hole \#4 having relatively less connectivity to the Source Hole (perhaps due to unfavorable fracture conditions, possibly caused by an intervening dike or vein like that described in Section 4.3.1).

\subsubsection{March 4 to 17, 2011-Drill Source Hole to TD}

Drilling resumed on March 4, 2011, and the 36-in. diameter U-15n Source Hole reached its TD of $60.7 \mathrm{~m}$ (199 ft) on March 17, 2011. Drilling was scheduled as a normal workday daytime operation and effectively dewatered the hole during the drilling process, so the groundwater partially recovered during the intervening nights and weekends. The Source Hole is in a critical location for creating groundwater elevation contour maps, but groundwater levels in the Source Hole could not be measured during this time interval due to the presence of the drill string. For this reason, groundwater contour maps for this time interval were not created.

On March 9, 2011, the Source Hole was advanced from a depth of 43.0 to $44.5 \mathrm{~m}$ (141 to $146 \mathrm{ft}$ ), and drilling effectively dewatered the Source Hole. Other than the Source Hole, the lowest and highest groundwater elevations on this day were measured in Instrument Holes \#3 and \#4, respectively, indicating that at this depth, Instrument Hole \#3 was still relatively more connected, and Instrument Hole \#4 was relatively less connected, to the Source Hole. 


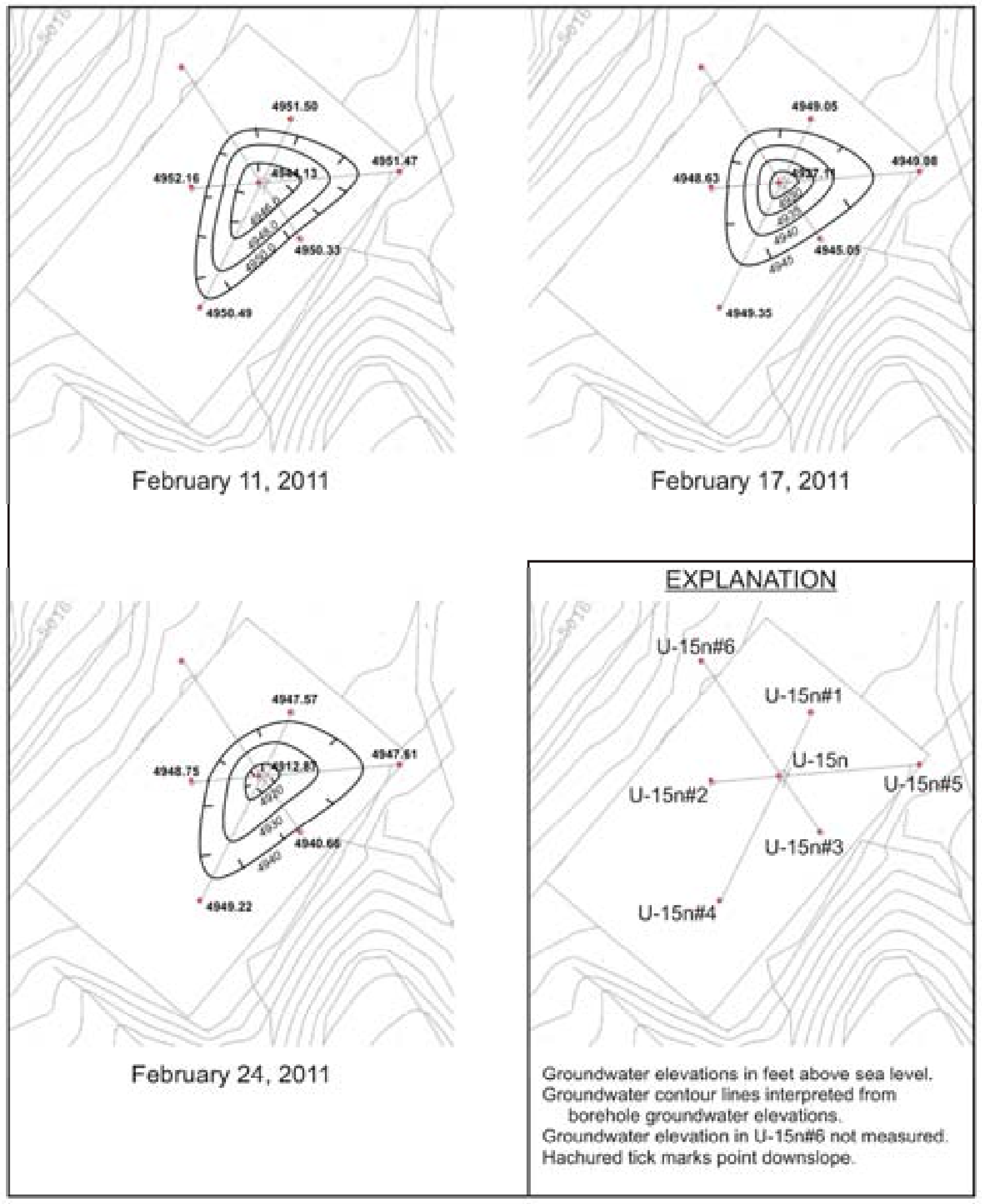

Figure 34

Groundwater Elevation Contour Maps for February 11, 17, and 24, 2011 
On March 17, 2011, the Source Hole reached TD at $60.7 \mathrm{~m}$ (199 ft), and drilling effectively dewatered the Source Hole. Other than the Source Hole, the lowest and highest groundwater elevations following TD on this day were measured in Instrument Holes \#1 and \#2, respectively, indicating that at this depth, Instrument Hole \#1 was relatively more connected, and Instrument Hole \#2 was relatively less connected, to the Source Hole.

These observations with the bottom of the Source Hole below a depth of $34.1 \mathrm{~m}(112 \mathrm{ft})$ are in

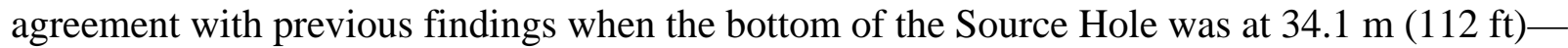
that is, the eastern Instrument Holes \#1, \#3, and \#5 are more responsive to groundwater level changes in the Source Hole than are Instrument Holes \#2 and \#4.

\subsubsection{March 18 to April 14, 2011-Ream, Log, and Place Canister}

After the Source Hole reached TD, a 30-in. diameter mandrel was run into the hole, but it

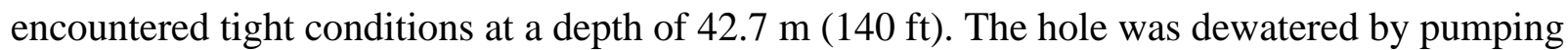
numerous times during this time interval, first for reaming the hole (beginning March 21, 2011), then for geophysical logging (March 30, 2011), and finally for placement of the explosives canister (April 13, 2011). Groundwater elevation contour maps for March 21, April 7, and April 14, 2011, reveal the following characteristics (Figure 35):

- During this time interval, groundwater levels in Instrument Holes \#1, \#3, and \#5 displayed the greatest response to dewatering in the Source Hole, indicating good hydrologic communication between these holes.

- Initially Instrument Hole \#4 displayed the least response to dewatering in the U-15n Source Hole, possibly due in part to natural recharge from up gradient sources.

- By the end of this time interval, Instrument Hole \#2 displayed the least response to dewatering in the U-15n Source Hole, suggesting that Instrument Hole \#2 is the most isolated from all the other holes.

\subsubsection{Summary of Groundwater Monitoring}

Based on previous reports about the geohydrology of Climax stock, geologists had concluded that any groundwater encountered at the shallow depths (upper $61 \mathrm{~m}$ [200 ft]) at the SPE site would be only minor amounts of perched groundwater. However, based on observations in the present investigation, at least a moderate amount of groundwater is present at shallow depths at the SPE site. The response of groundwater in instrument holes to dewatering episodes in the central Source Hole indicates that the flow of groundwater through the fractured granite rock is not uniform horizontally across the drill pad or vertically with increasing depth. This anisotropy is likely the result of fractures occurring in sets of certain orientations, apertures, spacing, and interconnectedness that vary with location and depth. The possible existence of an aplite dike or quartz vein may affect hydraulic conductivity, and drill mud and purged formation water in the sump may be recharging groundwater and causing a groundwater mound.

When the Source Hole was temporarily stopped at a depth of $34.1 \mathrm{~m}(112 \mathrm{ft})$, groundwater interconnectivity with the instrument holes was poor. When the Source Hole was drilled below a depth of $34.1 \mathrm{~m}$ (112 ft), groundwater communication improved with Instrument Holes \#1, \#3, and \#5 but remained poor with Instrument Holes \#2 and \#4. One or more groundwater barriers or 


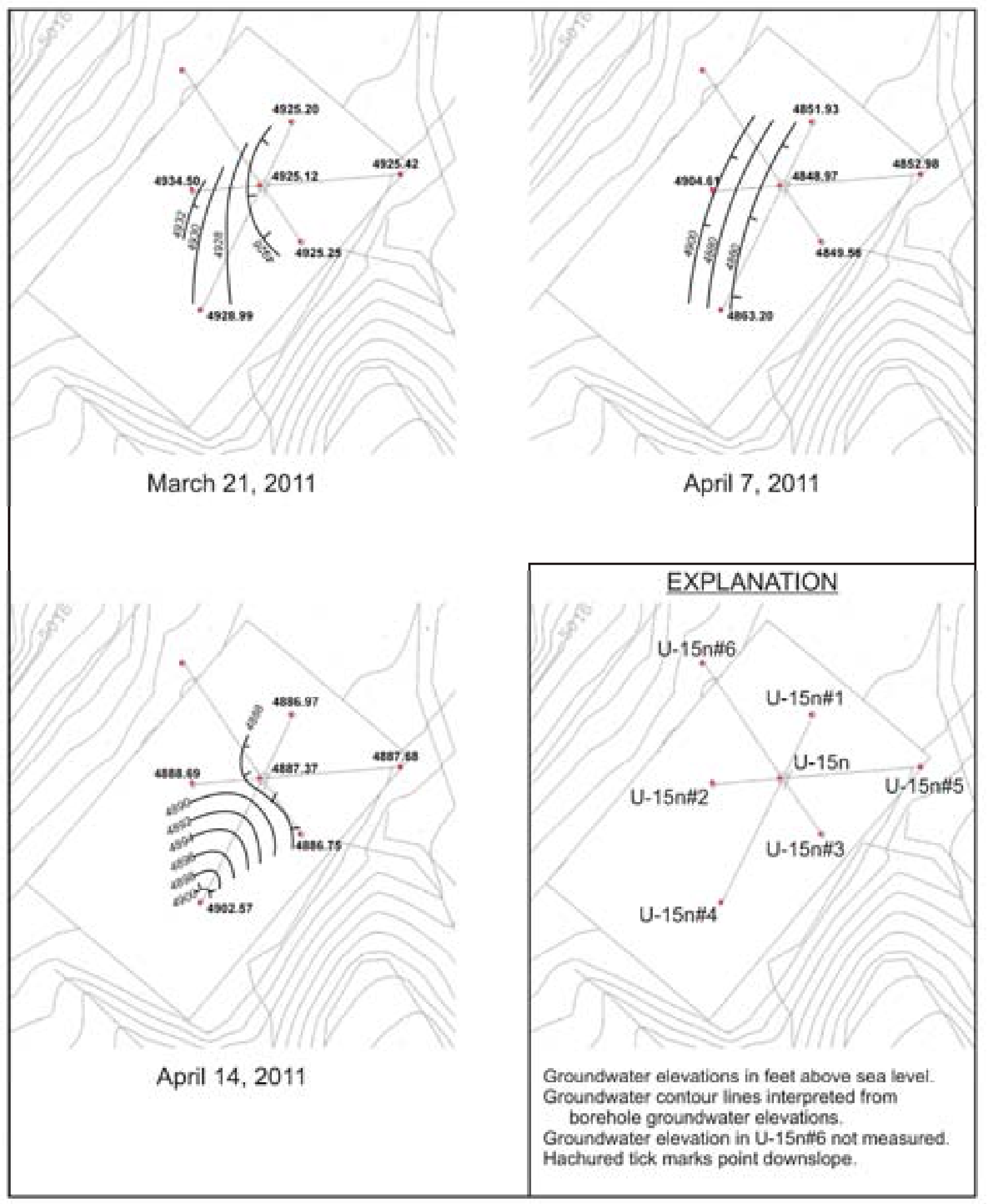

Figure 35

Groundwater Elevation Contour Maps for March 21, April 7, and April 14, 2011 
some configuration of the fracture pattern and fracture interconnectivity (or lack thereof) appear to exist that separate and isolate western Instrument Holes \#2 and \#4 from each other, and from the Source Hole and eastern Instrument Holes \#1, \#3, and \#5. Fractures in the eastern part of the SPE site are probably more interconnected.

As previously stated, these findings apply to the site hydrogeology for the time interval when the boreholes were open to inspection. It is difficult to determine if similar hydrogeologic conditions existed at this site before and after the time interval of this investigation - that is, has the site hydrogeology been significantly changed by the creation, existence, and subsequent stemming of the boreholes. No controlled hydrologic measurements have yet been made that could provide answers to these questions. 
This page intentionally left blank. 


\subsection{Summary}

A test bed for a series of chemical explosives tests known as Source Physics Experiments was constructed in the upper $61 \mathrm{~m}(200 \mathrm{ft})$ of the quartz monzonite of the Climax stock, in Area 15 of the NNSS in 2010-2011. The site is located approximately $245 \mathrm{~m}$ (800 ft) northwest, at closest approach, of the Boundary fault, one of the primary defining structures of the exposure of the Climax granite. Abundant geologic data are available for the area, primarily as a result of studies conducted in conjunction with the three UGTs conducted in the Climax granite in the 1960s and a few later studies of various types.

The first data collected to characterize the SPE site were core samples from a 159.9-m (196.5-ft) deep hole co-located with the explosives canister hole (Source Hole), on which numerous laboratory studies are being conducted. Samples of drill cuttings were collected from the three outer instrument holes and are available for examination if desired. A suite of geophysical logs was also run in the core hole and in all the instruments holes to obtain matrix and fracture properties. Detailed information on the character and density of fractures encountered was obtained from the borehole image logs run in these holes. A total of 2,488 fractures were identified in the seven boreholes, and these were ranked into six categories (0 through 5 ) on the basis of their degree of openness and continuity. The NSTec analysis considered only the higher ranked fractures (ranks 2 through 5), of which there were 1,215 (approximately 49 percent of all fractures identified from borehole image logs).

The fractures were grouped into sets based on their orientation. The most ubiquitous fracture set (50 percent of all higher ranked fractures) is a group of low-angle fractures (dips 0 to 30 degrees). Fractures with dips of 60 to 90 degrees account for 38 percent of high-ranked fractures, and the remaining 12 percent are fractures with moderate dips (30 to 60 degrees). The higher-angle fractures are further subdivided into three sets based on their dip direction: Fractures of Set 1 dip to the north-northeast, and fractures of Set 2 dip to the south-southwest. Sets 1 and 2 could be considered a single high-angle set with dip directions varying northeastward and southwestward off the vertical and a northwesterly strike. Set 3 consists of high-angle fractures that dip to the southeast and strike northeast. The low-angle fractures dip eastward and are designated Set 4. Fracture frequency does not appear to change substantially with depth. True fracture spacing averages 0.9 to $1.2 \mathrm{~m}$ (3 to $4 \mathrm{ft}$ ) for high-angle Sets 1, 2, and 3, and $0.6 \mathrm{~m}(2 \mathrm{ft})$ for Set 4 .

Two significant faults were observed in the core from U-15n, centered at the depths of 25.3 and $32.3 \mathrm{~m}$ (83 and $106 \mathrm{ft}$ ). The upper of these two faults dips 80 degrees to the north-northeast and thus is related to the Set- 1 fractures. The lower fault dips 79 degrees to the south-southwest and is related to SPE Set-2 fractures. Neither fault has an identifiable surface trace.

Groundwater was encountered in all holes drilled on the SPE test bed, and the fluid level averages about 15.2 to $18.3 \mathrm{~m}$ (50 to $60 \mathrm{ft}$ ) below ground surface. An informal study of variations in the fluid level in the holes conducted during various phases of construction of the test bed on a non-interference basis concluded that groundwater flow through the fractured granitic rocks is not uniform, and appears to be controlled by variations in the orientation and degree of interconnectedness of the fractures. It may also be possible that an aplite dike or quartz 
vein may be present in the test bed, which could act as a barrier to groundwater flow and, thus, could account for anisotropy seen in the groundwater recovery measurements.

Additional instrumentation holes were drilled in late 2011 for which geologic data are available, but not included in this report. NSTec geologists will report data from these holes as the analyses are completed, indicating how the newer data compare with the older data reported here. 


\subsection{References}

Allingham, J. W., and I. Zietz, 1962. “Geophysical Data on the Climax Stock, Nevada Test Site, Nye County, Nevada.” Geophysics, vol. 27, num. 5, pp. 599-610.

Ander, H. Dockery, 1984. Written Communication. Subject: "Rotation of Late Cenozoic Extensional Stresses, Yucca Flat Region, Nevada Test Site, Nevada.” Ph.D. Thesis, Rice University, Houston, TX. 77 p.

Barnes, H., F. N. Houser, and F. G. Poole, 1963. “Geologic Map of the Oak Spring Quadrangle, Nye County, Nevada.” U.S. Geological Survey Map GQ-214. Scale: 1:24,000. Washington, D.C. (Included as Plate 2)

Bechtel Nevada, 2006. A Hydrostratigraphic Model and Alternatives for the Groundwater Flow and Contaminant Transport Model of Corrective Action Unit 97: Yucca Flat-Climax Mine, Lincoln and Nye Counties, Nevada. DOE/NV/11718--1119. Las Vegas, NV.

Borg, I. Y., 1970. Survey of Piledriver Results and Preliminary Interpretation of Three Postshot Cores in and near the Cavity. Lawrence Radiation Laboratory Report TID-4500, UC-35. Livermore, CA.

Broome, S. T., and T. Pfeifle, 2011. Written communication prepared for the U.S. Department of Energy, National Security Administration Nevada Site Office. Subject: "Phase 1 Mechanical Testing Results on Core from Borehole U-15n, Nevada National Security Site, in Support of NCNS Source Physics Experiment.” Sandia National Laboratories Report dated June 8, 2011. Attached as Appendix G.

Blouin, S., L. Costin, and K. Wohletz, 2003. "Geotechnical Site Characteristics for HARD HAT and PILE DRIVER.” In Hard Rock Database Review: Final Report and Proceedings of the HRDR Workshop; Volume 1, Unclassified Material. Prepared by Defense Threat Reduction Information Analysis Center, DTRIAC-SR-03-V1, July 2003. Kirtland Air Force Base, NM.

Cording, E. J., 1967. Written Communication. Subject: “The Stability during Construction of Three Large Underground Openings in Rock.” Thesis submitted in partial fulfillment for Ph.D. in Civil Engineering, University of Illinois. 259 p.

Deere, D. U., and D. W. Deere, 1988. “The Rock Quality Designation (RQD) Index in Practice.” In Proceedings of Symposium on Rock Classification Systems for Engineering Purposes. ASTM Special Technical Publication 984, Philadelphia, pp. 91-101.

Deere, D. U., and D. W. Deere, 1989. Rock Quality Designation (RQD) after Twenty Years. U.S. Army Corps of Engineers Report No. GL-89-1, 92 p. 
Defense Threat Reduction Agency, 2003. Hard Rock Database Review: Final Report and Proceedings of the HRDR Workshop; Volume 1, Unclassified Material. Prepared by Defense Threat Reduction Information Analysis Center, DTRIAC-SR-03-V1, July 2003. Kirtland Air Force Base, NM.

DTRA, see Defense Threat Reduction Agency.

Ege, J. R., and R. E. Davis, 1965. Preliminary Appraisal of Proposed Tiny Tot Site \#2 and Exploratory Drill Hole Ue-15f, Area 15, Nevada Test Site. U.S. Geological Survey Technical Letter Area-15-6. Denver, CO.

Houser, F. N., and F. G. Poole, 1959. “Granite” Exploratory Hole, Area 15, Nevada Test Site, Nye County, Nevada-Interim Report, Part A, Structural, Petrographic, and Chemical Data. U.S. Geological Survey Report TEM-836.

Houser, F. N., and F. G. Poole, 1960. "Preliminary Geologic Map of the Climax Stock and Vicinity, Nye County, Nevada.” U.S. Geological Survey, Miscellaneous Geologic Investigations Map I-328. Washington, D.C. (Included as Plate 1)

Houser, F. N., and F. G. Poole, 1961. "Age Relations of the Climax Composite Stock, Nevada Test Site, Nye County, Nevada.” Short Papers in the Geologic and Hydrologic Sciences, U.S. Geological Survey Professional Paper 424-B, pp. B176-B177.

International Society for Rock Mechanics, 1981. "Basic Geotechnical Description of Rock Masses.” International Journal of Rock Mechanics, Mining Sciences, and Geomechanics Abstracts, vol. 18, pp. 85-110.

ISRM, see International Society for Rock Mechanics.

Maldonado, F., 1977. Summary of the Geology and Physical Properties of the Climax Stock, Nevada Test Site. Open-File Report 77-356. U.S. Geological Survey, Denver, CO.

McArthur, R. D., and J. B. Misz, 1960. Geology of the "Granite” Site, Area 15, Nevada Test Site. University of California Lawrence Radiation Laboratory Report GN 7-60, April 6, 1960. Livermore, California.

Merritt, J. L., 2003. “Topics in the Design of HARD HAT and PILE DRIVER Test Structures.” In Hard Rock Database Review: Final Report and Proceedings of the HRDR Workshop; Volume 1, Unclassified Material. Prepared by Defense Threat Reduction Information Analysis Center, DTRIAC-SR-03-V1, July 2003. Kirtland Air Force Base, NM.

Murray, W. A., 1981. Geohydrology of the Climax Stock Granite and Surrounding Rock Formations, NTS. UCRL-53138, Lawrence Livermore Laboratory, Livermore, CA.

Naiser, C. W., and F. Maldonado, 1981. Fission-Track Dating of the Climax and Gold Meadows Stocks, Nye County, Nevada. In: Short Contributions to Geochronology. U.S. Geological Survey Professional Paper 1199E, pp. 45-47. 
National Security Technologies, LLC, 2010. Written Communication. Subject: "Site Selection for Source Physics Experiments in Granite at the Nevada Test Site.” Prepared by M. Townsend, L. Prothro, and D. Haugstad, March 11, 2010. Attached as Appendix A.

National Security Technologies, LLC, 2011a. Written Communication. Subject: "Projected Extent of Two Faults Encountered in Core Hole U-15n.” Prepared by UGTA/Boreholes Geology Group. March 8, 2011. Attached as Appendix I.

National Security Technologies, LLC, 2011b. "Handling and Documenting Geologic Samples," Organization Procedure OP-2152.204, Rev. 0, May 2, 2011. Las Vegas, NV.

NSTec, see National Security Technologies, LLC.

Orkild, P. P., D. R. Townsend, M. J. Baldwin, D. L. Healey, G. D. Bath, C. E. Jahren, and J. G. Rosenbaum, 1983. Geologic and Geophysical Investigations of Climax Stock Intrusive, Nevada. Open-File Report 83-377. U. S. Geological Survey, Denver, CO.

Phelps, G. A., R. C. Jachens, B. C. Moring, and C. W. Roberts, 2004. Modeling of the Climax Stock and Related Plutons Based on the Inversion of Magnetic Data, Southwest Nevada. U.S. Geological Survey Open-File Report 2004-1345. Denver, CO.

Pohlmann, K., M. Ye, D. Reeves, D. Decker, J. Chapman, and M. Zavarin, 2007. Modeling of Groundwater Flow and Radionuclide Transport at the Climax Mine Sub-CAU, Nevada Test Site. DOE/NV/26838-06, Desert Research Institute Publication Number 45226. Las Vegas, NV.

Sargent, K. A., and P. P. Orkild, 1973. Geologic Map of the Wheelbarrow Peak-Rainier Mesa Area, Nye County, Nevada. U.S. Geological Survey Miscellaneous Geologic Investigations Map I-754, scale 1:48,000.

Shellum, C., Springfield Research Facility, 1996. Written communication to L. Ashbaugh and G. Baladi, Defense Special Weapons Agency. Subject: Climax Granite Weathering and Engineering Properties, September 24, 1996.

Shellum, C., and P. Fisher, Springfield Research Facility, 1996. Written communication to G. Baladi, Defense Special Weapons Agency. Subject: Mechanical Properties for Climax Granitic Rock, NTS. October 4, 1996.

Slate, J. L., M. E. Berry, P. D. Rowley, C. J. Fridrich, K. S. Morgan, J. B. Workman, O. D. Young, G. L. Dixon, V. S. Williams, E. H. McKee, D. A. Ponce, T. G. Hildenbrand, WC Swadley, S. C. Lundstrom, E. B. Ekren, R. G. Warren, J. C. Cole, R. J. Fleck, M. A. Lanphere, D. A. Sawyer, S. A. Minor, D. J. Grunwald, R. J. Laczniak, C. M. Menges, J. C. Yount and A. S. Jayko, 1999. Digital Geologic Map of the Nevada Test Site and Vicinity, Nye, Lincoln, and Clark Counties, Nevada and Inyo County, California. U.S. Geological Survey Open-File Report 99-554-A, scale 1:120,000. 
Townsend, M. J., National Security Technologies, LLC, 2010. Written communication. Email to Source Physics Experiment Subject Matter Experts. Subject: "Water in the SPE Holes." December 29, 2010. Attached as Appendix L.

USBR, see U.S. Bureau of Reclamation.

U.S. Bureau of Reclamation, 2007. Engineering Geology Field Manual. www.usbr.gov/pmts/geology/geolman/. Accessed on October 17, 2011.

U.S. Geological Survey. USGS/DOE Cooperative Studies in Nevada Website: Water-Level Wells, Nevada National Security Site. http://nevada.usgs.gov/doe_nv/ntsmap.htm Last accessed on September 13, 2011.

USGS, see U.S. Geological Survey.

Wilder, D. G., and J. L. Yow, Jr., 1984. Structural Geology Report Spent Fuel Test - Climax Nevada Test Site. Lawrence Livermore National Laboratory Report UCRL-53381. 


\title{
APPENDIX A
}

Site Selection for Source Physics Experiment in Granite at the Nevada Test Site

\author{
By
}

Margaret Townsend, Lance Prothro, and Dawn Haugstad UGTA/Boreholes Project National Security Technologies, LLC

March 11, 2010 


\title{
Site Selection for Source Physics Experiment in Granite at the Nevada Test Site
}

\author{
Margaret Townsend, Lance Prothro, and Dawn Haugstad \\ National Security Technologies, LLC, UGTA/Boreholes Project \\ March 11, 2010
}

\section{Introduction and Preliminary Criteria}

Discussions among the National Center for Nuclear Security Source Physics Experiment (SPE) subject matter experts, held at Sandia National Laboratories (SNL) in Albuquerque, New Mexico, on 22-23 February 2010, addressed very preliminary requirements for the experiment site, pending further development of the experiment design. These preliminary requirements included:

- "Homogeneous" granite, with surface weathered zone to be as thin as possible. Preliminary geologic info presented at the meeting suggested that weathering of the granite at Climax generally extends as much as 50 feet $(\mathrm{ft}$ ) or more from the surface, and is quite variable.

- No obvious faults in area, though it was recognized that there will be fractures, even in the unweathered granite at depth (these will be characterized within the source and gage holes by means of coring and geophysical logging).

- Avoid lithologic contacts, including that between the quartz monzonite (Kqm) and the granodiorite (Kgd) that make up the Climax body.

- Position as close as feasible to existing roads and other infrastructure.

- Keep appropriate distance from the surface ground zeros of the three underground nuclear tests conducted at Climax.

- The group envisioned one source hole (30 inches or less in diameter) with two rings of 6-inch diameter gage holes. A working sketch showed the two semicircular rings of six holes each ( 12 holes total) centered on the source hole. Distance from source hole to farthest gage hole to be approximately equal to one depth of burial. These specifications are factors in how large a site is needed.

- All holes nominally 100-150 feet deep. Depth might have to be adjusted based on knowledge of depth of weathering at the selected site.

- Depth of weathering to be mapped seismically by SNL at two or three preliminary sites prior to final site selection.

National Security Technologies, LLC, geologists have selected three sites for further study, incorporating the above criteria to the extent possible, and trying to provide a choice of sites in the two granitic rock types. Figures 1 and 2 show the three locations; Figure 1 is on an orthophoto base, and Figure 2 shows the surface geology. The sites are numbered 1, 2, and 3, which reflects our estimation of their ranking, based on our current understanding of the requirements.

\section{Discussion of three Area 15 sites selected for further study}

Sites 1 and 2 are both located on Kqm, and Site 3 is located on Kgd. Site 3 is higher in elevation than the other two sites, and in general the terrain on the Kgd surface seems rougher than that on the Kqm. Sites 1 and 2 are on or near existing pads, which could be expanded to suit the needs of the SPE. The pad for Site 3 would have to be constructed on "virgin" ground. 


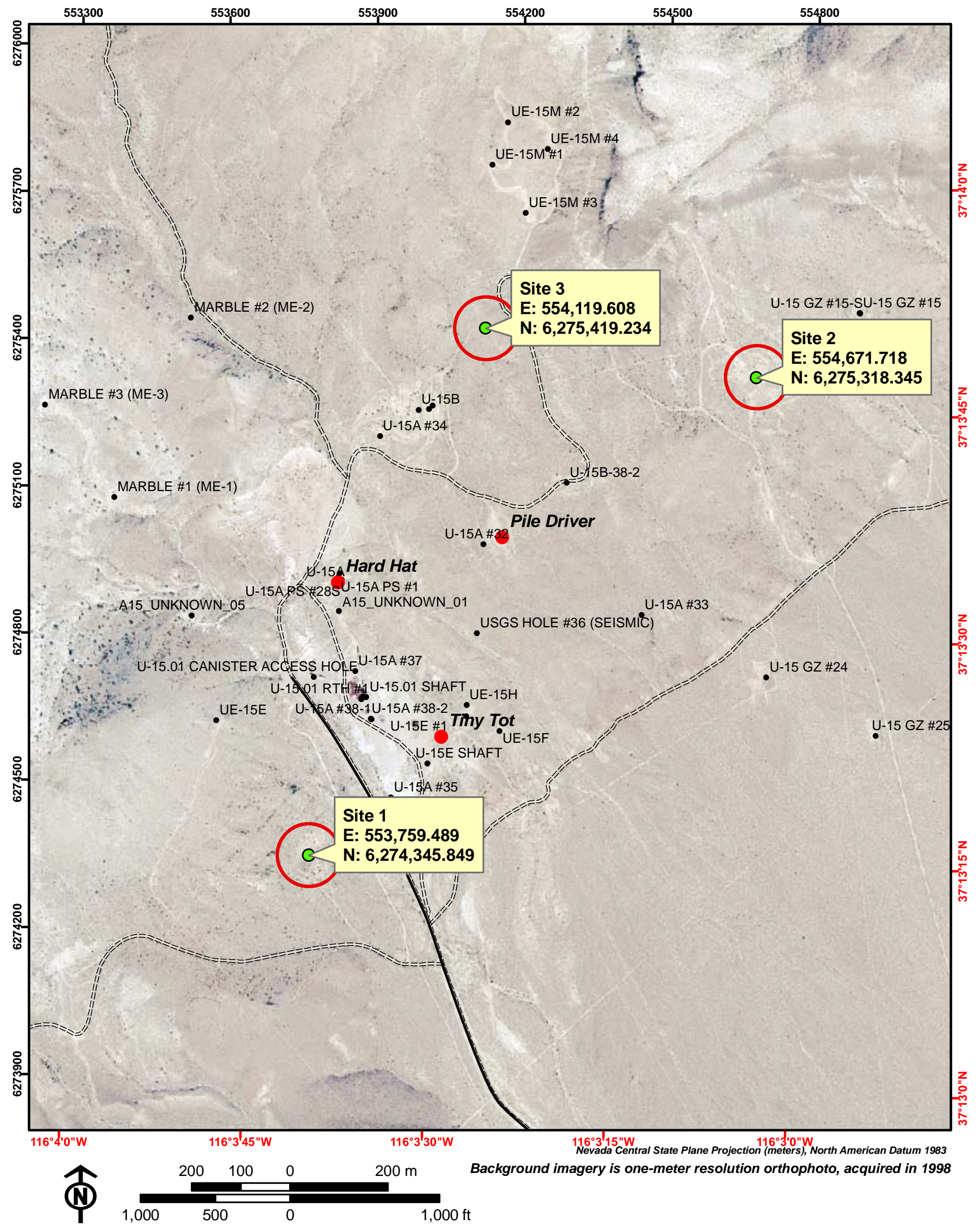

Figure 1. Orthophoto of Climax Stock Area Showing Locations of Three SPE Sites Selected for Further Study 


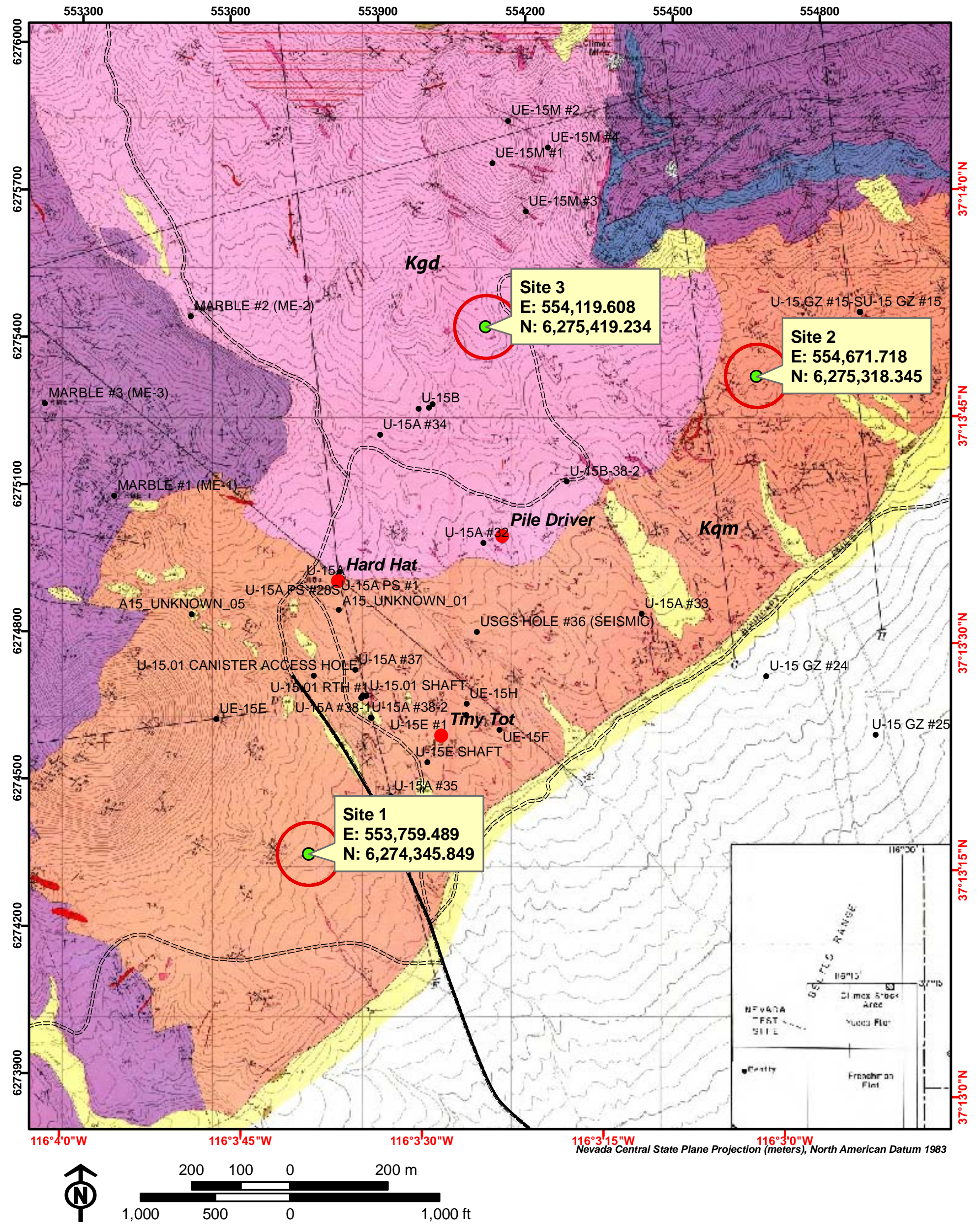

Figure 2. Geologic Map of Climax Stock Area Showing Locations of Three SPE Sites Selected for Further Study 
The most difficult aspect is predicting the depth of weathering. There are some core holes in the area, which we will evaluate in more detail in the next week or two. However, for the purpose of siting this test, we should place more weight on the SNL seismic mapping data for final site selection.

Site 1 is easily accessed from the main paved road. There is already a pad at the proposed site, but the purpose of the pad is unclear (no sign or record of a borehole, though there appears to be a mud pit associated with it). The pad would probably have to be expanded. We will continue to try to determine whether there is a borehole there. There are good outcrops of Kqm nearby, suggesting that weathering may be minimal here. This area may be more geologically homogenous than the other two sites, as fewer dikes are shown on geologic maps. The site is approximately 1,000 ft from Boundary fault (closest approach). See Photo \#1.

Site 2 is more than $4,000 \mathrm{ft}$ from the main paved road, but the road to it is in relatively good shape. This site may be more geologically heterogeneous than Site 1 , as more dikes are mapped. Weathering may be more extensive here as well, based on condition of nearby outcrops. The site is approximately $1,200 \mathrm{ft}$ from the Boundary fault (closest approach). This pad was constructed for the drilling of Hole U-15 GZ\#14, and there is a mud pit below the pad. The pad would have to be extended back or scraped down, and the mud pit filled, to increase its size and to avoid the existing borehole. See Photo \#2.

Site 3 is located on a narrow ridge between the pads for Holes U-15b and U-15b Ex. \#1. Few outcrops are present, making it difficult to assess weathering. Dirt roads pass near the site, but the suggested site itself has not been disturbed, and would require significant dirt-work. See Photo \#3.

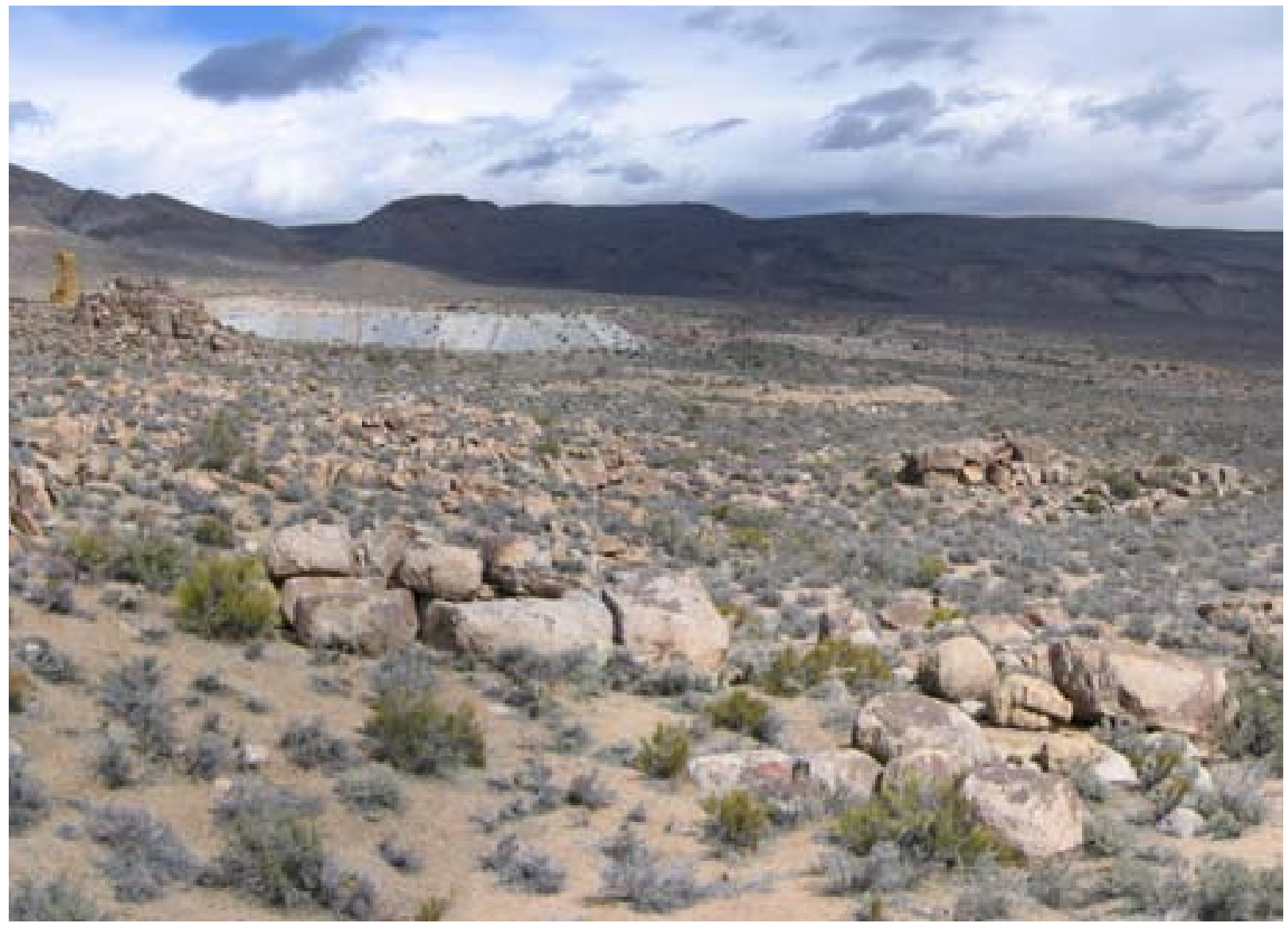

Photo 1. View of Site \#1 looking east. Pad is located in upper center of photo, above berm, below gray muckpile. 


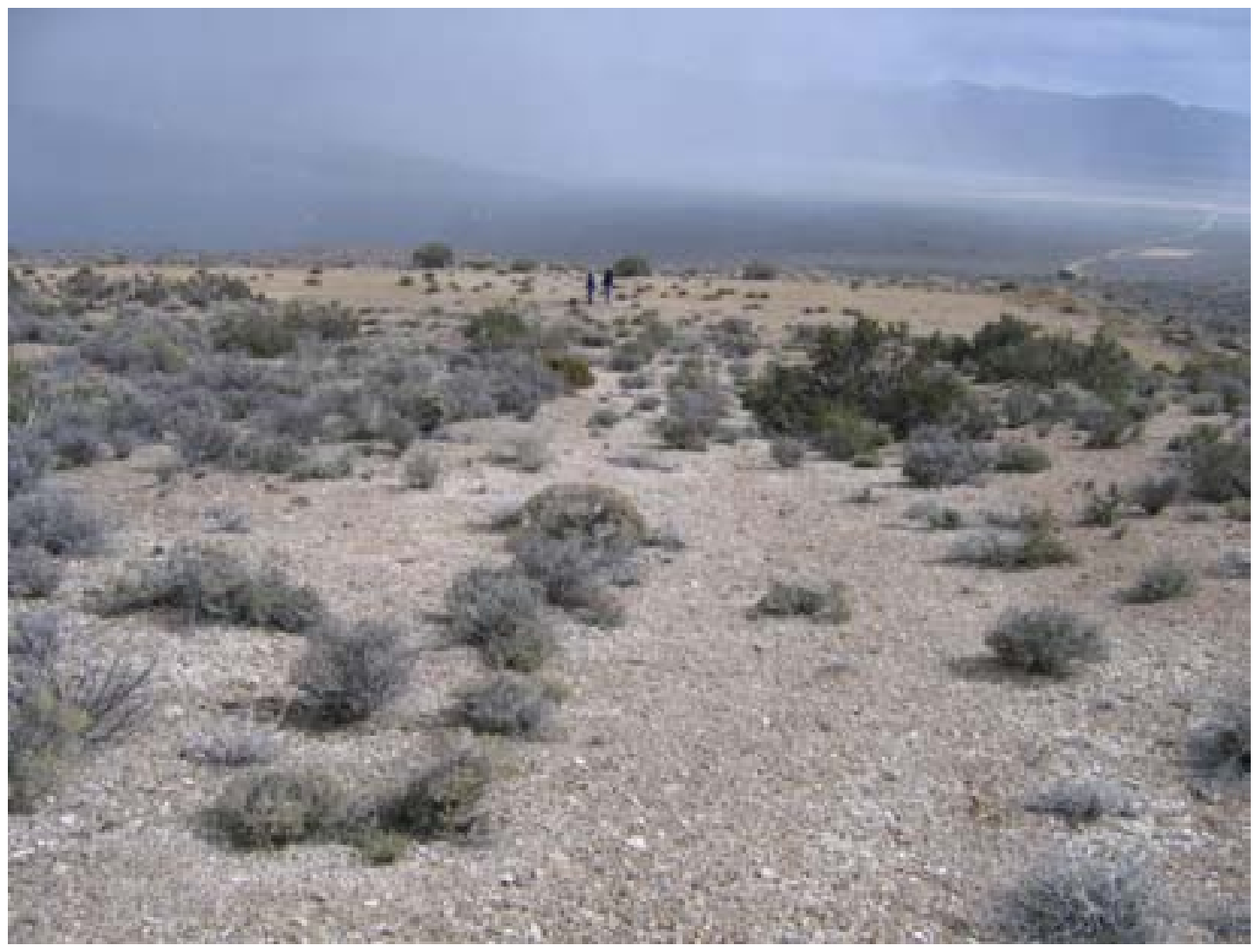

Photo 2. View of Site \#2 looking south. Two people are standing just to the right of the borehole collar

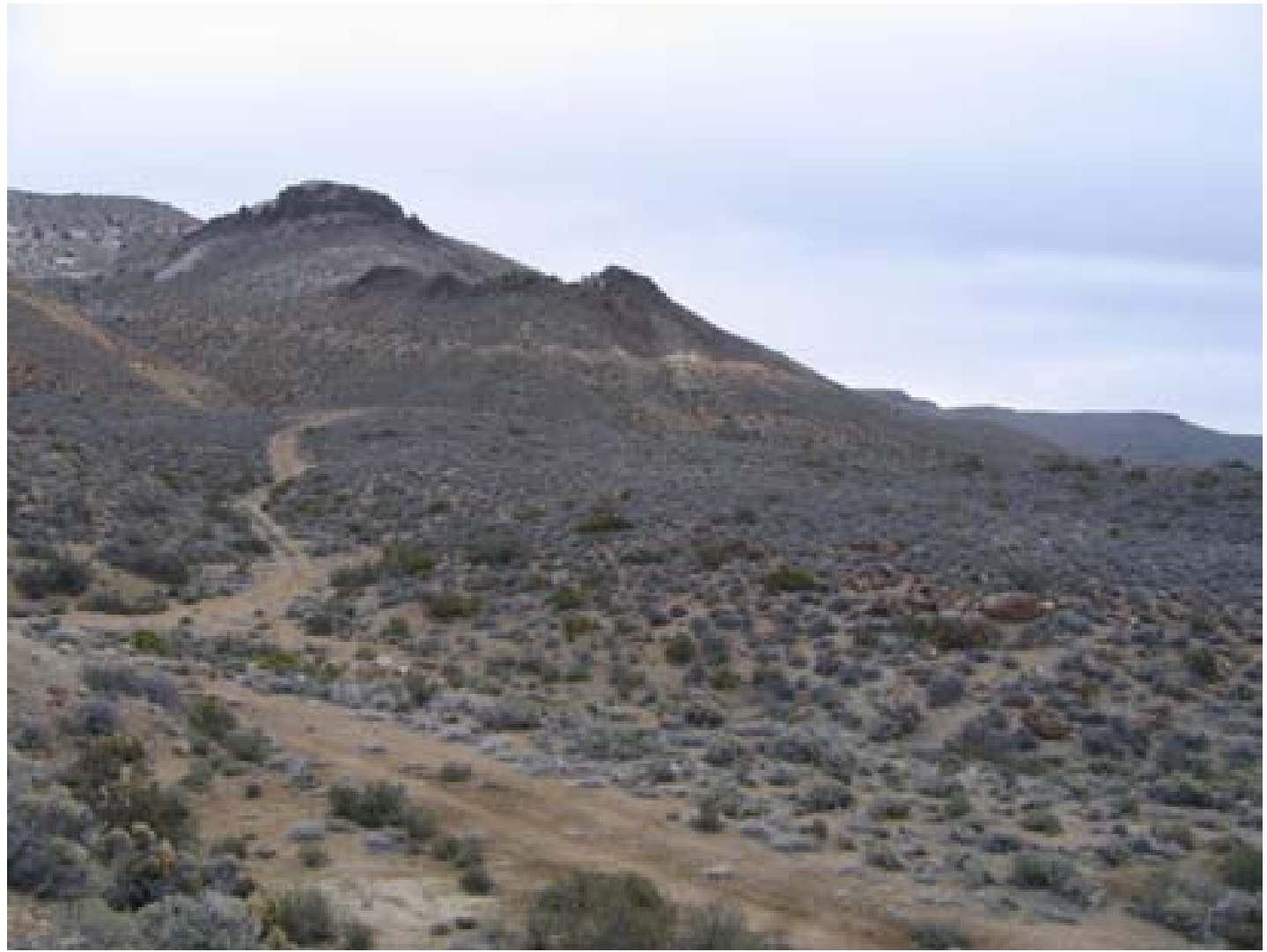

Photo 3. View of Site \#3 (foreground, right of small road) looking northeast from pad for borehole U-15b 


\section{APPENDIX B}

Drilling Narratives for the U-15n Boreholes

July 2010 through March 2011

Core Hole

36-Inch-Diameter Source Hole

8-Inch-Diameter Instrument Holes

By UGTA/Boreholes Group

National Security Technologies, LLC 


\section{APPENDIX B Drilling Narratives for the U-15n Boreholes \\ July 2010 through March 2011}

\section{B.1.0 Introduction}

Eight holes were drilled to construct the test bed in granite for the Source Physics Experiment (SPE): one exploratory core hole at the center of the planned test bed, six 8-inch (in.) diameter instrument holes, and a 36-in. diameter source hole, which was drilled at the location of the collar of the core hole. The planned depth for all holes was 58 meters $(\mathrm{m})$ (190 feet [ft]). The core hole and the first six instrument holes were constructed in the summer of 2010. The source hole was begun in 2010, but not completed till March 2011. A seventh instrument hole was drilled in 2011, prior to the second SPE test, as a replacement for one of the original holes in which instrumentation had failed after the first test. This and other additional instrument holes that are planned but not been completed at the time of this report will be described in a future report.

The core hole and instrument holes were drilled with few problems, but severe difficulties were encountered in drilling the 36 -in. Source Hole. This appendix provides detailed narratives of the drilling of the core hole, the source hole, and the first six instrument holes. The daily drilling reports for all drilling activities are provided in Appendix C. Construction information, including deviation plots, is provided in Appendix D.

\section{B.1.1 Site Configuration}

The test bed was designed to consist of a 36-in. diameter source hole at the center, surrounded by two rings of three instrument holes each (Figure B-1). The rings are located on radii of 10 and $20 \mathrm{~m}$ (33 and $66 \mathrm{ft}$ ) from the source hole. The three holes in each ring are positioned 120 degrees apart, and are staggered so that the holes in the inner ring are 60 degrees off the positions of the holes in the outer ring. The placement of the instrument holes was determined from the location of a hole in the outer ring (U-15n\#4), whose position was selected to be in line with an azimuth to U16b Tunnel from the U-15n Source Hole.

The drilling plan included an initial core hole at the center of the site that would provide information on the geology of the site and rock samples for later laboratory testing.

\section{B.1.2 Preparations for Drilling}

The selected site had once been graded, and included a constructed pit that might have been planned as a mud pit for a drilling project. This graded area is visible on air photos taken in 1964, but the original date of pad construction is unknown. Near the center of the site was found a small depression with a pipe nearby. There was concern that a borehole might have been drilled at this site, which, if cased, could cause a problem for future experiments. The drilling archives of National Security Technologies, LLC (NSTec), and other sources were checked to determine whether a hole had previously been drilled at this location, but nothing was found to indicate this was the case. In addition, the area was checked with a hand-held magnetometer to determine if any buried metal (which could indicate a drill casing) was present. No indication of subsurface metal items was found, so work proceeded to prepare the site. 


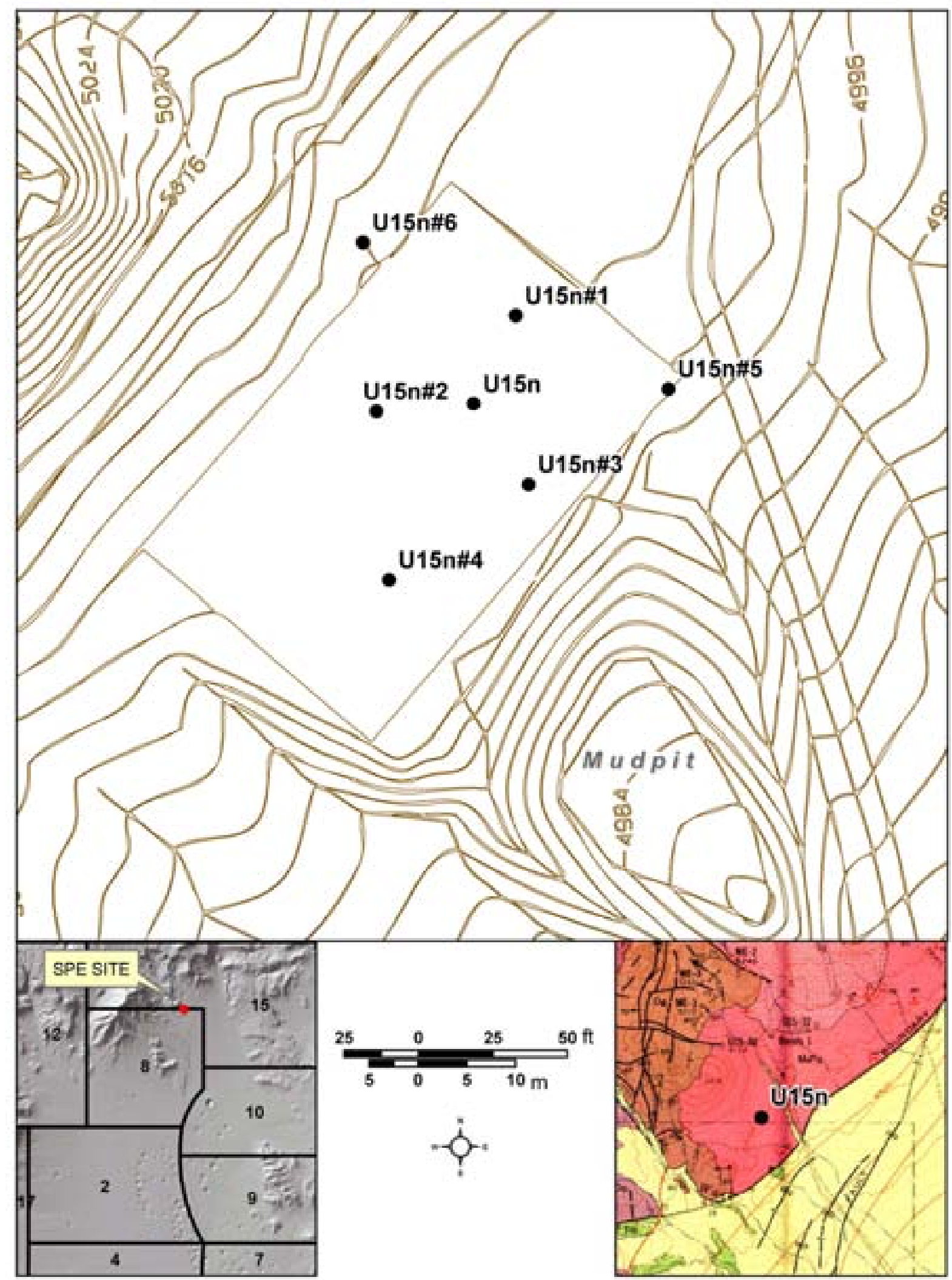

Figure B-1

Map of Source Physics Experiment Site Showing Layout of Holes

B-2 
Table B-1

Construction Data for Holes Drilled at the U15n Site

(As-built coordinates and elevations as of December 14, 2011)

\begin{tabular}{|c|c|c|c|c|c|c|c|c|c|c|c|}
\hline \multirow{2}{*}{$\begin{array}{l}\text { Hole } \\
\text { Name }\end{array}$} & \multicolumn{2}{|c|}{$\begin{array}{l}\text { State Planar } \\
\text { Coordinates }^{\mathrm{a}}\end{array}$} & \multicolumn{2}{|c|}{ UTM Coordinates ${ }^{b}$} & \multicolumn{2}{|c|}{ Well Coordinates $^{c}$} & \multirow{2}{*}{$\begin{array}{c}\begin{array}{c}\text { Ground } \\
\text { Elev }^{d}\end{array} \\
\text { feet }\end{array}$} & \multirow{2}{*}{$\begin{array}{c}\text { Conductor } \\
\text { Hole }\end{array}$} & \multirow{2}{*}{$\begin{array}{c}\text { Conductor } \\
\text { Casing }\end{array}$} & \multirow{2}{*}{$\begin{array}{c}\begin{array}{c}\text { Drilled } \\
\text { Depth }\end{array} \\
\text { feet }\end{array}$} & \multirow{2}{*}{$\begin{array}{c}\text { TD } \\
\text { Date }\end{array}$} \\
\hline & $\begin{array}{c}\text { Northing } \\
\text { feet }\end{array}$ & $\begin{array}{c}\text { Easting } \\
\text { feet }\end{array}$ & $\begin{array}{c}\text { Northing } \\
\text { meters }\end{array}$ & $\begin{array}{c}\text { Easting } \\
\text { meters }\end{array}$ & Latitude & Longitude & & & & & \\
\hline $\begin{array}{l}\text { U-15n } \\
\text { (core hole) }\end{array}$ & $900,077.28$ & $676,640.62$ & $4,119,823.7$ & $583,318.7$ & 37.221195 & 116.060867 & $5,001.82$ & $7.3^{e}$ & $6.7^{\mathrm{g}}$ & 196.5 & 7/28/2010 \\
\hline $\begin{array}{l}\text { U-15n } \\
\text { (36-in. hole) }\end{array}$ & $900,077.28$ & $676,640.62$ & $4,119,823.7$ & $583,318.7$ & 37.221195 & 116.060867 & $5,001.82$ & $7.5^{f}$ & $7.0^{h}$ & $\begin{array}{c}112 \\
\text { (Temp.) } \\
199 \\
\text { (Final) } \\
\end{array}$ & $\begin{array}{c}\text { Temp. TD, } \\
\text { 10/21/2010 } \\
\text { Final } \\
\text { 3/15/2011 } \\
\end{array}$ \\
\hline U-15n\#1 & $900,107.01$ & $676,655.17$ & $4,119,832.8$ & $583,323.1$ & 37.221267 & 116.060816 & $5,002.00$ & $7^{e}$ & $6.5^{i}$ & $190^{j}$ & $8 / 25 / 2010$ \\
\hline U-15n\#2 & $900,075.27$ & $676,608.54$ & $4,119,823.1$ & $583,308.9$ & 37.221190 & 116.060977 & $5,002.16$ & $10^{\mathrm{e}}$ & $9.5^{i}$ & $190^{j}$ & $9 / 16 / 2010$ \\
\hline$U-15 n \# 3$ & $900,050.67$ & $676,659.48$ & $4,119,815.6$ & $583,324.5$ & 37.221121 & 116.060803 & $5,001.66$ & $10^{\mathrm{e}}$ & $9.5^{i}$ & $190^{j}$ & $8 / 23 / 2010$ \\
\hline U-15n\#4 & $900,018.48$ & $676,612.53$ & $4,119,805.8$ & $583,310.2$ & 37.221034 & 116.060965 & $5,001.59$ & $10^{e}$ & $9.5^{i}$ & $192^{j}$ & 9/18/2010 \\
\hline$U-15 n \# 5$ & $900,082.71$ & $676,706.51$ & $4,119,825.5$ & $583,338.8$ & 37.221208 & 116.060641 & $5,001.29$ & $10^{\mathrm{e}}$ & $9.5^{i}$ & $192^{j}$ & $9 / 17 / 2010$ \\
\hline $\mathrm{U}-15 n \# 6$ & $900,131.75$ & $676,603.86$ & $4,119,840.3$ & $583,307.4$ & 37.221345 & 116.060992 & $5,005.07$ & $7^{\mathrm{e}}$ & $6.5^{i}$ & $190^{j}$ & $8 / 27 / 2010$ \\
\hline
\end{tabular}

a. Central Nevada State Planar coordinates, in feet, NAD 27

b. Universal Transverse Mercator, zone 11, in meters, NAD 83

c. Lat/Long presented as decimal degrees.

d. National Geodetic Vertical Datum, 1929

e. 121/4-inch hole

\begin{tabular}{|c|c|c|c|}
\hline \multicolumn{4}{|c|}{ Township and Range, All Holes } \\
\hline Qtr Sec & Sec & Town & Range \\
\hline $\begin{array}{c}\text { NW } 1 / 4 \text { of } \\
\text { NW1/4 }\end{array}$ & 27 & $8 S$ & $53 E$ \\
\hline
\end{tabular}

f. 48-inch hole

g. 51/2-inch casing in core hole only. Removed when 36 -inch hole was drilled.

h. 42-inch steel casing

i. 10-inch steel casing

J. 8-inch hole 
The area planned for construction of the SPE test bed was surveyed and graded starting on July 8, 2010. NSTec surveyors then laid out and marked locations for the core hole and six instrument holes, and provided lay-out coordinates and collar elevations for each. The site was designated U15n (" $n$ " was the next sequential alphabetic identifier for construction sites in Area 15), and each hole name includes that identifier. See Table B-1 for construction information for all holes drilled to date.

\section{B.2.0 Drilling Narratives}

This section describes the construction of the eight SPE holes drilled in 2010.

\section{B.2.1 Surface Hole Construction}

The surface holes for the core hole and all the first six instrument holes were drilled and cased on July 23-24, 2010. The NSTec drill crew used an auger rig to drill a $12^{1 / 4}$-in. diameter surface hole to the depth of $10 \mathrm{ft}$ at each location. The crew installed a 10-in. steel conductor casing to the depth of $9.5 \mathrm{ft}$ in Instrument Holes U-15n\#2, \#3, \#4, and \#5. Instrument Holes U-15n\#1 and \#6 were drilled to $7 \mathrm{ft}$ and the 10 -in. casing was set at $6.5 \mathrm{ft}$. The annulus between the casing and the borehole wall of each instrument hole was sealed with Type 2 cement.

The drillers used the Nevada National Security Site (NNSS) Failing rig to drill a $12 \frac{1}{4}$-in. diameter surface hole for the U-15n Core Hole to the depth of $7.3 \mathrm{ft}$, and set a string of $51 / 2$-in. surface casing to the depth of $6.7 \mathrm{ft}$. The annulus of the surface casing for the core hole was filled with gravel, rather than cement, to permit removal of the casing for drilling of the 36-in. hole at this location later.

\section{B.2.2 Core Hole}

The U-15n Core Hole was cored from the depth of $7.3 \mathrm{ft}$ to a total depth (TD) of $196.5 \mathrm{ft}$ by NSTec drillers using the Failing drill rig on July 26-28, 2010. The core size was 2.5 in. ("HQ"), which produced a borehole 3.8 in. in diameter. Drilling was conducted during the day shift only, and proceeded quickly. No problems were encountered. The total cored length was $189.2 \mathrm{ft}$, and total core recovery was $187.6 \mathrm{ft}$ (99.2 percent). The daily drilling reports are compiled in Appendix C.

NSTec geologists documented and boxed the core as it was extracted from the hole, recording standard drilling data, such as drilled interval, recovery, drilling time, etc. In addition, the geologists selected samples for preservation (see Section 3.1 of the main document). A total of 37 samples were preserved, equaling $31.2 \mathrm{ft}$ (16.6 percent of the core).

A suite of geophysical logs recommended by the SPE subject matter expert group was run in the borehole by Colog on July 31, 2010. Fill was encountered at the depth of $157 \mathrm{ft}$ during logging. The drill crew ran the drill string back in the hole and cleaned out the sloughed material so that the logging tools could survey all the way to the TD. After cleaning out the hole, they blew the residual drill fluid out using high-pressure air, but the fluid level recovered quickly to the depth of $36 \mathrm{ft}$. This fluid was too murky to obtain clear images with the camera, but did not cause problems with any of the other planned logs. See the main report for discussions of the logs. A list of samples and other core data are provided in Appendix E.

All core from the U-15n Core Hole was delivered to the U.S. Geological Survey (USGS) Data Center and Core Library in Mercury, Nevada for storage. The geophysical logs were provided to 
participating organizations in digital and paper format, and are available from the NSTec Underground Test Area (UGTA)/Boreholes Programs and Operations group, Mercury, Nevada. Plots of the geophysical logs are reproduced in Appendix F.

\section{B.2.3 Instrument Holes}

All six of the original SPE instrument holes are 8 in. in diameter. NSTec drillers used the Failing rig to drill the first three holes. Due to mechanical problems with the Failing rig, the NSTec drilling subcontractor, United Drilling Incorporated (UDI), was brought in to drill the last three holes, for which they used the UDI GD 2500 rig. The drill dates for the holes are listed below. The order was determined by the logistics of setting the flow line and need to re-position various equipment on the pad. See Appendix C for the daily rig operations reports.

- U-15n\#3 (August 21-23, 2010)

- U-15n\#1 (August 24-25, 2010)

- U-15n\#6 (August 26-27, 2010)

- U-15n\#2 (September 15-17, 2010)

- U-15n\#5 (September 17, 2010)

- U-15n\#4 (September 18, 2010)

The NSTec drill crew started drilling the instrument holes after it was decided to use UDI to finish drilling the partially completed 36-in. hole. NSTec completed three instrument holes while the procurement process for UDI was in progress. The last three holes were drilled by UDI while drilling of the 36-in. hole was shut down to wait for replacement of a damaged bit. See Section B.2.4 for information on the construction of the 36-in. hole.

All the instrument holes were drilled with an air-foam drill fluid. Pairs of one-pint samples (duplicates) of the drill cuttings were collected by NSTec geologists from the three outer instrument holes (U-15n \#4, \#5, and \#6) at 10-ft intervals during drilling.

Following drilling, the fluid levels in the instruments were measured at depths ranging from about 57 to $77 \mathrm{ft}$. The required suite of geophysical logs was run in all six boreholes by Colog on September 20, 2010. No fill was encountered during logging of any of the holes. See Section 3.2 of the main report for a list of logs run in the boreholes.

The drill cuttings samples collected during drilling of the three outer instrument holes were delivered to the USGS Data Center and Core Library in Mercury, Nevada, where one set was washed and boxed according to standard Core Library procedures and the other set was archived unwashed. The geophysical logs were provided to participating organizations in digital and paper format, and are available from the NSTec UGTA/Boreholes Programs and Operations group, Mercury, Nevada. Plots of the geophysical logs are reproduced in Appendix F.

\section{B.2.4 36-Inch Diameter Source Hole}

NSTec drillers began work on the 36-in. diameter Source Hole, centered at the location of the collar of the U-15n Core Hole, on August 5, 2010. They augered a 48-in. diameter hole from the surface to the depth of $5 \mathrm{ft}$, but encountered difficulty with a ledge of hard rock at the depth of $2.5 \mathrm{ft}$. The 
next day they moved the Failing rig onto the hole and drilled a 121/4-in. hole from 5 to $7 \mathrm{ft}$, though drilling was slow due to very hard rock. Next they picked up a 5-in. hammer bit and drilled several holes to $10 \mathrm{ft}$, within the footprint of the planned hole, to try to break up the rock. The next day they brought the auger rig back on and used a 48-in. bit to drill from 5 to $7.5 \mathrm{ft}$. The crew then landed a string of 42-in. case at the depth of $7 \mathrm{ft}$, and cemented it in place with type HLNCC grout. The next day the annulus was cemented to the surface with HLNCC grout.

It took four days to prepare the collar assembly and flow line, move additional compressors to the site, and set up for drilling the 36-in. hole with the NNSS Cardwell rig. The NSTec drill crew started drilling from the top of the cement in the conductor hole at $5 \mathrm{ft}$ on August 8, 2010, using a 36-in. hammer bit. They drilled to the depth of $21 \mathrm{ft}$ by August 14, 2010 (again very slowly due to hard rock) then spent seven days working on the rig and the hammer bit, and adding more compressors. They still encountered severe drilling difficulties, and on August 19, 2010, the shaft between the king swivel and the power swivel twisted off. A crane was used to remove the power swivel, and drilling operations were suspended.

The drilling subcontractor UDI and their GD 2500 rig were in to complete the 36-in. hole. Drilling resumed on August 31, 2010, but the UDI rig also experienced mechanical problems, including leaks in the flow system and small failures of various components. On September 9, 2010, after 14.5 hours of drilling advanced the hole only $1 \mathrm{ft}$ (to the depth of $94 \mathrm{ft}$ ), the decision was made to pull out of the hole and check the hammer bit. Visual inspection of the bit showed that some of the drive pins on the bit spline were broken, and the bit was sent out for repair. While waiting on the bit repair, the UDI crew used their rig with an 8-in. bit to drill the remaining three instrument holes (see Section B.2.3).

After the drill string was removed from the 36-in. diameter hole, NSTec ran a camera in the borehole to check conditions. The borehole appeared to be severely deviated from vertical, with a "corkscrew" path, so it was decided to run a mandrel designed to match the size and shape of the explosives canister to determine whether the hole was straight enough to install the canister.

The mandrel run was conducted on September 24, 2010. The mandrel was blocked due to severe borehole deviation at the depth of $34.5 \mathrm{ft}$. The decision was made to cement the lower portion of the hole and re-drill it to correct the deviation. The first cement stage consisted of 425 cubic feet $\left(\mathrm{ft}^{3}\right)$ of Type 2 cement, which brought the top of the cement to the depth of $48 \mathrm{ft}$. The second stage of $210 \mathrm{ft}^{3}$ of Type 2 cement brought the top of the cement to the depth of $24.7 \mathrm{ft}$ ) on September 25, 2010.

On September 27, 2010, the drilling assembly was brought back to the rig site. An additional reamer had been added to stiffen the drill string, which was expected to improve the plumbness of the hole. A crane was used to lower the assembly into the hole, but the assembly was blocked at the depth of $17 \mathrm{ft}$, so it was removed and returned to the shop for evaluation. The drilling assembly was brought back to the site and lowered into the hole successfully the next day, and the hole was re-drilled through the cement to the depth of $53 \mathrm{ft}$. The decision was made to add a second reamer to the drill string, so the drilling assembly was again removed and taken to the shop to add the reamer.

During disassembly of the bit at the shop on September 29, 2010, a chain failed and an employee was slightly injured. Drilling operations were suspended while safety assessments were made both 
at the shop and at the SPE drill site. After minor issues were addressed, the safety suspension was lifted so that operations could resume on October 4, 2010. However, it was found that additional required components had to be obtained to complete assembly of the drill string with the additional reamer, so no drilling took place the week of October 4, 2010. After receipt, installation, and inspection of the additional drilling assembly sections, UDI resumed drilling on October 15, 2010.

Reaming and drilling by the UDI crew and rig had advanced to the depth of $75 \mathrm{ft}$ on October 15, 2010, when the shaft on the rotary table transmission twisted apart. Drilling resumed the next day after the rotary table was replaced; however, the rig continued to suffer various mechanical problems. The bolts that hold the rotating rubber on the drilling assembly were found to be missing when it was pulled to add pipe, so the rotating rubber was replaced and bolted on. The transmission drive train failed and had to be replaced, and a U-joint in the rotary table drive line failed and had to be repaired. At the depth of $112 \mathrm{ft}$ on October 21, 2010, high torque caused the kelly to fail. A new kelly was brought up and installed the next day, but continuing high torque during drilling began to cause similar wear on the new kelly.

The decision was made to suspend drilling and take steps to obtain a more robust drill rig to complete the hole. When the crew attempted to pull the bit assembly from the hole on October 27, 2010, the bit parted from the hammer and was left in the borehole. Over the next few days a pump was run in the hole to lower the water level so that a camera could be used to examine the lost bit. Fishing operations to recover the bit began on November 1, 2010, alternating with pumping and repeated camera runs to help guide placement of the fishing tools. The bit was recovered on November 3, 2010, but one of its retaining rings was found to be missing, presumably left in the hole.

The mandrel was successfully run to the bottom of the borehole at $112 \mathrm{ft}$ on November 4, 2010, indicating that the re-drilled hole was remaining fairly straight.

The UDI rig was demobilized from the site, and equipment left at the site was prepared for winter. There was no drilling activity at the site until the end of January 2011, when preparations began to bring in a leased raise-bore type drill rig, through the UDI subcontract, to complete the hole. The raise-bore rig is capable of approximately four times the rotary torque of the UDI GD 2500 rig, and its hydraulic controls enable better control of rotary speed and torque than a standard rotary rig.

The hammer bit was refurbished and all necessary components checked. An auger rig with a 36-in. bit was brought in to clean out the borehole and clear a tight spot at $89 \mathrm{ft}$. During the cleaning operation, the hole was periodically dewatered and a camera run to check for the metal ring lost from the bit. In addition, a magnet was run in the hole, but no metal was recovered. The auger rig experienced a mechanical failure and a rented rig was brought in to finish cleaning out the hole. After the final cleaning with the auger, no metal parts were found, but another survey with the metal detector indicated the presence of metal, so the magnet was run again and recovered half of the missing retaining ring from the bit on February 25, 2011.

During this time preparations were underway to build a "strongback" at the hole collar, on which to set the raise-bore rig. Cement was placed in the borehole to the level of $96 \mathrm{ft}$, to isolate any remaining metal parts that might be stuck in a fracture or void in the borehole wall. Drilling with the raise-bore rig began at the top of the cement on March 3, 2011. Below the depth of $140 \mathrm{ft}$, the rig experienced very high torque. When the depth of $146 \mathrm{ft}$ was reached, on Thursday, March 10, 2011, 
the drilling assembly was removed and the reamers were found to be damaged. The reamers were shipped out for repair and returned by the following Monday. The hole was drilled to the final depth of $199 \mathrm{ft}$ on March 15, 2011.

The mandrel was run in the borehole but would not pass the depth of $140 \mathrm{ft}$. During the week of March 21, 2011, the drilling assembly was rebuilt to add two tungsten-carbide-coated stabilizers (to serve as reamers) and a smaller (26-in.) rotary bit (to increase circulation at the bottom of the hole for removal of cuttings). The hole was reamed to the depth of $195 \mathrm{ft}$ to remove the tight spots that had obstructed the mandrel. The drilling assembly, pipe, and drill rig were then removed and the mandrel was successfully run to the depth of $192 \mathrm{ft}$ on March 25, 2011. All drilling equipment was demobilized from the site the week of March 28, 2011, to allow for final installation of the emplacement canister in the U-15n Source Hole and the rest of the accelerometer packages in the instrument holes. 


\title{
APPENDIX C
}

Daily Rig Operations Reports for U15n Source Physics Experiment National Security Technologies, LLC

\author{
Appendix C-1: Core Hole \\ Appendix C-2: 36-Inch-Diameter Source Hole \\ Appendix C-3: 8-Inch-Diameter Instrument Holes
}




\section{Appendix C-1}

NSTec Daily Rig Operations Reports for the U-15n Core Hole 


\section{Daily Rig Operations Report}

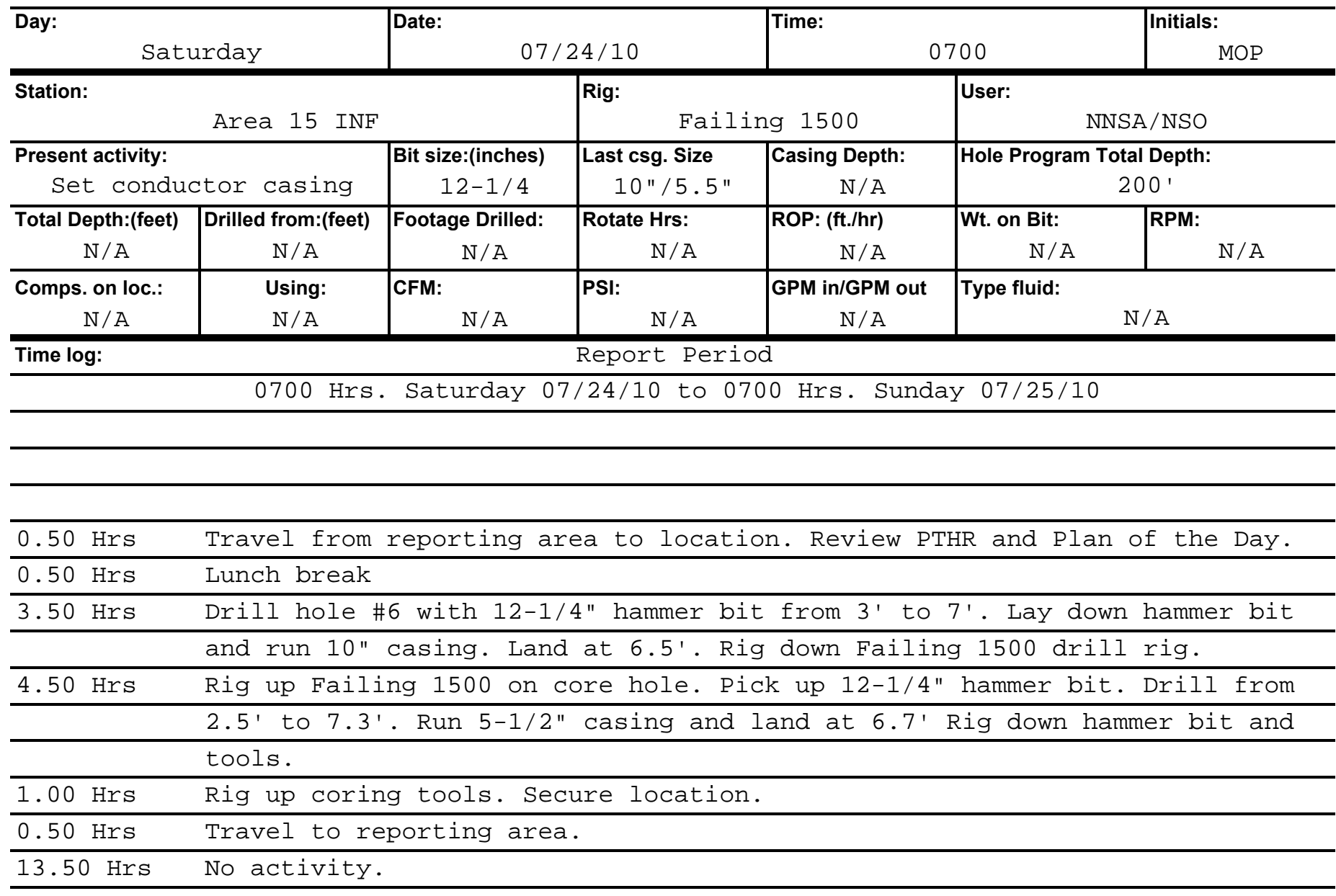

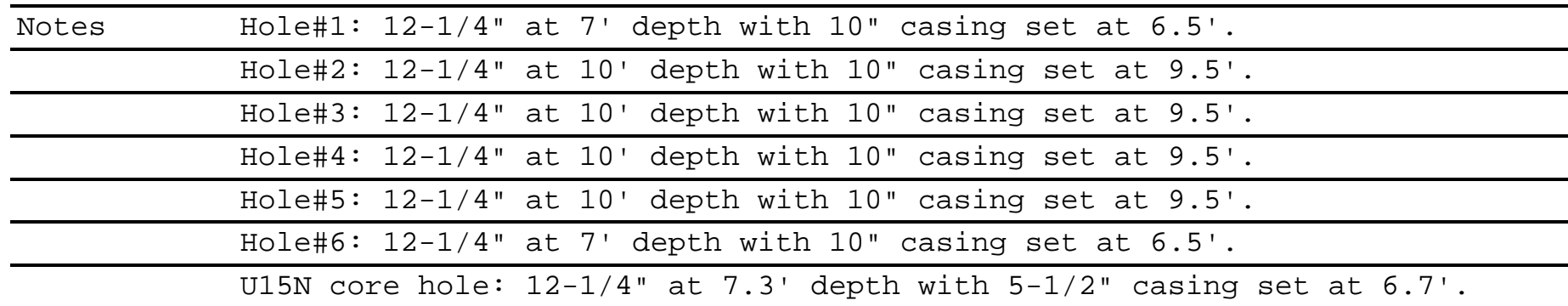




\section{Daily Rig Operations Report}

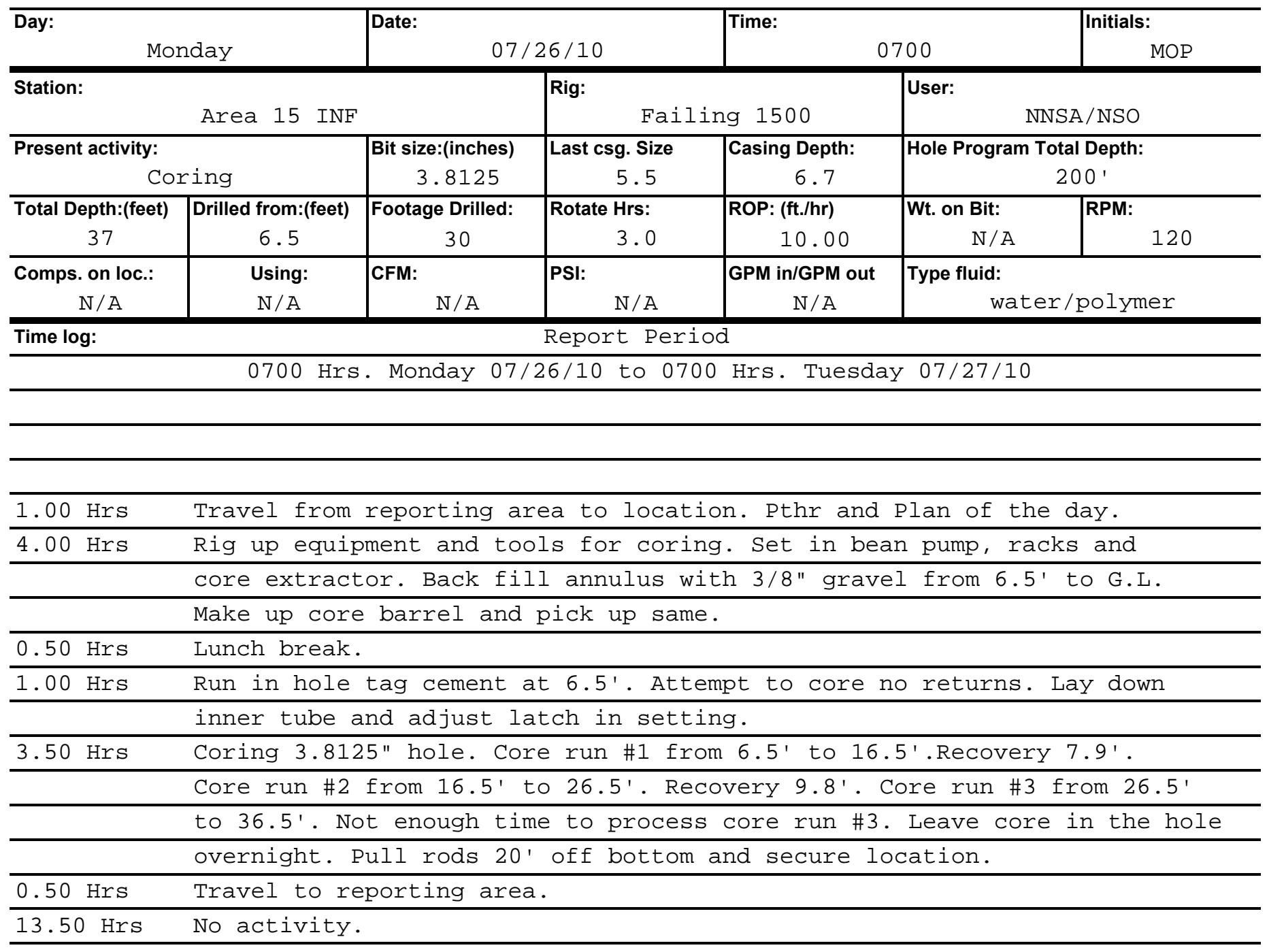




\section{Daily Rig Operations Report}

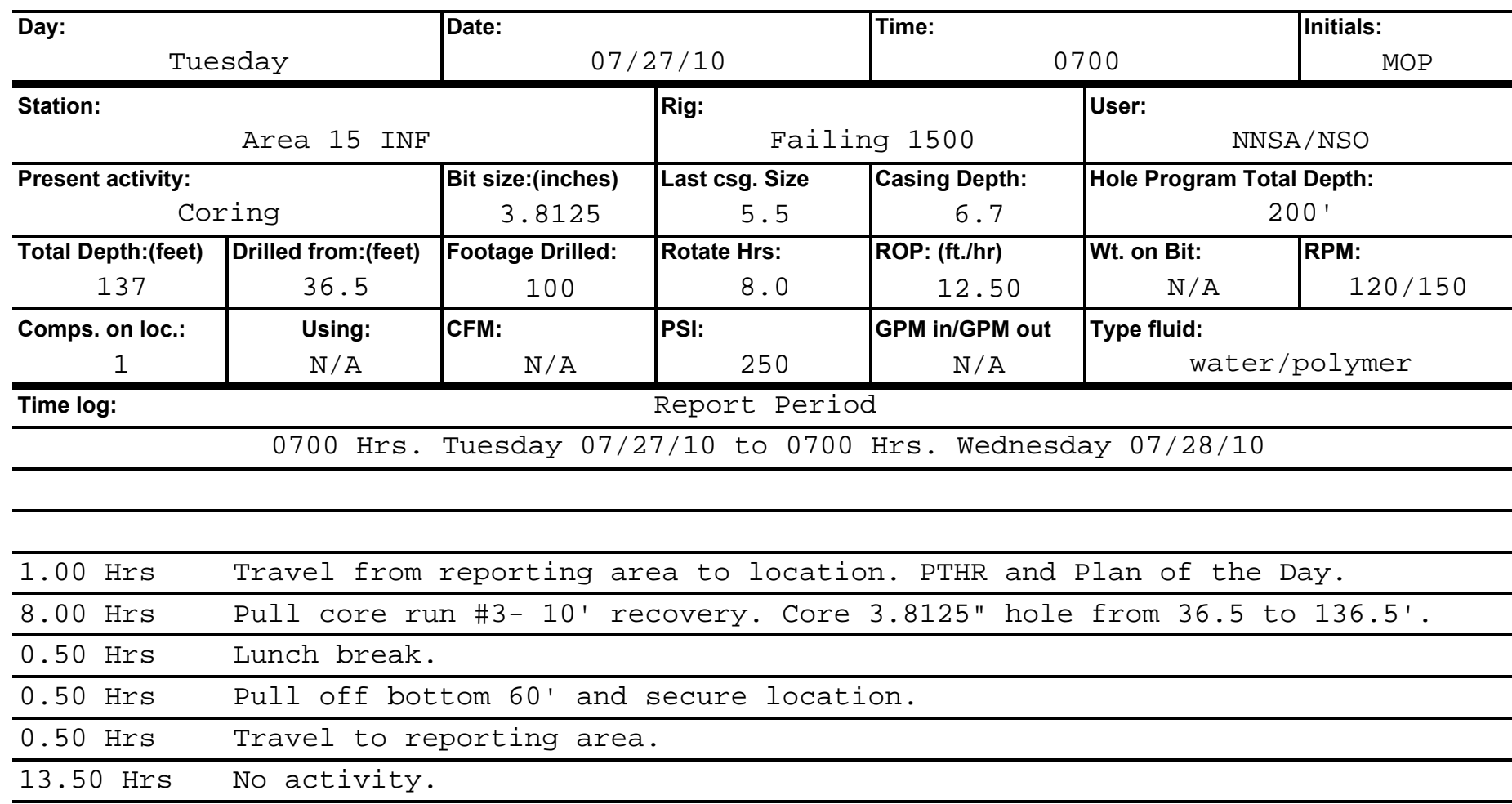

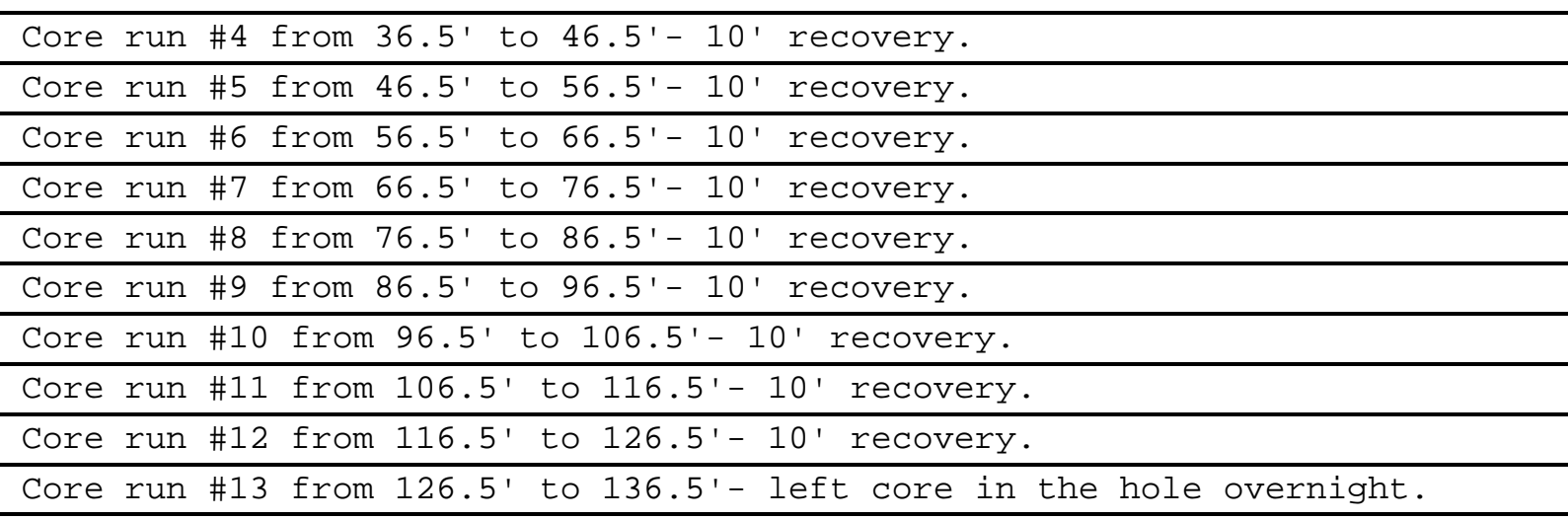




\section{Daily Rig Operations Report}

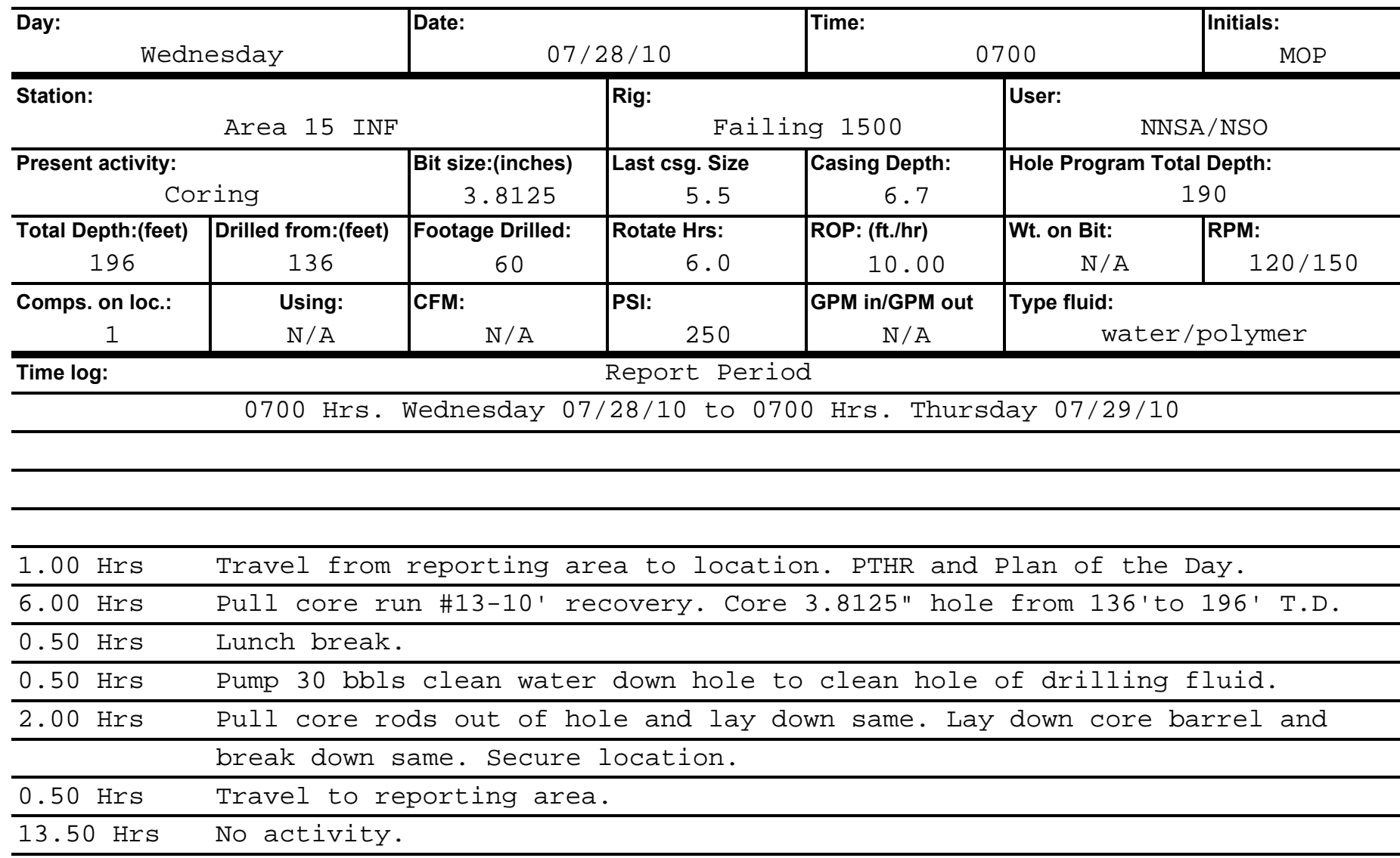

Core run $\# 14$ from 136.5 to $146.5^{\prime}-10^{\prime}$ recovery.
Core run $\# 15$ from 146.5 to $156.5^{\prime}-9.8^{\prime}$ recovery.
Core run $\# 16$ from 156.5 to $166.5^{\prime}-10^{\prime}$ recovery.
Core run $\# 17$ from 166.5 to $176.5^{\prime}-10^{\prime}$ recovery.
Core run $\# 18$ from 176.5 to $186.5^{\prime}-10^{\prime}$ recovery.
Core run $\# 19$ from 186.5 to $196^{\prime}-10^{\prime}$ recovery.




\section{Daily Rig Operations Report}

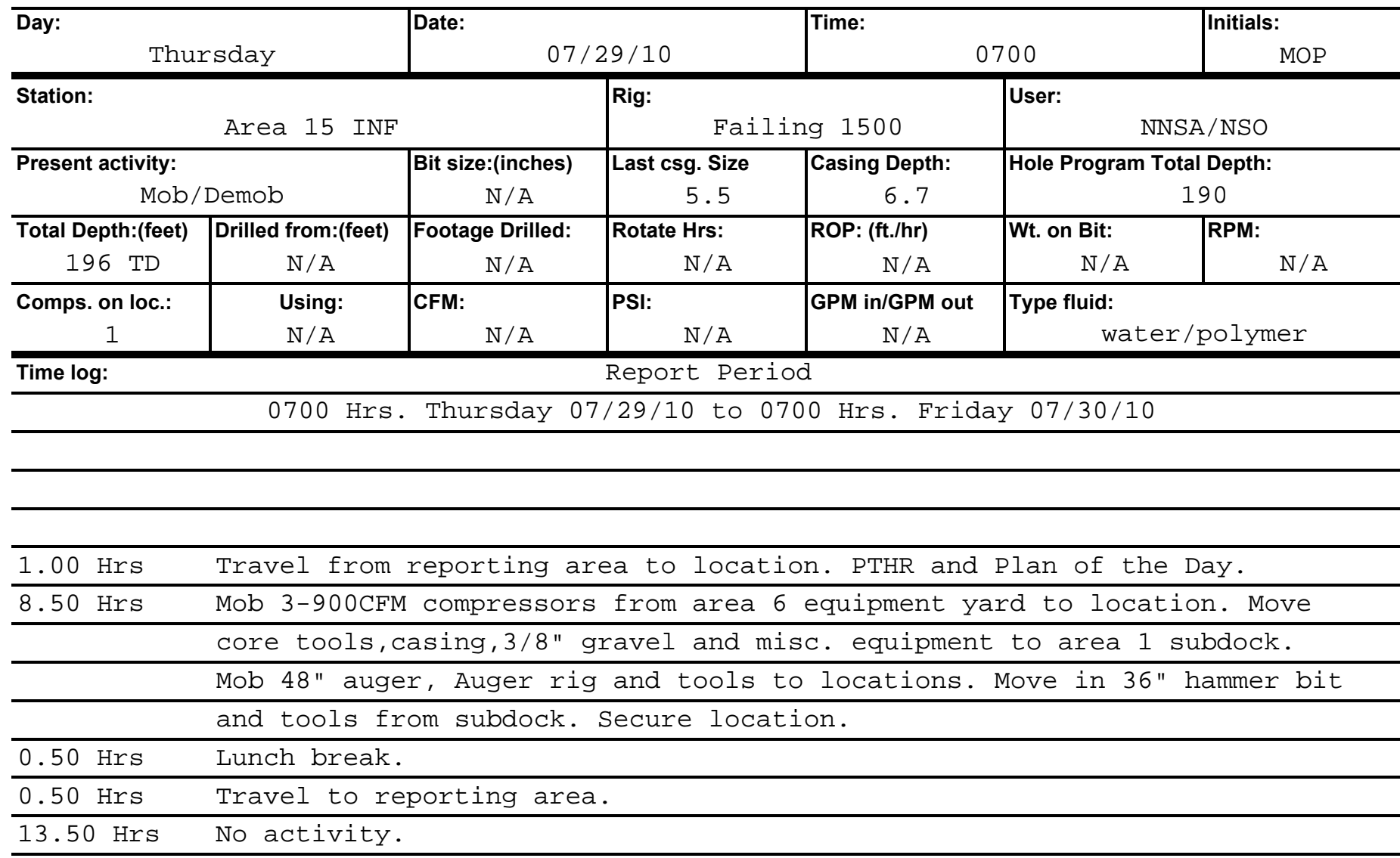

\begin{tabular}{ll}
\hline Notes: & Tire truck replace bad tire on Failing 1500. \\
\hline & Mechanic repair mixing tub on bean pump skid. \\
\hline & Fluid in core hole at $47^{\prime}$ at $1600 \mathrm{hrs}$. \\
\hline
\end{tabular}




\section{Daily Rig Operations Report}

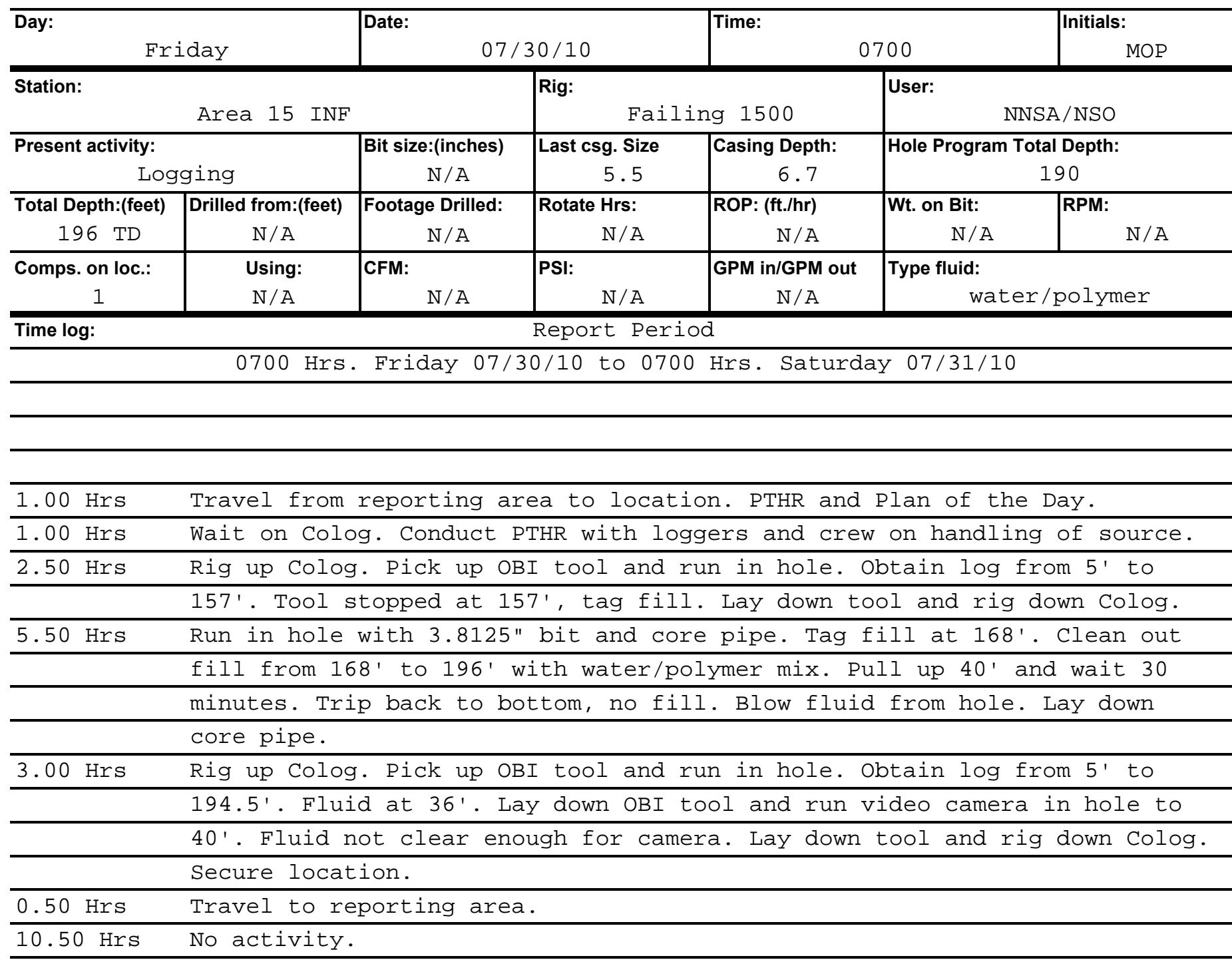

Colog on location at $0850 \mathrm{Hrs}$. 


\section{Daily Rig Operations Report}

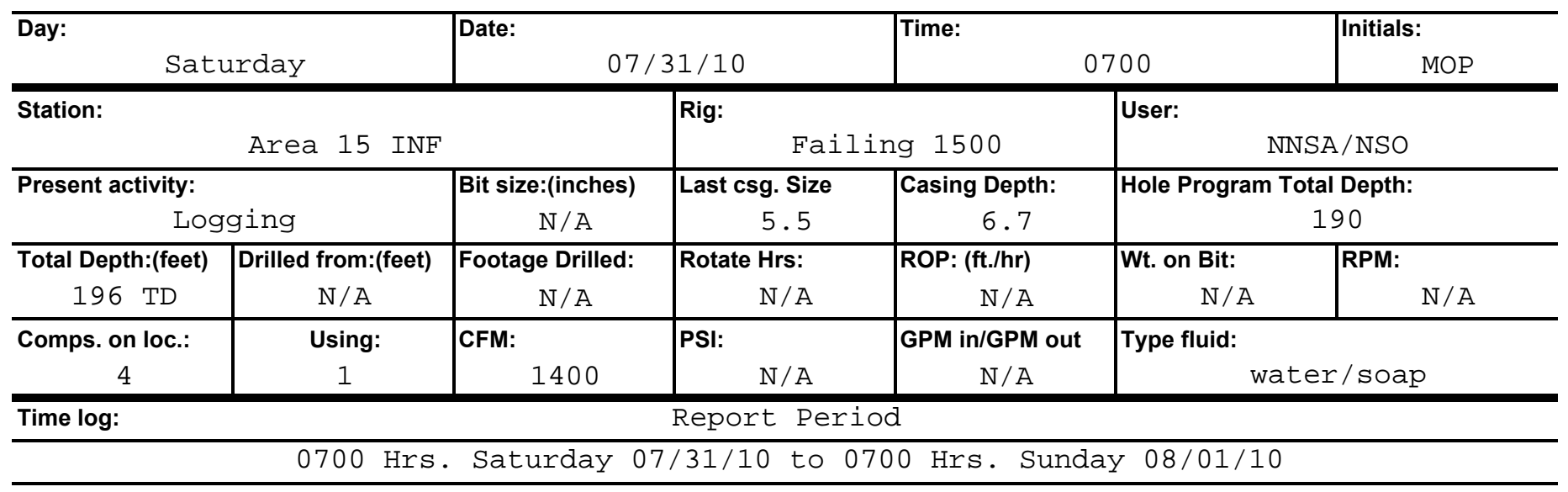

\begin{tabular}{|c|c|}
\hline $0.50 \mathrm{HrS}$ & Crew travel from reporting area to location. \\
\hline 1.50 & Wait on Colog. Conduct PTHR and Plan of the Day with rig crew and Colog. \\
\hline 2.00 & Rig up Colog. Pick up ABI tool and run in the hole. TD at 191', fluid \\
\hline & at $46^{\prime}$. Obtain $\log$ from $191^{\prime}$ to $13^{\prime}$. Lay down tool. \\
\hline $2.00 \mathrm{HrS}$ & Pick up CDL-Cal tool. Tool not working, swap out tools. Run tool in the \\
\hline & hole, TD at 188'. Obtain log from $188^{\prime}$ to $7^{\prime}$. Repeat run, TD at $188^{\prime}$. Lay \\
\hline & down tool. \\
\hline $2.50 \mathrm{HrS}$ & Pick up Elog, GR, SP tool and run in the hole, TD at 186.7'. Obtain log \\
\hline & from 186' to $7^{\prime}$. Lay down tool. Run in hole with 3 arm Caliper, TD 185.9. \\
\hline & Obtain log from 185' to 7'. Lay down tool. Run in hole with FWS, GR tool. \\
\hline & TD at 185.5'. Obtain log from 185' to $7^{\prime}$. Lay down tool. Rig down Colog. \\
\hline $3.0 \odot$ & Rig up 1.9" tubing tools. Run in hole with 1.9" tubing open ended. Tag \\
\hline & fill at $181^{\prime}$. Clean fill from $181^{\prime}$ to $196^{\prime}$ with air/foam. Blow fluid out \\
\hline & of hole. Lay down tubing and rig down tools. \\
\hline $1.50 \mathrm{HrS}$ & Rig up Colog. Run video camera in the hole. TD at 195 , fluid at $89^{\prime}$. Lay \\
\hline & down camera and rig down Colog. Secure location. \\
\hline $0.50 \mathrm{HrS}$ & Travel to reporting \\
\hline $10.50 \mathrm{Hrs}$ & \\
\hline
\end{tabular}




\section{Daily Rig Operations Report}

\begin{tabular}{|c|c|c|c|c|c|c|}
\hline \multicolumn{2}{|c|}{ Monday } & Date: & $2 / 10$ & \multicolumn{2}{|c|}{$\odot 7 \odot \odot$} & $\begin{array}{r}\text { Initials: } \\
\text { MOP }\end{array}$ \\
\hline \multicolumn{3}{|c|}{ Area 15 INF } & \multicolumn{2}{|c|}{ Failing 1500} & \multicolumn{2}{|c|}{ NNSA/NSO } \\
\hline $\begin{array}{r}\text { Present activity: } \\
\text { Mob for }\end{array}$ & cementing & $\begin{array}{c}\text { Bit size:(inches) } \\
\text { N/A }\end{array}$ & $\begin{array}{c}\text { Last csg. Size } \\
5.5\end{array}$ & $\begin{array}{c}\text { Casing Depth: } \\
6.7\end{array}$ & Hole Program & $\begin{array}{l}\text { Depth: } \\
90\end{array}$ \\
\hline $\begin{array}{c}\text { Total Depth:(feet) } \\
196 \text { TD }\end{array}$ & $\begin{array}{c}\text { Drilled from:(feet) } \\
\text { N/A }\end{array}$ & $\begin{array}{c}\text { Footage Drilled: } \\
\text { N/A }\end{array}$ & $\begin{array}{r}\text { Rotate Hrs: } \\
\text { N/A }\end{array}$ & $\begin{array}{r}\text { ROP: (ft./hr) } \\
\text { N/A }\end{array}$ & $\begin{array}{r}\text { Wt. on Bit: } \\
\text { N/A }\end{array}$ & RPM: \\
\hline $\begin{array}{c}\text { Comps. on loc.: } \\
4\end{array}$ & $\begin{array}{l}\text { Using: } \\
N / A\end{array}$ & CFM: & PSI: & $\begin{array}{c}\text { GPM in/GPM out } \\
N / A\end{array}$ & Type fluid: & /A \\
\hline Time log: & & & Report Per & & & \\
\hline
\end{tabular}

\begin{tabular}{ll}
\hline $1.00 \mathrm{Hrs}$ & Travel from reporting area to location. PTHR and Plan of the Day \\
\hline $9.00 \mathrm{Hrs}$ & Wait on cementing program. Mob pump truck and cementing equipment from \\
\hline & area 1 to location. Rig up same. Clean out mixing tub on bean pump skid \\
\hline & for cementing. Work on grant head. \\
\hline $0.50 \mathrm{Hrs}$ & Travel to reporting area. \\
\hline $13.50 \mathrm{Hrs}$ & No activity.
\end{tabular}

Note: $\quad$ Fluid at 51' at $1000 \mathrm{hrs}$.




\section{Daily Rig Operations Report}

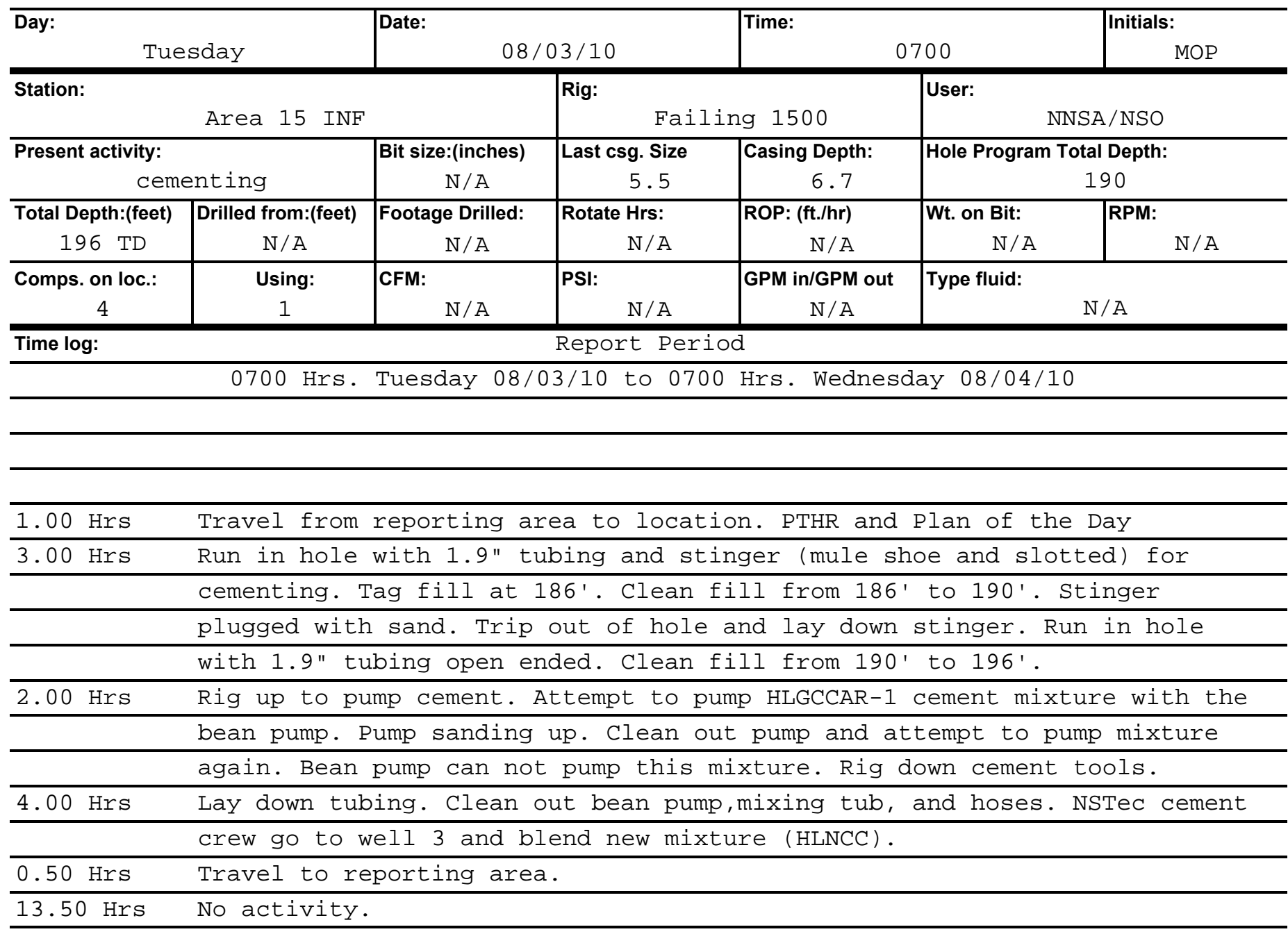




\section{Daily Rig Operations Report}

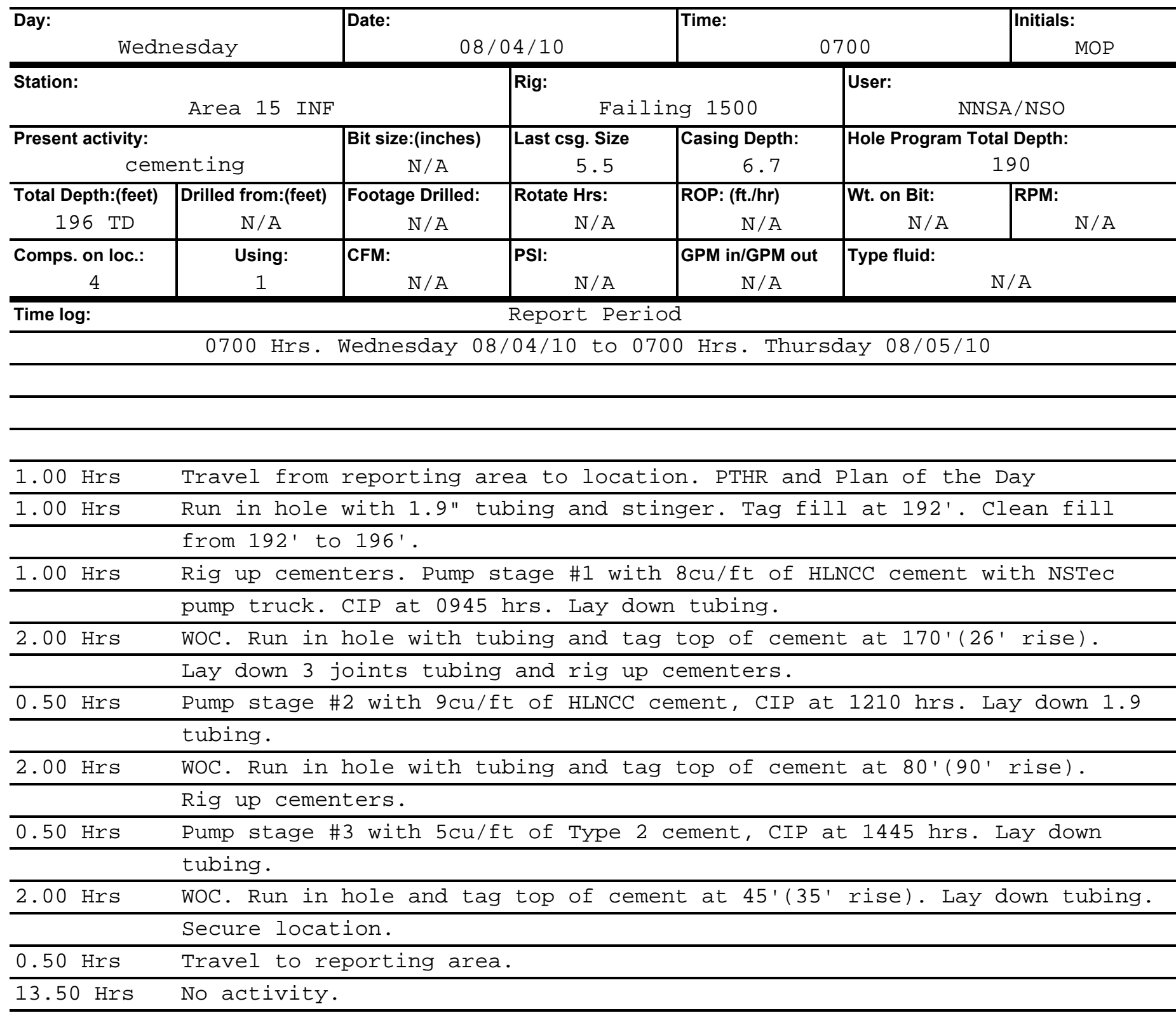




\section{Appendix C-2}

\section{NSTec Daily Rig Operations Reports for the U-15n 36-inch Diameter Source Hole}

Includes excerpts from weekly reports by the SPE Project Manager covering periods without daily rig operations reports. 


\section{Daily Rig Operations Report}

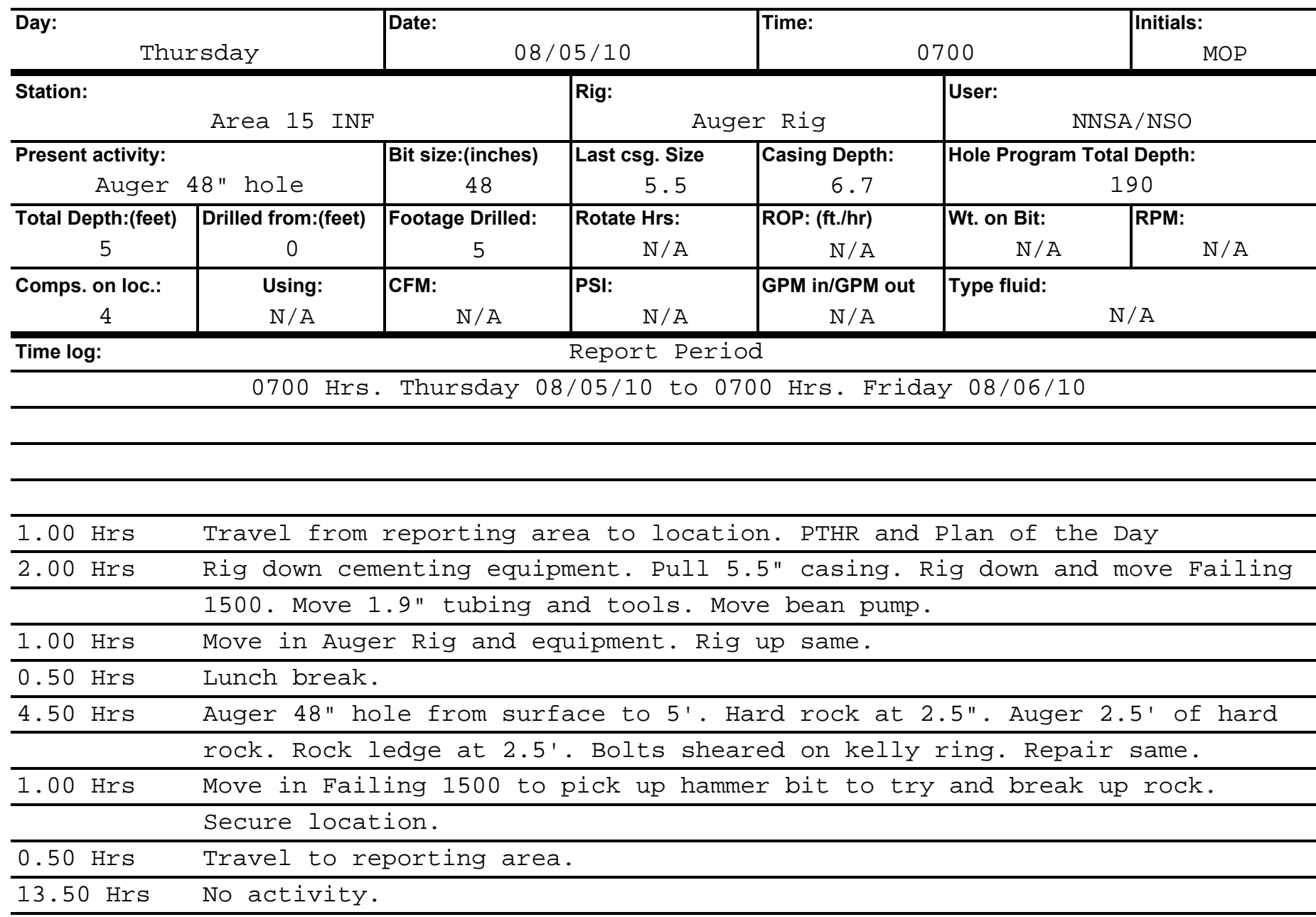




\section{Daily Rig Operations Report}

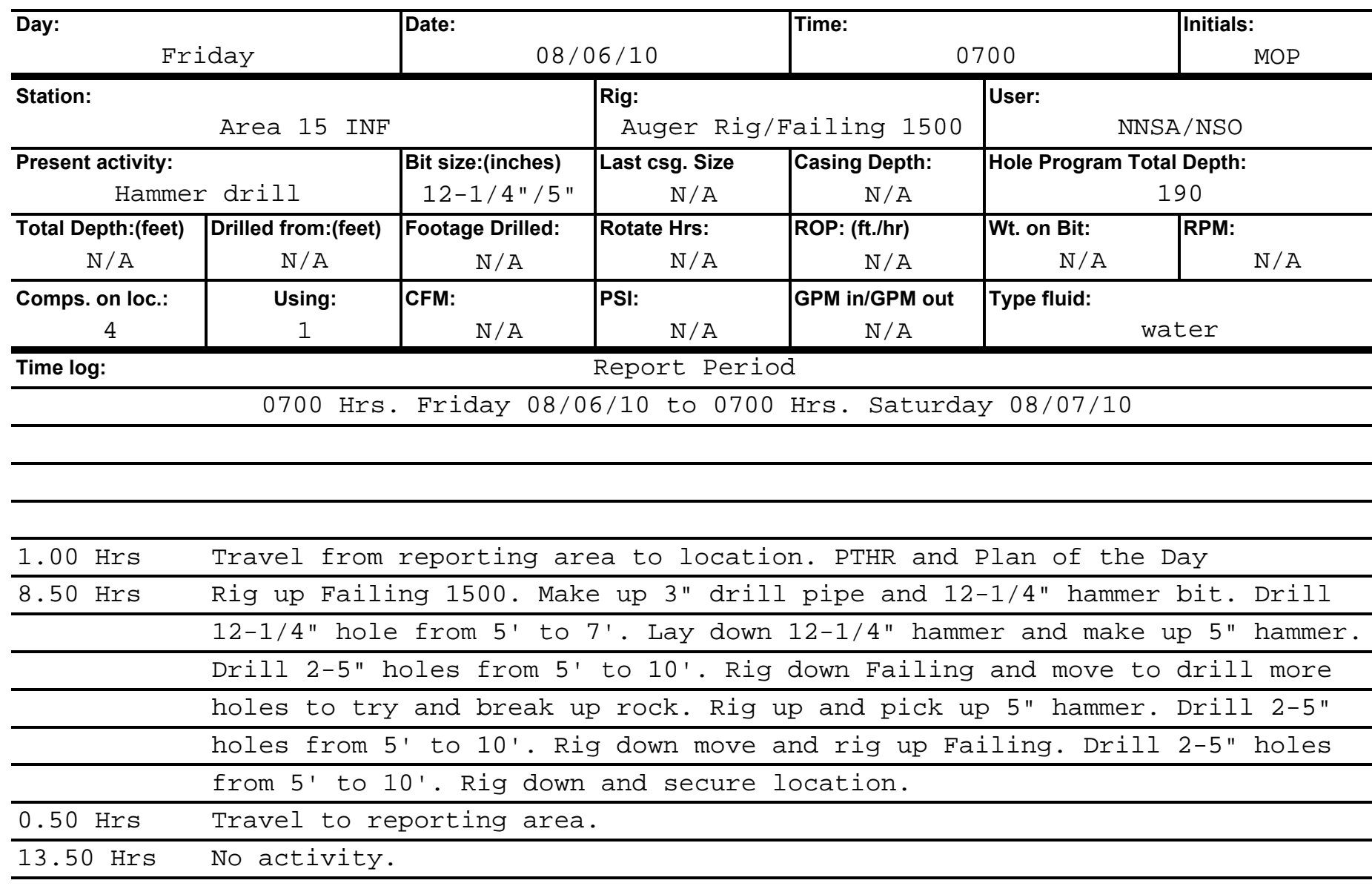




\section{Daily Rig Operations Report}

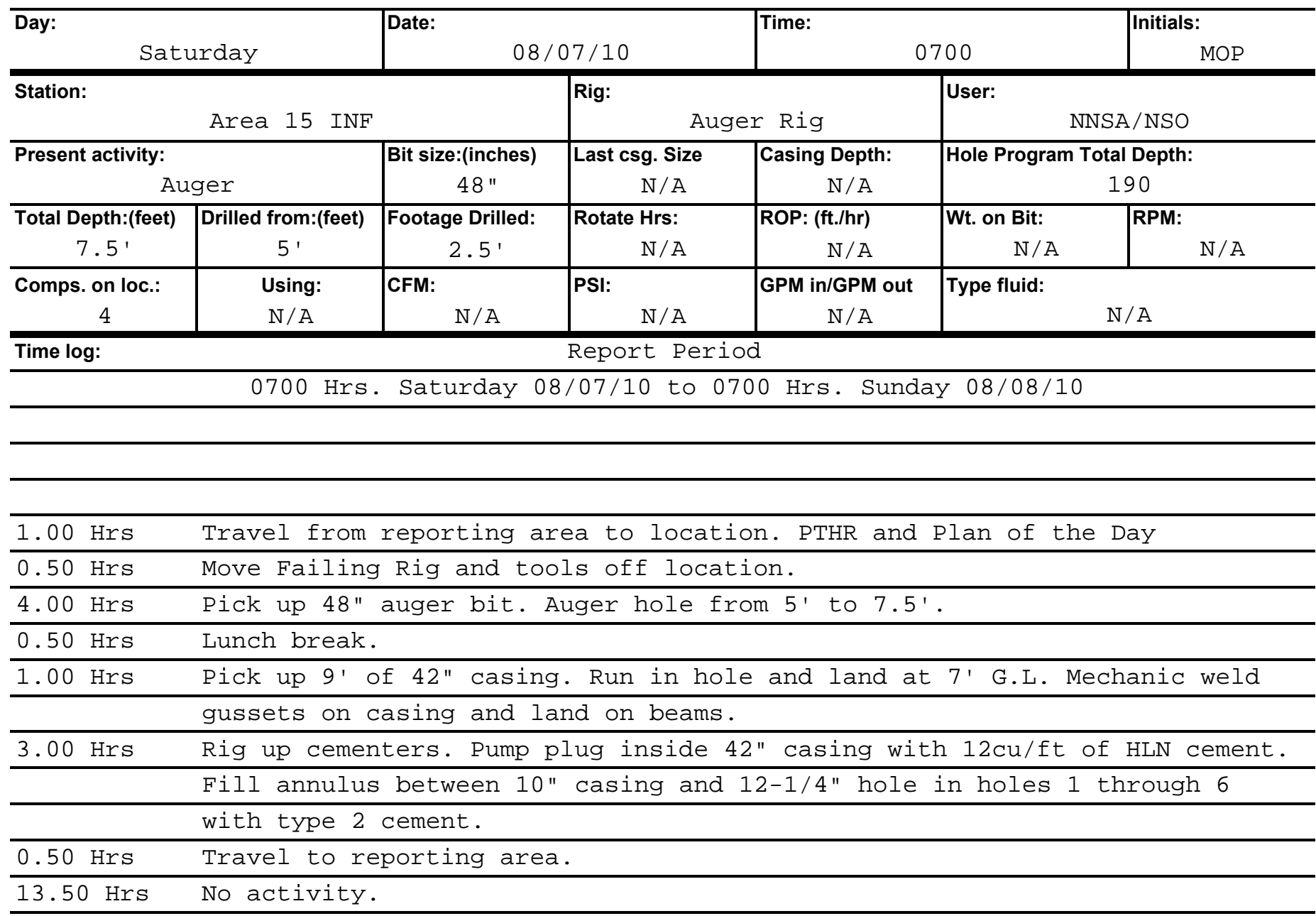




\section{Daily Rig Operations Report}

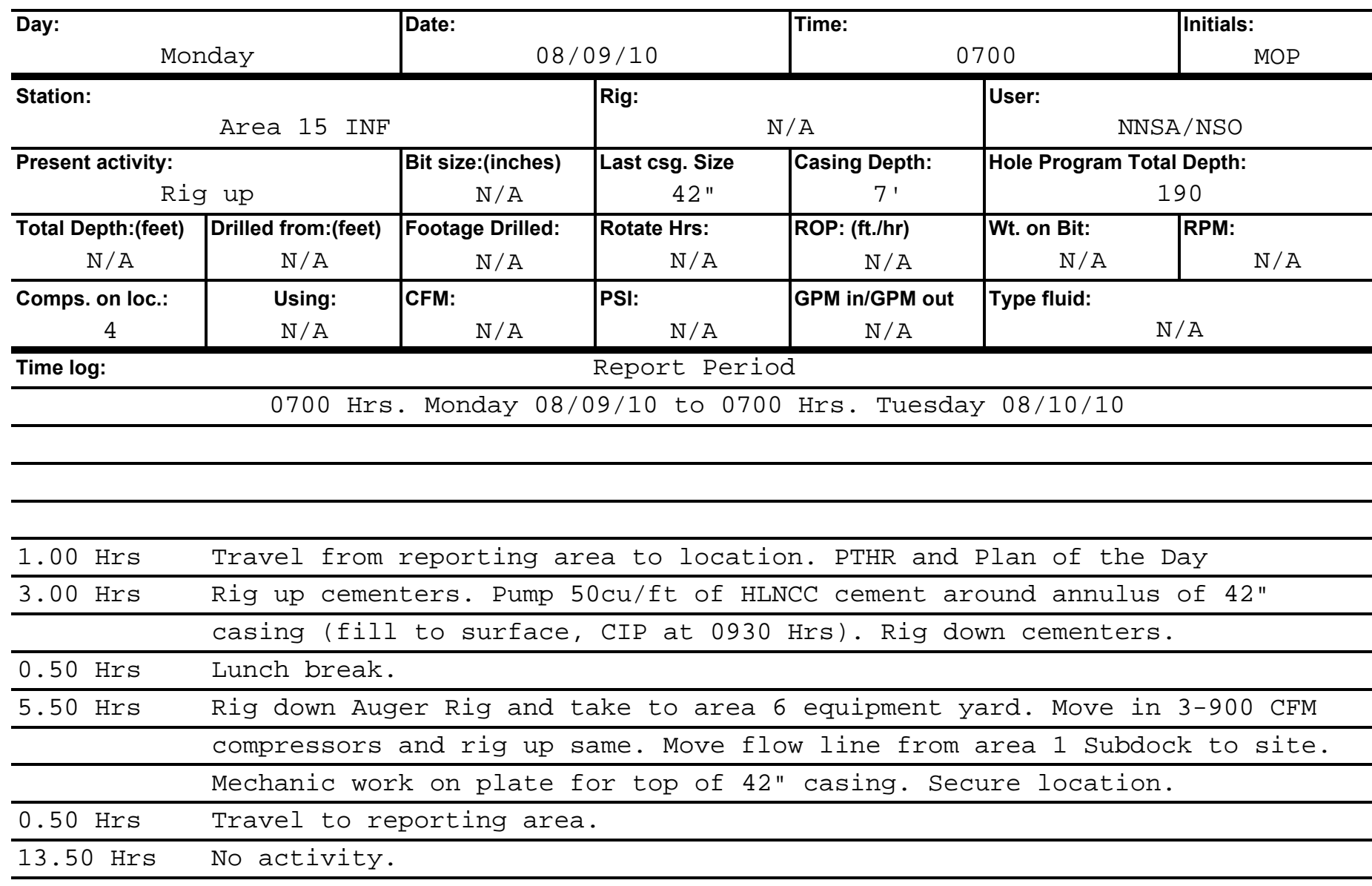




\section{Daily Rig Operations Report}

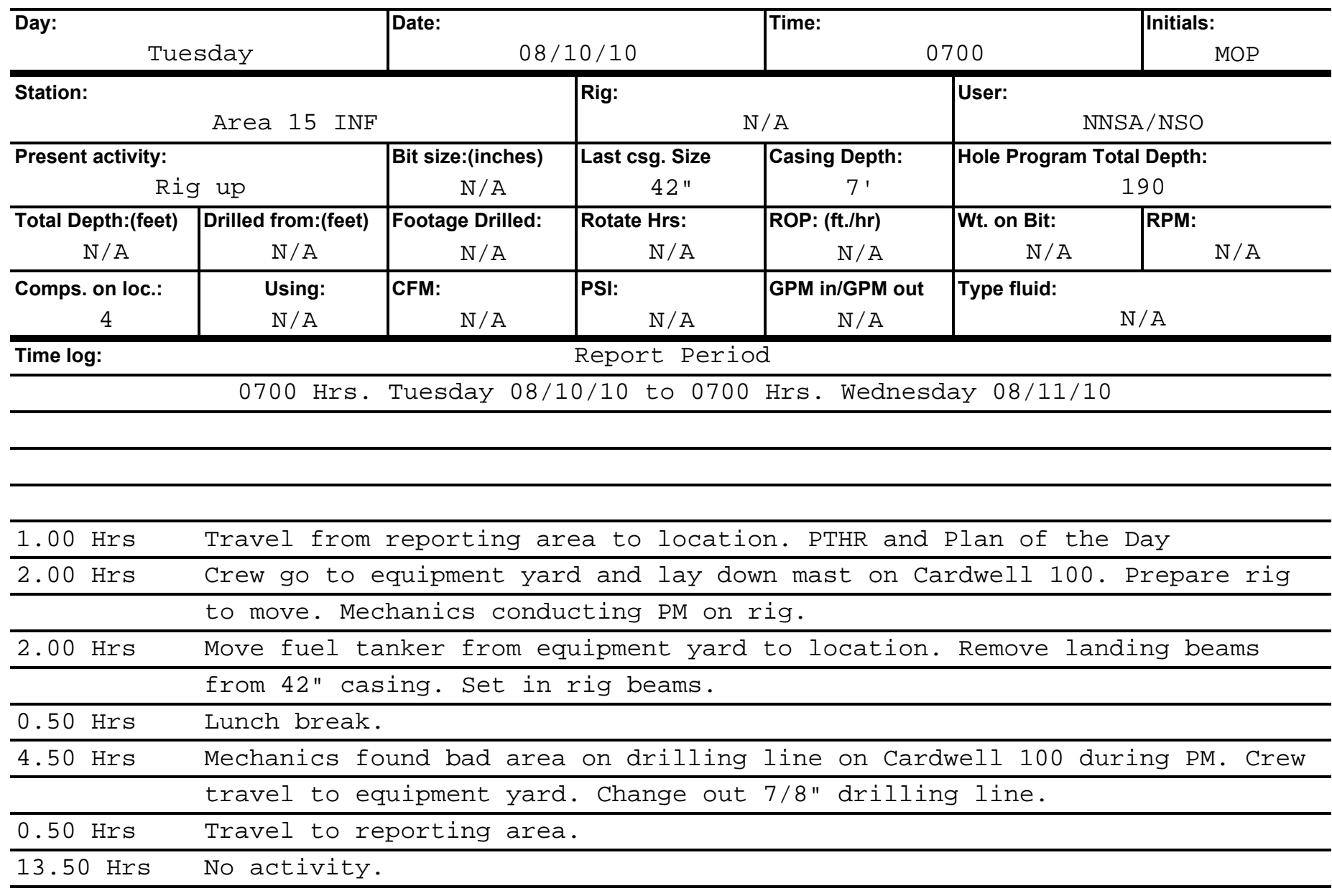




\section{Daily Rig Operations Report}

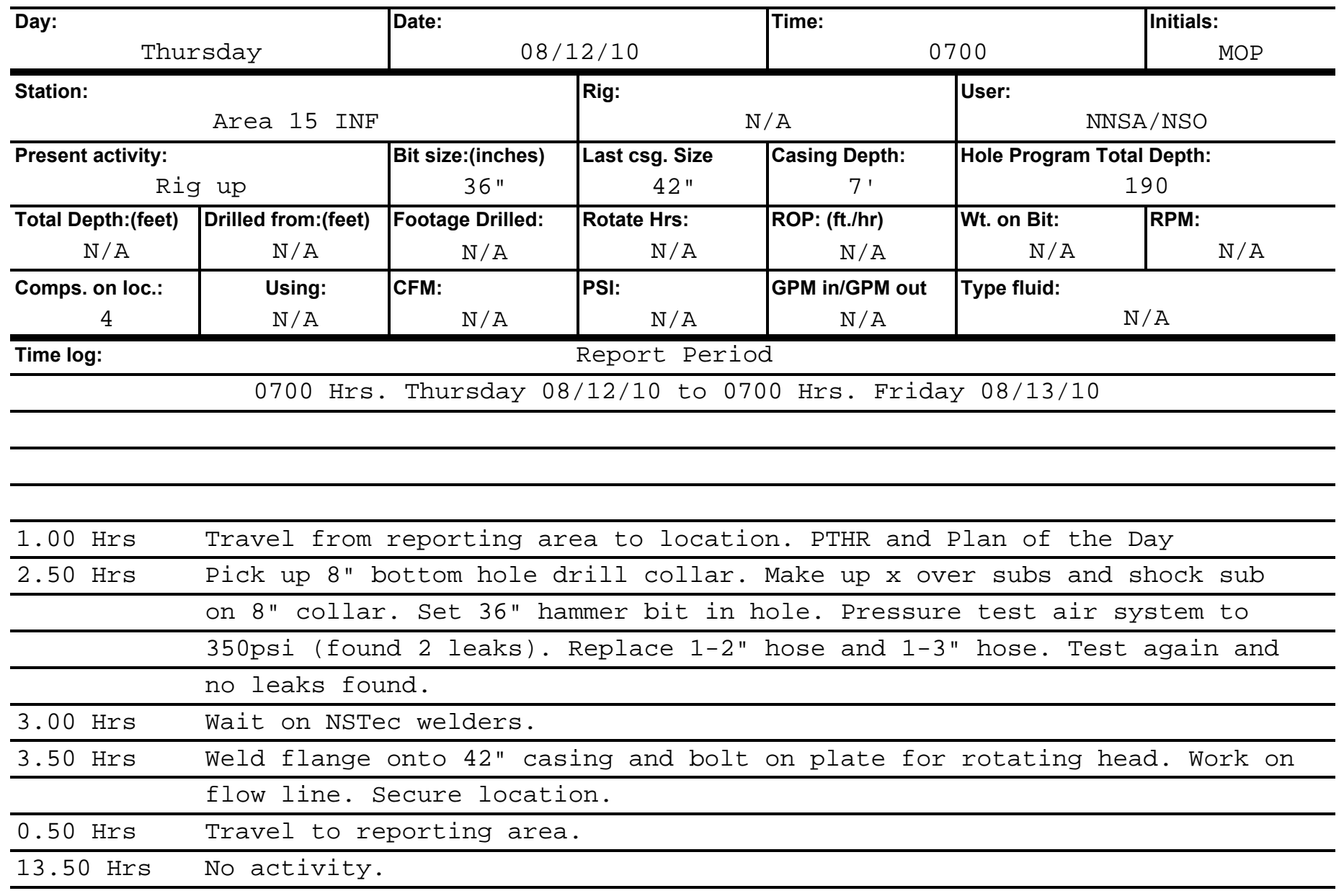

Note: $\quad$ NSTec welders on location at $1330 \mathrm{hrs}$. 


\section{Daily Rig Operations Report}

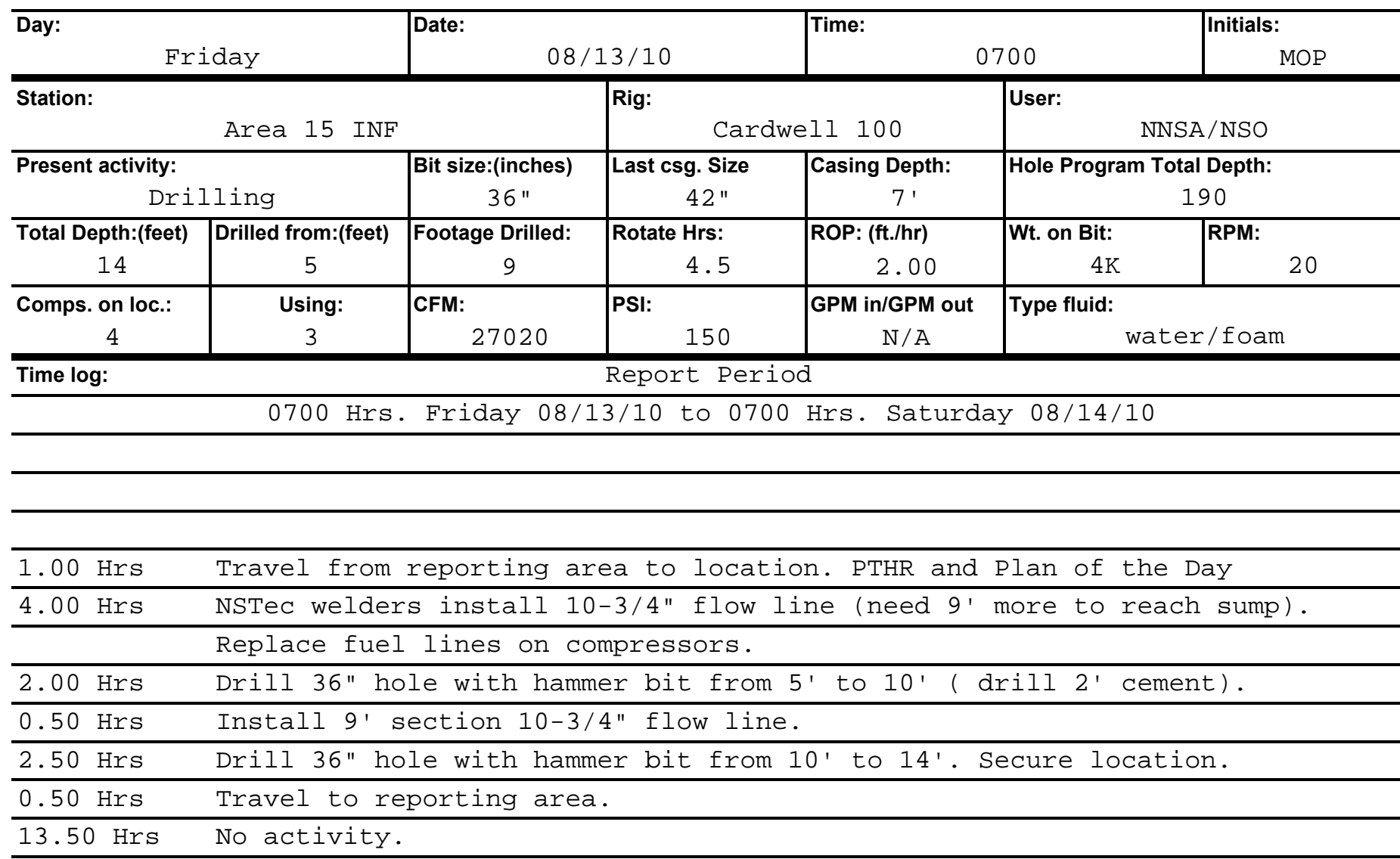




\section{Daily Rig Operations Report}

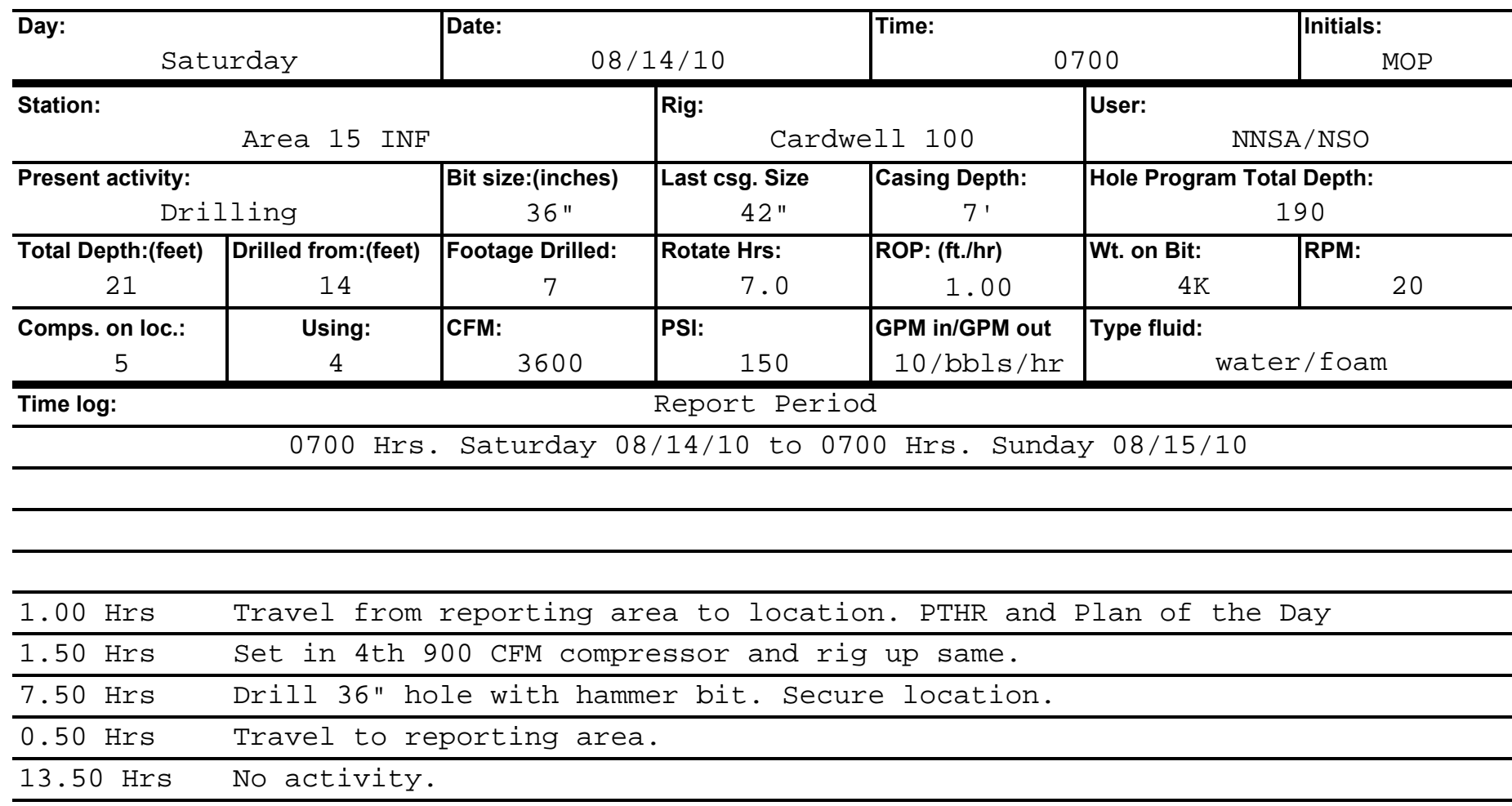




\section{Daily Rig Operations Report}

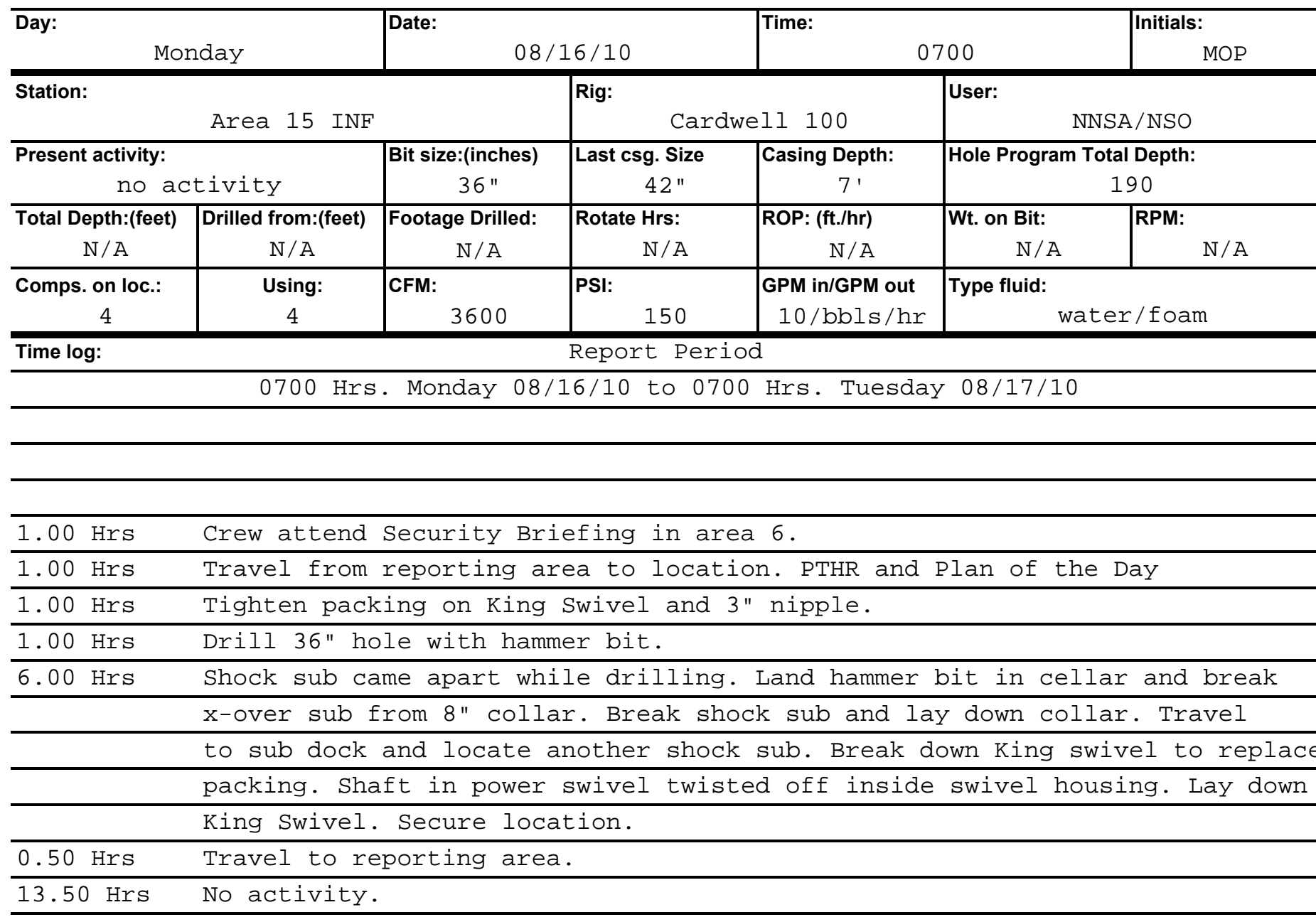




\section{Daily Rig Operations Report}

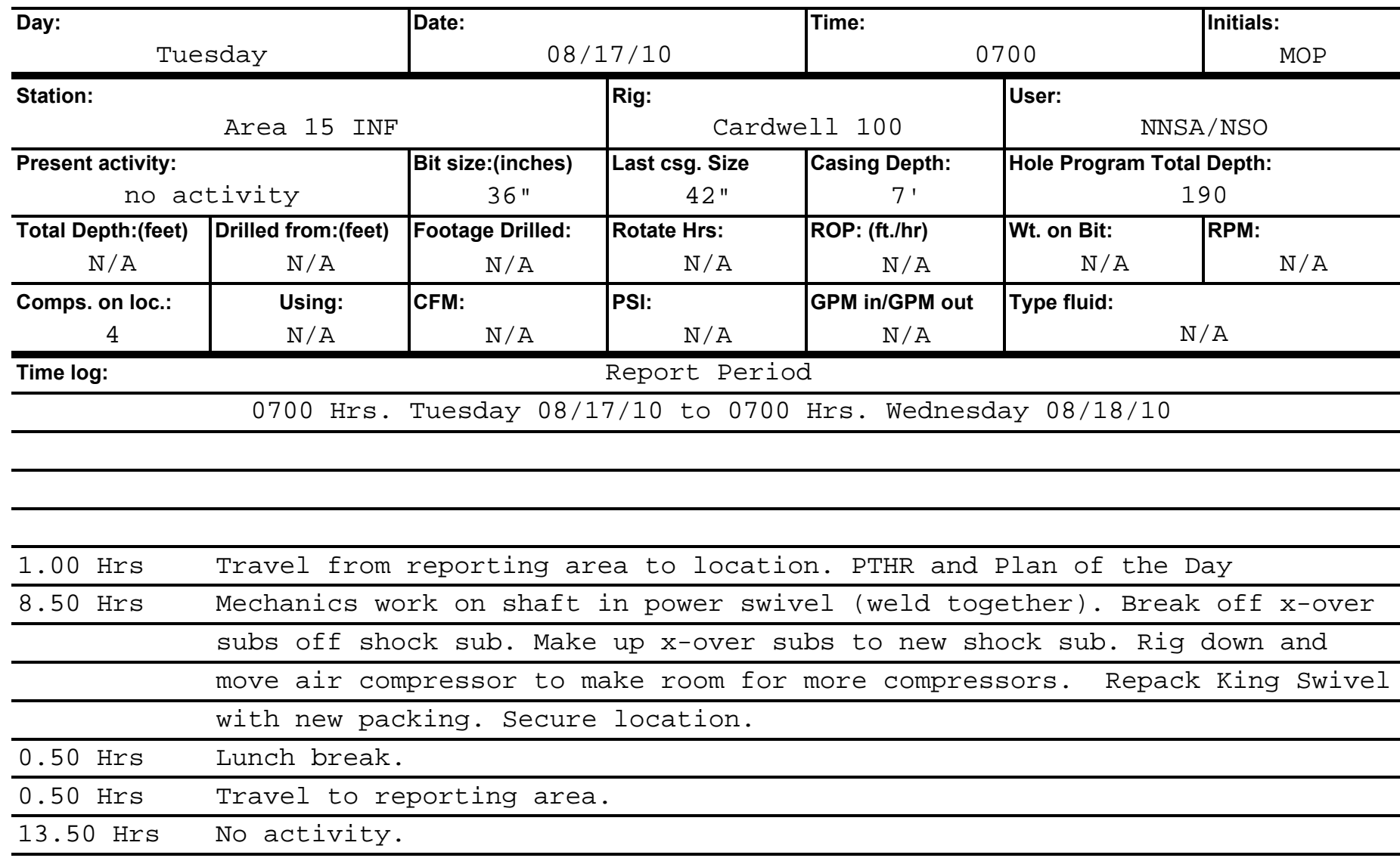




\section{Daily Rig Operations Report}

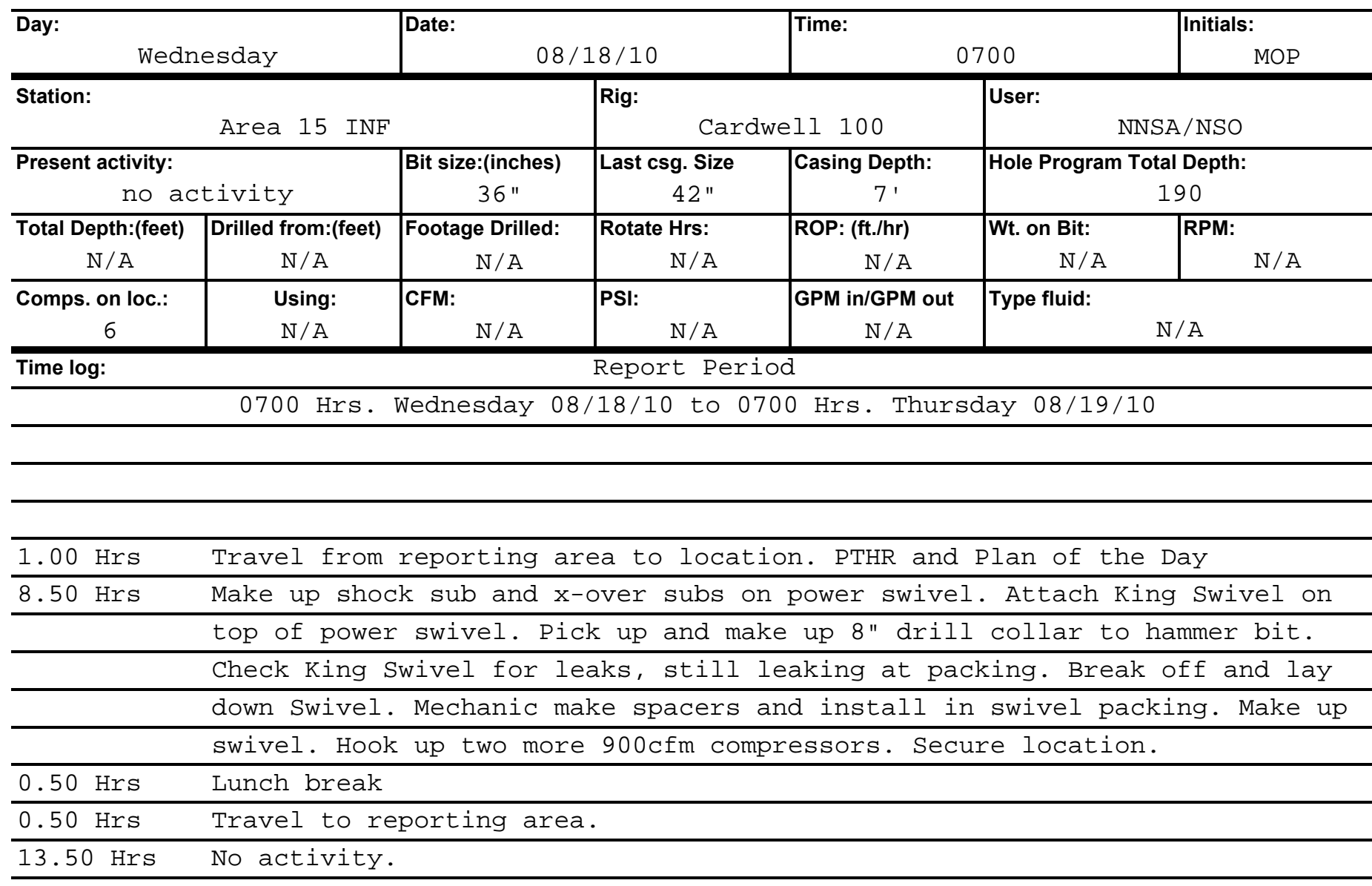




\section{Daily Rig Operations Report}

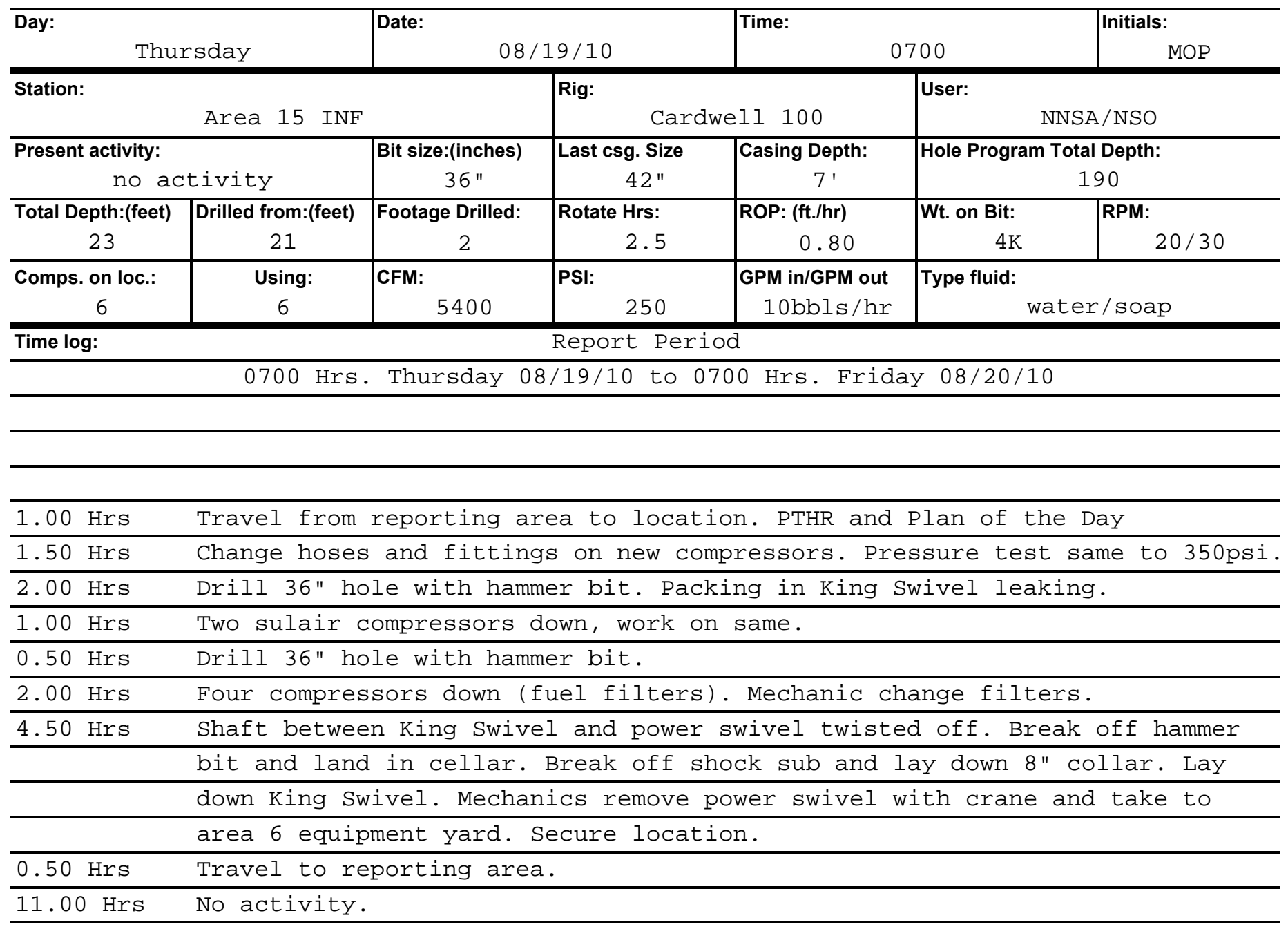




\section{Daily Rig Operations Report}

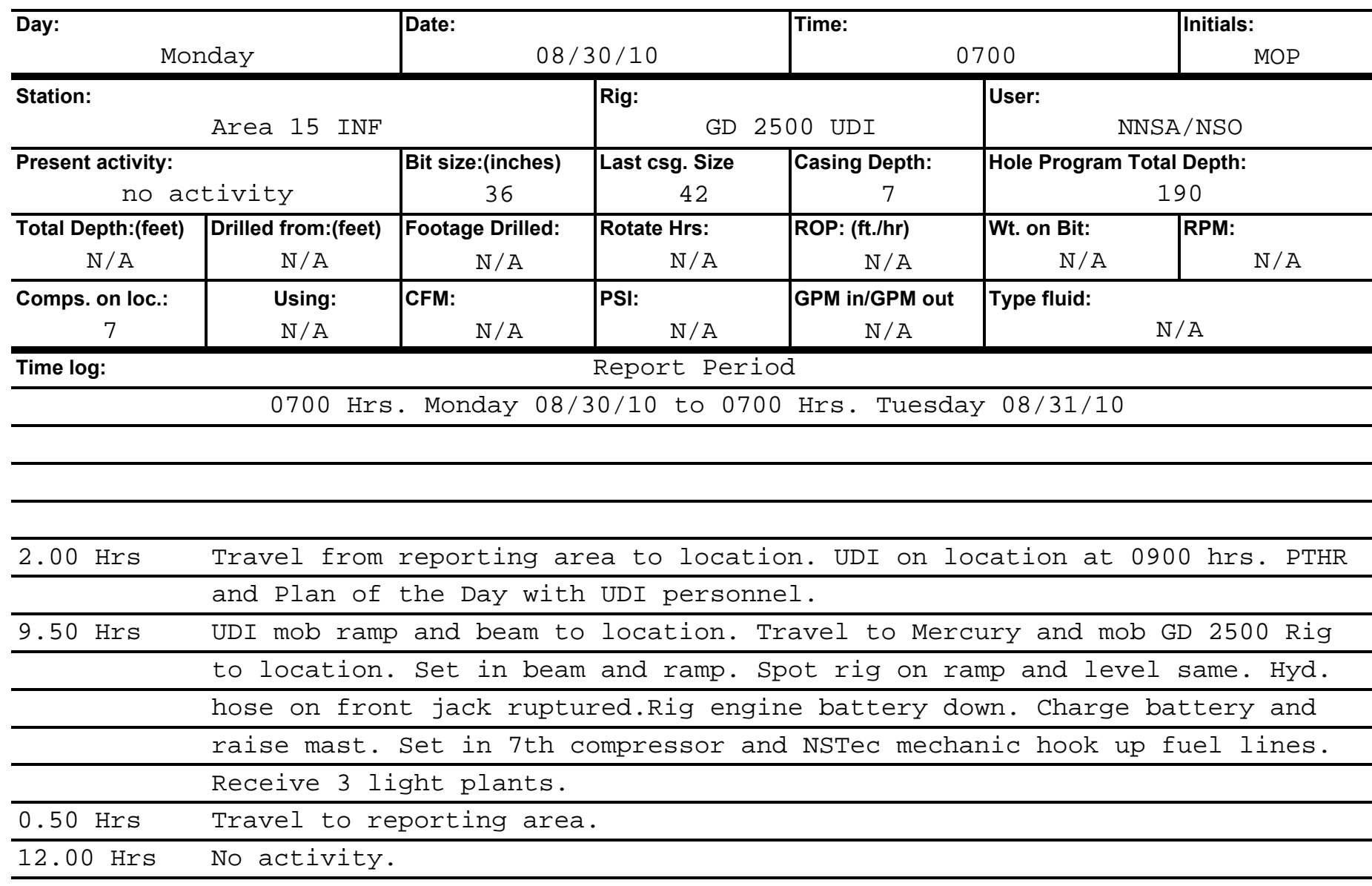




\section{Daily Rig Operations Report}

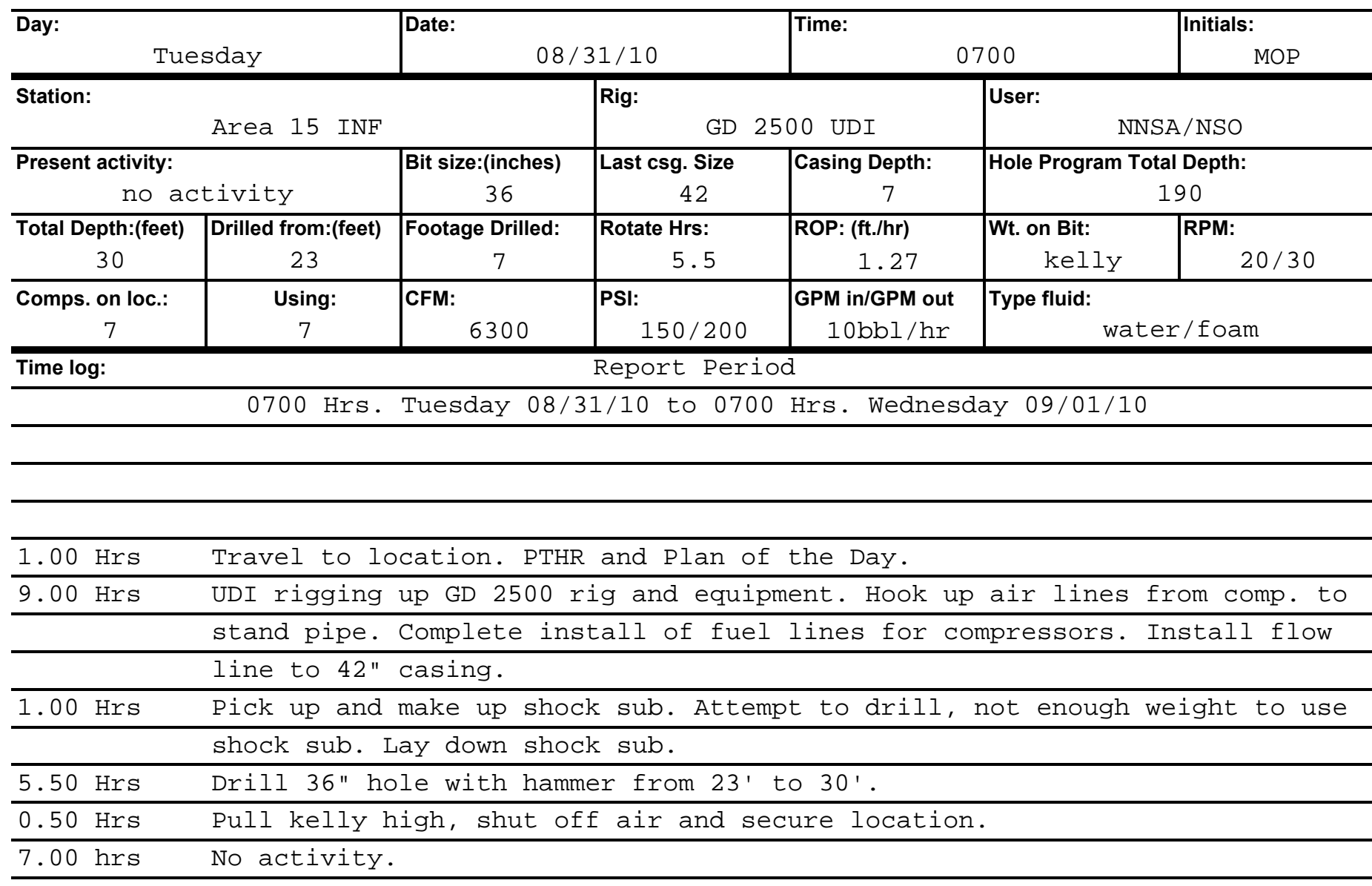




\section{Daily Rig Operations Report}

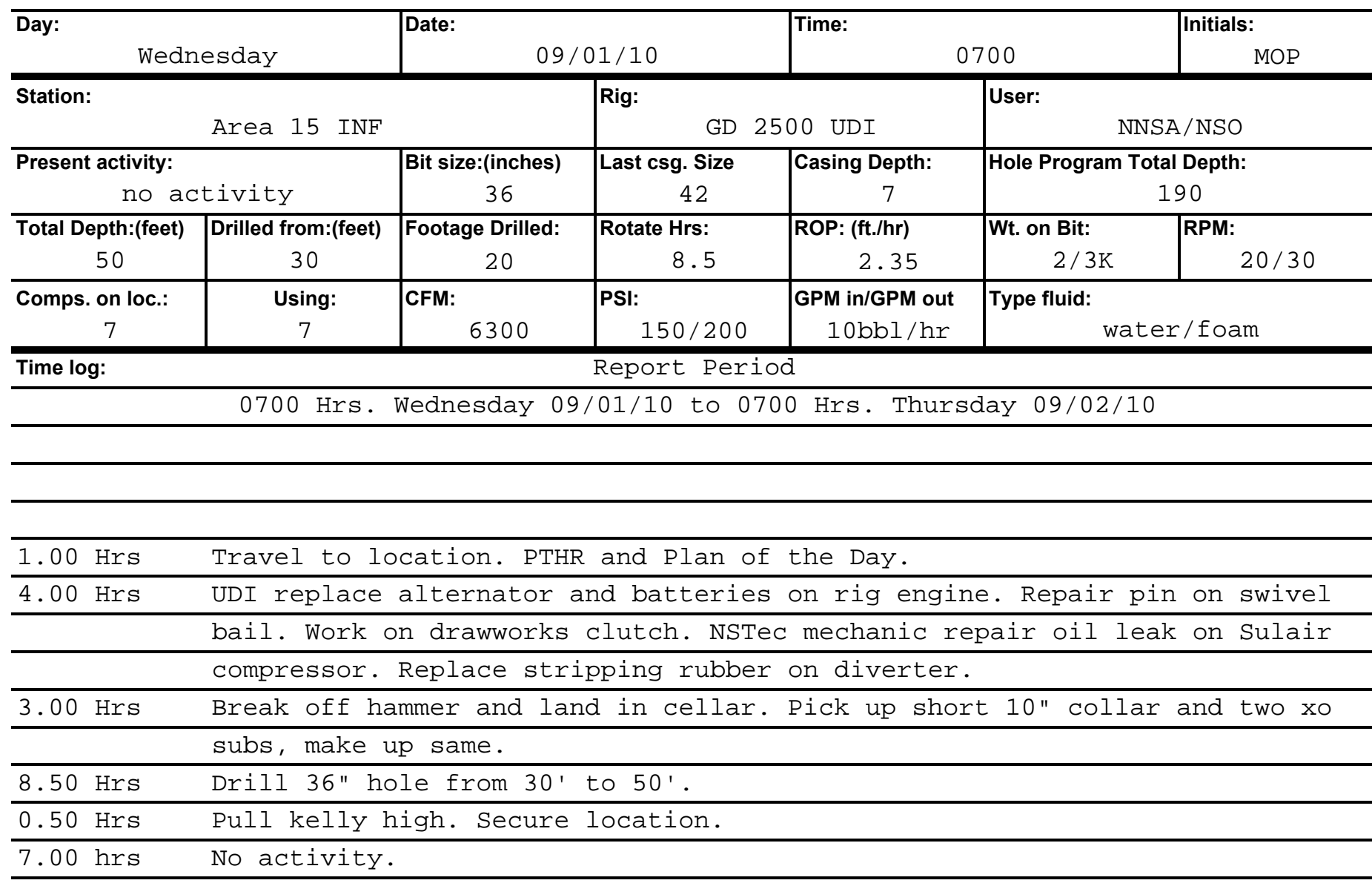




\section{Daily Rig Operations Report}

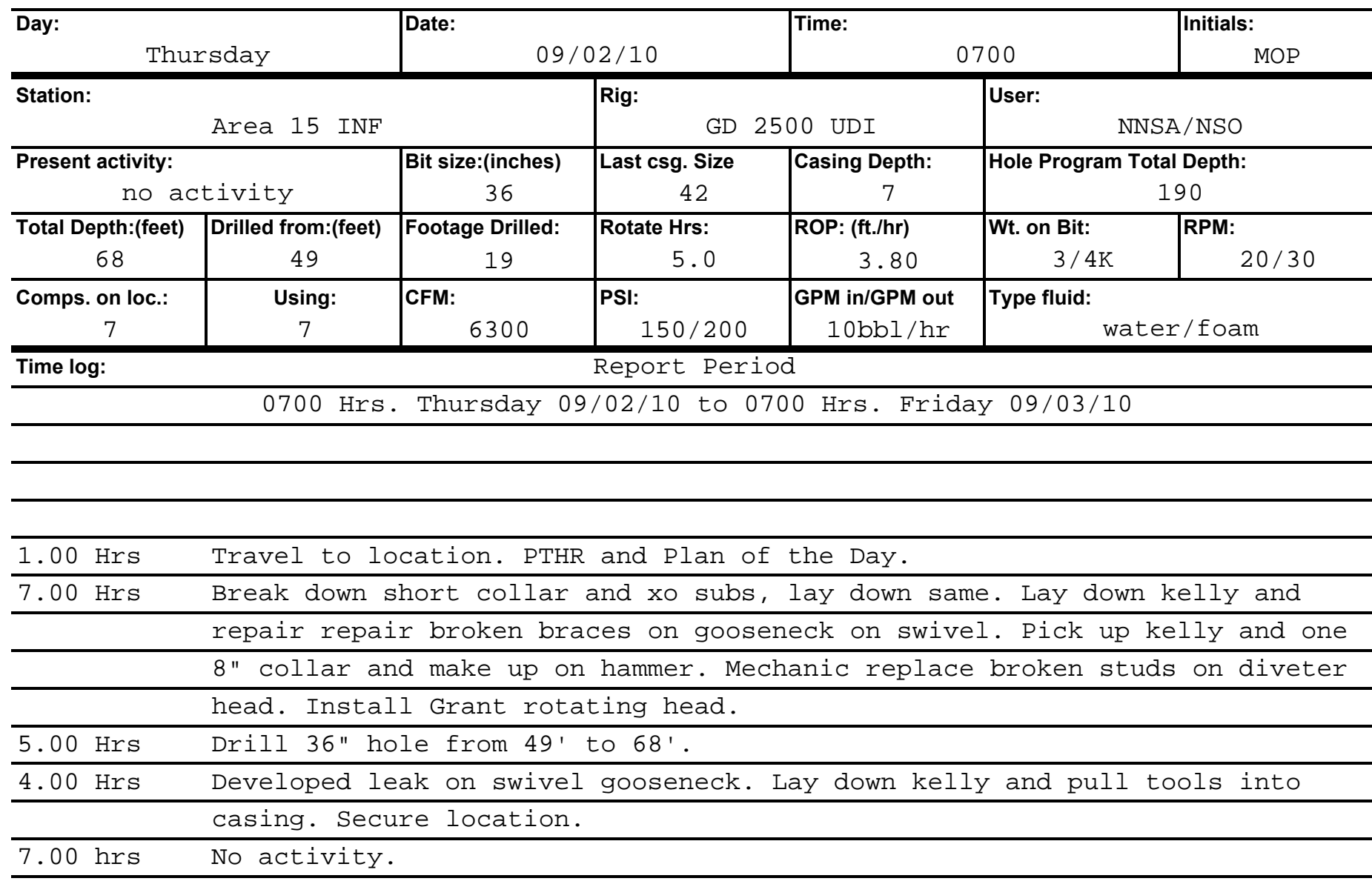




\section{Daily Rig Operations Report}

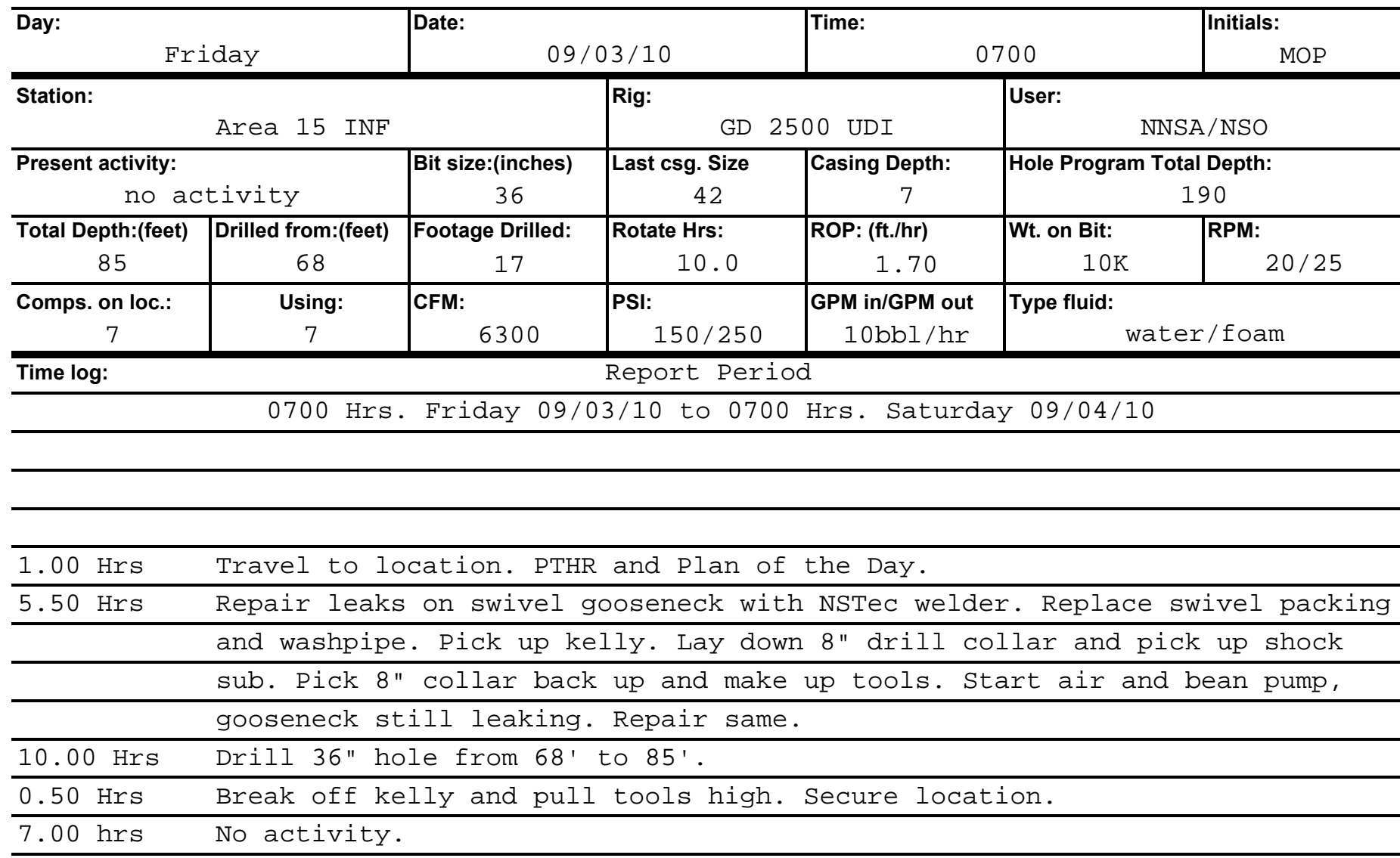

Note: $\quad$ Put 7 gallons AWF fluid in compressors \#08-614 \& 08-615 (14 gals total). 


\section{Daily Rig Operations Report}

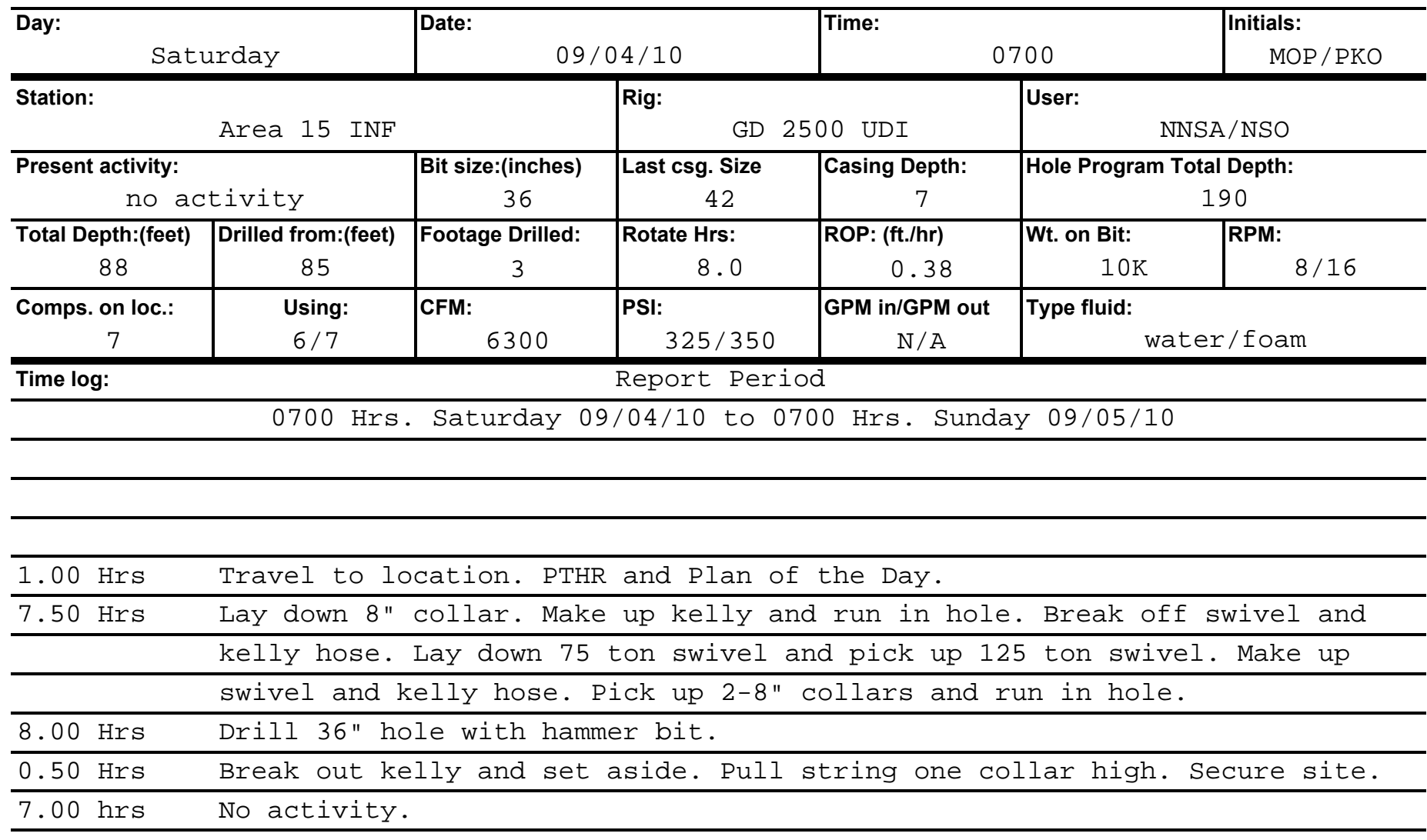

Note Compressors running hot and unable to put all seven on line ( on high).




\section{Daily Rig Operations Report}

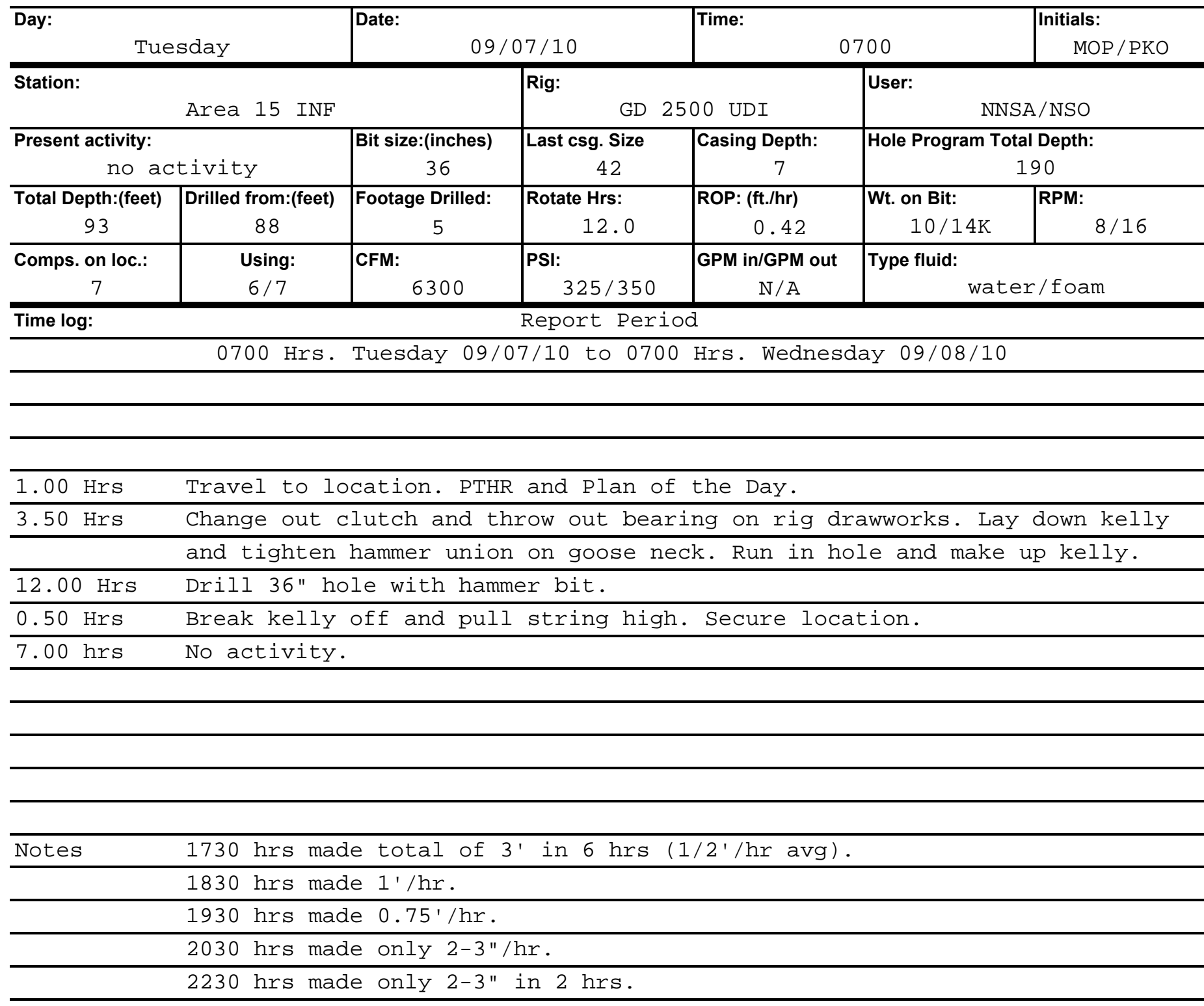




\section{Daily Rig Operations Report}

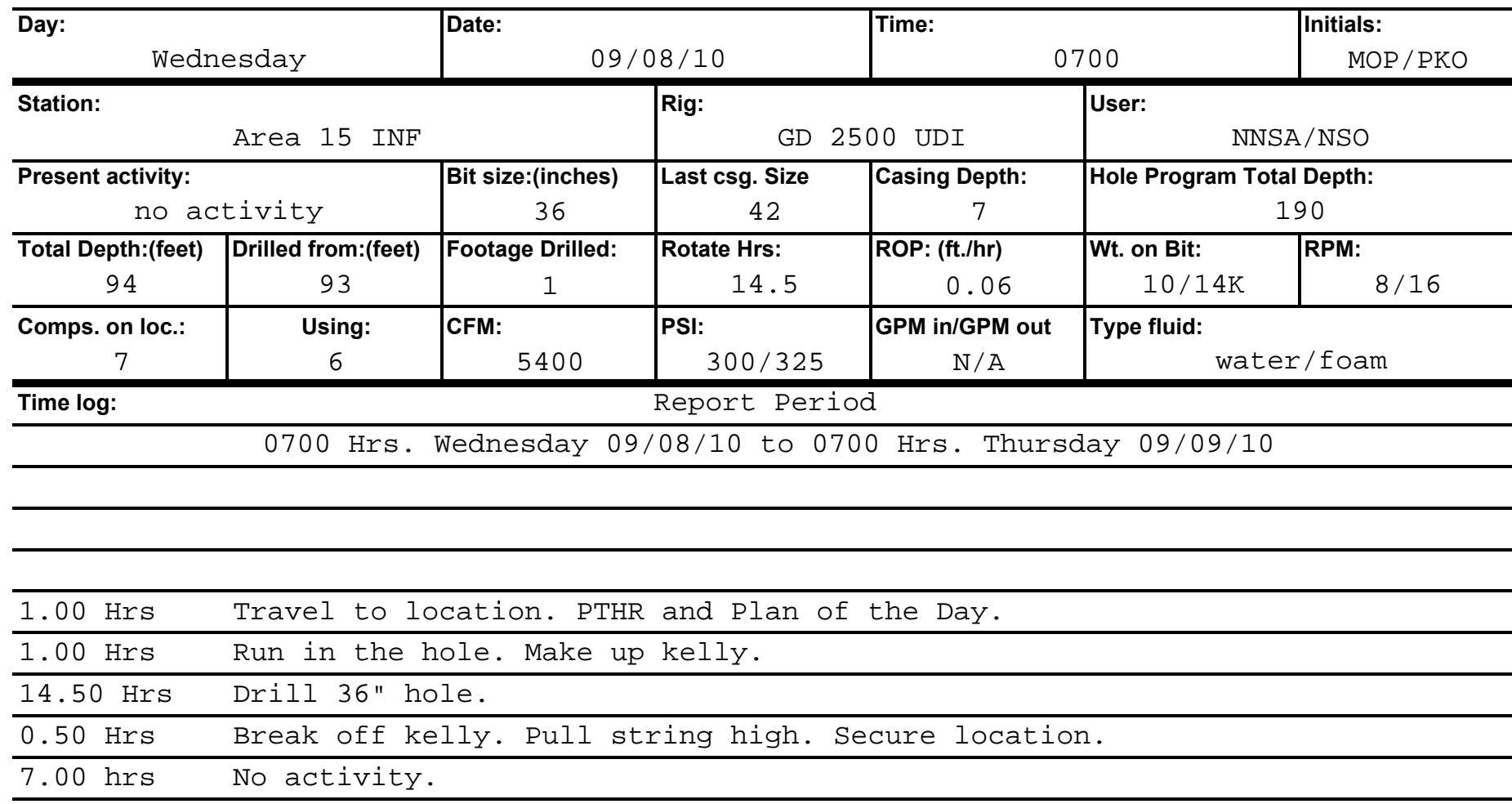

\begin{tabular}{ll}
\hline Notes & Install pressure gage on rig standpipe, 325psi at comp.and $200 p s i$ at rig. \\
\hline & Install new pressure gage, 325psi at comp and 275psi at rig standpipe. \\
\hline & Pressure test system to 350psi and no leaks. \\
\hline & Run light weight on bit and speed up rpm to 35, no change in drilling.
\end{tabular}




\section{Daily Rig Operations Report}

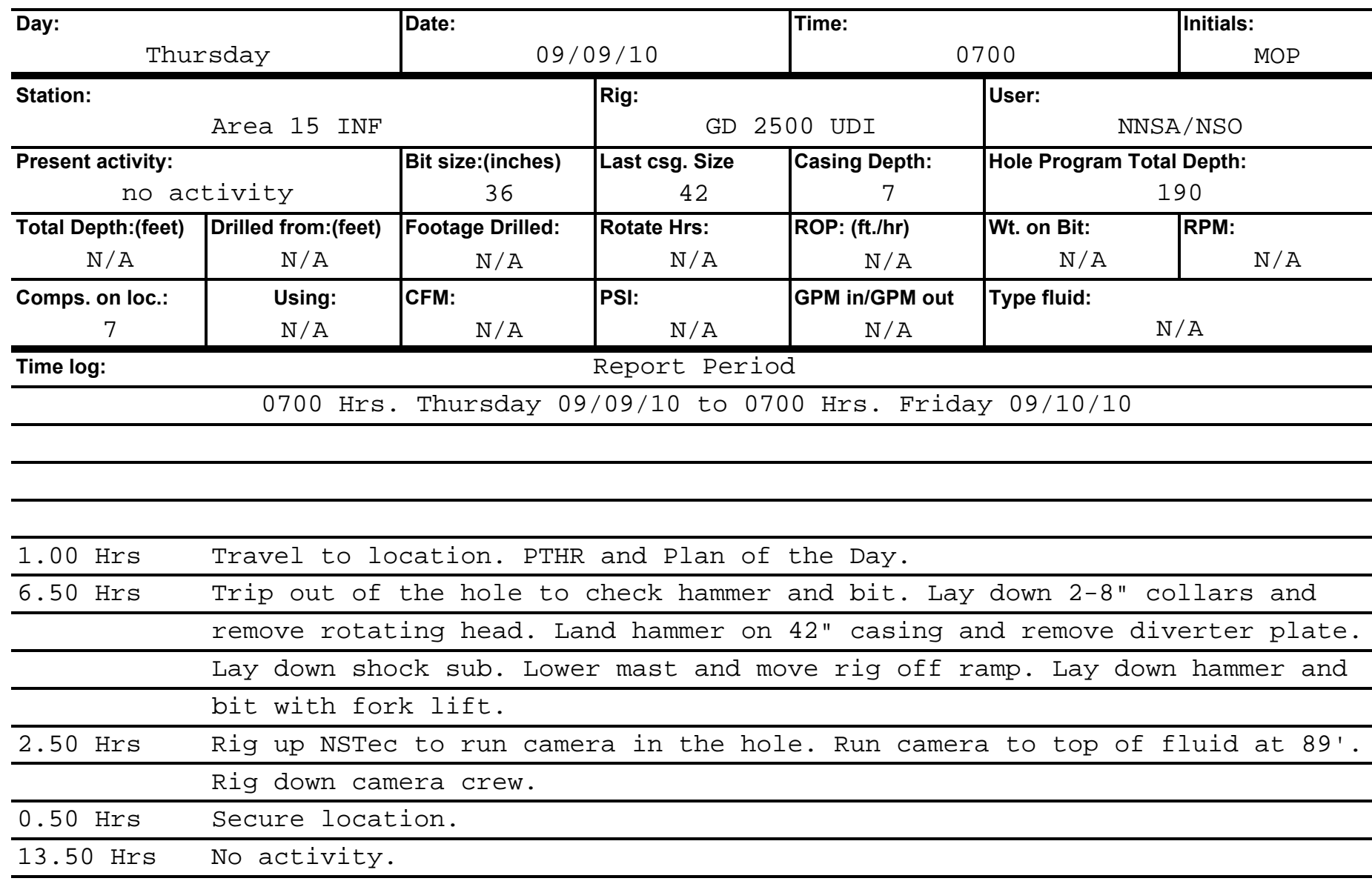




\section{Daily Rig Operations Report}

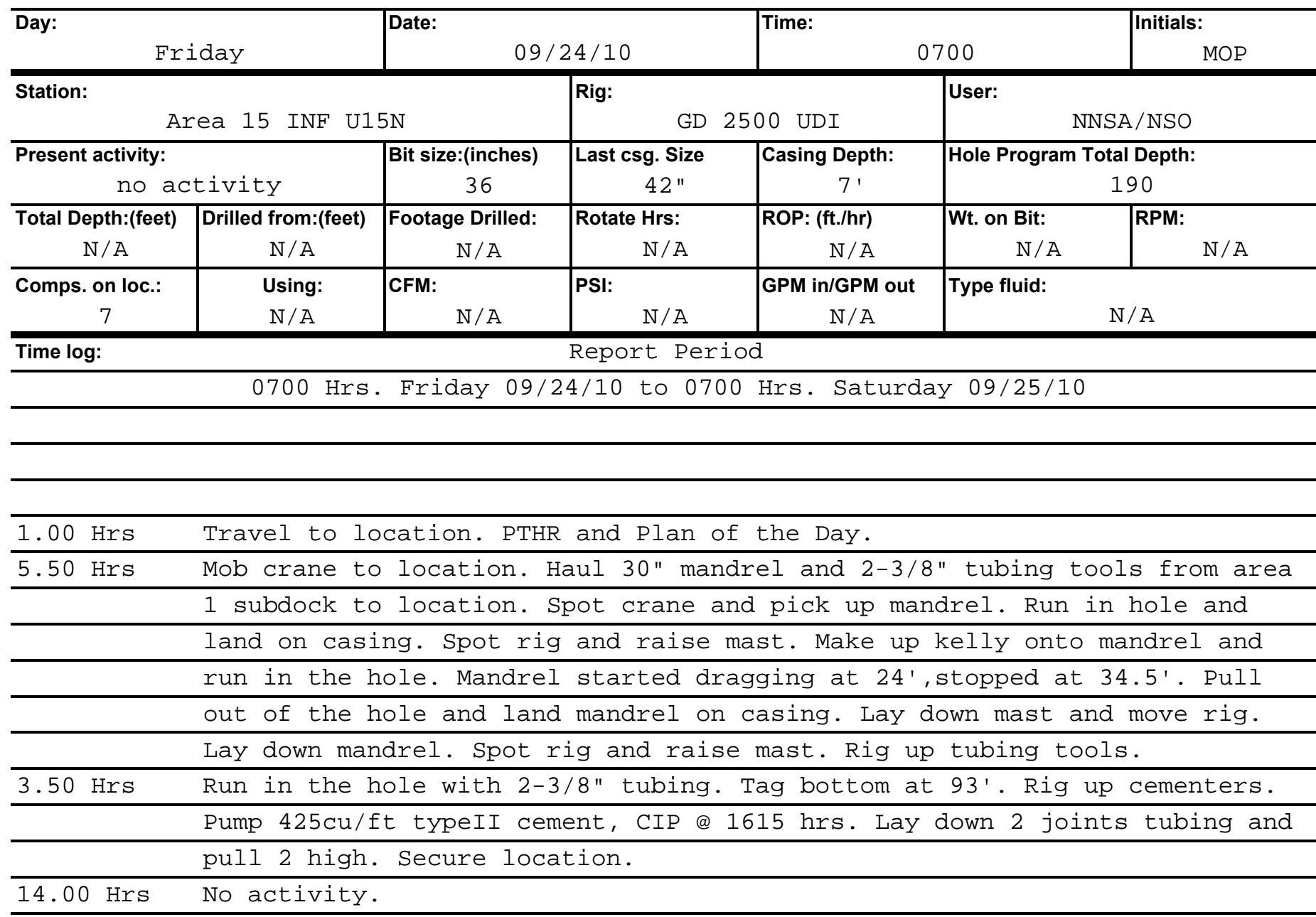




\section{Daily Rig Operations Report}

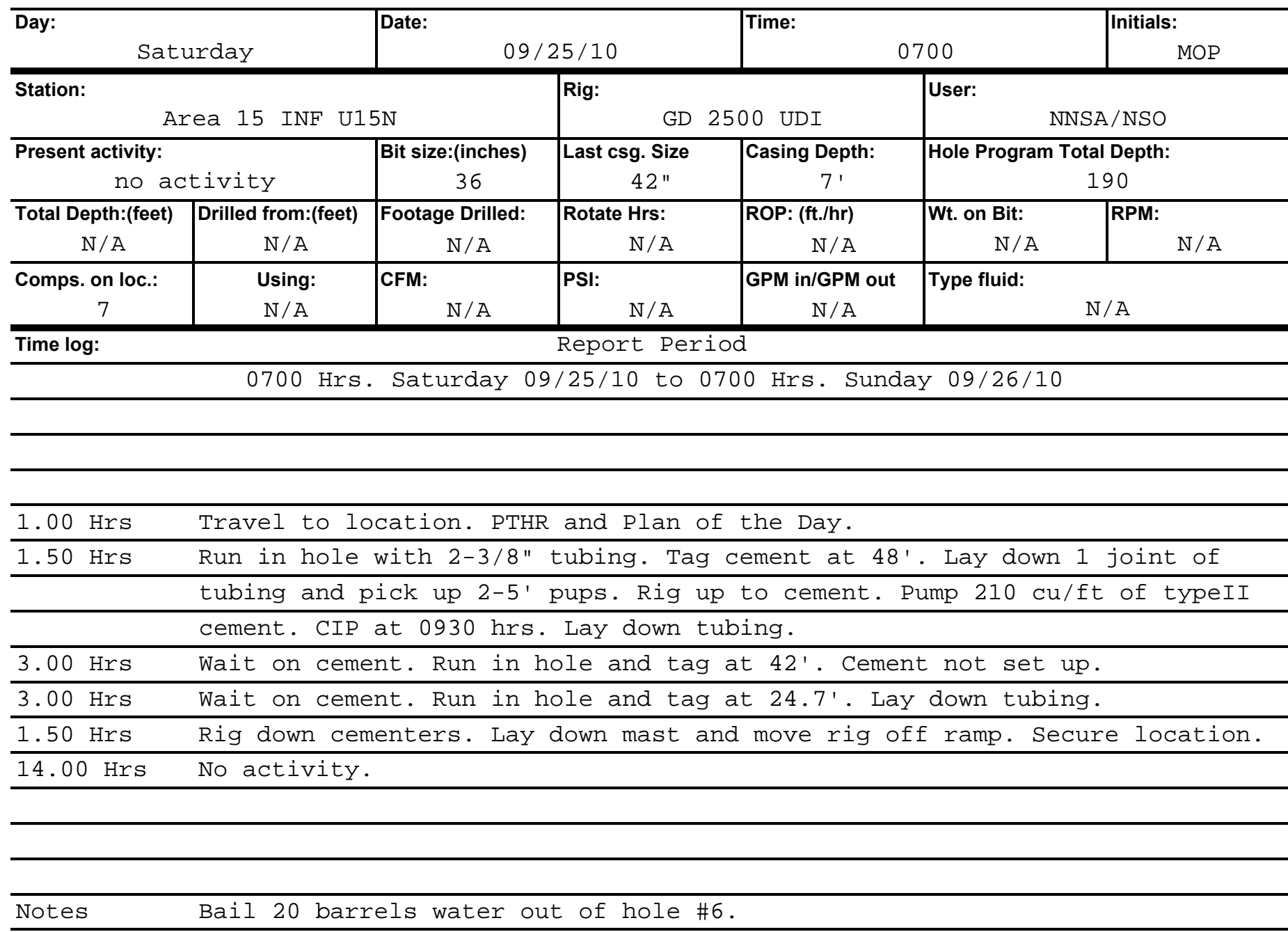




\section{Daily Rig Operations Report}

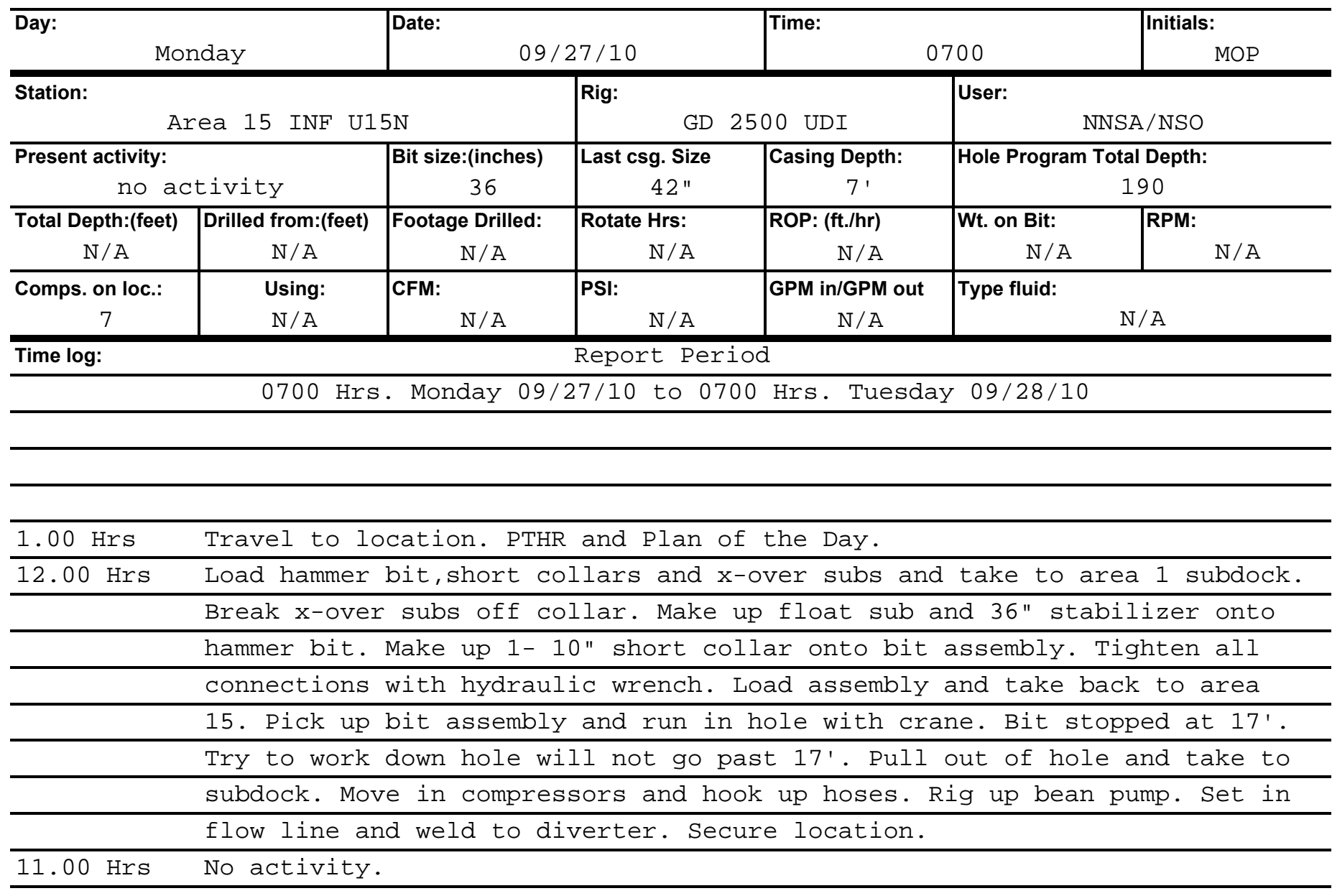




\section{Daily Rig Operations Report}

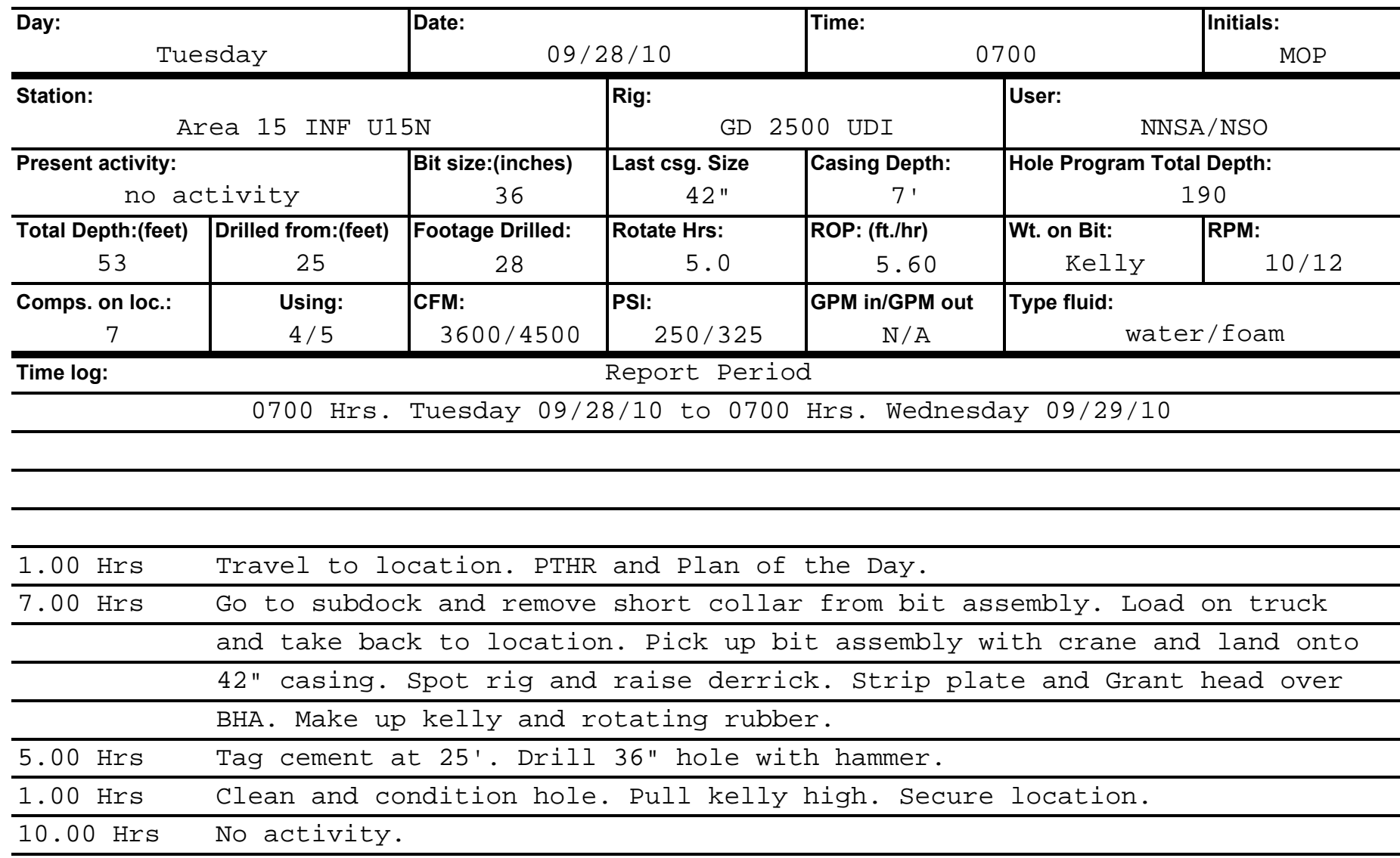




\section{Daily Rig Operations Report}

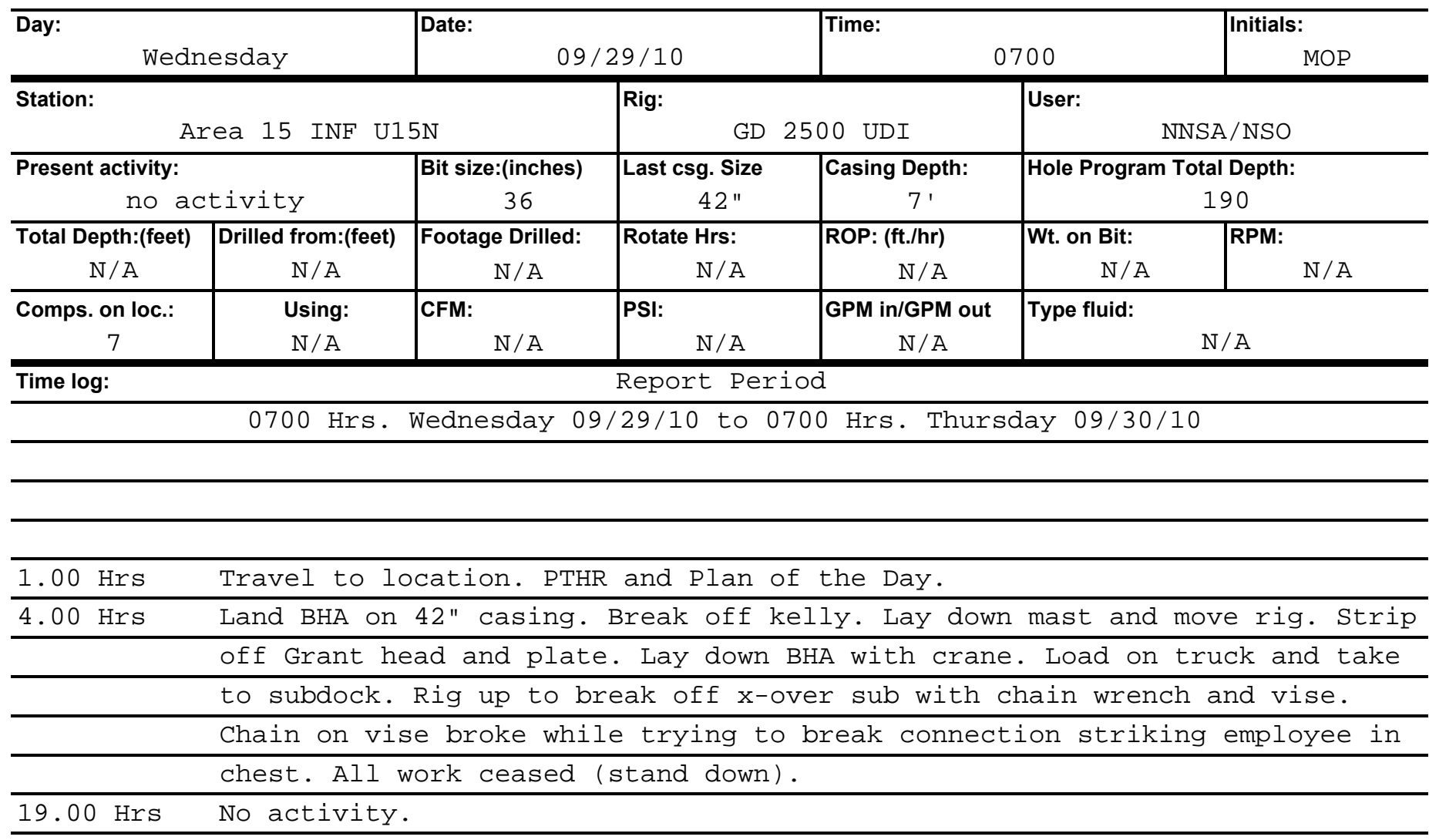




\section{Daily Rig Operations Report}

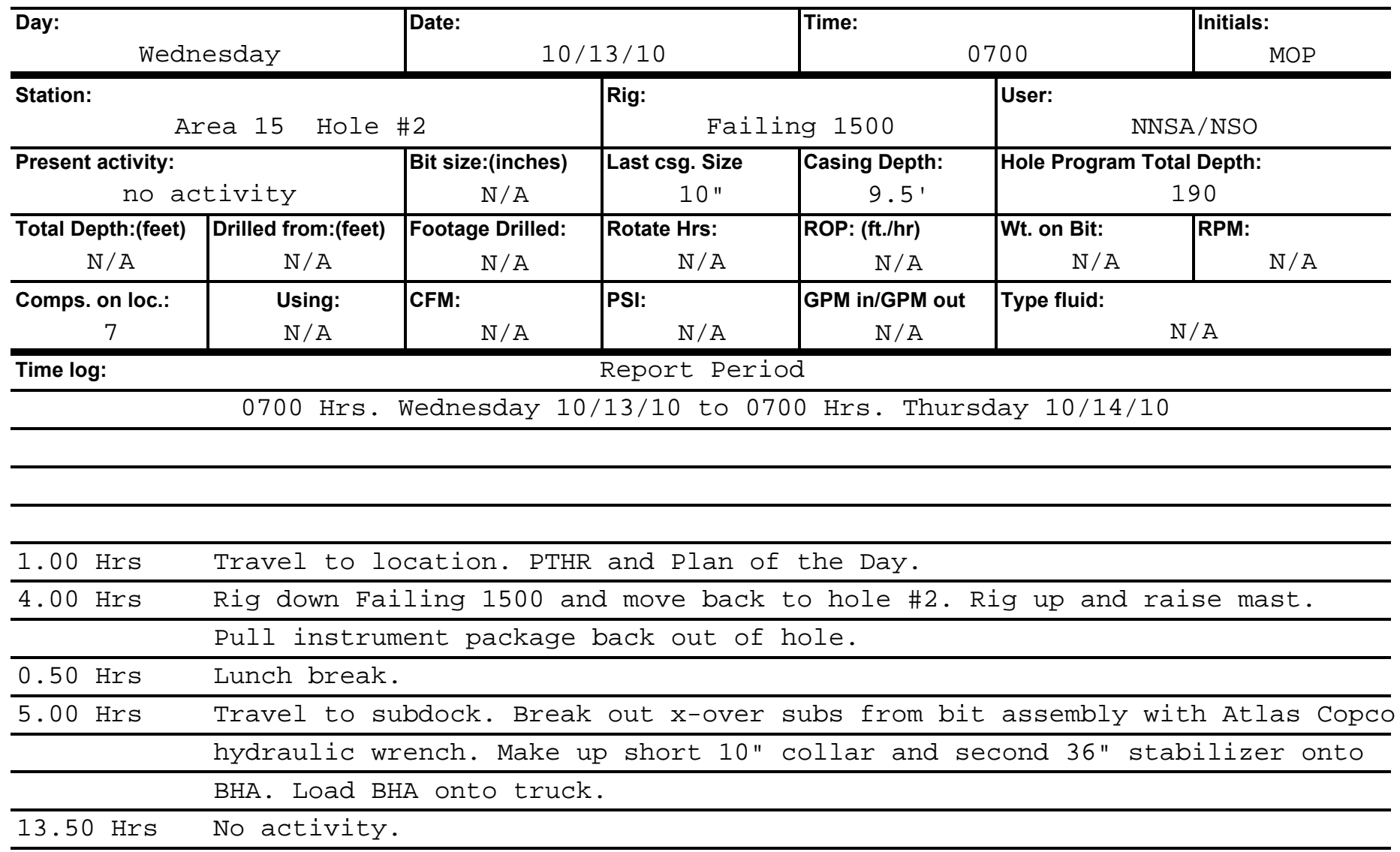




\section{Daily Rig Operations Report}

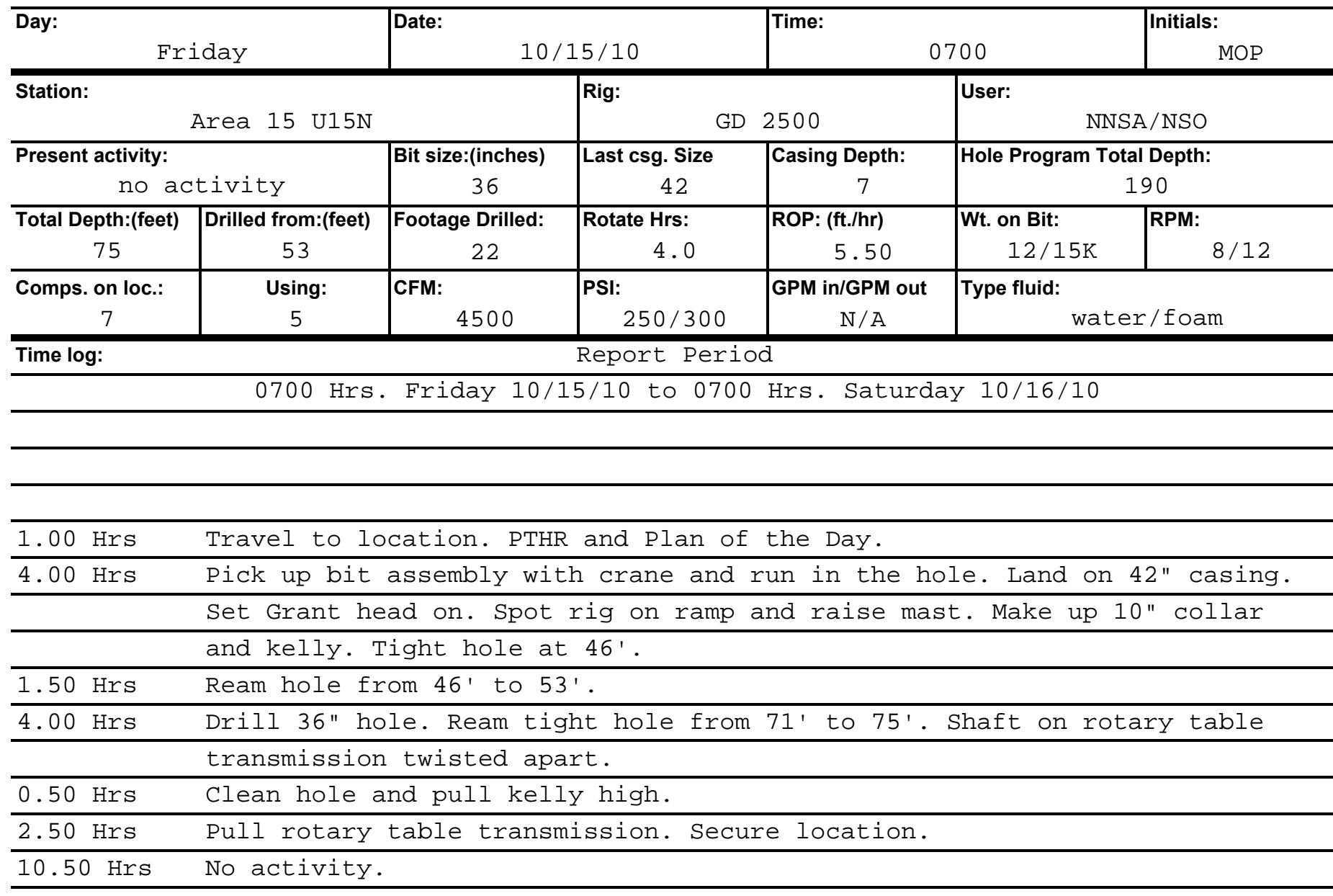

\begin{tabular}{ll}
\hline Notes & Pre start meeting with UDI and NSTec personnel. \\
\hline Inspect all cables, drilling line, tugger line, snub lines, slings, blocks, \\
\hline crown and cat head on UDI equipment before start up.
\end{tabular}




\section{Daily Rig Operations Report}

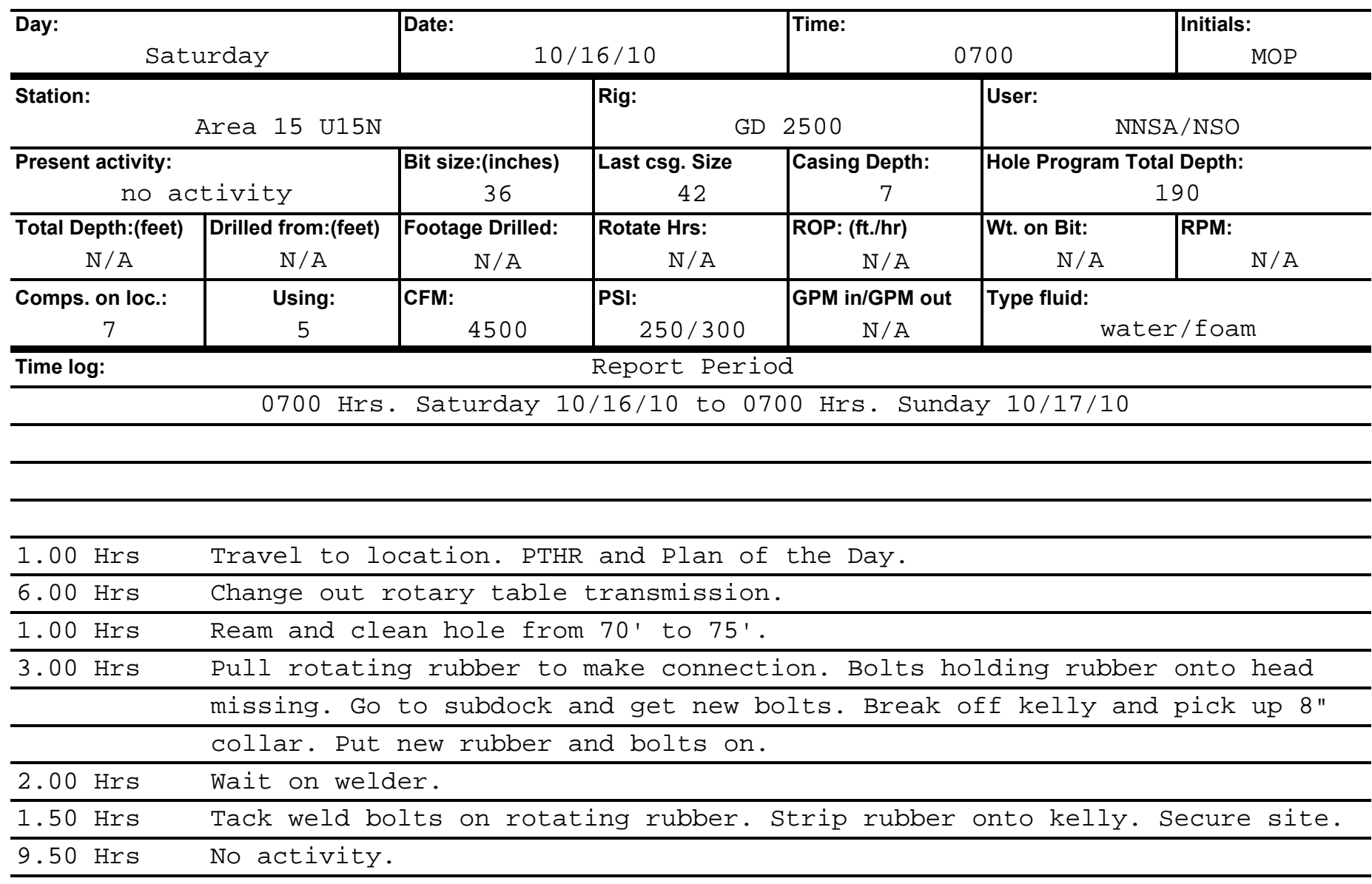




\section{Daily Rig Operations Report}

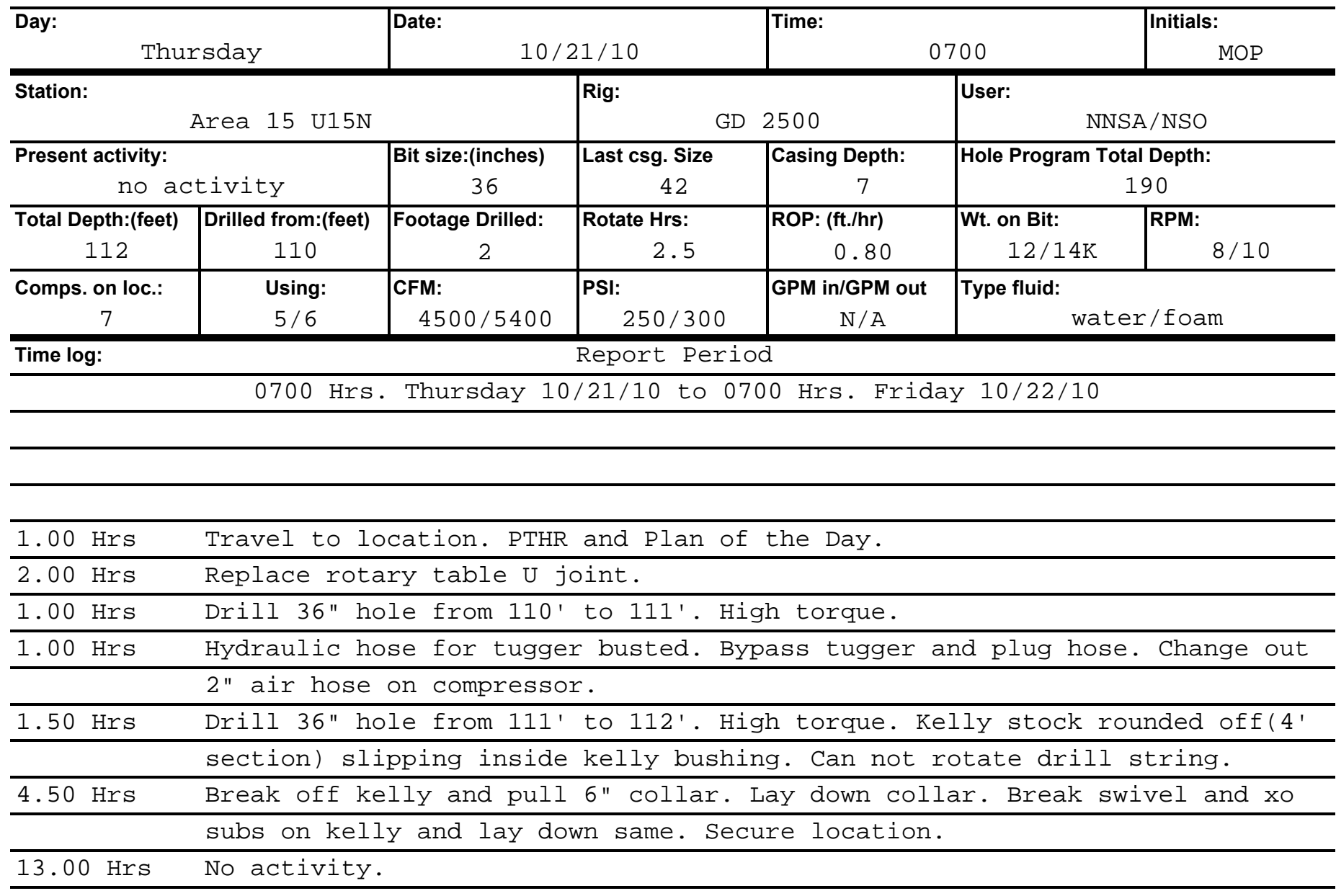




\section{Daily Rig Operations Report}

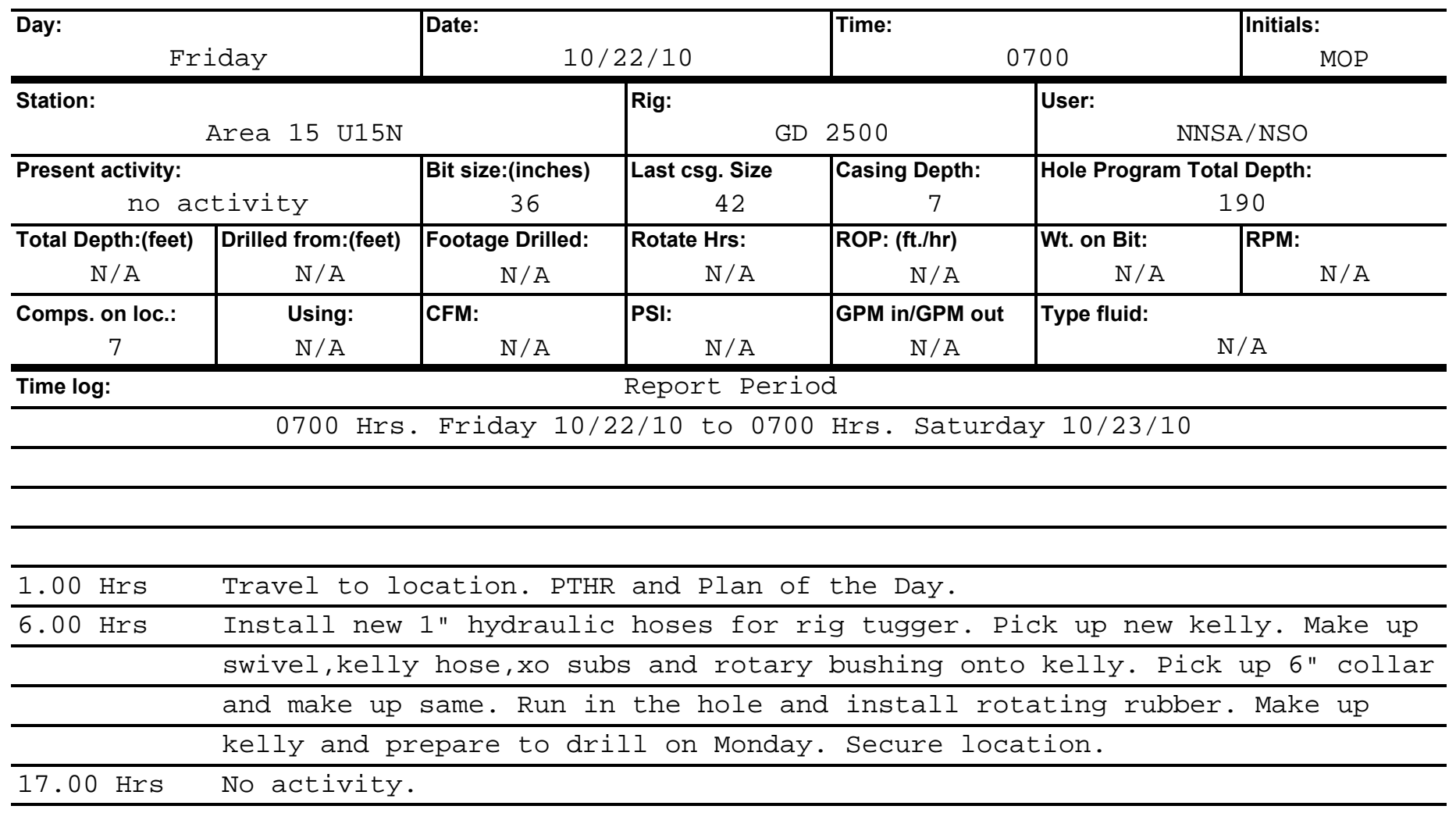




\section{Daily Rig Operations Report}

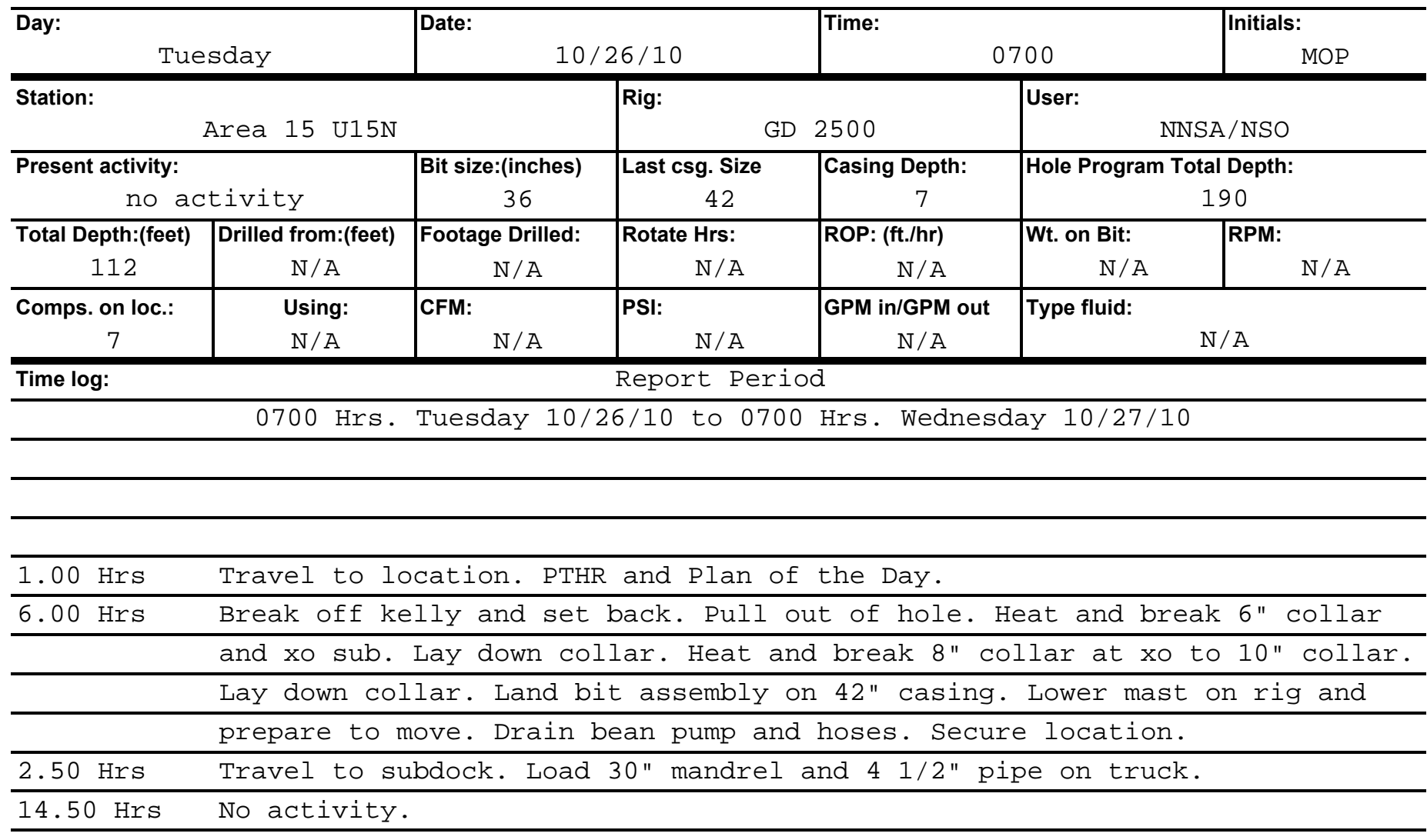




\section{Daily Rig Operations Report}

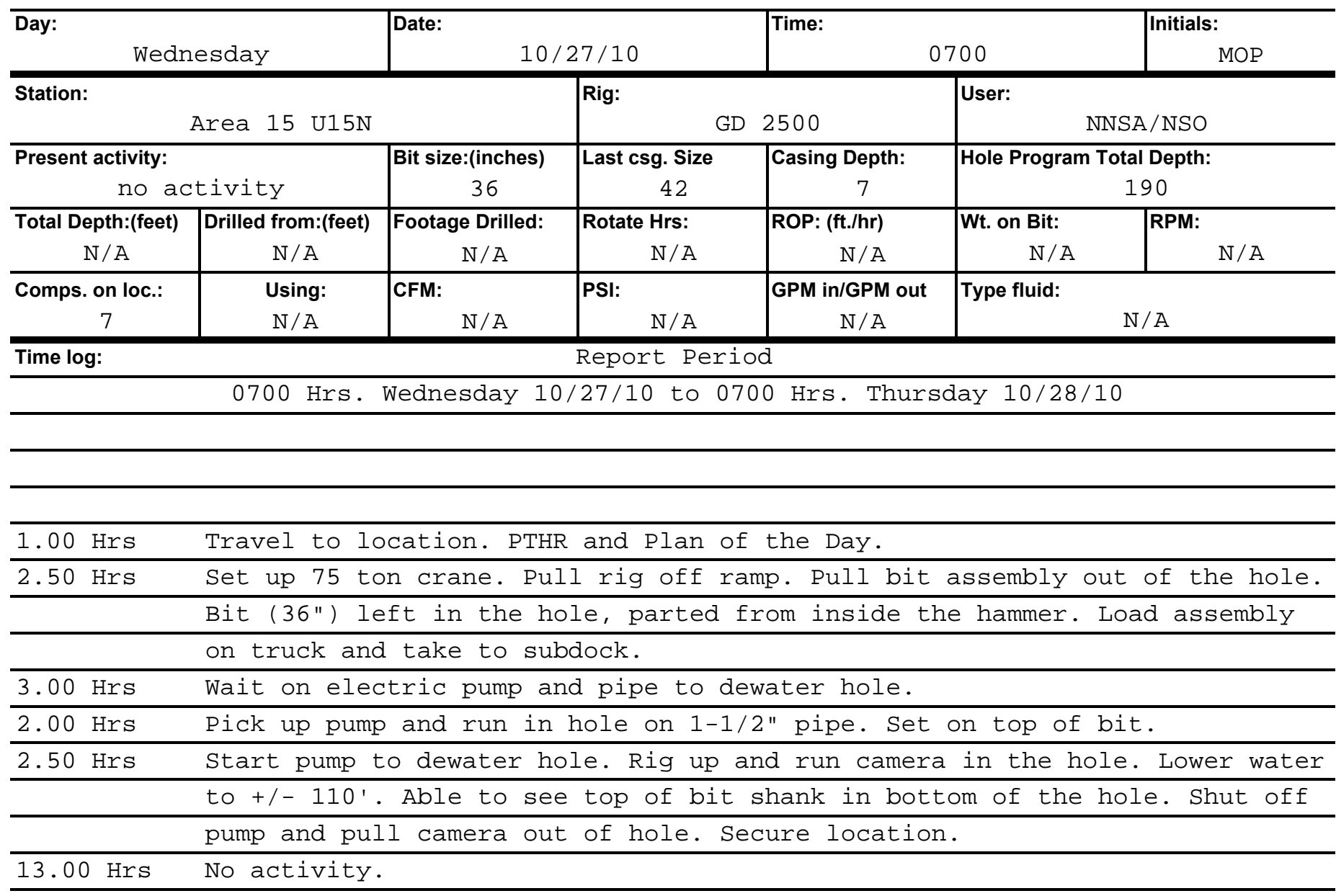




\section{Daily Rig Operations Report}

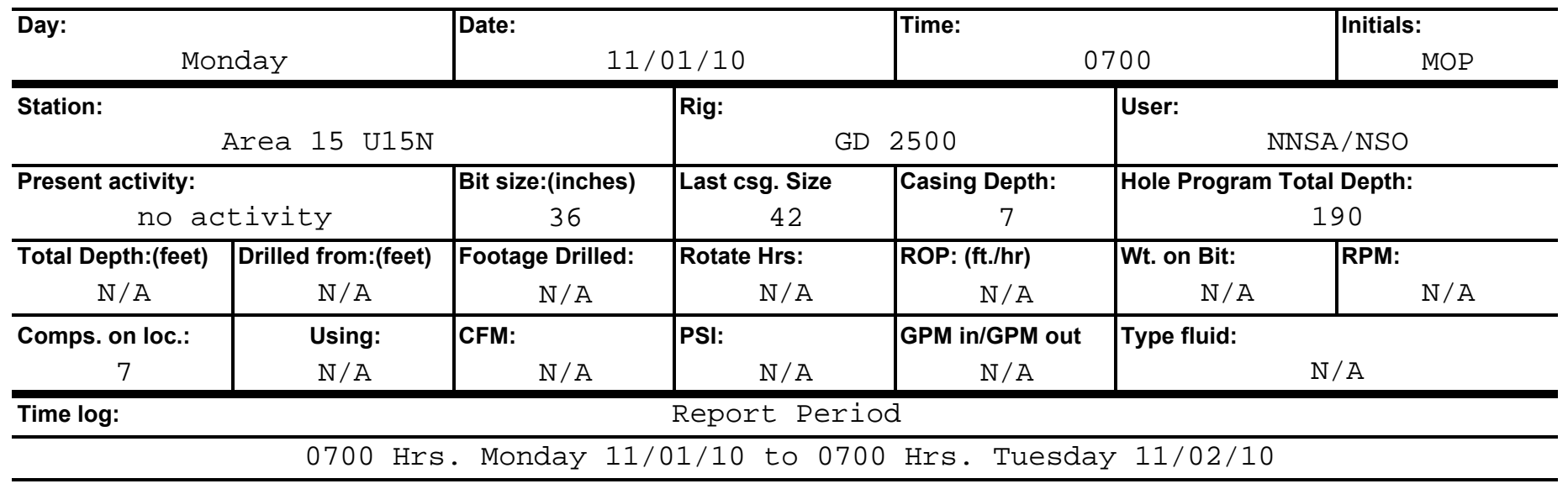

\begin{tabular}{|c|c|}
\hline L. $\odot \odot \mathrm{HrS}$ & Travel to location. PTHR and Plan of the Day. \\
\hline $2.0 \odot \mathrm{HrS}$ & on electrician. \\
\hline \multirow[t]{3}{*}{$3.00 \mathrm{HrS}$} & Pick up 1 joint of 1-1/2" pipe and run pump to bottom. Electrician hook \\
\hline & up pump and start pumping water. Run pump for 1-1/2 hours to lower water \\
\hline & below bit shank. Lay down pipe and pump. \\
\hline \multirow[t]{4}{*}{$6.00 \mathrm{HrS}$} & Pick up overshot, bumper sub and jars. Make all connections on tools. Run \\
\hline & in hole with 6" collars. Make up kelly. Run camera in the hole. Attempt \\
\hline & to latch onto fish with overshot. Unable to get over fish. Pull camera out \\
\hline & of hole. Trip out with tools to redress tools. Secure location. \\
\hline $12.00 \mathrm{HrS}$ & No activity. \\
\hline
\end{tabular}




\section{Daily Rig Operations Report}

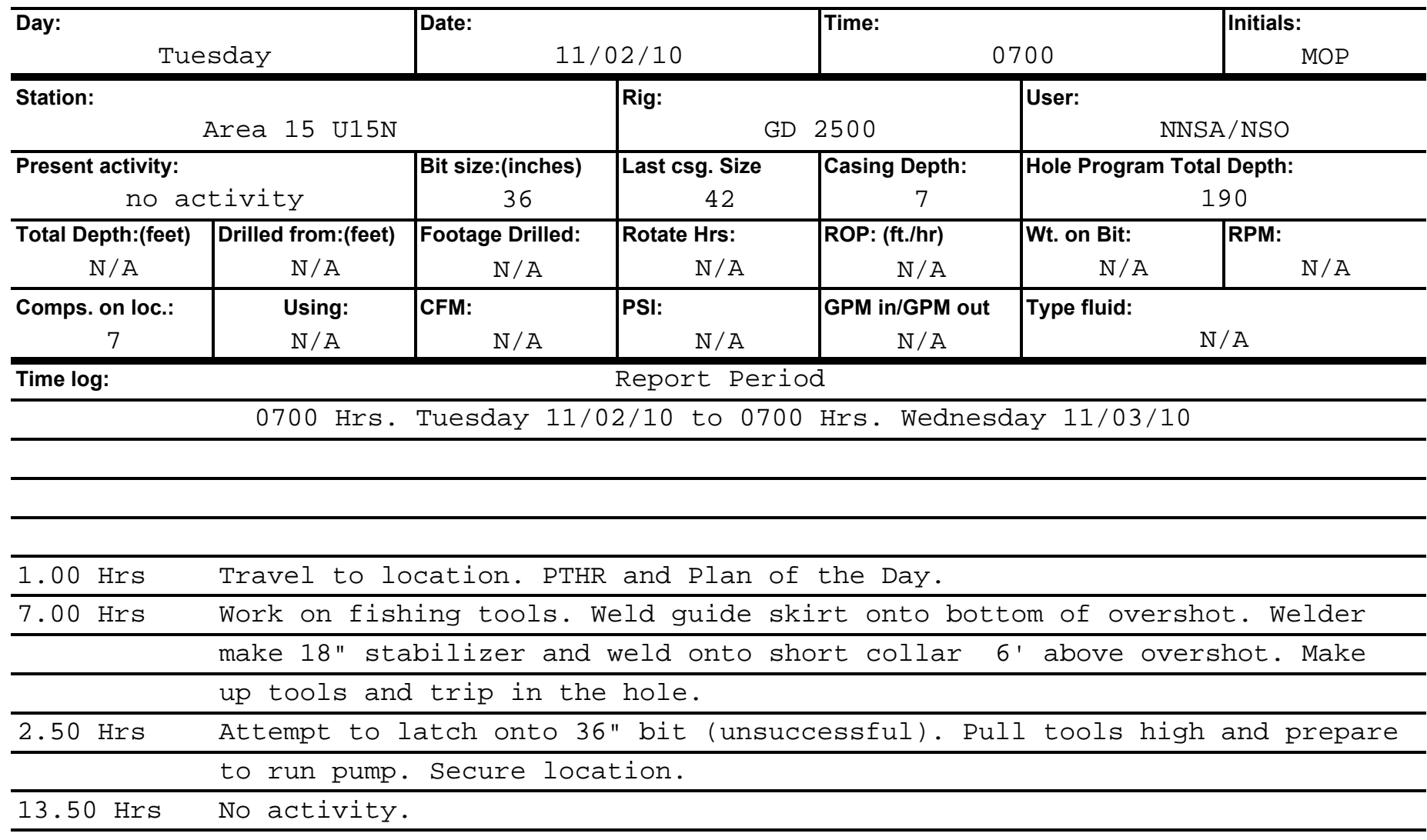




\section{Daily Rig Operations Report}

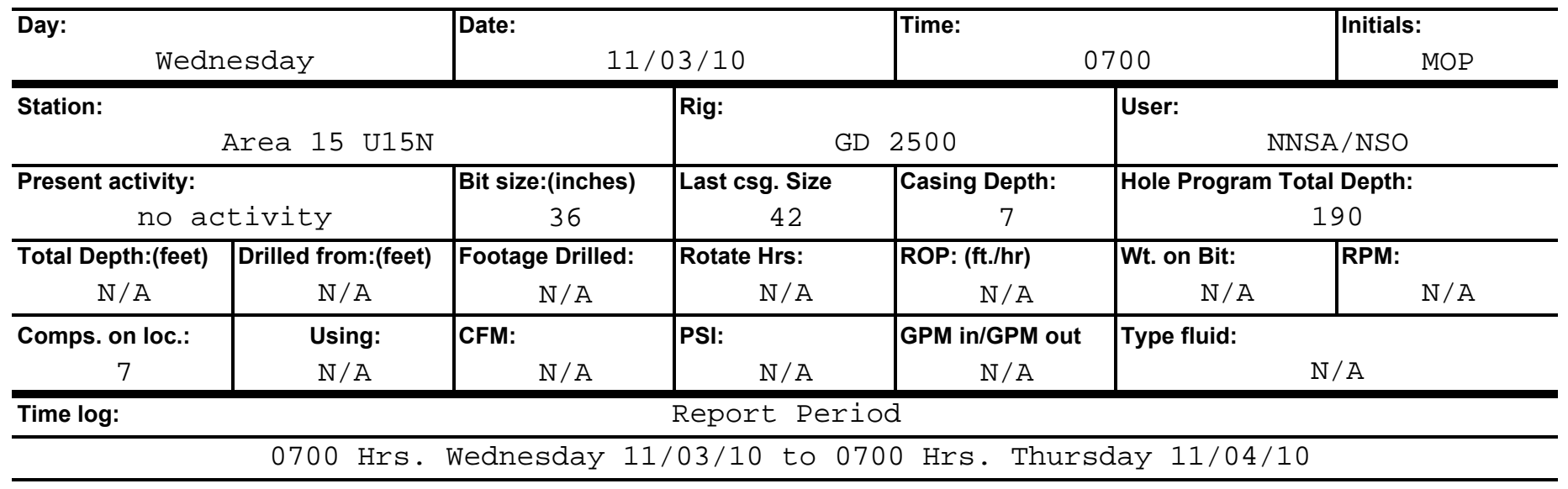

1.00 Hrs Travel to location. PTHR and Plan of the Day.

$2.50 \mathrm{Hrs}$ Pick up electric pump and run in the hole. Dewater hole for 1 hour. Lay down pump.

$3.00 \mathrm{Hrs} \quad$ Run camera in the hole. Fish for bit with overshot and stabilizer. Broke stabilizer off pipe (retrieve same with hook and cable). Unable to get over bit. Pull camera out of hole. Trip out of hole with tools.

$5.00 \mathrm{Hrs} \quad$ Break off overshot and lay down short collar. Bend joint of 4 1/2" drill pipe to approx. 8 degrees. Pick up jars and bumper sub. Make up overshot on bent joint and trip in hole. Latch onto bit and pull free with jars. Trip out of hole with fish. Land on plate on top of casing. Secure location $12.50 \mathrm{Hrs} \quad$ No activity. 


\section{Daily Rig Operations Report}

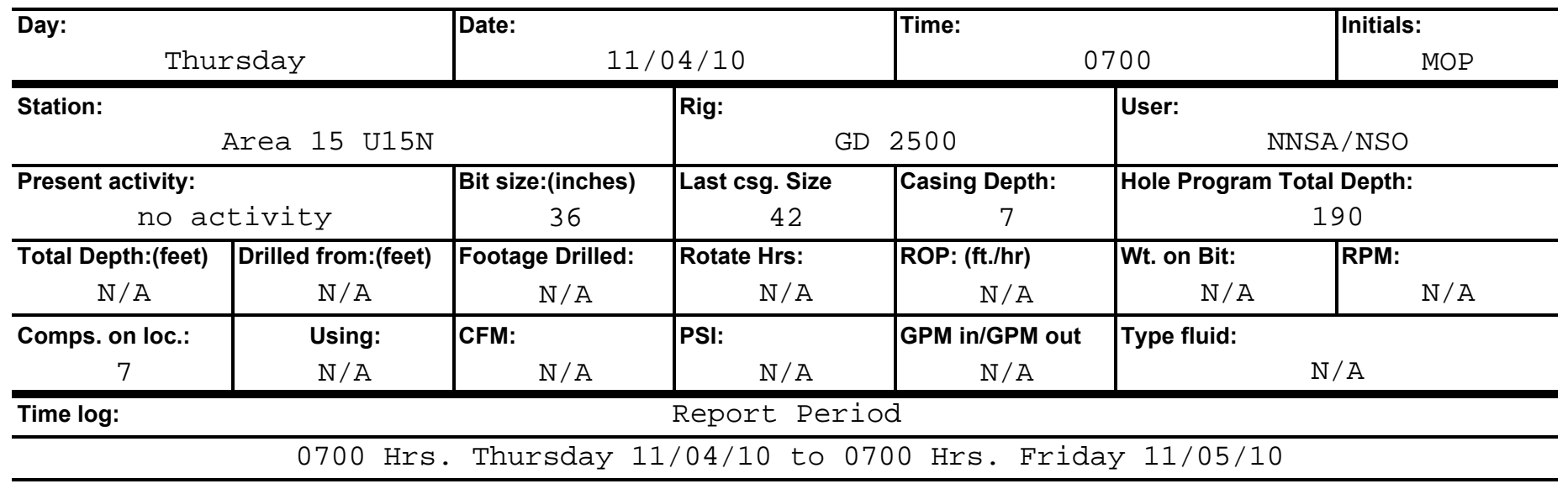

\begin{tabular}{|c|c|}
\hline \multirow{2}{*}{$\frac{1.00 \mathrm{Hrs}}{2.50 \mathrm{HrS}}$} & Travel to location. PTHR and Plan of the Day. \\
\hline & Release 36" bit from overshot. Break down jars, bumper sub and cross over \\
\hline & subs. Lay down tools. \\
\hline \multirow[t]{3}{*}{$2.00 \mathrm{HrS}$} & Lay mast down and move rig off ramp. Rig up crane. Pick up 30" mandrel and \\
\hline & set in hole. Land on plate on top of casing. Rig down crane. Back rig on \\
\hline & ramp and raise mast. \\
\hline $0.50 \mathrm{HrS}$ & Lunch break. \\
\hline \multirow[t]{4}{*}{$3.50 \mathrm{HrS}$} & Run mandrel in hole on 4 1/2" pipe using kelly to lower each joint. Tag \\
\hline & bottom at 112'. Trip out of hole. Land mandrel. Lay down mast and move rig \\
\hline & Rig up crane and pull mandrel out of hole. Cover hole with plate. Rig down \\
\hline & crane. Secure location. \\
\hline $14.50 \mathrm{HrS}$ & No activity. \\
\hline
\end{tabular}

Note: $\quad$ Release UDI at $1530 \mathrm{Hrs.}$


National Security Technologies, LLC, Daily Operations Reports for drilling of the U-15n 36-inch diameter Source Hole end with the report dated 11/04/10. However, the weekly reports prepared by Dennis Barker, Source Physics Experiment Project Manager, cover the period from November 8, 2010, through April 1, 2011, and provide information regarding the completion of the Source Hole. Relevant drilling information has been extracted from these reports and compiled on the following pages. 
November 8-10, 2010

- Demobilized United Drilling, Incorporated (UDI) drill rig.

November 15-24, 2010

- One company has been found that expressed an interest in supporting our drilling with a capable rig. Negotiations will commence via the procurement department with assistance from our drilling engineer.

December 6-10, 2010

- Procurement has an Acquisition Strategy and Plan to acquire the drill rig required to complete the 36-inch bore hole on the proposed SPE schedule.

\section{December 13-17, 2010}

- Procurement has issued a task order to UDI under their existing contract to provide an appropriate drill rig to complete the 36-inch bore hole for SPE. The acquisition schedule is intended to place this rig on SPE site by mid-February.

December 20-23, 2010

- Procurement of a drill rig and related equipment is proceeding as planned.

December 26, 2010-January 7, 2011

- A purchase requisition for drilling the explosives canister emplacement bore hole has been signed. The contract award is expected early next week. The drill rig will have 158,000 foot-pounds of rotary torque.

- The regeneration of work packages required to restart drilling operations at the SPE site in Area 15 has been initiated.

January 10-13, 1011

- A Task Order has been awarded to UDI to provide a raise-bore drill rig to complete the 36-inch canister bore hole for the SPE. The drill rig will have a working rotary torque rating of 127,000 foot-pounds and a maximum torque rating of 182,000 foot-pounds, or approximately four times the rotary torque of the previously used drill rig. In addition, the new rig is hydraulic and capable of much finer control of the rotary speed and applied torque. The drill rig will be on location Monday, February 14, 2011.

- The reamers have been sent to the vendor for refurbishing and are on schedule to arrive prior to the mobilization of the drill rig.

- The GearWrench assemblies that require refurbishing are packed and ready for an expected pickup January 13 for shipment to the vendor. They are on schedule to return prior to the mobilization of the drill rig.

- The hammer drill repair parts are ordered; they are in stock and expected to be delivered next week, so work on the hammer drill can be completed before the drill rig is mobilized. A list of spares is under development to hold at Nevada National Security Site (NNSS) to shorten repair time in case of a hammer drill failure.

- The rotary head is in the maintenance shop for refurbishing and is on schedule to be completed prior to the mobilization of the drill rig. 
January 18-21, 2011

- The leased drill rig is expected to be on the SPE site on February 14, 2011. Preparations are being made to have all required support equipment on the site and ready to work during the week of February 7.

- The hammer drill repair parts have been received, and the repair will be conducted on schedule to make the drill available prior to the arrival of the rig.

January 24-28, 2011

- The leased drill rig is expected to be on the SPE site on February 14. Preparations are being made to have all required support equipment on the site and ready to work during the week of February 7.

January 31-February 4, 2011

- The leased drill rig is expected to be on the SPE site on February 14. Preparations are being made to have all required support equipment on the site and ready to work during the week of February 7.

- Work packages have been revised as required to resume drilling operations at SPE site.

- The GearWrench tool has been rebuilt and certified by a factory technician.

- Procurements have been placed for equipment, materials, and supplies required to resume drilling operations, and delivery will occur the week of February 7.

- Two highly experienced drillers travelled to Denver, Colorado, to measure and study the drill rig so we can be sure the base platform we build will fit the rig.

February 7-11, 2011

- A management walk-through was conducted on February 8. The SPE drilling location was found to be neat and well maintained with proper work procedures being followed and safety equipment present, in good condition, and being used by the drillers preparing the 36 -inch bore hole for resumption of drilling.

- The leased drill rig is expected to be on the SPE site on February 14. Preparations are being made to have all required support equipment on the site and ready to work during the week of February 7 , so drilling can commence the week of February 14.

- The hammer drill has been refurbished and additional spare parts ordered against future issues.

- The reamers have arrived and been coupled to the hammer, completing the bottom hole assembly.

- A magnet has been run to capture any metal in the bottom of the 36 -inch bore hole from the previous hammer drill failure. An auger bit has been run in the 36-inch bore hole to clean out the muck at the bottom and clear a tight spot at 89 feet. No metal was recovered with either the auger or the magnet, but a chunk of plastic from the hammer failure was recovered.

- A camera run was made after cleaning and dewatering the hole. No metal was observed. There is no obvious place where water is entering the bore hole in any large quantity.

February 14-18, 2011

- The leased drill rig arrived on February 14, 2011. The strong-back support for the rig has been constructed and the anchors set on location. Equipment is ready to commence drilling as soon as the hole can be cleaned and the remaining metal fished out or isolated in the side wall.

- The NSTec auger rig suffered a transmission/gearbox failure while cleaning muck from the bottom of the 36-inch bore hole. The rig is in the mechanic shop where repairs are being expedited. The NSTec auger rig is estimated to be available no earlier than February 28, even with expedited service. To 
mitigate this, a local auger rig has been leased and will be on location February 22 to finish cleaning the muck from the bore hole. At that time the hole will be dewatered, a magnet will be run, and a camera run will be made to ascertain whether the lost metal rings from the damaged hammer drill are at the bottom of the bore hole. If so, they will be fished out with the magnet and/or the auger. If they are not found, approximately 10 feet of cement will be pumped in the bore hole to stabilize the lost metal away from the bottom of the hole, and drilling will commence.

\section{February 22-25, 2011}

- The rented auger rig completed the task of cleaning the muck from the bottom of the 36-inch hole and recovered some plastic parts that were lost when the hammer drill was damaged.

- A camera run was made, and all indications are that the 36 -inch bore hole is stable. There was no visual evidence of the missing steel ring parts in the sidewall or at the bottom of the hole.

- A metal detector was run to the bottom of the hole, and a slight indication was noted.

- Fishing operations with a magnet and compressed air recovered half of the missing hardened-steel retaining ring on Thursday, February 24 . Operations will be continued on Friday, in an attempt to recover the second half, if it is on the bottom of the hole.

- On Friday, February 24, cement will be poured to cover the top of the washout at the bottom of the hole (about 10 feet of cement) and isolate any metal fragments that may be in the sidewall of the hole.

\section{February 28-March 4, 2011}

- A safety walkdown was conducted this week at the SPE drill site prior to commencing drilling operations with the raise-bore machine. No issues were found.

- The rented raise-bore rig was set in place over the 36-inch bore hole on a custom-made strong-back, and anchored securely in place. The required generator, compressor, and auxiliary equipment were also installed on the SPE drill pad.

- Drilling commenced at 12:15 pm on Thursday, March 3, at 96 feet, the top of the emplaced cement, and continued to 106 feet.

- Drilling resumed on Friday and is proceeding at the expected rate of approximately 2 to 3 feet per hour. The total depth at the end of the day Friday, March 4, is 122 feet.

- The drilling operation suffered two instances of king swivel connection failure. NNSS craft promptly repaired the king swivel connection parts and returned them to service early Friday morning, March 4.

March 7-10, 2011

- Drilling reached the depth of 146 feet.

- The drilling operation incurred very high torque readings (90,000 foot-pounds) while drilling the last few feet. The bottom hole assembly was pulled from the hole and examined. The reamers were found to be damaged and will be sent to Bakersfield, California, for repairs over the weekend. No parts were lost in the hole. Drilling operations are expected to resume on Monday, March 14, using only one reamer to reduce the stress on the drill string and bottom hole assembly.

March 14-18, 2011

- Installed the new drill stem stabilizer and rebuilt the bottom hole assembly (BHA) at the subdock and transported it to the SPE site.

- Lowered the BHA into the hole with a crane and replaced the raise-bore rig over the hole. 
- Drilled the 36-inch bore hole to 199 feet. This allows 10 feet of extra hole in case there is some filling in after drilling as has commonly occurred in the recent past.

- Ran the 30-inch diameter test mandrel. The mandrel will not pass 140 feet. The path forward is to obtain an additional reamer/stabilizer, install both reamer/stabilizers about 15 feet apart with a small rotary bit on the bottom of the drill string, and use the assembly to smooth off the corners in the deviated portion of the hole. The purpose of the small bit is to allow circulation to remove cuttings from the hole.

\section{March 21-24, 2011}

- The federal facility manager did a safety walkdown of the SPE site and reported there were no issues found.

- The bottom hole assembly was rebuilt with two tungsten carbide coated stabilizers (functioning as reamers) and a 26-inch rotary bit to allow circulation to be established to remove cuttings.

- The BHA was lowered into the hole with a crane, and the raise-bore rig was moved over the hole.

- The emplacement hole was reamed to 195 feet, with special attention to the locations that were tight on the previous mandrel run.

- On Friday, March 25, we plan to pull the pipe, remove the drill rig, remove the bottom hole assembly, place the mandrel in the hole, replace the drill rig, and run the mandrel to total depth to verify the hole is ready to receive the explosive canister.

\section{March 28-April 1, 2011}

- The test mandrel was run to 192 feet with no problem, and the 36-inch canister emplacement hole is now able to receive the explosive canister at the required 180 -foot depth.

- A caliper log, deviation survey, and camera were run in the 36-inch bore hole. They show the hole is suitable to proceed with the experiment.

- The drilling equipment for the 36-inch bore hole has been removed from the SPE site and transported to the Area 1 drilling yard, where it will remain on standby for use later. 


\section{Appendix C-3}

NSTec Daily Rig Operations Reports for the 8-Inch-Diameter Instrument Holes (U-15n \#1 through U-15n\#6) 


\section{Daily Rig Operations Report}

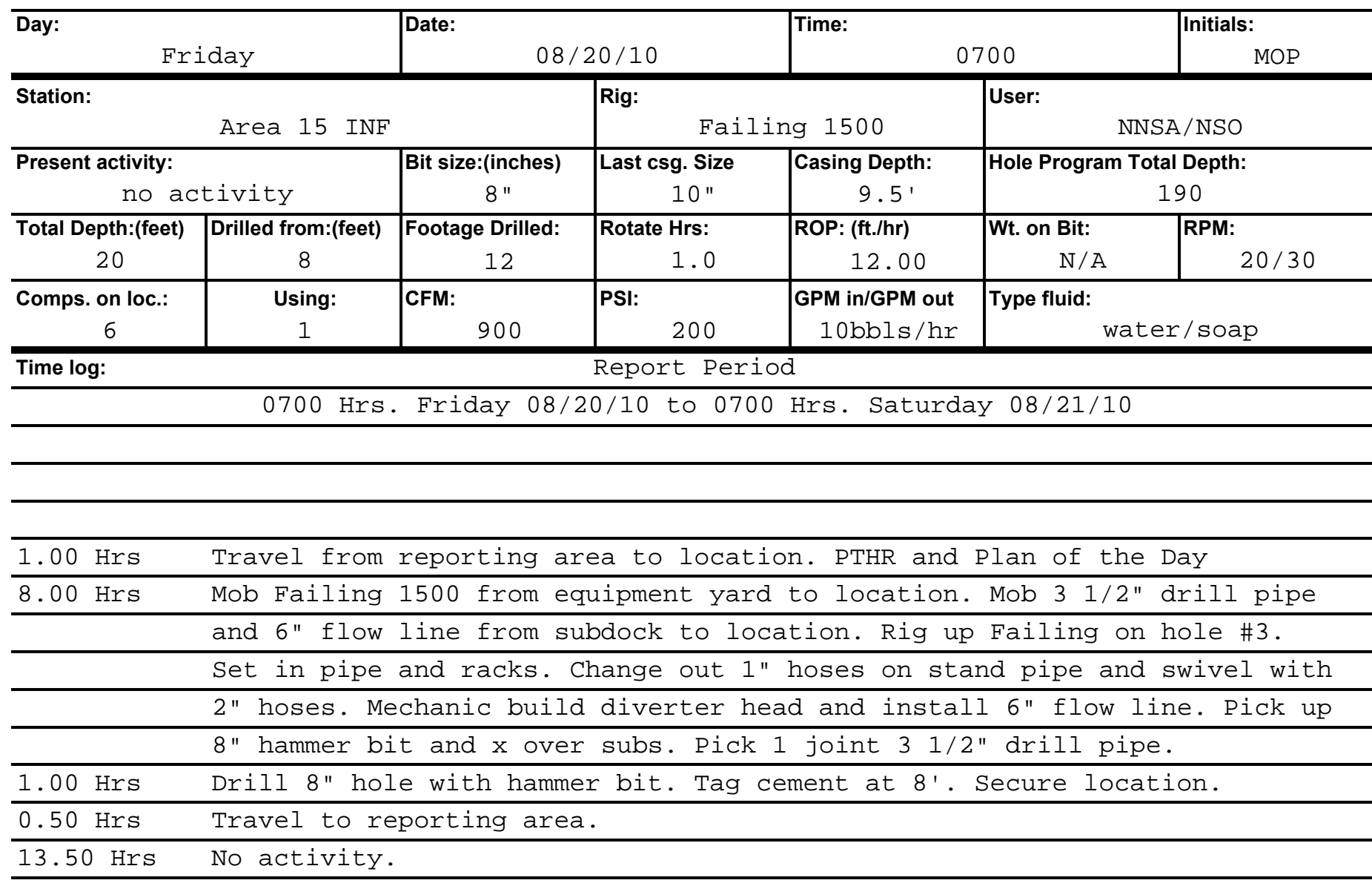




\section{Daily Rig Operations Report}

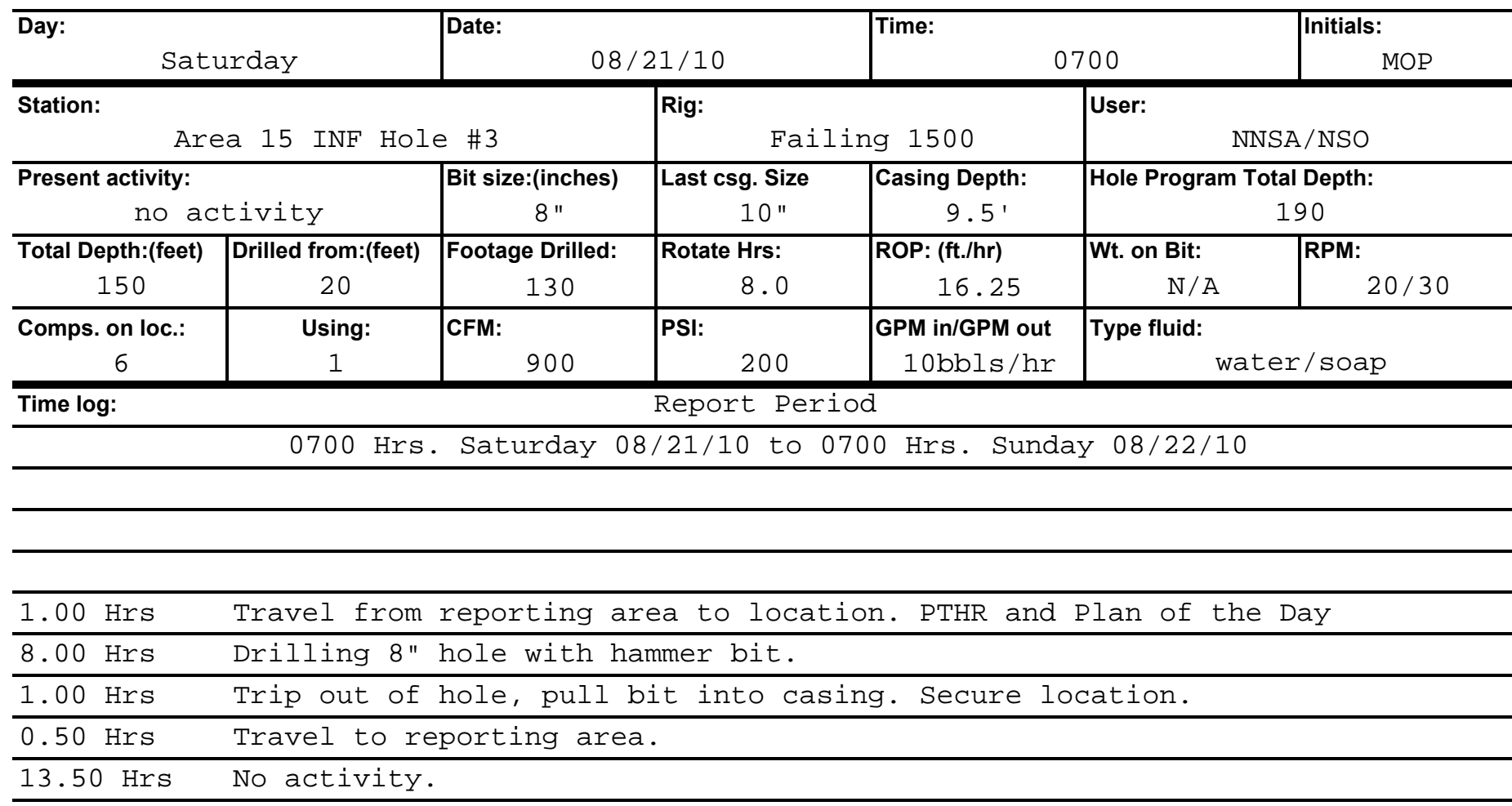




\section{Daily Rig Operations Report}

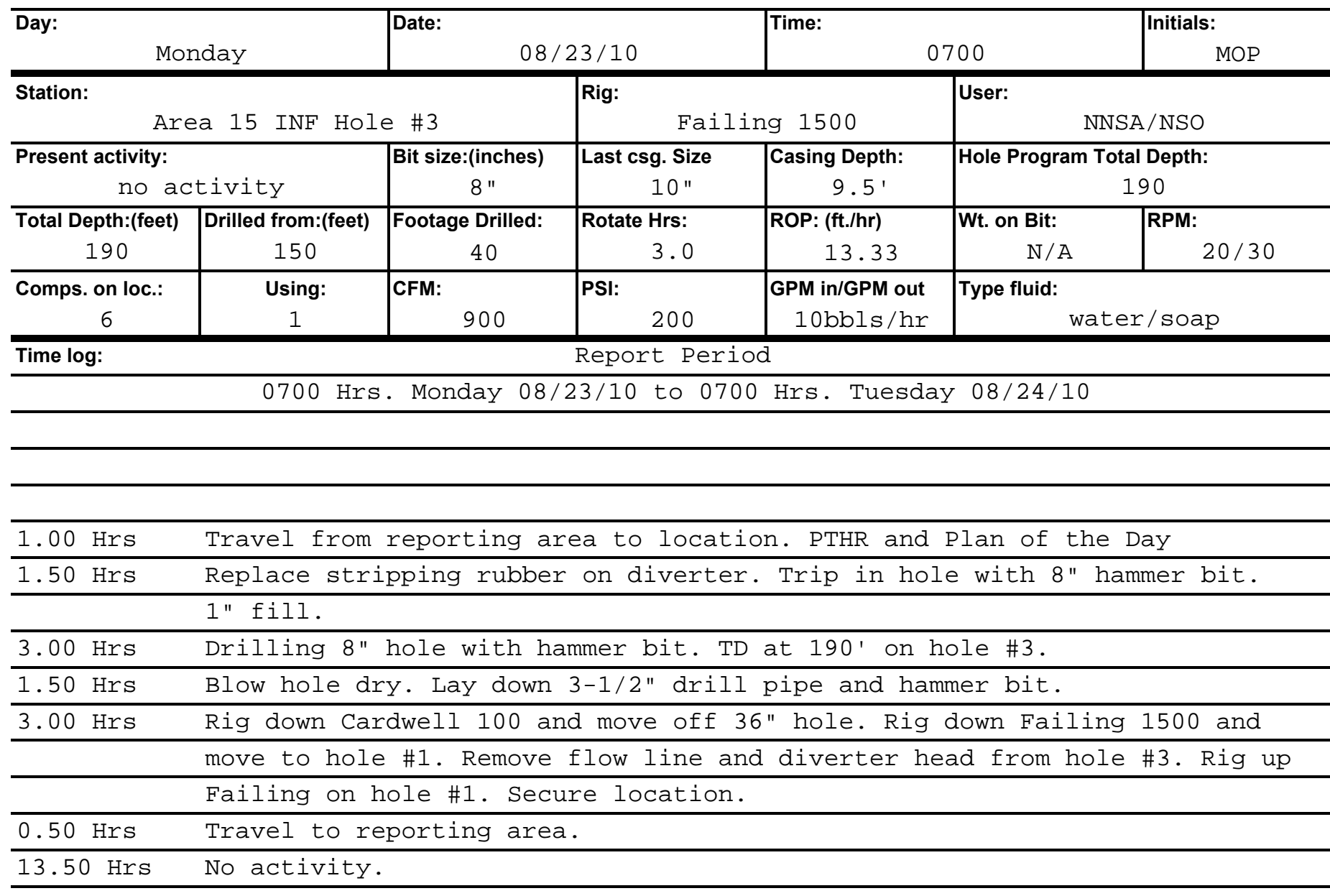




\section{Daily Rig Operations Report}

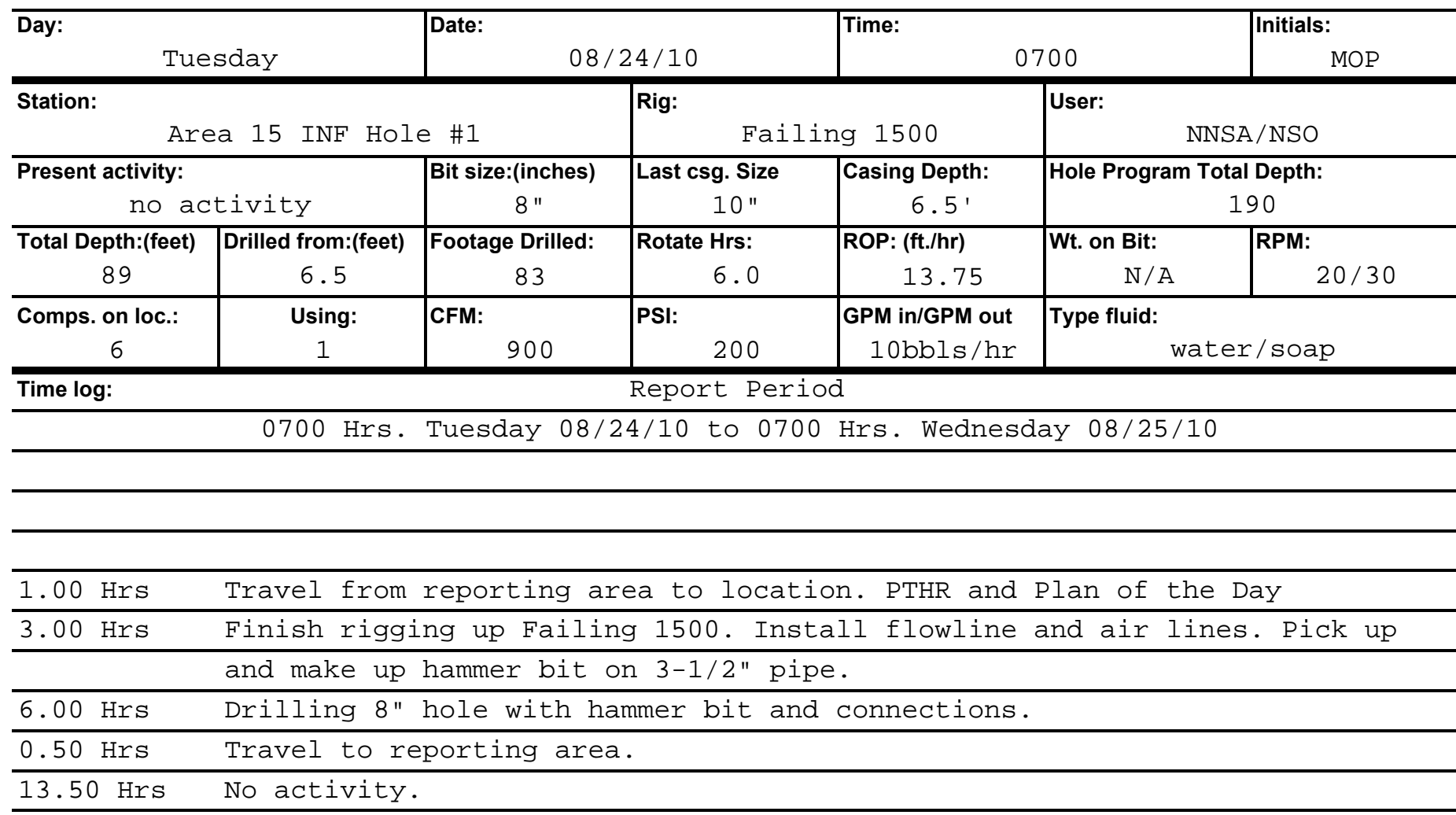




\section{Daily Rig Operations Report}

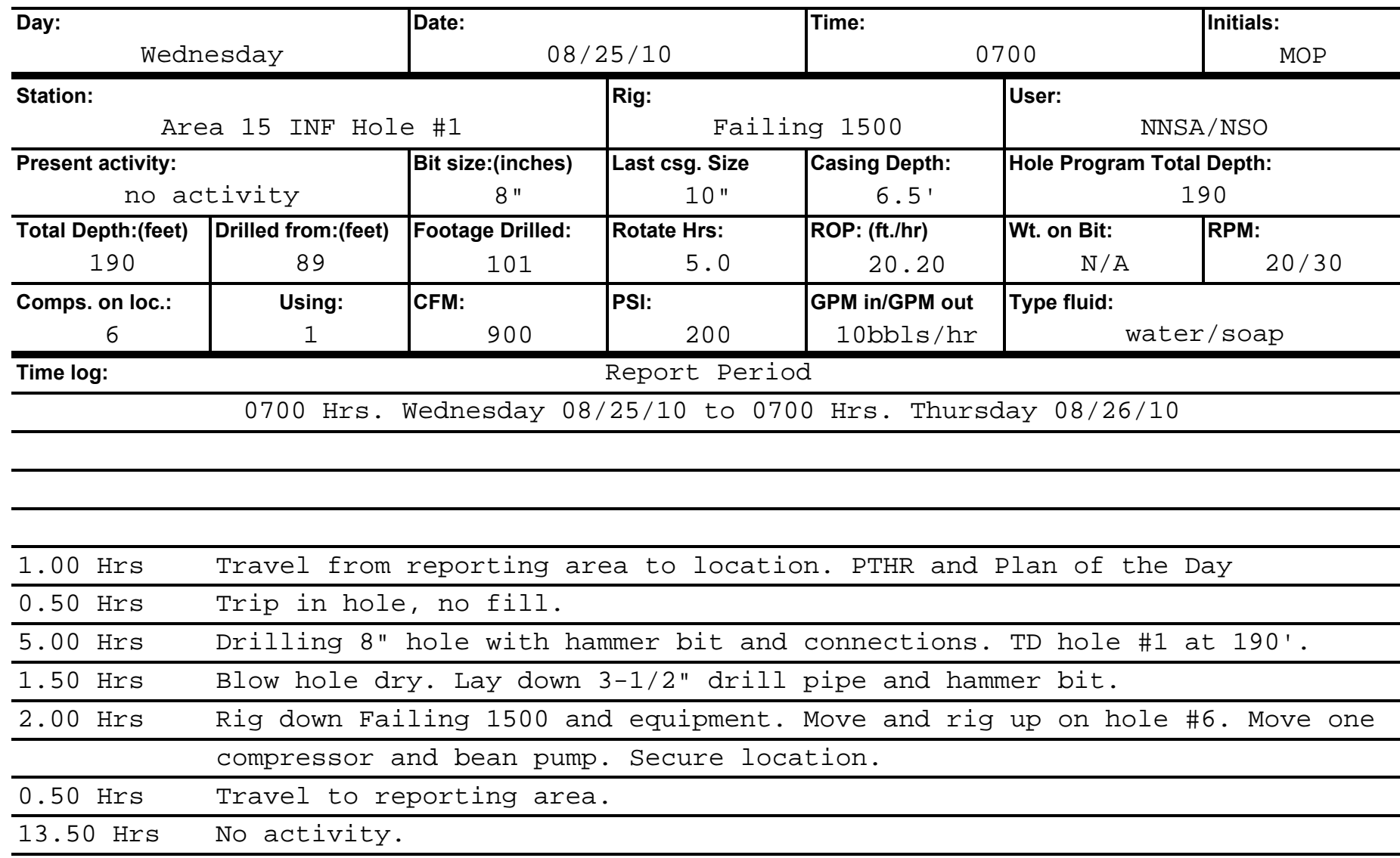




\section{Daily Rig Operations Report}

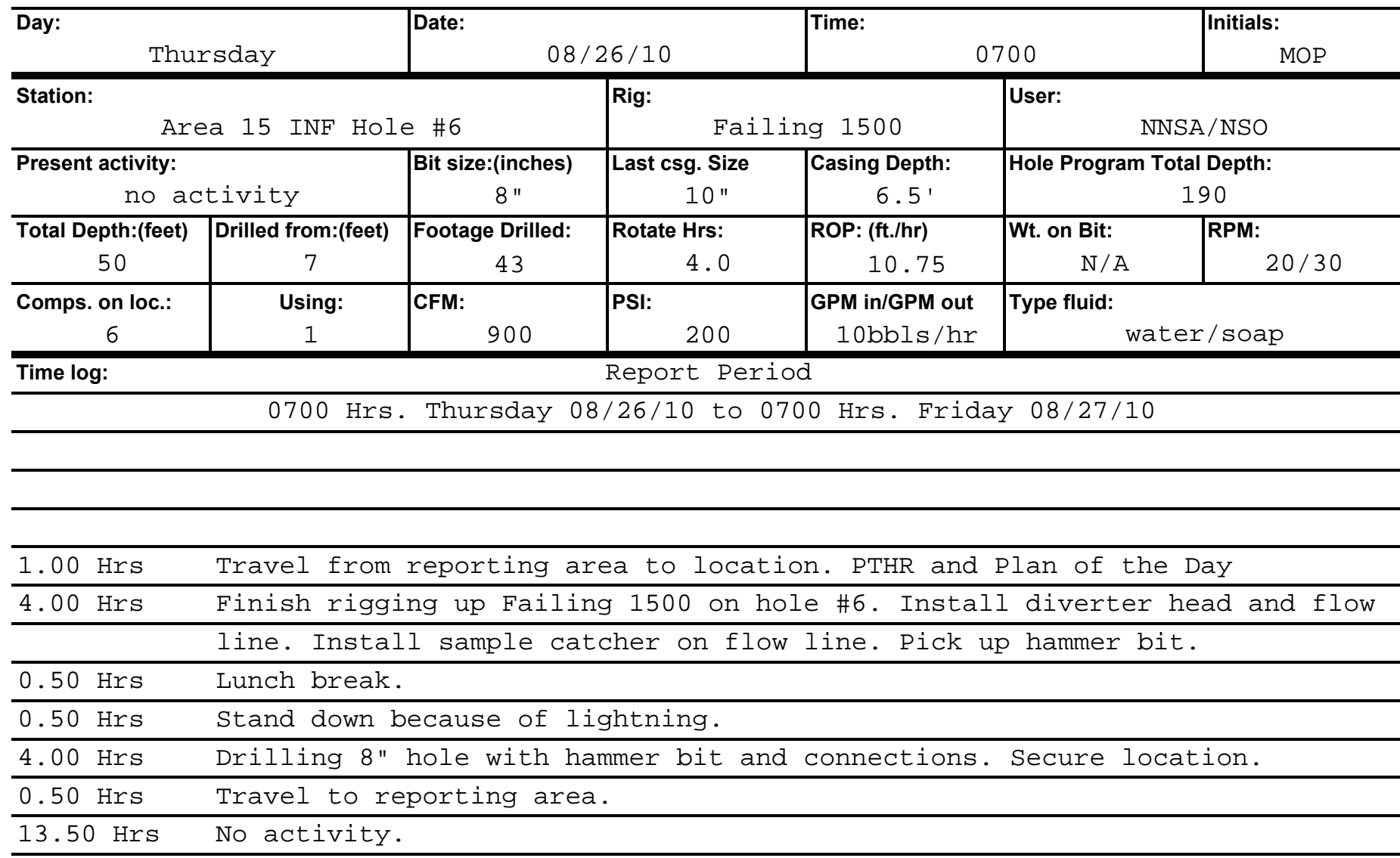




\section{Daily Rig Operations Report}

\begin{tabular}{|c|c|c|c|c|c|c|}
\hline \multicolumn{2}{|c|}{ Friday } & \multicolumn{2}{|c|}{$08 / 27 / 10$} & \multicolumn{2}{|c|}{$\odot 7 \odot \odot$} & $\begin{array}{r}\text { Initials: } \\
\text { MOP }\end{array}$ \\
\hline \multicolumn{3}{|c|}{ Area 15 INF Hole \#6 } & \multicolumn{2}{|c|}{ Failing 1500} & \multicolumn{2}{|c|}{ User: $\quad$ NNSA/NSO } \\
\hline \multicolumn{2}{|c|}{ no activity } & $\begin{array}{c}\text { Bit size:(inches) } \\
8^{\prime \prime}\end{array}$ & $\begin{array}{c}\text { Last csg. Size } \\
10^{\prime \prime}\end{array}$ & $\begin{array}{c}\text { Casing Depth: } \\
6.5^{\prime}\end{array}$ & \multicolumn{2}{|c|}{$\begin{array}{c}\text { Hole Program Total Depth: } \\
190\end{array}$} \\
\hline $\begin{array}{c}\text { Total Depth:(feet) } \\
190\end{array}$ & $\begin{array}{c}\text { Drilled from:(feet) } \\
50 \\
\end{array}$ & $\begin{array}{c}\text { Footage Drilled: } \\
140 \\
\end{array}$ & $\begin{array}{r}\text { Rotate Hrs: } \\
7.0 \\
\end{array}$ & $\begin{array}{r}\text { ROP: (ft./hr) } \\
20.00\end{array}$ & $\begin{array}{r}\text { Wt. on Bit: } \\
\text { N/A }\end{array}$ & $\begin{array}{r}\text { RPM: } \\
20 / 30\end{array}$ \\
\hline $\begin{array}{c}\text { Comps. on loc.: } \\
6\end{array}$ & $\begin{array}{l}\text { Using: } \\
1\end{array}$ & $\begin{array}{l}\text { CFM: } \\
\\
\end{array}$ & $\begin{array}{l}\text { PSI: } \\
200\end{array}$ & $\begin{array}{l}\text { GPM in/GPM out } \\
10 \mathrm{bbls} / \mathrm{hr}\end{array}$ & \multicolumn{2}{|c|}{$\begin{array}{l}\text { Type fluid: } \\
\text { water / soap }\end{array}$} \\
\hline \multicolumn{7}{|c|}{$\begin{array}{ll}\text { Time log: } & \text { Report Period }\end{array}$} \\
\hline \multicolumn{7}{|c|}{$0700 \mathrm{Hrs}$. Friday $08 / 27 / 10$ to $0700 \mathrm{Hrs}$. Saturday $08 / 28 / 10$} \\
\hline $1.00 \mathrm{Hrs}$ & \multicolumn{6}{|c|}{ Travel from reporting area to location. PTHR and Plan of the Day } \\
\hline $0.50 \mathrm{HrS}$ & \multicolumn{6}{|c|}{ Trip in hole, no fill. } \\
\hline $7.00 \mathrm{HrS}$ & \multicolumn{6}{|c|}{ Drilling 8" hole and connections. TD at $190^{\prime}$ on hole \#6. } \\
\hline $1.50 \mathrm{Hrs}$ & \multicolumn{6}{|c|}{ Blow hole dry. Lay down 3-1/2" pipe and hammer bit. Secure location. } \\
\hline $0.50 \mathrm{HrS}$ & \multicolumn{6}{|c|}{ Travel to reporting area. } \\
\hline
\end{tabular}




\section{Daily Rig Operations Report}

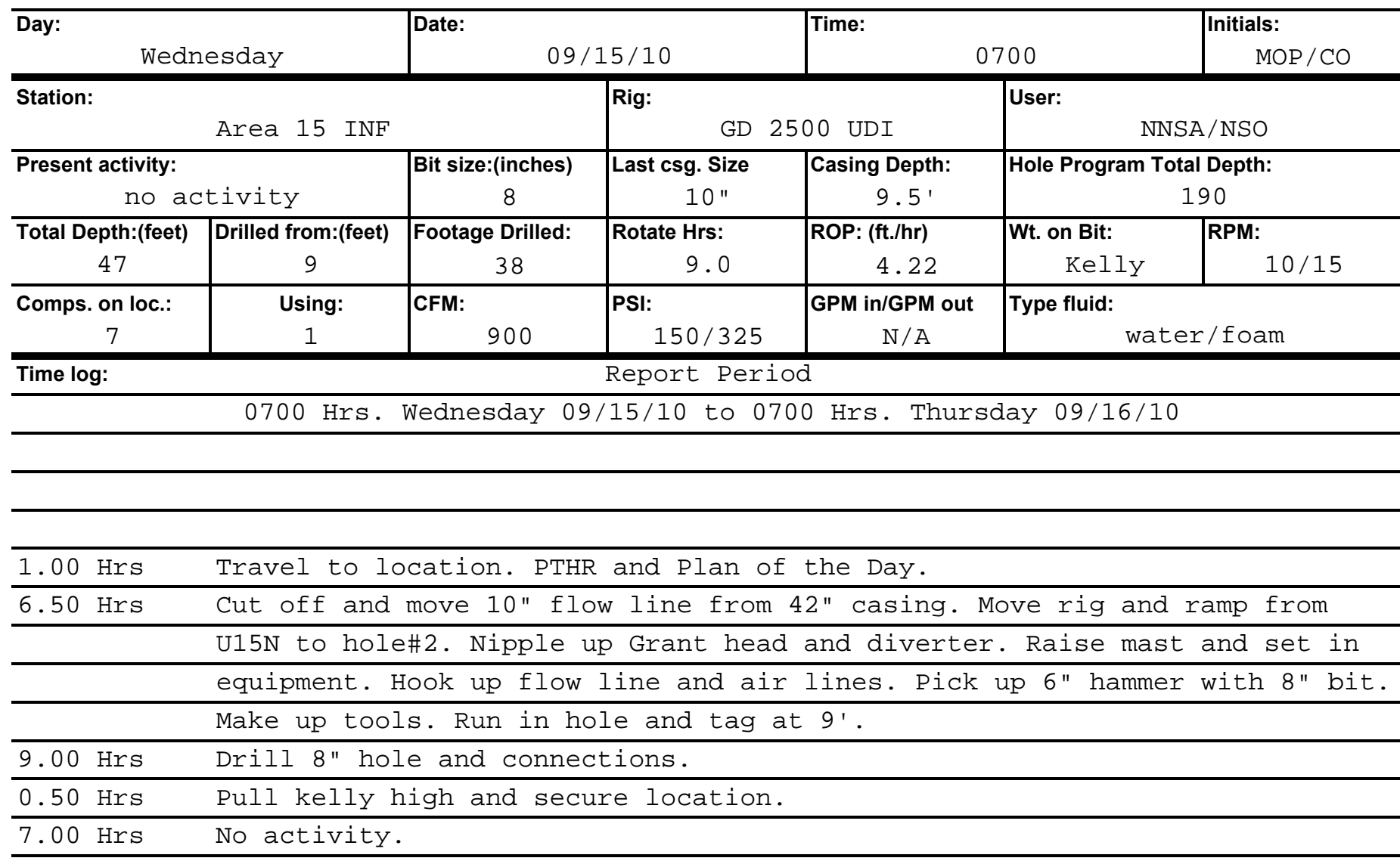




\section{Daily Rig Operations Report}

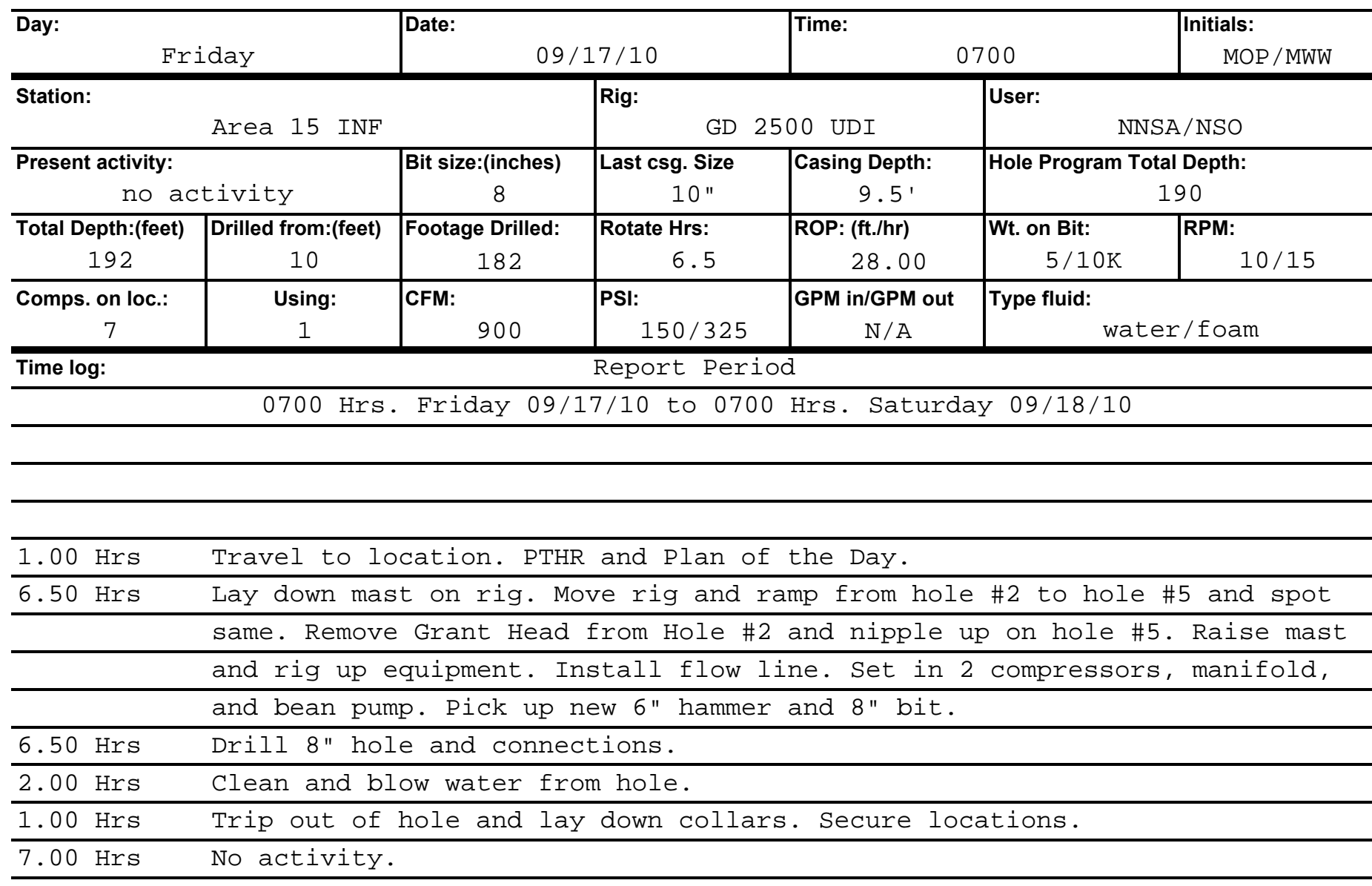




\section{Daily Rig Operations Report}

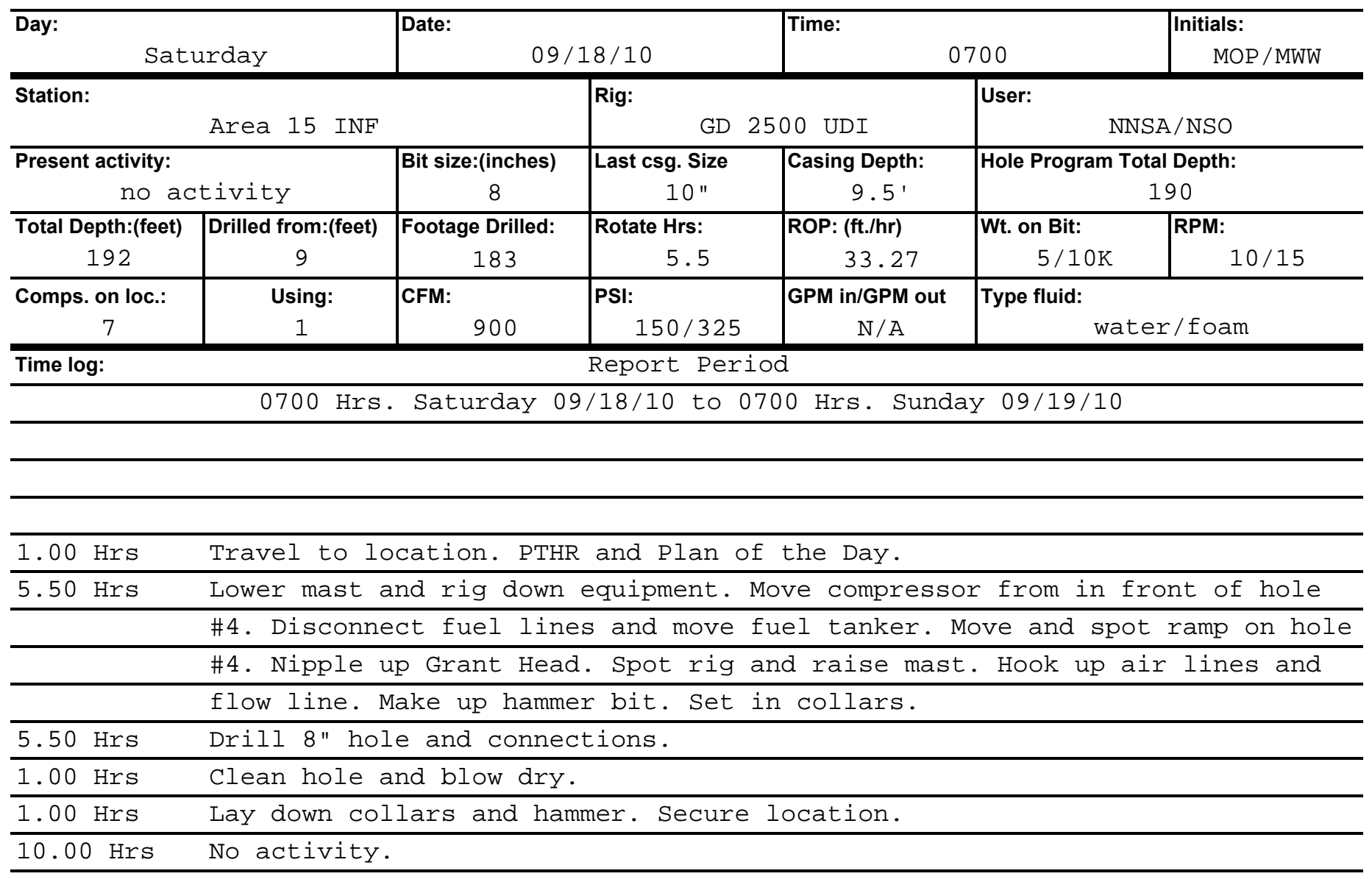




\section{Daily Rig Operations Report}

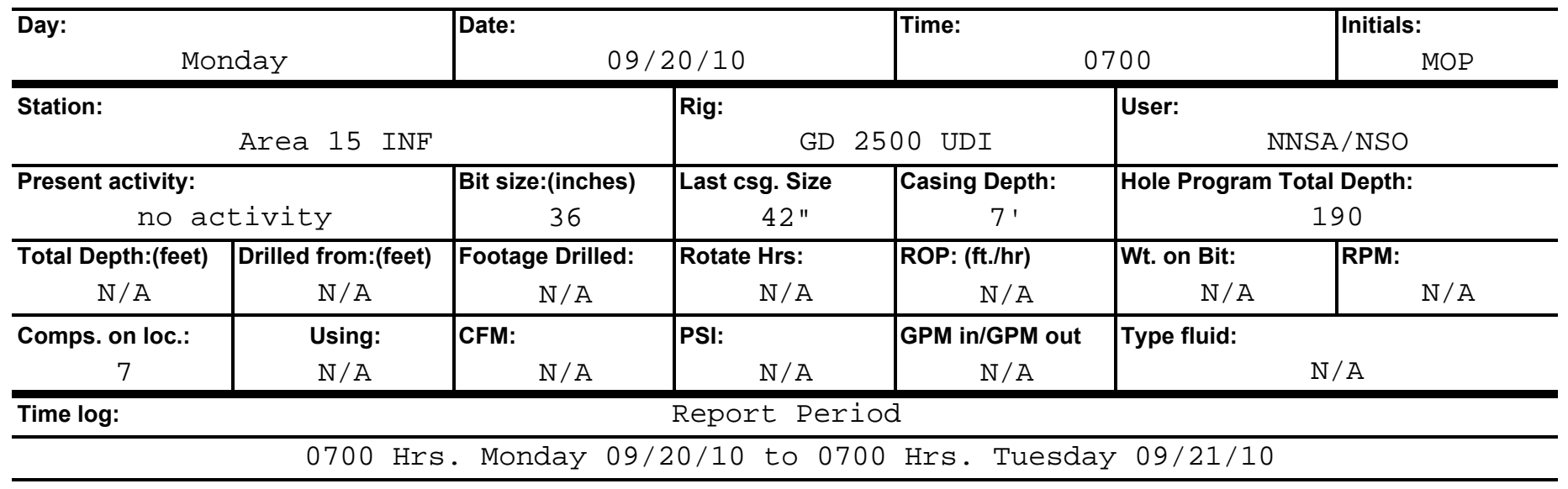

\begin{tabular}{ll}
\hline $1.00 \mathrm{HrS}$ & Travel to location. PTHR and Plan of the Day. \\
\hline $10.00 \mathrm{Hrs}$ & Lay mast down. Rig down compressors and bean pump. Move fuel tanker and \\
\hline & compressors. Move and spot rig and ramp onto hole U15N. Remove Grant Head \\
\hline & and flow line from hole \#4.Set in air manifold. Move equipment and tools \\
\hline & away from holes for loggers. Colog logging holes \#1-\#6. \\
\hline $13.00 \mathrm{Hrs}$ & No activity.
\end{tabular}

\begin{tabular}{|c|c|}
\hline Notes & Colog on location at $0900 \mathrm{Hrs}$. \\
\hline & Hole \#1 Fluid at 58.3'. TD at 187.1. \\
\hline & Hole \#2 Fluid at $77^{\prime}$. TD at 191.2. \\
\hline & Hole \#3 Fluid at 58'. TD at 179.2. \\
\hline & Hole \#4 Fluid at 61'. TD at 188.5. \\
\hline & Hole \#5 Fluid at 57.3'. TD at 192.2. \\
\hline
\end{tabular}




\section{APPENDIX D}

Survey Data and Borehole Deviation Data for Source Physics Experiment Holes 


\section{Notes for U-15n Borehole Deviation Coordinates}

Surface coordinates provided by NSTec Survey Department.

Borehole deviation surveys performed by Colog, a Division of Layne Christensen Company

$\begin{array}{ll}\text { A/B } & \text { As-Built Coordinates (final) } \\ \text { ags } & \text { above ground surface } \\ \text { CL } & \text { Centerline of casing } \\ \text { Dia } & \text { Diameter } \\ \text { ft } & \text { feet } \\ \text { GEO } & \text { Geographic Coordinate System } \\ \text { GS } & \text { Ground Surface } \\ \text { in } & \text { inches } \\ \text { L/O } & \text { Lay-Out Coordinates (preliminary) } \\ \text { NAD } & \text { North American Datum } \\ \text { NAVD } & \text { North American Vertical Datum } \\ \text { NGVD } & \text { National Geodetic Vertical Datum } \\ \text { SPC } & \text { State Plane Coordinate System } \\ \text { TD } & \text { Total Depth } \\ \text { TOC } & \text { Top of Casing (stickup distance above ground surface) }\end{array}$


Summary Of U-15n Borehole Surface Coordinates

\begin{tabular}{|c|c|c|c|c|c|c|}
\hline \multirow{2}{*}{$\begin{array}{l}\text { Hole } \\
\text { Name }\end{array}$} & \multirow{2}{*}{$\begin{array}{c}\text { Survey Report } \\
\text { Date }\end{array}$} & \multirow{2}{*}{$\begin{array}{c}\text { Survey } \\
\text { Type }\end{array}$} & \multirow{2}{*}{$\begin{array}{c}\text { Reference } \\
\text { Point }\end{array}$} & $\begin{array}{c}\text { Northing } \\
\text { feet }\end{array}$ & $\begin{array}{c}\text { Easting } \\
\text { feet }\end{array}$ & \multirow{2}{*}{\begin{tabular}{|c|}
$\begin{array}{c}\text { Elevation } \\
\text { feet }\end{array}$ \\
NGVD29 \\
\end{tabular}} \\
\hline & & & & \multicolumn{2}{|c|}{ Nevada SPC NAD27 } & \\
\hline U-15n & $6 / 23 / 2010$ & $\mathrm{~L} / \mathrm{O}$ & GS & $900,077.65$ & $676,640.92$ & $5,003.12$ \\
\hline U-15n & $5 / 26 / 2011$ & $A / B$ & TOC CL & $900,077.22$ & $676,640.60$ & $5,002.37$ \\
\hline U-15n & 8/18/2011 & $A / B$ & TOC CL & $900,077.22$ & $676,640.60$ & $5,002.37$ \\
\hline U-15n & $11 / 29 / 2011$ & $A / B$ & TOC CL & $900,077.28$ & $676,640.62$ & $5,002.42$ \\
\hline U-15n & $12 / 14 / 2011$ & $A / B$ & TOC CL & $900,077.28$ & $676,640.62$ & $5,002.42$ \\
\hline U-15n\#1 & $6 / 23 / 2010$ & $\mathrm{~L} / \mathrm{O}$ & GS & $900,107.23$ & $676,655.11$ & $5,003.19$ \\
\hline U-15n\#1 & $5 / 26 / 2011$ & $A / B$ & TOC CL & $900,106.97$ & $676,655.15$ & $5,002.60$ \\
\hline$U-15 n \# 1$ & 8/18/2011 & $A / B$ & TOC CL & $900,106.97$ & $676,655.15$ & $5,002.60$ \\
\hline U-15n\#1 & $12 / 14 / 2011$ & $\mathrm{~A} / \mathrm{B}$ & TOC CL & $900,107.01$ & $676,655.17$ & $5,002.60$ \\
\hline U-15n\#1A & 8/18/2011 & $\mathrm{L} / \mathrm{O}$ & GS & $900,109.95$ & $676,645.65$ & - \\
\hline U-15n\#1A & $12 / 14 / 2011$ & $A / B$ & TOC CL & $900,109.89$ & $676,645.66$ & $5,002.60$ \\
\hline$U-15 n \# 2$ & $6 / 23 / 2010$ & $\mathrm{~L} / \mathrm{O}$ & GS & $900,075.16$ & $676,608.20$ & $5,003.28$ \\
\hline$U-15 n \# 2$ & $5 / 26 / 2011$ & $A / B$ & TOC CL & $900,075.28$ & $676,608.56$ & $5,002.81$ \\
\hline$U-15 n \# 2$ & 8/18/2011 & $A / B$ & TOC CL & $900,075.28$ & $676,608.56$ & $5,002.81$ \\
\hline$U-15 n \# 2$ & $12 / 14 / 2011$ & $A / B$ & TOC CL & $900,075.27$ & $676,608.54$ & $5,002.81$ \\
\hline U-15n\#3 & $6 / 23 / 2010$ & $\mathrm{~L} / \mathrm{O}$ & GS & $900,050.57$ & $676,659.44$ & $5,002.85$ \\
\hline U-15n\#3 & $5 / 26 / 2011$ & $A / B$ & TOC CL & $900,050.70$ & $676,659.44$ & $5,002.18$ \\
\hline$U-15 n \# 3$ & 8/18/2011 & $A / B$ & TOC CL & $900,050.70$ & $676,659.44$ & $5,002.18$ \\
\hline U-15n\#3 & $12 / 14 / 2011$ & $A / B$ & TOC CL & $900,050.67$ & $676,659.48$ & $5,002.26$ \\
\hline$U-15 n \# 4$ & $6 / 23 / 2010$ & L/O & GS & $900,018.49$ & $676,612.53$ & $5,002.79$ \\
\hline$U-15 n \# 4$ & $5 / 26 / 2011$ & $A / B$ & TOC CL & $900,018.53$ & $676,612.52$ & $5,002.29$ \\
\hline$U-15 n \# 4$ & $8 / 18 / 2011$ & $\mathrm{~A} / \mathrm{B}$ & TOC CL & $900,018.53$ & $676,612.52$ & $5,002.29$ \\
\hline$U-15 n \# 4$ & $12 / 14 / 2011$ & $\mathrm{~A} / \mathrm{B}$ & TOC CL & $900,018.48$ & $676,612.53$ & $5,002.34$ \\
\hline U-15n\#5 & $6 / 23 / 2010$ & $\mathrm{~L} / \mathrm{O}$ & GS & $900,082.65$ & $676,706.35$ & $5,001.27$ \\
\hline$U-15 n \# 5$ & $5 / 26 / 2011$ & $A / B$ & TOC CL & $900,082.68$ & $676,706.48$ & $5,001.94$ \\
\hline$U-15 n \# 5$ & $8 / 18 / 2011$ & $A / B$ & TOC CL & $900,082.68$ & $676,706.48$ & $5,001.94$ \\
\hline U-15n\#5 & $12 / 14 / 2011$ & $A / B$ & TOC CL & $900,082.71$ & $676,706.51$ & $5,001.94$ \\
\hline U-15n\#6 & $6 / 23 / 2010$ & L/O & GS & $900,131.82$ & $676,603.88$ & $5,005.10$ \\
\hline U-15n\#6 & $5 / 26 / 2011$ & $A / B$ & TOC CL & $900,131.71$ & $676,603.87$ & $5,005.72$ \\
\hline U-15n\#6 & $8 / 18 / 2011$ & $A / B$ & TOC CL & $900,131.71$ & $676,603.87$ & $5,005.72$ \\
\hline U-15n\#6 & $12 / 14 / 2011$ & $A / B$ & TOC CL & $900,131.75$ & $676,603.86$ & $5,005.69$ \\
\hline
\end{tabular}


U-15n Core

\begin{tabular}{|c|c|c|c|c|c|c|}
\hline \multicolumn{2}{|c|}{$\begin{array}{r}\text { Spud: } 7 / 26 / 2010 \\
\text { Completion: } 7 / 28 / 2010 \\
\end{array}$} & \multicolumn{2}{|c|}{$\begin{array}{l}\text { BH Dia: } 3.8125 \text { in } \\
\text { TD: } 196 \mathrm{ft} \\
\end{array}$} & \multicolumn{3}{|c|}{$\begin{array}{l}\text { Data: s-Built } 11 / 29 / 11 \text { (source ho } \\
\text { TOC: } \quad 0.60 \mathrm{ft} \text { ags }\end{array}$} \\
\hline Vertical & Northing & Easting & Elevation & Latitude & Longitude & Elevation \\
\hline Depth & \multicolumn{2}{|c|}{ SPC NAD27 ft } & NGVD29 ft & \multicolumn{2}{|c|}{ GEO NAD83 deg } & NAVD88 ft \\
\hline 0.00 & $900,077.28$ & $676,640.62$ & $5,001.82$ & 37.221195 & 116.060867 & 5005.13 \\
\hline 5.20 & $900,077.28$ & $676,640.62$ & $4,996.62$ & 37.221195 & 116.060867 & 4999.93 \\
\hline 10.00 & $900,077.29$ & $676,640.56$ & $4,991.82$ & 37.221195 & 116.060867 & 4995.13 \\
\hline 15.00 & $900,077.30$ & $676,640.62$ & $4,986.82$ & 37.221195 & 116.060867 & 4990.13 \\
\hline 20.00 & $900,077.32$ & $676,640.68$ & $4,981.82$ & 37.221195 & 116.060867 & 4985.13 \\
\hline 25.00 & $900,077.36$ & $676,640.75$ & $4,976.82$ & 37.221195 & 116.060867 & 4980.13 \\
\hline 30.00 & $900,077.39$ & $676,640.82$ & $4,971.82$ & 37.221195 & 116.060866 & .13 \\
\hline 35.00 & $900,077.42$ & $676,640.88$ & $4,966.82$ & 37.221195 & 116.060866 & .13 \\
\hline 40.00 & $900,077.45$ & $676,640.95$ & $4,961.82$ & 37.221195 & 116.060866 & 5.13 \\
\hline 45.00 & $900,077.48$ & $676,641.01$ & $4,956.82$ & 37.221195 & 116.060866 & .13 \\
\hline 50.00 & $900,077.50$ & $676,641.07$ & $4,951.82$ & 37.221195 & 116.060866 & 5.13 \\
\hline 54.99 & $900,077.52$ & $676,641.12$ & $4,946.83$ & 37.221195 & 116.060865 & 0.13 \\
\hline 59.99 & $900,077.54$ & $676,641.18$ & $4,941.83$ & 37.221195 & 116.060865 & 5.13 \\
\hline 64.99 & $900,077.56$ & $676,641.23$ & $4,936.83$ & 37.221195 & 116.060865 & 0.13 \\
\hline 69.99 & $900,077.58$ & $676,641.27$ & $4,931.83$ & 37.221195 & 116.060865 & \\
\hline 74.99 & $900,077.60$ & $676,641.32$ & $4,926.83$ & 37.221196 & 116.060865 & 4930.13 \\
\hline 79.99 & $900,077.63$ & $676,641.37$ & $4,921.83$ & 37.221196 & 116.060864 & 4925.13 \\
\hline 84.99 & $900,077.67$ & $676,641.42$ & $4,916.83$ & 37.221196 & 116.060864 & 0.13 \\
\hline 89.99 & $900,077.70$ & 676,64 & $4,911.83$ & 37.221196 & 116.060864 & 13 \\
\hline 94.99 & 77.73 & 676,64 & $4,906.83$ & 37.221196 & .060864 & .14 \\
\hline 99.99 & 77.76 & $676,641.55$ & $4,901.83$ & 37.221196 & 116.060864 & 5.14 \\
\hline 104.99 & $900,077.80$ & $676,641.60$ & $4,896.83$ & 37.221196 & 116.060864 & 0.14 \\
\hline 109.99 & $900,077.84$ & $676,641.66$ & 4,891.83 & 37.221196 & 116.060863 & 5.14 \\
\hline 114.99 & $900,077.88$ & $676,641.72$ & $4,886.83$ & 37.221196 & 116.060863 & 0.14 \\
\hline 119.99 & $900,077.92$ & $676,641.77$ & $4,881.83$ & 37.221196 & 116.060863 & 4885.14 \\
\hline 124.99 & $900,077.96$ & $676,641.82$ & $4,876.83$ & 37.221196 & 116.060863 & 4880.14 \\
\hline 129.99 & $900,078.00$ & $676,641.87$ & $4,871.83$ & 37.221197 & 116.060863 & 4875.14 \\
\hline 134.99 & $900,078.04$ & $676,641.93$ & $4,866.83$ & 37.221197 & 116.060863 & 4870.14 \\
\hline 139.99 & $900,078.08$ & $676,641.98$ & $4,861.83$ & 37.221197 & 116.060862 & 4865.14 \\
\hline 144.99 & $900,078.12$ & $676,642.03$ & $4,856.83$ & 37.221197 & 116.060862 & 4860.14 \\
\hline 149.99 & $900,078.16$ & $676,642.08$ & $4,851.83$ & 37.221197 & 116.060862 & 5.14 \\
\hline 154.99 & $900,078.20$ & $676,642.12$ & $4,846.83$ & 37.221197 & 116.060862 & 4850.14 \\
\hline 159.99 & $900,078.24$ & $676,642.17$ & $4,841.83$ & 37.221197 & 116.060862 & 4845.14 \\
\hline 164.99 & $900,078.27$ & $676,642.21$ & $4,836.83$ & 37.221197 & 116.060862 & 4840.14 \\
\hline 169.99 & $900,078.31$ & $676,642.26$ & 4,831.83 & 37.221197 & 116.060861 & 4835.14 \\
\hline 174.99 & $900,078.34$ & $676,642.29$ & $4,826.83$ & 37.221198 & 116.060861 & 4830.14 \\
\hline 179.99 & $900,078.37$ & $676,642.34$ & $4,821.83$ & 37.221198 & 116.060861 & 4825.14 \\
\hline 184.99 & $900,078.40$ & $676,642.37$ & $4,816.83$ & 37.221198 & 116.060861 & 4820.14 \\
\hline 189.99 & $900,078.43$ & $676,642.42$ & $4,811.84$ & 37.221198 & 116.060861 & 4815.14 \\
\hline 194.59 & $900,078.45$ & $676,642.45$ & $4,807.24$ & 37.221198 & 116.060861 & 4810.54 \\
\hline
\end{tabular}




\section{U-15n Core Deviation Plot - Plan View}

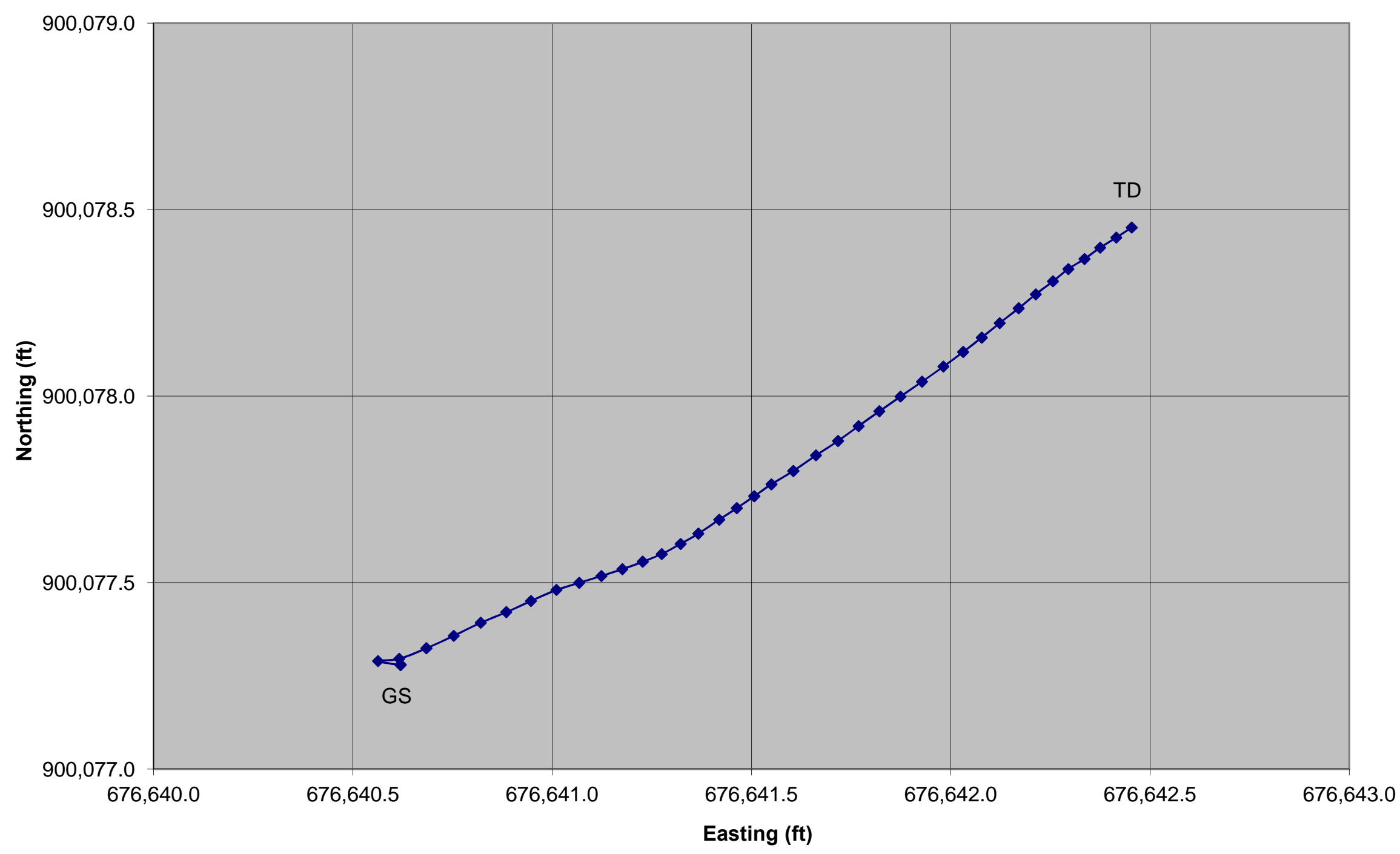


U-15n Source

\begin{tabular}{|c|c|c|c|c|c|c|}
\hline \multicolumn{2}{|c|}{$\begin{array}{c}\text { Spud: } 8 / 5 / 2010 \\
\text { Compl: } 3 / 17 / 2011\end{array}$} & \multicolumn{2}{|c|}{$\begin{array}{r}\text { BH Dia: } 36 \text { in } \\
\text { TD: } 199 \mathrm{ft} \\
\end{array}$} & $\begin{array}{l}\text { Data: } \\
\text { TOC: }\end{array}$ & \multicolumn{2}{|c|}{$\begin{array}{c}\text { As-Built 12/14/11 } \\
0.60 \mathrm{ft} \text { ags }\end{array}$} \\
\hline \multirow{2}{*}{$\begin{array}{l}\text { Vertical } \\
\text { Depth }\end{array}$} & Northing & $\overline{\text { Easting }}$ & Elevation & Latitude & Longitude & Elevation \\
\hline & \multicolumn{2}{|c|}{ SPC NAD27 ft } & NGVD29 ft & \multicolumn{2}{|c|}{ GEO NAD83 deg } & NAVD88 ft \\
\hline 0.00 & $900,077.28$ & $676,640.62$ & $5,001.82$ & 37.221195 & 116.060867 & 5005.13 \\
\hline 5.00 & $900,077.29$ & $676,640.59$ & $4,996.82$ & 37.221195 & 116.060867 & 5000.13 \\
\hline 9.99 & $900,077.36$ & $676,640.58$ & $4,991.83$ & 37.221195 & 116.060867 & 4995.14 \\
\hline 14.99 & $900,077.34$ & $676,640.56$ & $4,986.83$ & 37.221195 & 116.060867 & 4990.14 \\
\hline 19.98 & $900,077.26$ & $676,640.56$ & $4,981.84$ & 37.221195 & 116.060867 & 4985.15 \\
\hline 24.97 & $900,077.18$ & $676,640.51$ & $4,976.85$ & 37.221194 & 116.060867 & 4980.15 \\
\hline 29.97 & $900,077.15$ & $676,640.45$ & $4,971.85$ & 37.221194 & 116.060868 & 4975.16 \\
\hline 34.96 & $900,077.09$ & $676,640.47$ & $4,966.86$ & 37.221194 & 116.060868 & 4970.16 \\
\hline 39.95 & $900,076.93$ & $676,640.52$ & $4,961.87$ & 37.221194 & 116.060867 & 4965.17 \\
\hline 44.95 & $900,076.90$ & $676,640.43$ & $4,956.87$ & 37.221194 & 116.060868 & 4960.18 \\
\hline 49.94 & $900,076.93$ & $676,640.36$ & $4,951.88$ & 37.221194 & 116.060868 & 4955.19 \\
\hline 54.93 & $900,076.82$ & $676,640.46$ & $4,946.89$ & 37.221193 & 116.060868 & 4950.19 \\
\hline 59.93 & $900,076.67$ & $676,640.48$ & $4,941.89$ & 37.221193 & 116.060868 & 4945.20 \\
\hline 64.92 & $900,076.59$ & $676,640.38$ & $4,936.90$ & 37.221193 & 116.060868 & 4940.21 \\
\hline 69.91 & $900,076.52$ & $676,640.39$ & $4,931.91$ & 37.221193 & 116.060868 & 4935.21 \\
\hline 74.91 & $900,076.49$ & $676,640.42$ & $4,926.91$ & 37.221192 & 116.060868 & 4930.22 \\
\hline 79.90 & $900,076.44$ & $676,640.43$ & $4,921.92$ & 37.221192 & 116.060868 & 4925.22 \\
\hline 84.90 & $900,076.38$ & $676,640.34$ & $4,916.92$ & 37.221192 & 116.060868 & 4920.23 \\
\hline 89.89 & $900,076.37$ & $676,640.33$ & $4,911.93$ & 37.221192 & 116.060868 & 4915.24 \\
\hline 94.88 & $900,076.24$ & $676,640.56$ & $4,906.94$ & 37.221192 & 116.060867 & 4910.25 \\
\hline 99.87 & $900,076.07$ & $676,640.52$ & 4,90 & 37.221191 & 116.060867 & 4905.26 \\
\hline 104.86 & $900,076.05$ & $676,640.33$ & 4,89 & 37.221191 & 116.060868 & 4900.27 \\
\hline 109.85 & $900,076.14$ & $676,640.44$ & 4,89 & 37.221192 & 116.060868 & 4895.28 \\
\hline 114.85 & $900,076.07$ & $676,640.47$ & 4,88 & 37.221191 & 116.060868 & 4890.28 \\
\hline 119.84 & $900,075.89$ & $676,640.42$ & $4,881.98$ & 37.221191 & 116.060868 & 4885.29 \\
\hline 124.83 & $900,075.92$ & $676,640.33$ & $4,876.99$ & 37.221191 & 116.060868 & 4880.30 \\
\hline 129.82 & $900,075.99$ & $676,640.44$ & $4,872.00$ & 37.221191 & 116.060868 & 4875.31 \\
\hline 134.81 & $900,075.79$ & $676,640.69$ & $4,867.01$ & 37.221191 & 116.060867 & 4870.32 \\
\hline 139.79 & $900,075.54$ & $676,640.59$ & $4,862.03$ & 37.221190 & 116.060867 & 4865.34 \\
\hline 144.78 & $900,075.54$ & $676,640.41$ & $4,857.04$ & 37.221190 & 116.060868 & 4860.34 \\
\hline 149.77 & $900,075.65$ & $676,640.57$ & $4,852.05$ & 37.221190 & 116.060867 & 4855.35 \\
\hline 154.75 & $900,075.34$ & $676,640.80$ & $4,847.07$ & 37.221189 & 116.060866 & 4850.38 \\
\hline 159.74 & $900,075.11$ & $676,640.63$ & $4,842.09$ & 37.221189 & 116.060867 & 4845.39 \\
\hline 164.73 & $900,075.23$ & $676,640.55$ & $4,837.09$ & 37.221189 & 116.060867 & 4840.40 \\
\hline 169.71 & $900,075.18$ & $676,640.84$ & $4,832.11$ & 37.221189 & 116.060866 & 4835.42 \\
\hline 174.69 & $900,074.82$ & $676,640.85$ & $4,827.13$ & 37.221188 & 116.060866 & 4830.44 \\
\hline 179.68 & $900,074.76$ & $676,640.63$ & $4,822.14$ & 37.221188 & 116.060867 & 4825.45 \\
\hline 184.67 & $900,074.91$ & $676,640.78$ & $4,817.15$ & 37.221188 & 116.060867 & 4820.46 \\
\hline 189.64 & $900,074.53$ & $676,641.03$ & $4,812.18$ & 37.221187 & 116.060866 & 4815.49 \\
\hline 192.61 & $900,074.14$ & $676,641.07$ & $4,809.21$ & 37.221186 & 116.060866 & 4812.52 \\
\hline
\end{tabular}




\section{U-15n Source Deviation Plot - Plan View}

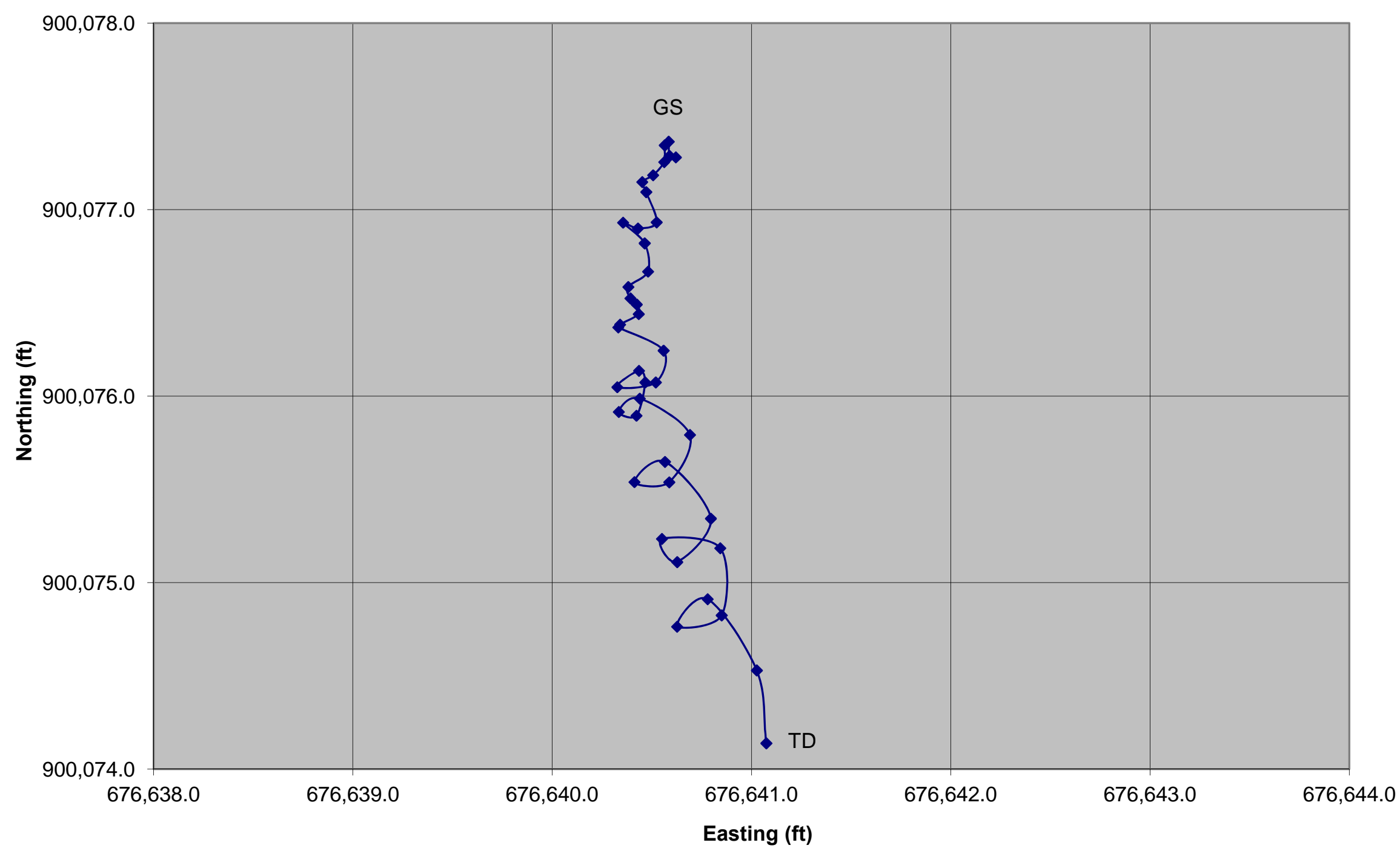


U-15n\#1

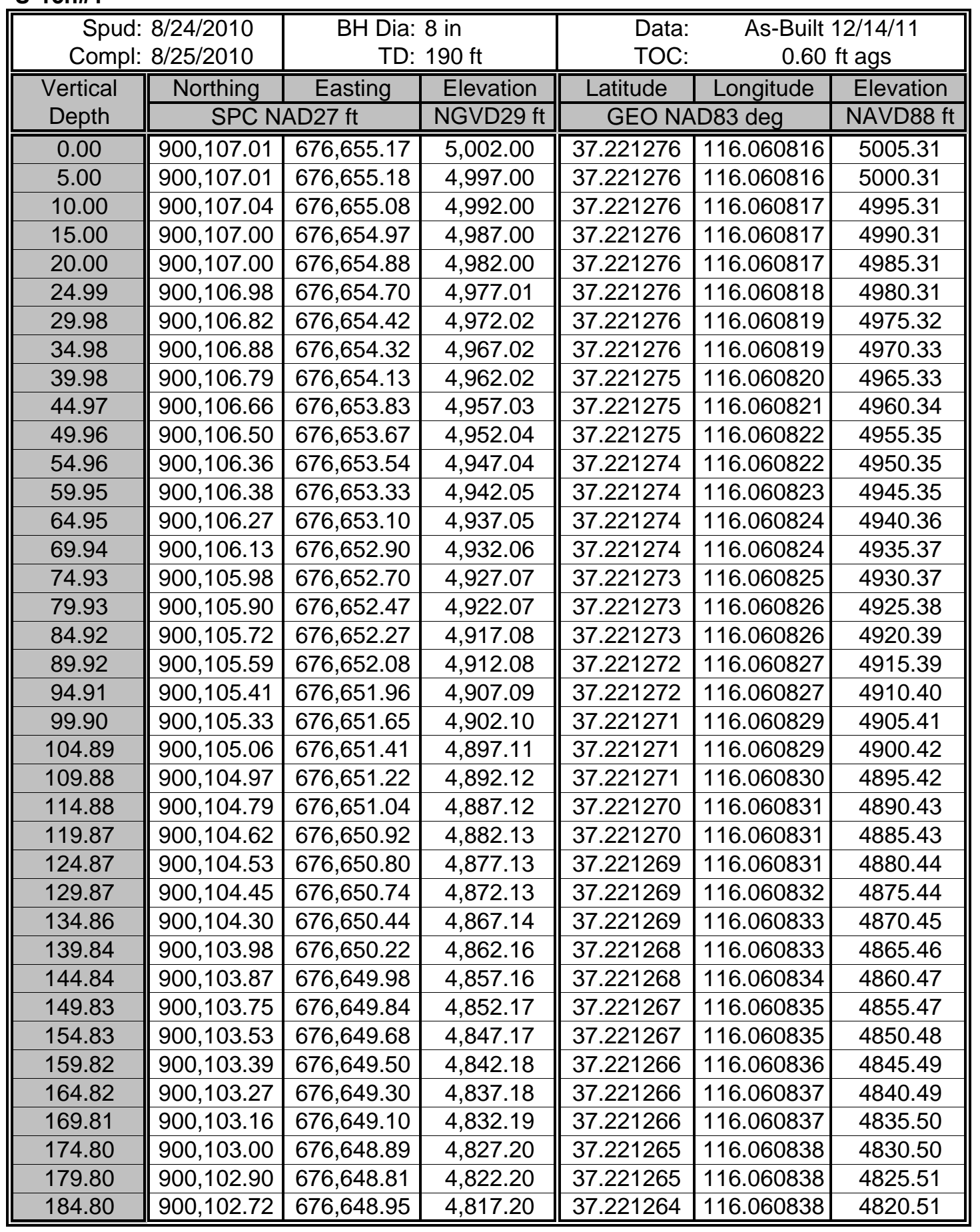




\section{U-15n\#1 Deviation Plot - Plan View}

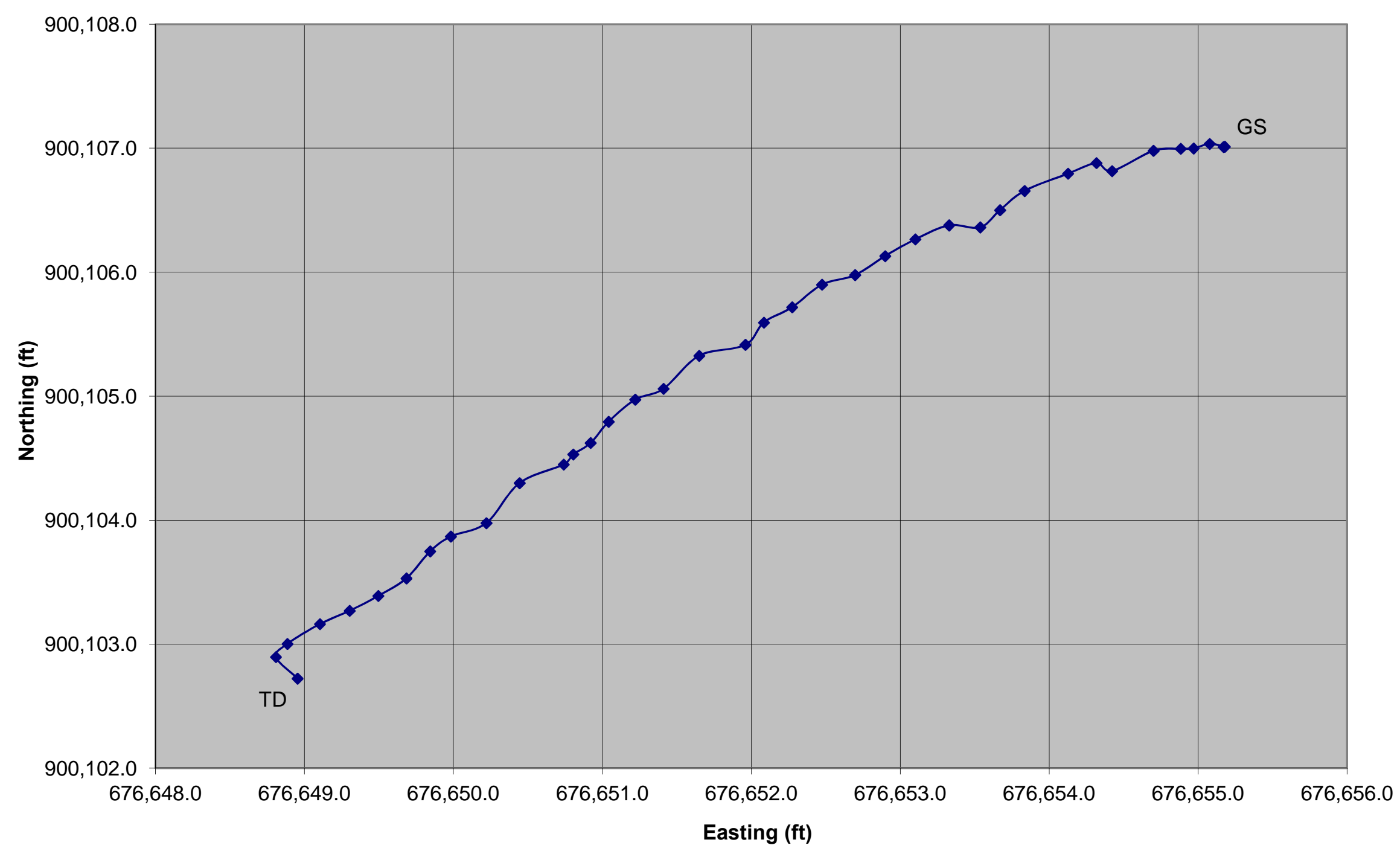


U-15n\#1A

\begin{tabular}{|c|c|c|c|c|c|c|}
\hline \multicolumn{2}{|c|}{$\begin{array}{r}\text { Spud: } 8 / 25 / 2011 \\
\text { Compl: } 8 / 27 / 2011\end{array}$} & \multicolumn{2}{|c|}{$\begin{array}{l}\text { BH Dia: } 8 \text { in } \\
\text { TD: } 194 \mathrm{ft} \\
\end{array}$} & $\begin{array}{l}\text { Data: } \\
\text { TOC: }\end{array}$ & \multicolumn{2}{|c|}{$\begin{array}{c}\text { As-Built 12/14/11 } \\
0.49 \mathrm{ft} \text { ags }\end{array}$} \\
\hline$\overline{\text { Vertical }}$ & Northing & $\overline{\text { Easting }}$ & Elevation & Latitude & Longitude & Elevation \\
\hline Depth & \multicolumn{2}{|c|}{ SPC NAD27 ft } & NGVD29 ft & \multicolumn{2}{|c|}{ GEO NAD83 deg } & NAVD88 ft \\
\hline 0.00 & $900,109.89$ & $676,645.66$ & $5,002.11$ & 37.221284 & 116.060849 & 5005.42 \\
\hline 5.50 & $900,109.89$ & $676,645.66$ & $4,996.61$ & 37.221284 & 116.060849 & 4999.92 \\
\hline 10.50 & $900,109.89$ & $676,645.63$ & $4,991.61$ & 37.221284 & 116.060849 & 4994.92 \\
\hline 15.50 & $900,109.87$ & $676,645.64$ & $4,986.61$ & 37.221284 & 116.060849 & 4989.92 \\
\hline 20.50 & $900,109.85$ & $676,645.64$ & $4,981.61$ & 37.221284 & 116.060849 & 4984.92 \\
\hline 25.50 & $900,109.83$ & $676,645.62$ & $4,976.61$ & 37.221284 & 116.060849 & 4979.92 \\
\hline 30.50 & $900,109.84$ & $676,645.59$ & $4,971.61$ & 37.221284 & 116.060849 & 4974.92 \\
\hline 35.50 & $900,109.84$ & $676,645.54$ & 4,96 & 37.221284 & 116.060849 & 4969.92 \\
\hline 40.50 & $900,109.86$ & $676,645.50$ & 4,96 & 37.221284 & 116.060850 & 4964.92 \\
\hline 45.50 & $900,109.87$ & $676,645.47$ & 4,95 & 37.221284 & 116.060850 & 4959.92 \\
\hline 50.50 & $900,109.89$ & $676,645.44$ & 4,95 & 37.221284 & 116.060850 & 4954.92 \\
\hline 55.50 & $900,109.91$ & $676,645.41$ & 4,92 & 37.221284 & 116.060850 & 4949.92 \\
\hline 60.50 & $900,109.95$ & $676,645.40$ & $4,941.61$ & 37.221284 & 116.060850 & 4944.92 \\
\hline 65.50 & $900,109.99$ & $676,645.38$ & $4,936.61$ & 37.221284 & 116.060850 & 4939.92 \\
\hline 70.50 & $900,109.98$ & $676,645.34$ & $4,931.61$ & 37.221284 & 116.060850 & 4934.92 \\
\hline 75.50 & $900,109.99$ & $676,645.30$ & $4,926.61$ & 37.221284 & 116.060850 & 4929.92 \\
\hline 80.50 & $900,110.00$ & $676,645.25$ & $4,921.61$ & 37.221284 & 116.060850 & 4924.92 \\
\hline 85.50 & $900,110.03$ & $676,645.21$ & $4,916.61$ & 37.221285 & 116.060851 & 4919.92 \\
\hline 90.50 & $900,110.00$ & $676,645.14$ & $4,911.61$ & 37.221284 & 116.060851 & 4914.92 \\
\hline 95.50 & $900,109.99$ & $676,645.11$ & $4,906.61$ & 37.221284 & 116.060851 & 4909.92 \\
\hline 100.50 & $900,109.96$ & $676,645.10$ & 4,90 & 37.221284 & 116.060851 & 4904.92 \\
\hline 105.50 & $900,109.94$ & $676,645.09$ & 4,89 & 37.221284 & 116.060851 & 4899.92 \\
\hline 110.50 & $900,109.92$ & $676,645.11$ & $4,8 \mathrm{~s}$ & 37.221284 & 116.060851 & 4894.92 \\
\hline 115.50 & $900,109.90$ & $676,645.13$ & 4,88 & 37.221284 & 116.060851 & 4889.92 \\
\hline 120.50 & $900,109.90$ & $676,645.15$ & 4,88 & 37.221284 & 116.060851 & 4884.92 \\
\hline 125.50 & $900,109.91$ & $676,645.17$ & 4,87 & 37.221284 & 116.060851 & 4879.92 \\
\hline 130.50 & $900,109.90$ & $676,645.19$ & $4,871.61$ & 37.221284 & 116.060851 & 4874.92 \\
\hline 135.50 & $900,109.88$ & $676,645.21$ & $4,866.61$ & 37.221284 & 116.060851 & 4869.92 \\
\hline 140.50 & $900,109.87$ & $676,645.22$ & $4,861.61$ & 37.221284 & 116.060851 & 4864.92 \\
\hline 145.50 & $900,109.85$ & $676,645.23$ & $4,856.61$ & 37.221284 & 116.060851 & 4859.92 \\
\hline 150.50 & $900,109.83$ & $676,645.24$ & $4,851.61$ & 37.221284 & 116.060850 & 4854.92 \\
\hline 160.50 & $900,109.80$ & $676,645.26$ & $4,841.61$ & 37.221284 & 116.060850 & 4844.92 \\
\hline 165.50 & $900,109.79$ & $676,645.29$ & $4,836.62$ & 37.221284 & 116.060850 & 4839.92 \\
\hline 170.50 & $900,109.76$ & $676,645.33$ & $4,831.62$ & 37.221284 & 116.060850 & 4834.92 \\
\hline 175.50 & $900,109.75$ & $676,645.32$ & $4,826.62$ & 37.221284 & 116.060850 & 4829.92 \\
\hline 180.50 & $900,109.72$ & $676,645.32$ & $4,821.62$ & 37.221284 & 116.060850 & 4824.92 \\
\hline 185.50 & $900,109.71$ & $676,645.32$ & $4,816.62$ & 37.221284 & 116.060850 & 4819.92 \\
\hline 190.50 & $900,109.72$ & $676,645.30$ & $4,811.62$ & 37.221284 & 116.060850 & 4814.92 \\
\hline 192.50 & $900,109.72$ & $676,645.30$ & $4,809.62$ & 37.221284 & 116.060850 & 4812.92 \\
\hline
\end{tabular}




\section{U-15n\#1A Core Deviation Plot - Plan View}

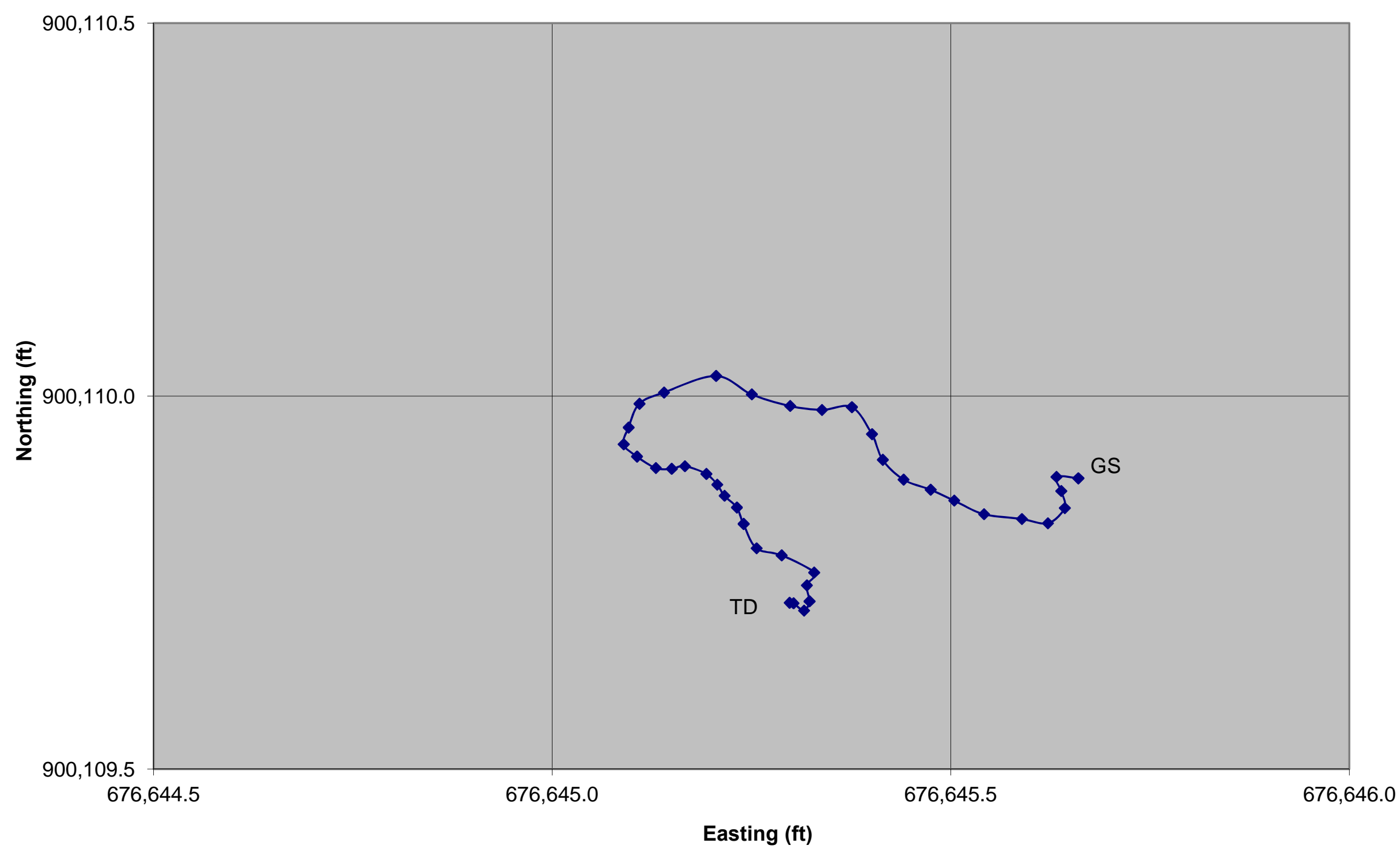


U-15n\#2

\begin{tabular}{|c|c|c|c|c|c|c|}
\hline \multicolumn{2}{|c|}{$\begin{array}{r}\text { Spud: } 9 / 15 / 2010 \\
\text { Compl: 9/16/2010 }\end{array}$} & \multicolumn{2}{|c|}{$\begin{array}{l}\text { BH Dia: } 8 \text { in } \\
\text { TD: } 191.2 \mathrm{ft} \\
\end{array}$} & \multicolumn{3}{|c|}{$\begin{array}{c}\text { As-Built 12/14/11 } \\
0.65 \mathrm{ft} \text { ags } \\
\end{array}$} \\
\hline Vertical & Northing & $\overline{\text { Easting }}$ & Elevation & $\overline{\text { Latitude }}$ & Longitude & Elevation \\
\hline Depth & \multicolumn{2}{|c|}{ SPC NAD27 ft } & NGVD29 ft & \multicolumn{2}{|c|}{ GEO NAD83 deg } & NAVD88 ft \\
\hline 0.00 & $900,075.27$ & $2676,608.54$ & $5,002.16$ & 37.221190 & 116.060977 & 5005.47 \\
\hline 5.00 & $900,075.32$ & $676,608.51$ & $4,997.16$ & 37.221190 & 116.060977 & 5000.47 \\
\hline 10.00 & $900,075.35$ & $676,608.44$ & $4,992.16$ & 37.221190 & 116.060978 & 4995.47 \\
\hline 14.99 & $900,075.54$ & $676,608.54$ & $4,987.17$ & 37.221190 & 116.060977 & 4990.47 \\
\hline 19.99 & $900,075.57$ & $676,608.55$ & $4,982.17$ & 37.221191 & 116.060977 & 4985.47 \\
\hline 24.99 & $900,075.52$ & $676,608.63$ & $4,977.17$ & 37.221190 & 116.060977 & 4980.47 \\
\hline 29.99 & $900,075.64$ & $676,608.81$ & $4,972.17$ & 37.221191 & 116.060976 & 4975.48 \\
\hline 34.98 & $900,075.69$ & $676,609.04$ & $4,967.18$ & 37.221191 & 116.060976 & 4970.48 \\
\hline 39.97 & $900,075.91$ & $676,609.37$ & $4,962.19$ & 37.221191 & 116.060974 & 4965.50 \\
\hline 44.97 & $900,075.89$ & $676,609.53$ & $4,957.19$ & 37.221191 & 116.060974 & 4960.50 \\
\hline 49.96 & $900,075.94$ & $676,609.69$ & 2.20 & 37.221192 & 116.060973 & 4955.50 \\
\hline 54.96 & $900,075.94$ & $676,609.84$ & 7.20 & 37.221191 & 116.060973 & 4950.51 \\
\hline 59.95 & $900,076.07$ & $676,610.17$ & 42.21 & 37.221192 & 116.060972 & 4945.52 \\
\hline 64.95 & $900,076.06$ & $676,610.25$ & 37.21 & 37.221192 & 116.060971 & 4940.52 \\
\hline 69.94 & $900,076.10$ & $676,610.45$ & 32.22 & 37.221192 & 116.060971 & 4935.52 \\
\hline 74.94 & $900,076.14$ & $676,610.62$ & $4,927.22$ & 37.221192 & 116.060970 & 4930.53 \\
\hline 79.94 & $900,076.15$ & $676,610.78$ & $4,922.22$ & 37.221192 & 116.060970 & 4925.53 \\
\hline 84.93 & $900,076.09$ & $676,611.01$ & $4,917.23$ & 37.221192 & 116.060969 & 4920.54 \\
\hline 89.93 & $900,076.08$ & $676,611.22$ & $4,912.23$ & 37.221192 & 116.060968 & 4915.54 \\
\hline 94.92 & $900,076.09$ & $676,611.40$ & $4,907.24$ & 37.221192 & 116.060967 & 4910.54 \\
\hline 99.91 & $900,076.04$ & $676,611.75$ & $4,902.25$ & 37.221192 & 116.060966 & 4905.56 \\
\hline 104.91 & $900,076.03$ & $676,611.93$ & 7.25 & 37.221192 & 116.060966 & 4900.56 \\
\hline 109.90 & $900,075.99$ & $676,612.18$ & 2.26 & 37.221192 & 116.060965 & 4895.57 \\
\hline 114.90 & $900,075.92$ & $676,612.34$ & 7.26 & 37.221191 & 116.060964 & 4890.57 \\
\hline 119.89 & $900,075.83$ & $676,612.58$ & 82.27 & 37.221191 & 116.060963 & 4885.58 \\
\hline 124.89 & $900,075.75$ & $676,612.66$ & 77.27 & 37.221191 & 116.060963 & 4880.58 \\
\hline 129.89 & $900,075.76$ & $676,612.81$ & $4,872.27$ & 37.221191 & 116.060963 & 4875.58 \\
\hline 134.89 & $900,075.73$ & $676,612.94$ & $4,867.27$ & 37.221191 & 116.060962 & 4870.58 \\
\hline 139.89 & $900,075.63$ & $676,612.96$ & $4,862.27$ & 37.221191 & 116.060962 & 4865.58 \\
\hline 144.89 & $900,075.71$ & $676,612.94$ & $4,857.27$ & 37.221191 & 116.060962 & 4860.58 \\
\hline 149.88 & $900,075.67$ & $676,613.16$ & $4,852.28$ & 37.221191 & 116.060961 & 4855.59 \\
\hline 154.87 & $900,075.79$ & $676,613.47$ & $4,847.29$ & 37.221191 & 116.060960 & 4850.60 \\
\hline 159.86 & $900,075.82$ & $676,613.75$ & $4,842.30$ & 37.221191 & 116.060959 & 4845.61 \\
\hline 164.86 & $900,075.74$ & $676,613.76$ & $4,837.30$ & 37.221191 & 116.060959 & 4840.61 \\
\hline 169.86 & $900,075.75$ & $676,613.76$ & $4,832.30$ & 37.221191 & 116.060959 & 4835.61 \\
\hline 174.85 & $900,075.75$ & $676,614.04$ & $4,827.31$ & 37.221191 & 116.060958 & 4830.61 \\
\hline 179.85 & $900,075.66$ & $676,614.19$ & $4,822.31$ & 37.221191 & 116.060958 & 4825.62 \\
\hline 184.85 & $900,075.64$ & $676,614.38$ & $4,817.31$ & 37.221191 & 116.060957 & 4820.62 \\
\hline 189.83 & $900,075.52$ & $676,614.81$ & $4,812.33$ & 37.221190 & 116.060956 & 4815.64 \\
\hline
\end{tabular}




\section{U-15n\#2 Deviation Plot - Plan View}

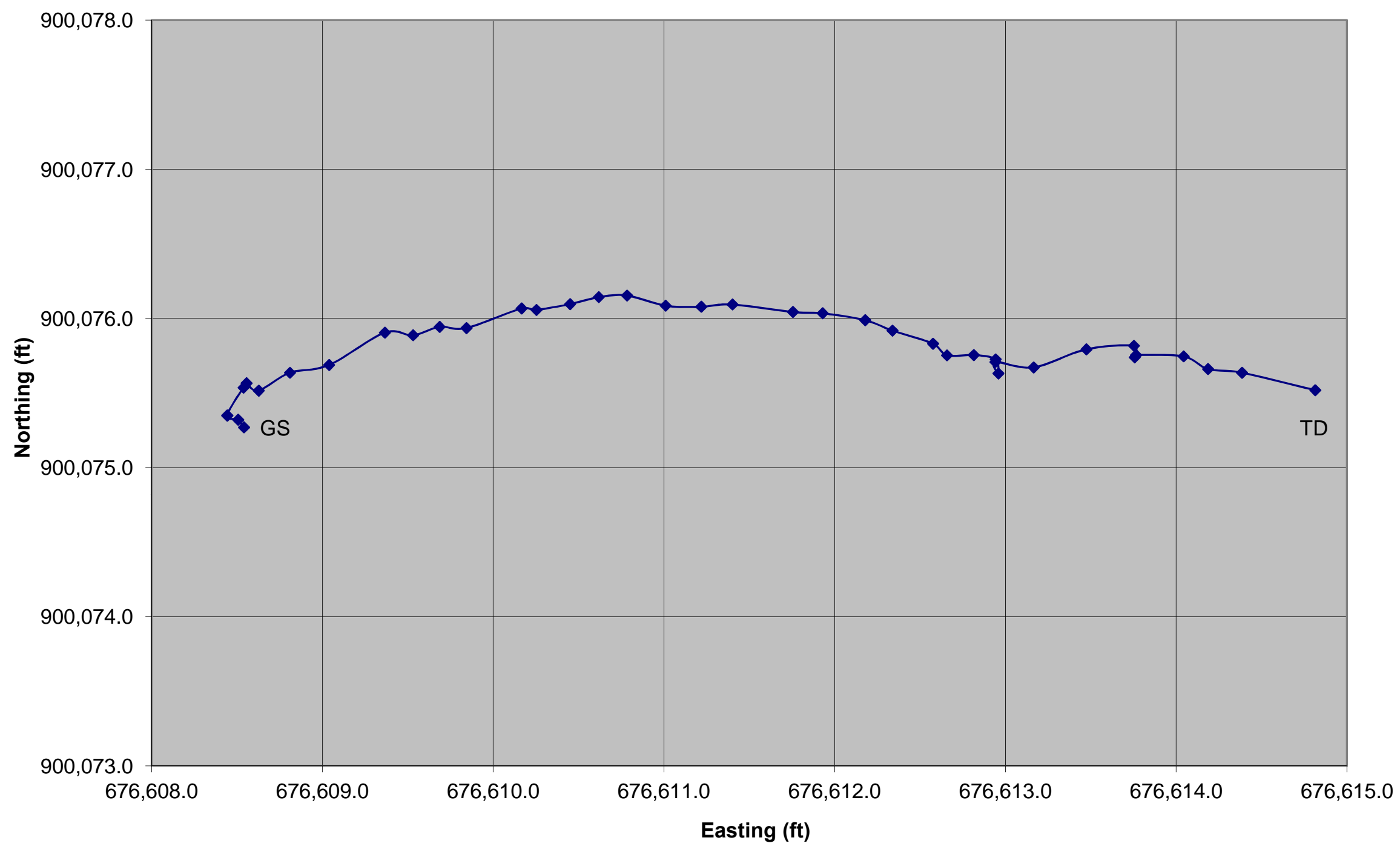


U-15n\#3

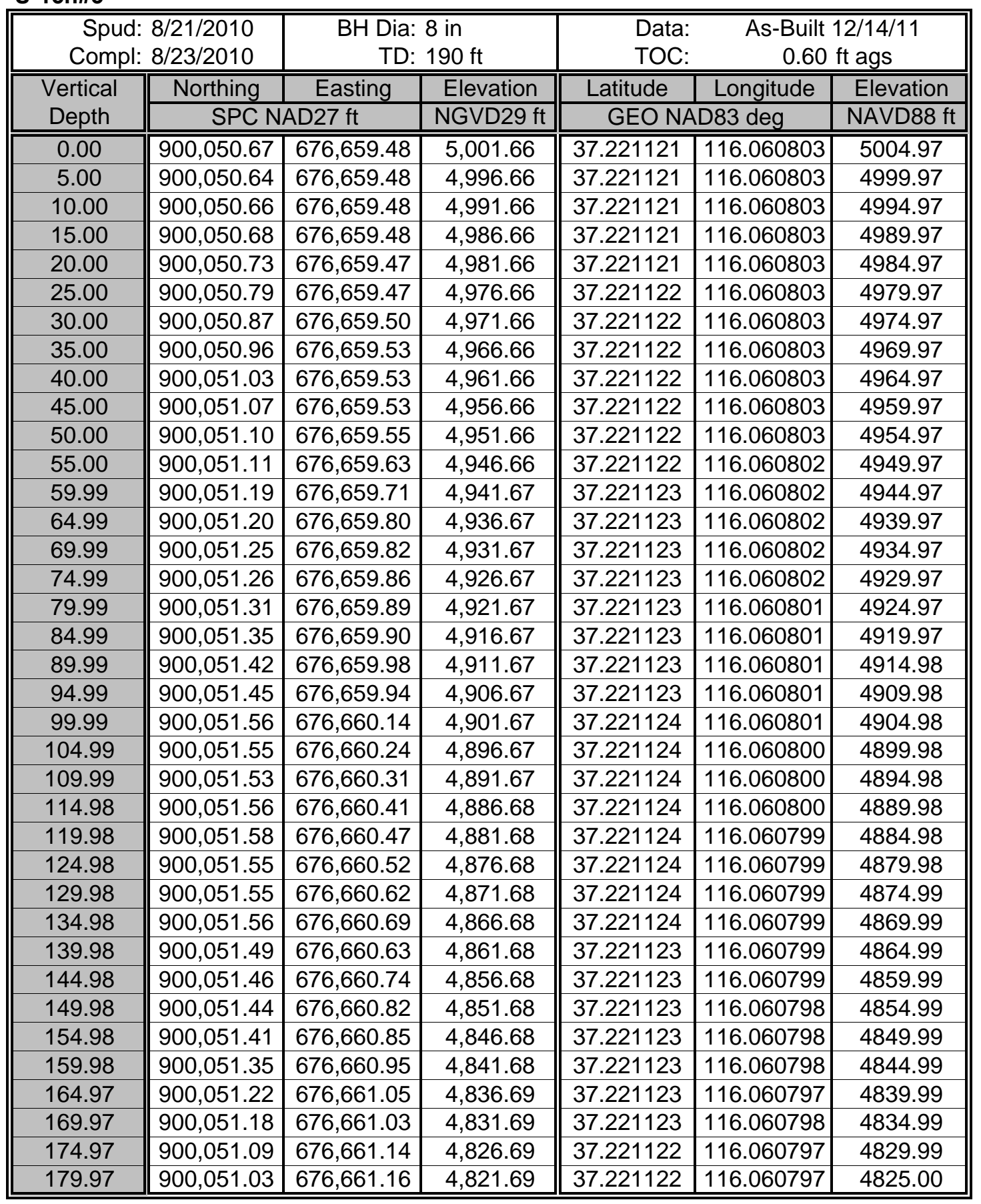




\section{U-15n\#3 Deviation Plot - Plan View}

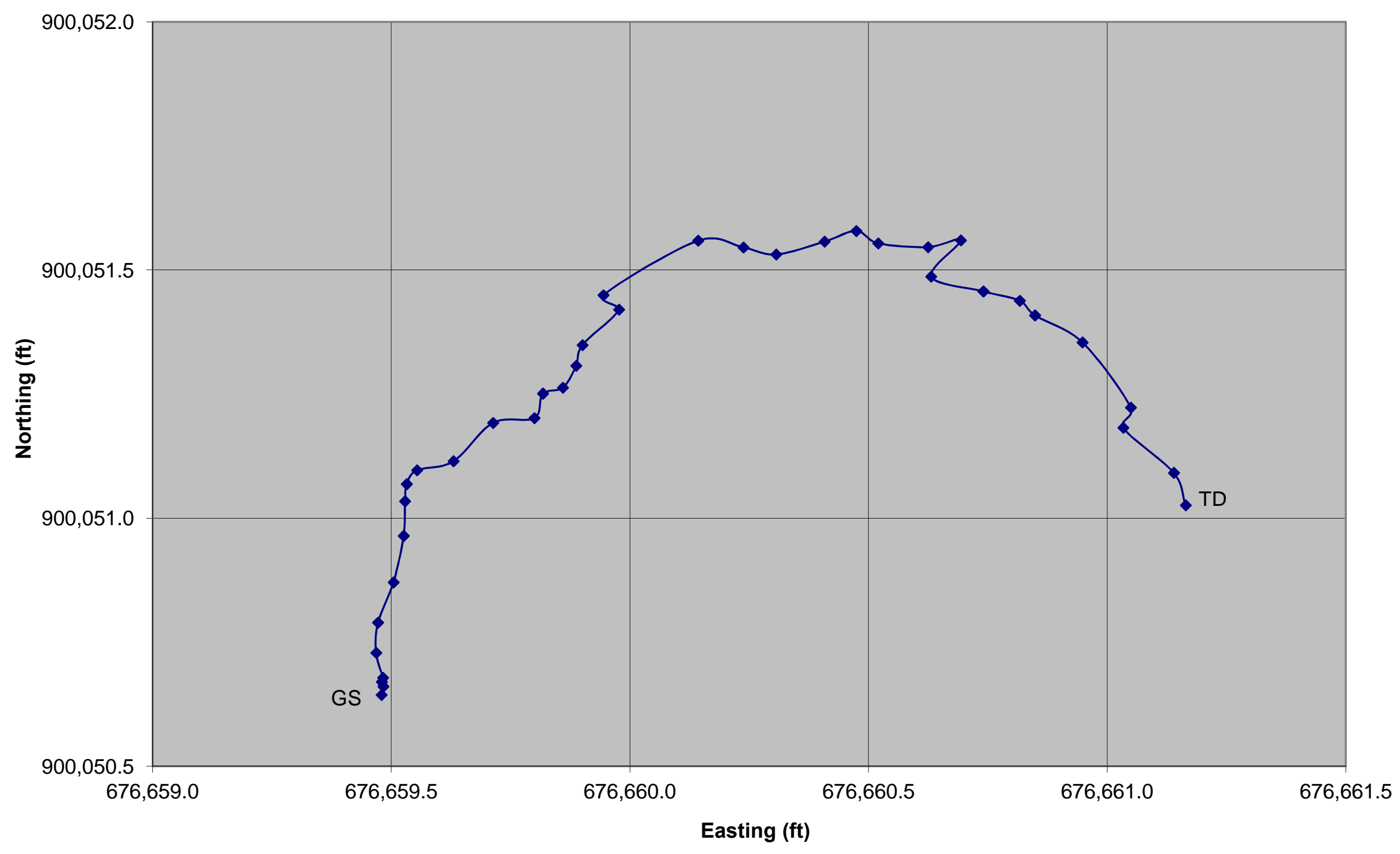


U-15n\#4

\begin{tabular}{|c|c|c|c|c|c|c|}
\hline \multicolumn{2}{|c|}{$\begin{array}{r}\text { Spud: 9/18/2010 } \\
\text { Compl: 9/18/2010 }\end{array}$} & \multicolumn{2}{|c|}{$\begin{array}{l}\text { BH Dia: } 8 \text { in } \\
\text { TD: } 192 \mathrm{ft}\end{array}$} & \multicolumn{3}{|c|}{$\begin{array}{c}\text { As-Built 12/14/11 } \\
0.75 \mathrm{ft} \text { ags } \\
\end{array}$} \\
\hline \multirow{2}{*}{$\begin{array}{l}\text { Vertical } \\
\text { Depth }\end{array}$} & Northing & Easting & Elevation & Latitude & Longitude & Elevation \\
\hline & \multicolumn{2}{|c|}{ SPC NAD27 ft } & NGVD29 ft & \multicolumn{2}{|c|}{ GEO NAD83 deg } & NAVD88 ft \\
\hline 0.00 & $900,018.48$ & $676,612.53$ & $5,001.59$ & 37.221034 & 116.060965 & 5004.90 \\
\hline 5.00 & $900,018.44$ & $676,612.57$ & $4,996.59$ & 37.221034 & 116.060965 & 4999.90 \\
\hline 10.00 & $900,018.47$ & $676,612.57$ & $4,991.59$ & 37.221034 & 116.060965 & 4994.90 \\
\hline 15.00 & $900,018.45$ & $676,612.62$ & $4,986.59$ & 37.221034 & 116.060965 & 4989.90 \\
\hline 20.00 & $900,018.41$ & $676,612.69$ & $4,981.59$ & 37.221033 & 116.060964 & 4984.90 \\
\hline 25.00 & $900,018.31$ & $676,612.67$ & $4,976.59$ & 37.221033 & 116.060964 & 4979.90 \\
\hline 30.00 & $900,018.26$ & $676,612.69$ & $4,971.59$ & 37.221033 & 116.060964 & 4974.90 \\
\hline 35.00 & $900,018.22$ & $676,612.69$ & $4,966.59$ & 37.221033 & 116.060964 & 4969.90 \\
\hline 40.00 & $900,018.15$ & $676,612.73$ & $4,961.59$ & 37.221033 & 116.060964 & 4964.90 \\
\hline 44.99 & $900,018.00$ & $676,612.69$ & $4,956.60$ & 37.221032 & 116.060964 & 4959.90 \\
\hline 49.99 & $900,017.89$ & $676,612.66$ & $4,951.60$ & 37.221032 & 116.060964 & 4954.90 \\
\hline 54.99 & $900,017.66$ & $676,612.70$ & $4,946.60$ & 37.221031 & 116.060964 & 4949.91 \\
\hline 59.99 & $900,017.59$ & $676,612.72$ & $4,941.60$ & 37.221031 & 116.060964 & 4944.91 \\
\hline 64.99 & $900,017.47$ & $676,612.71$ & $4,936.60$ & 37.221031 & 116.060964 & 4939.91 \\
\hline 69.98 & $900,017.35$ & $676,612.65$ & $4,931.61$ & 37.221031 & 116.060964 & 4934.91 \\
\hline 74.98 & $900,017.13$ & $676,612.74$ & $4,926.61$ & 37.221030 & 116.060964 & 4929.92 \\
\hline 79.98 & $900,017.03$ & $676,612.71$ & $4,921.61$ & 37.221030 & 116.060964 & 4924.92 \\
\hline 84.98 & $900,016.97$ & $676,612.62$ & $4,916.61$ & 37.221029 & 116.060965 & 4919.92 \\
\hline 89.97 & $900,016.85$ & $676,612.70$ & $4,911.62$ & 37.221029 & 116.060964 & 4914.92 \\
\hline 94.97 & $900,016.69$ & $676,612.79$ & $4,906.62$ & 37.221029 & 116.060964 & 4909.93 \\
\hline 99.97 & $900,016.66$ & $676,612.75$ & $4,901.62$ & 37.221029 & 116.060964 & 4904.93 \\
\hline 104.97 & $900,016.53$ & $676,612.67$ & $4,896.62$ & 37.221028 & 116.060964 & 4899.93 \\
\hline 109.97 & $900,016.43$ & $676,612.78$ & $4,891.62$ & 37.221028 & 116.060964 & 4894.93 \\
\hline 114.96 & $900,016.26$ & $676,612.74$ & $4,886.63$ & 37.221028 & 116.060964 & 4889.93 \\
\hline 119.96 & $900,016.15$ & $676,612.72$ & $4,881.63$ & 37.221027 & 116.060964 & 4884.94 \\
\hline 124.96 & $900,016.00$ & $676,612.77$ & $4,876.63$ & 37.221027 & 116.060964 & 4879.94 \\
\hline 129.96 & $900,015.93$ & $676,612.75$ & $4,871.63$ & 37.221027 & 116.060964 & 4874.94 \\
\hline 134.96 & $900,015.92$ & $676,612.83$ & $4,866.63$ & 37.221027 & 116.060964 & 4869.94 \\
\hline 139.95 & $900,015.76$ & $676,612.75$ & $4,861.64$ & 37.221026 & 116.060964 & 4864.94 \\
\hline 144.95 & $900,015.54$ & $676,612.66$ & $4,856.64$ & 37.221026 & 116.060964 & 4859.95 \\
\hline 149.95 & $900,015.44$ & $676,612.72$ & $4,851.64$ & 37.221025 & 116.060964 & 4854.95 \\
\hline 154.95 & $900,015.41$ & $676,612.68$ & $4,846.64$ & 37.221025 & 116.060964 & 4849.95 \\
\hline 159.94 & $900,015.27$ & $676,612.62$ & $4,841.65$ & 37.221025 & 116.060965 & 4844.95 \\
\hline 164.94 & $900,015.10$ & $676,612.50$ & $4,836.65$ & 37.221024 & 116.060965 & 4839.96 \\
\hline 169.94 & $900,015.00$ & $676,612.37$ & $4,831.65$ & 37.221024 & 116.060965 & 4834.96 \\
\hline 174.94 & $900,014.88$ & $676,612.37$ & $4,826.65$ & 37.221024 & 116.060965 & 4829.96 \\
\hline 179.93 & $900,014.67$ & $676,612.29$ & $4,821.66$ & 37.221023 & 116.060966 & 4824.97 \\
\hline 184.93 & $900,014.54$ & $676,612.24$ & $4,816.66$ & 37.221023 & 116.060966 & 4819.97 \\
\hline 189.93 & $900,014.45$ & $676,612.20$ & $4,811.66$ & 37.221023 & 116.060966 & 4814.97 \\
\hline 194.93 & $900,014.28$ & $676,612.13$ & $4,806.66$ & 37.221022 & 116.060966 & 4809.97 \\
\hline
\end{tabular}




\section{U-15n\#4 Deviation Plot - Plan View}

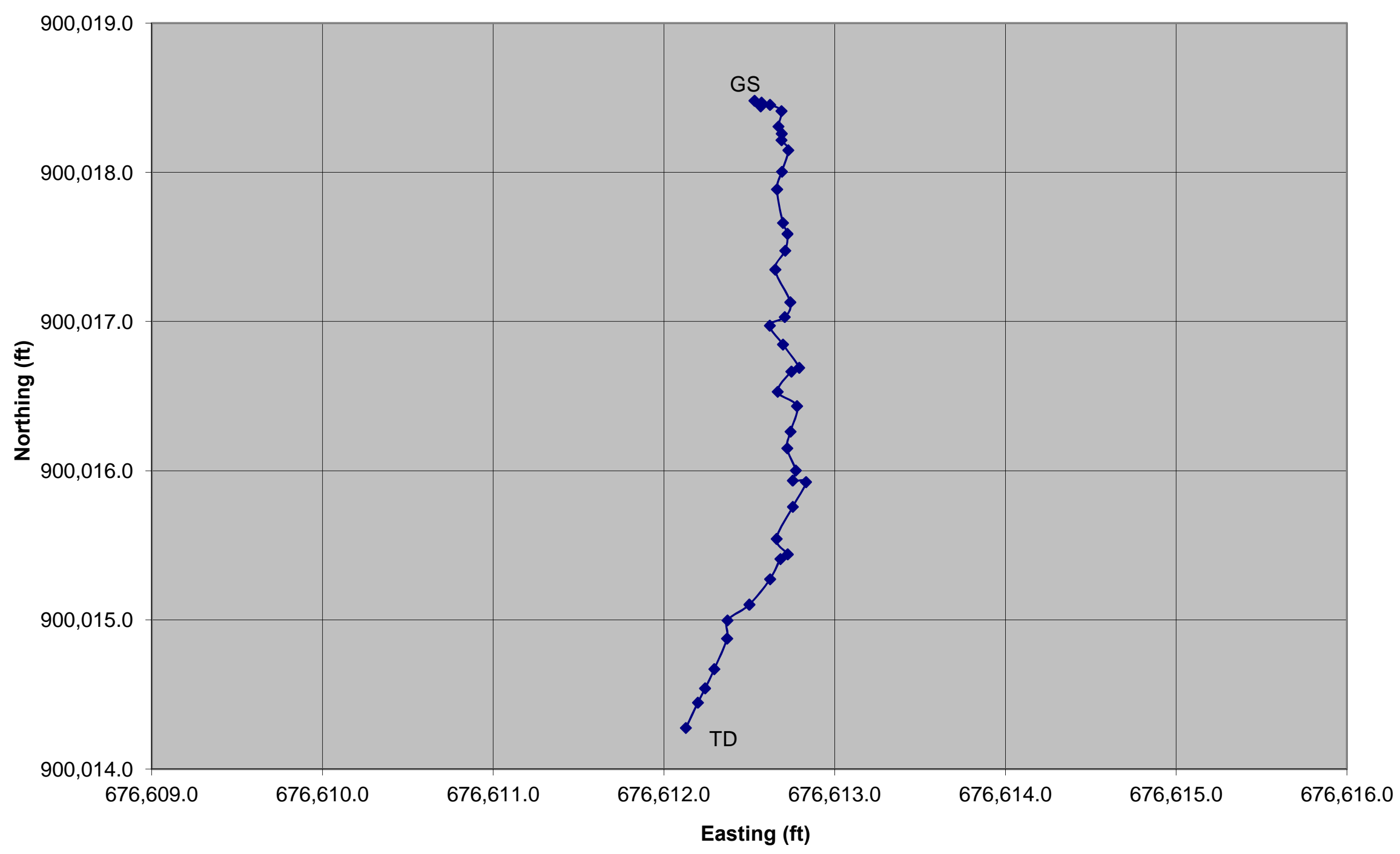


U-15n\#5

\begin{tabular}{|c|c|c|c|c|c|c|}
\hline \multicolumn{2}{|c|}{$\begin{array}{r}\text { Spud: } 9 / 17 / 2010 \\
\text { Compl: } 9 / 17 / 2010\end{array}$} & \multicolumn{2}{|c|}{$\begin{array}{l}\text { BH Dia: } 8 \text { in } \\
\text { TD: } 192 \mathrm{ft} \\
\end{array}$} & \multicolumn{3}{|c|}{$\begin{array}{c}\text { As-Built 12/14/11 } \\
0.65 \mathrm{ft} \text { ags }\end{array}$} \\
\hline \multirow{2}{*}{$\begin{array}{l}\text { Vertical } \\
\text { Depth }\end{array}$} & Northing & Easting & Elevation & Latitude & Longitude & Elevation \\
\hline & \multicolumn{2}{|c|}{ SPC NAD27 ft } & NGVD29 ft & \multicolumn{2}{|c|}{ GEO NAD83 deg } & NAVD88 ft \\
\hline 0.00 & $900,082.71$ & $676,706.51$ & $5,001.29$ & 37.221208 & 116.060641 & 5004.60 \\
\hline 5.00 & $900,082.77$ & $676,706.47$ & $4,996.29$ & 37.221209 & 116.060641 & 4999.60 \\
\hline 10.00 & $900,082.69$ & $676,706.53$ & $4,991.29$ & 37.221208 & 116.060641 & 4994.60 \\
\hline 15.00 & $900,082.77$ & $676,706.58$ & $4,986.29$ & 37.221209 & 116.060640 & 4989.60 \\
\hline 20.00 & $900,082.84$ & $676,706.62$ & $4,981.29$ & 37.221209 & 116.060640 & 4984.60 \\
\hline 24.99 & $900,082.98$ & $676,706.70$ & $4,976.30$ & 37.221209 & 116.060640 & 4979.60 \\
\hline 29.99 & $900,083.02$ & $676,706.67$ & $4,971.30$ & 37.221209 & 116.060640 & 4974.60 \\
\hline 34.99 & $900,083.10$ & $676,706.73$ & $4,966.30$ & 37.221209 & 116.060640 & 4969.60 \\
\hline 39.99 & 83.10 & $676,706.72$ & $4,961.30$ & 37.221209 & 116.060640 & 4964.60 \\
\hline 44.99 & $900,083.23$ & $676,706.81$ & $4,956.30$ & 37.221210 & 116.060640 & 4959.61 \\
\hline 49.99 & $900,083.27$ & $676,706.71$ & $4,951.30$ & 37.221210 & 116.060640 & 4954.61 \\
\hline 54.99 & $900,083.37$ & $676,706.70$ & $4,946.30$ & 37.221210 & 116.060640 & 4949.61 \\
\hline 59.99 & $900,083.52$ & $676,706.76$ & $4,941.30$ & 37.221211 & 116.060640 & 4944.61 \\
\hline 64.98 & $900,083.66$ & $676,706.80$ & $4,936.31$ & 37.221211 & 116.060640 & 4939.61 \\
\hline 69.98 & $900,083.74$ & $676,706.75$ & $4,931.31$ & 37.221211 & 116.060640 & 4934.61 \\
\hline 74.98 & $900,083.69$ & $676,706.67$ & $4,926.31$ & 37.221211 & 116.060640 & 4929.62 \\
\hline 79.98 & $900,083.79$ & $676,706.78$ & $4,921.31$ & 37.221211 & 116.060640 & 4924.62 \\
\hline 84.98 & $900,083.82$ & $676,706.70$ & $4,916.31$ & 37.221211 & 116.060640 & 4919.62 \\
\hline 89.98 & 33.80 & $676,706.75$ & $4,911.31$ & 37.221211 & 116.060640 & 4914.62 \\
\hline 94.98 & 3.89 & $676,706.68$ & $4,906.31$ & 37.221212 & 116.060640 & 4909.62 \\
\hline 99.98 & 3.98 & $676,706.69$ & $4,901.31$ & 37.221212 & 116.060640 & 4904.62 \\
\hline 104.98 & $900,083.88$ & $676,706.65$ & $4,896.31$ & 37.221212 & 116.060640 & 4899.62 \\
\hline 109.98 & $900,083.94$ & $676,706.62$ & 4,891.31 & 37.221212 & 116.060640 & 4894.62 \\
\hline 114.98 & $900,083.89$ & $676,706.61$ & $4,886.31$ & 37.221212 & 116.060640 & 4889.62 \\
\hline 119.97 & $900,083.84$ & $676,706.57$ & $4,881.32$ & 37.221212 & 116.060640 & 4884.62 \\
\hline 124.97 & $900,083.97$ & $676,706.56$ & $4,876.32$ & 37.221212 & 116.060640 & 4879.62 \\
\hline 129.97 & $900,084.02$ & $676,706.53$ & $4,871.32$ & 37.221212 & 116.060641 & 4874.62 \\
\hline 134.97 & $900,083.96$ & $676,706.56$ & $4,866.32$ & 37.221212 & 116.060640 & 4869.63 \\
\hline 139.97 & $900,083.96$ & $676,706.47$ & $4,861.32$ & 37.221212 & 116.060641 & 4864.63 \\
\hline 144.97 & $900,083.94$ & $676,706.49$ & $4,856.32$ & 37.221212 & 116.060641 & 4859.63 \\
\hline 149.97 & $900,083.87$ & $676,706.43$ & $4,851.32$ & 37.221212 & 116.060641 & 4854.63 \\
\hline 154.97 & $900,083.67$ & $676,706.42$ & $4,846.32$ & 37.221211 & 116.060641 & 4849.63 \\
\hline 159.97 & $900,083.65$ & $676,706.40$ & $4,841.32$ & 37.221211 & 116.060641 & 4844.63 \\
\hline 164.97 & $900,083.54$ & $676,706.40$ & $4,836.32$ & 37.221211 & 116.060641 & 4839.63 \\
\hline 169.97 & $900,083.53$ & $676,706.42$ & $4,831.32$ & 37.221211 & 116.060641 & 4834.63 \\
\hline 174.97 & $900,083.53$ & $676,706.44$ & $4,826.32$ & 37.221211 & 116.060641 & 4829.63 \\
\hline 179.97 & $900,083.53$ & $676,706.44$ & $4,821.32$ & 37.221211 & 116.060641 & 4824.63 \\
\hline 184.96 & $900,083.54$ & $676,706.52$ & $4,816.33$ & 37.221211 & 116.060641 & 4819.63 \\
\hline 189.96 & $900,083.54$ & $676,706.52$ & $4,811.33$ & 37.221211 & 116.060641 & 4814.63 \\
\hline
\end{tabular}




\section{U-15n\#5 Deviation Plot - Plan View}

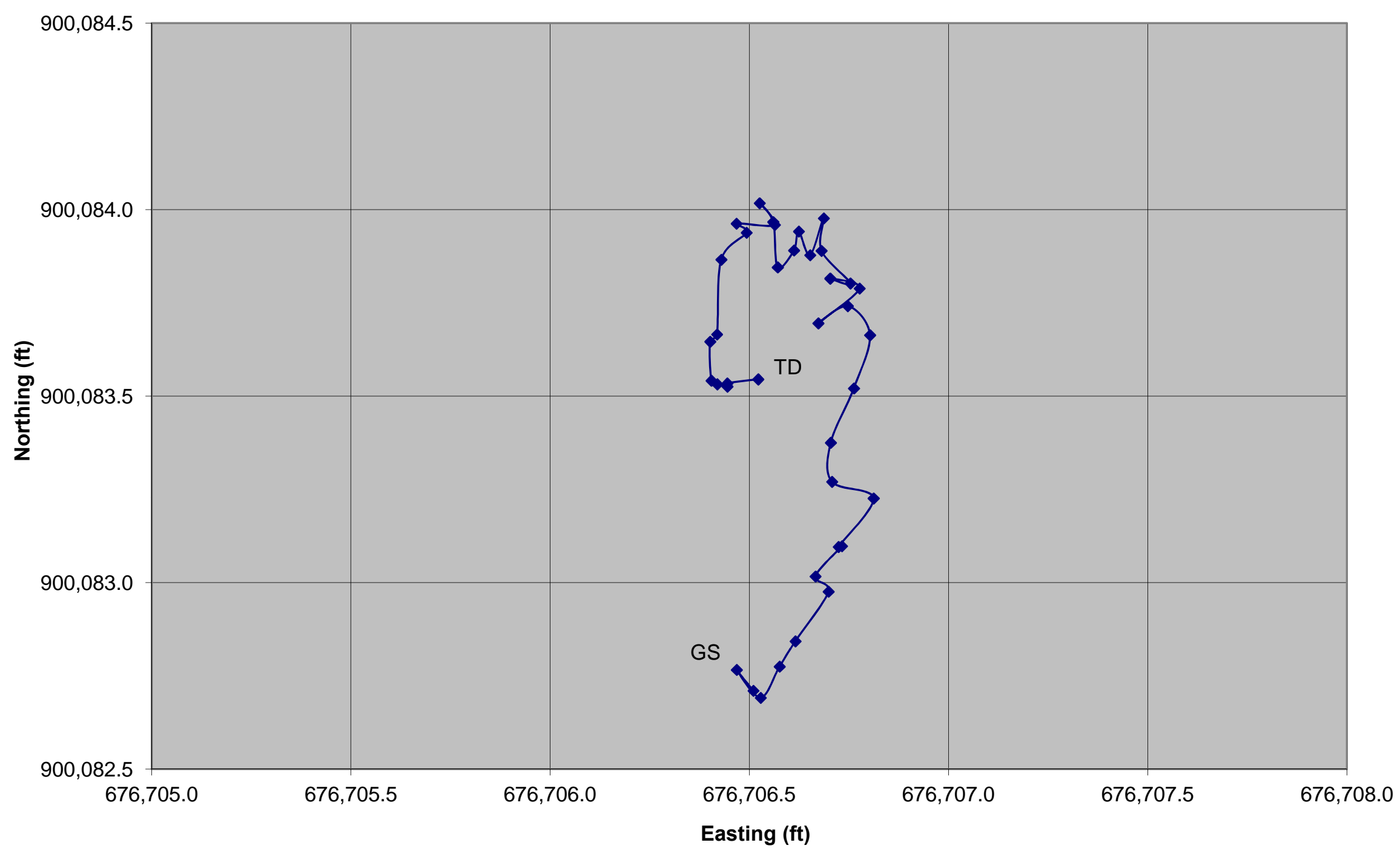


U-15n\#6

\begin{tabular}{|c|c|c|c|c|c|c|}
\hline \multicolumn{2}{|c|}{$\begin{array}{r}\text { Spud: } 8 / 26 / 2010 \\
\text { Compl: } 8 / 27 / 2010\end{array}$} & \multicolumn{2}{|c|}{$\begin{array}{l}\text { BH Dia: } 8 \text { in } \\
\text { TD: } 190 \mathrm{ft} \\
\end{array}$} & \multicolumn{3}{|c|}{$\begin{array}{c}\text { As-Built 12/14/11 } \\
0.62 \mathrm{ft} \text { ags }\end{array}$} \\
\hline \multirow{2}{*}{$\begin{array}{l}\text { Vertical } \\
\text { Depth }\end{array}$} & Northing & Easting & Elevation & Latitude & Longitude & Elevation \\
\hline & \multicolumn{2}{|c|}{ SPC NAD27 ft } & NGVD29 ft & \multicolumn{2}{|c|}{ GEO NAD83 deg } & NAVD88 ft \\
\hline 0.00 & $900,131.75$ & $676,603.86$ & $5,005.07$ & 37.221345 & 116.060992 & 5008.38 \\
\hline 5.00 & $900,131.76$ & $676,603.86$ & $5,000.07$ & 37.221345 & 116.060992 & 5003.38 \\
\hline 10.00 & $900,131.67$ & $676,603.87$ & $4,995.07$ & 37.221345 & 116.060992 & 4998.38 \\
\hline 15.00 & $900,131.70$ & $676,603.91$ & $4,990.07$ & 37.221345 & 116.060992 & 4993.38 \\
\hline 20.00 & $900,131.76$ & $676,603.89$ & $4,985.07$ & 37.221345 & 116.060992 & 4988.38 \\
\hline 25.00 & $900,131.78$ & $676,603.91$ & $4,980.07$ & 37.221345 & 116.060992 & 4983.38 \\
\hline 30.00 & $900,131.73$ & $676,603.96$ & $4,975.07$ & 37.221345 & 116.060992 & 4978.38 \\
\hline 35.00 & 31.70 & $676,604.02$ & $4,970.07$ & 37.221345 & 116.060992 & 4973.38 \\
\hline 40.00 & $900,131.65$ & $676,604.07$ & $4,965.07$ & 37.221345 & 116.060991 & 4968.38 \\
\hline 45.00 & $900,131.61$ & $676,604.12$ & $4,960.07$ & 37.221345 & 116.060991 & 4963.38 \\
\hline 50.00 & $900,131.56$ & $676,604.15$ & $4,955.07$ & 37.221344 & 116.060991 & 4958.38 \\
\hline 55.00 & $900,131.52$ & $676,604.20$ & $4,950.07$ & 37.221344 & 116.060991 & 4953.38 \\
\hline 59.99 & $900,131.43$ & $676,604.28$ & $4,945.08$ & 37.221344 & 116.060991 & 4948.38 \\
\hline 64.99 & $900,131.49$ & $676,604.37$ & $4,940.08$ & 37.221344 & 116.060990 & 4943.38 \\
\hline 69.99 & $900,131.40$ & $676,604.34$ & $4,935.08$ & 37.221344 & 116.060990 & 4938.39 \\
\hline 74.99 & $900,131.46$ & $676,604.44$ & $4,930.08$ & 37.221344 & 116.060990 & 4933.39 \\
\hline 79.99 & $900,131.38$ & $676,604.45$ & $4,925.08$ & 37.221344 & 116.060990 & 4928.39 \\
\hline 84.98 & $900,131.14$ & $676,604.44$ & $4,920.09$ & 37.221343 & 116.060990 & 4923.39 \\
\hline 89.98 & 900,1 & $676,604.40$ & $4,915.09$ & 37.221343 & 116.060990 & 4918.39 \\
\hline 94.98 & 1.22 & $676,604.48$ & 4,91 & 37.221343 & 116.060990 & 4913.39 \\
\hline 99.98 & $900,131.16$ & $676,604.52$ & $4,905.09$ & 37.221343 & 116.060990 & 4908.39 \\
\hline 104.98 & $900,131.12$ & $676,604.58$ & $4,900.09$ & 37.221343 & 116.060990 & 4903.40 \\
\hline 109.98 & $900,131.07$ & $676,604.70$ & $4,895.09$ & 37.221343 & 116.060989 & 4898.40 \\
\hline 114.98 & $900,131.17$ & $676,604.80$ & $4,890.09$ & 37.221343 & 116.060989 & 4893.40 \\
\hline 119.98 & $900,131.11$ & $676,604.75$ & $4,885.09$ & 37.221343 & 116.060989 & 4888.40 \\
\hline 124.97 & $900,131.16$ & $676,605.02$ & $4,880.10$ & 37.221343 & 116.060988 & 4883.41 \\
\hline 129.97 & $900,131.04$ & $676,605.02$ & $4,875.10$ & 37.221343 & 116.060988 & 4878.41 \\
\hline 134.97 & $900,130.94$ & $676,605.07$ & $4,870.10$ & 37.221343 & 116.060988 & 4873.41 \\
\hline 139.97 & $900,131.00$ & $676,605.13$ & $4,865.10$ & 37.221343 & 116.060988 & 4868.41 \\
\hline 144.97 & $900,130.86$ & $676,605.11$ & $4,860.10$ & 37.221342 & 116.060988 & 4863.41 \\
\hline 149.97 & $900,130.82$ & $676,605.11$ & $4,855.10$ & 37.221342 & 116.060988 & 4858.41 \\
\hline 154.97 & $900,130.78$ & $676,605.10$ & $4,850.10$ & 37.221342 & 116.060988 & 4853.41 \\
\hline 159.96 & $900,130.73$ & $676,605.10$ & $4,845.11$ & 37.221342 & 116.060988 & 4848.41 \\
\hline 164.96 & $900,130.72$ & $676,605.14$ & $4,840.11$ & 37.221342 & 116.060988 & 4843.41 \\
\hline 169.96 & $900,130.70$ & $676,605.18$ & $4,835.11$ & 37.221342 & 116.060988 & 4838.41 \\
\hline 174.96 & $900,130.63$ & $676,605.27$ & $4,830.11$ & 37.221342 & 116.060987 & 4833.41 \\
\hline 179.96 & $900,130.57$ & $676,605.26$ & $4,825.11$ & 37.221342 & 116.060987 & 4828.41 \\
\hline 184.96 & $900,130.51$ & $676,605.27$ & $4,820.11$ & 37.221341 & 116.060987 & 4823.42 \\
\hline 189.96 & $900,130.43$ & $676,605.37$ & $4,815.11$ & 37.221341 & 116.060987 & 4818.42 \\
\hline
\end{tabular}




\section{U-15n\#6 Deviation Plot - Plan view}

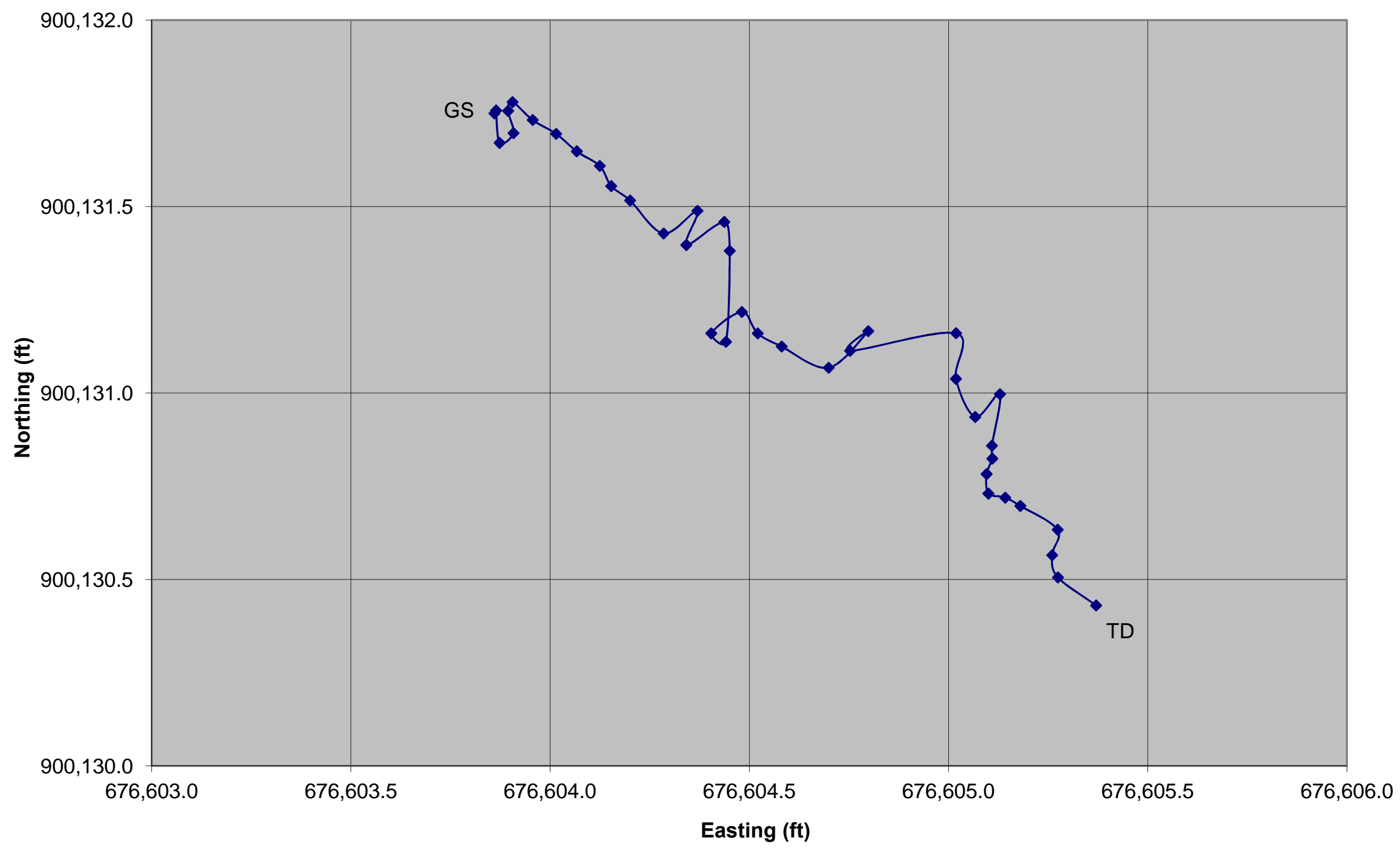


Borehole Deviation - Plan View - Deepest Point Shown By Open Square

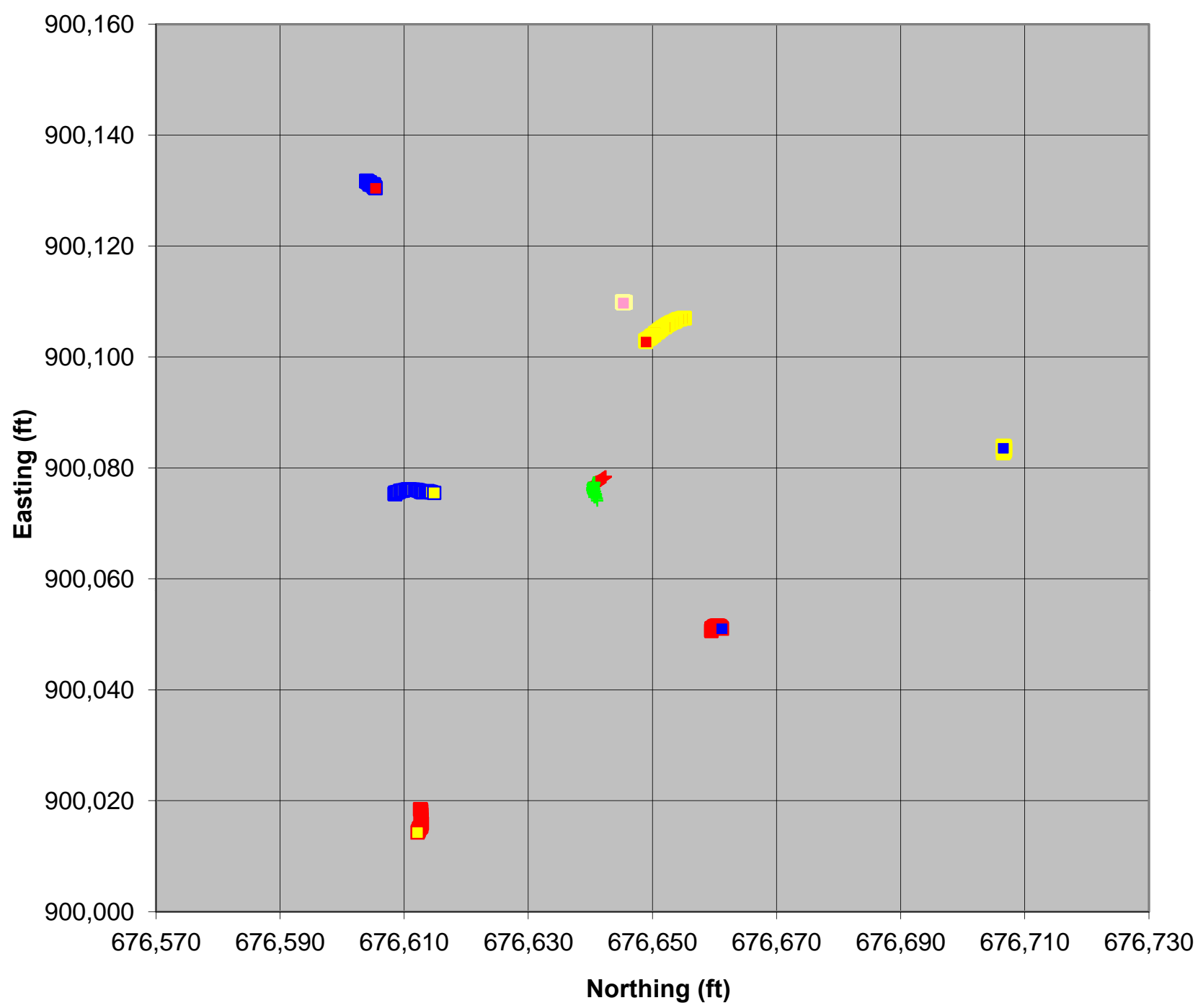

+ U-15n Core
+ U-15n Source
$\square U-15 n \# 1$
$\square U-15 n \# 1 A$
$\square U-15 n \# 2$
$\square U-15 n \# 3$
$\square U-15 n \# 4$
$\square U-15 n \# 5$
$\square U-15 n \# 6$




\section{APPENDIX E Data for U-15n Core Hole:}

\section{Appendix E-1: RQD Data}

Appendix E-2: List of Preserved Samples

Appendix E-3: Fracture Log (from visual evaluation) 


\section{Appendix E-1 \\ Rock Quality Designation (RQD) Data for the U-15n Core Hole (Including RQD Procedure Information)}


U-15n Core Hole

\begin{tabular}{|r|r|r|r|r|r|r|r|}
\hline \multicolumn{1}{r|}{ Run\# } & Run Top & \multicolumn{1}{c|}{$\begin{array}{r}\text { Run } \\
\text { Bottom }\end{array}$} & $\begin{array}{c}\text { Amount } \\
\text { Drilled }\end{array}$ & \multicolumn{1}{c|}{ Loss } & Sound & Run Top & \multicolumn{1}{c|}{ RQD } \\
\hline 1 & 7.3 & 16.5 & 9.2 & 1.3 & 6.7 & 7.3 & 73 \\
\hline 2 & 16.5 & 26.5 & 10.0 & 0.2 & 5.2 & 16.5 & 52 \\
\hline 3 & 26.5 & 36.5 & 10.0 & 0.0 & 8.1 & 26.5 & 81 \\
\hline 4 & 36.5 & 46.5 & 10.0 & 0.0 & 8.1 & 36.5 & 81 \\
\hline 5 & 46.5 & 56.5 & 10.0 & 0.0 & 9.3 & 46.5 & 93 \\
\hline 6 & 56.5 & 66.5 & 10.0 & 0.0 & 8.0 & 56.5 & 80 \\
\hline 7 & 66.5 & 76.5 & 10.0 & 0.0 & 9.6 & 66.5 & 96 \\
\hline 8 & 76.5 & 86.5 & 10.0 & 0.0 & 7.1 & 76.5 & 71 \\
\hline 9 & 86.5 & 96.5 & 10.0 & 0.1 & 8.7 & 86.5 & 87 \\
\hline 10 & 96.5 & 106.5 & 10.0 & 0.0 & 8.0 & 96.5 & 80 \\
\hline 11 & 106.5 & 116.5 & 10.0 & 0.0 & 9.5 & 106.5 & 95 \\
\hline 12 & 116.5 & 126.5 & 10.0 & 0.0 & 7.9 & 116.5 & 79 \\
\hline 13 & 126.5 & 136.5 & 10.0 & 0.0 & 9.6 & 126.5 & 96 \\
\hline 14 & 136.5 & 146.5 & 10.0 & 0.0 & 10.0 & 136.5 & 100 \\
\hline 15 & 146.5 & 156.5 & 10.0 & 0.2 & 9.3 & 146.5 & 93 \\
\hline 16 & 156.5 & 166.5 & 10.0 & 0.0 & 7.7 & 156.5 & 77 \\
\hline 17 & 166.5 & 176.5 & 10.0 & 0.0 & 7.9 & 166.5 & 79 \\
\hline 18 & 176.5 & 186.5 & 10.0 & +0.2 & 9.9 & 176.5 & 99 \\
\hline 19 & 186.5 & 196.5 & 10.0 & 0.0 & 9.2 & 186.5 & 92 \\
\hline
\end{tabular}

Rock Quality Designation (RQD) logging of core is a standard, internationally accepted means of estimating rock quality for engineering purposes. The technique has been used for more than 40 years, and a large database of experience has been built (Deere and Deere, 1988; 1989). The RQD is modified core-recovery percentage in which all sound core pieces more than 4 inches (100 millimeters) long are summed and divided by the length of the core run (see Figure D-6 in the following excerpt). Thus, RQD logging is basically a measurement of the percentage of "good" rock recovered from an interval of a borehole.

The following pages are an excerpt from NSTec Organization Procedure OP-2152.203, "Rock Descriptions," describing the method for RQD logging.

References:

Deere, D. U., and D. W. Deere, 1988. "The Rock Quality Designation (RQD) Index in Practice." In Proceedings of Symposium on Rock Classification Systems for Engineering Purposes. ASTM Special Technical Publications 984, Philadelphia, pp. 91-101.

Deere, D. U., and D. W. Deere, 1989. Rock Quality Designation (RQD) after Twenty Years. U.S. Army Corps of Engineers Report No. GL-89-1, 92 p. 
NATIONAL SECURITY TECHNOLOGIES ORGANIZATION PROCEDURE

\begin{tabular}{|l|l|l}
\hline Document Number: OP-2152.203 & Rev. $\mathbf{0}$ & Effective Date: 5/2/2011 \\
\hline
\end{tabular}

APPENDIX D (continued)

Guidelines for Measurements to Support Rock Mass Classification

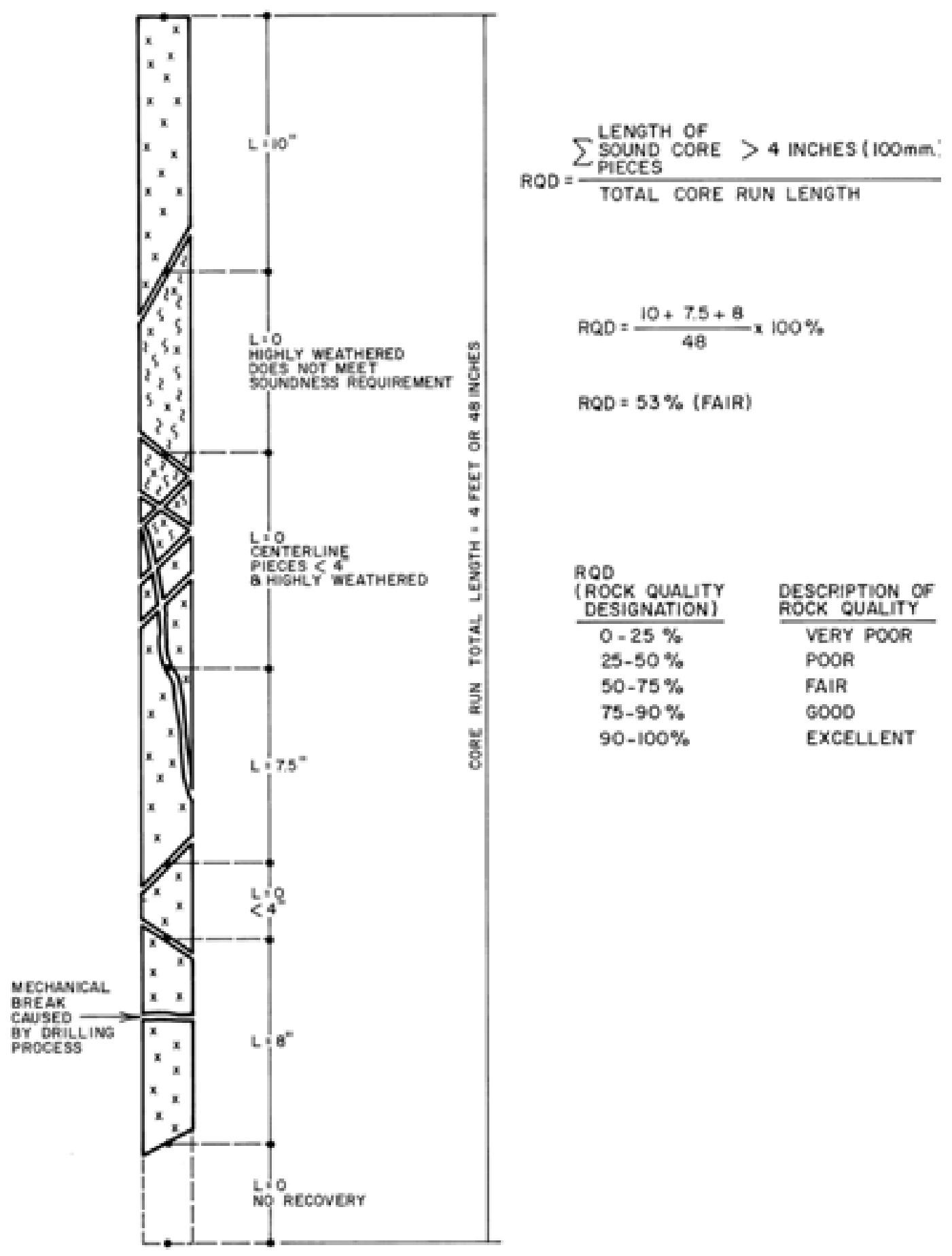

Figure D-6. Example of How to Measure Core Pieces to Determine RQD (from Deere and Deere, 1989) 
NATIONAL SECURITY TECHNOLOGIES ORGANIZATION PROCEDURE

\begin{tabular}{|l|l|l|}
\hline Document Number: OP-2152.203 & Rev. $\mathbf{0}$ & \multicolumn{2}{|l|}{ Effective Date: $\mathbf{5 / 2 / 2 0 1 1}$} \\
\hline Document Title: Rock Descriptions & Page $\mathbf{4 6}$ of $\mathbf{5 5}$ \\
\hline
\end{tabular}

\section{APPENDIX D (continued) \\ Guidelines for Measurements to Support Rock Mass Classification \\ Section D-5: RQD Logging (continued)}

\subsection{METHOD}

2.1 RQD can be measured on a range of core sizes, but its use on the very smallest diameter cores (i.e., "BQ" and "BX") is discouraged. Core segment lengths should be measured as shown in Figure D-8. Core pieces either side of a break caused by the drilling process should be fitted together and counted as one piece. Determination of whether a break is natural or due to drilling may be difficult, but generally natural joints and fractures can be recognized by the presence of slickensides, polished surfaces, or mineral coatings. Drilling-induced breaks typically have a rougher, more jagged, fresh-looking appearance (Figure D-7).

2.2 Because some clay-rich rocks such as shales or claystones may break into smaller pieces with time or due to drying, the RQD should be done at the drill site while the core is fresh. If break-up of the core with time is observed, this should be noted on the core log.

2.3 Data required to determine RQD on core should be recorded on Form FRM-1078, "Core Data Sheet" (this sheet may also be used for recording Core Index $(\mathrm{Cl})$ data [see Appendix E]). For both applications, the following data must be recorded on each form:

- Hole name

- Project

- Geologist's name

- Total depth of hole

2.3.1 Similar data are recorded for these two types of core quality measurements (RQD and $\mathrm{Cl}$ ), including those listed below. Refer to Appendix $\mathrm{E}$ of this procedure for more information on collection of these data.

- $\quad$ Core run number

- Amount drilled

- Drilled interval

- Amount recovered

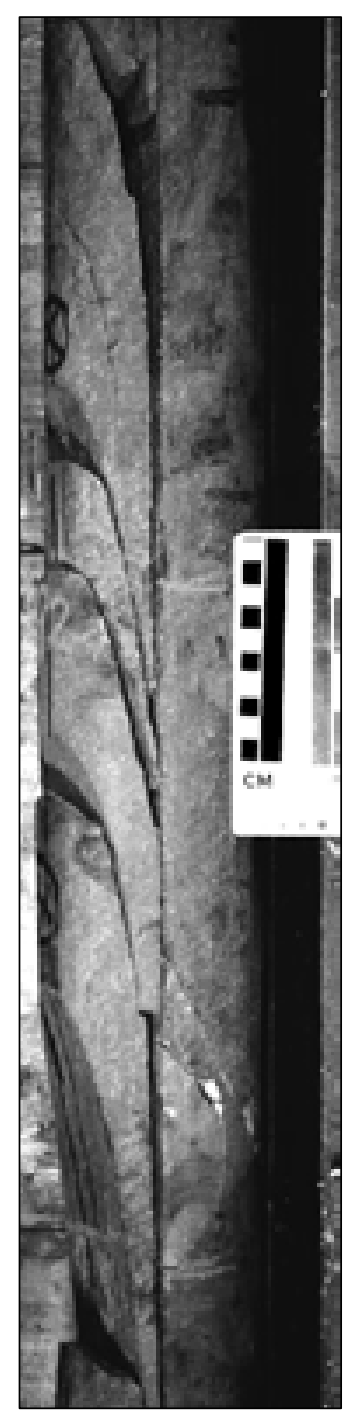

Figure D-7. Photo of Drilling-Induced Break in Core (petal centerline fracture)

2.4 The RQD determination requires measurement in each run of the total amount "sound" core. Sound core pieces are those 4 in. or longer that have not been weakened by weathering or other alteration. For each run, the RQD is calculated by dividing the length of sound core by the total length of core drilled, to derive a percentage of sound rock for that run. For core on which $\mathrm{Cl}$ is not required, the "Joints" and "Cl" columns on FRM-1078 can be crossed out. 
NATIONAL SECURITY TECHNOLOGIES ORGANIZATION PROCEDURE

\begin{tabular}{|l|l|l|}
\hline Document Number: OP-2152.203 & Rev. $\mathbf{0}$ & \multicolumn{1}{l|}{ Effective Date: 5/2/2011 } \\
\hline Document Title: Rock Descriptions & Page $\mathbf{4 7}$ of $\mathbf{5 5}$ \\
\hline
\end{tabular}

APPENDIX D (continued)

Guidelines for Measurements to Support Rock Mass Classification
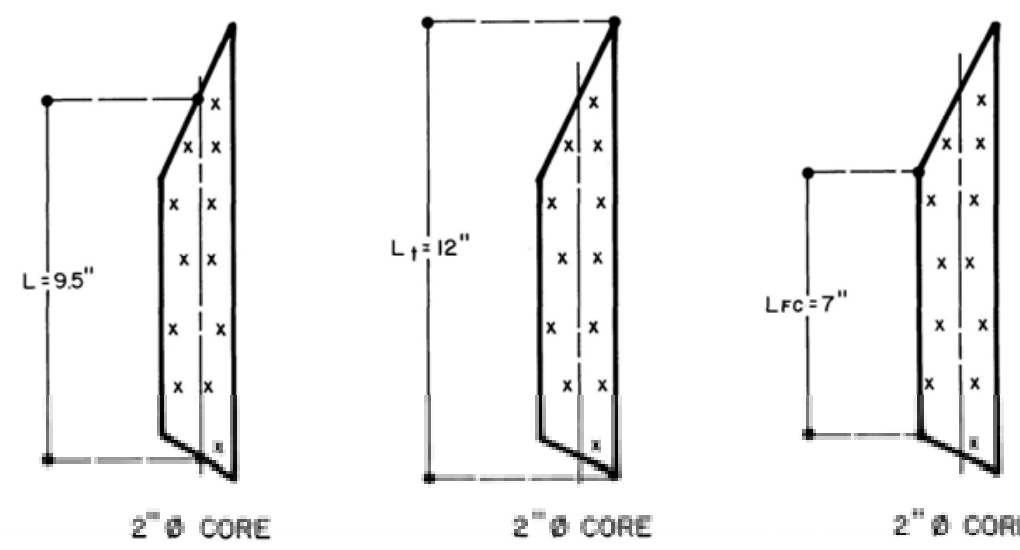

2" D CORE

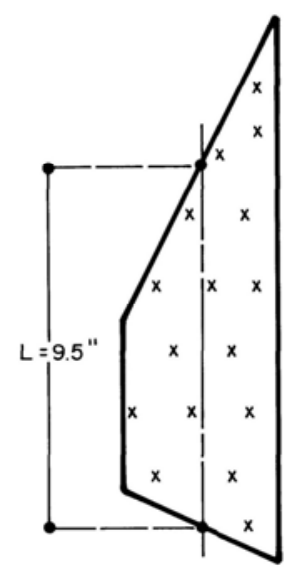

4"D CORE

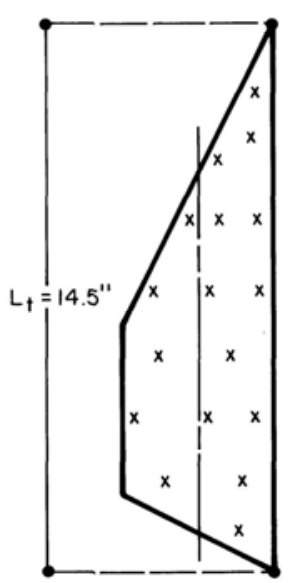

4"ø CORE

TIP TO TIP

8. INCORRECT METHCO FOR COAE LENGTH MEASURENENT - LENITH DEPENDENT ON CORE DIA.

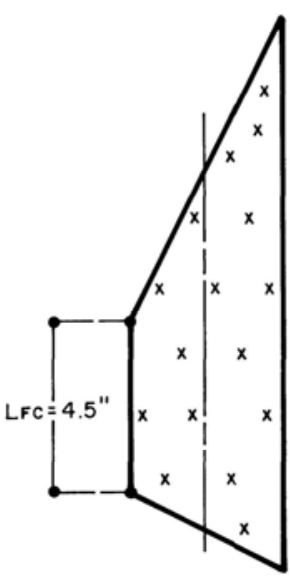

$4^{\prime \prime}$ ब CORE

FULLY CIRCULAR

C. NCORERECT METHOO FOR COAE LENGTH MEASUREMENT - LENGTH DEPENDENT ON COAE DIA
LENOTH MEASURENENT - LENOTH OF CORE

ANCPENDENT OF CORE DIA. 
Appendix E-2

List of Preserved Samples from the U-15n Core Hole 
U-15n

Preserved Core Samples

\begin{tabular}{|c|c|c|c|}
\hline Top & Bottom & Length & Notes \\
\hline (feet) & (feet) & (feet) & \\
\hline 10.1 & 11.3 & 1.2 & \\
\hline 19.9 & 21.0 & 1.1 & \\
\hline 22.3 & 23.7 & 1.4 & \\
\hline 33.7 & 34.4 & 0.7 & \\
\hline 35.6 & 36.5 & 0.9 & \\
\hline 40.1 & 41.1 & 1.0 & \\
\hline 45.2 & 46.1 & 0.9 & \\
\hline 49.3 & 50.2 & 0.9 & \\
\hline 55.6 & 56.5 & 0.9 & \\
\hline 60.1 & 60.8 & 0.7 & \\
\hline 65.5 & 66.1 & 0.6 & \\
\hline 66.1 & 66.5 & 0.4 & \\
\hline 68.3 & 69.1 & 0.8 & \\
\hline 73.5 & 74.4 & 0.9 & \\
\hline 76.5 & 77.7 & 1.2 & \\
\hline 85.8 & 86.5 & 0.7 & \\
\hline 91.2 & 91.9 & 0.7 & \\
\hline 95.3 & 96.4 & 1.1 & \\
\hline 98.4 & 99.1 & 0.7 & \\
\hline 102.0 & 102.9 & 0.9 & \\
\hline 108.8 & 109.5 & 0.7 & \\
\hline 113.3 & 114.2 & 0.9 & \\
\hline 117.7 & 118.6 & 0.9 & \\
\hline 120.7 & 121.5 & 0.8 & \\
\hline 127.9 & 128.5 & 0.6 & \\
\hline 130.7 & 131.5 & 0.8 & \\
\hline 138.1 & 139.0 & 0.9 & \\
\hline 143.3 & 144.0 & 0.7 & \\
\hline 148.1 & 148.8 & 0.7 & \\
\hline 152.4 & 153.1 & 0.7 & \\
\hline 156.5 & 157.5 & 1.0 & healed frac \\
\hline 163.9 & 164.5 & 0.6 & \\
\hline 169.2 & 169.9 & 0.7 & healed frac \\
\hline 175.9 & 176.5 & 0.6 & \\
\hline 181.2 & 181.9 & 0.7 & healed frac \\
\hline 185.9 & 186.5 & 0.7 & \\
\hline 187.7 & 188.6 & 0.9 & healed frac \\
\hline 194.2 & 194.8 & 0.6 & \\
\hline
\end{tabular}




\section{Appendix E-3}

NSTec Fracture Log for the U-15n Core Hole (from visual evaluation) 


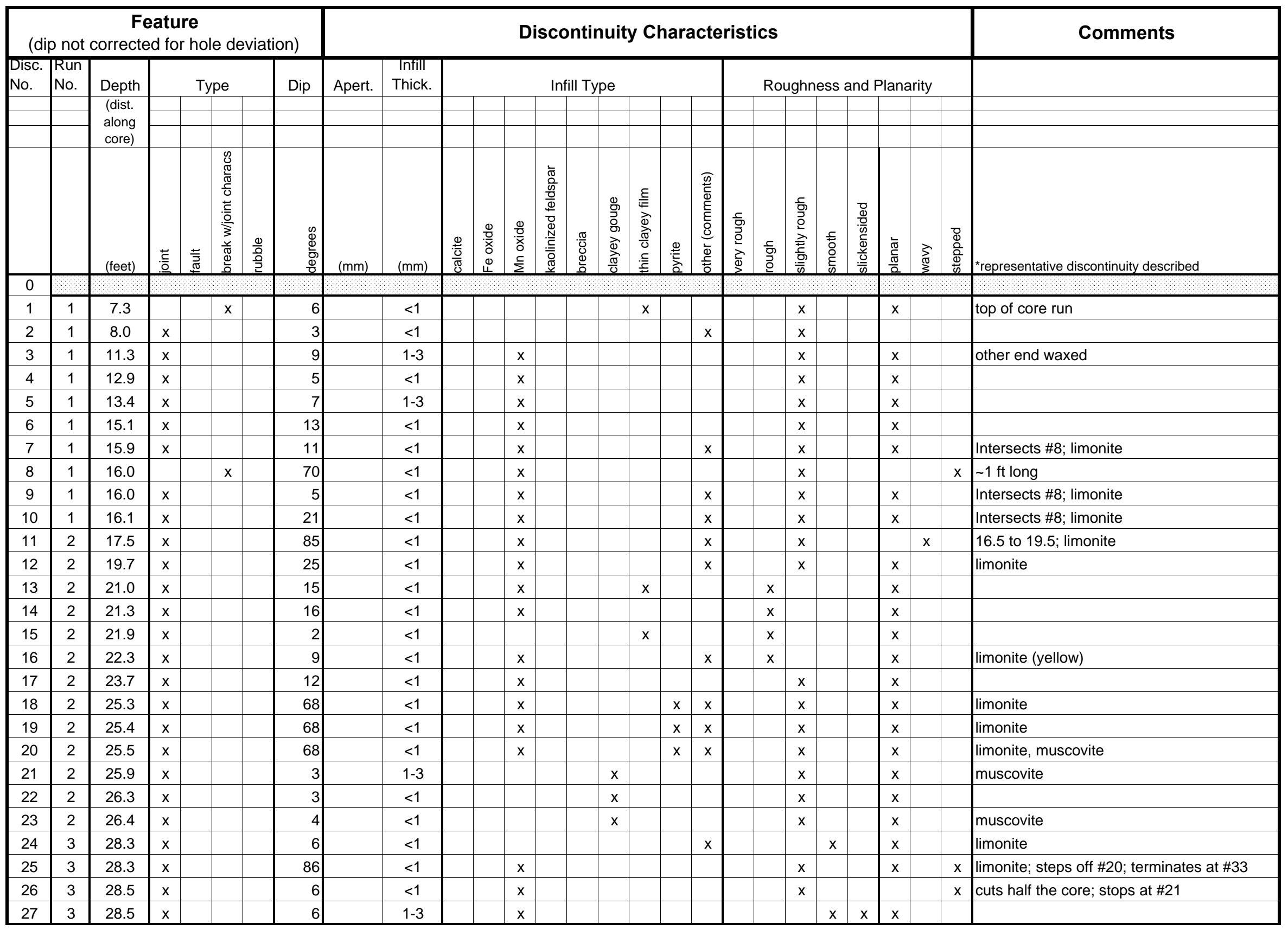




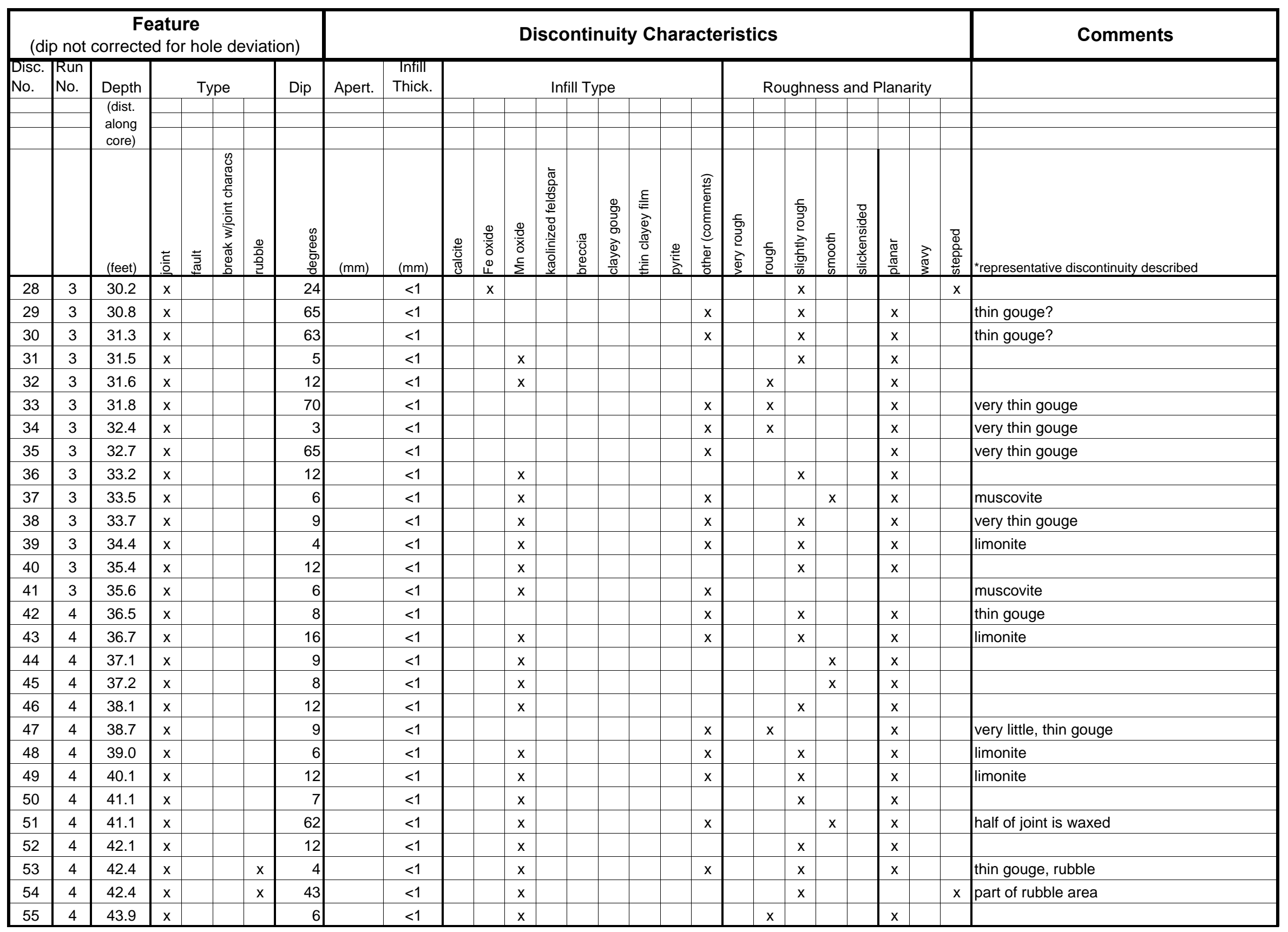




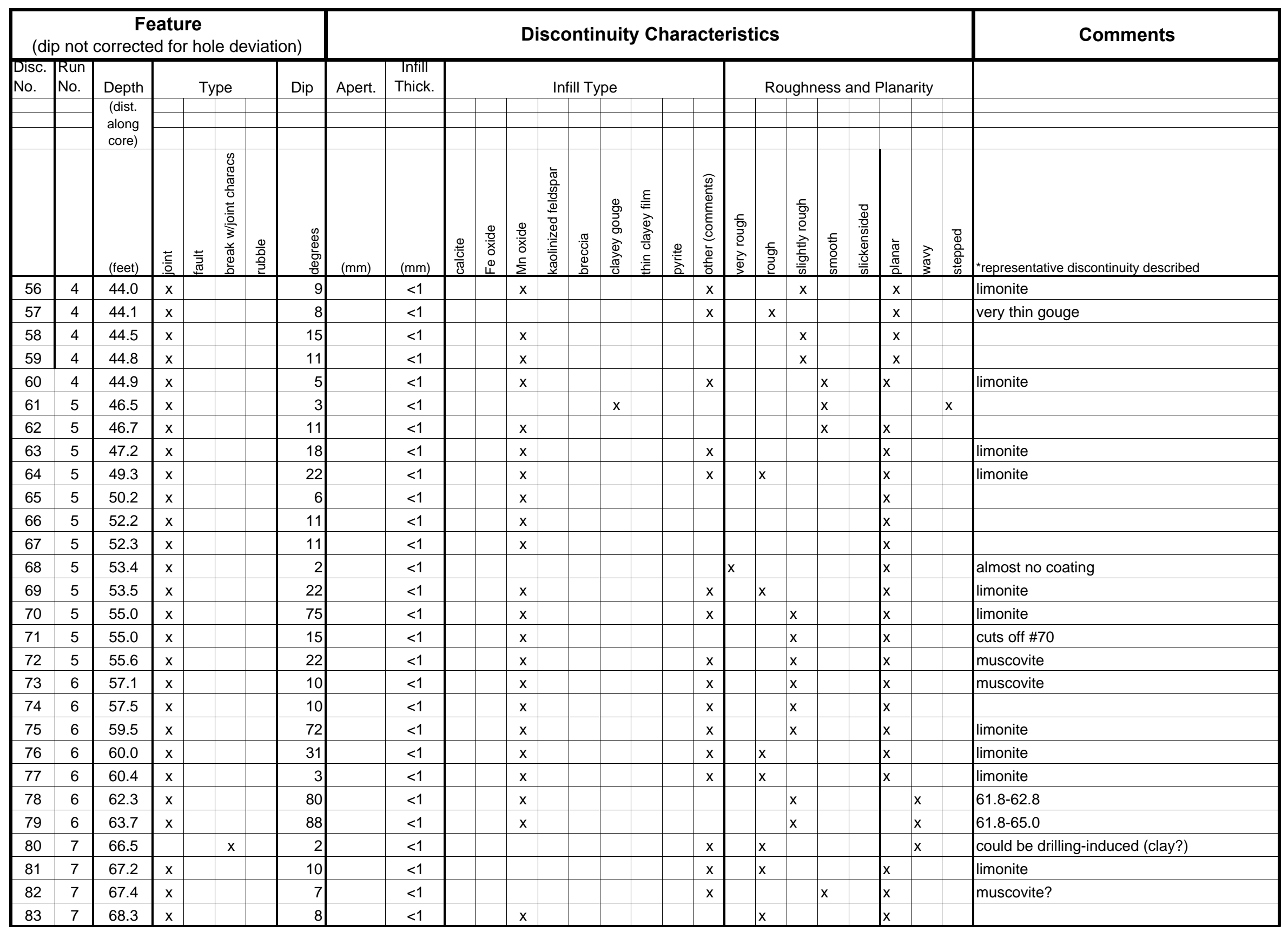




\begin{tabular}{|c|c|c|c|c|c|c|c|c|c|c|c|c|c|c|c|c|c|c|c|c|c|c|c|c|c|c|c|}
\hline \multicolumn{8}{|c|}{$\begin{array}{c}\text { Feature } \\
\text { (dip not corrected for hole deviation) }\end{array}$} & \multicolumn{19}{|c|}{ Discontinuity Characteristics } & \multirow[t]{2}{*}{ Comments } \\
\hline $\begin{array}{l}\text { Disc. } \\
\text { No. }\end{array}$ & $\begin{array}{l}\text { Run } \\
\text { No. }\end{array}$ & Depth & & & pe & & Dip & Apert. & $\begin{array}{l}\text { Infill } \\
\text { Thick. }\end{array}$ & \multicolumn{9}{|c|}{ Infill Type } & \multicolumn{8}{|c|}{ Roughness and Planarity } & \\
\hline & & core) & & & & & & & & & & & & & & & & & & & & & & & & & \\
\hline & & (feet) & : & 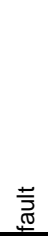 & 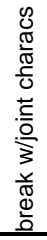 & $\frac{0}{\frac{0}{2}}$ & $\begin{array}{l}\mathscr{D} \\
\mathbb{W} \\
\bar{\Xi} \\
\frac{\mathbb{Q}}{0} \\
\end{array}$ & $(\mathrm{~mm})$ & $(\mathrm{mm})$ & 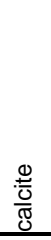 & 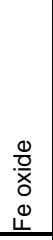 & 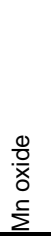 & 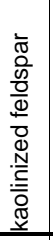 & 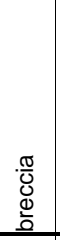 & 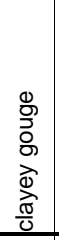 & 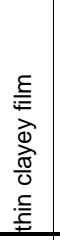 & 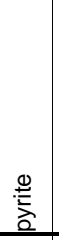 & 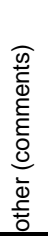 & $\begin{array}{l}\frac{c}{\overline{0}} \\
\frac{0}{0} \\
\frac{0}{2} \\
\frac{0}{0} \\
\end{array}$ & \begin{tabular}{|} 
\\
동 \\
임 \\
\end{tabular} & 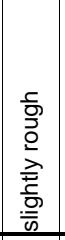 & 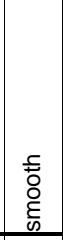 & $\begin{array}{l}\frac{D}{d} \\
\frac{d}{n} \\
\frac{0}{d} \\
\frac{.0}{\omega} \\
\frac{.0}{\omega} \\
\end{array}$ & \begin{tabular}{|l}
$\frac{1}{\pi}$ \\
$\frac{\pi}{2}$ \\
\end{tabular} & $\underset{\substack{\pi \\
3}}{\substack{\pi \\
3}}$ & $\begin{array}{l}\frac{8}{0} \\
\frac{0}{0} \\
\frac{0}{\omega} \\
\end{array}$ & *representative discontinuity described \\
\hline 84 & 7 & 71.0 & $x$ & & & & 3 & & $<1$ & & & $x$ & & & & & & & & \begin{tabular}{|l|l}
$x$ \\
\end{tabular} & & & & $x$ & & & \\
\hline 85 & 7 & 72.7 & $x$ & & & & 9 & & $<1$ & & & $\mathrm{x}$ & & & & & & & & & $x$ & & & $x$ & & & \\
\hline 86 & 7 & 75.1 & $x$ & & & & 2 & & $<1$ & & & & & & & & & $\mathrm{x}$ & & & & $x$ & & $x$ & & & thin gouge \\
\hline 87 & 8 & 78.1 & $x$ & & $x$ & & 75 & & $<1$ & & & & & & & & & & $x$ & & & & & & $x$ & & fault zone starts at 77.7 \\
\hline 88 & 8 & 79.2 & $x$ & & $x$ & & 80 & & $<1$ & & & & & & & & & $x$ & & $x$ & & & & & $x$ & & thin gouge; "fault zone" \\
\hline 89 & 8 & 79.5 & $x$ & & $x$ & & 80 & & $<1$ & & & & & & & & & $x$ & & $x$ & & & & & $x$ & & thin gouge; "fault zone" \\
\hline 90 & 8 & 81.0 & $x$ & & $x$ & & 70 & & $<1$ & & & $x$ & & & & & & & & & & & $x$ & & & & part of "fault zone" \\
\hline 91 & 8 & 81.4 & $x$ & & $x$ & & 82 & & $<1$ & & & $x$ & & & & & & & & & & & $x$ & & $x$ & & part of "fault zone" \\
\hline 92 & 8 & 83.0 & $x$ & & $x$ & & 80 & & $<1$ & & & $x$ & & & & & & & & & & & $x$ & & $x$ & & part of "fault zone" \\
\hline 93 & 8 & 83.3 & $x$ & & $x$ & & 60 & & $<1$ & & & $x$ & & & & & & & & & $x$ & & $x$ & & & & part of "fault zone" \\
\hline 94 & 8 & 84.2 & $\mathrm{x}$ & & $x$ & & 65 & & $<1$ & & & & & & & & & $x$ & & & $x$ & & & & & & fault zone ends wtih this joint \\
\hline 95 & 8 & 85.6 & $x$ & & & & 65 & & $<1$ & & & $x$ & & & & & & & & $x$ & & & & $x$ & & & \\
\hline 96 & 9 & 87.4 & $x$ & & & & 14 & & $<1$ & & & $x$ & & & & & & & & $x$ & & & & $x$ & & & \\
\hline 97 & 9 & 88.5 & $x$ & & & & 80 & & $<1$ & & & $x$ & & & & & & & & & $x$ & & & $x$ & & & possibly 2 slip surfaces \\
\hline 98 & 9 & 89.3 & $x$ & & & & 8 & & $<1$ & & & & & $\mathrm{x}$ & & & & & & & & $x$ & & $x$ & & & \\
\hline 99 & 9 & 91.3 & $x$ & & & & 8 & & $<1$ & & & $x$ & & & & & & & & $x$ & & & & $x$ & & & \\
\hline 100 & 9 & 91.9 & $x$ & & & & 9 & & $<1$ & & & & & $\mathrm{x}$ & & & & & & & $x$ & & & $x$ & & & \\
\hline 101 & 9 & 93.1 & $x$ & & & & 13 & & $<1$ & & & $x$ & & & & & & & & & $x$ & & & $x$ & & & \\
\hline 102 & 10 & 100.3 & $x$ & & & & 12 & & $<1$ & & & $x$ & & & & & & & & $x$ & & & & $x$ & & & \\
\hline 103 & 10 & 102.0 & $x$ & & & & 8 & & 1.0 & & & $\mathrm{x}$ & & & & & & $\mathrm{x}$ & $x$ & & & & & $x$ & & & Ilimonite; quartz crystals \\
\hline 104 & 10 & 102.9 & $x$ & & & & 10 & & $<1$ & & & & & & & & & $x$ & & & & $x$ & & $x$ & & & Ilimonite \\
\hline 105 & 10 & 104.7 & $x$ & $x$ & & & 80 & & $<1$ & & & $x$ & & & & & & & & & $x$ & & & $x$ & & & fault zone starts at 104.0 \\
\hline 106 & 10 & 105.2 & $\mathrm{x}$ & $x$ & & & 80 & & $<1$ & & & & & & & & & $x$ & & & & $x$ & & & & & thin gouge; part of fault zone \\
\hline 107 & \multicolumn{3}{|c|}{$106.0-106.5$} & & & $\mathrm{x}$ & & & & & & & & & & & & & & & & & & & & & rubble zone \\
\hline 108 & 11 & 106.6 & $x$ & $x$ & & & 84 & & $<1$ & & & & & & & & & $x$ & & & $x$ & & & $x$ & & & thin gouge \\
\hline 109 & 11 & 106.8 & $x$ & $x$ & & & 7 & & $<1$ & & & & & & & & & $x$ & & & $x$ & & & $x$ & & & limonite \\
\hline 110 & 11 & 107.2 & $x$ & $x$ & & & 76 & & $<1$ & & & & & & & & & $x$ & & & $x$ & & & $x$ & & & part of fault zone \\
\hline 111 & 11 & 107.6 & $x$ & $\mathrm{x}$ & & & 73 & & $<1$ & & & & & & & & & $\mathrm{x}$ & & & $x$ & & & $x$ & & & thin gouge; part of fault zone \\
\hline
\end{tabular}




\begin{tabular}{|c|c|c|c|c|c|c|c|c|c|c|c|c|c|c|c|c|c|c|c|c|c|c|c|c|c|c|c|}
\hline \multicolumn{8}{|c|}{$\begin{array}{c}\text { Feature } \\
\text { (dip not corrected for hole deviation) }\end{array}$} & \multicolumn{19}{|c|}{ Discontinuity Characteristics } & \multirow[t]{2}{*}{ Comments } \\
\hline \multirow[t]{3}{*}{\begin{tabular}{|l|l} 
Disc. \\
No.
\end{tabular}} & \multirow[t]{3}{*}{$\begin{array}{l}\text { Run } \\
\text { No. }\end{array}$} & \multirow{2}{*}{$\begin{array}{c}\text { Depth } \\
\text { (dist. } \\
\text { along } \\
\text { core) }\end{array}$} & \multicolumn{4}{|c|}{ Type } & Dip & Apert. & $\begin{array}{l}\text { Infill } \\
\text { Thick. }\end{array}$ & \multicolumn{9}{|c|}{ Infill Type } & \multicolumn{8}{|c|}{ Roughness and Planarity } & \\
\hline & & & & & & & & & & & & & & & & & & & & & & & & & & & \\
\hline & & & & & & & & & & & & & & & & & & & & & & & & & & & \\
\hline & & (feet) & : & 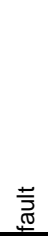 & 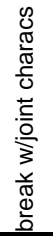 & $\frac{0}{0}$ & $\begin{array}{l}\mathbb{\Xi} \\
\mathbb{\Phi} \\
\mathbb{\Xi} \\
\mathbb{\Phi} \\
\end{array}$ & $(\mathrm{mm})$ & $(\mathrm{mm})$ & $\begin{array}{l}\frac{0}{0} \\
\frac{.0}{\pi} \\
\\
\end{array}$ & 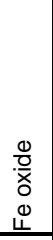 & 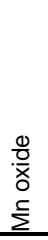 & 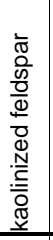 & 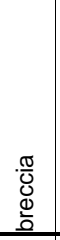 & $\begin{array}{l}\frac{0}{0} \\
\overline{0} \\
\bar{d} \\
\vec{d} \\
\frac{\sigma}{v} \\
\end{array}$ & 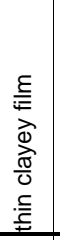 & 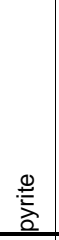 & 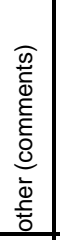 & $\begin{array}{l}\frac{}{\overline{0}} \\
\overline{0} \\
\frac{0}{2} \\
\text { 일 }\end{array}$ & $\begin{array}{l} \\
\text { 등 } \\
\text { 옹 } \\
\end{array}$ & 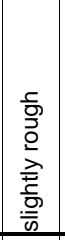 & 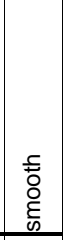 & 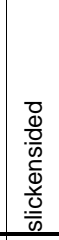 & \begin{tabular}{|l}
$\frac{\pi}{\pi}$ \\
$\frac{\pi}{\alpha}$ \\
\end{tabular} & $\underset{\substack{\pi \\
3}}{\substack{\pi \\
3}}$ & $\begin{array}{l}\frac{0}{0} \\
\frac{0}{0} \\
\frac{0}{\omega} \\
\end{array}$ & *representative discontinuity described \\
\hline 112 & 11 & 108.1 & $\mathrm{x}$ & $x$ & & & 74 & & $<1$ & & & & & & & & & $\mathrm{x}$ & & & $\mathrm{x}$ & & & $x$ & & & thin gouge; end of fault zone \\
\hline 113 & 11 & 108.8 & $\mathrm{x}$ & & & & 8 & & $<1$ & & & $x$ & & & & & & & & $x$ & & & & $x$ & & & \\
\hline 114 & 11 & 111.8 & $\mathrm{x}$ & & & & 76 & & $<1$ & & & $x$ & & & & & & $x$ & & & & $x$ & & & $x$ & & thin gouge \\
\hline 115 & 11 & 114.9 & $x$ & & & & 17 & & $<1$ & & & $\mathrm{x}$ & & & & & & $\mathrm{x}$ & & $x$ & & & & $x$ & & & thin gouge \\
\hline 116 & 12 & 117.0 & $\mathrm{x}$ & & & & 70 & & $<1$ & & & $x$ & & & & & & $x$ & & & $x$ & & & $x$ & & & thin gouge \\
\hline 117 & 12 & 117.7 & $x$ & & & & 4 & & $<1$ & & & & & & & & & $x$ & & & & $x$ & & $x$ & & & limonite \\
\hline 118 & 12 & 121.5 & $x$ & & & & 7 & & $<1$ & & & $x$ & & & & & & & & $x$ & & & & & & $x$ & \\
\hline 119 & 12 & 121.9 & $x$ & & & & 11 & & $<1$ & & & $x$ & & & & & & & & & $x$ & & & $x$ & & & \\
\hline 120 & 12 & 122.2 & $x$ & & & & 14 & & $1-3$ & & & $x$ & & & & & & $x$ & $x$ & & & & & $x$ & & & quartz lined \\
\hline 121 & 12 & 123.7 & $x$ & & & & 12 & & $<1$ & & & & & & & & & $\mathrm{x}$ & & & & & $x$ & $x$ & & & limonite \\
\hline 122 & 12 & 123.9 & $x$ & & & & 18 & & $<1$ & & & $x$ & & & & & & $x$ & & & & $x$ & & & & & limonite \\
\hline 123 & 12 & 124.4 & $x$ & & & & 12 & & $<1$ & & & $x$ & & & & & & $x$ & & & $x$ & & & $x$ & & & limonite \\
\hline 124 & 12 & 124.7 & $x$ & & & & 14 & & $<1$ & & & $x$ & & & & & & & & & $x$ & & & $x$ & & & \\
\hline 125 & 12 & 124.3 & $x$ & & & & 86 & & $<1$ & & & $x$ & & & & & & & & & $x$ & & & $x$ & & & \\
\hline 126 & 12 & 124.5 & $x$ & & & & 12 & & $<1$ & & & $x$ & & & & & & & & & & $x$ & & $x$ & & & \\
\hline 127 & 12 & 125.5 & $x$ & & & & 11 & & $<1$ & & & $x$ & & & & & & $x$ & & & $x$ & & & $x$ & & & thin yellow coating \\
\hline 128 & 12 & 125.8 & $\mathrm{x}$ & & & & 5 & & 1.0 & & & $\mathrm{x}$ & & & & & & & & & $x$ & & & & & $x$ & thin yellow coating \\
\hline 129 & 12 & 126.3 & $\mathrm{x}$ & & & & 7 & & $<1$ & & & & & & & & & & & $x$ & & & & $x$ & & & almost no infill \\
\hline 130 & 13 & 127.4 & $\mathrm{x}$ & & & & 11 & & $1-3$ & & & $\mathrm{x}$ & & & & & & $x$ & & & & $x$ & & $x$ & & & intersected by long high-angle frac (\#131) \\
\hline 131 & 13 & 127.5 & $\mathrm{x}$ & & & & 66 & & $<1$ & & & & & & & & & $x$ & & & & & & & $x$ & & limonite (yellowish) \\
\hline 132 & 13 & 127.9 & $\mathrm{x}$ & & & & 11 & & $<1$ & & & $\mathrm{x}$ & & & & & & $\mathrm{x}$ & & & & $x$ & & $x$ & & & limonite \\
\hline 133 & 13 & 131.5 & $x$ & & & & 13 & & $<1$ & & & & & & & & & $x$ & & & $x$ & & & $x$ & & & limonite \\
\hline 134 & 13 & 132.7 & $x$ & & & & 15 & & $<1$ & & & $x$ & & & & & & $x$ & & & & $x$ & & $x$ & & & limonite \\
\hline 135 & 13 & 133.6 & $x$ & & & & 56 & & 1.0 & & & $x$ & & & & & & $x$ & & & $x$ & & & $x$ & & & limonite \\
\hline 136 & 13 & 134.2 & $x$ & & & & 54 & & $<1$ & & & & & & & & & $x$ & & $x$ & & & & $x$ & & & limonite \\
\hline 137 & 13 & 134.9 & $x$ & & & & 22 & & $<1$ & & & $x$ & & & & & & & $\mathrm{x}$ & & & & & $x$ & & & \\
\hline 138 & 13 & 133.9 & $x$ & & & & 8 & & $<1$ & & & $x$ & & & & & & & & & $x$ & & & & & $x$ & \\
\hline 139 & 13 & 135.7 & $\mathrm{x}$ & & & & 22 & & $<1$ & & & $x$ & & & & & & & & $x$ & & & & $x$ & & & \\
\hline
\end{tabular}




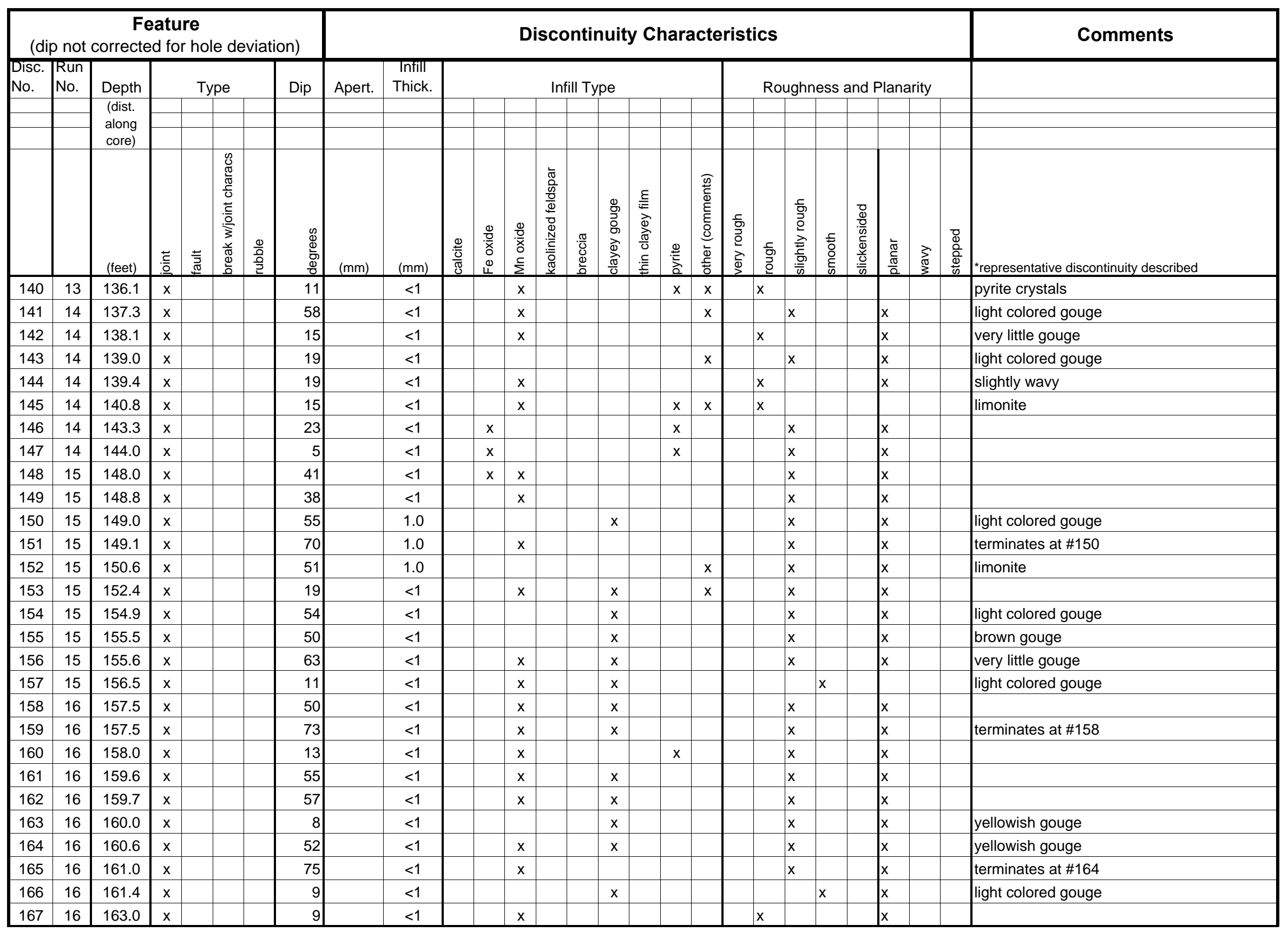




\begin{tabular}{|c|c|c|c|c|c|c|c|c|c|c|c|c|c|c|c|c|c|c|c|c|c|c|c|c|c|c|c|}
\hline \multicolumn{8}{|c|}{$\begin{array}{c}\text { Feature } \\
\text { (dip not corrected for hole deviation) }\end{array}$} & \multicolumn{19}{|c|}{ Discontinuity Characteristics } & \multirow[t]{2}{*}{ Comments } \\
\hline \multirow[t]{3}{*}{\begin{tabular}{|l|} 
Disc. \\
No.
\end{tabular}} & \multirow[t]{3}{*}{$\begin{array}{l}\text { Run } \\
\text { No. }\end{array}$} & \multirow{2}{*}{$\begin{array}{c}\text { Depth } \\
\text { (dist. } \\
\text { along } \\
\text { core) }\end{array}$} & \multicolumn{4}{|c|}{ Type } & Dip & Apert. & $\begin{array}{l}\text { Infill } \\
\text { Thick. }\end{array}$ & \multicolumn{9}{|c|}{ Infill Type } & \multicolumn{8}{|c|}{ Roughness and Planarity } & \\
\hline & & & & & & & & & & & & & & & & & & & & & & & & & & & \\
\hline & & & & & & & & & & & & & & & & & & & & & & & & & & & \\
\hline & & (feet) & : & 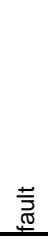 & 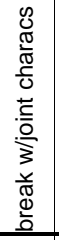 & $\frac{0}{0}$ & $\begin{array}{l}\mathbb{\Xi} \\
\mathbb{\Xi} \\
\mathbb{\Xi} \\
\mathbb{\Phi} \\
\end{array}$ & $(\mathrm{mm})$ & $(\mathrm{mm})$ & 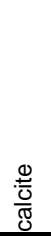 & 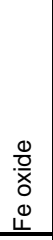 & 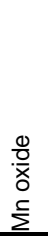 & 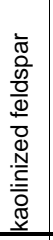 & 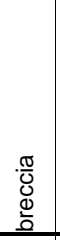 & $\begin{array}{l}\frac{0}{0} \\
\overline{0} \\
\bar{d} \\
\vec{d} \\
\frac{\sigma}{v} \\
\end{array}$ & 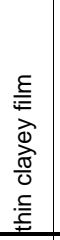 & $\stackrel{0}{\stackrel{0}{2}}$ & 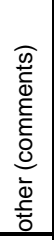 & 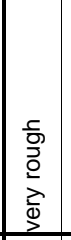 & \begin{tabular}{|c} 
\\
동 \\
임 \\
\end{tabular} & 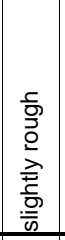 & 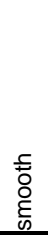 & $\begin{array}{l}\frac{D}{d} \\
\frac{d}{0} \\
\frac{0}{d} \\
\frac{.0}{\omega} \\
\frac{.0}{\omega} \\
\end{array}$ & \begin{tabular}{|l}
$\frac{1}{\pi}$ \\
$\frac{\pi}{2}$ \\
\end{tabular} & $\sum_{\substack{\pi \\
3\\
}}^{\pi}$ & $\begin{array}{l}\frac{0}{0} \\
\frac{0}{2} \\
\frac{0}{v} \\
\end{array}$ & *representative discontinuity described \\
\hline 168 & 16 & 163.3 & $x$ & & & & 4 & & 1.0 & & & $x$ & & & $\mathrm{x}$ & & & & & $\mathrm{x}$ & & & & $x$ & & & \\
\hline 169 & 16 & 163.7 & $\mathrm{x}$ & & & & 58 & & $<1$ & & & $x$ & & & & & & & & & $x$ & & & $x$ & & & \\
\hline 170 & 16 & 165.4 & $\mathrm{x}$ & & & & 6 & & $<1$ & & & & & & $x$ & & & & & & $x$ & & & $x$ & & & light colored gouge \\
\hline 171 & 16 & 166.5 & $\mathrm{x}$ & & & & 7 & & $<1$ & & & & & & & & & & $x$ & & & & & $x$ & & & light colored gouge \\
\hline 172 & 17 & 167.8 & $\mathrm{x}$ & & & & 28 & & $<1$ & & & & & & $x$ & & & & & & $x$ & & & $x$ & & & limonite \\
\hline 173 & 17 & 167.9 & $x$ & & & & 25 & & $<1$ & & & & & & $x$ & & & & & & $x$ & & & $x$ & & & limonite \\
\hline 174 & 17 & 168.0 & $x$ & & & & 67 & & $<1$ & & & $x$ & & & $x$ & & & & & & $x$ & & & $x$ & & & \\
\hline 175 & 17 & 168.6 & $x$ & & & & 69 & & $<1$ & & & & & & $x$ & & & & & $x$ & & & & $x$ & & & $\# 175$ and \#176 intersect \\
\hline 176 & 17 & 169.9 & $x$ & & & & 82 & & $<1$ & & & & & & $x$ & & & & & $x$ & & & & $x$ & & & almost no gouge \\
\hline 177 & 17 & 170.8 & $x$ & & & & 67 & & $<1$ & & & $x$ & & & $x$ & & & & & & $x$ & & & $x$ & & & \\
\hline 178 & 17 & 171.9 & $\mathrm{x}$ & & & & 20 & & $<1$ & & & $x$ & & & $x$ & & & & & & $x$ & & & $x$ & & & \\
\hline 179 & 17 & 172.8 & $x$ & & & & 80 & & $<1$ & & & $x$ & & & & & & & & & $x$ & & & $x$ & & & $\# 179$ cuts $\# 180$ \\
\hline 180 & 17 & 173.2 & $x$ & & & & 8 & & $1-3$ & & & & & & $x$ & & & & & & $x$ & & & $x$ & & & yellowish gouge \\
\hline 181 & 17 & 174.3 & $x$ & & & & 25 & & $<1$ & & & $x$ & & & & & & & & & $x$ & & & $x$ & & & \\
\hline 182 & 17 & 174.6 & $\mathrm{x}$ & & & & 15 & & 1.0 & & & $x$ & & & & & & & & & $x$ & & & $x$ & & & \\
\hline 183 & 17 & 174.7 & $x$ & & & & 11 & & $<1$ & & & & & & $x$ & & & & & $x$ & & & & $x$ & & & yellowish soft gouge \\
\hline 184 & 17 & 175.5 & $x$ & & & & 75 & & $<1$ & & & $x$ & & & & & & & & & $x$ & & & & & $x$ & \\
\hline 185 & 17 & 175.9 & $x$ & & & & 14 & & $<1$ & & & $x$ & & & $x$ & & & & & $x$ & & & & $x$ & & & $\# 185$ and \#186 intersect \\
\hline 186 & 17 & 176.0 & $x$ & & & & 70 & & $<1$ & & & $x$ & & & & & & & & $x$ & & & & $x$ & & & almost no fill \\
\hline 187 & 18 & 179.2 & $x$ & & & & 11 & & $<1$ & & & & & & & & & $\mathrm{x}$ & & $x$ & & & & $x$ & & & light colored gouge \\
\hline 188 & 18 & 179.6 & $x$ & & & & 3 & & $<1$ & & & $x$ & & & & & $\mathrm{x}$ & & & & $x$ & & & $x$ & & & \\
\hline 189 & 18 & 179.9 & $x$ & & & & 44 & & $<1$ & & & & & & & & & $x$ & & & $x$ & & & $x$ & & & limonite \\
\hline 190 & 18 & 181.2 & $\mathrm{x}$ & & & & 10 & & $<1$ & & & $x$ & & & & & & $x$ & & $x$ & & & & $x$ & & & limonite \\
\hline 191 & 18 & 182.0 & $\mathrm{x}$ & & & & 33 & & $<1$ & & & & & & & & & $x$ & & & $x$ & & & $x$ & & & limonite \\
\hline 192 & 18 & 183.4 & $x$ & & & & 12 & & $<1$ & & & $x$ & & & & & & $\mathrm{x}$ & & & $x$ & & & $x$ & & & limonite \\
\hline 193 & 18 & 185.5 & $x$ & & & & 13 & & $<1$ & & & & & & $x$ & & & & & & $x$ & & & $x$ & & & light colored gouge \\
\hline 194 & 19 & 186.5 & $x$ & & & & 10 & & $<1$ & & & & & & $x$ & & $\mathrm{x}$ & & & & $x$ & & & & & $x$ & light colored gouge (light gray) \\
\hline 195 & 19 & 187.7 & $\mathrm{x}$ & & & & 19 & & $<1$ & & & & & & & & & $x$ & & & $x$ & & & & & & limonite \\
\hline
\end{tabular}




\begin{tabular}{|c|c|c|c|c|c|c|c|c|c|c|c|c|c|c|c|c|c|c|c|c|c|c|c|c|c|c|c|}
\hline \multicolumn{8}{|c|}{$\begin{array}{c}\text { Feature } \\
\text { (dip not corrected for hole deviation) }\end{array}$} & \multicolumn{19}{|c|}{ Discontinuity Characteristics } & \multirow[t]{2}{*}{ Comments } \\
\hline \multirow[t]{4}{*}{$\begin{array}{l}\text { Disc. } \\
\text { No. }\end{array}$} & \multirow[t]{4}{*}{$\begin{array}{l}\text { Run } \\
\text { No. }\end{array}$} & \multirow{3}{*}{$\begin{array}{c}\text { Depth } \\
\text { (dist. } \\
\text { along } \\
\text { core) }\end{array}$} & \multicolumn{4}{|c|}{ Type } & \multirow[t]{2}{*}{ Dip } & \multirow[t]{2}{*}{ Apert. } & \multirow[t]{2}{*}{$\begin{array}{l}\text { Infill } \\
\text { Thick. }\end{array}$} & \multicolumn{9}{|c|}{ Infill Type } & \multicolumn{8}{|c|}{ Roughness and Planarity } & \\
\hline & & & & & & & & & & & & & & & & & & & & & & & & & & & \\
\hline & & & & & & & & & & & & & & & & & & & & & & & & & & & \\
\hline & & (feet) & : & 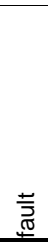 & 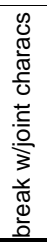 & $\frac{0}{\frac{0}{0}}$ & 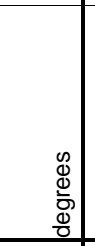 & $(\mathrm{mm})$ & $(\mathrm{mm})$ & 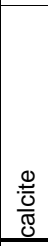 & 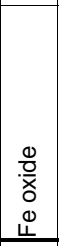 & 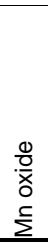 & 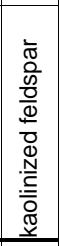 & 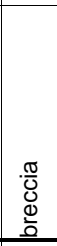 & $\begin{array}{l}\frac{0}{0} \\
\overline{0} \\
\text { बे } \\
\frac{\pi}{0} \\
\frac{\pi}{v} \\
\end{array}$ & 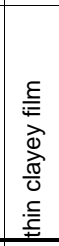 & 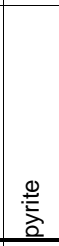 & 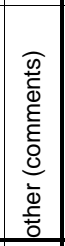 & $\begin{array}{l}\frac{}{\overline{0}} \\
\overline{0} \\
\frac{0}{2} \\
\text { 일 }\end{array}$ & $\begin{array}{l}\text { 등 } \\
\text { 흠 }\end{array}$ & 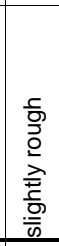 & 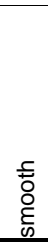 & 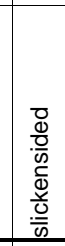 & \begin{tabular}{|l}
$\bar{\sigma}$ \\
$\frac{\pi}{\alpha}$ \\
$\frac{\pi}{\alpha}$ \\
\end{tabular} & $\begin{array}{l}\overbrace{\pi}^{2} \\
3 \\
3\end{array}$ & $\begin{array}{l}\frac{0}{0} \\
\frac{0}{2} \\
\frac{0}{\omega} \\
\end{array}$ & *representative discontinuity described \\
\hline 196 & 19 & 188.6 & $x$ & & & & 9 & & $<1$ & & & & & & $\mathrm{x}$ & & & & & & $x$ & & & $x$ & & & light colored gouge \\
\hline 197 & 19 & 188.8 & $x$ & & & & 59 & & $<1$ & & & $x$ & & & $\mathrm{x}$ & & & & & & $x$ & & & $x$ & & & \\
\hline 198 & 19 & 190.9 & $\mathrm{x}$ & & & & 2 & & $<1$ & & & & & & $x$ & & $x$ & & & & $x$ & & & $x$ & & & light colored, very soft gouge \\
\hline 199 & 19 & 192.9 & $\mathrm{x}$ & & & & 28 & & $<1$ & & & & & & & & & & & $x$ & & & & $x$ & & & almost no gouge \\
\hline 200 & 19 & 195.9 & $\mathrm{x}$ & & & & 80 & & $<1$ & & & $x$ & & & & $x$ & & & & & $x$ & & & & $x$ & & light colored gouge \\
\hline \multirow[t]{2}{*}{201} & 19 & 196.2 & $x$ & & & & 75 & & $<1$ & & & $x$ & & & & $x$ & & & & & & & & & & $\mathrm{x}$ & light colored gouge \\
\hline & & & & & & & & & & & & & & & & & & & & & & & & & & & (jt ends at core break at $196.2 \mathrm{ft}$ ) \\
\hline \multicolumn{3}{|c|}{$T D=196.5 \mathrm{ft}$} & & & & & & & & & & & & & & & & & & & & & & & & & \\
\hline
\end{tabular}




\section{APPENDIX F}

Borehole Geophysical Log Plots by Colog, Inc., Source Physics Experiment Holes:

Appendix F-1: U-15n Core Hole Appendix F-2: Instrument Hole U-15n\#1 Appendix F-3: Instrument Hole U-15n\#2 Appendix F-4: Instrument Hole U-15n\#3 Appendix F-5: Instrument Hole U-15n\#4 Appendix F-6: Instrument Hole U-15n\#5 Appendix F-7: Instrument Hole U-15n\#6 
Appendix F-1

Borehole Geophysical Log Plots for the U-15n Core Hole 


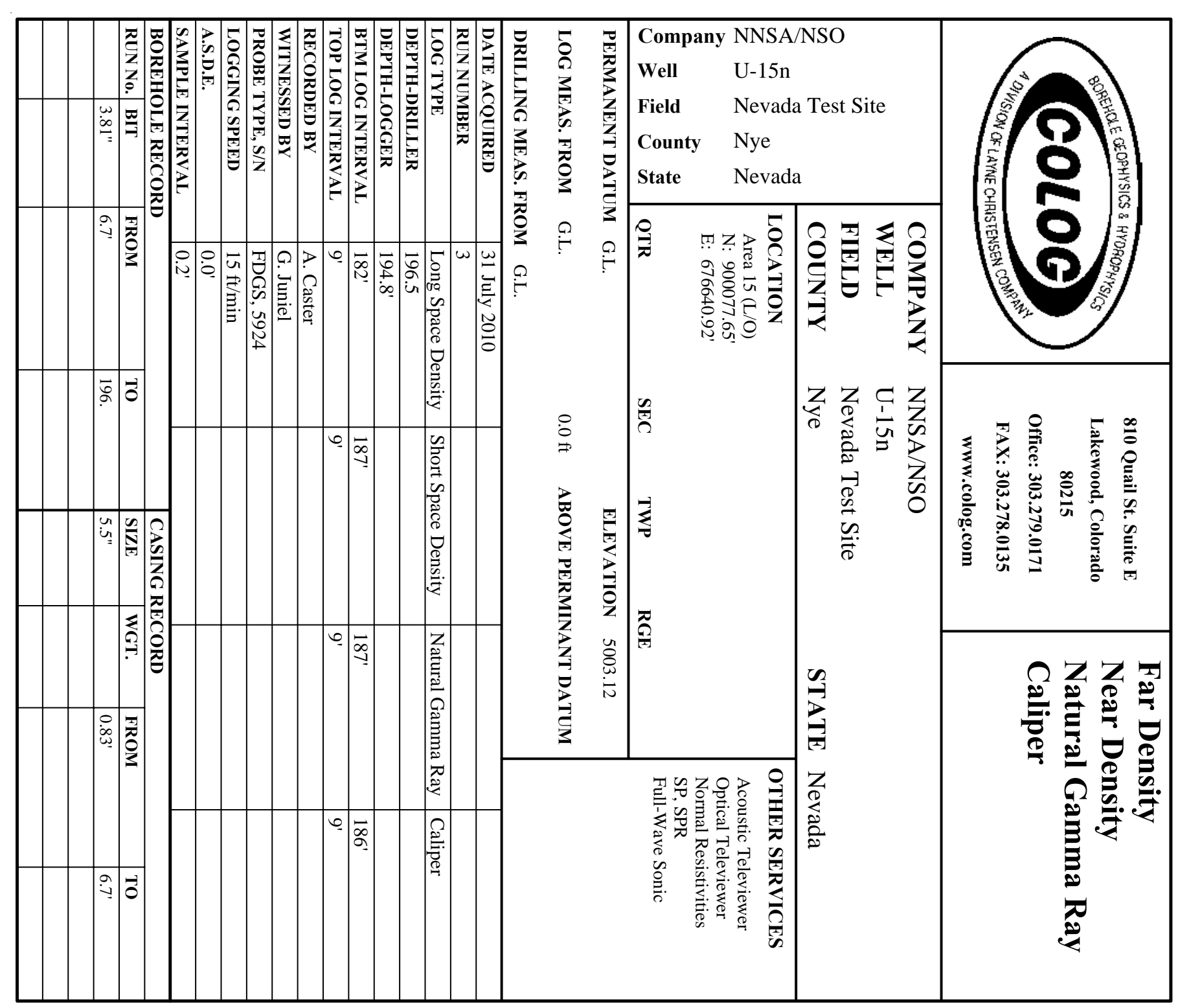

COMMENTS

NA - Not Available, N/A - Not Applicable

Matrix Density or 2.64 used to calculate Density Porosity

Could not reach driller's TD, due to fill. 

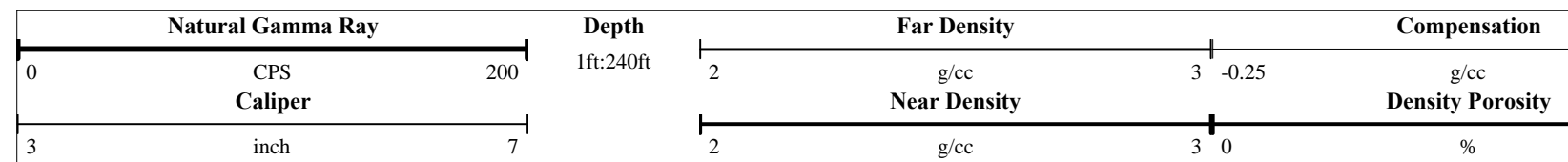

g/cc
Compensated Density
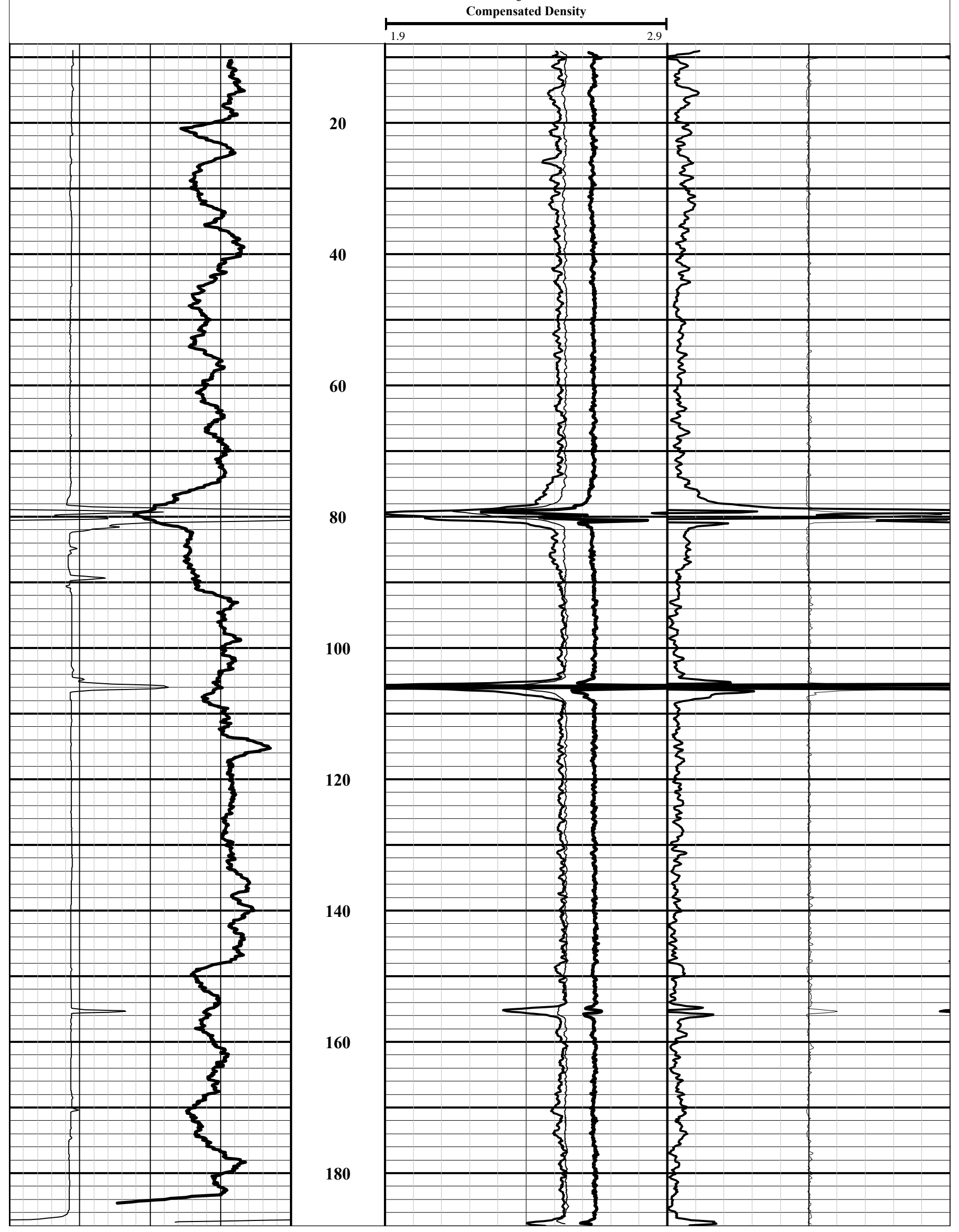


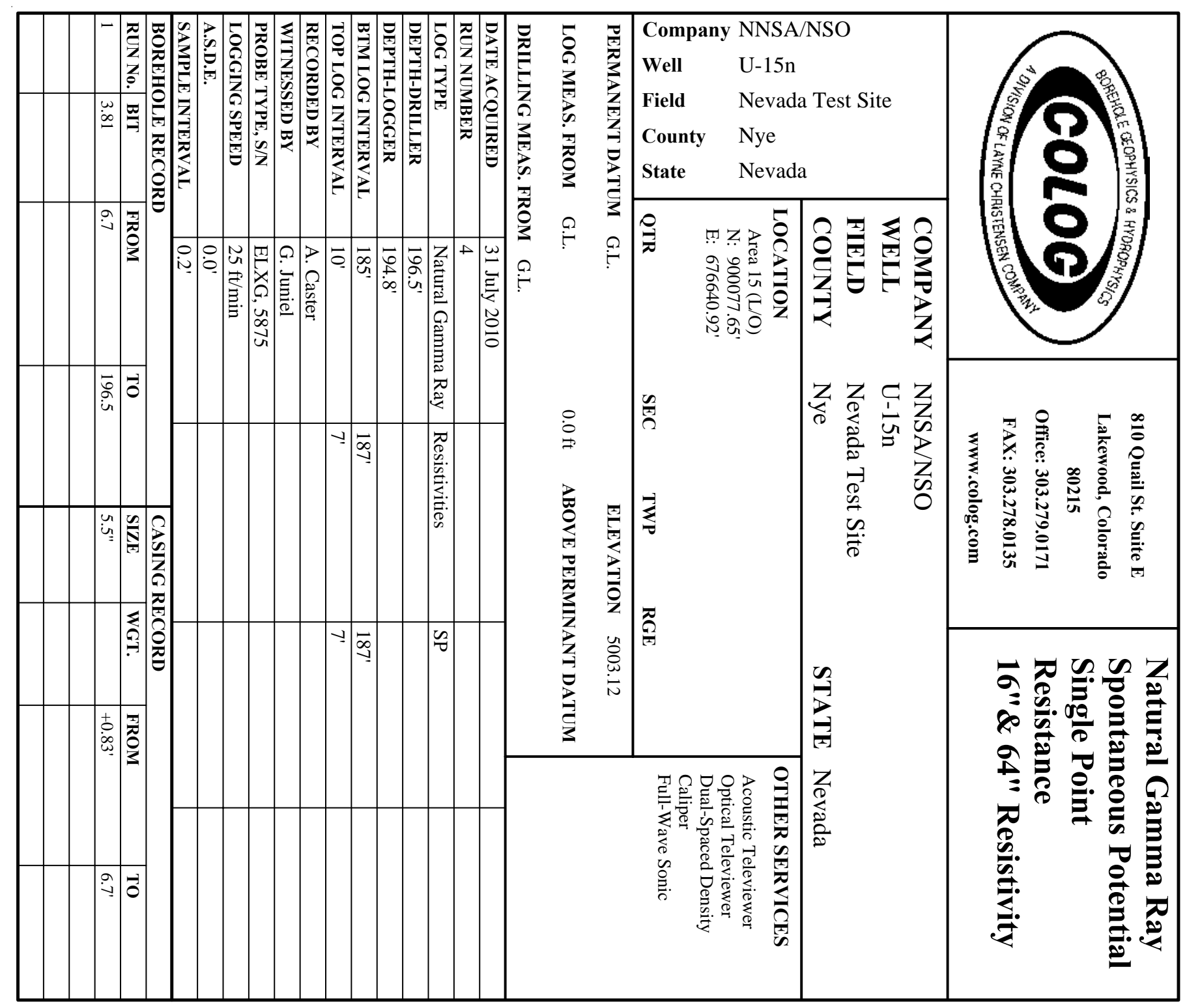




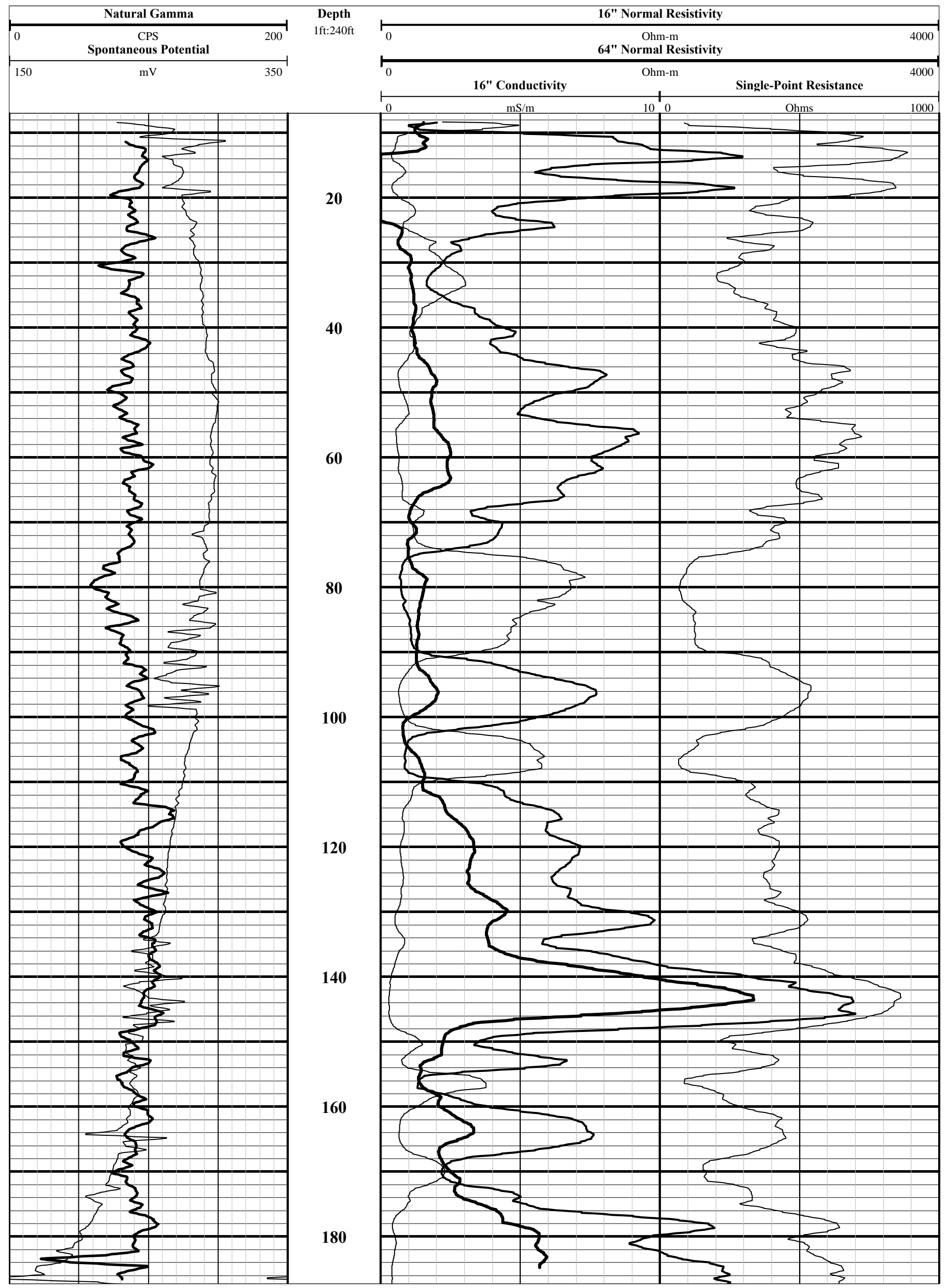




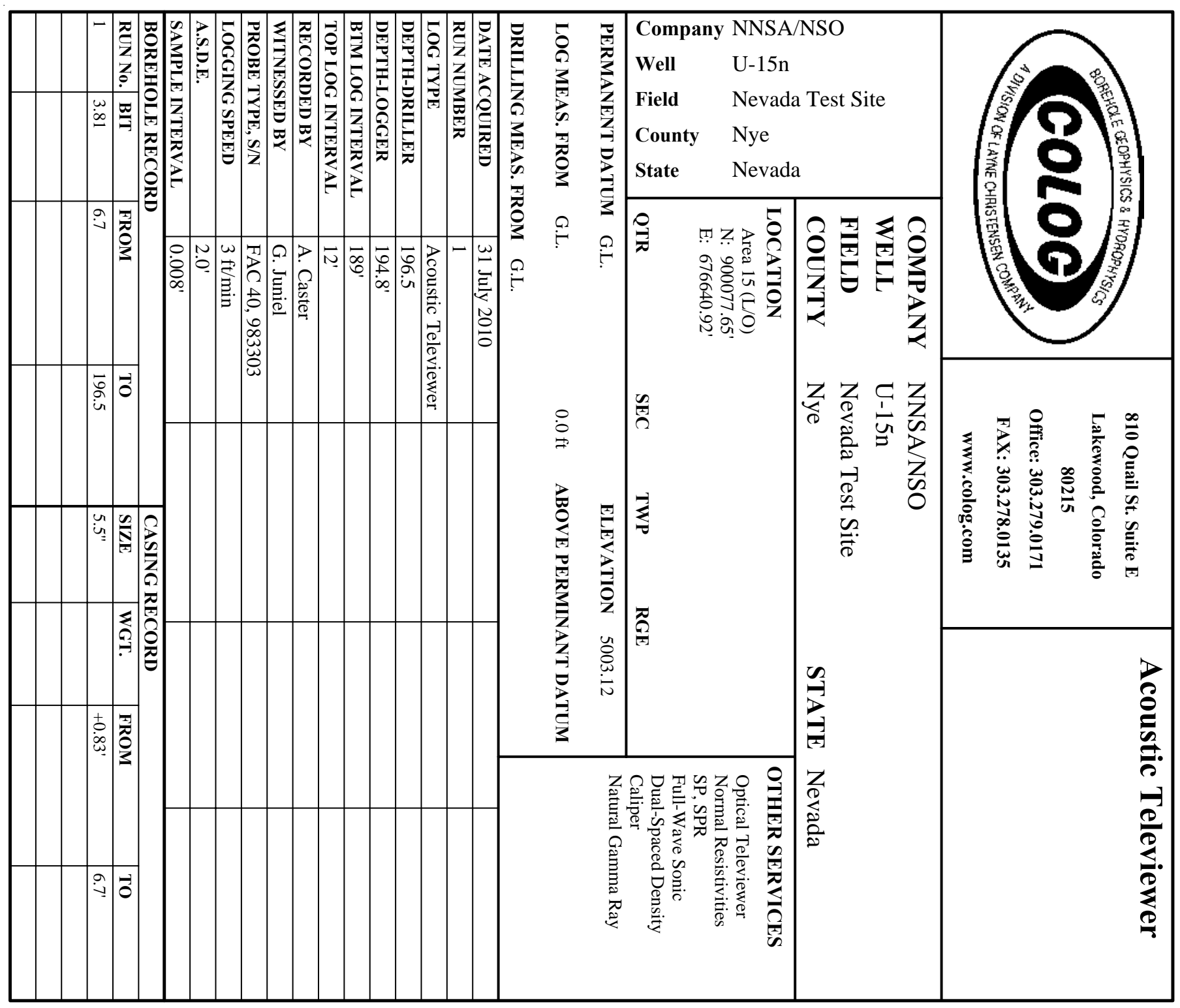

COMMENTS

NA - Not Available, N/A - Not Applicable

Images, Projections, and Tadpoles are relative to Magnetic North.

Magnetic declination of 12.85 degrees East added to all directions so that all Stereonets and Rose Diagrams are with respect to True North.

Could not reach driller's TD, due to fill. 

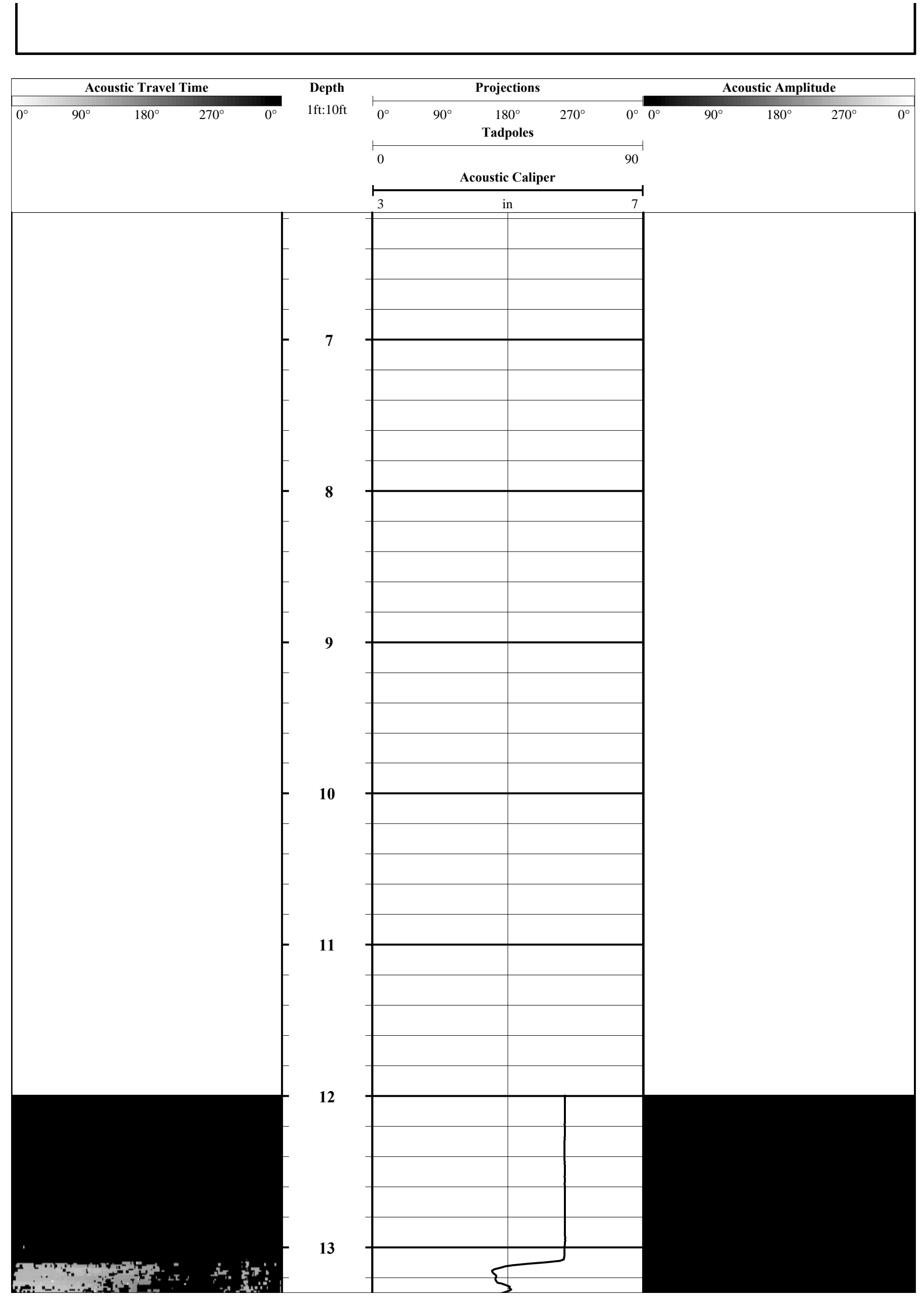

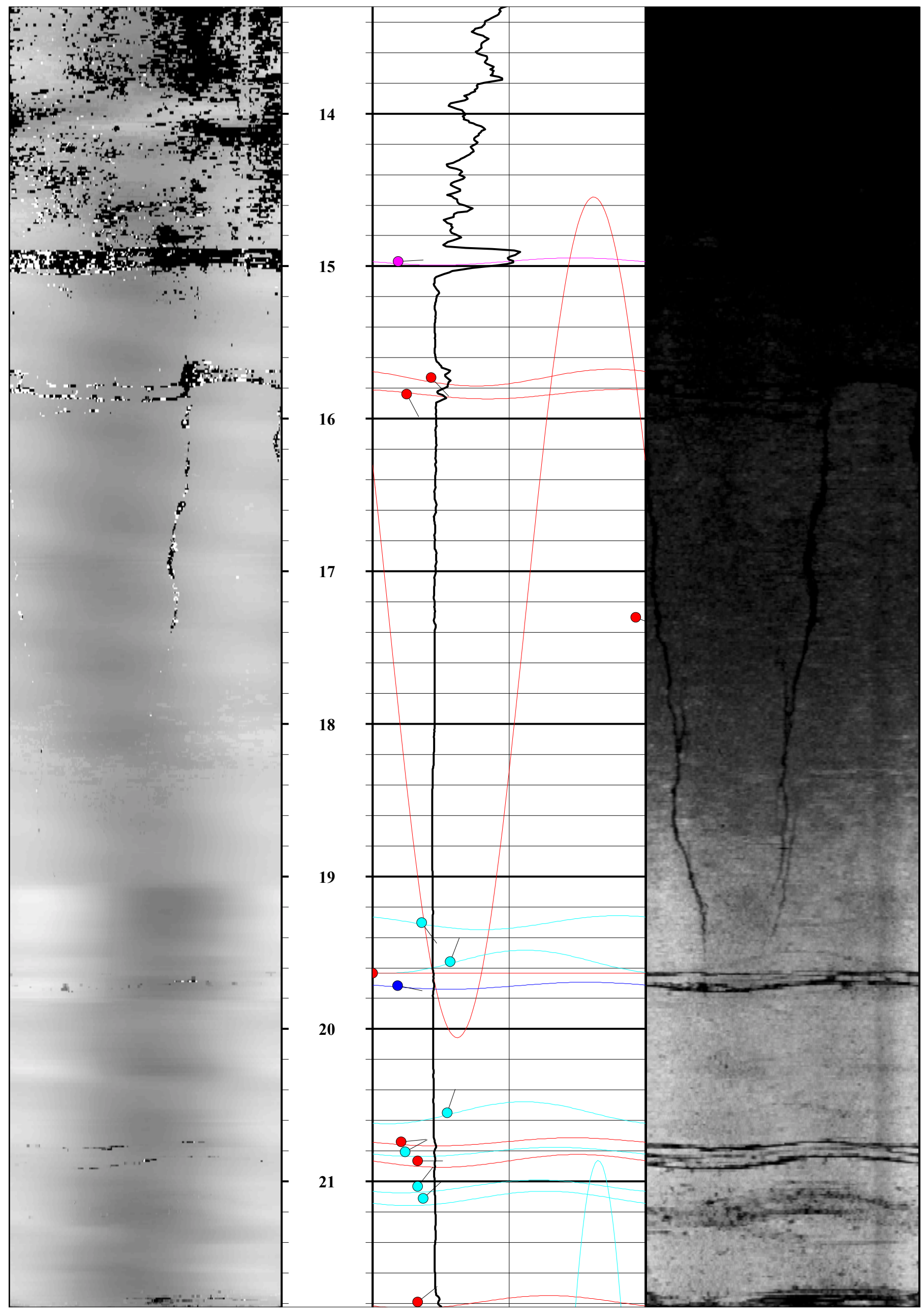


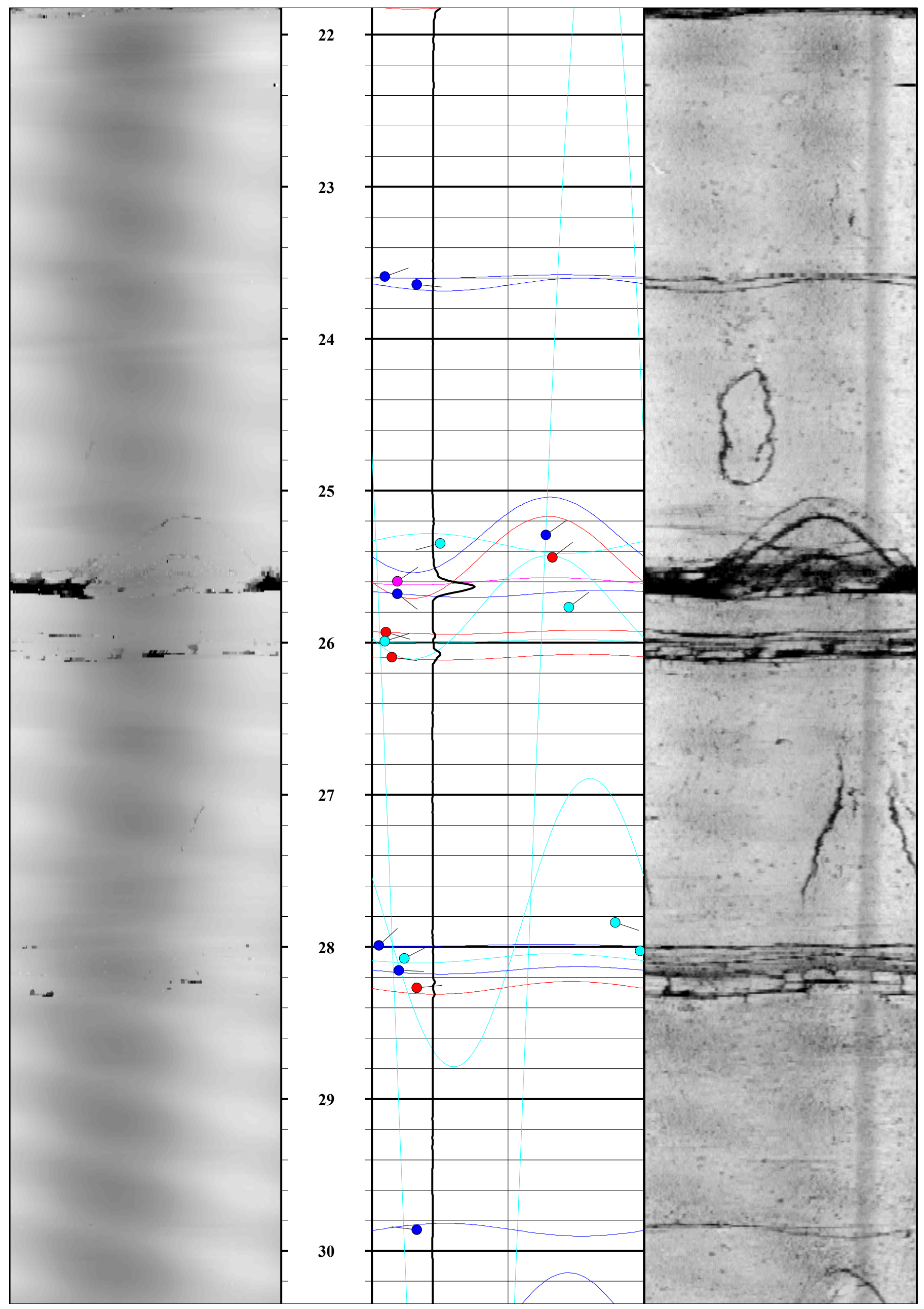




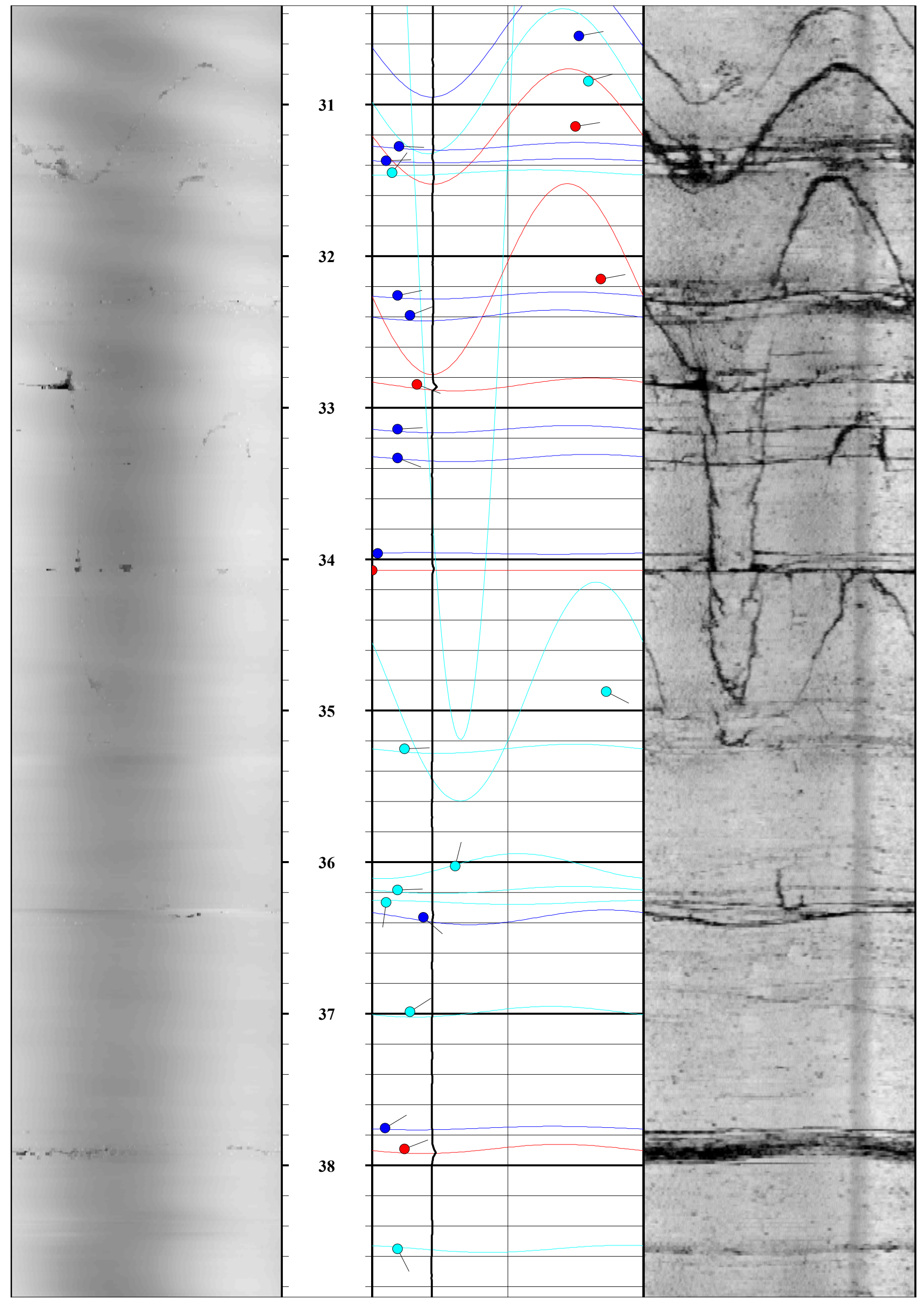




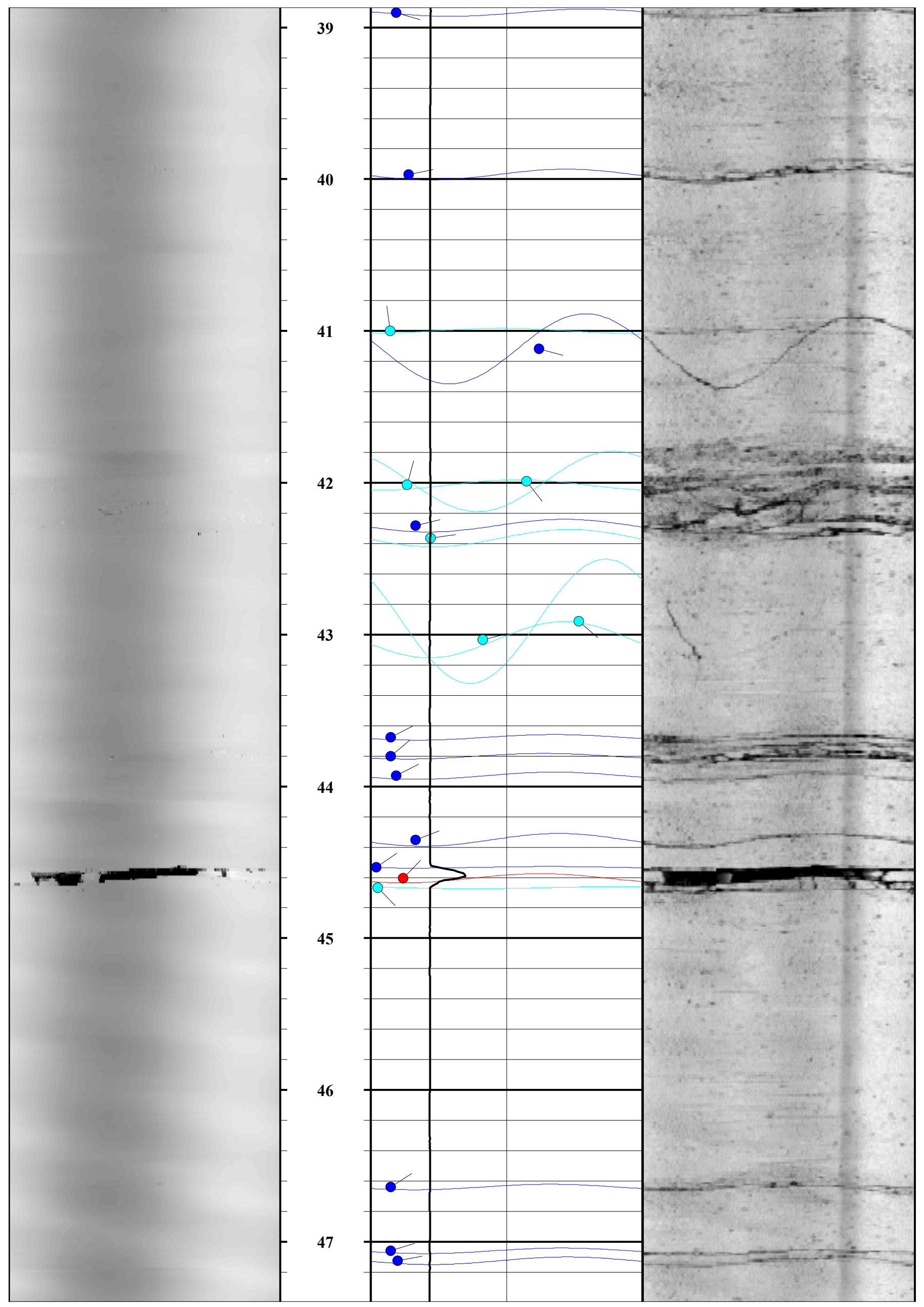




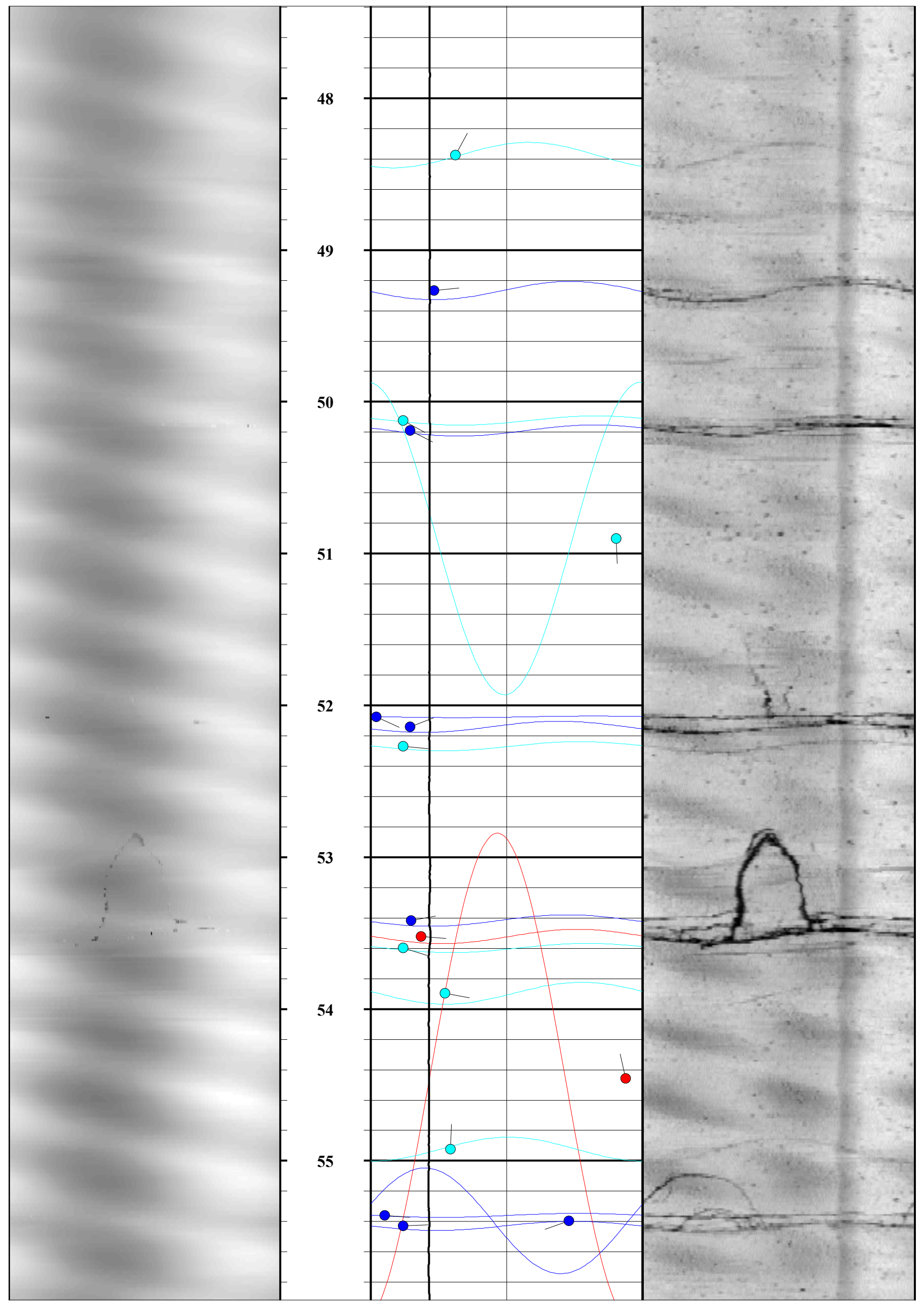

Page 7 


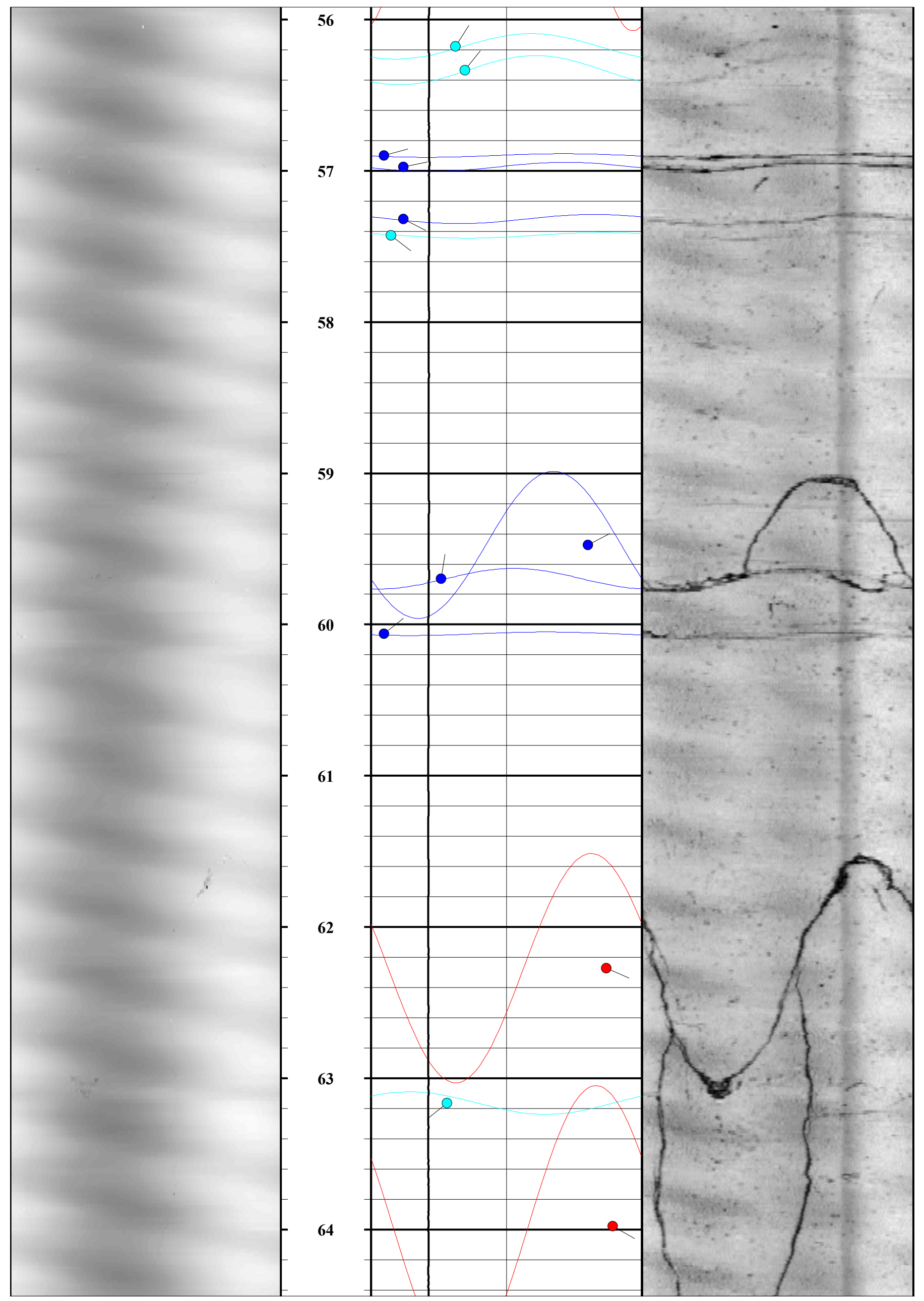

Page 8 


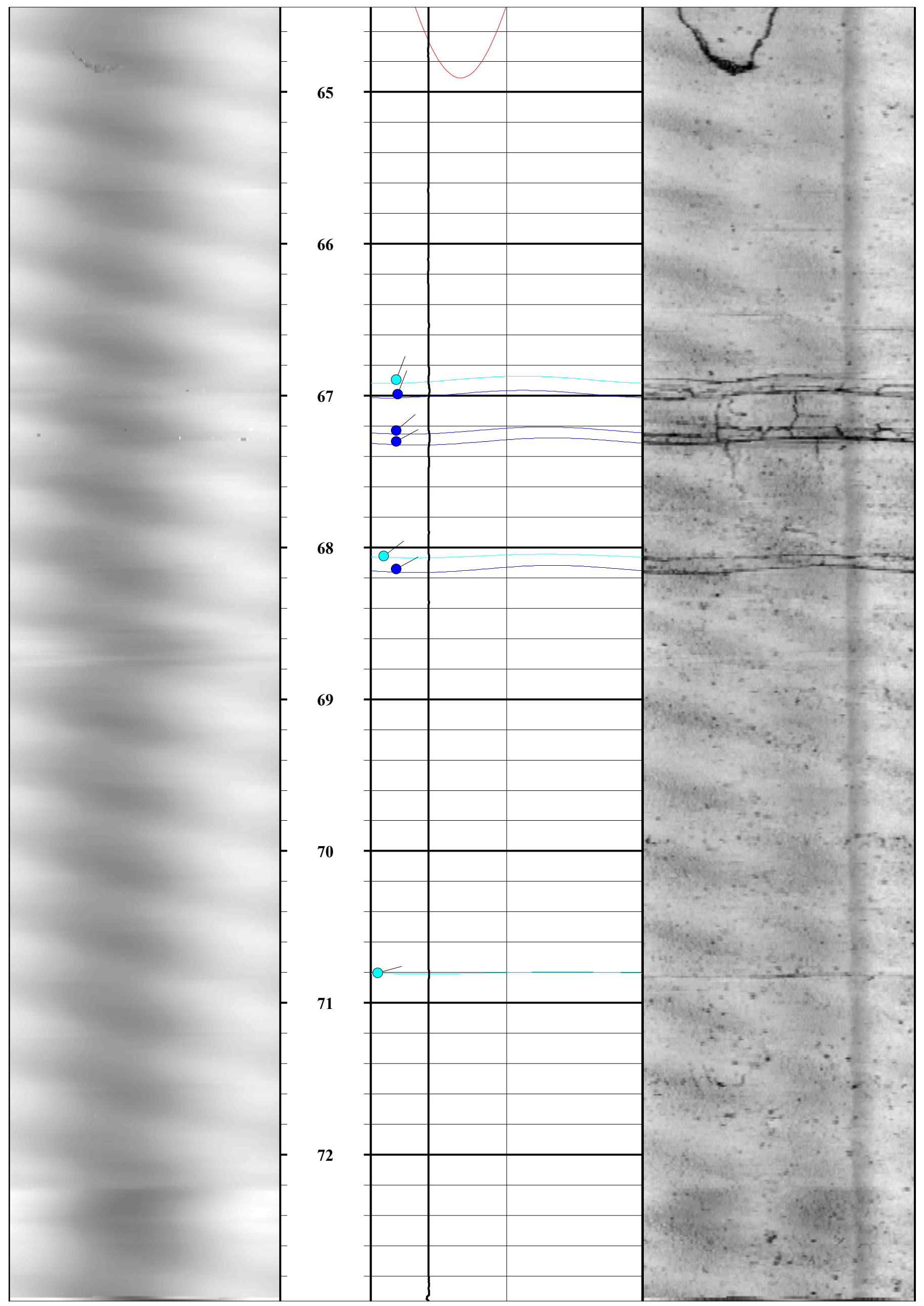




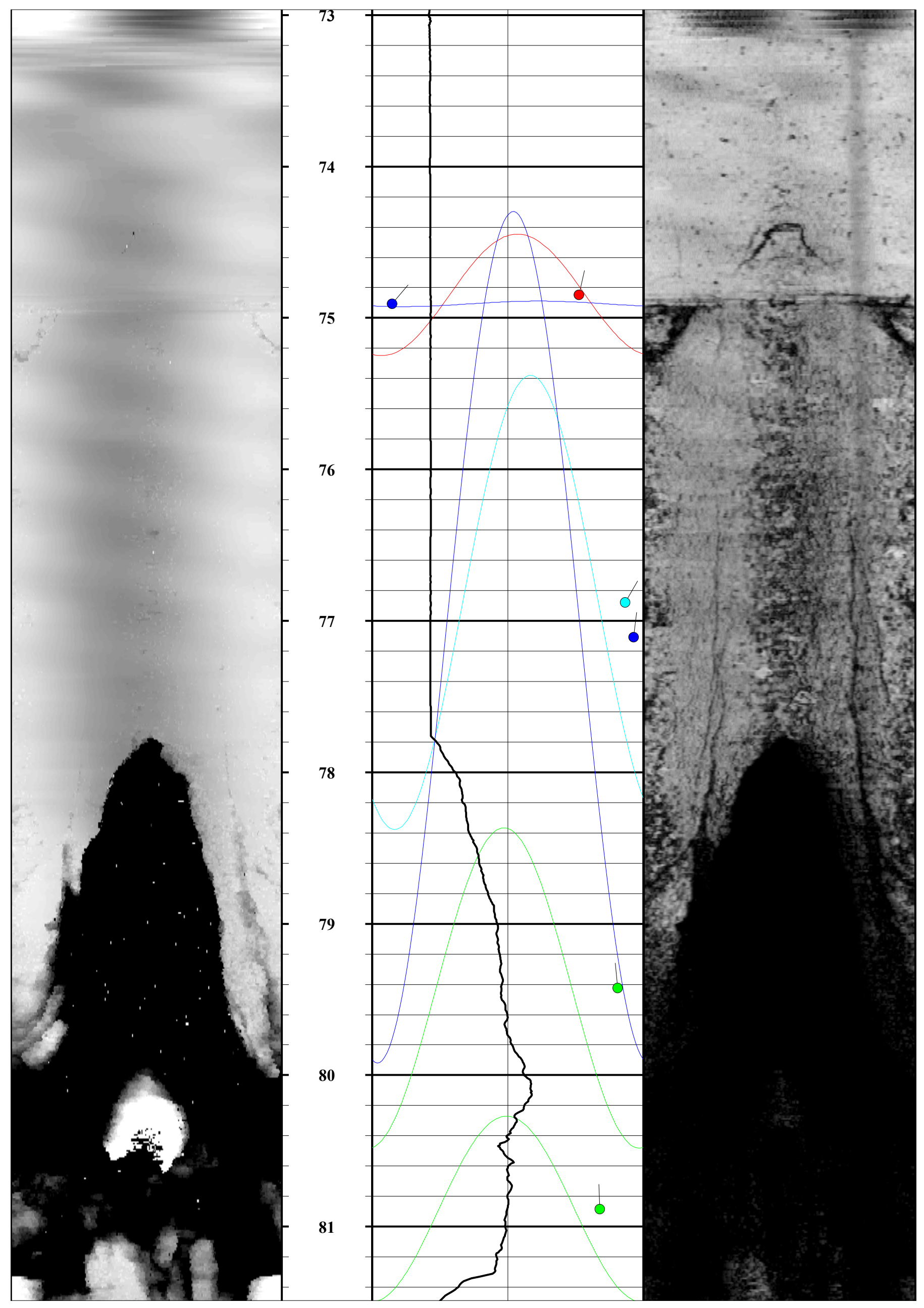

Page 10 


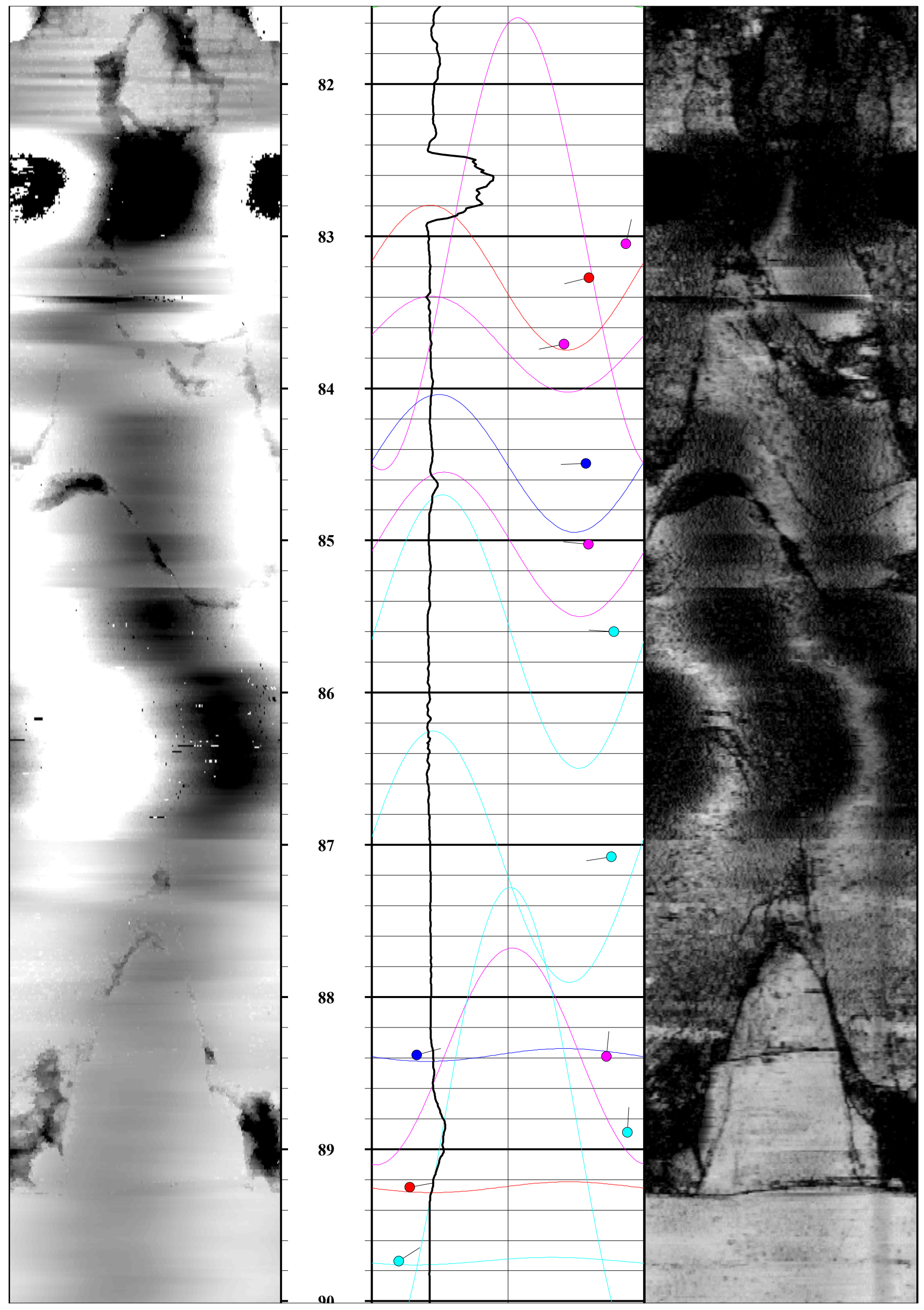




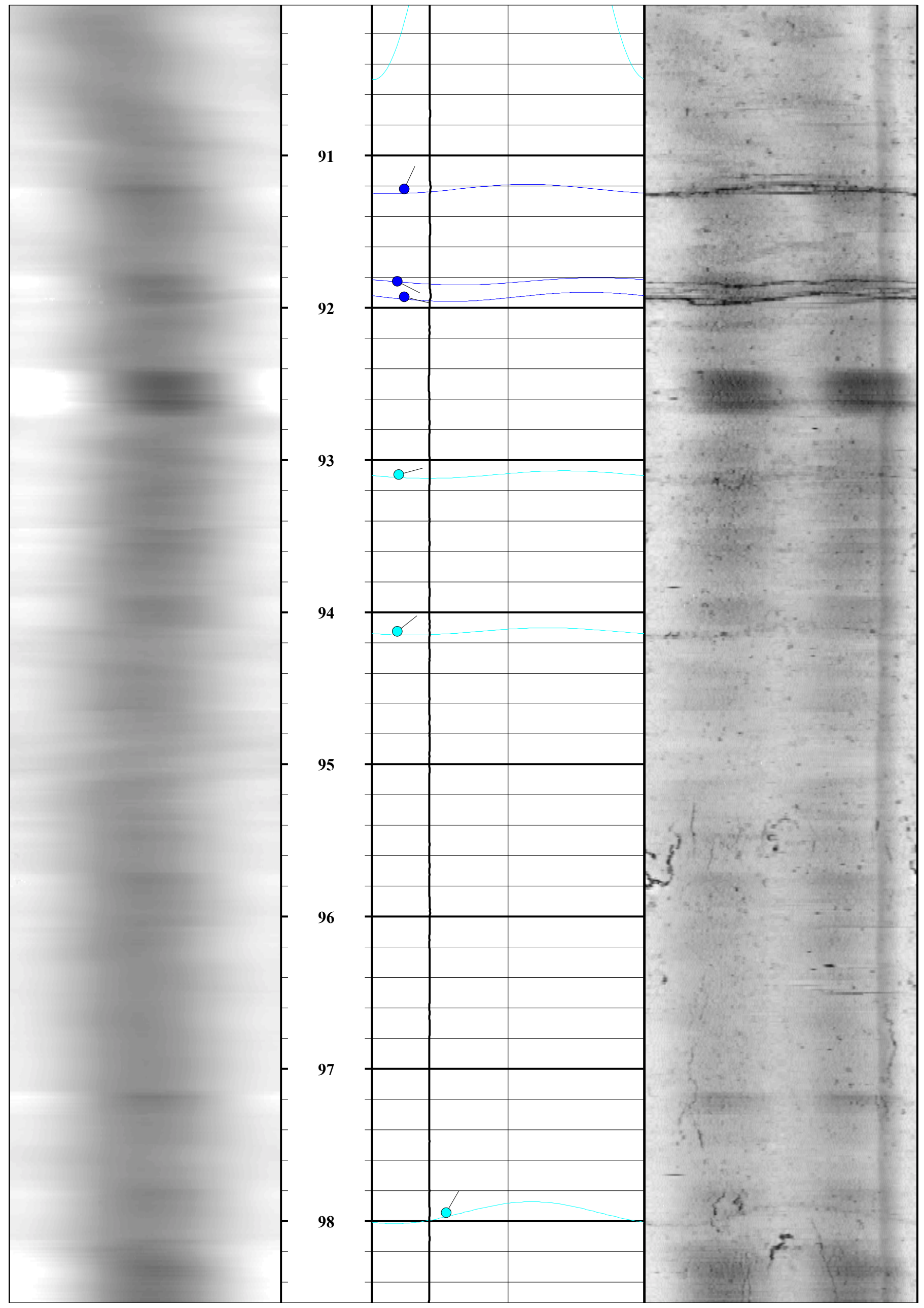

Page 12 


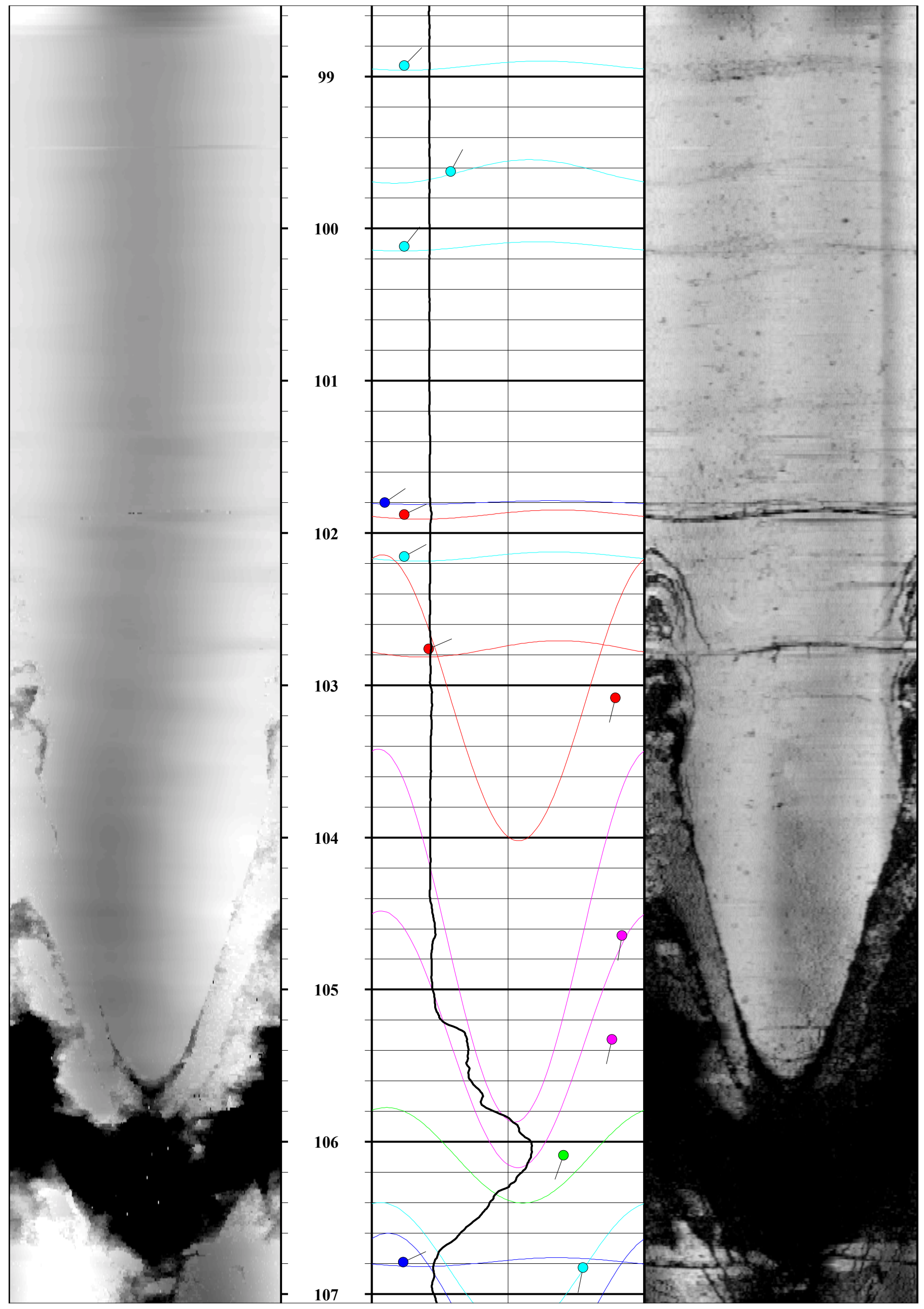




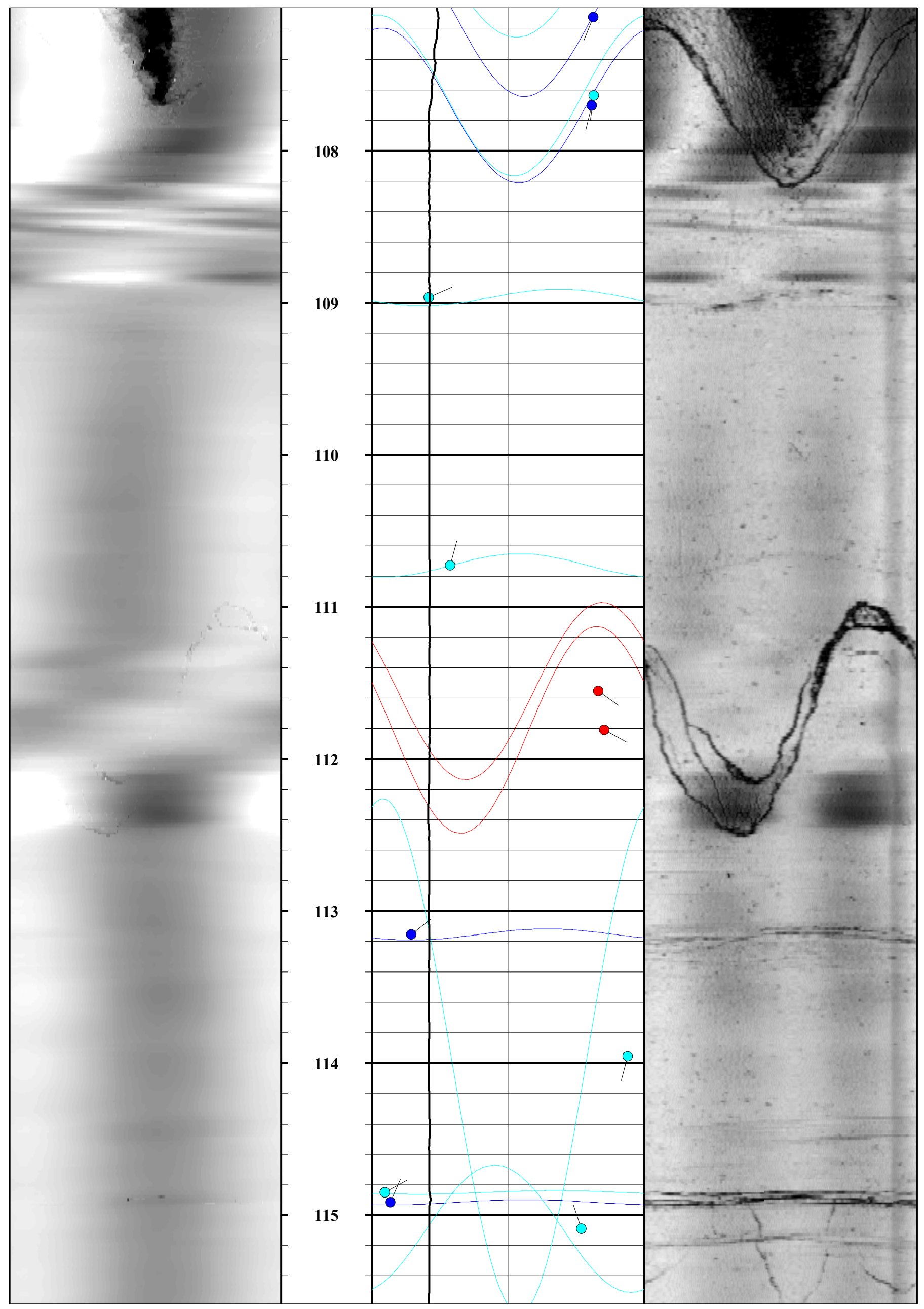

Page 14 


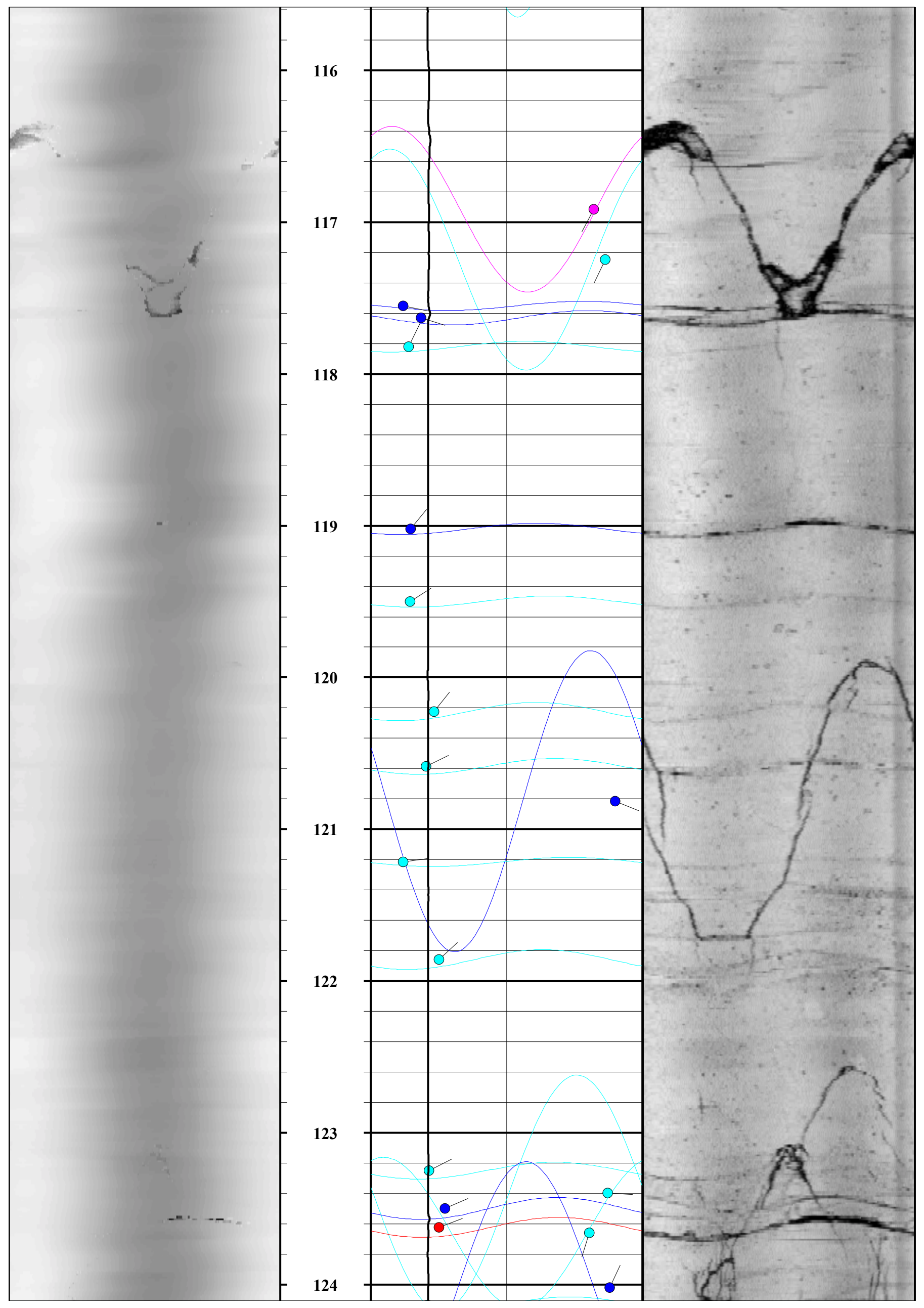

Page 15 


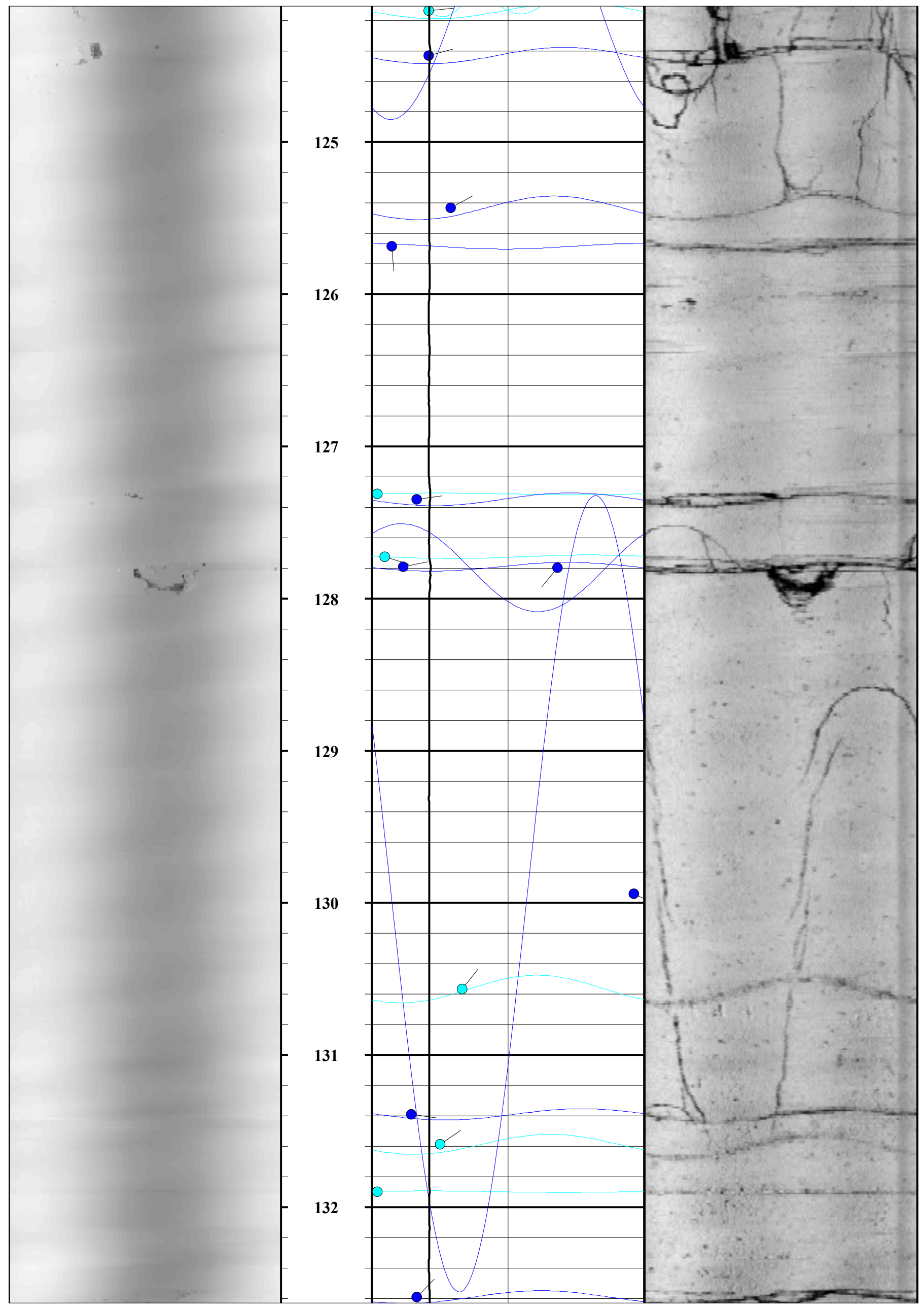

Page 16 


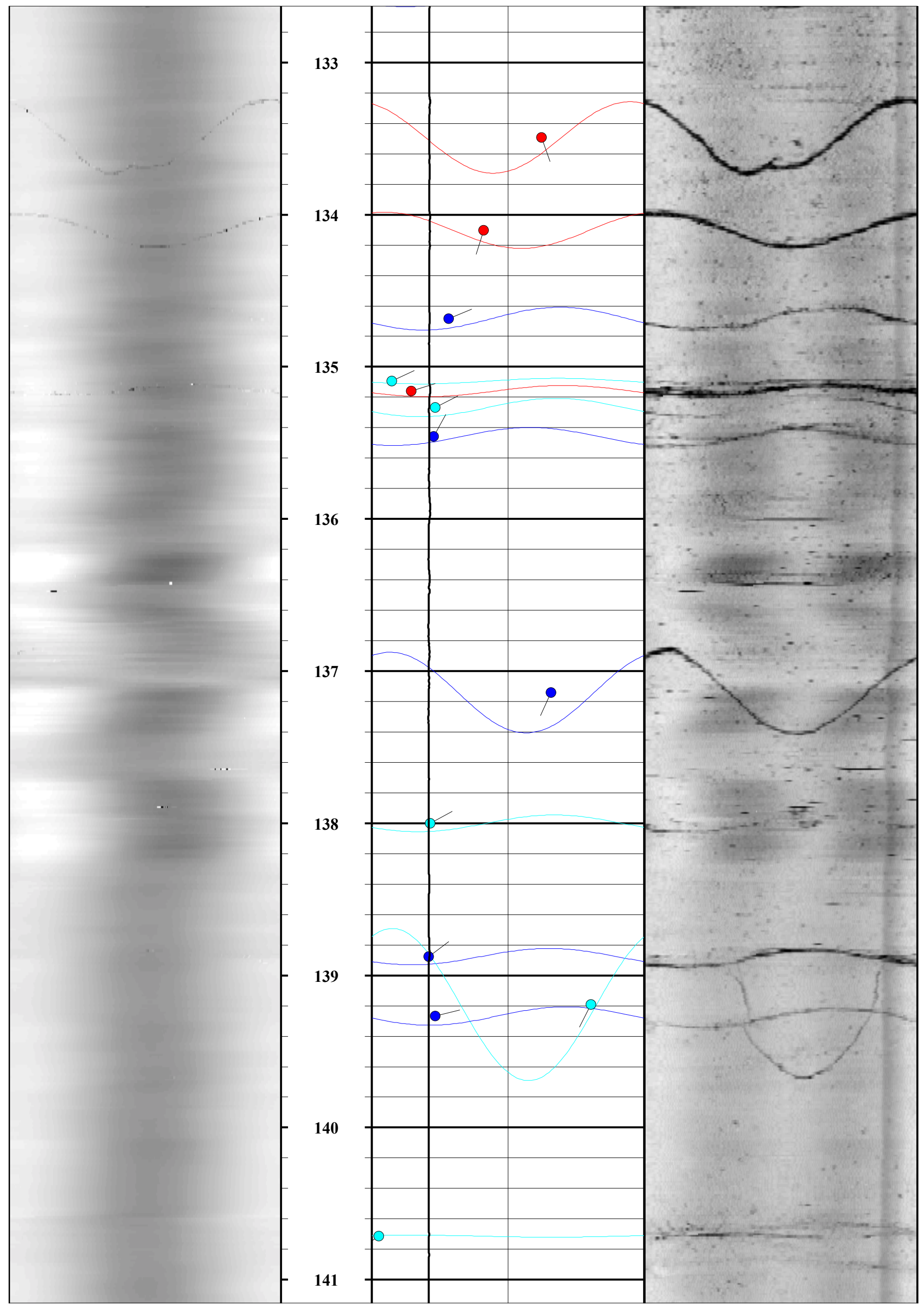

Page 17 


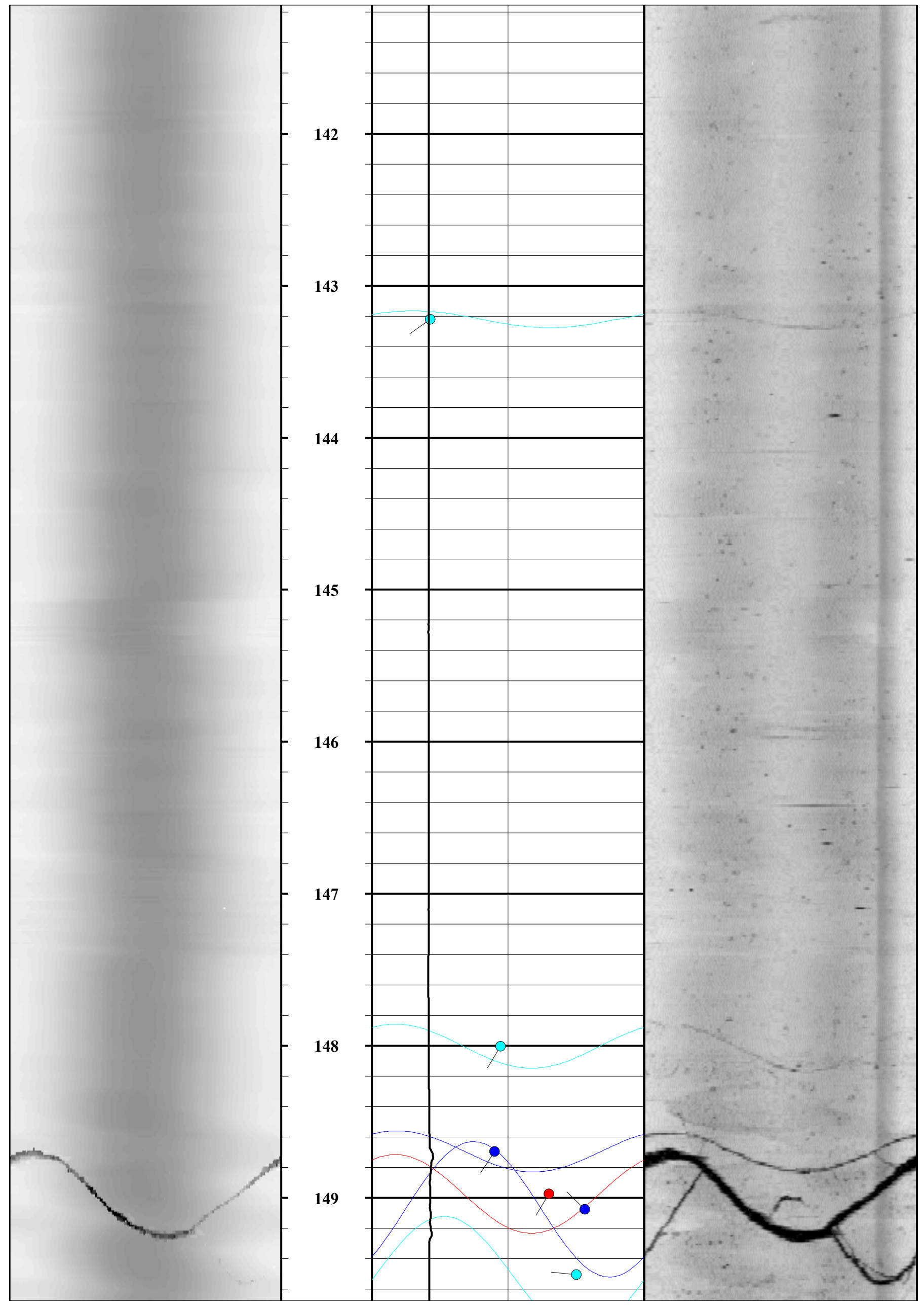

Page 18 


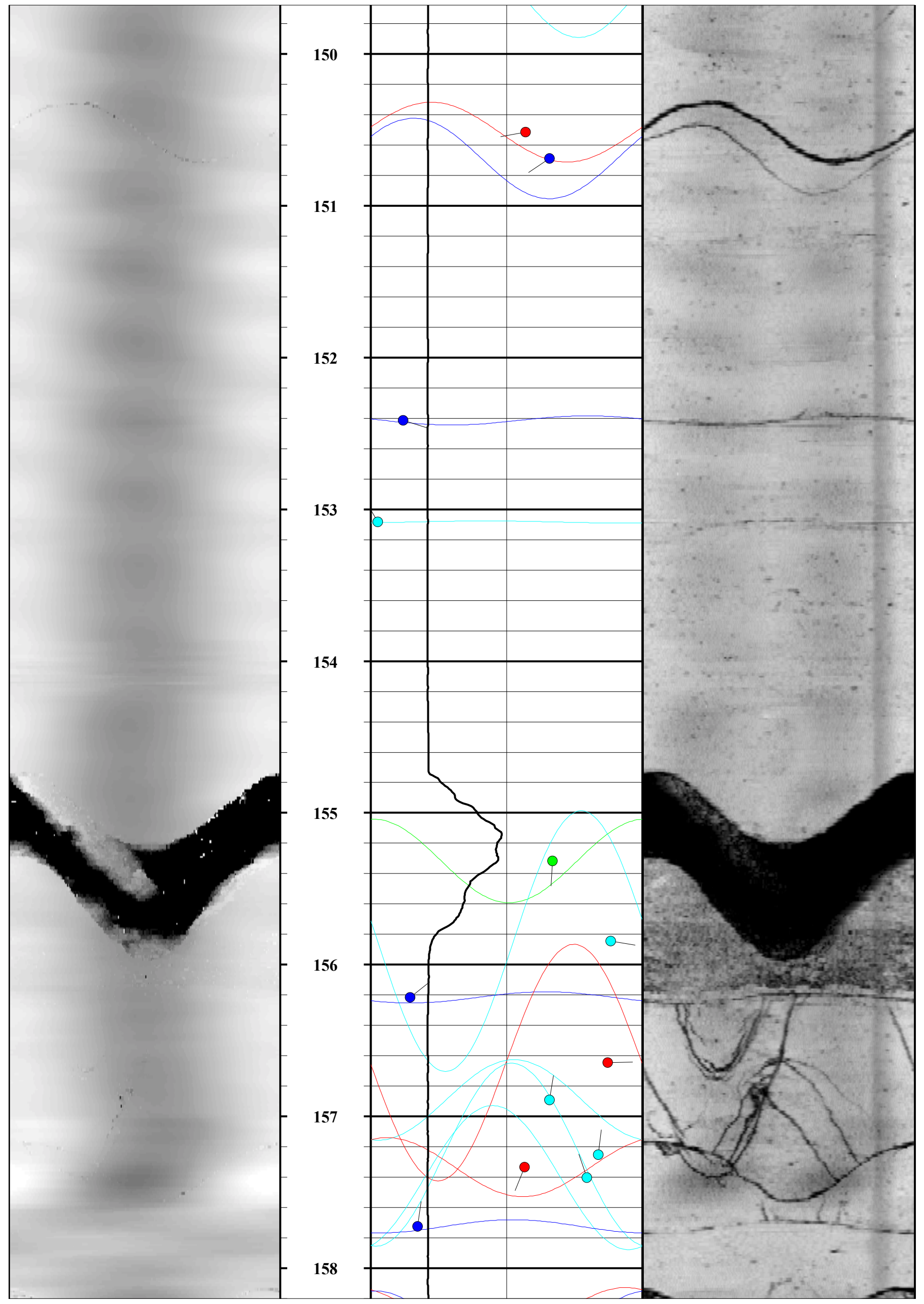

Page 19 


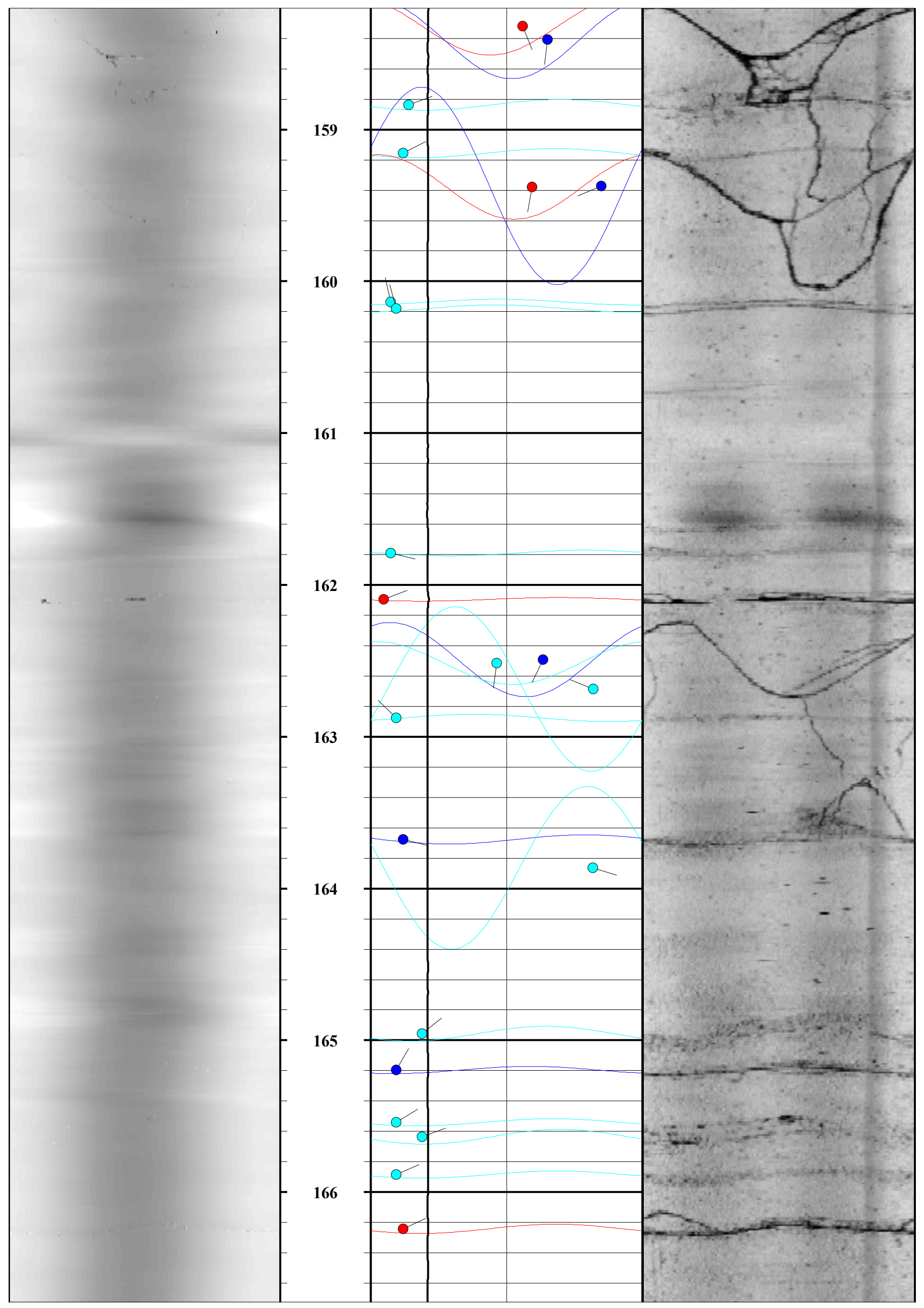

Page 20 


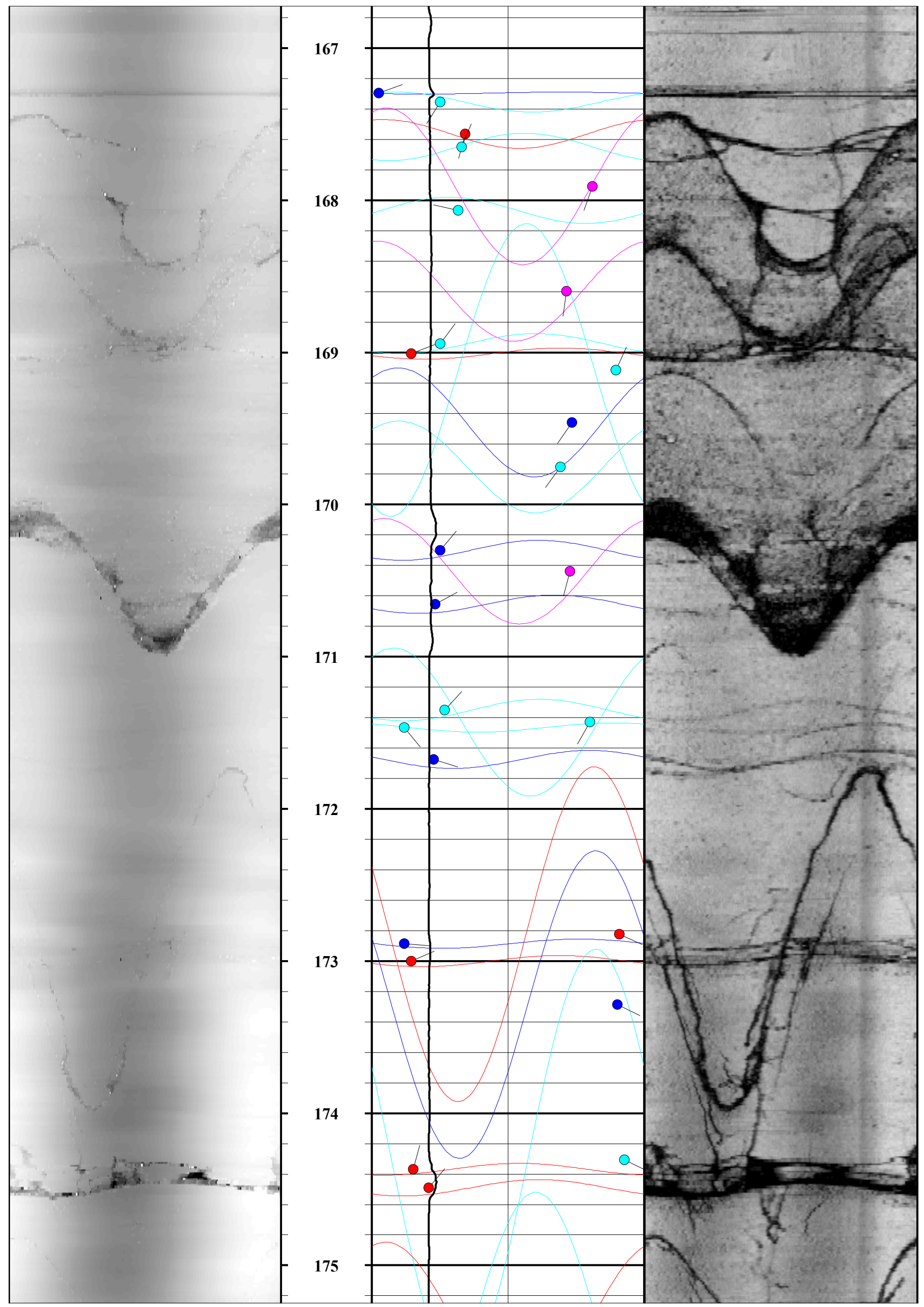

Page 21 


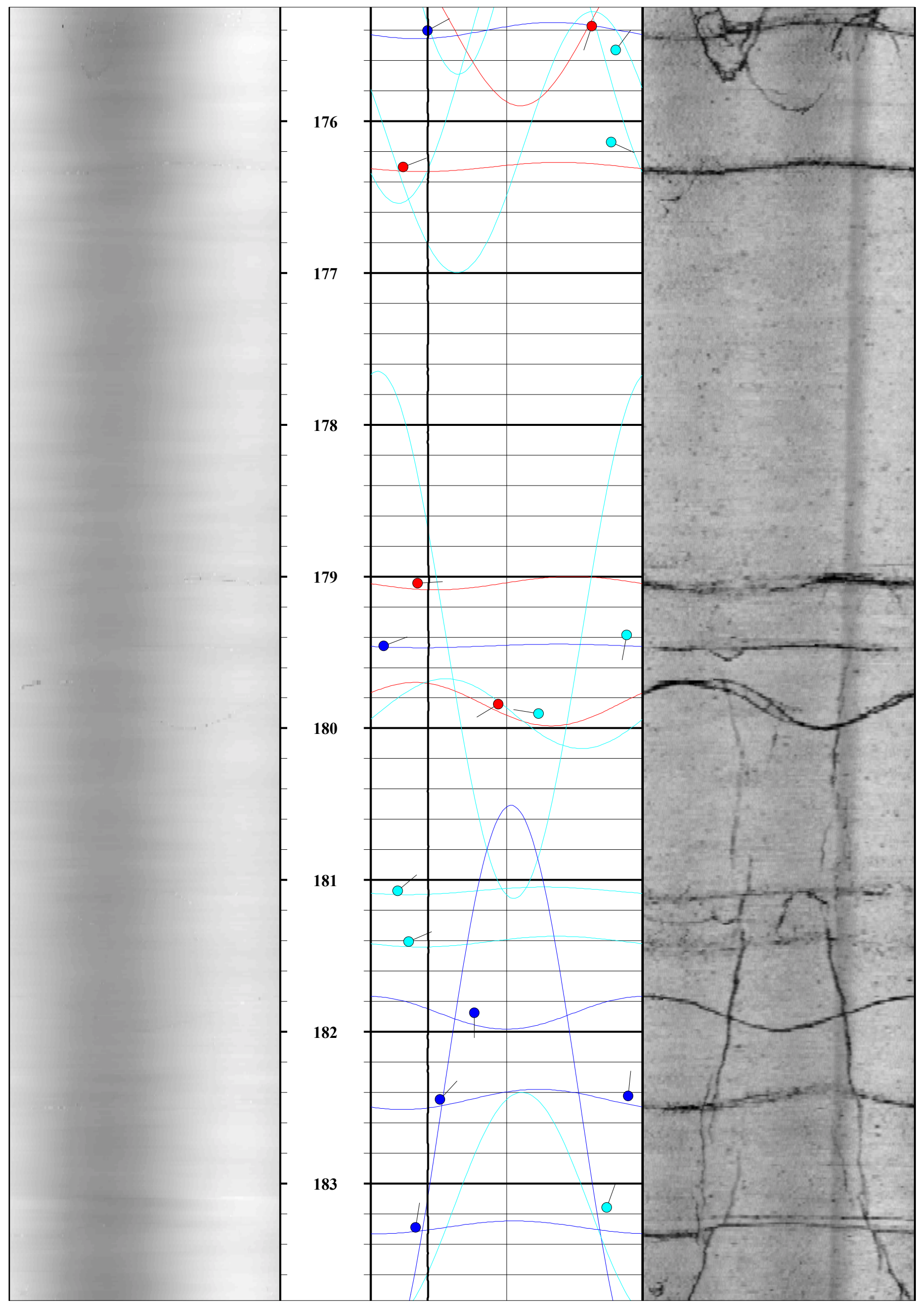

Page 22 


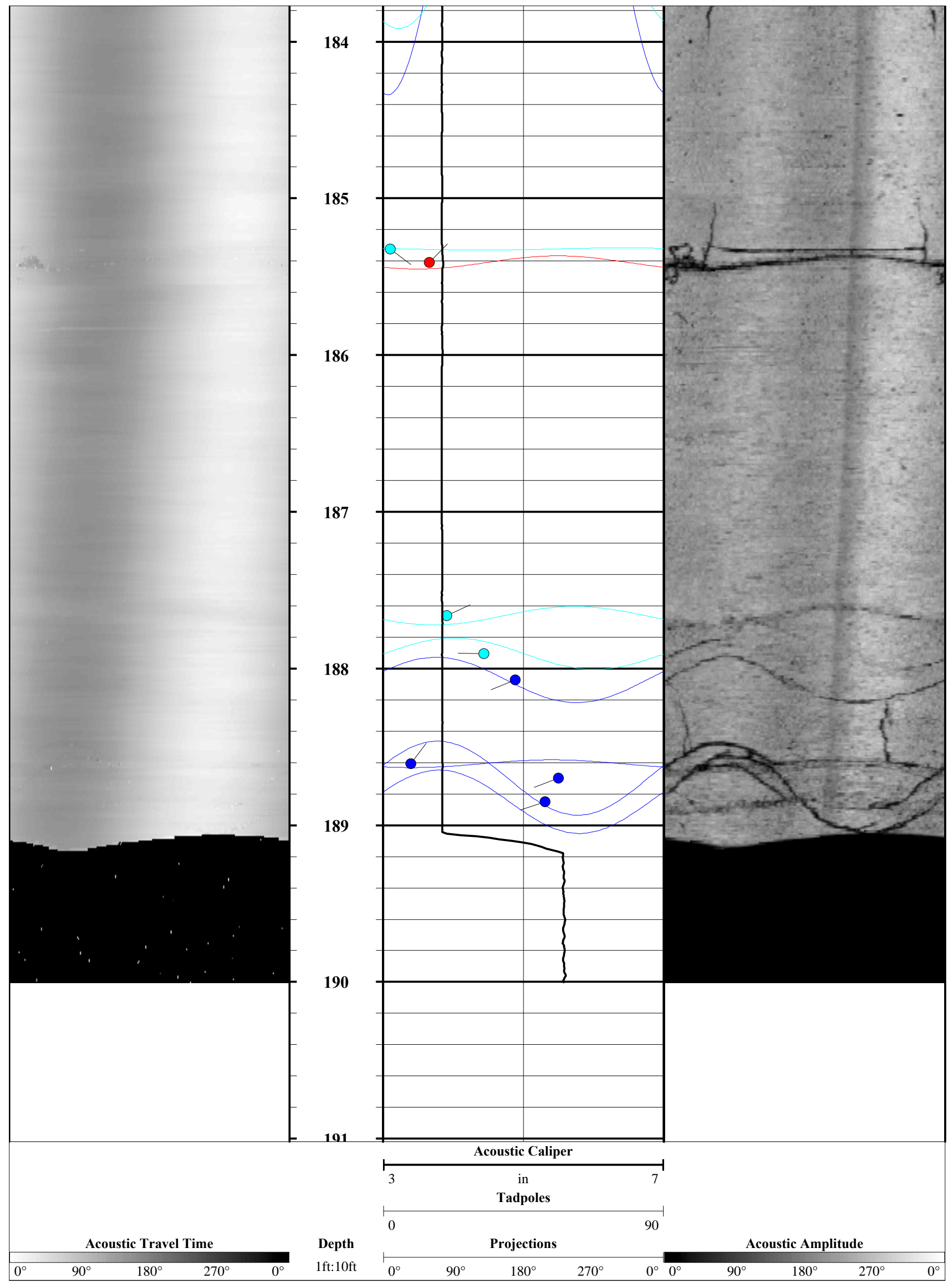

Page 23 


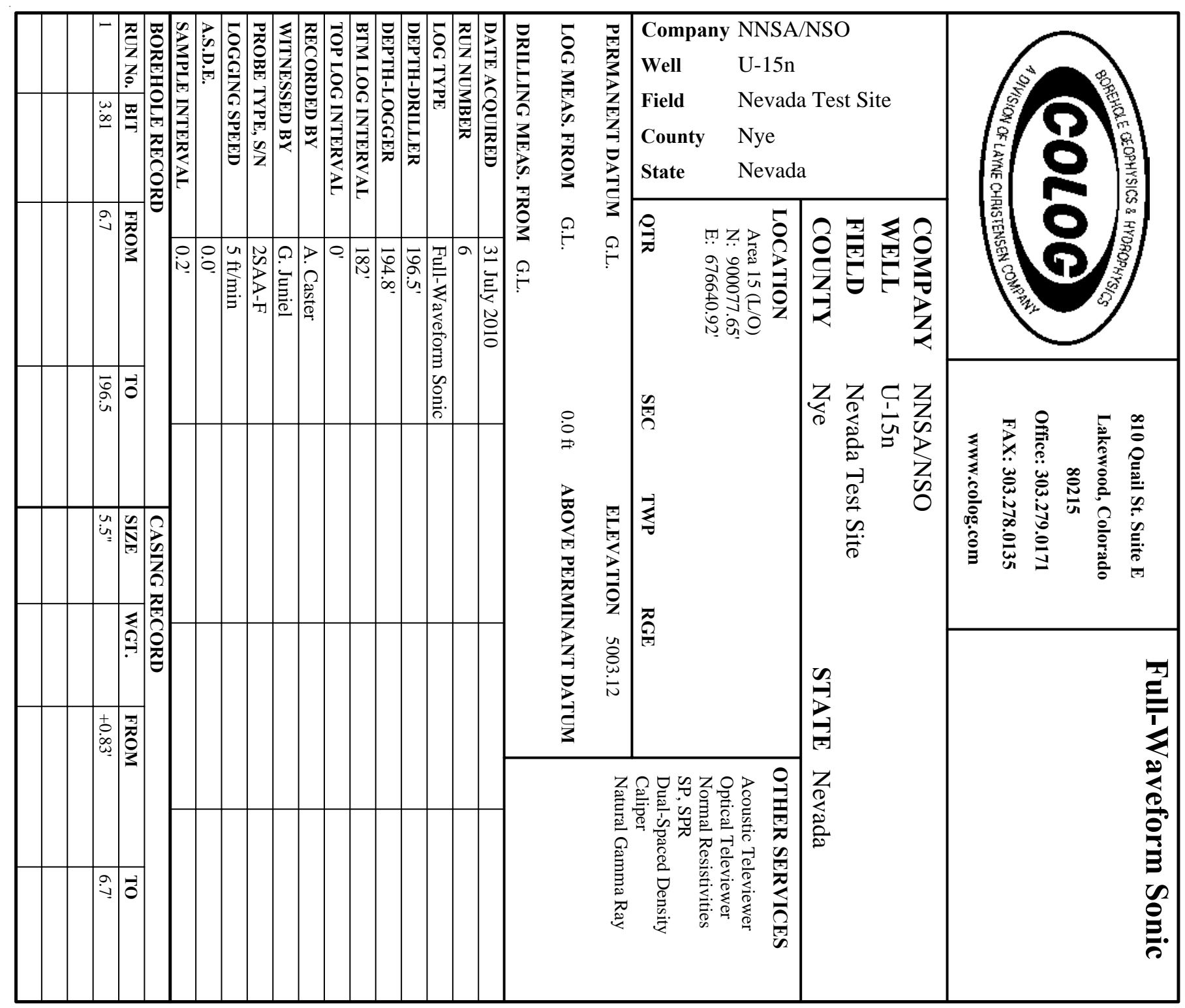

COMMENTS

NA - Not Available, N/A - Not Applicable

Could not reach driller's TD, due to fill.

P-wave and S-wave Slowness and Velocity calculated from all three receivers, using a semblance algorythm. 


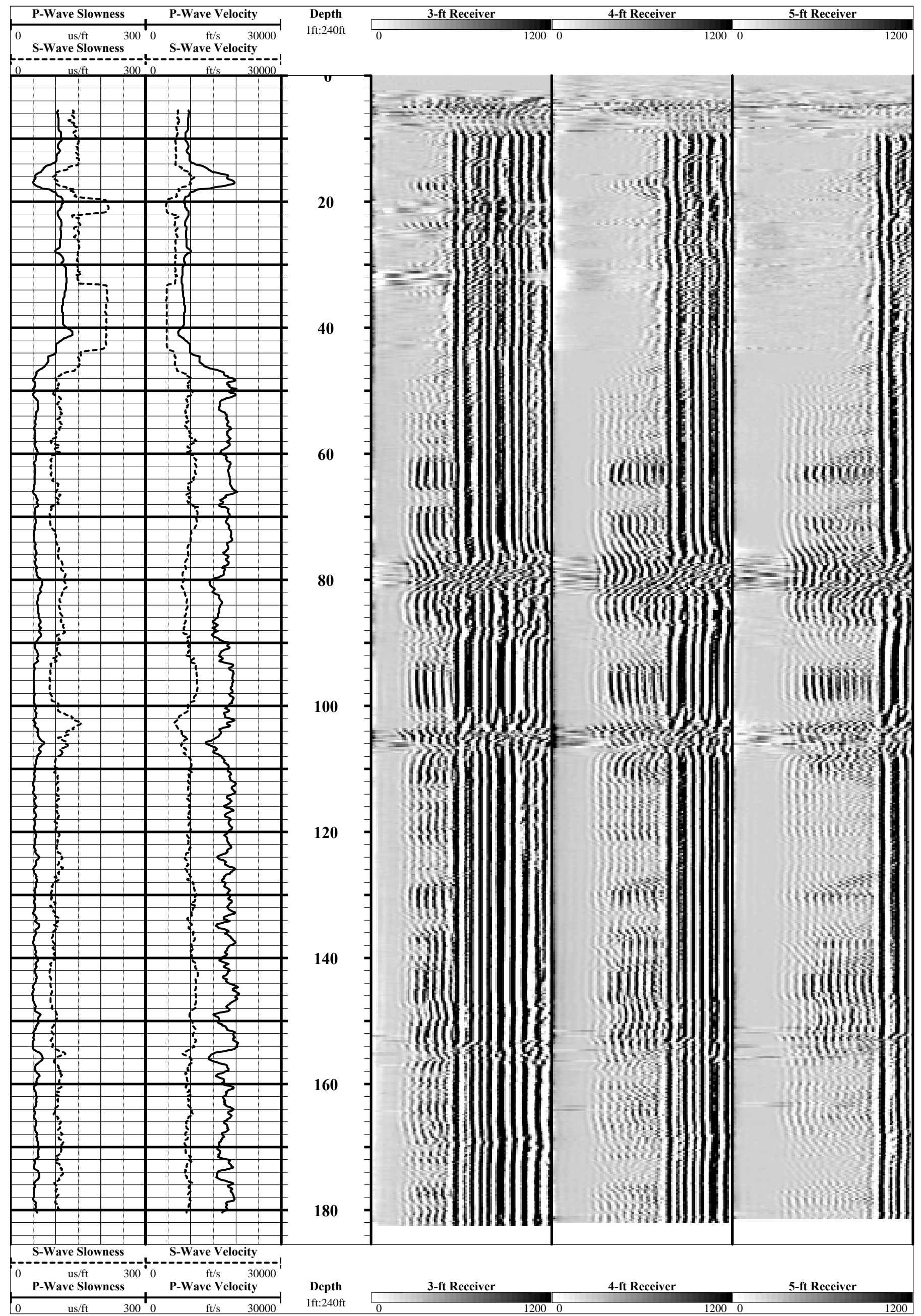




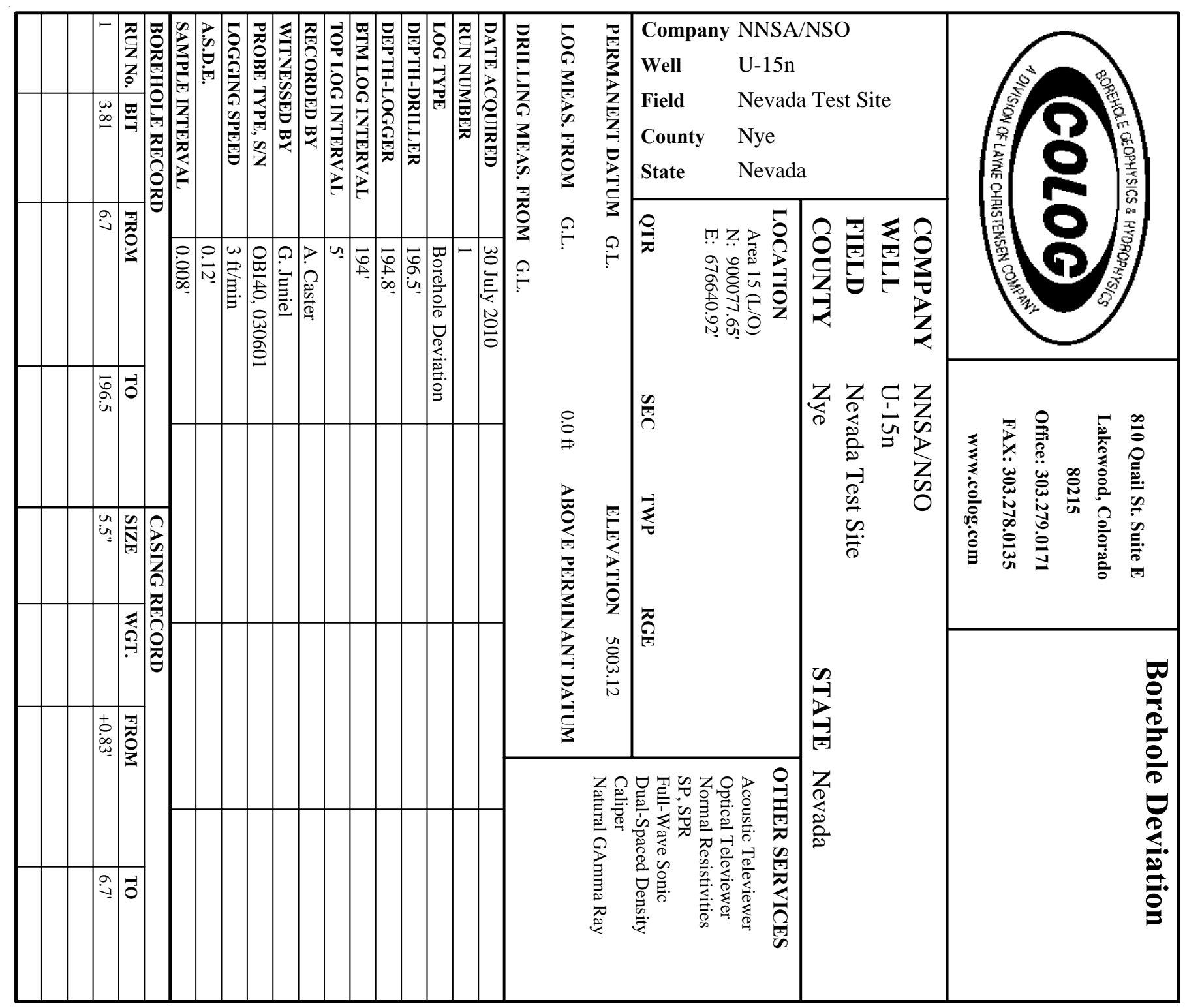

COMMENTS

NA - Not Available, N/A - Not Applicable

Could not reach driller's TD, due to fill.

Magnetic declination of 12.85 degrees East added to correct magnetic azimuth to True North. 


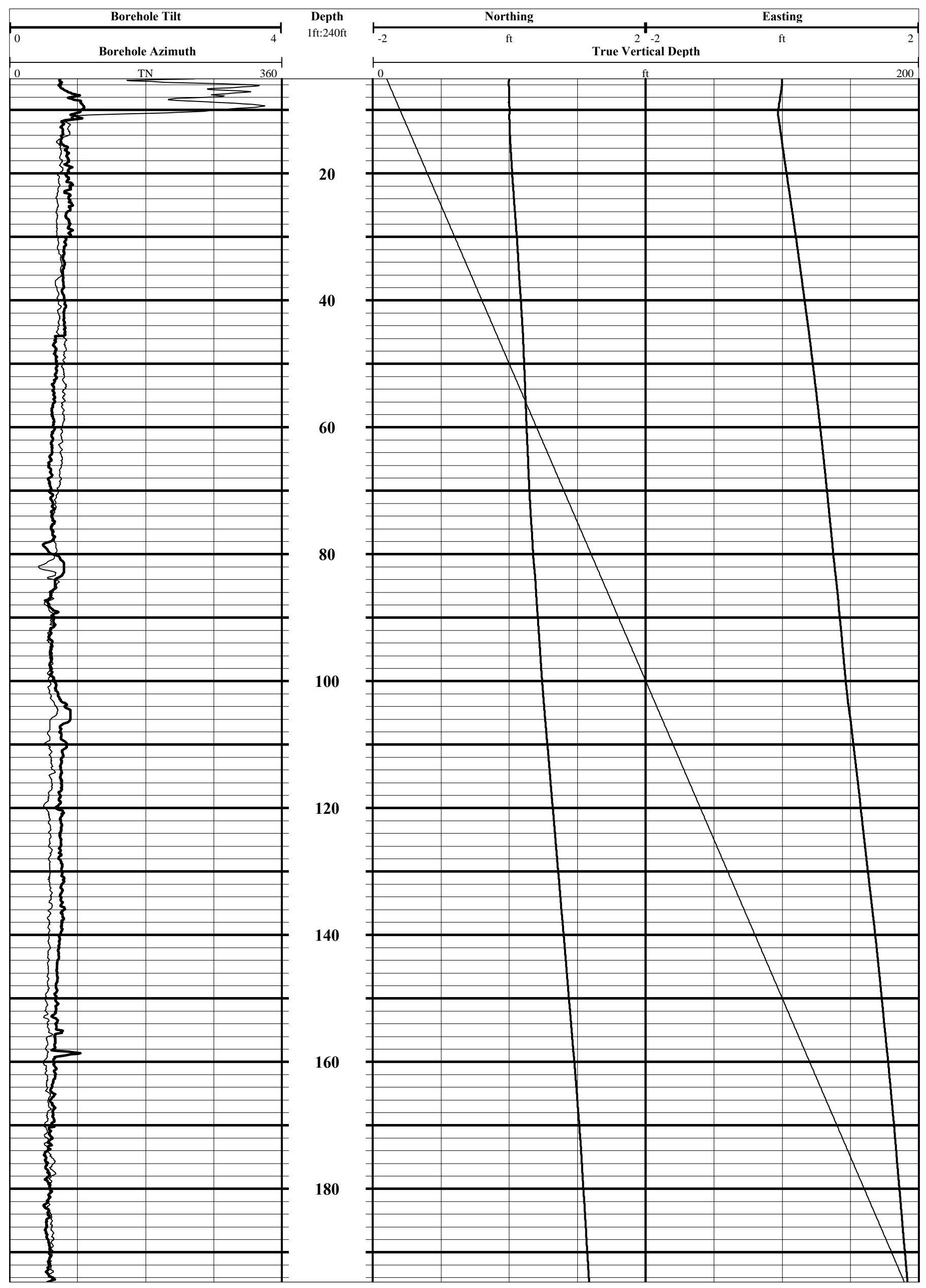




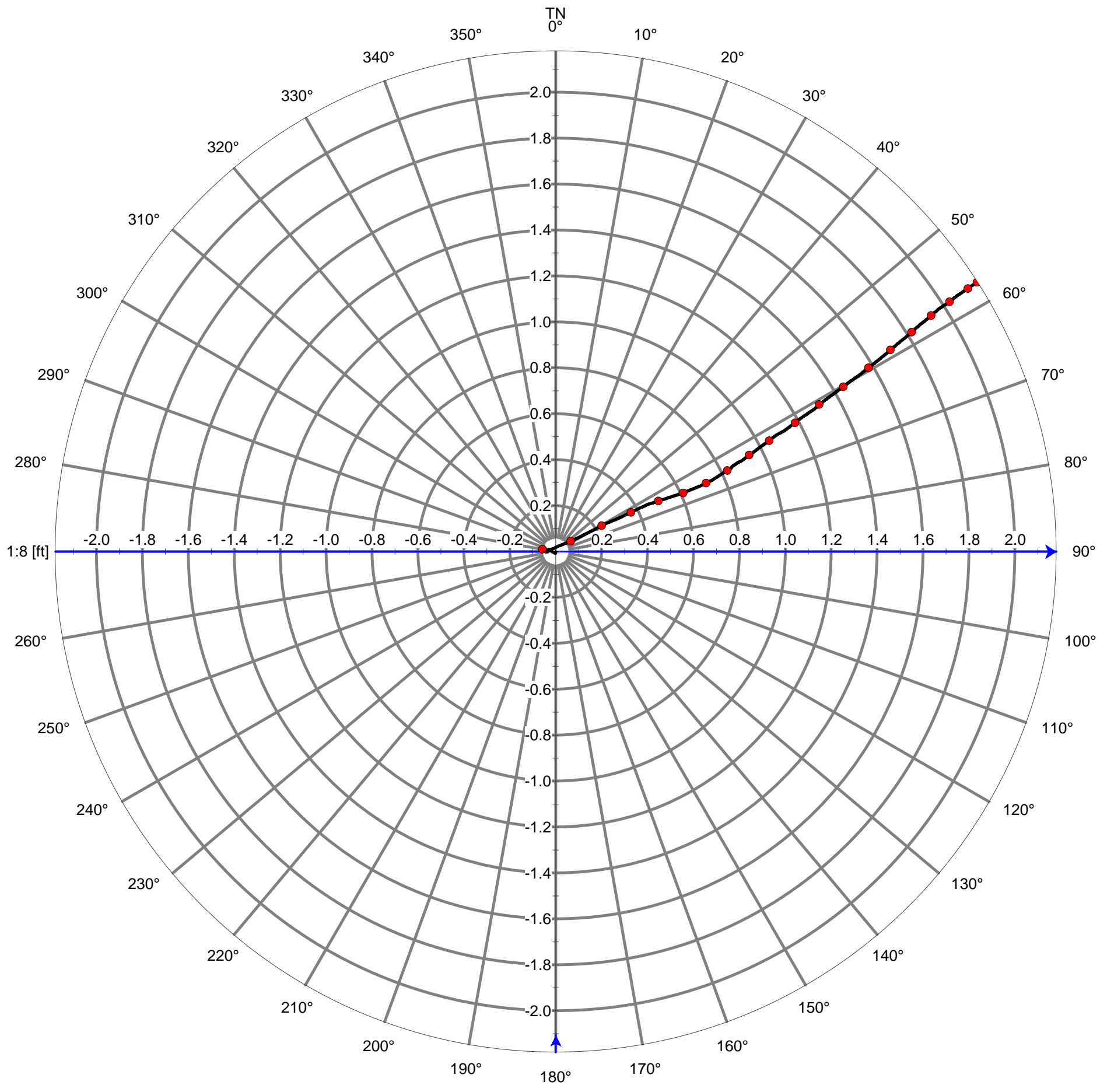




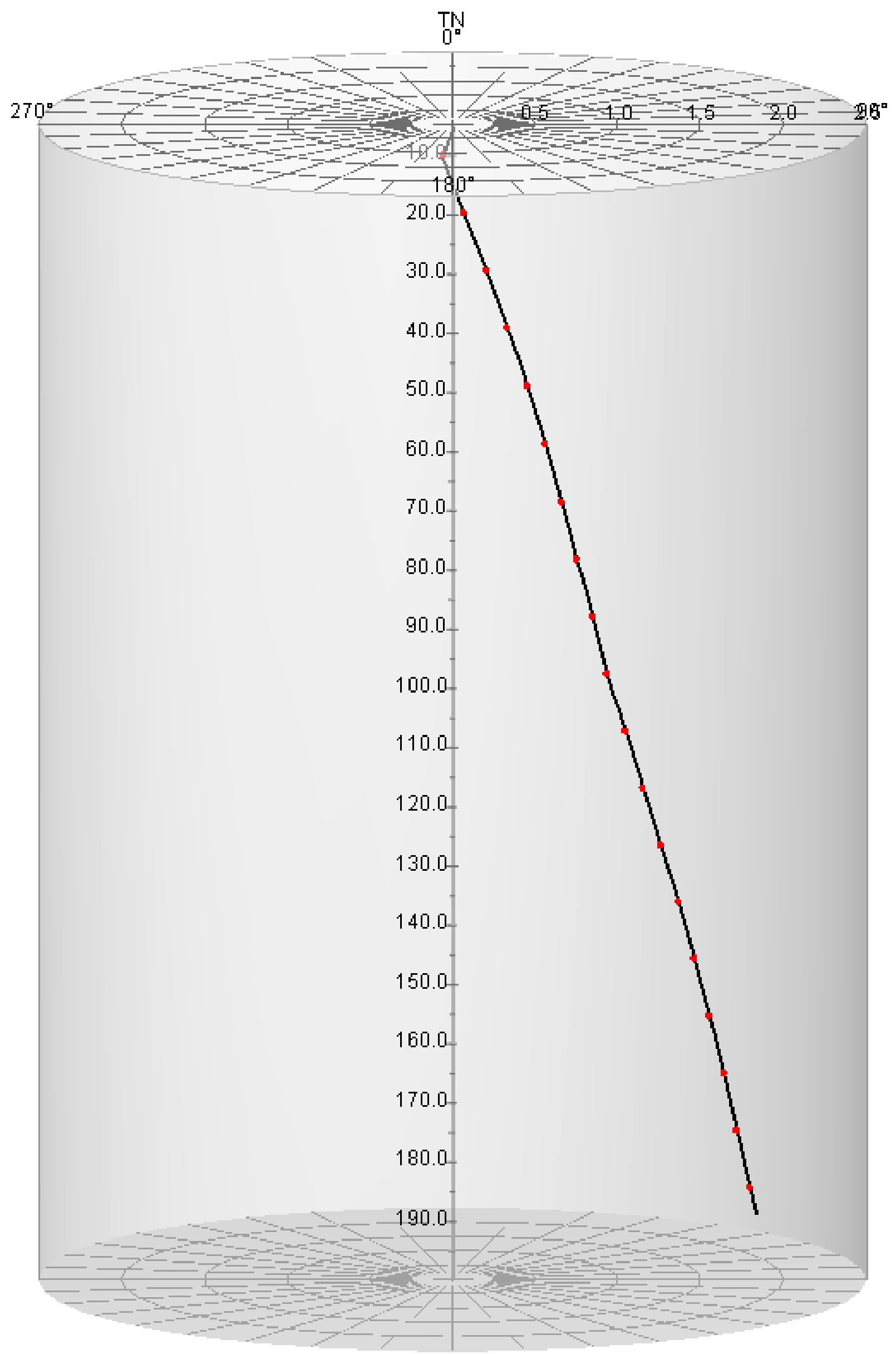


Appendix F-2

Borehole Geophysical Log Plots for Instrument Hole U-15n\#1 


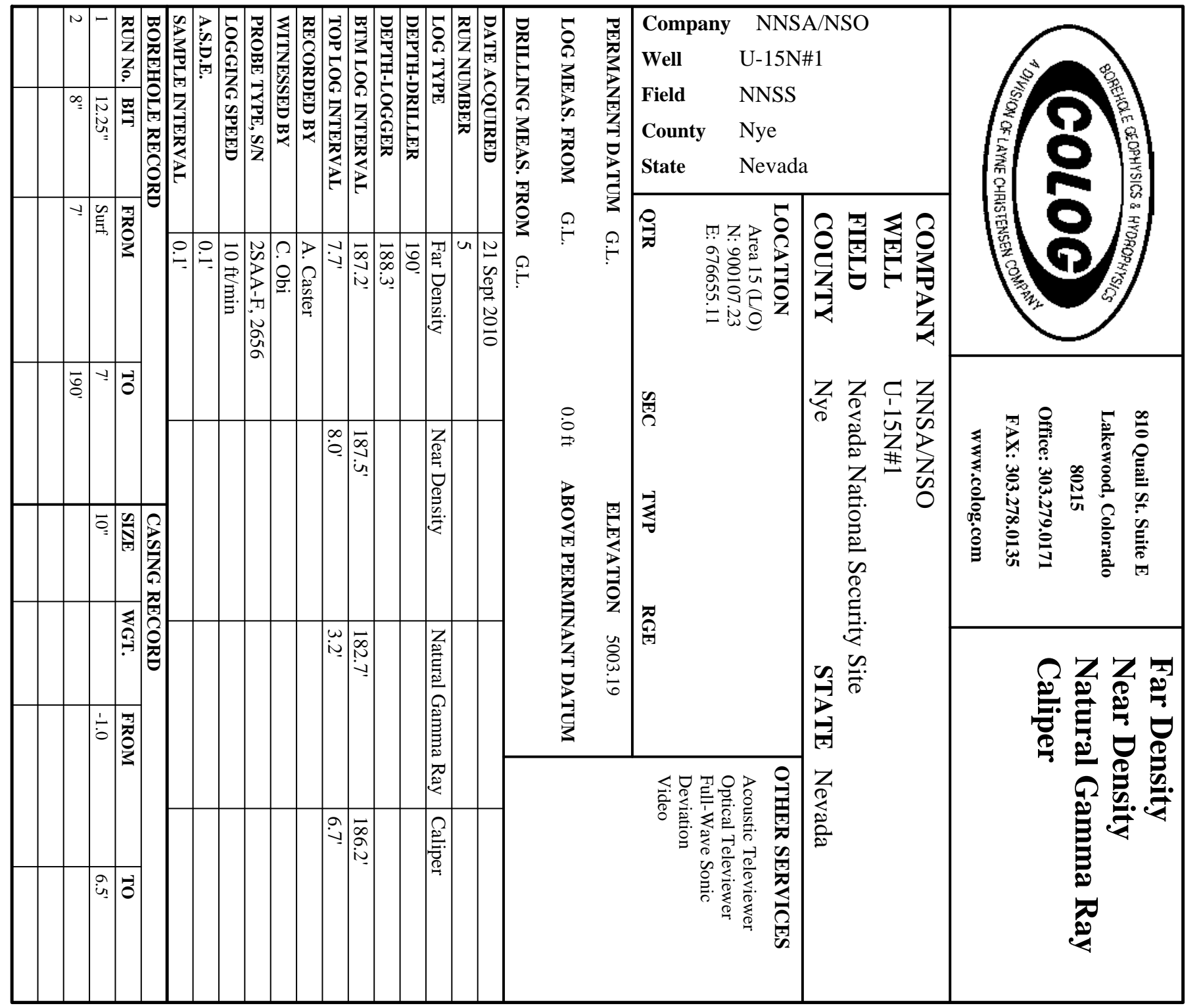

\section{COMMENTS}

NA - Not Available, N/A - Not Applicable

Matrix Density of 2.64 used to calculate Density Porosity 


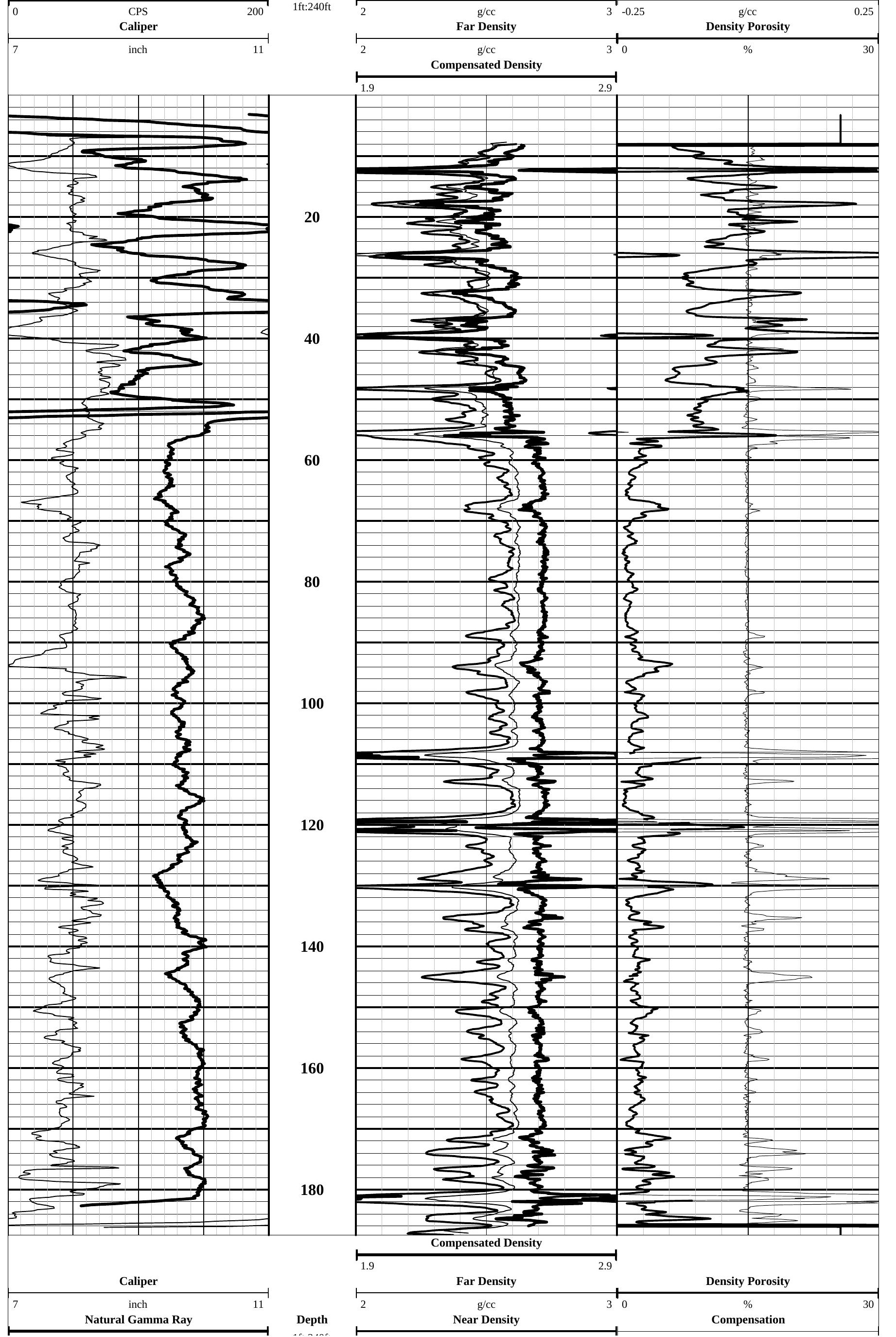




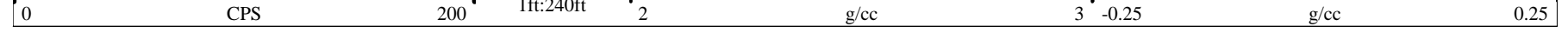




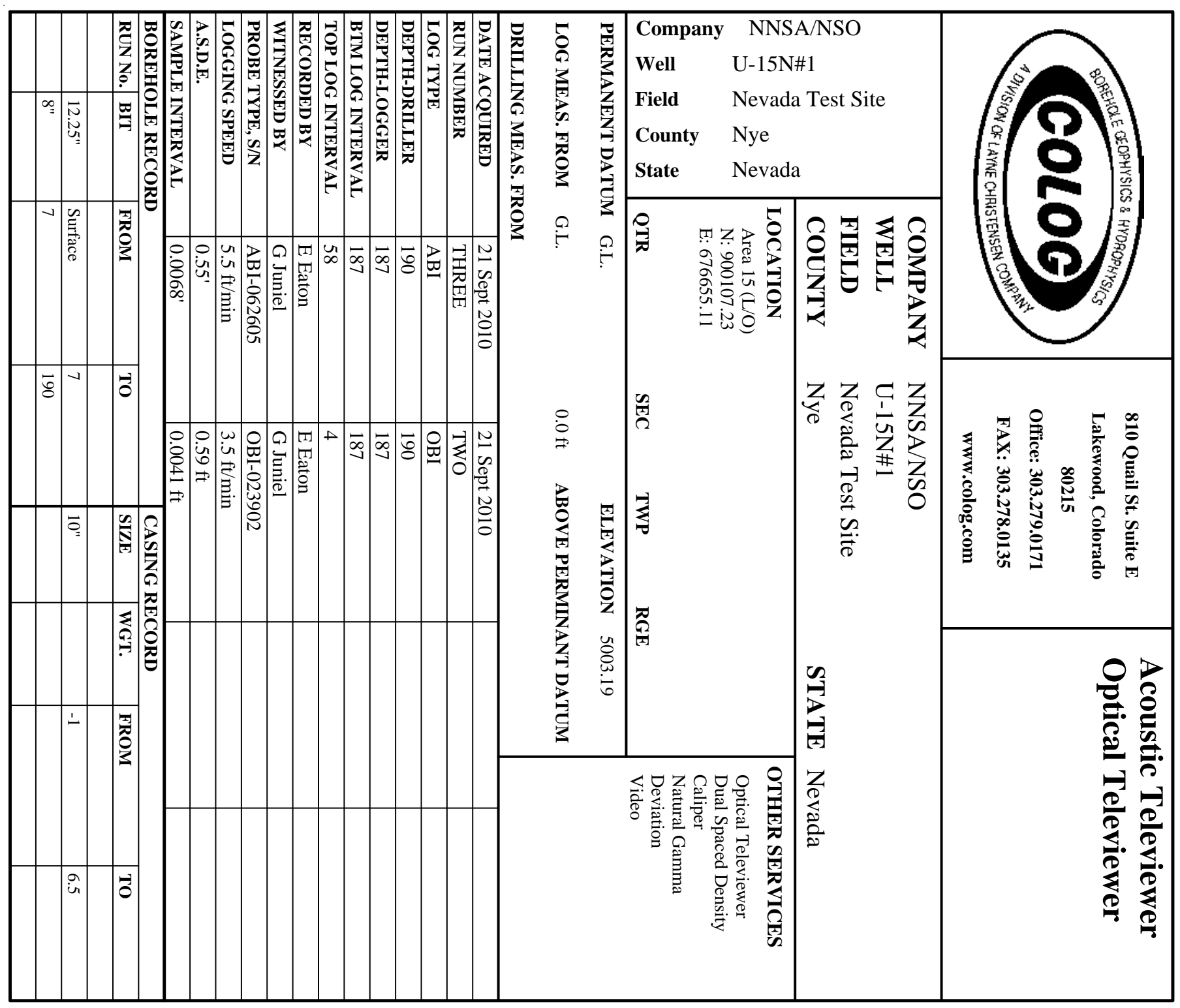




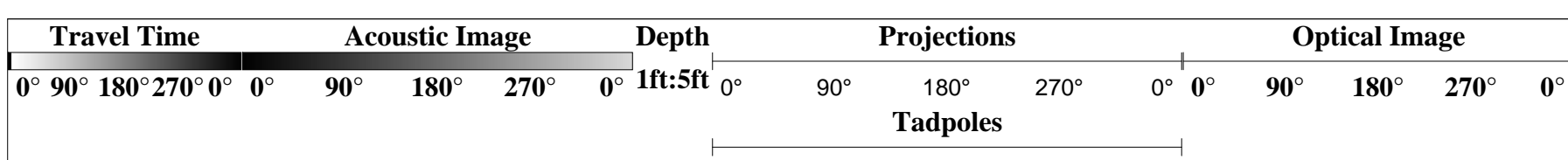

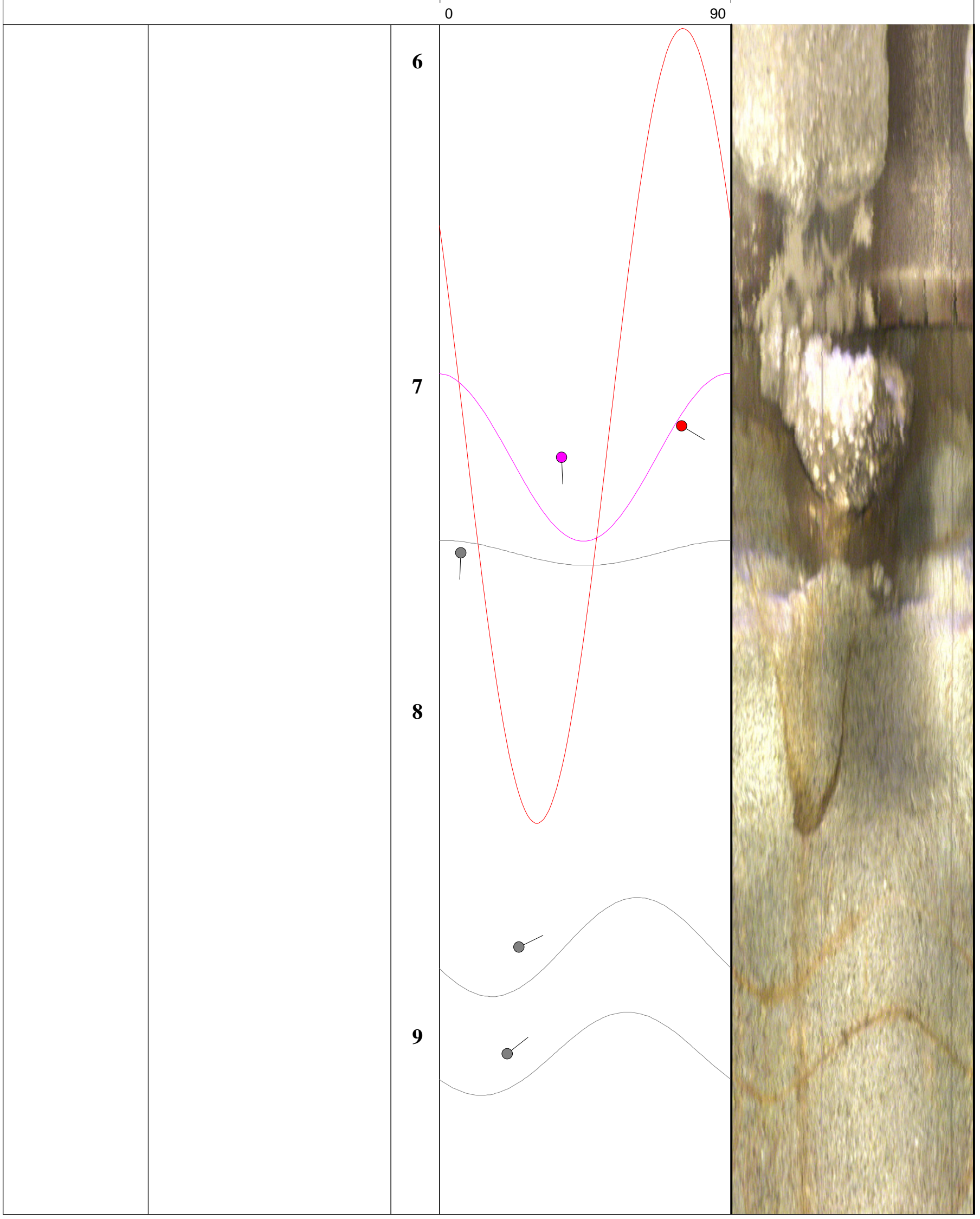




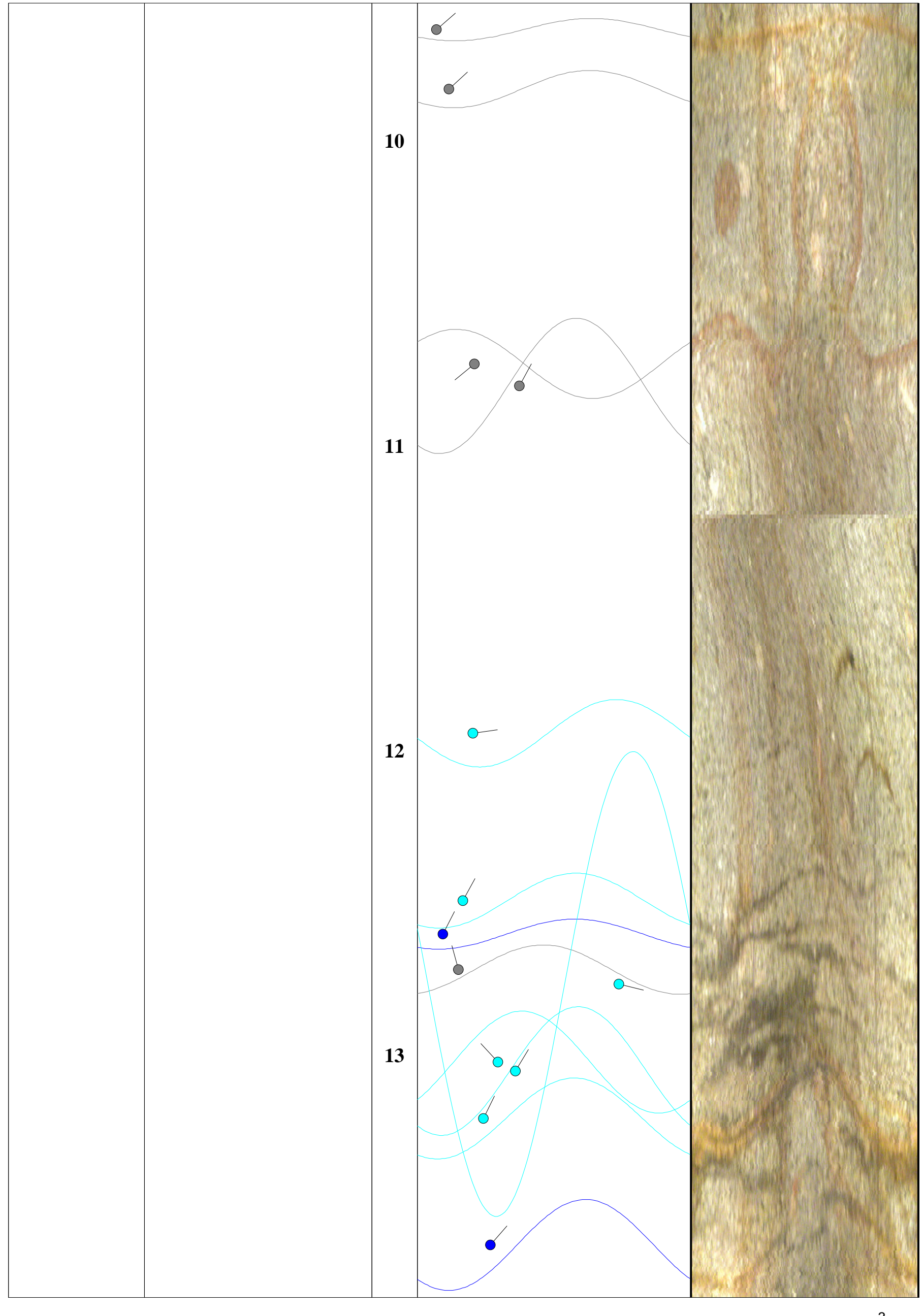




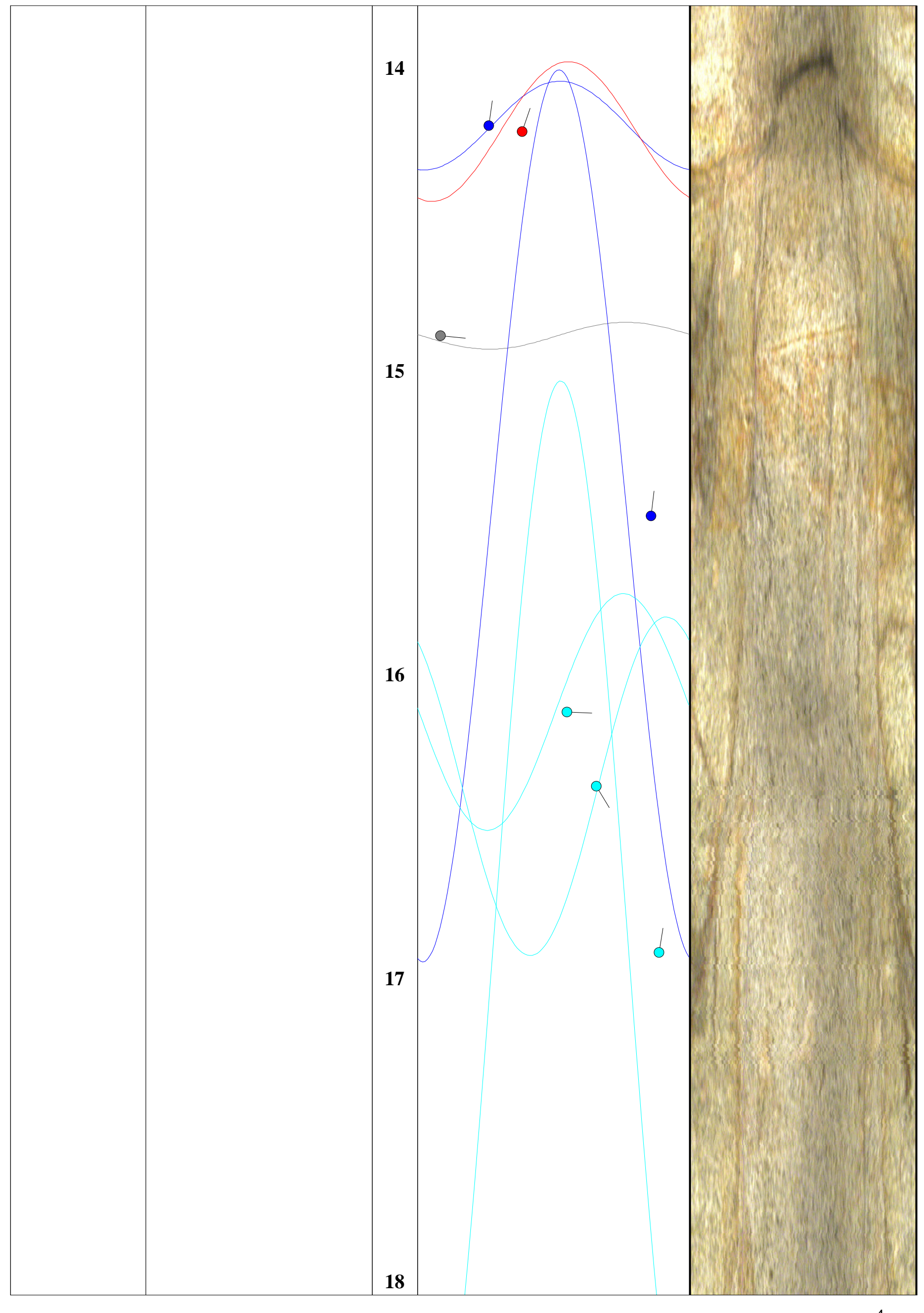




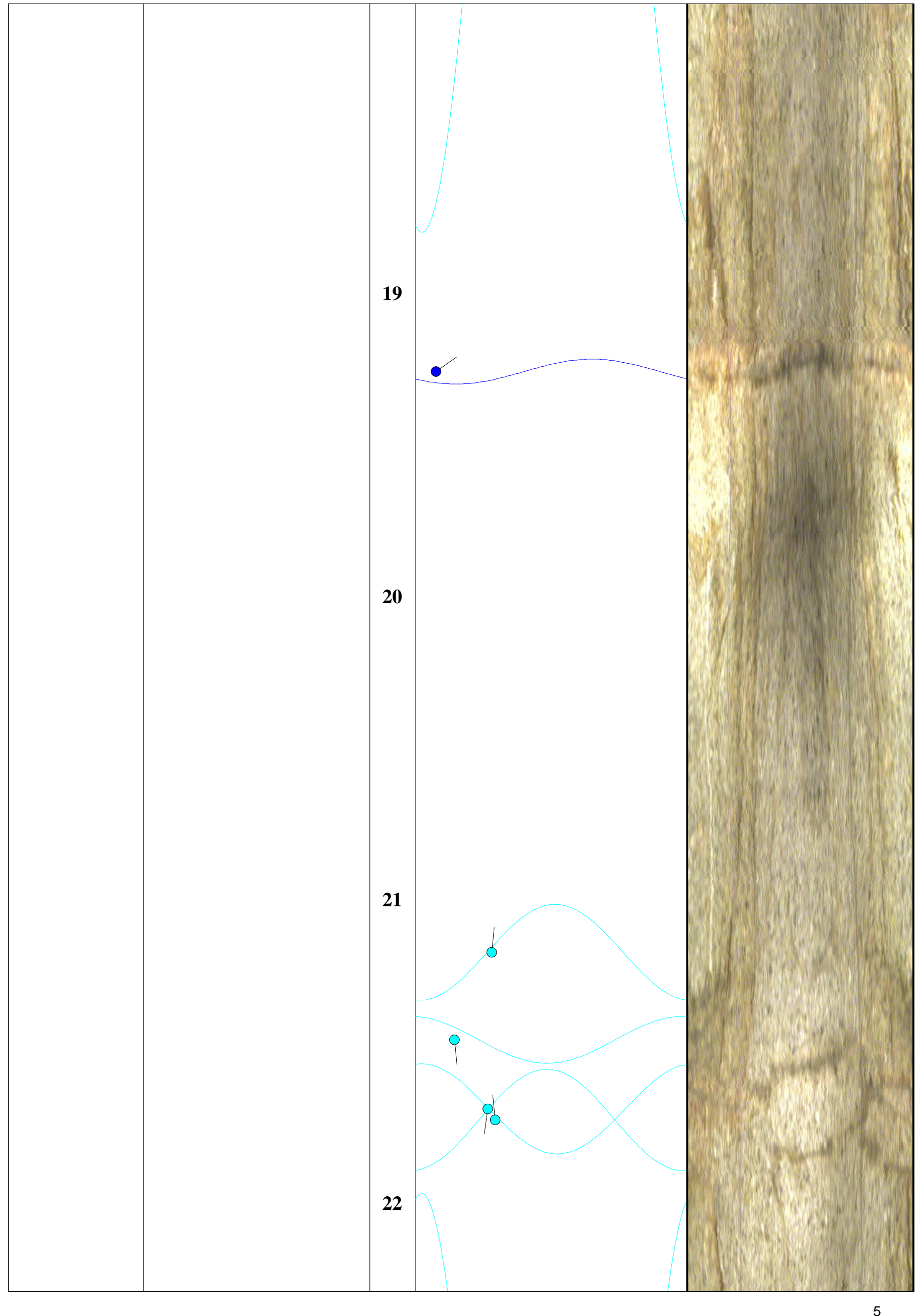




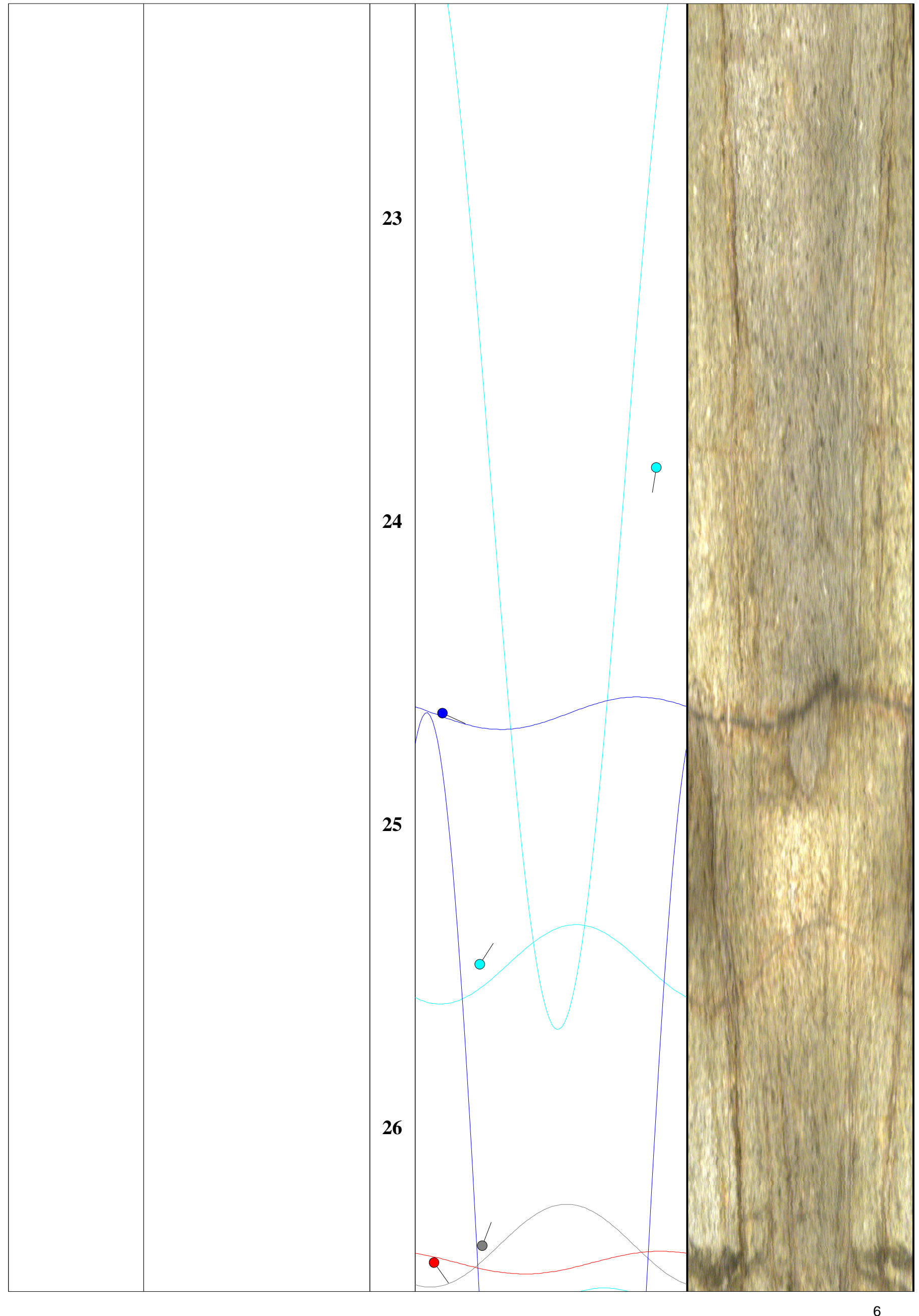




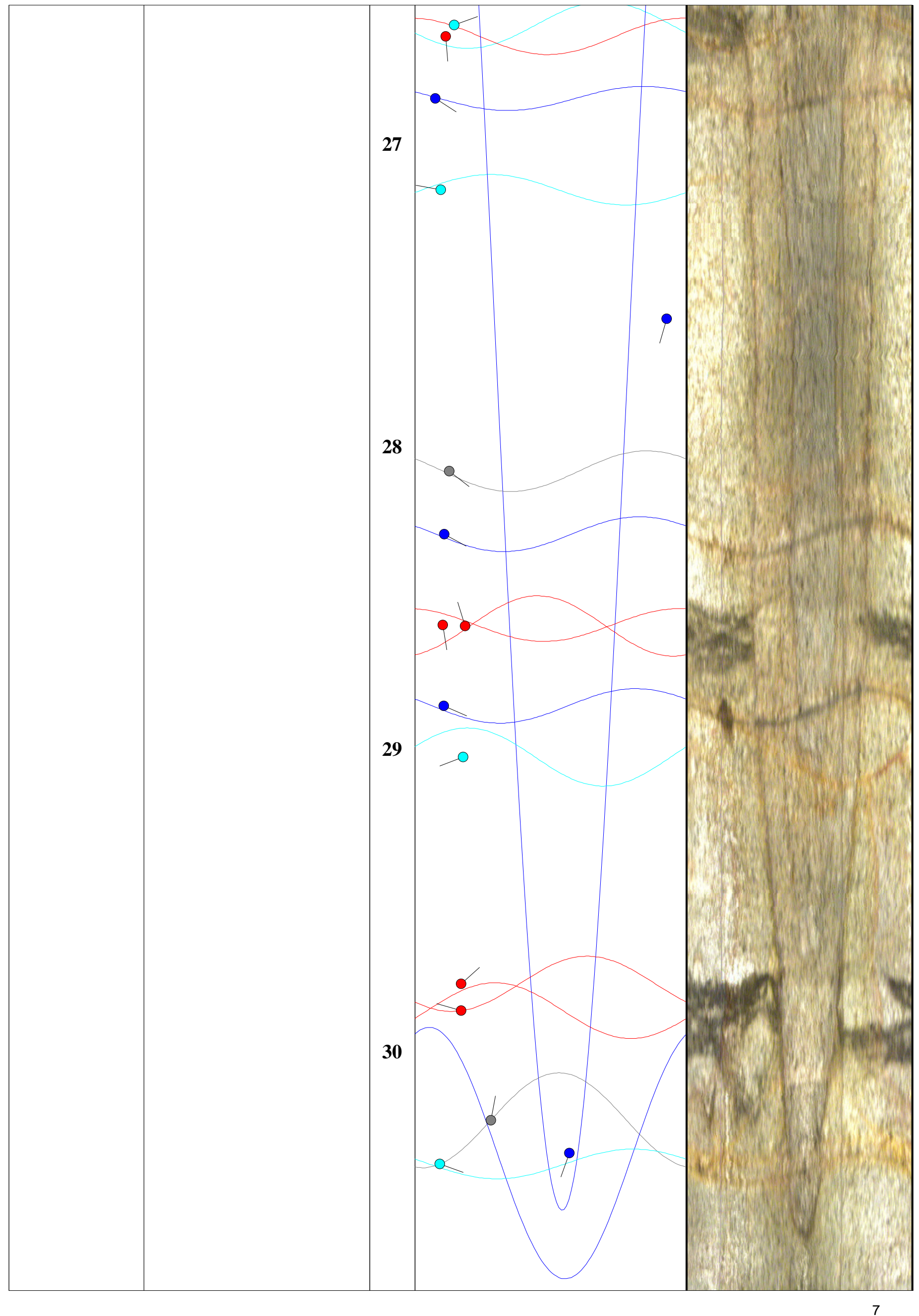




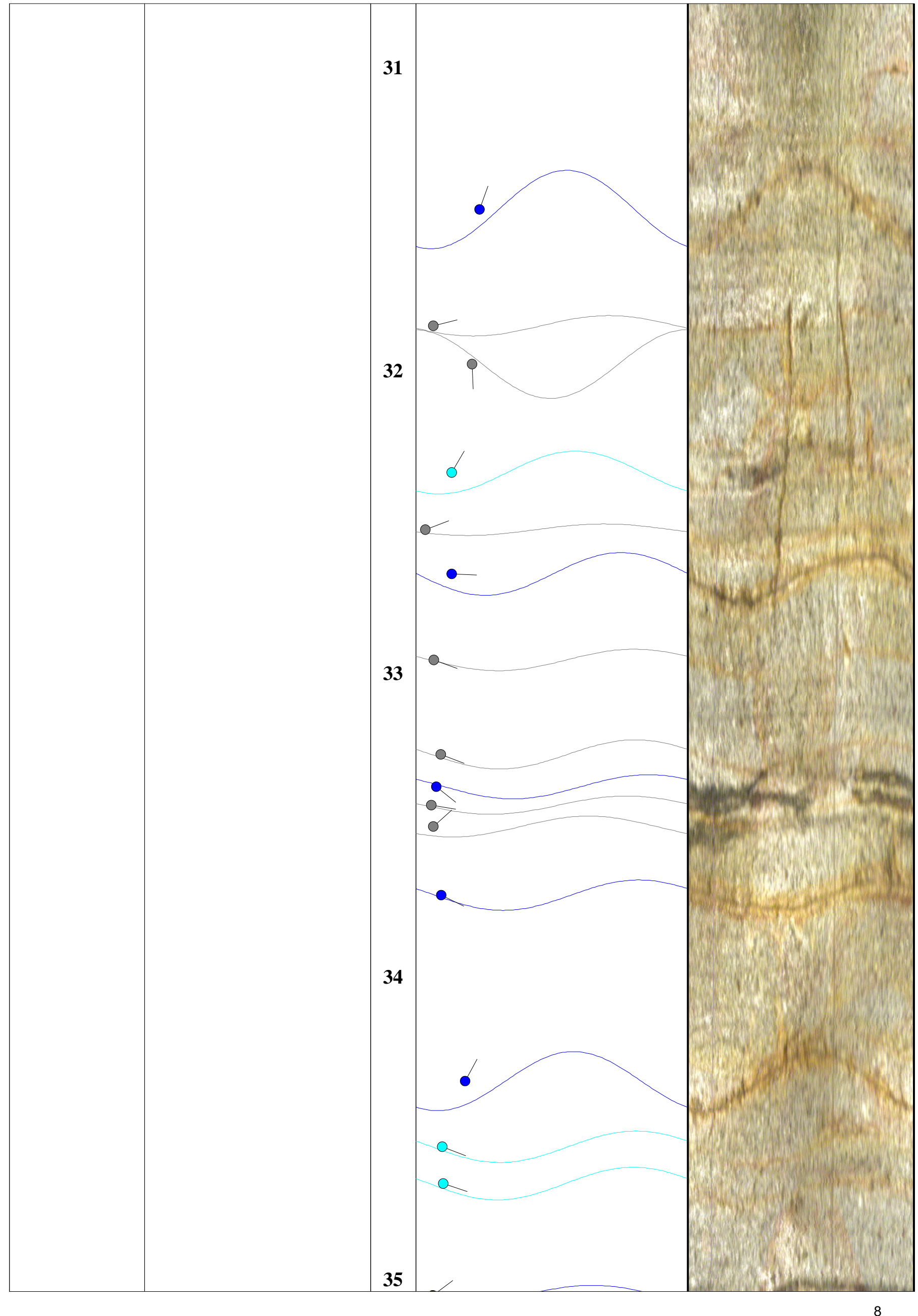




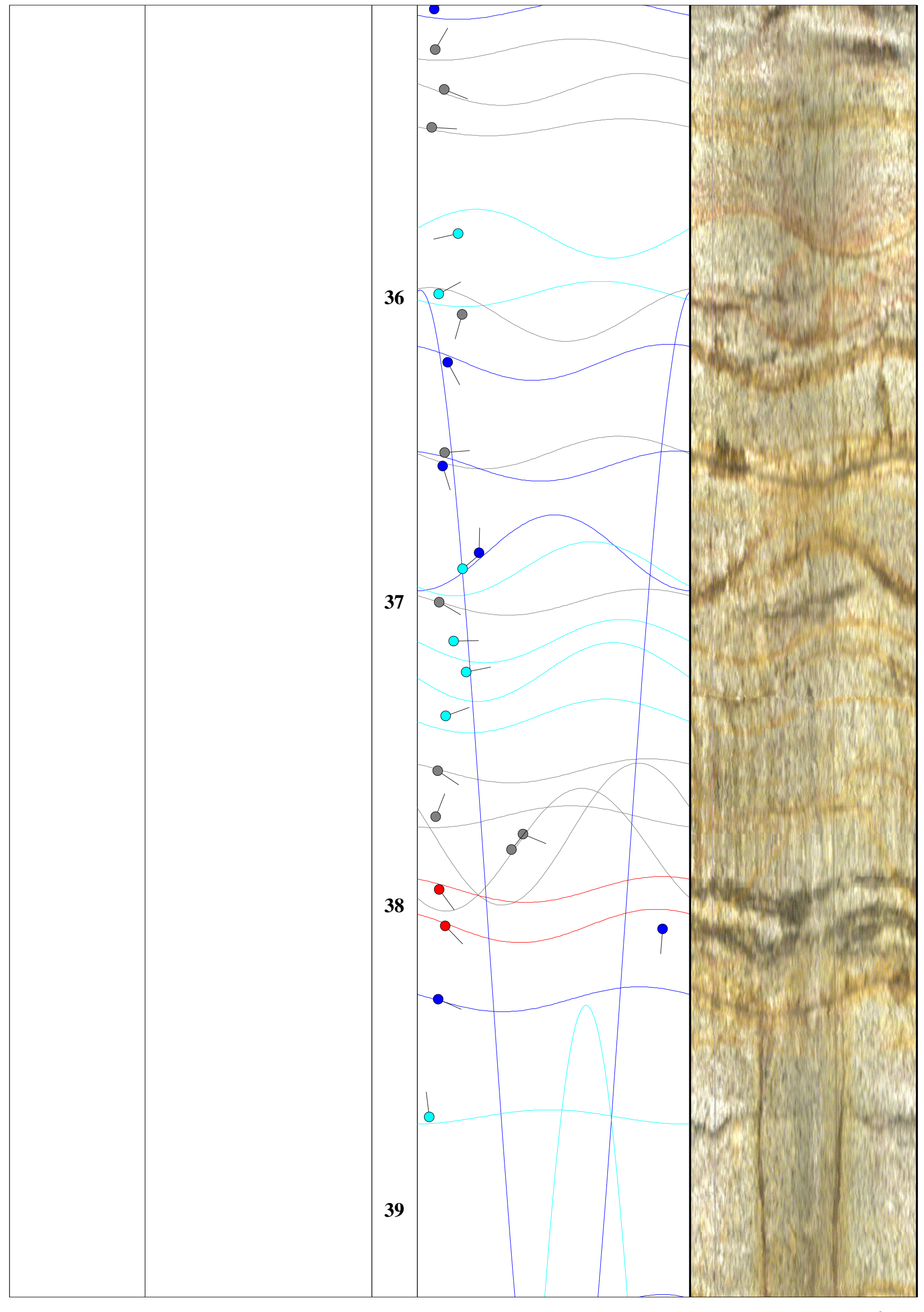




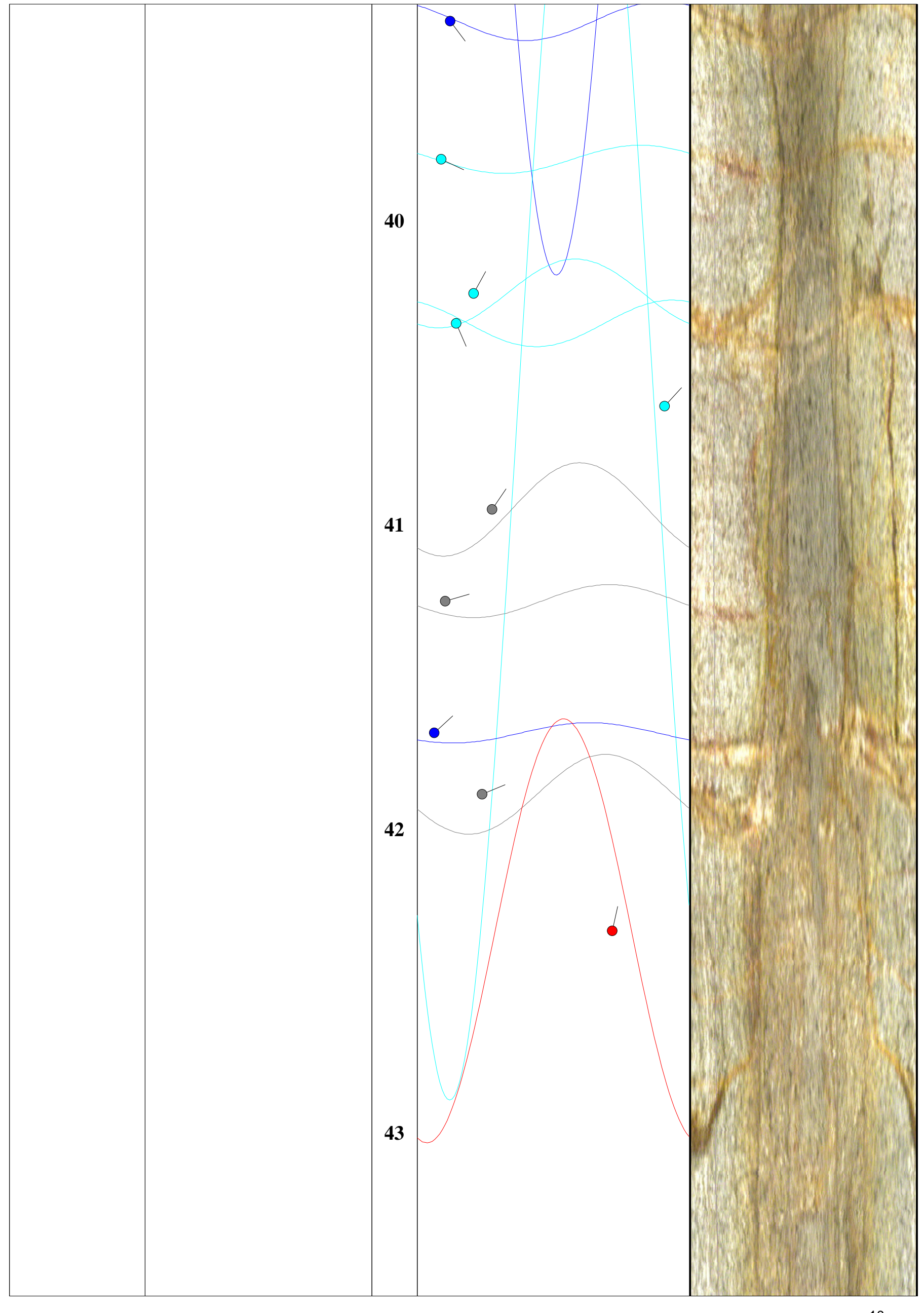




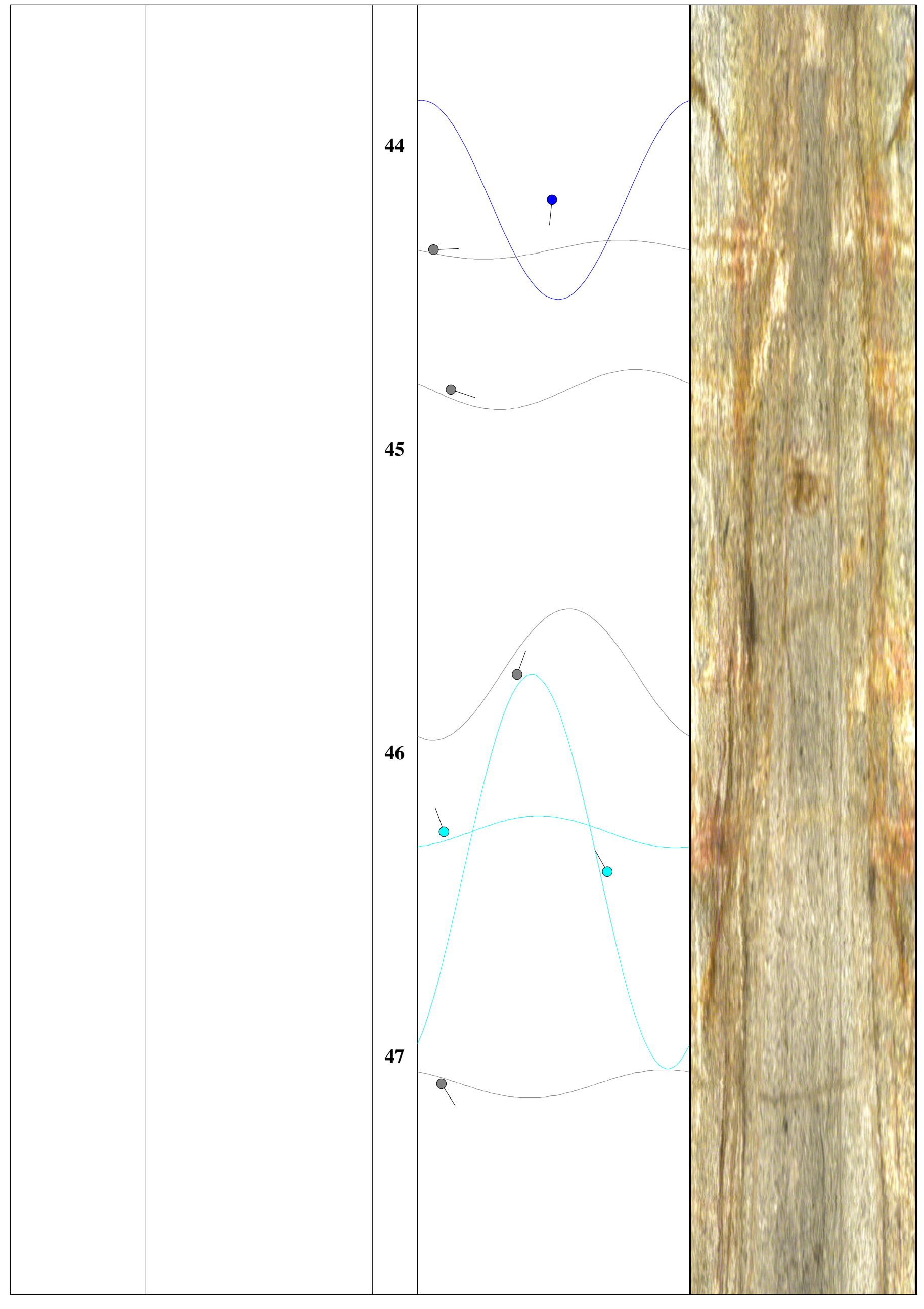




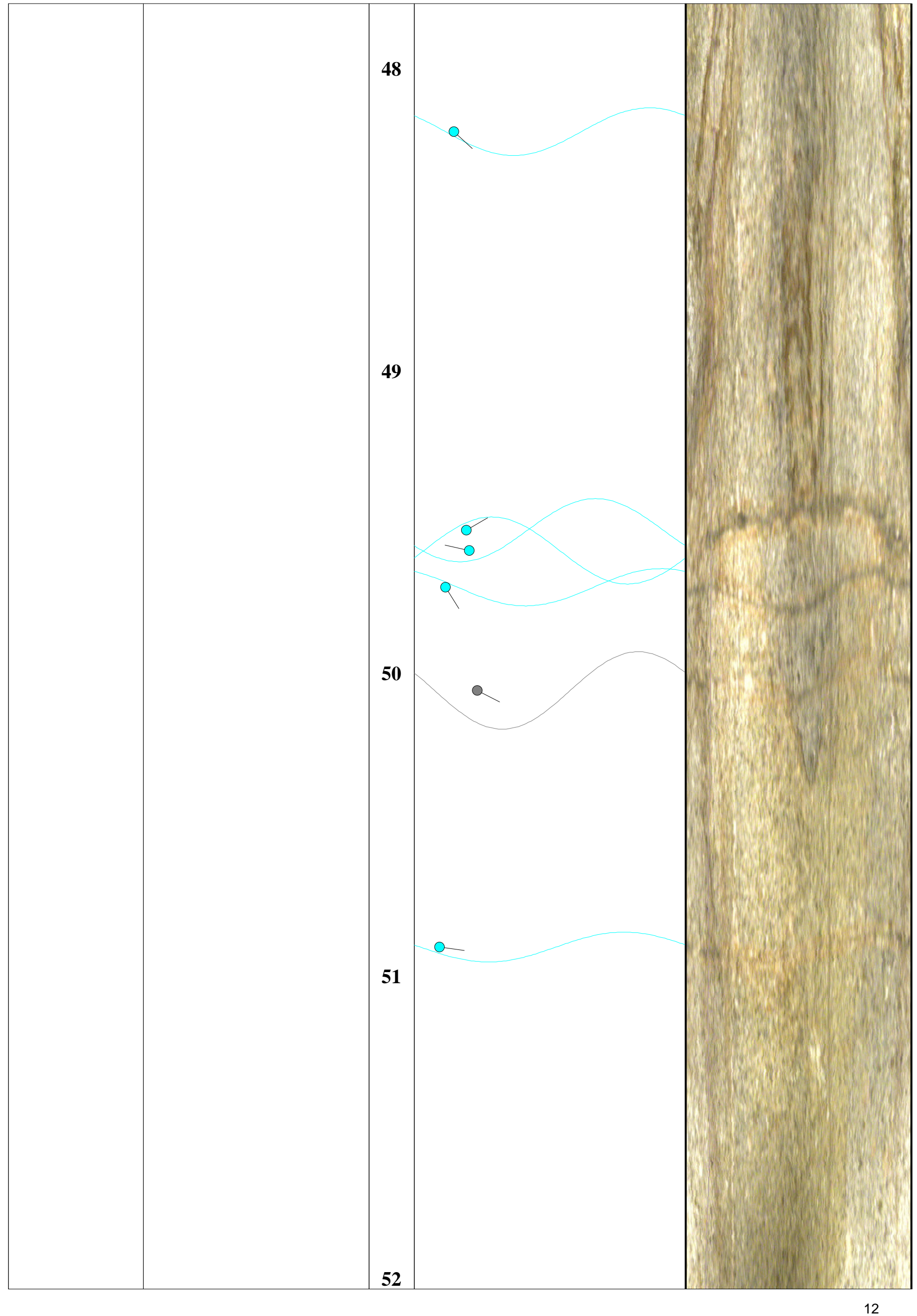




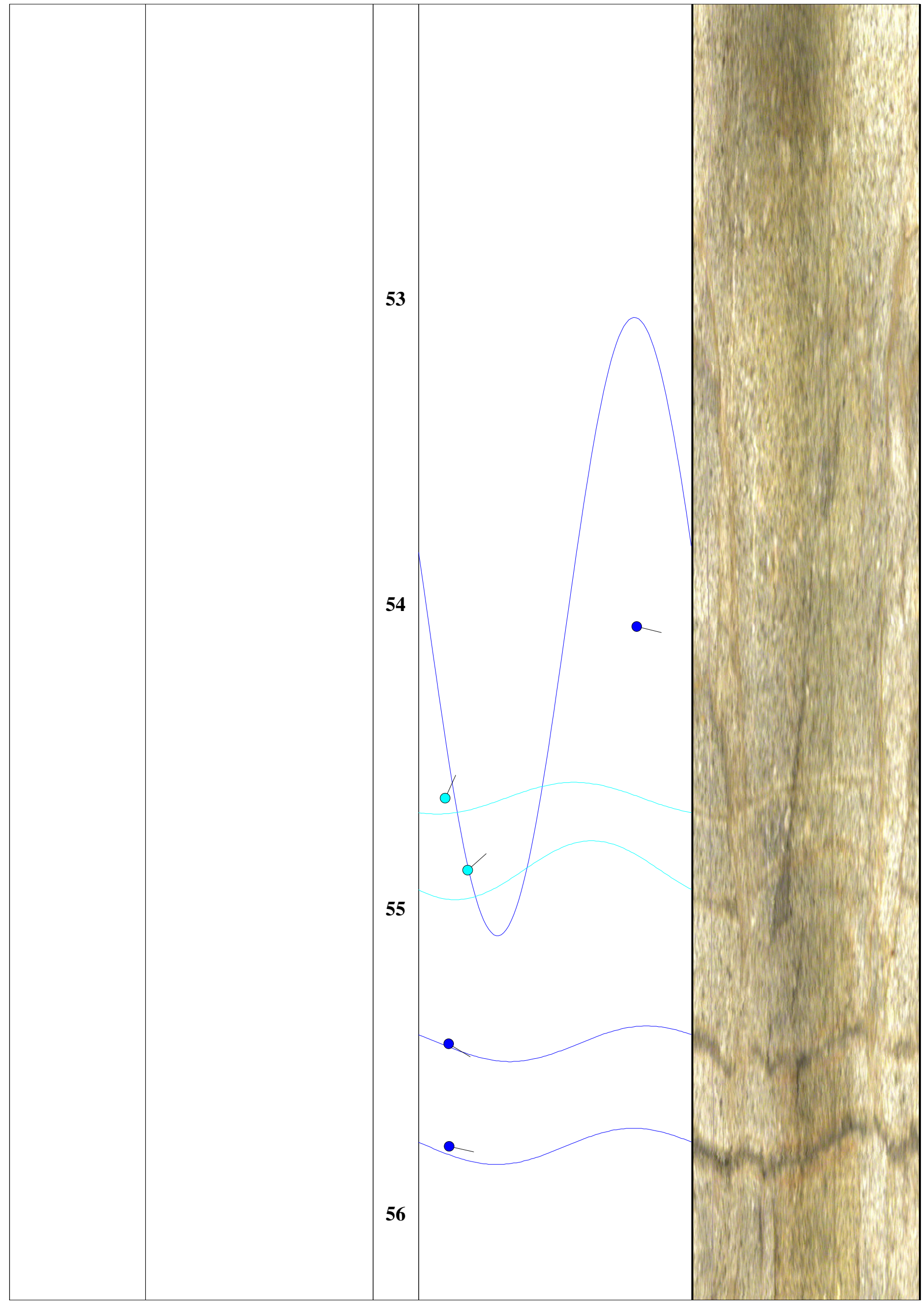




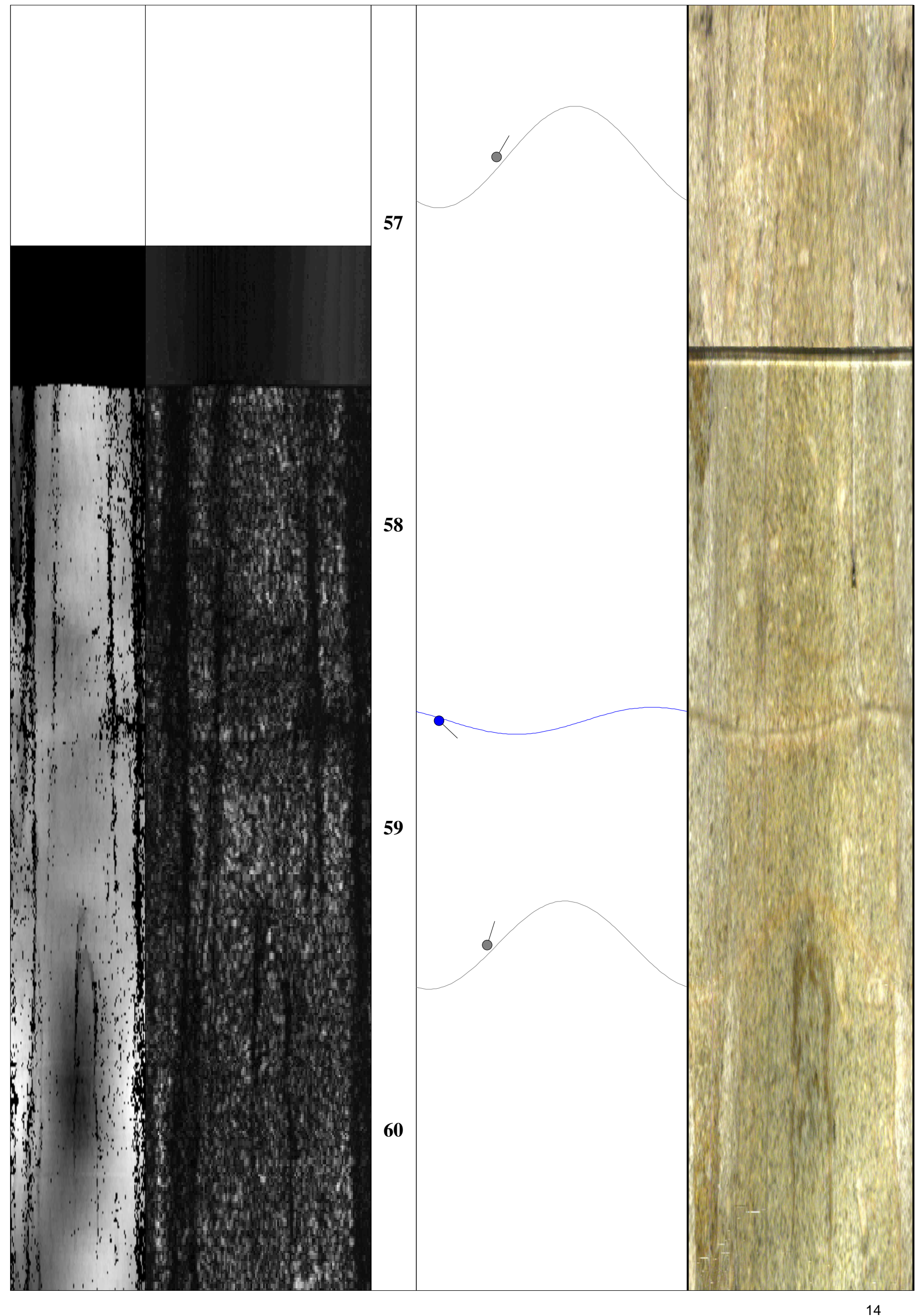




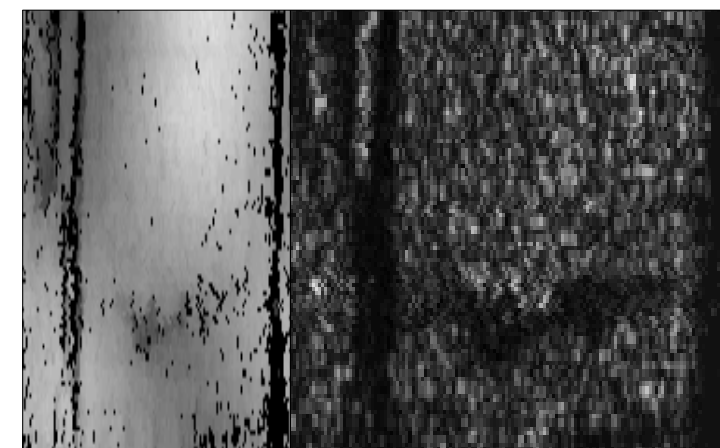

61

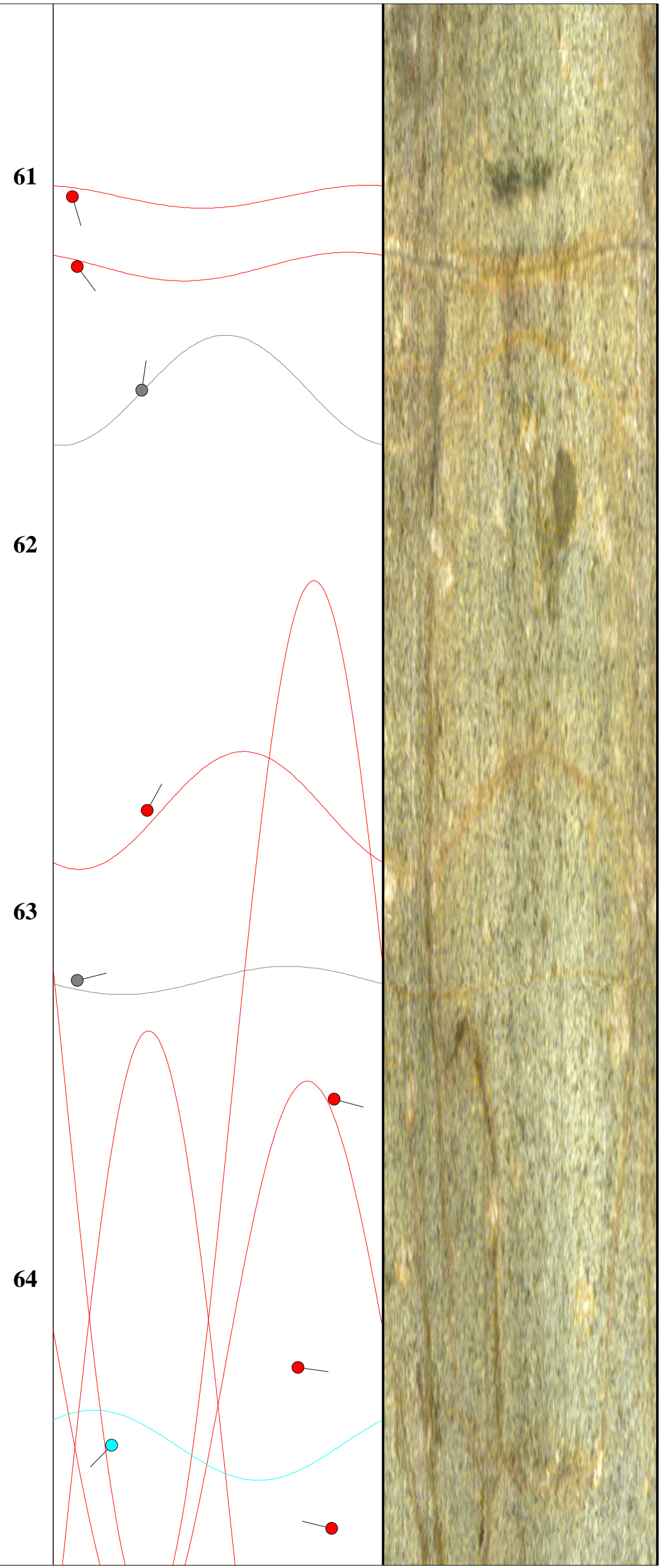




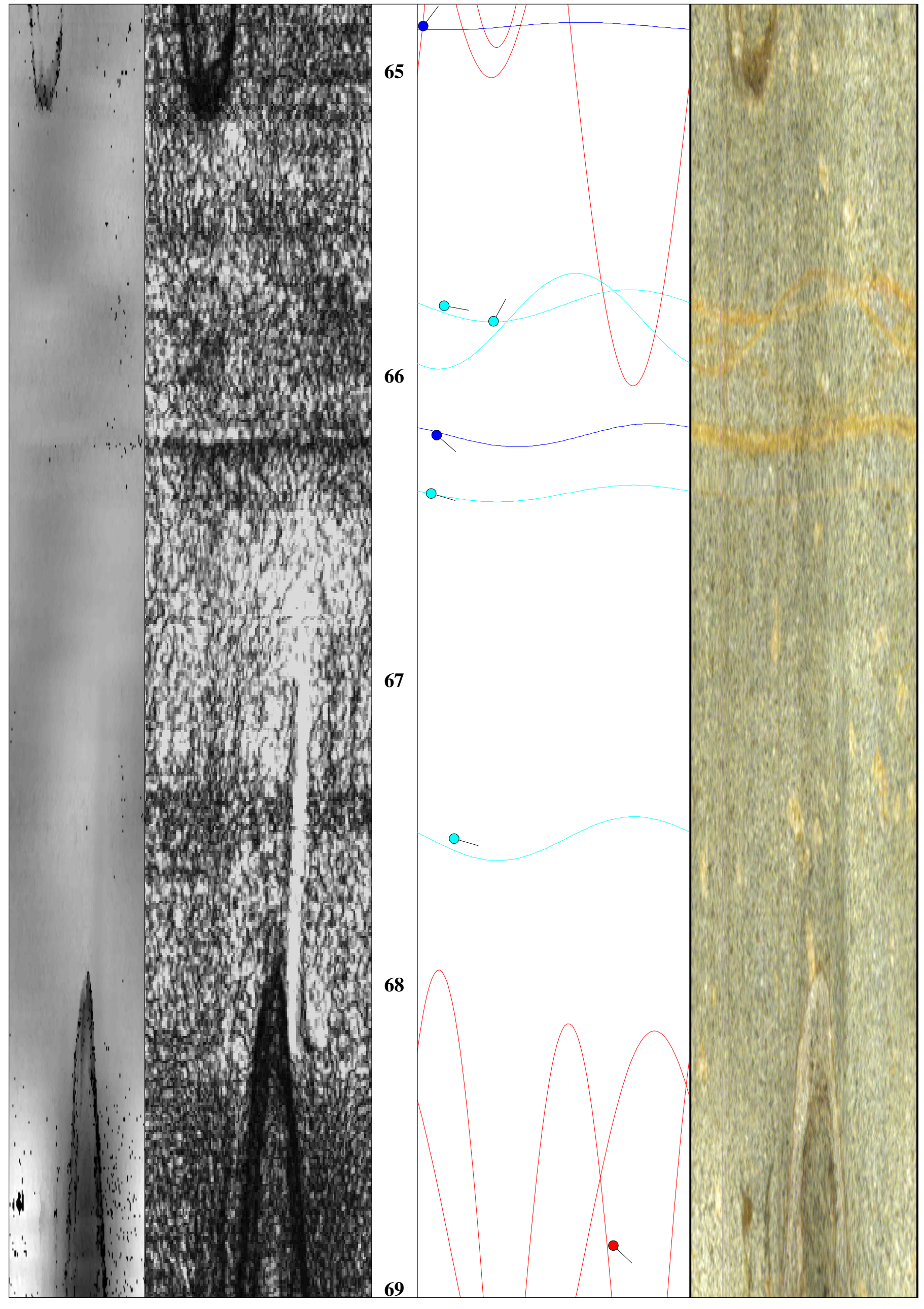




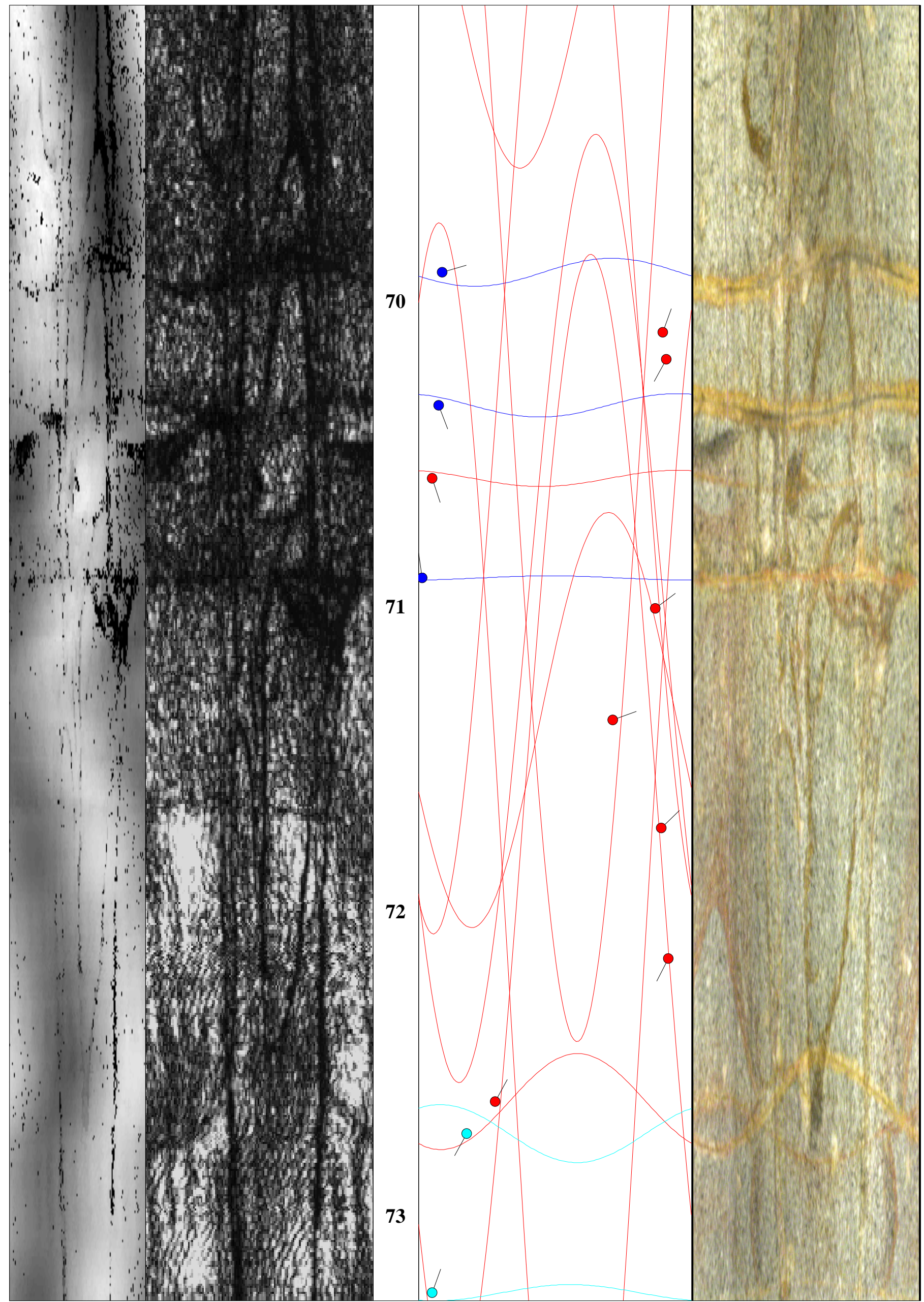




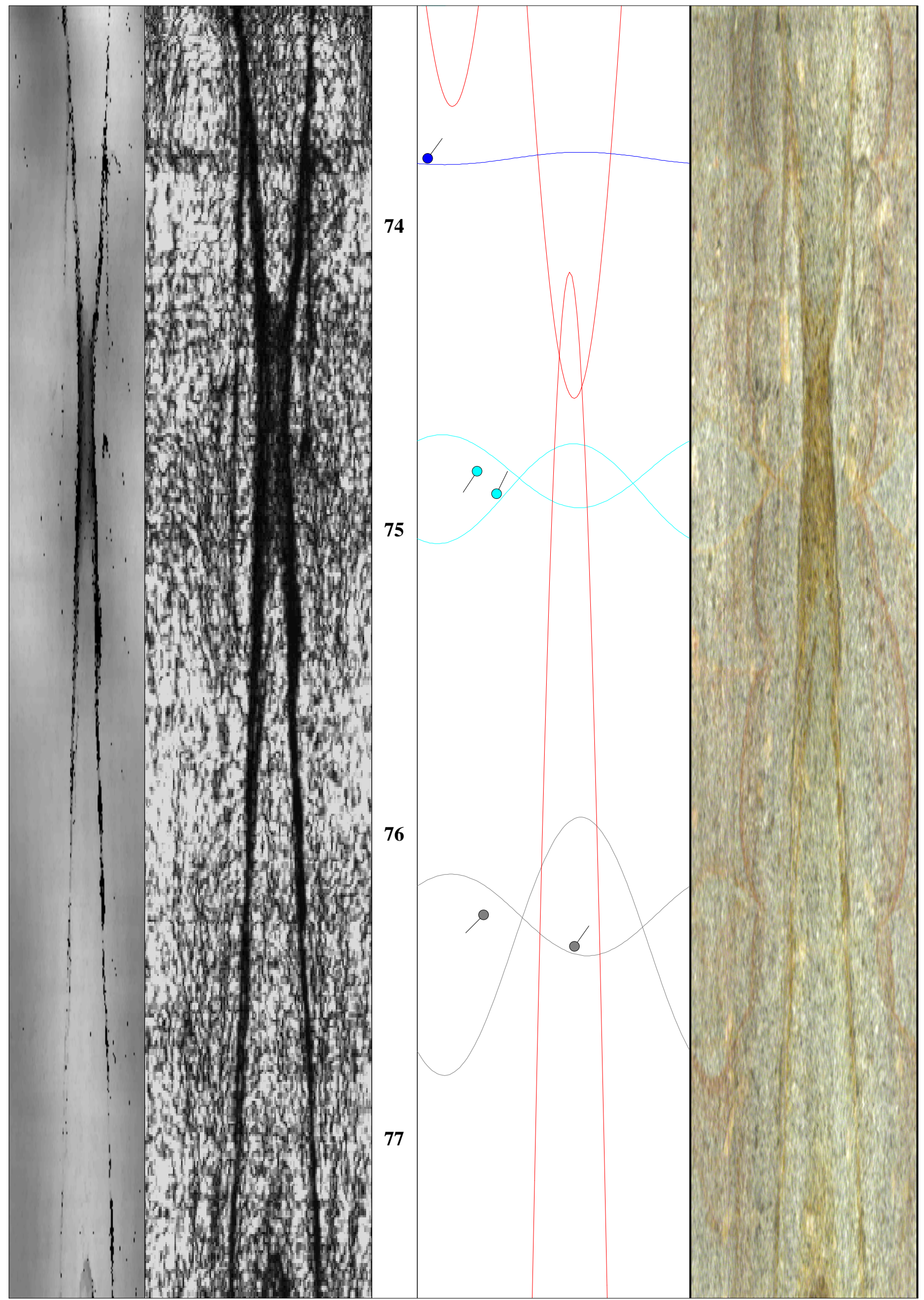




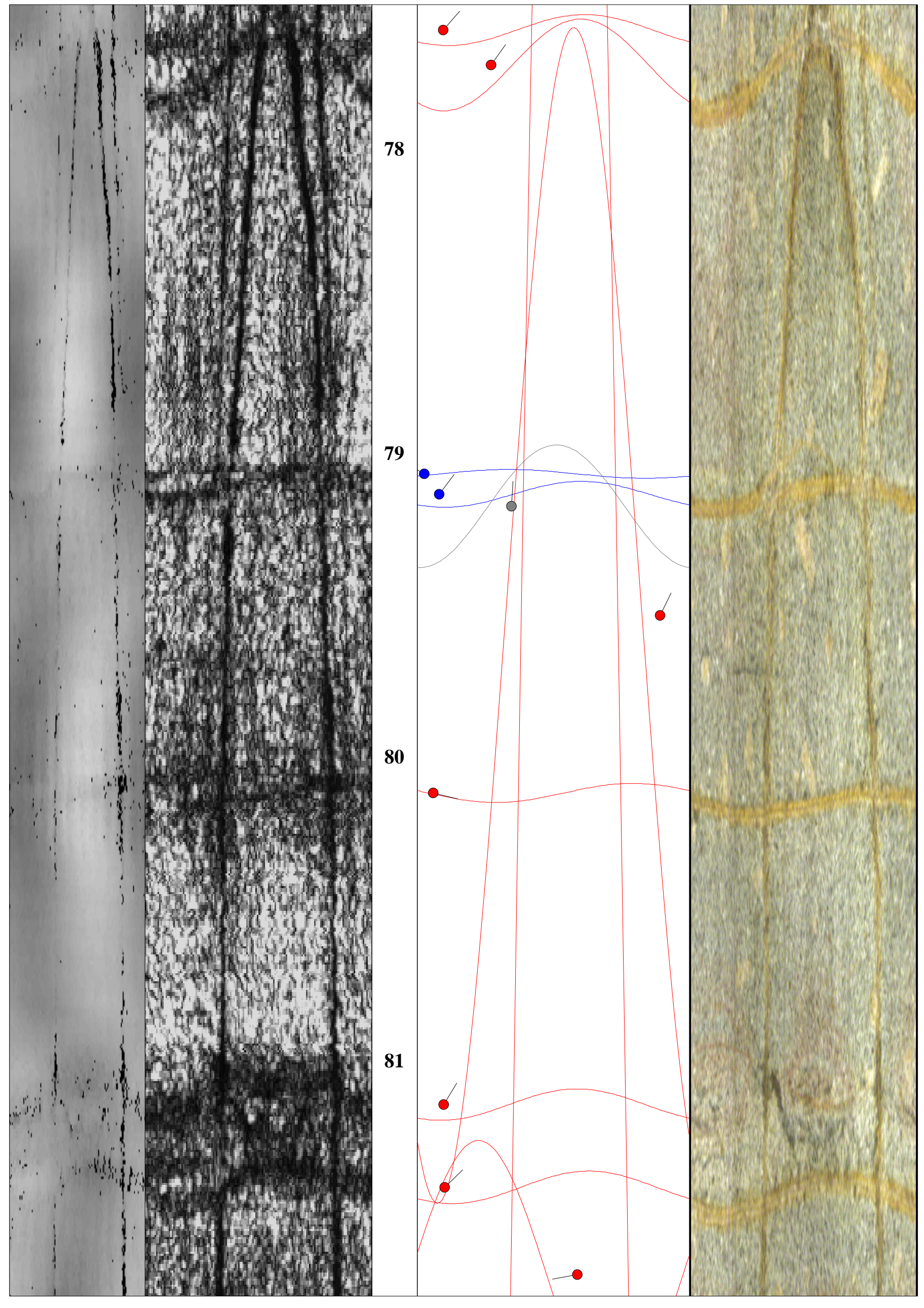




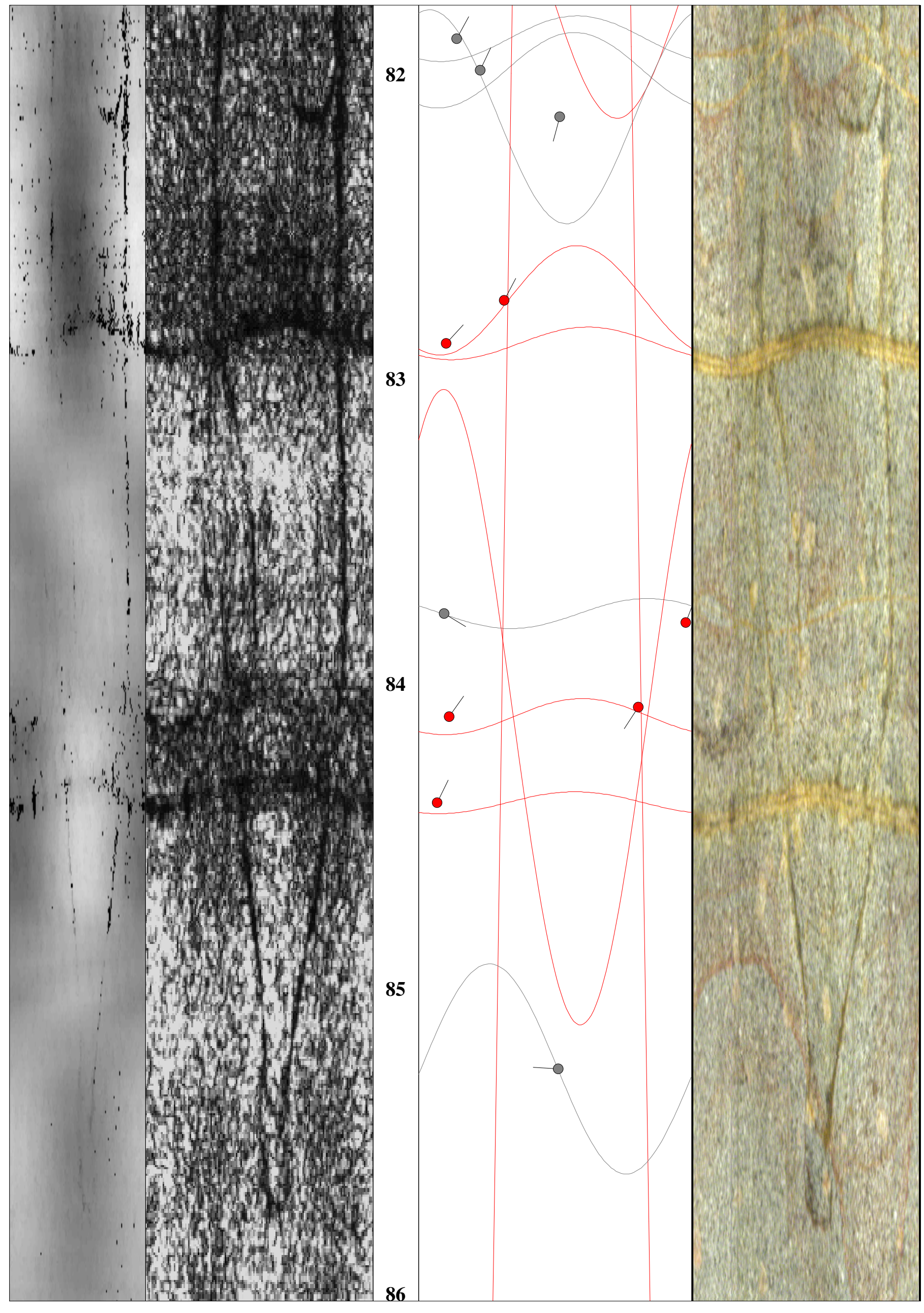




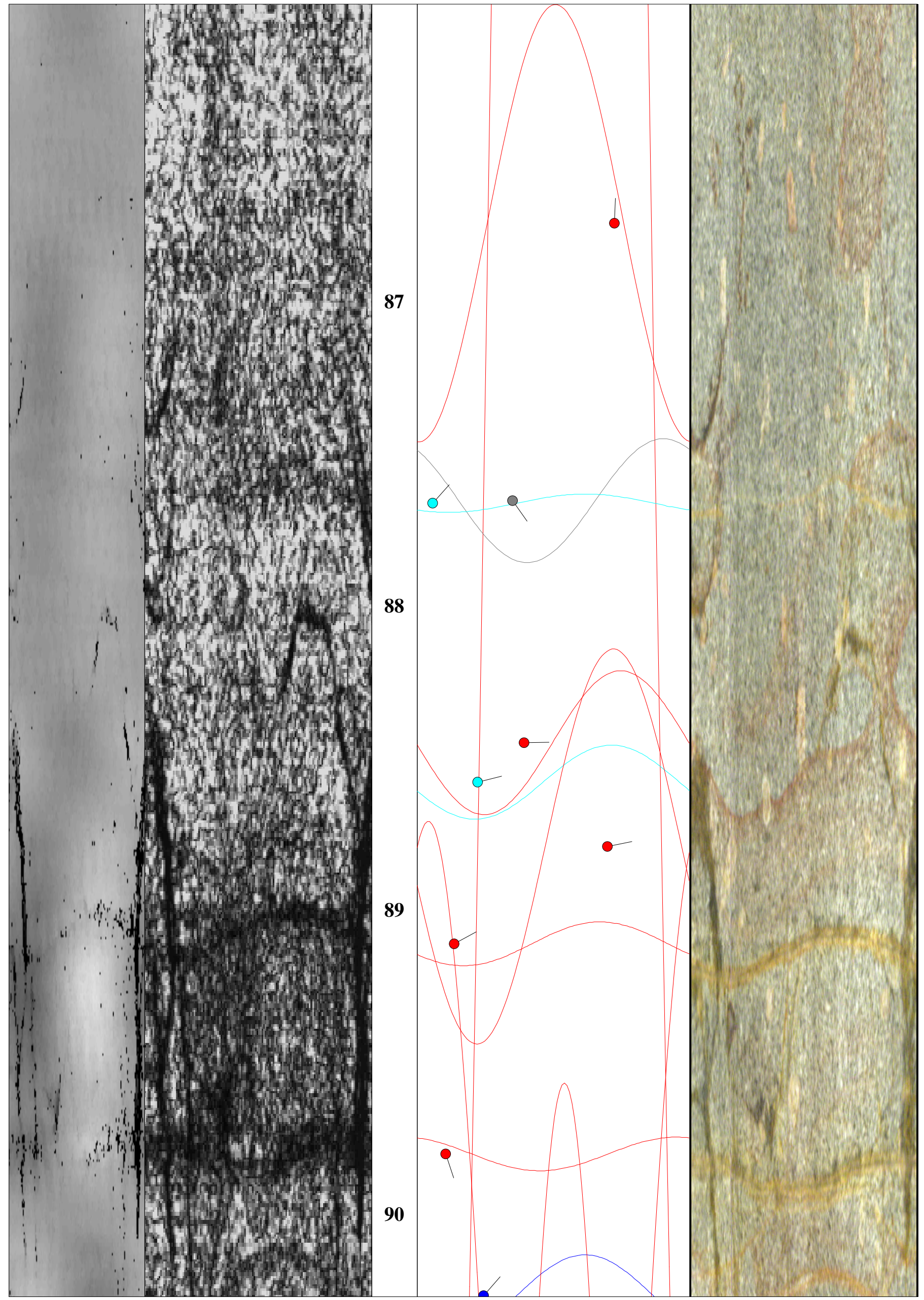




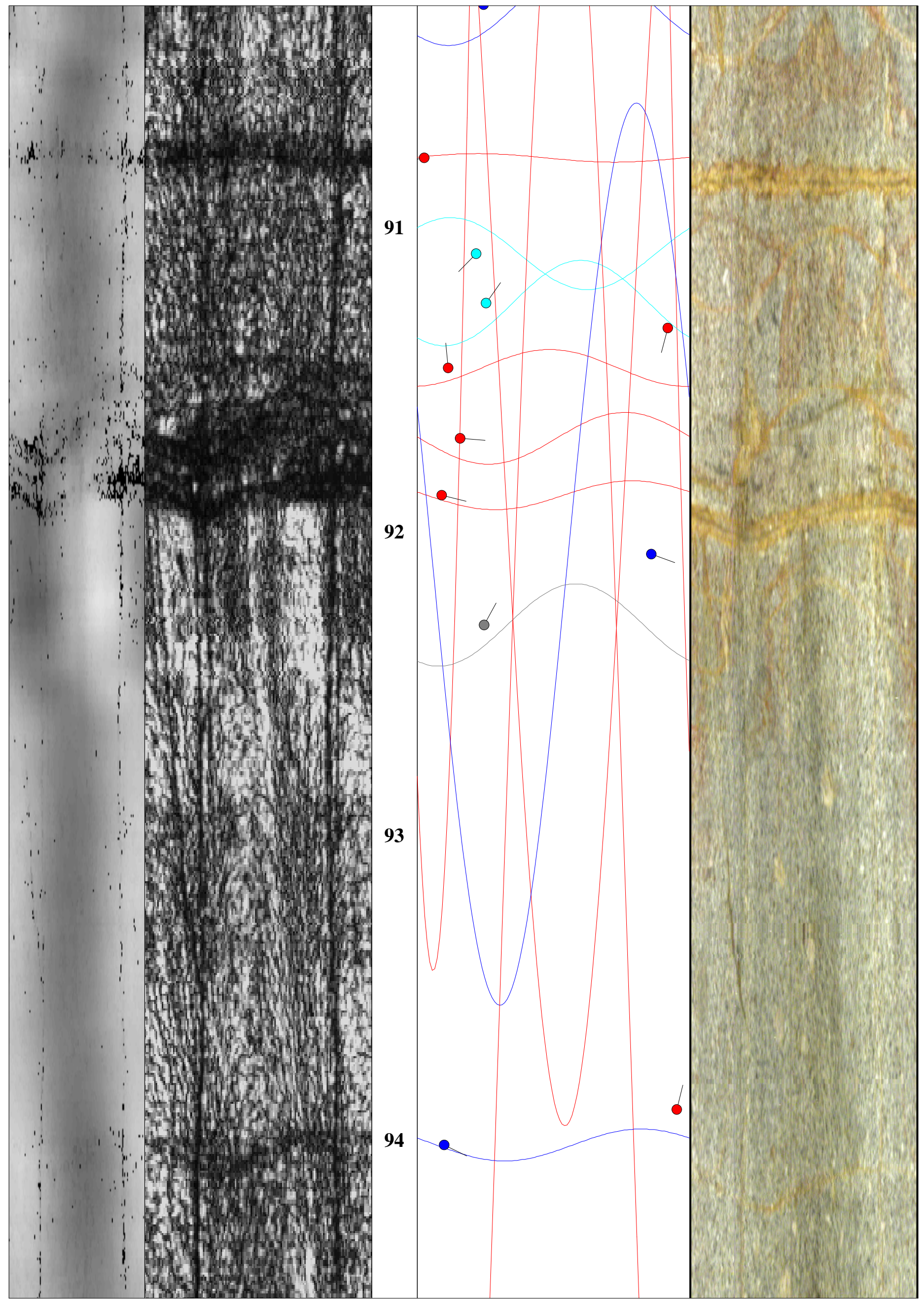




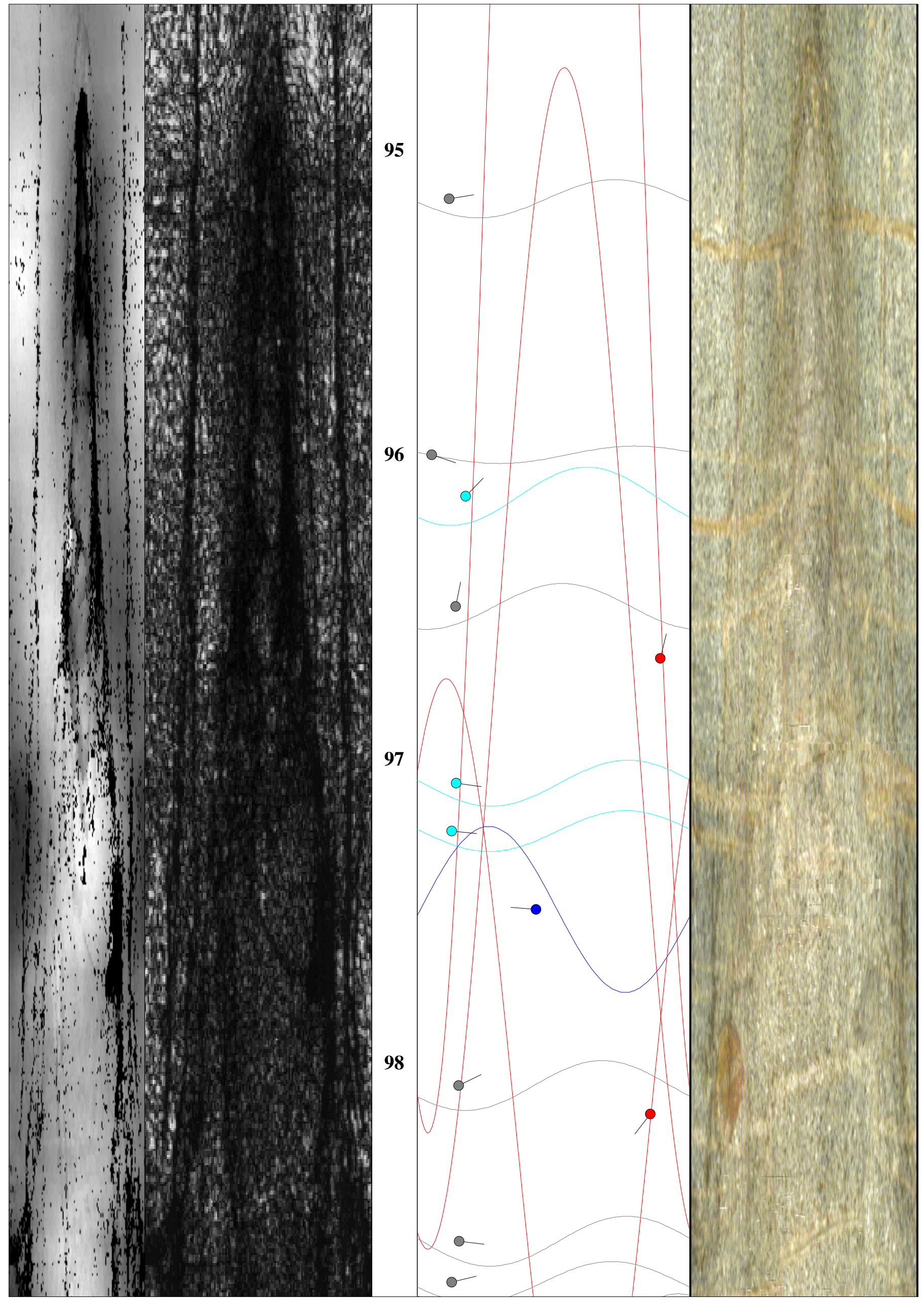




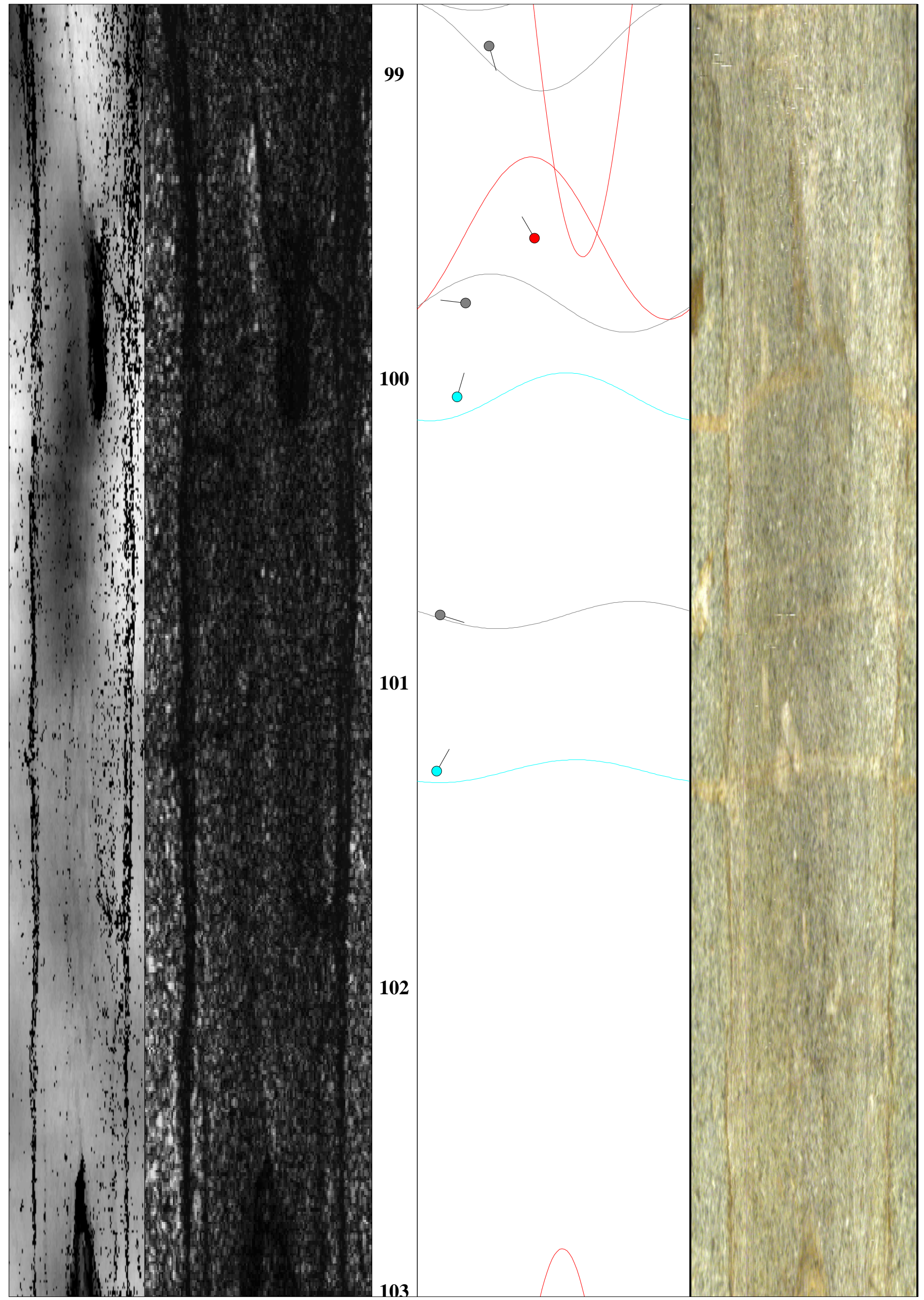




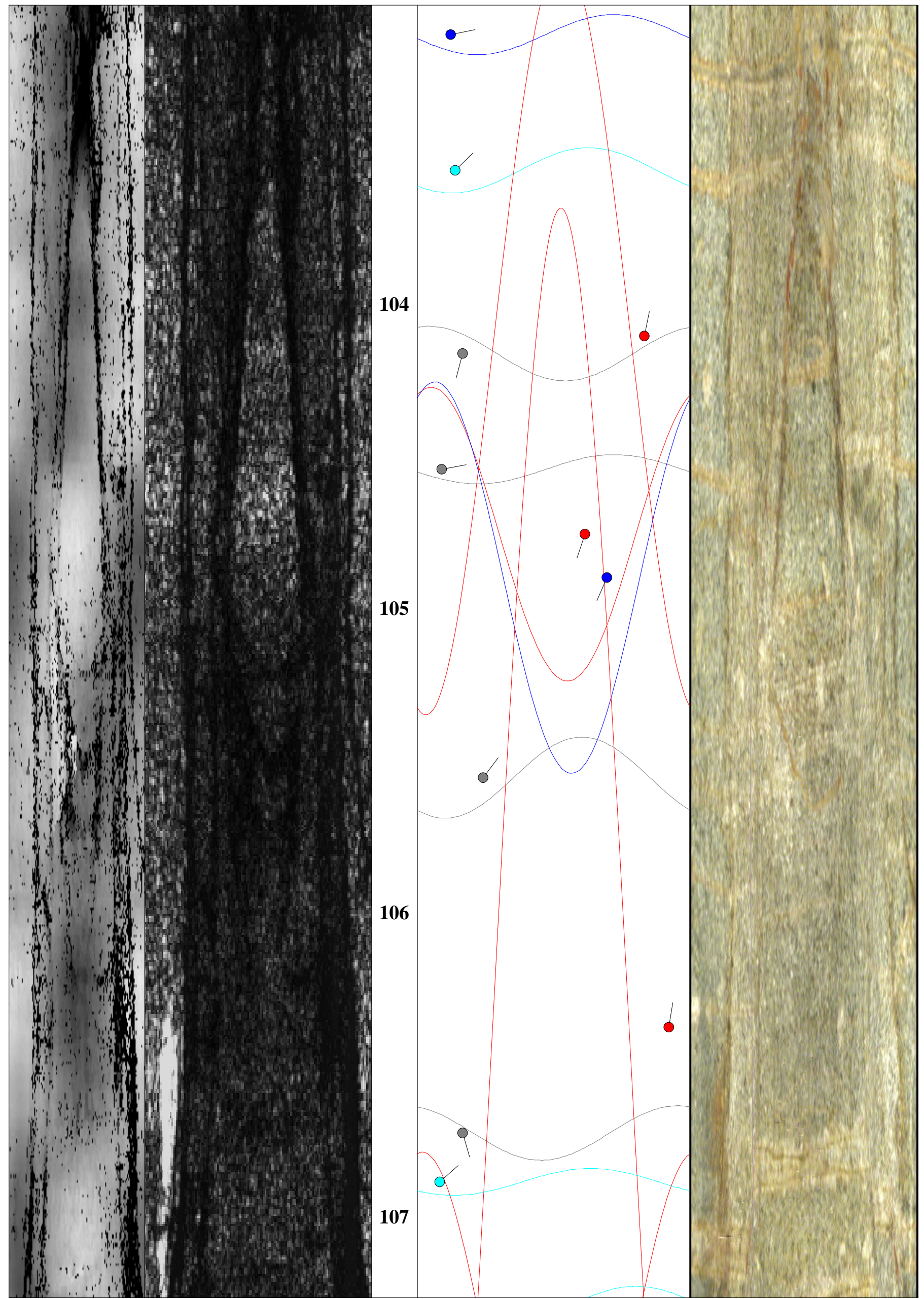




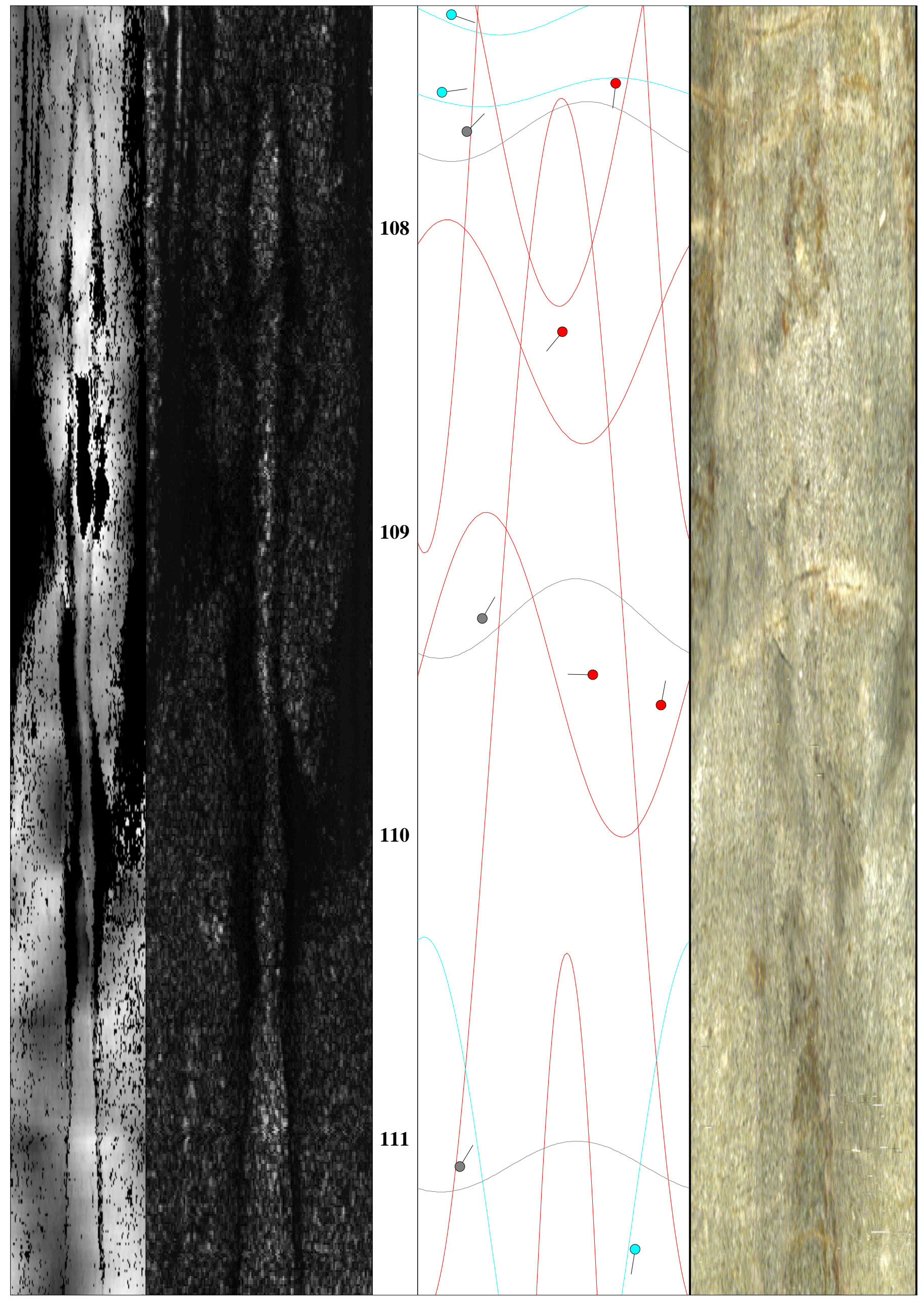




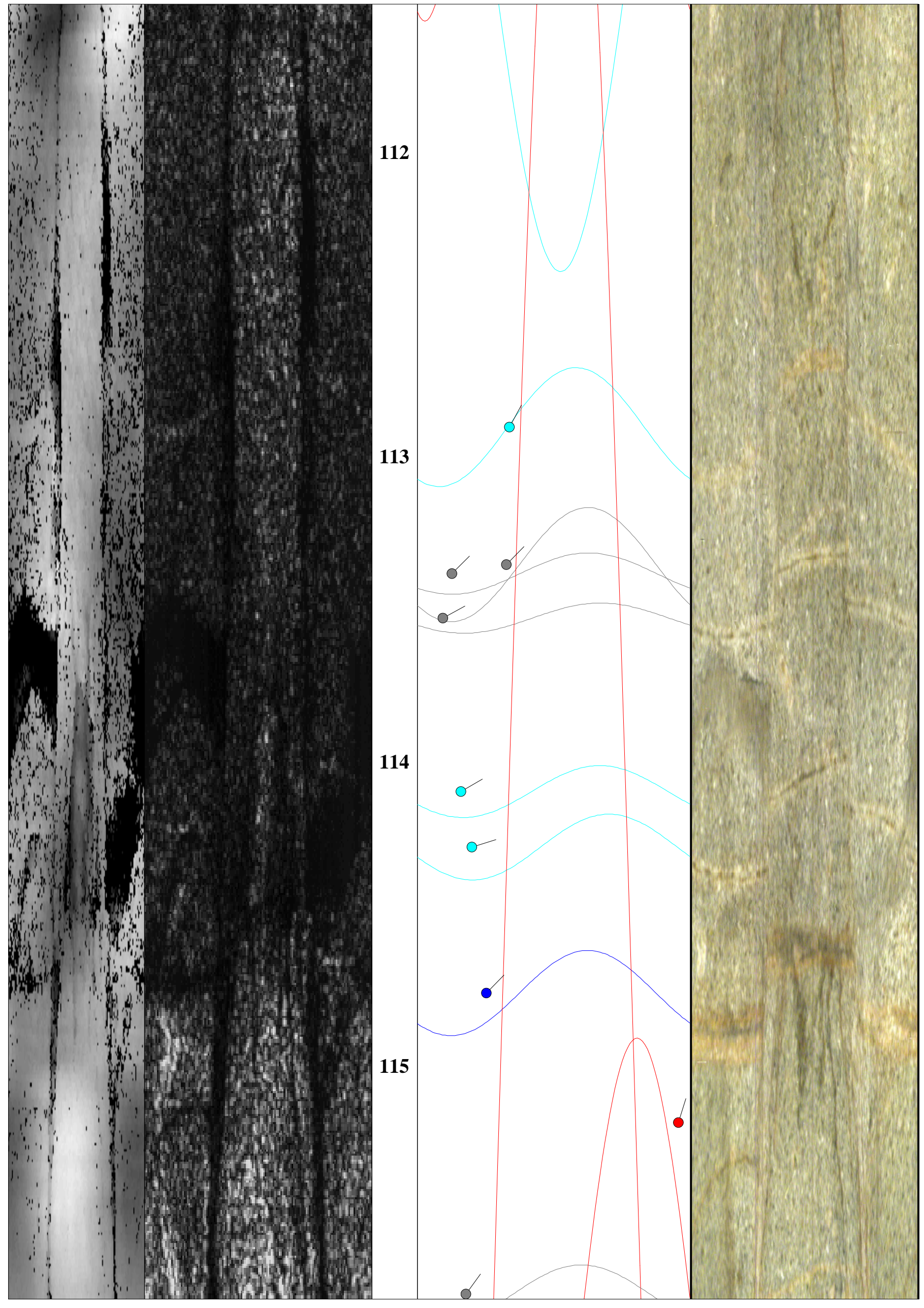




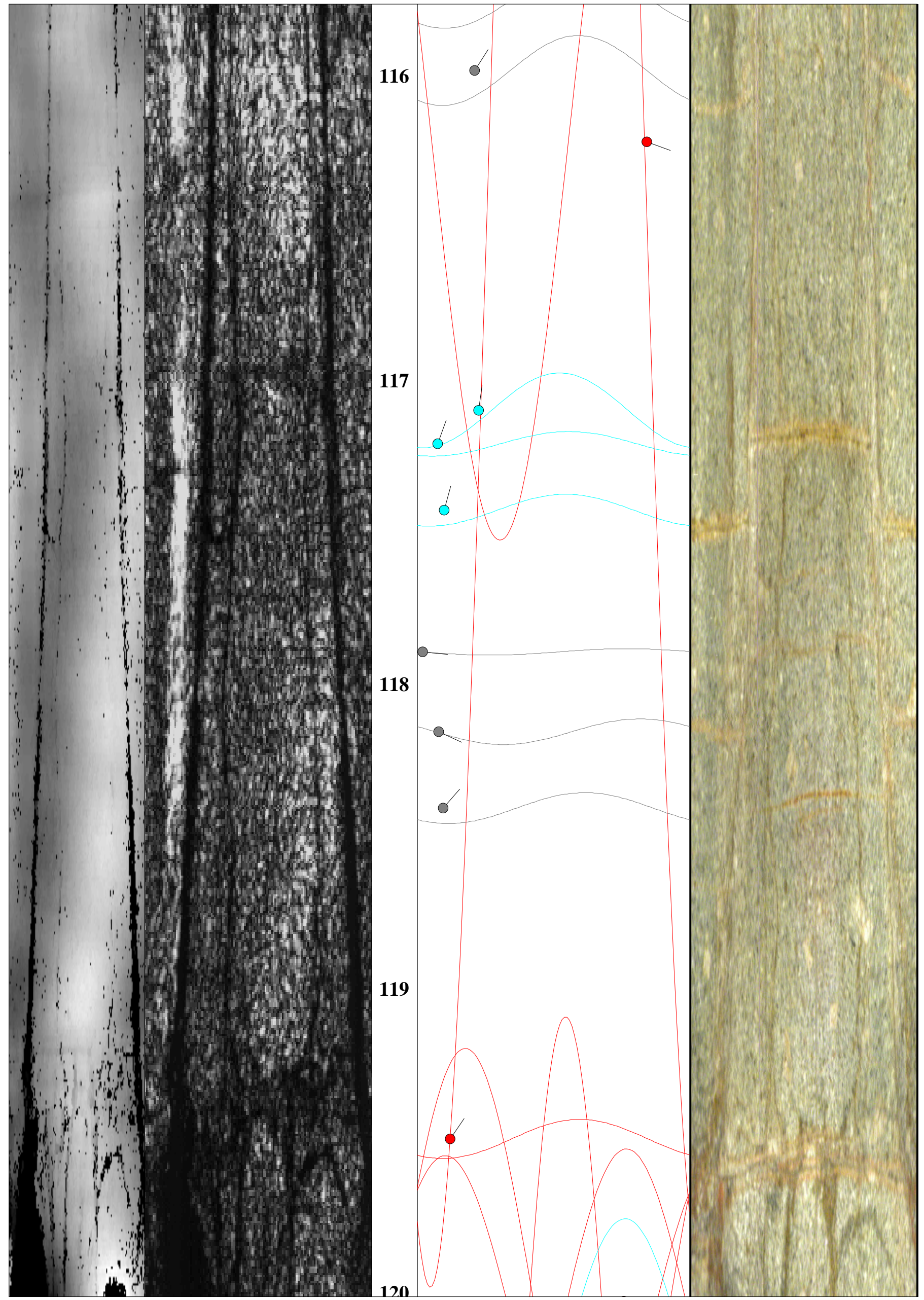




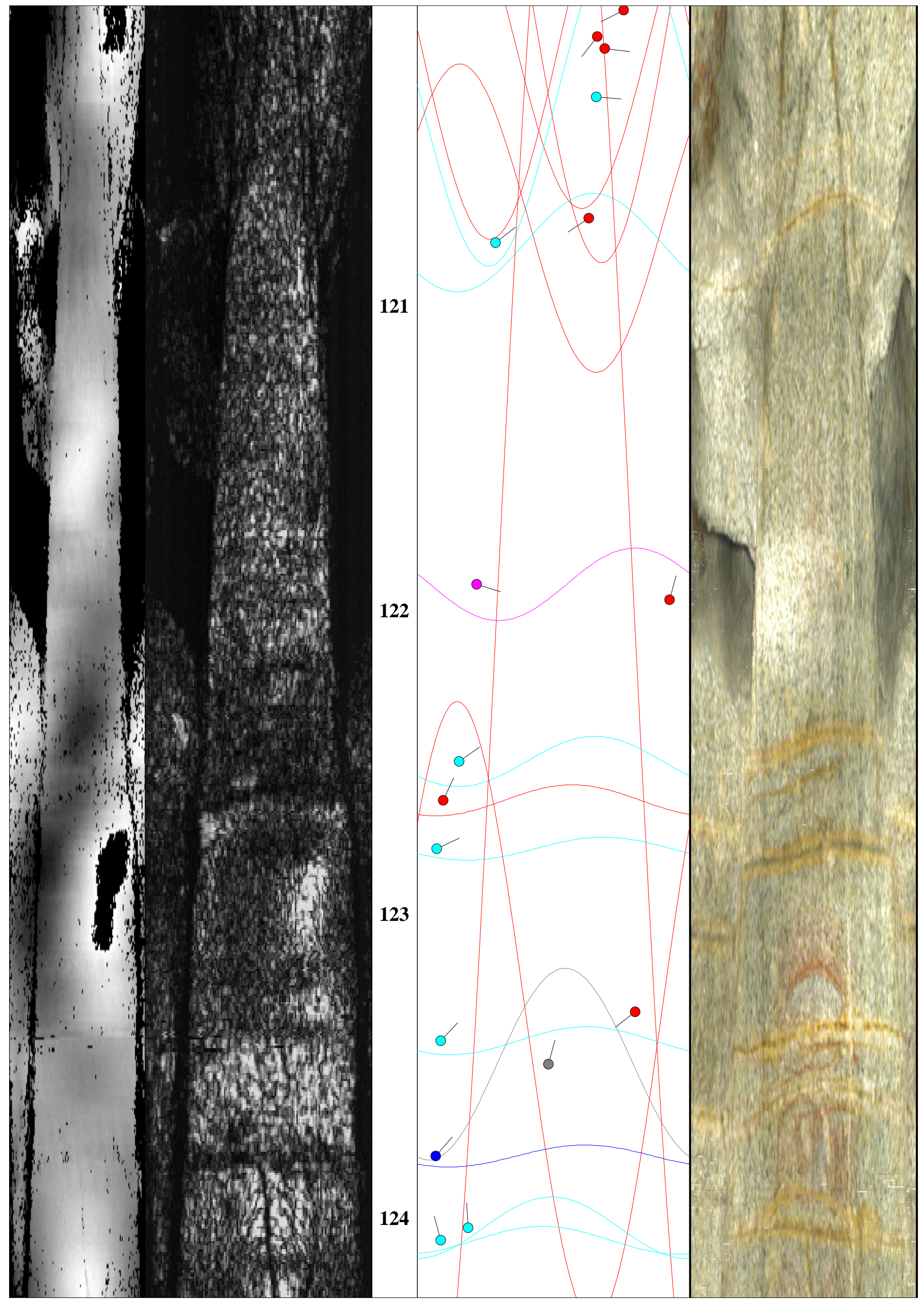




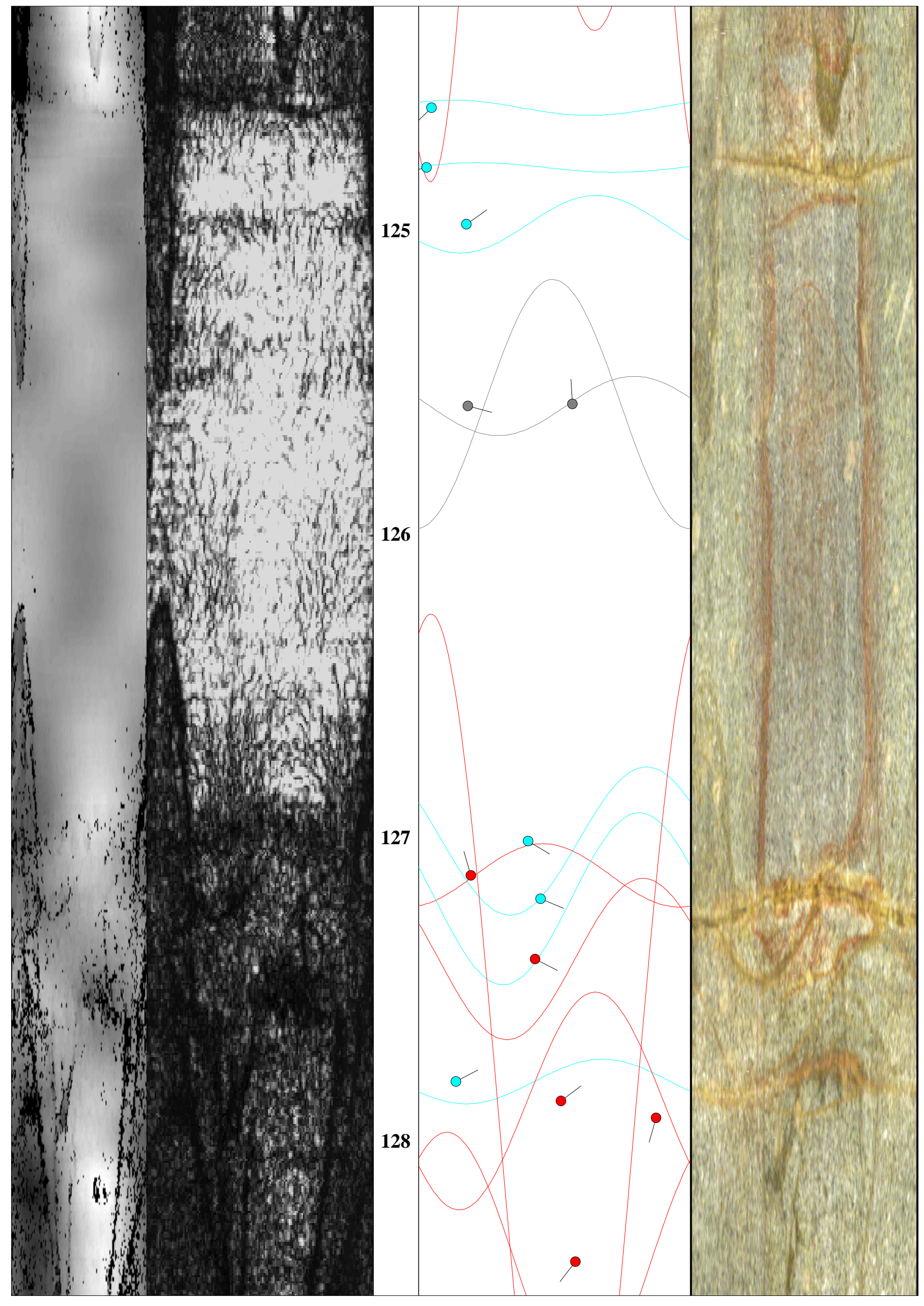




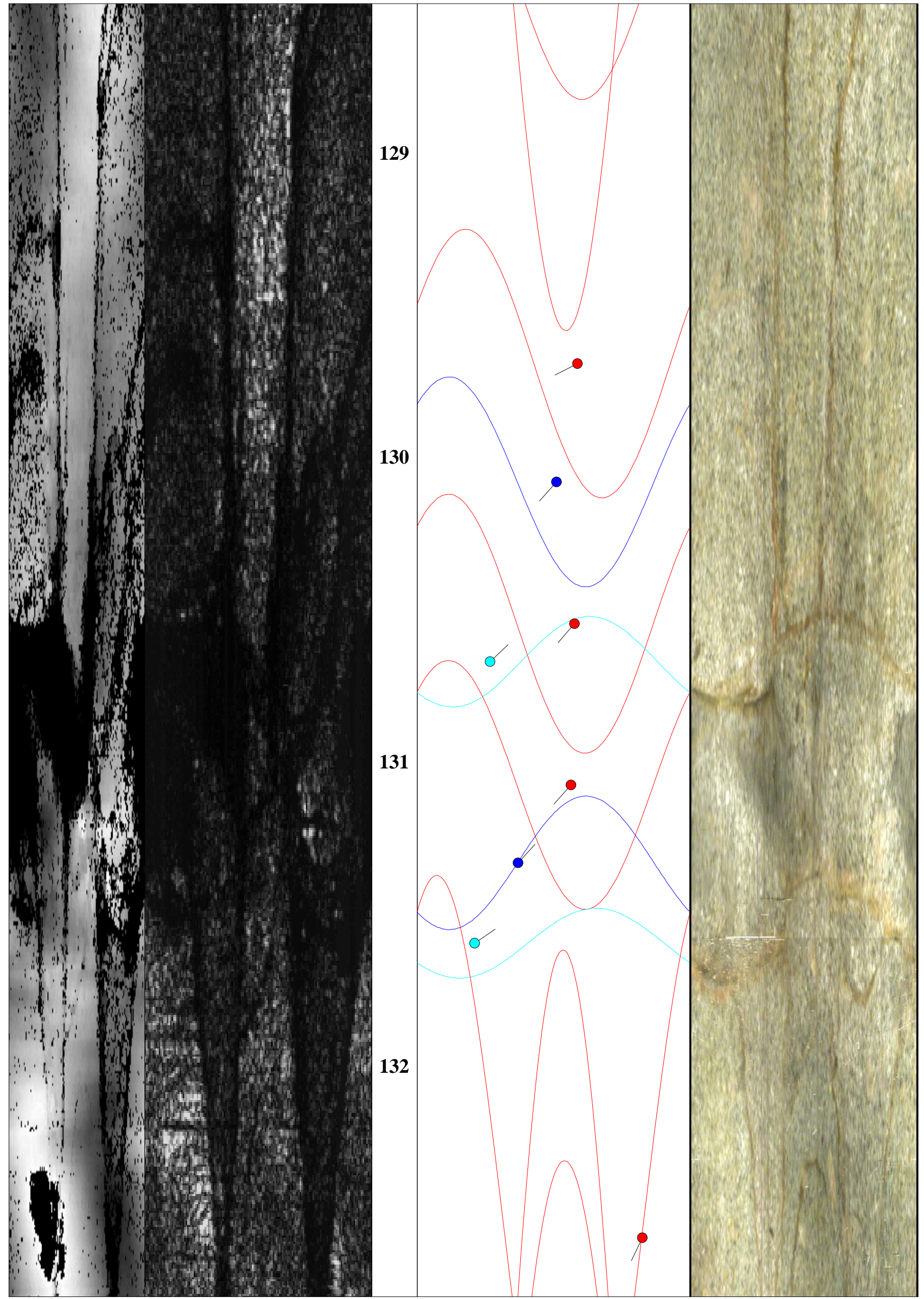




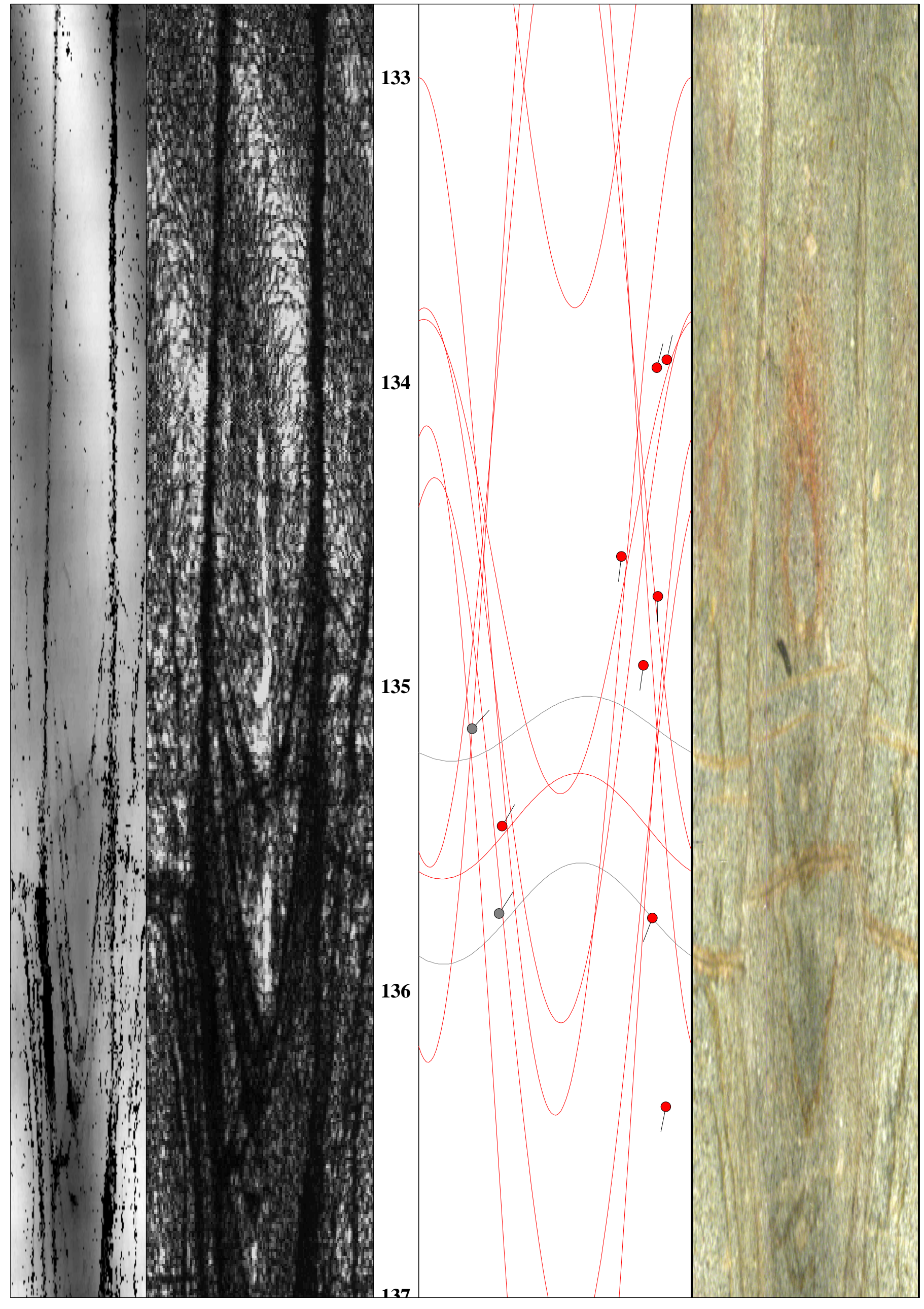




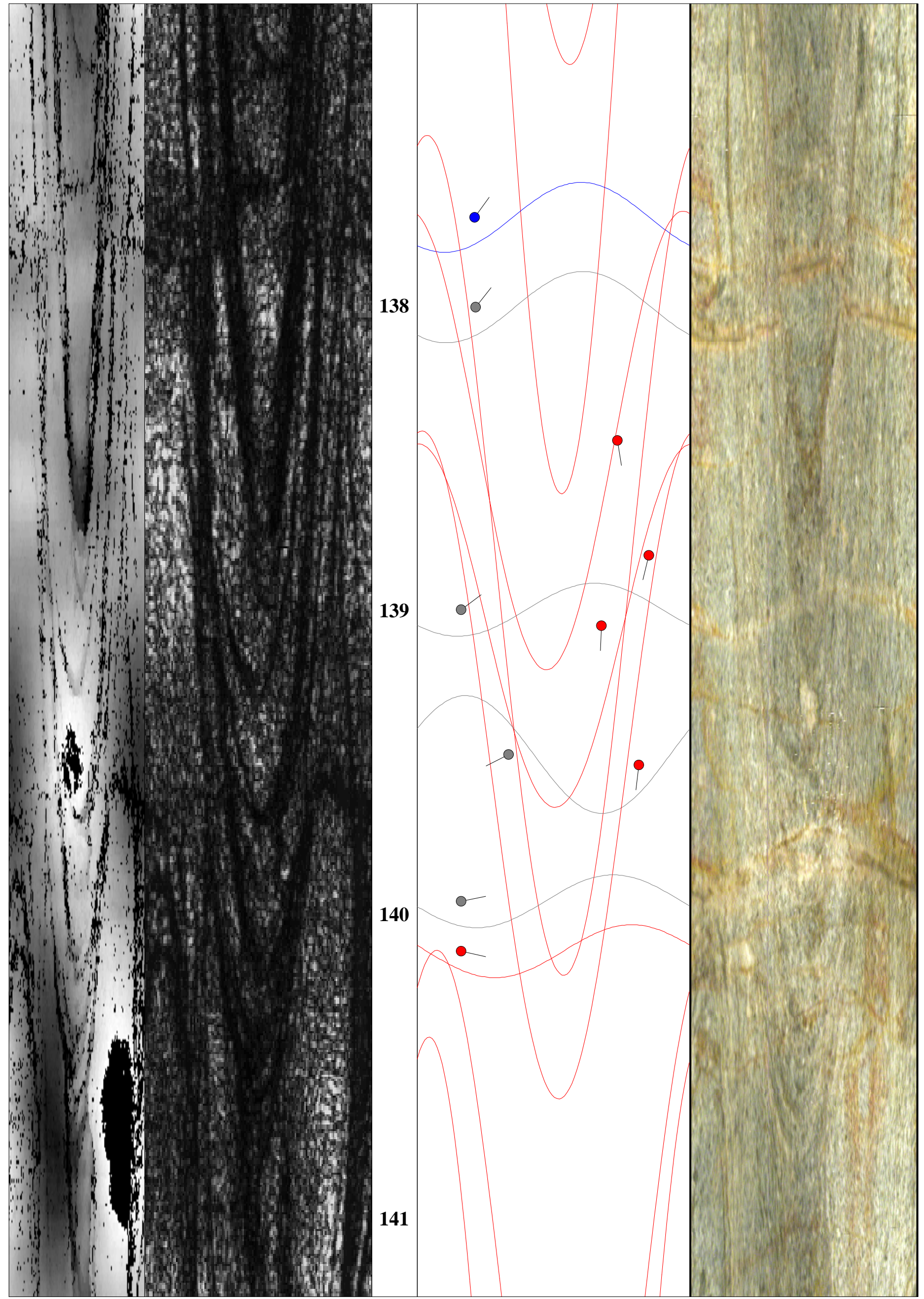




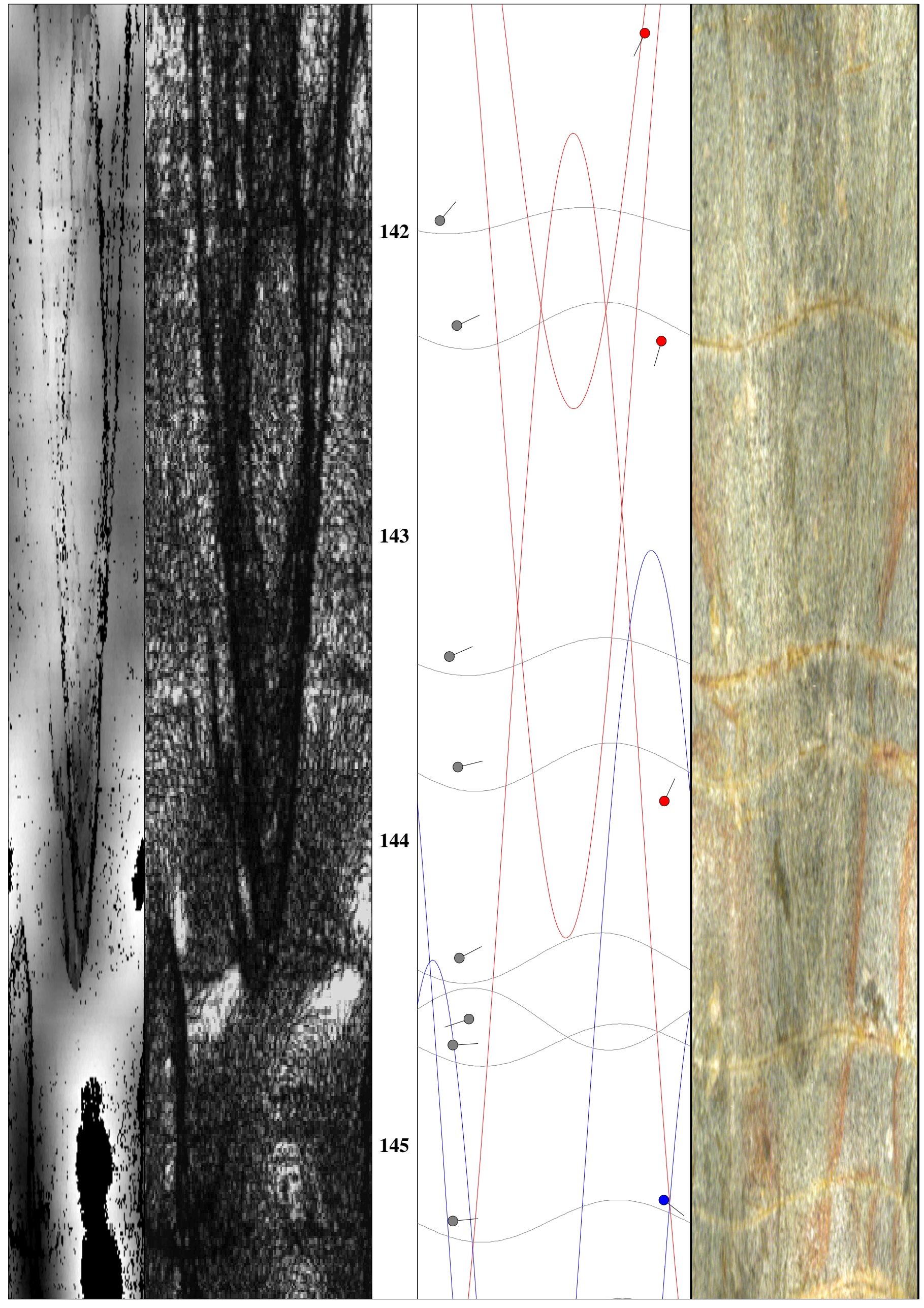




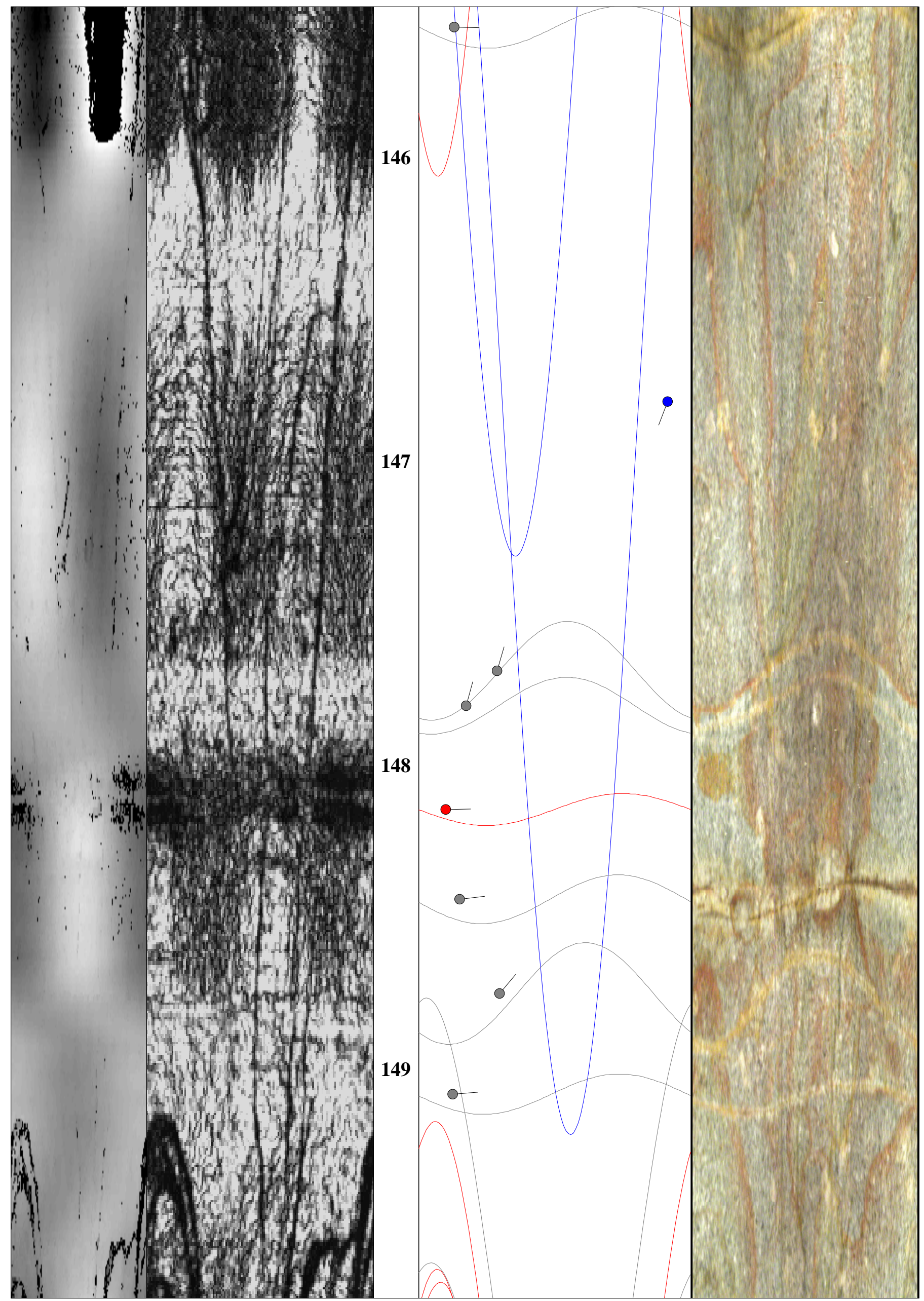




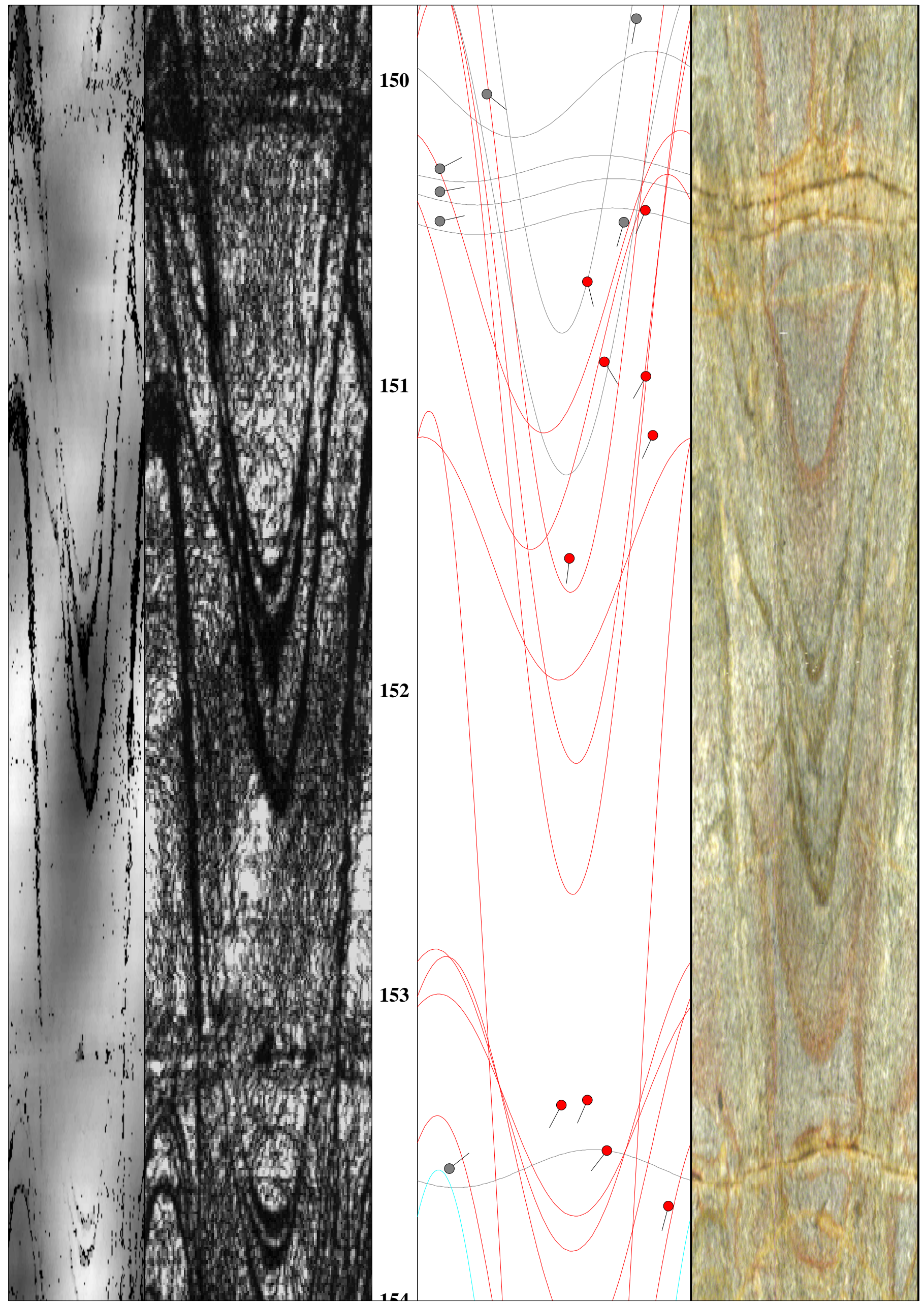




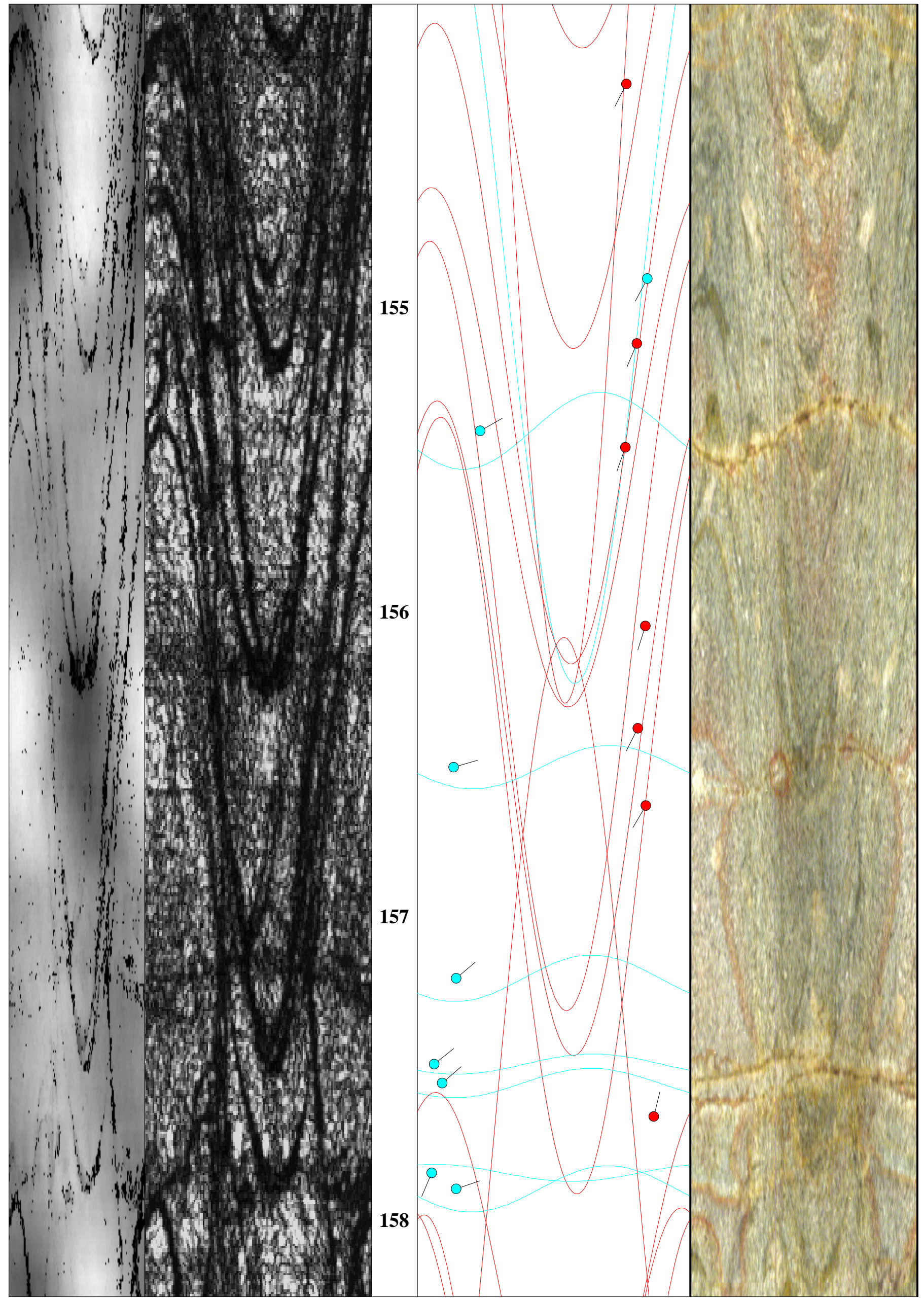




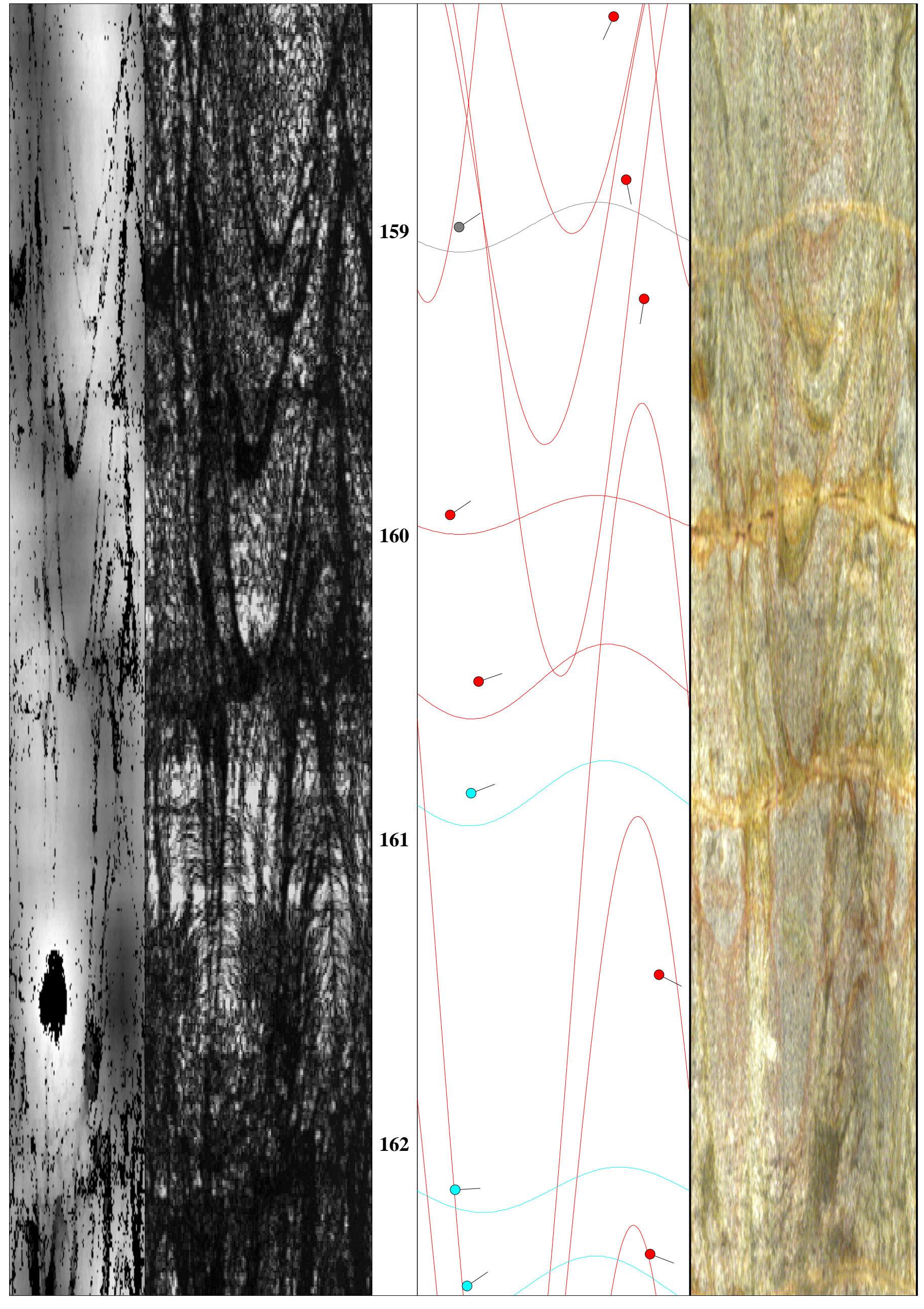




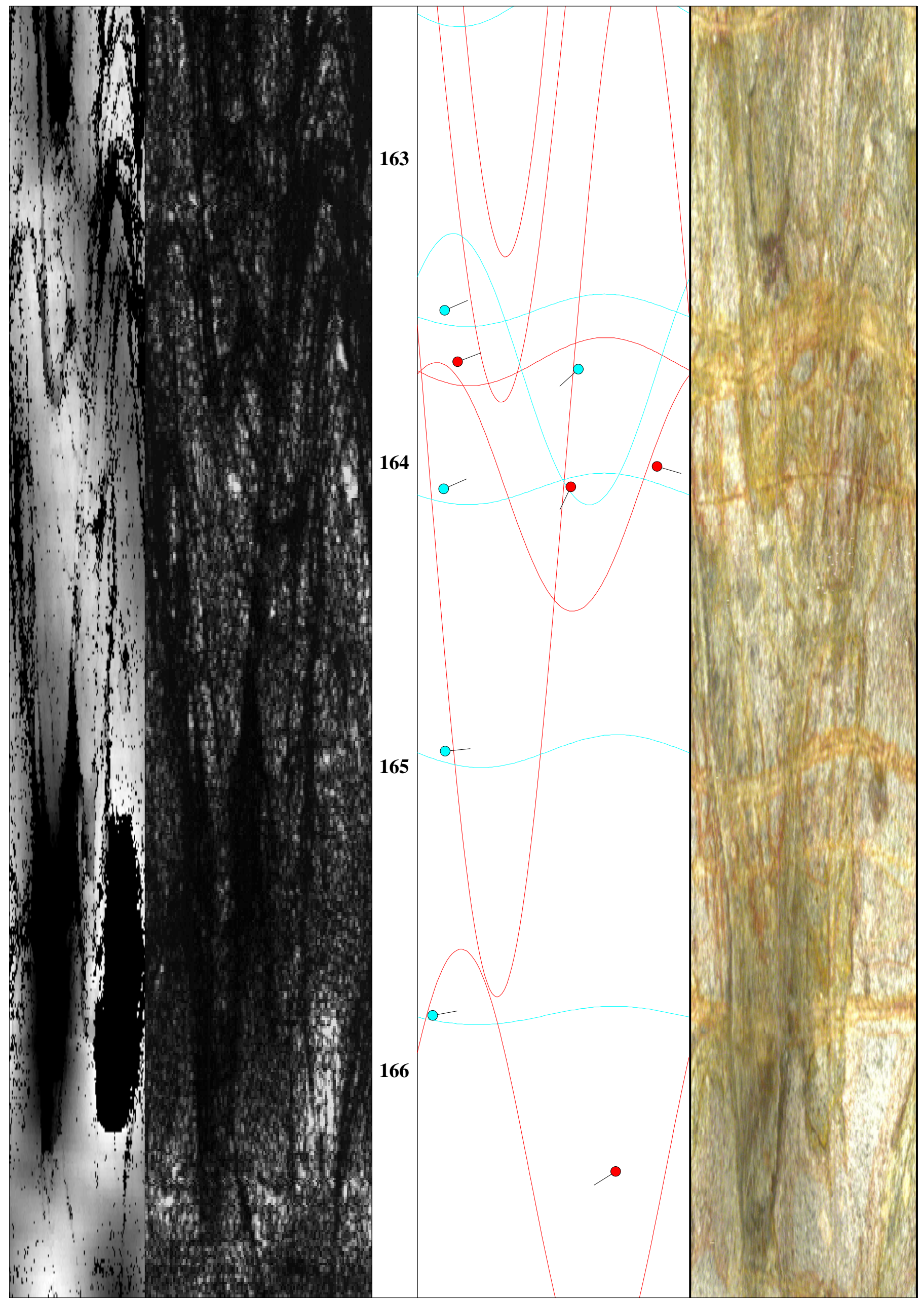




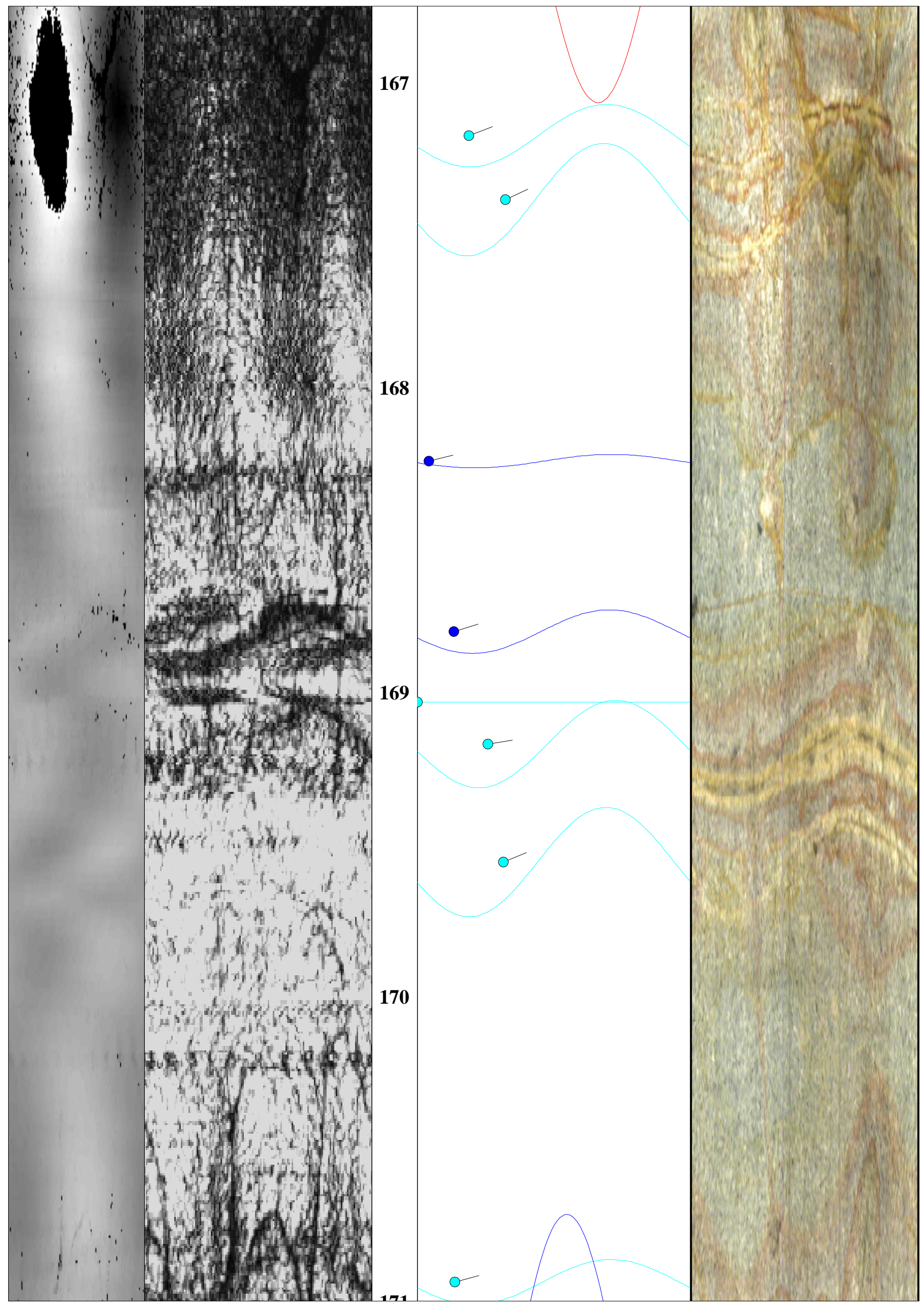




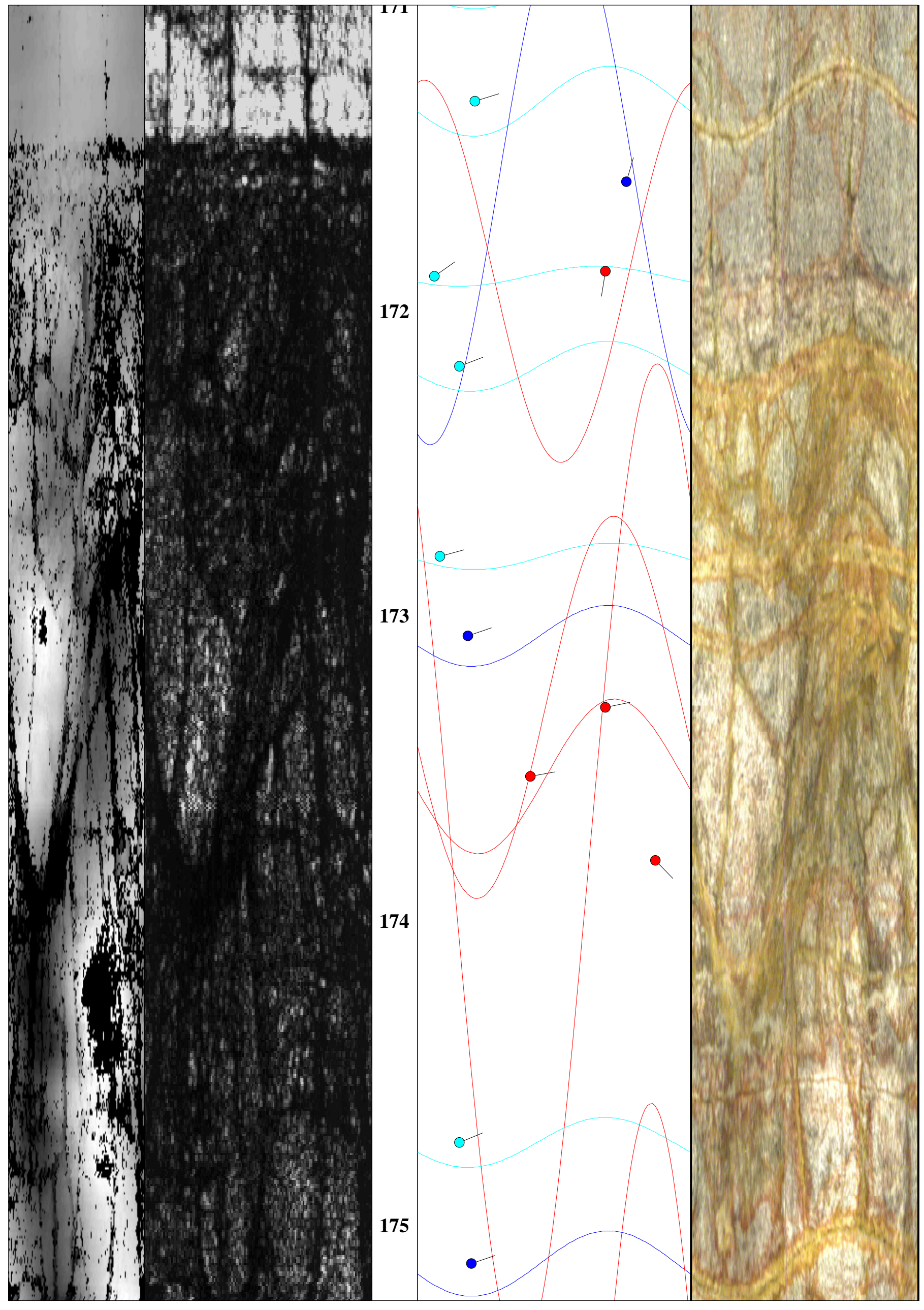




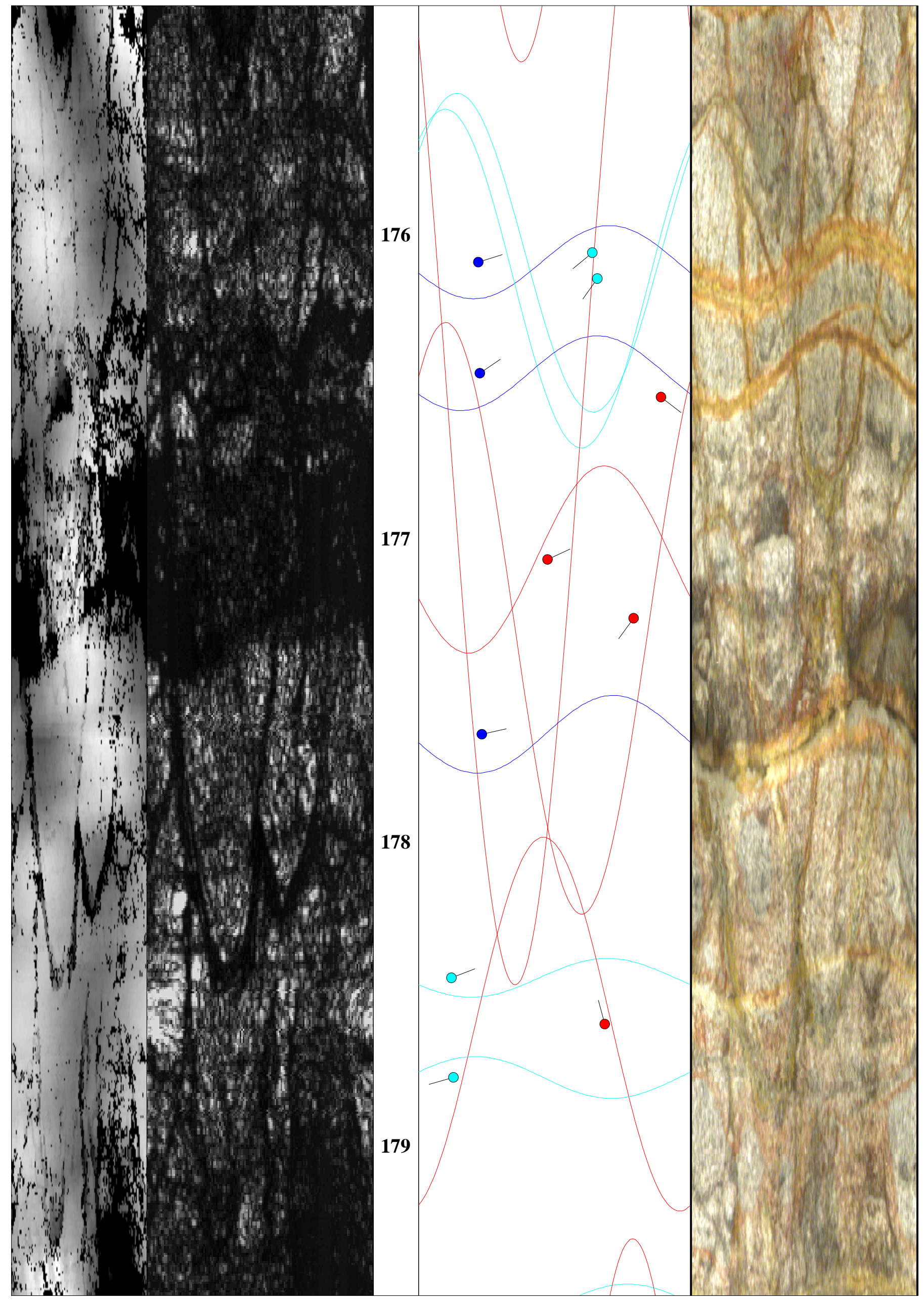




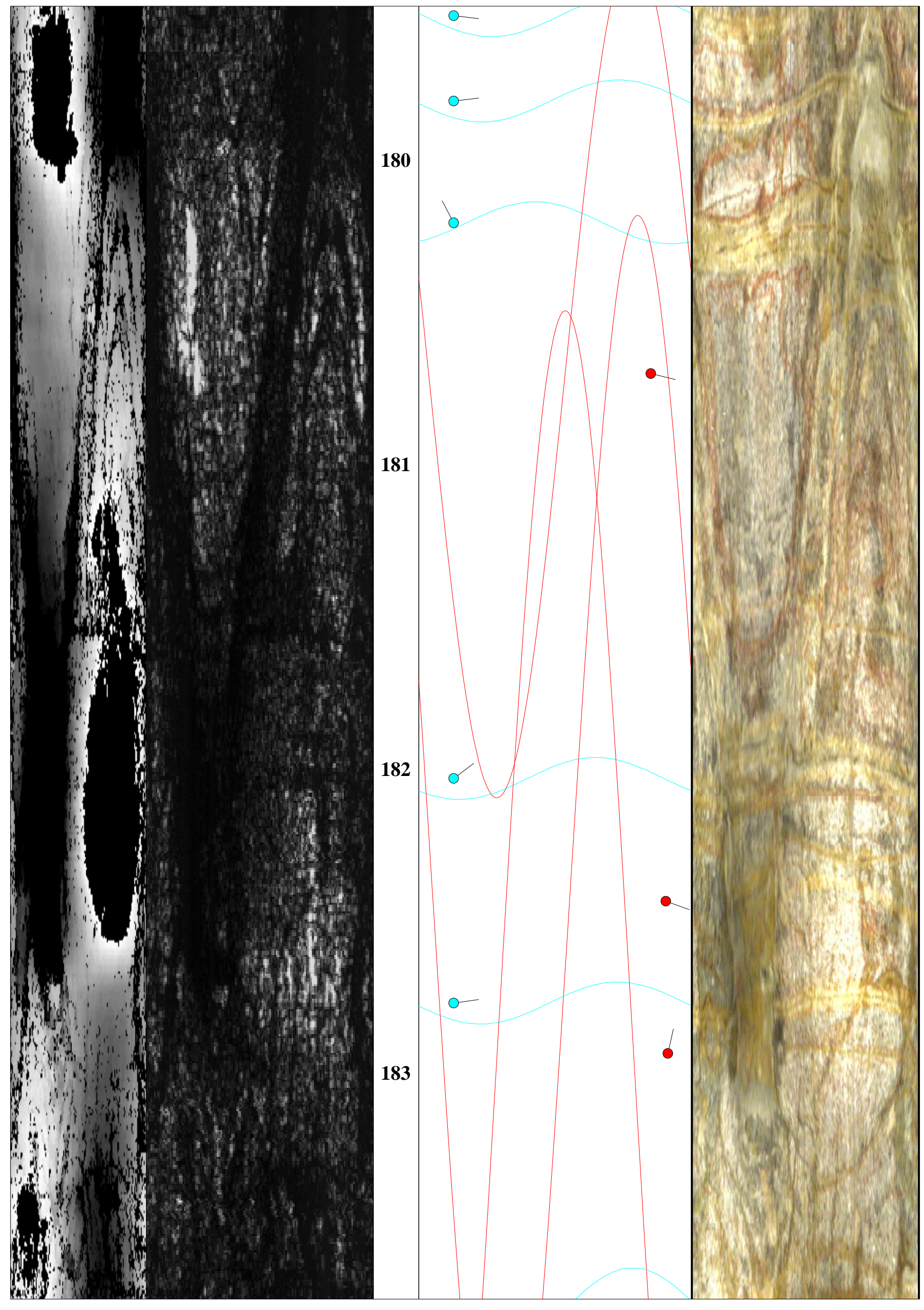




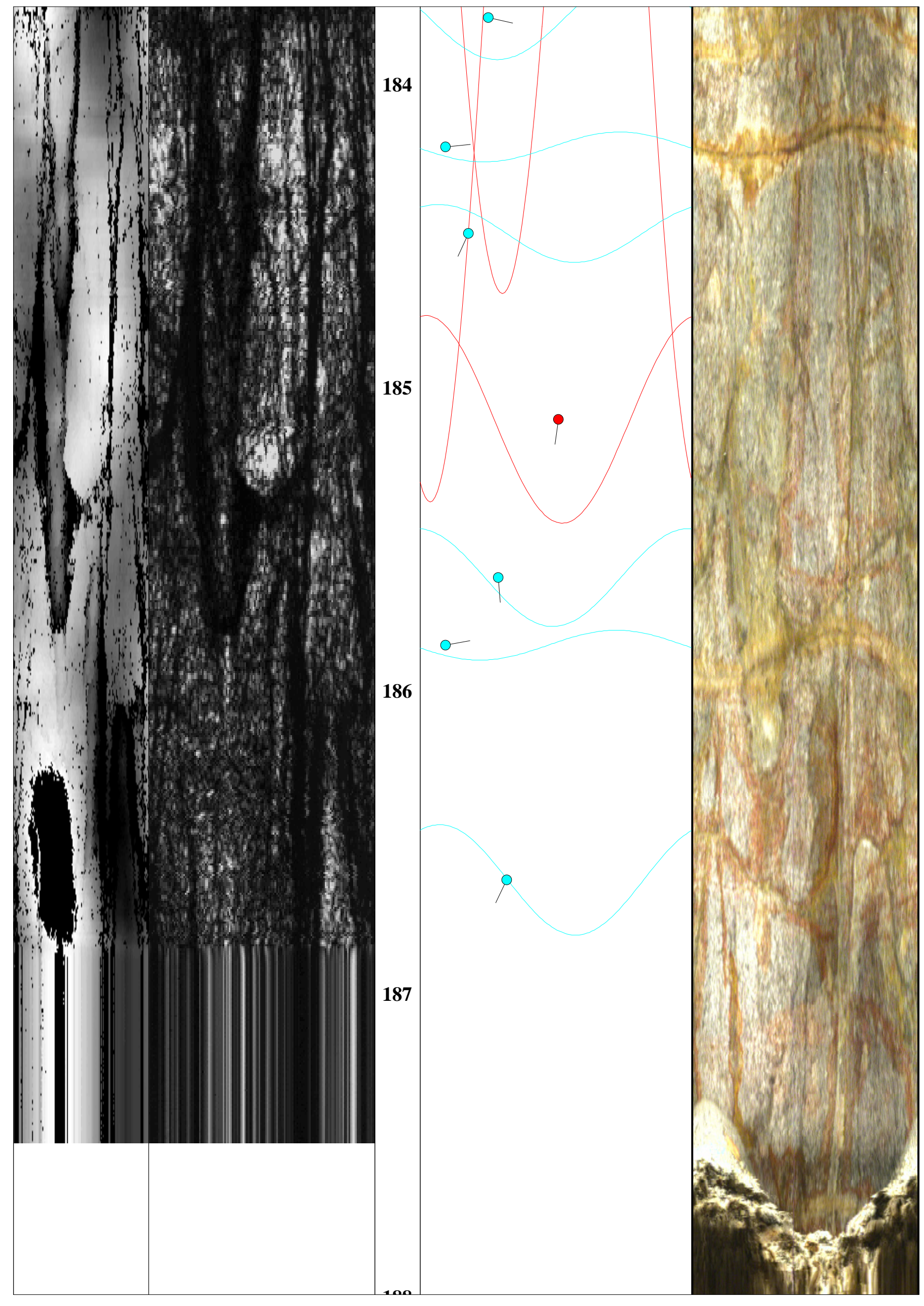




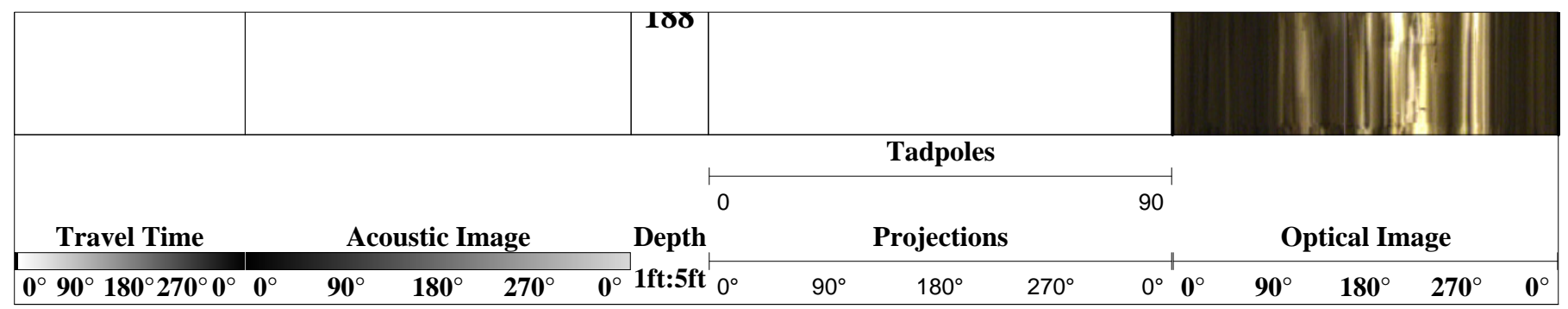




\section{Stereonet Diagram - Schmidt Projection}

Acoustic Televiewer Features

Nevada Test Site

Source Physics Experiment

U-15n1

NNSA/NSO

21 Sept 2010

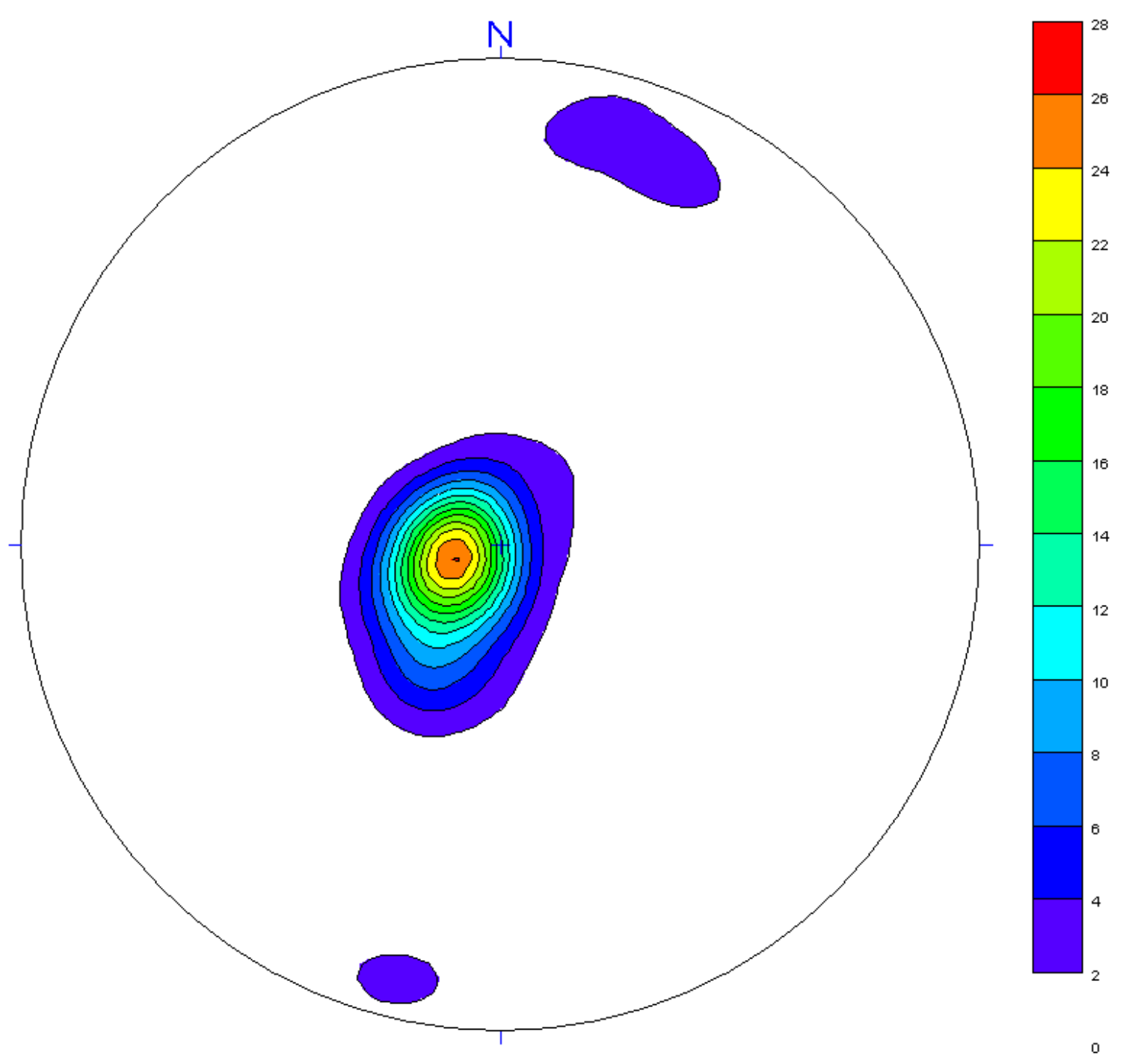

All directions are with respect to True North. 


\section{Stereonet Diagram - Schmidt Projection \\ Acoustic Televiewer Features \\ Nevada Test Site \\ Source Physics Experiment \\ U-15n1 \\ NNSA/NSO \\ 21 Sept 2010}

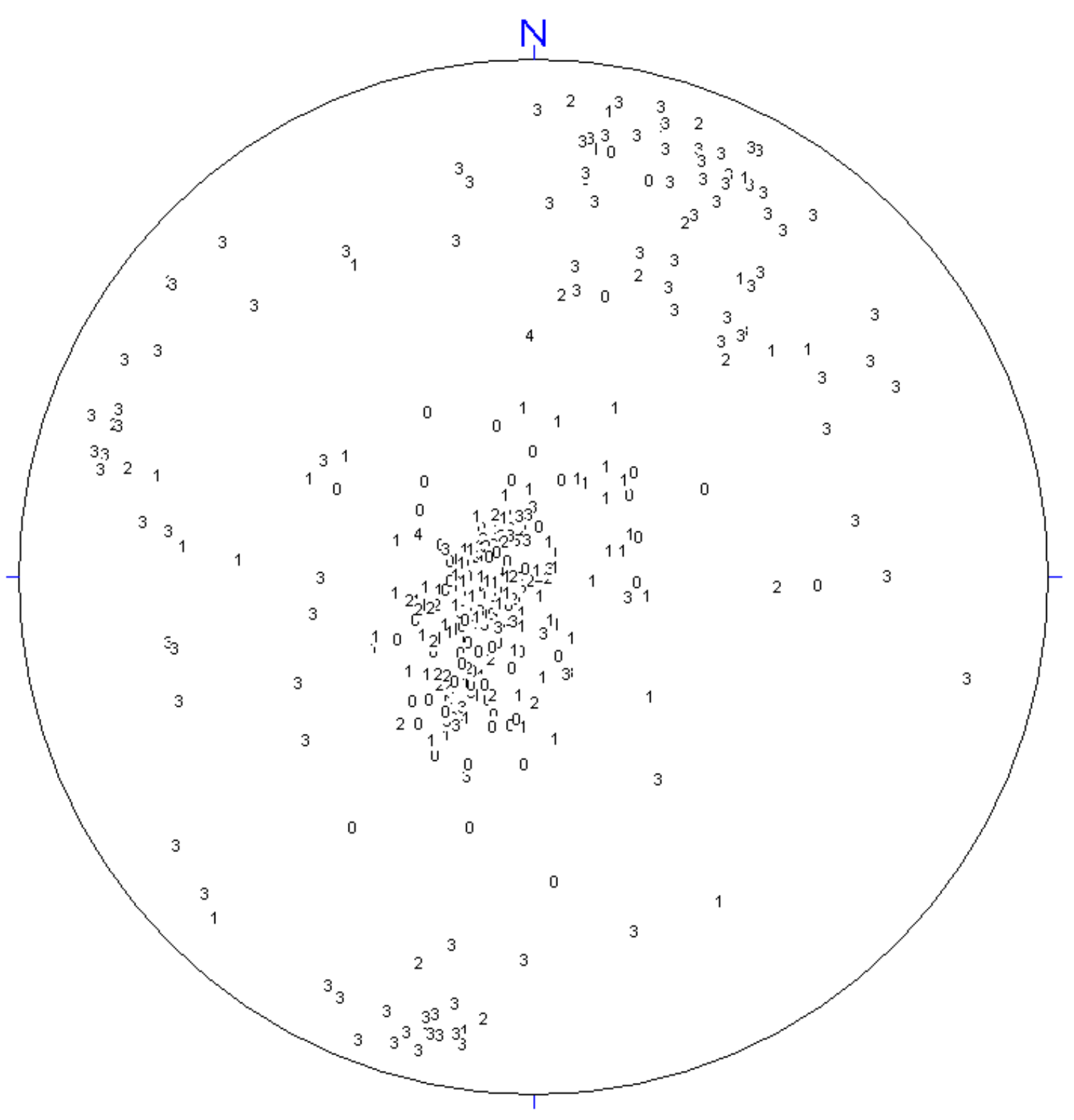

All directions are with respect to True North. 


\section{Rose Diagram - Dip Directions \\ Acoustic Televiewer Features \\ Nevada Test Site \\ Source Physics Experiment \\ U-15n1 \\ NNSA/NSO \\ 21 Sept 2010}

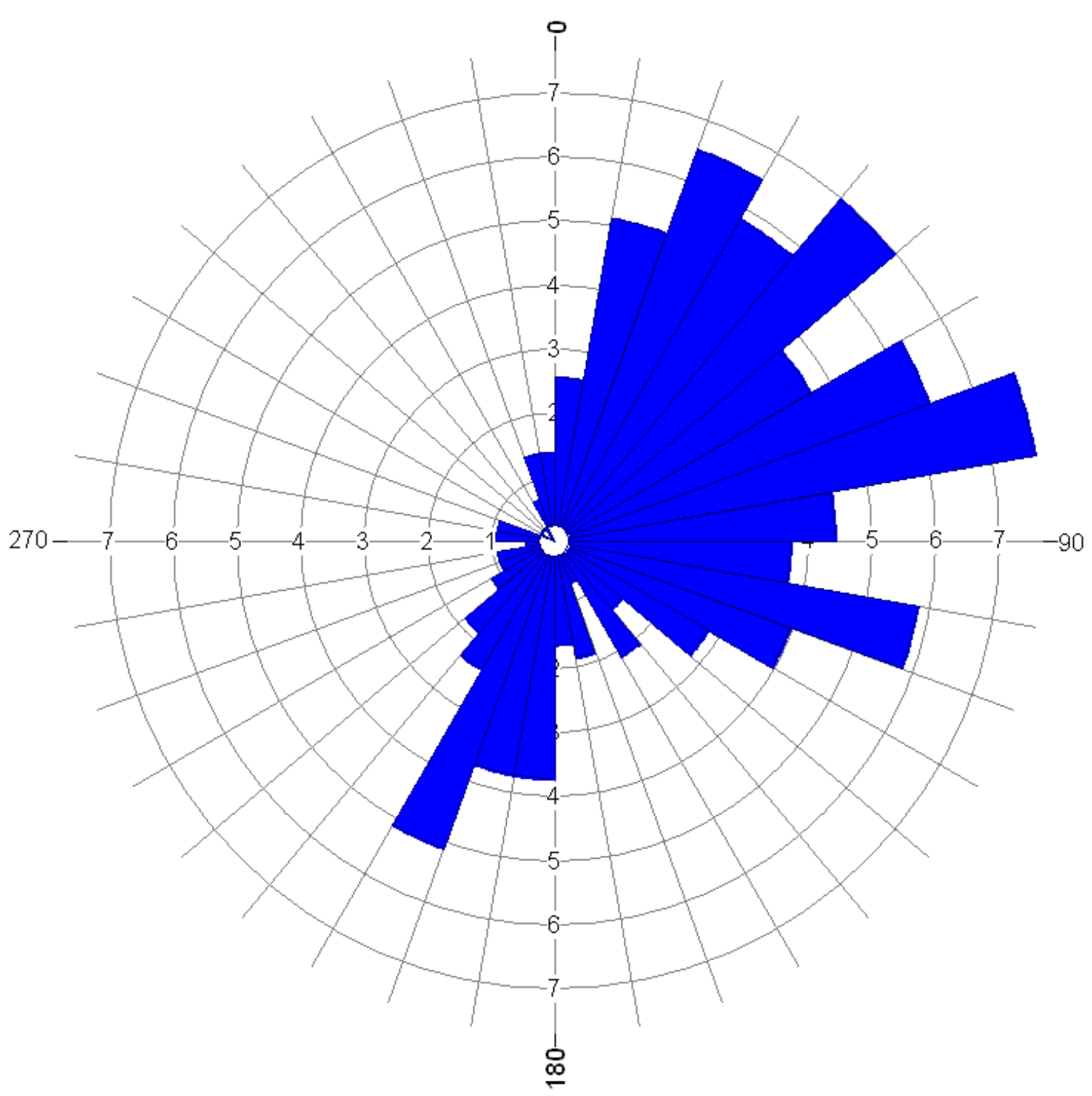




\section{Rose Diagram - Dip Angles \\ Acoustic Televiewer Features \\ Nevada Test Site \\ Source Physics Experiment \\ U-15n1 \\ NNSA/NSO \\ 21 Sept 2010}

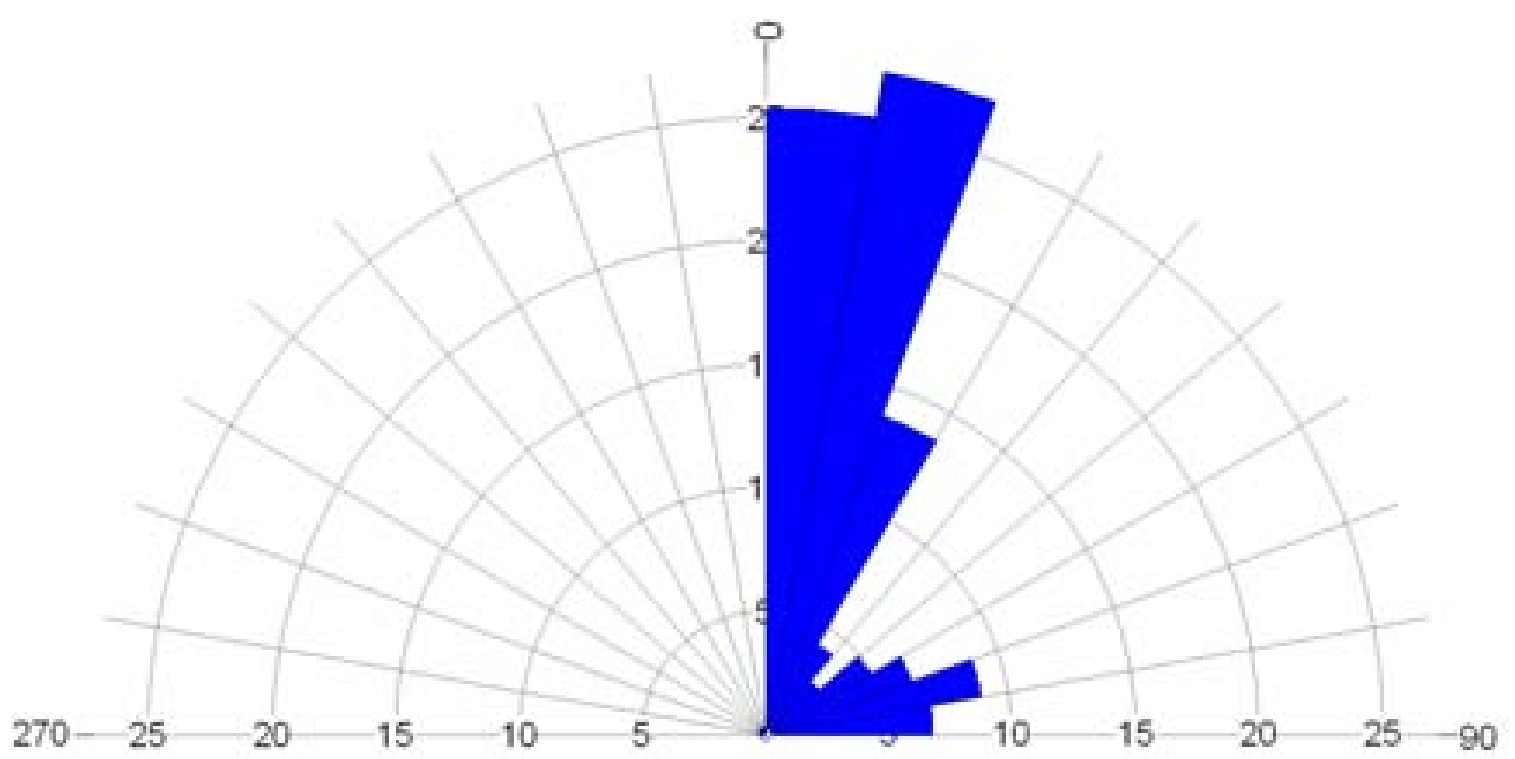




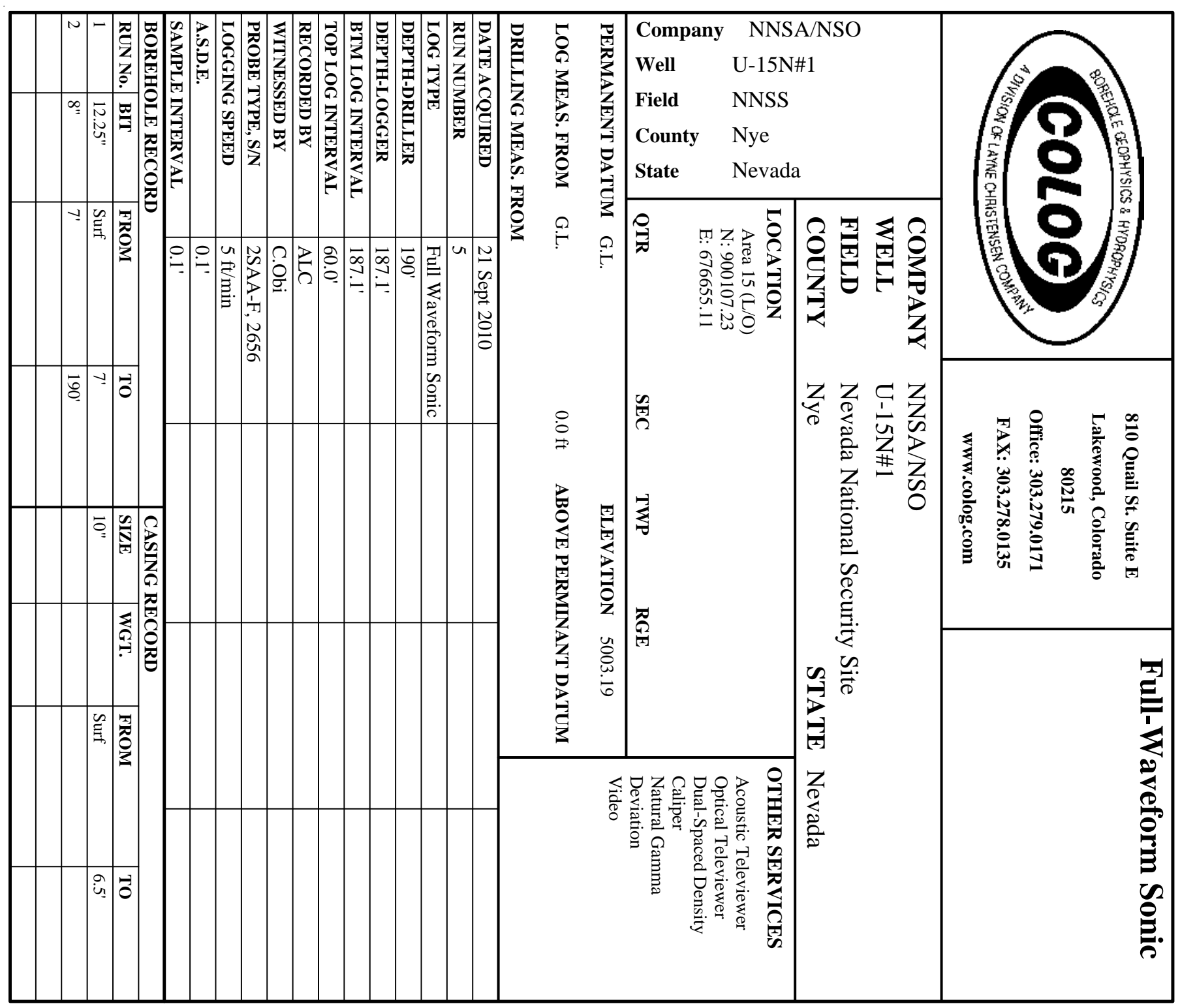

COMMENTS

NA - Not Available, N/A - Not Applicable 


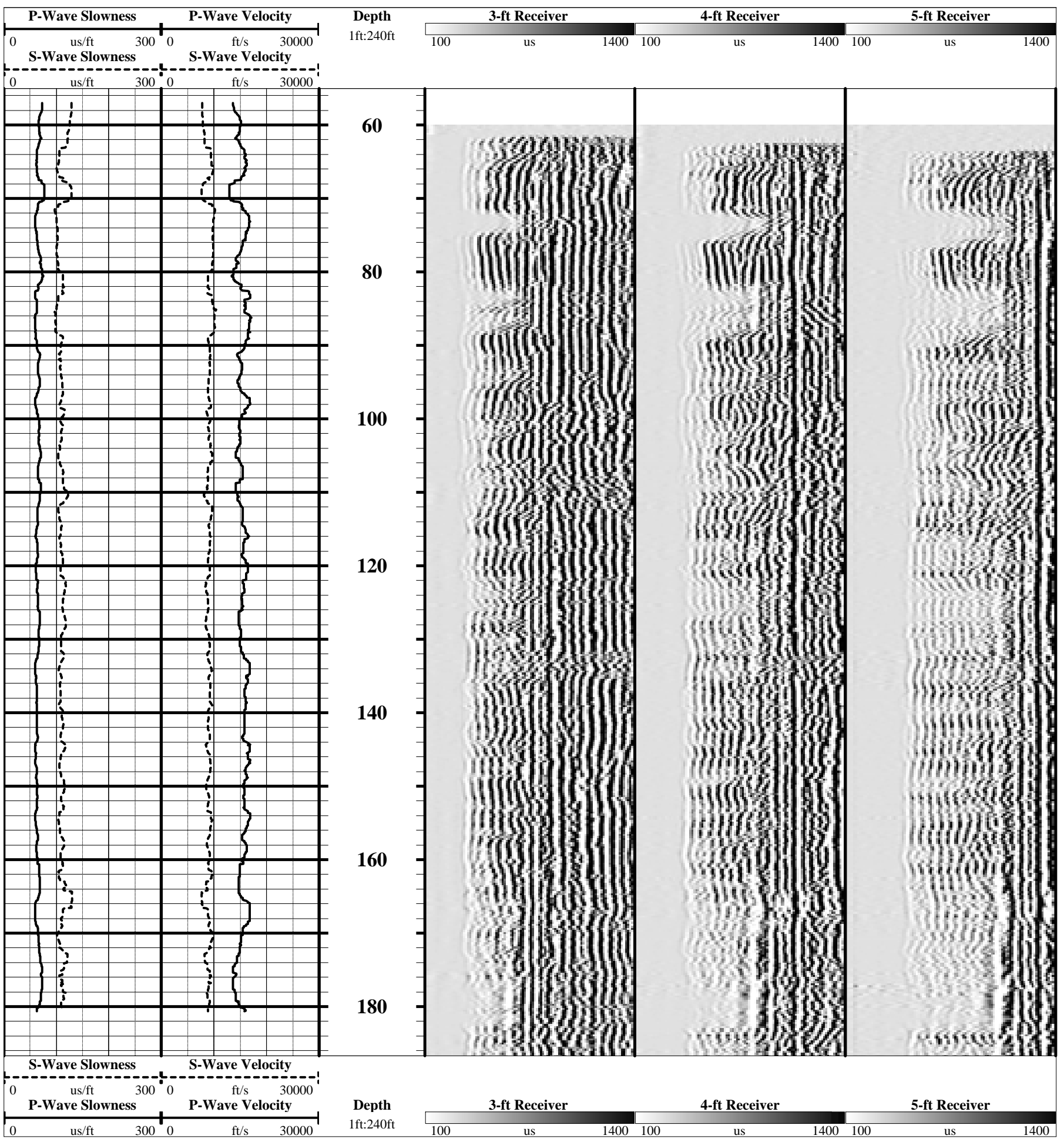




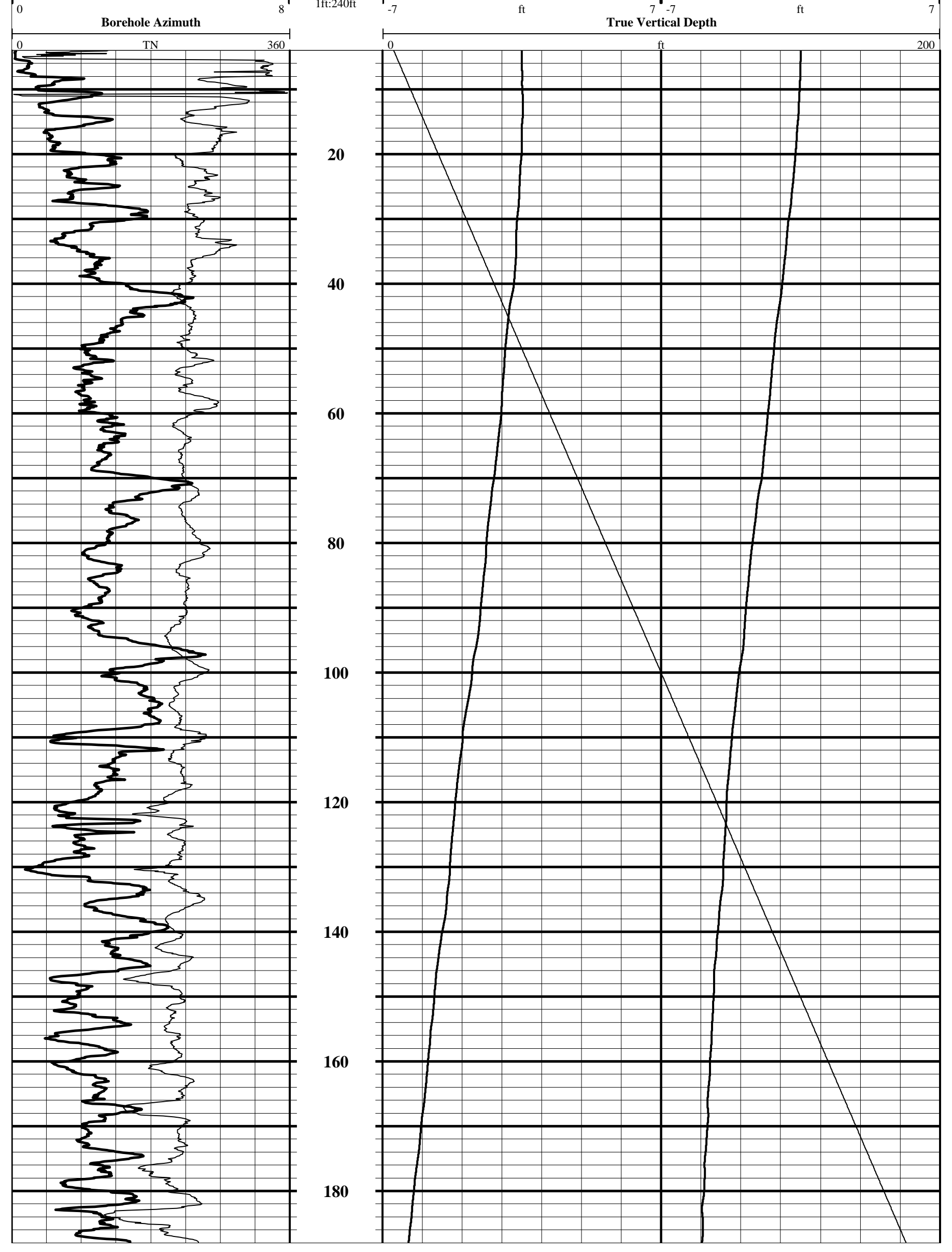




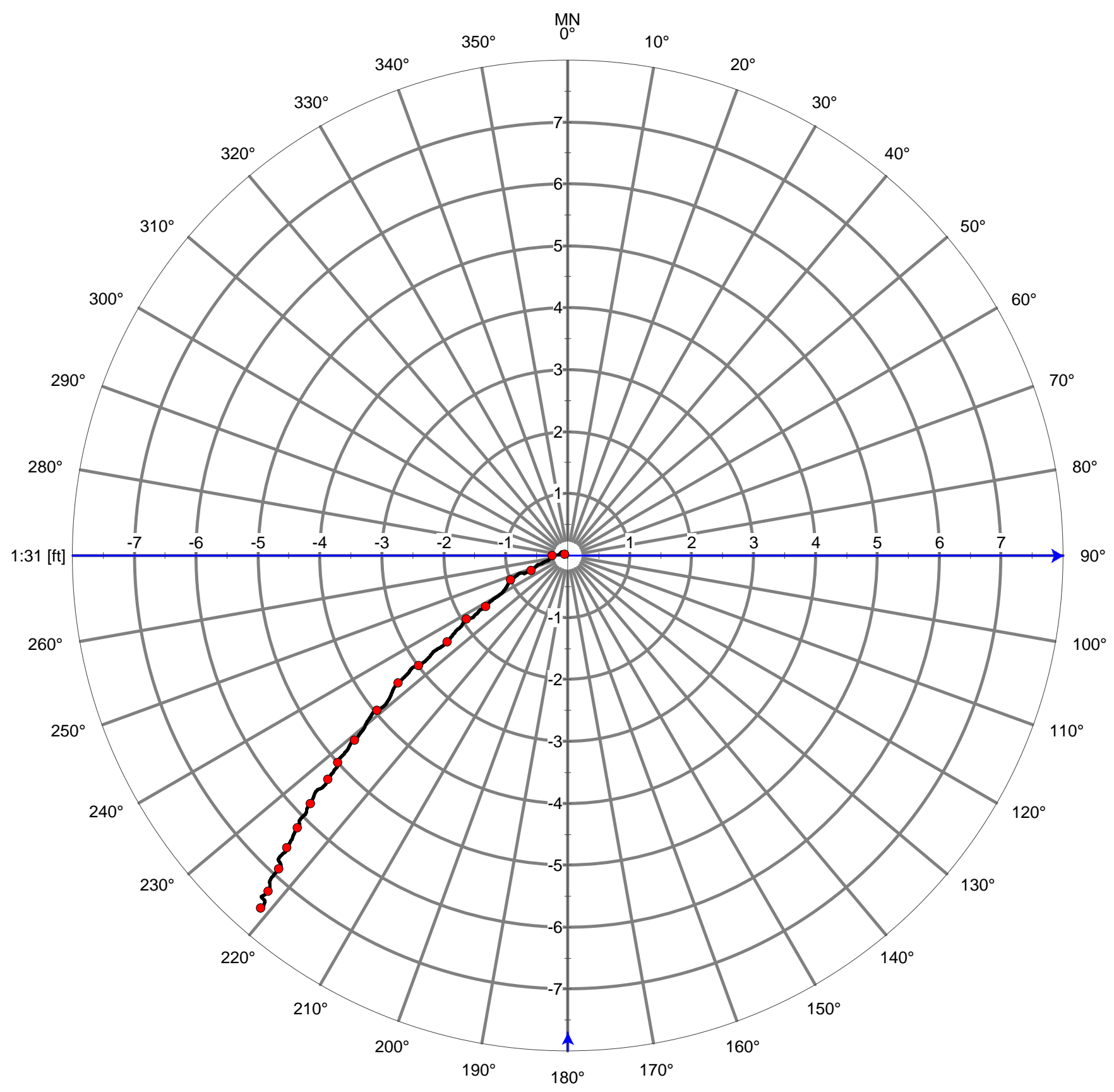




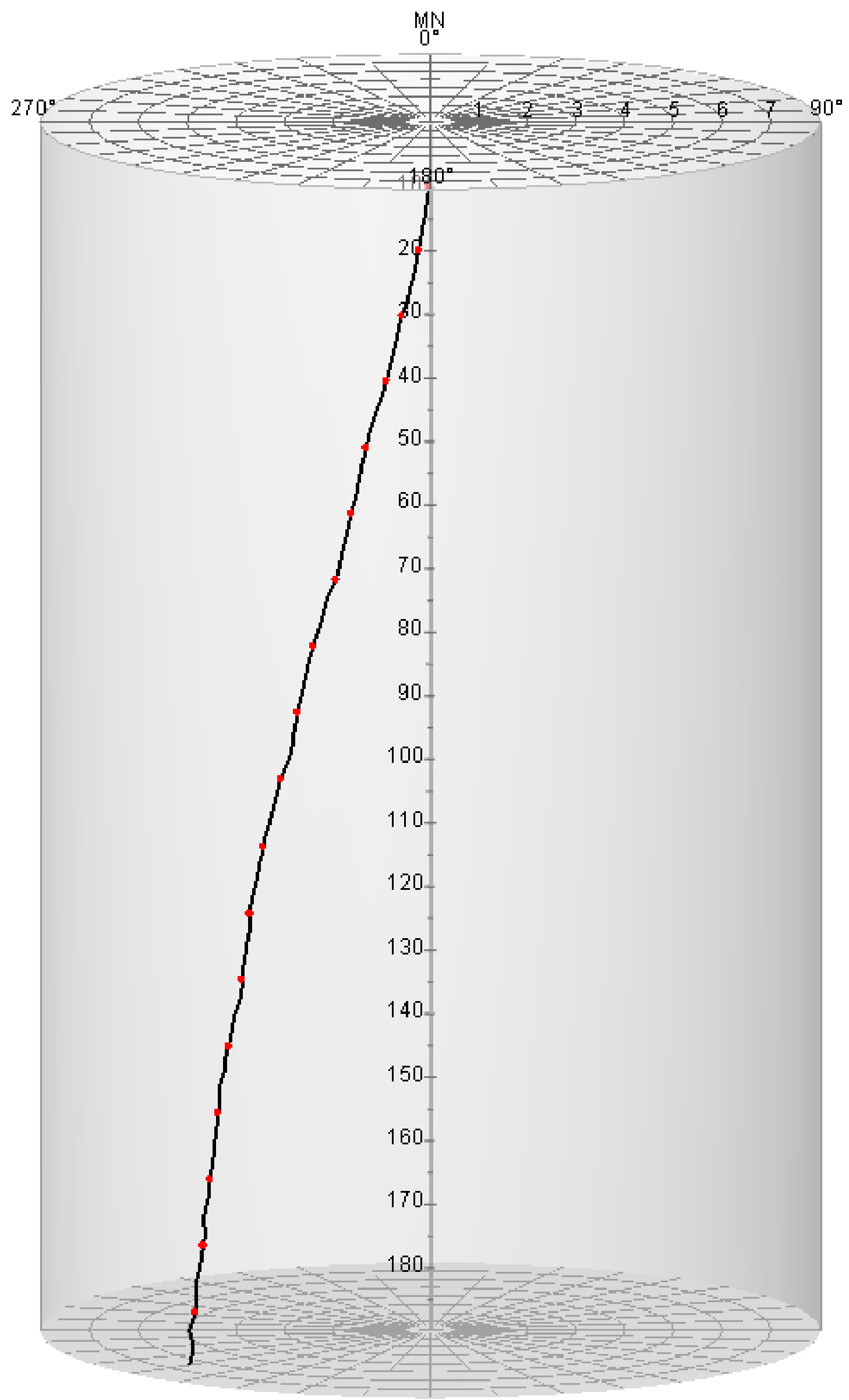


Appendix F-3

Borehole Geophysical Log Plots for Instrument Hole U-15n\#2 


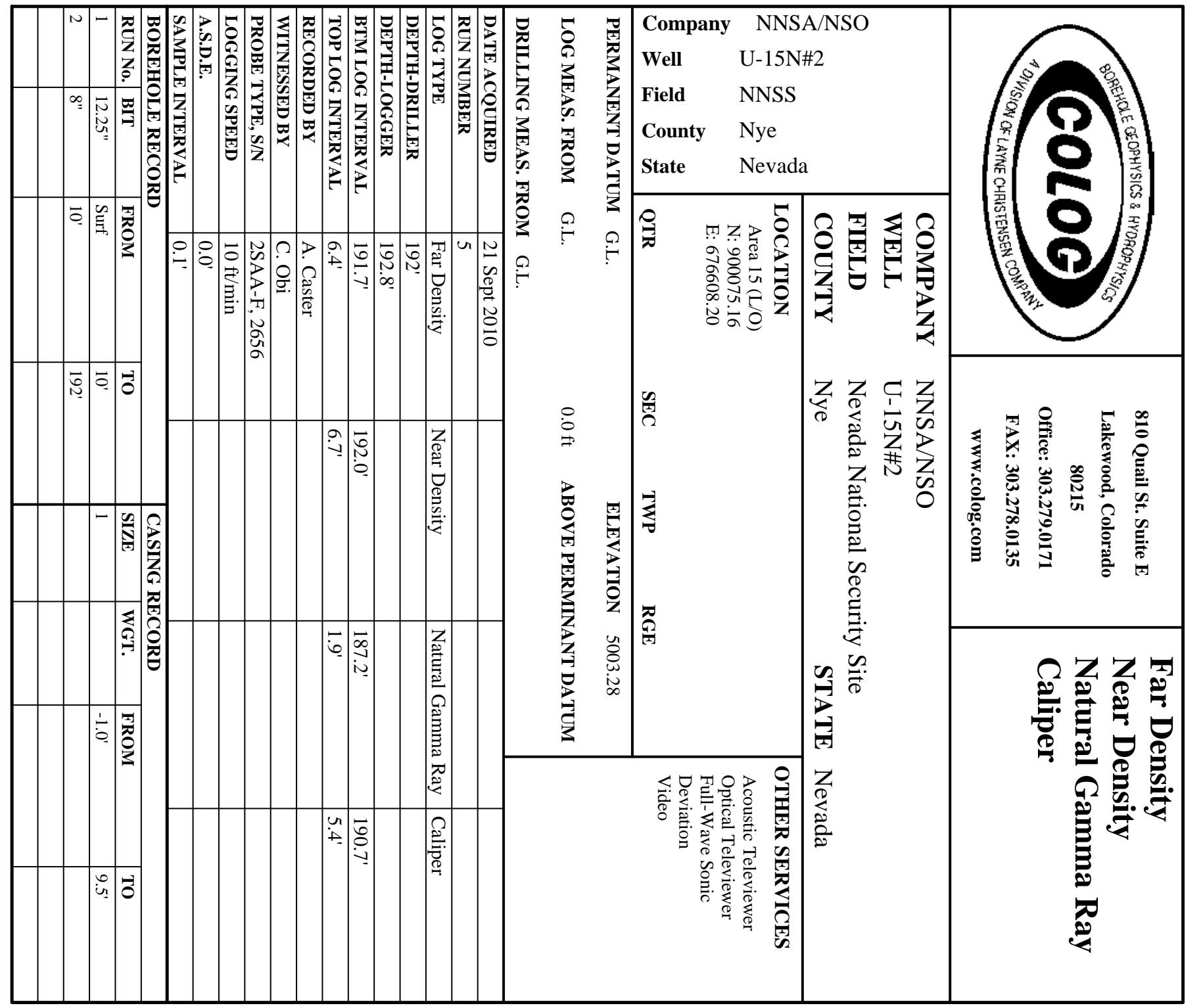

\section{COMMENTS}

NA - Not Available, N/A - Not Applicable

Matrix Density of 2.64 used to calculate Density Porosity 


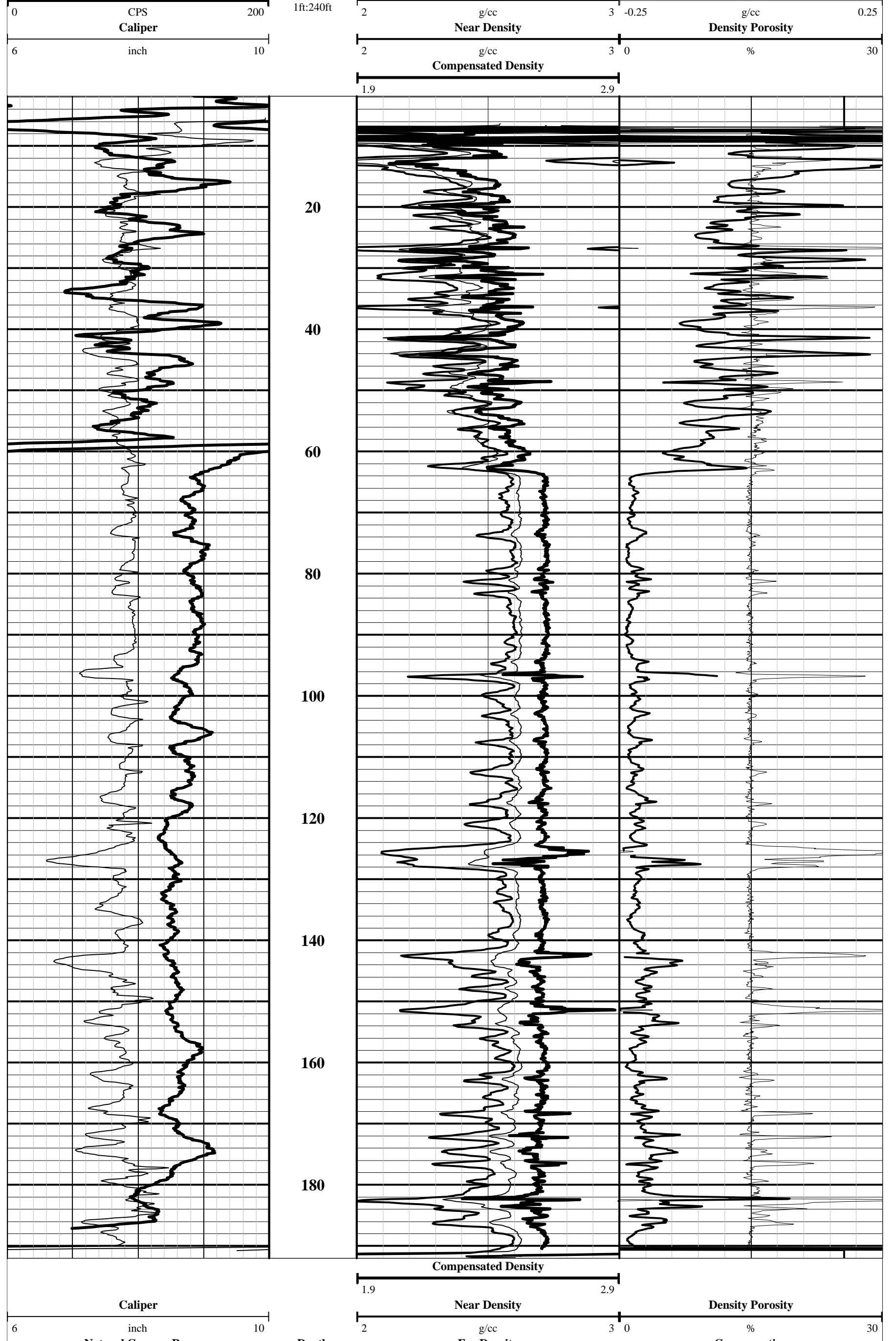


0

anc

$1 \mathrm{ft}: 240 \mathrm{ft}$

$3^{n}-0.25$

g/CC 0.25 


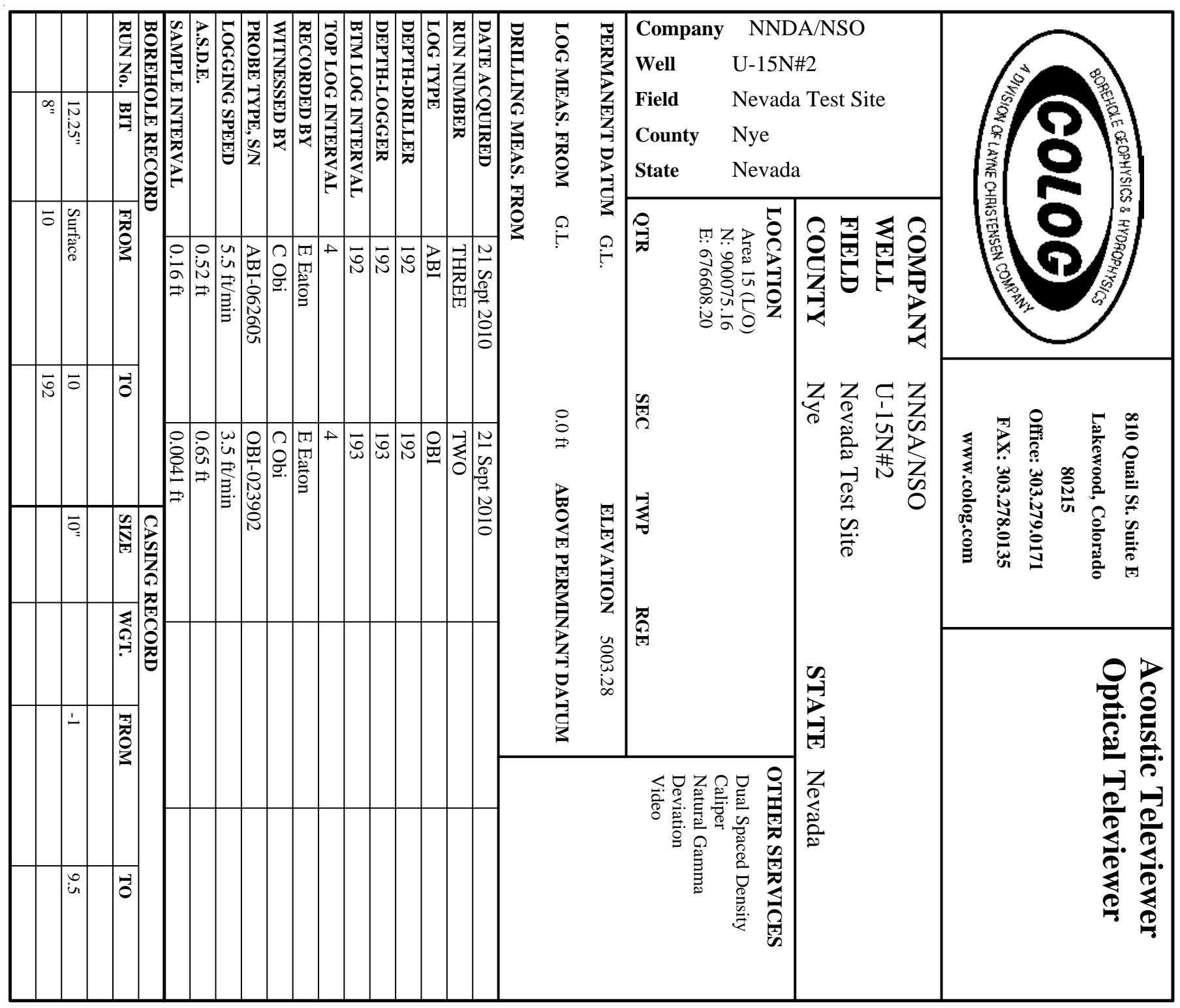




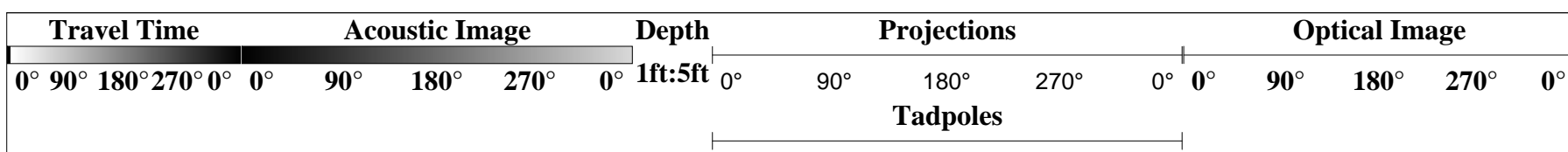

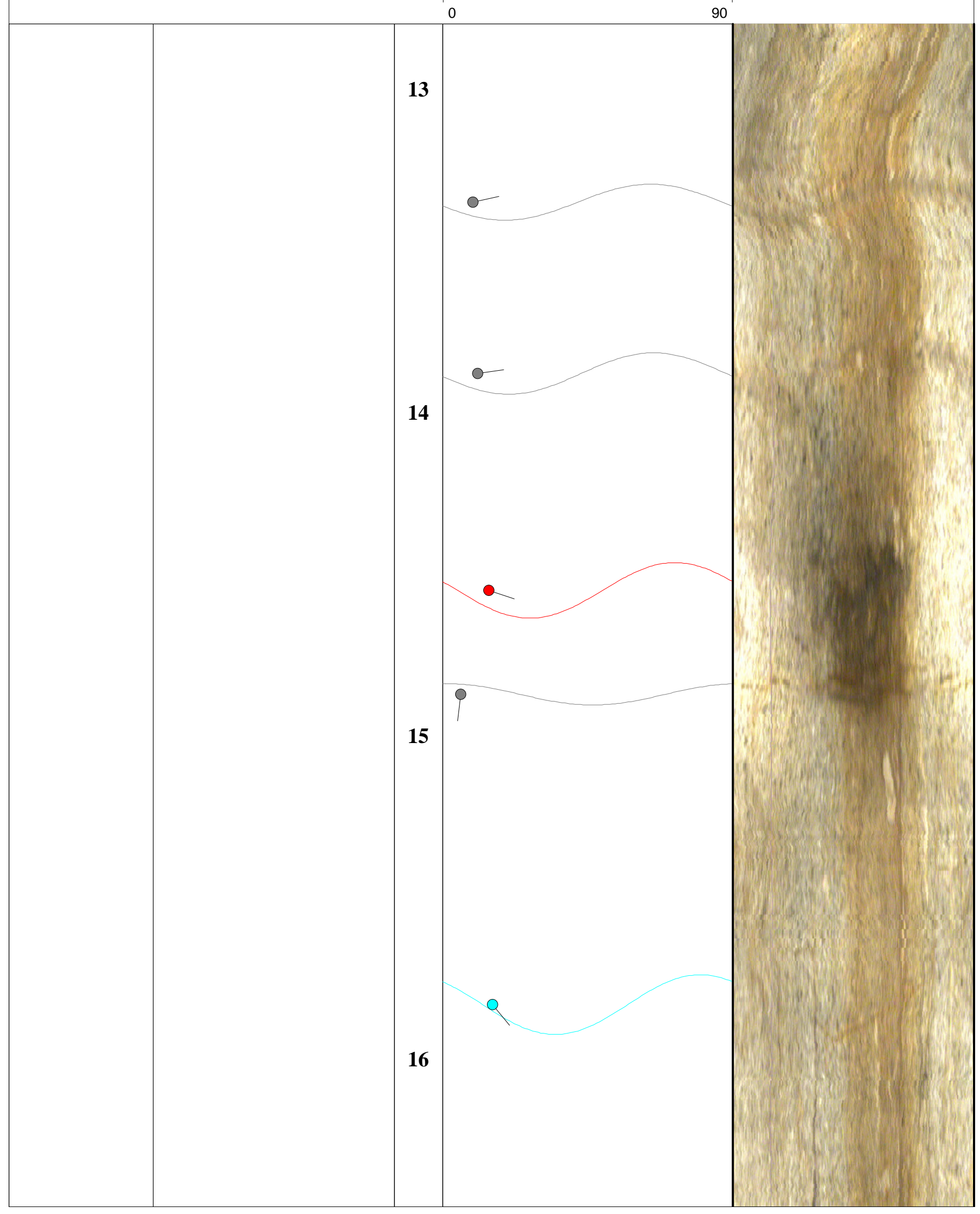




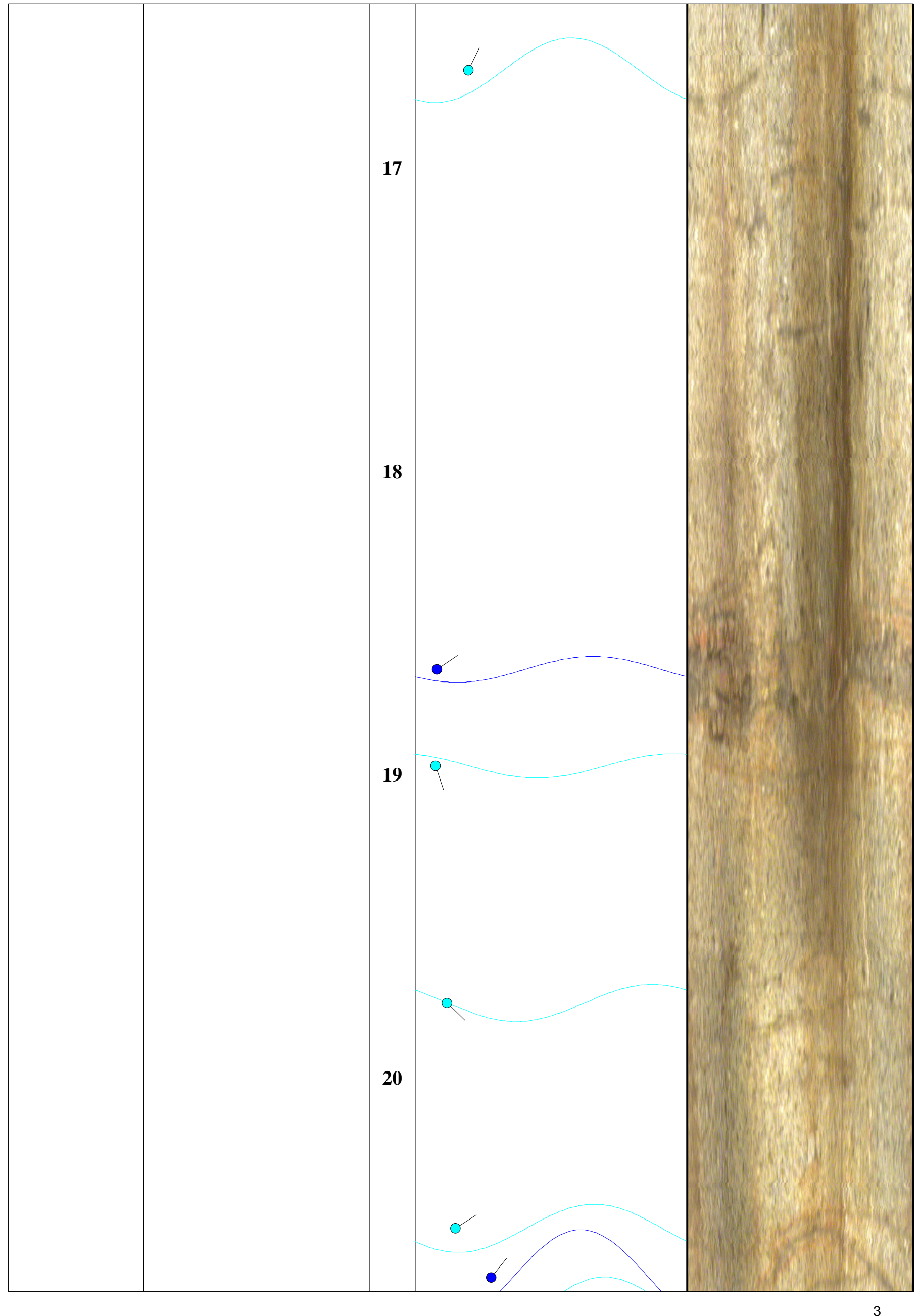




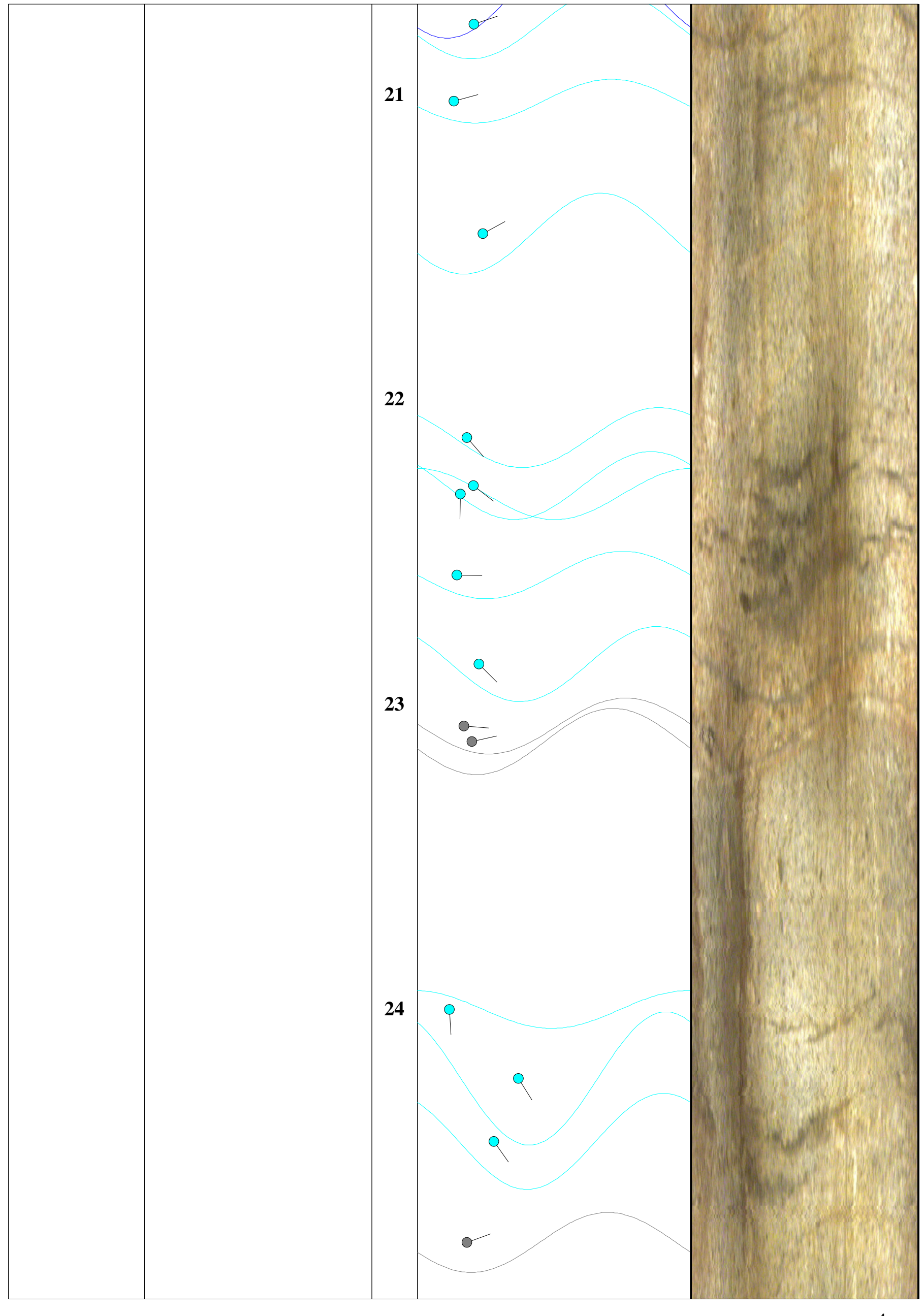




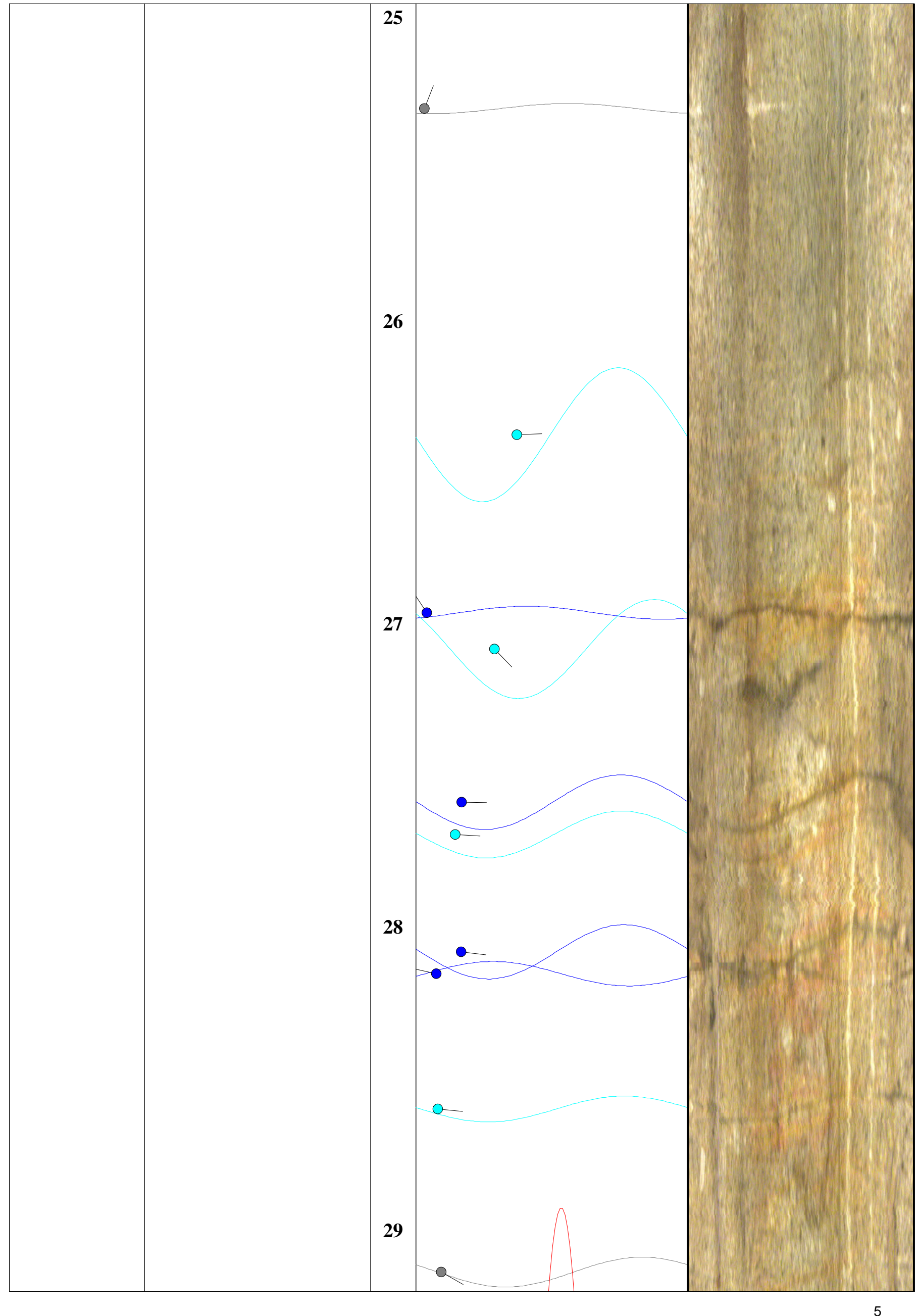




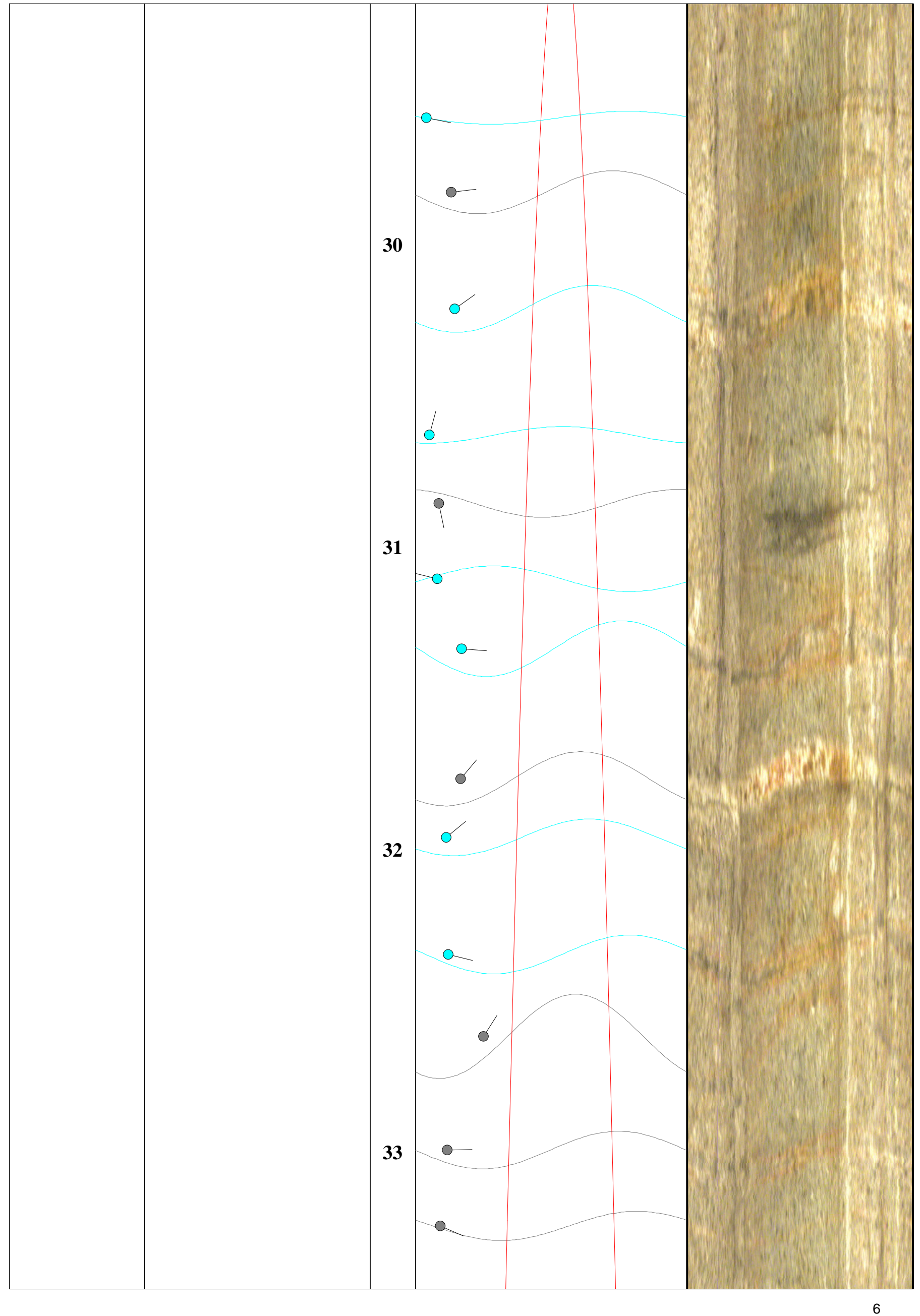




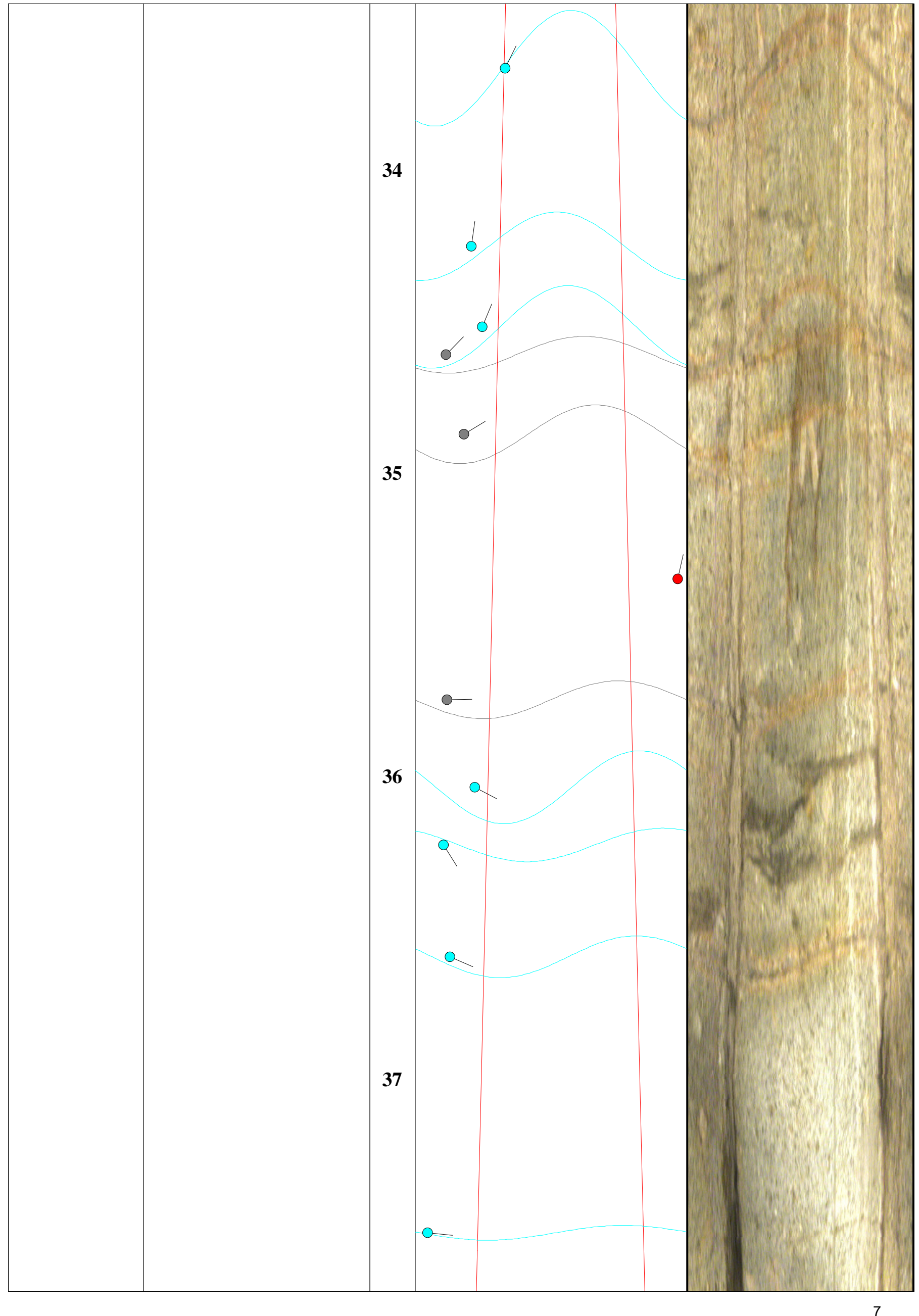




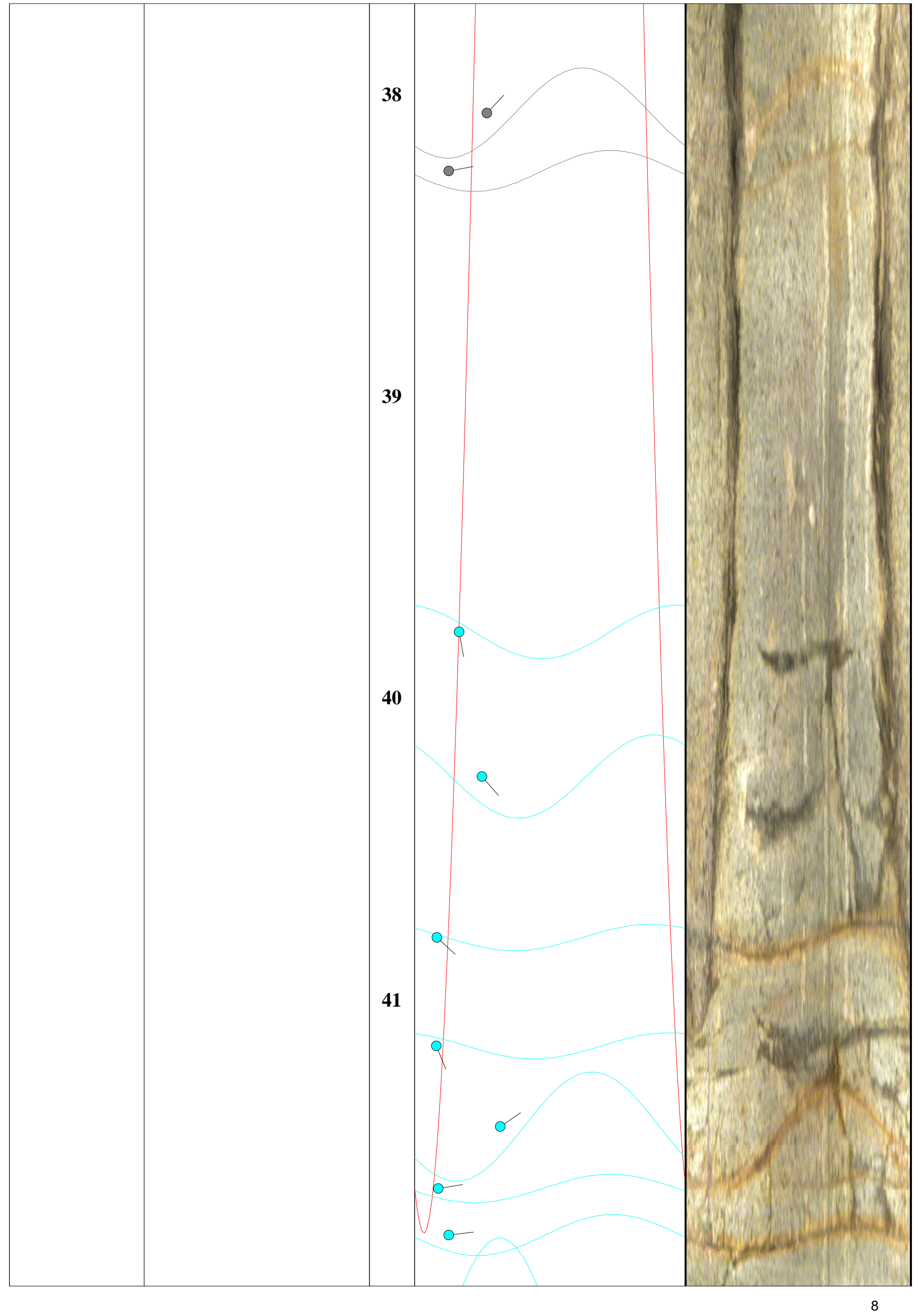




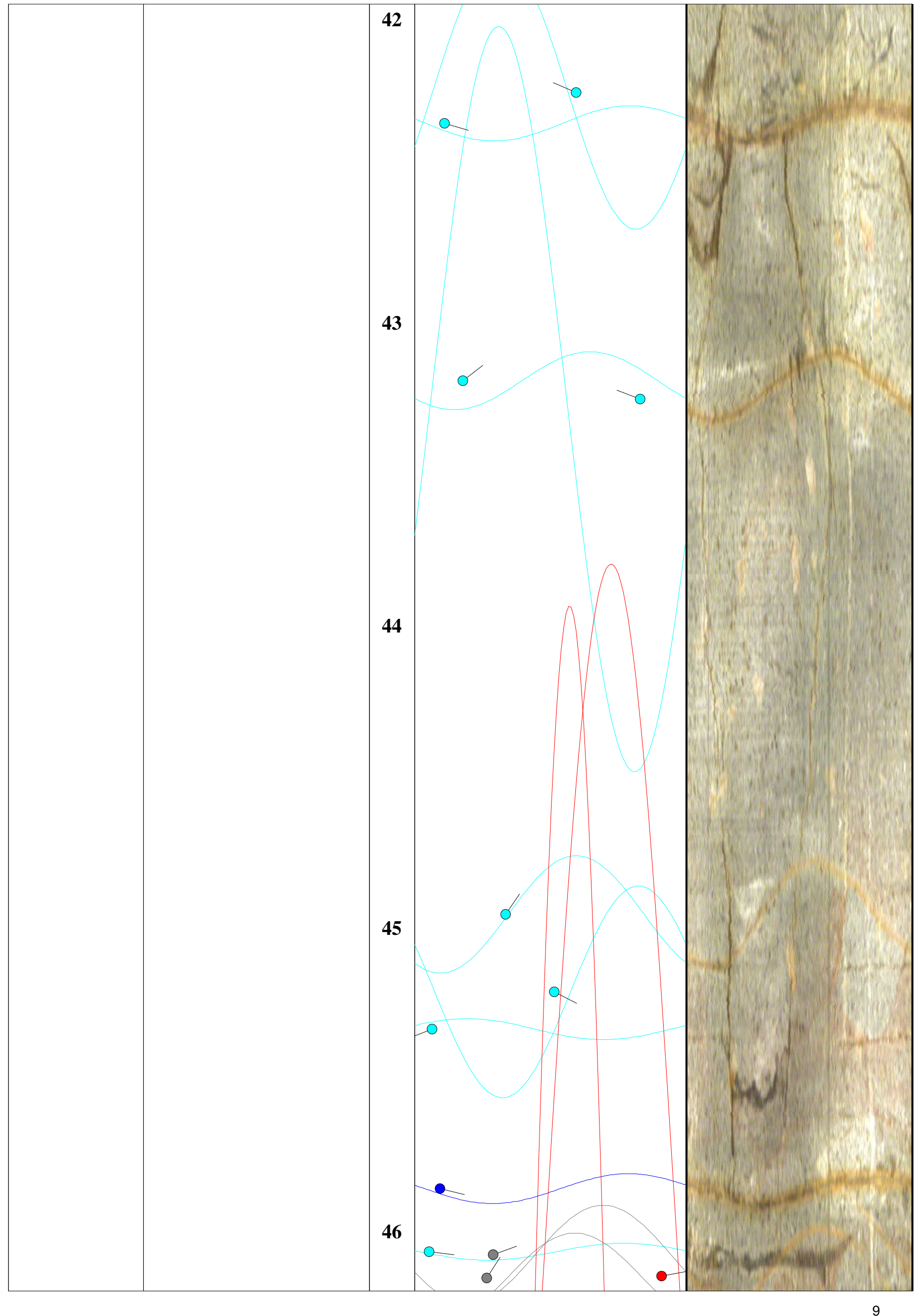




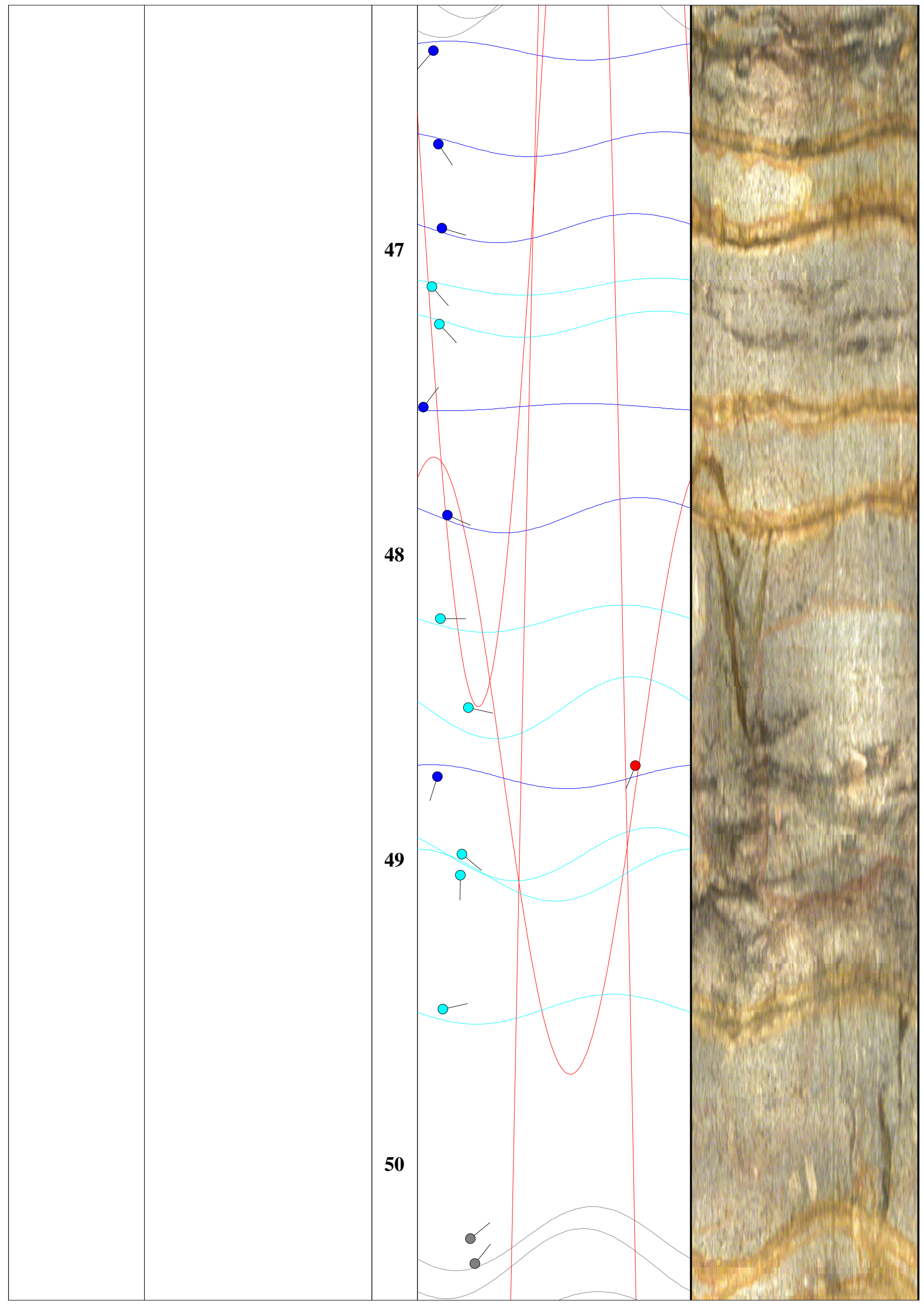




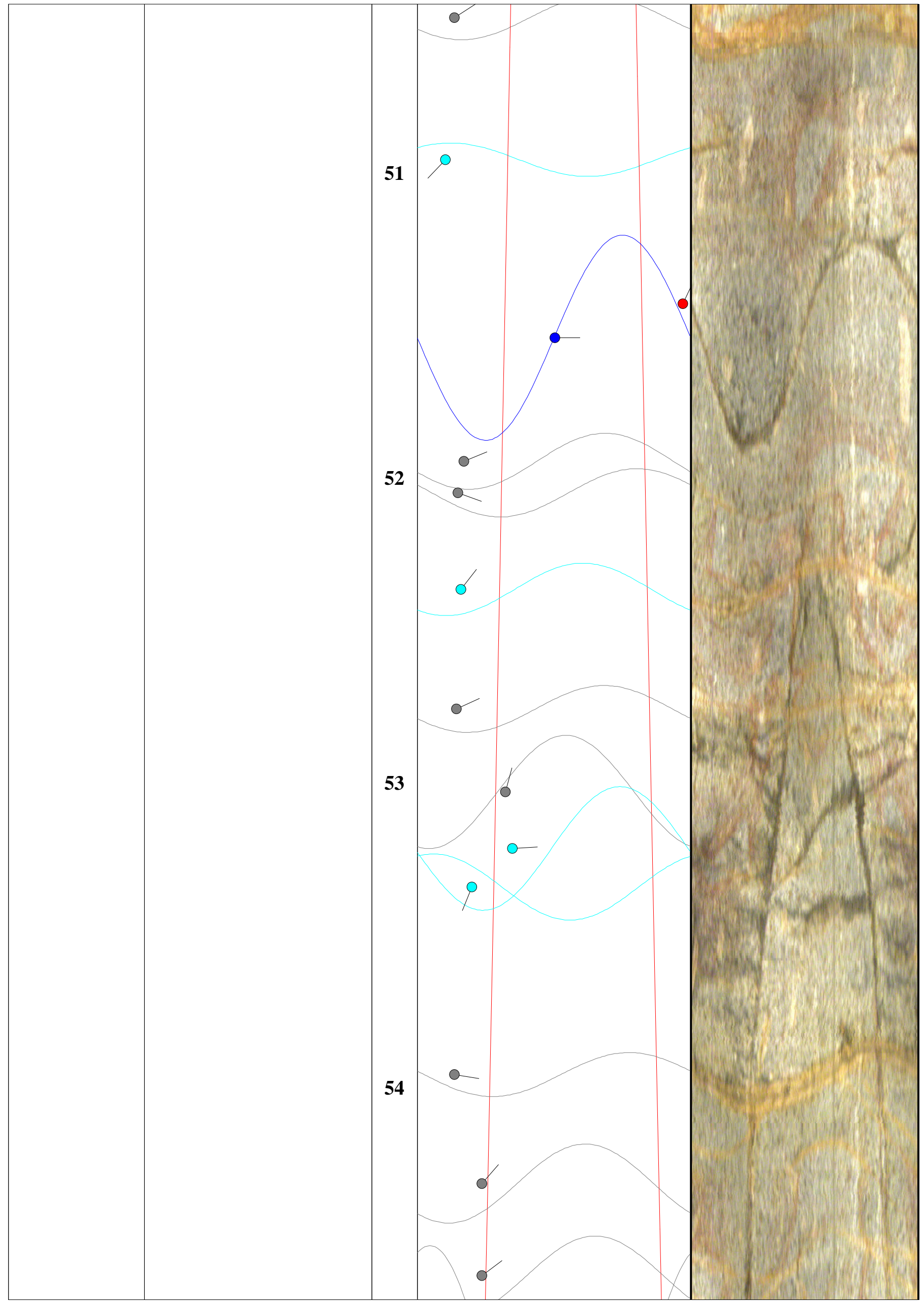




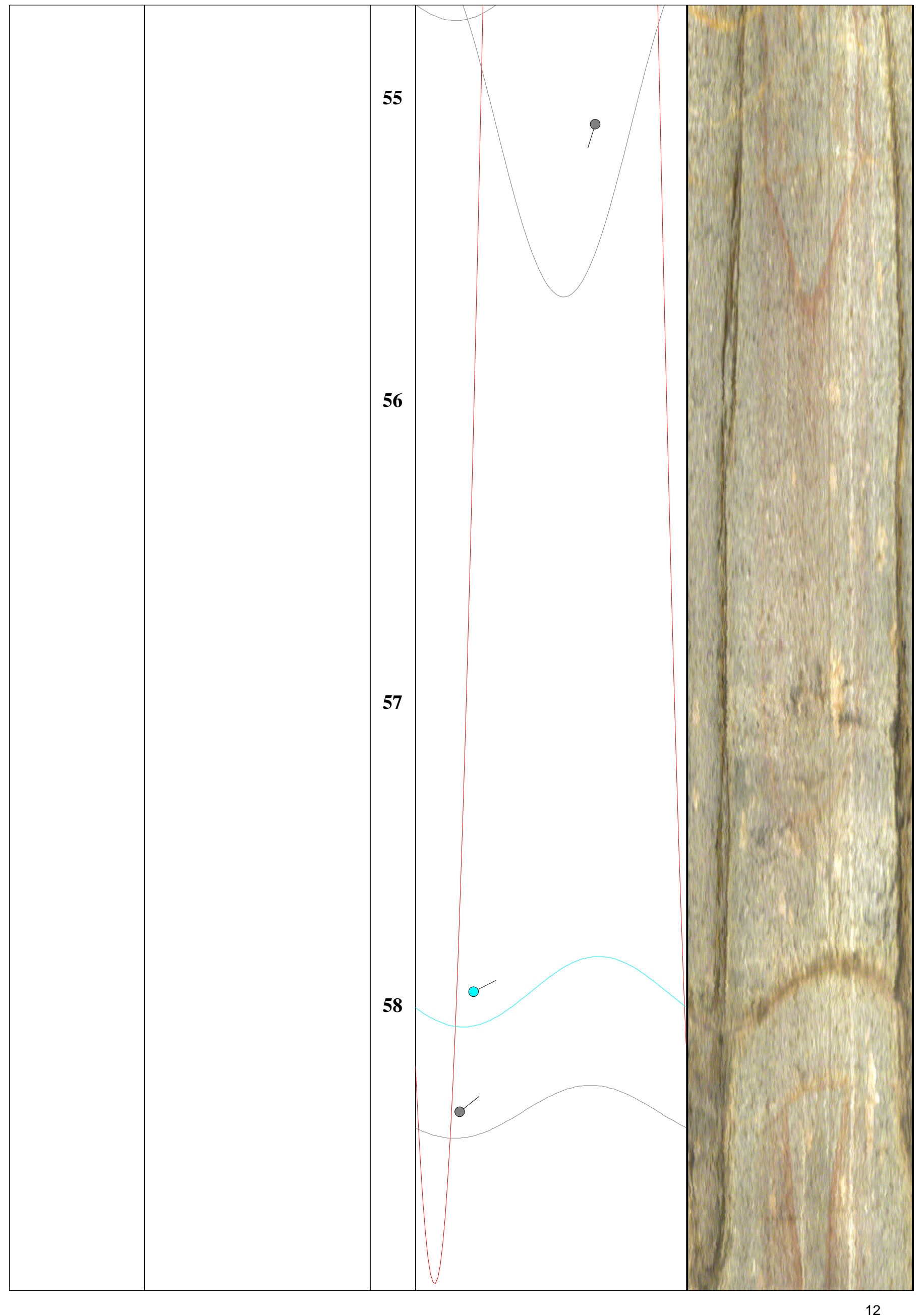




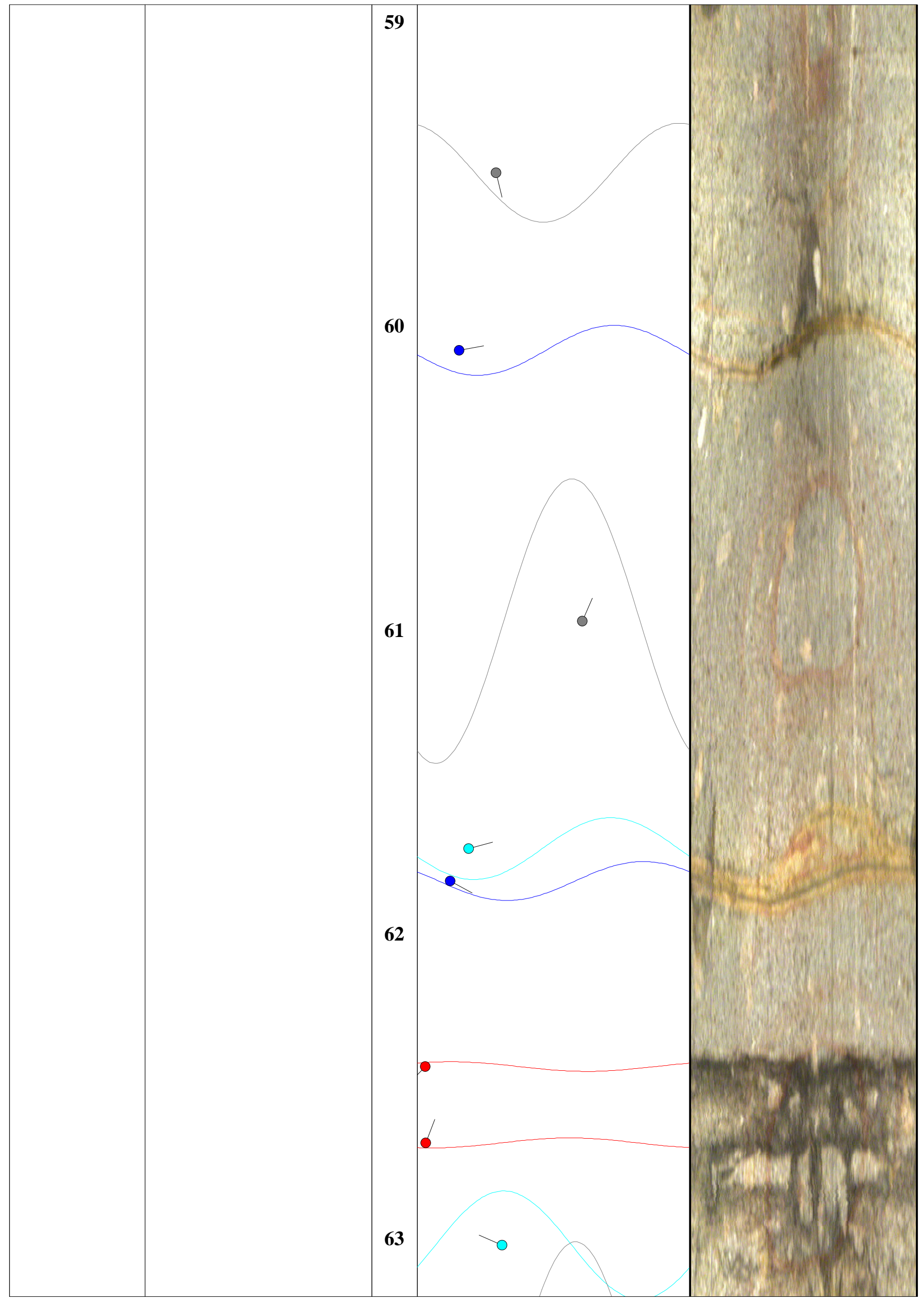




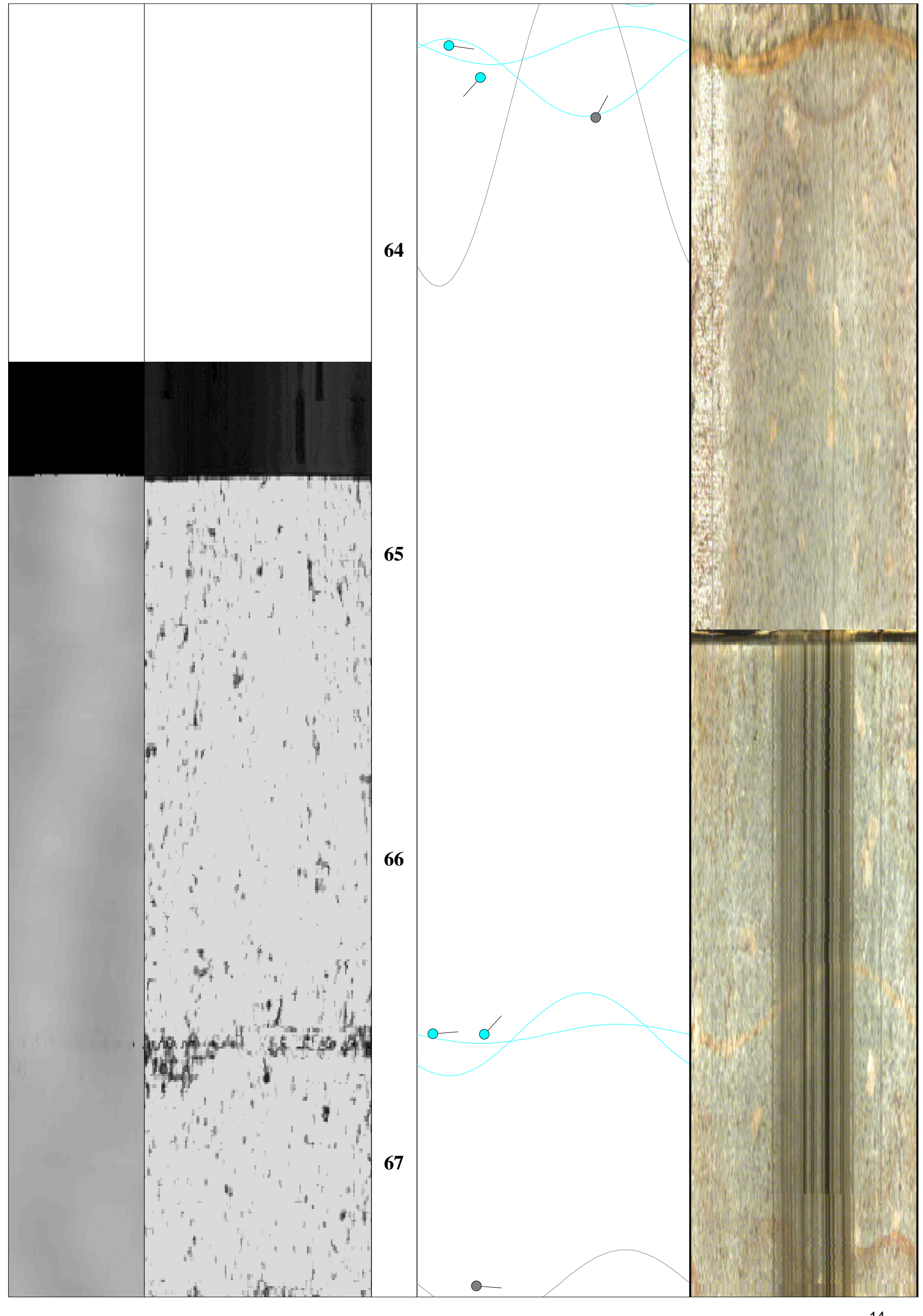




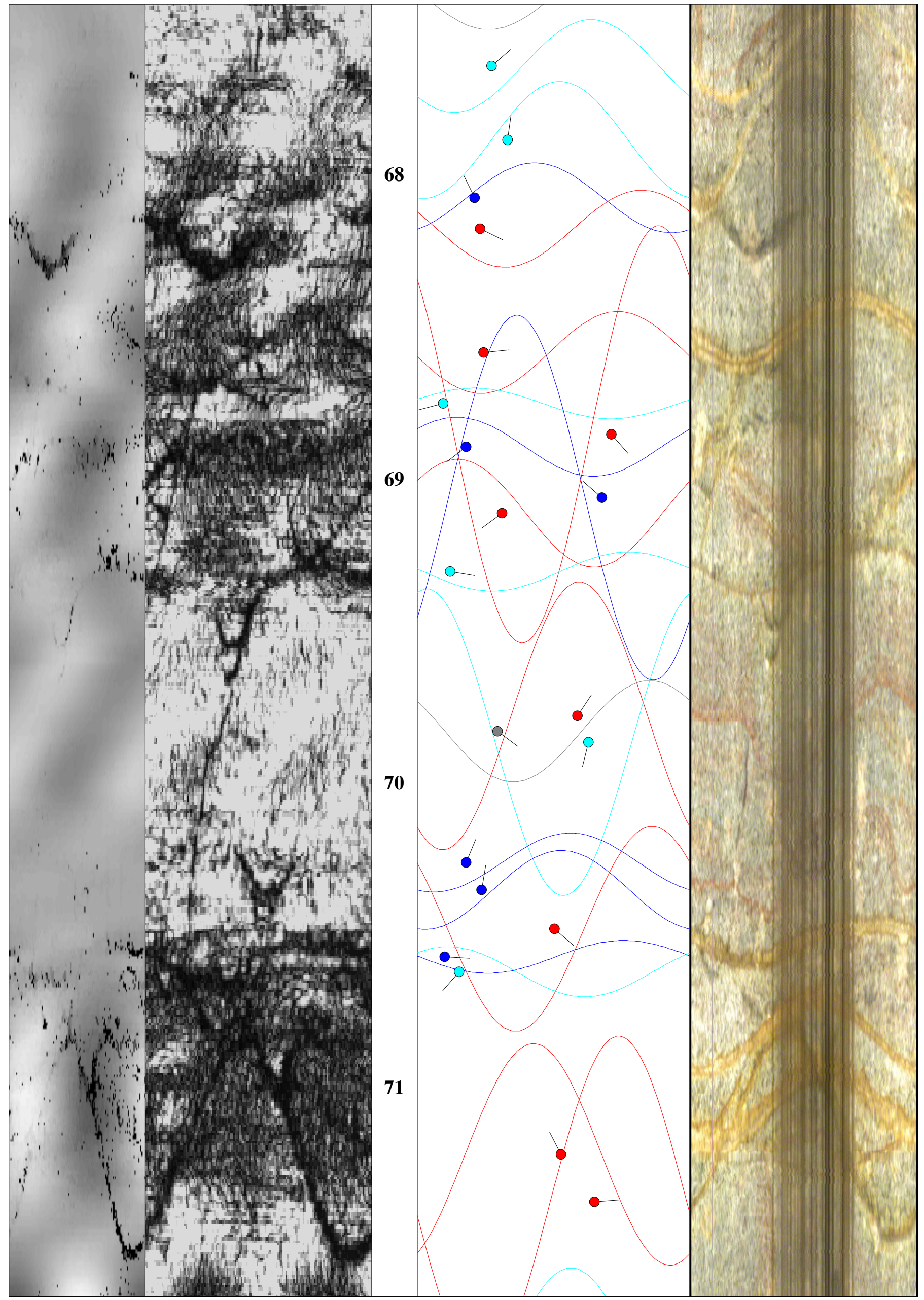




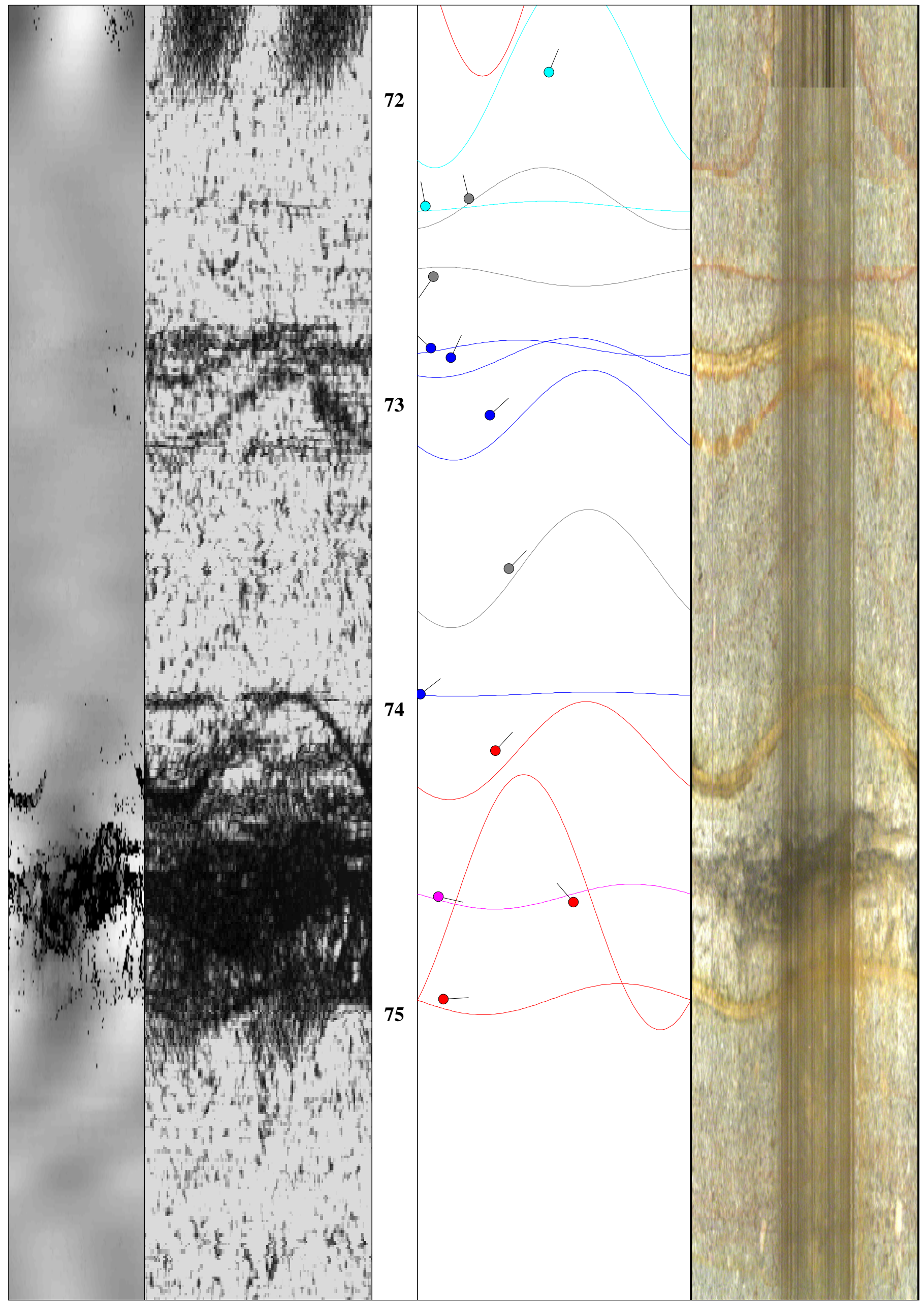




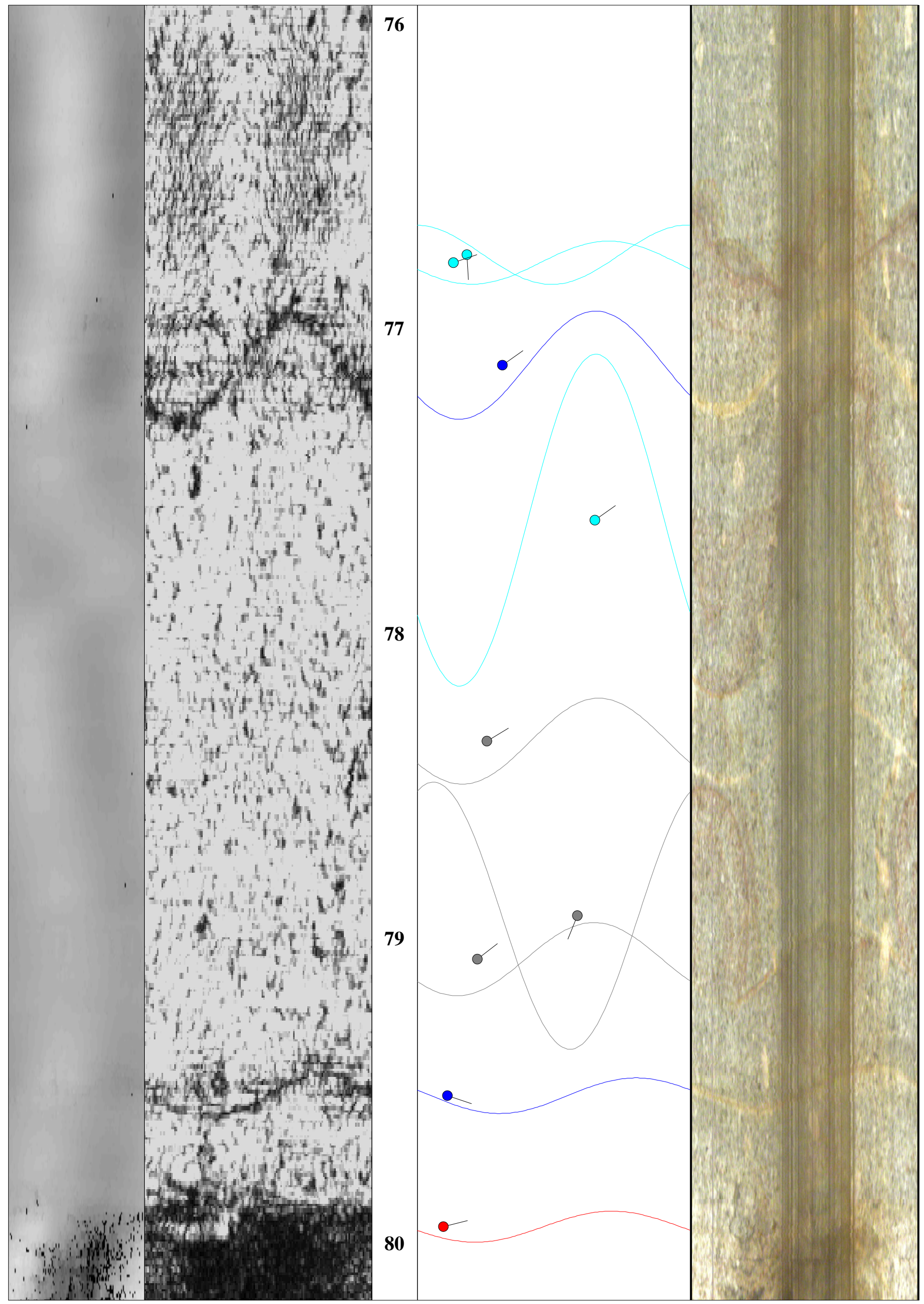




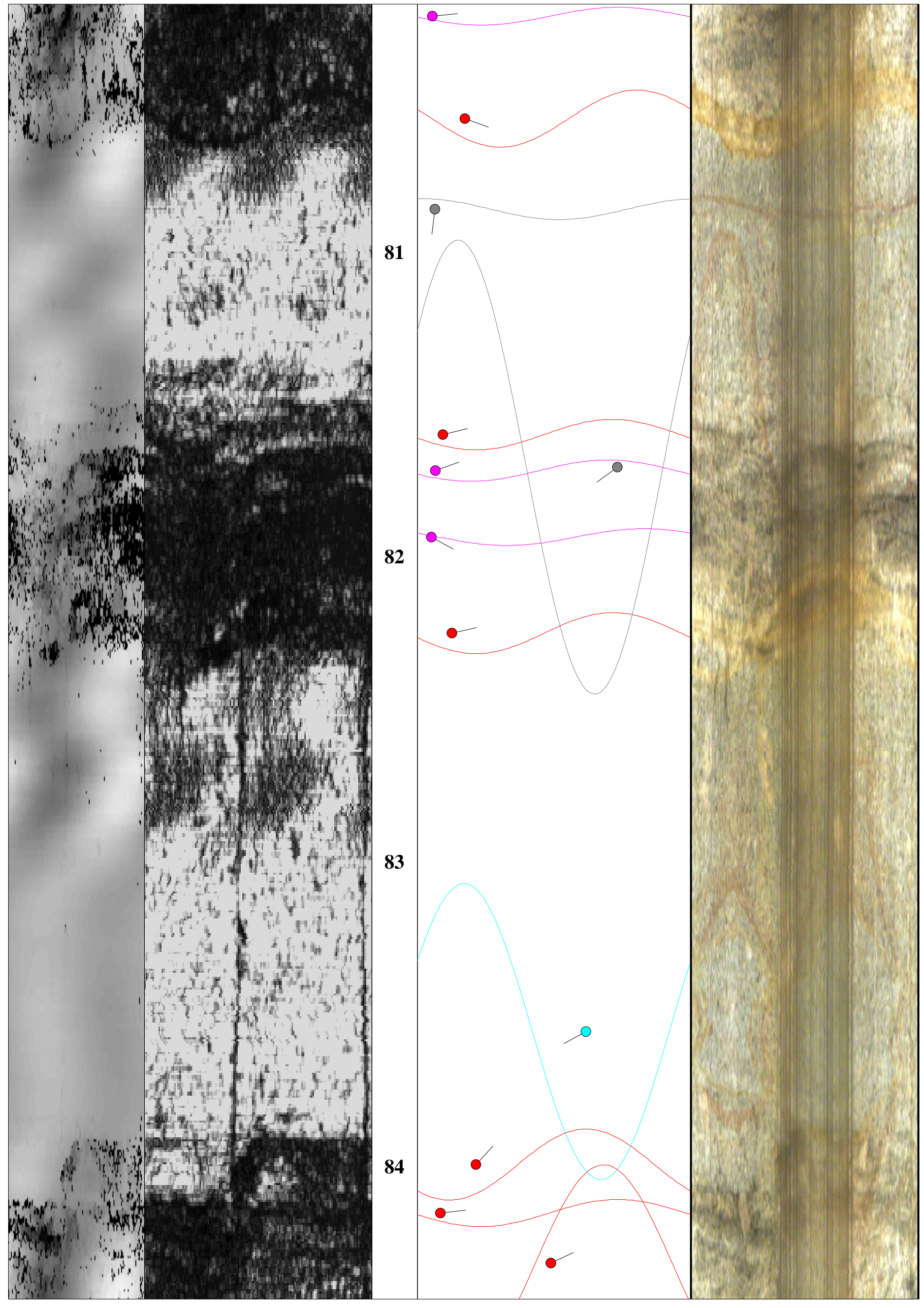




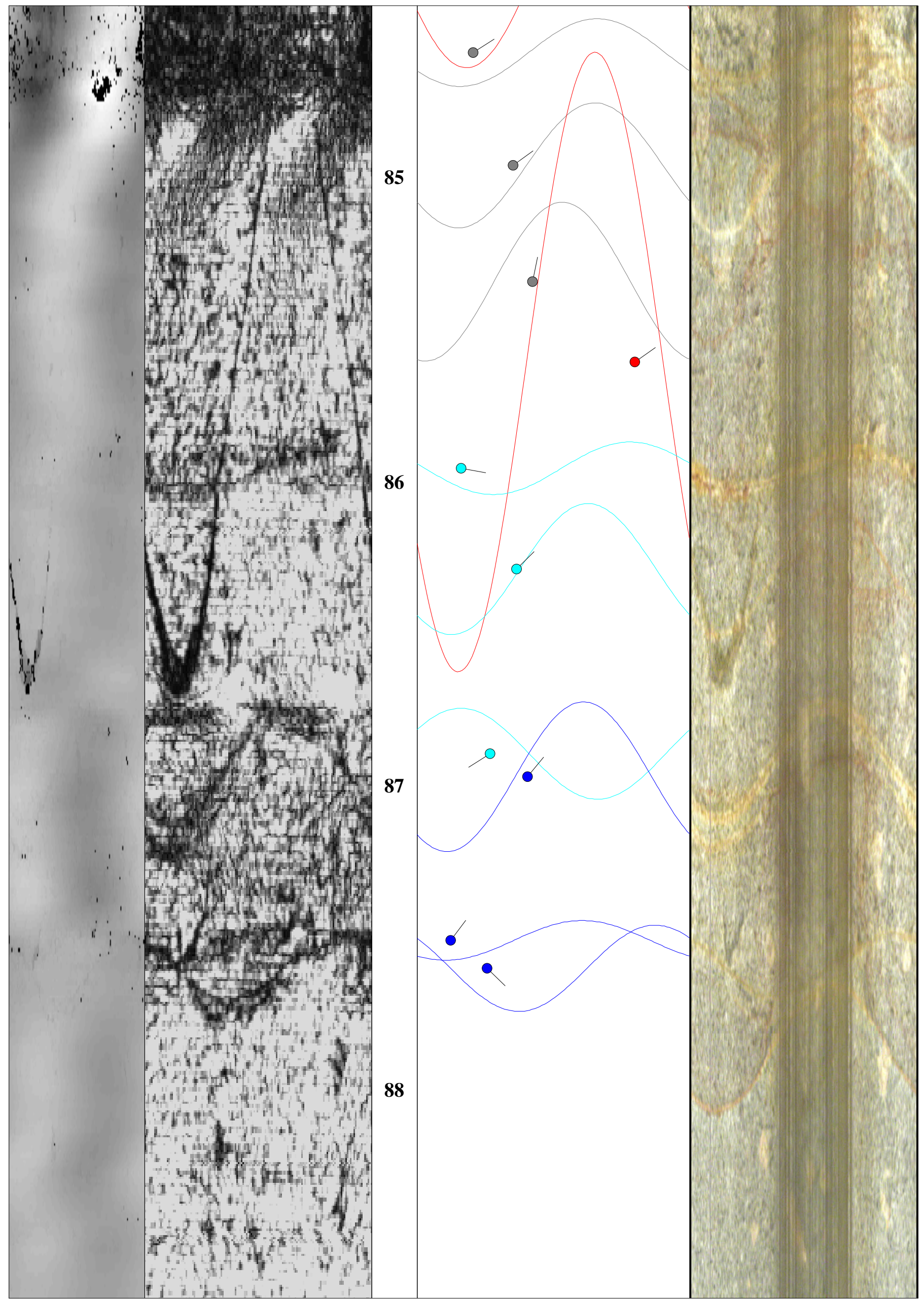




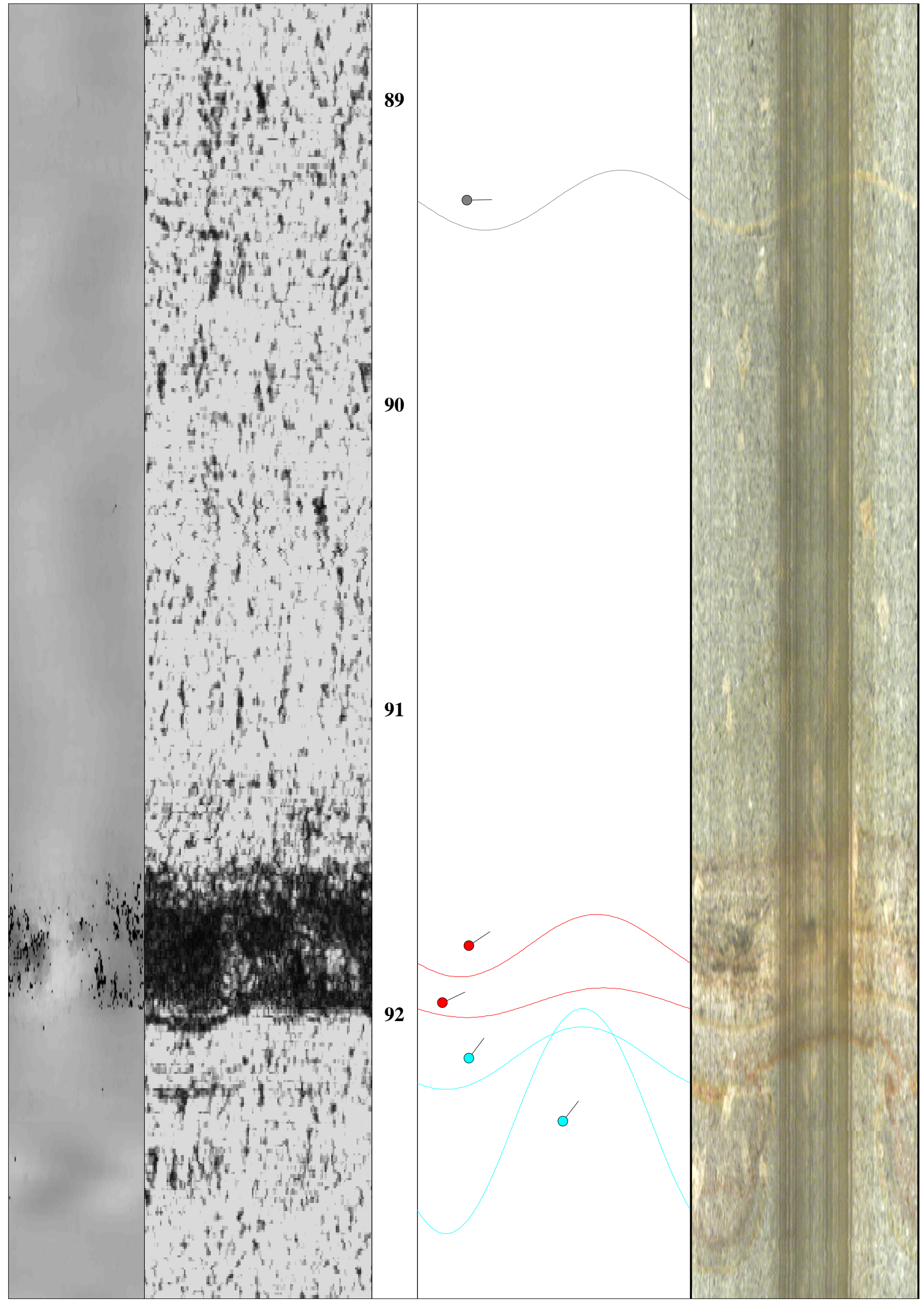




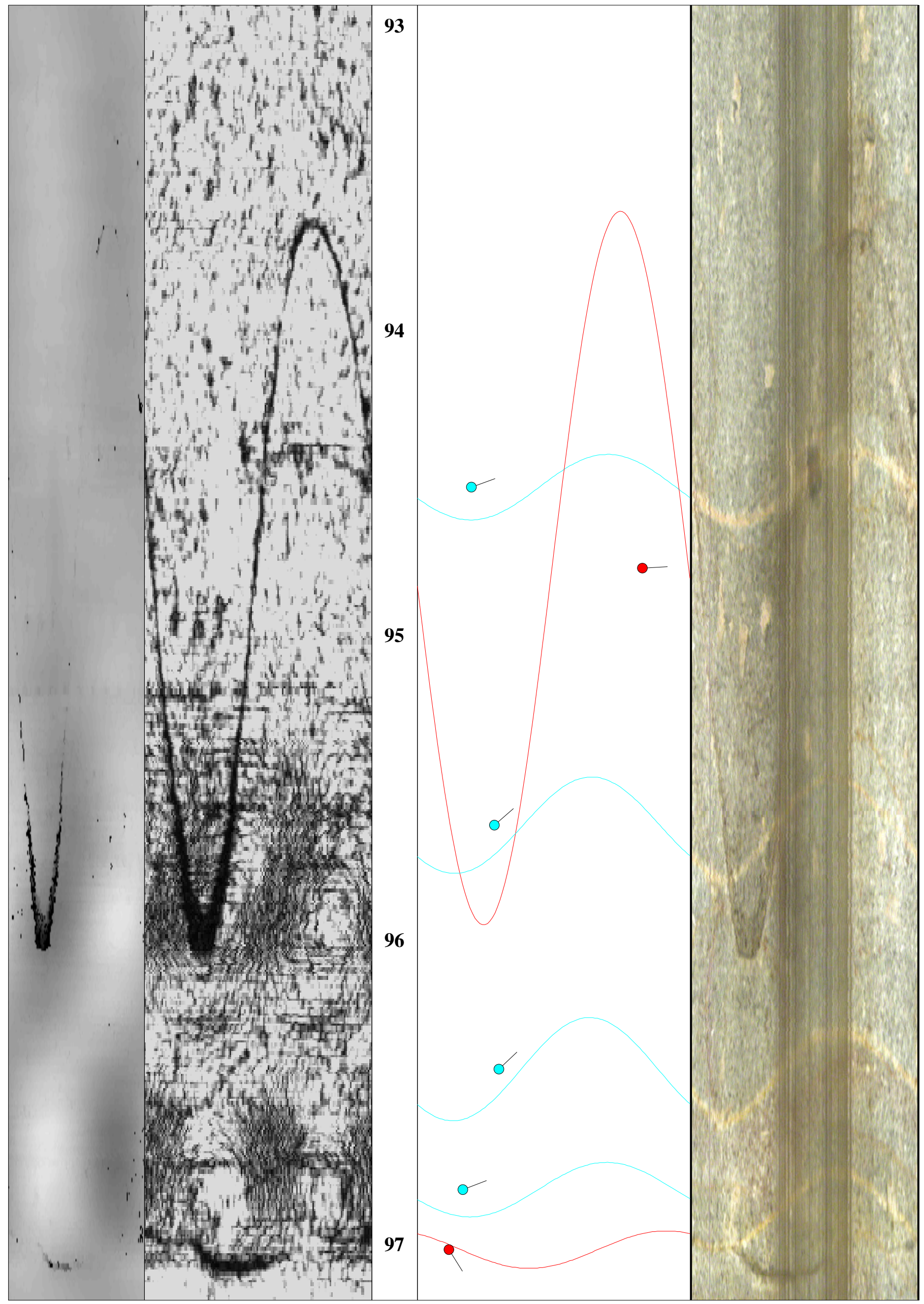




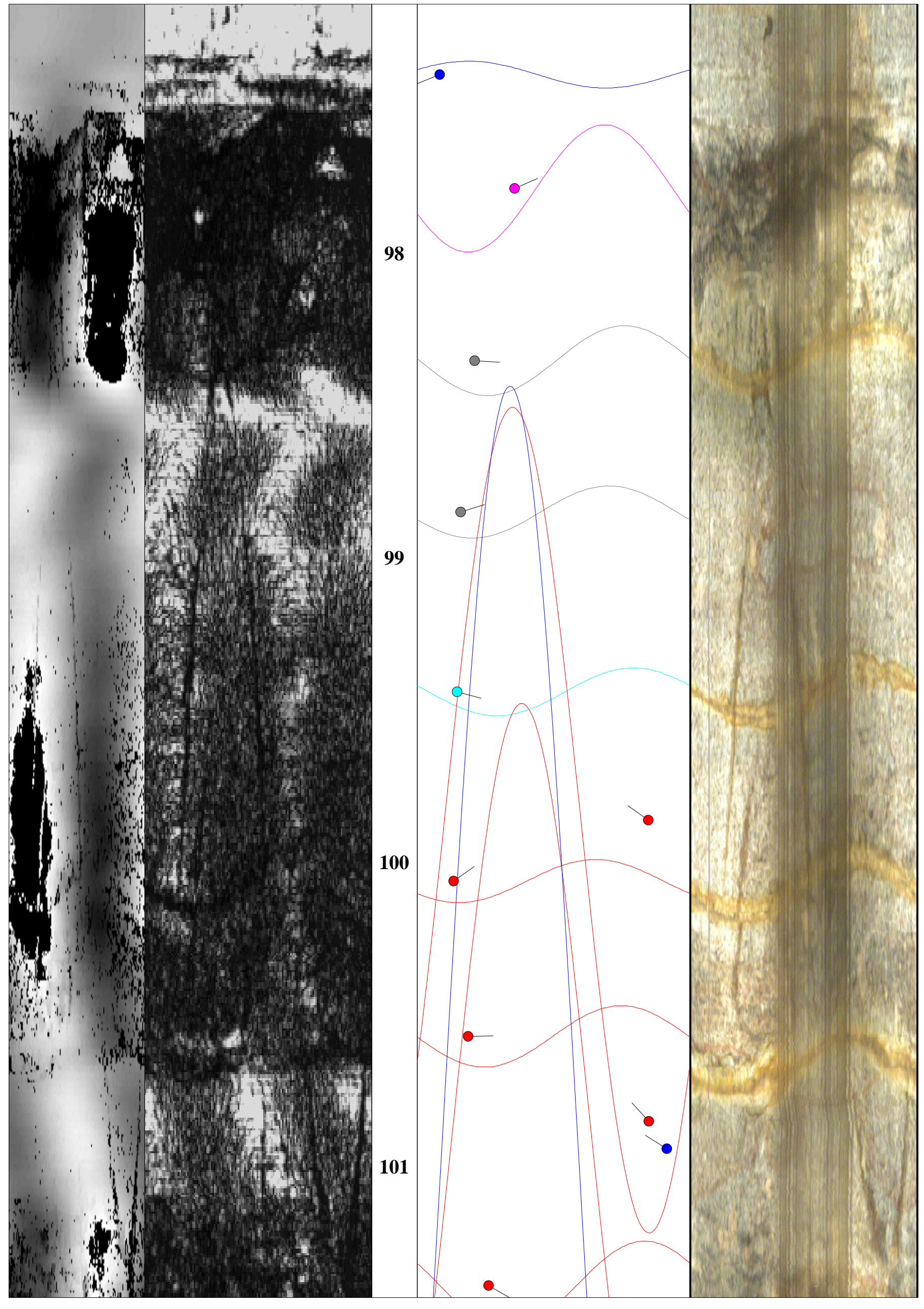




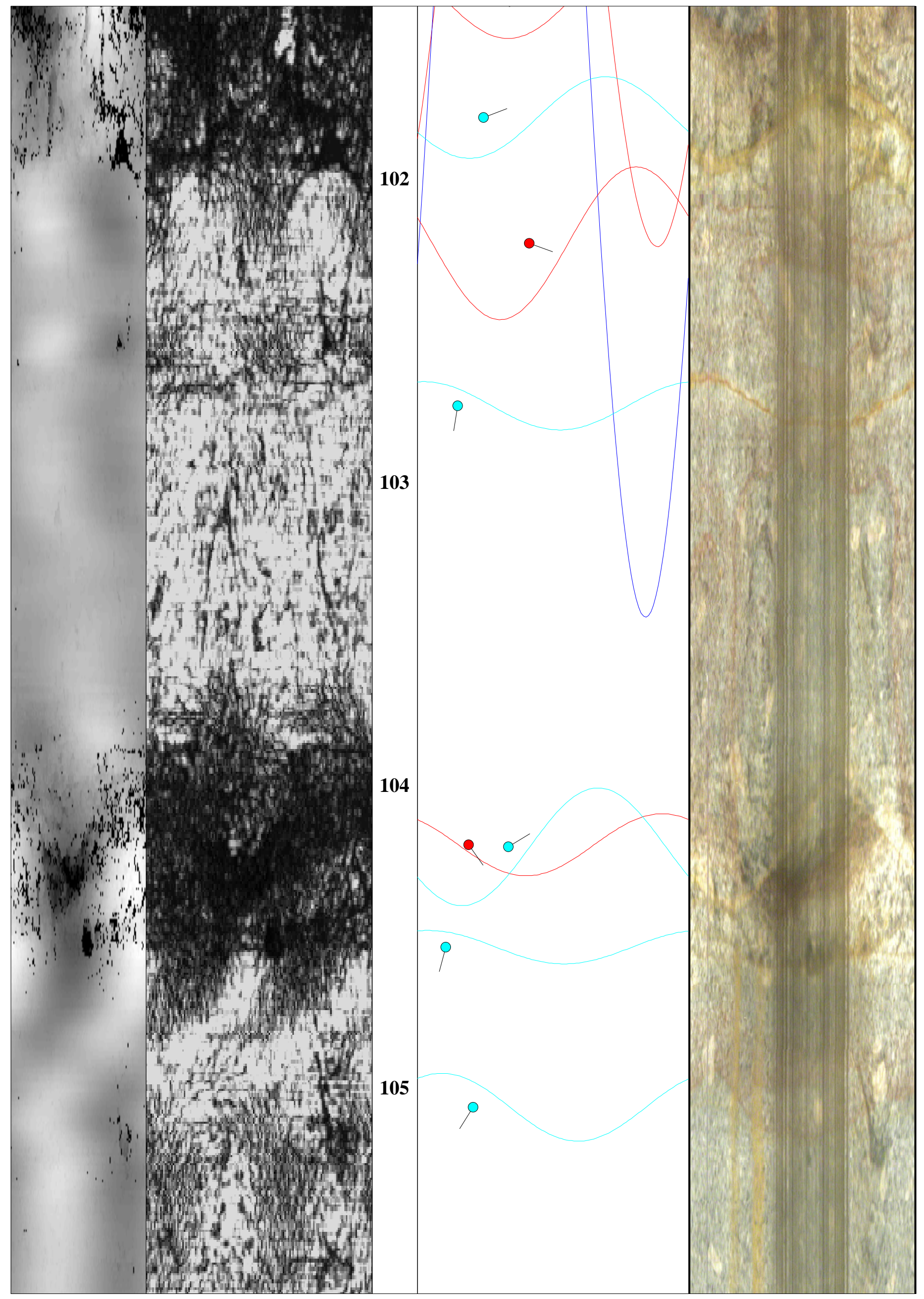




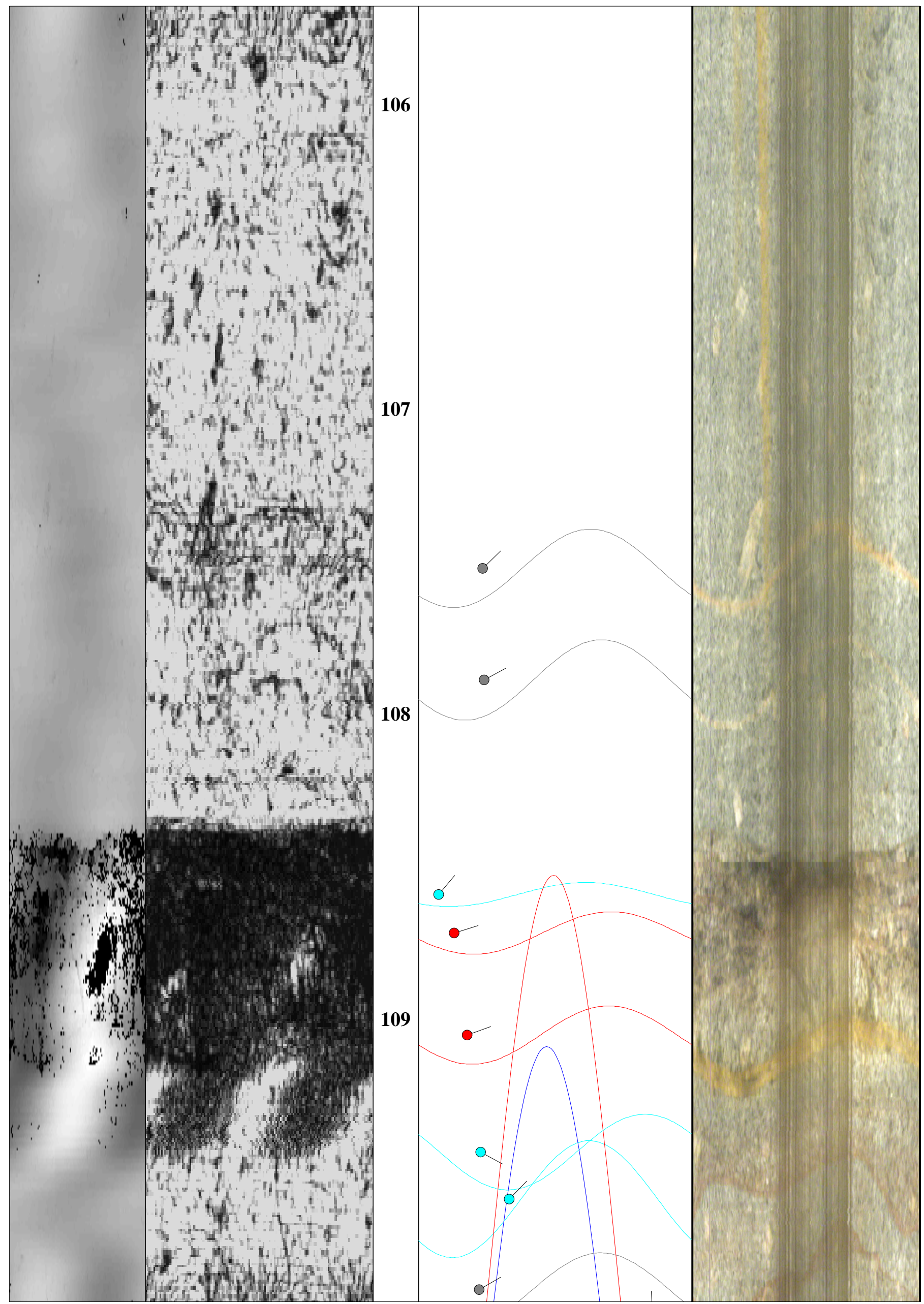




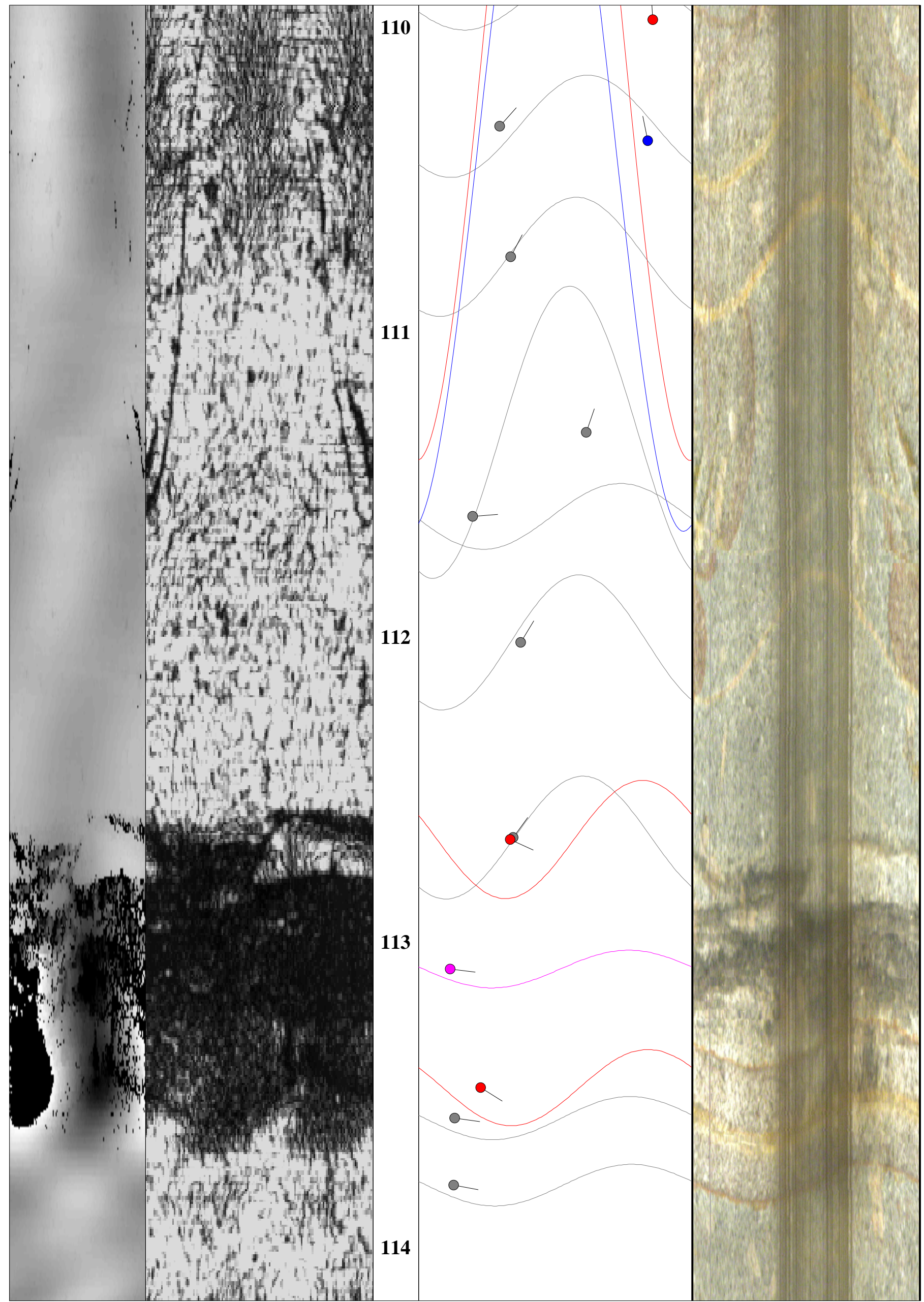




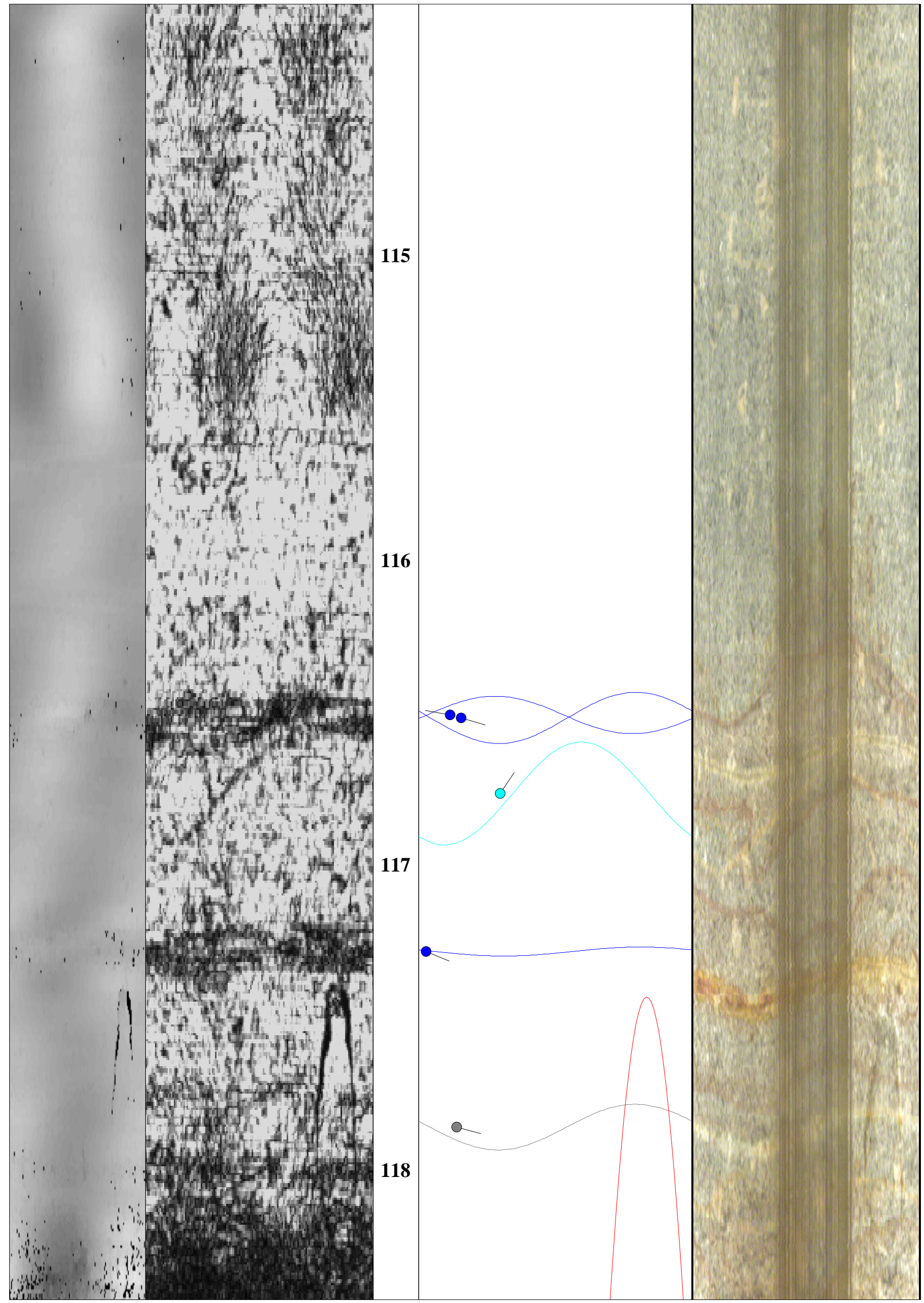



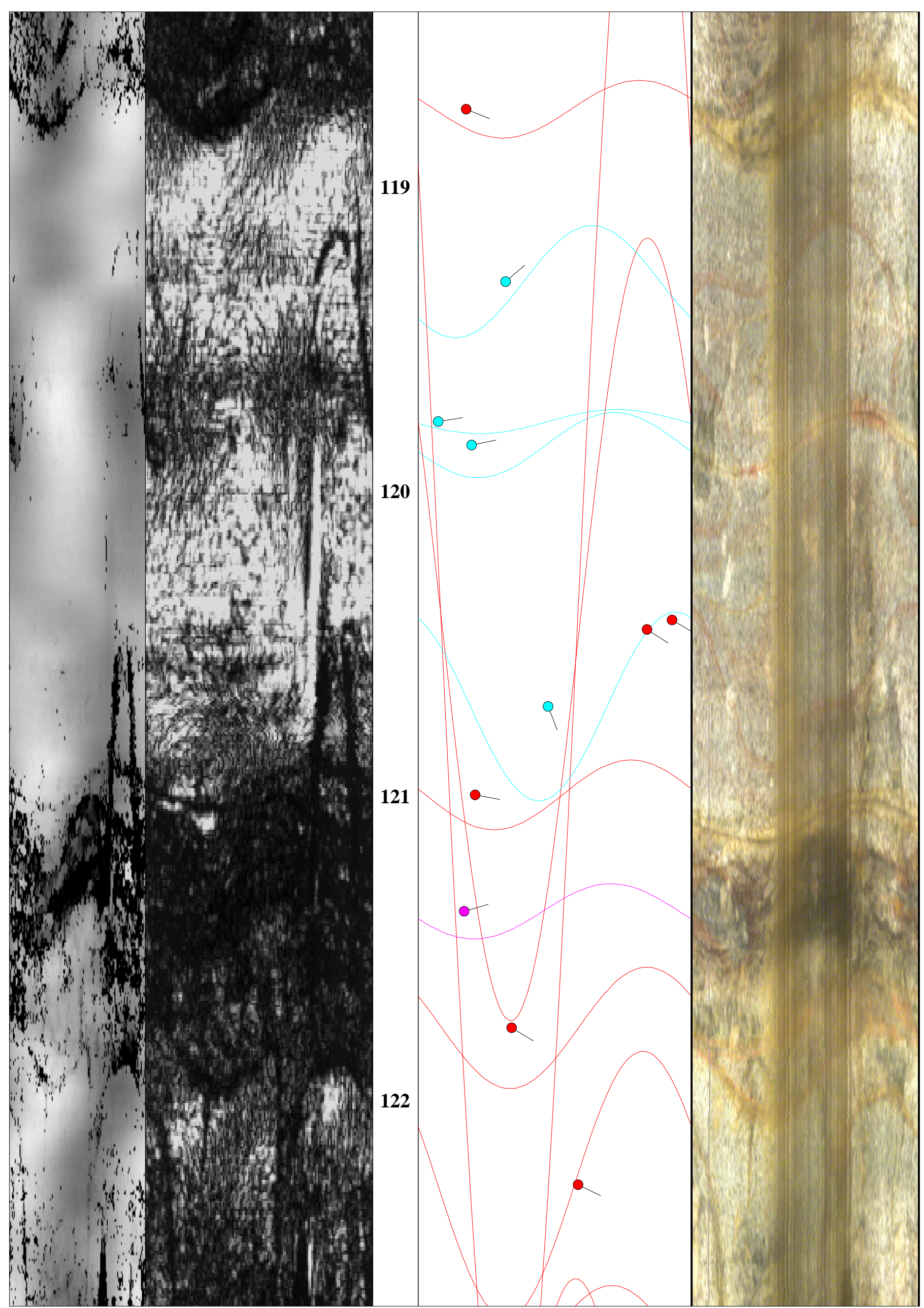


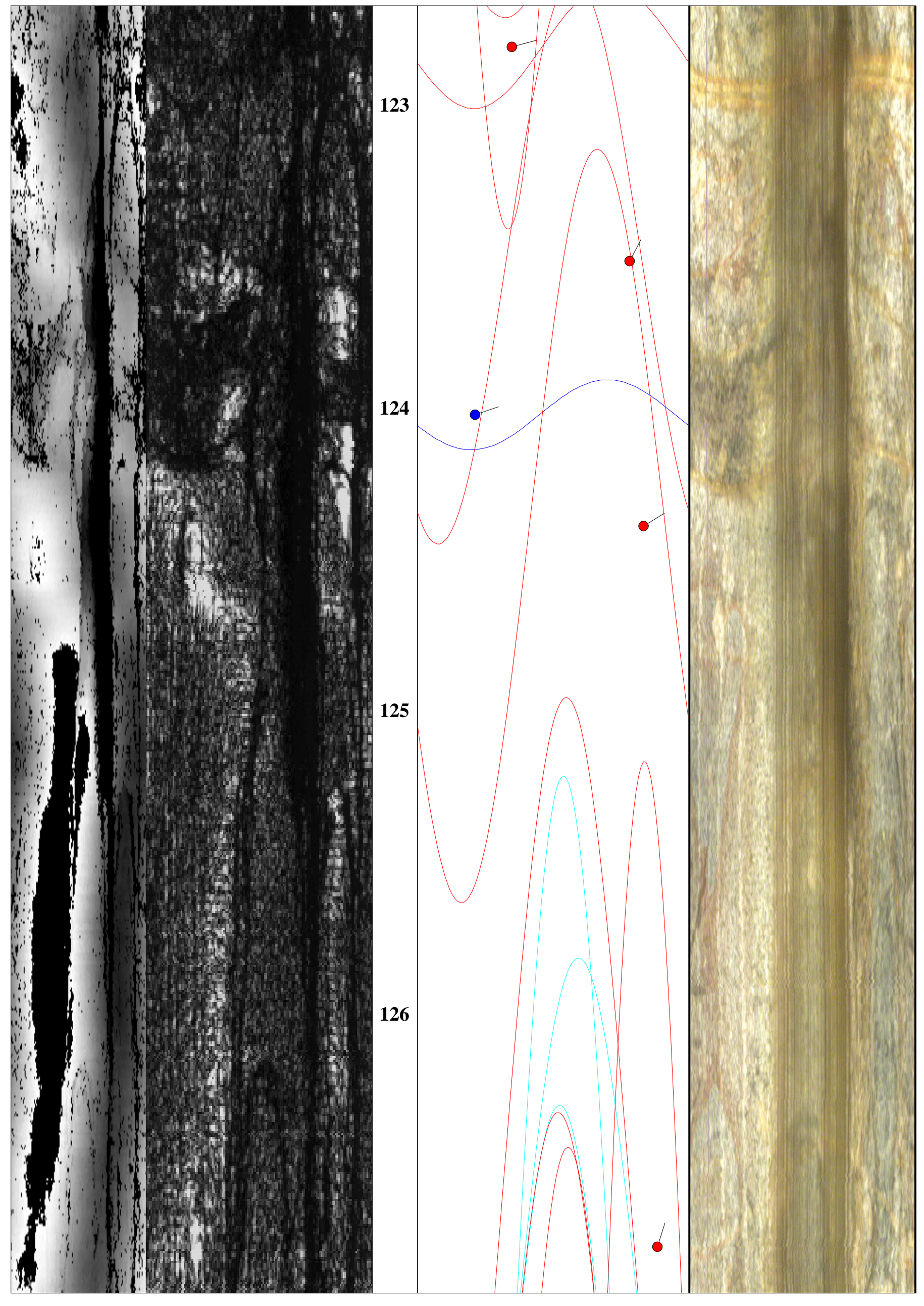




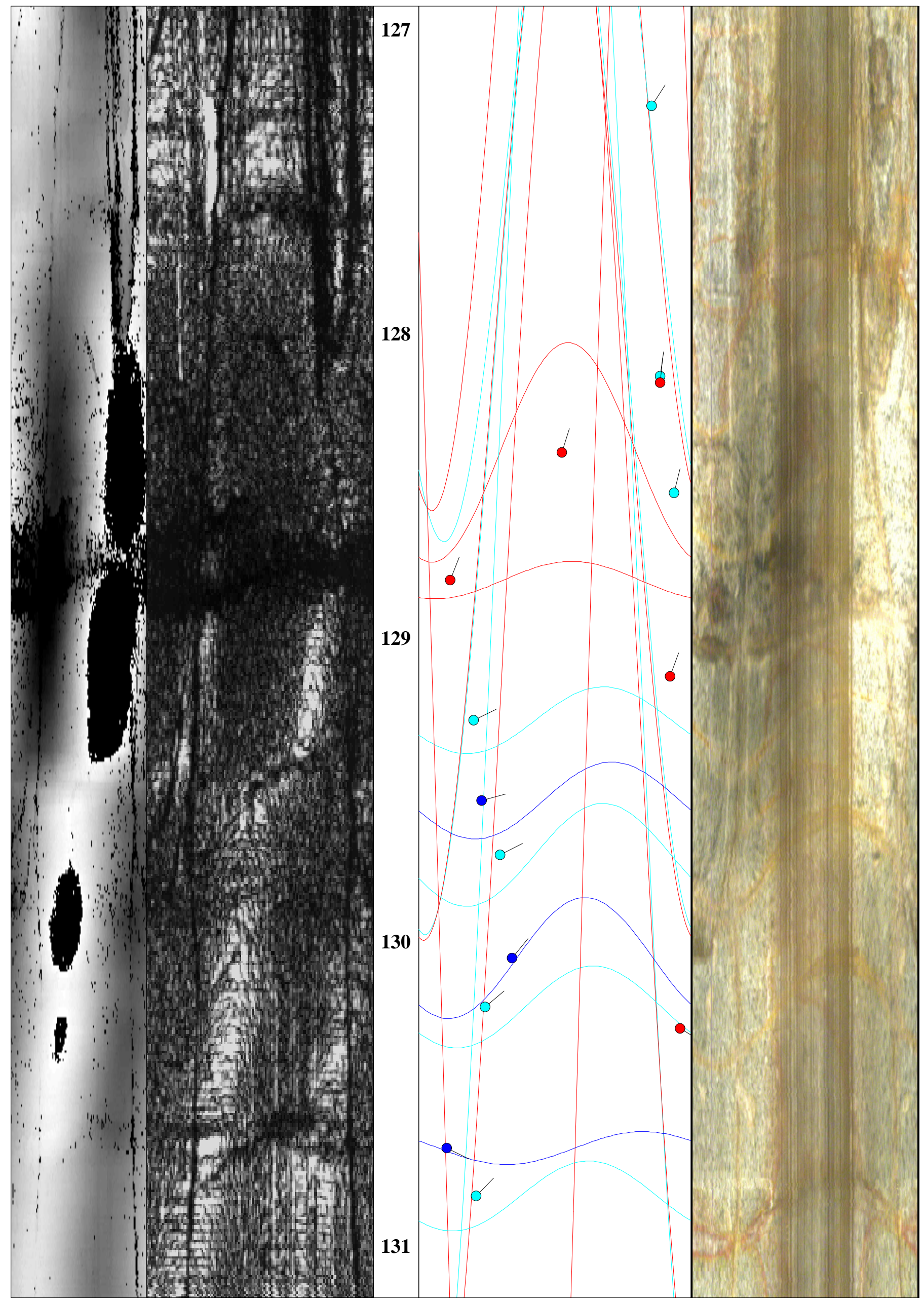




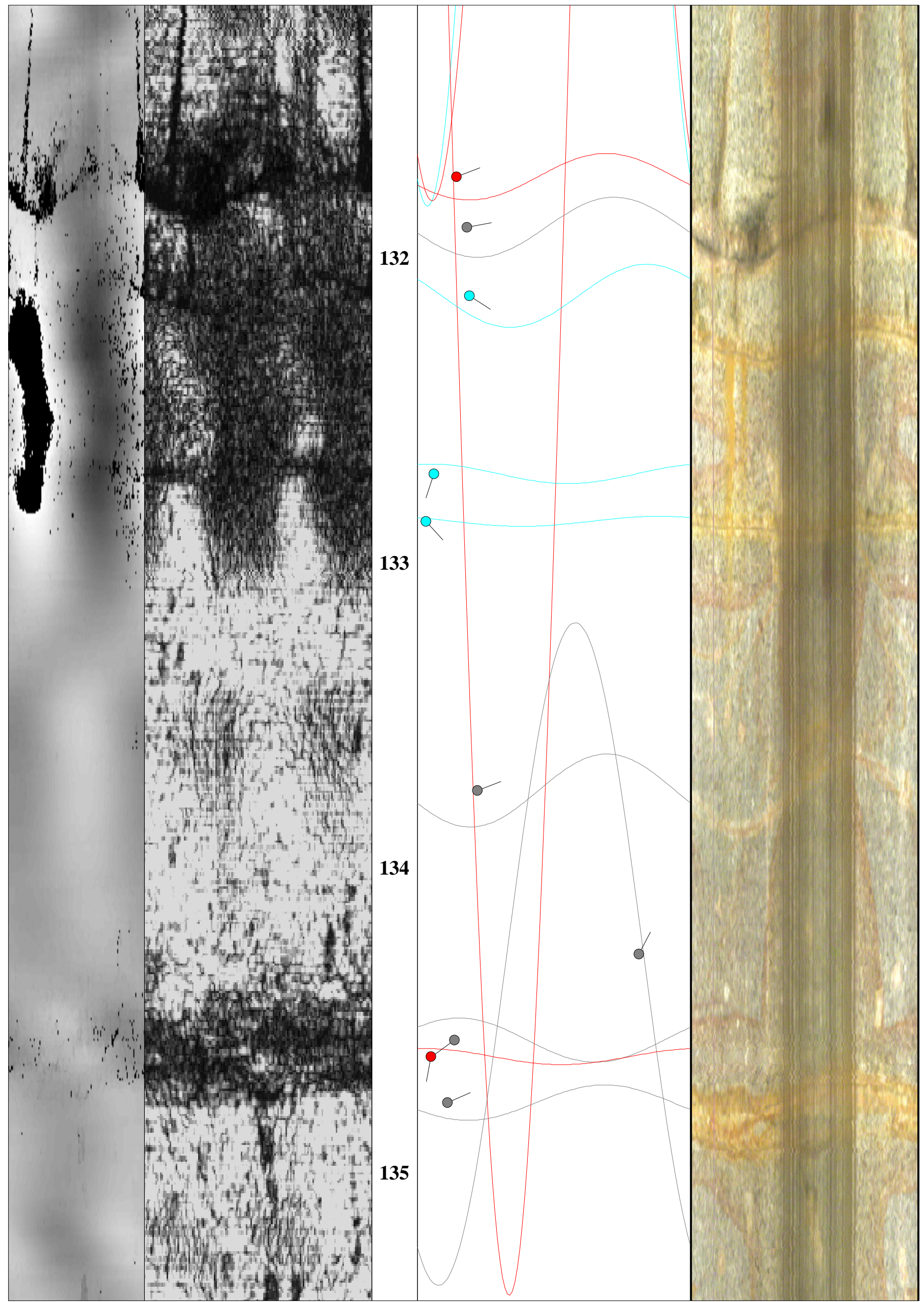




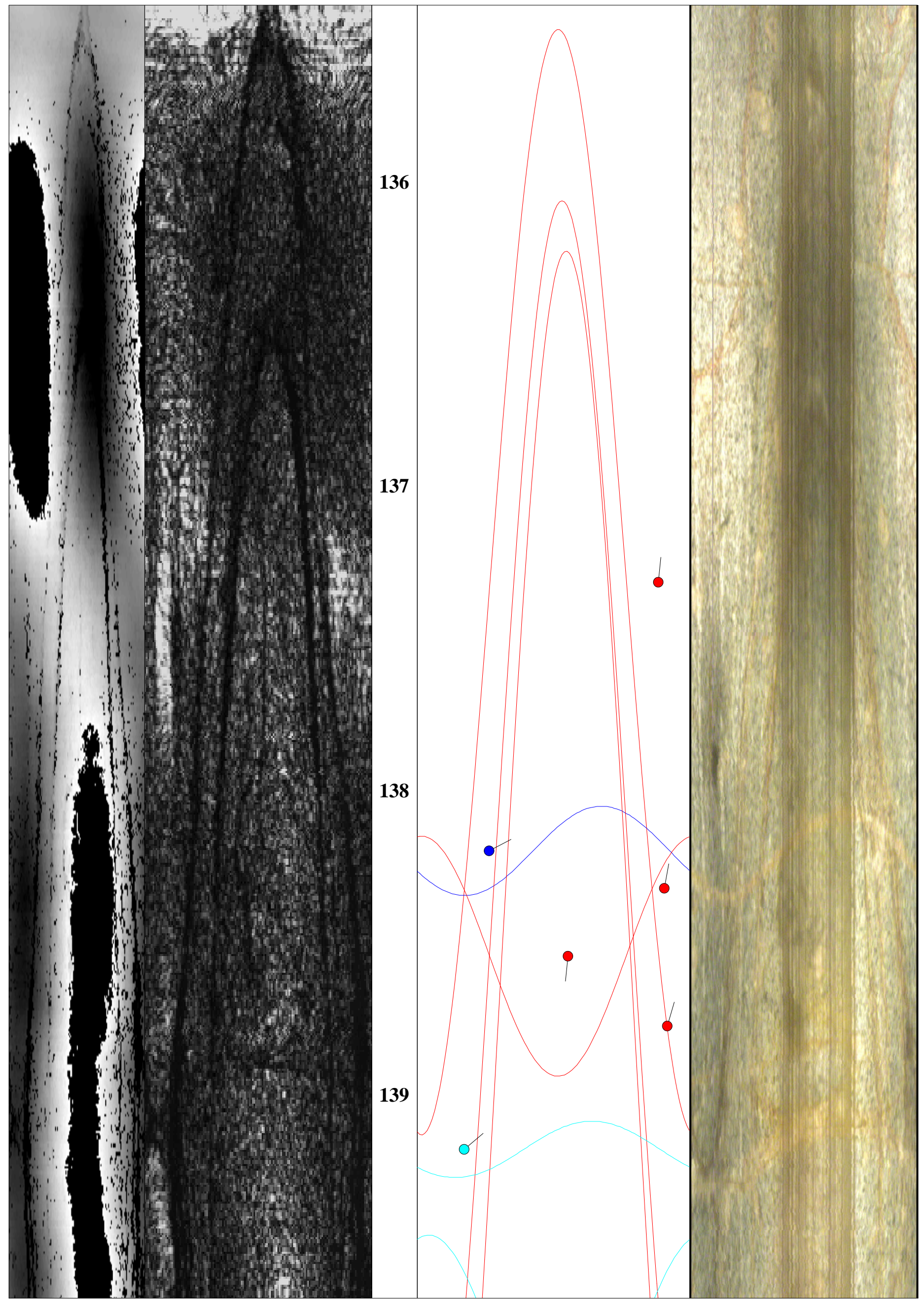




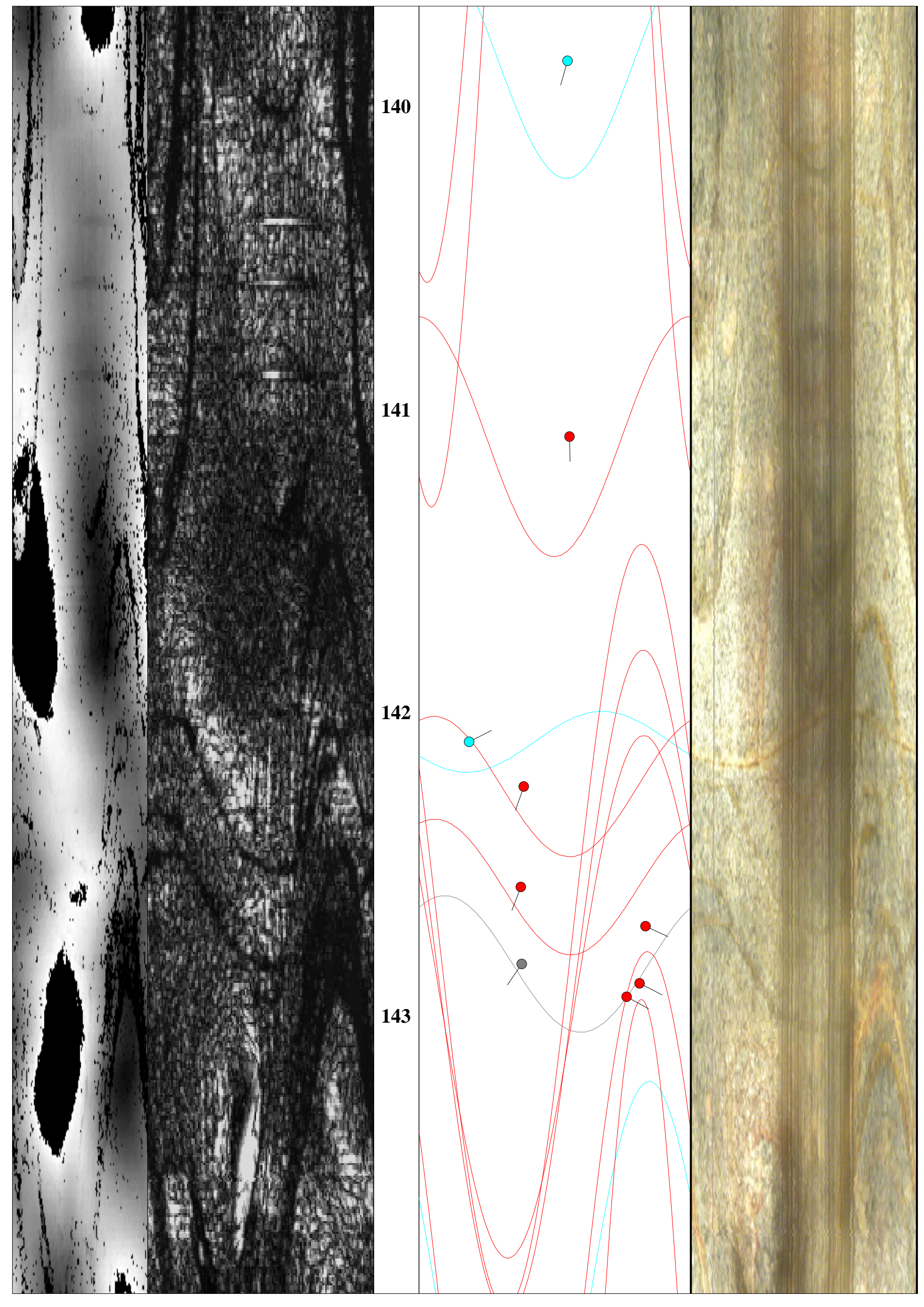




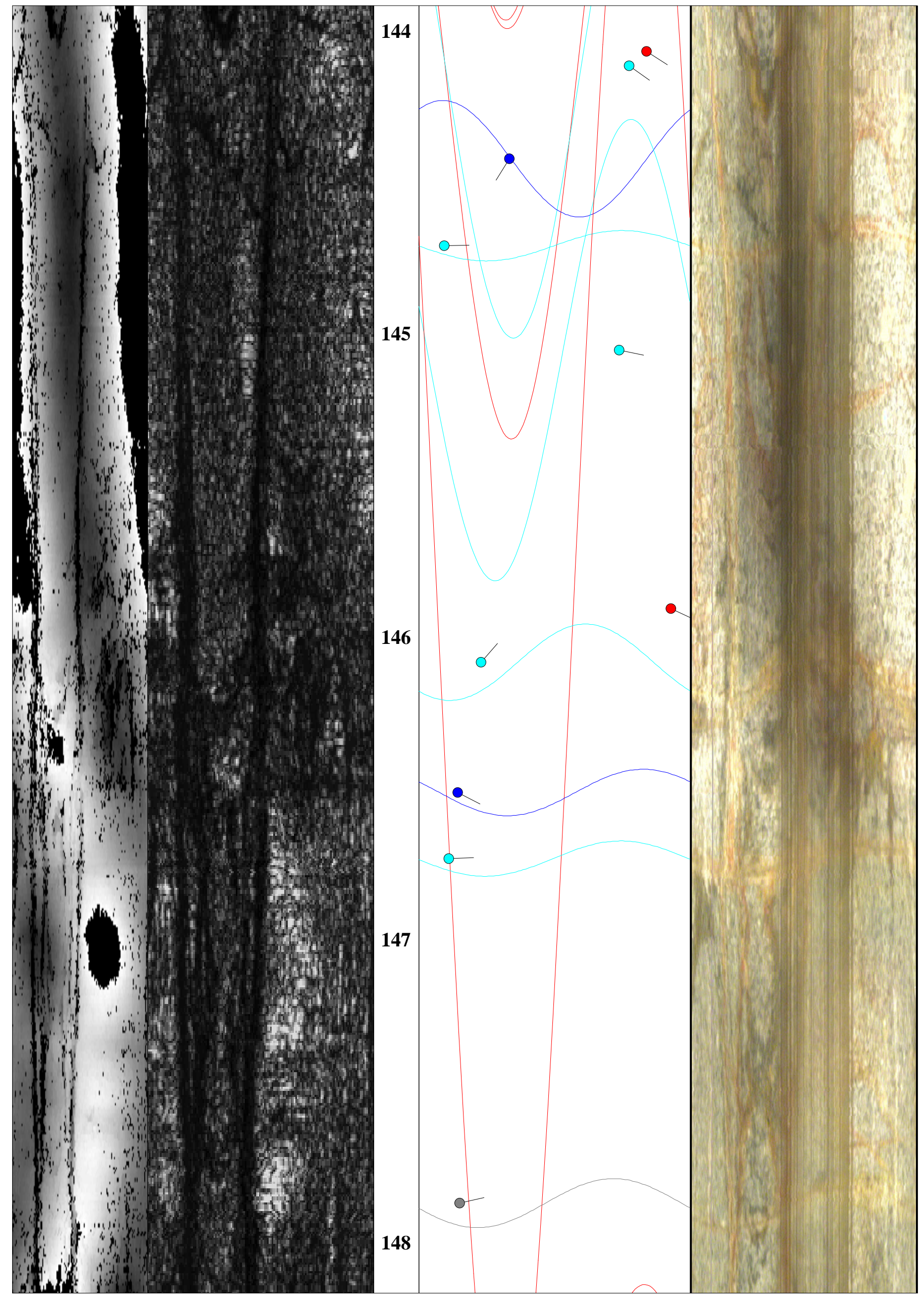




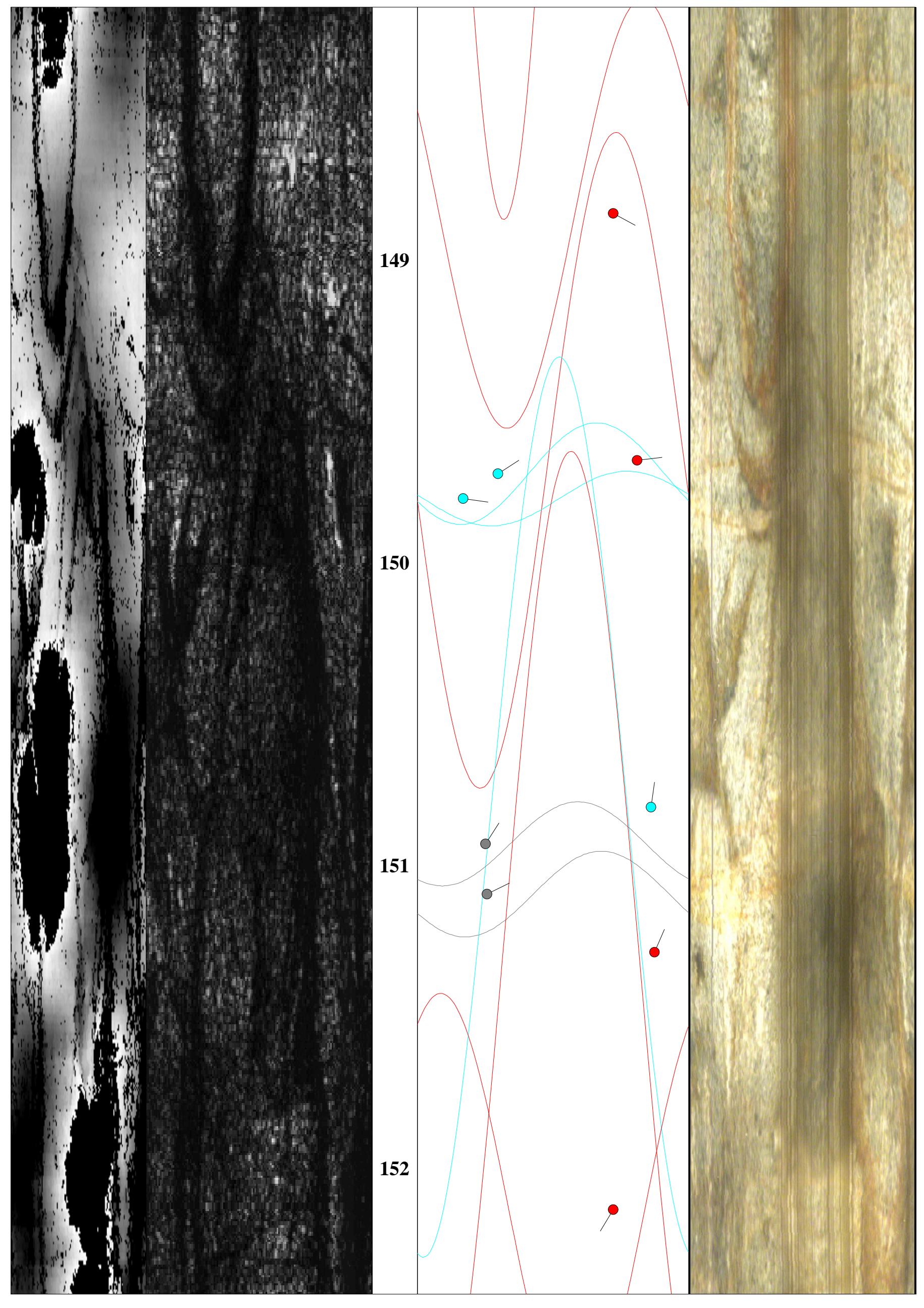




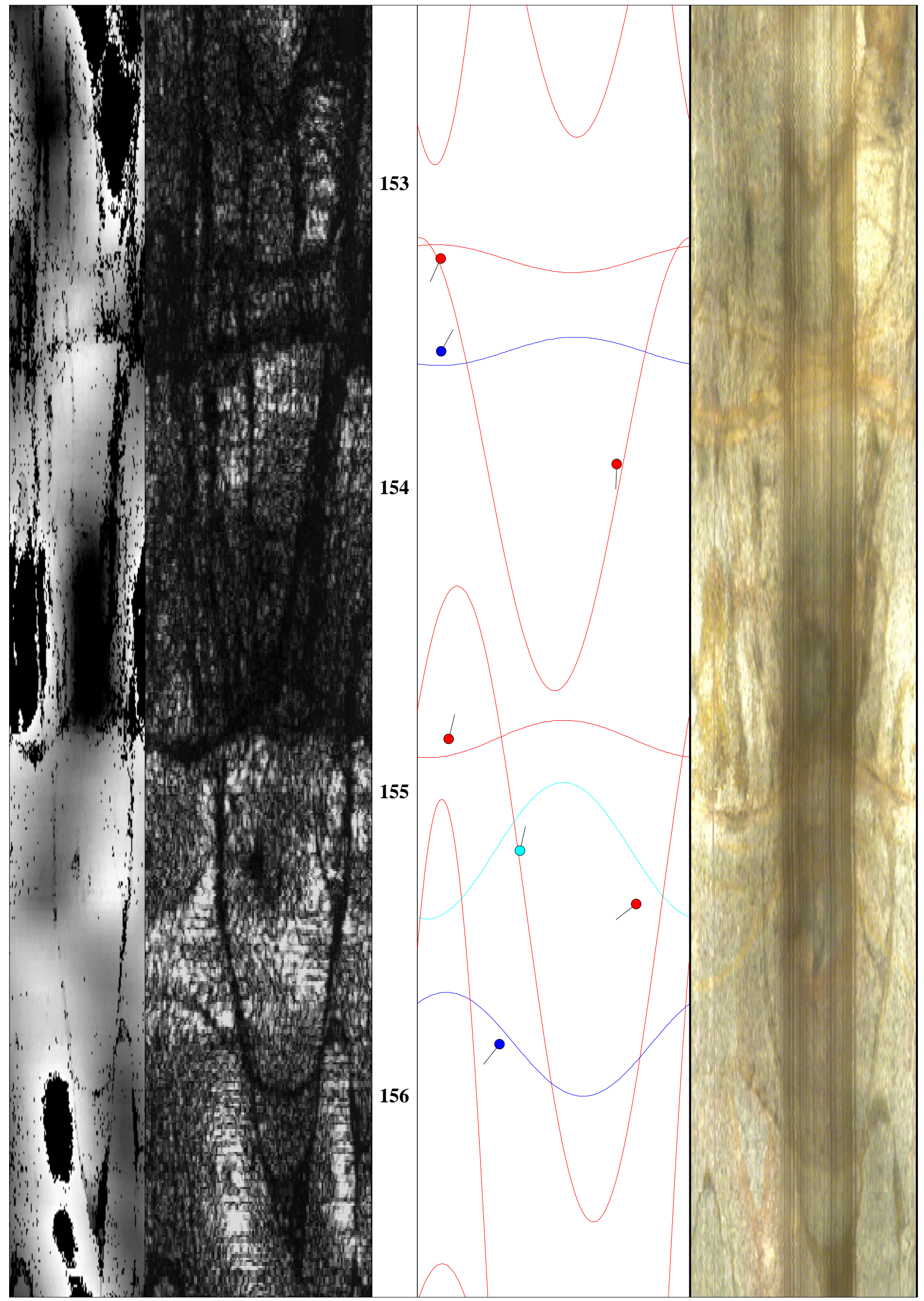




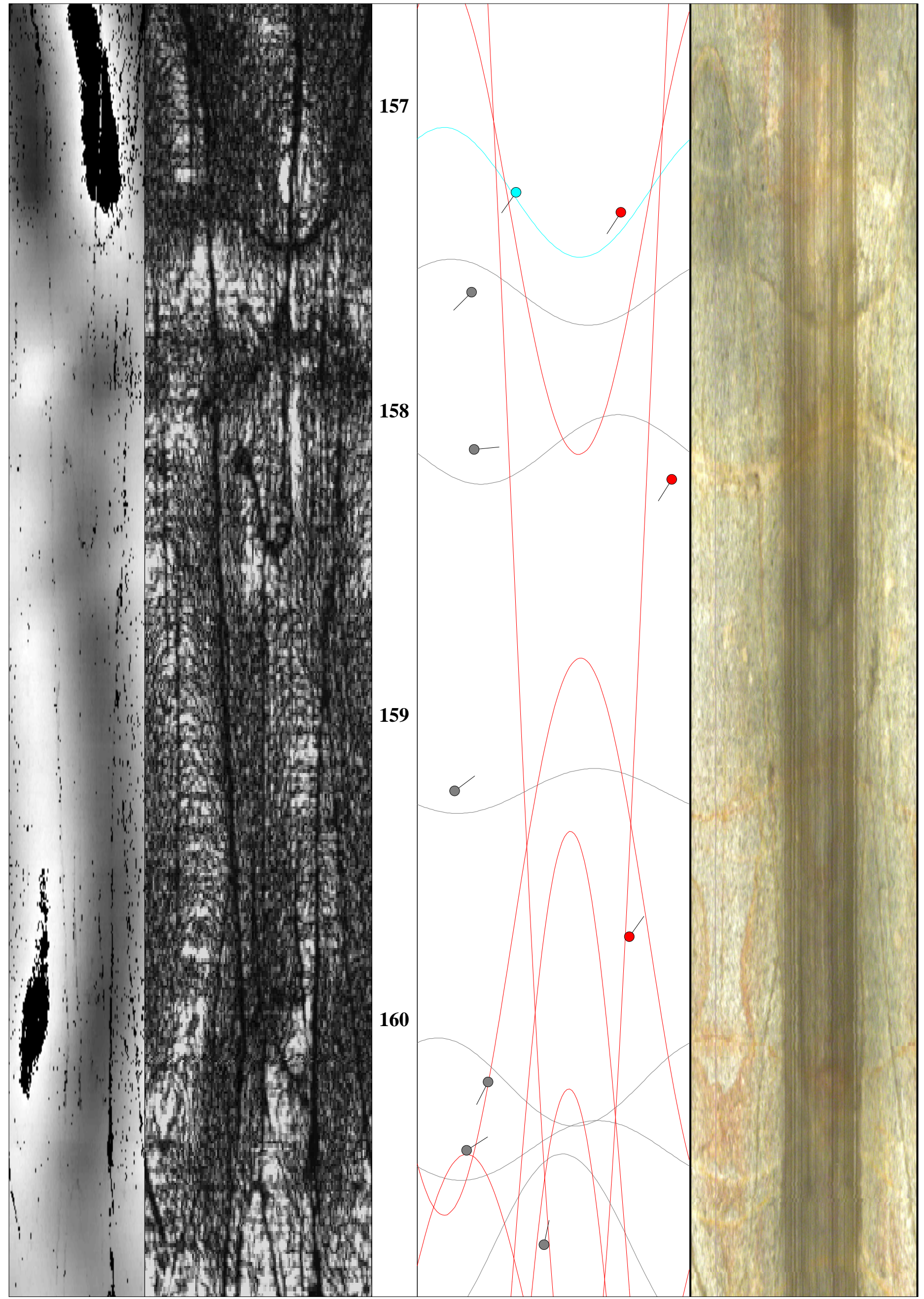




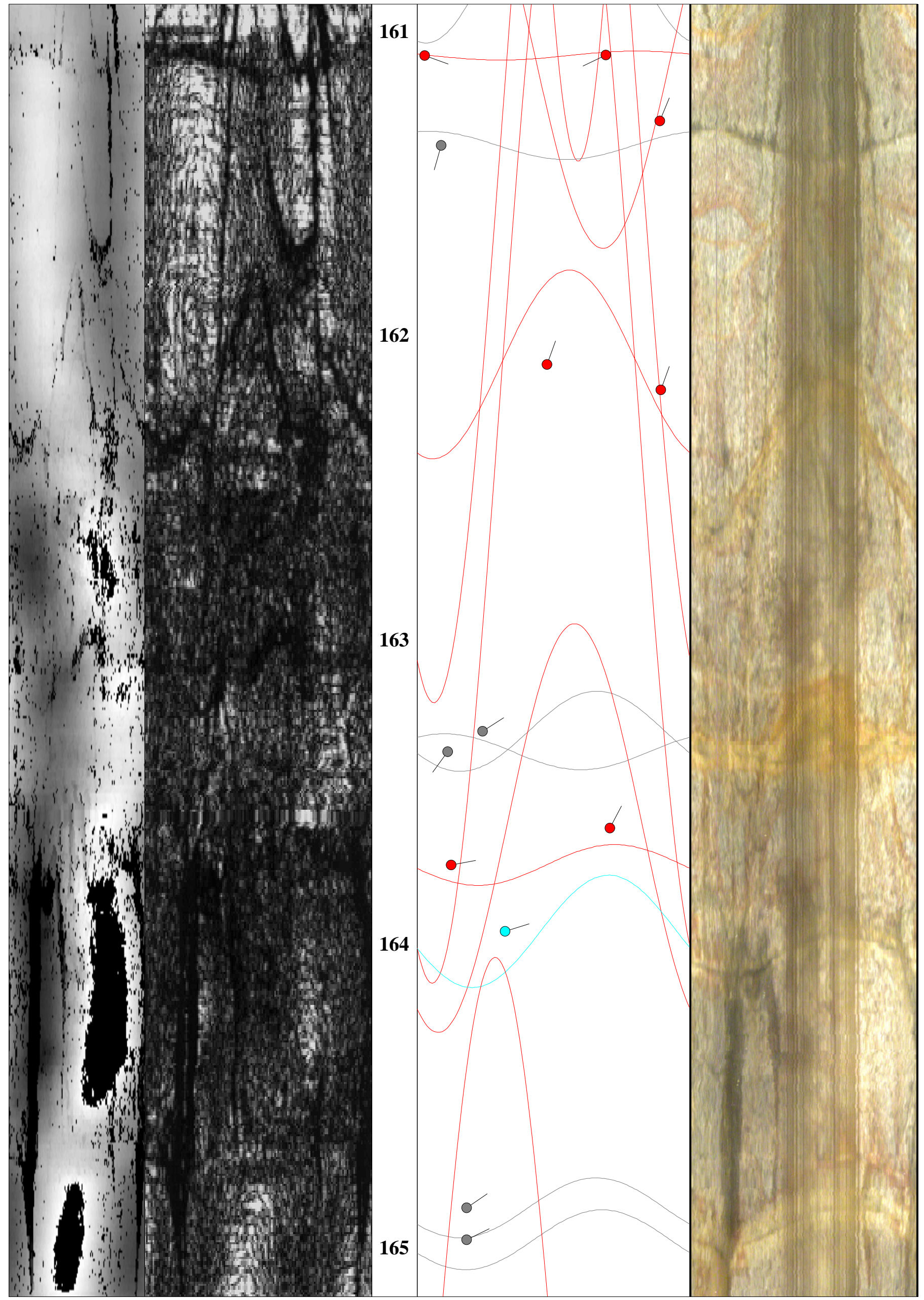




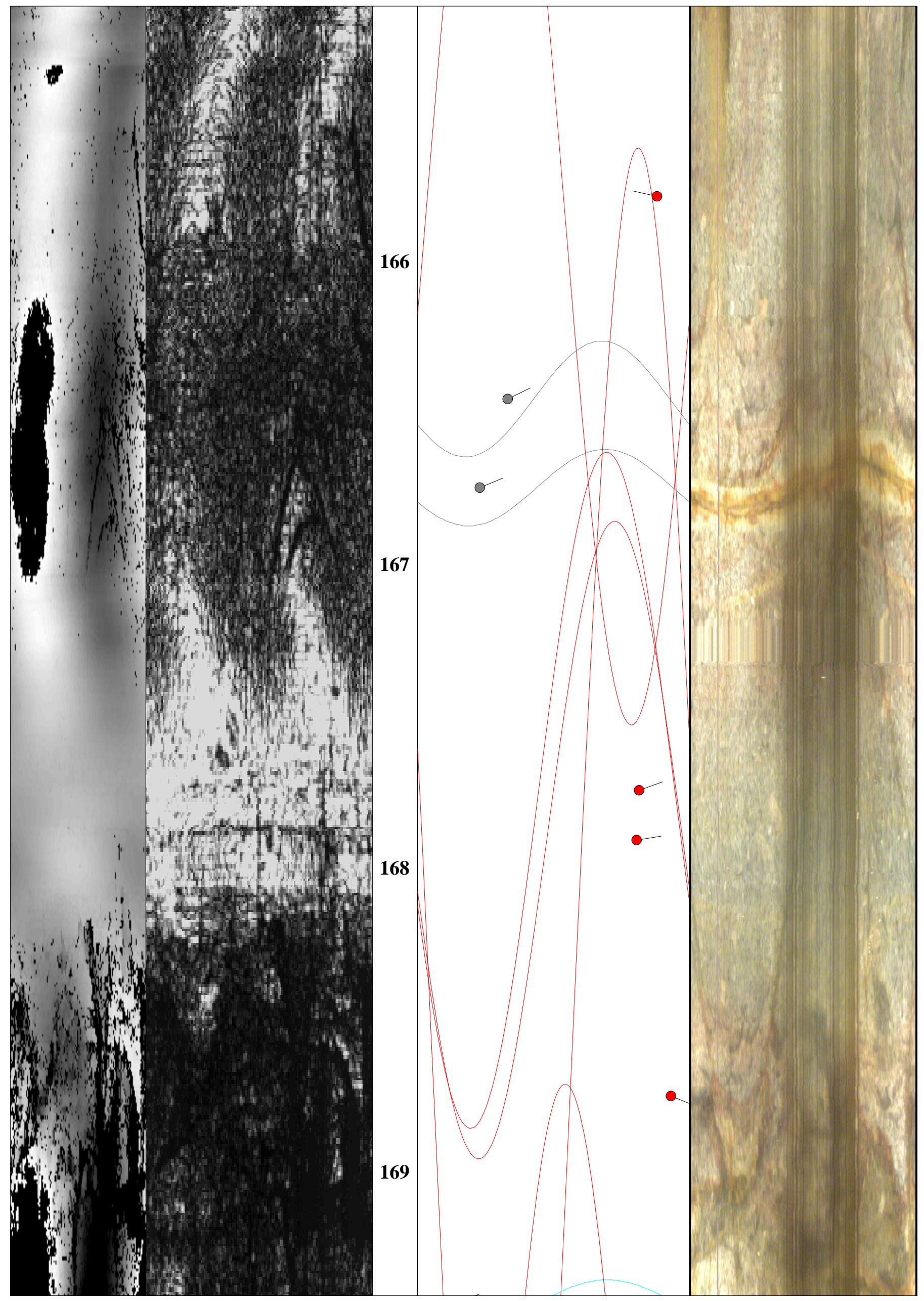




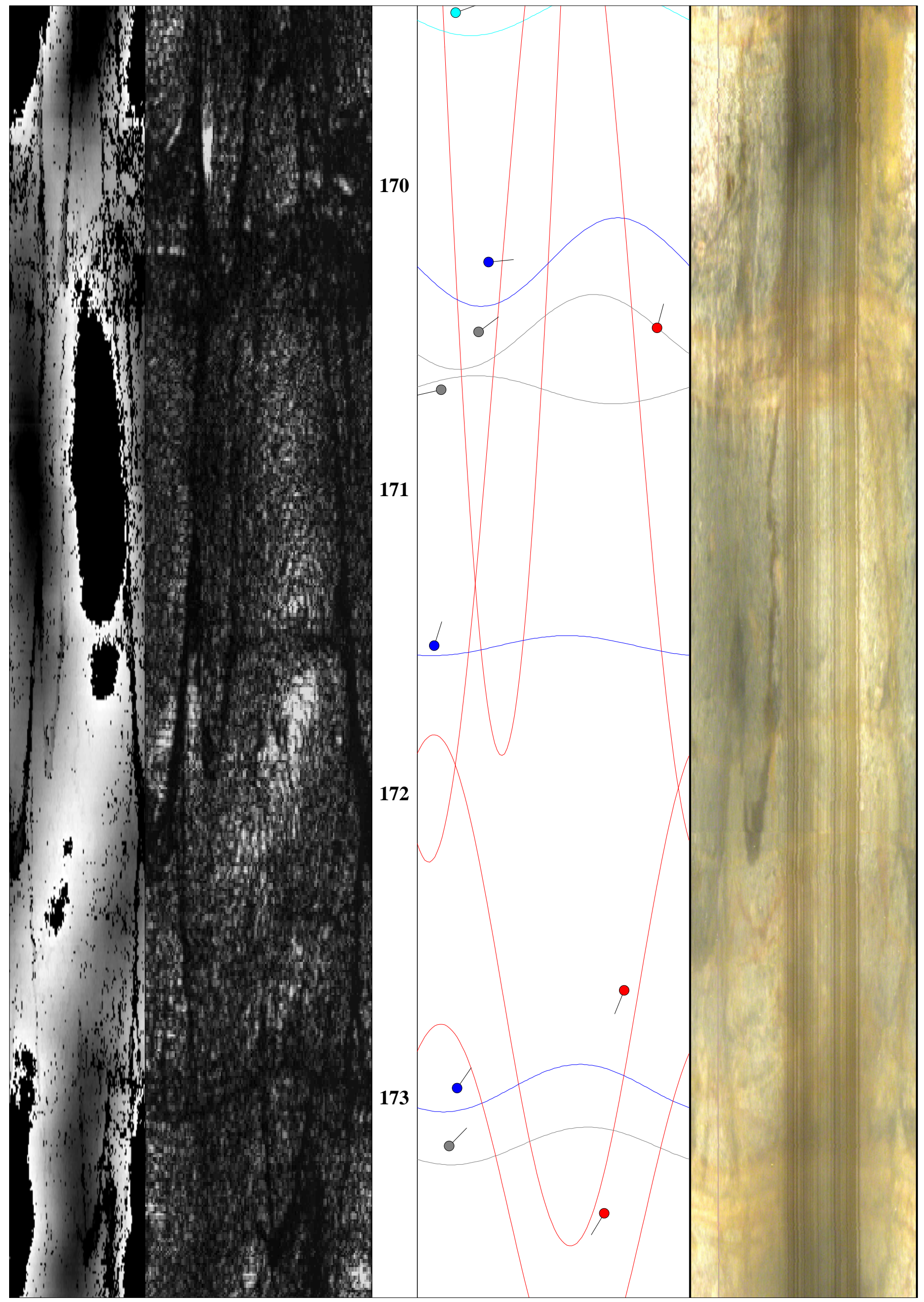




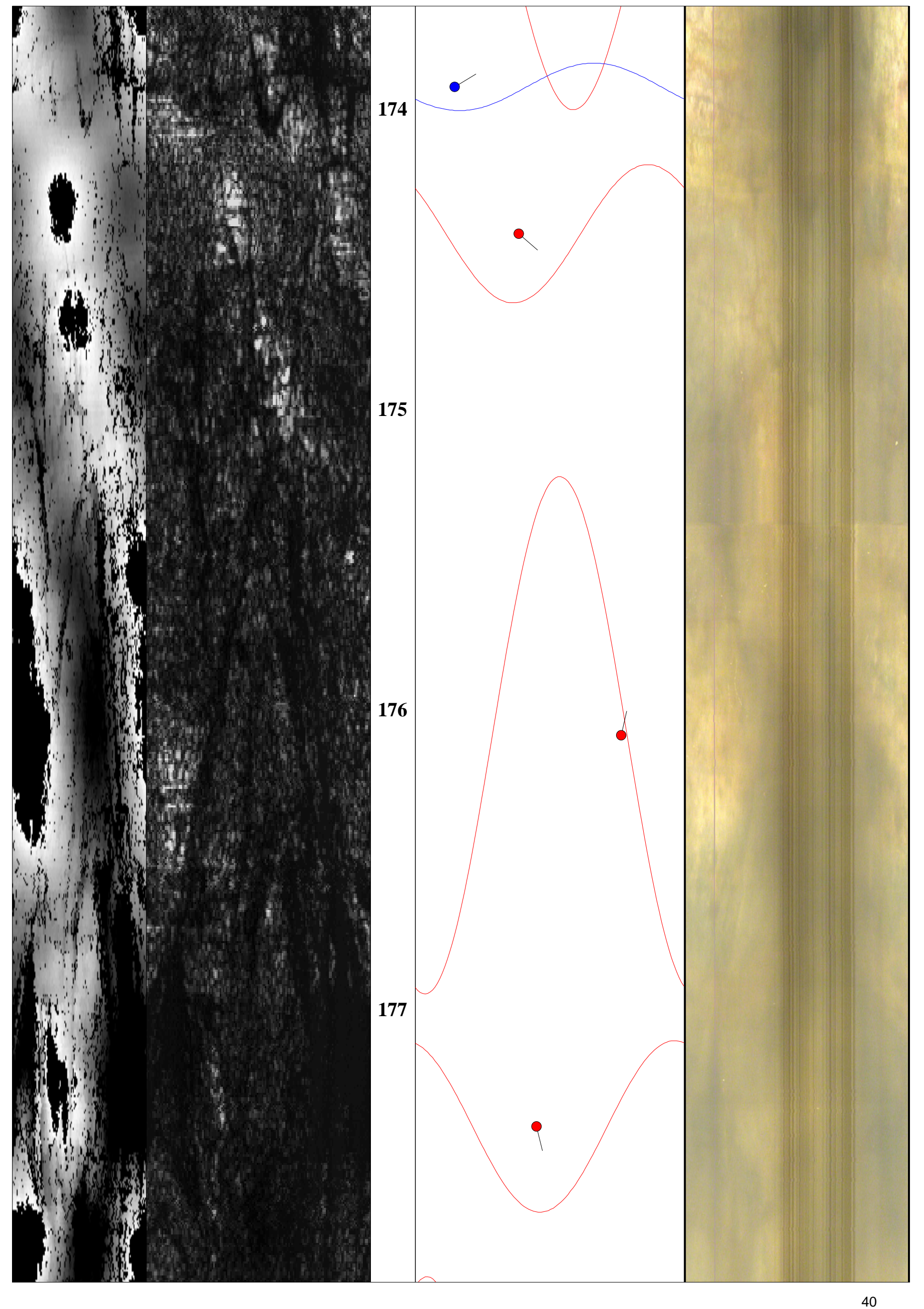




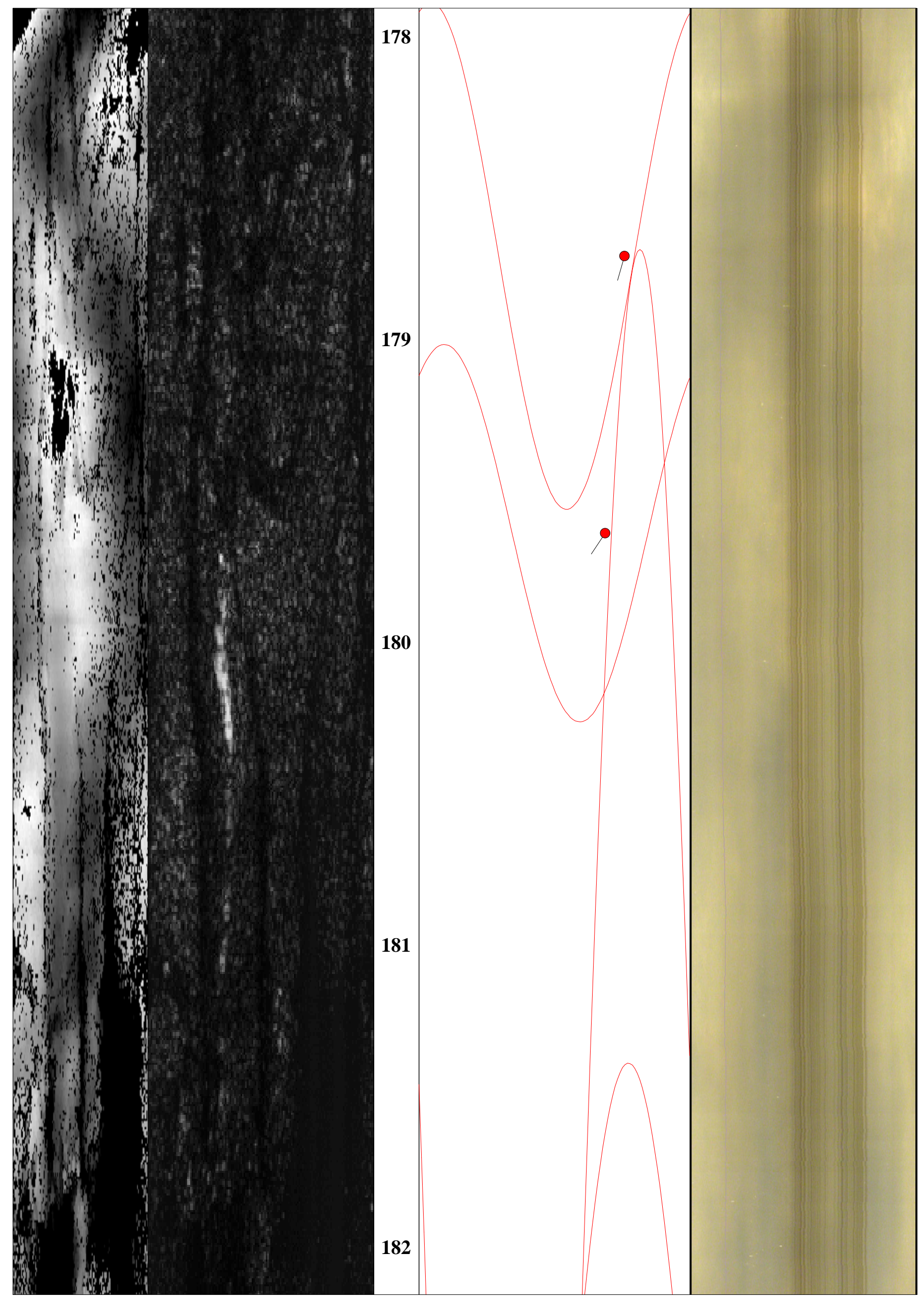




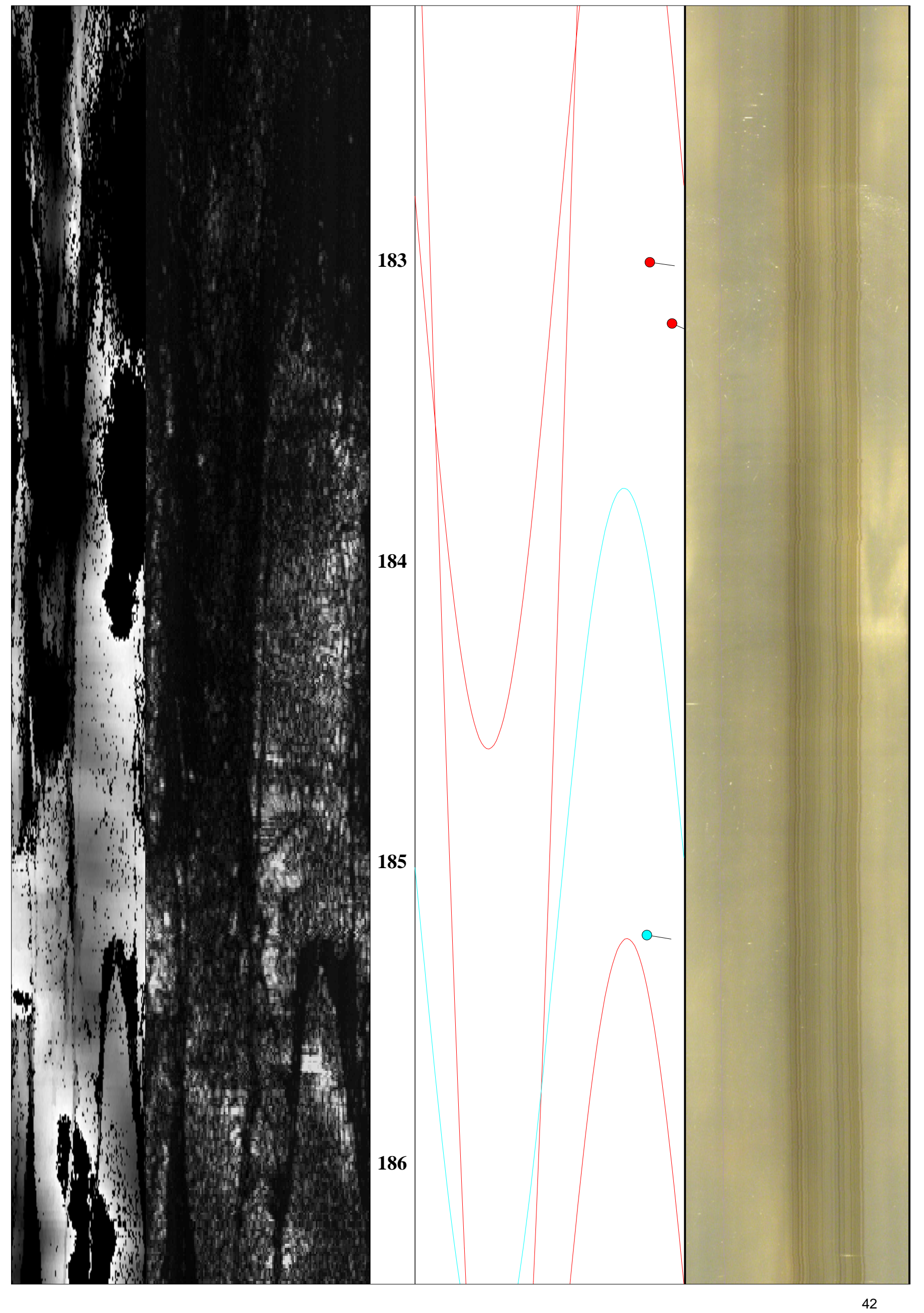




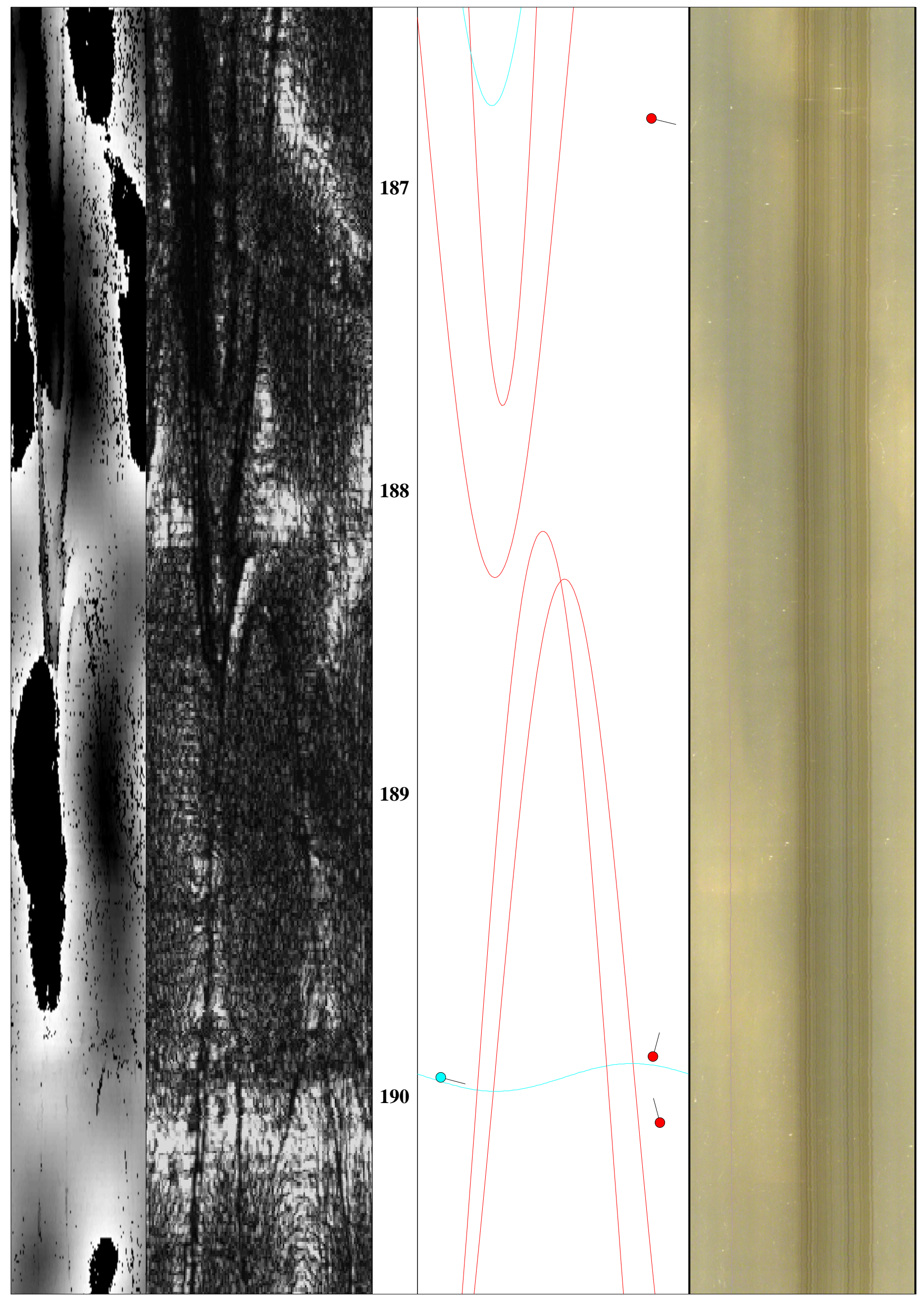




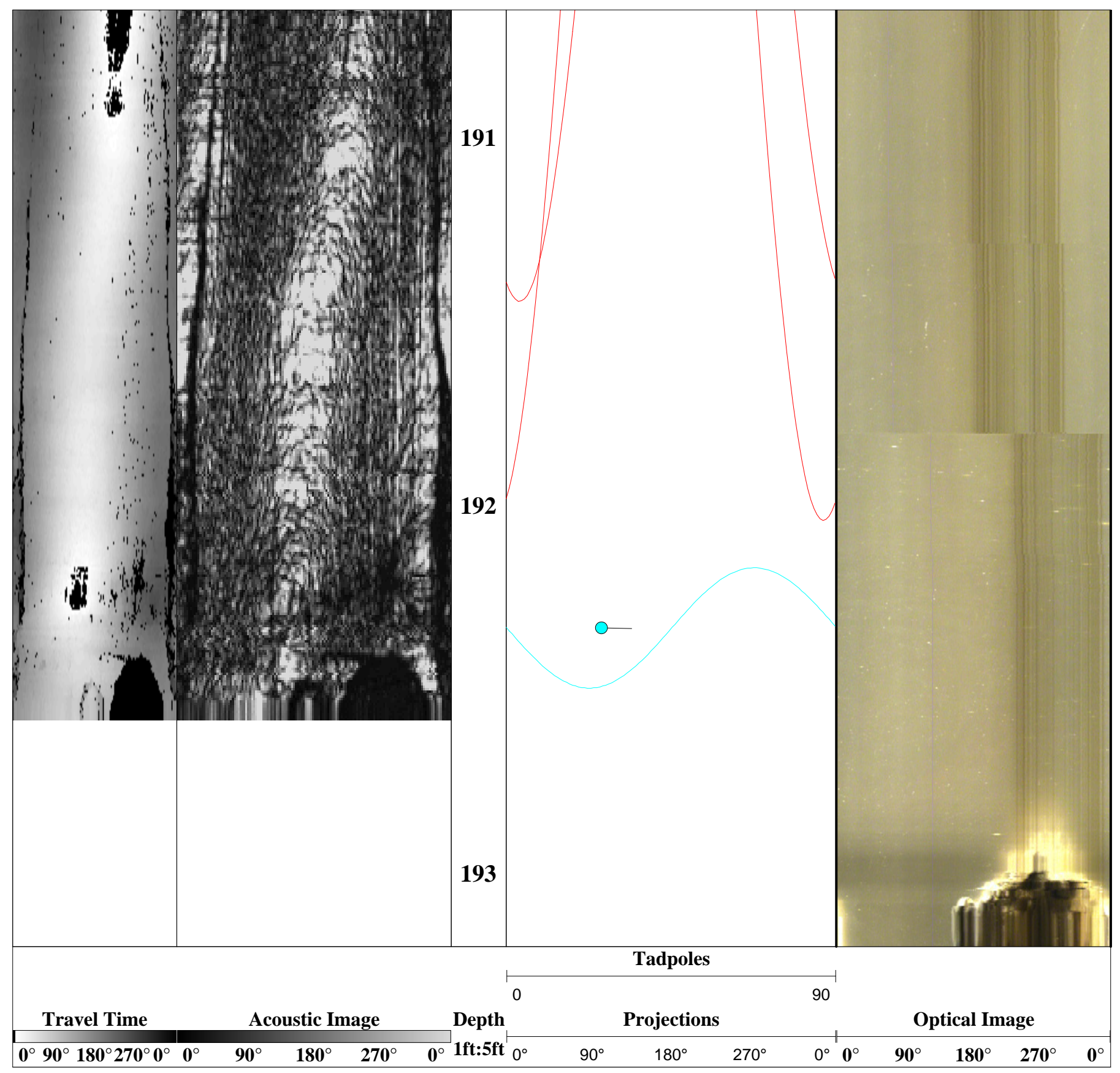




\section{Stereonet Diagram - Schmidt Projection}

Acoustic Televiewer Features

Nevada Test Site

Source Physics Experiment

U-15n2

NNSA/NSO

21 Sept 2010

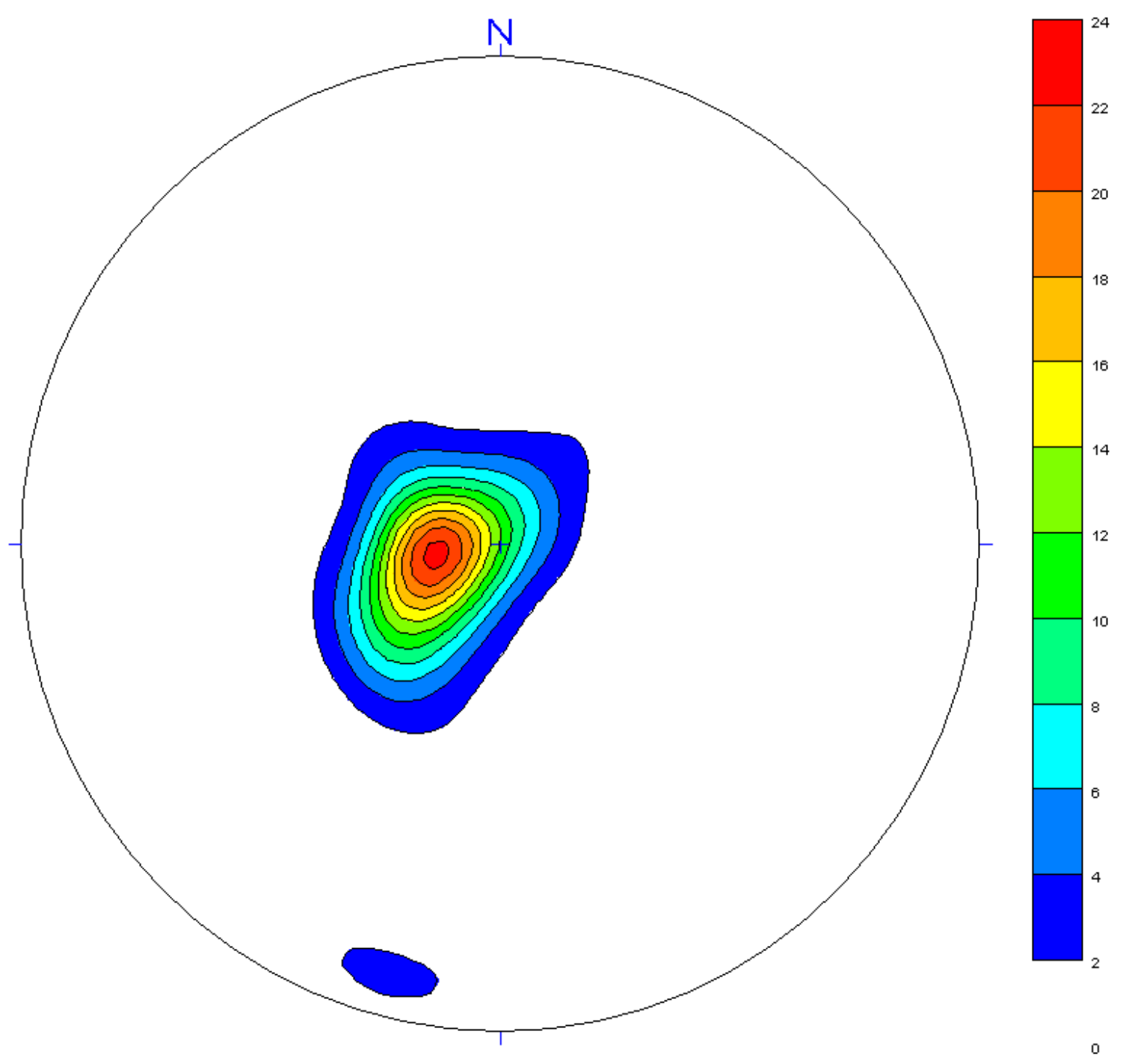

All directions are with respect to True North. 


\section{Stereonet Diagram - Schmidt Projection}

Acoustic Televiewer Features

Nevada Test Site

Source Physics Experiment

U-15n2

NNSA/NSO

21 Sept 2010

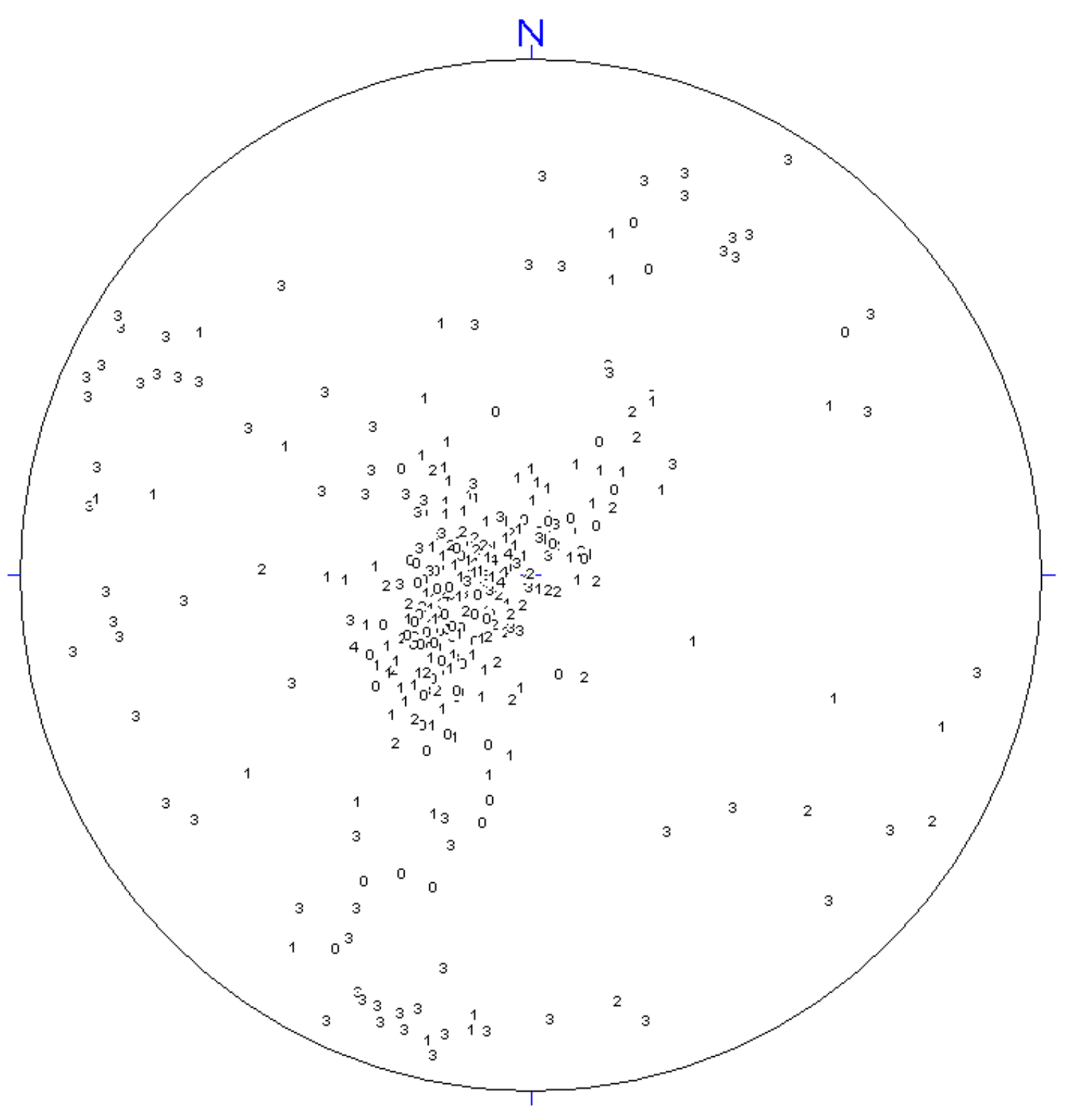

All directions are with respect to True North. 


\section{Rose Diagram - Dip Directions \\ Acoustic Televiewer Features \\ Nevada Test Site \\ Source Physics Experiment \\ U-15n2 \\ NNSA/NSO \\ 21 Sept 2010}

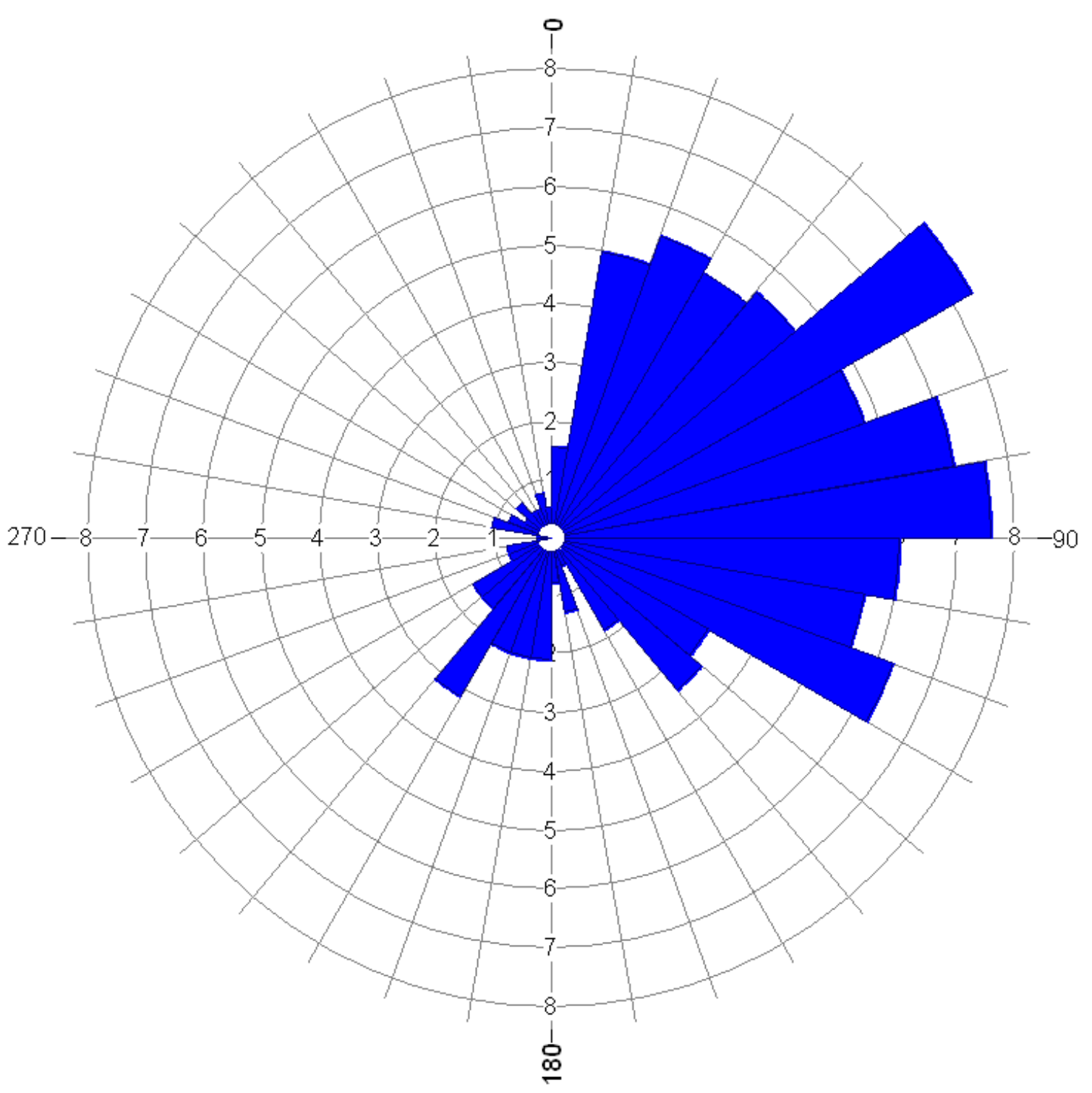

All directions are with respect to True North. 


\section{Rose Diagram - Dip Angles \\ Acoustic Televiewer Features \\ Nevada Test Site \\ Source Physics Experiment \\ U-15n2 \\ NNSA/NSO \\ 21 Sept 2010}

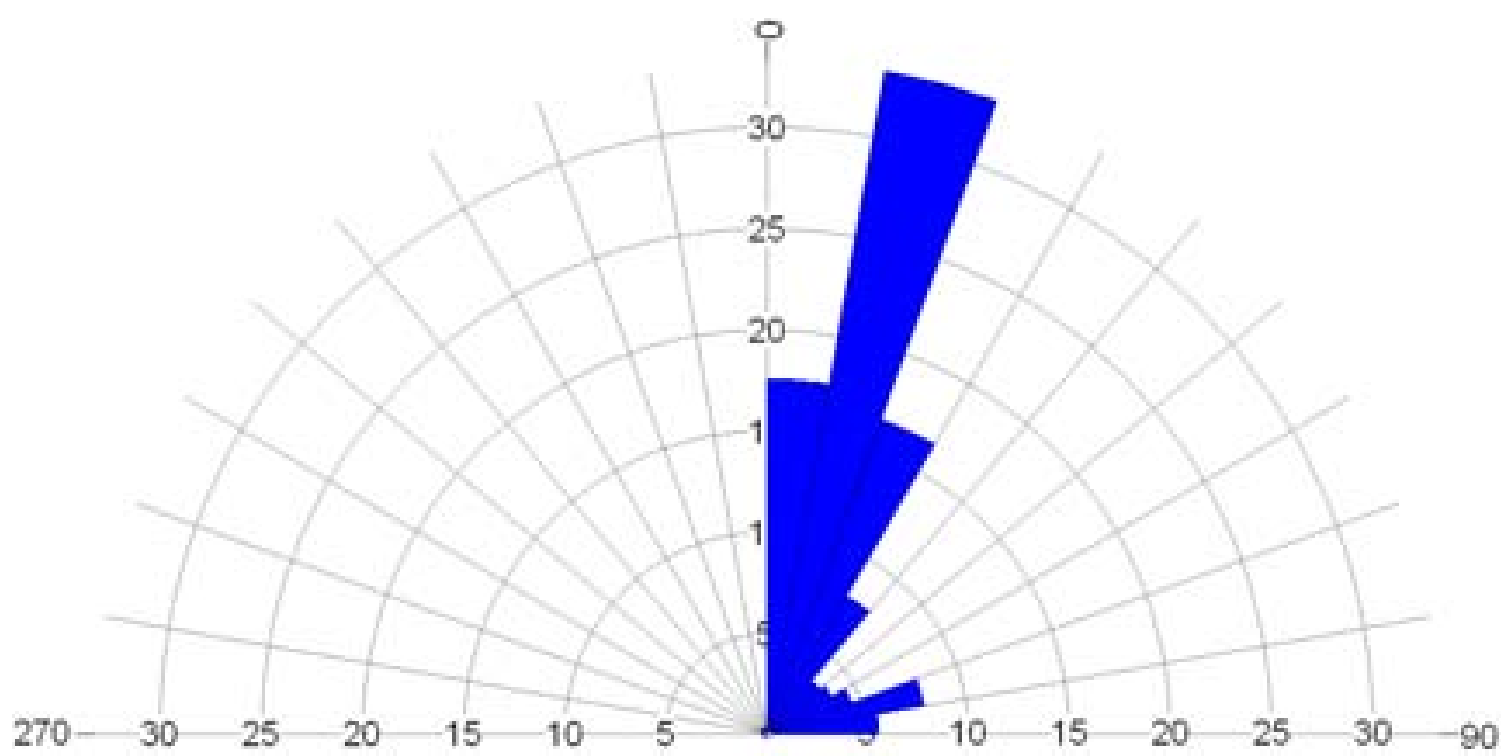

All directions are with respect to True North. 


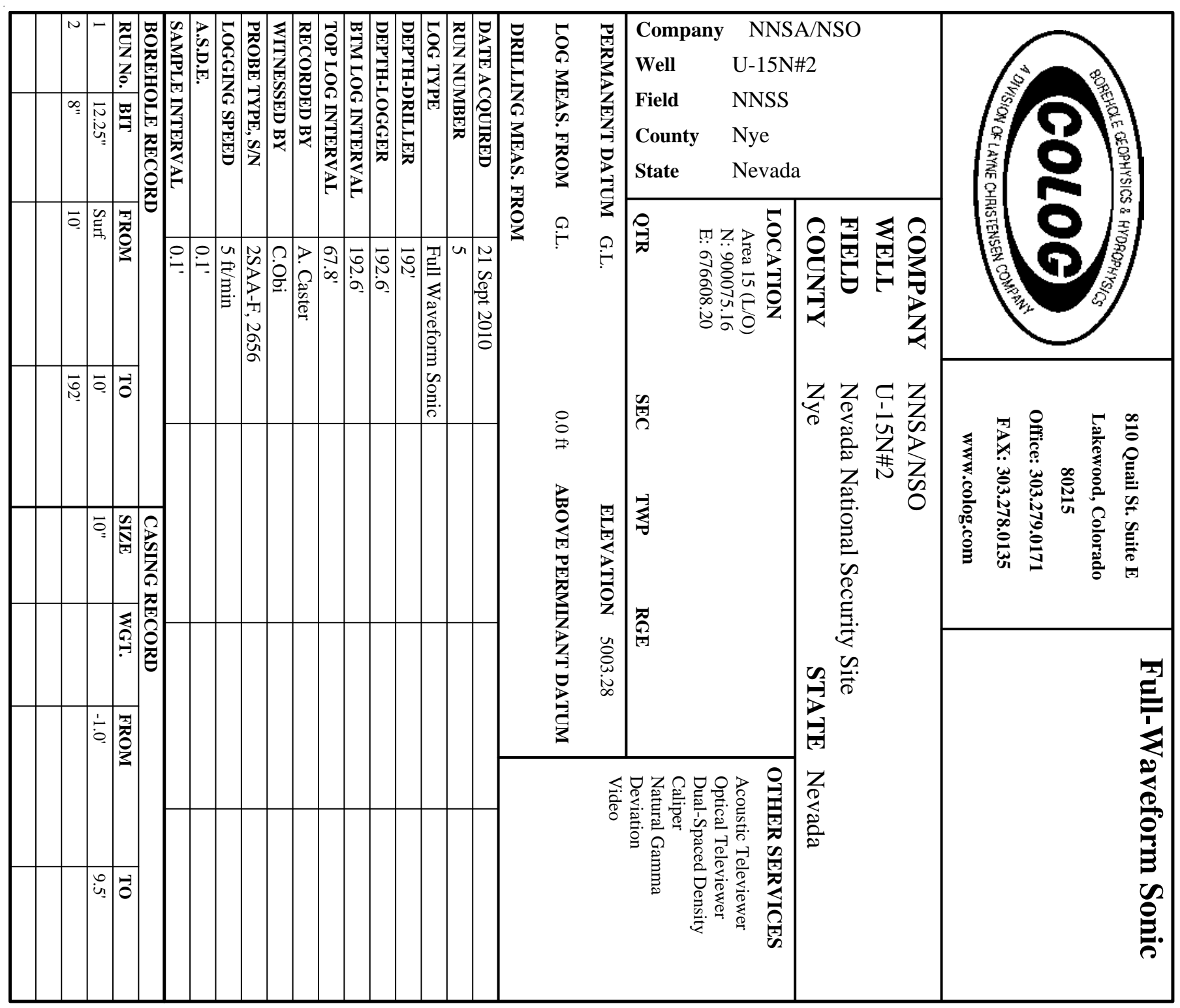

COMMENTS

NA - Not Available, N/A - Not Applicable 


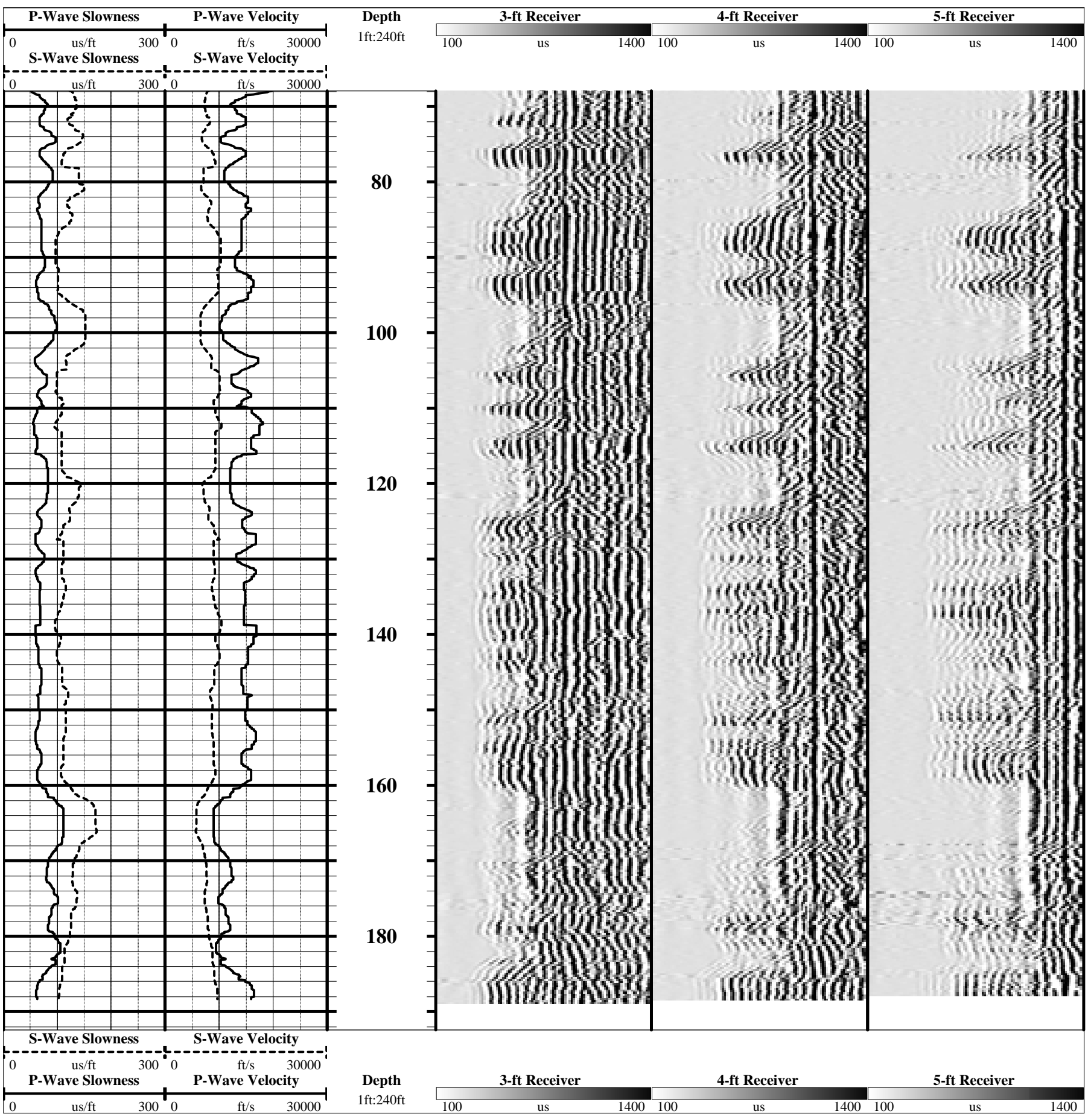




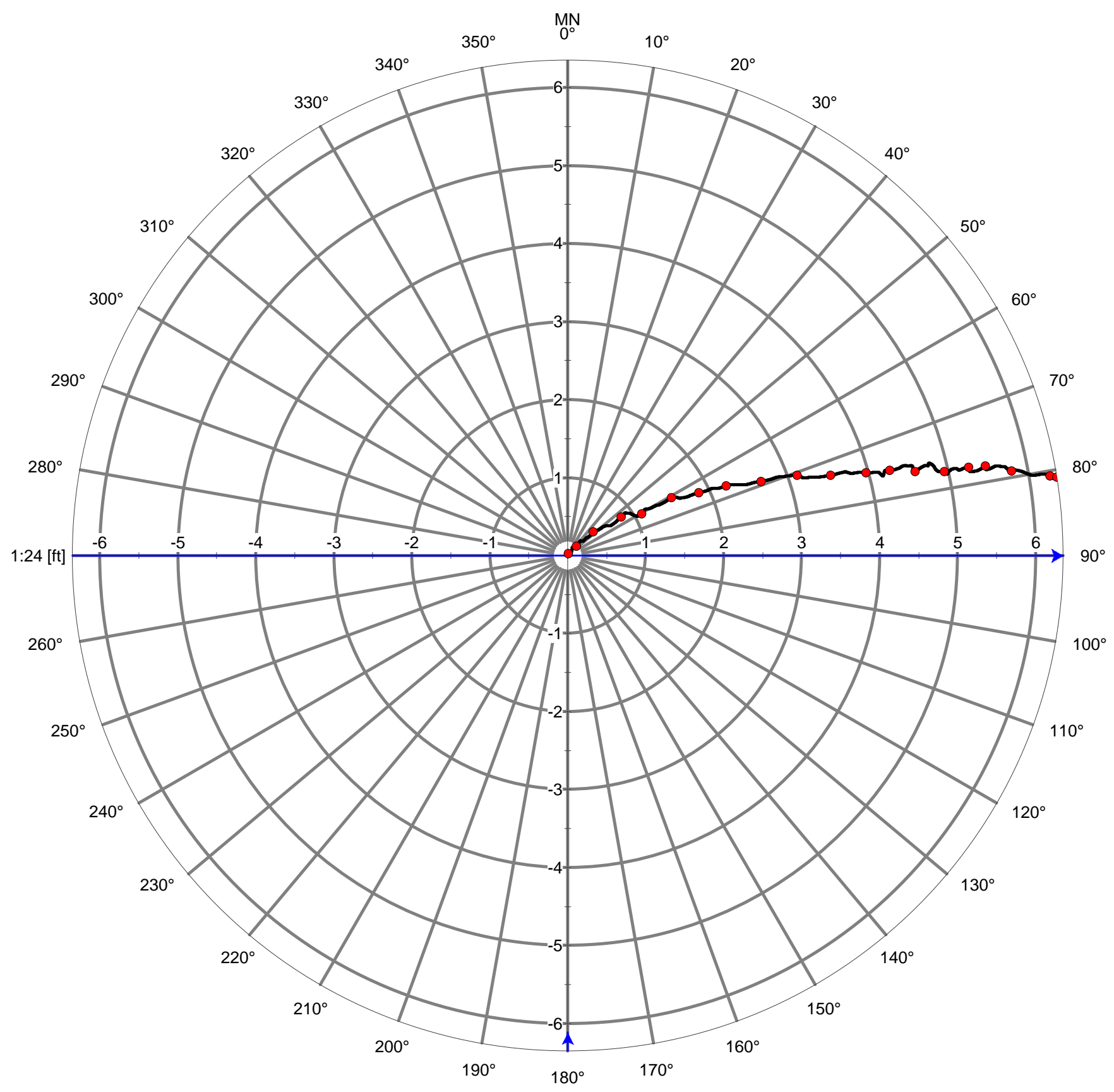




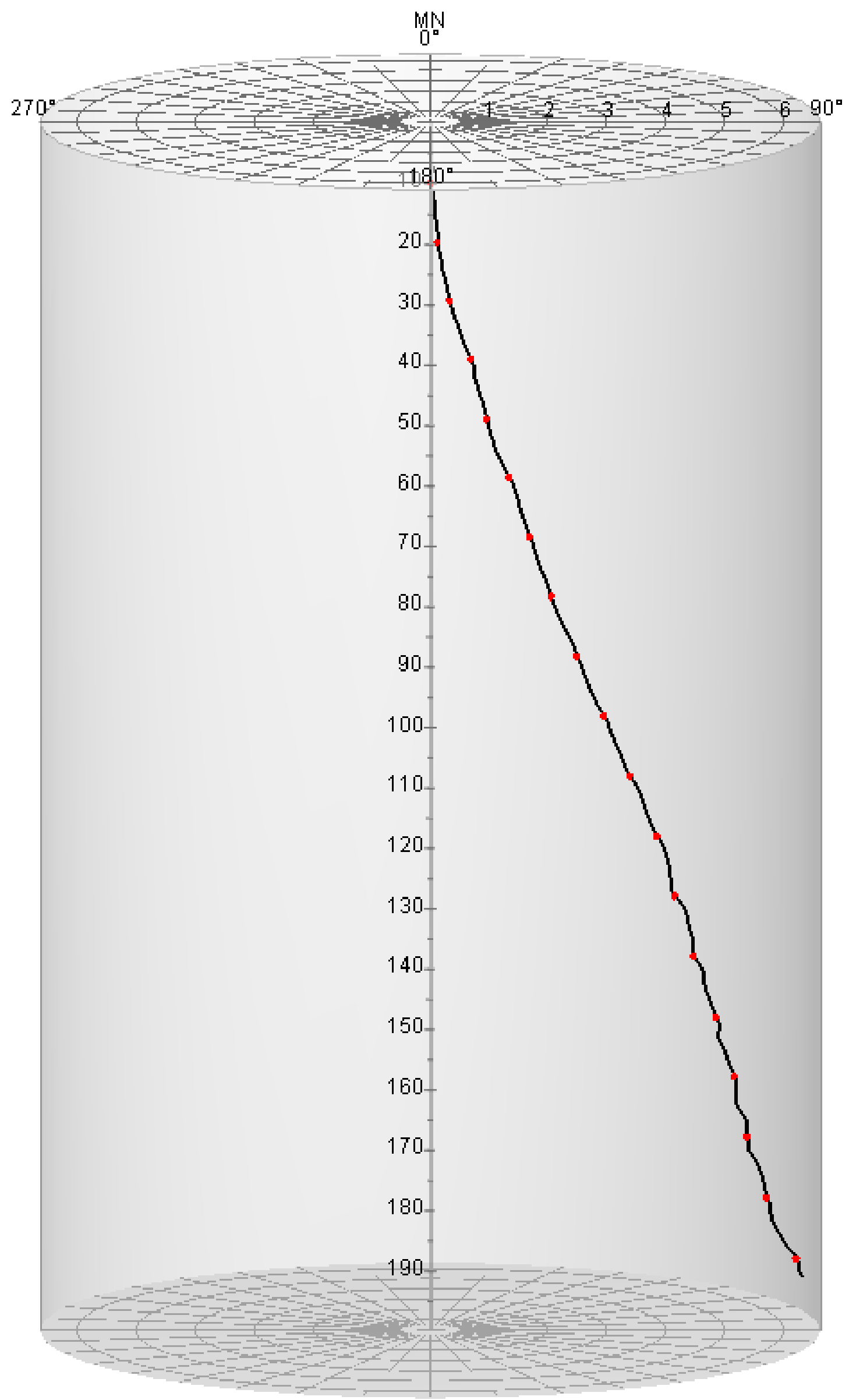




\section{Appendix F-4}

Borehole Geophysical Log Plots for Instrument Hole U-15n\#3 


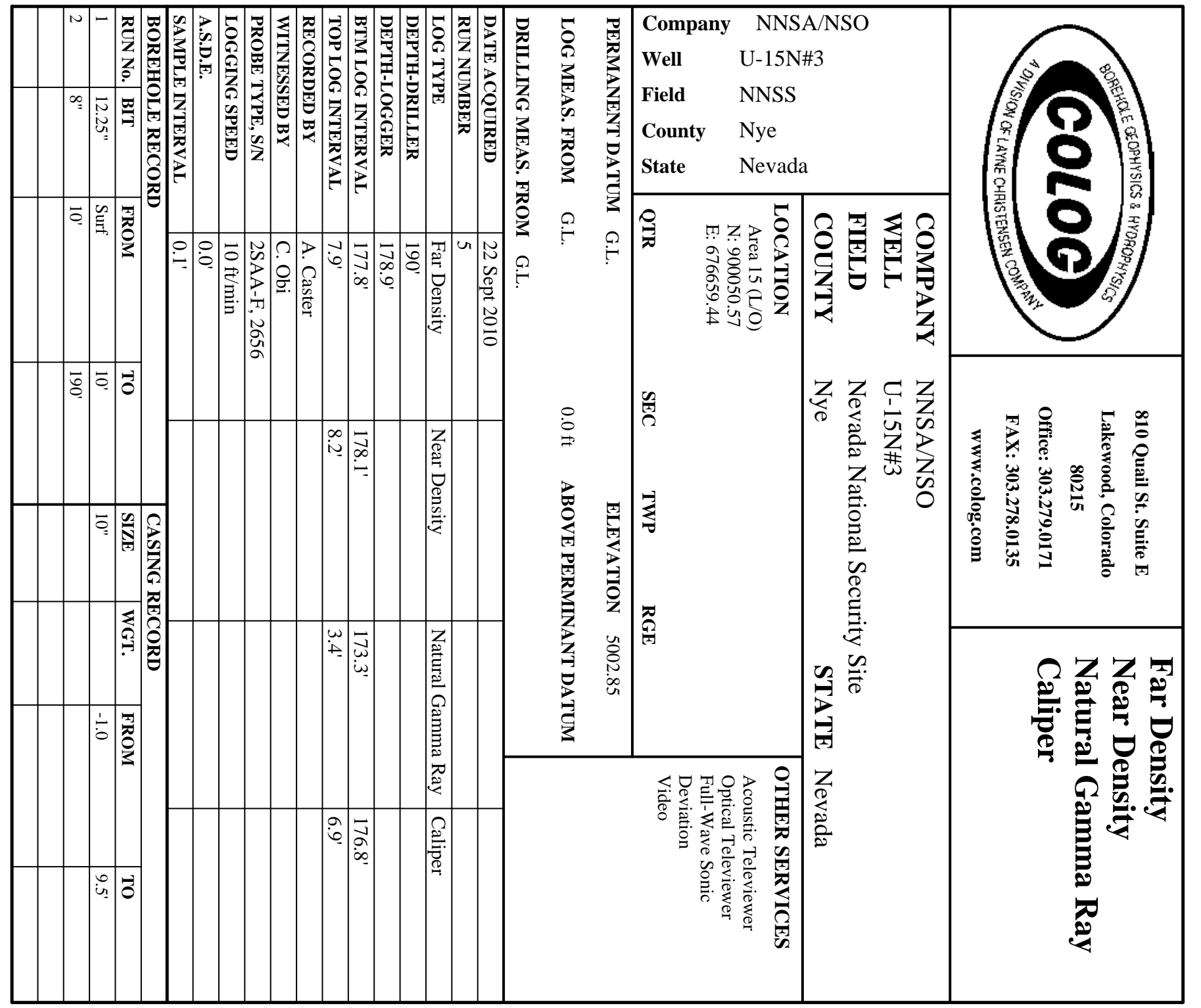

\section{COMMENTS}

NA - Not Available, N/A - Not Applicable

Matrix Density of 2.64 used to calculate Density Porosity 


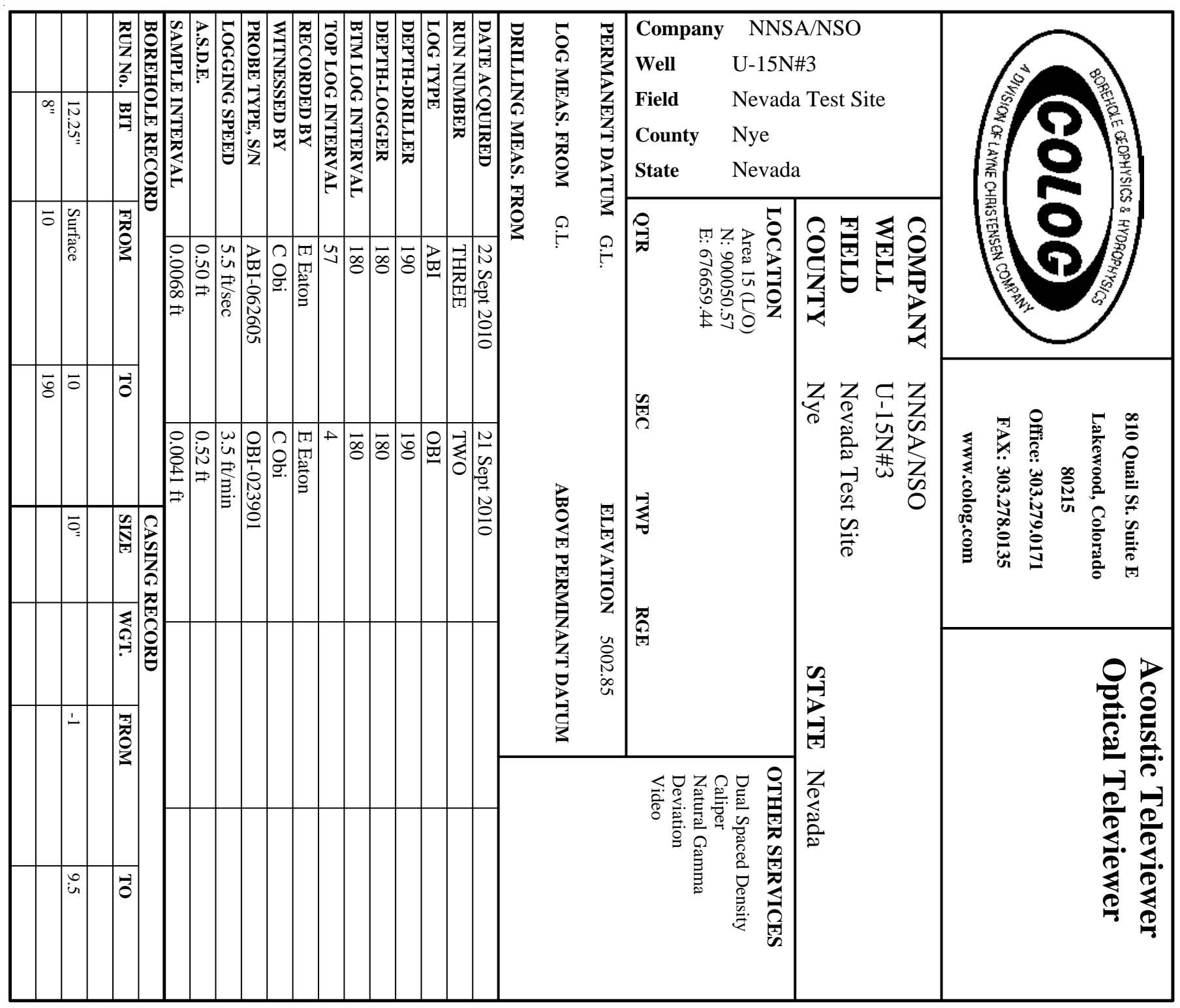




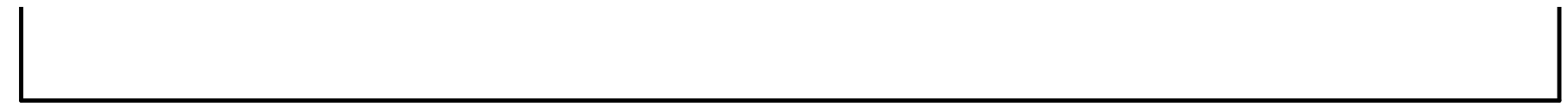

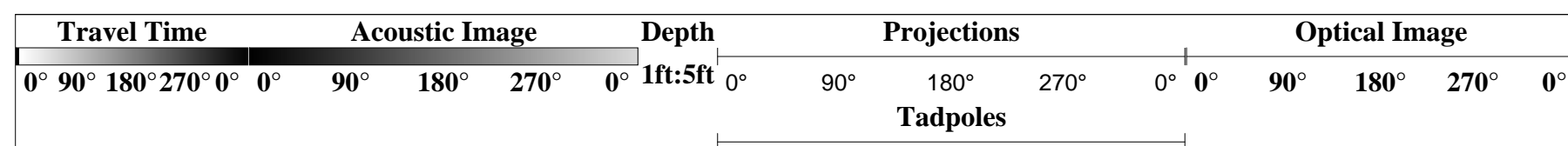

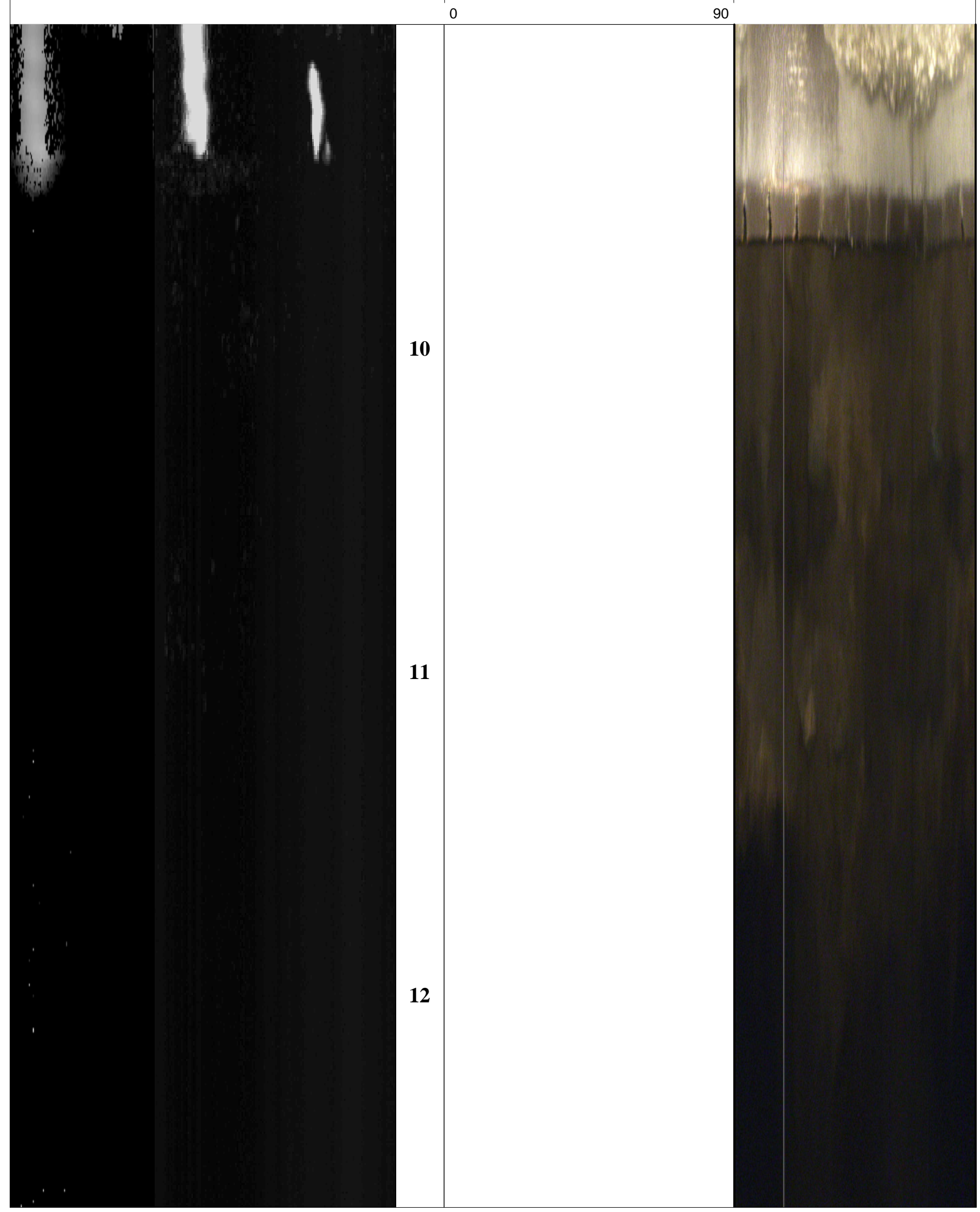




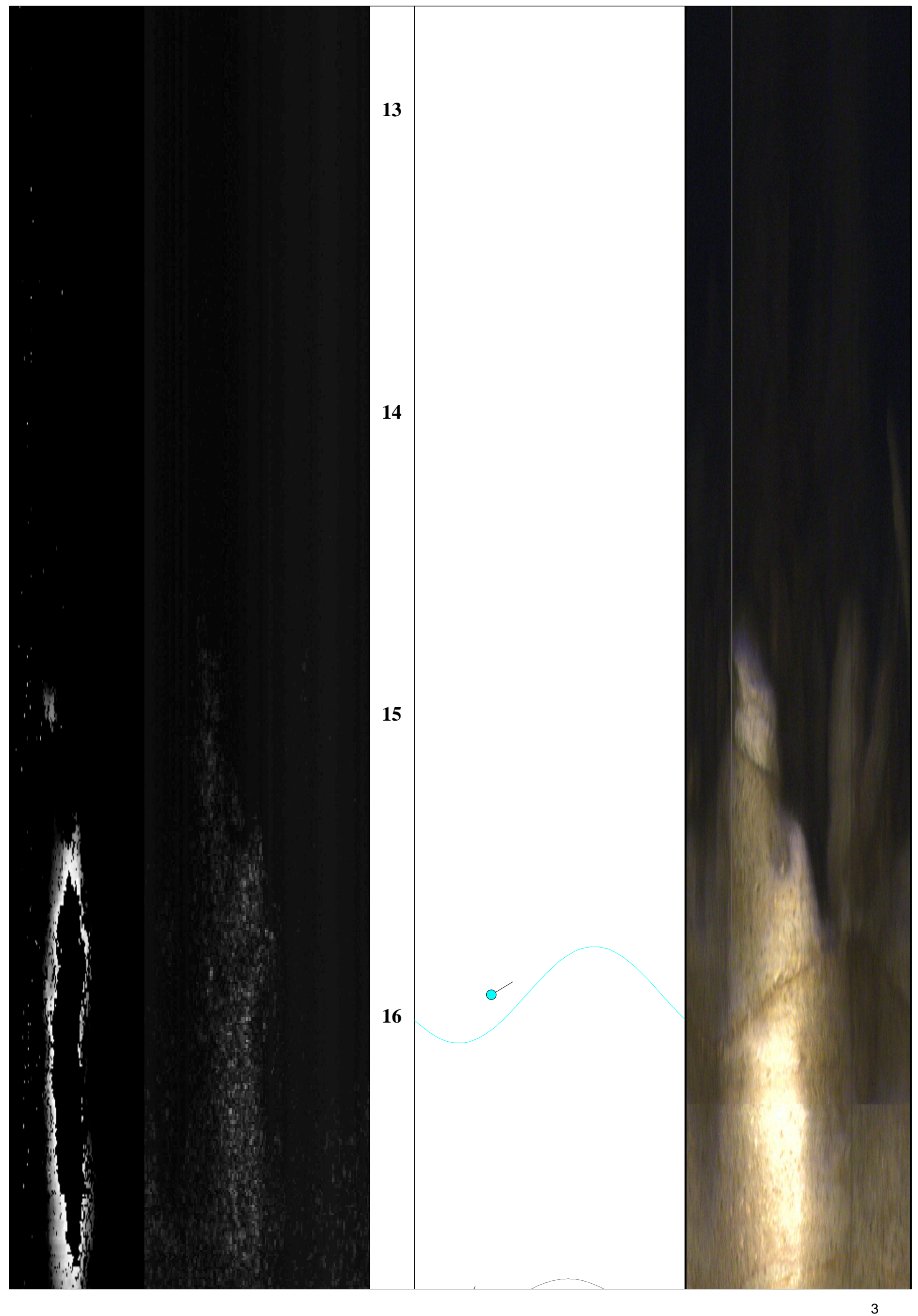




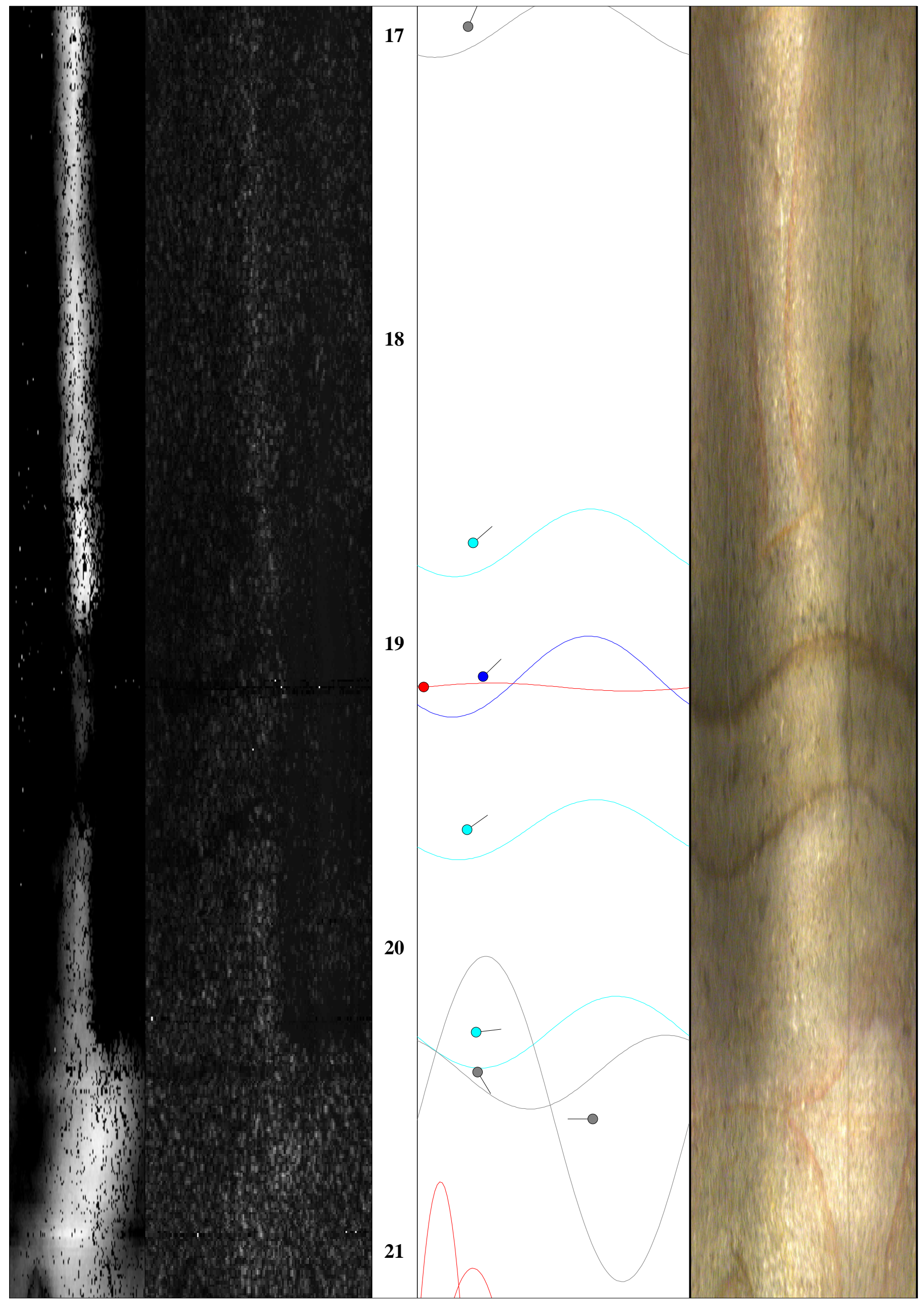



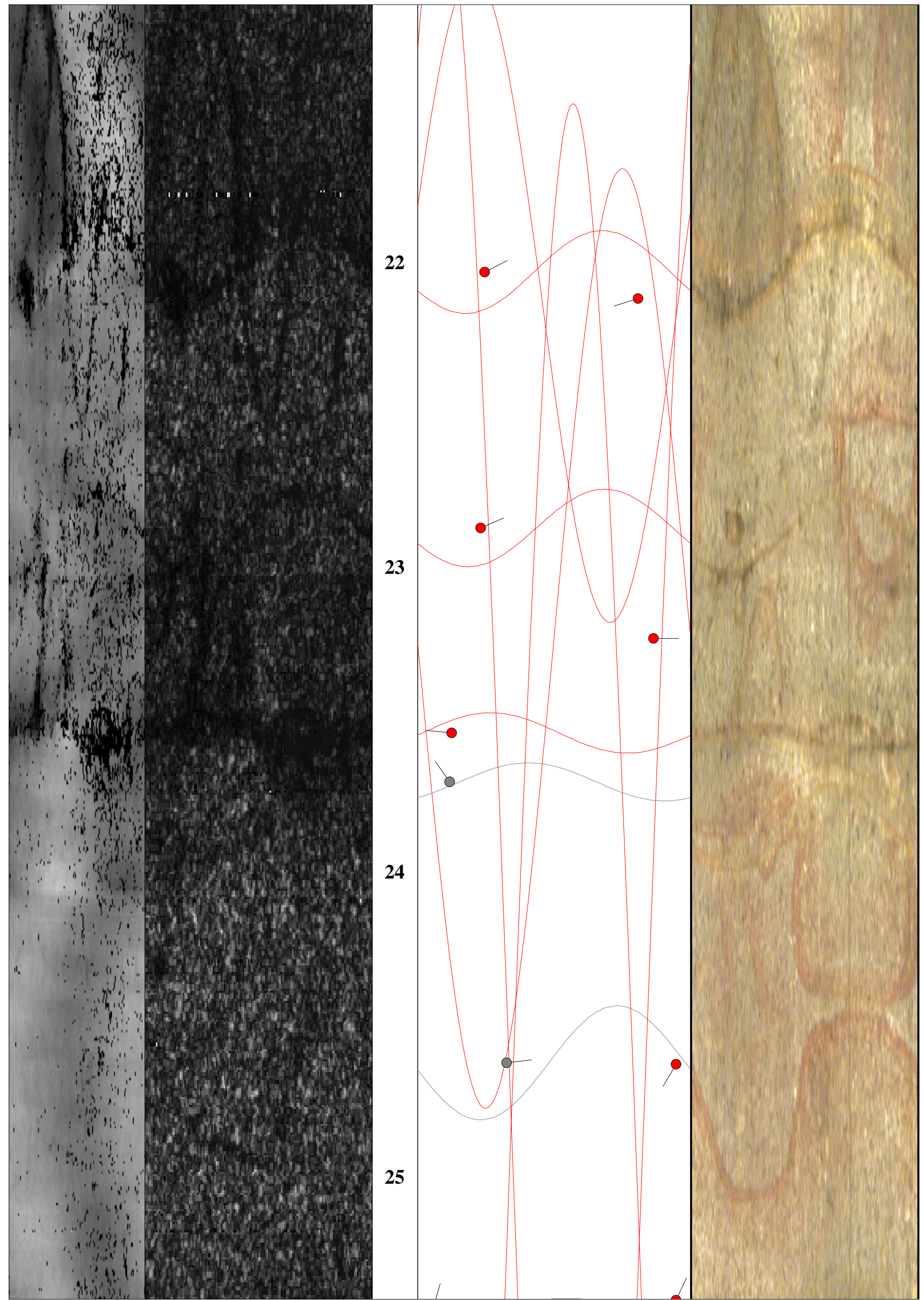


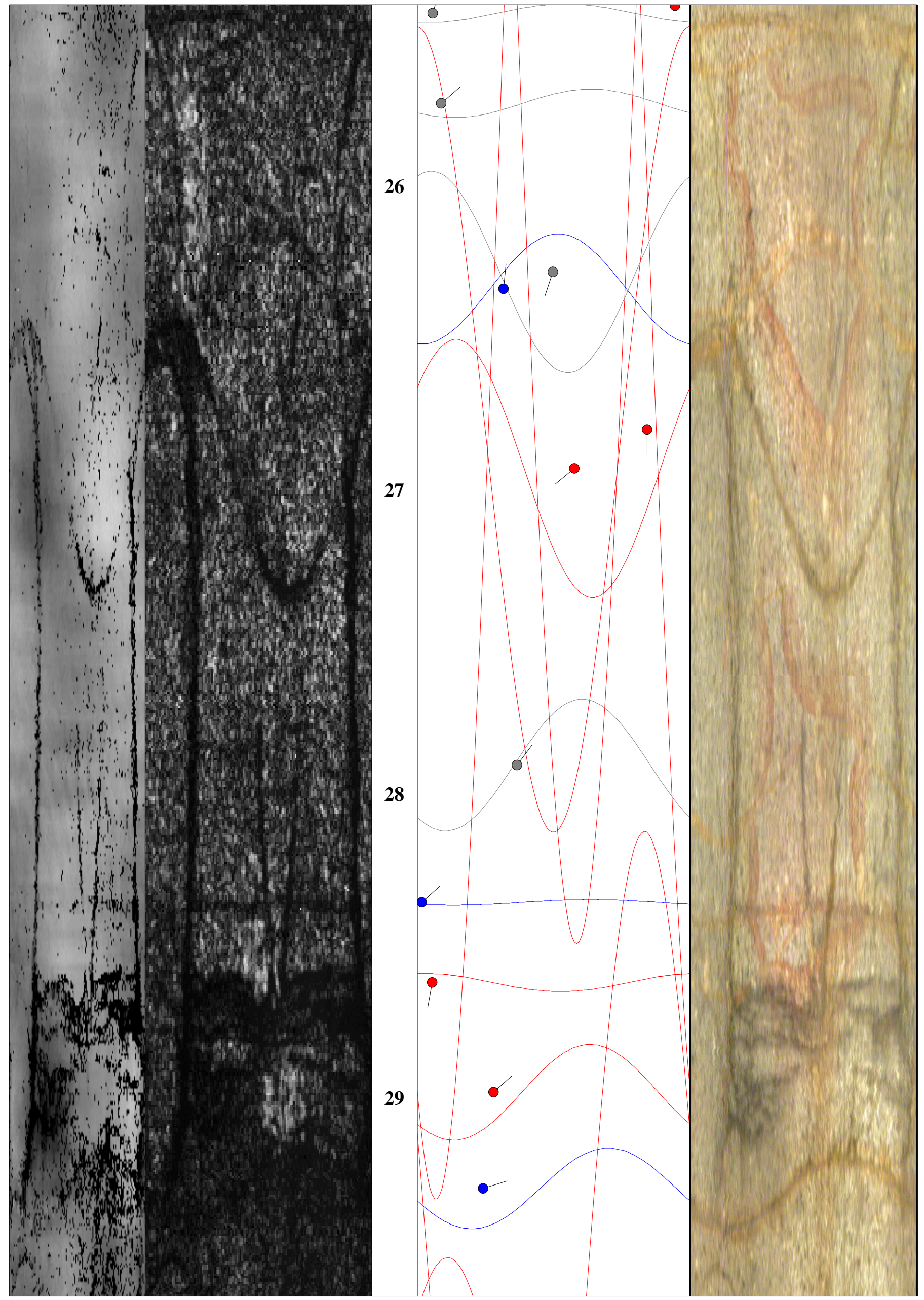




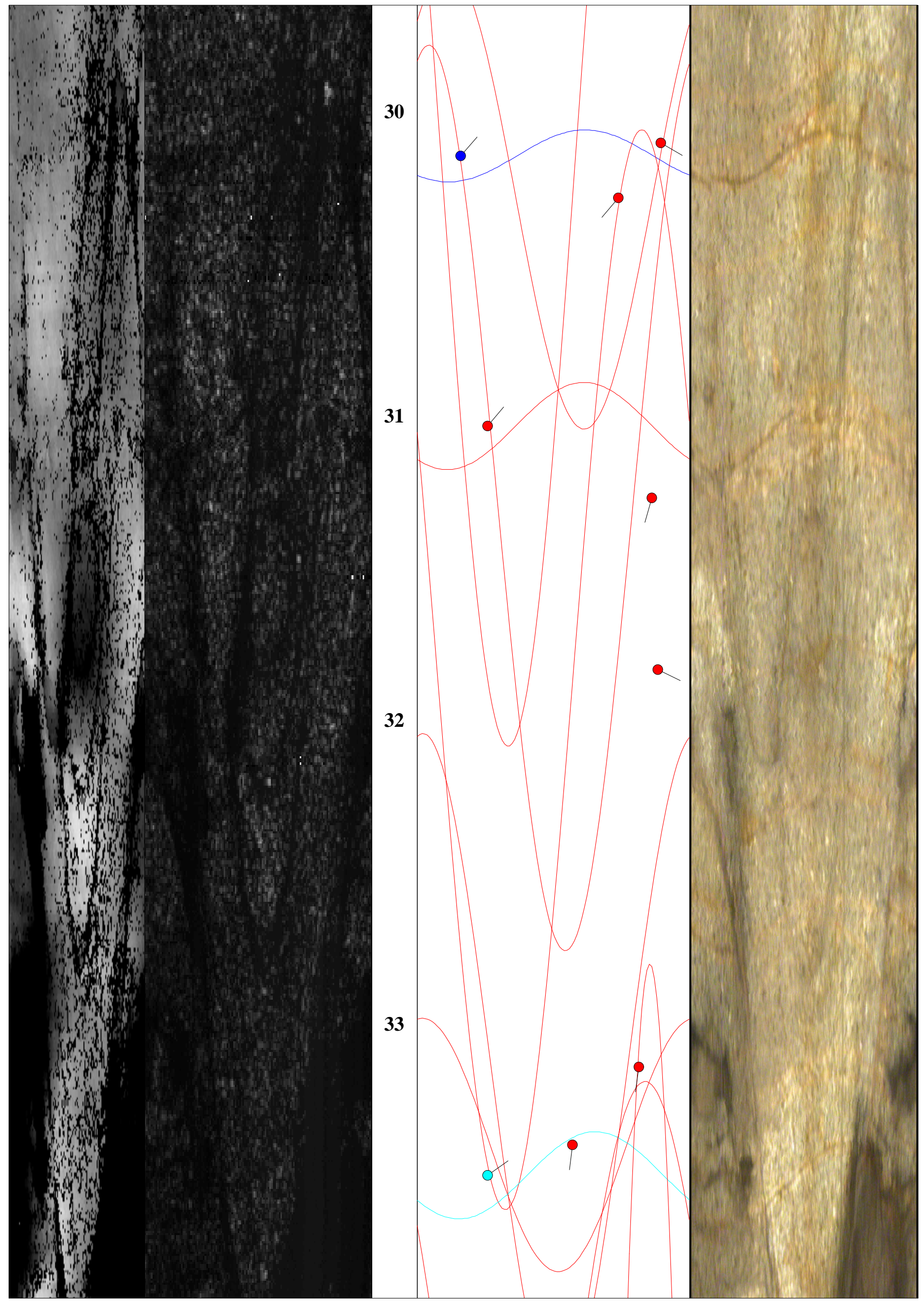



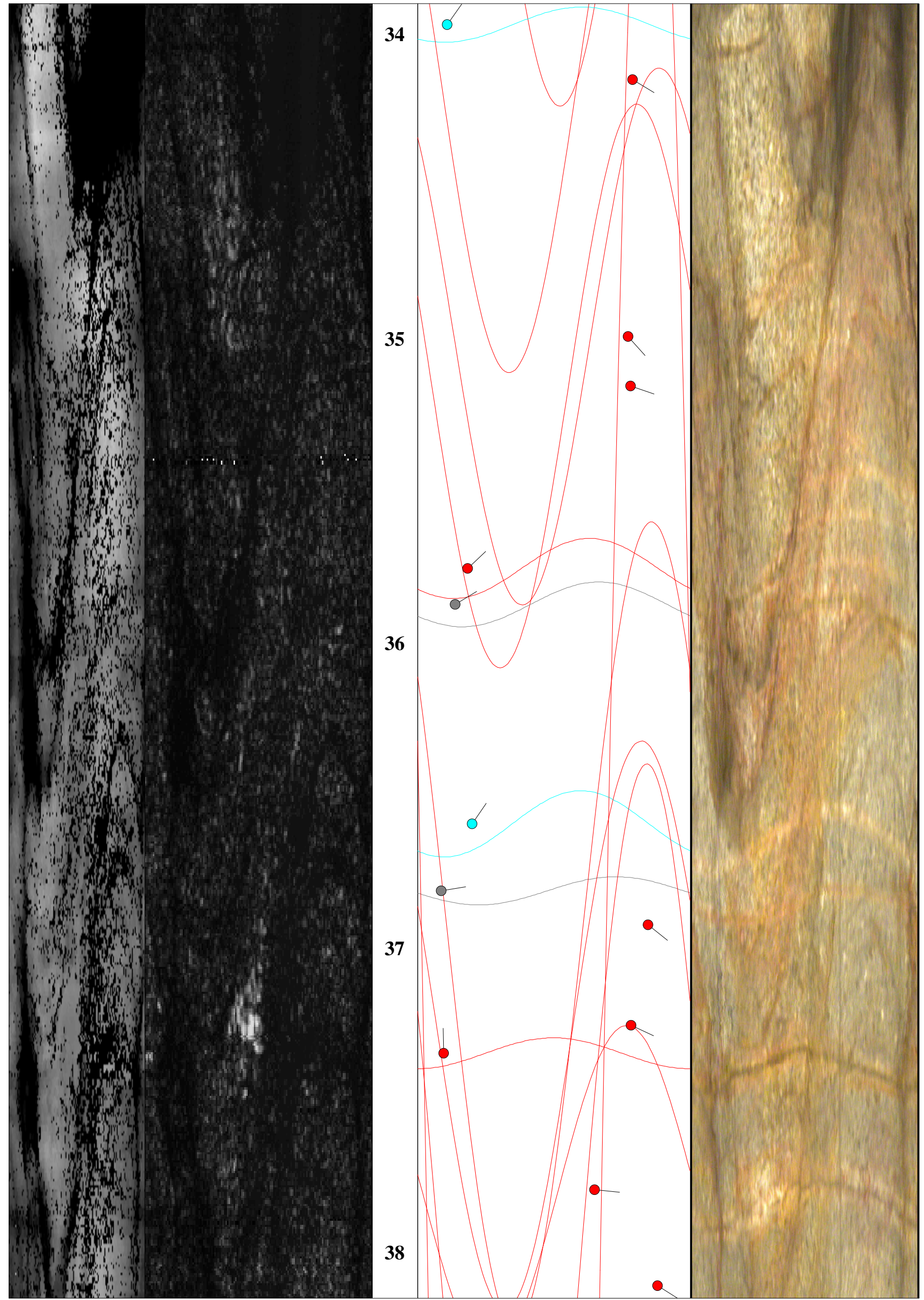


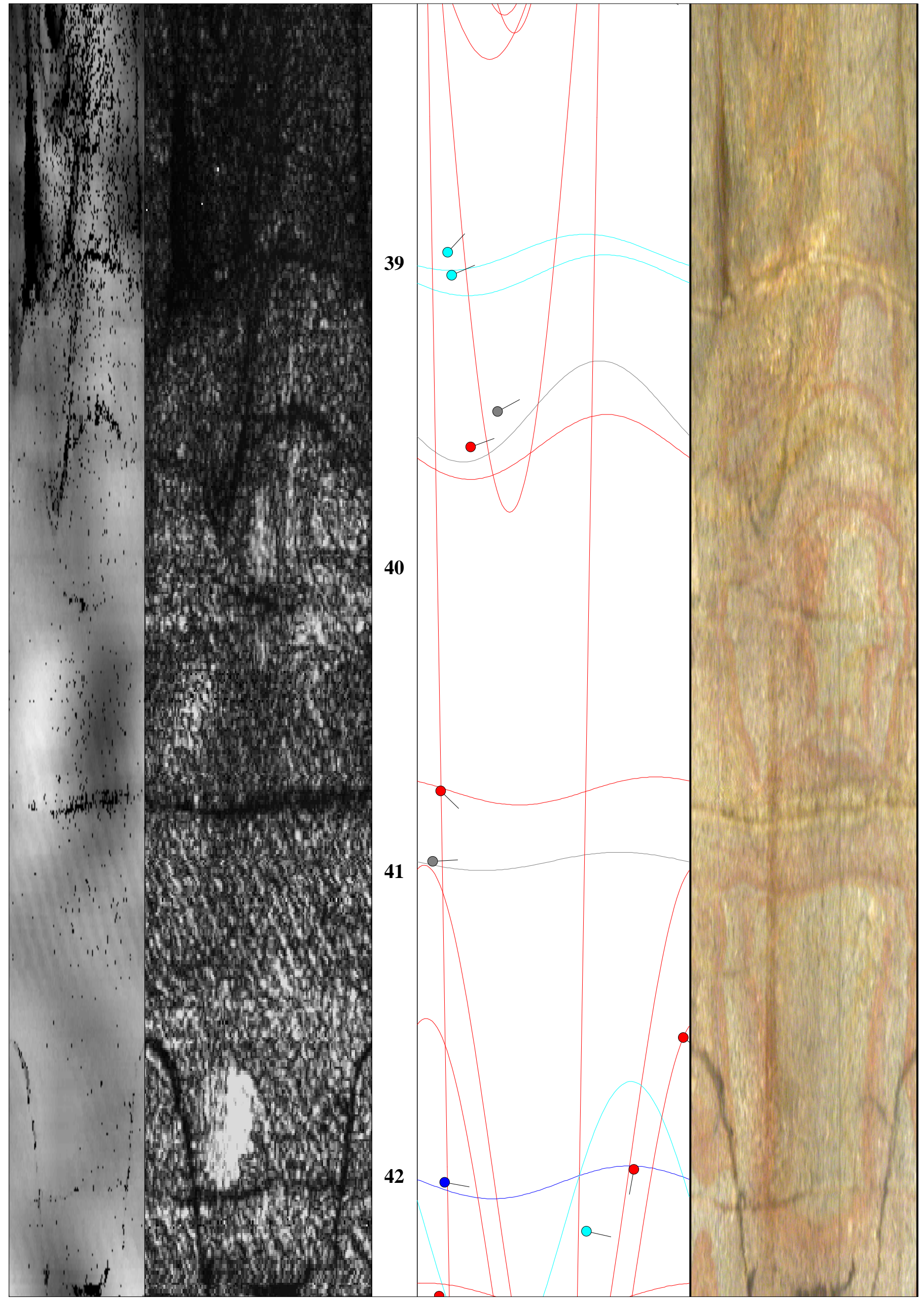




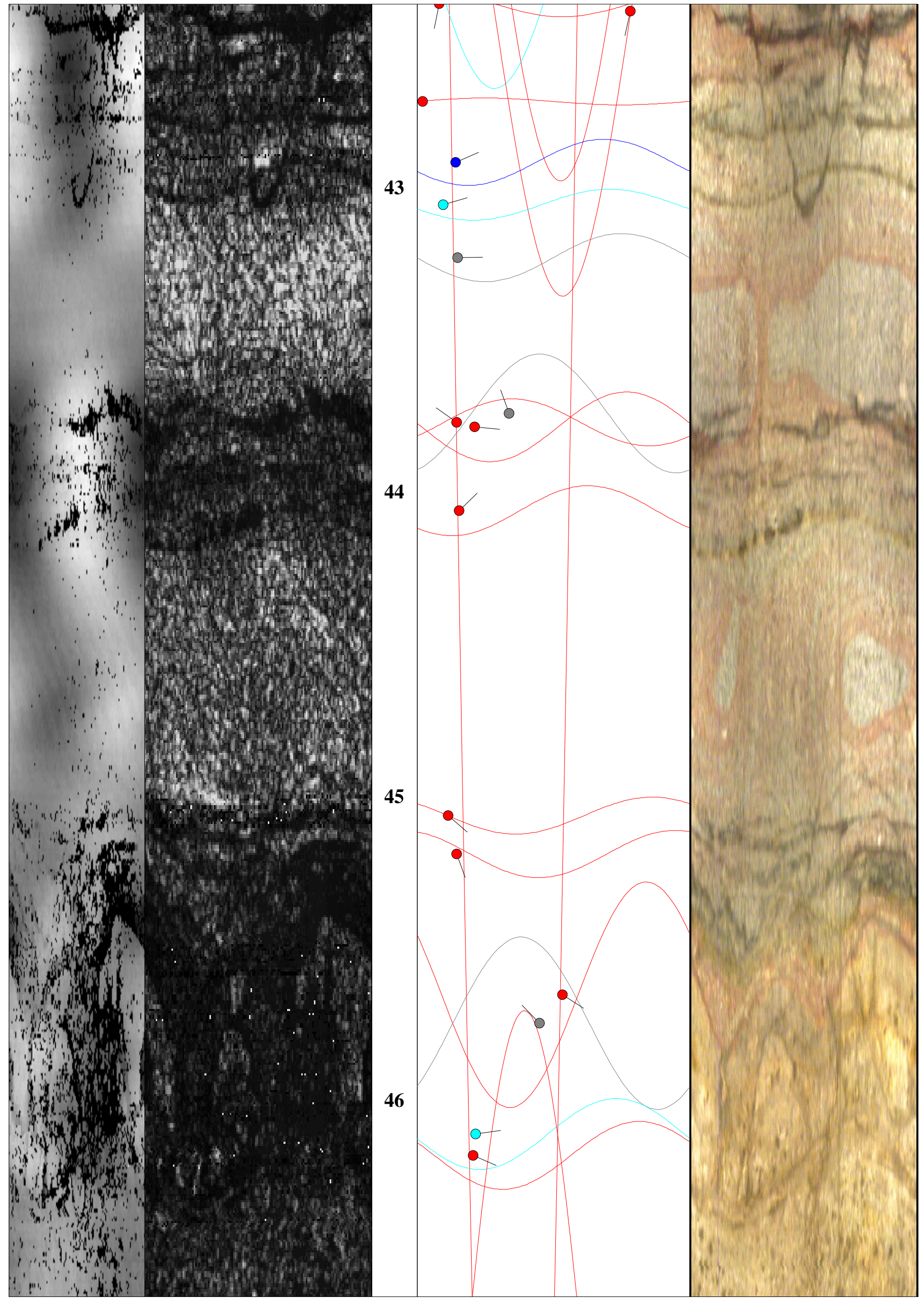




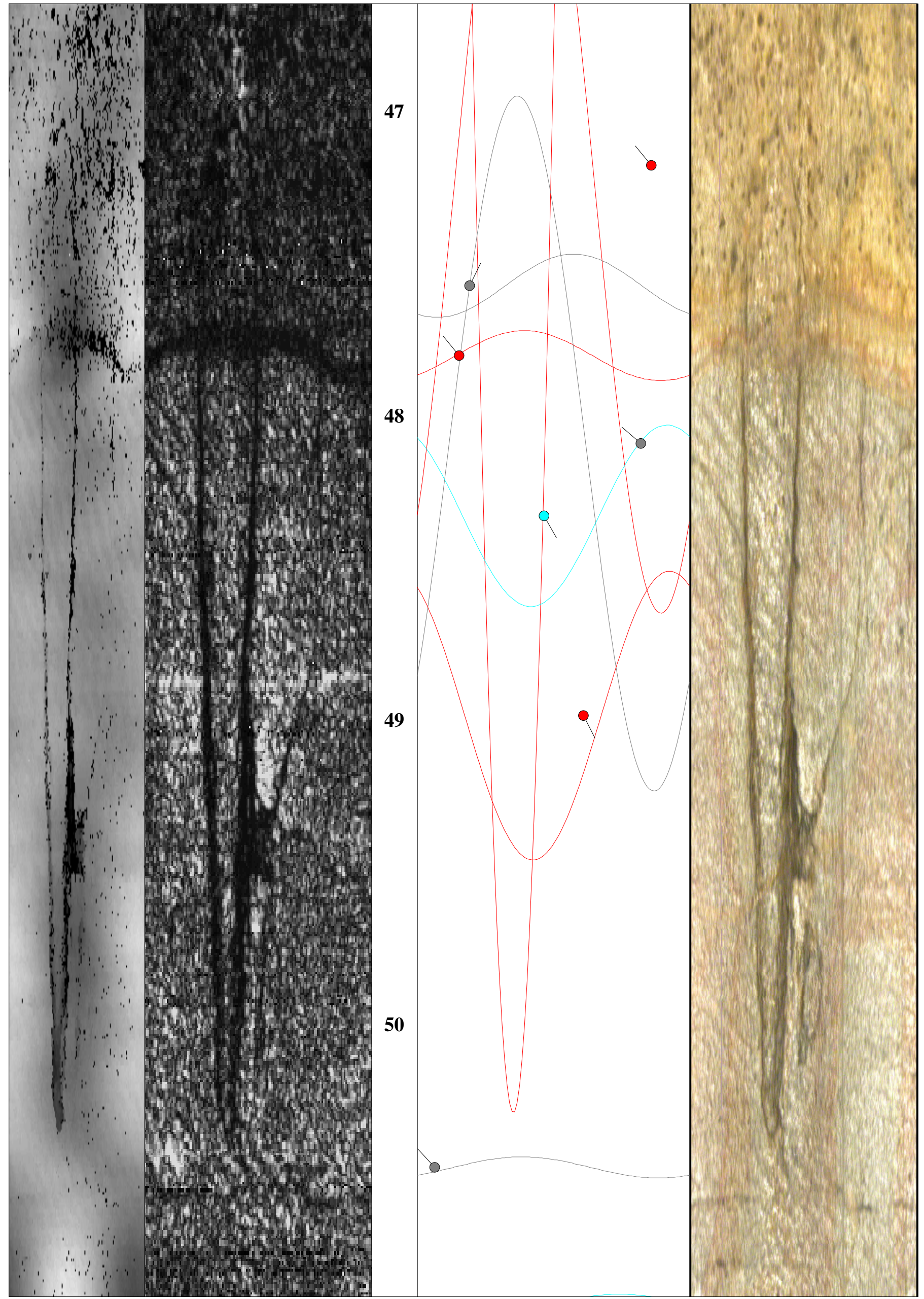




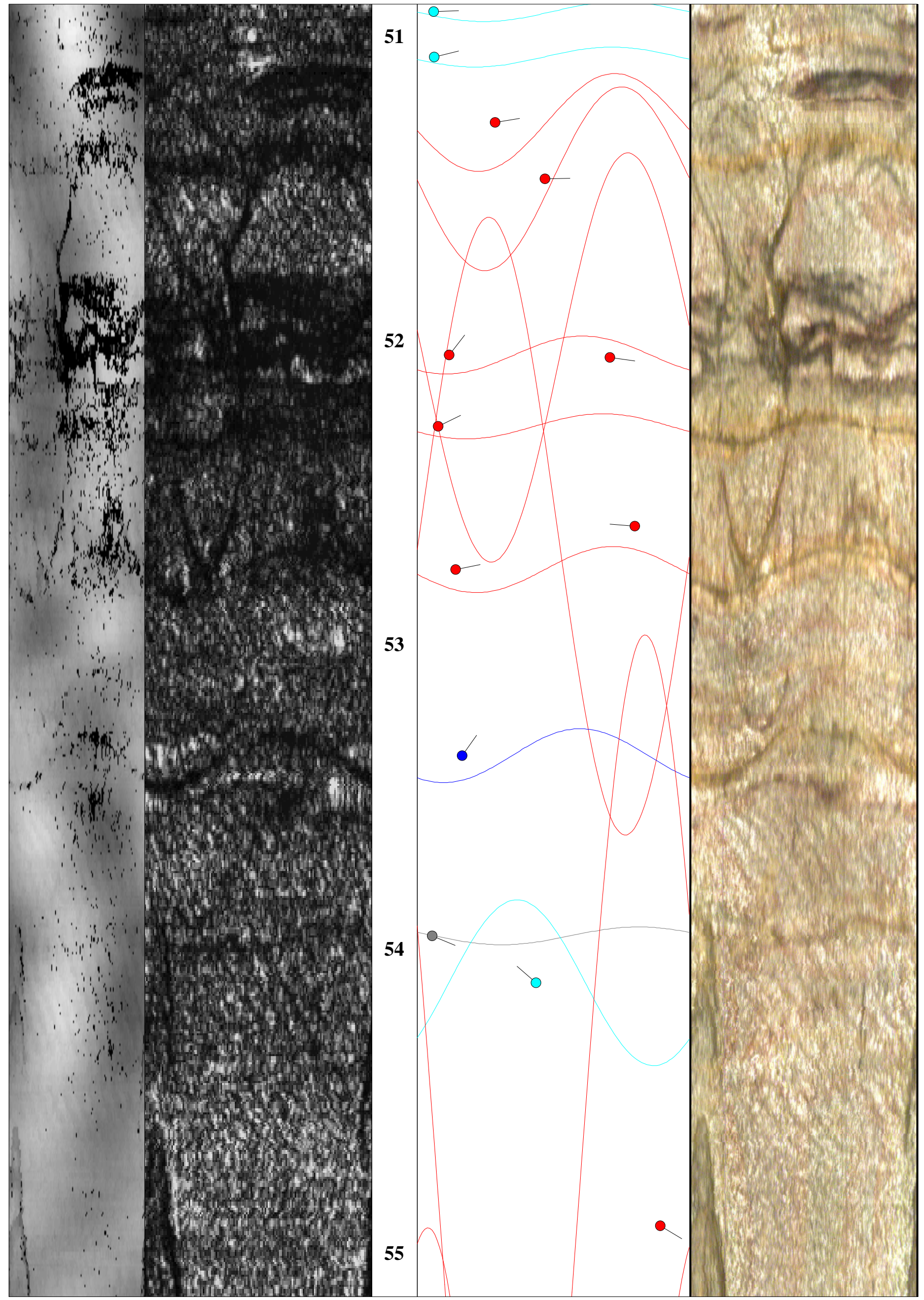




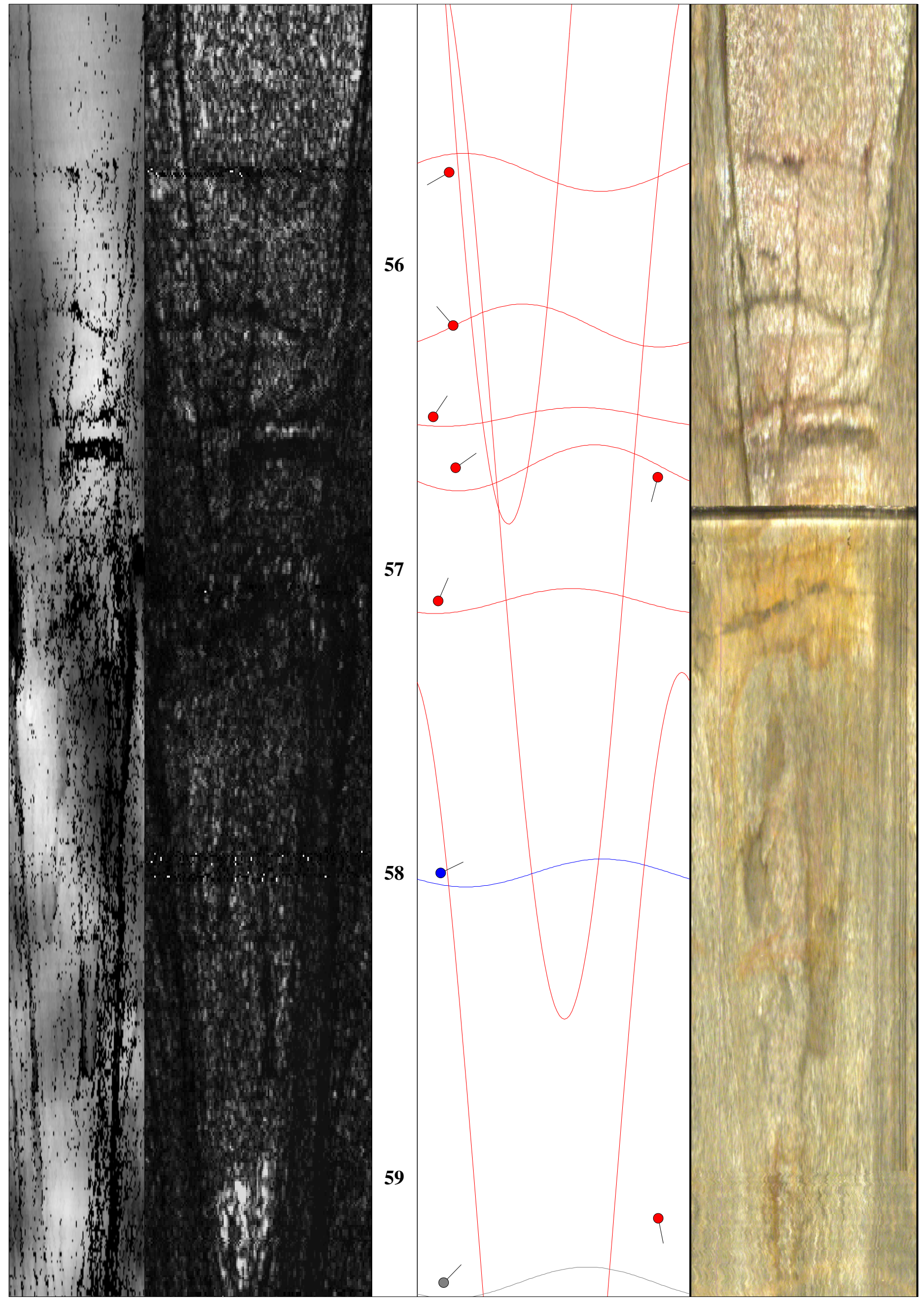




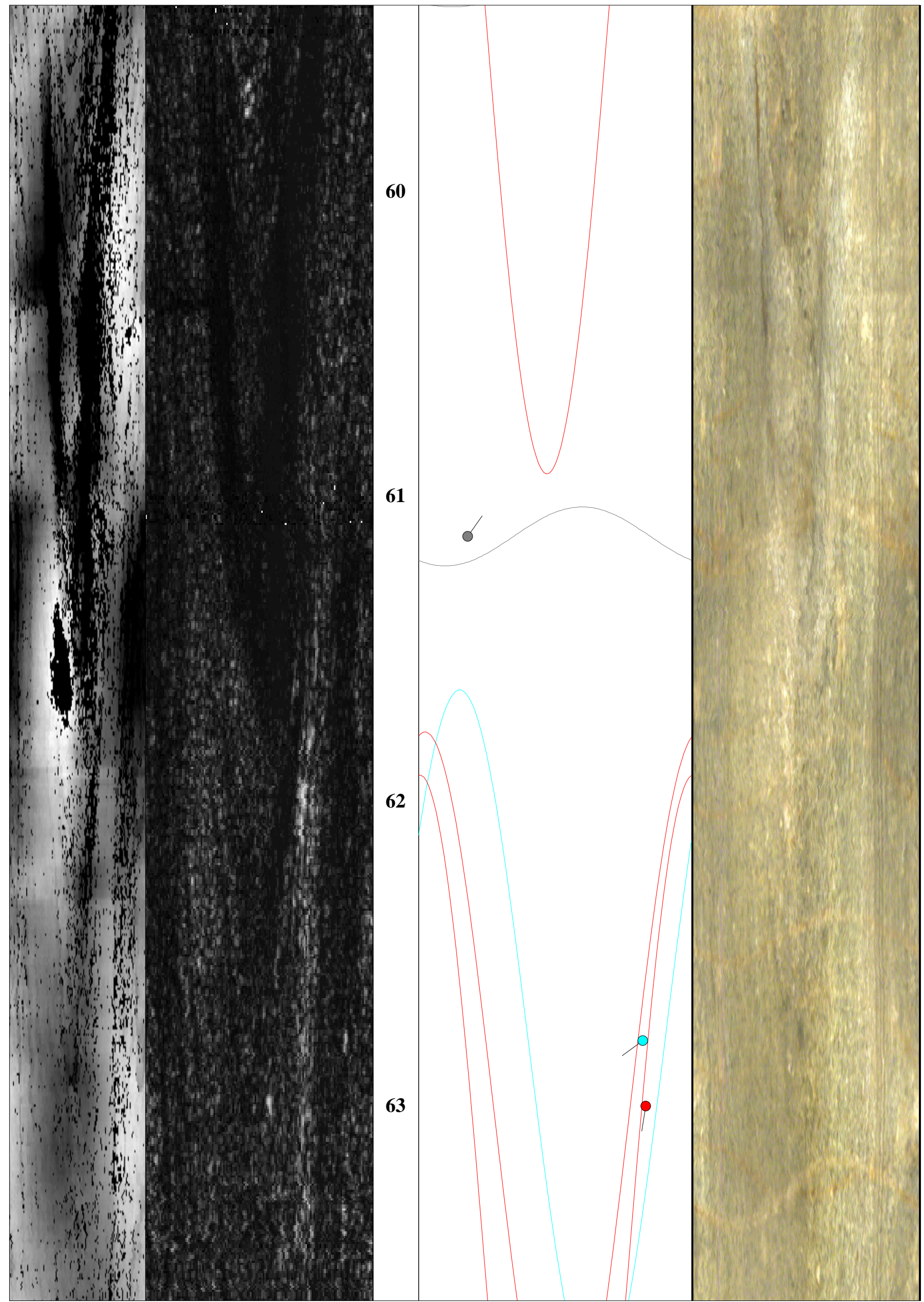




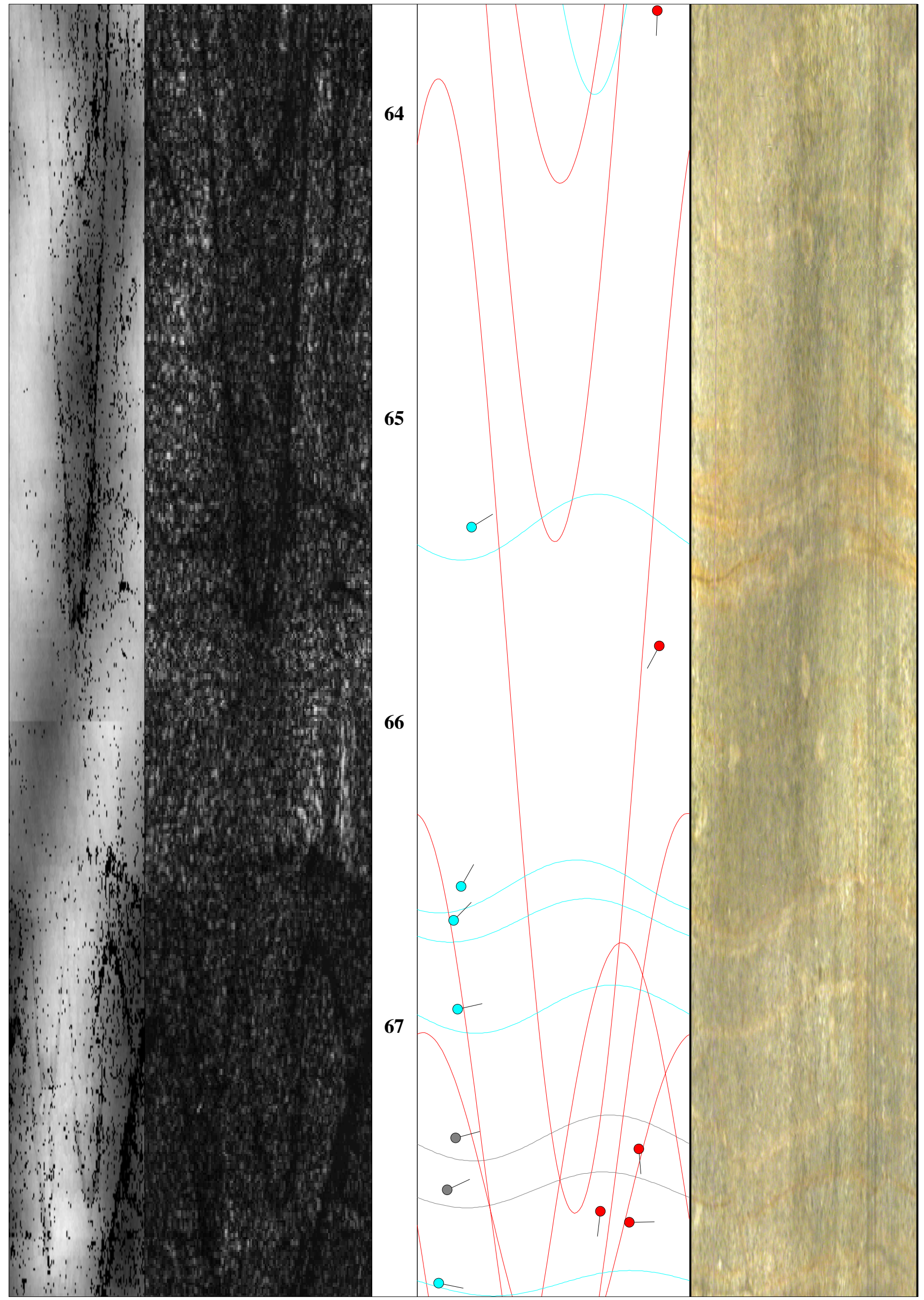




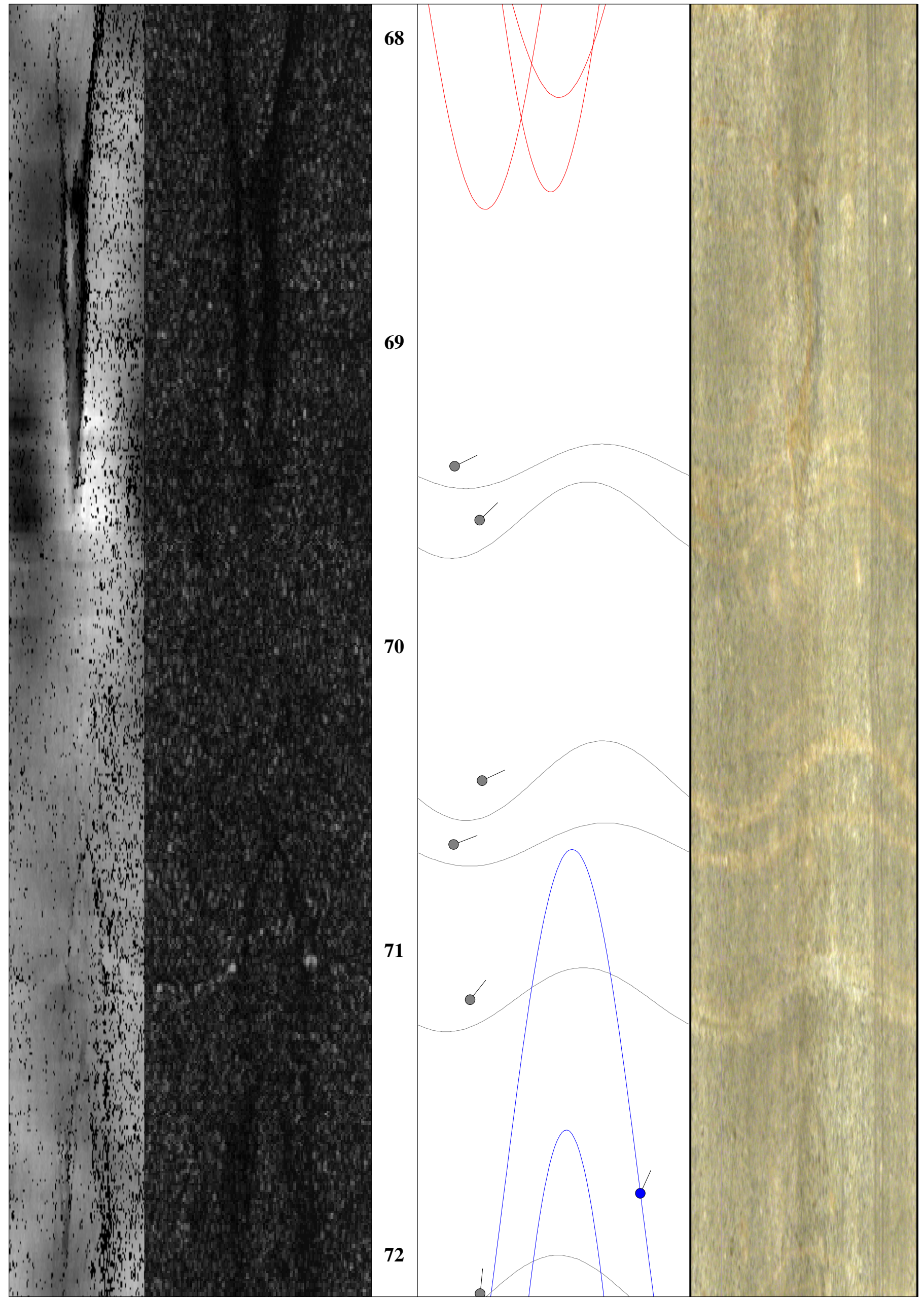




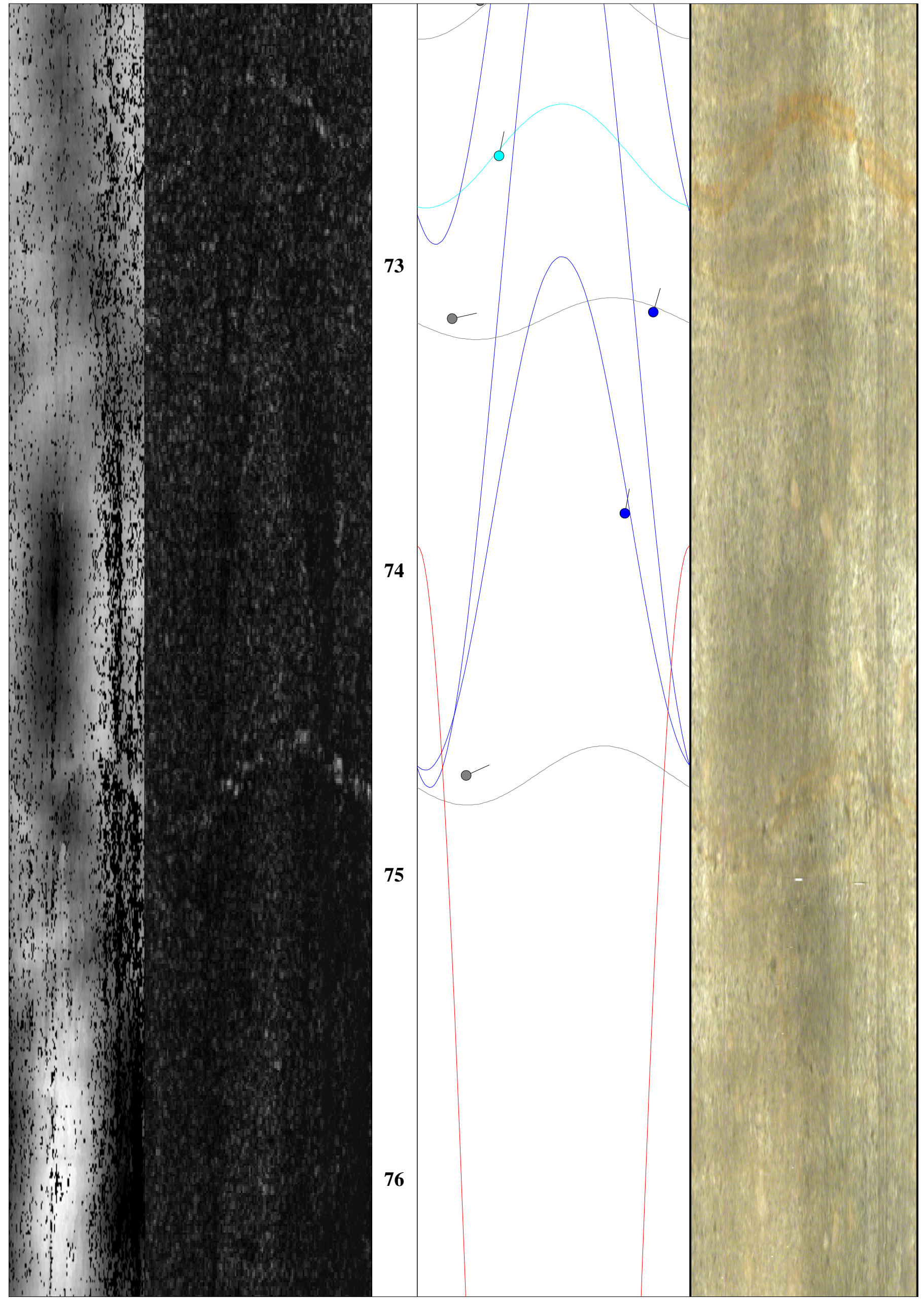




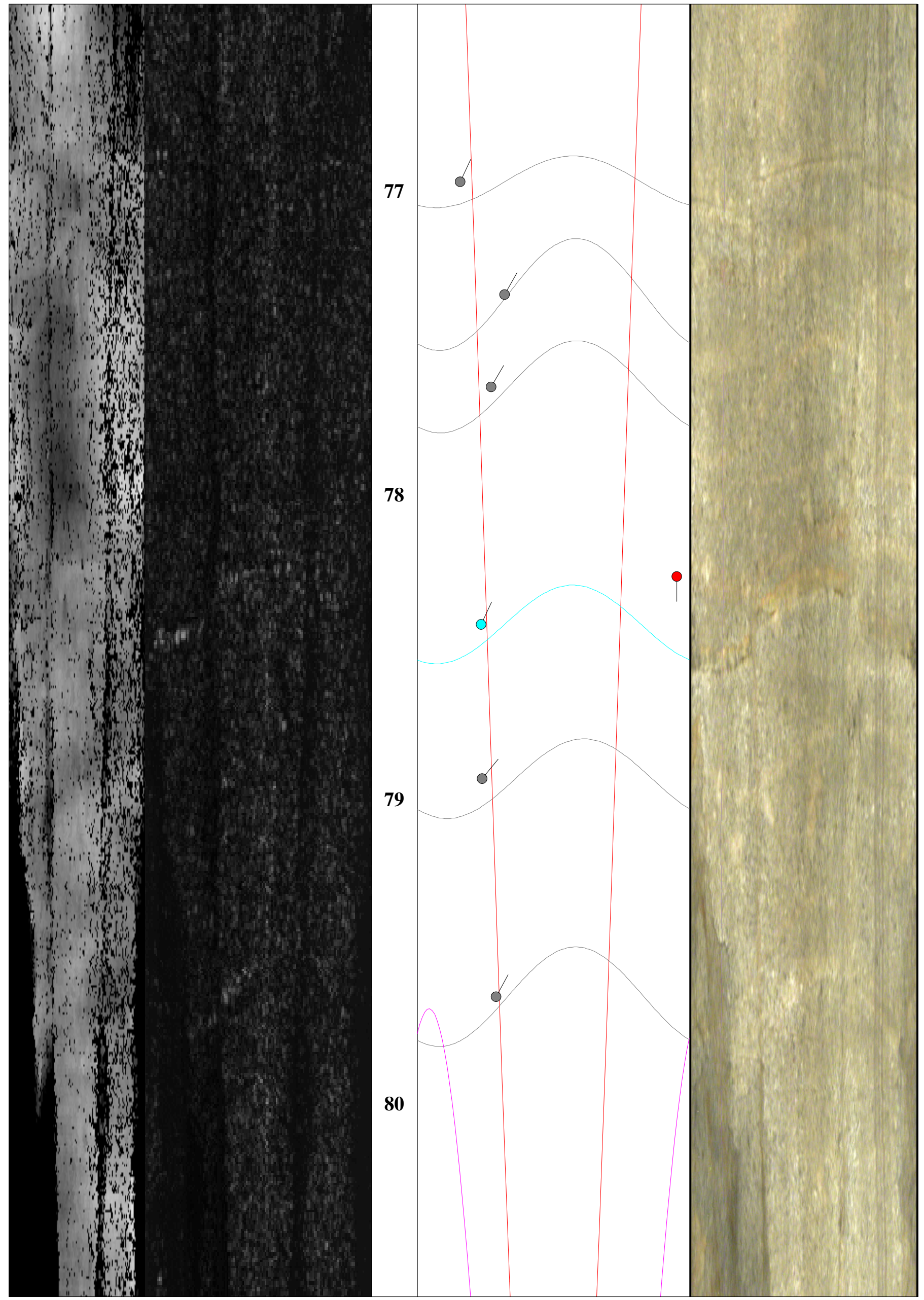




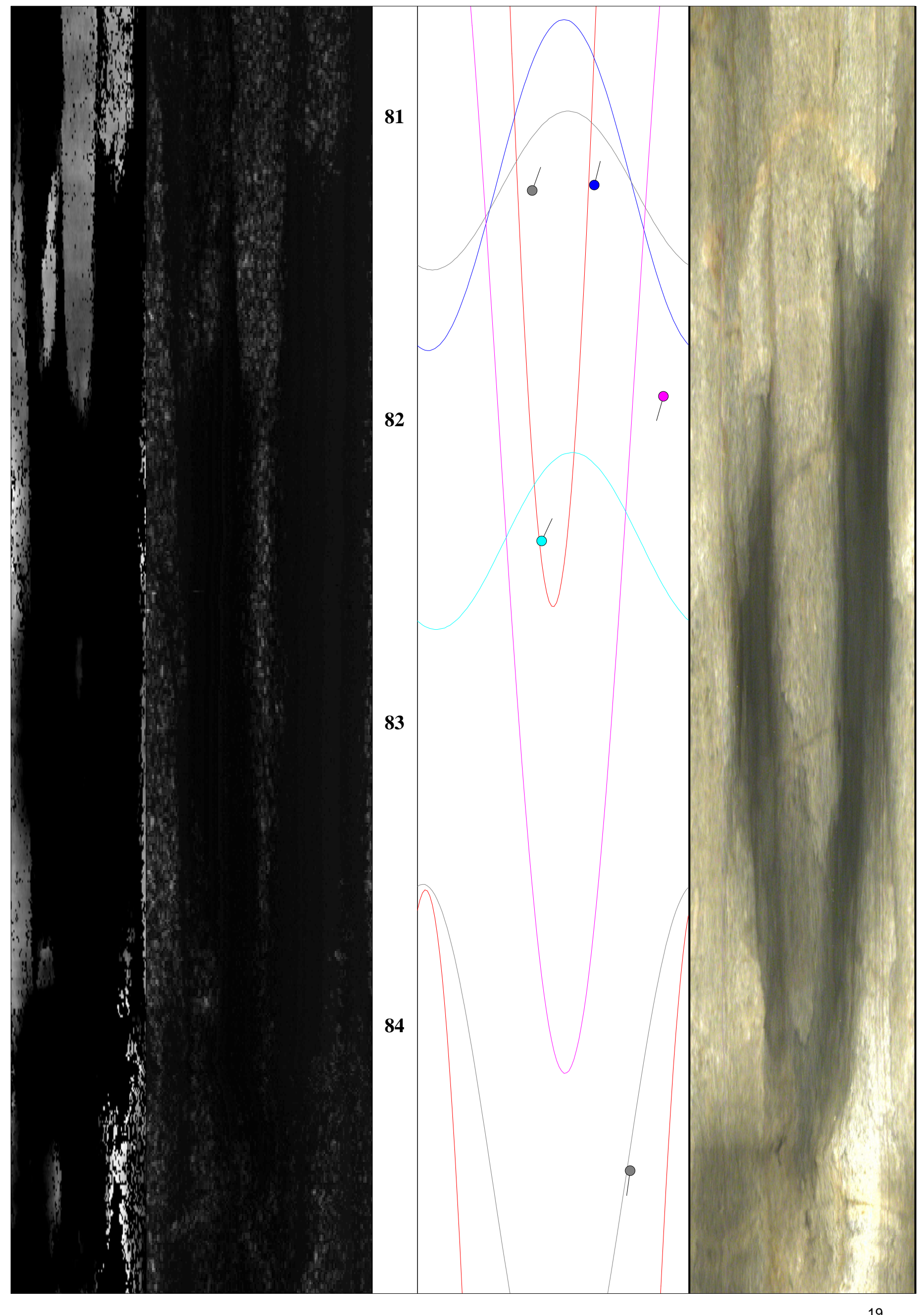




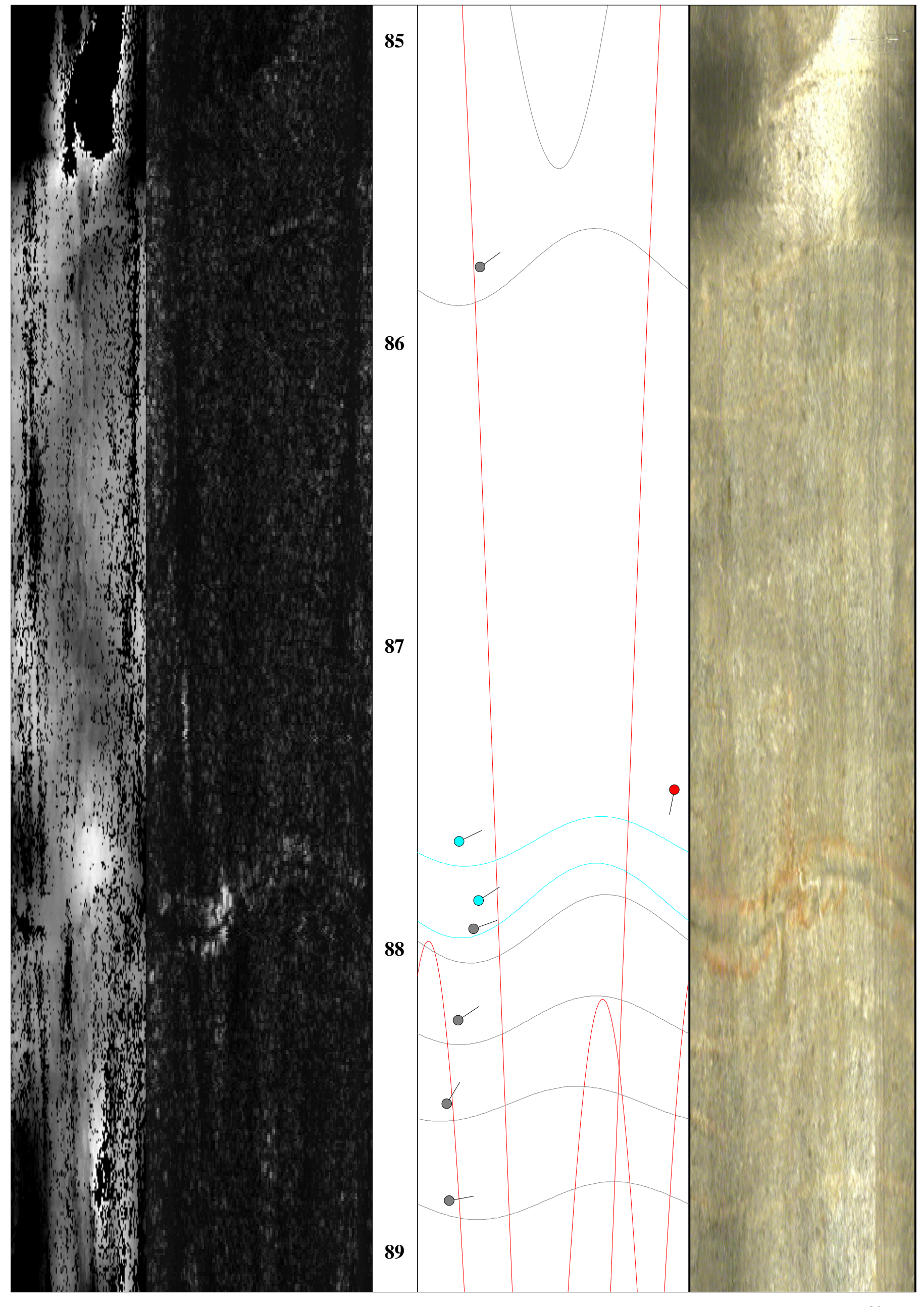




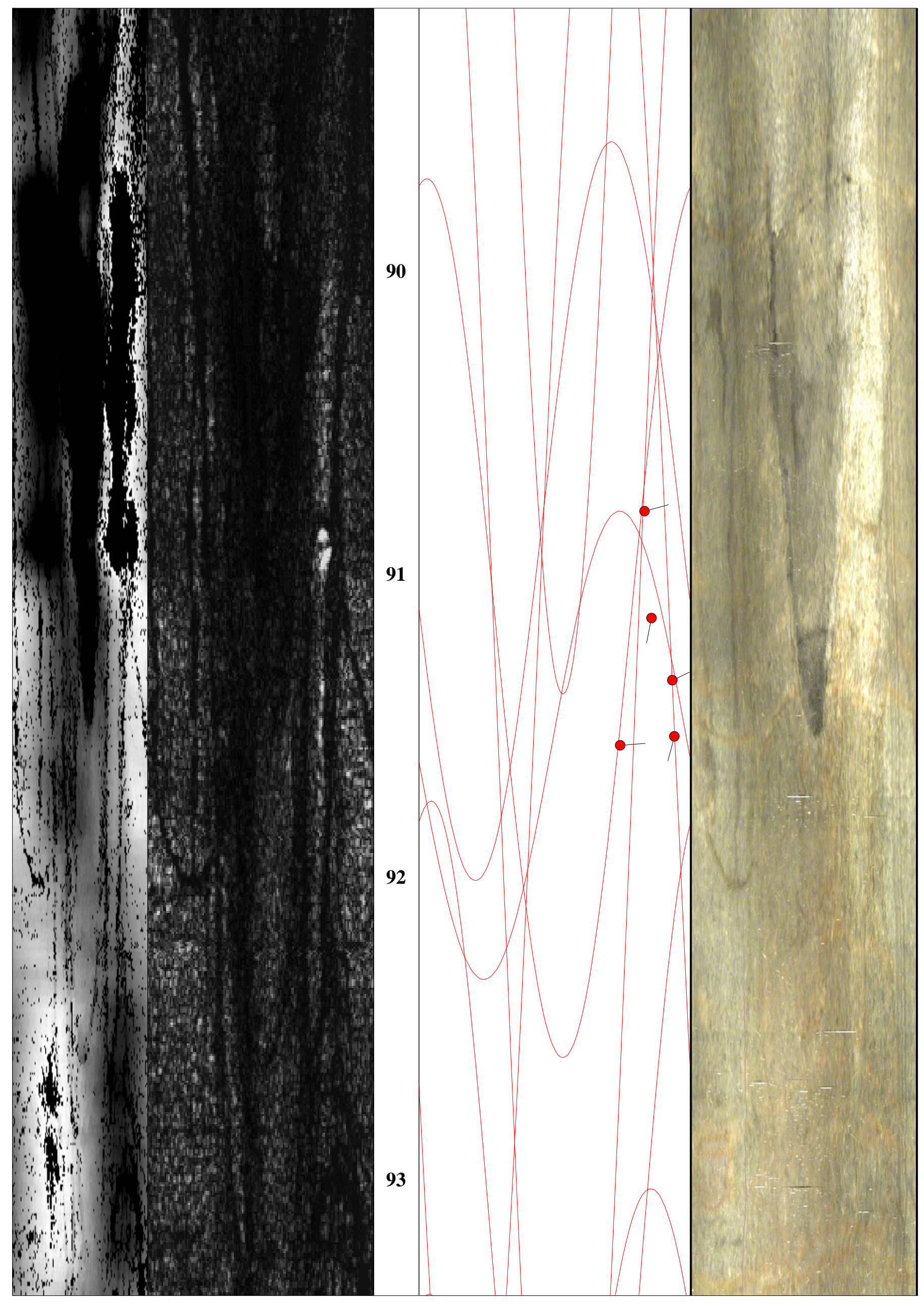




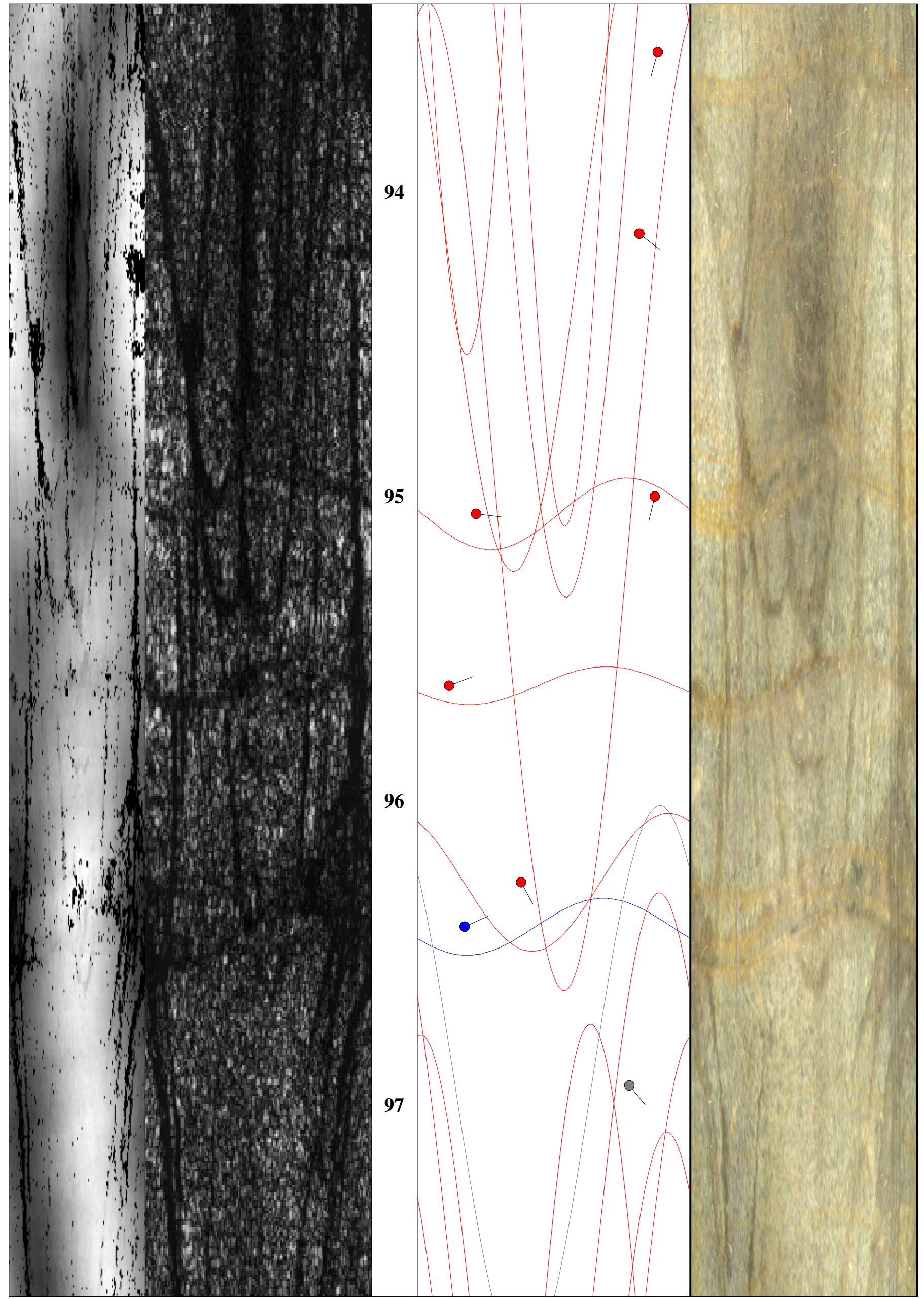




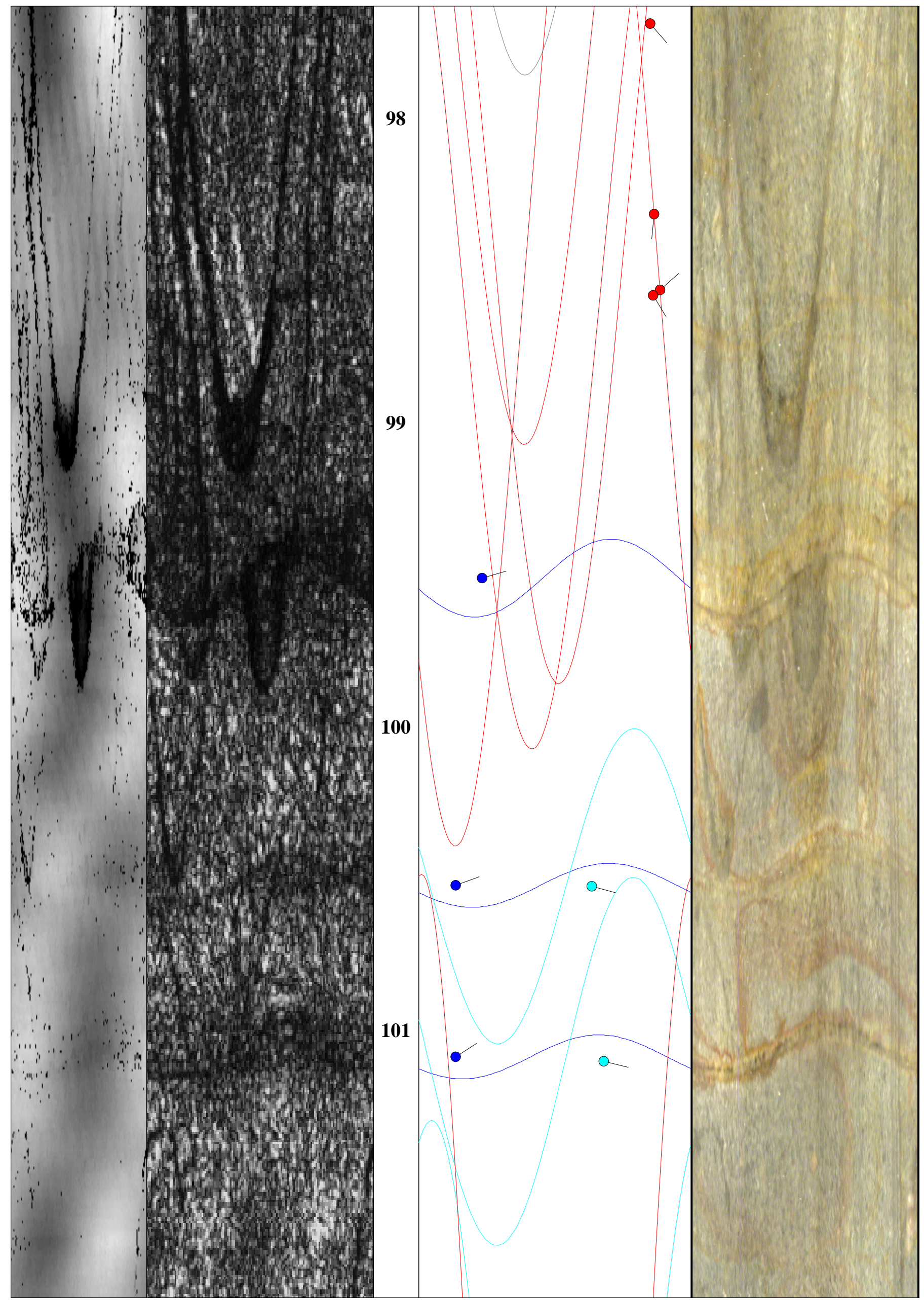




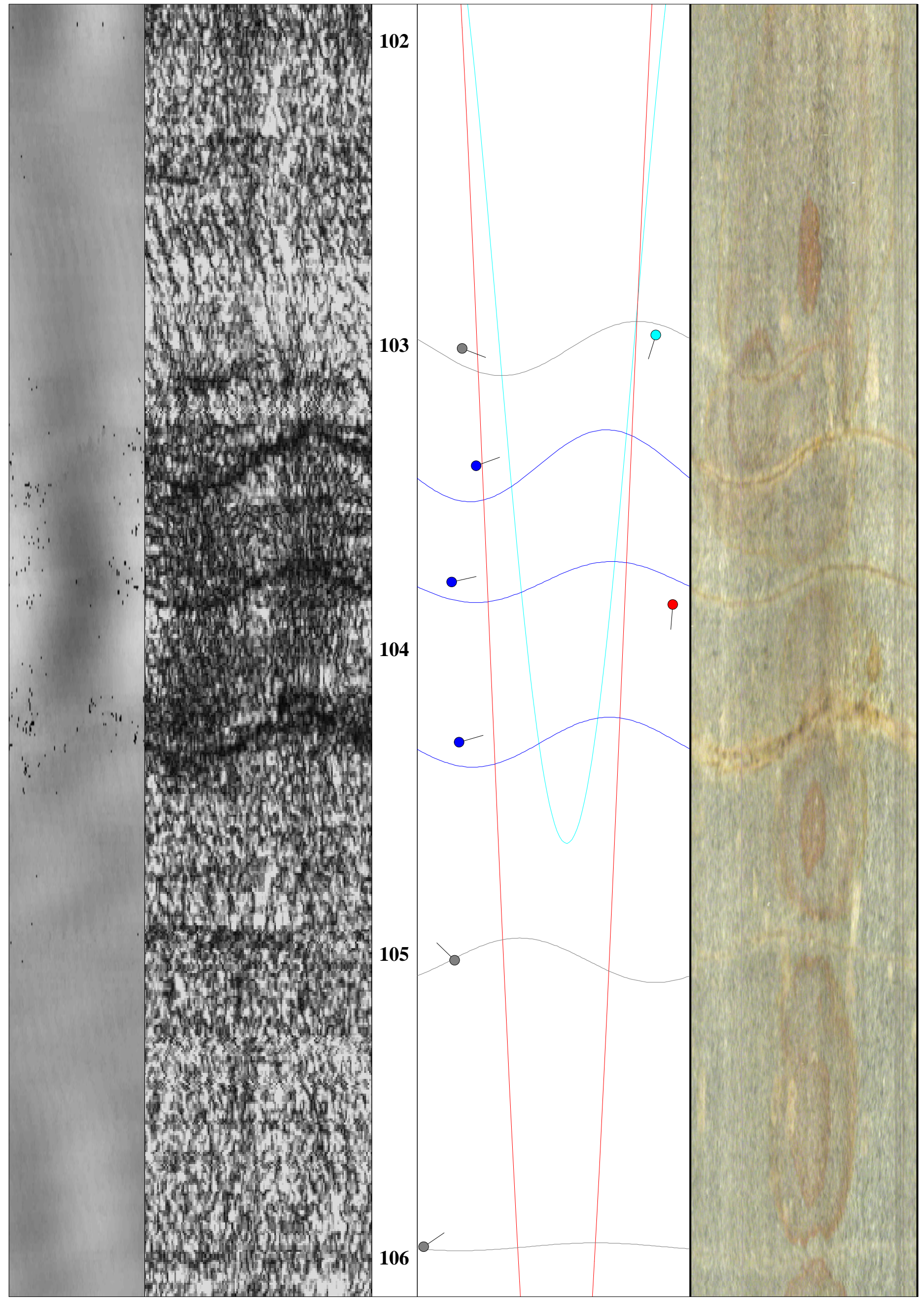




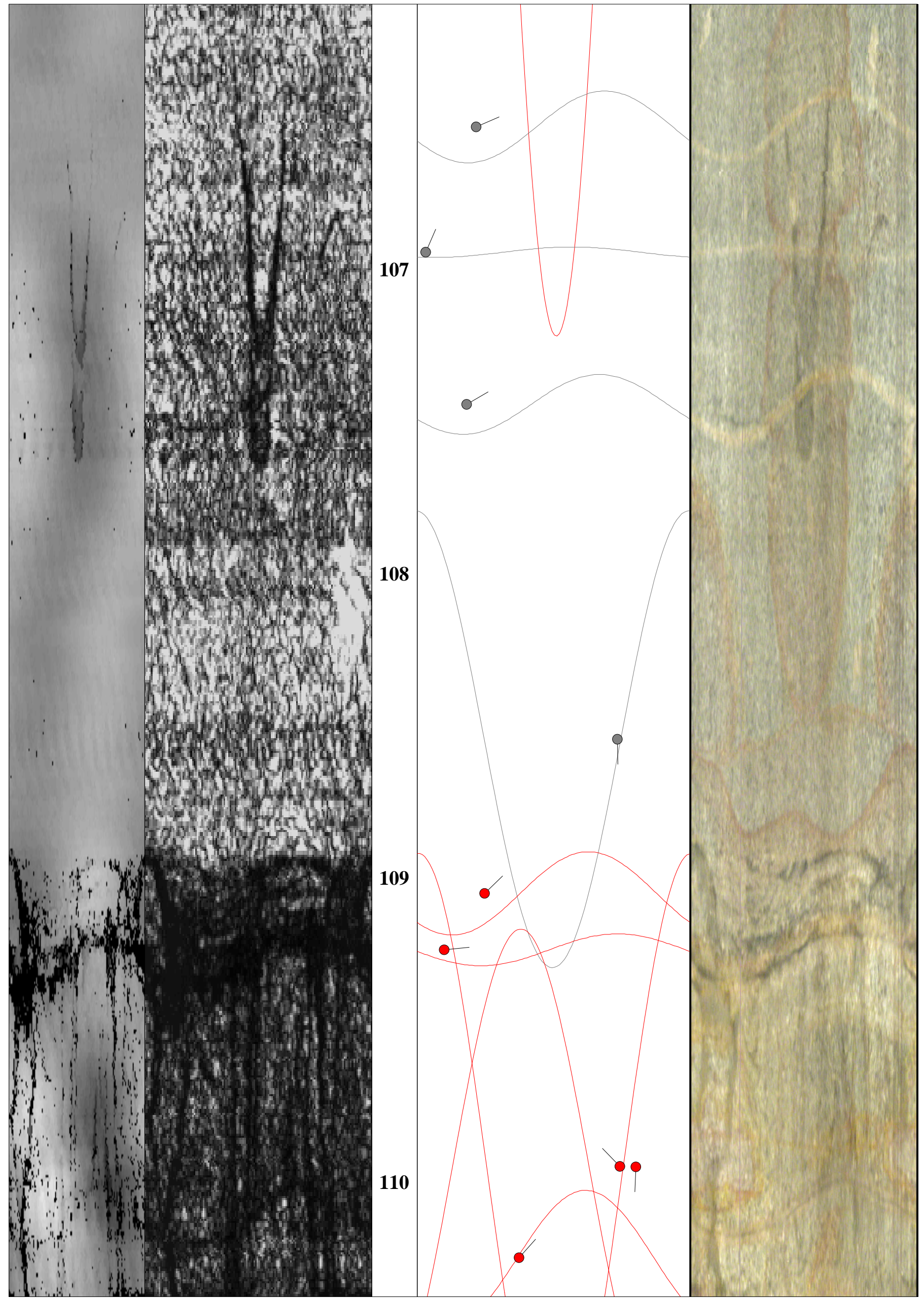




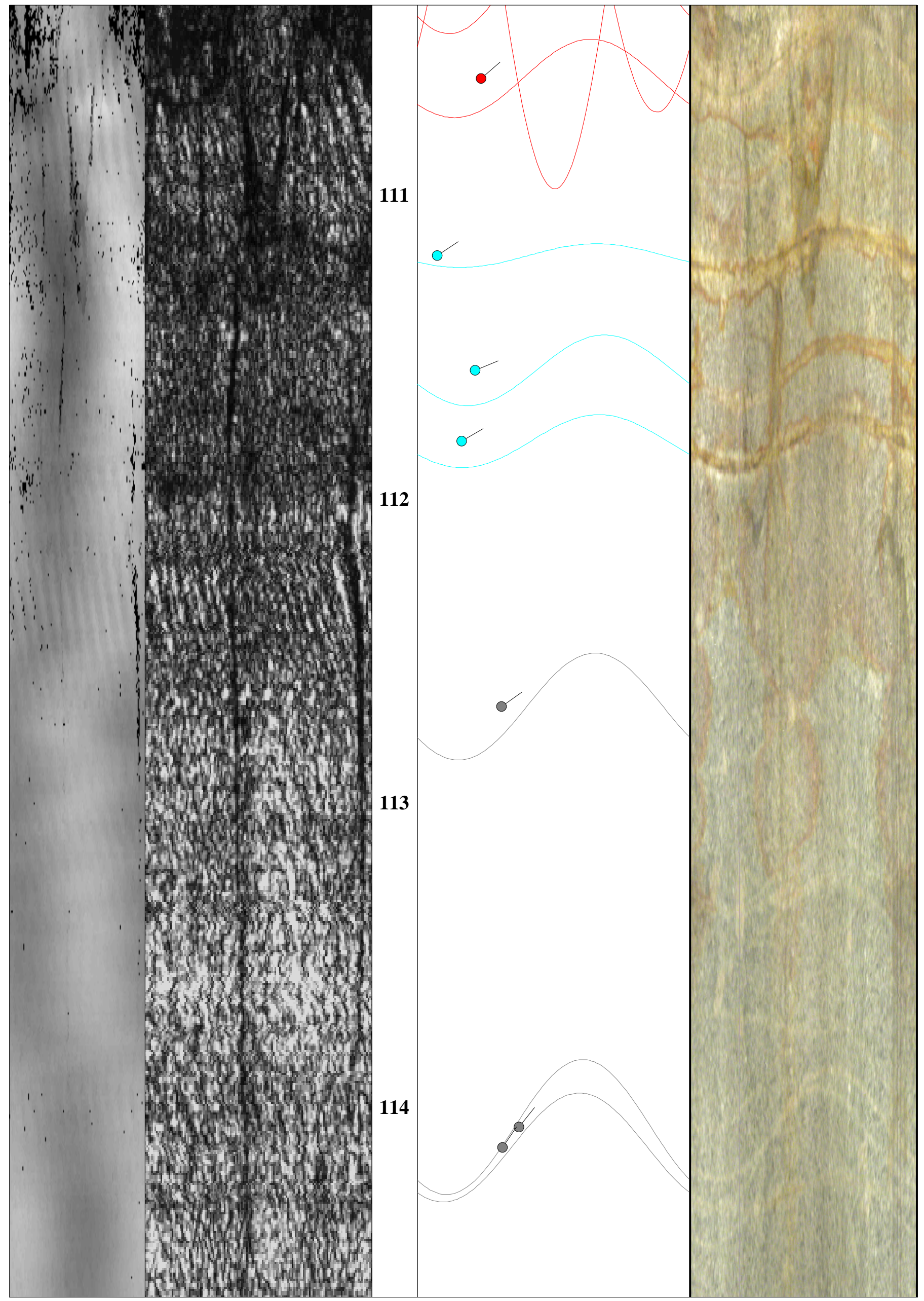




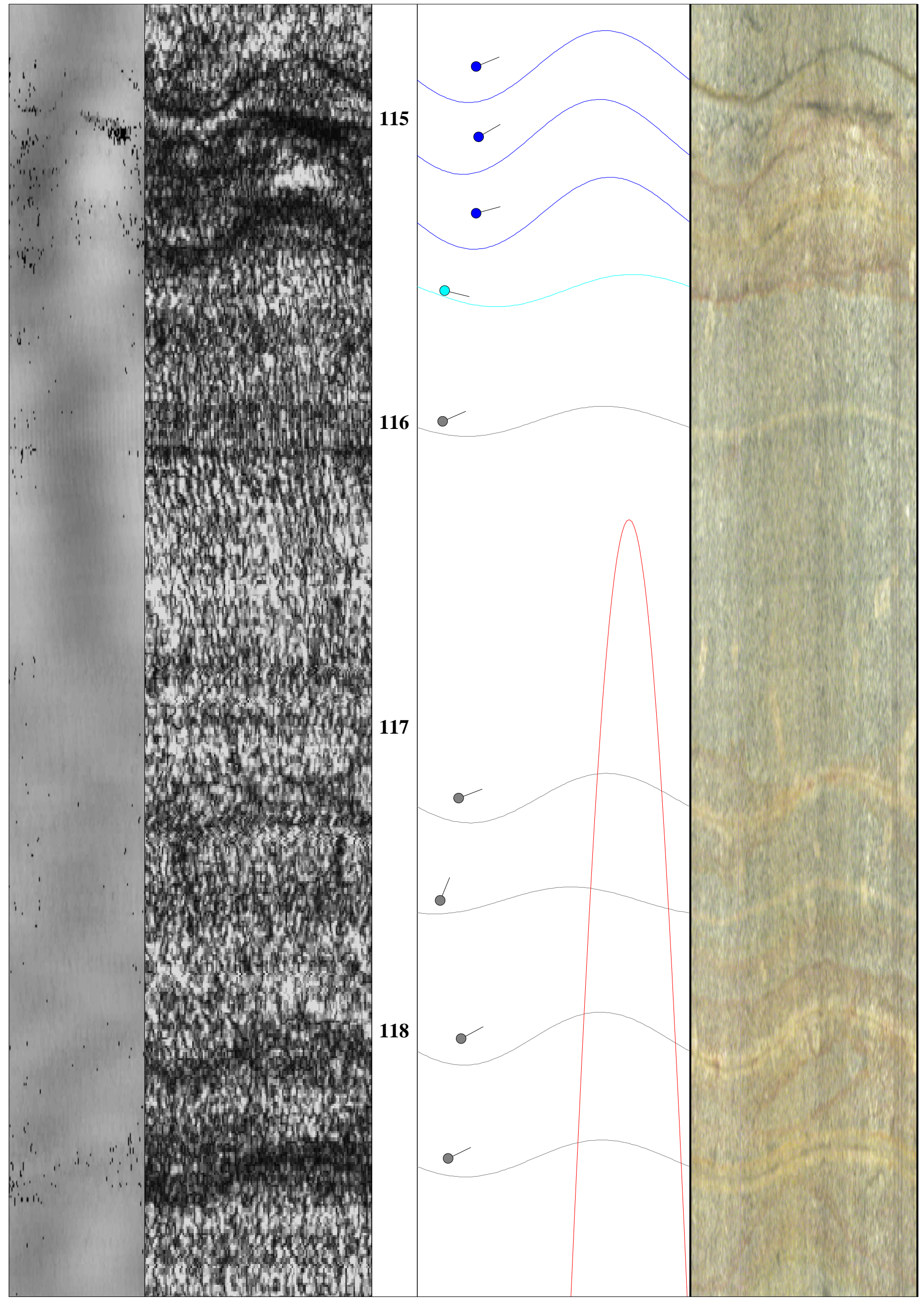




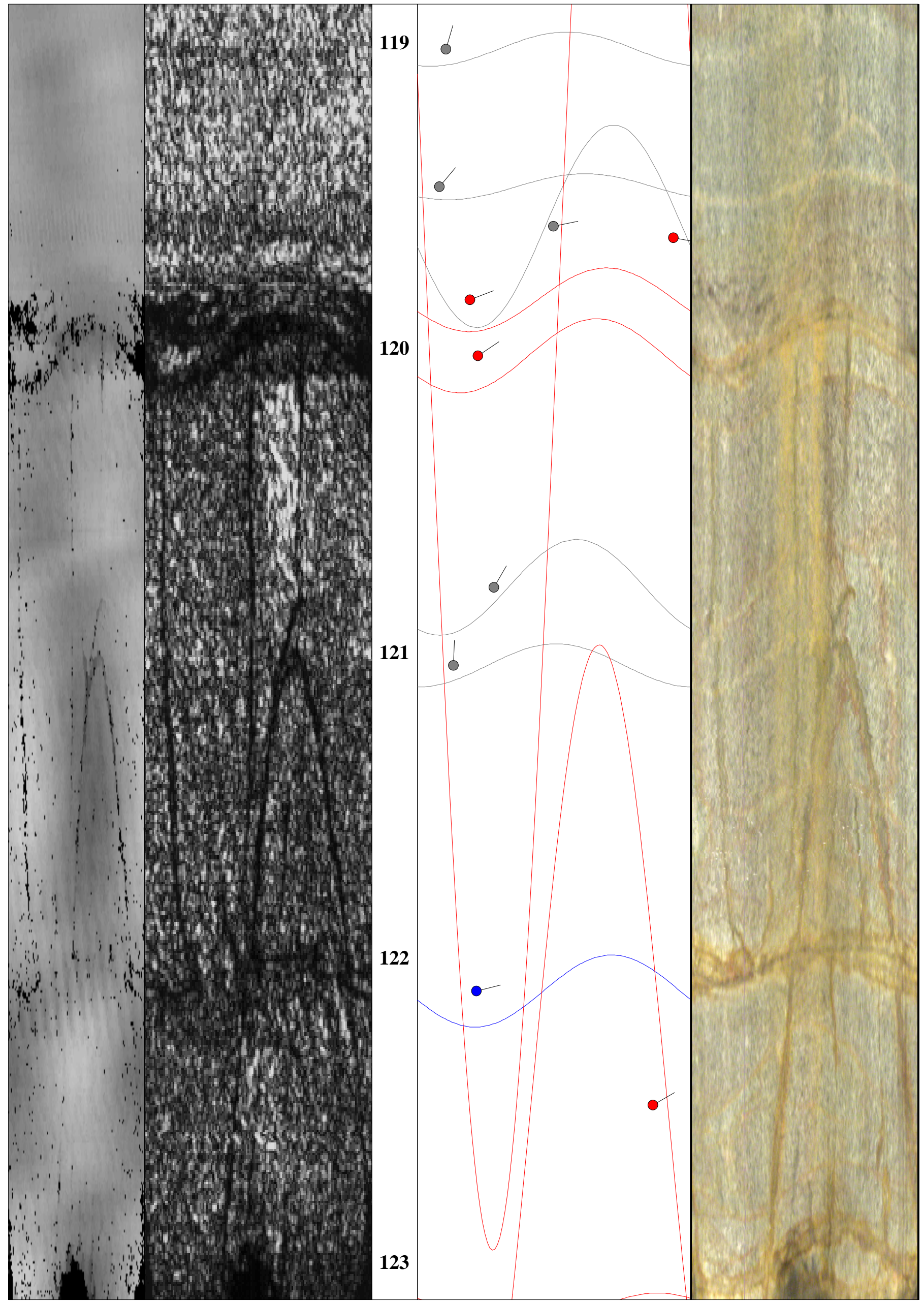




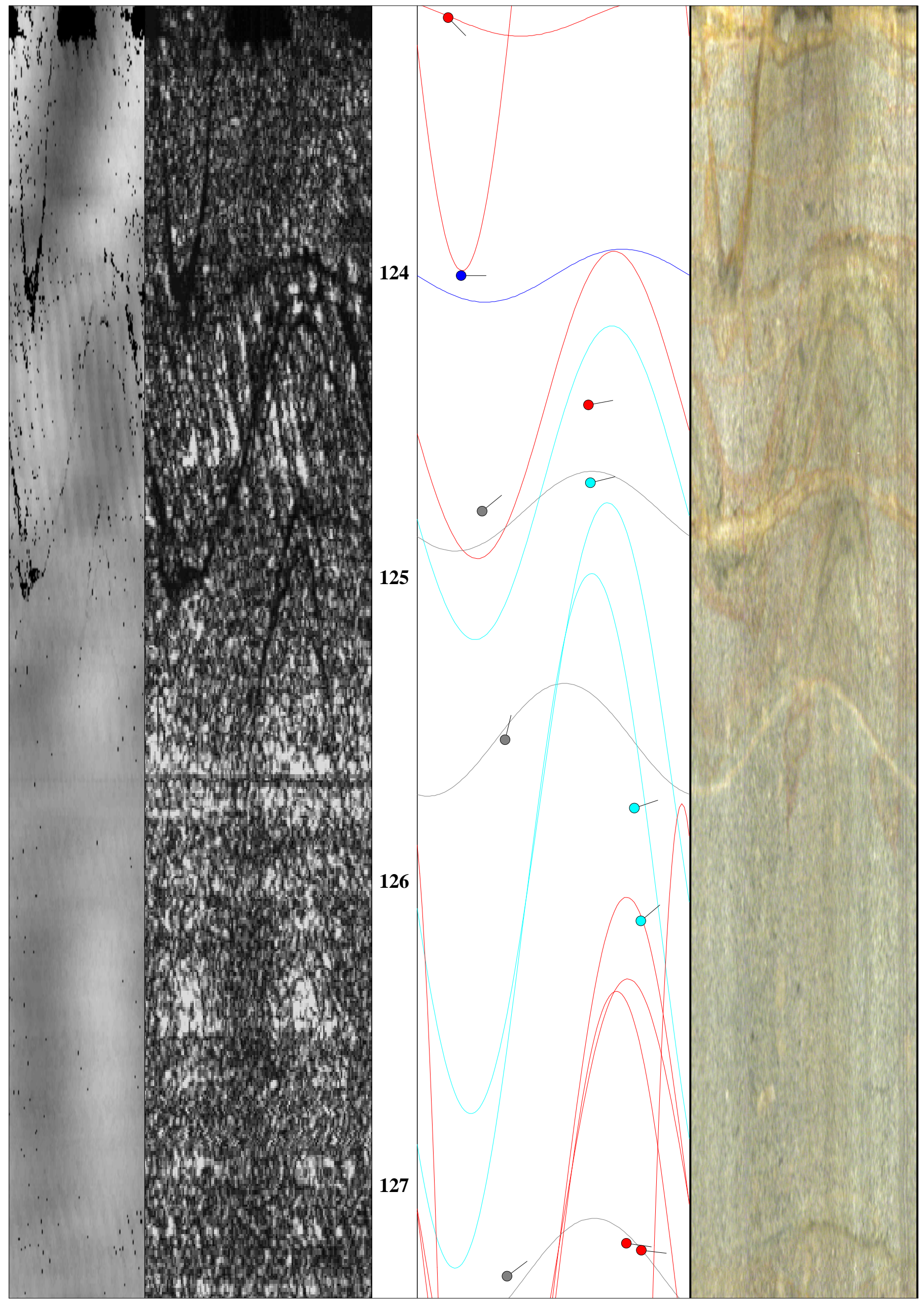




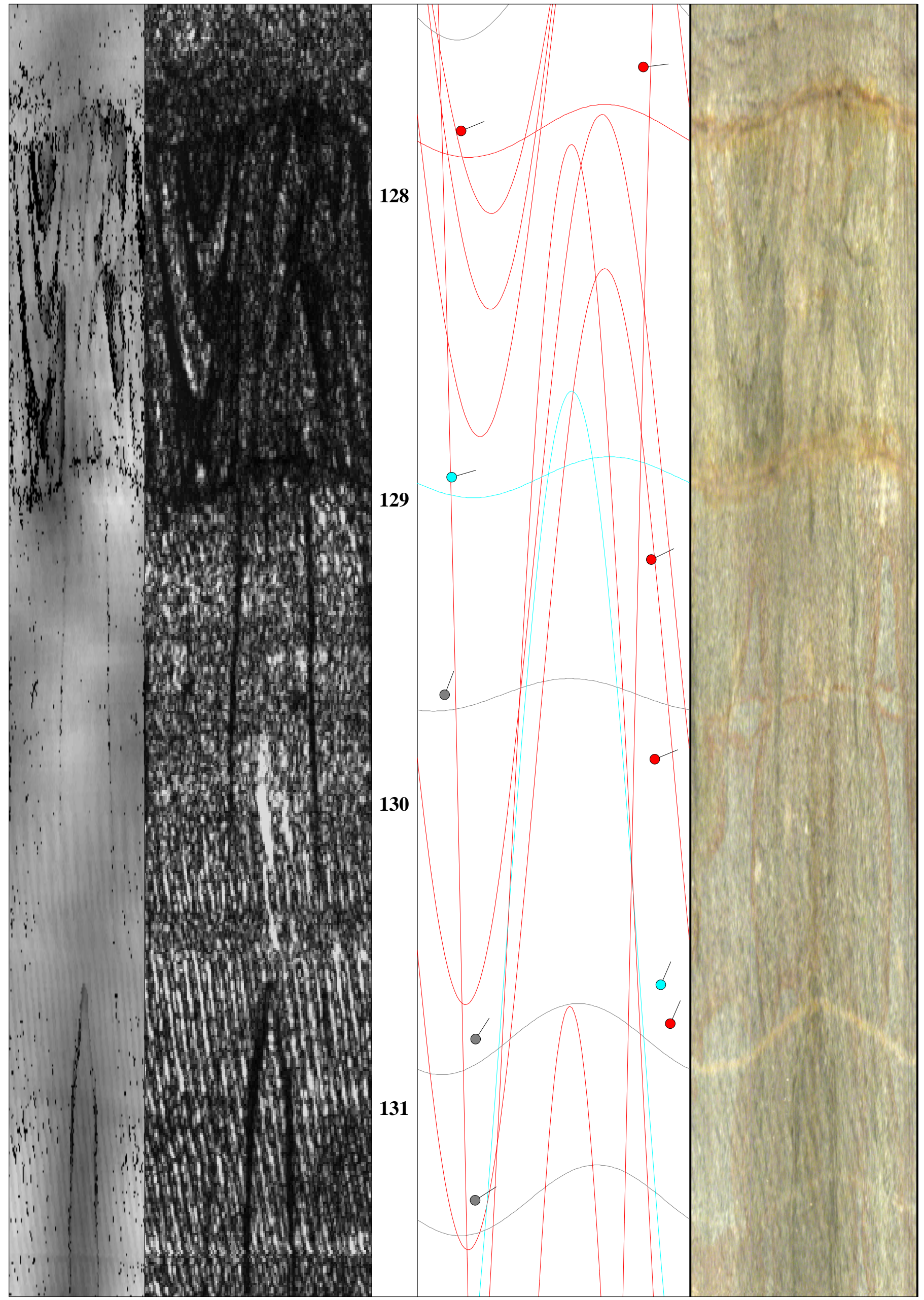




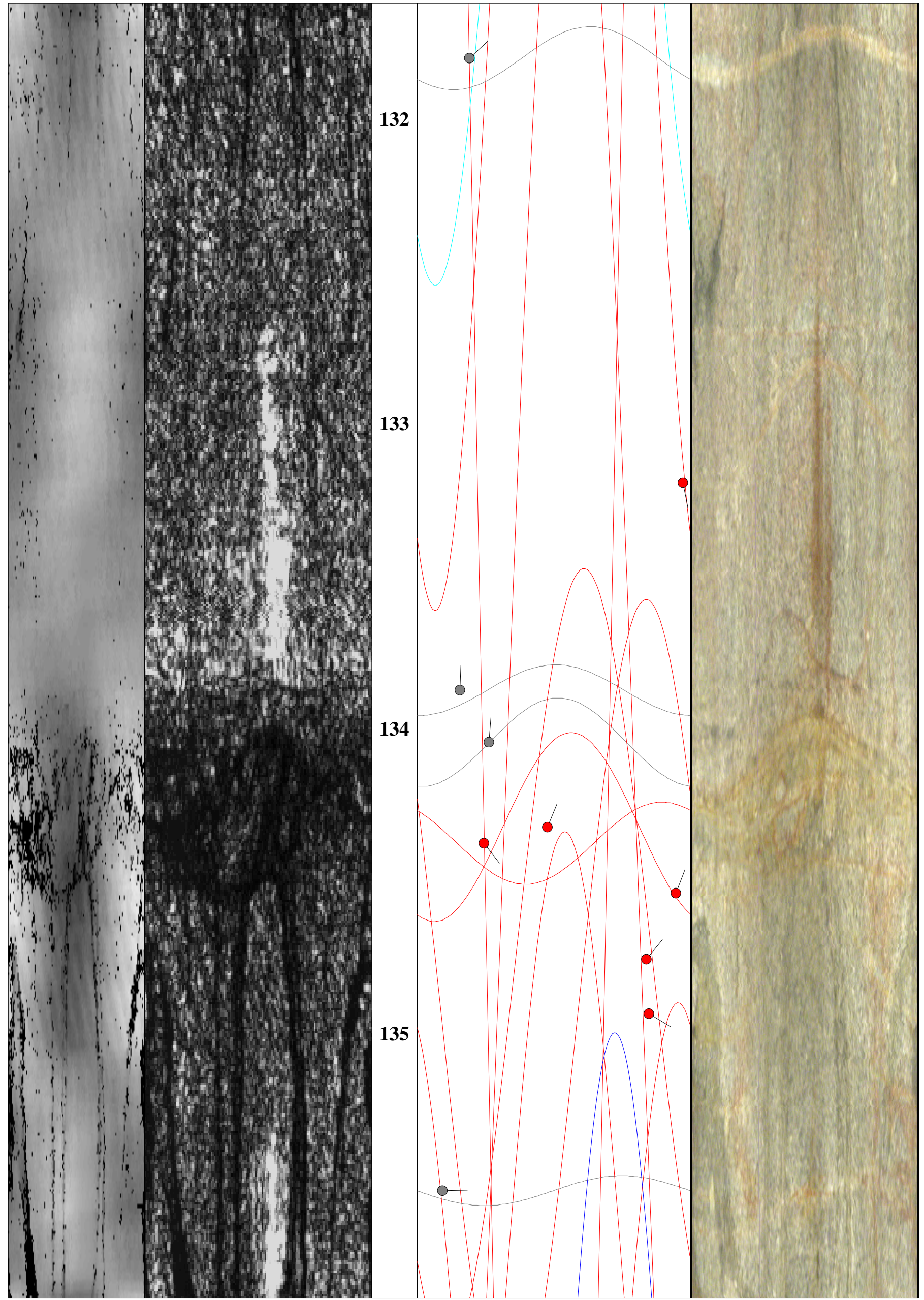




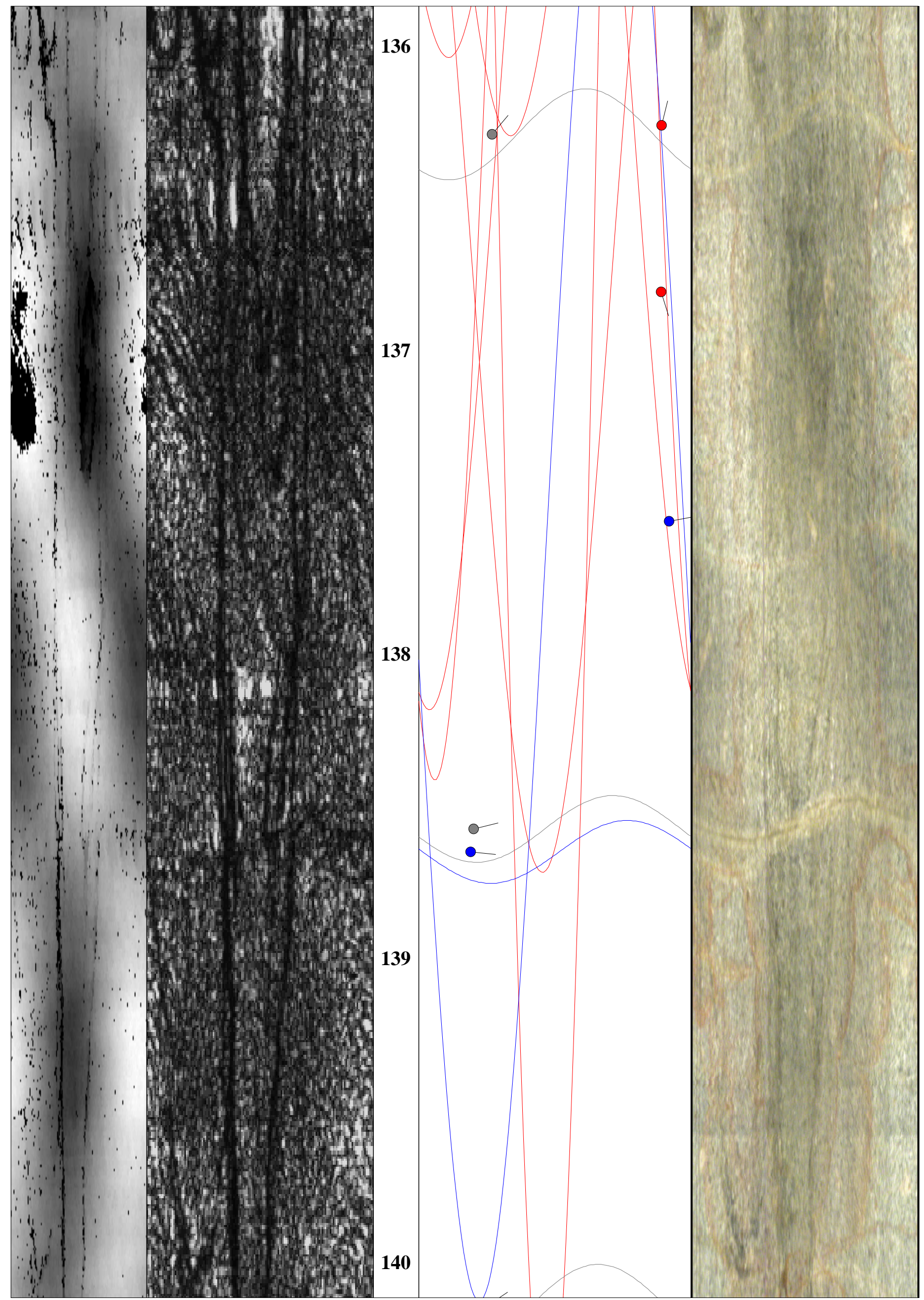




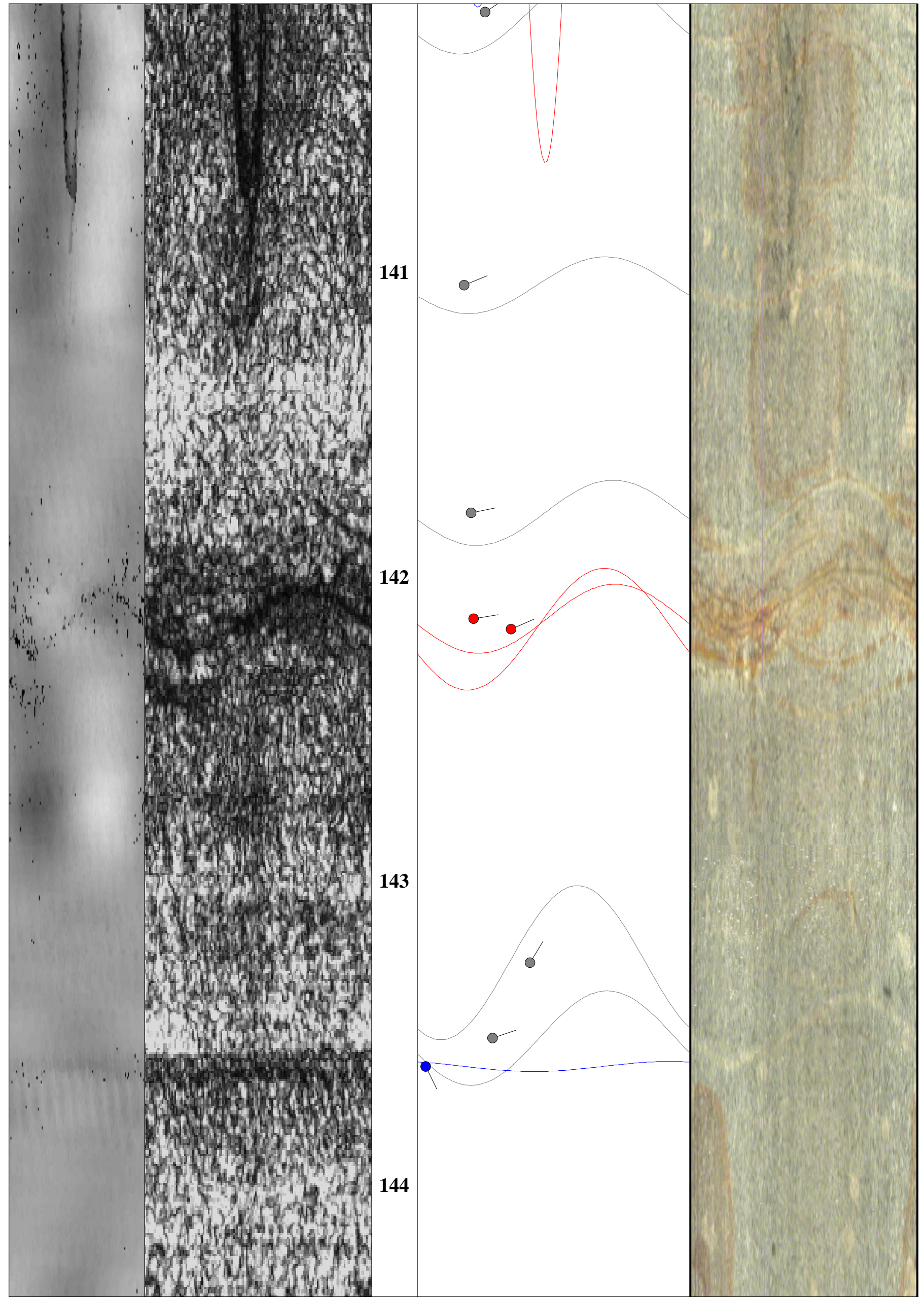




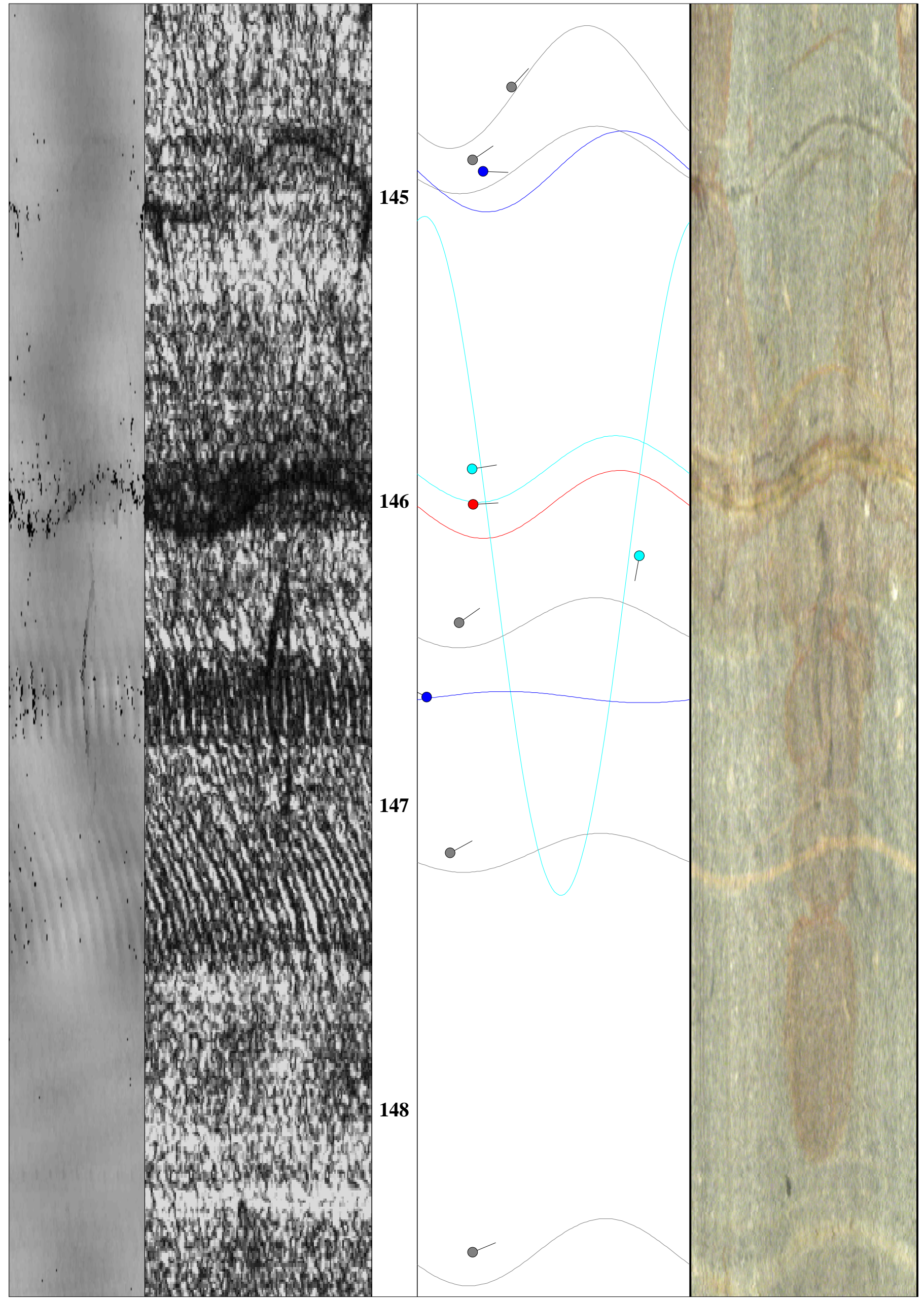




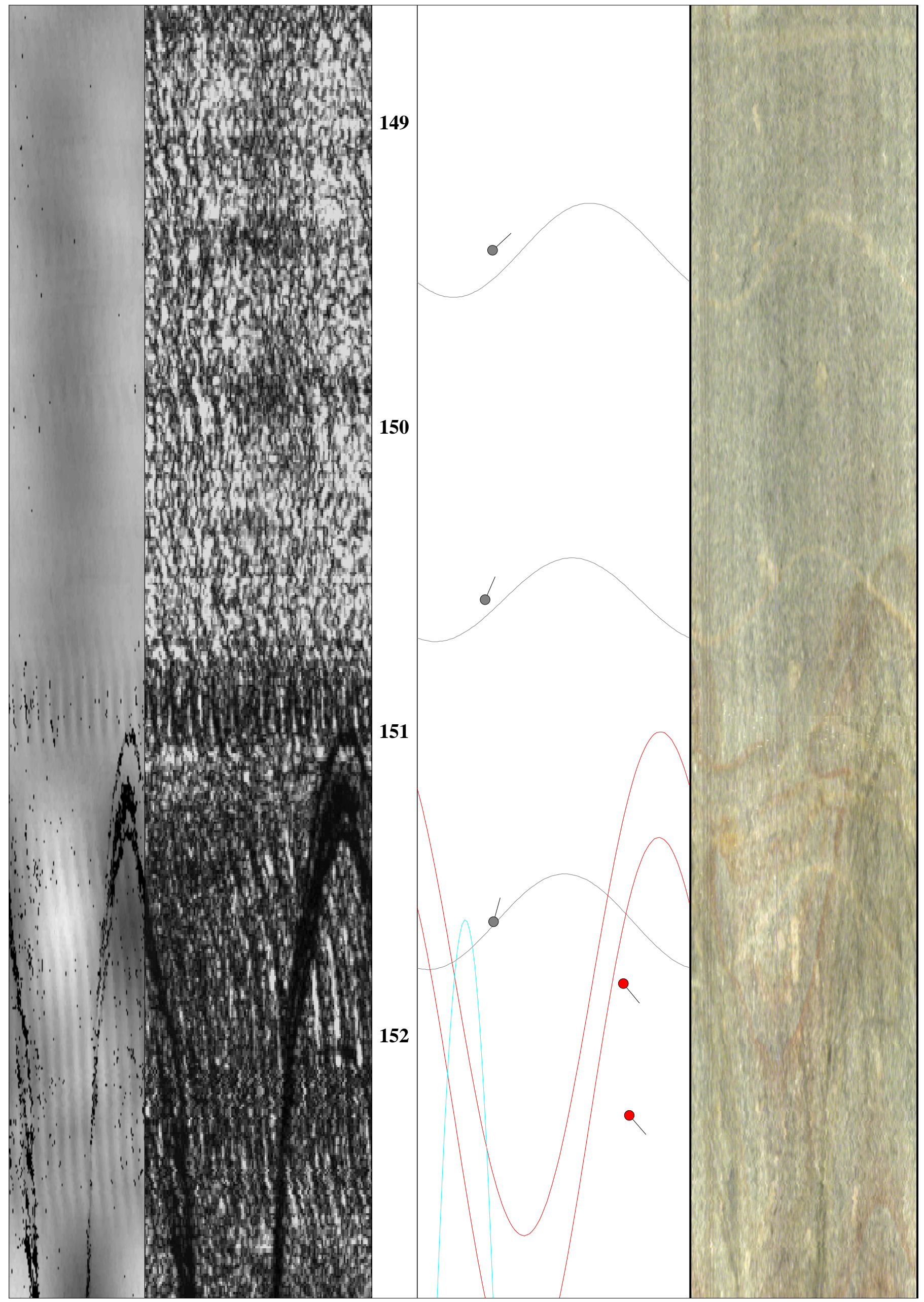




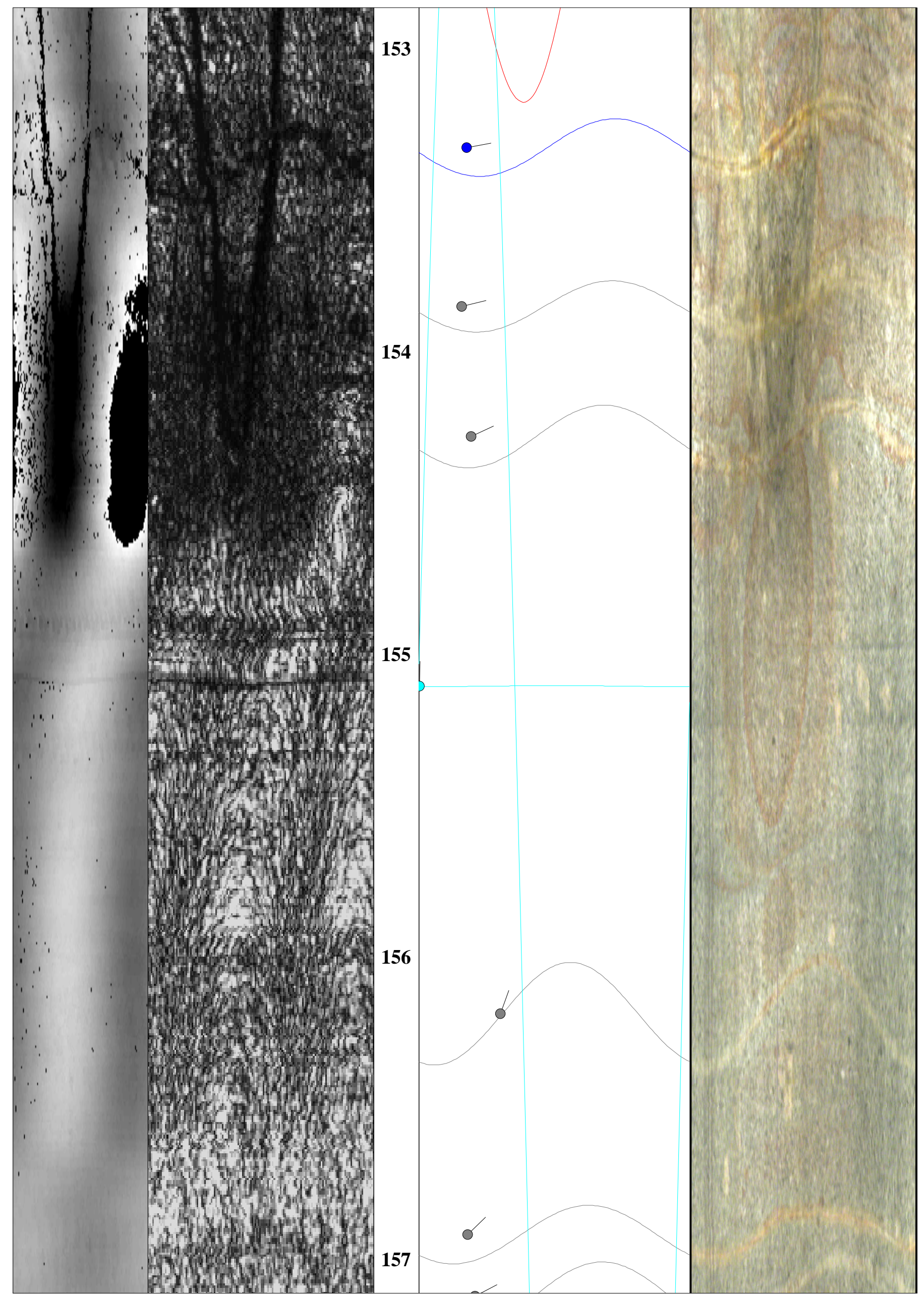




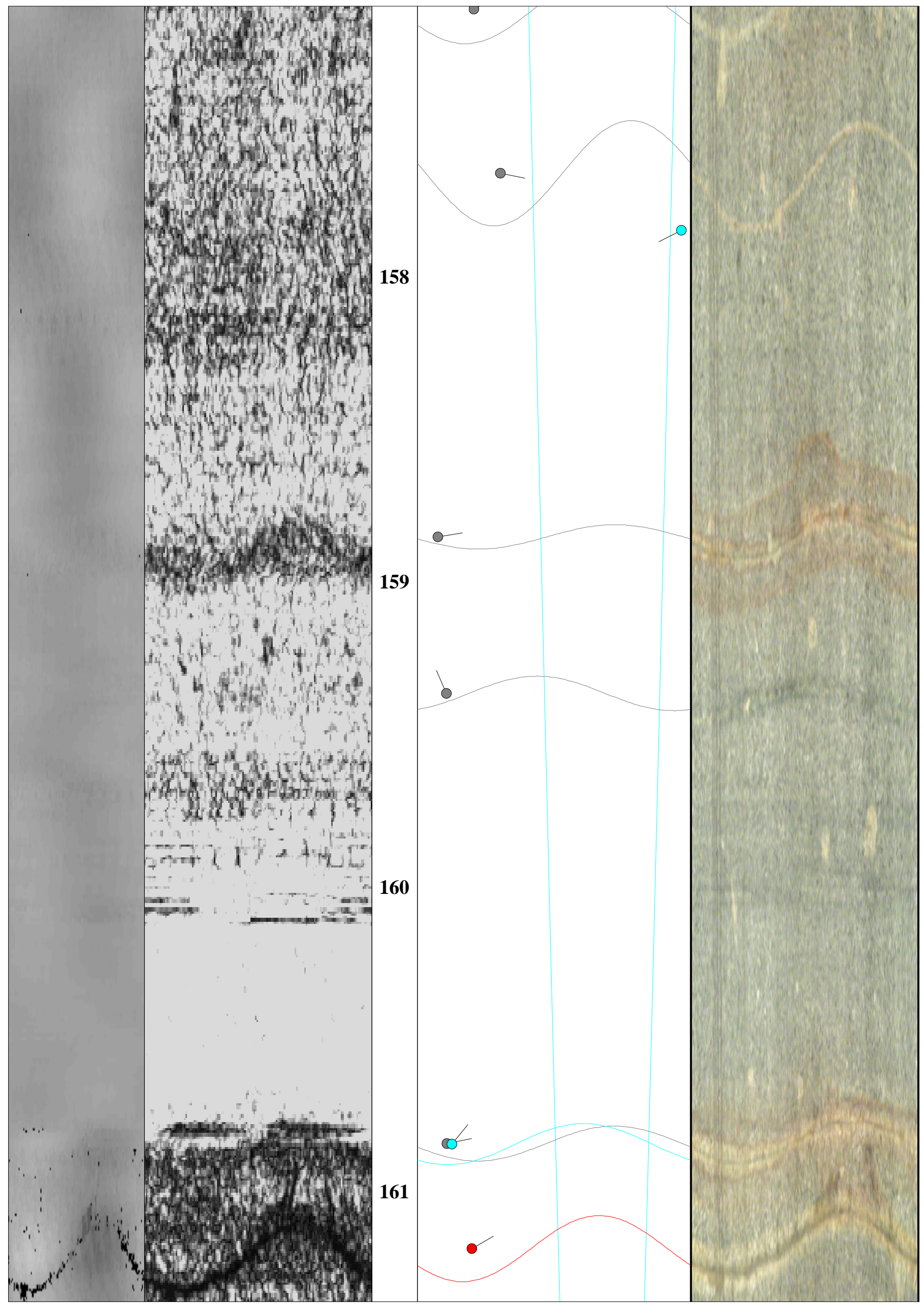




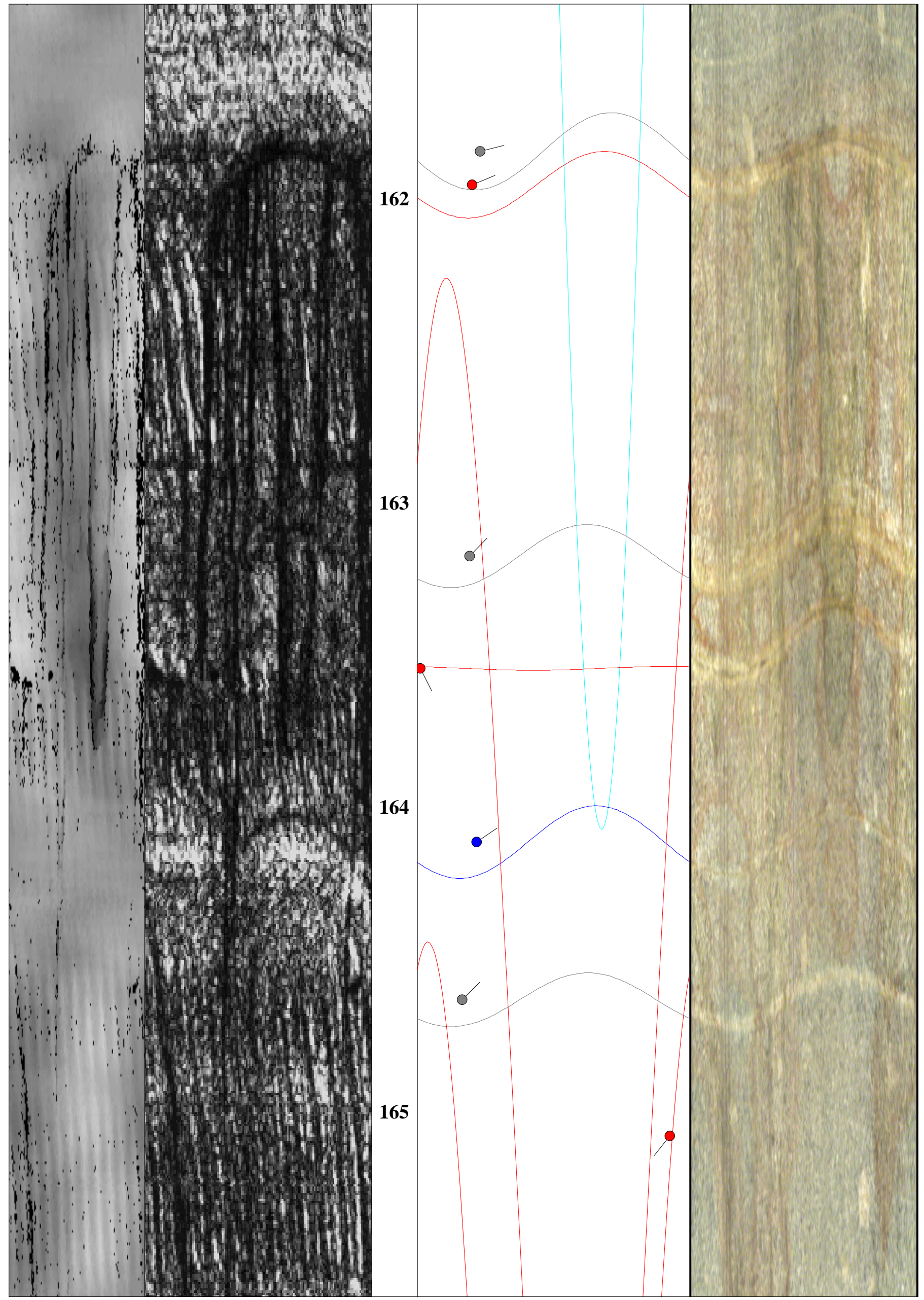




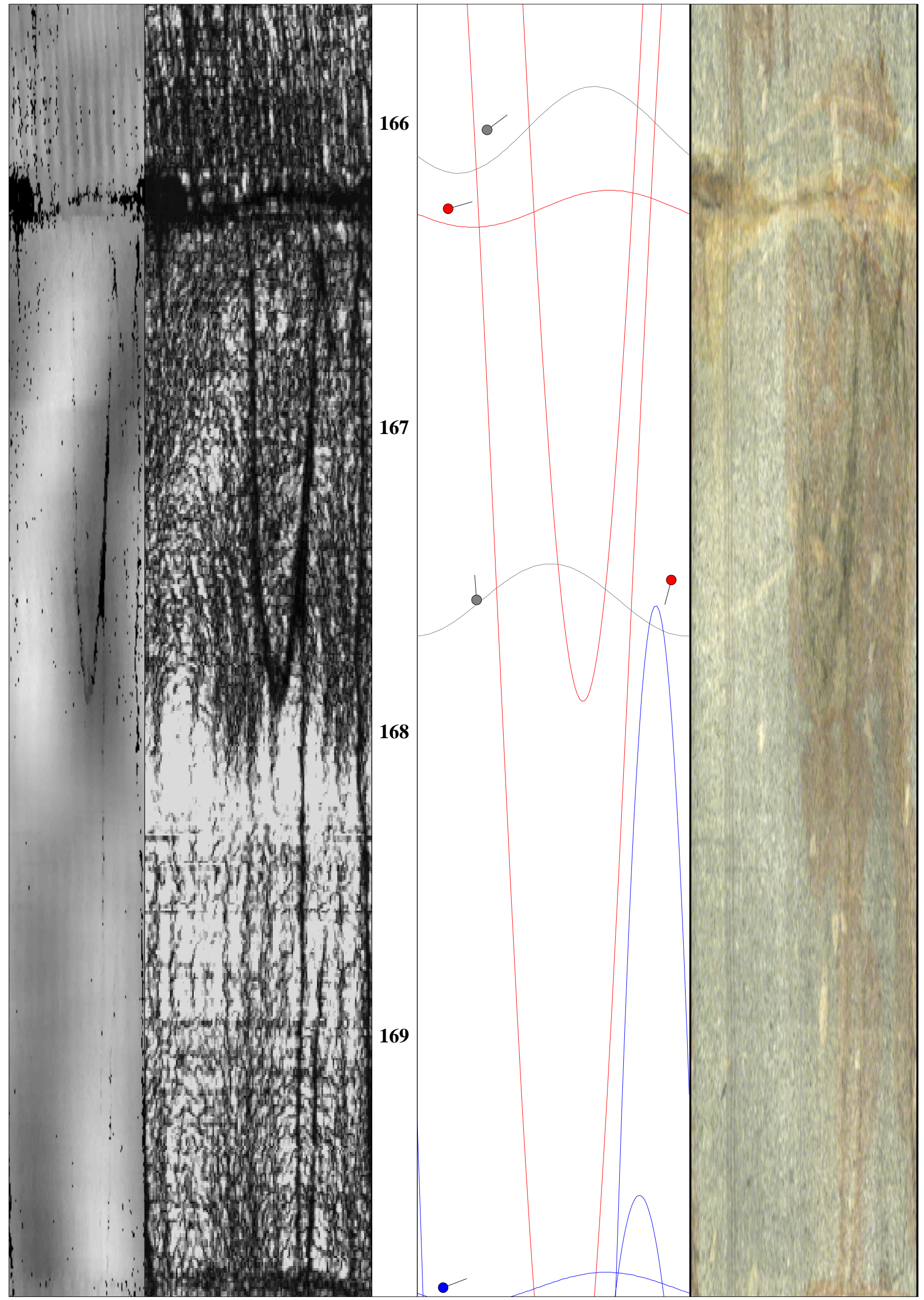




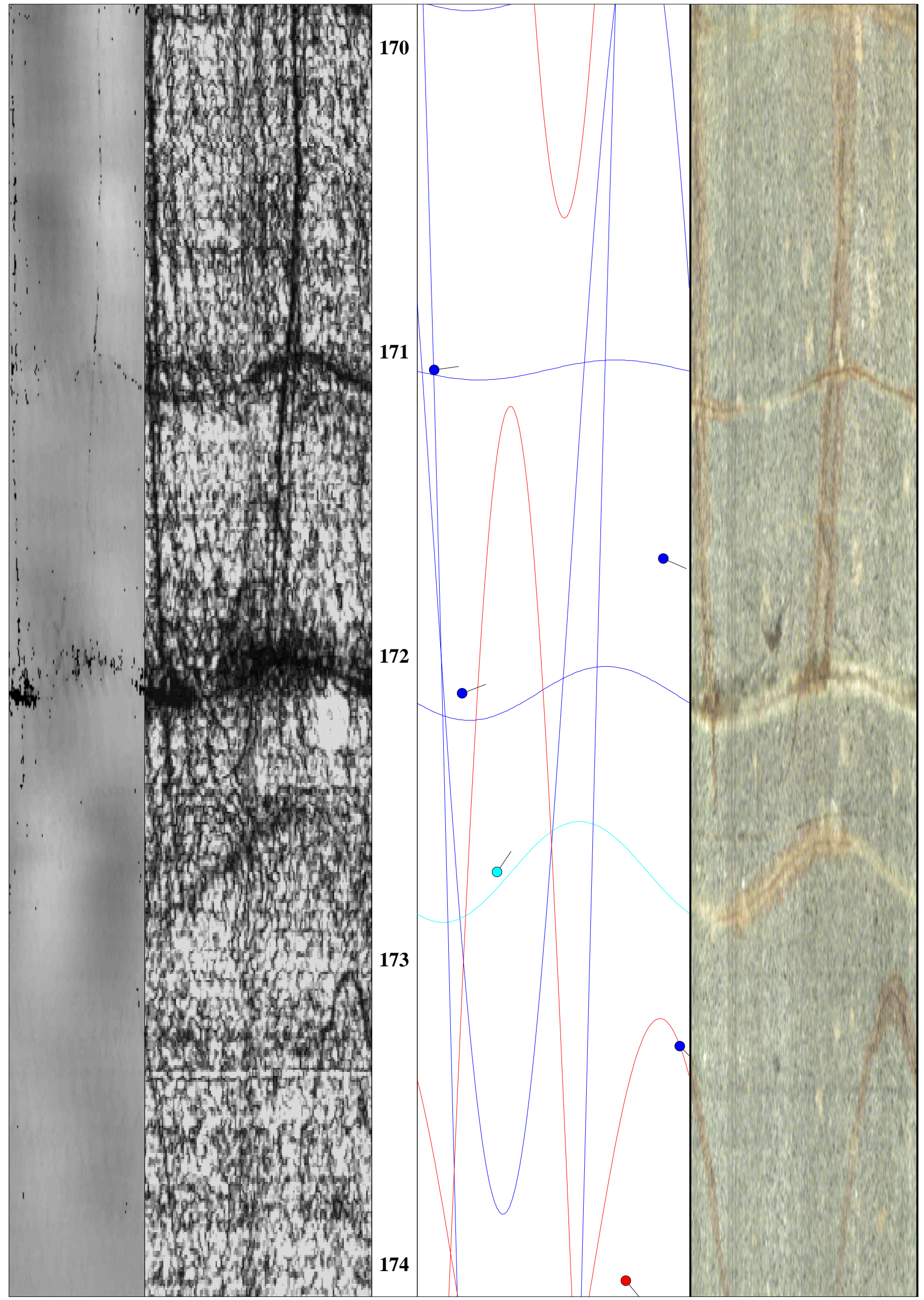




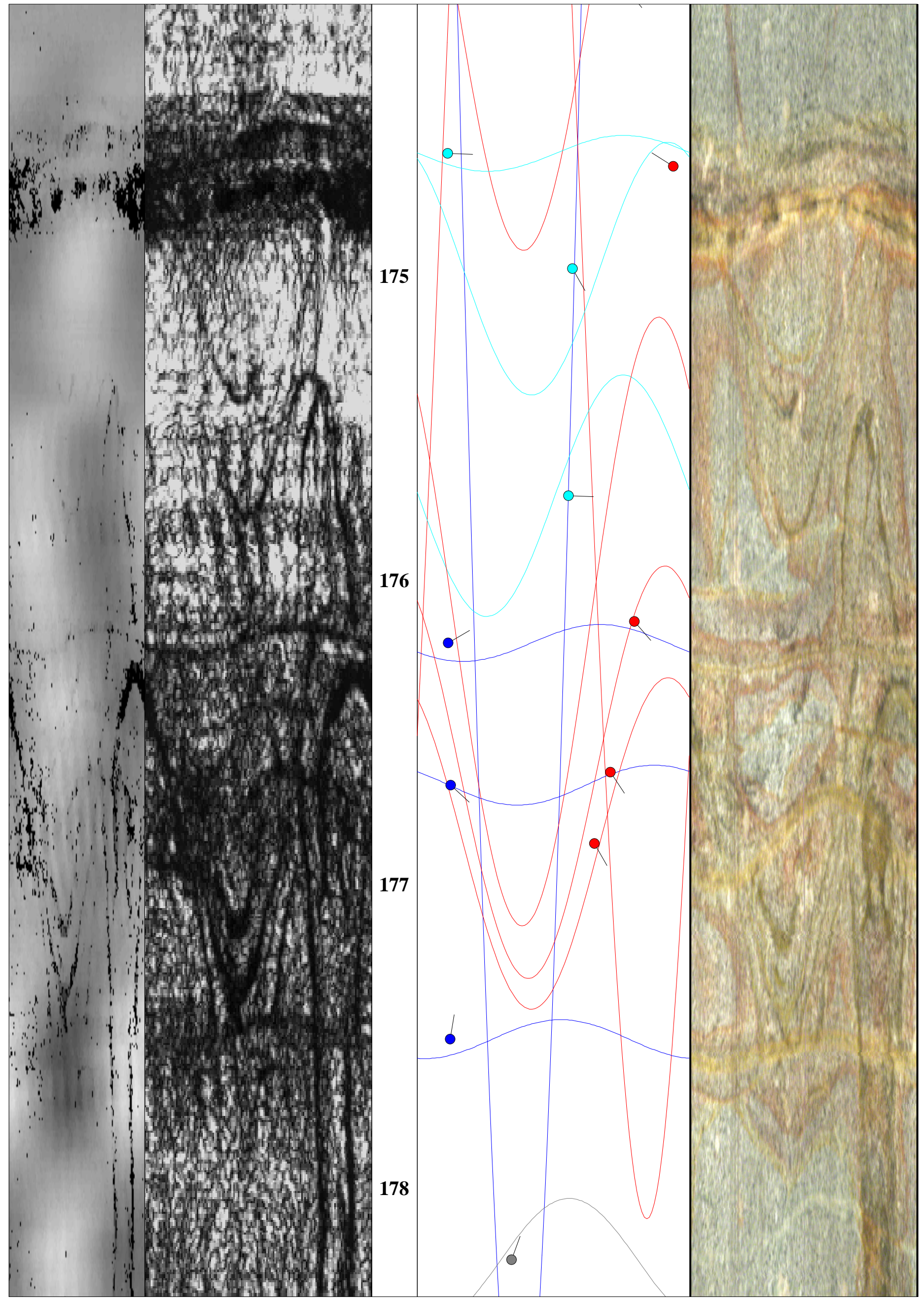




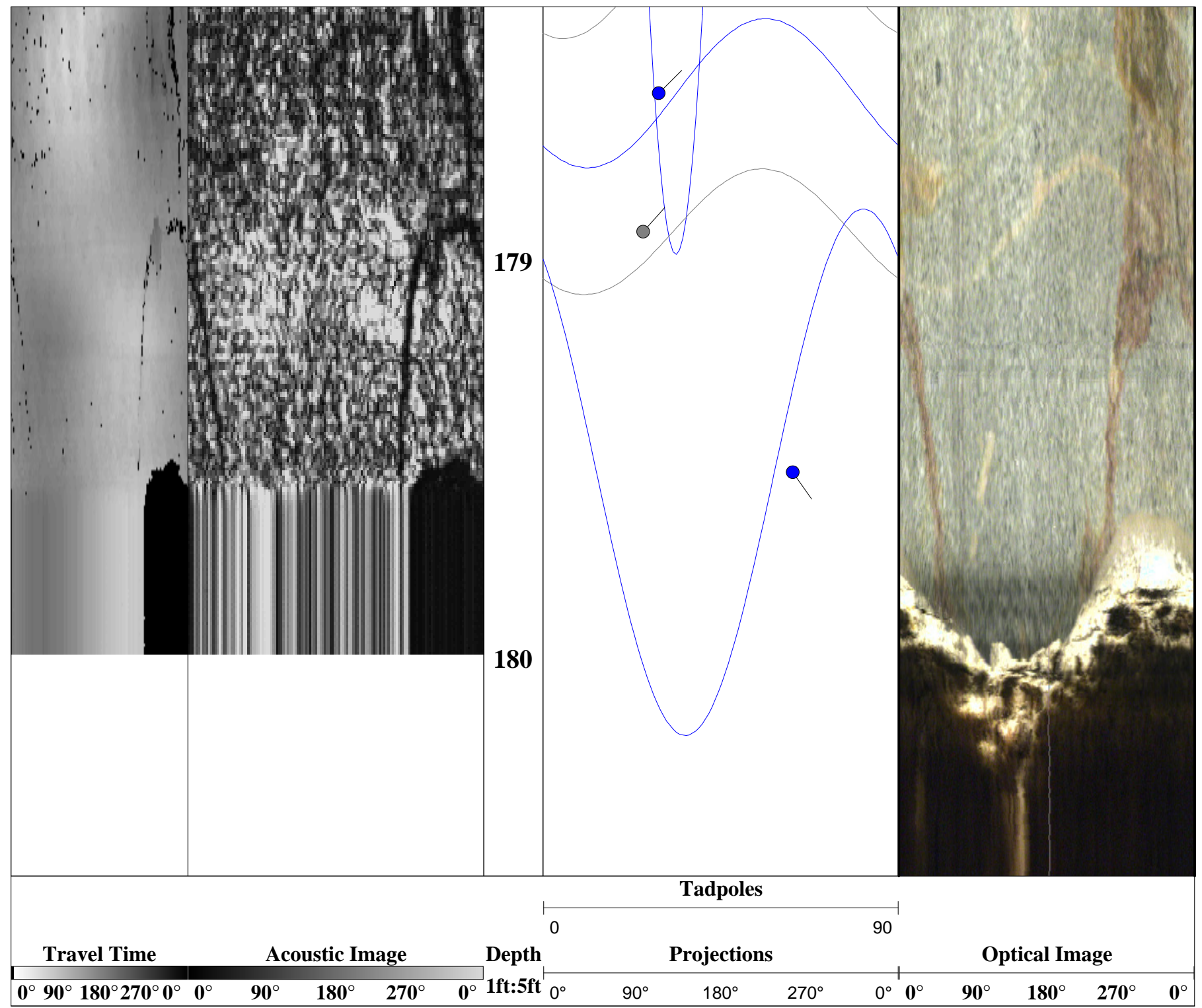




\section{Stereonet Diagram - Schmidt Projection}

Acoustic Televiewer Features

Nevada Test Site

Source Physics Experiment

U-15n3

NNSA/NSO

$21 \& 22$ Sept 2010

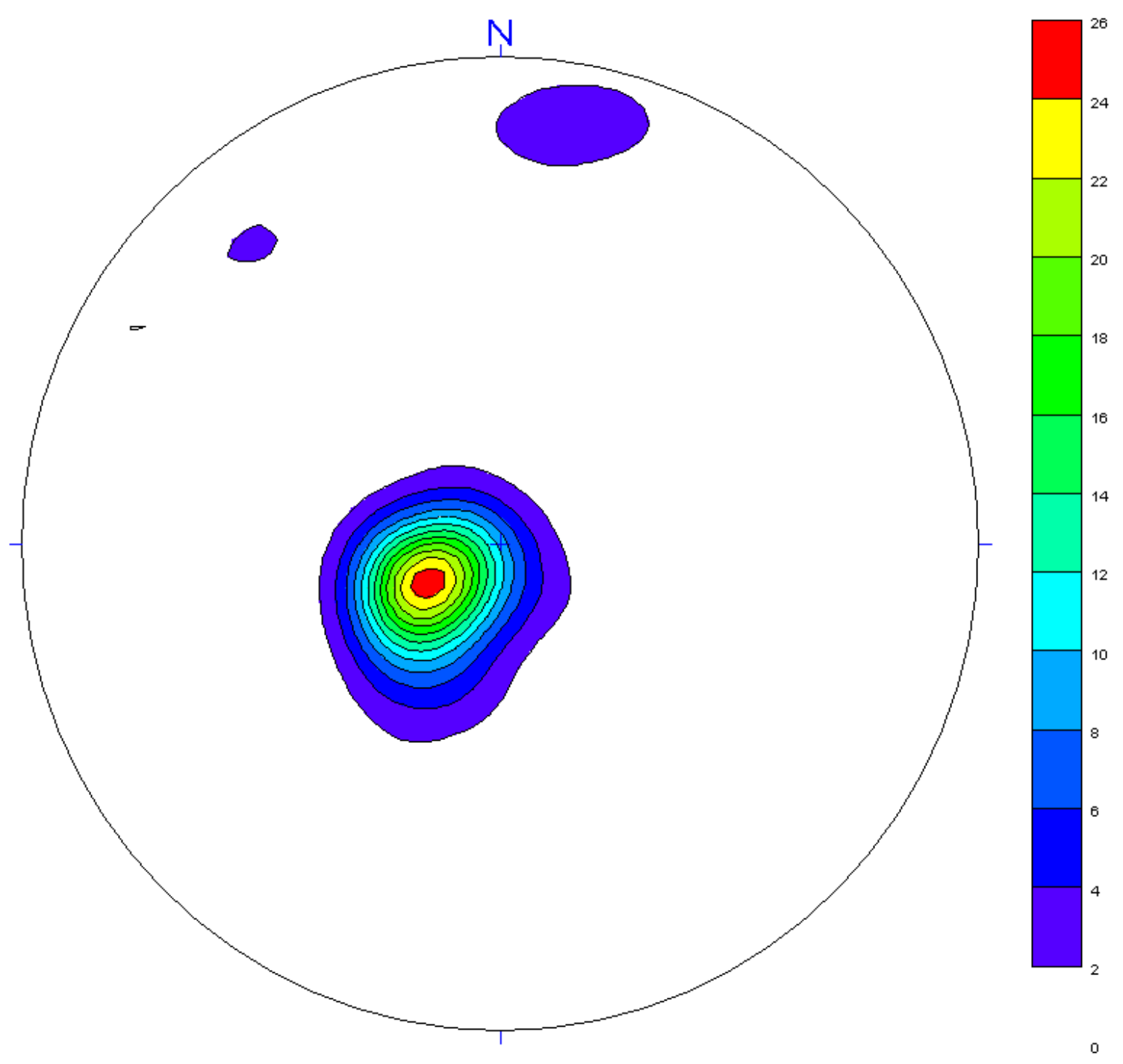

All directions are with respect to True North. 


\section{Stereonet Diagram - Schmidt Projection \\ Acoustic Televiewer Features \\ Nevada Test Site \\ Source Physics Experiment \\ U-15n3 \\ NNSA/NSO \\ $21 \& 22$ Sept 2010}

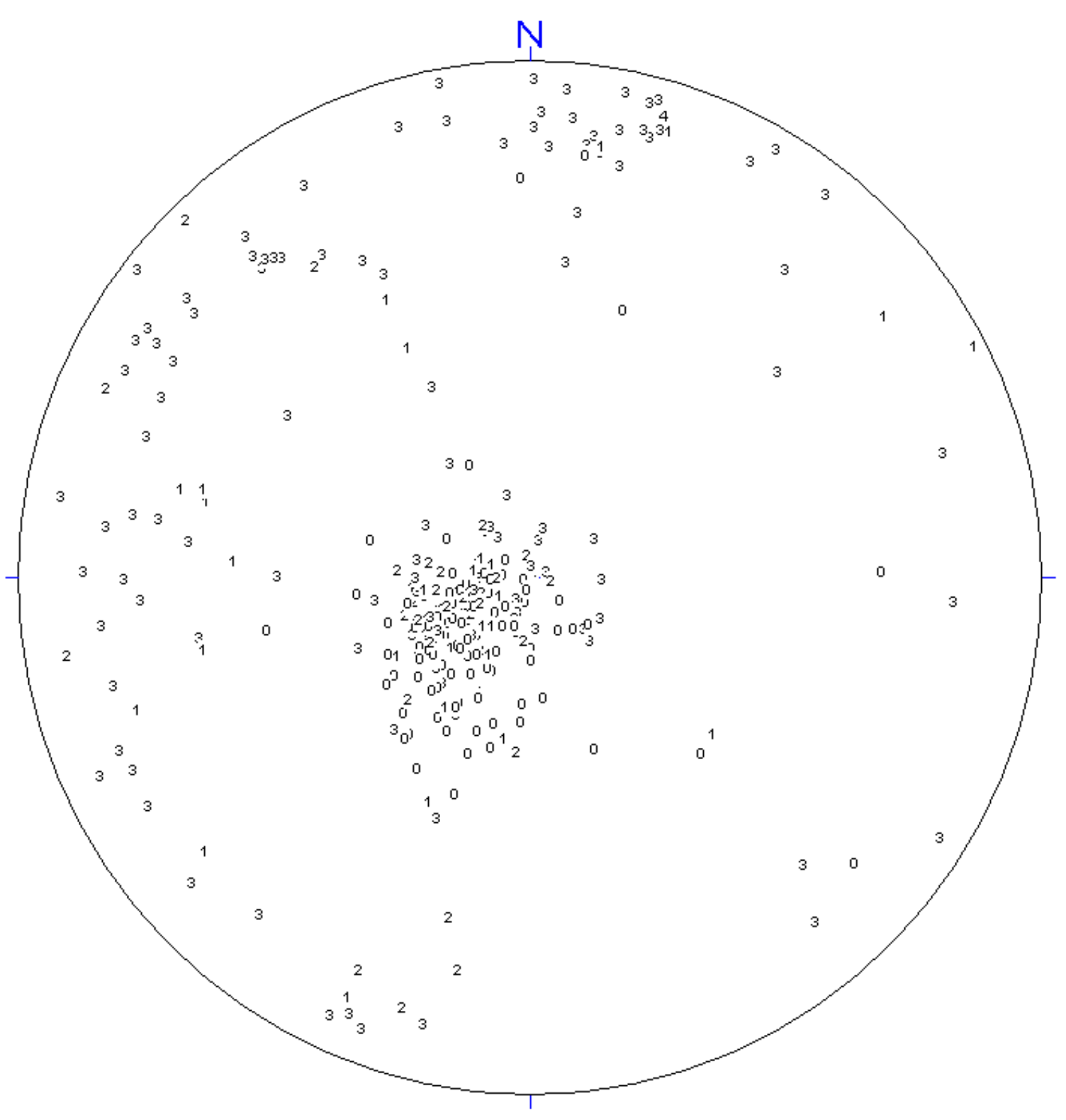

All directions are with respect to True North. 


\section{Rose Diagram - Dip Directions \\ Acoustic Televiewer Features \\ Nevada Test Site \\ Source Physics Experiment \\ U-15n3 \\ NNSA/NSO \\ $21 \& 22$ Sept 2010}

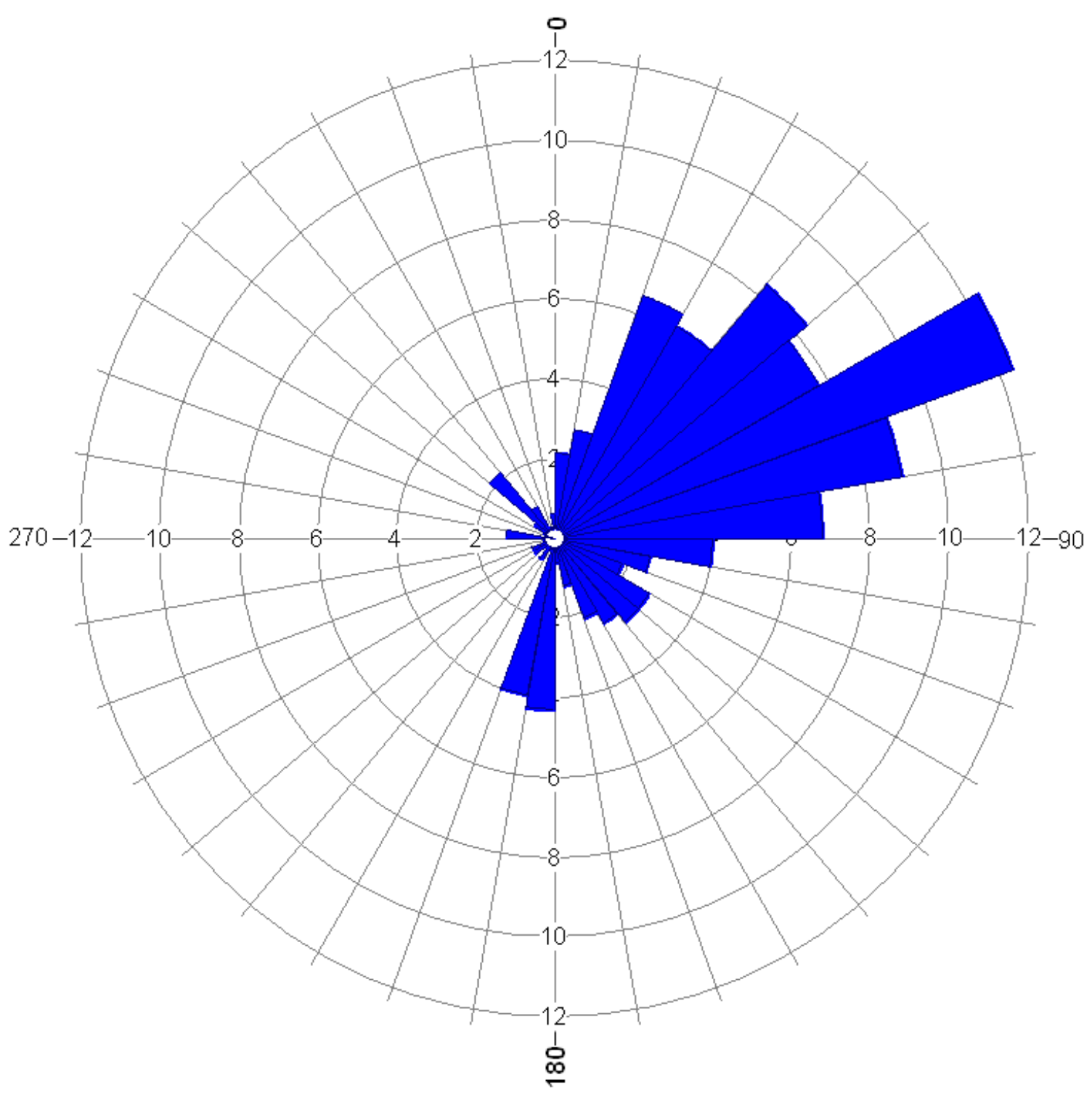

All directions are with respect to True North. 


\section{Rose Diagram - Dip Angles \\ Acoustic Televiewer Features \\ Nevada Test Site \\ Source Physics Experiment \\ U-15n3 \\ NNSA/NSO \\ $21 \& 22$ Sept 2010}

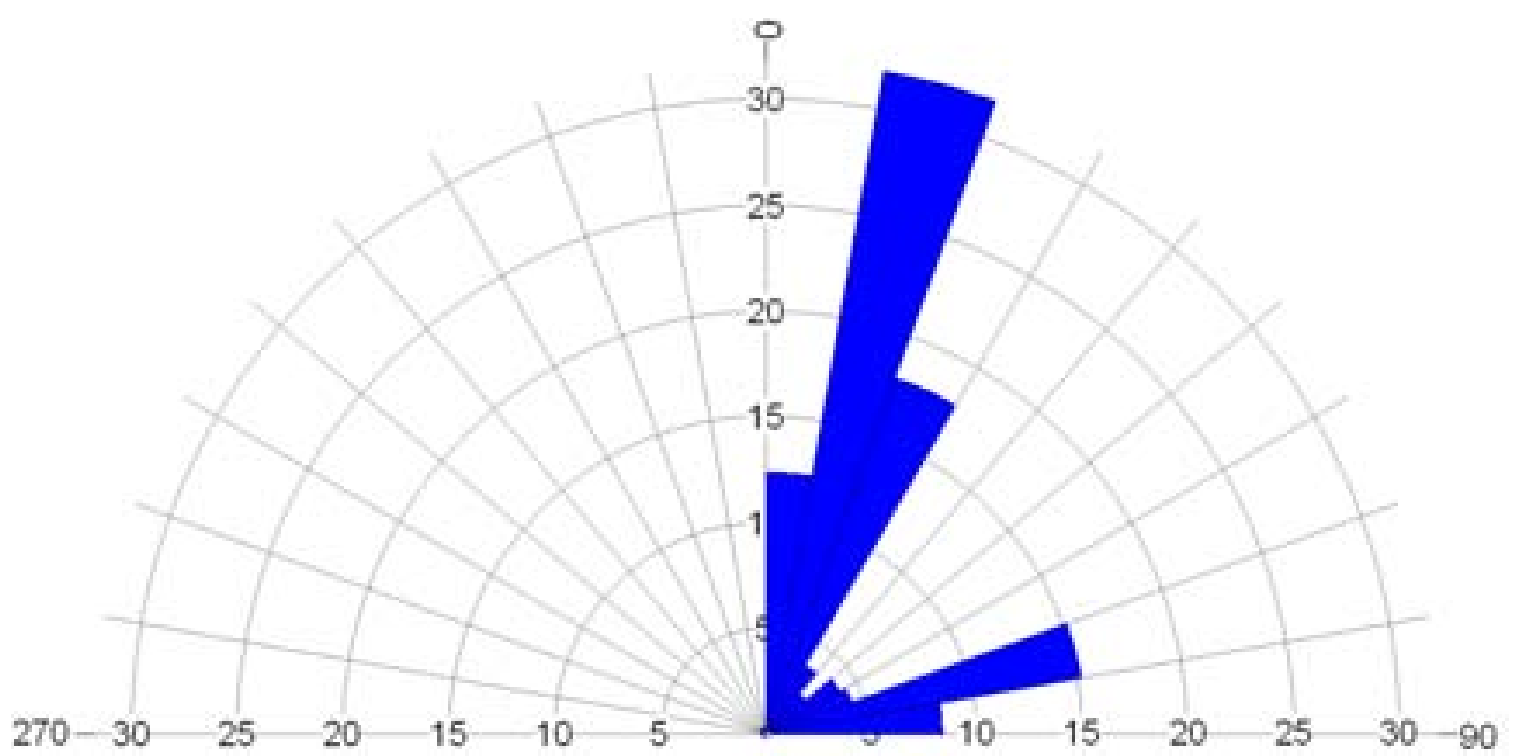

All directions are with respect to True North. 


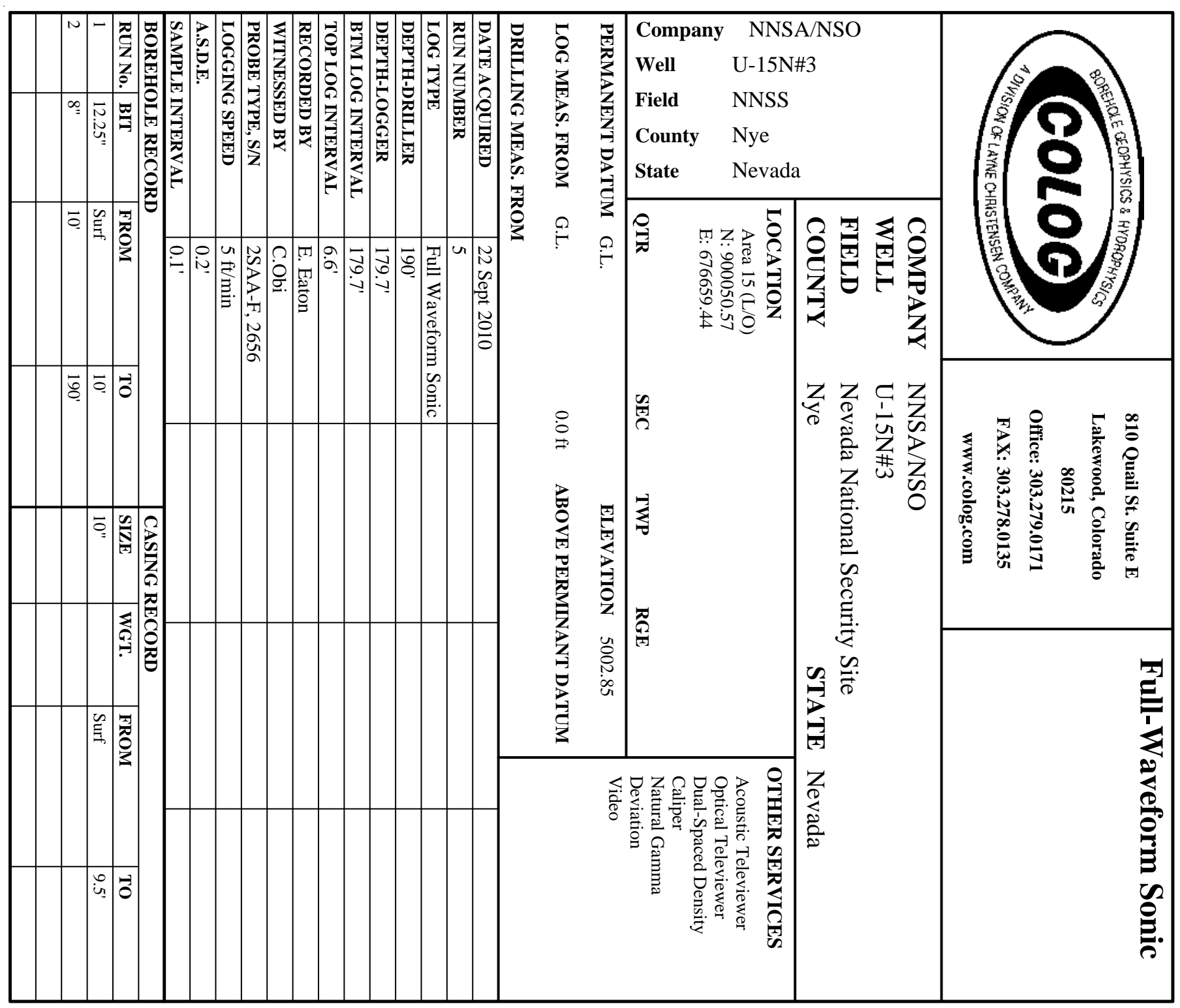

COMMENTS

NA - Not Available, N/A - Not Applicable 


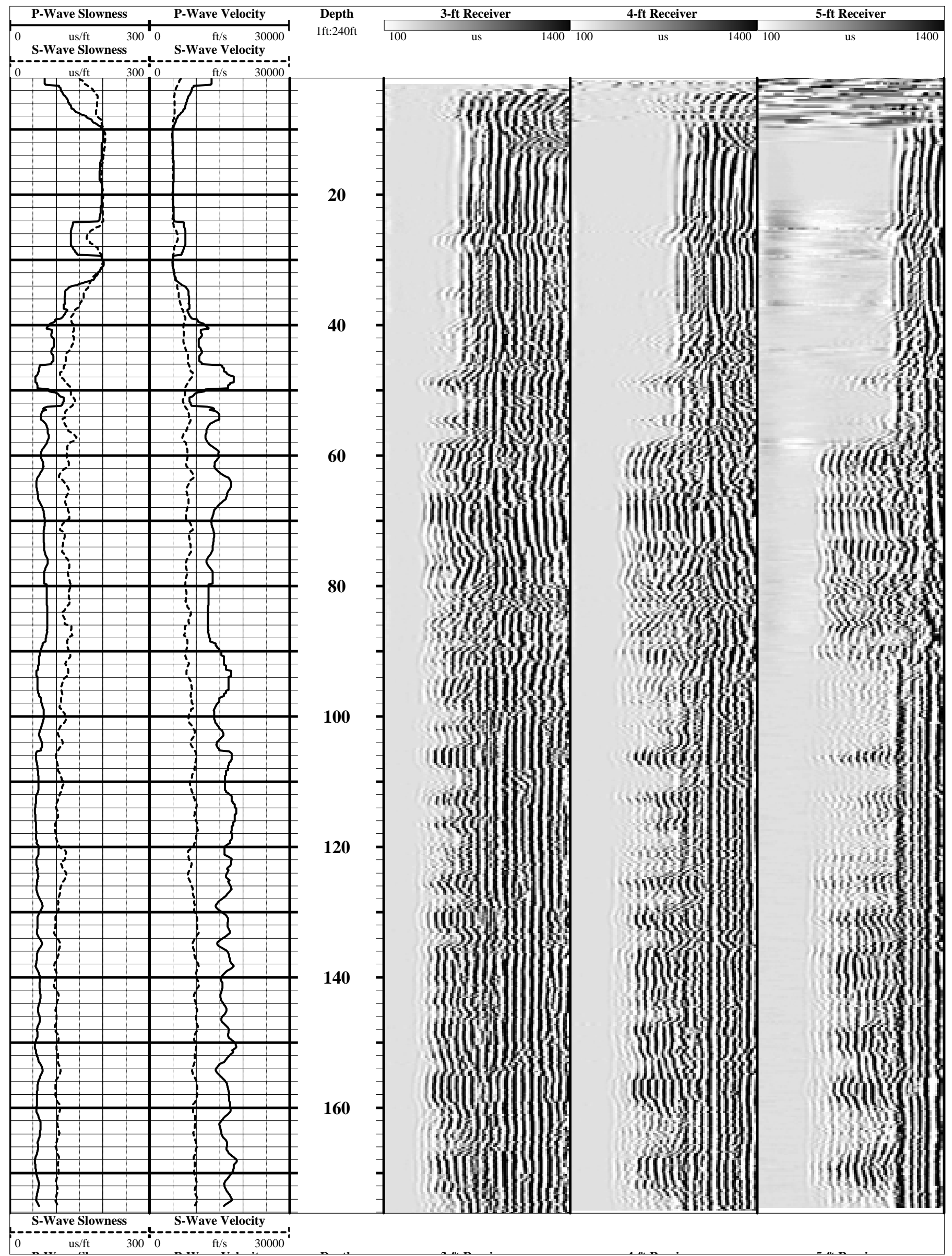




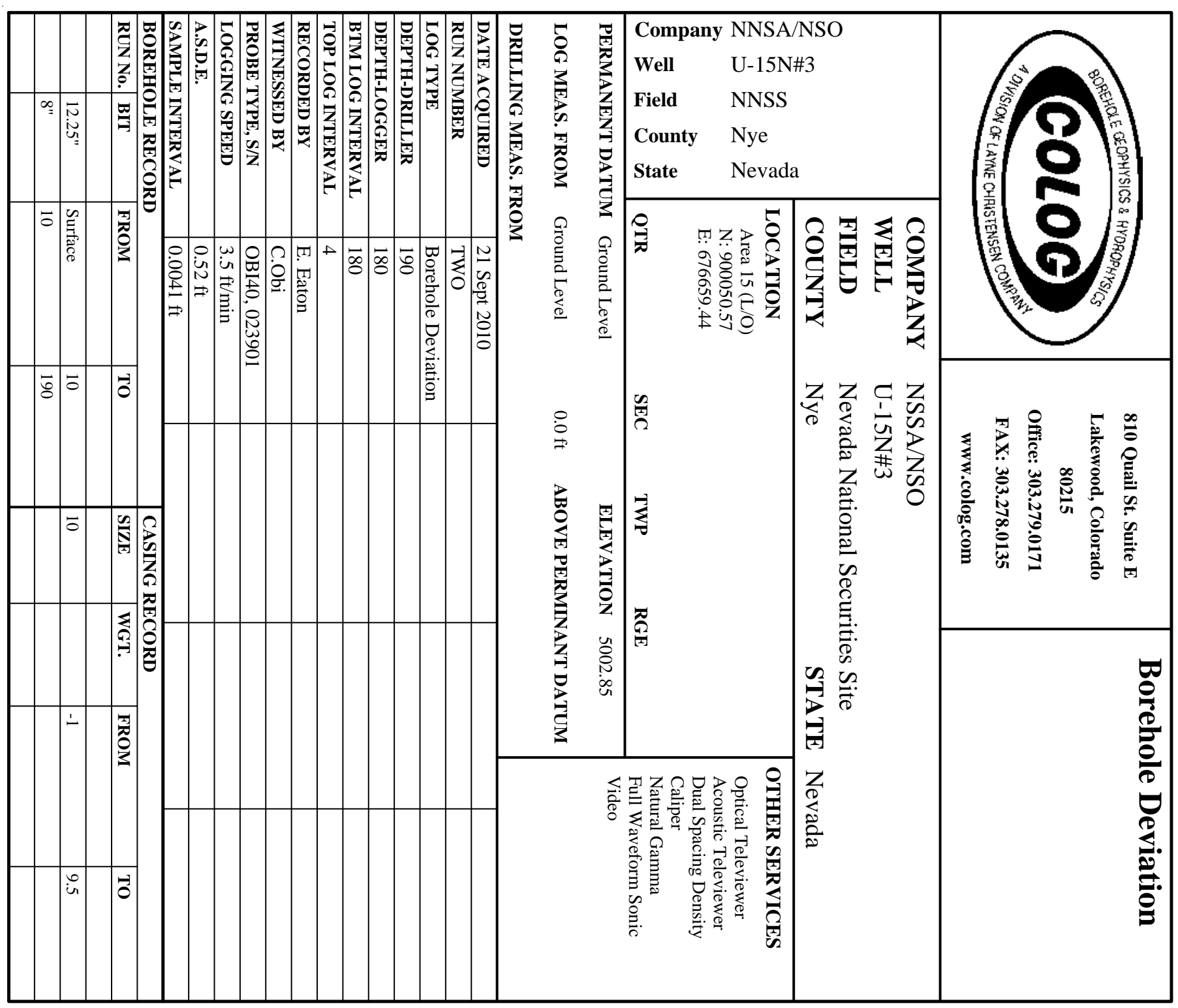

COMMENTS

Could not reach driller's TD, due to fill.

NA - Not Available, N/A - Not Applicable

Magnetic declination of 12.85 degrees East added to correct magnetic azimuth to True North. 

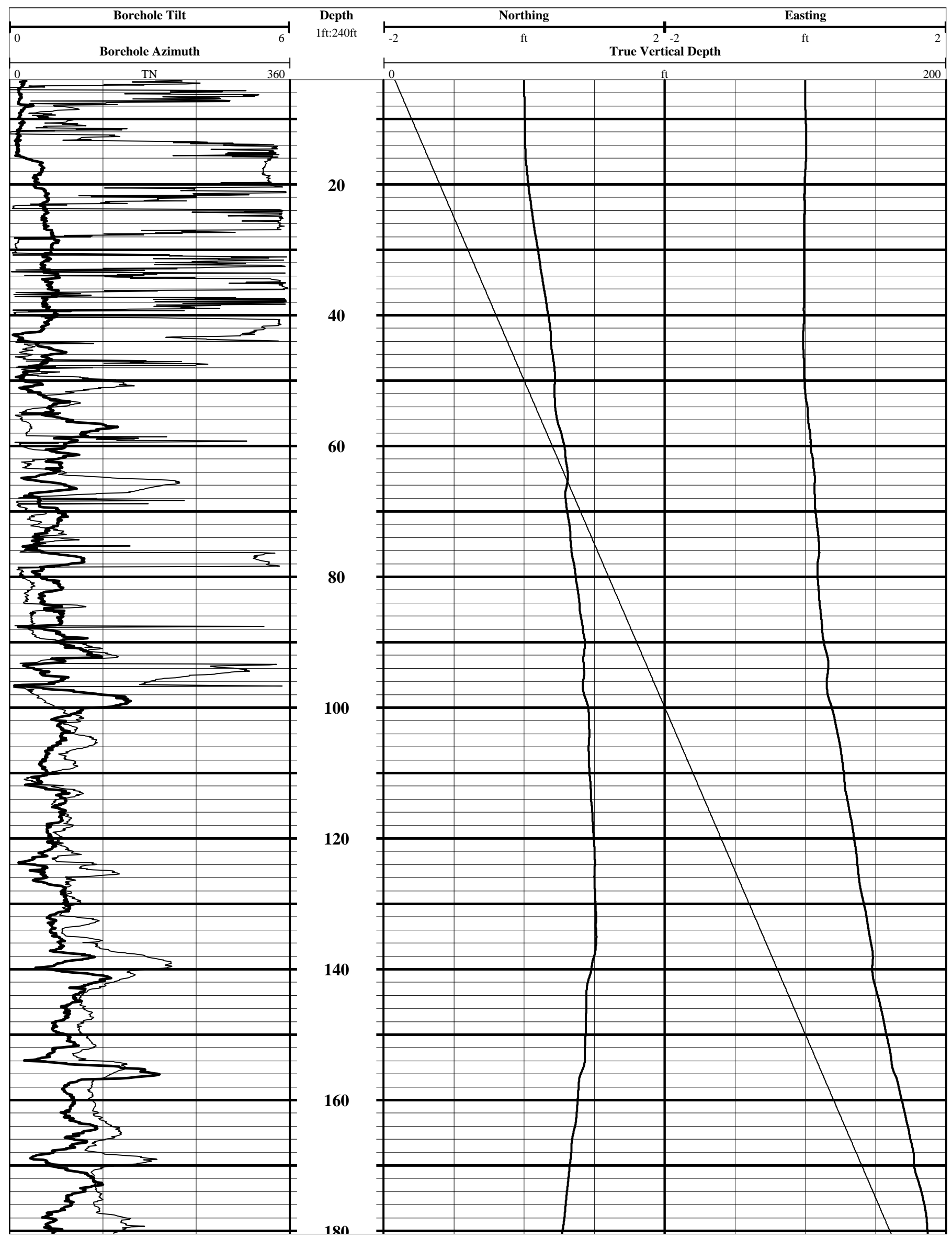


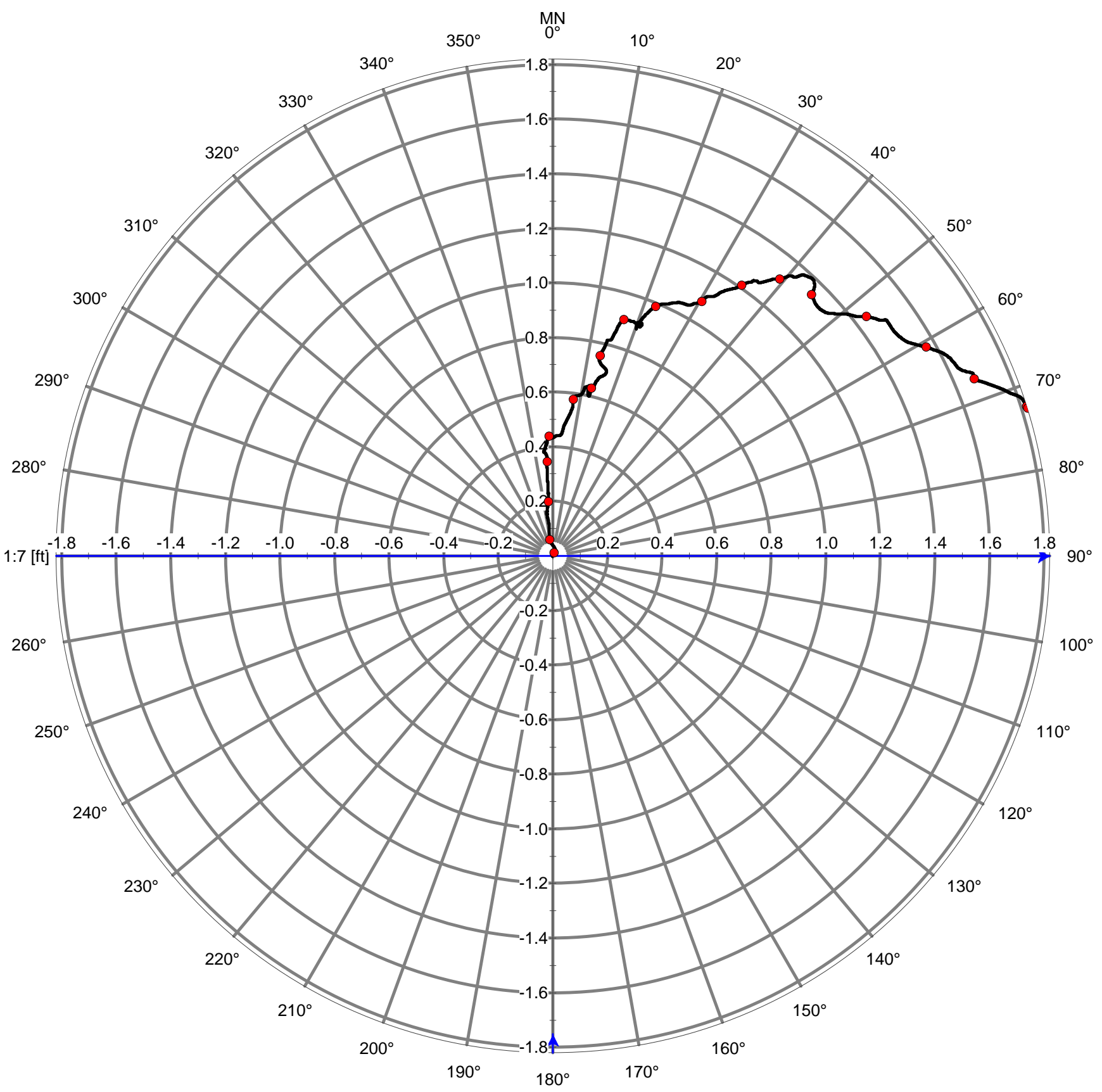




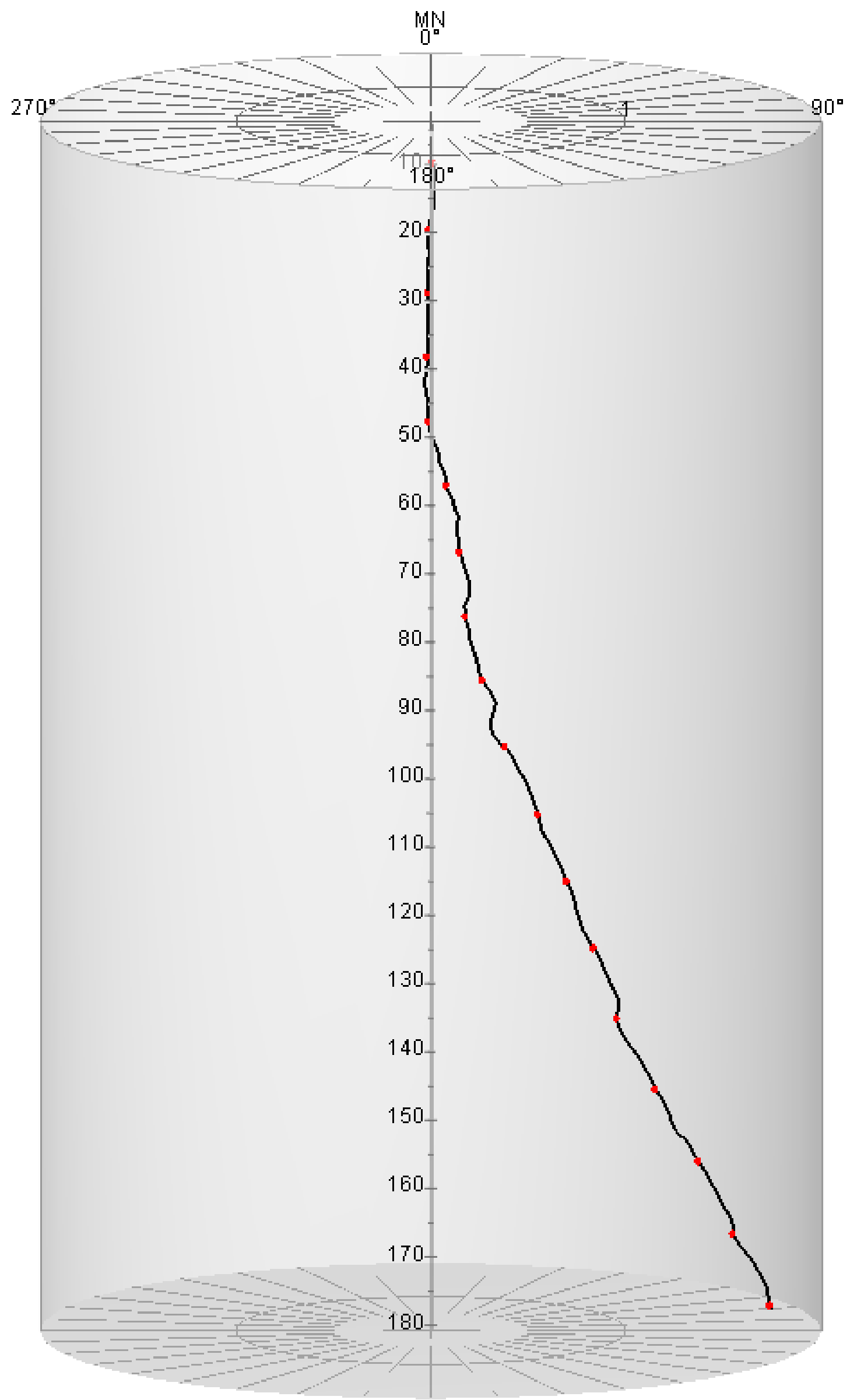




\section{Appendix F-5}

Borehole Geophysical Log Plots for Instrument Hole U-15n\#4 


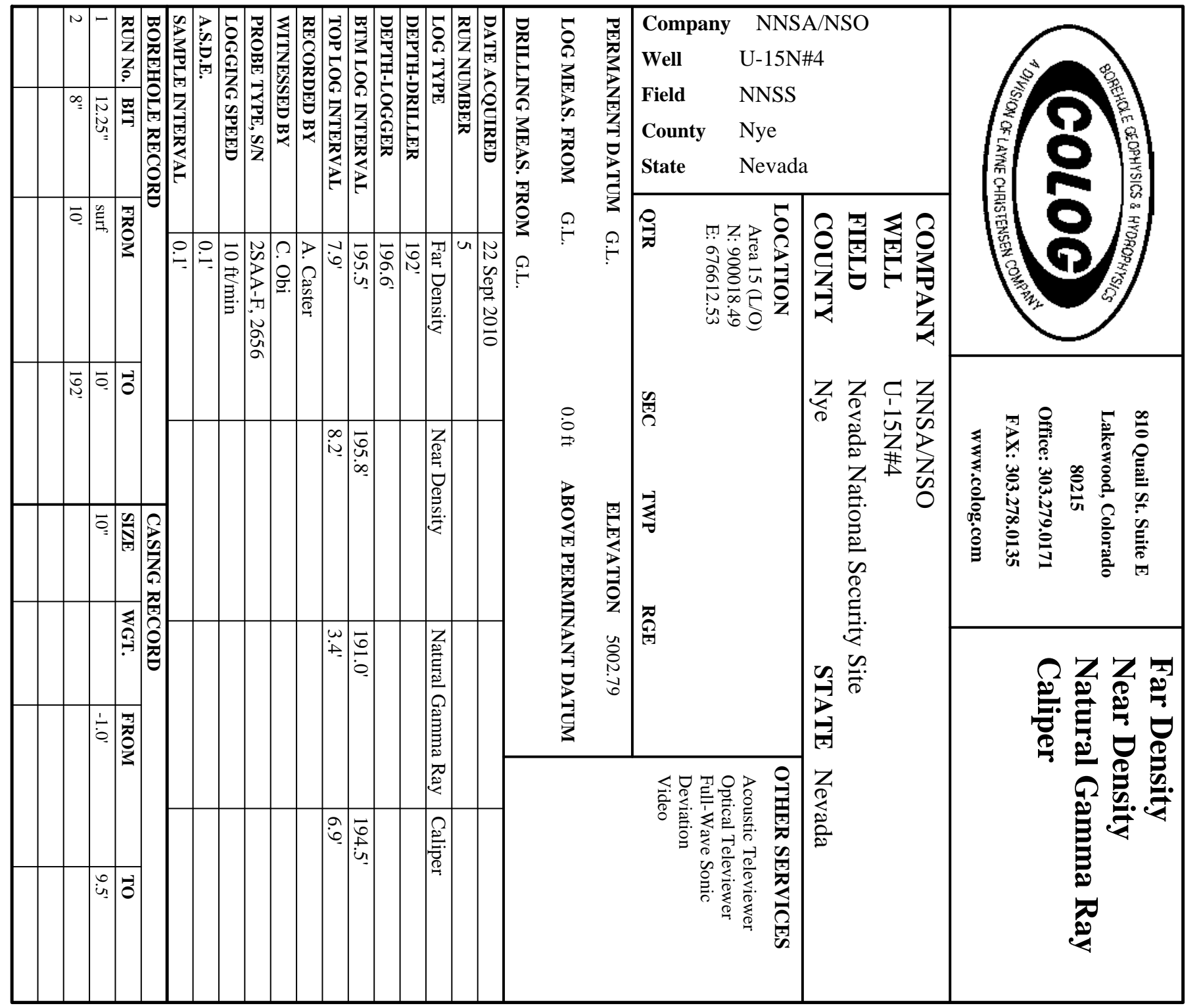

\section{COMMENTS}

NA - Not Available, N/A - Not Applicable

Matrix Density of 2.64 used to calculate Density Porosity 


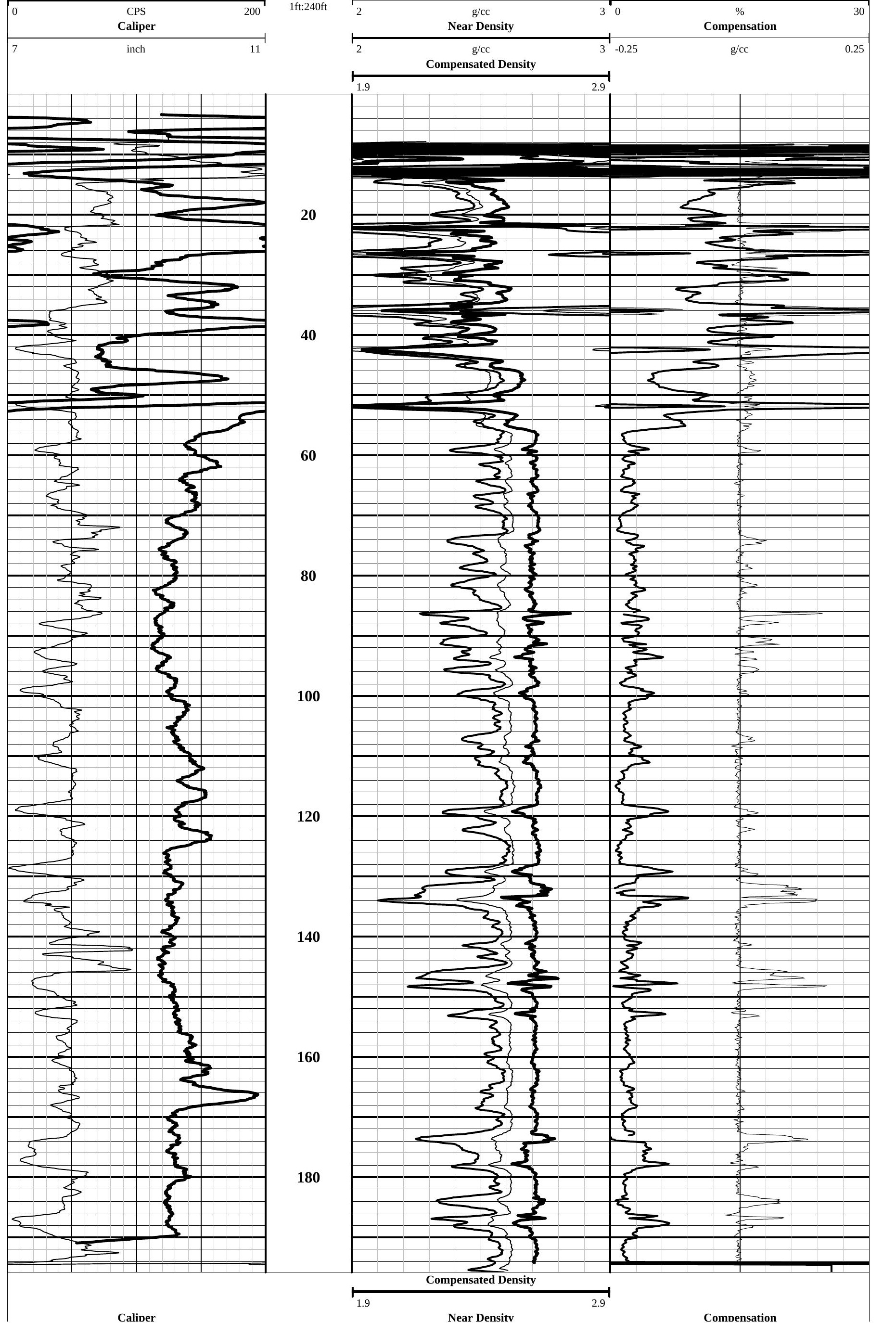




\begin{tabular}{|c|c|c|c|c|c|c|c|c|}
\hline & & & & & & & & \\
\hline 7 & $\begin{array}{l}\text { inch } \\
\text { Natural Gamma Ray }\end{array}$ & 11 & Depth & 2 & $\begin{array}{c}\mathrm{g} / \mathrm{cc} \\
\text { Far Density }\end{array}$ & $3^{\prime \prime}-0.25$ & $\begin{array}{c}\mathrm{g} / \mathrm{cc} \\
\text { Density Porosity }\end{array}$ & 0.25 \\
\hline 0 & CPS & 200 & $1 \mathrm{ft}: 240 \mathrm{ft}$ & 2 & $\mathrm{~g} / \mathrm{cc}$ & 30 & $\%$ & 30 \\
\hline
\end{tabular}




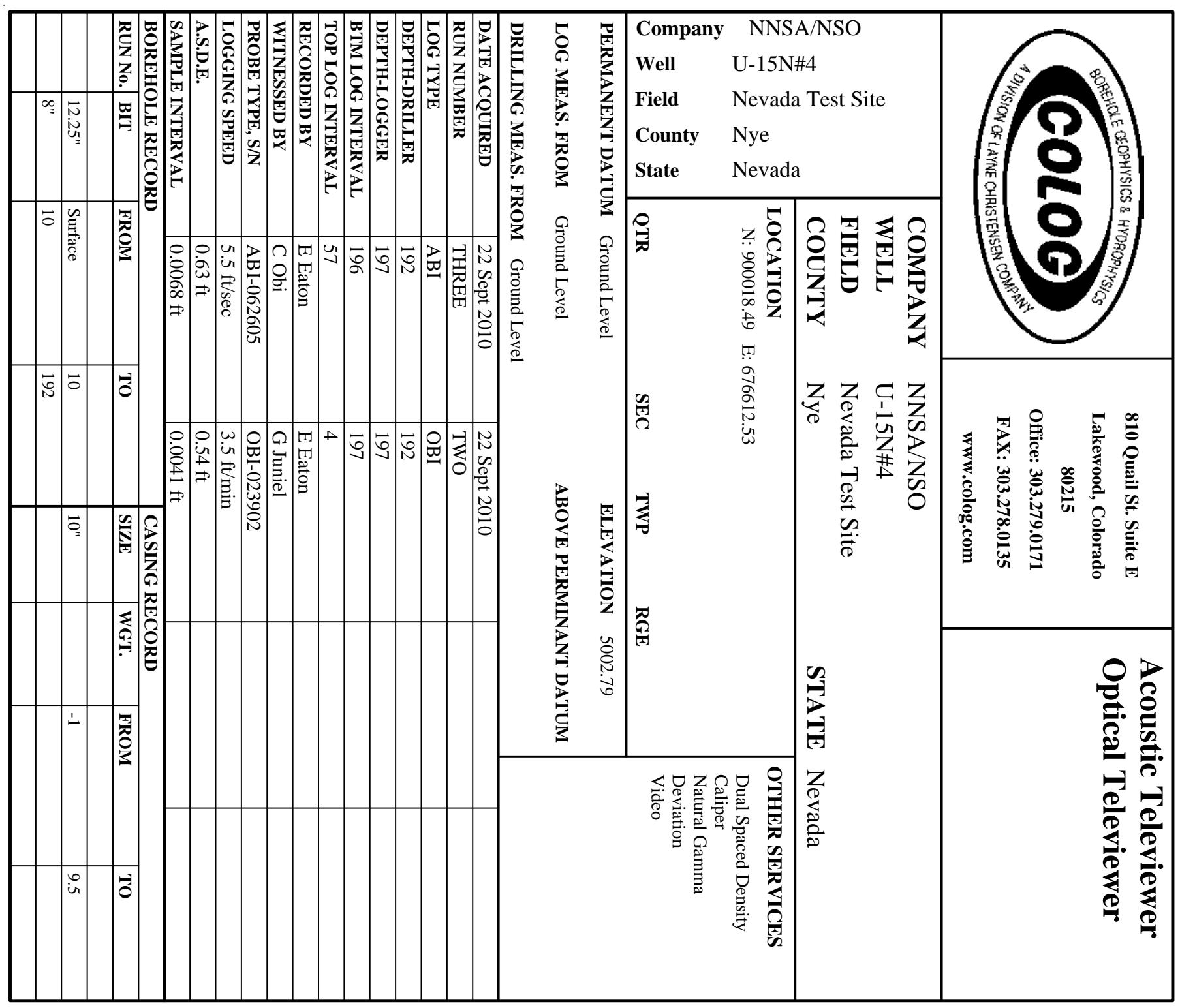




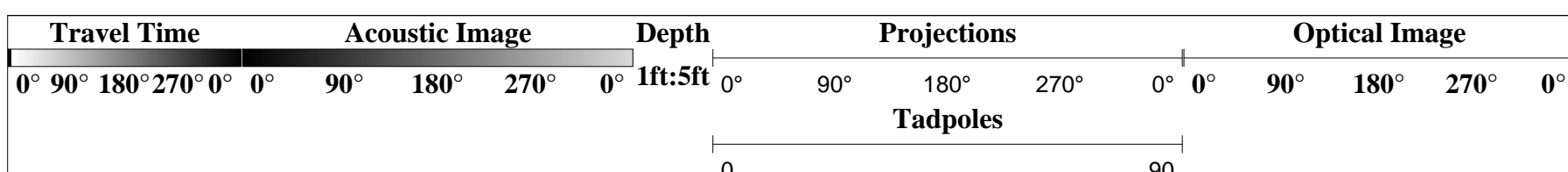

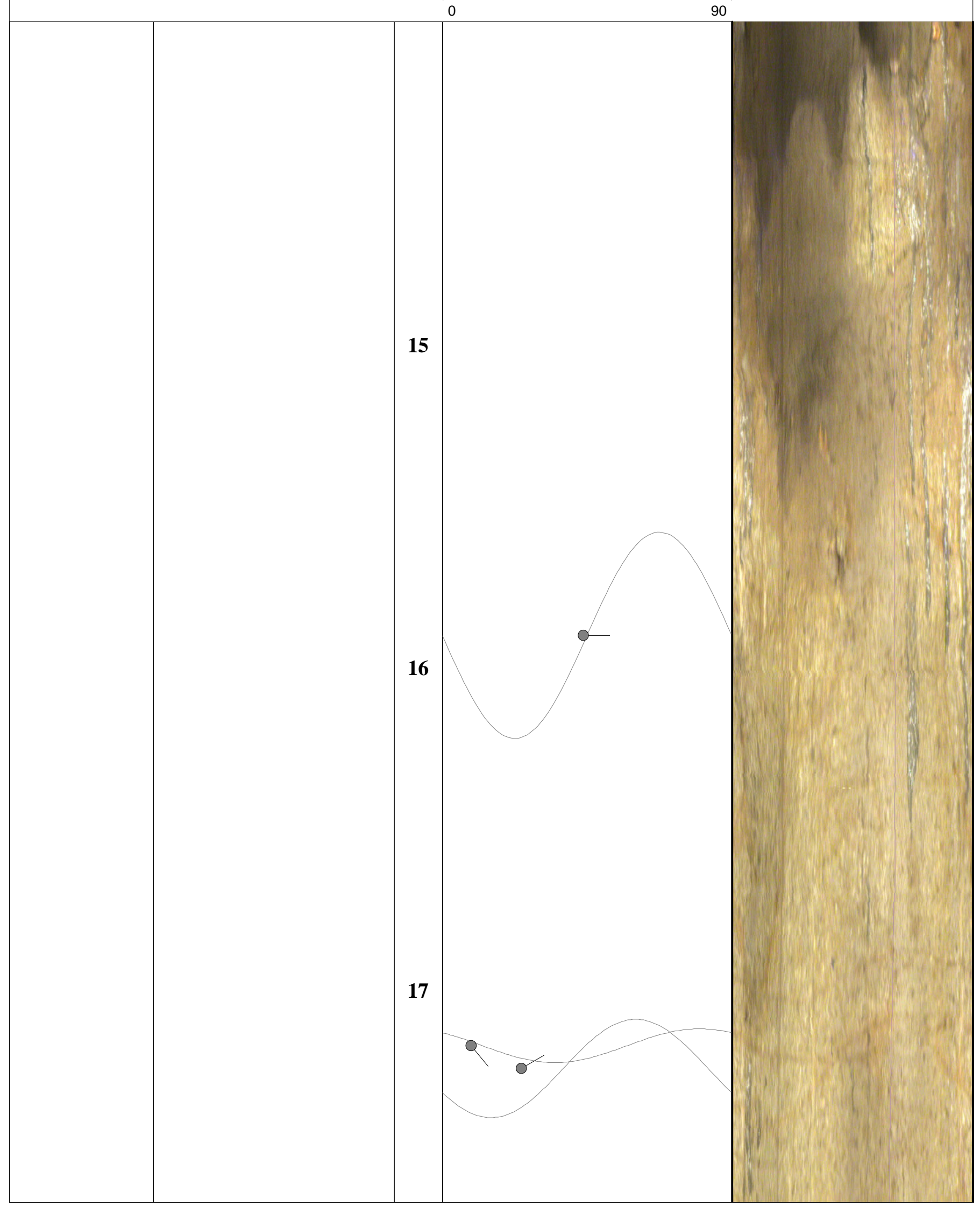




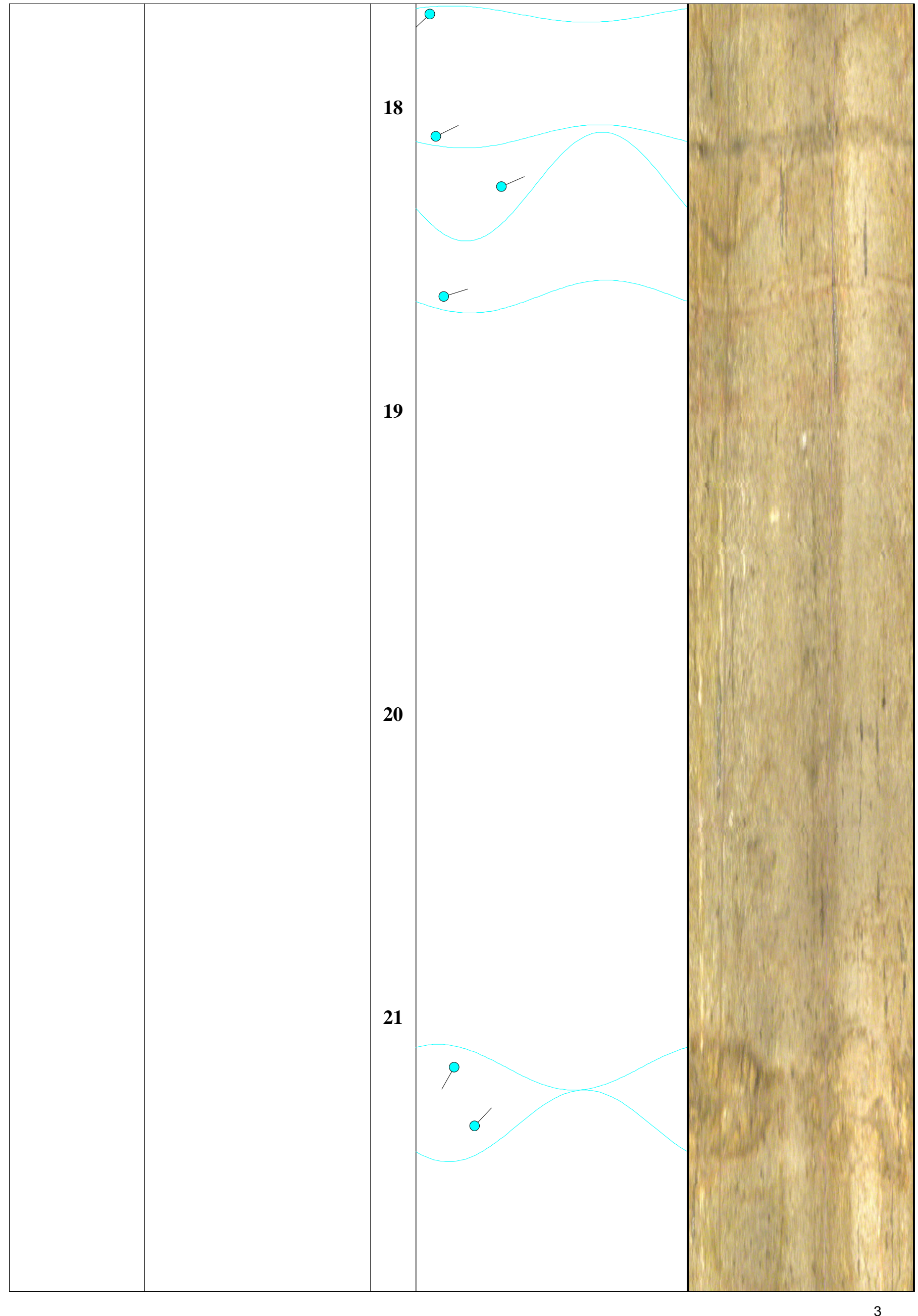




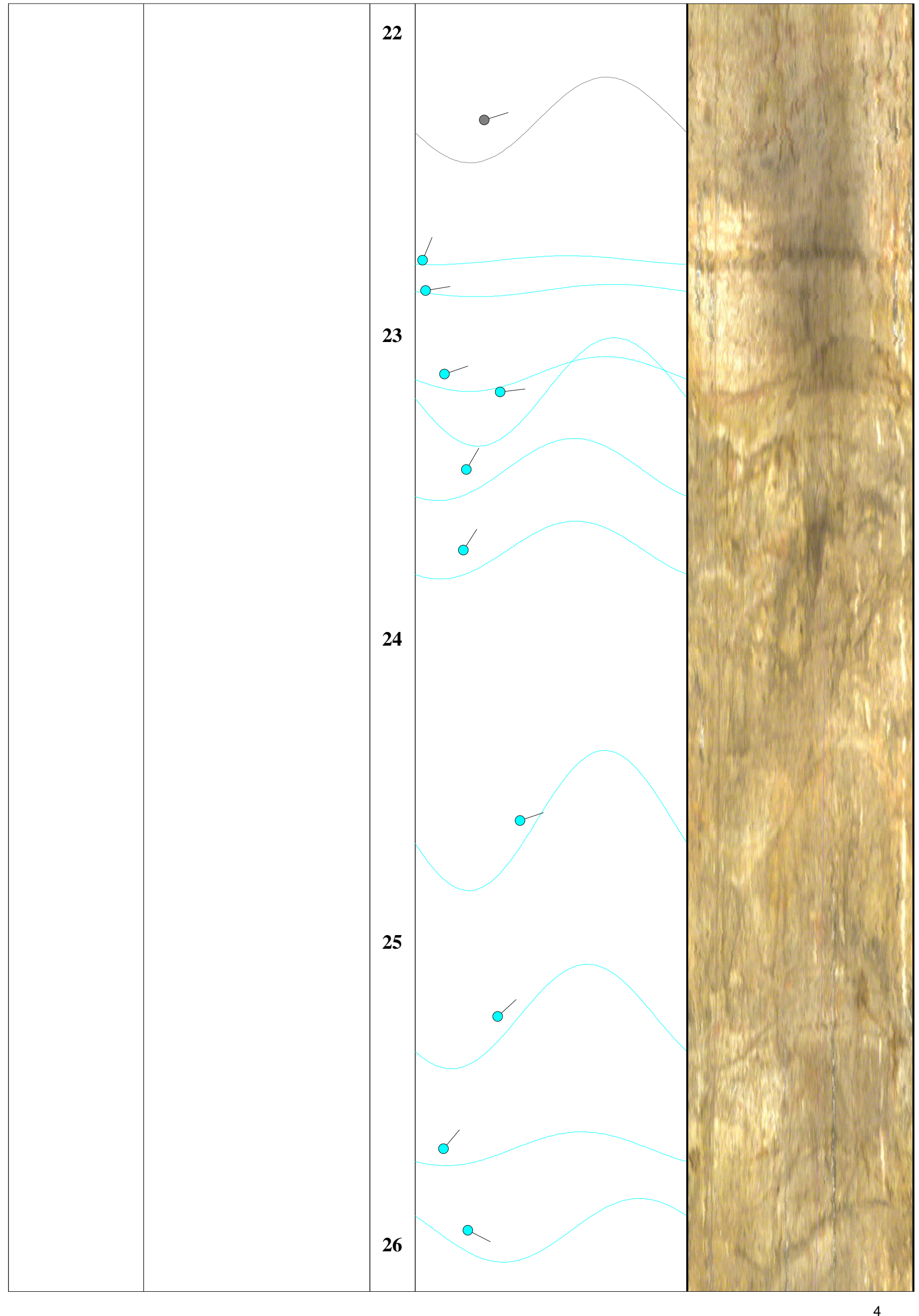




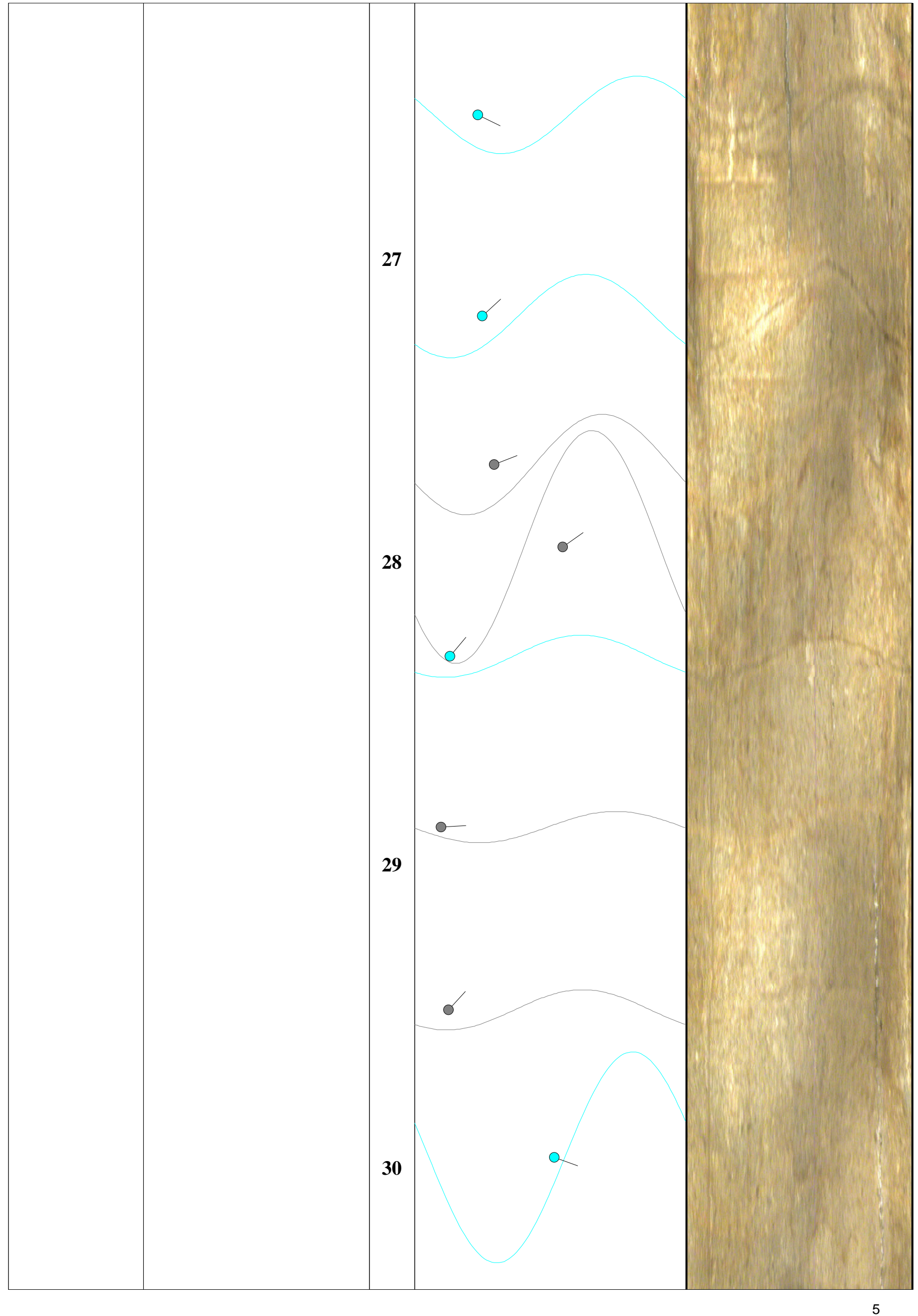




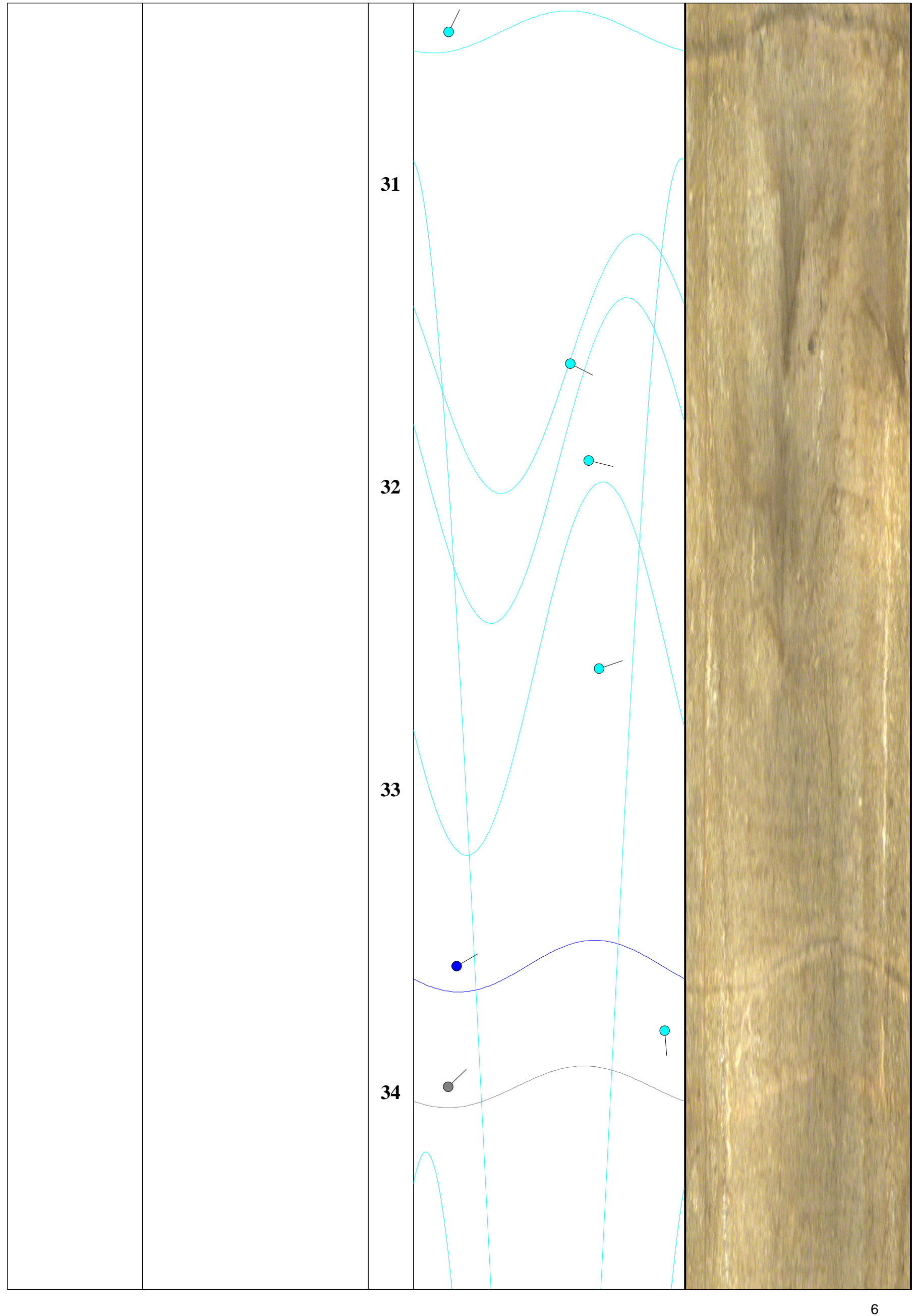




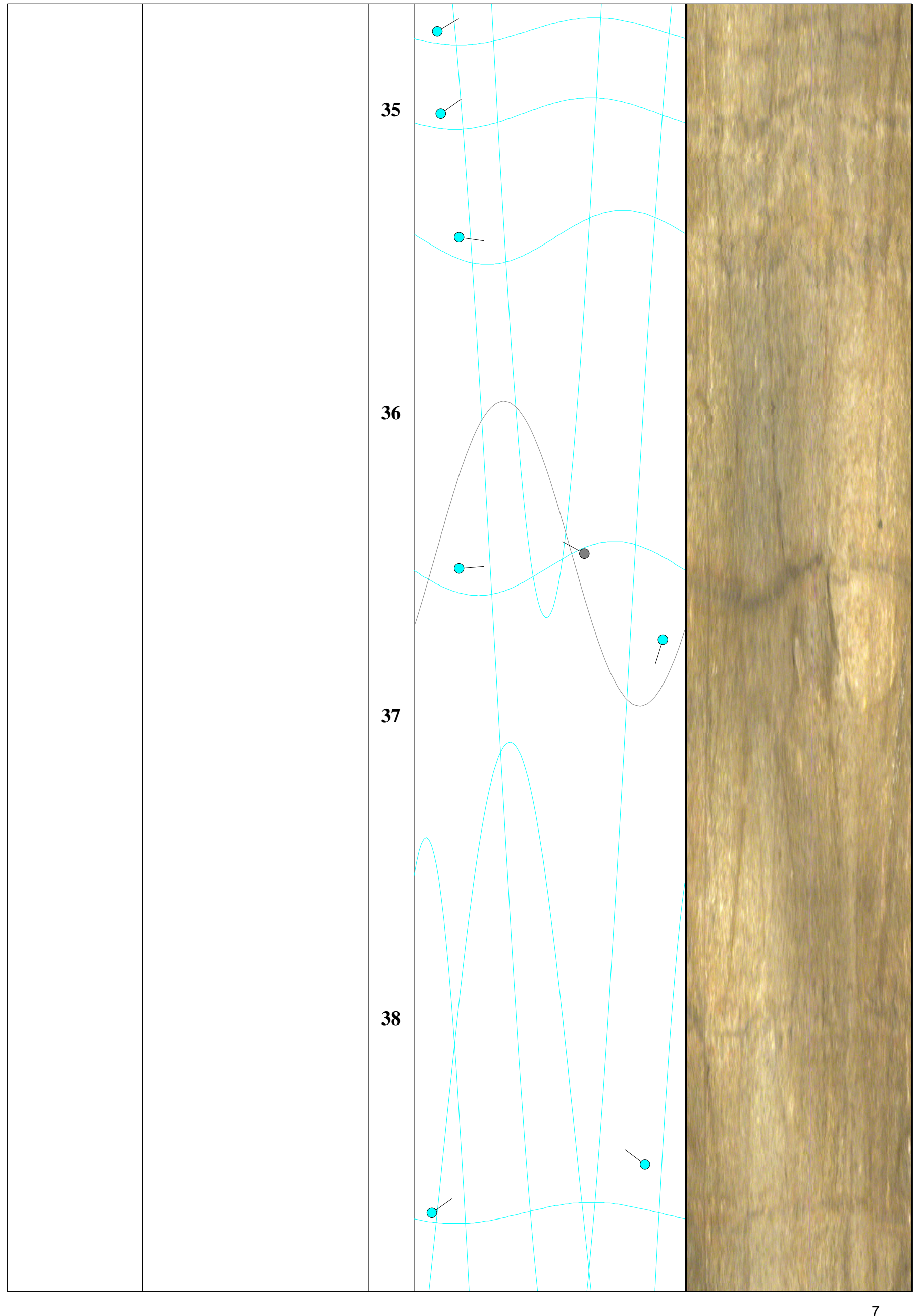




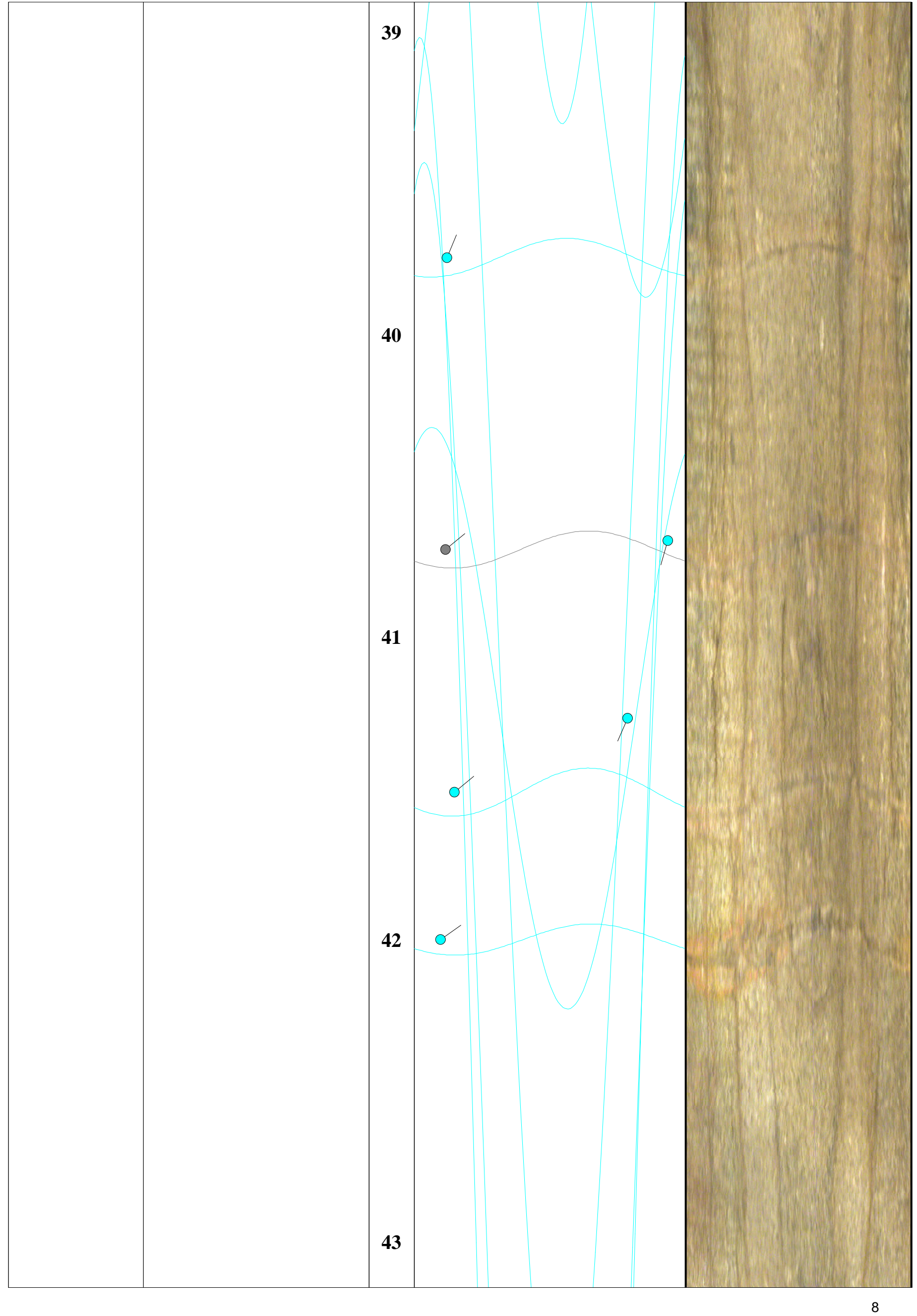






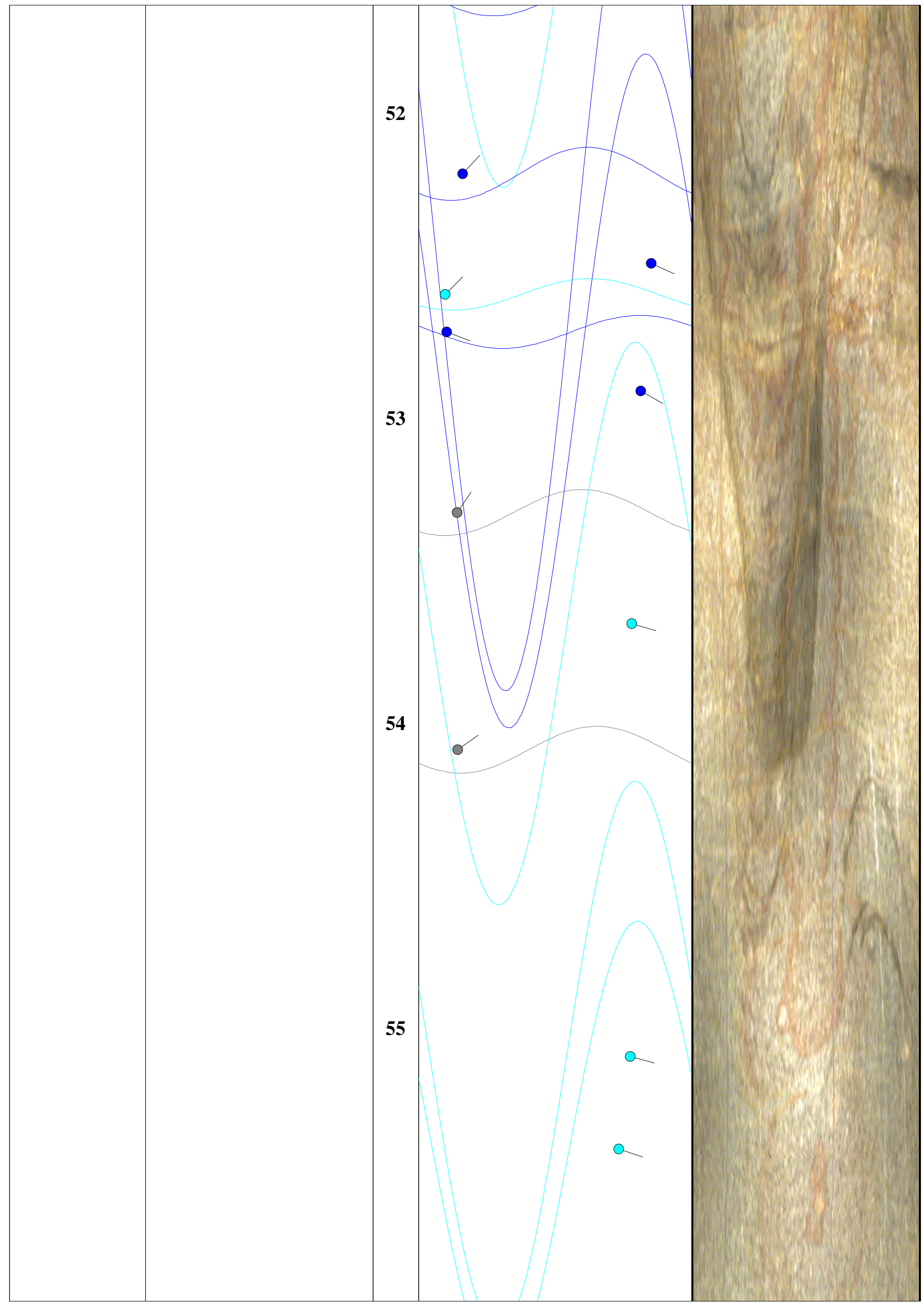




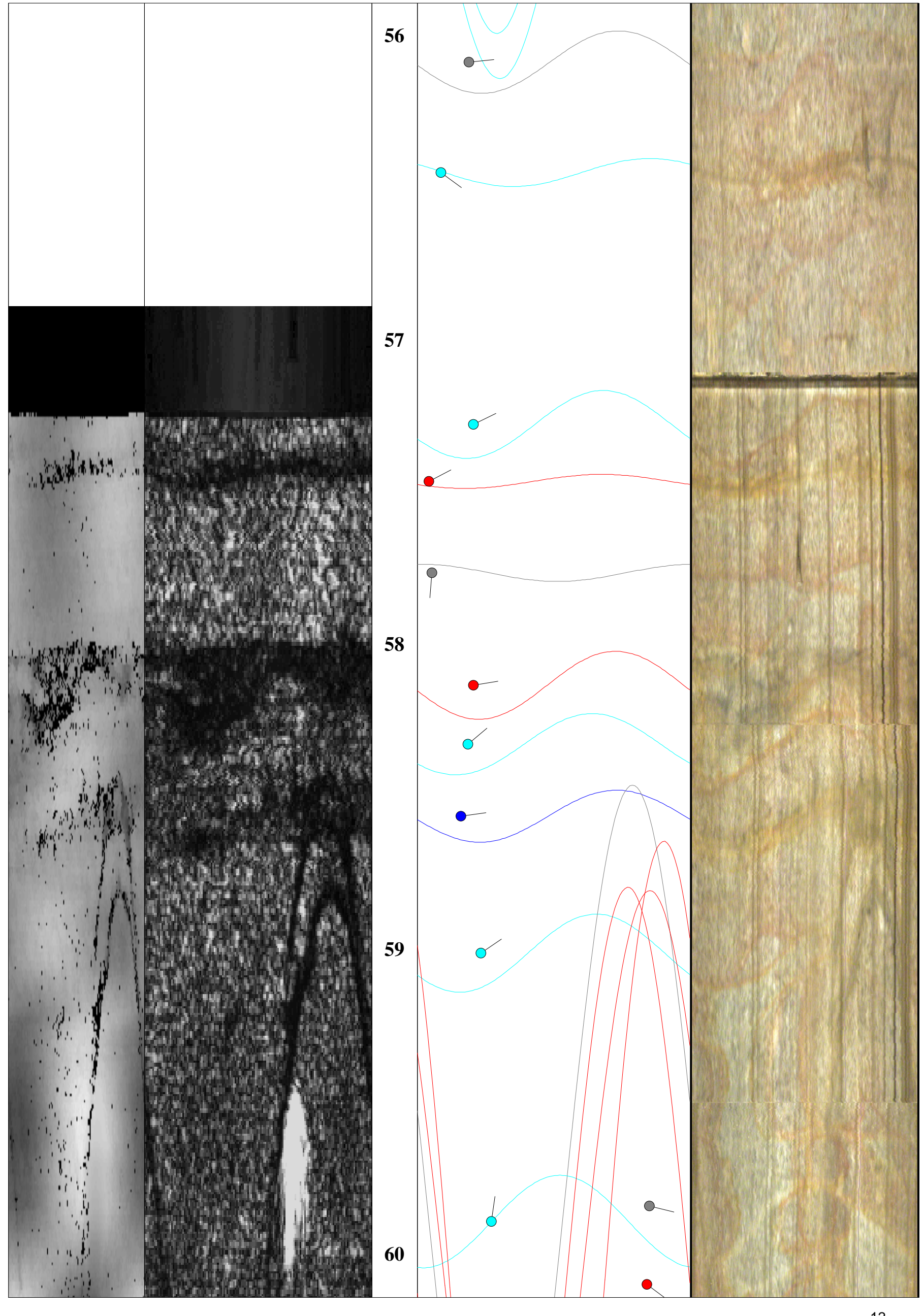




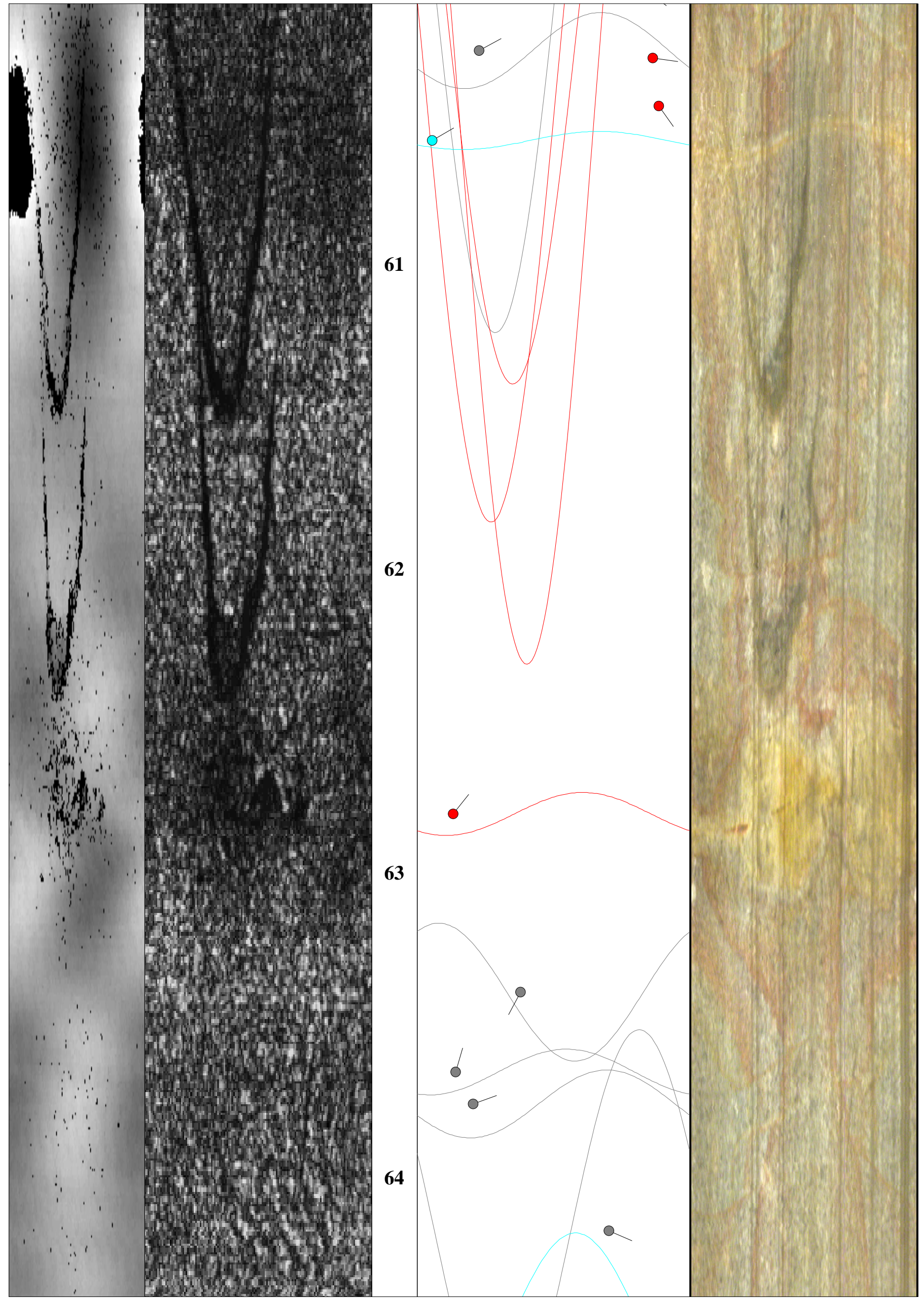




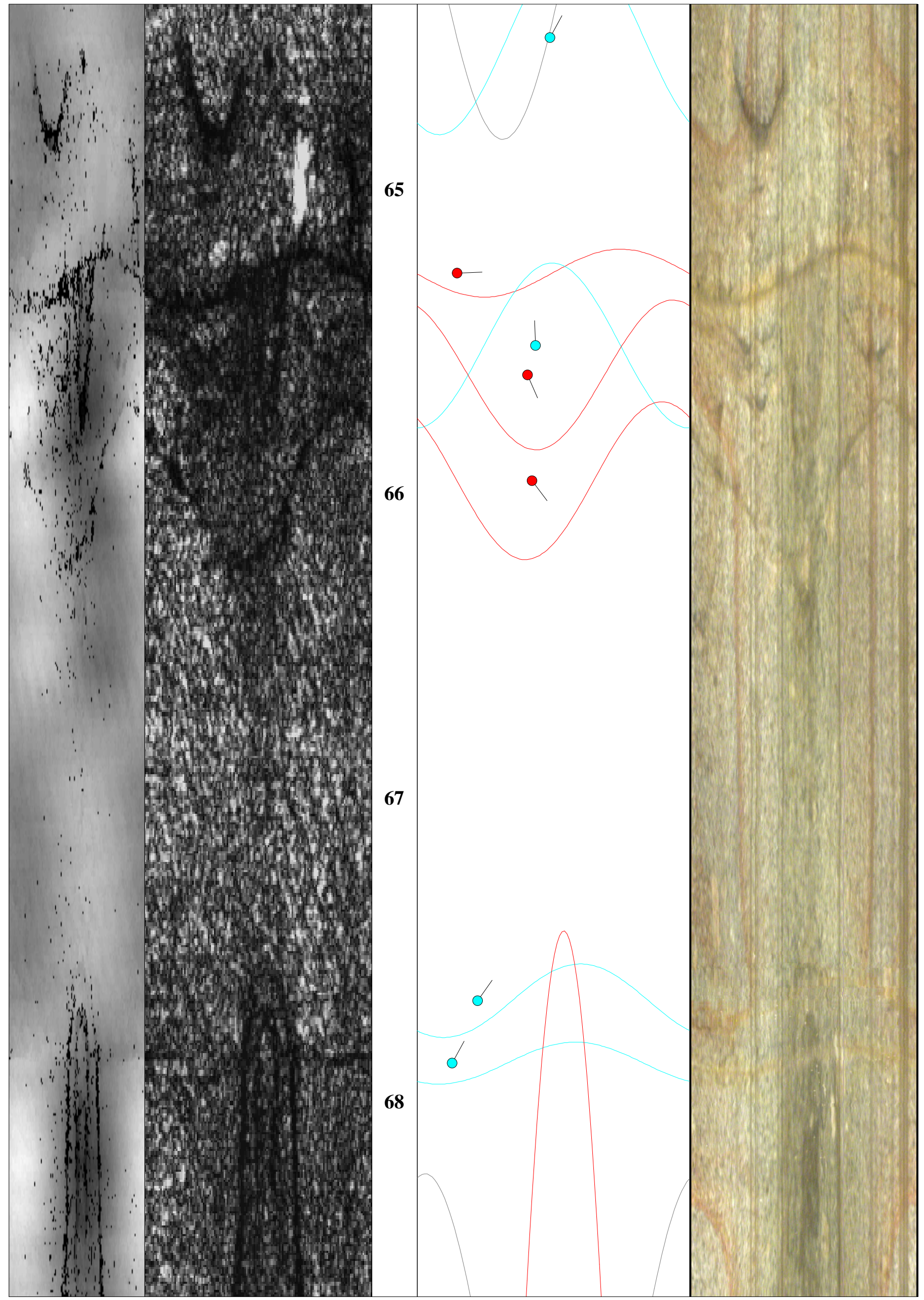




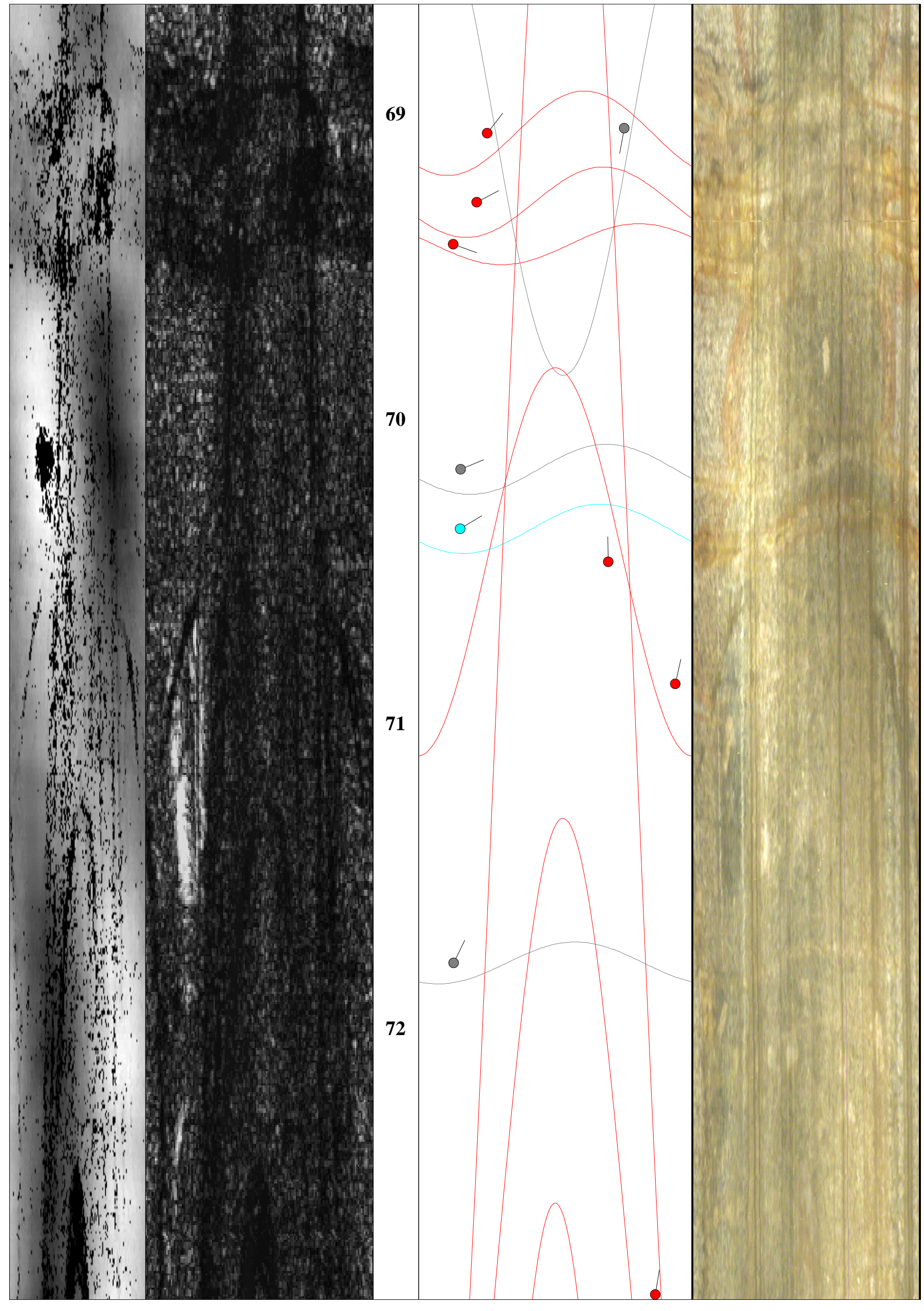




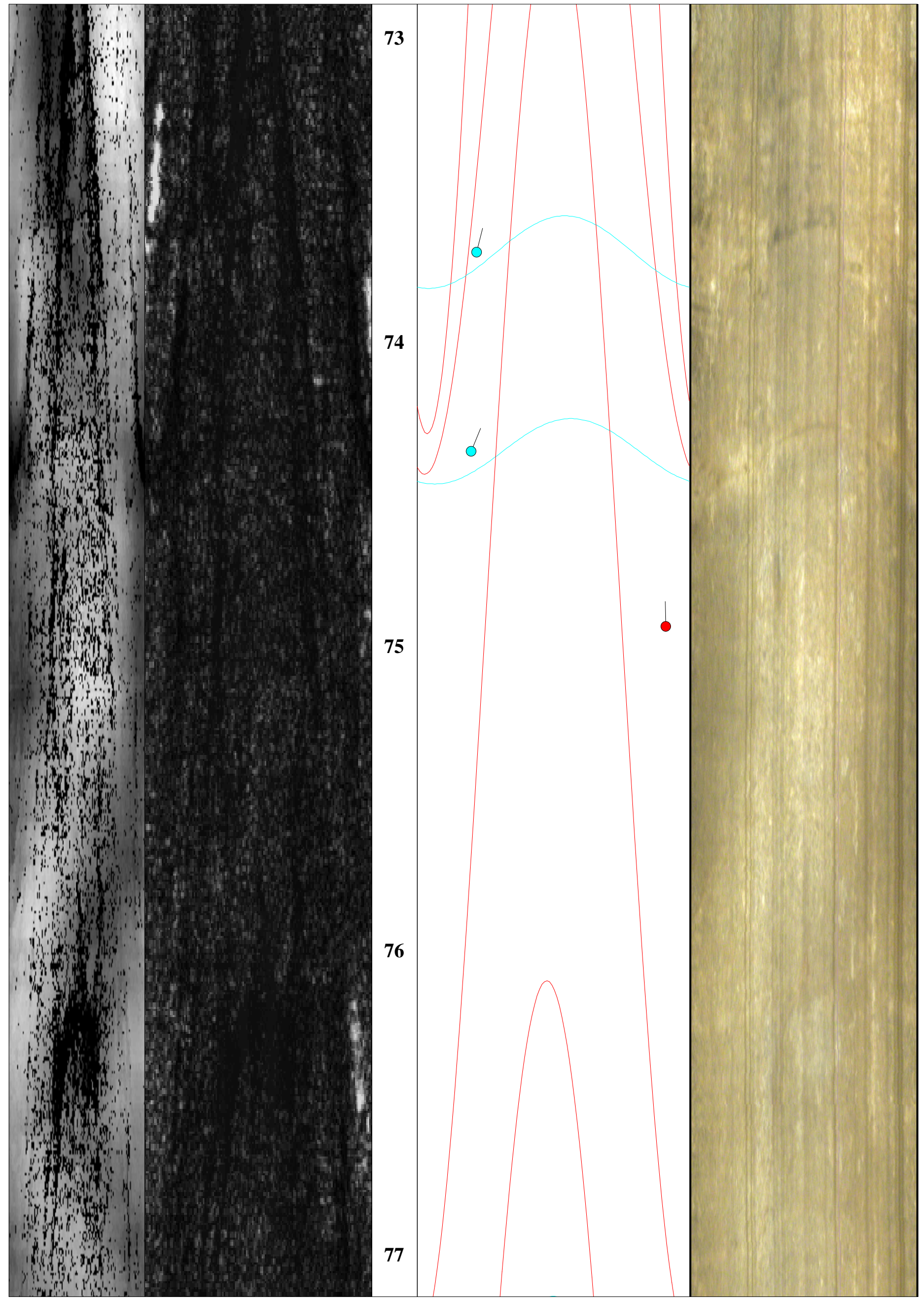




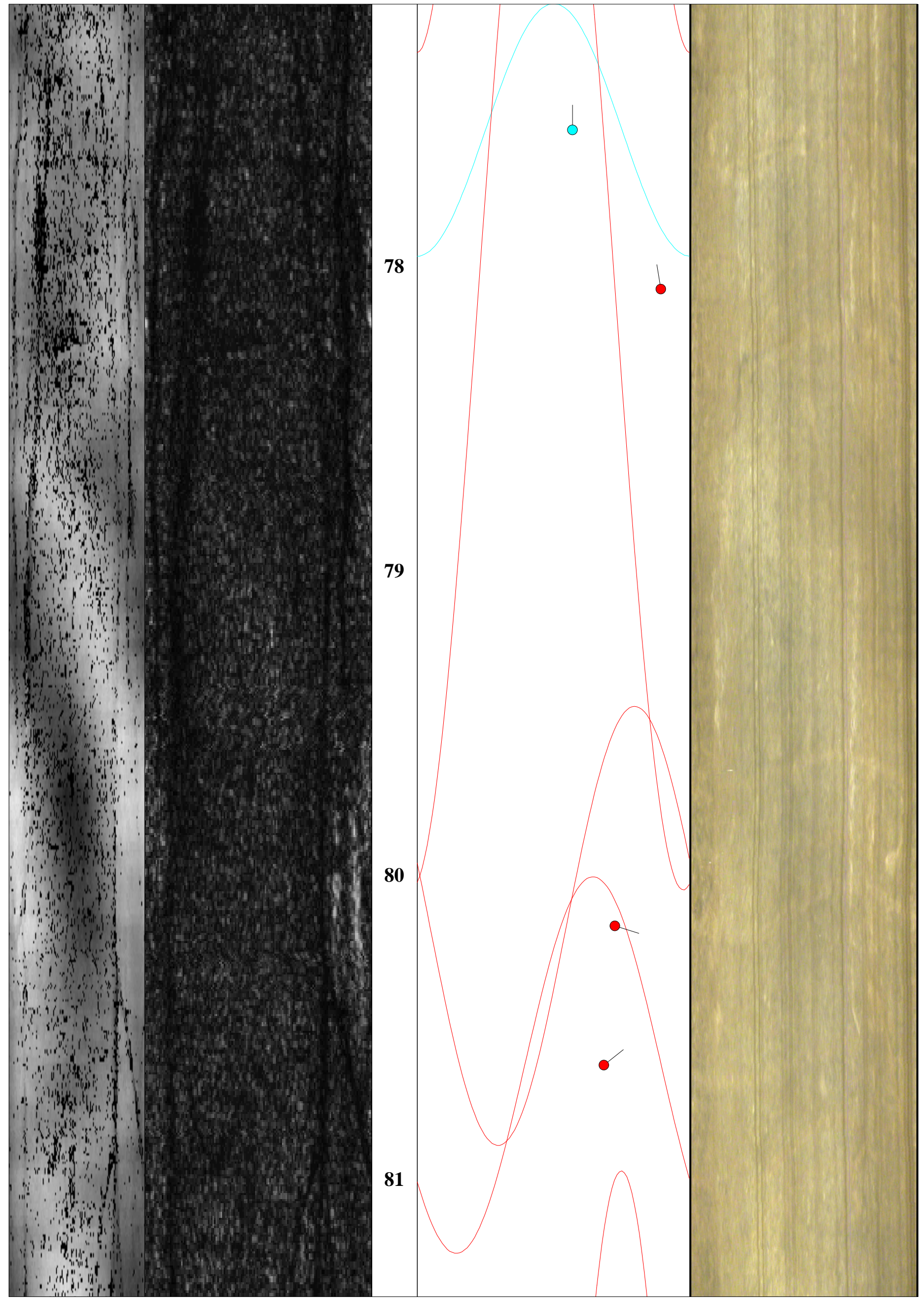




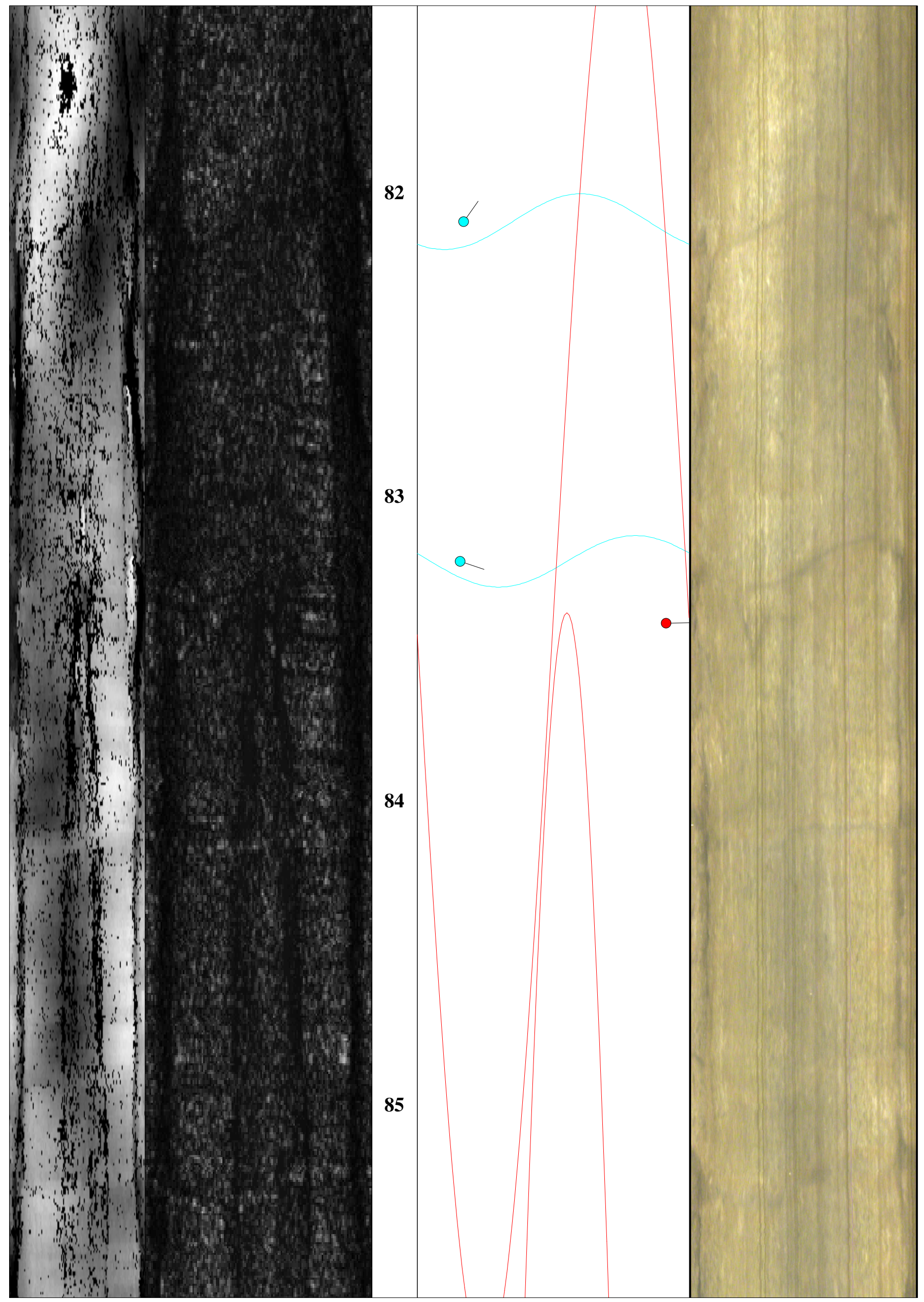




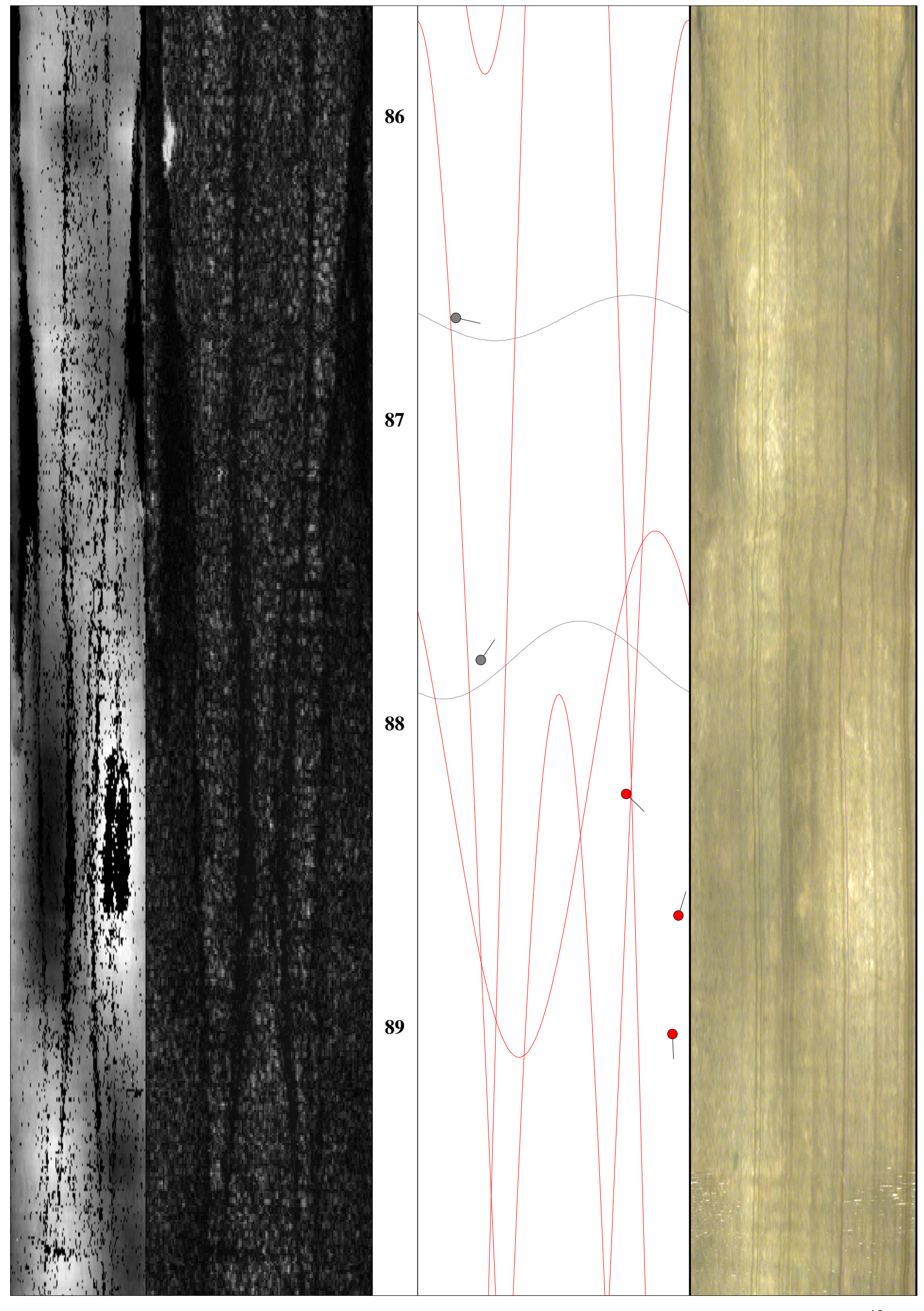




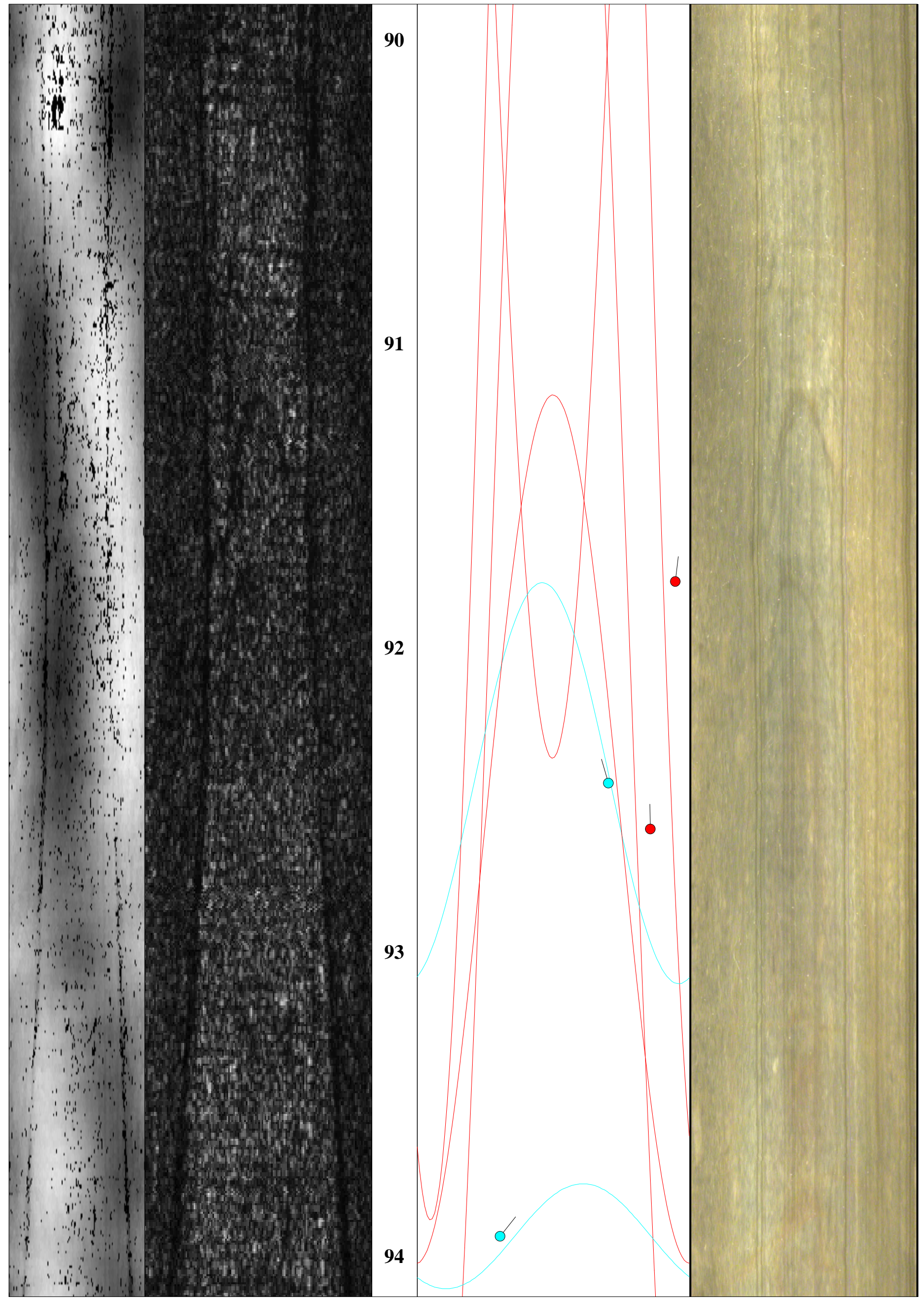




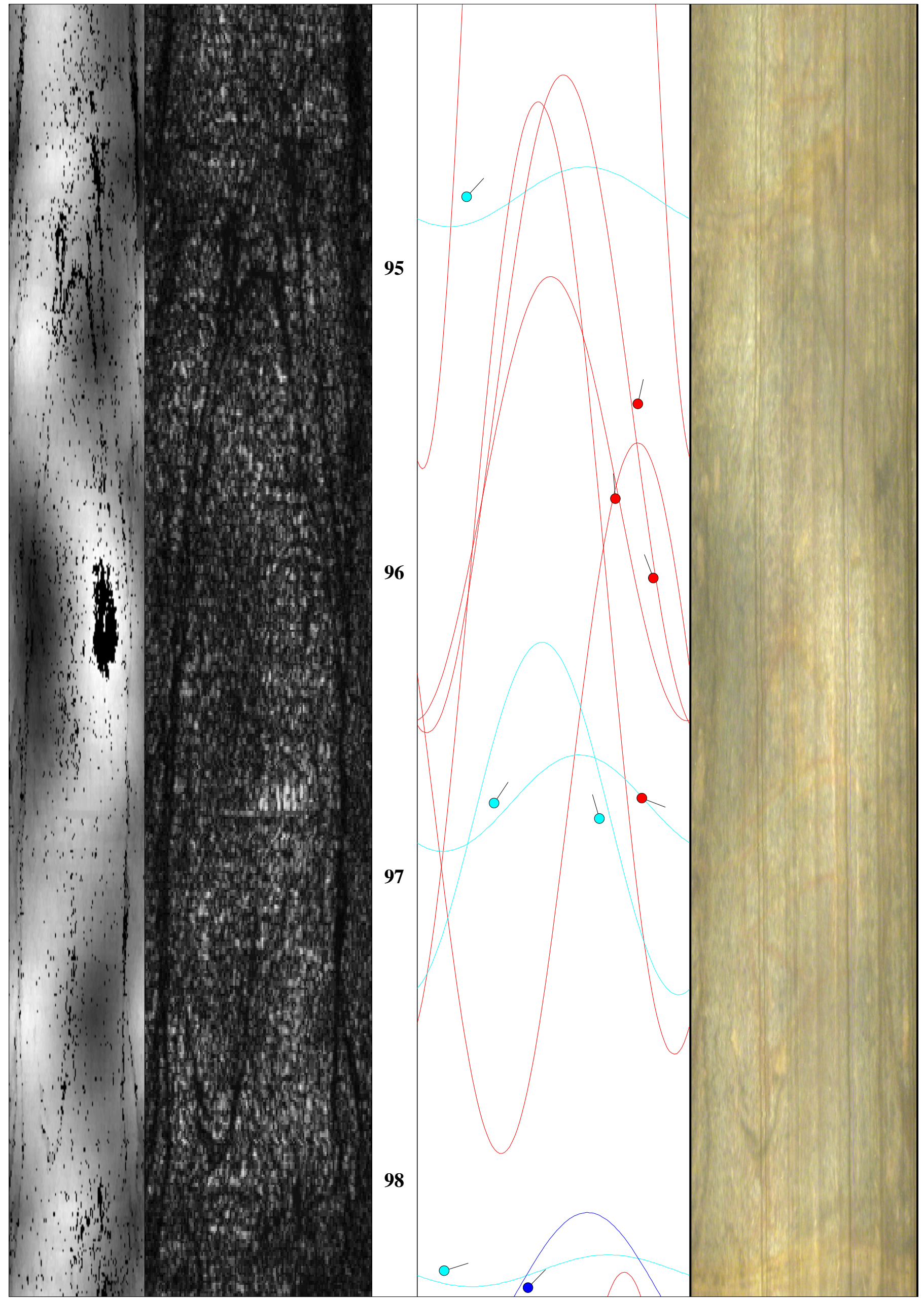




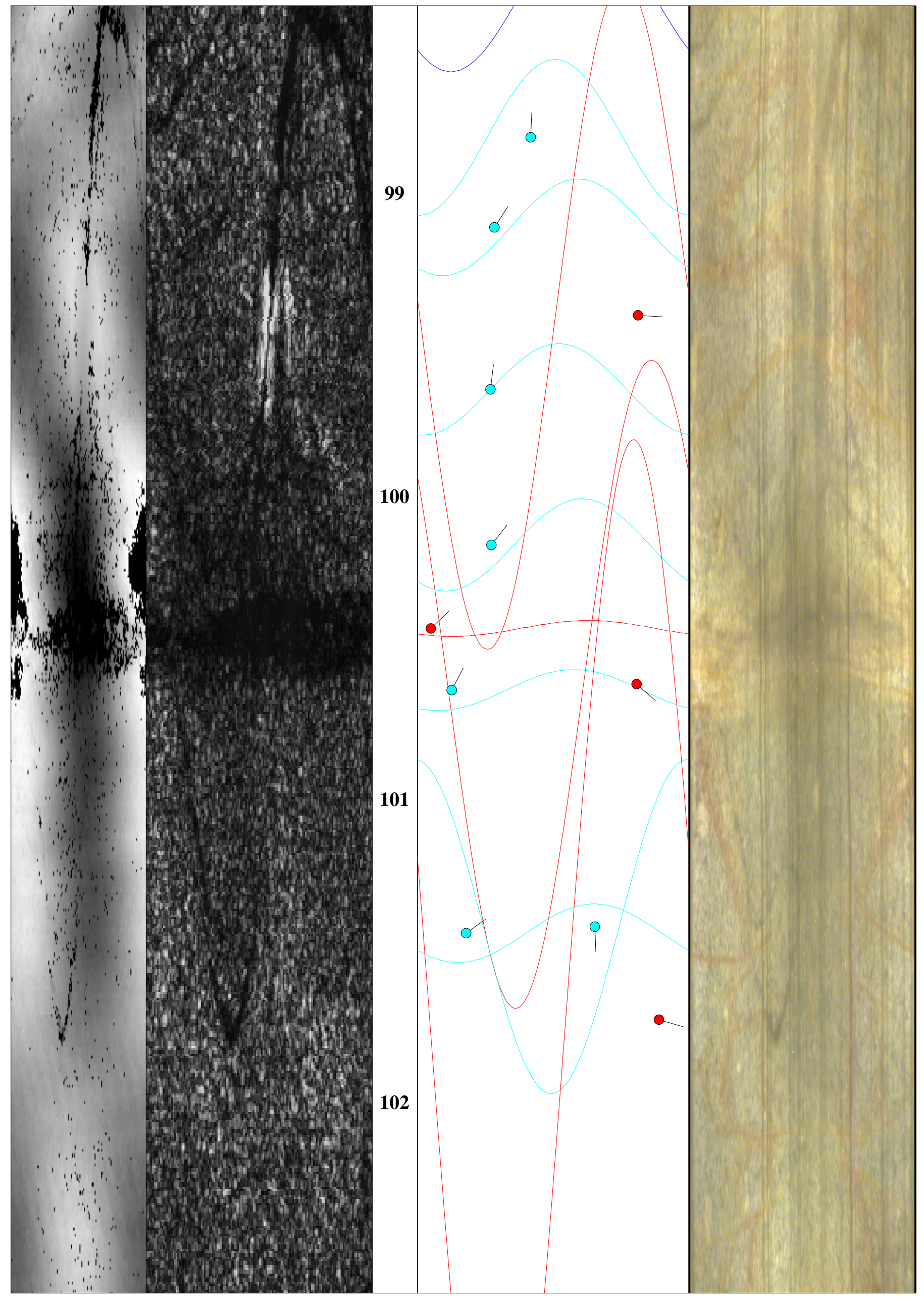




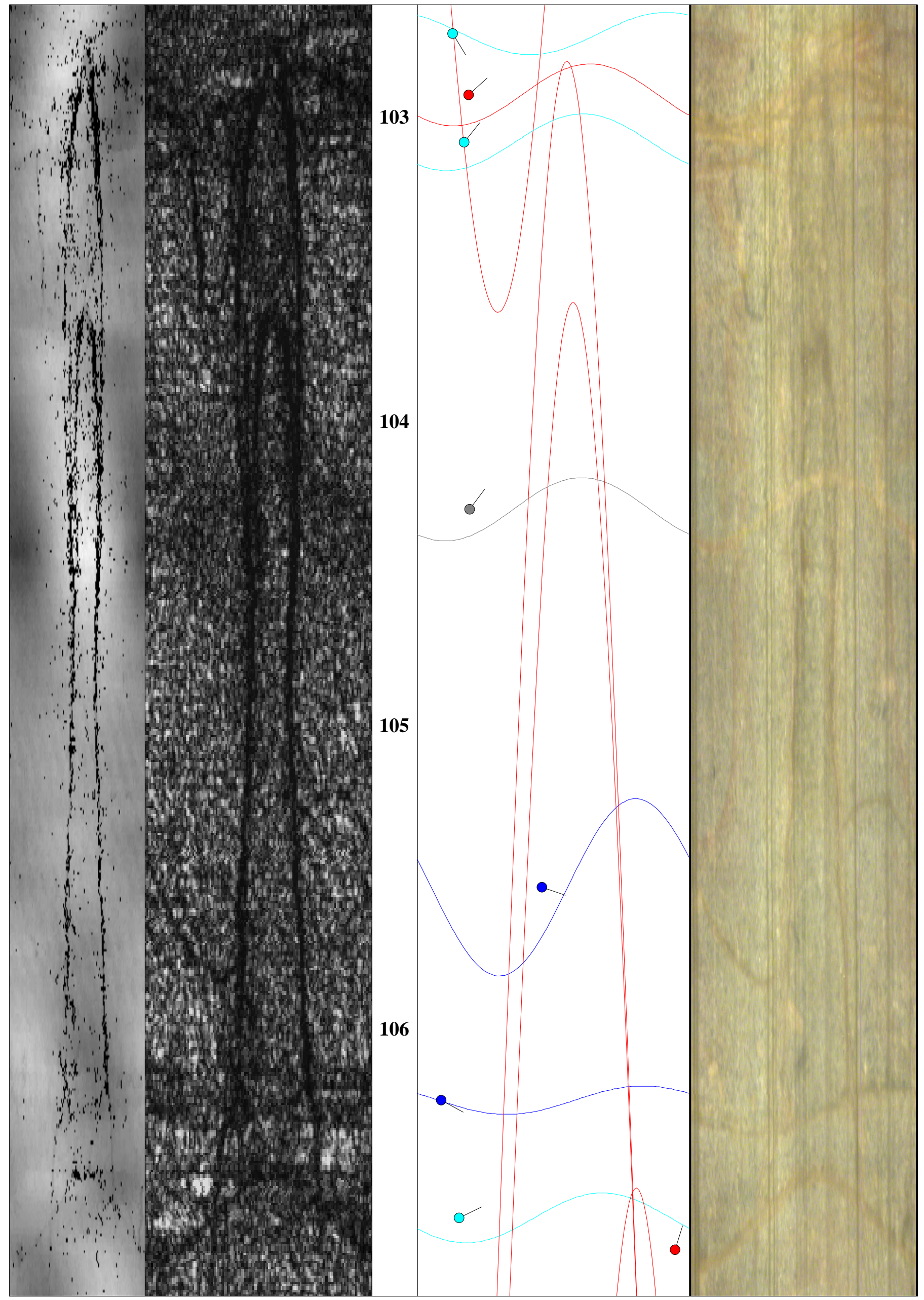




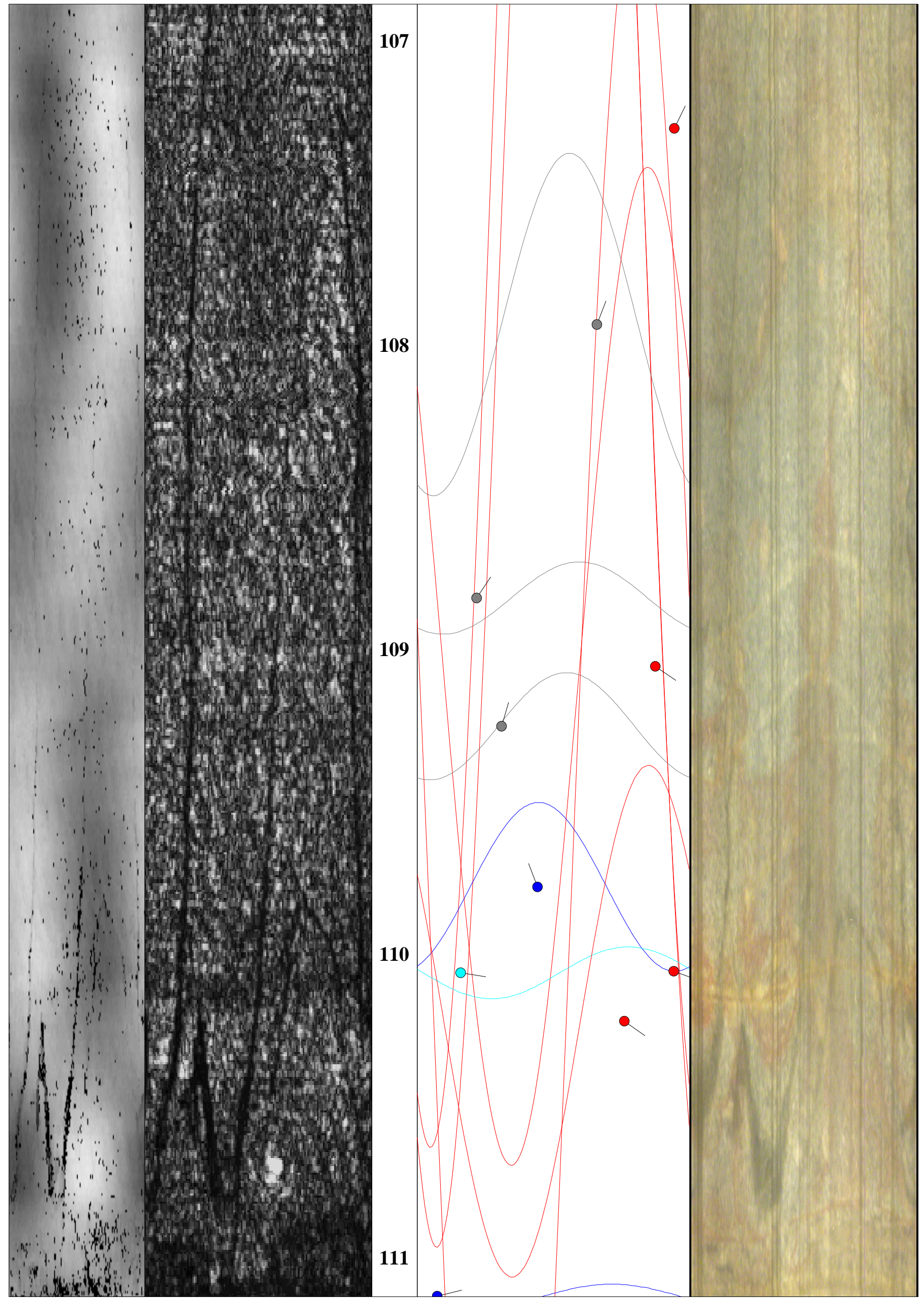




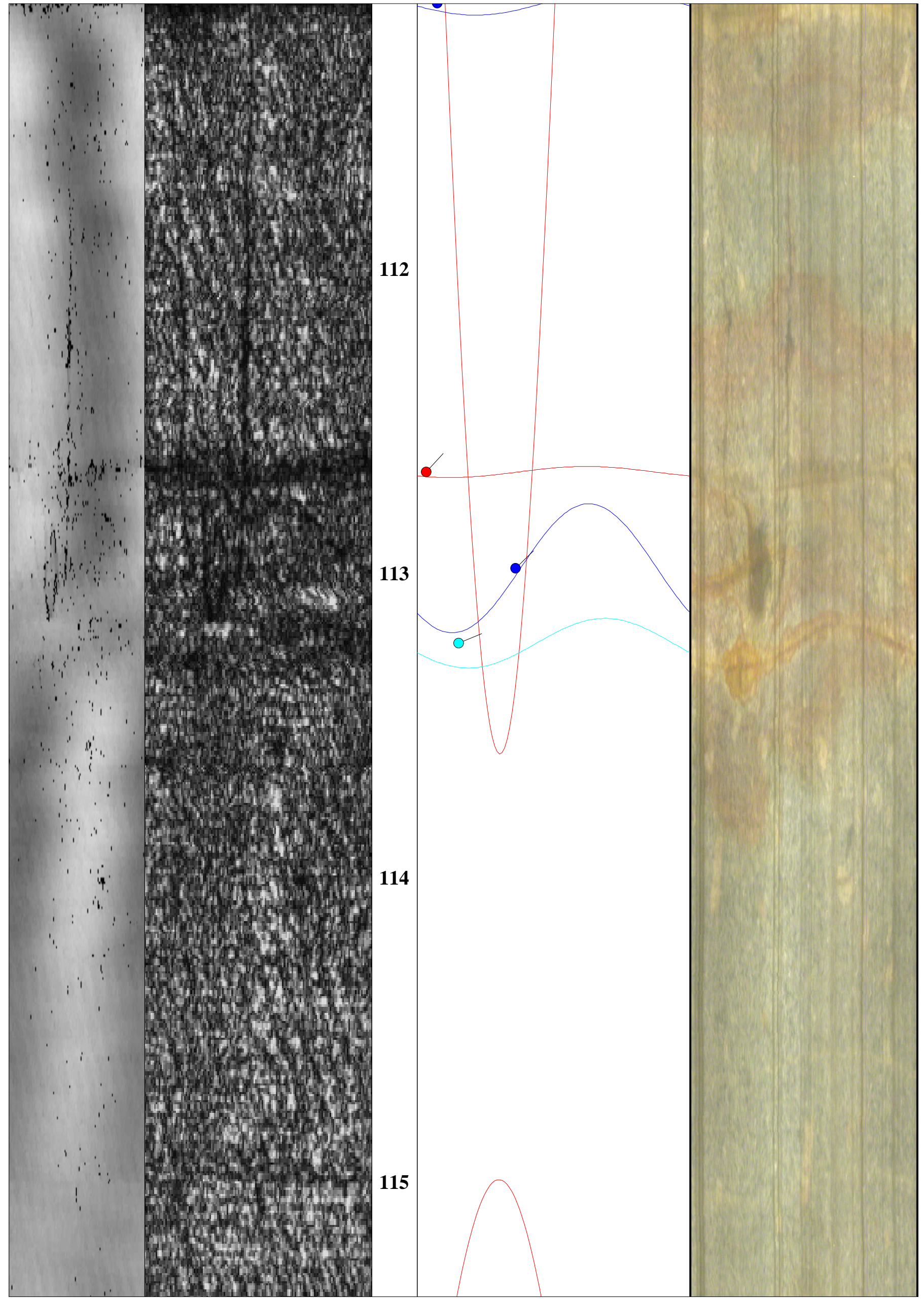




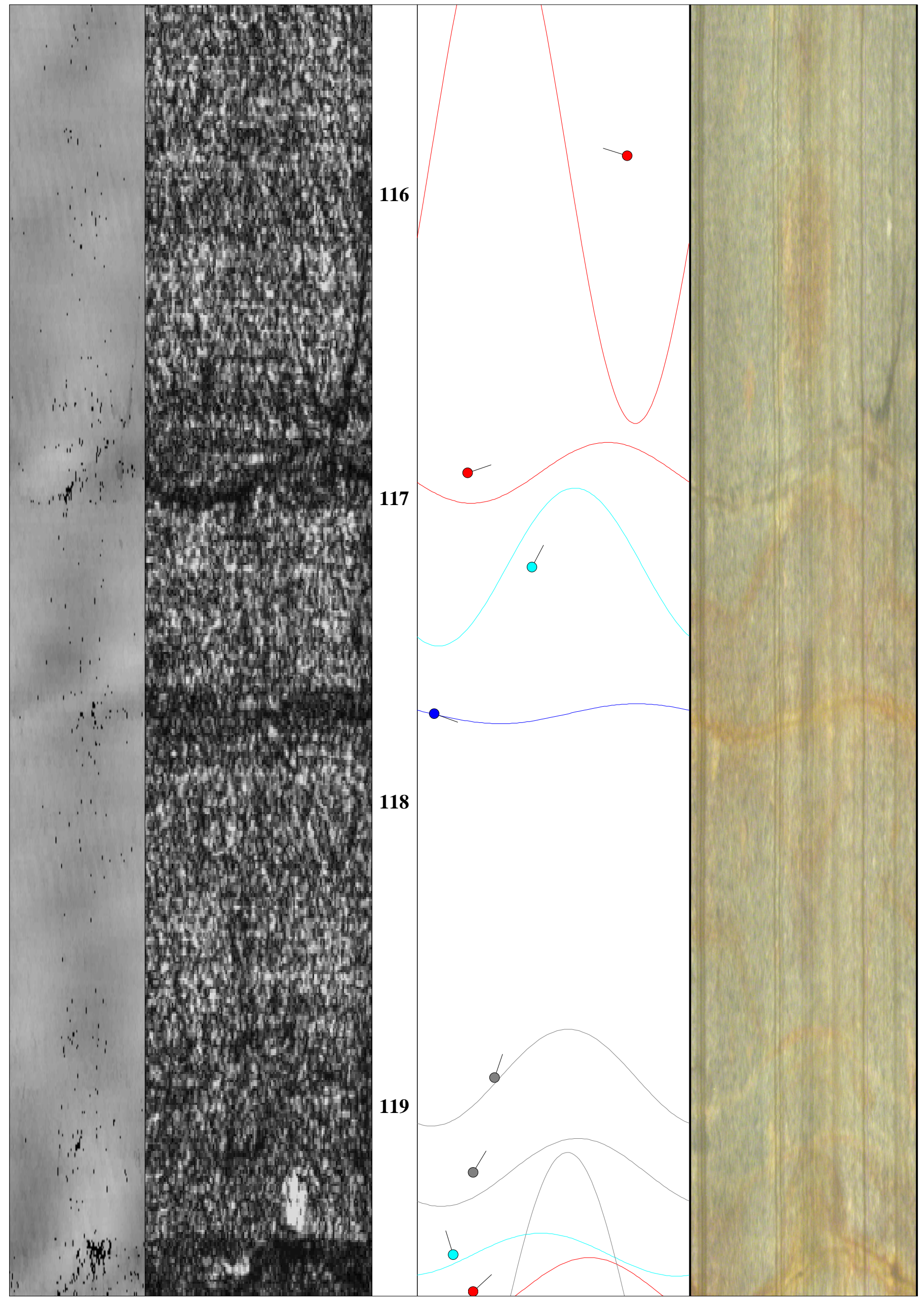




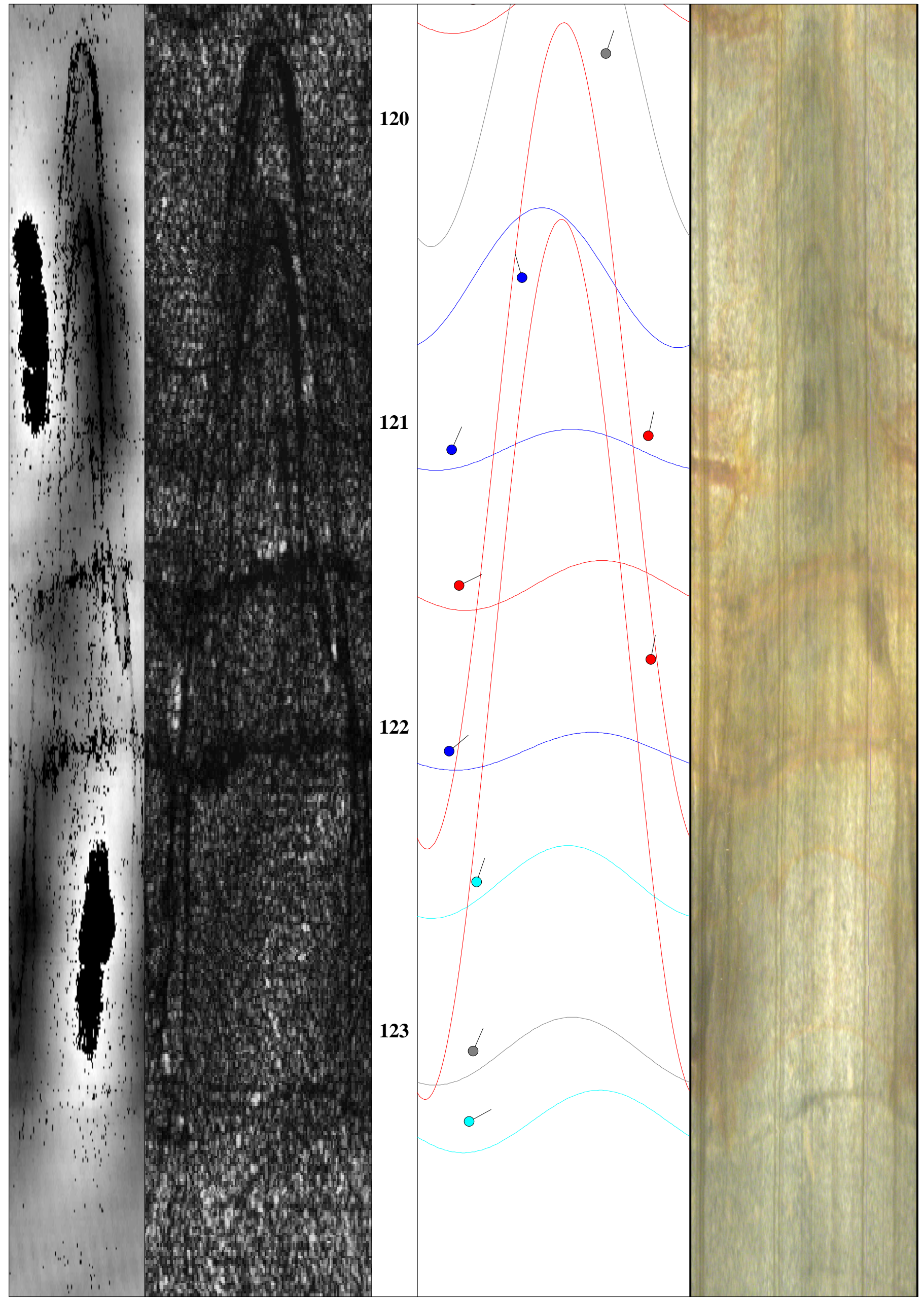




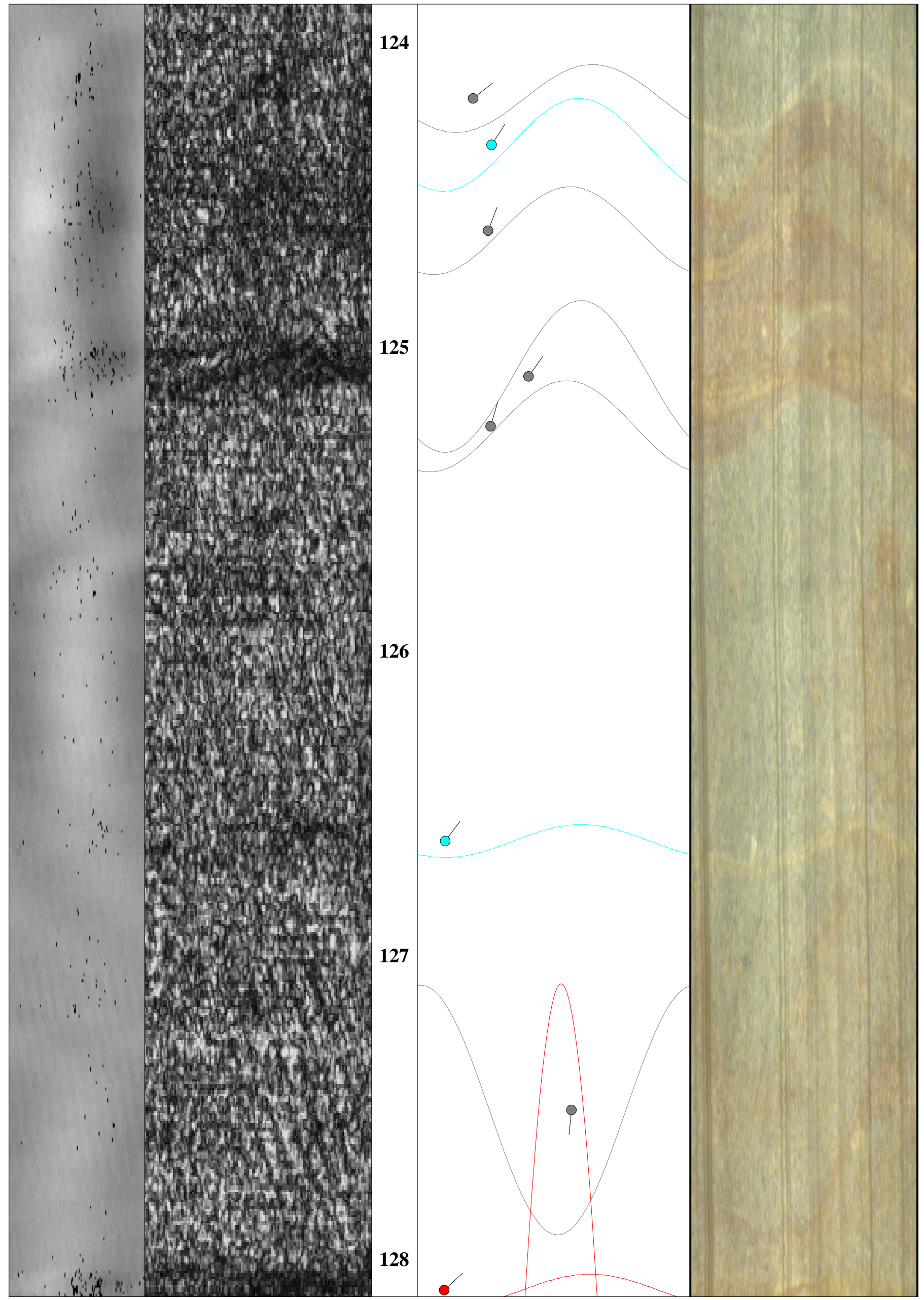




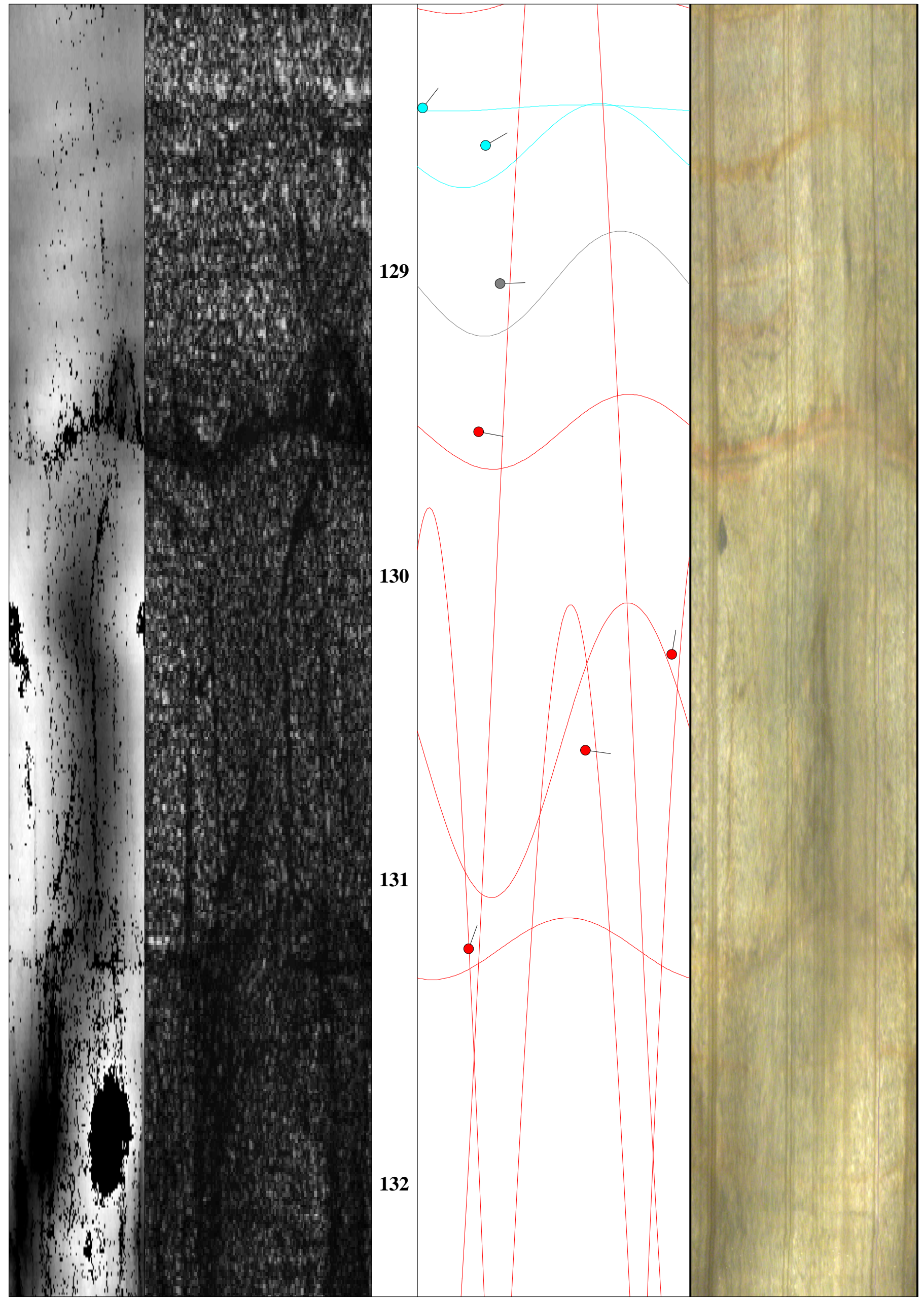




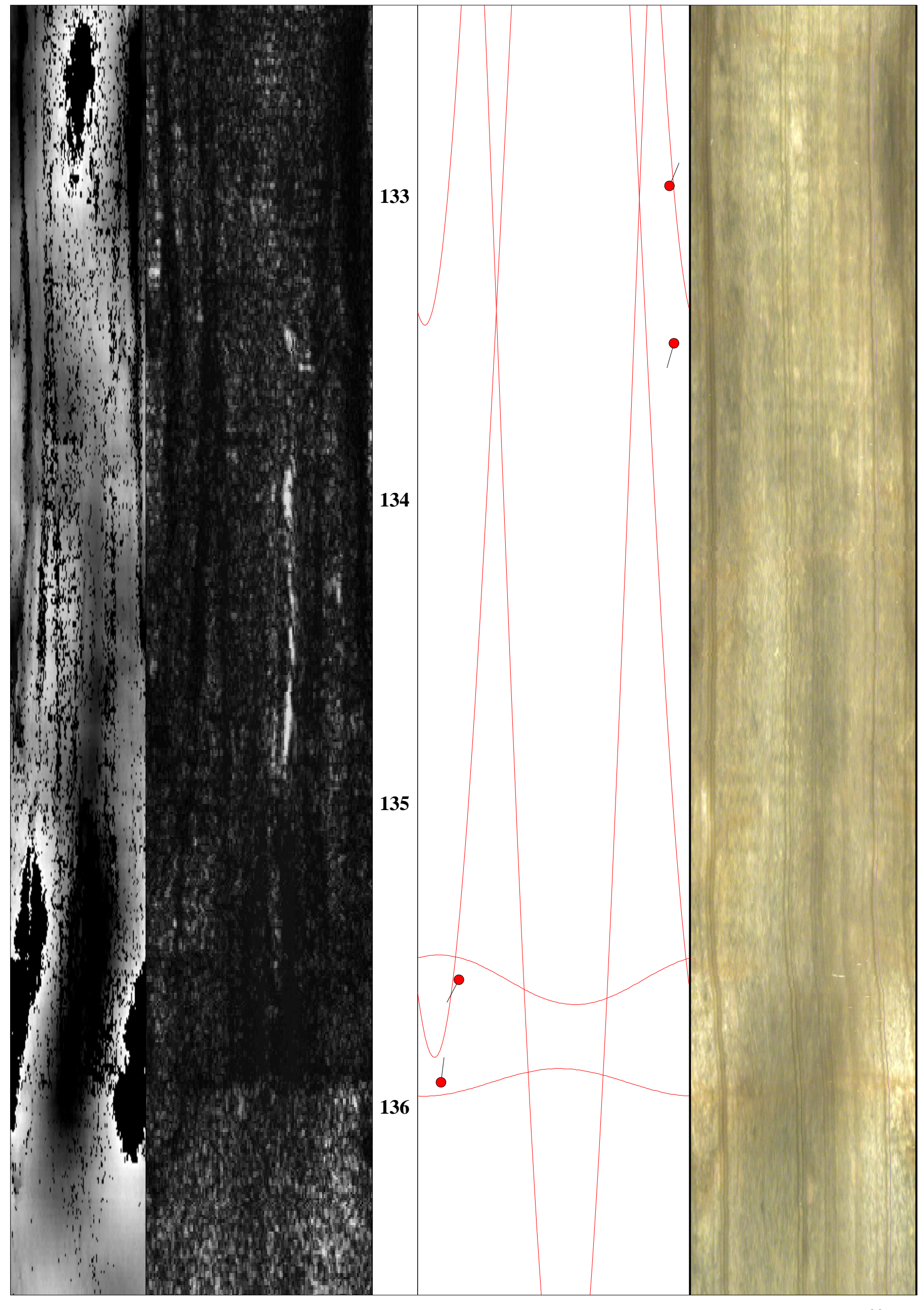




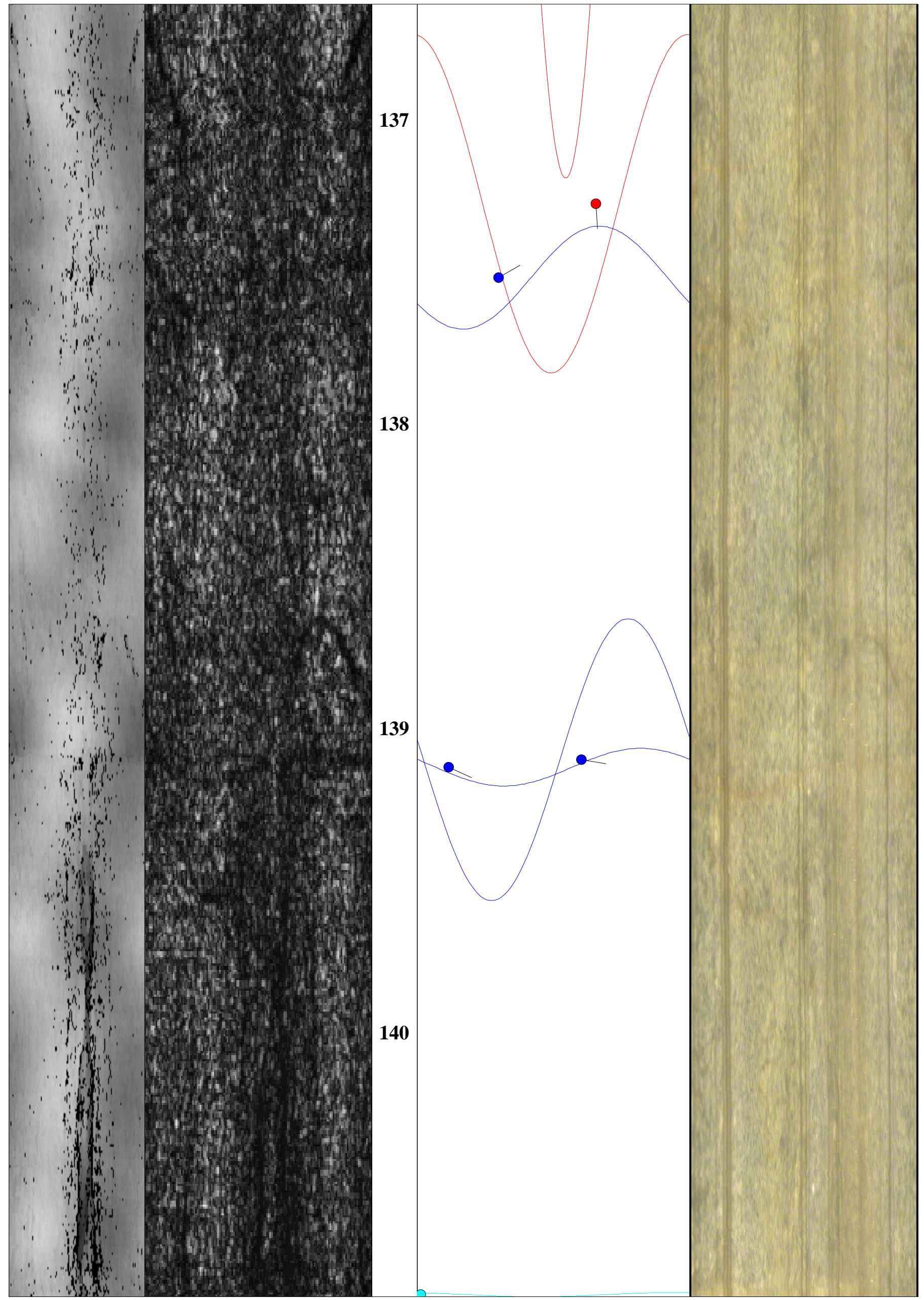




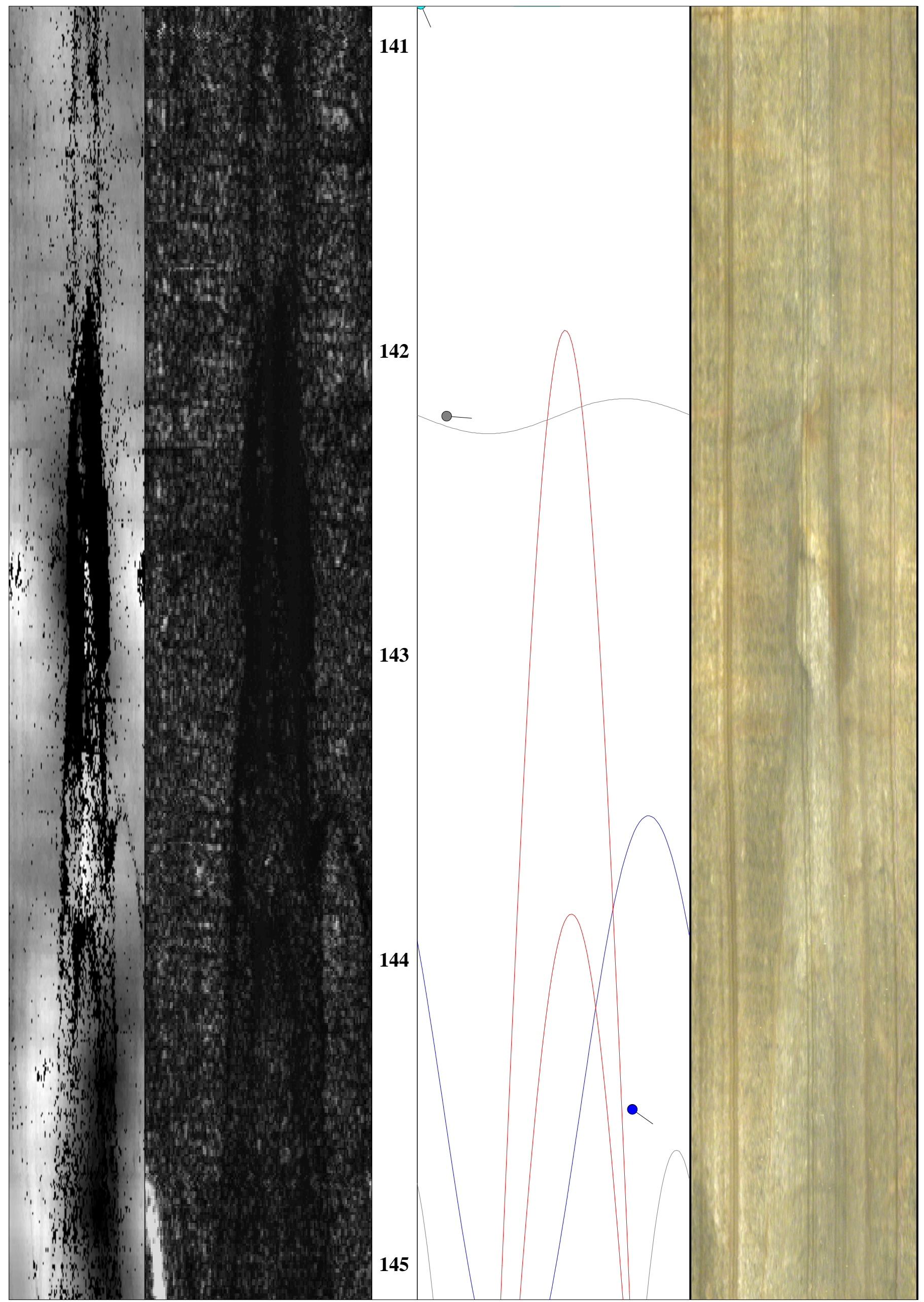




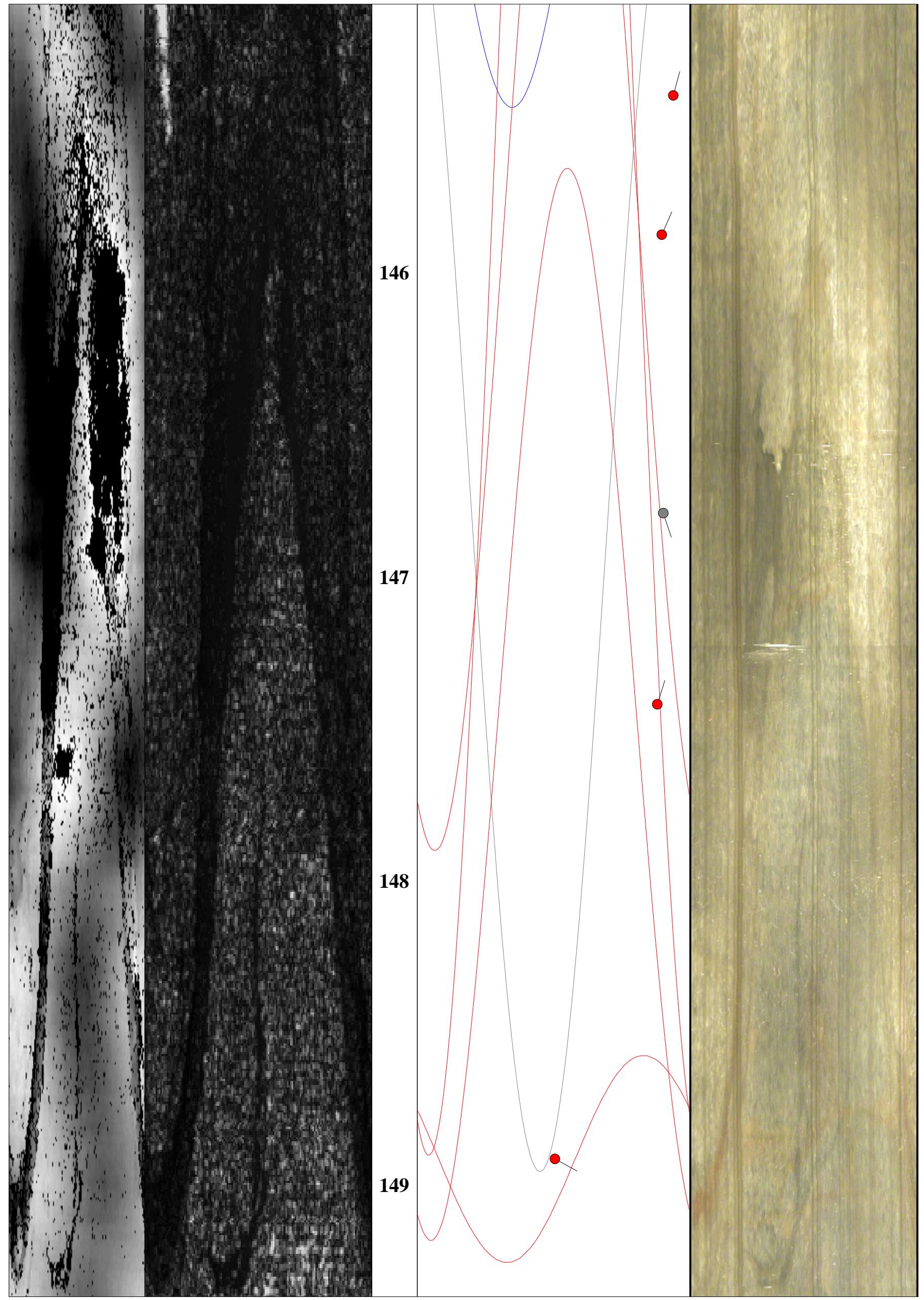




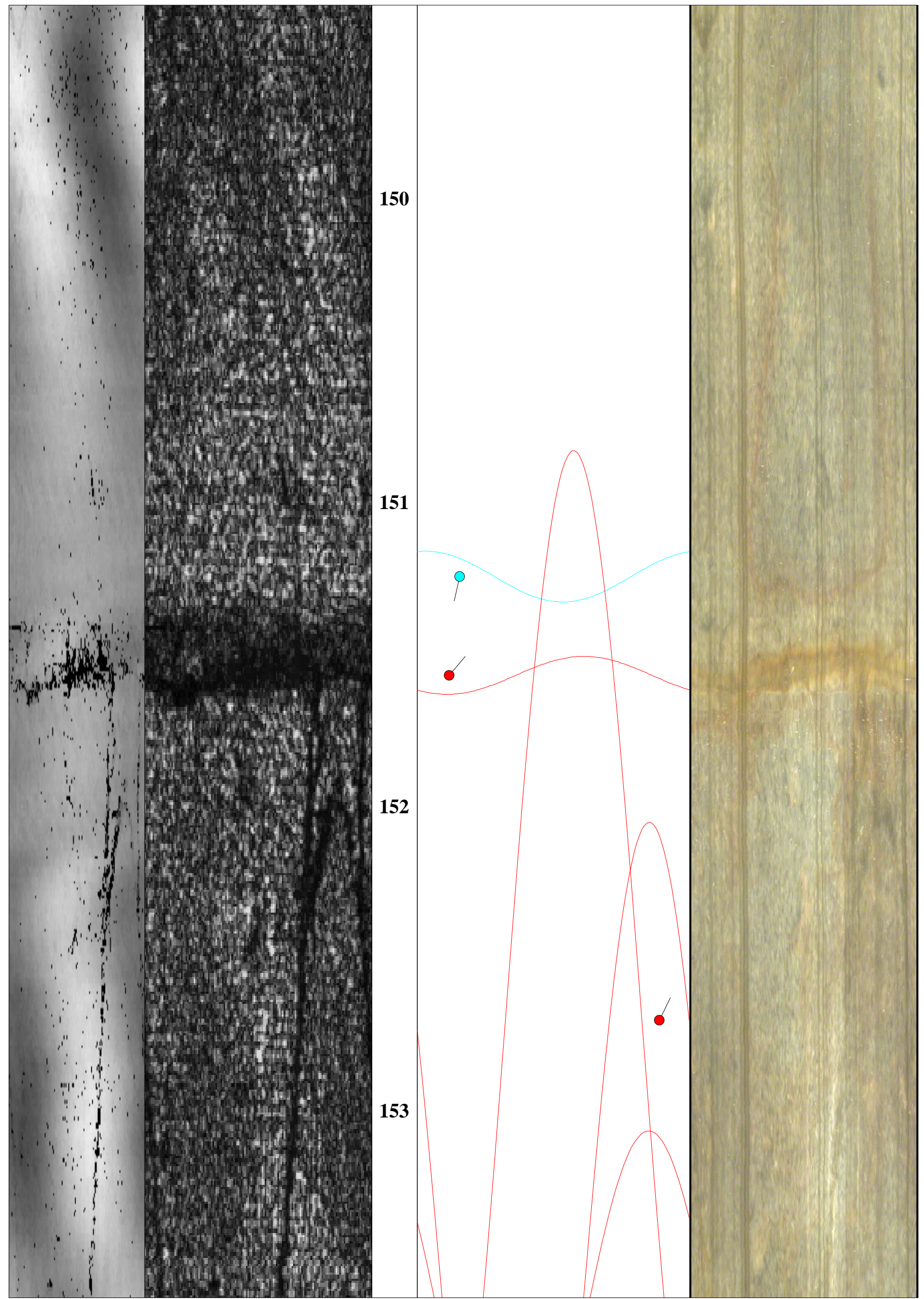




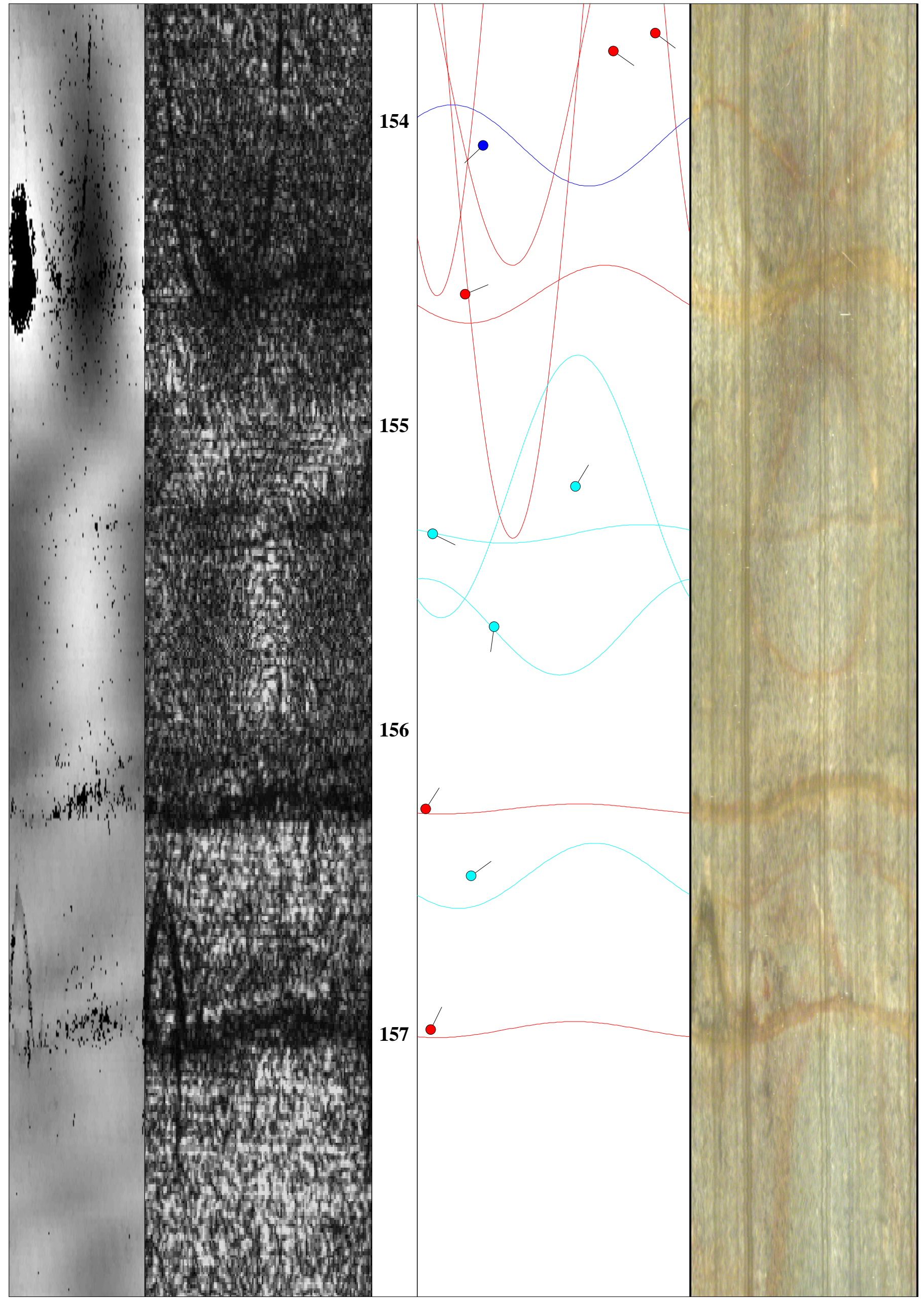




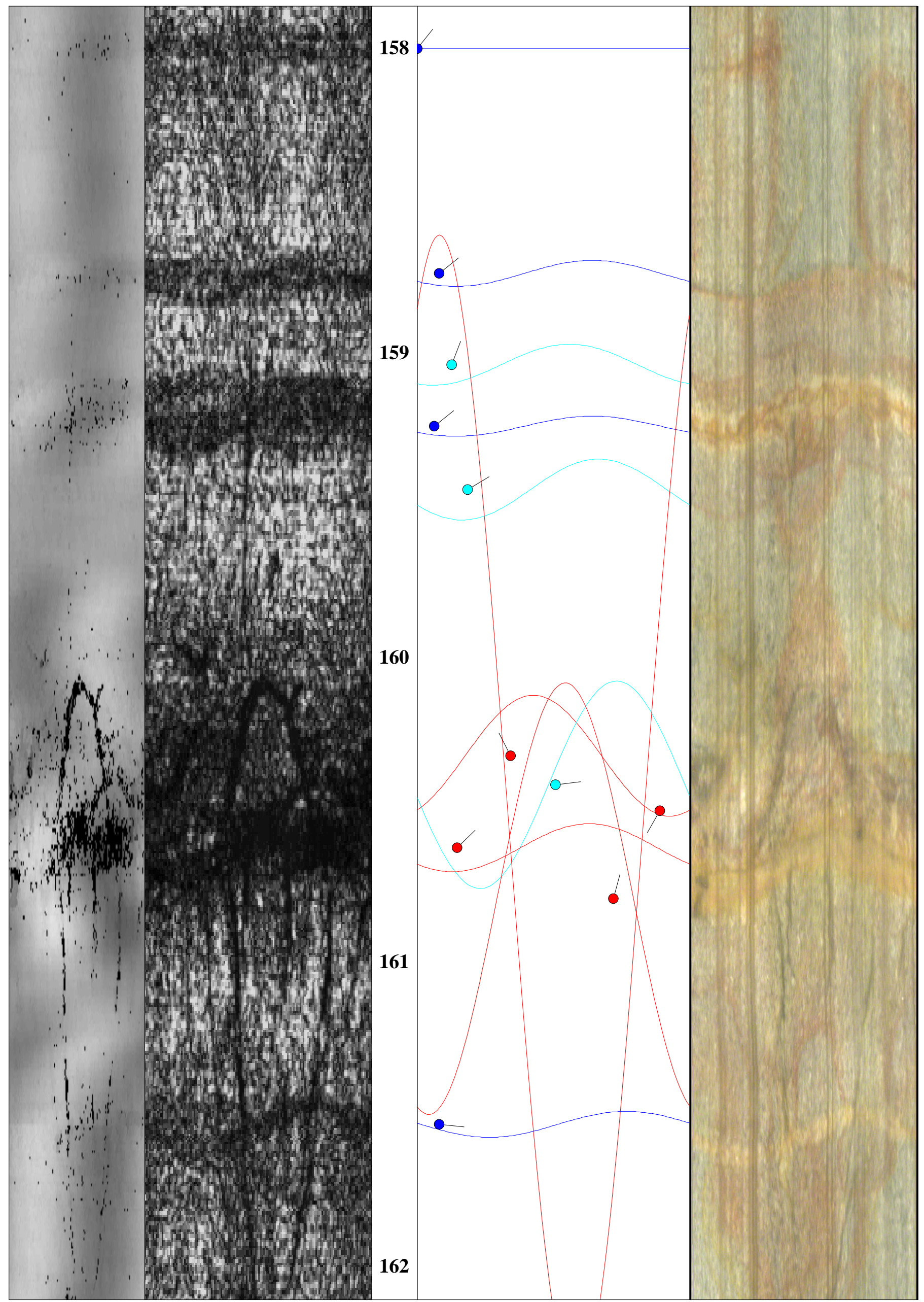




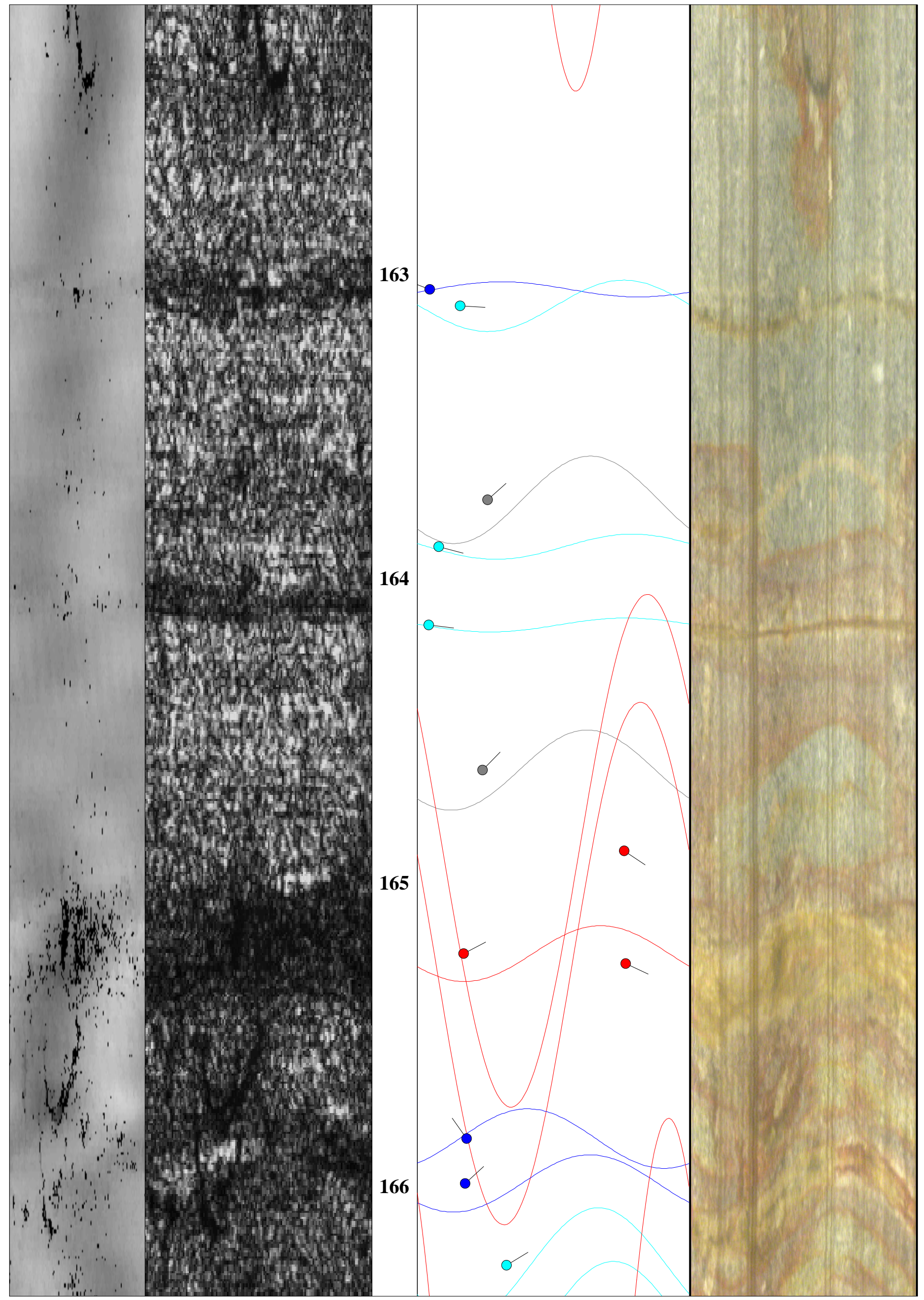




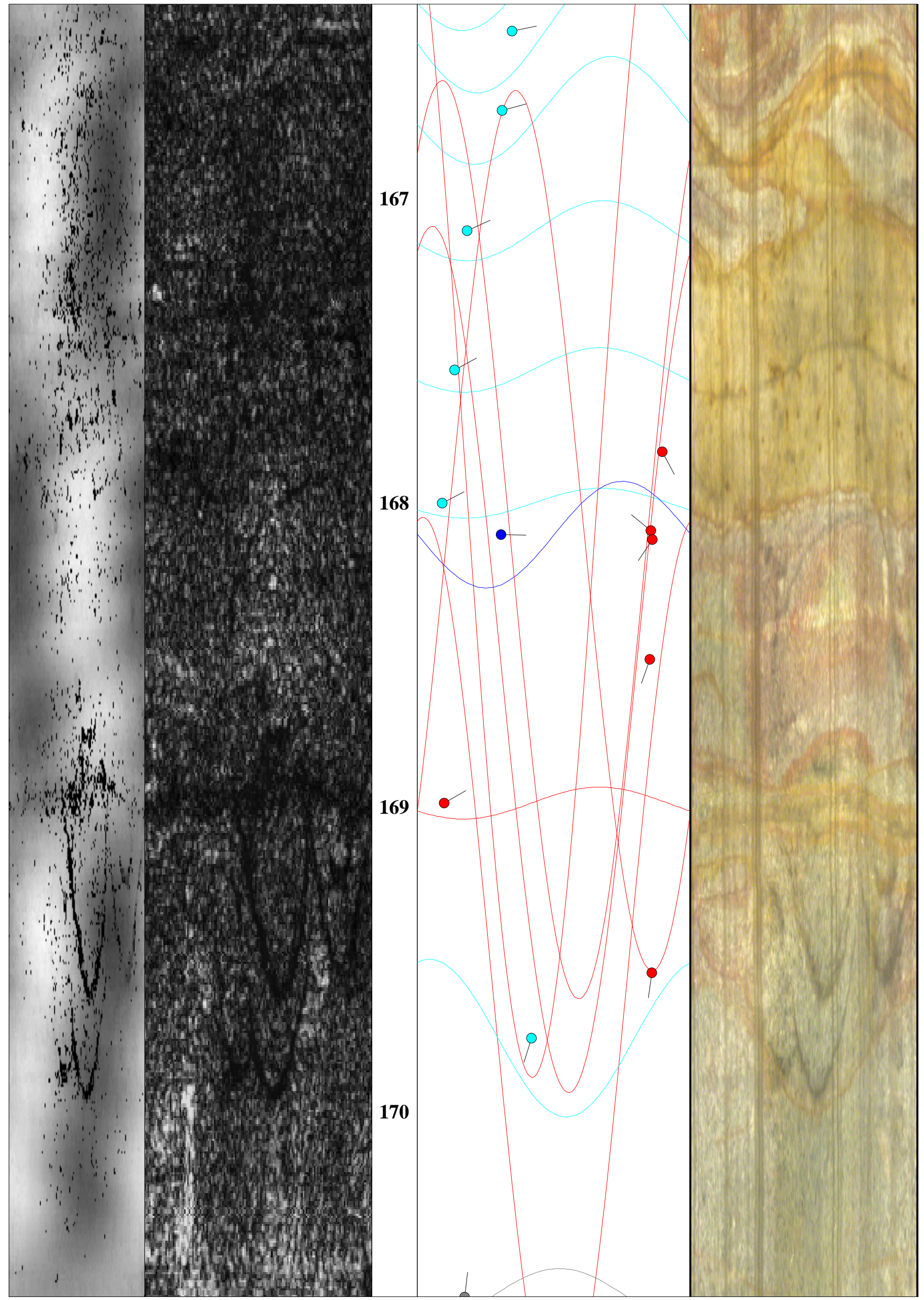




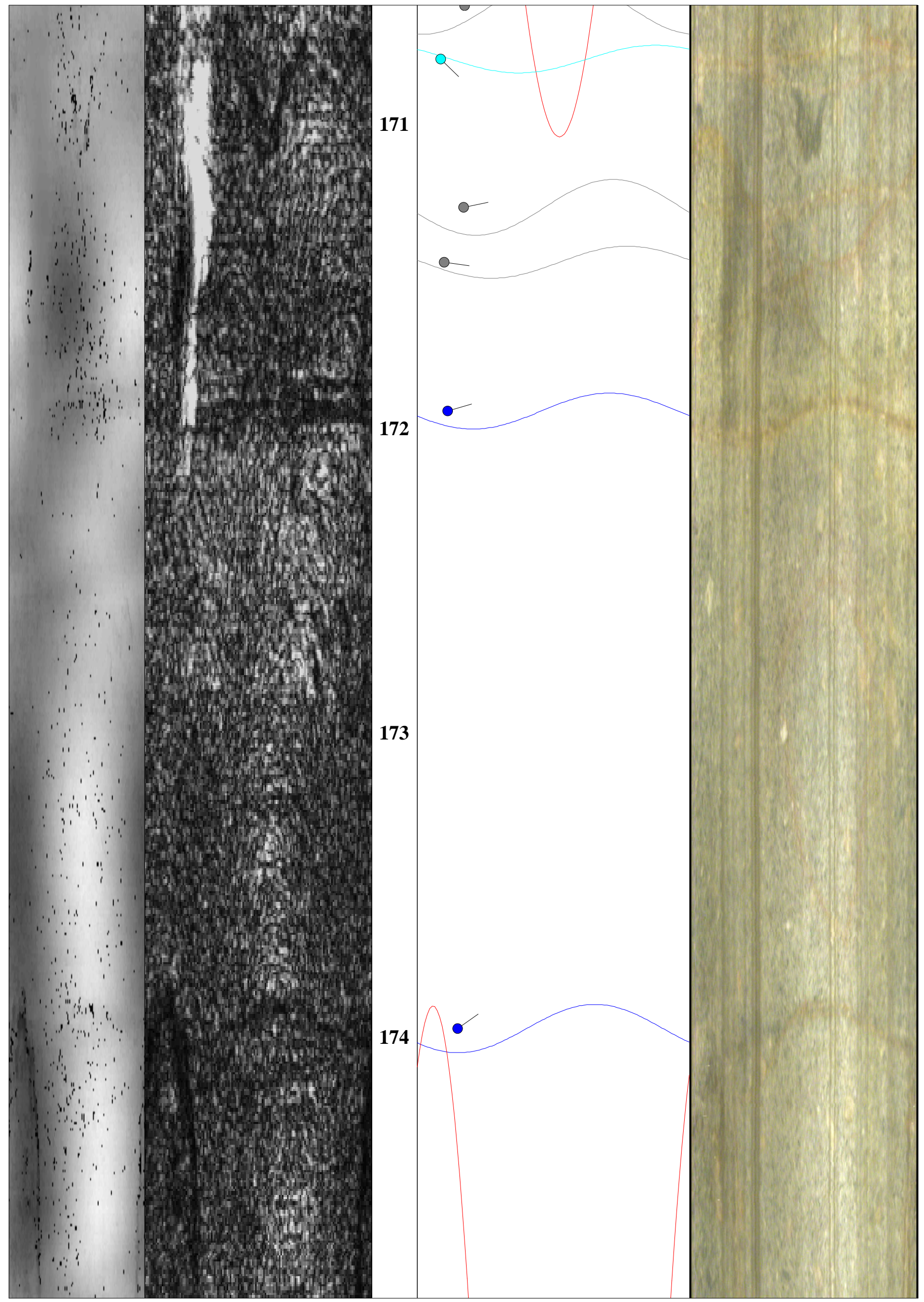




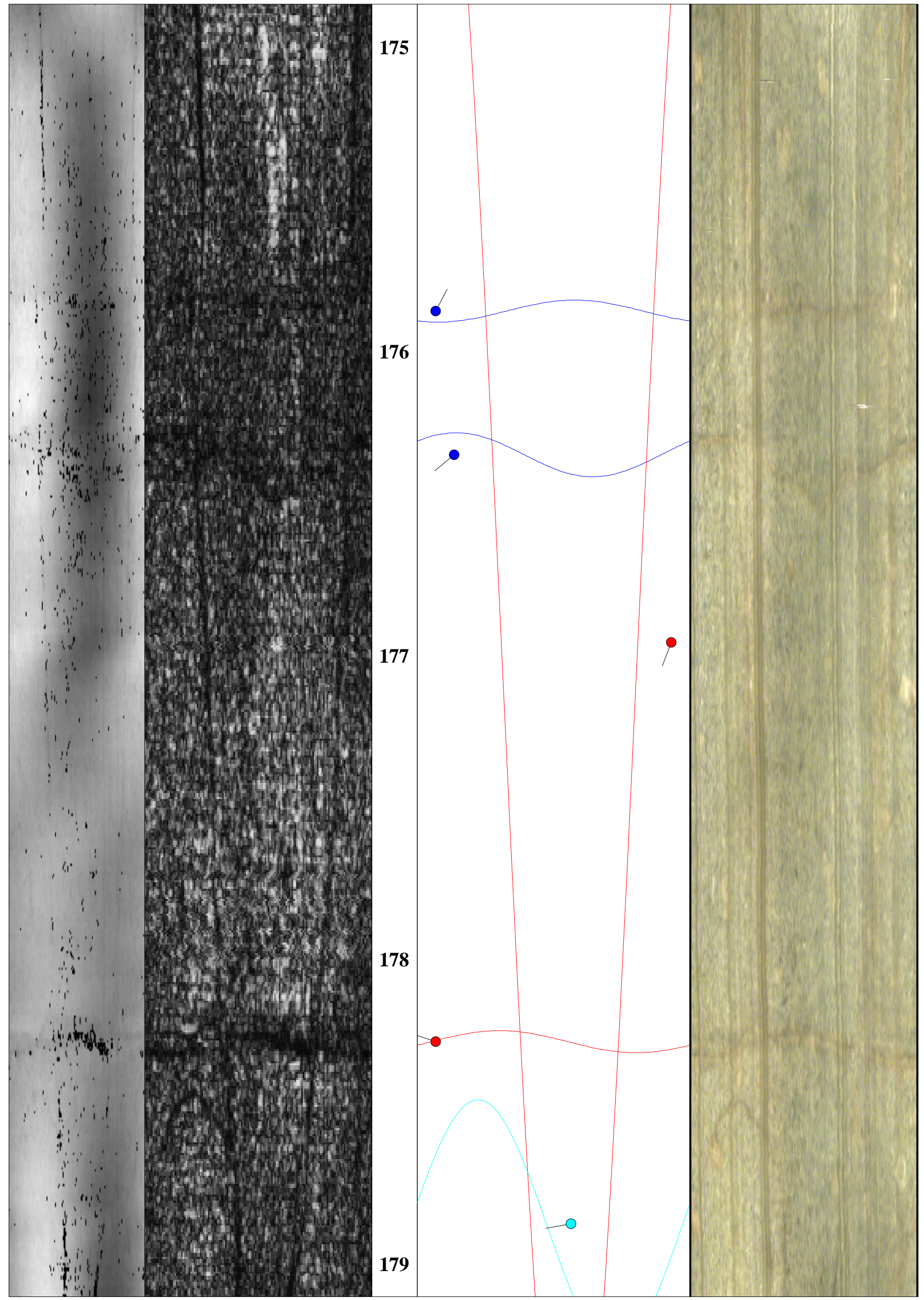




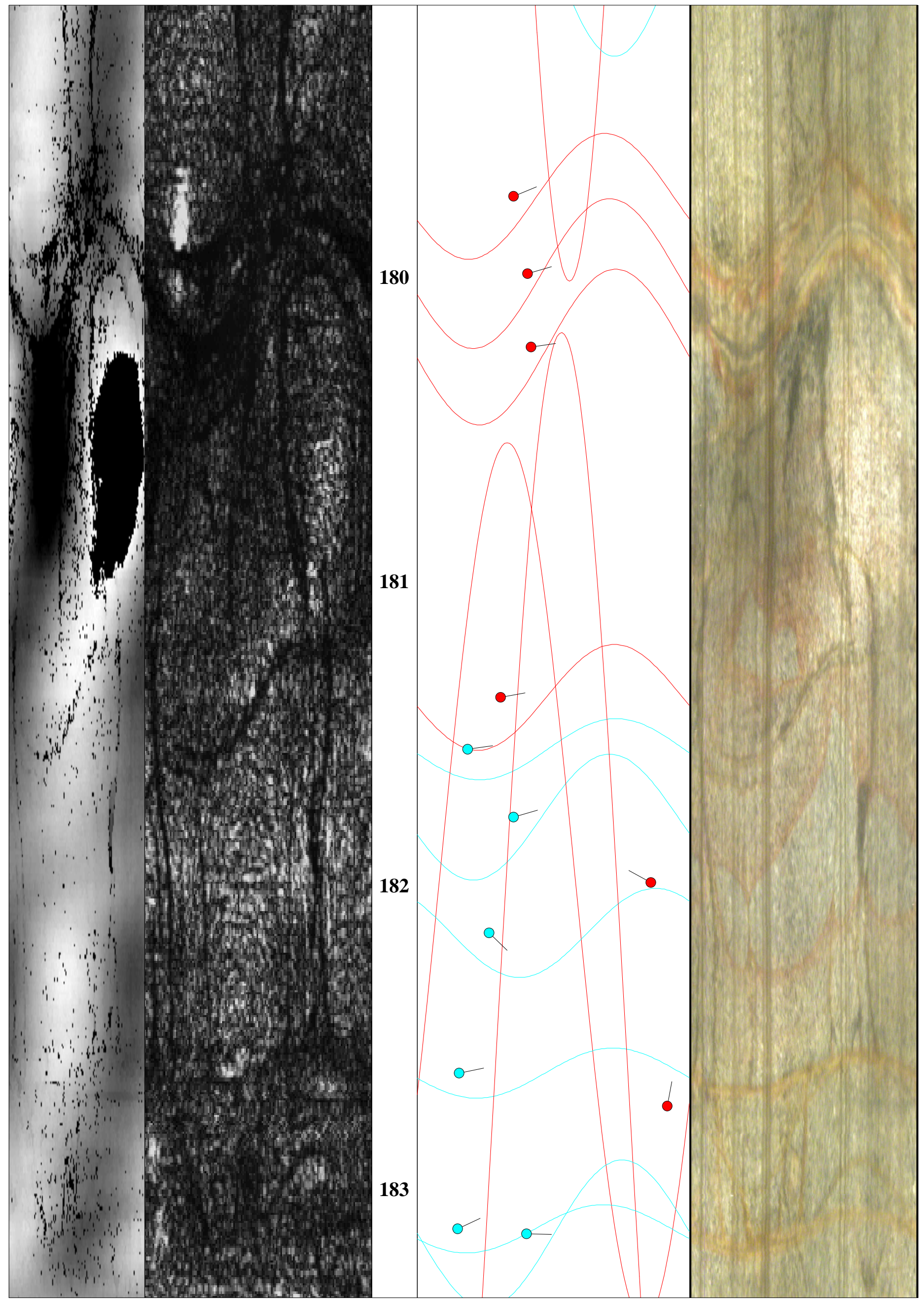




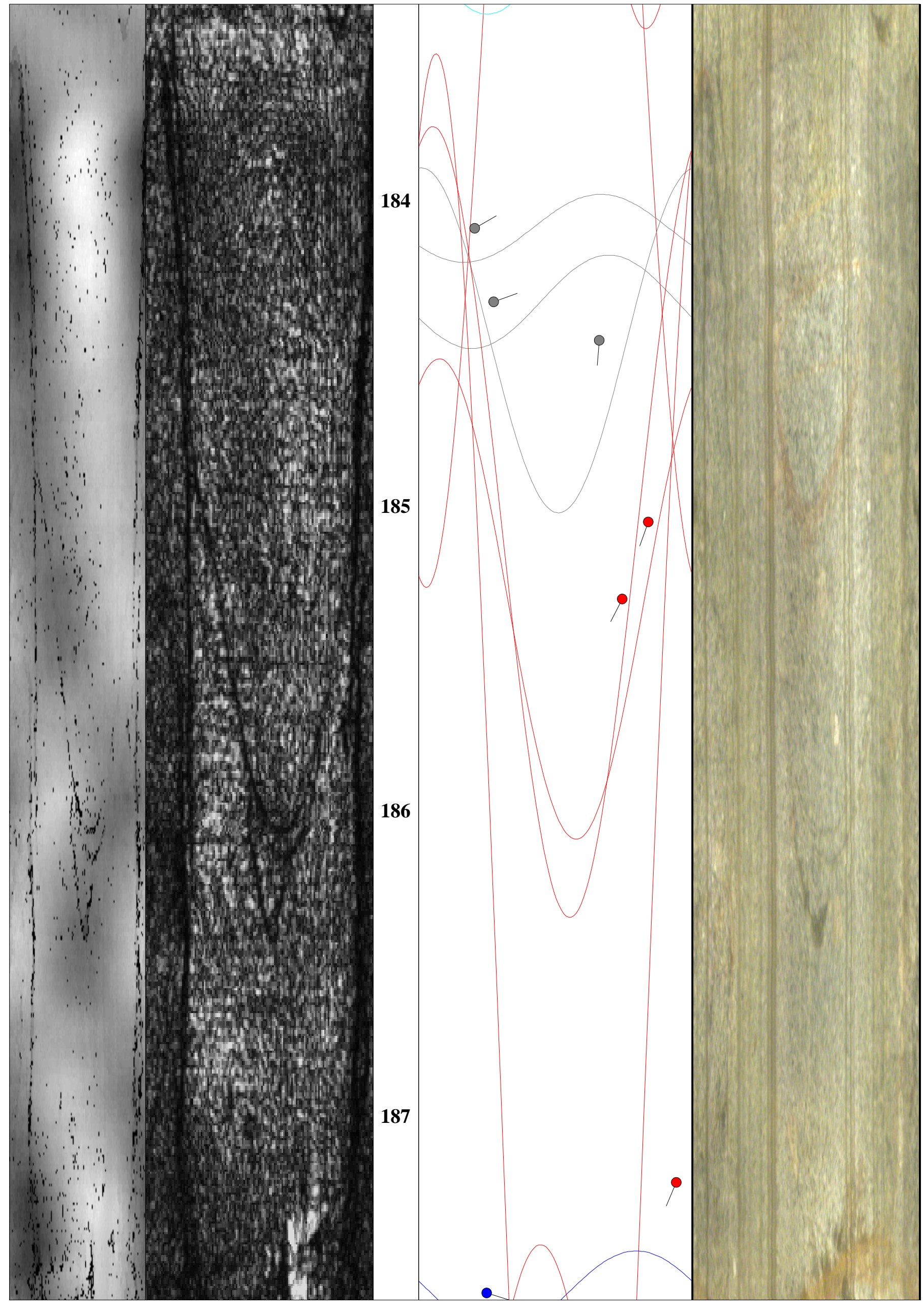




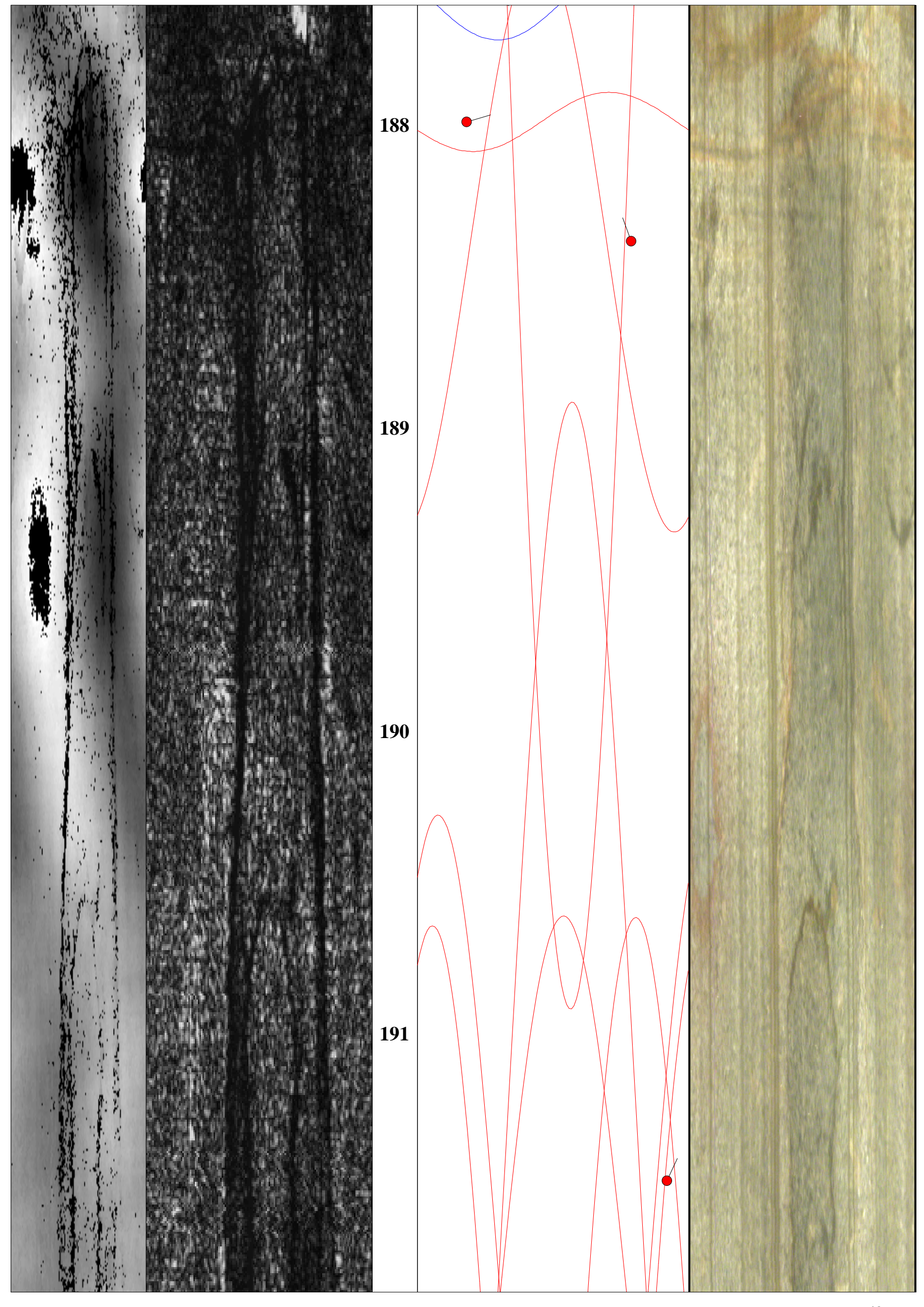




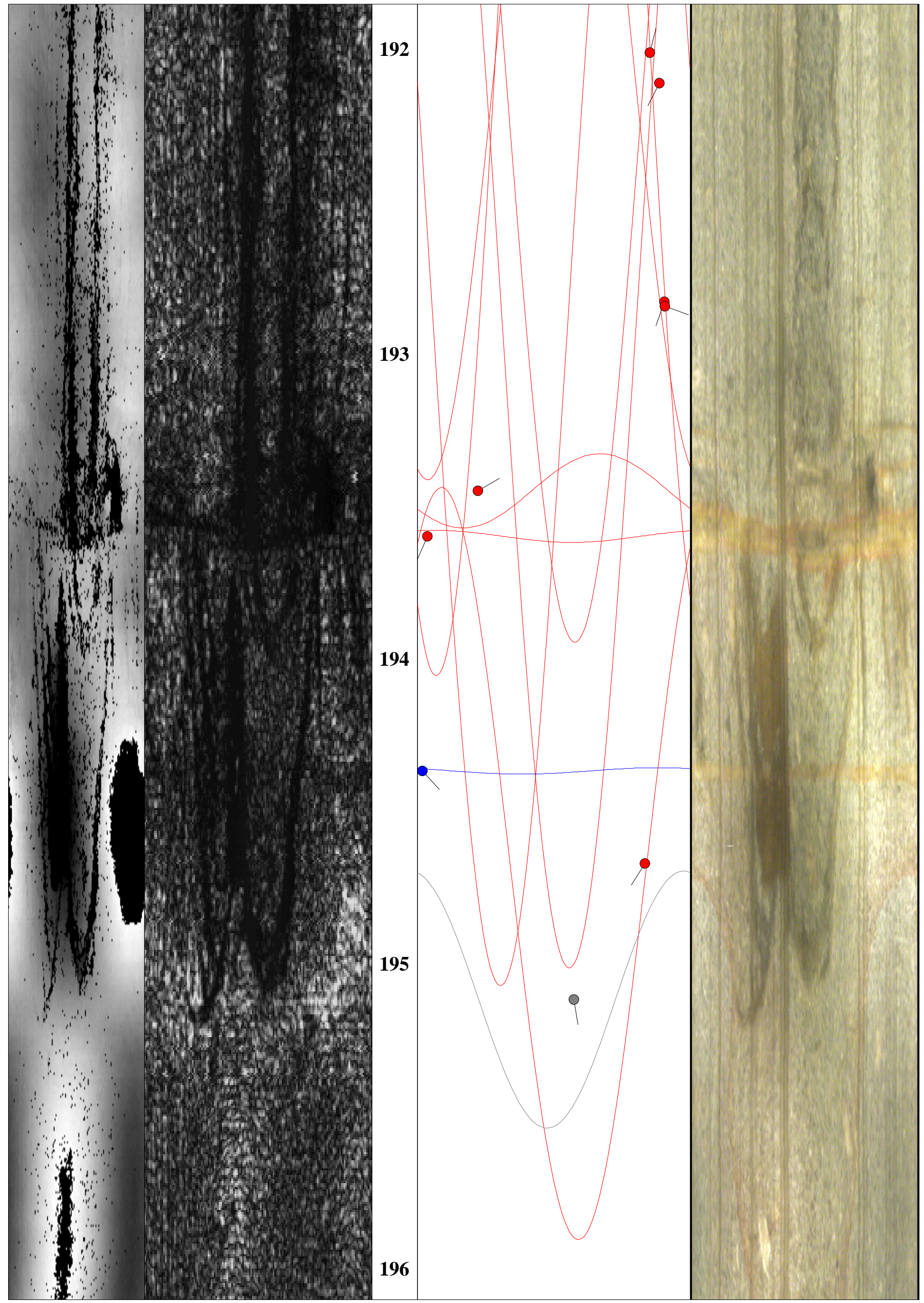




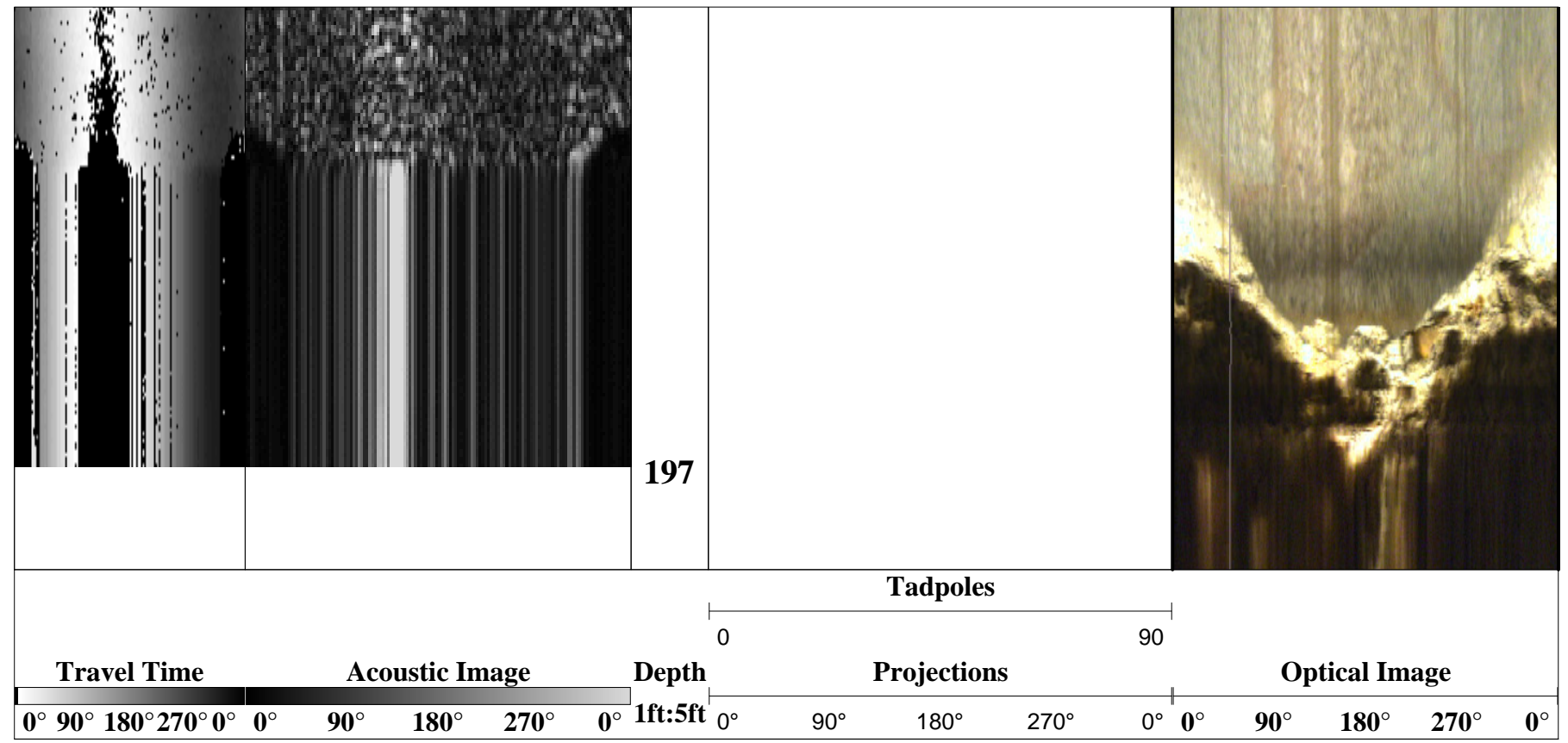




\section{Stereonet Diagram - Schmidt Projection}

Acoustic Televiewer Features

Nevada Test Site

Source Physics Experiment

U-15n4

NNSA/NSO

22 Sept 2010

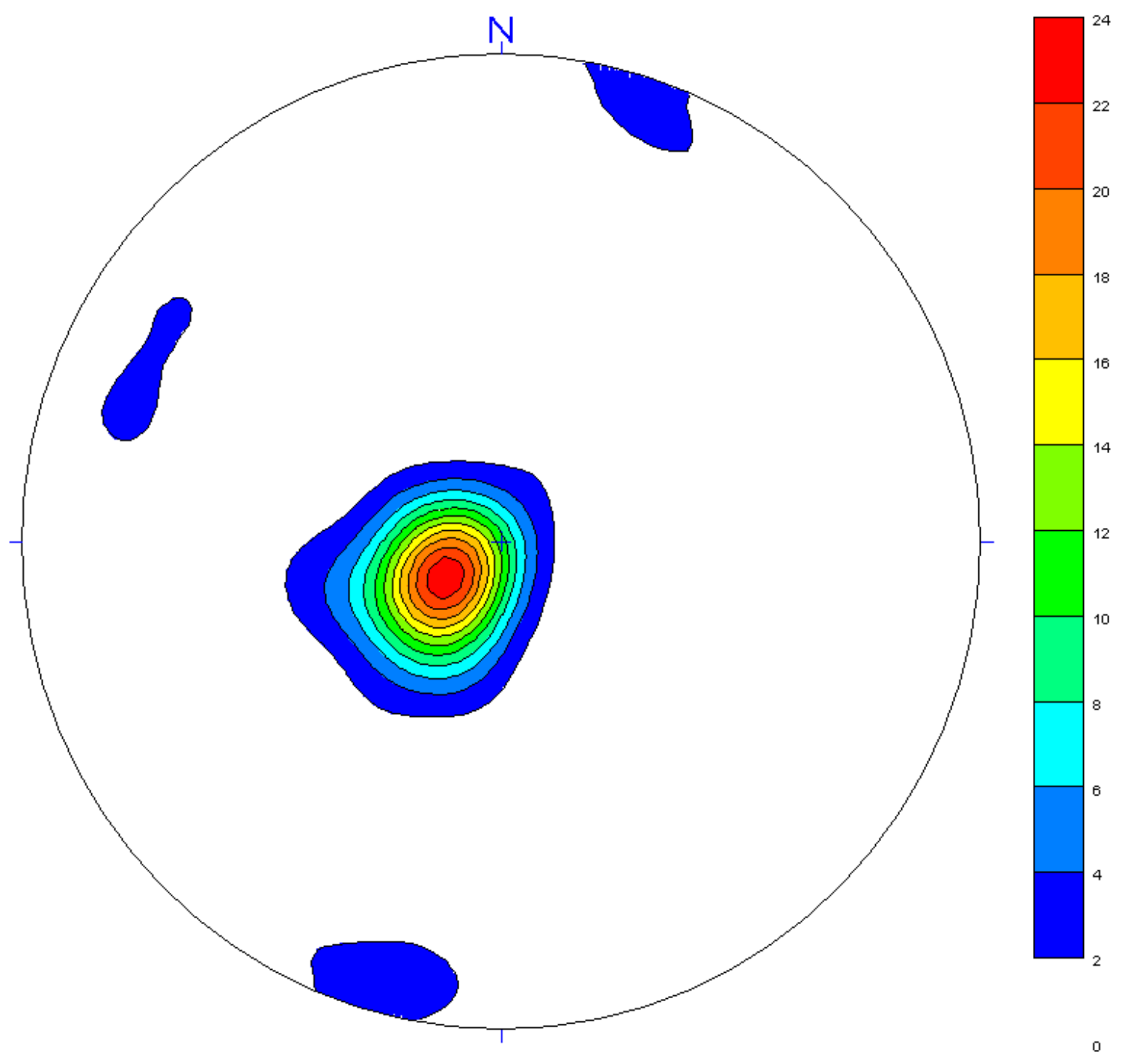

All directions are with respect to True North. 


\section{Stereonet Diagram - Schmidt Projection \\ Acoustic Televiewer Features \\ Nevada Test Site \\ Source Physics Experiment \\ U-15n4 \\ NNSA/NSO \\ 22 Sept 2010}

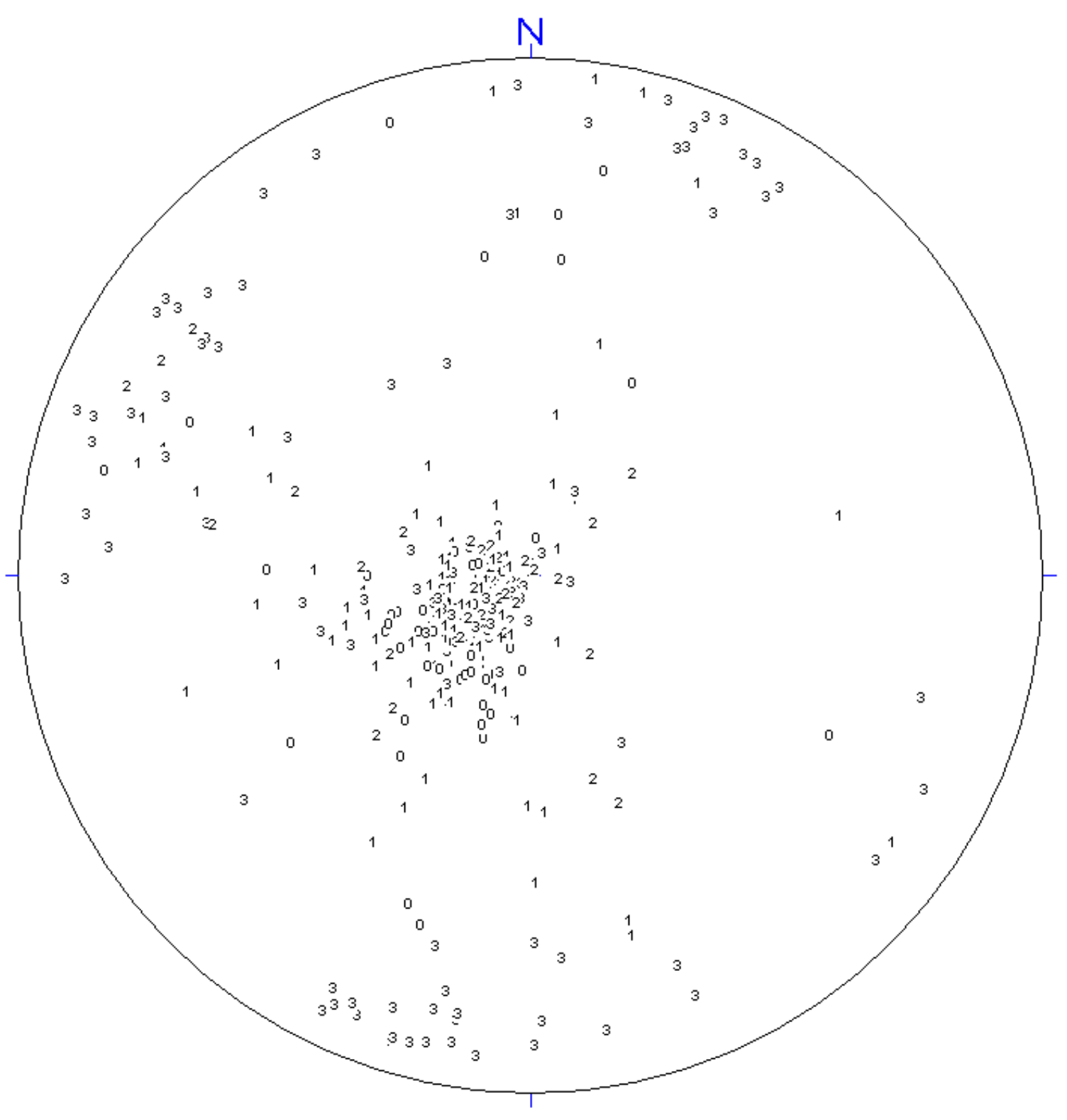

All directions are with respect to True North. 


\section{Rose Diagram - Dip Directions \\ Acoustic Televiewer Features \\ Nevada Test Site \\ Source Physics Experiment \\ U-15n4 \\ NNSA/NSO \\ 22 Sept 2010}

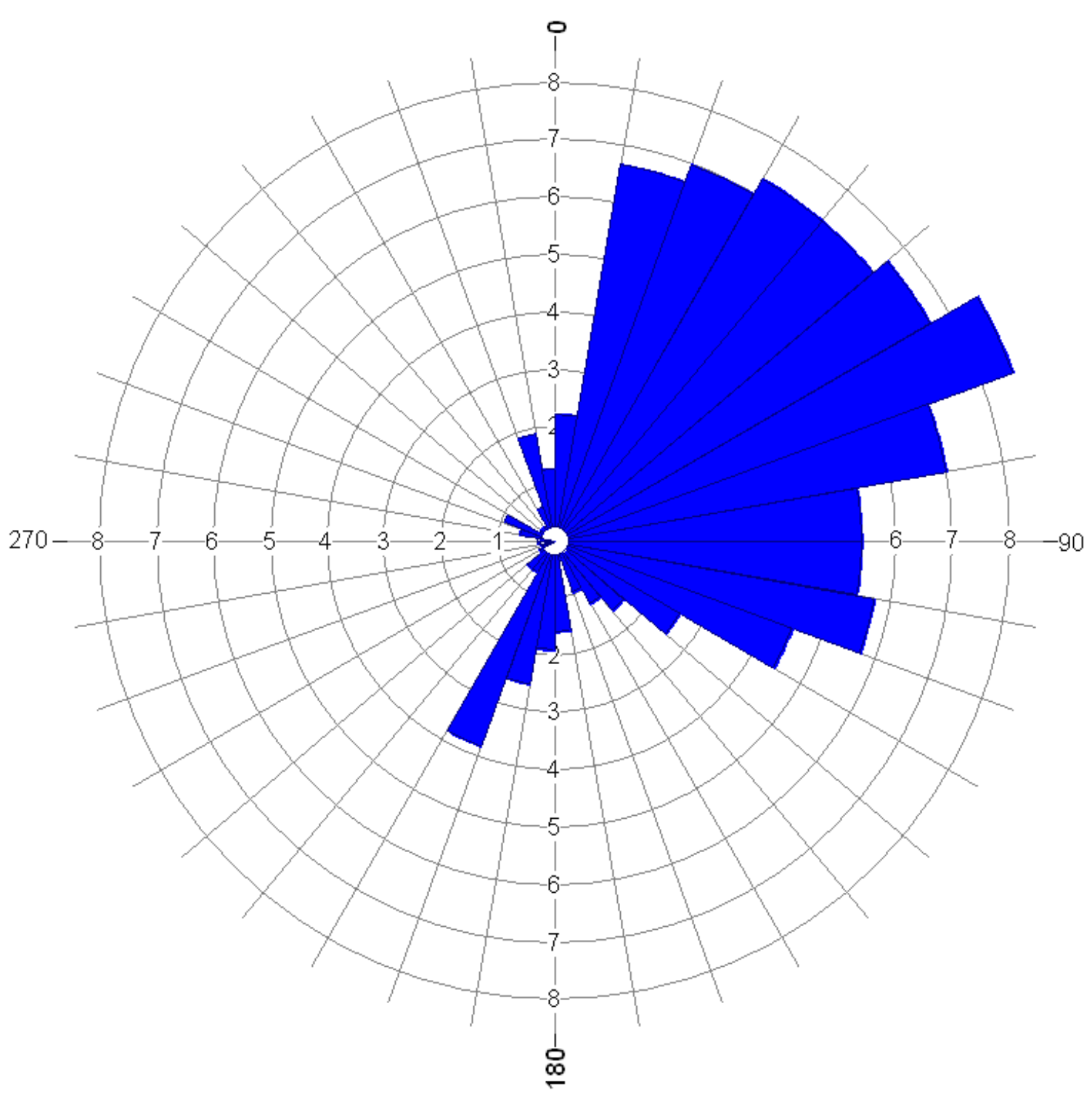




\section{Rose Diagram - Dip Angles \\ Acoustic Televiewer Features \\ Nevada Test Site \\ Source Physics Experiment \\ U-15n4 \\ NNSA/NSO \\ 22 Sept 2010}

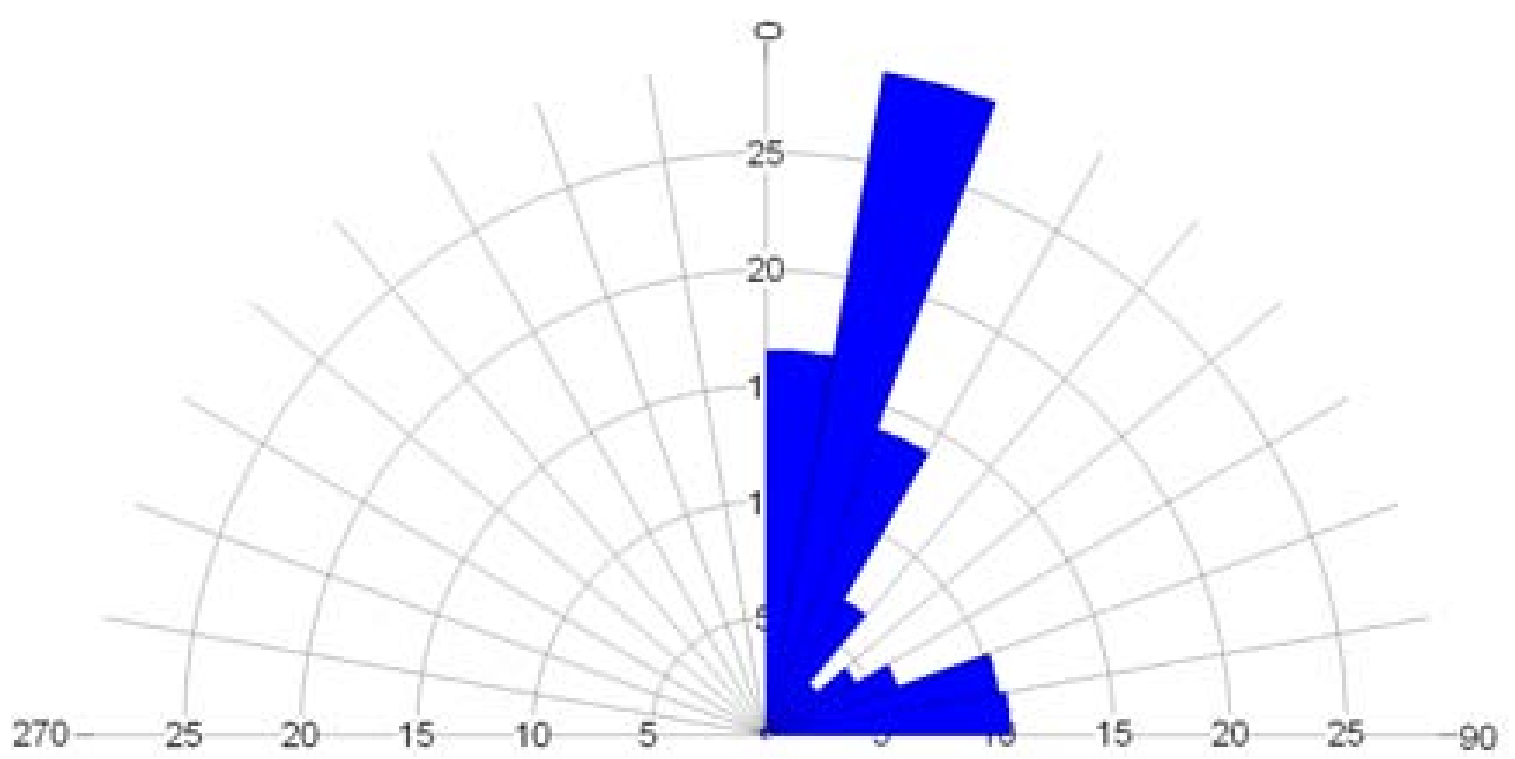




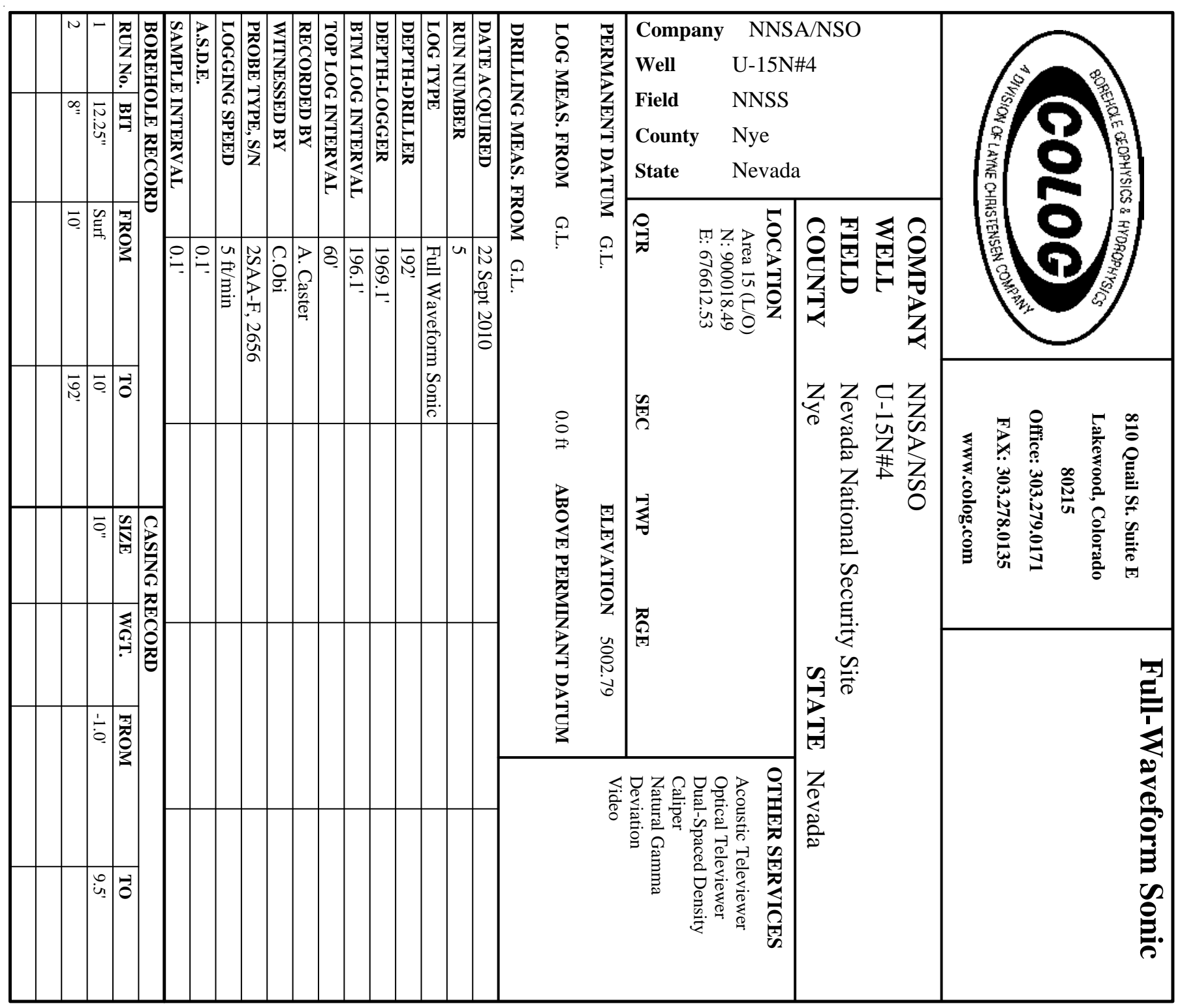

COMMENTS

NA - Not Available, N/A - Not Applicable 


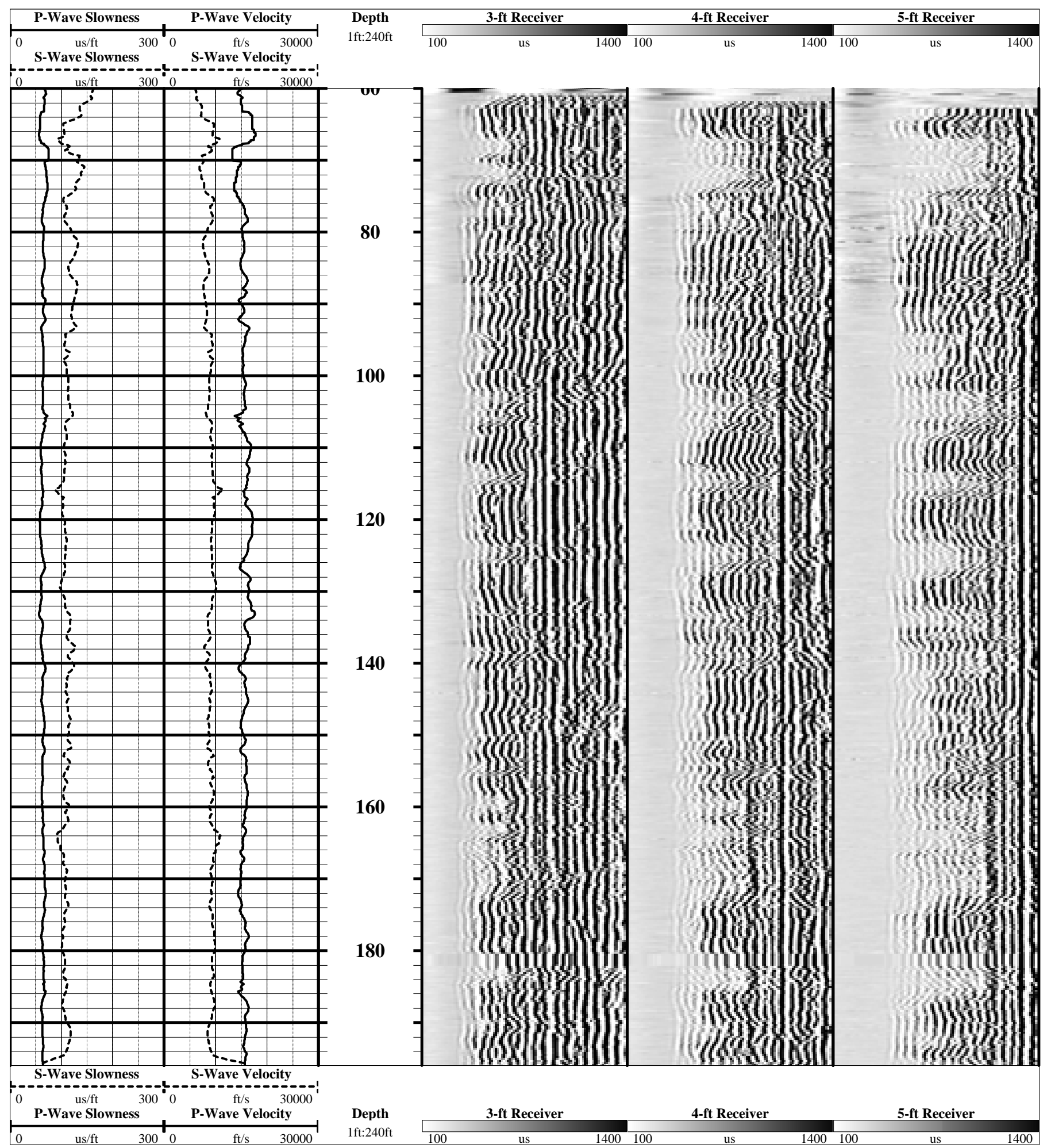




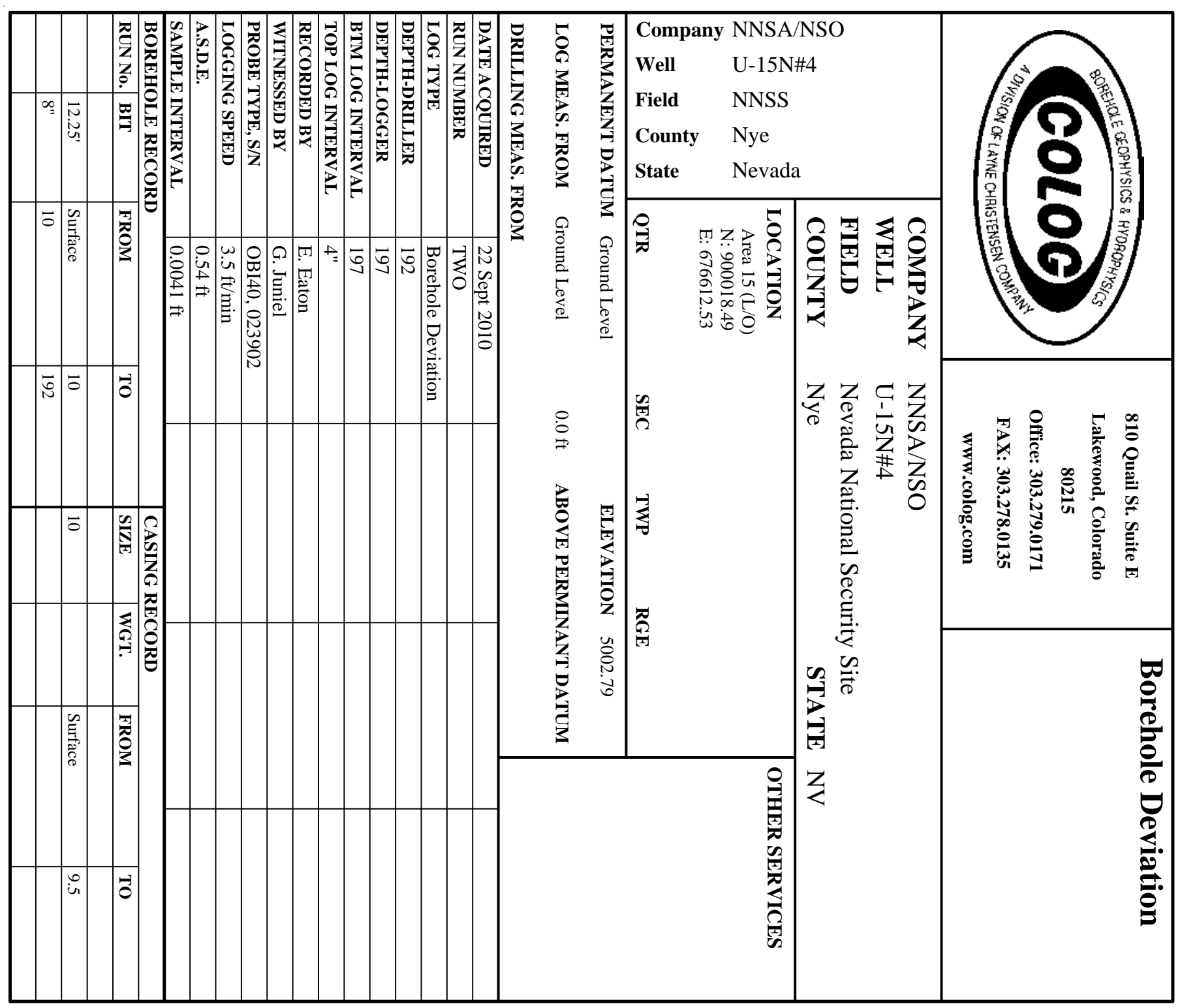

COMMENTS

NA - Not Available, N/A - Not Applicable 

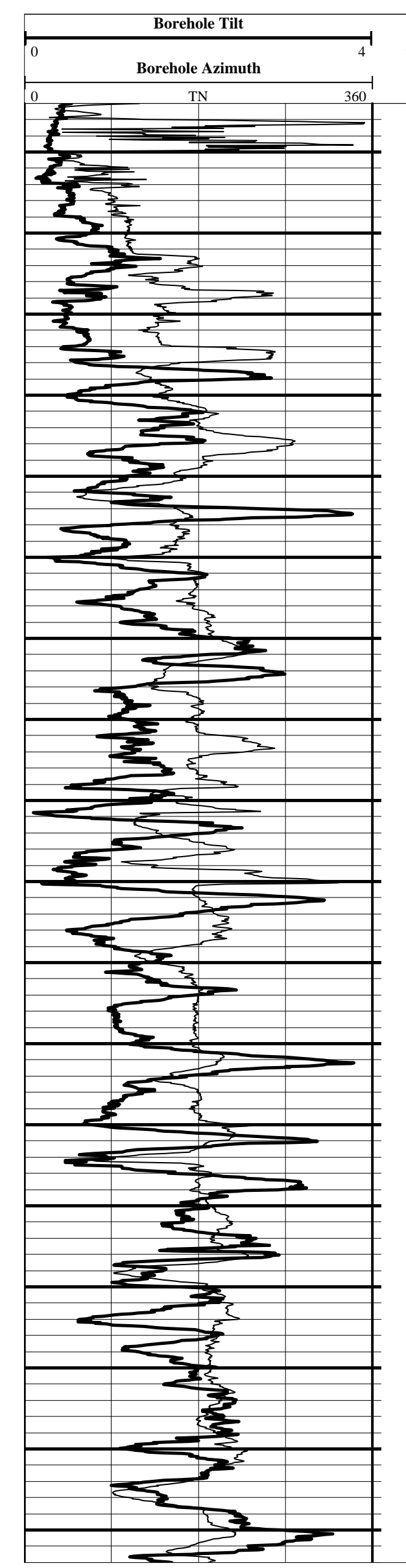

40

60

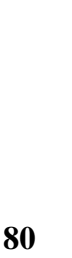

Depth
1ft:240ft

20

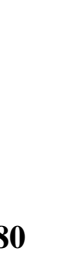

100

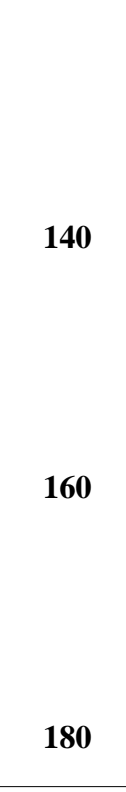

140

160
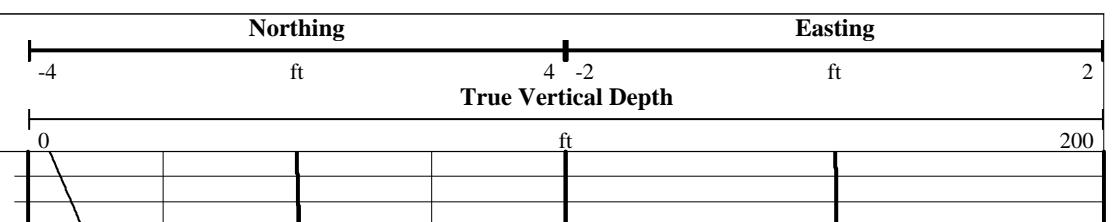


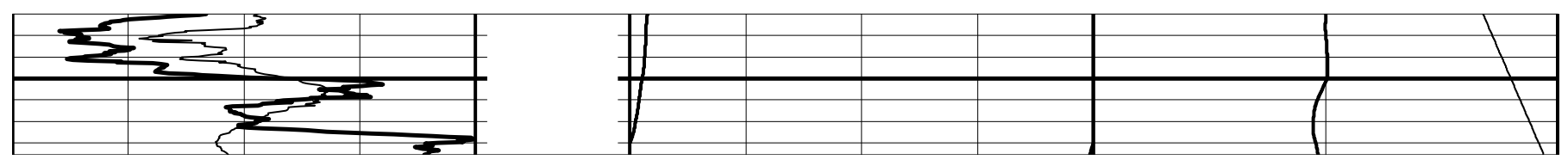

Page 3 


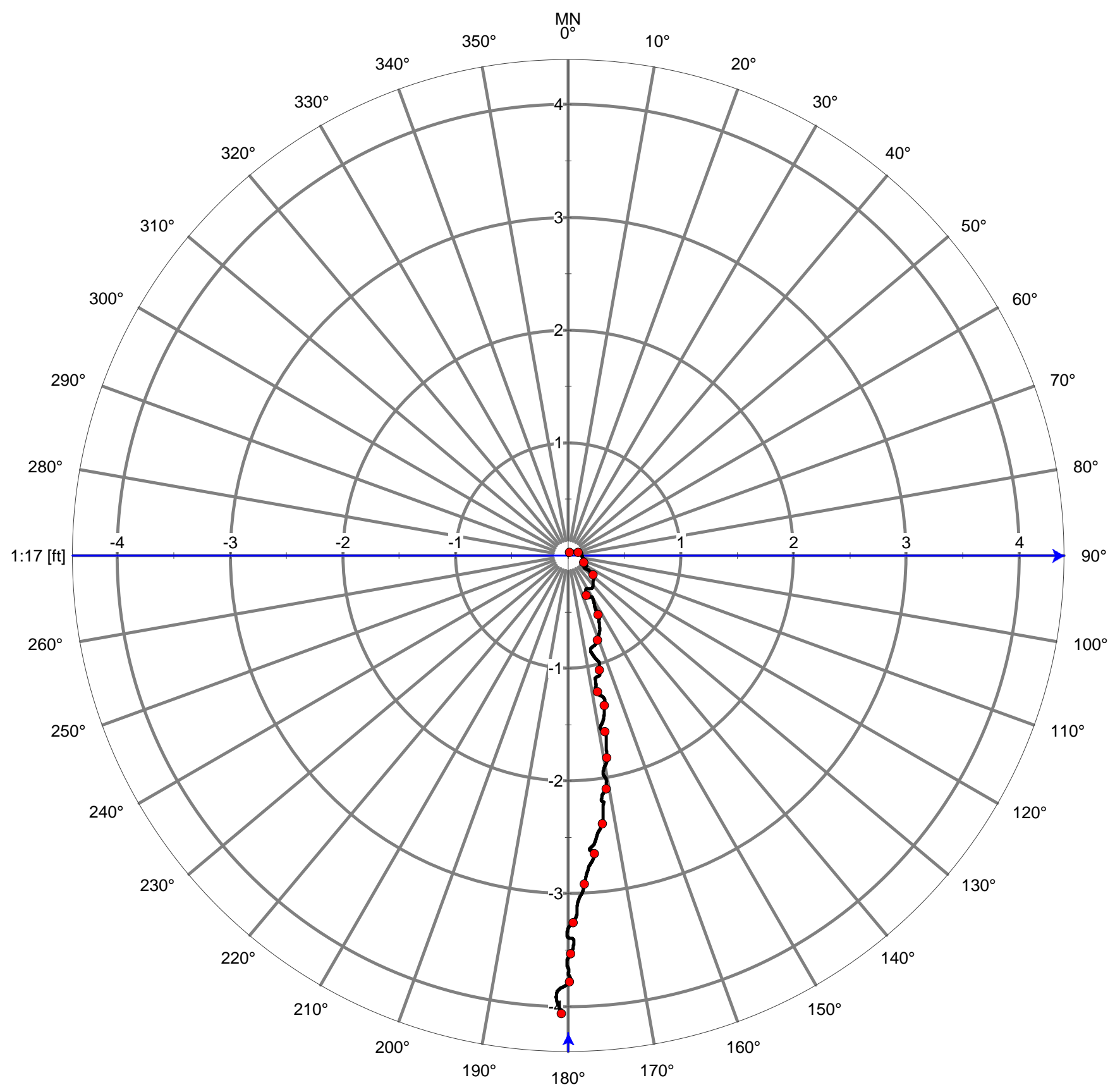




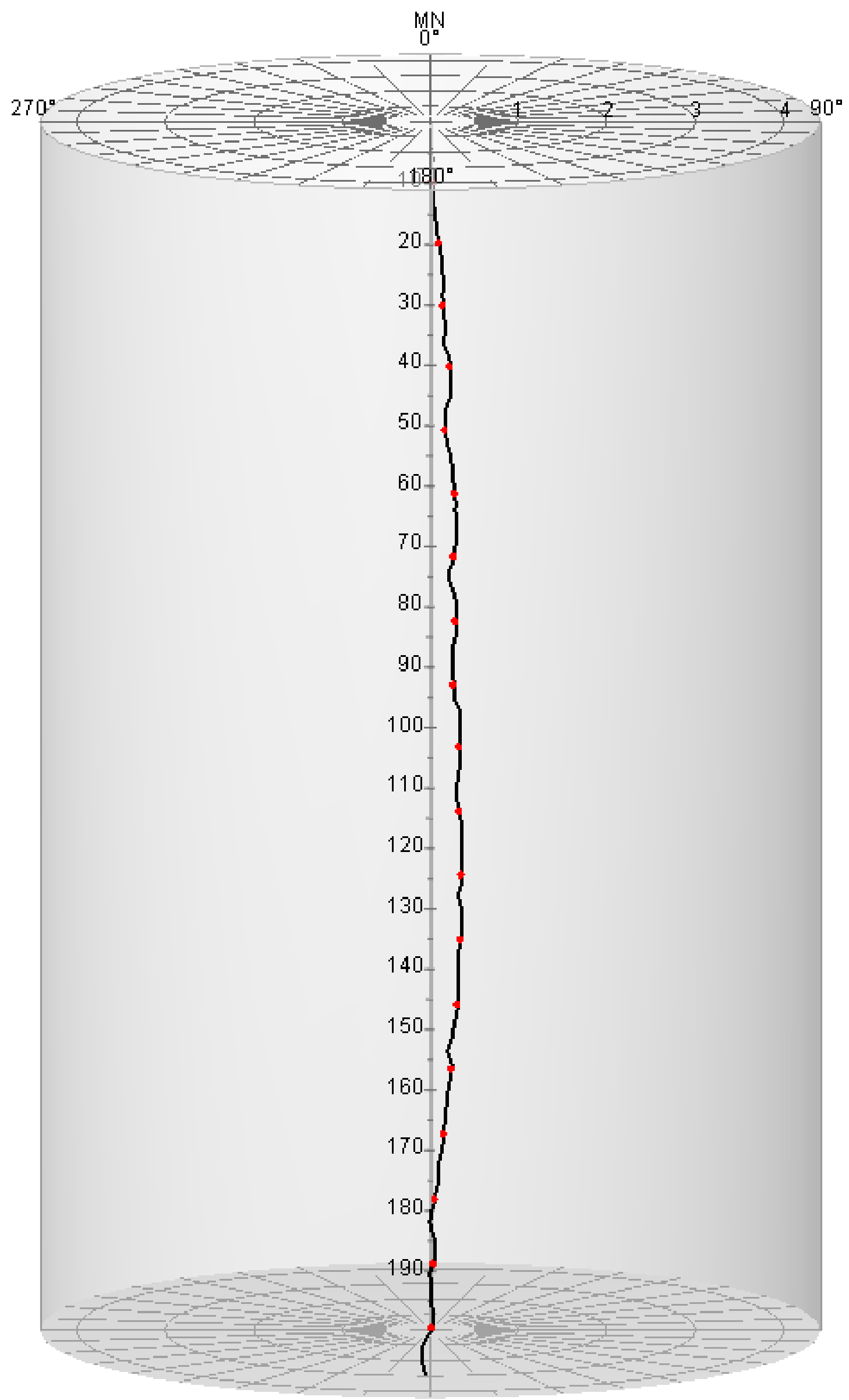


Appendix F-6

Borehole Geophysical Log Plots for Instrument Hole U-15n\#5 


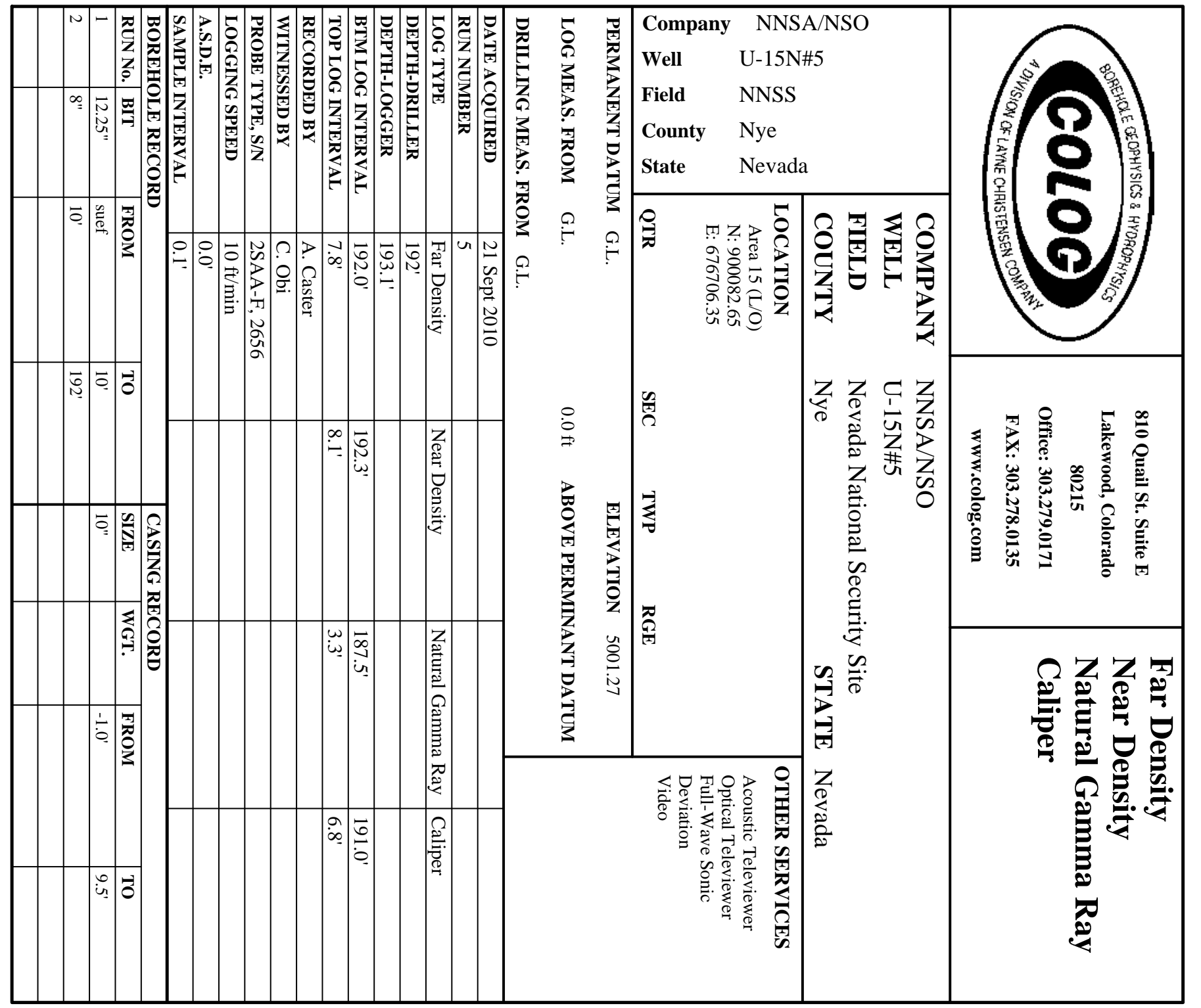

\section{COMMENTS}

NA - Not Available, N/A - Not Applicable

Matrix Density of 2.64 used to calculate Density Porosity 


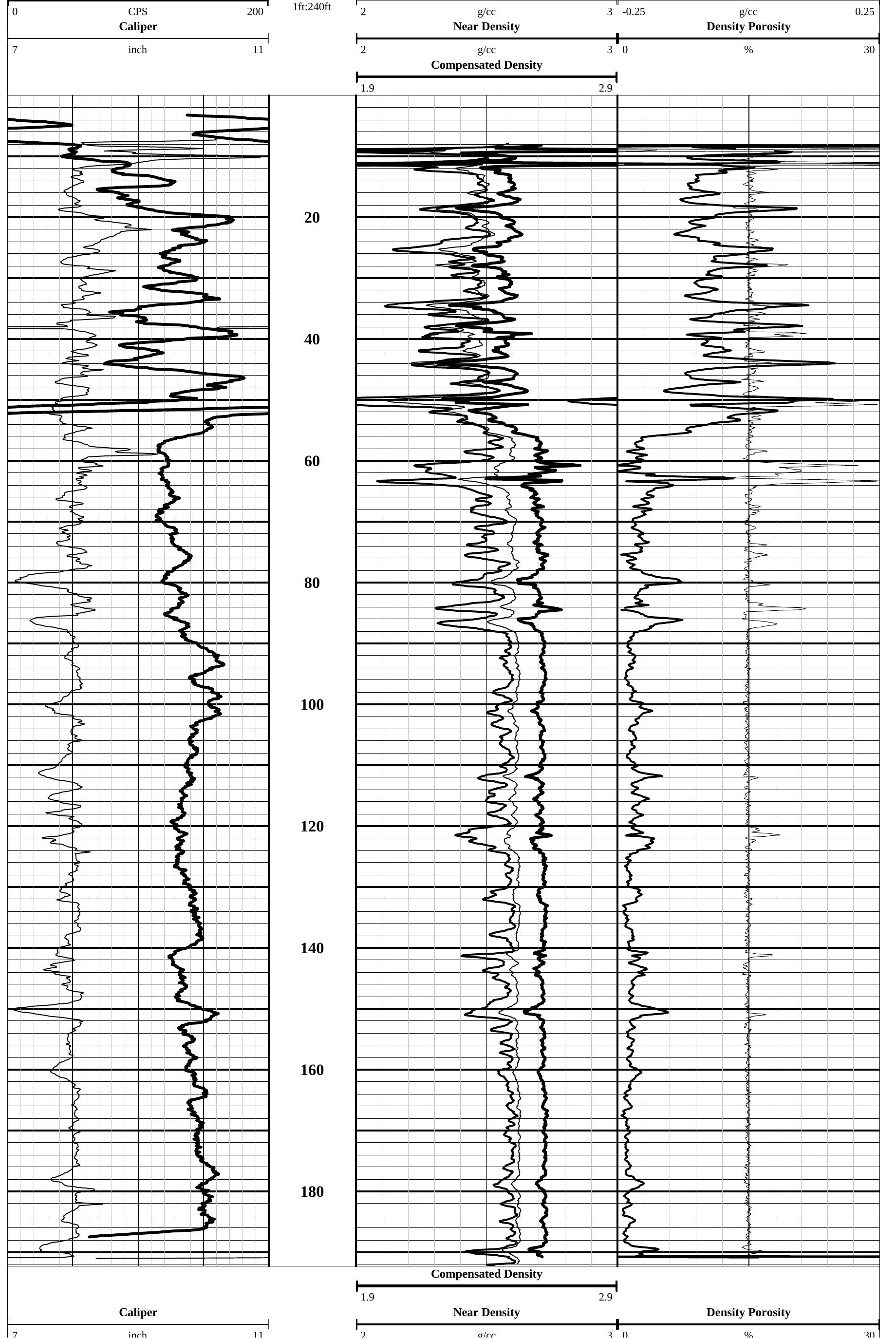




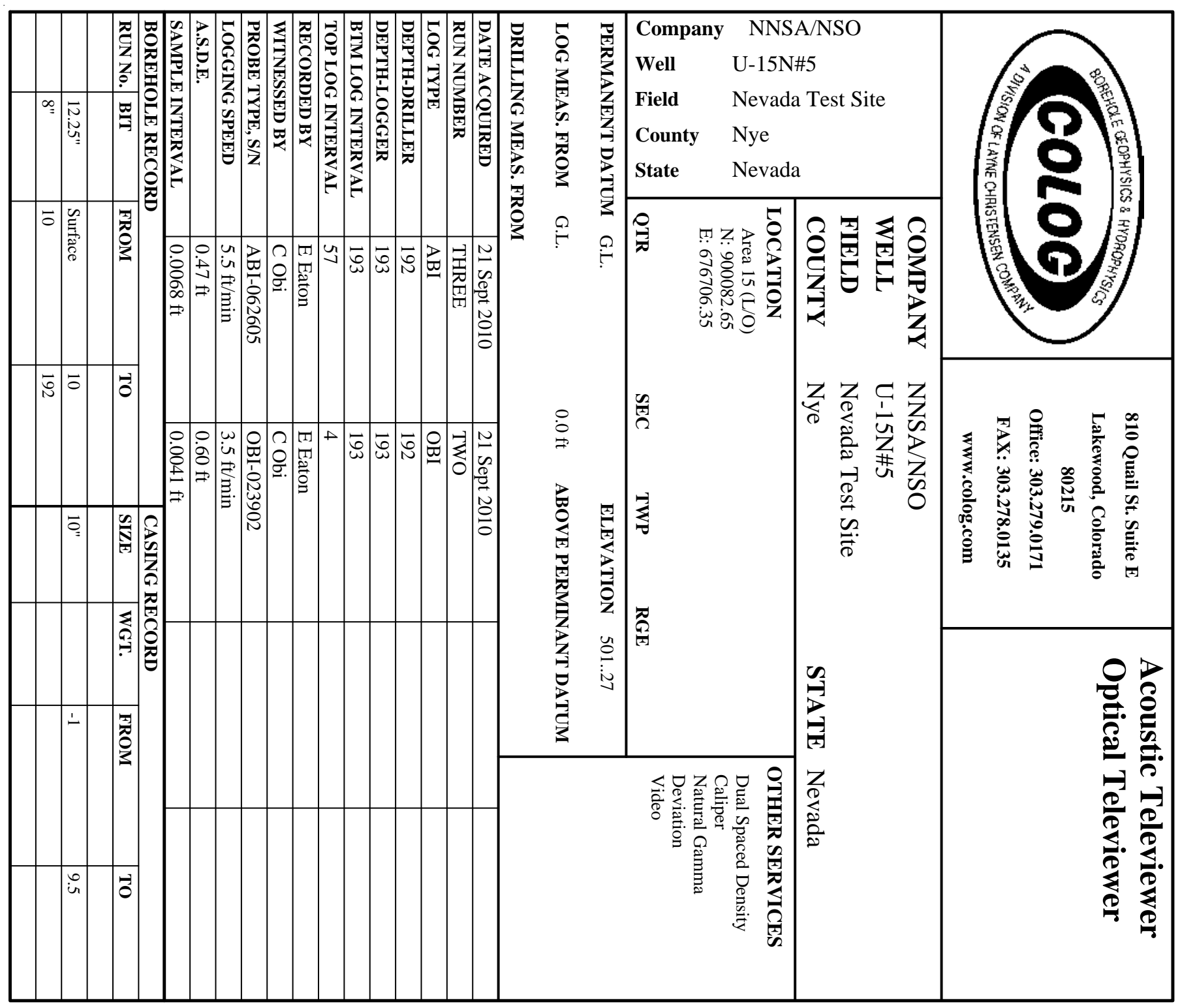




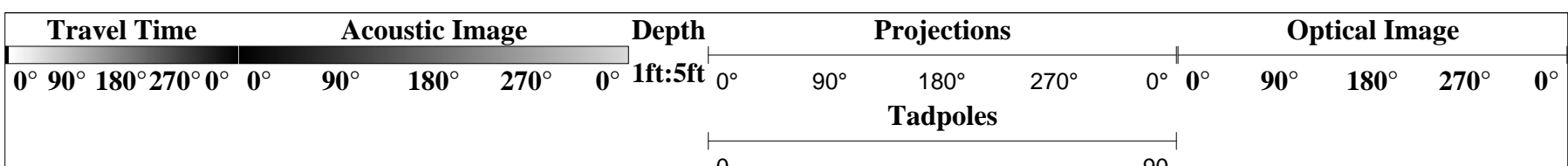

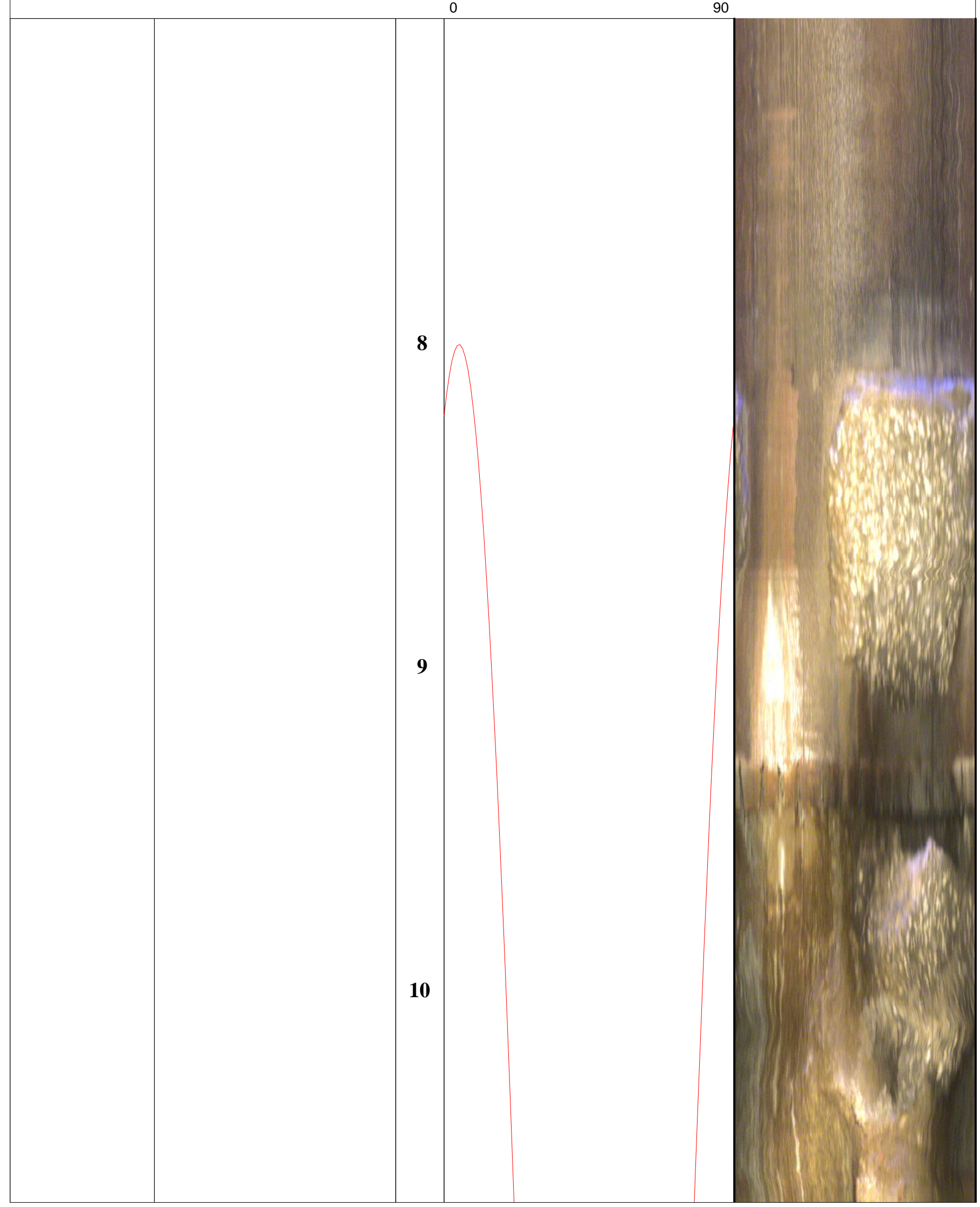




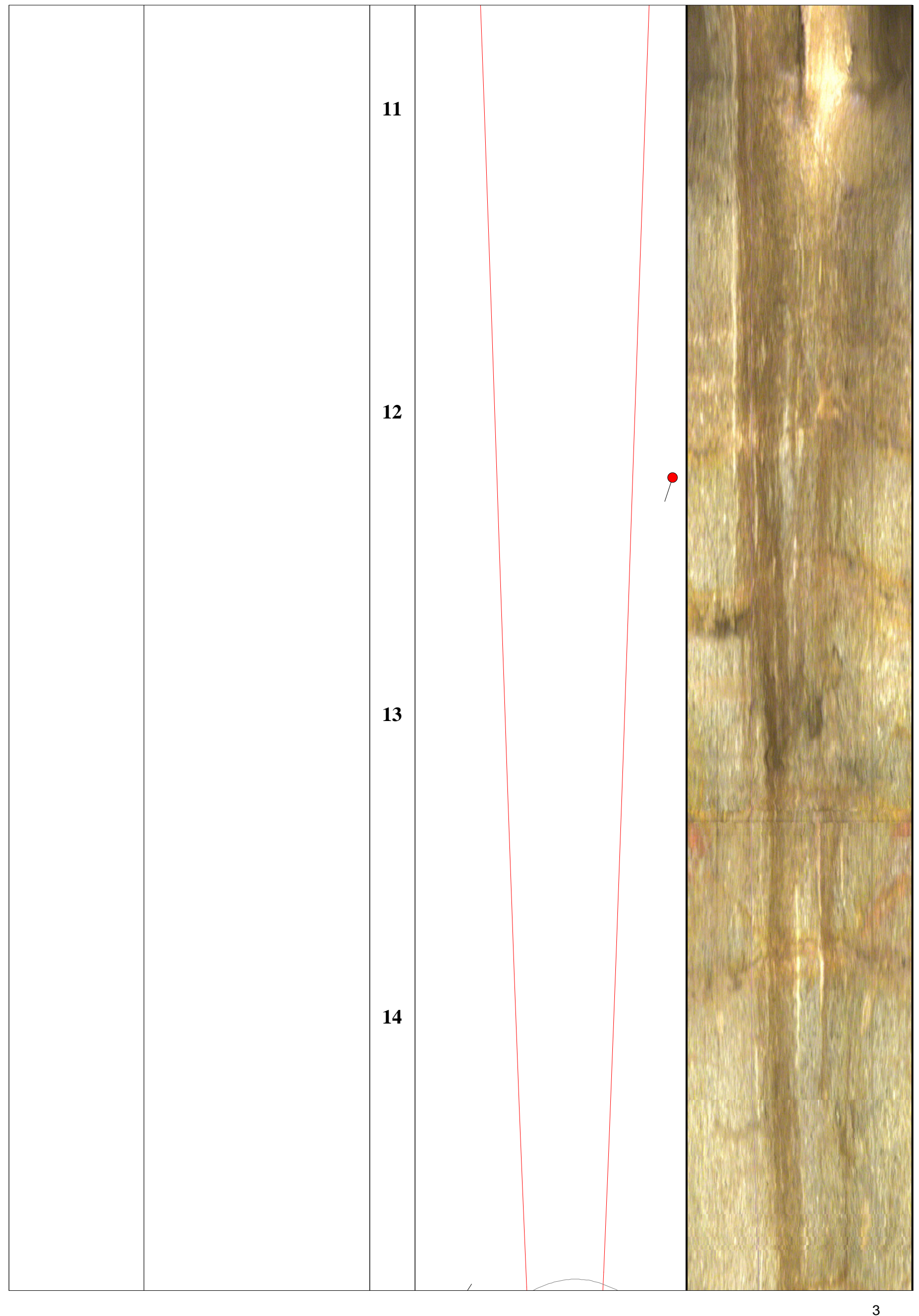




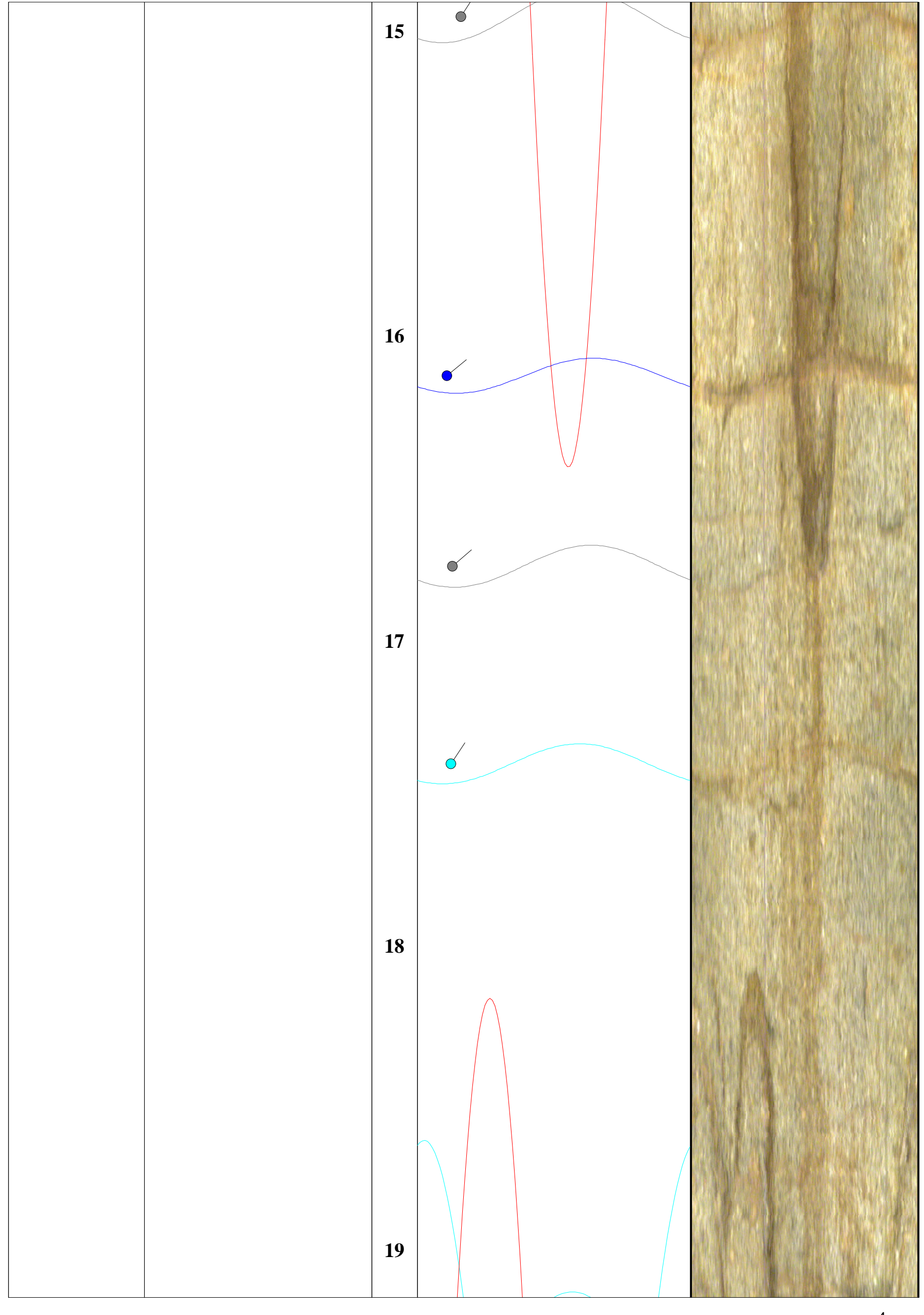




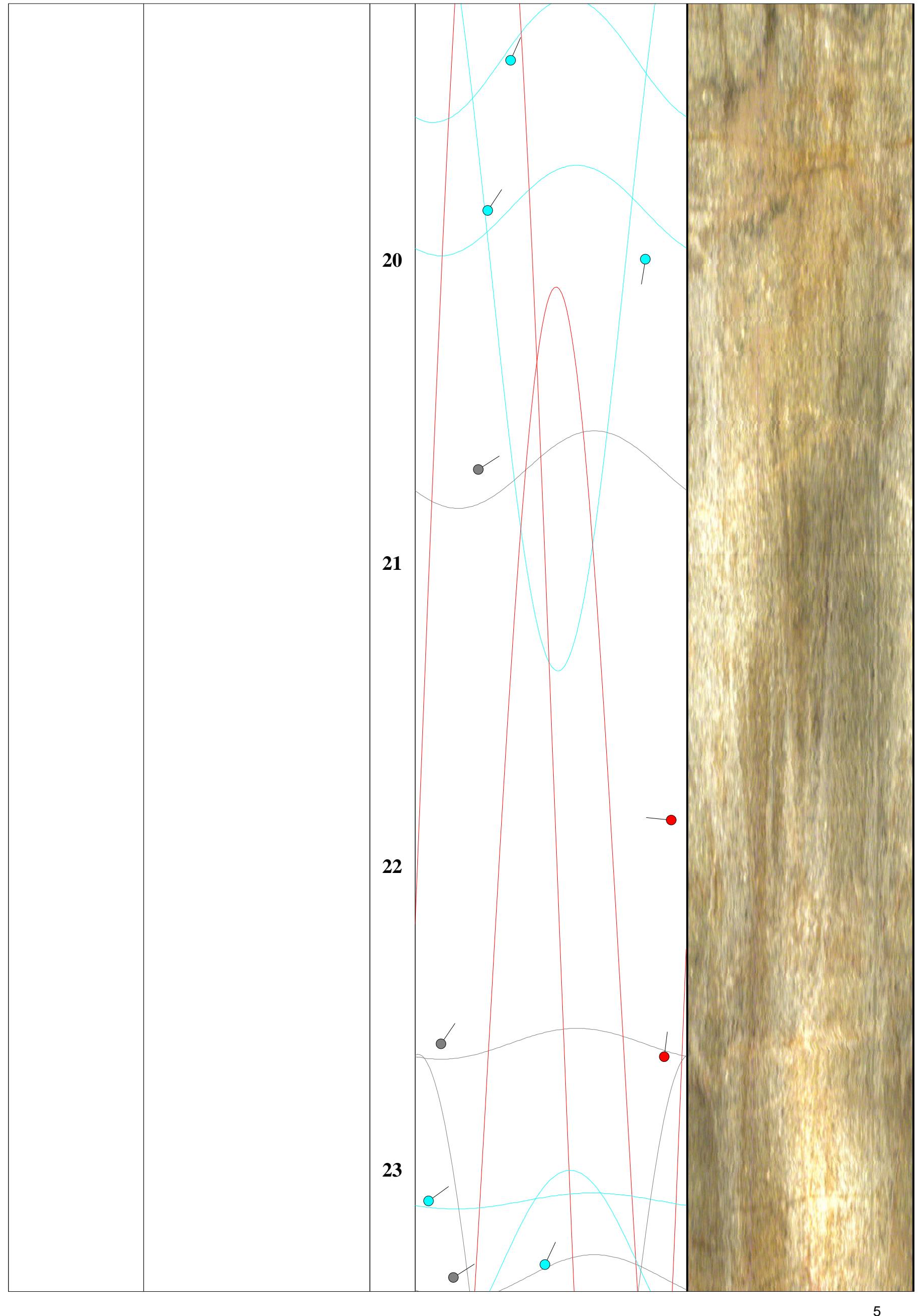




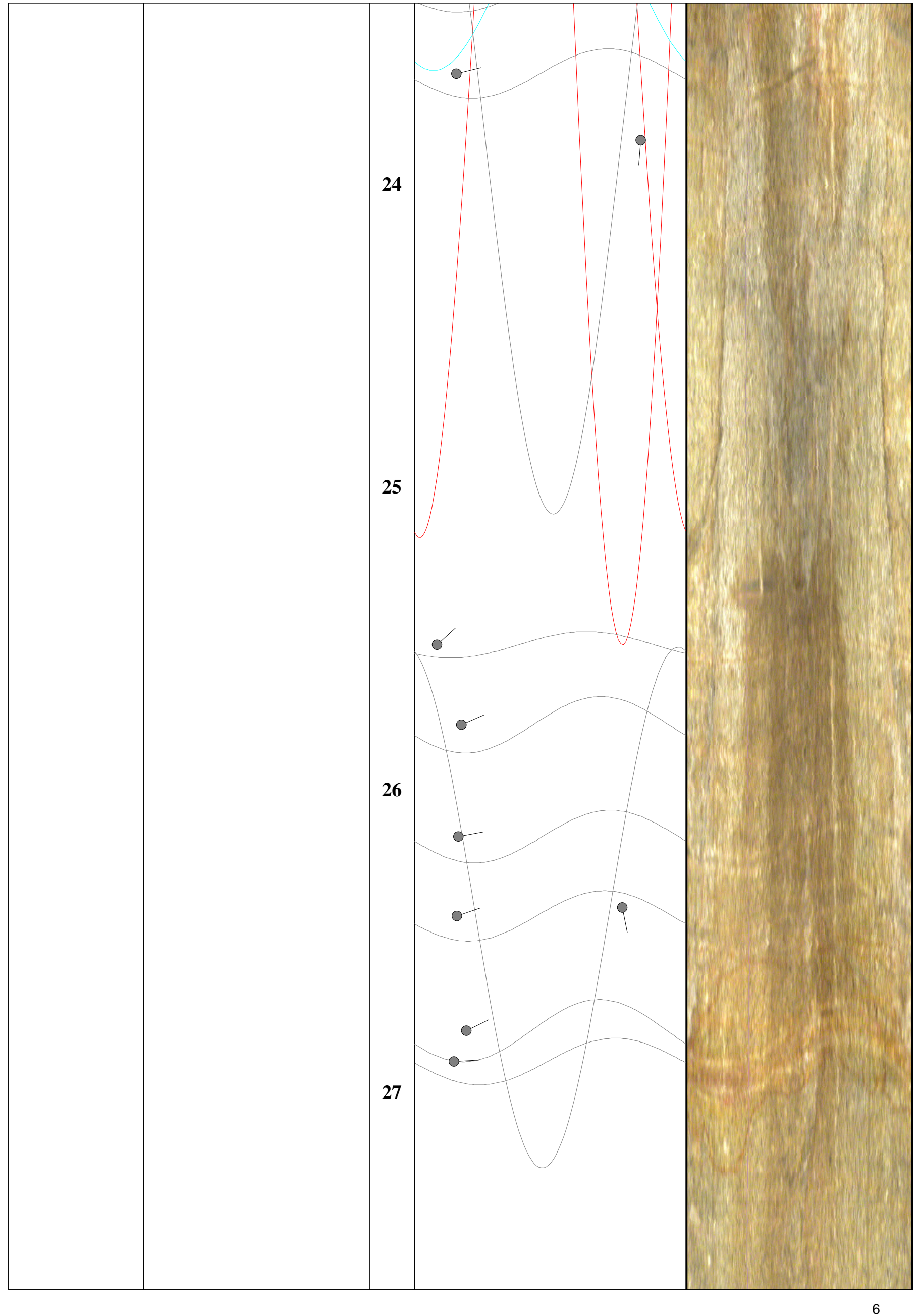




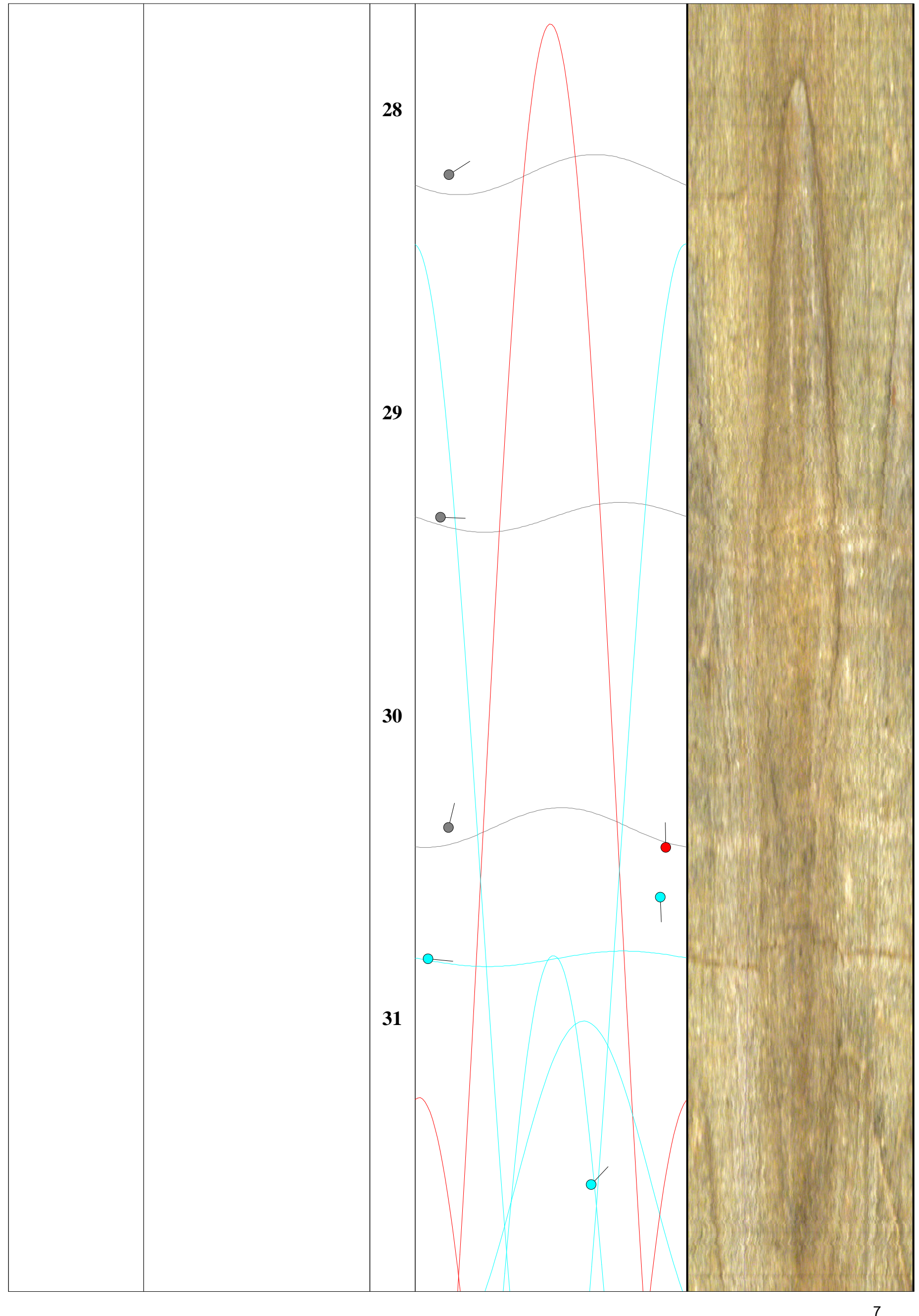




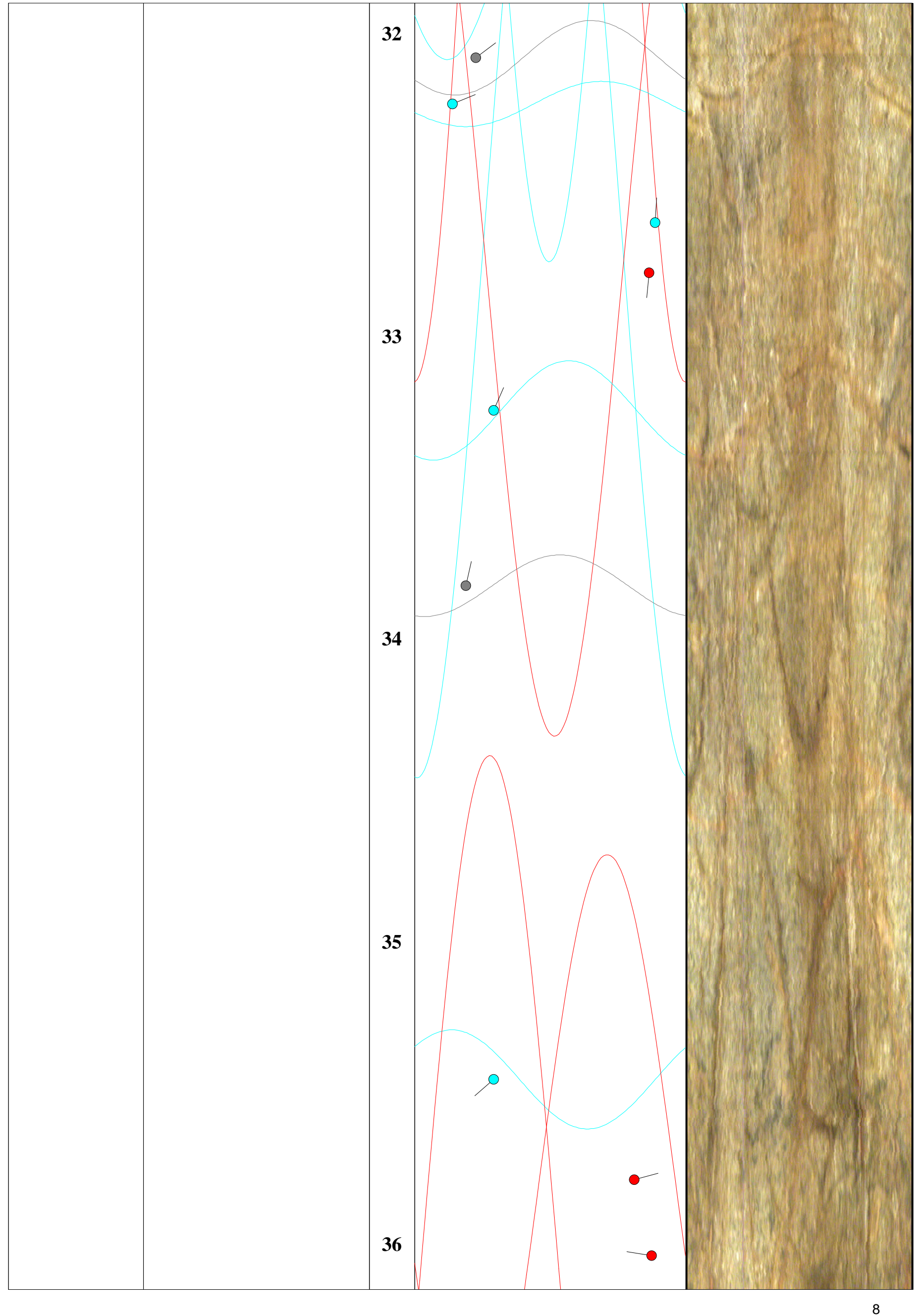




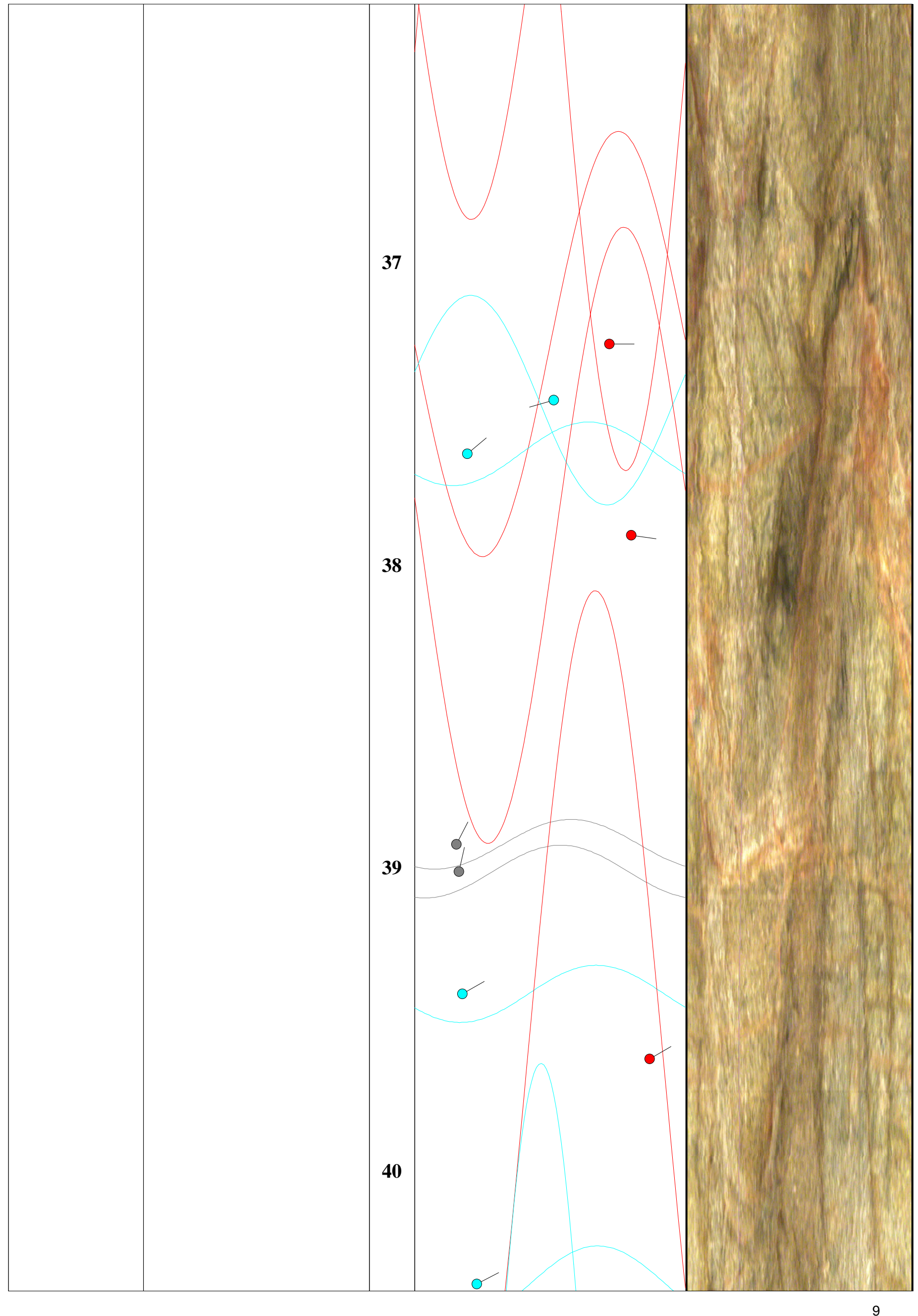




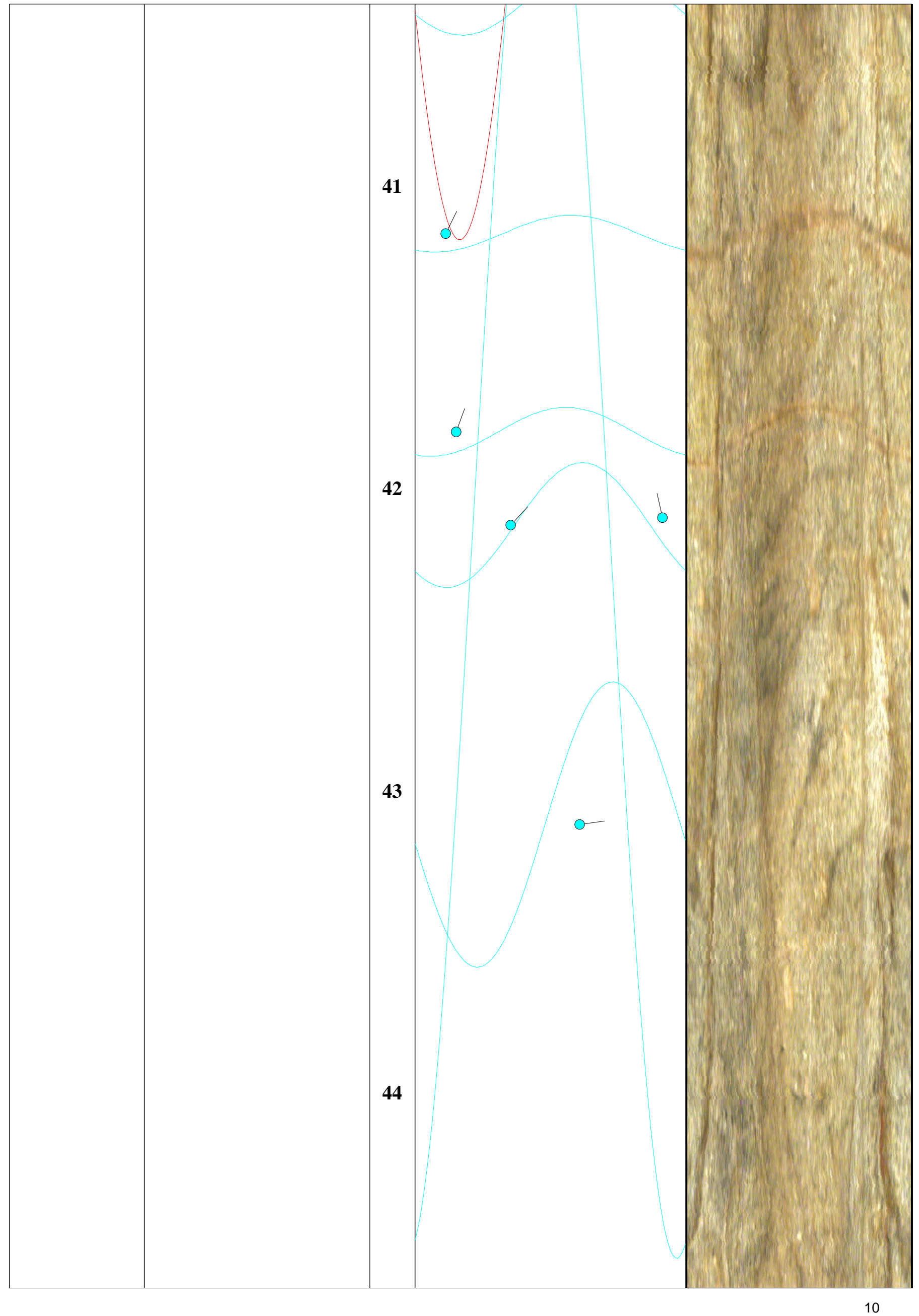




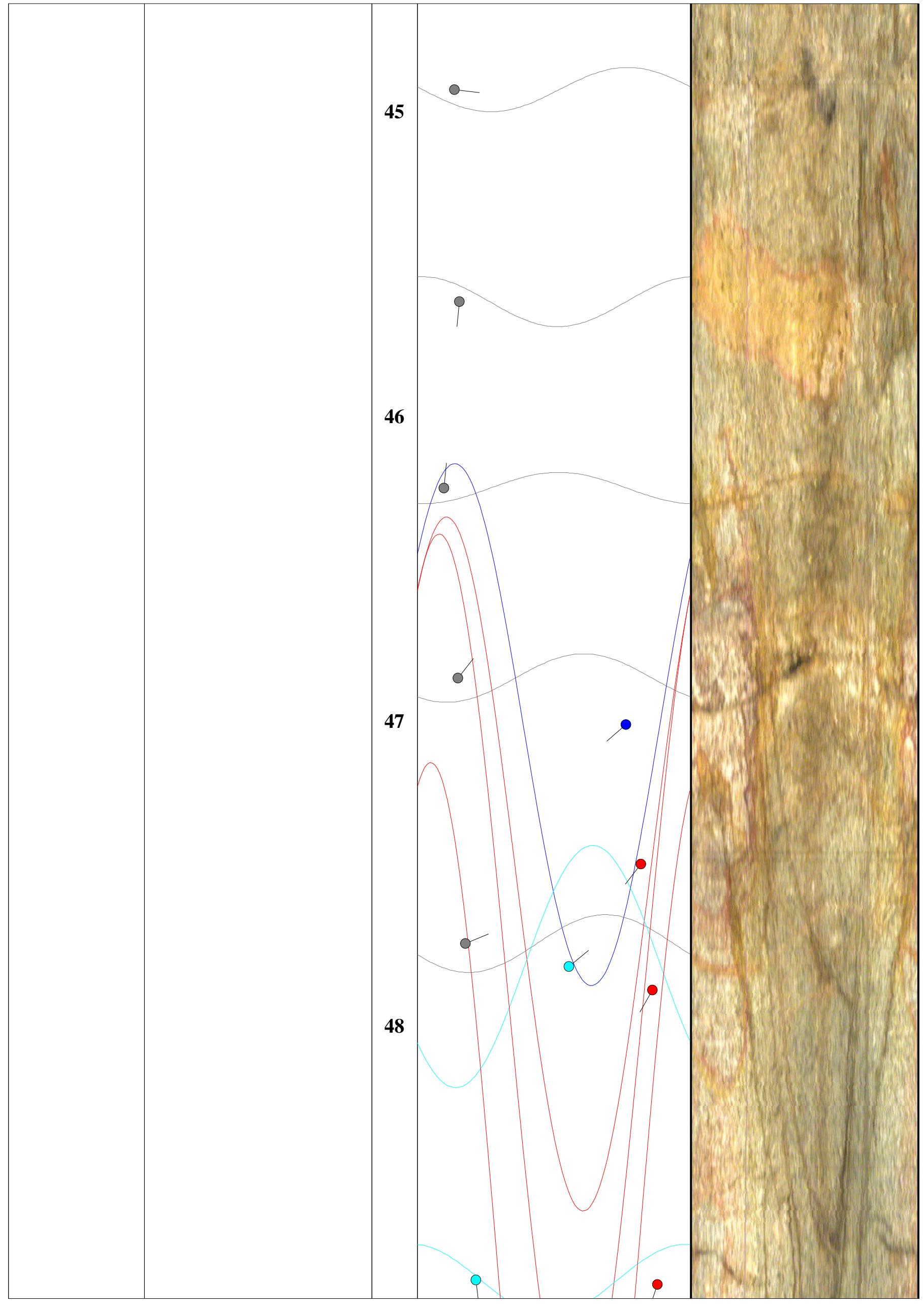




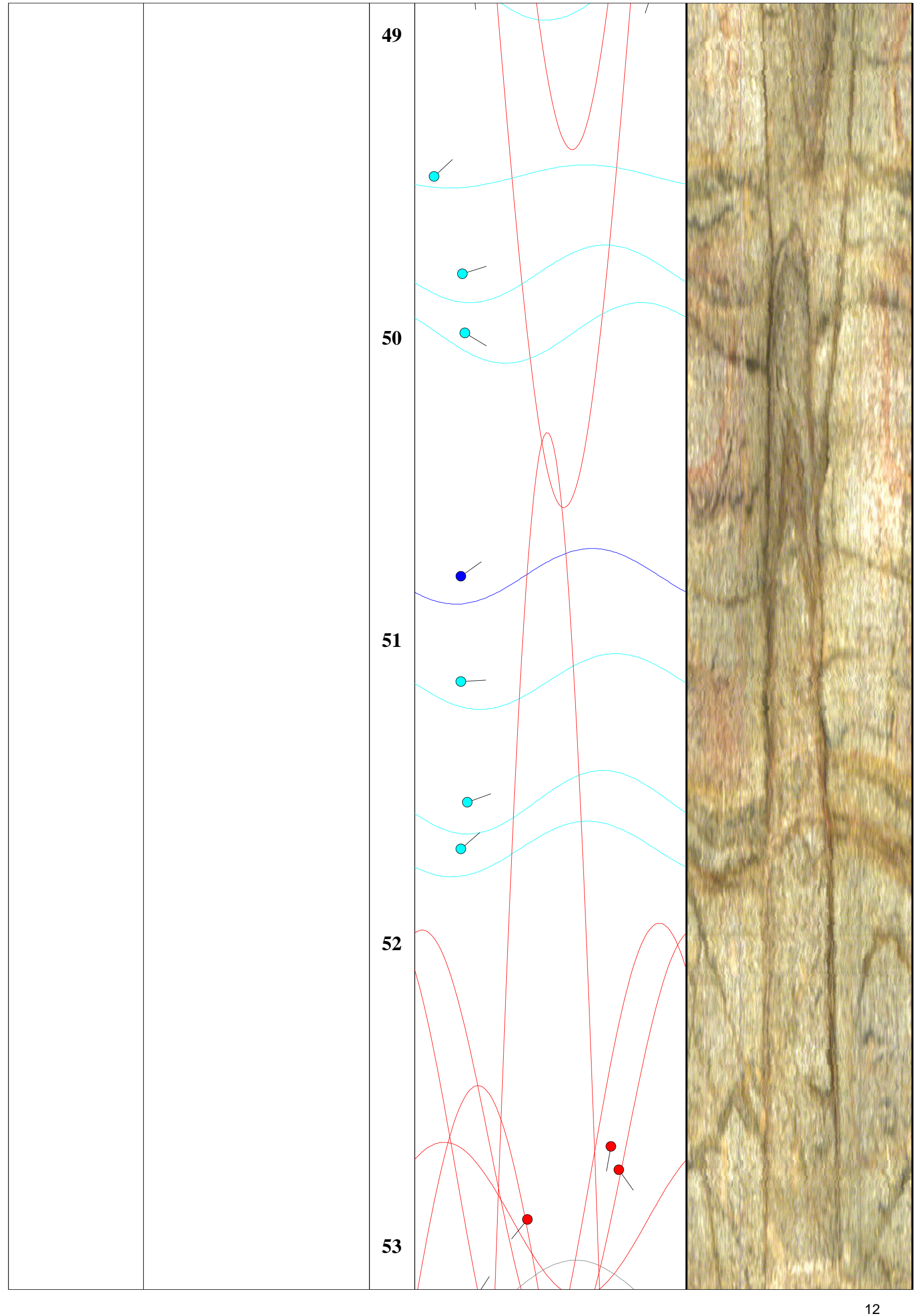




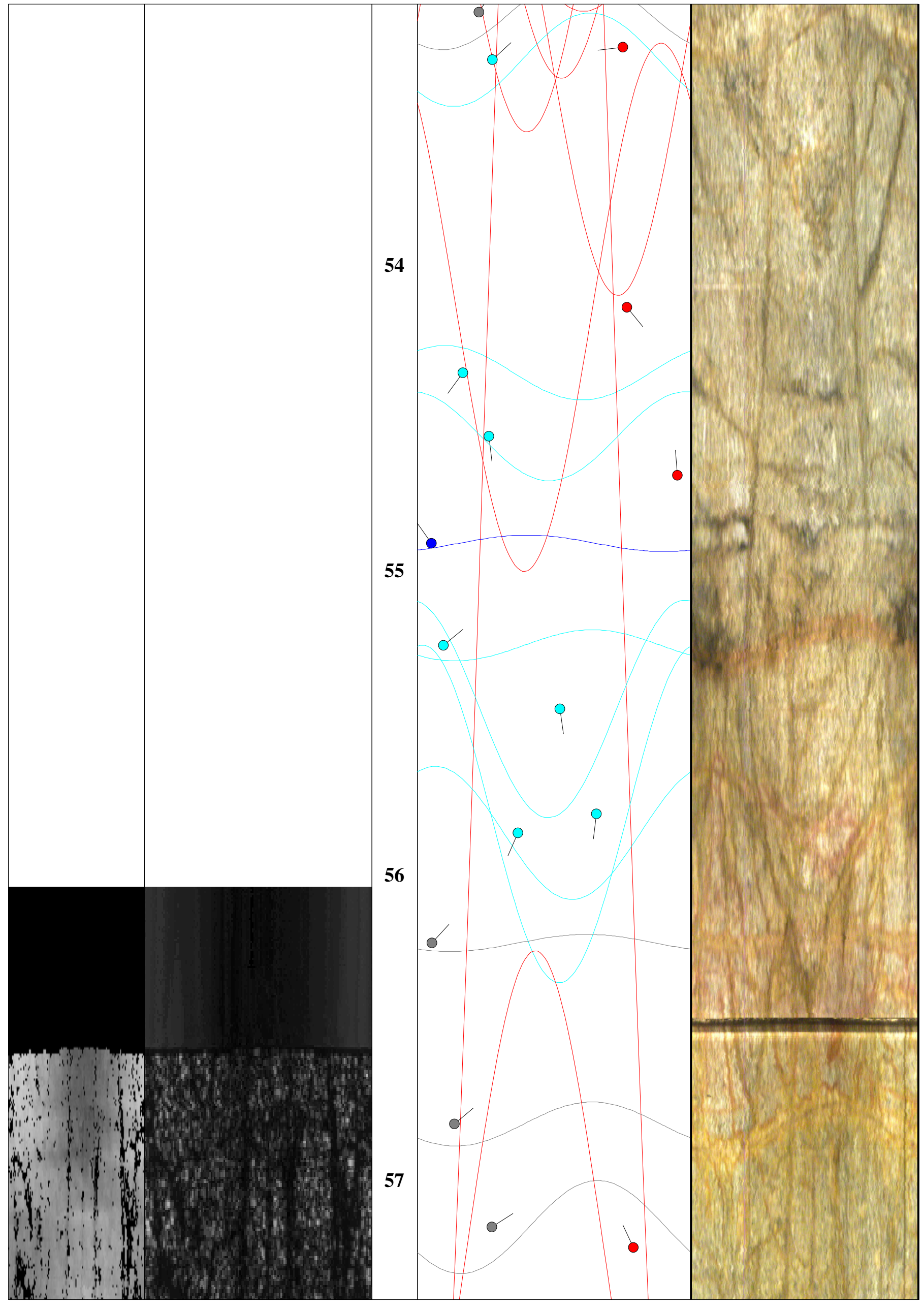




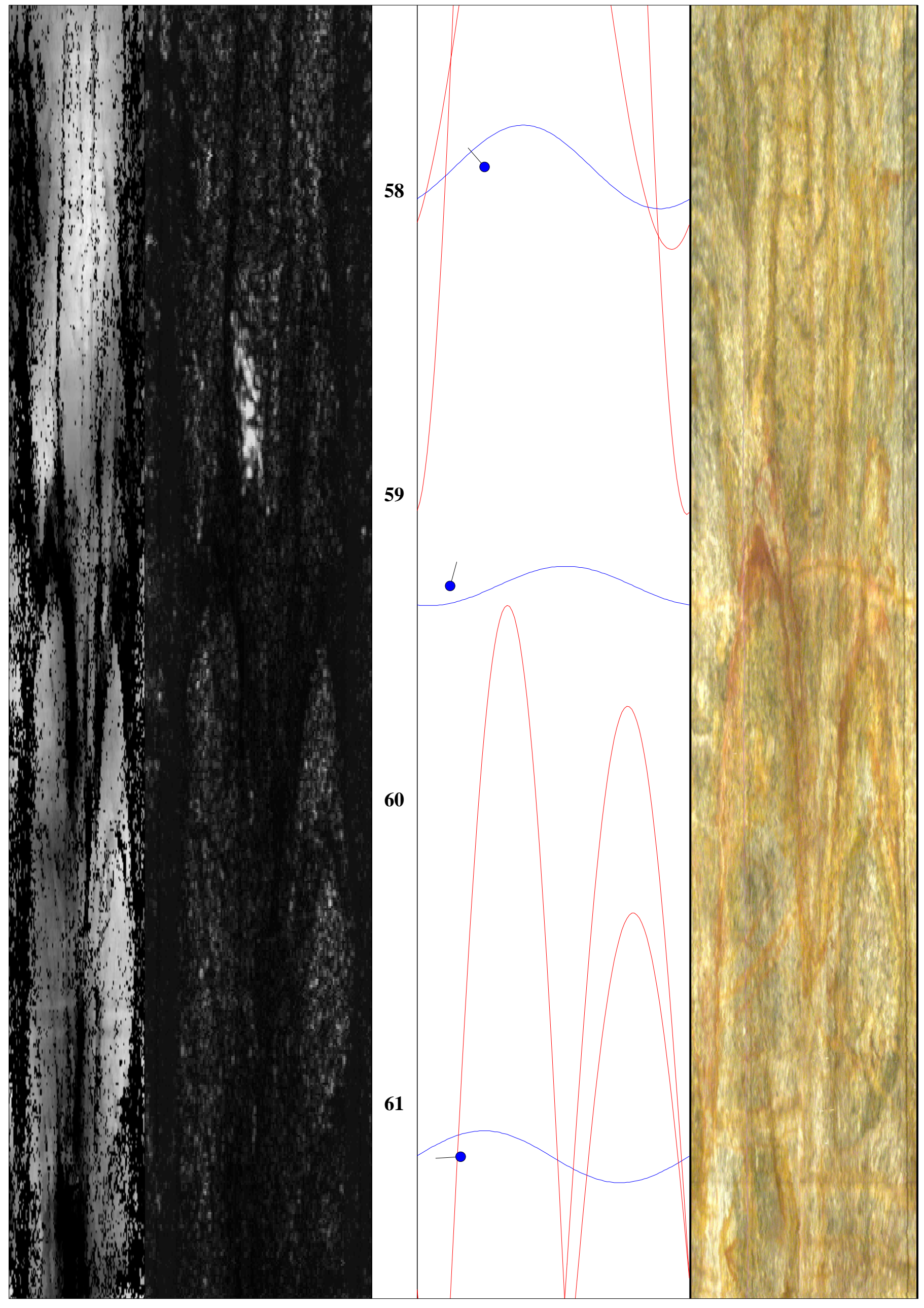




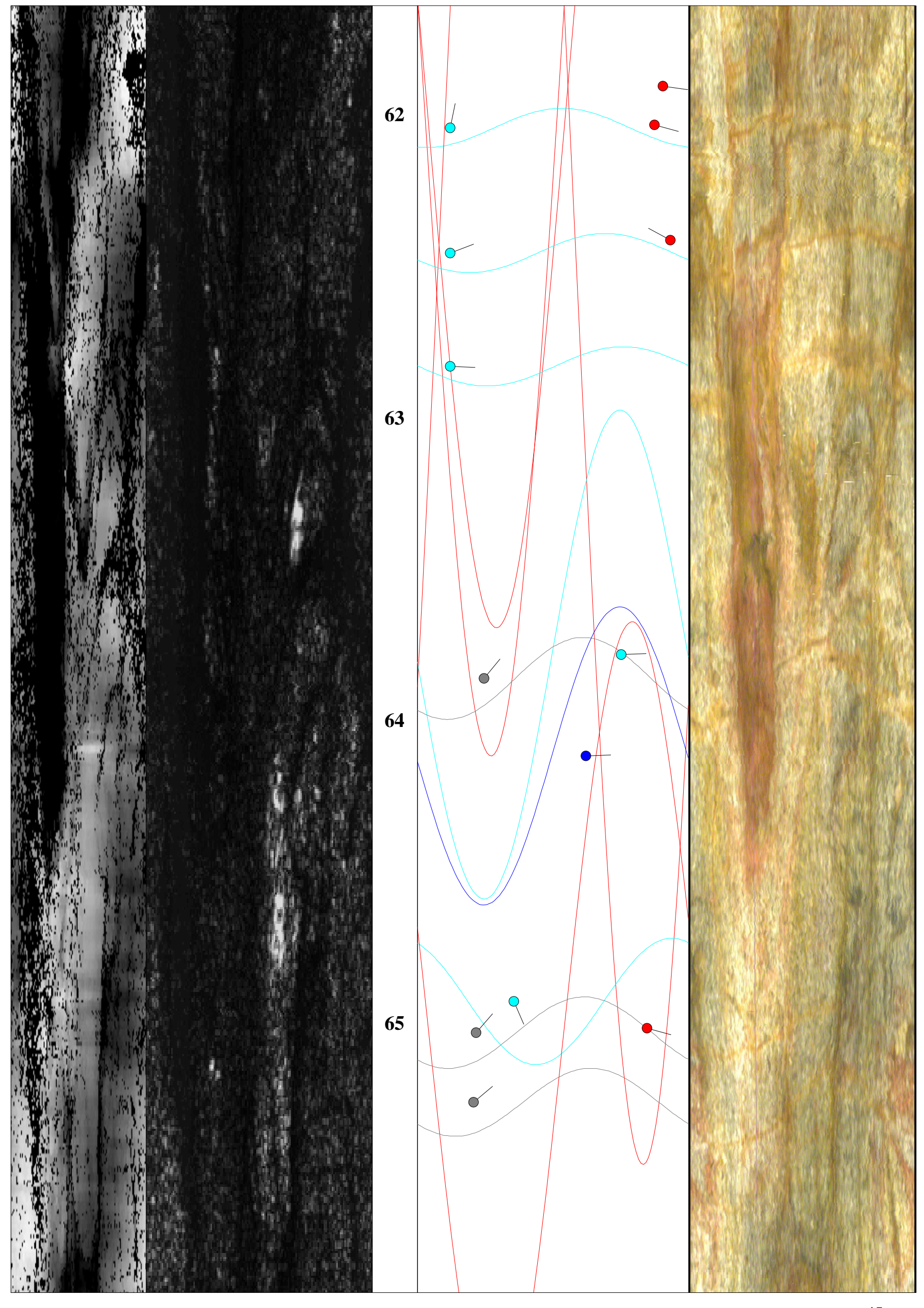



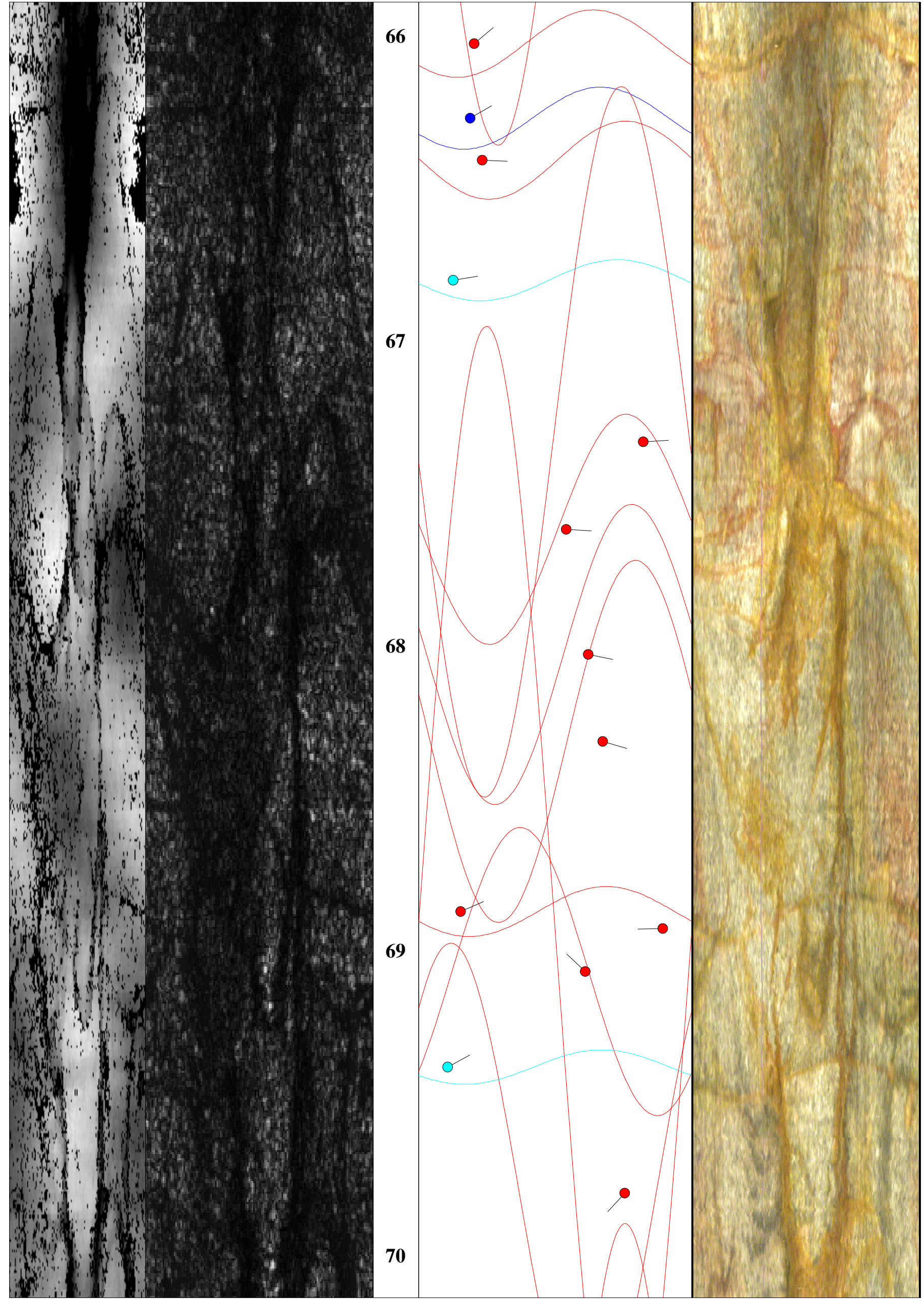


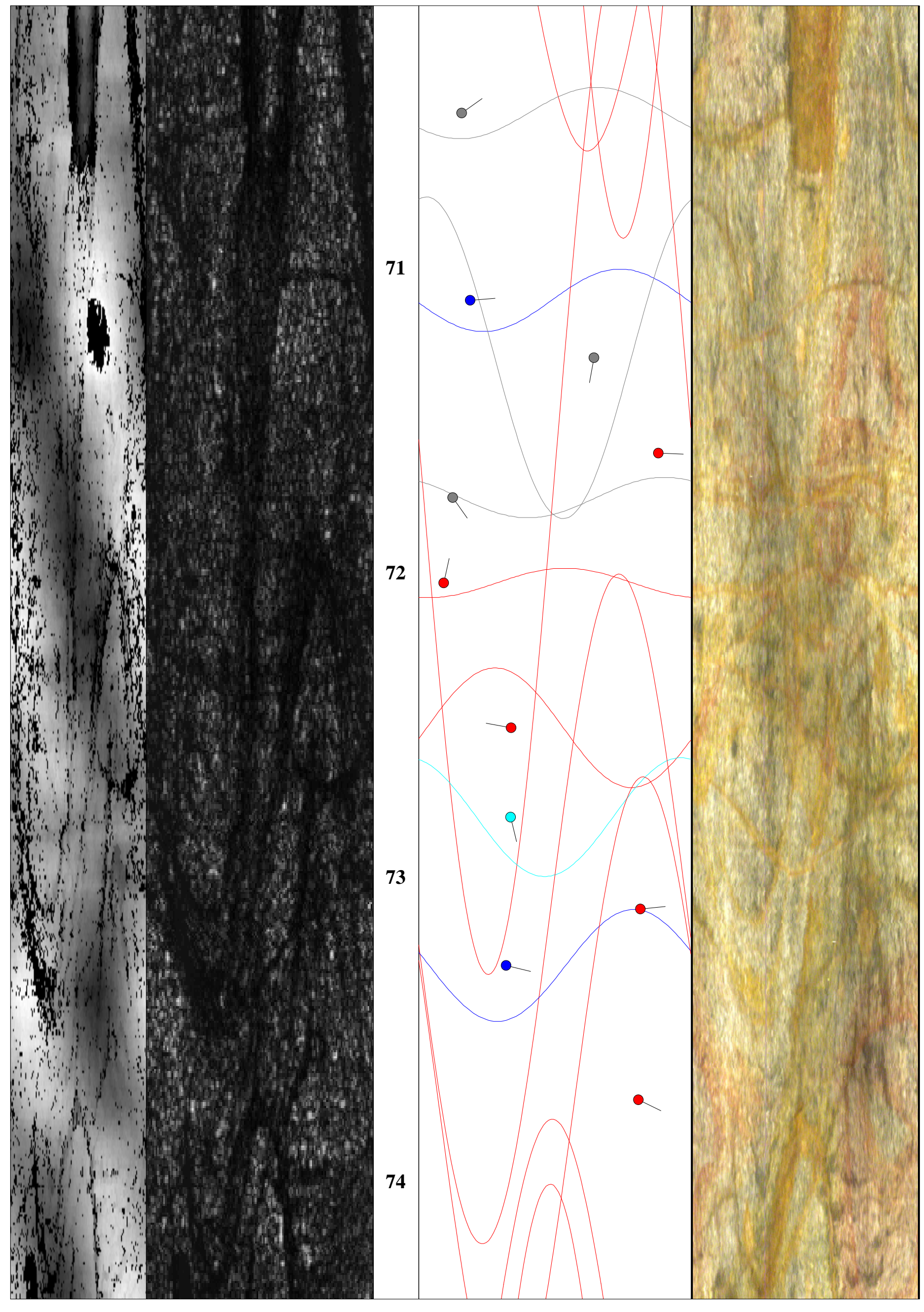




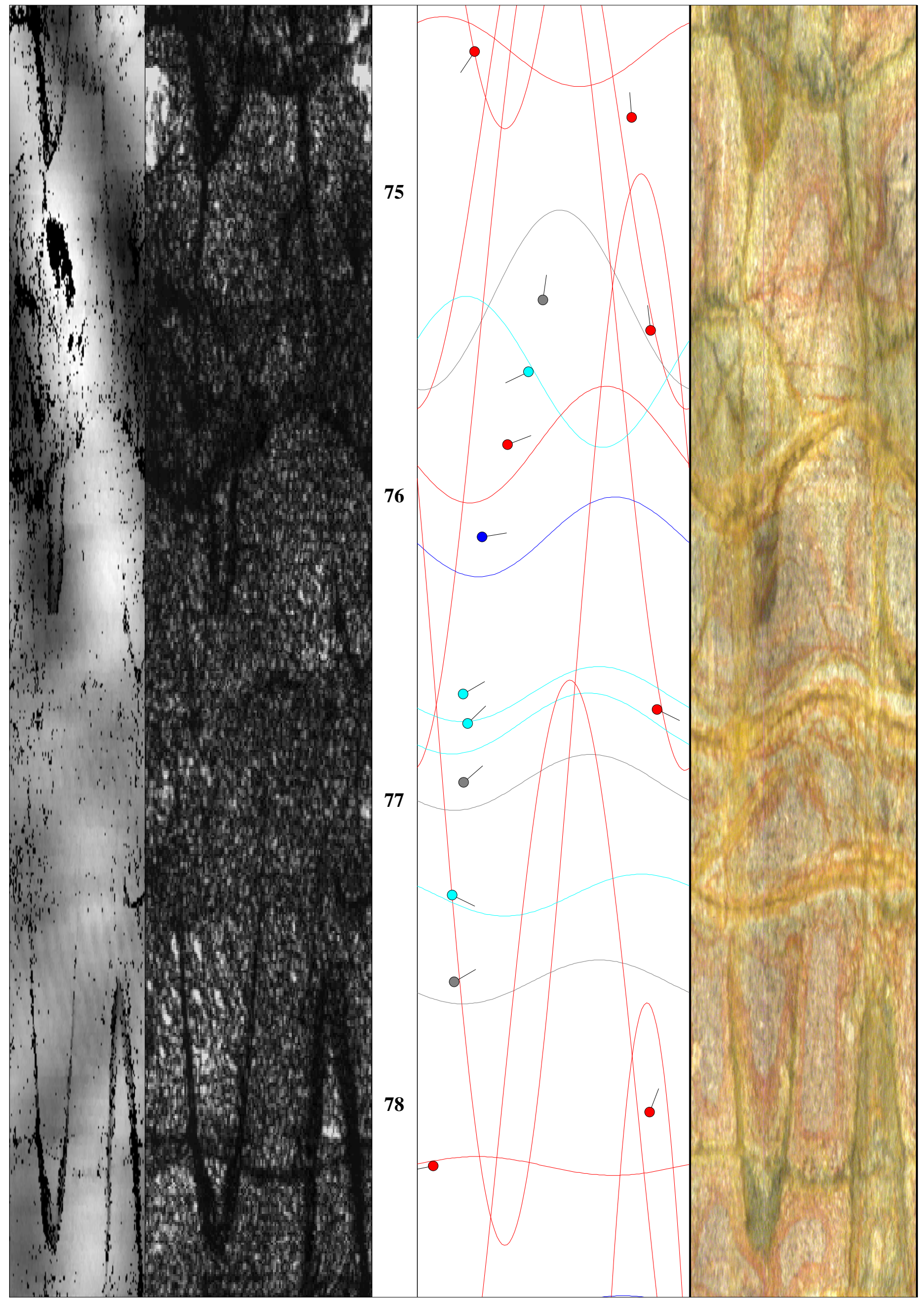




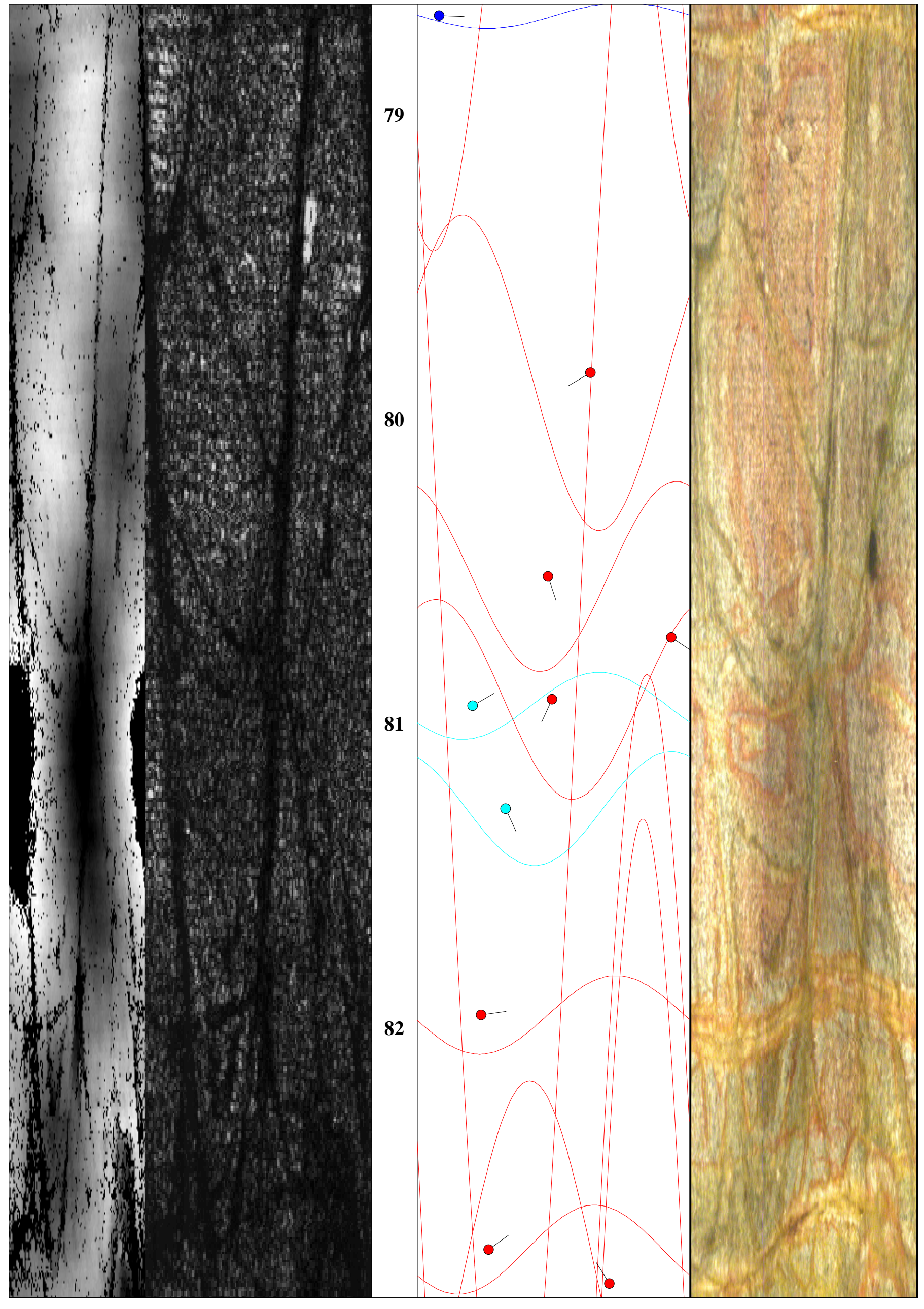




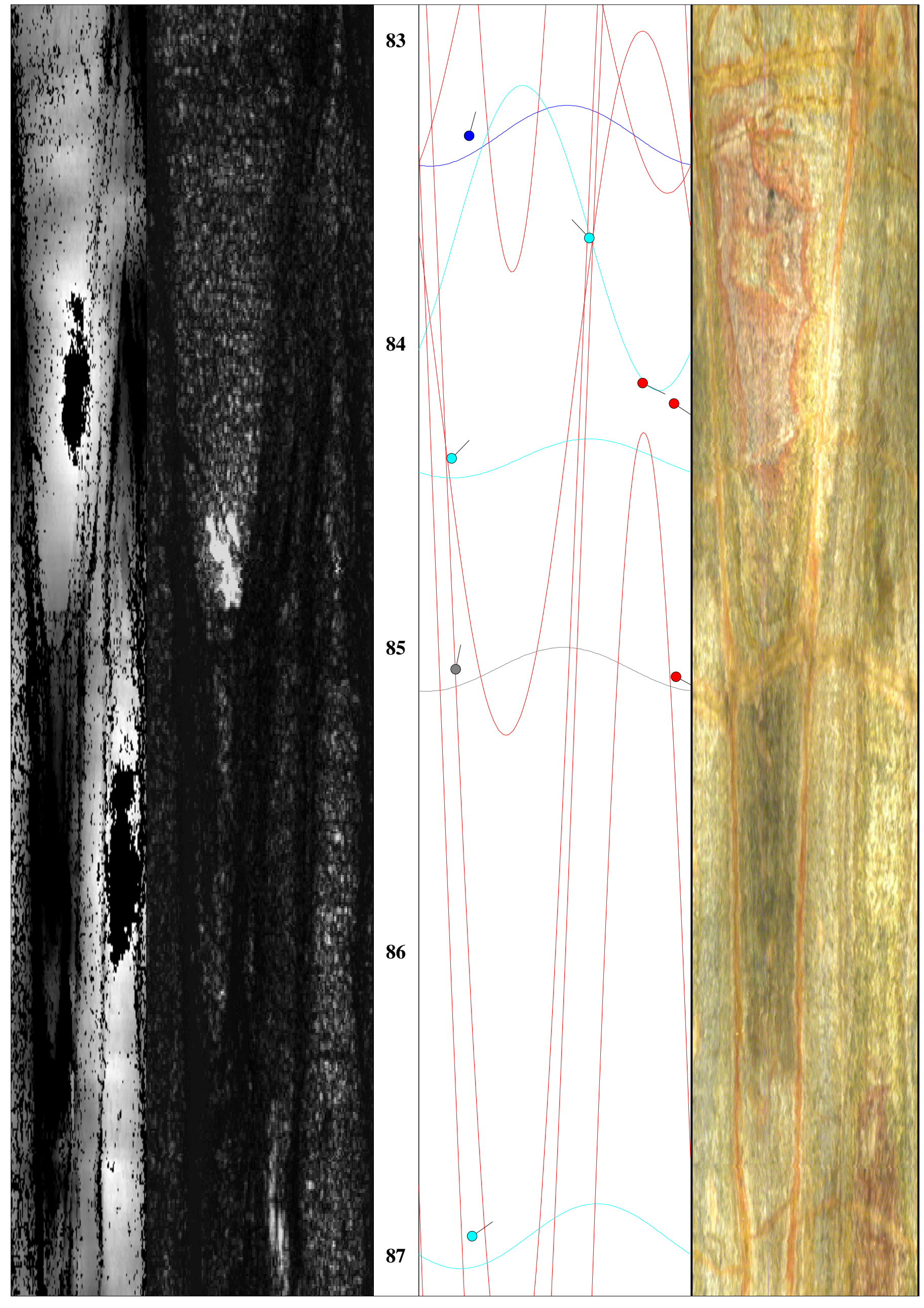




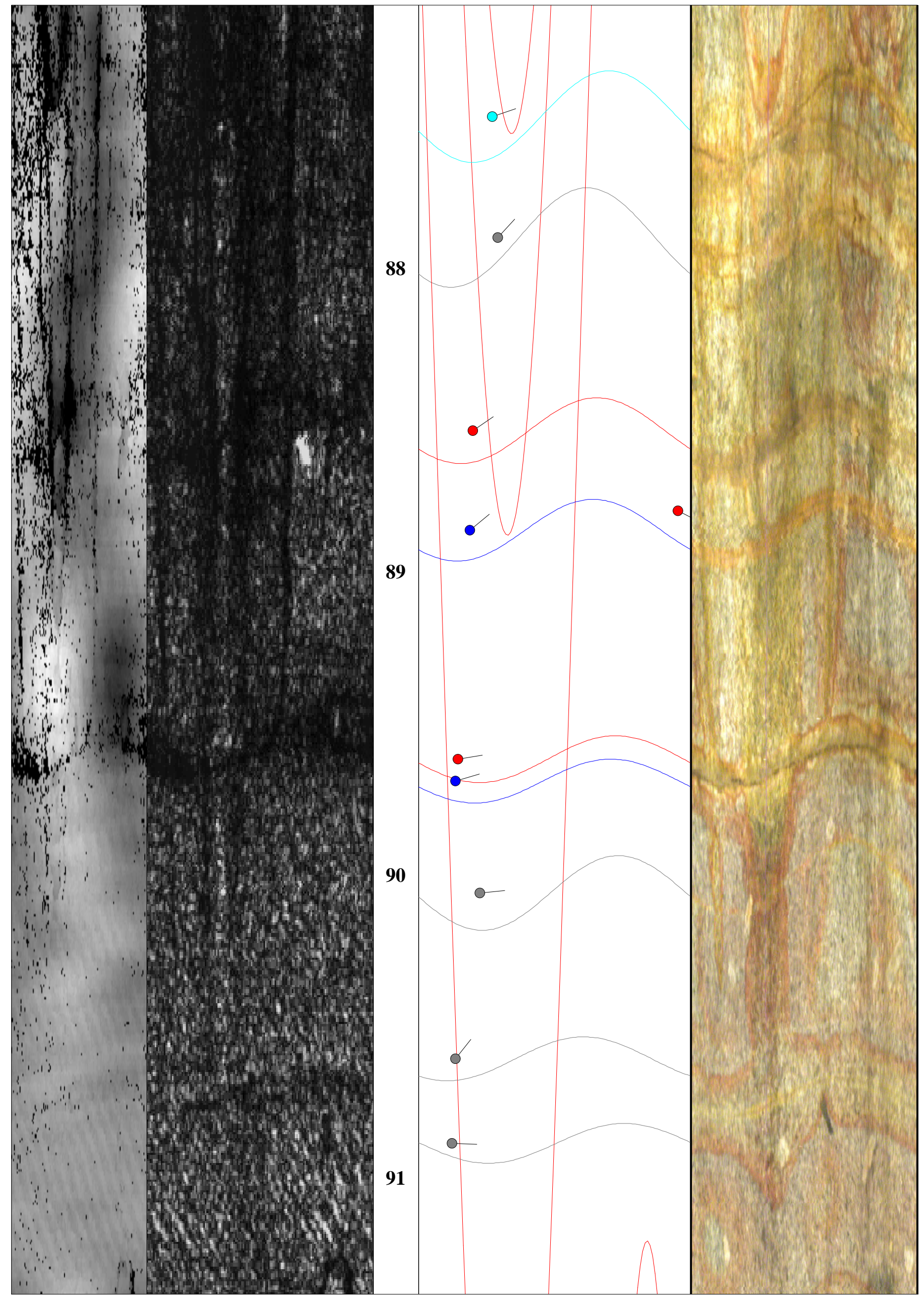




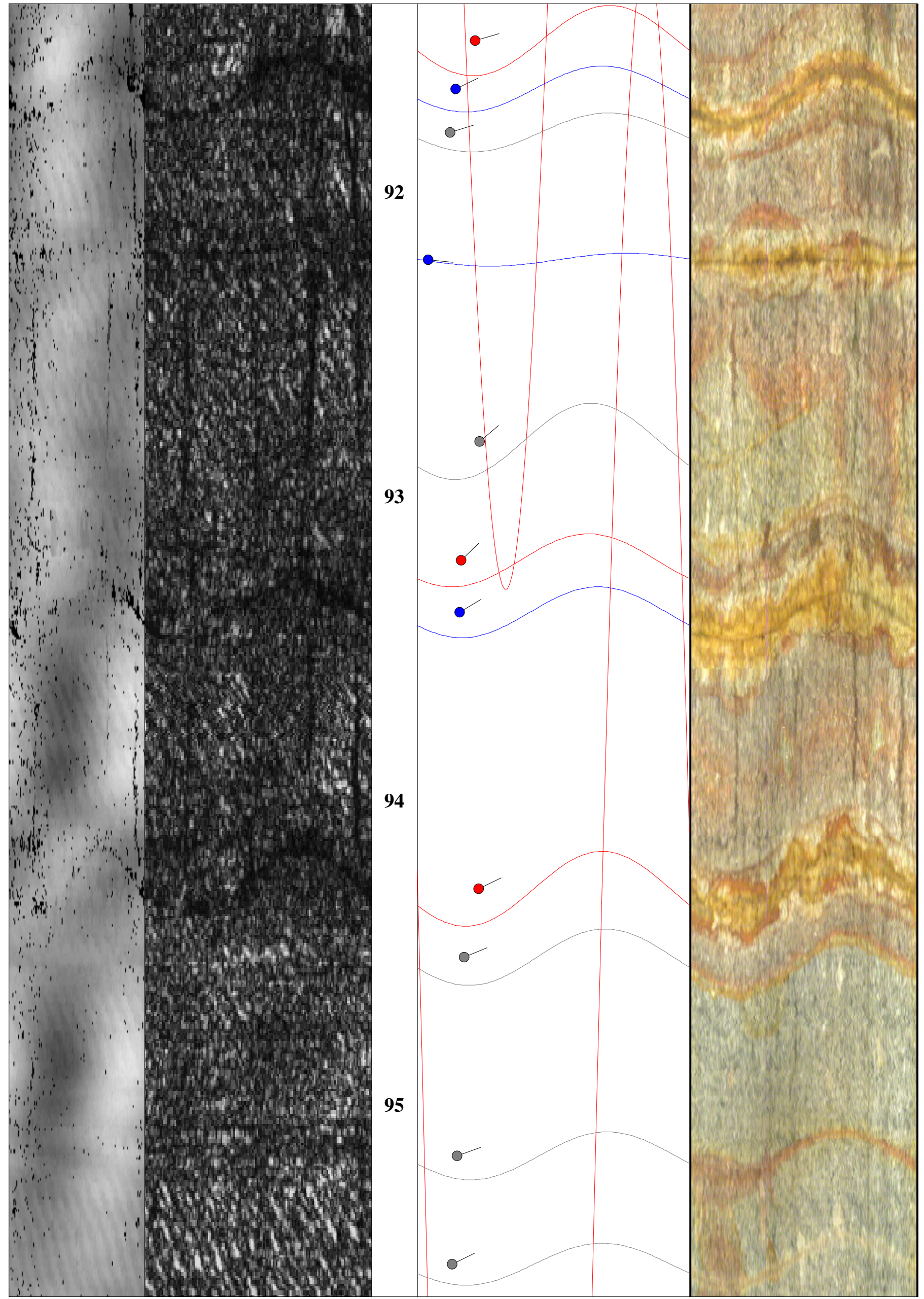




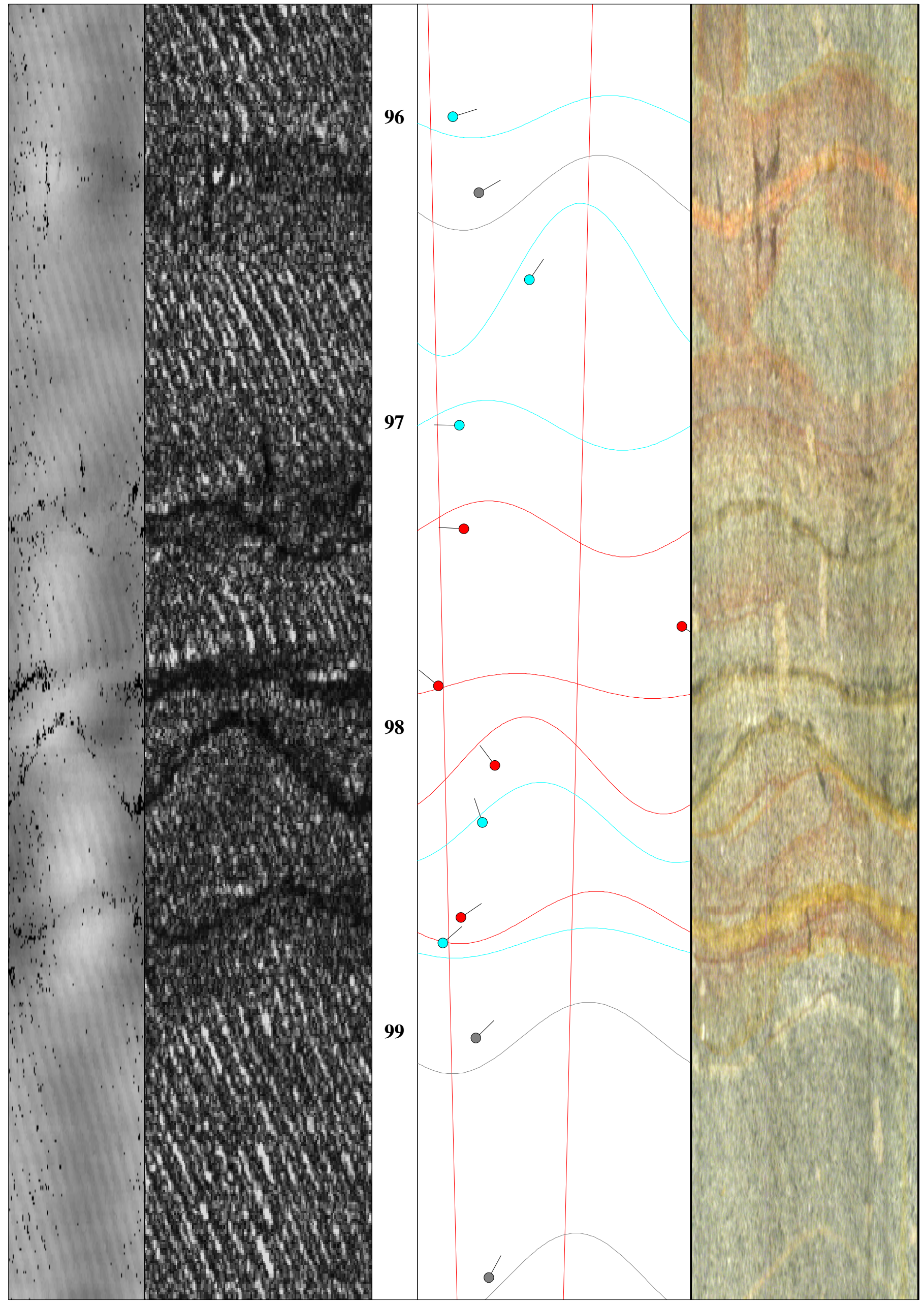




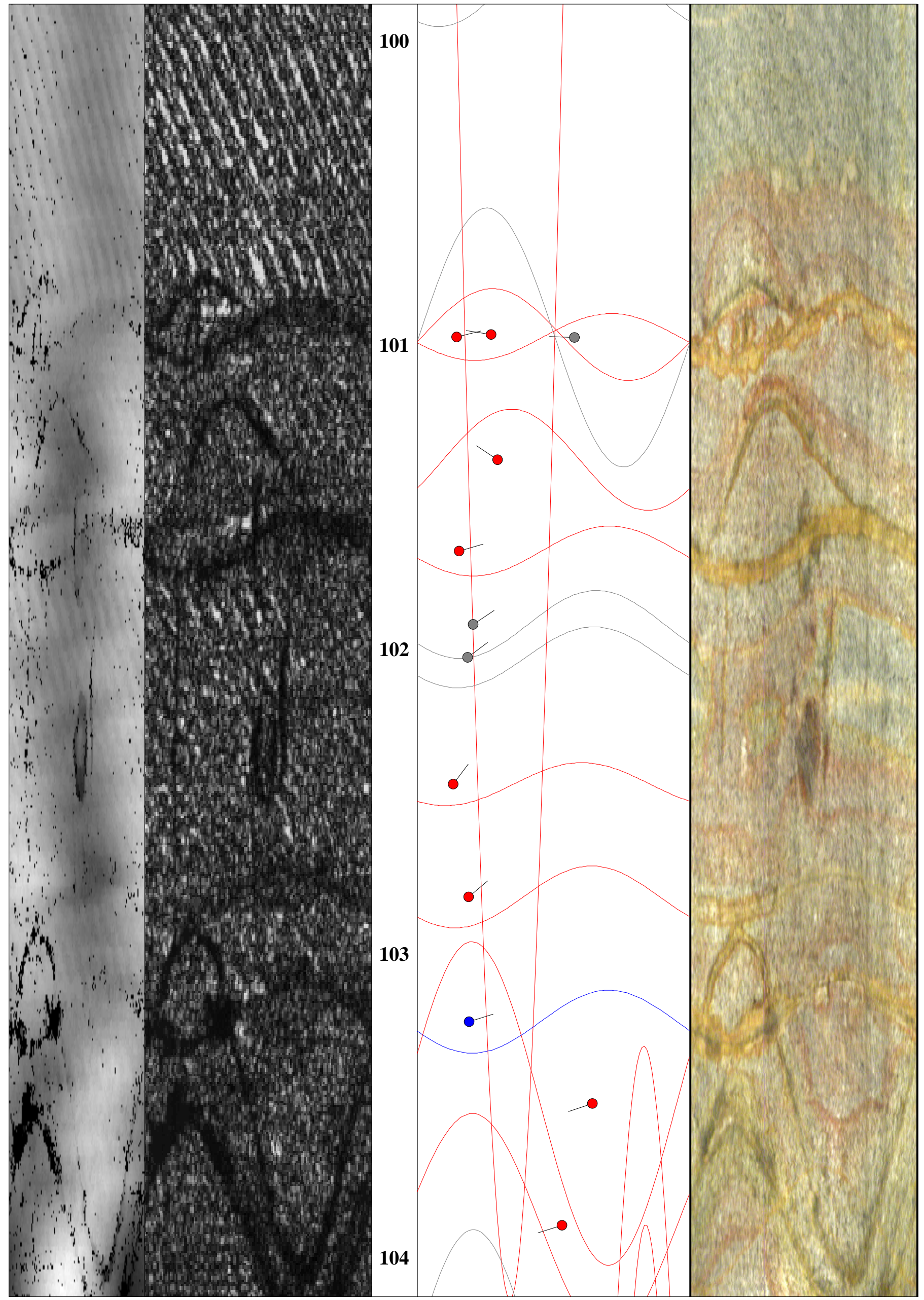




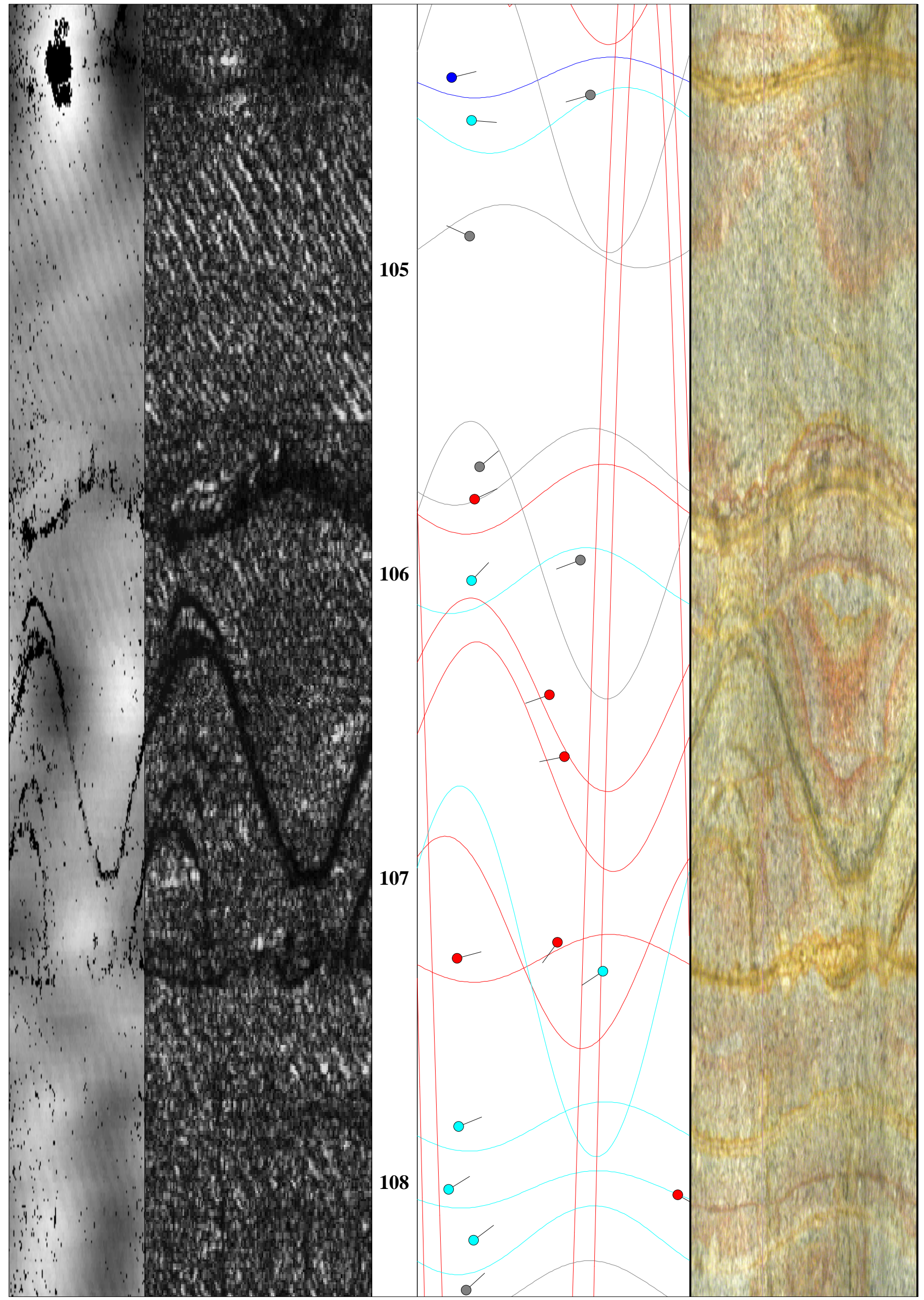




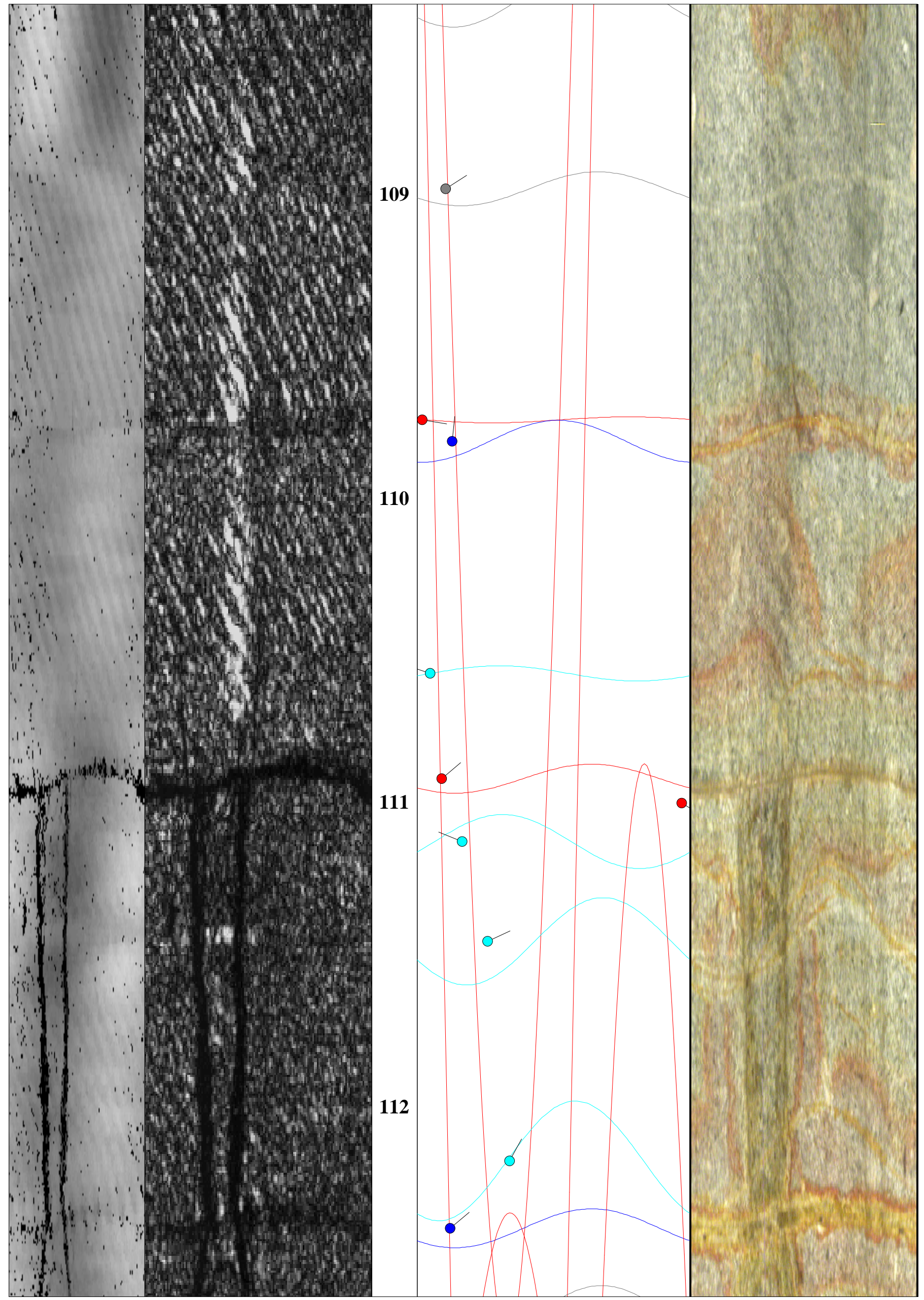




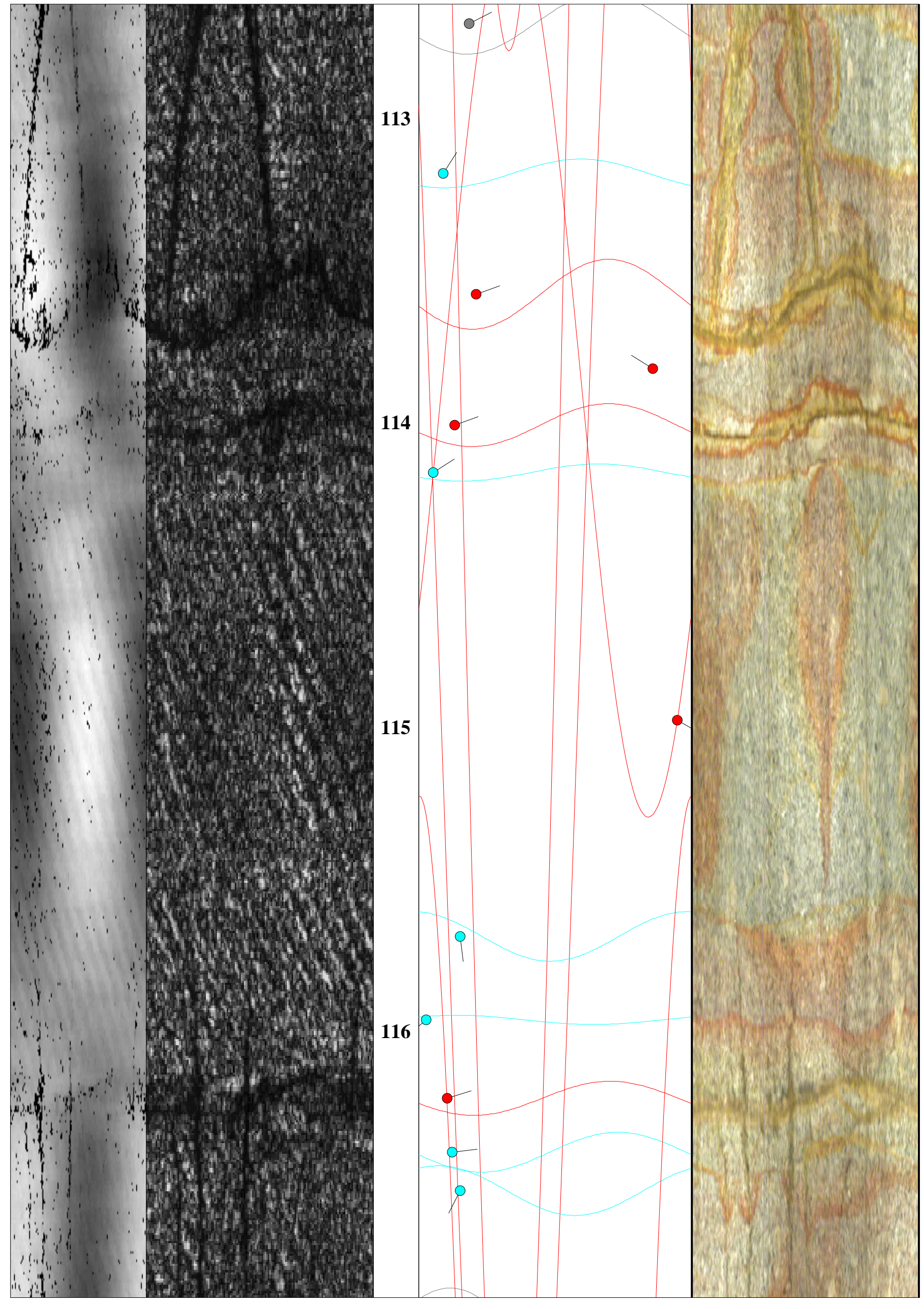




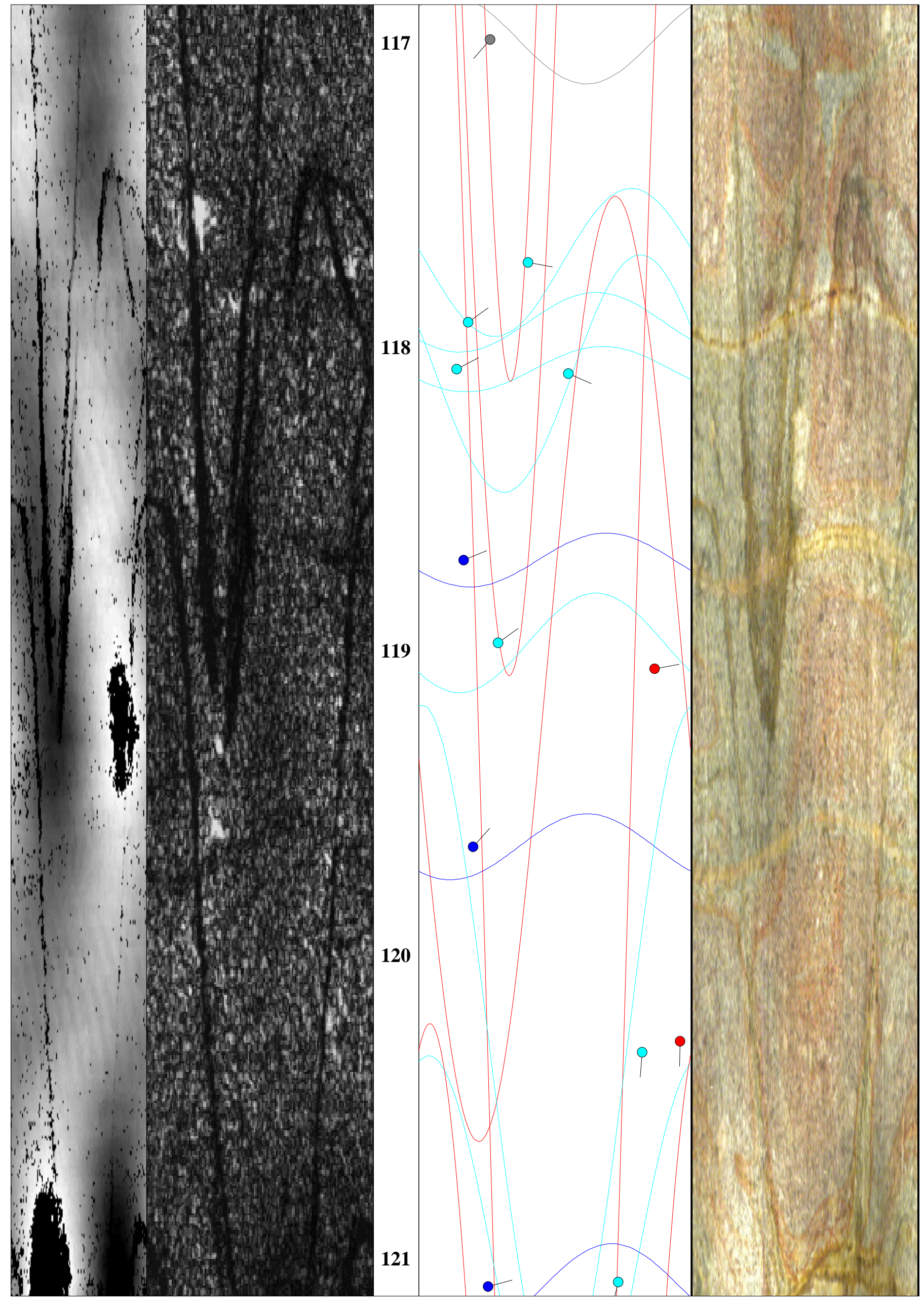




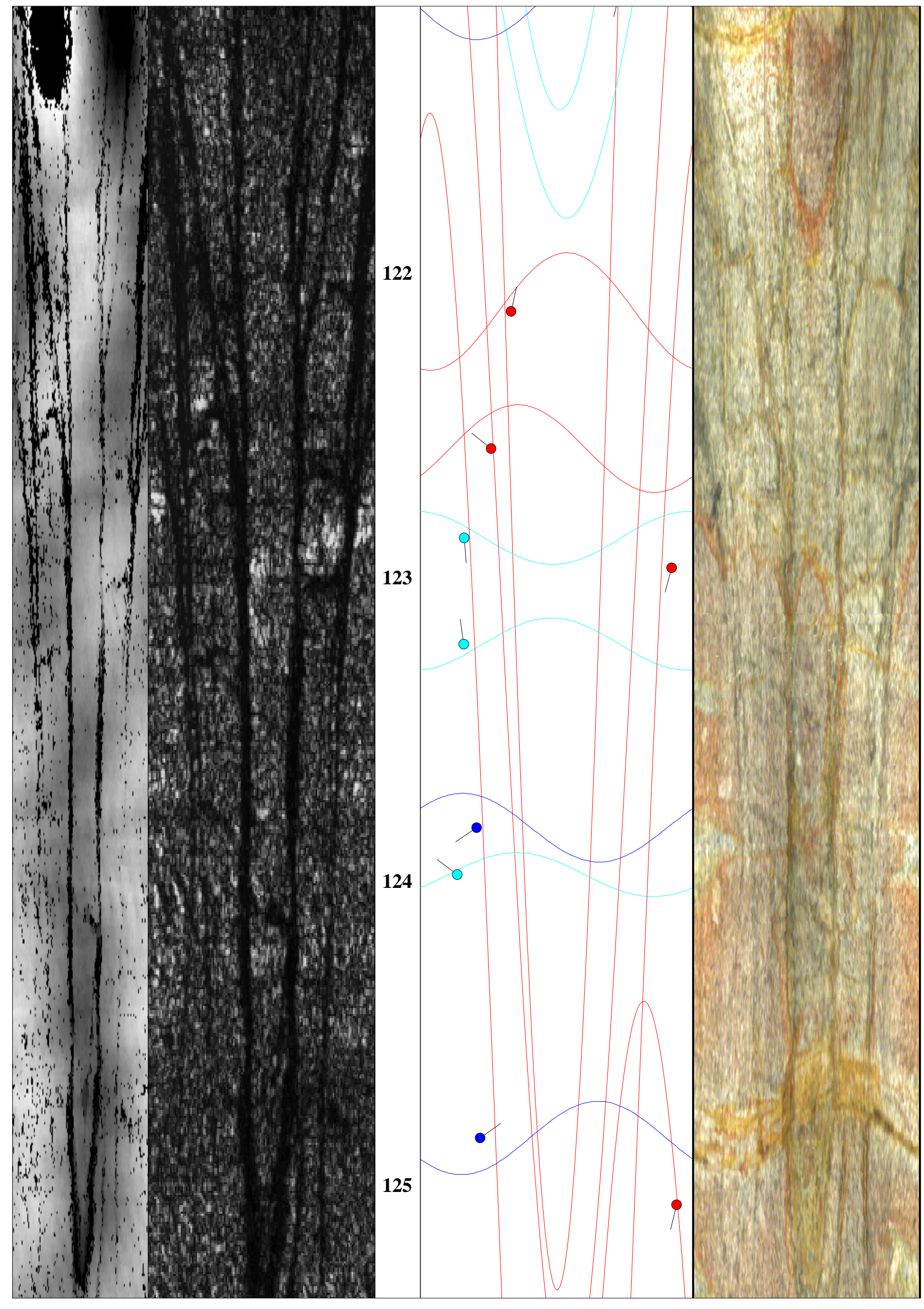




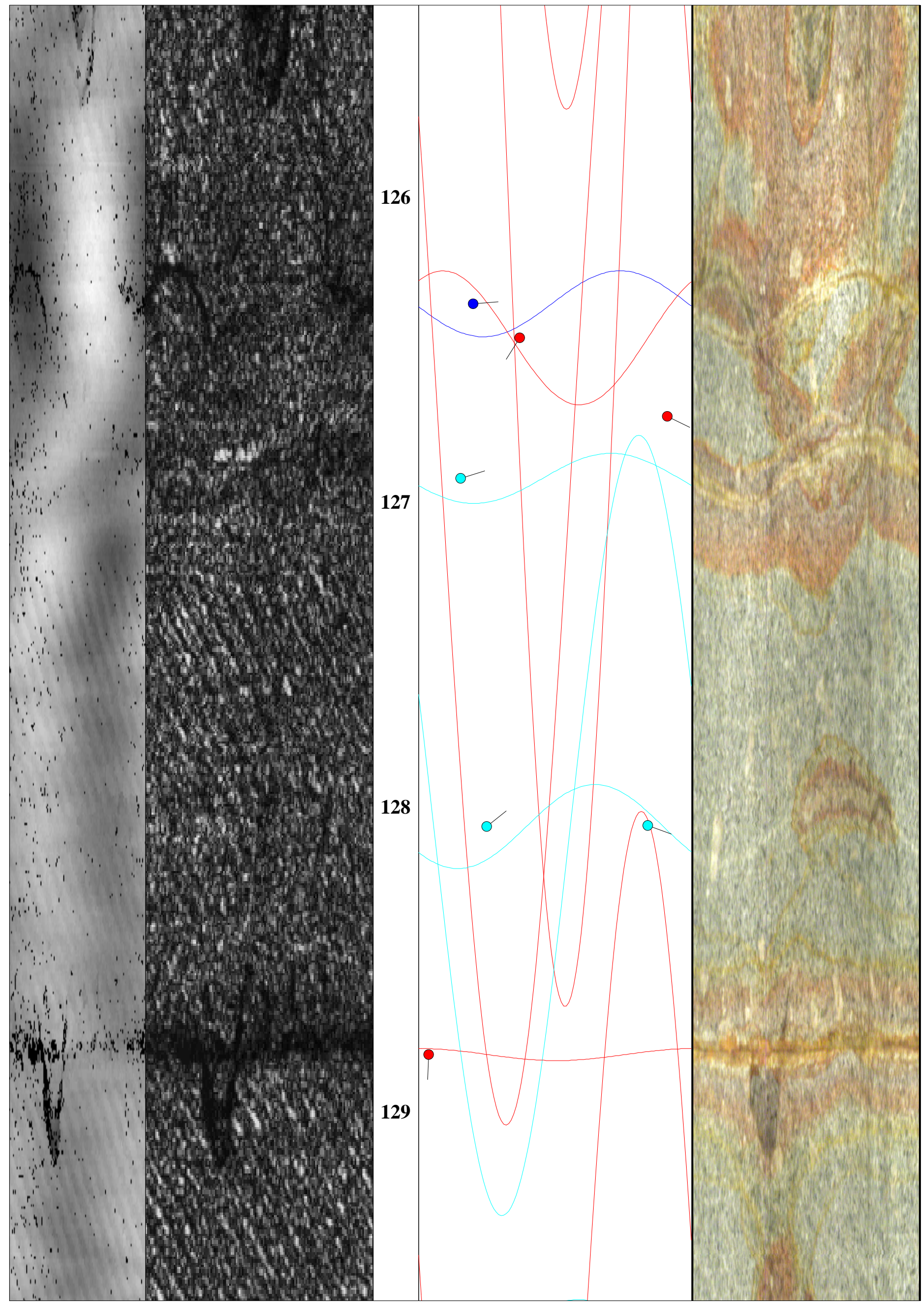




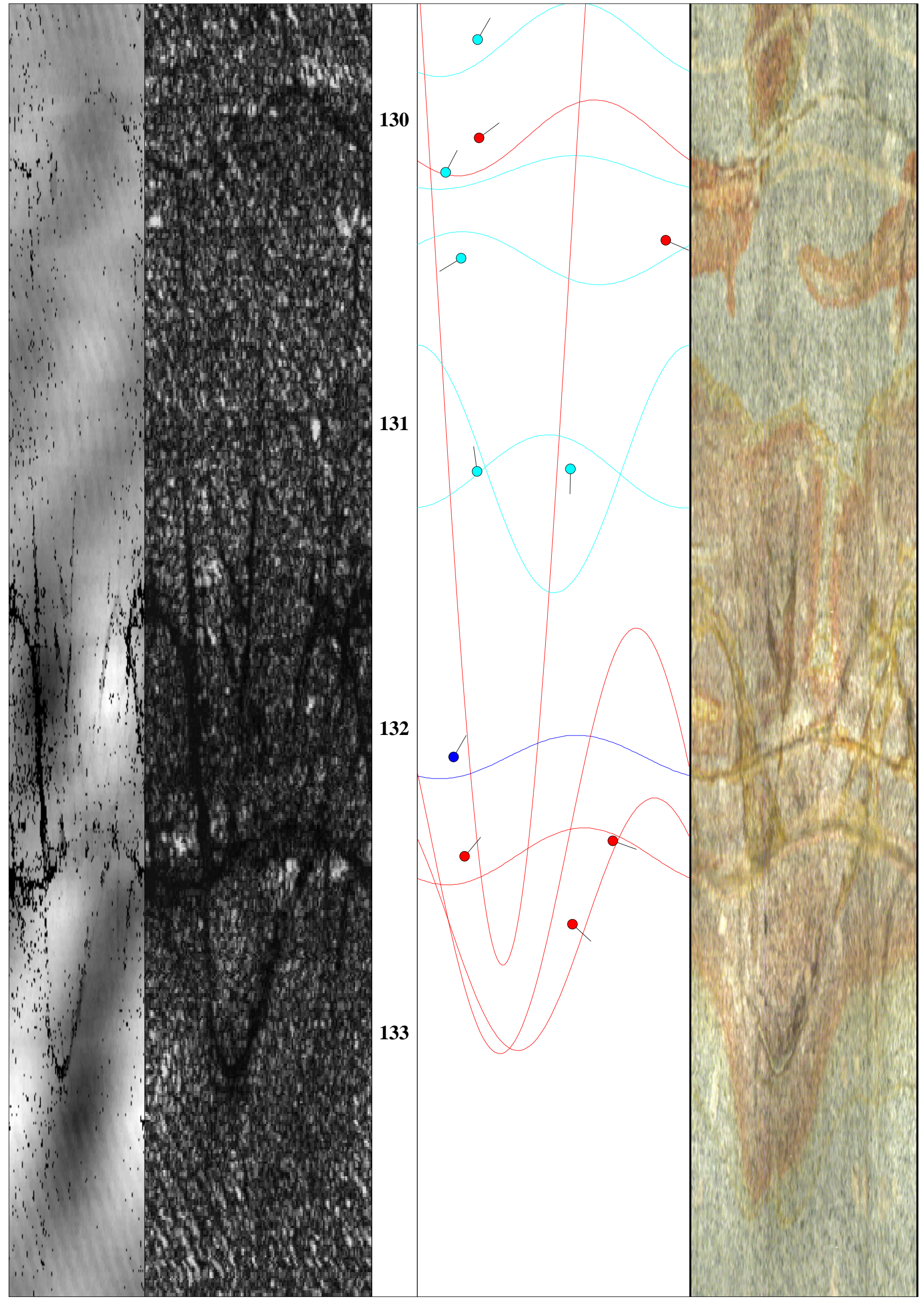




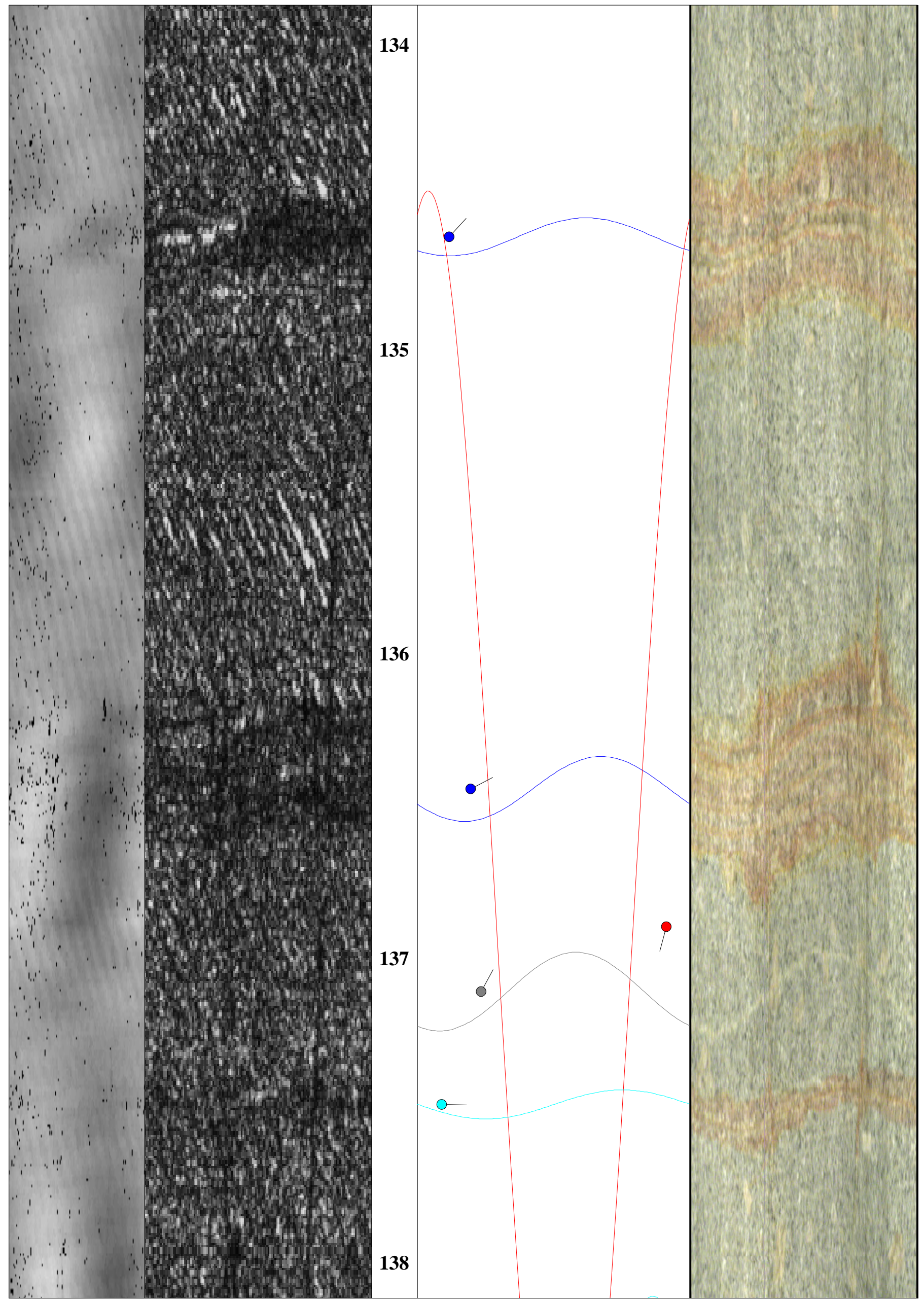




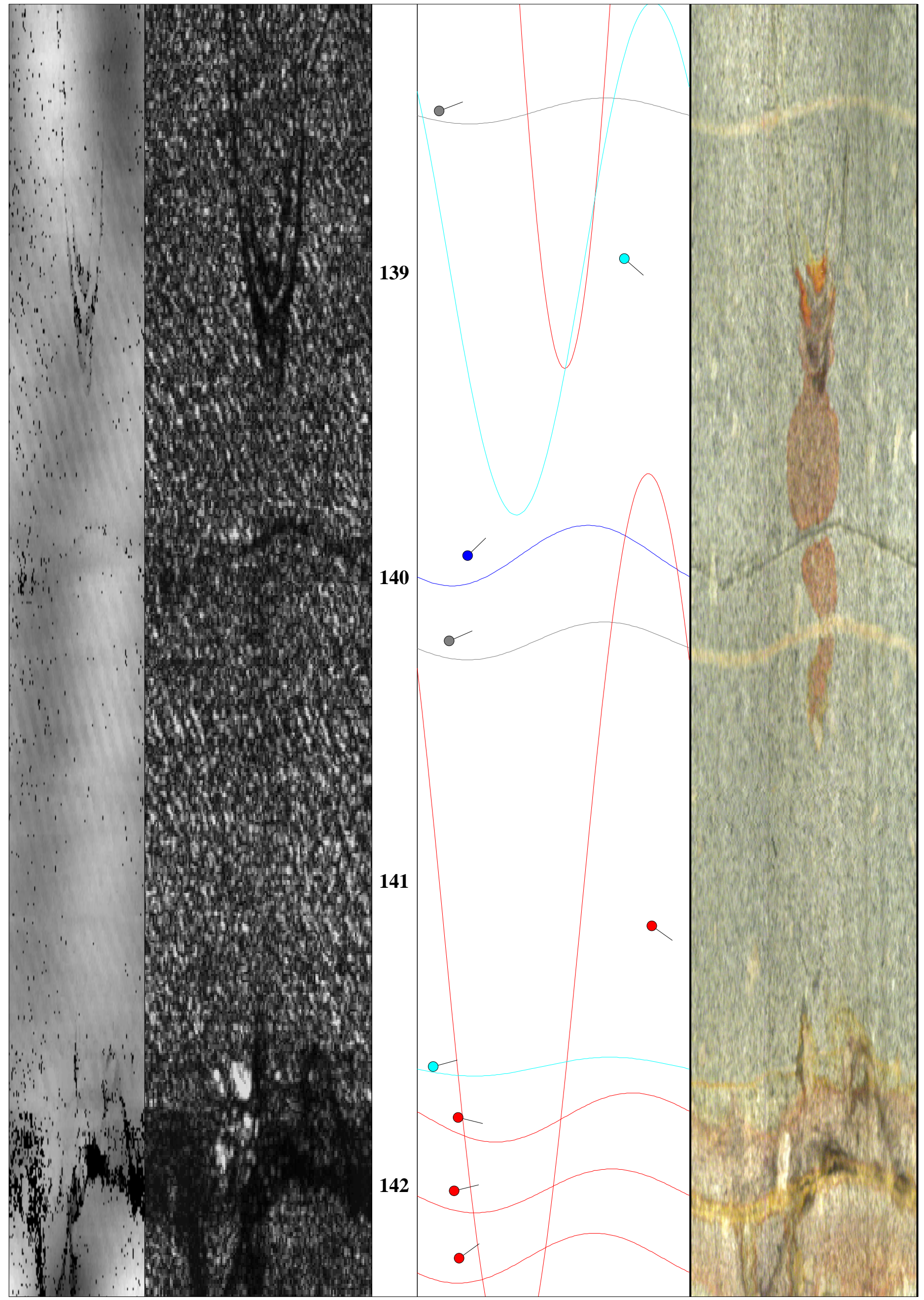




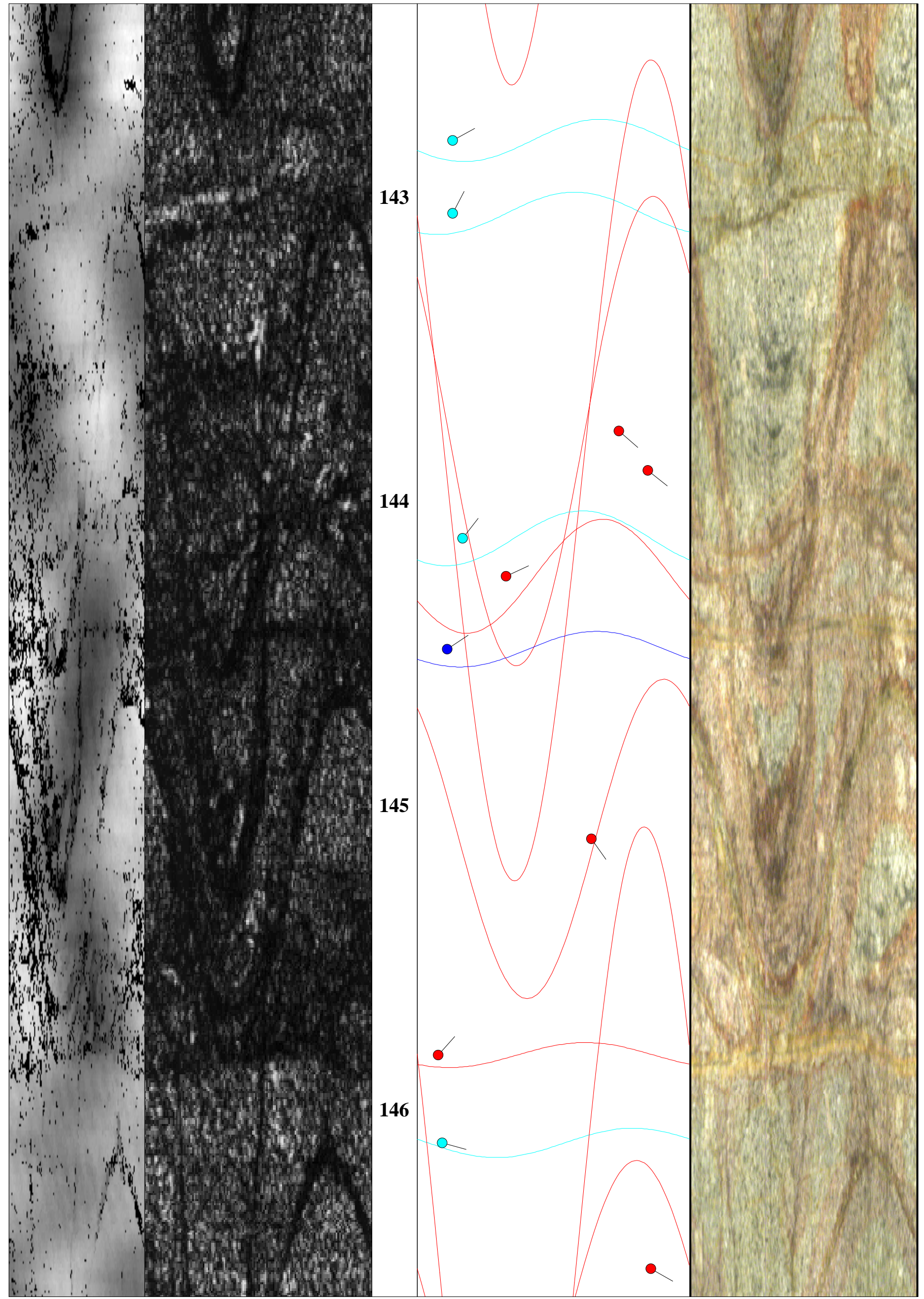




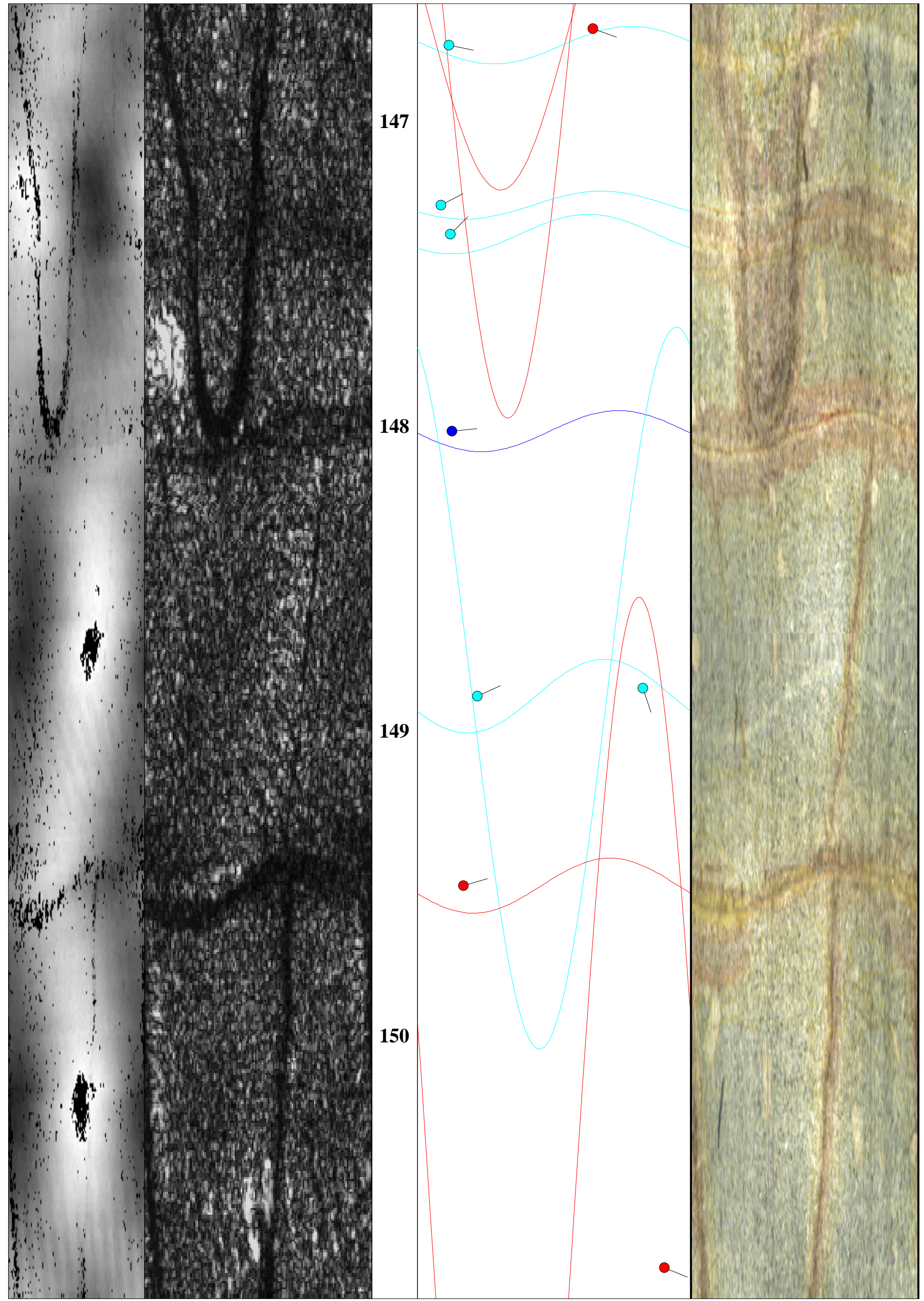




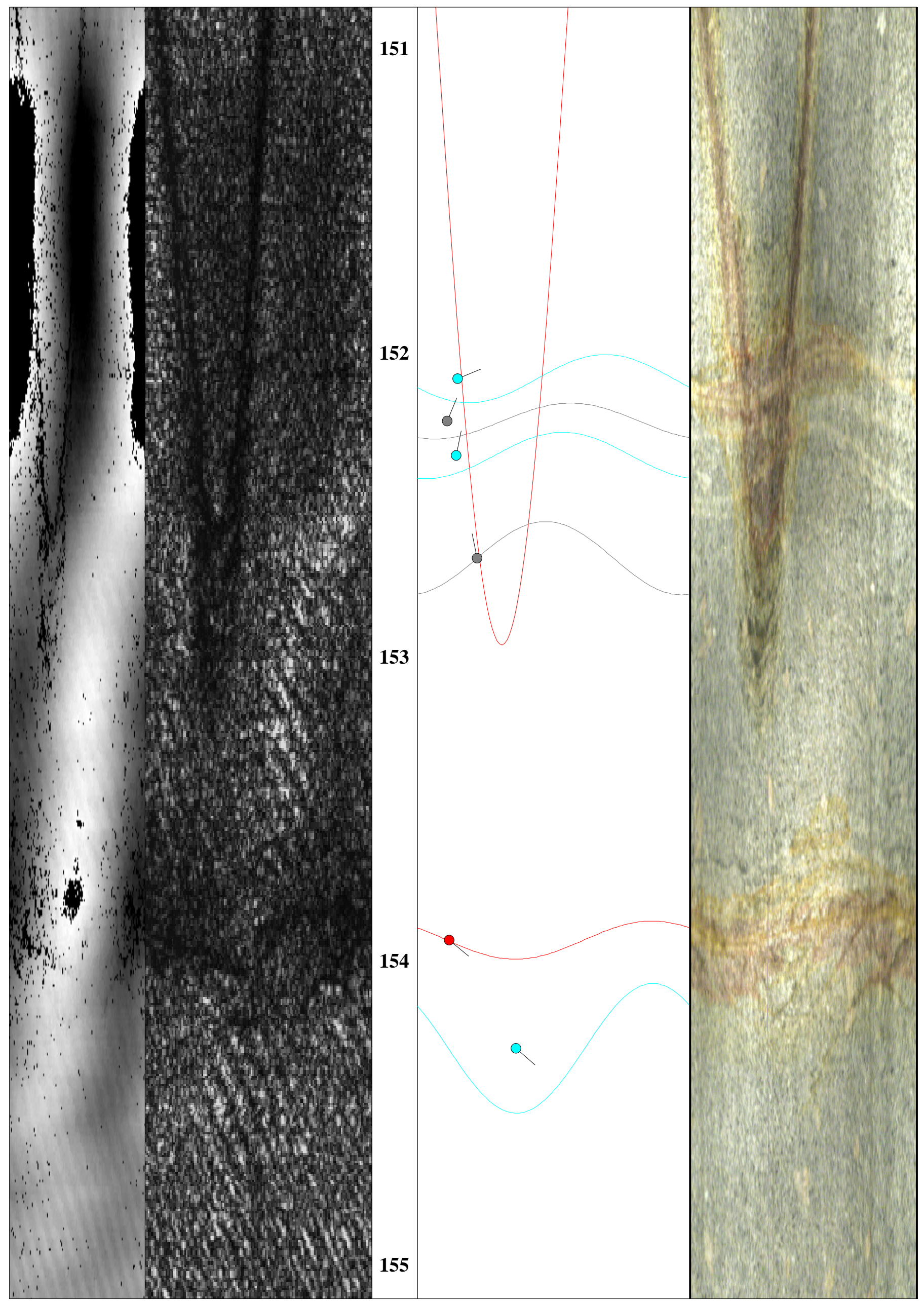




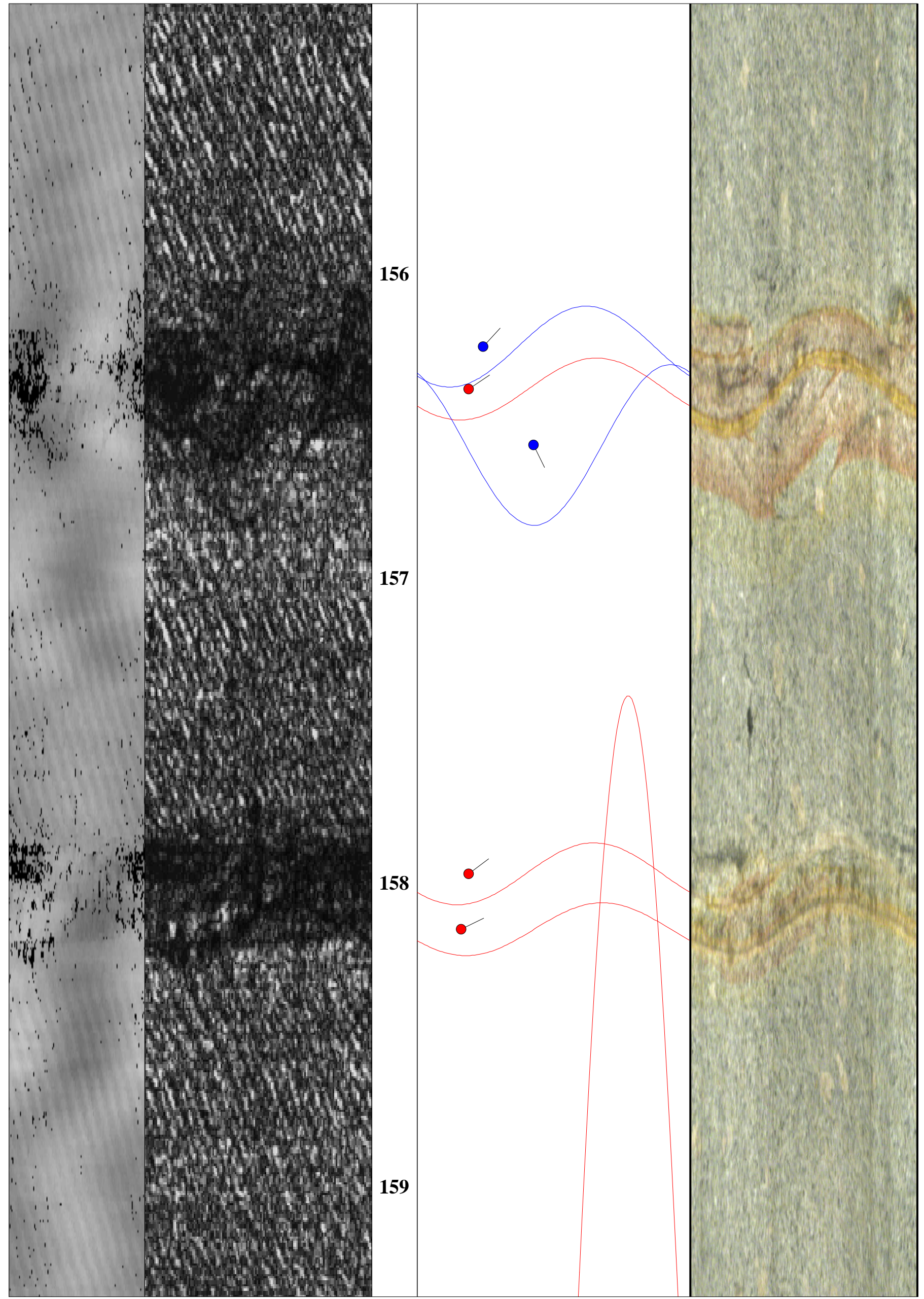




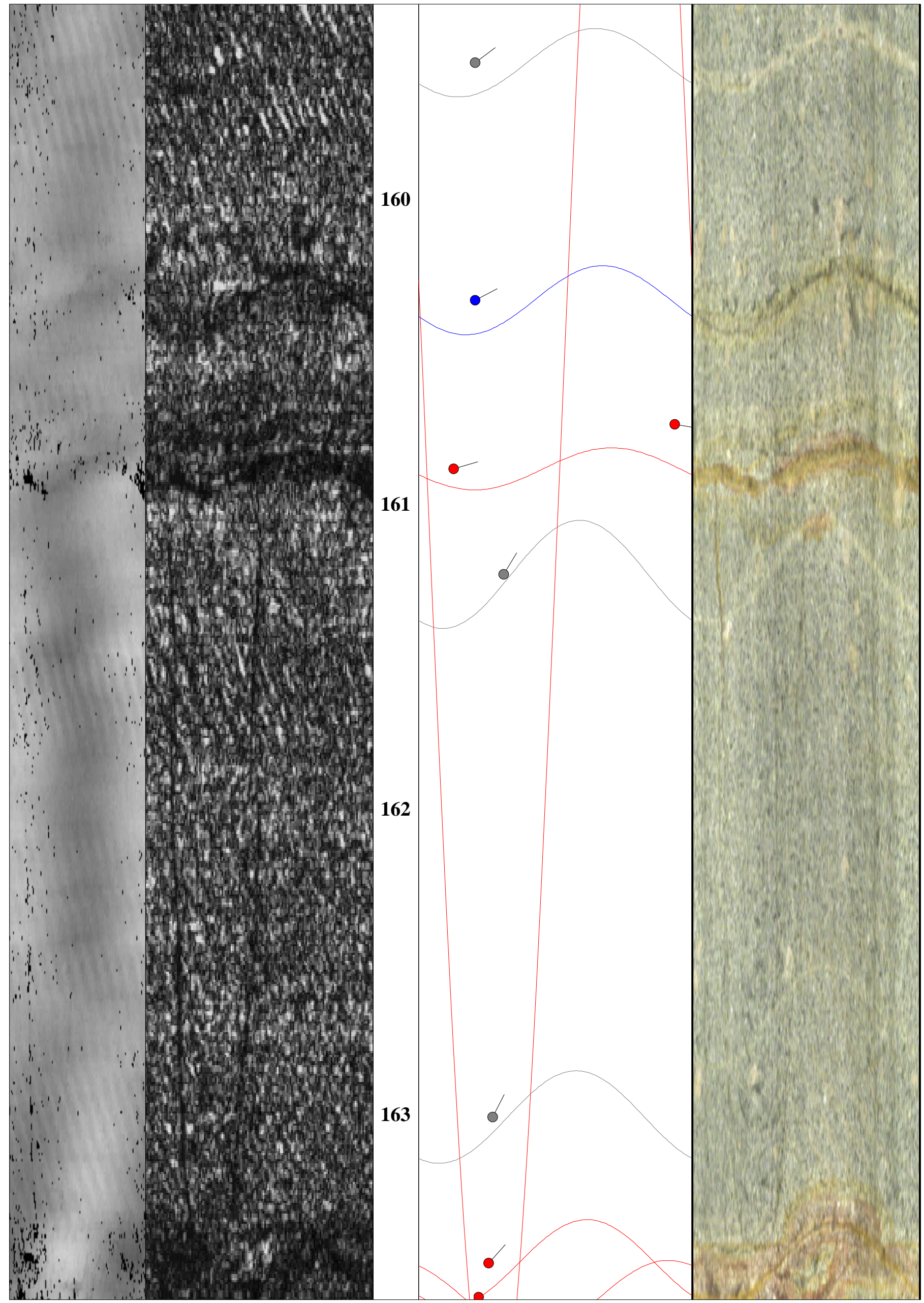




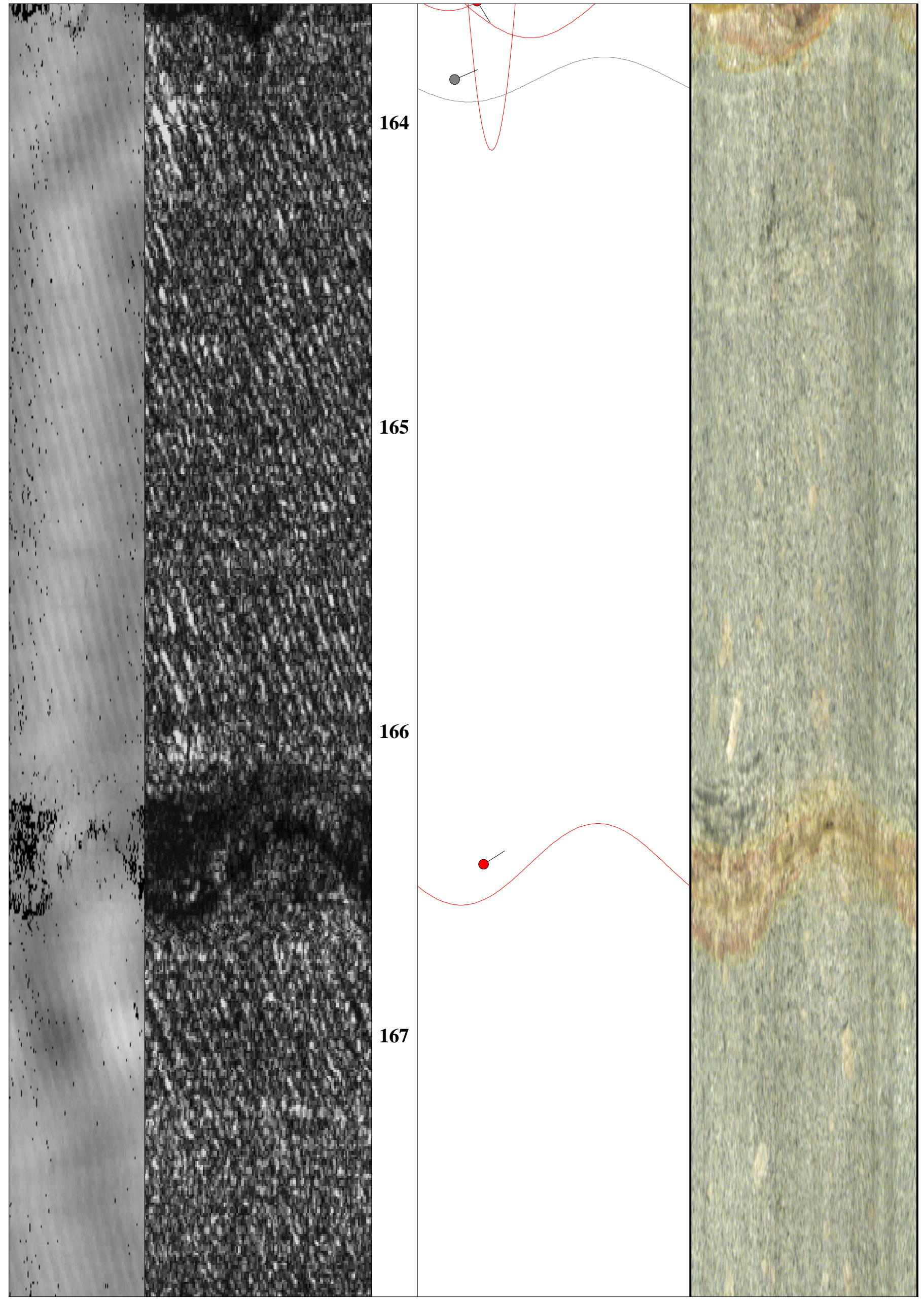




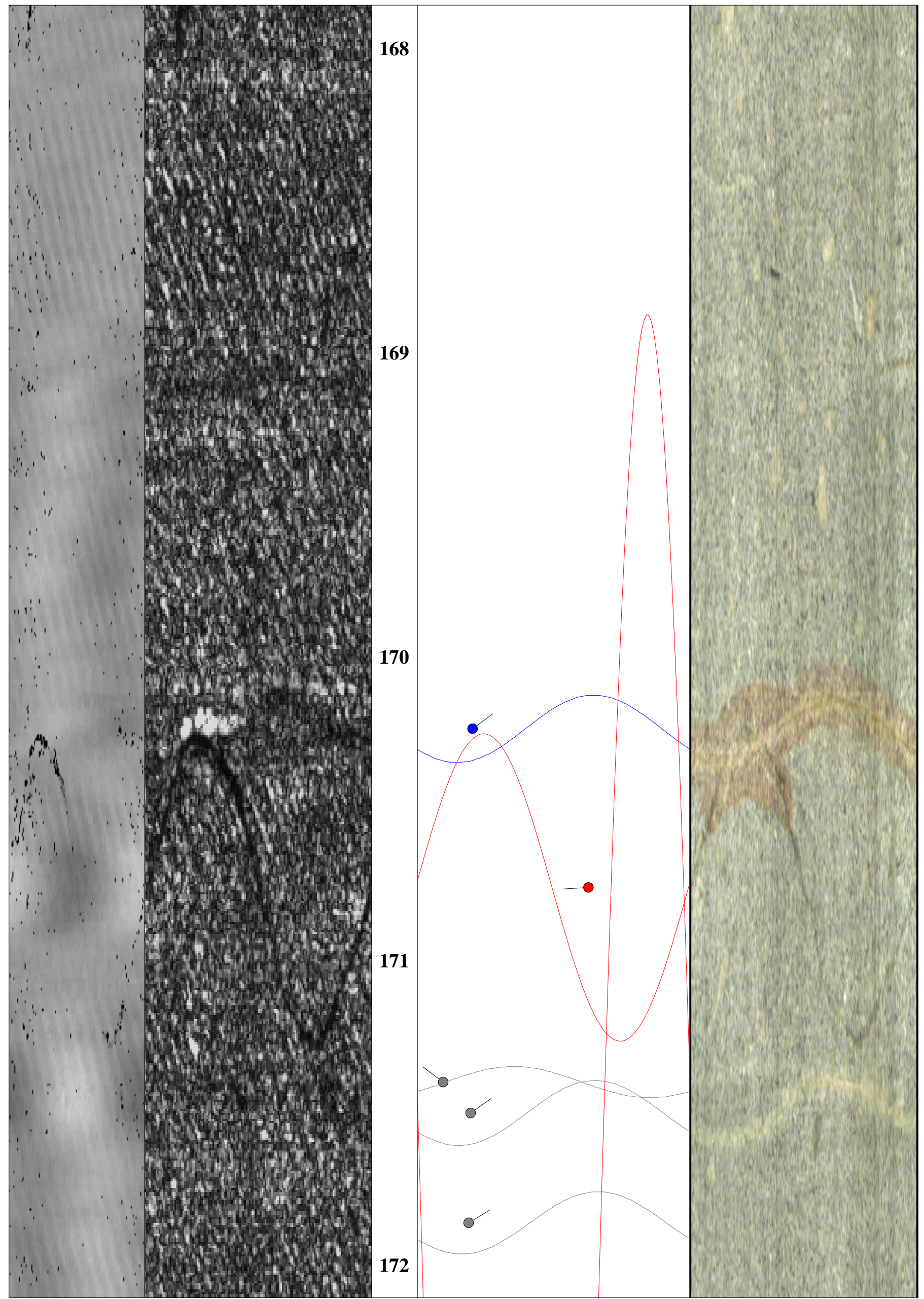




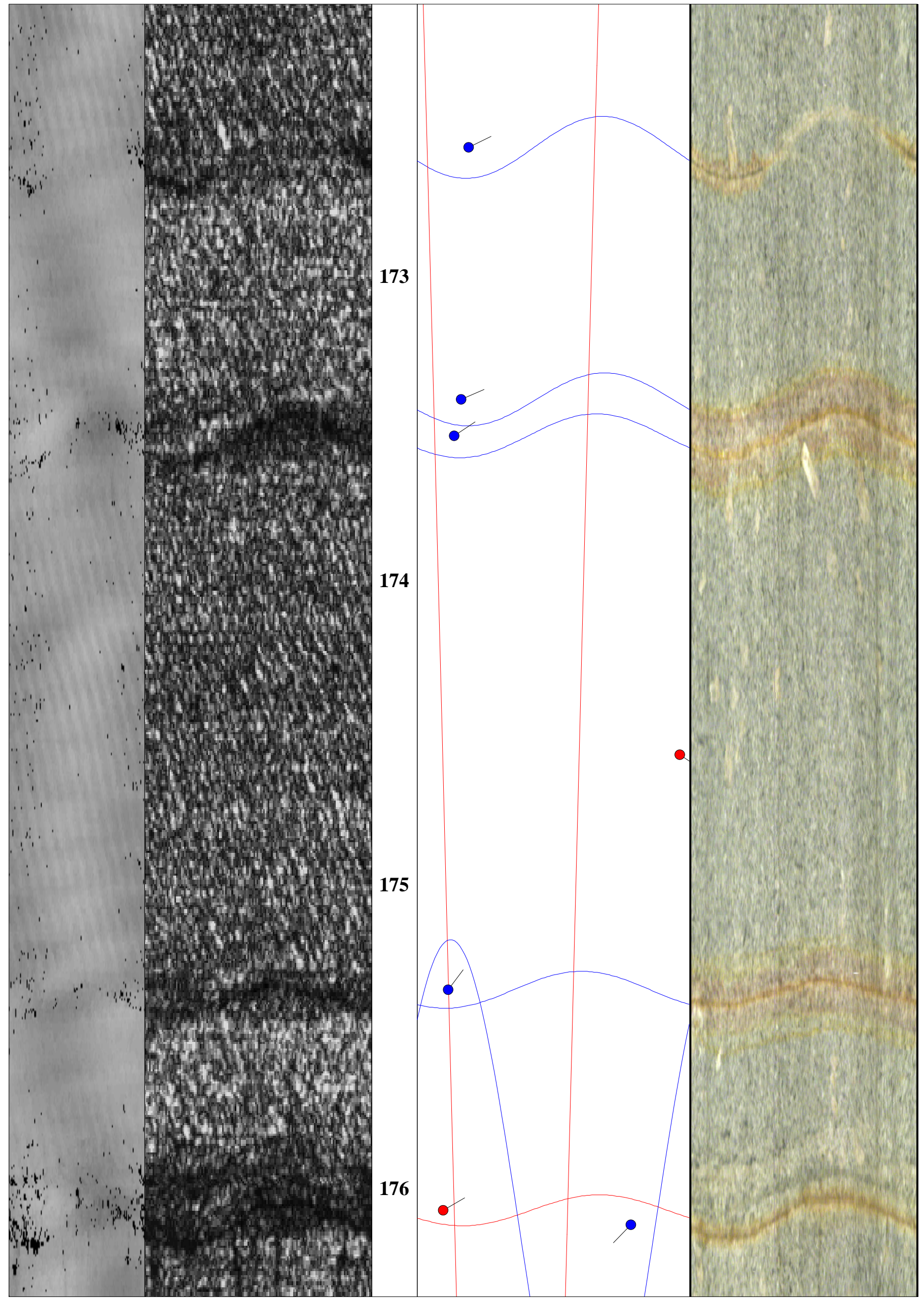




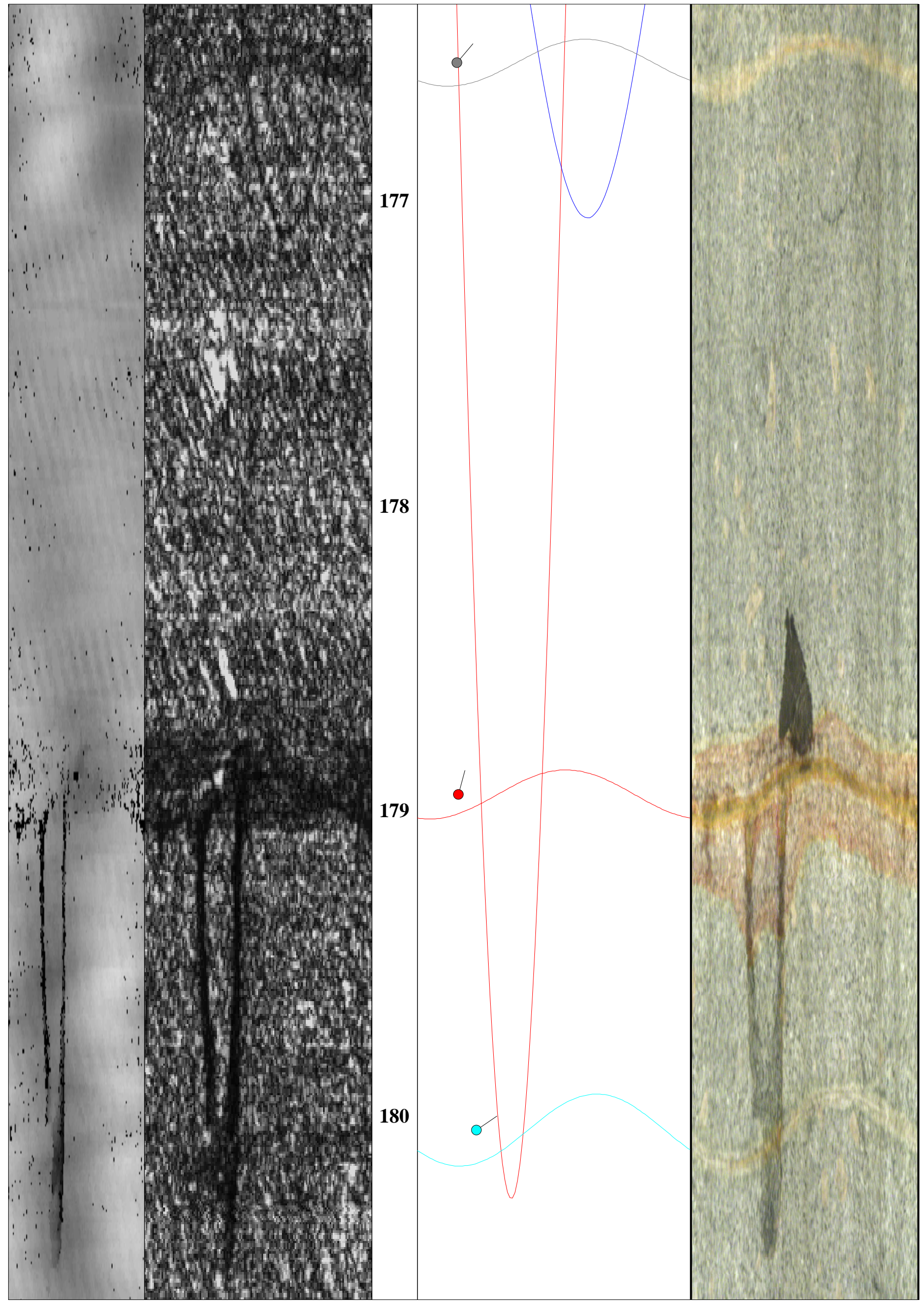




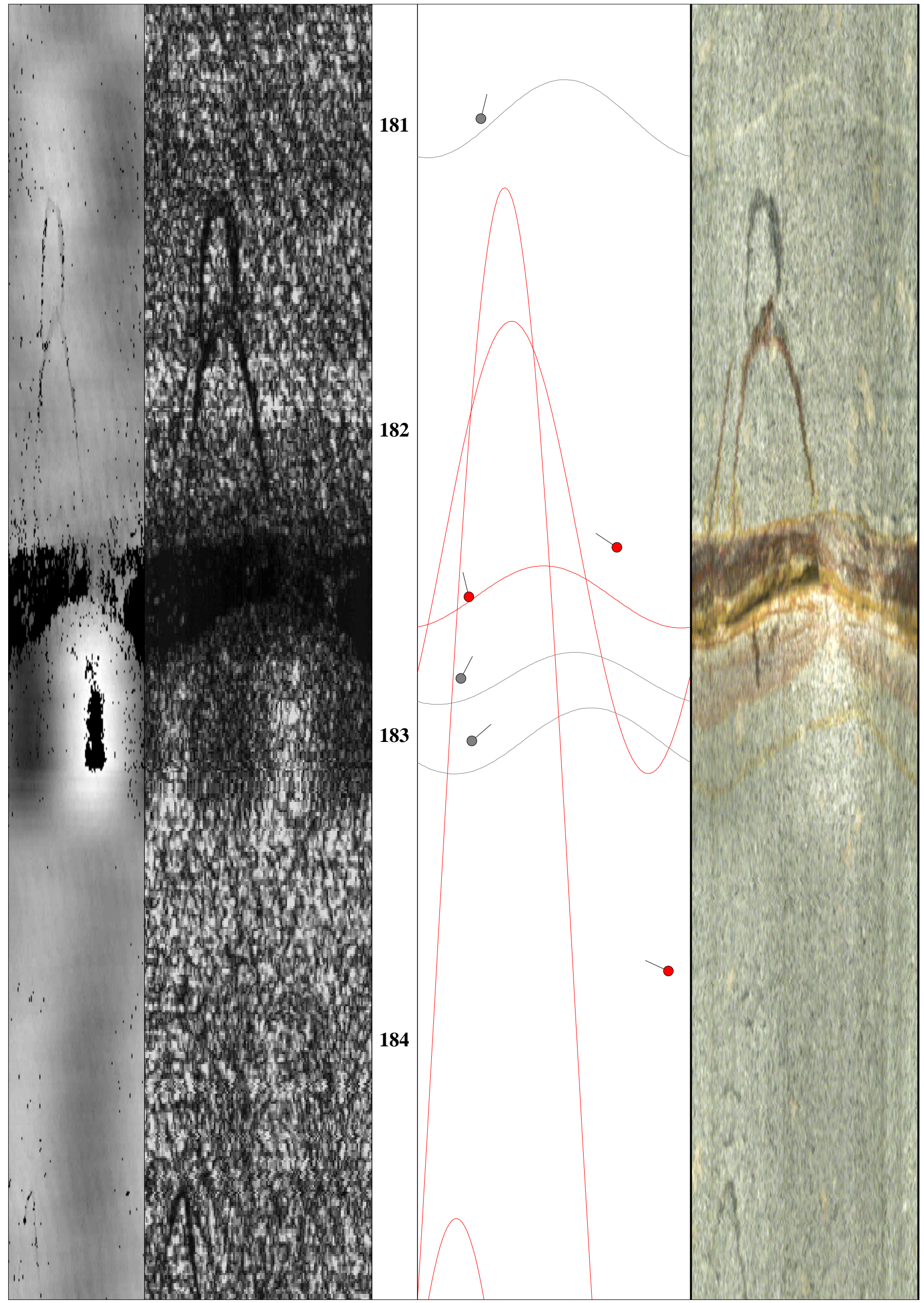




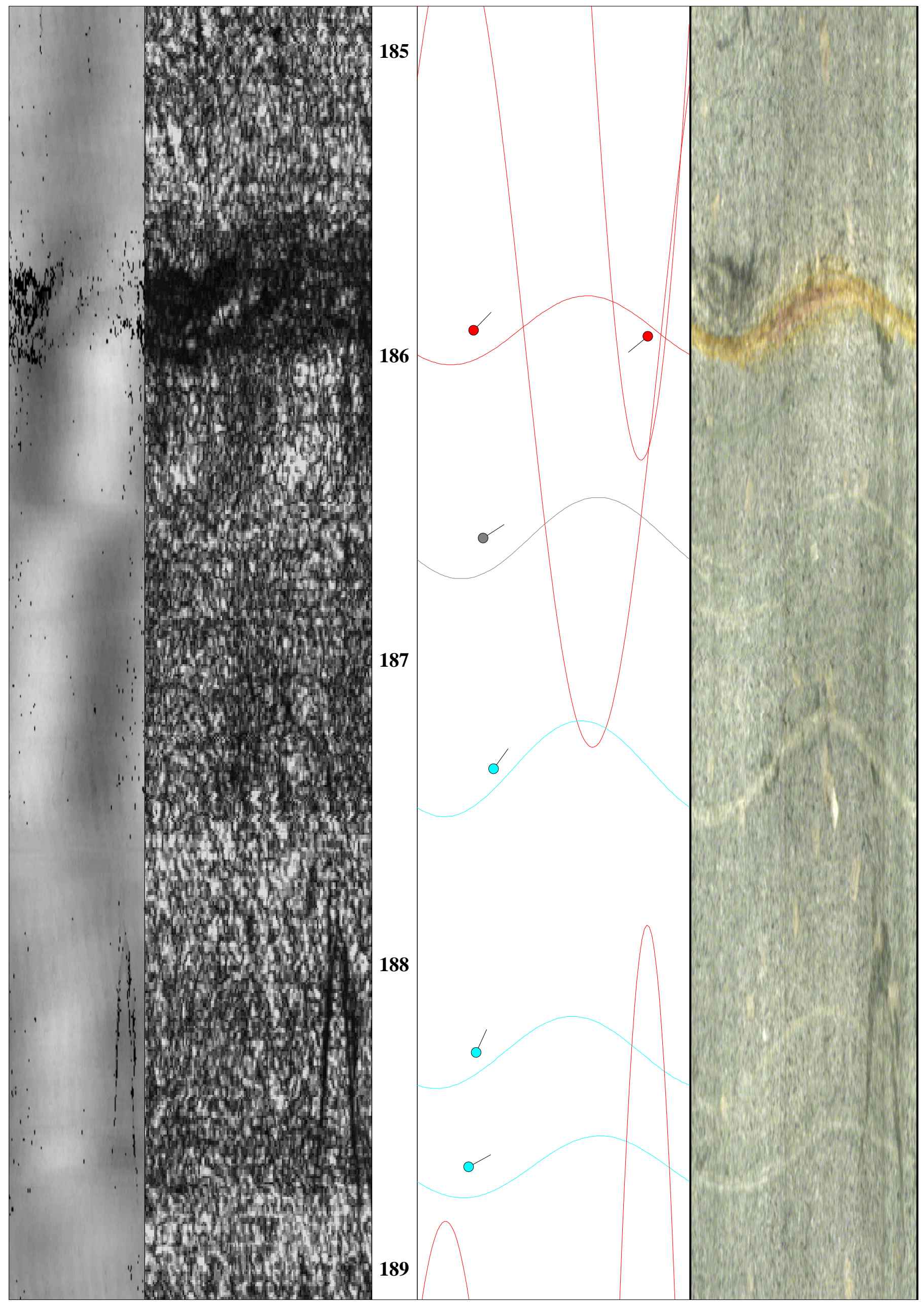




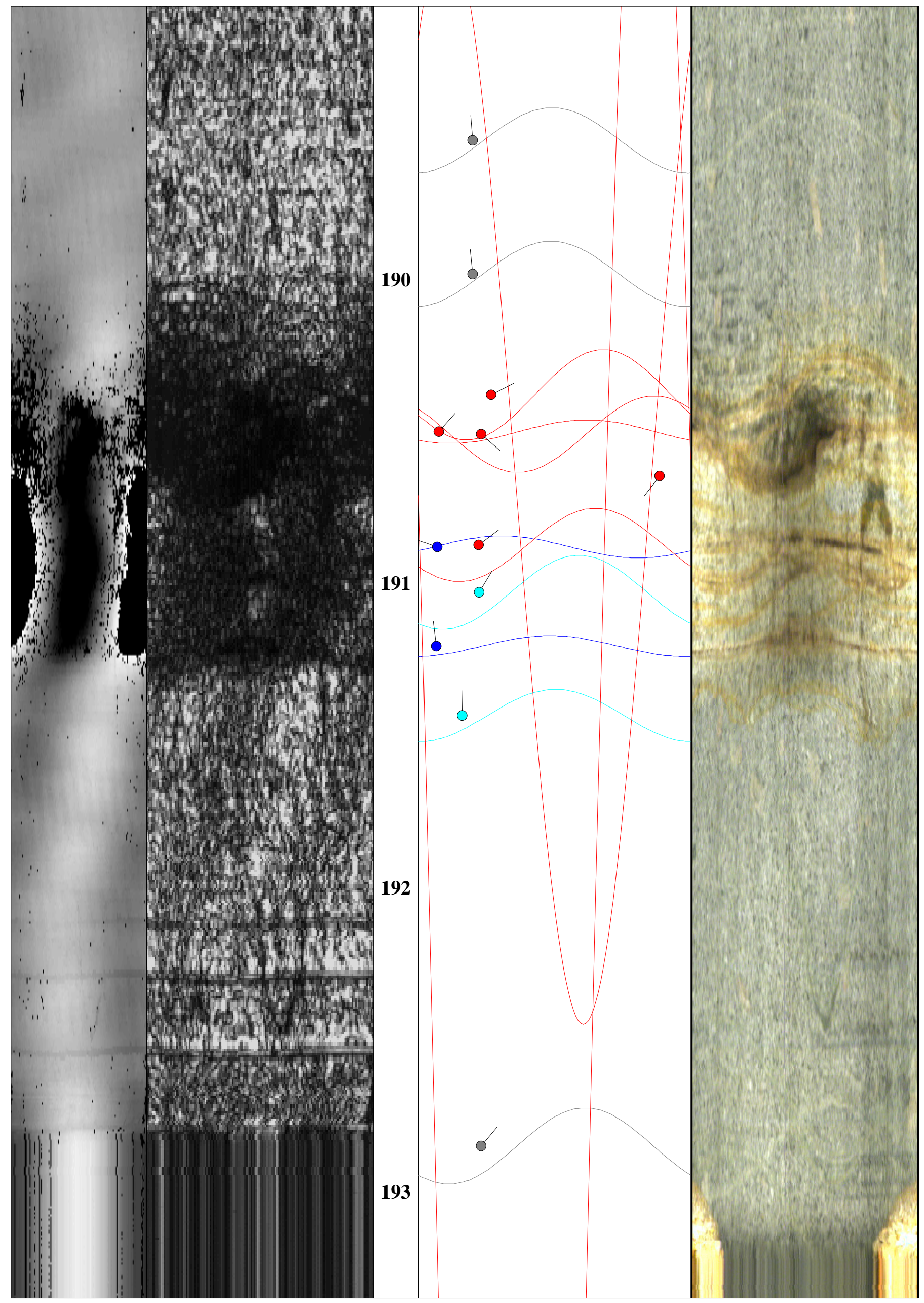




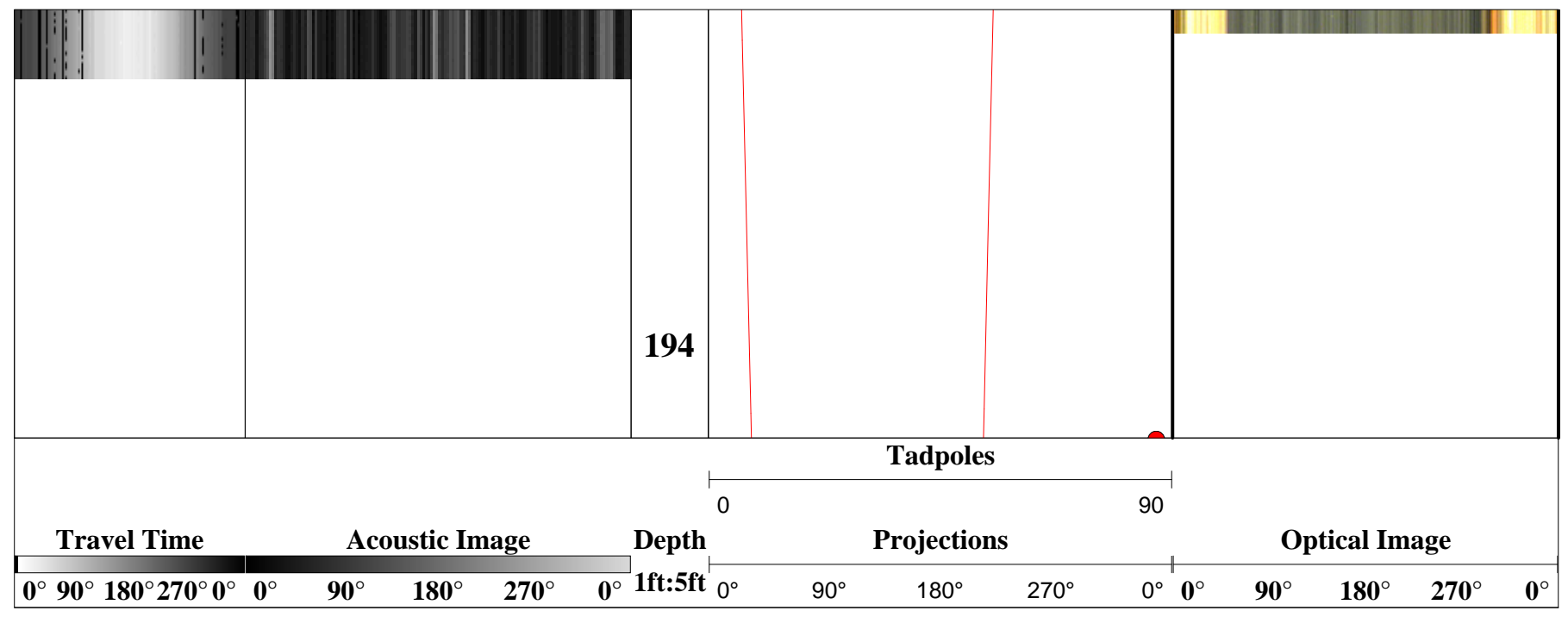




\section{Stereonet Diagram - Schmidt Projection}

Acoustic Televiewer Features

Nevada Test Site

Source Physics Experiment

U-15n5

NNSA/NSO

21 Sept 2010

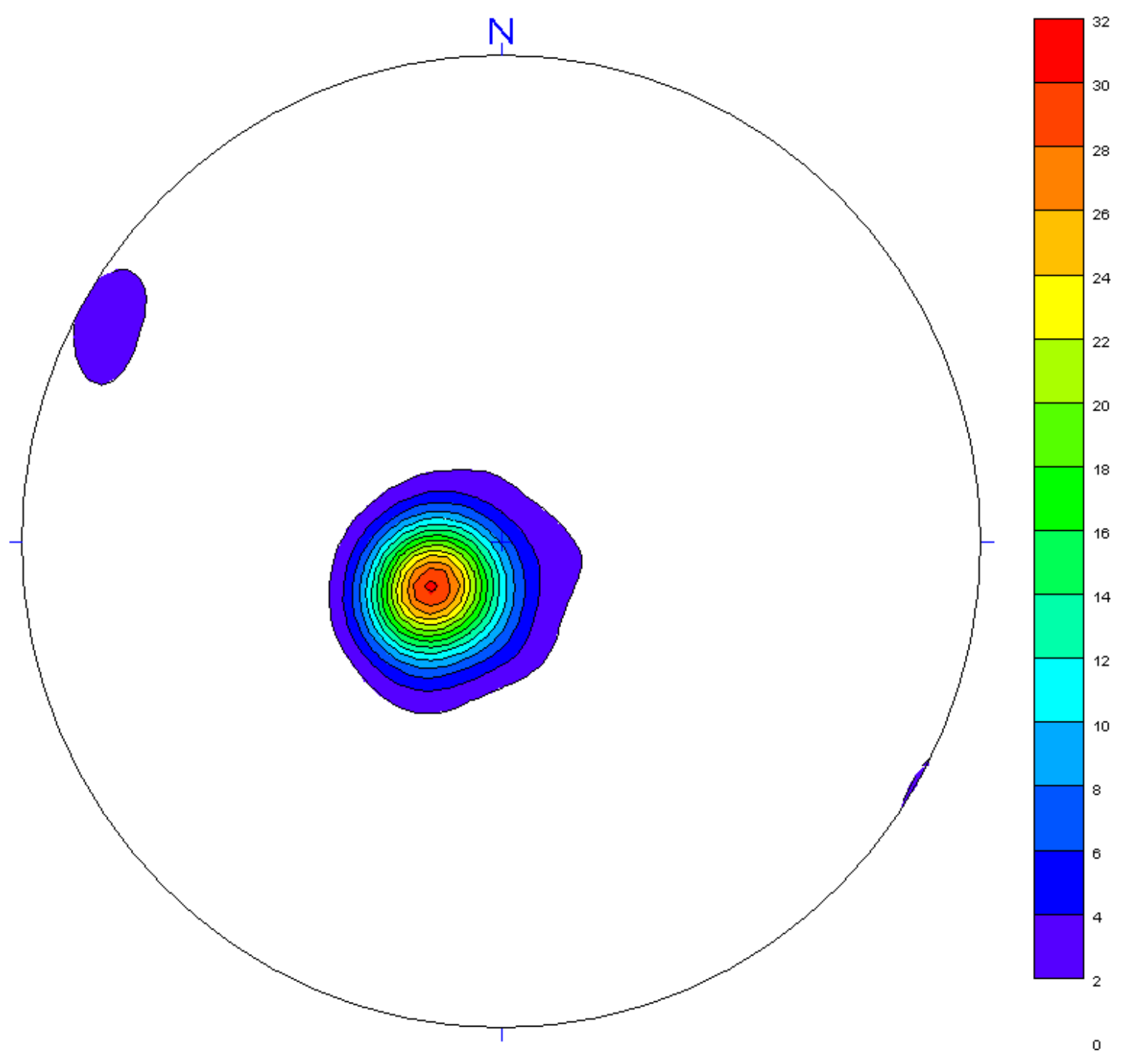

All directions are with respect to True North. 


\section{Stereonet Diagram - Schmidt Projection \\ Acoustic Televiewer Features \\ Nevada Test Site \\ Source Physics Experiment \\ U-15n5 \\ NNSA/NSO \\ 21 Sept 2010}

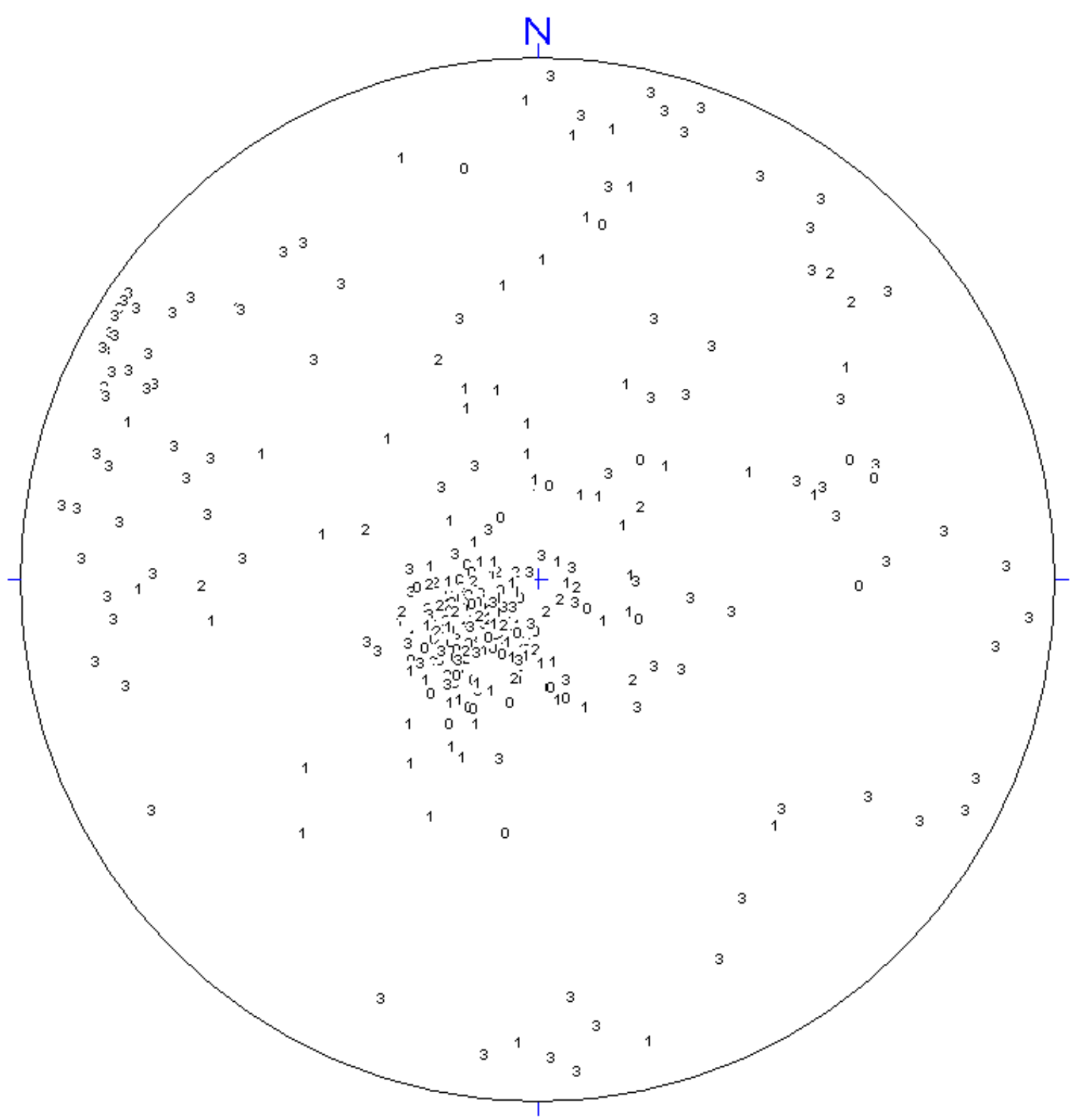

All directions are with respect to True North. 


\section{Rose Diagram - Dip Directions \\ Acoustic Televiewer Features \\ Nevada Test Site \\ Source Physics Experiment \\ U-15n5 \\ NNSA/NSO \\ 21 Sept 2010}

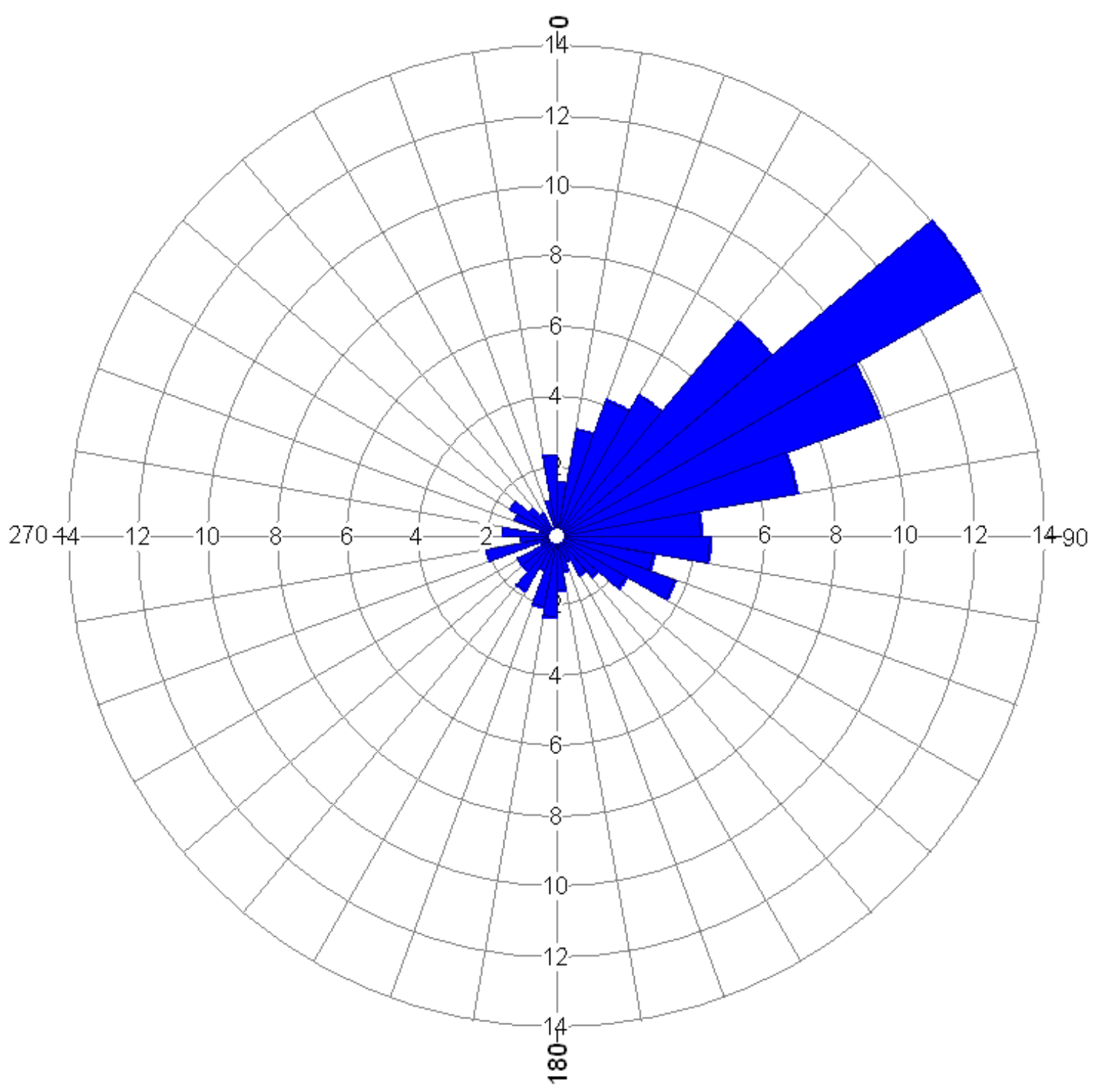

All directions are with respect to True North. 


\section{Rose Diagram - Dip Angles \\ Acoustic Televiewer Features \\ Nevada Test Site \\ Source Physics Experiment \\ U-15n5 \\ NNSA/NSO \\ 21 Sept 2010}

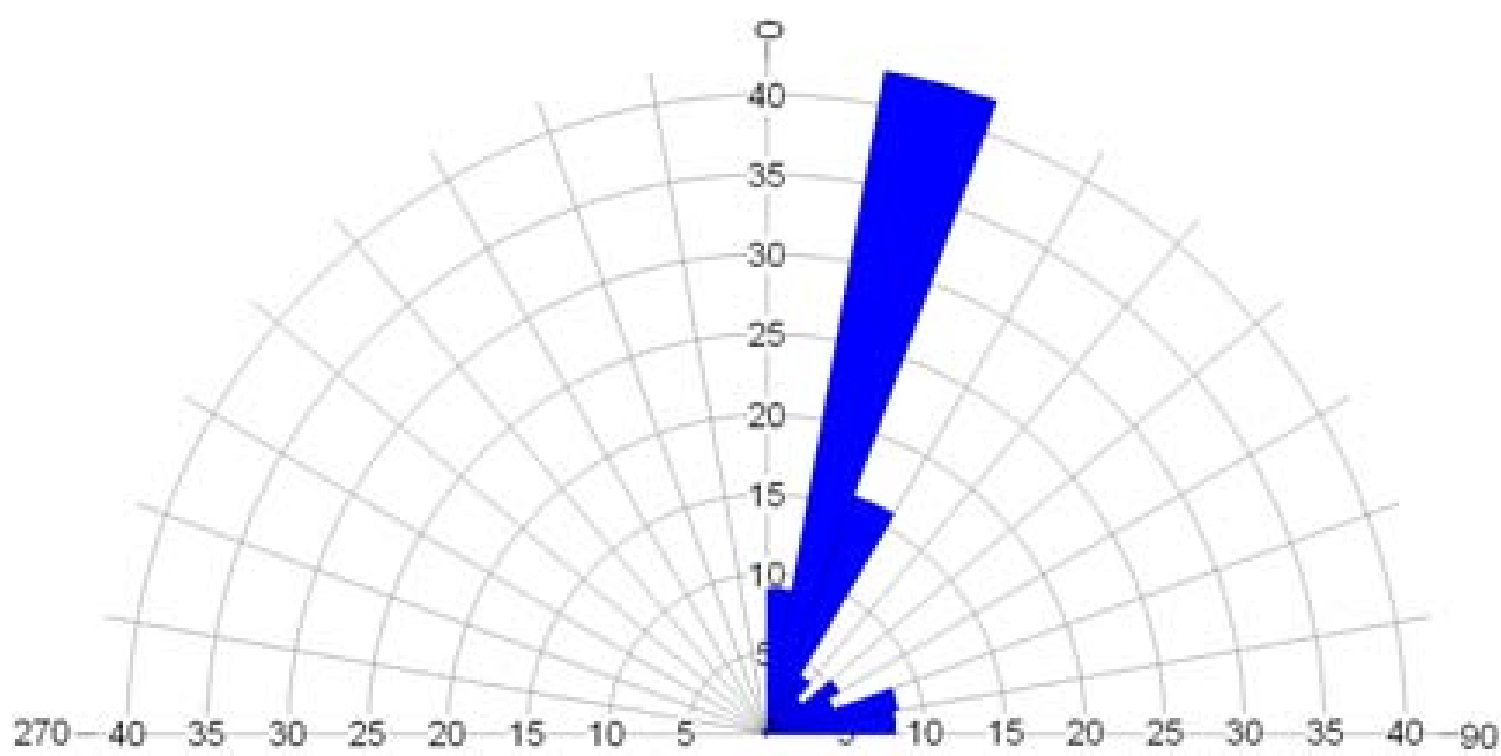




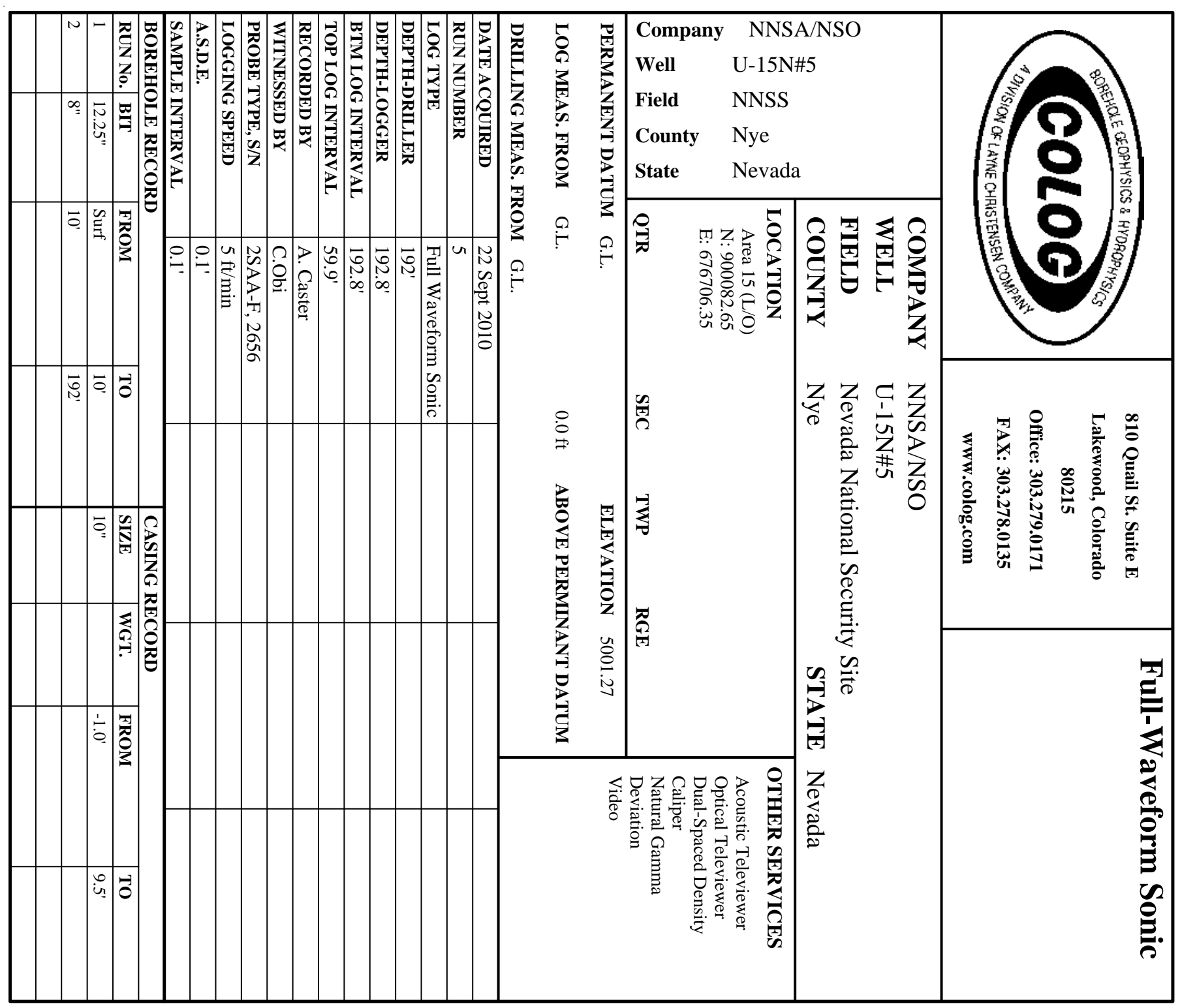

COMMENTS

NA - Not Available, N/A - Not Applicable 


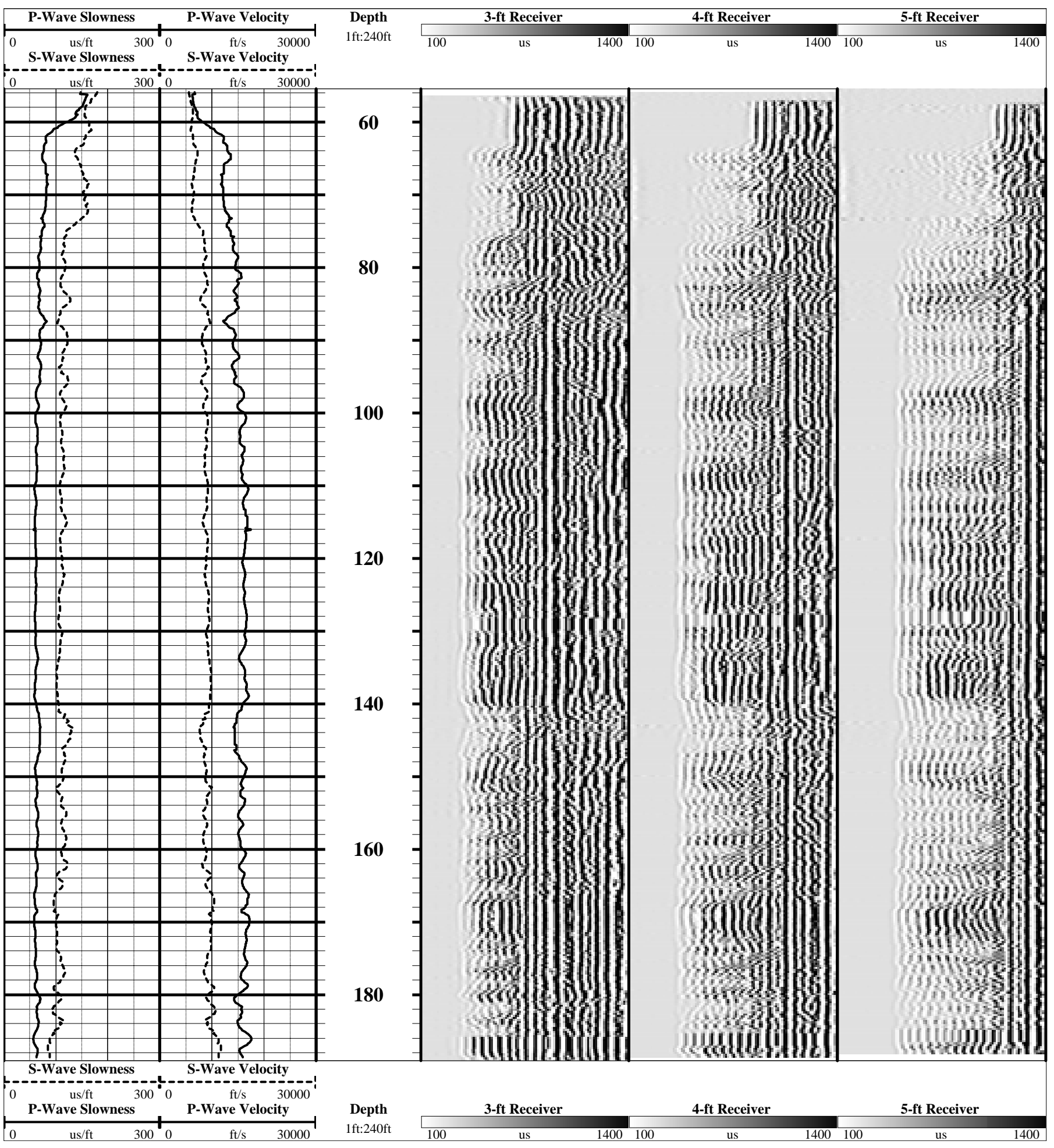




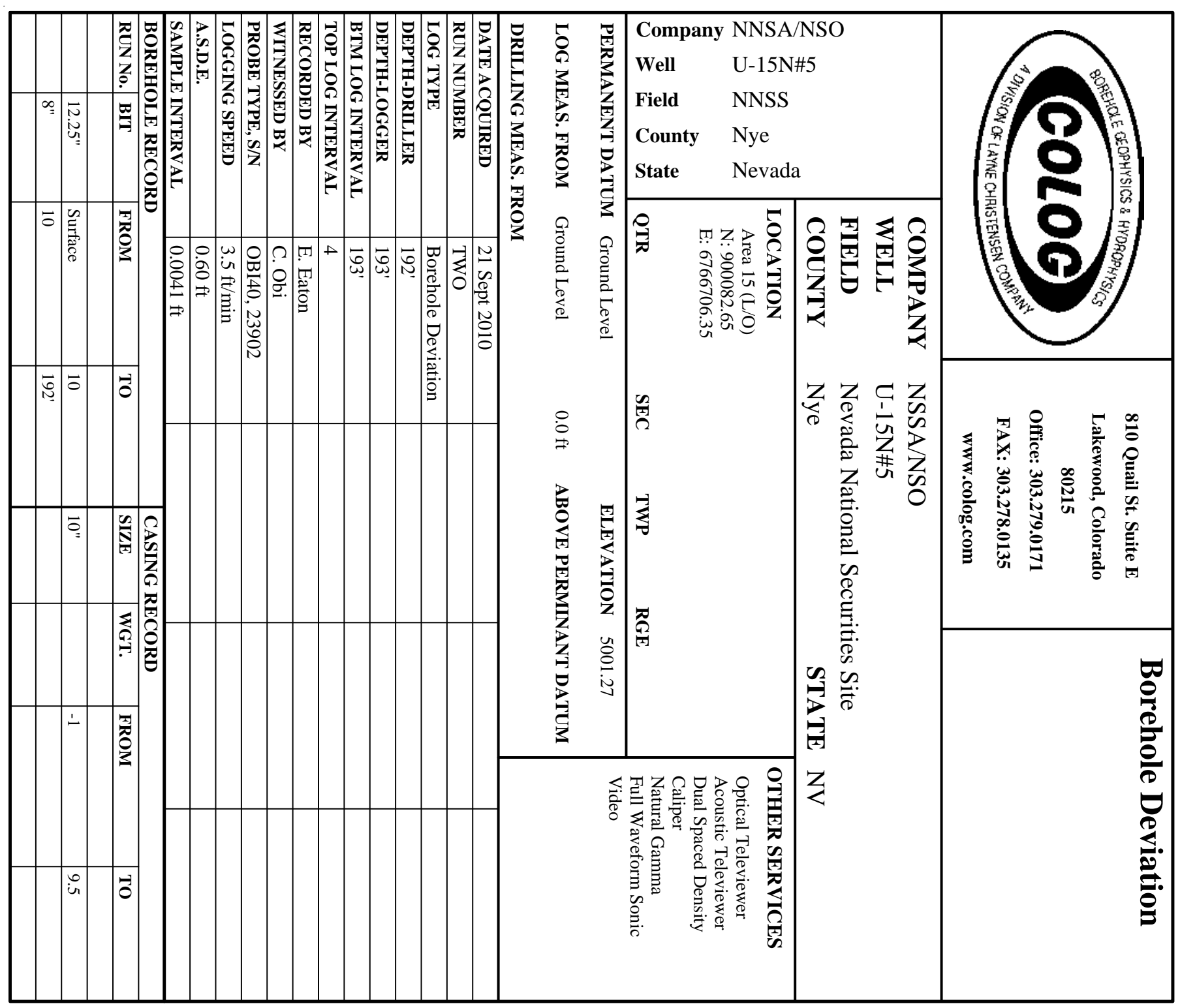

COMMENTS

NA - Not Available, N/A - Not Applicable 

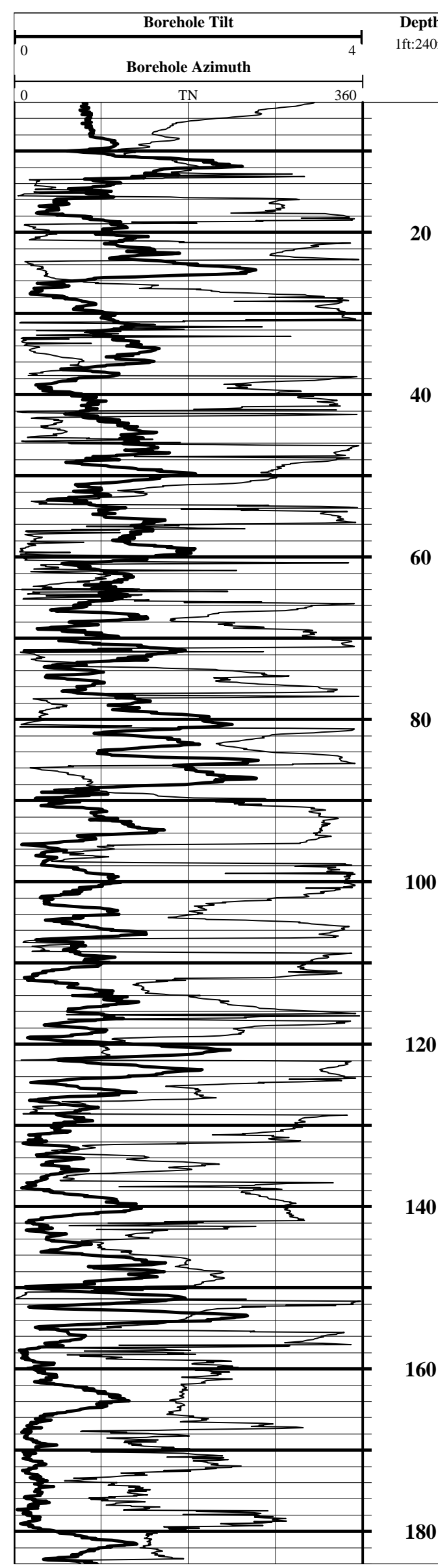

60

100

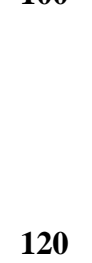

140

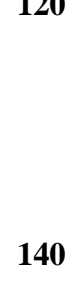

160

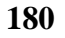

20

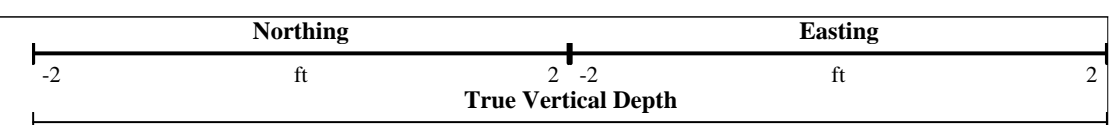

\begin{tabular}{|l|l|l}
\hline 0 & $\mathrm{ft}$ & 200 \\
\hline
\end{tabular}

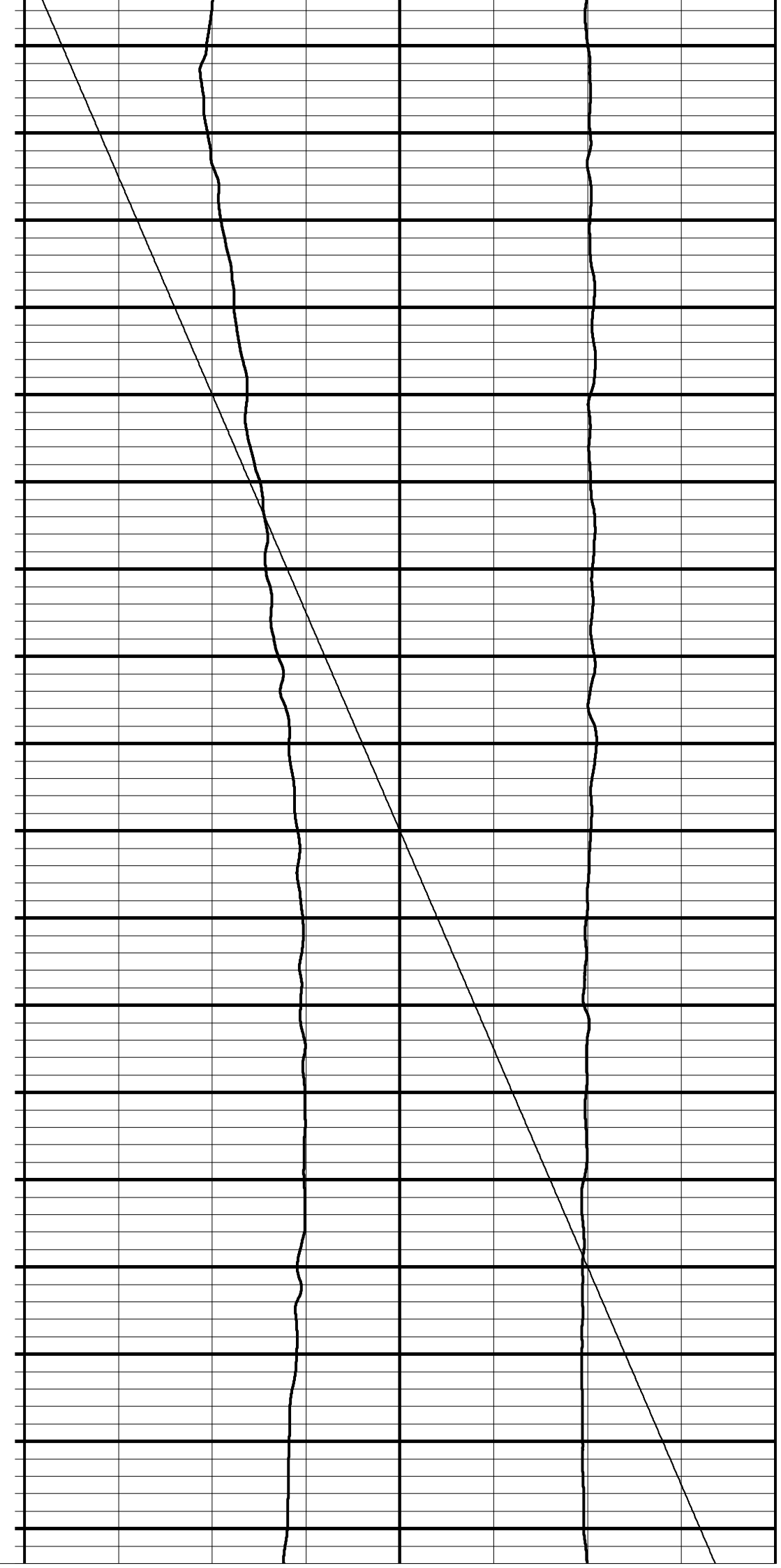




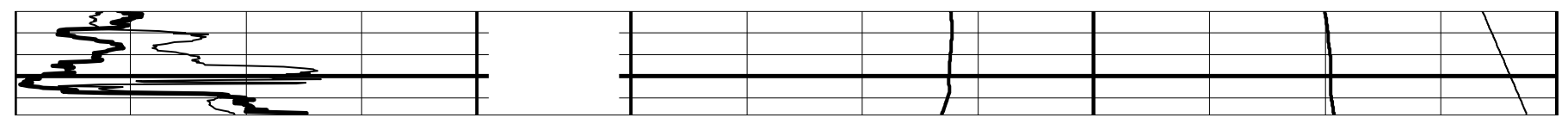




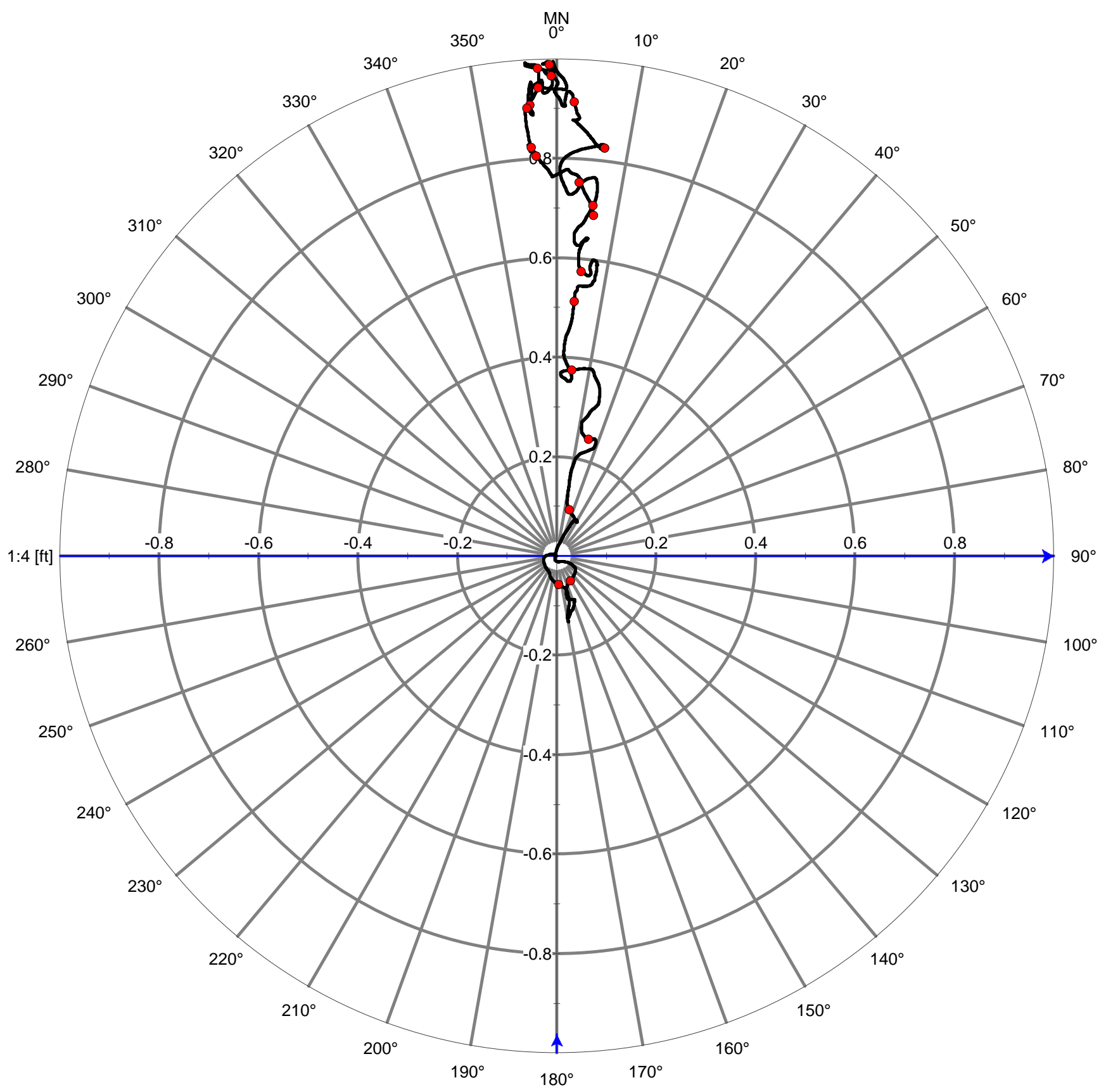




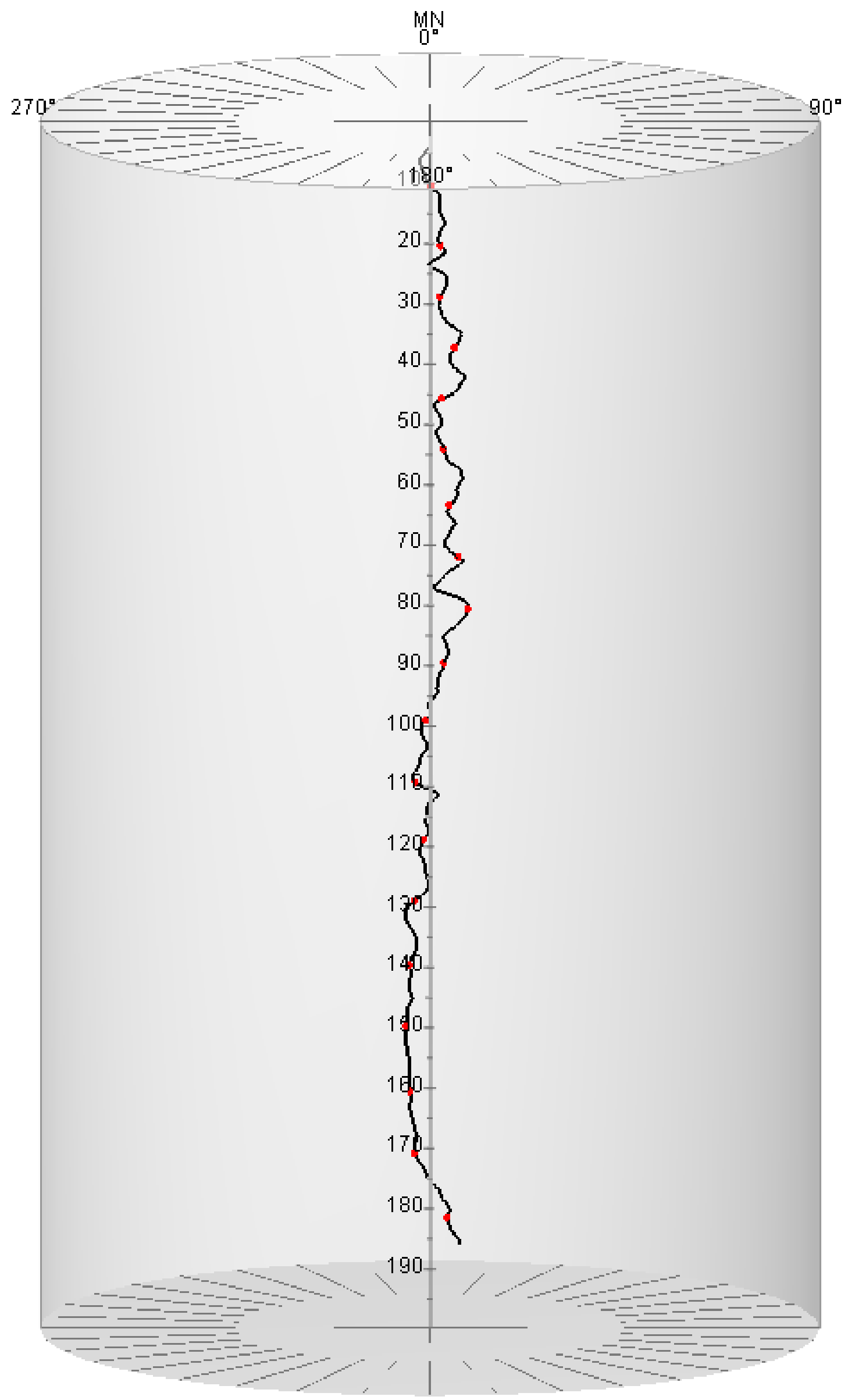




\section{Appendix F-7}

Borehole Geophysical Log Plots for Instrument Hole U-15n\#6 


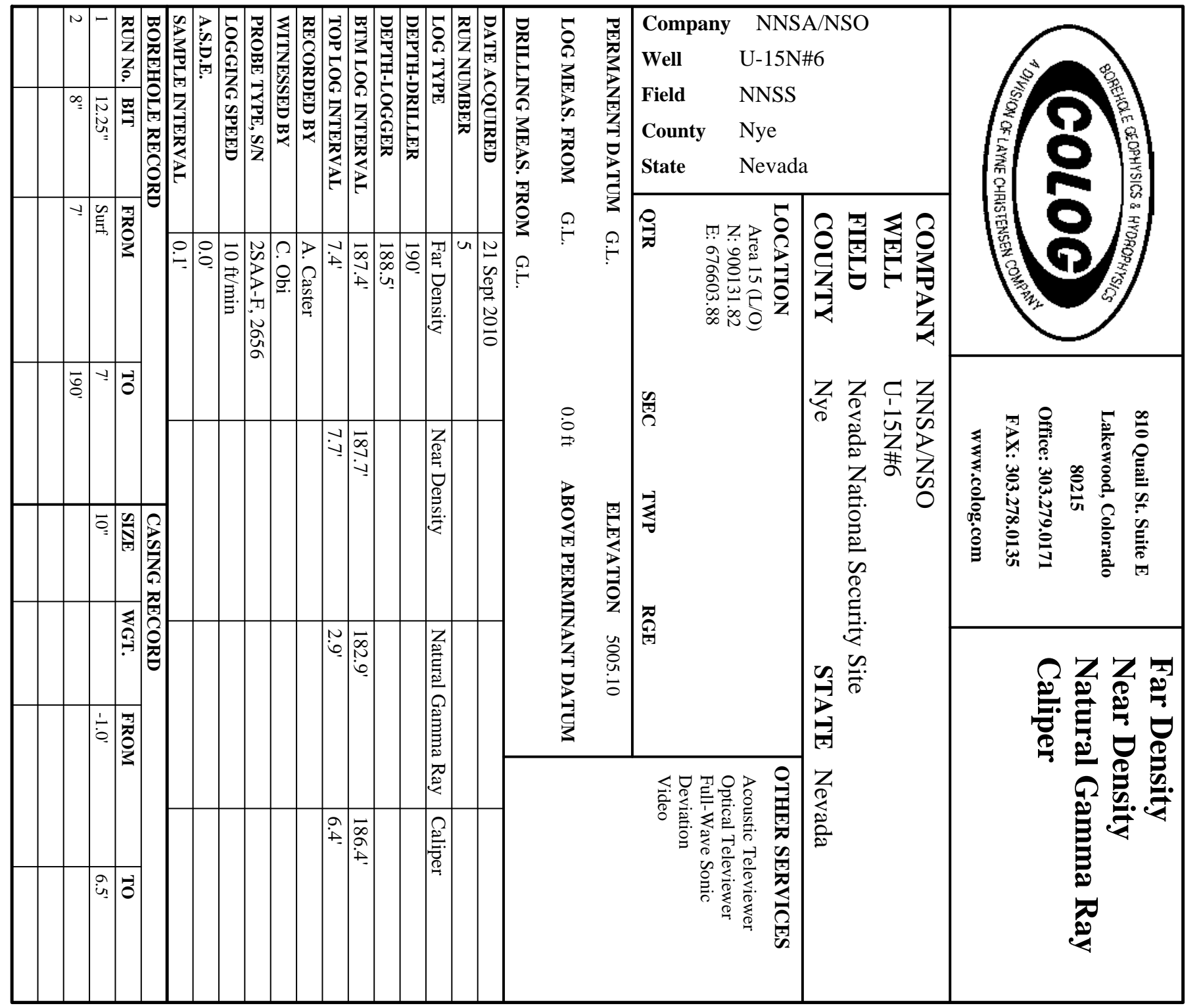

\section{COMMENTS}

NA - Not Available, N/A - Not Applicable

Matrix Density of 2.64 used to calculate Density Porosity 


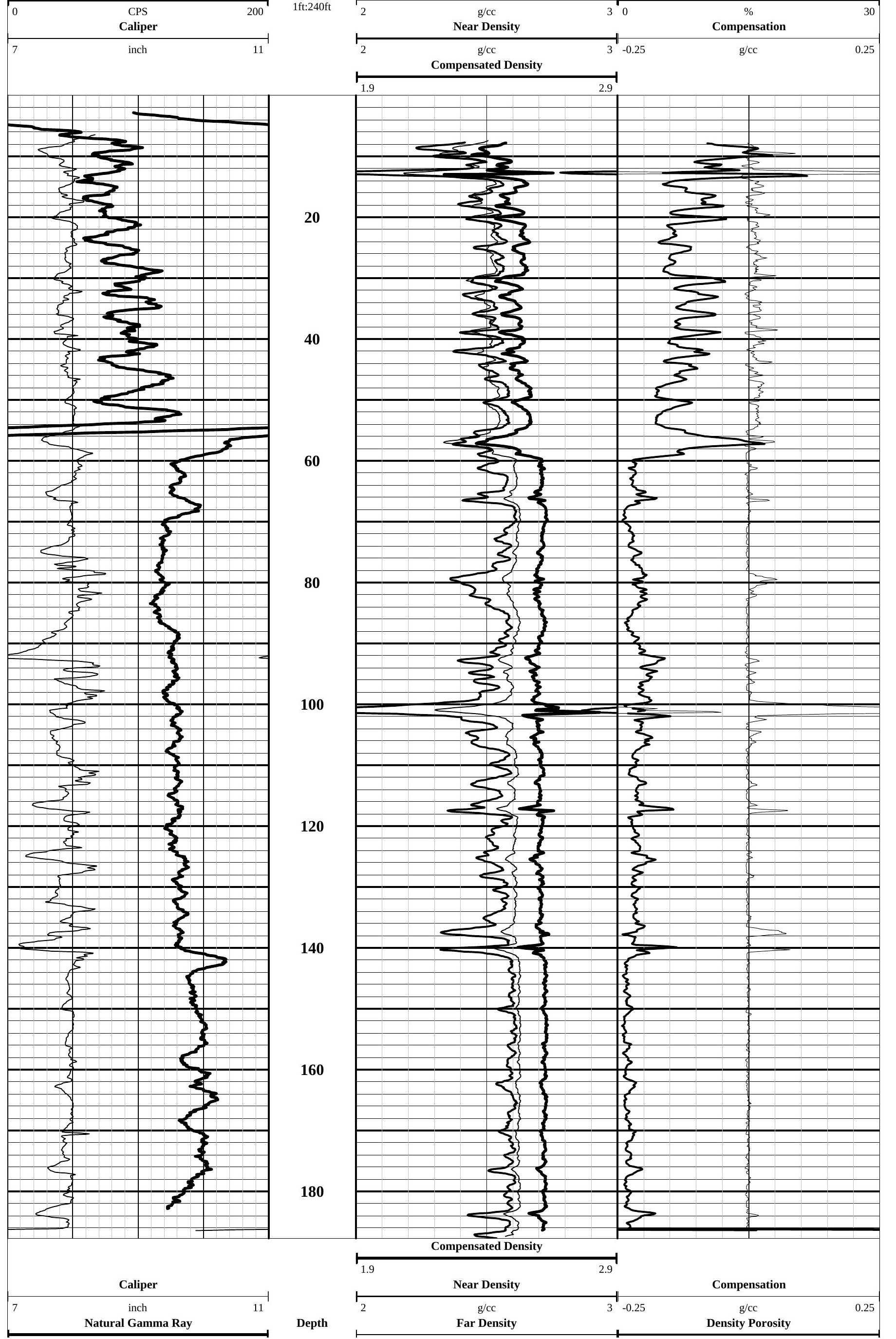




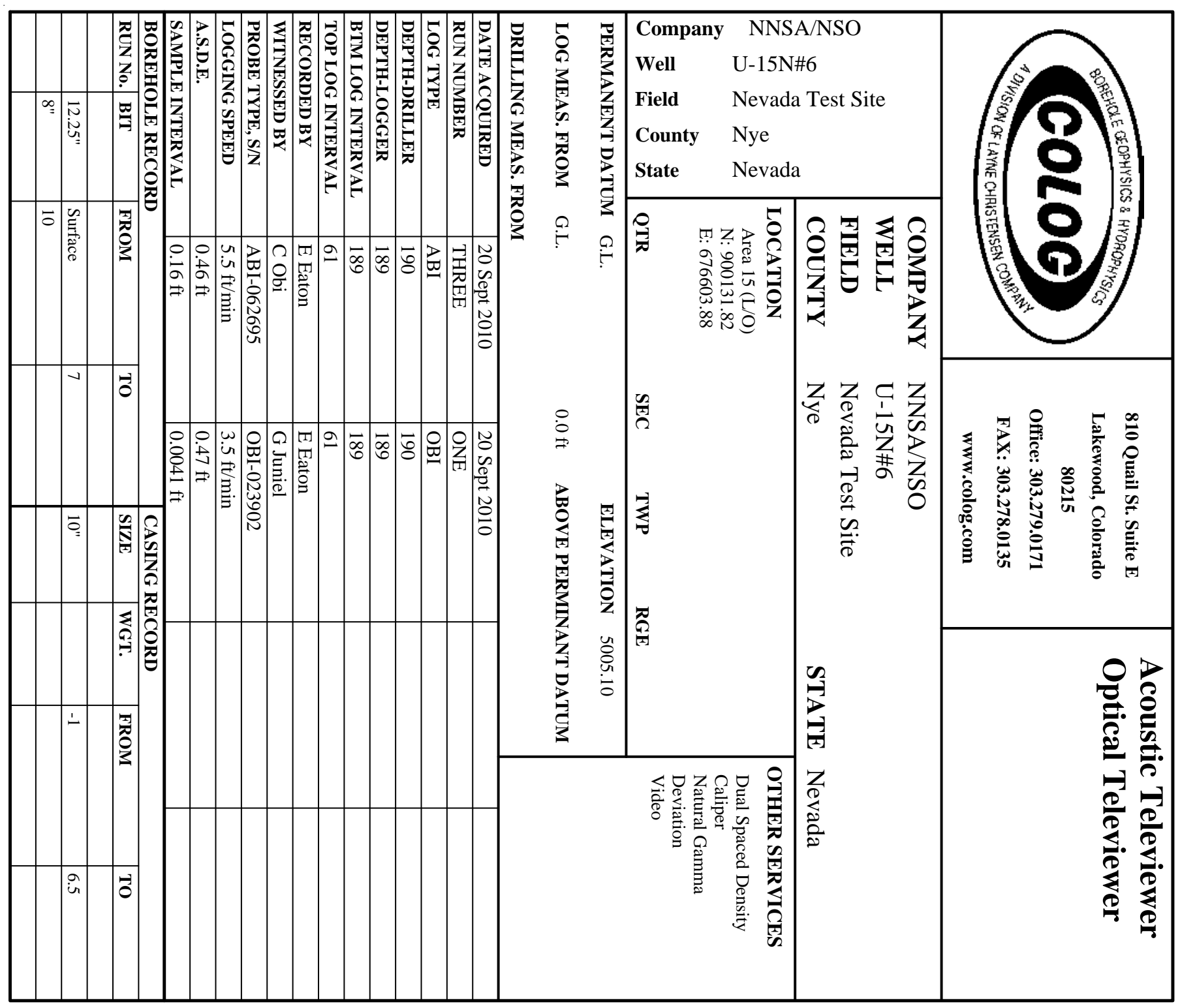




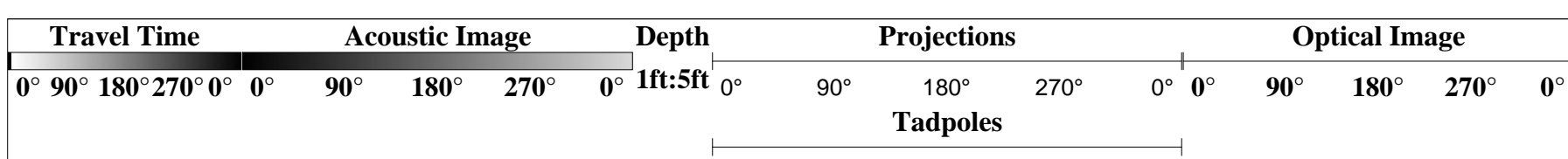

90

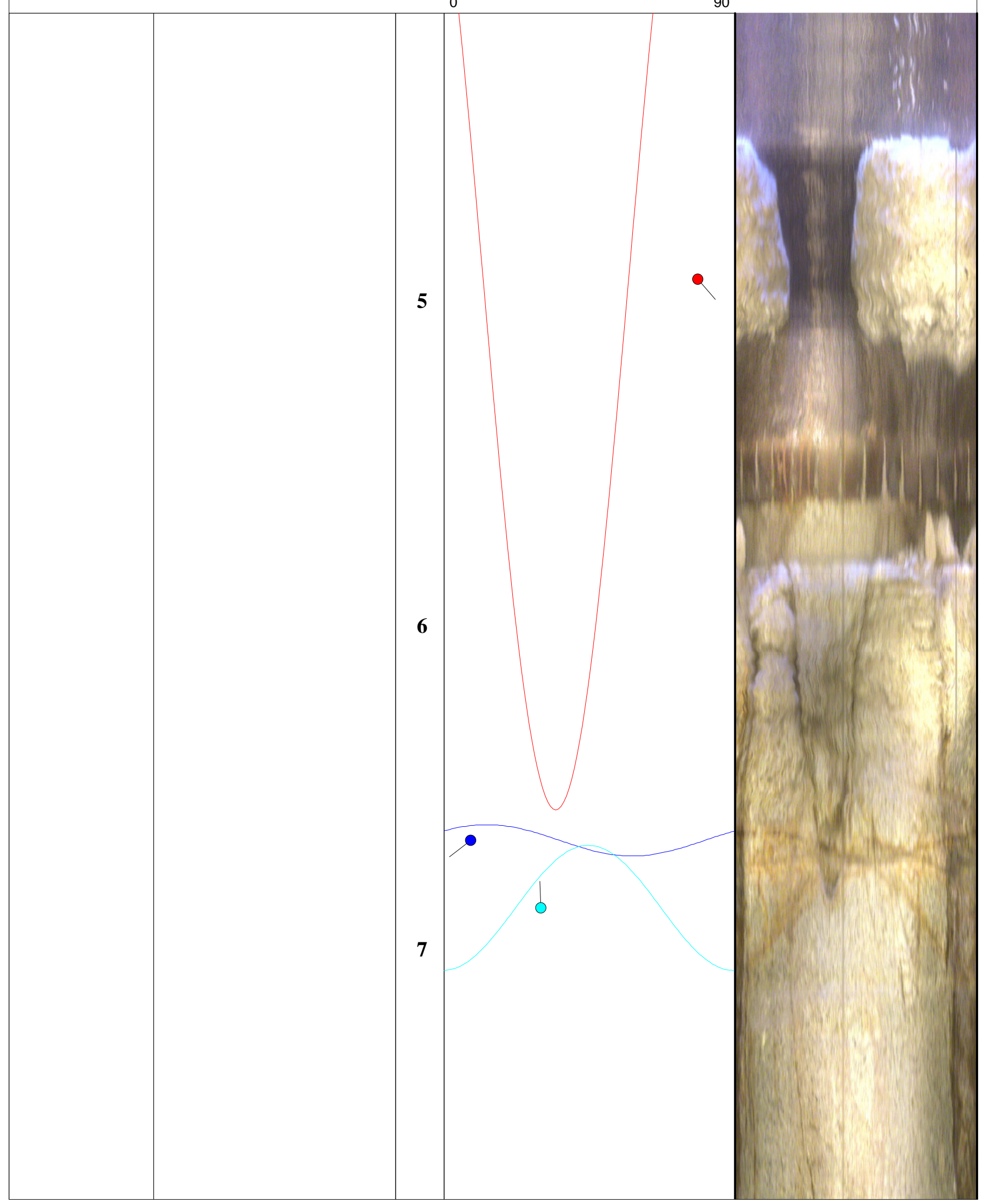




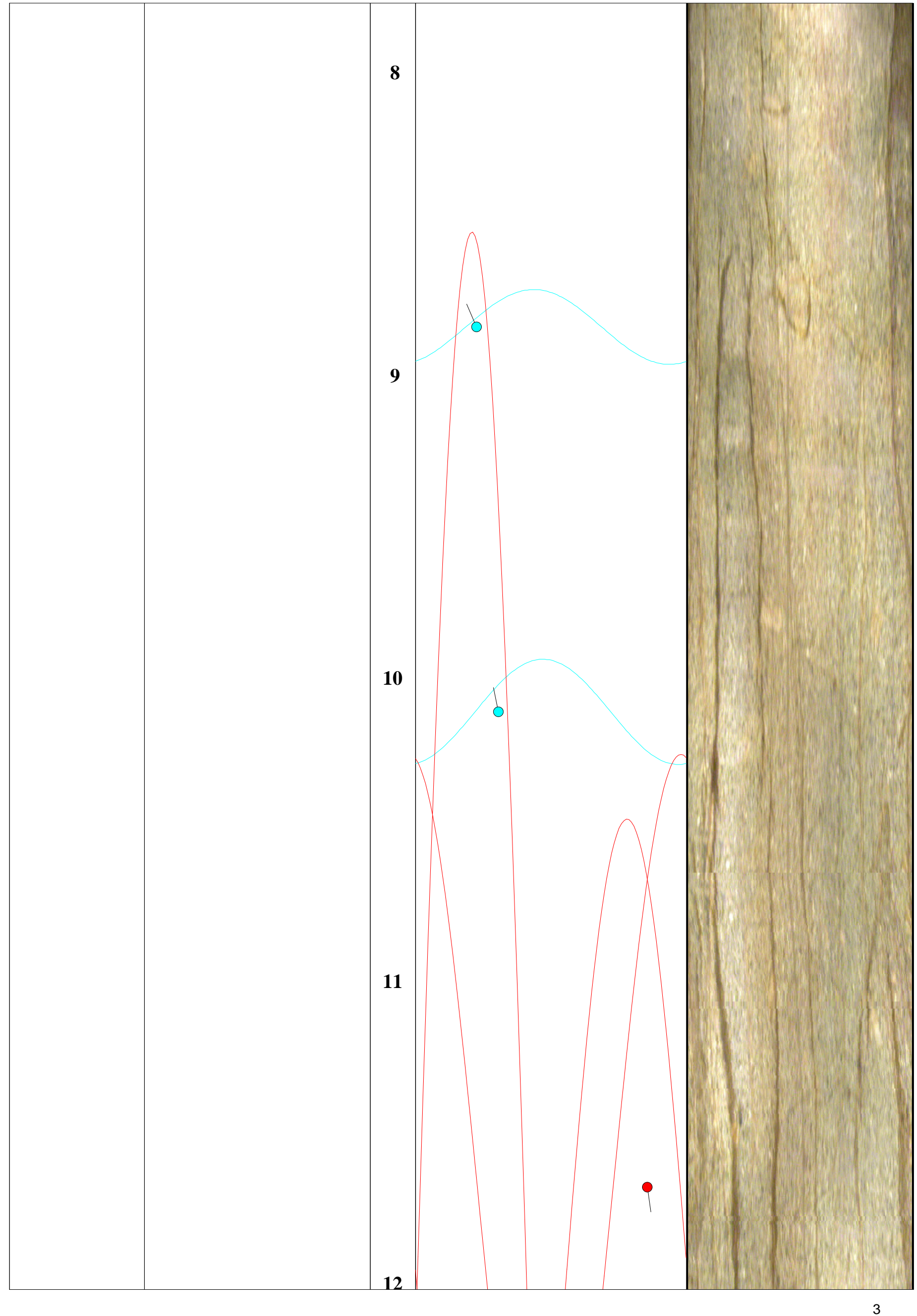




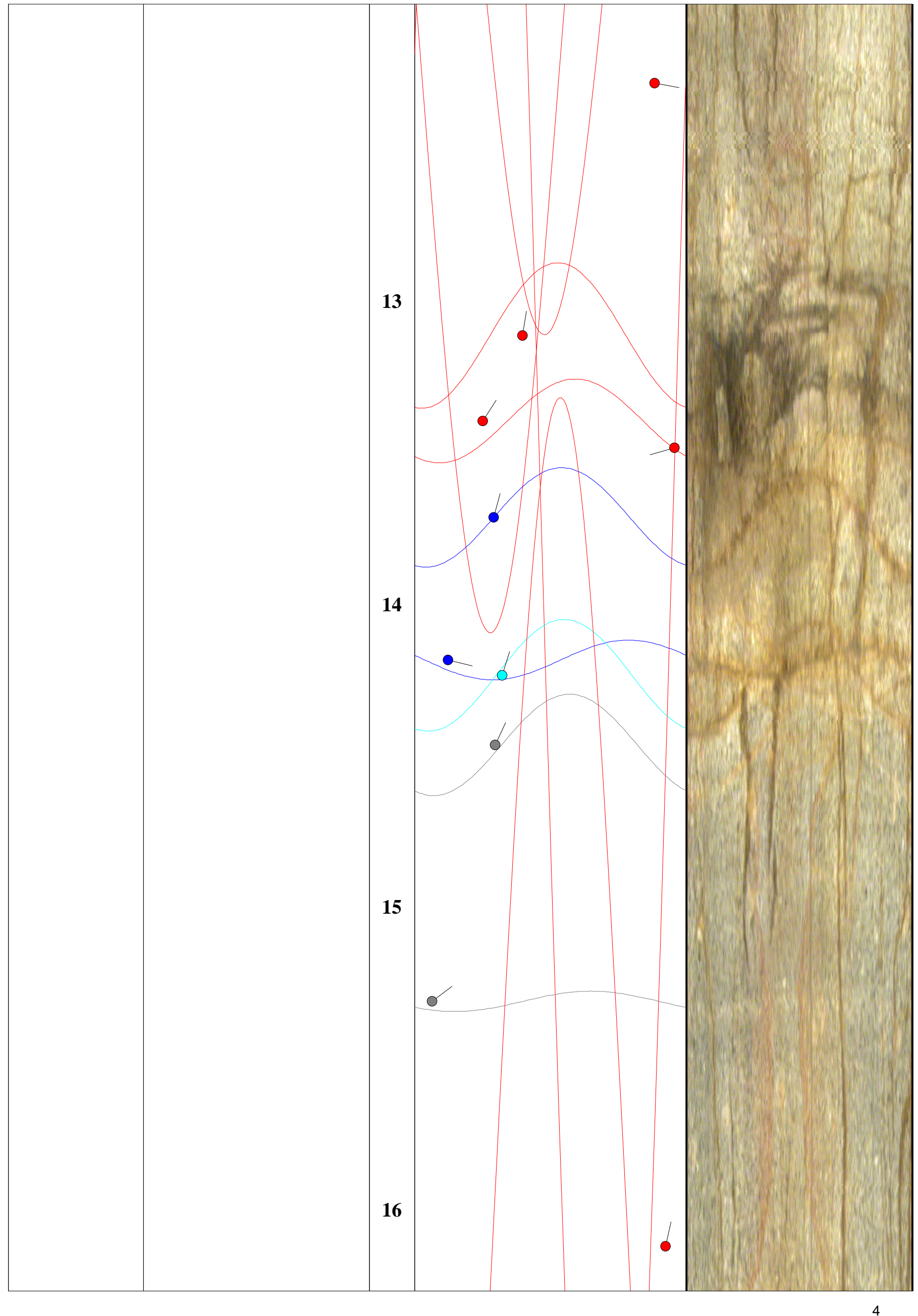




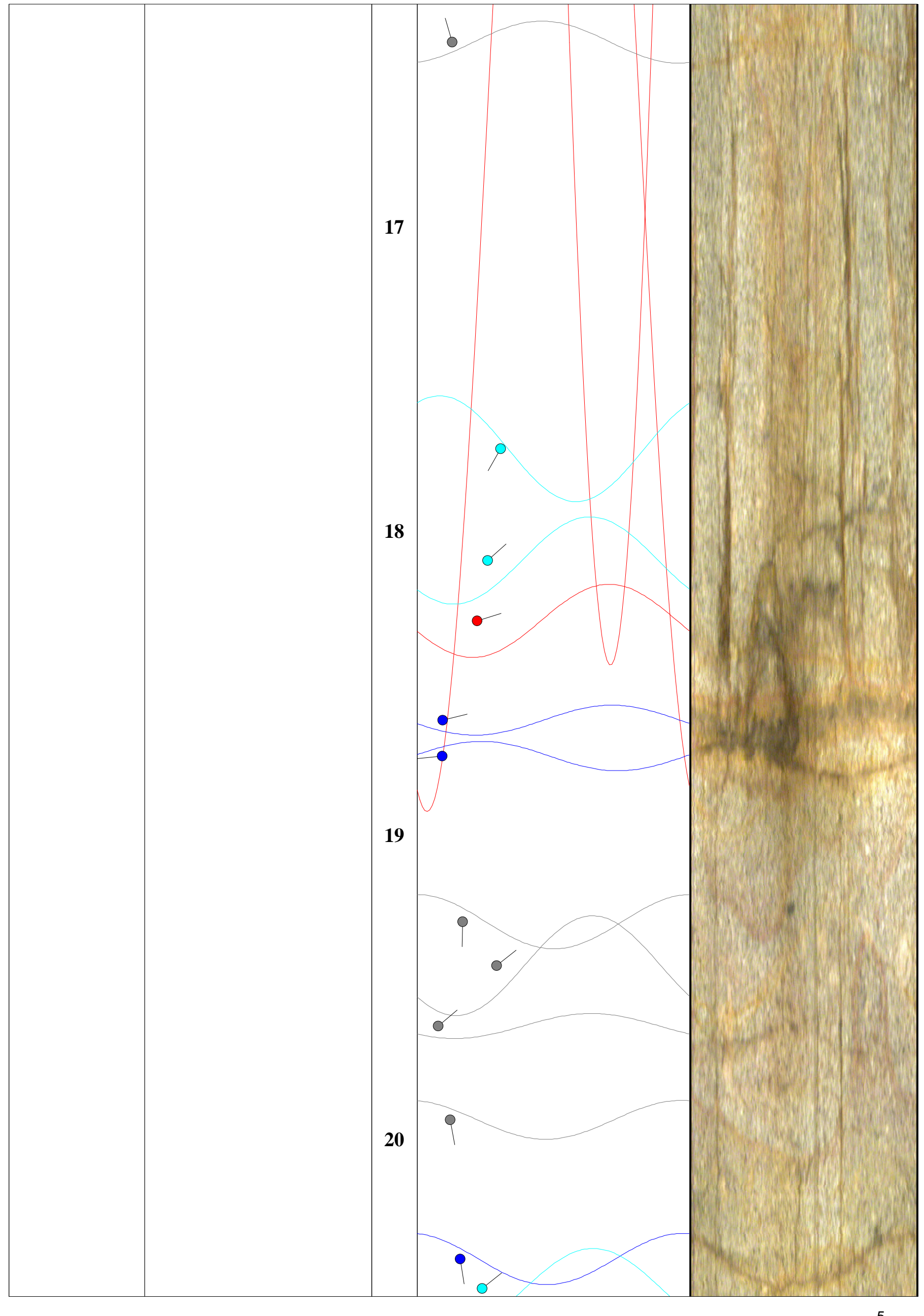




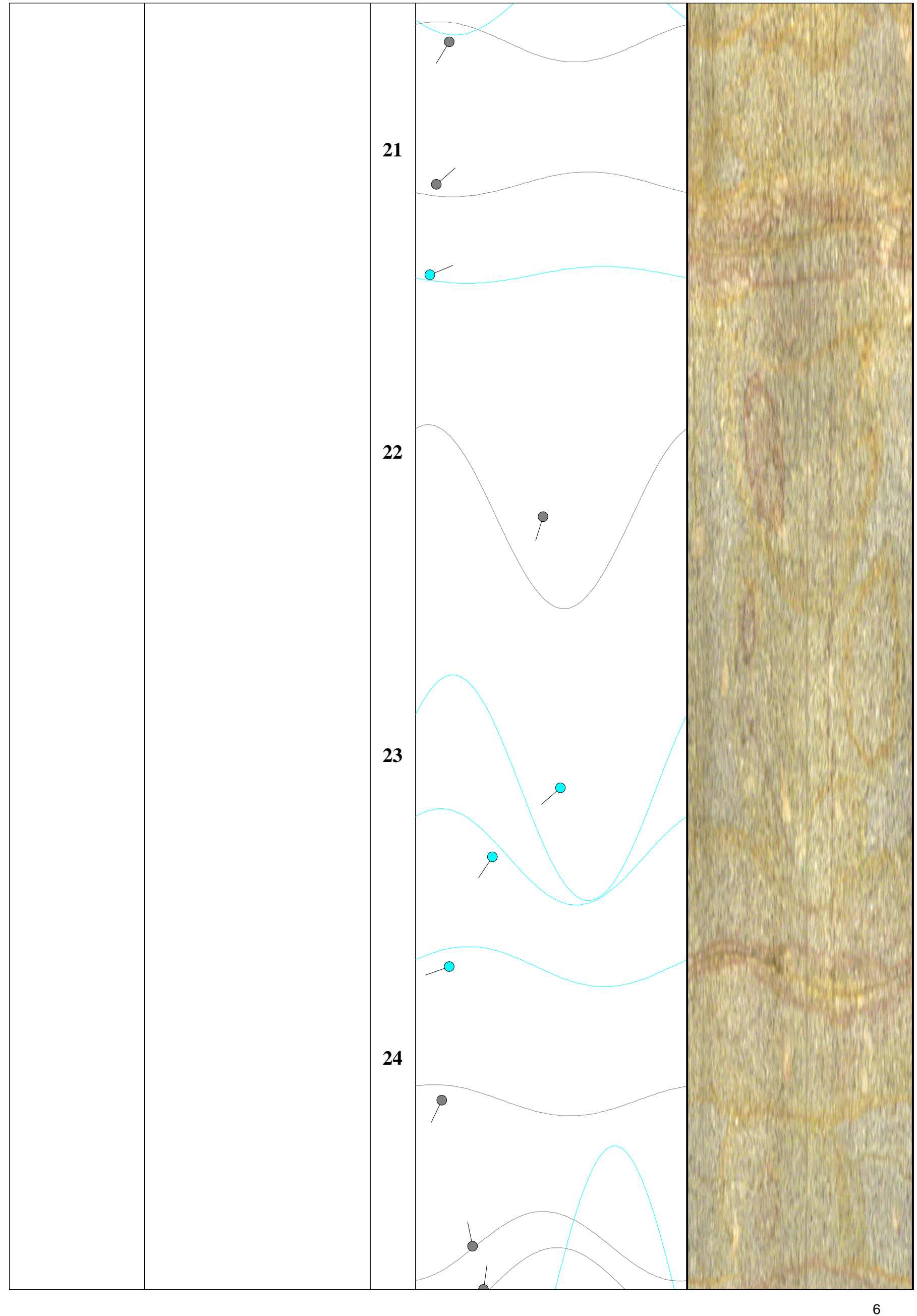




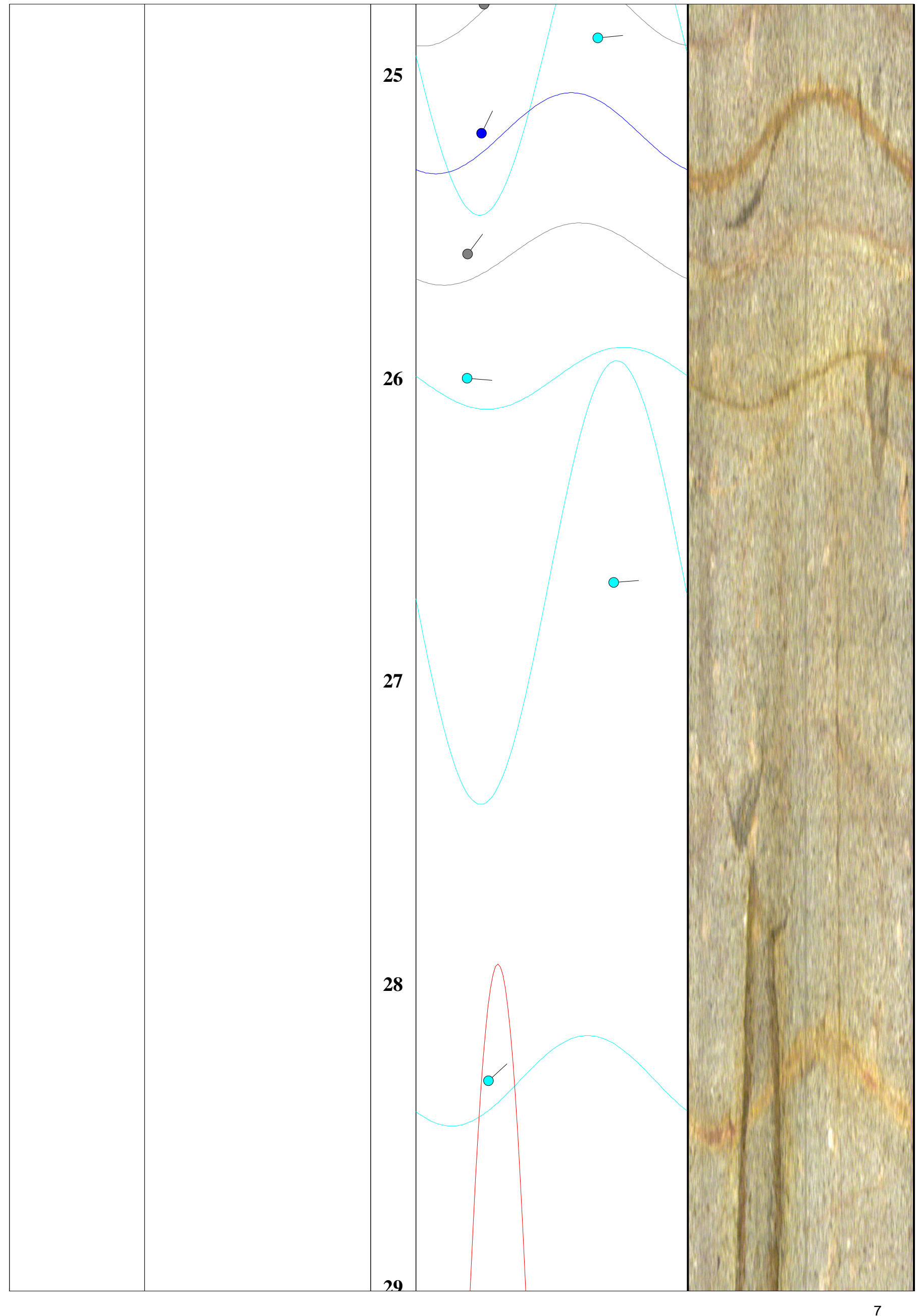




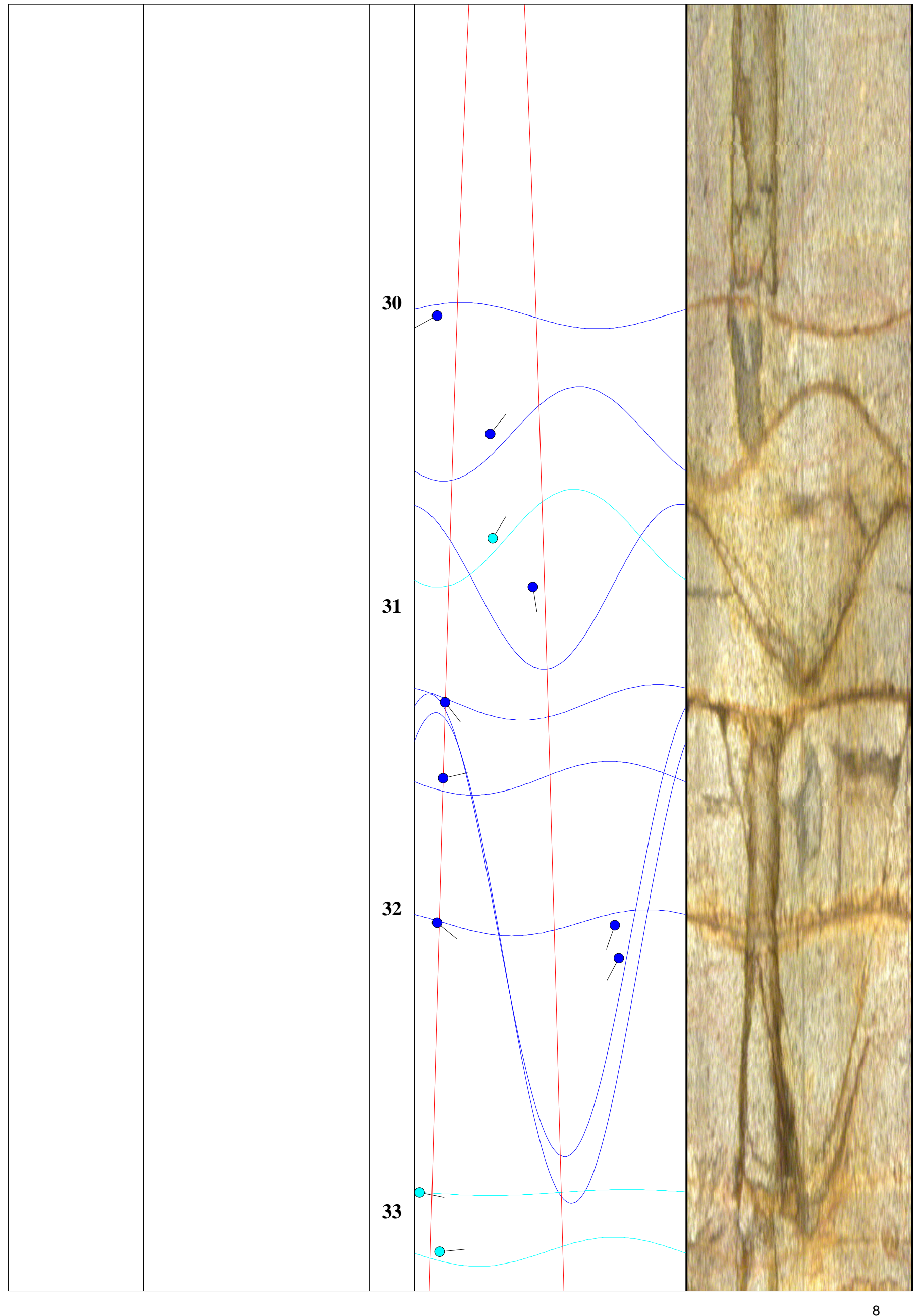




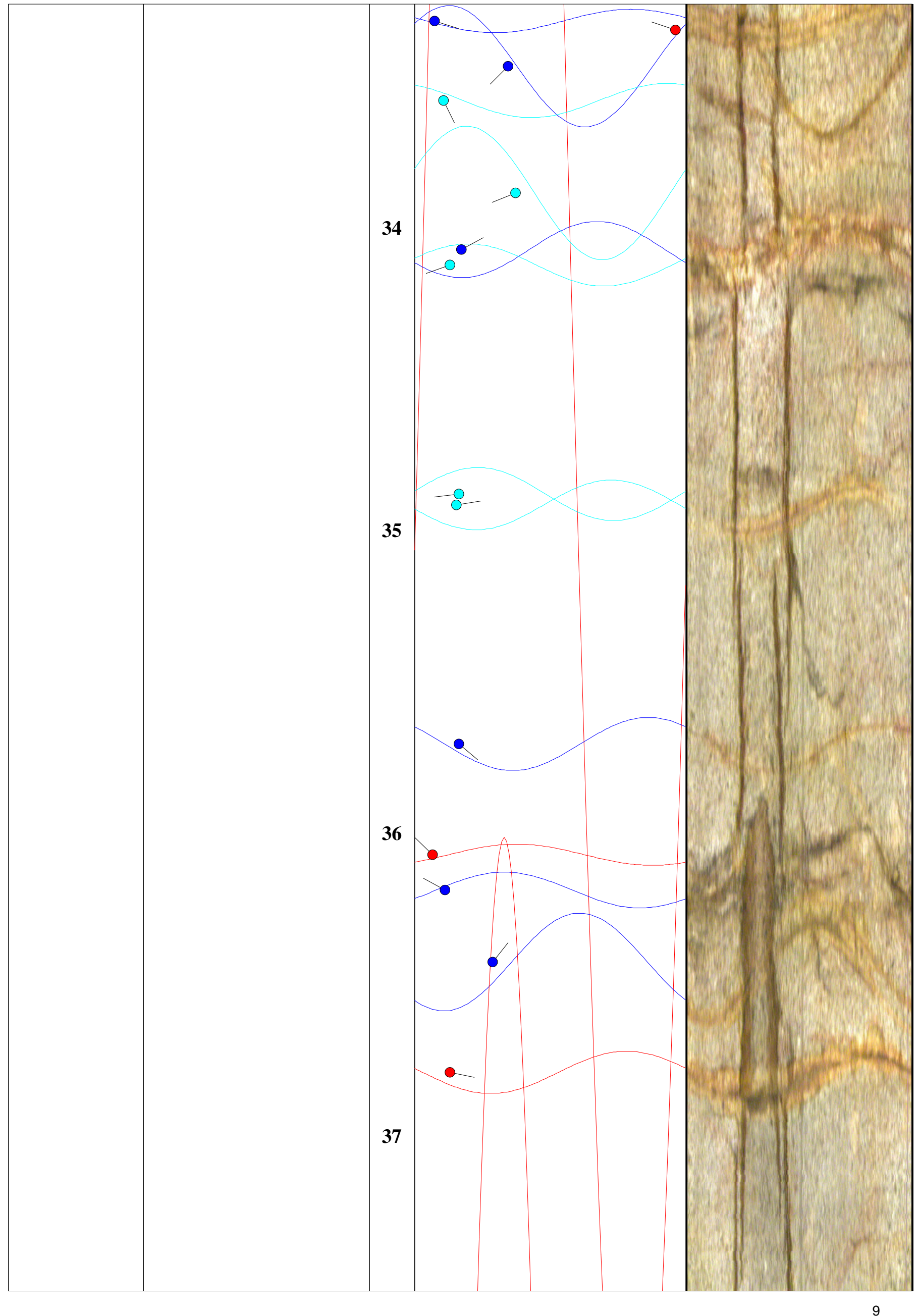




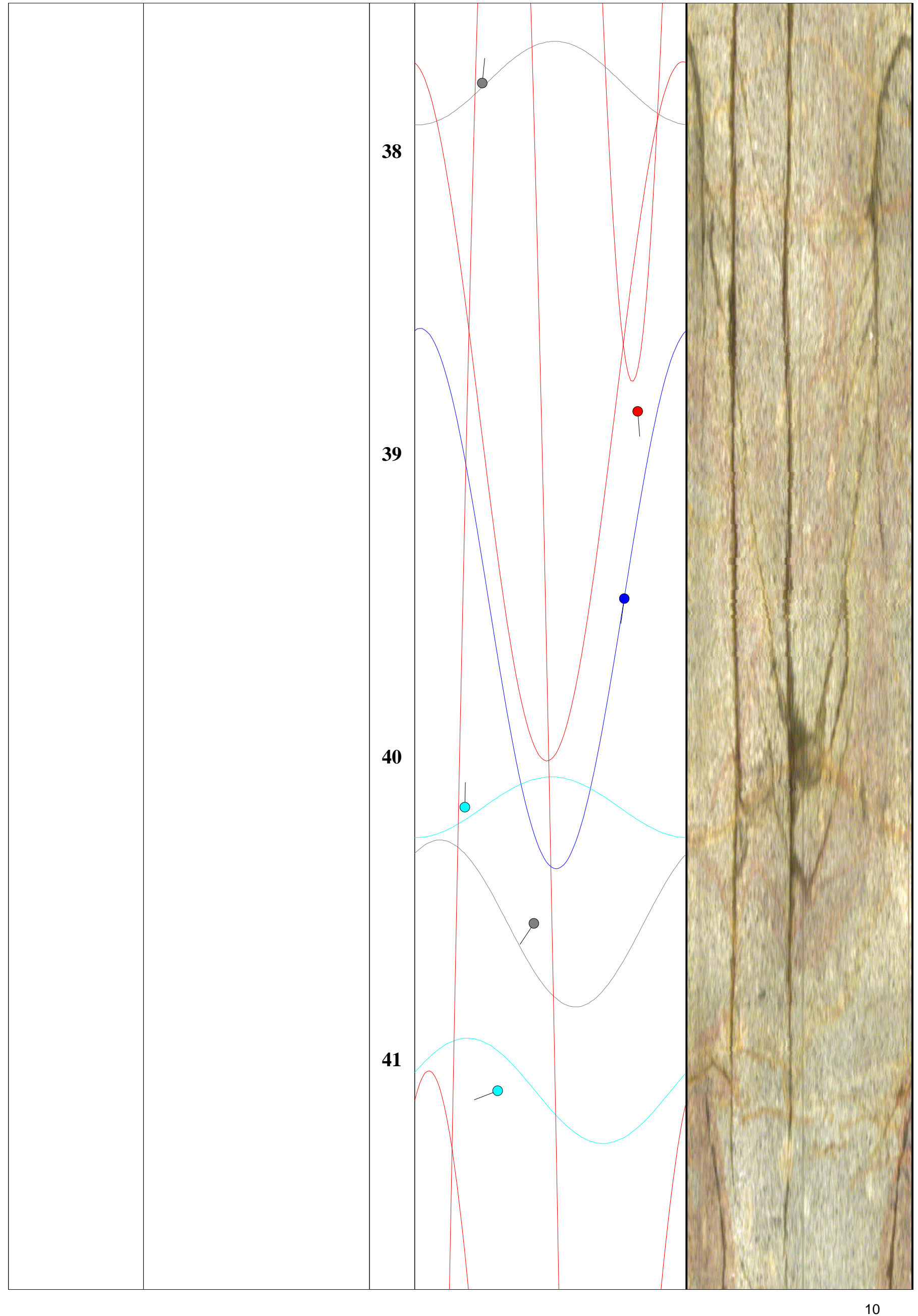




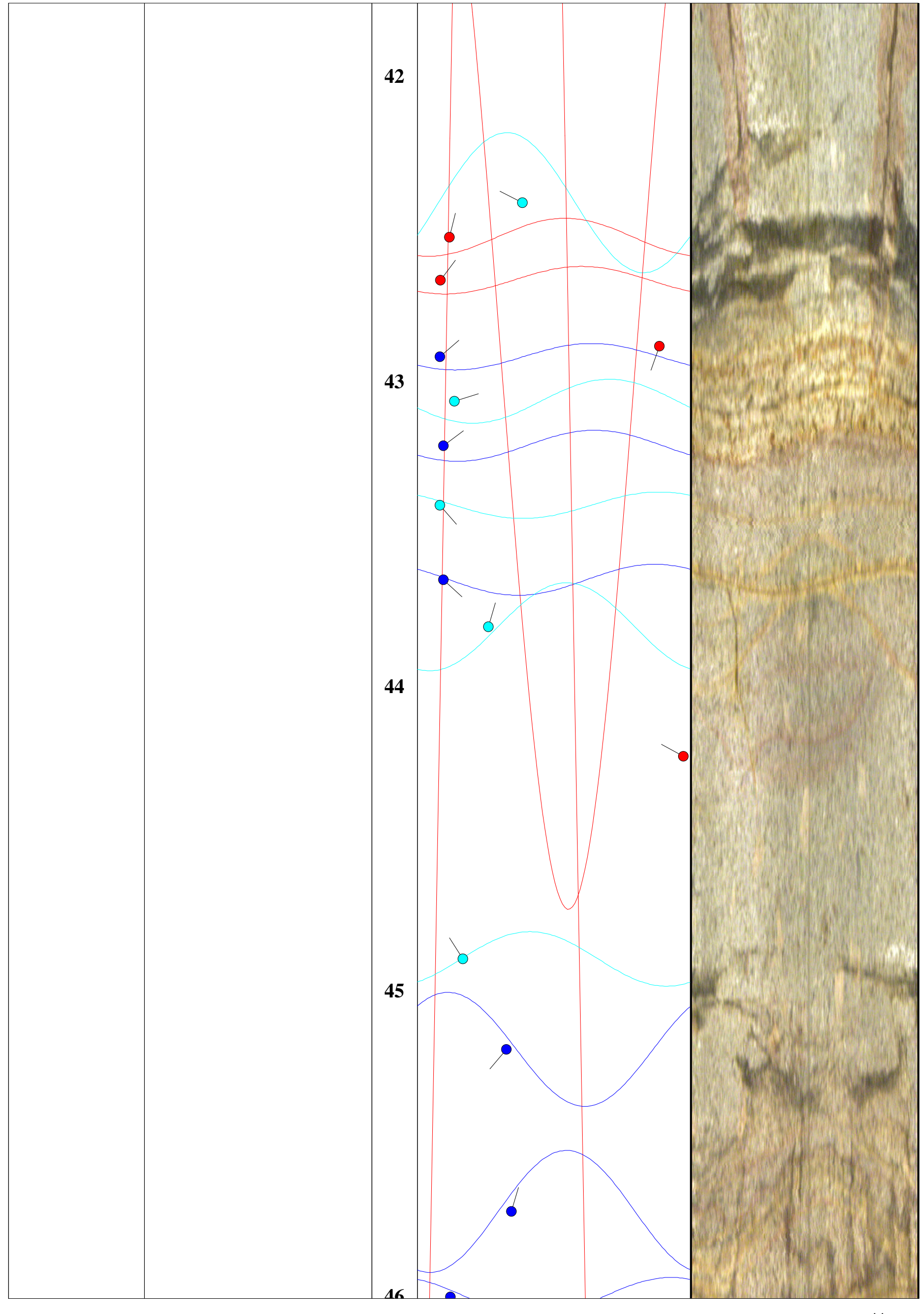




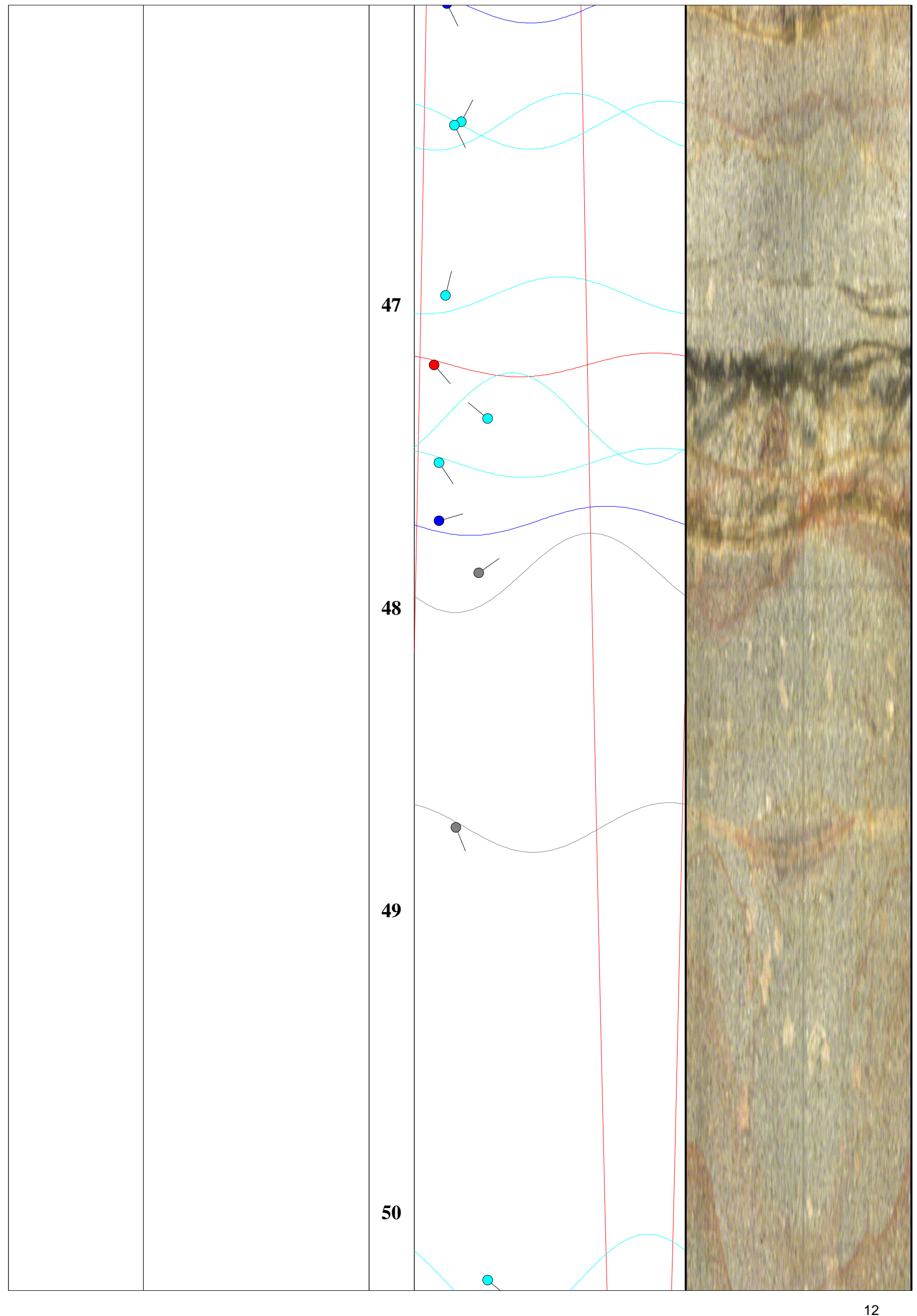




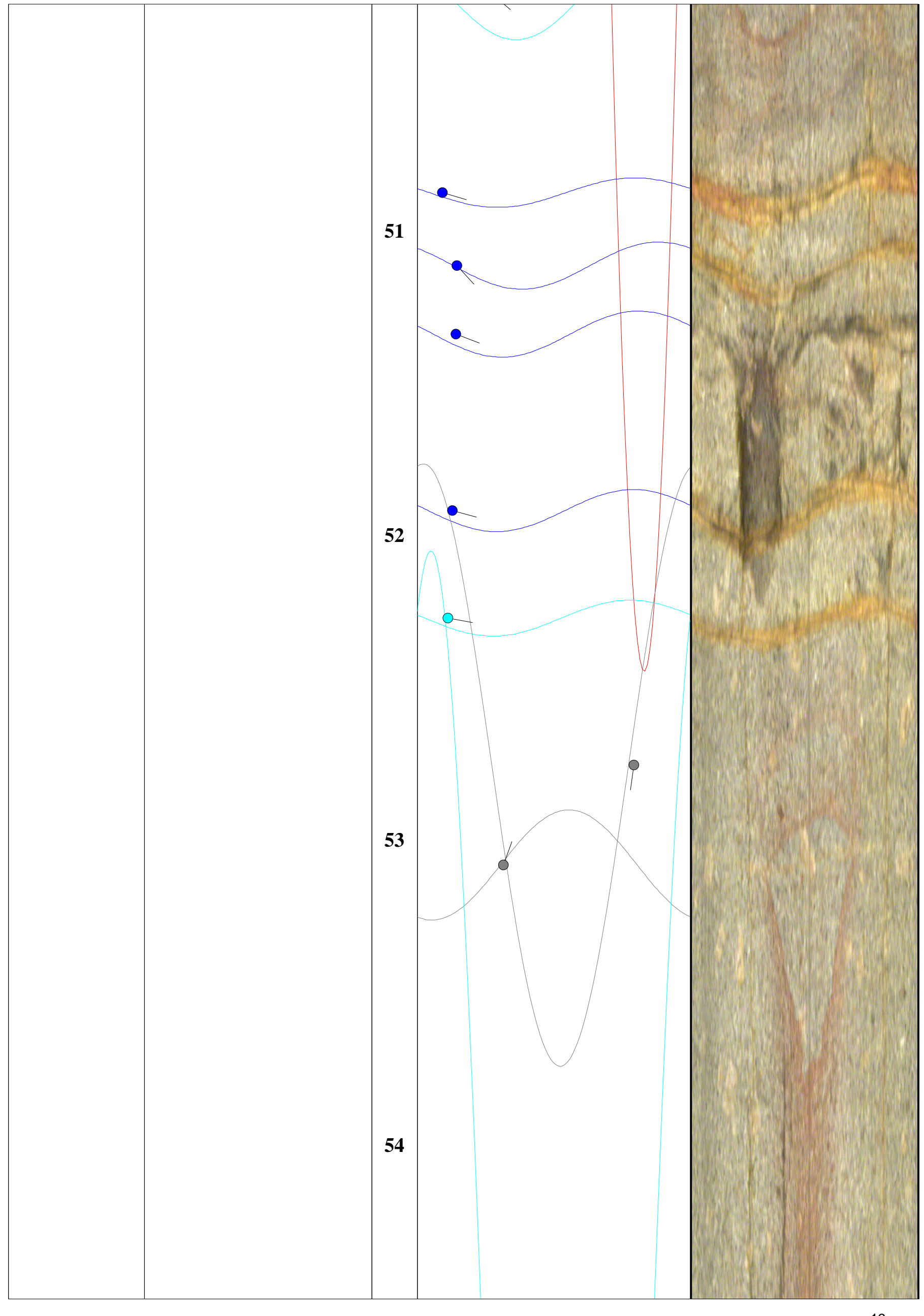




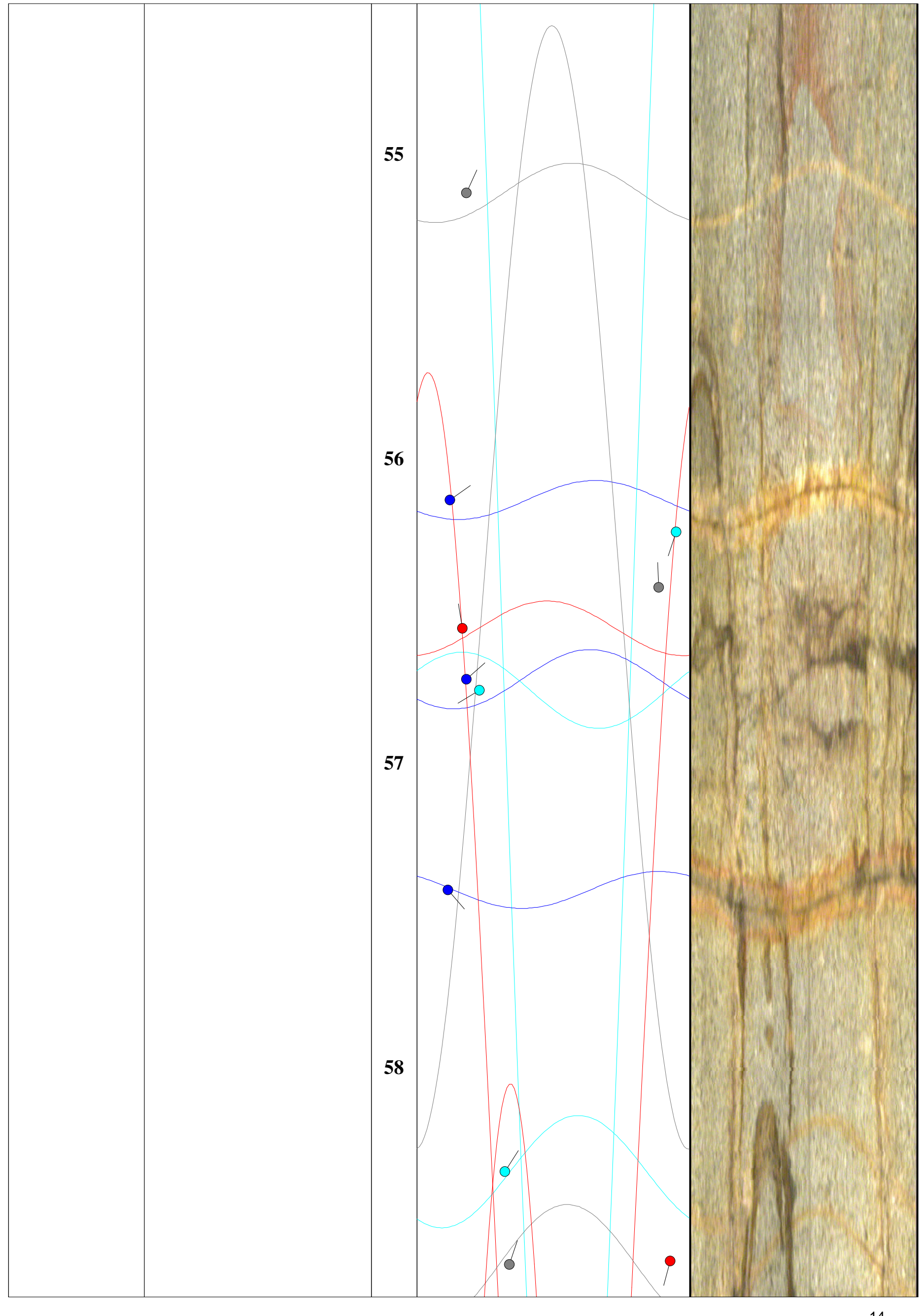




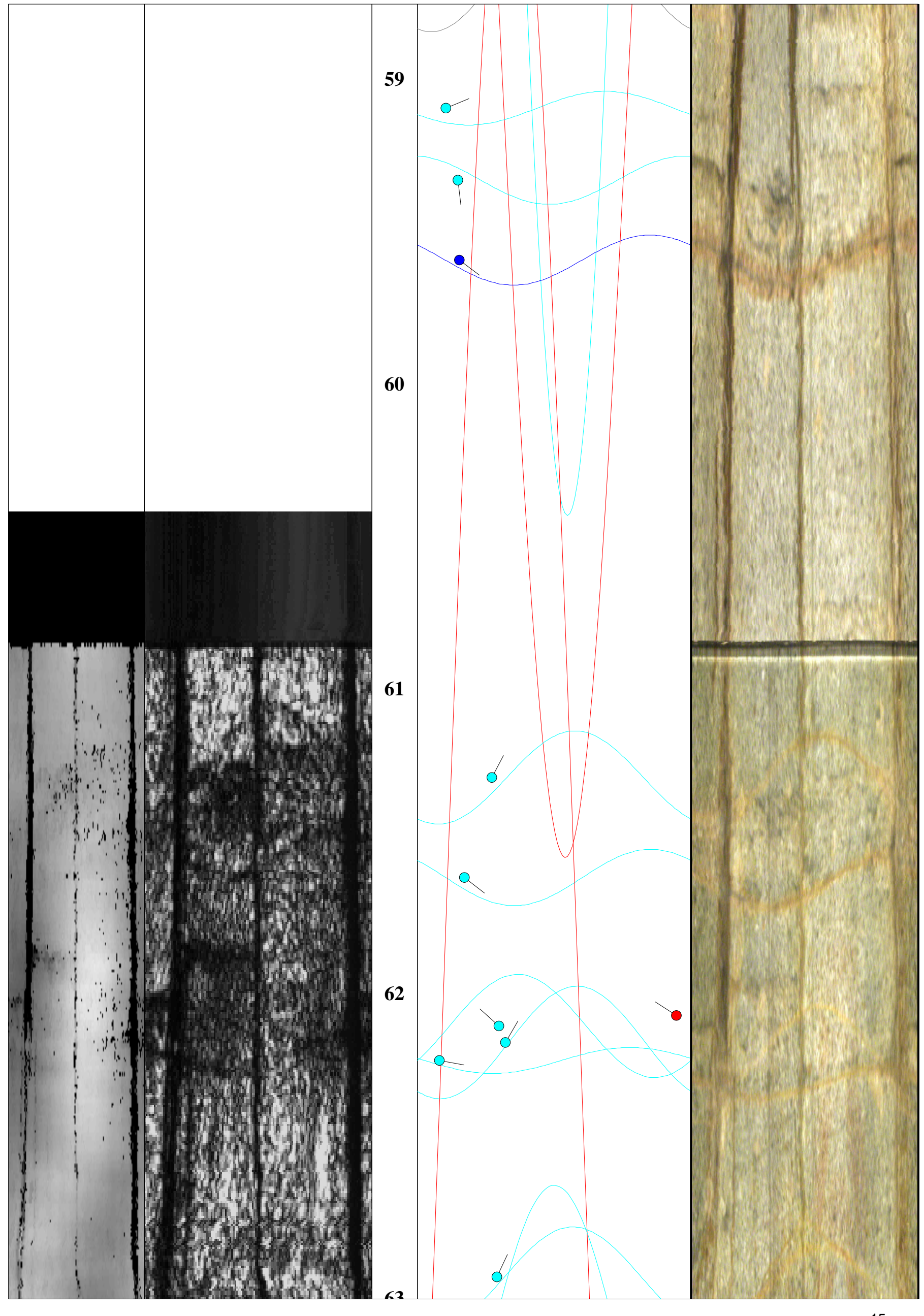




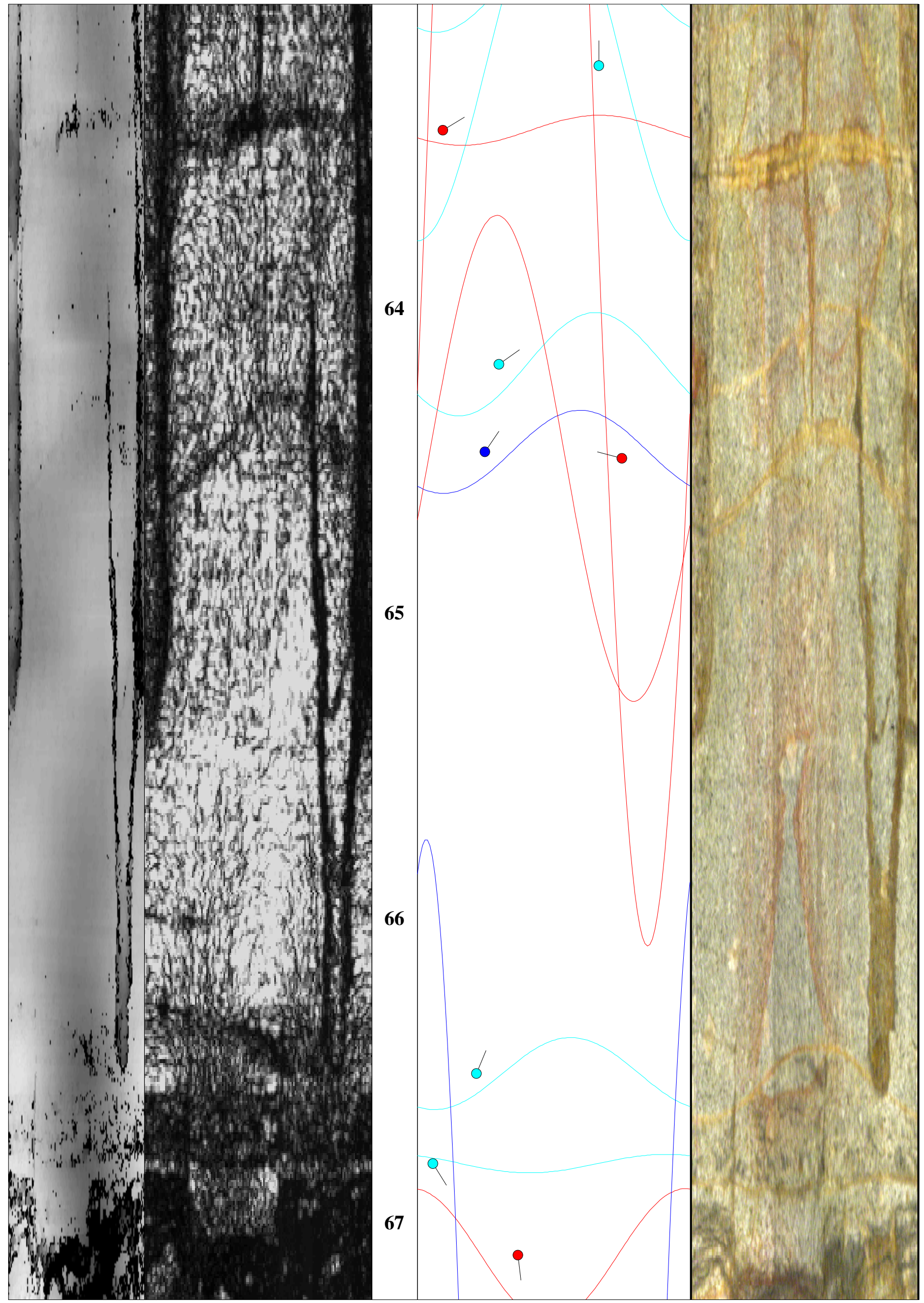



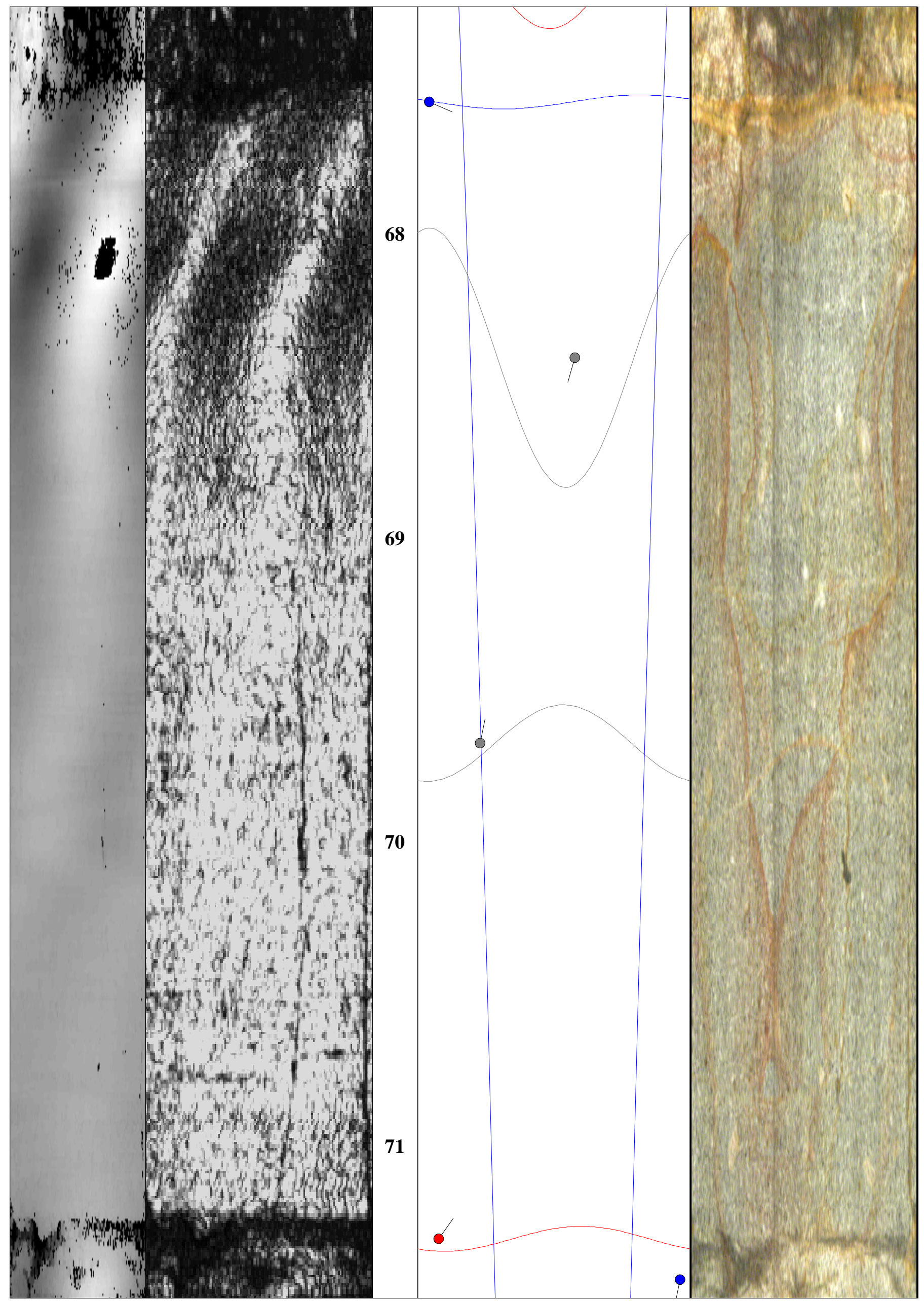


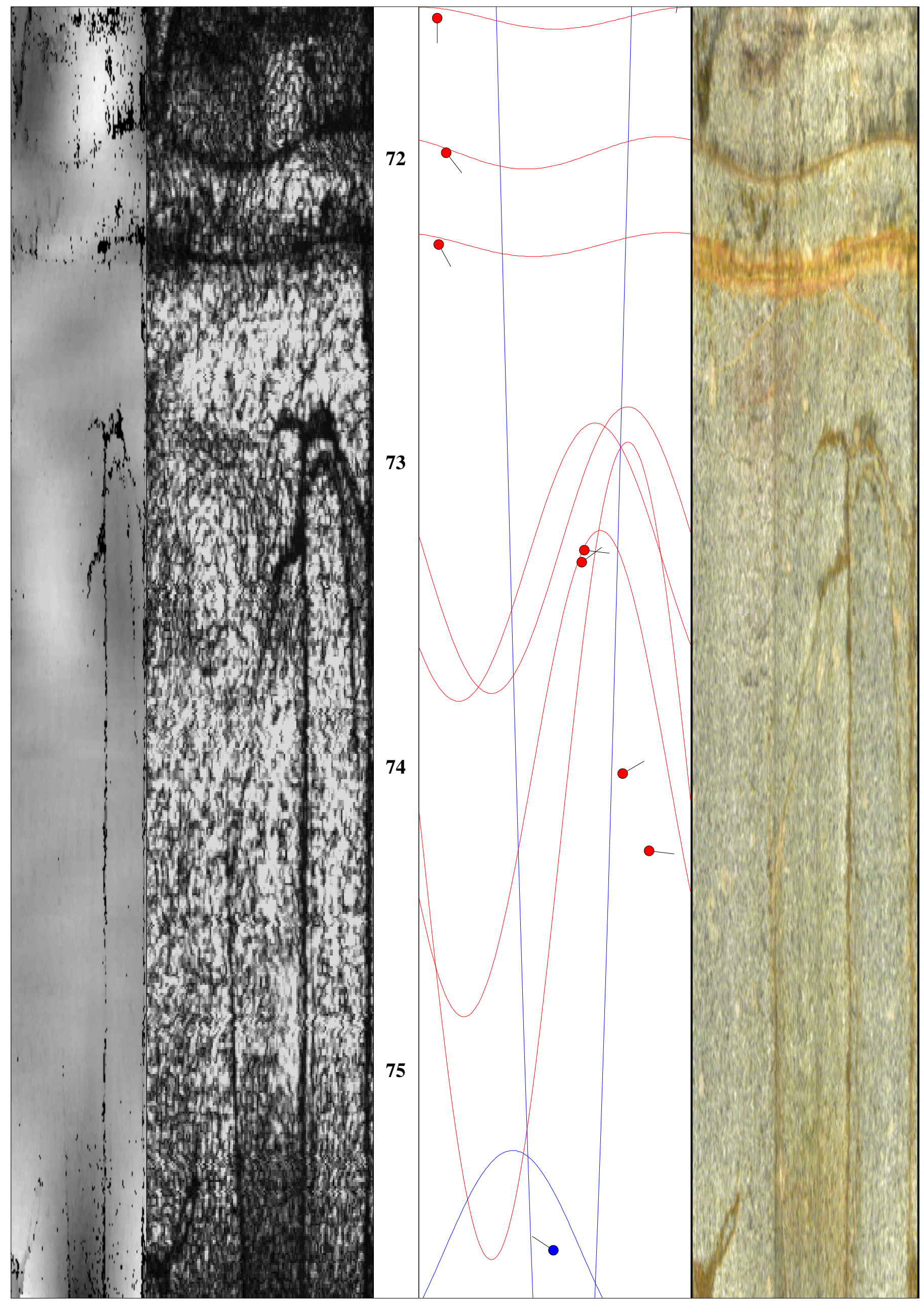




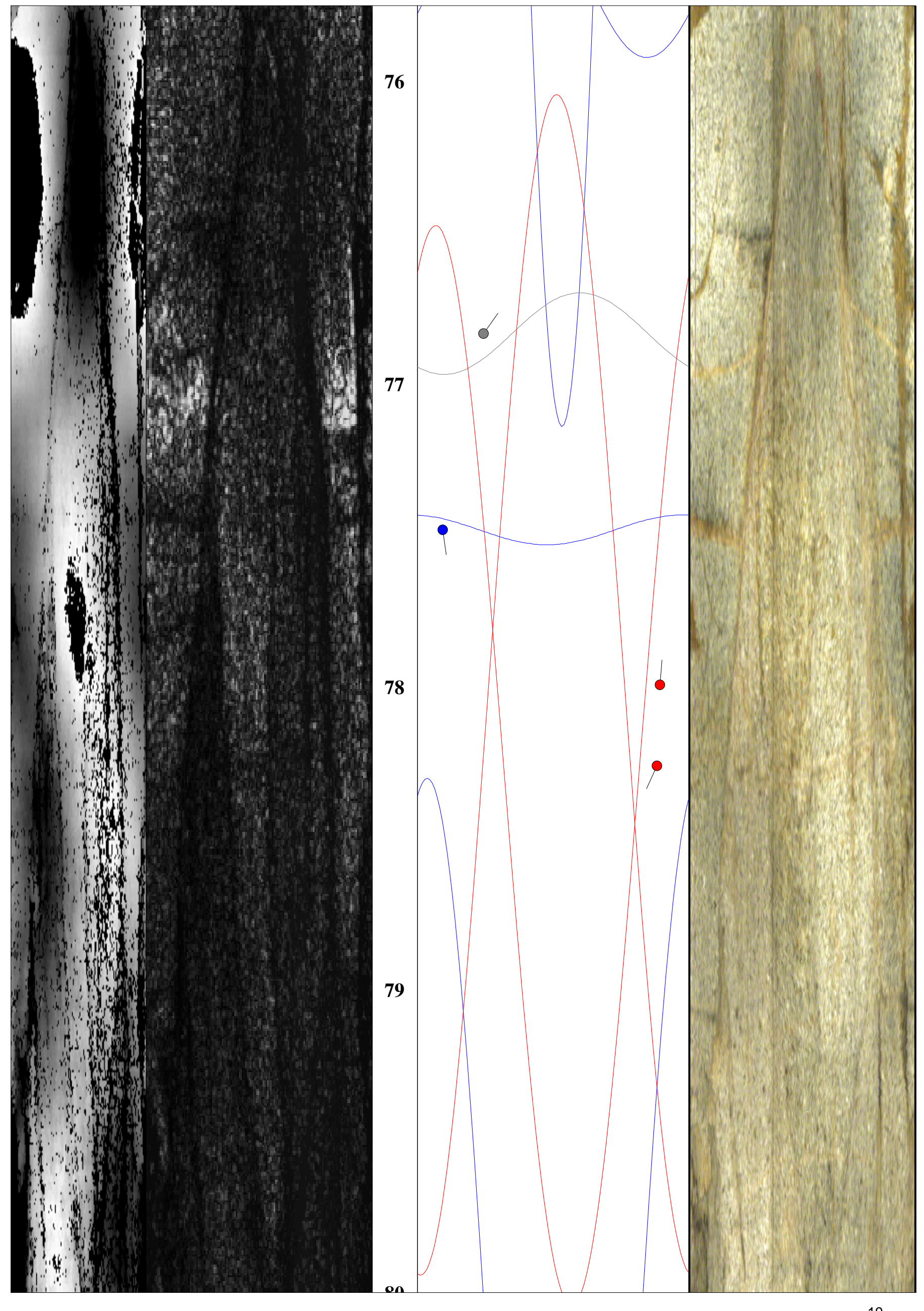




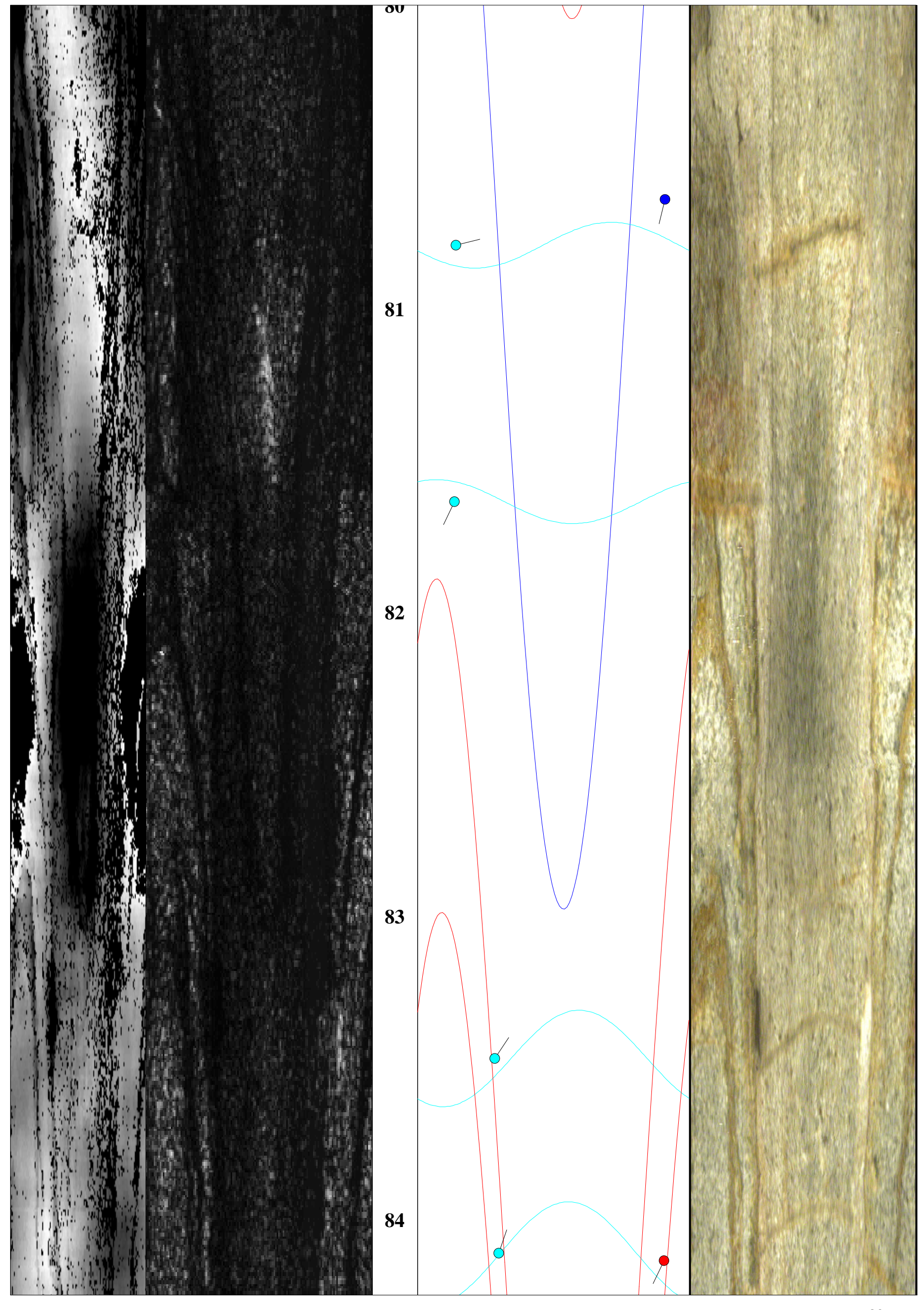




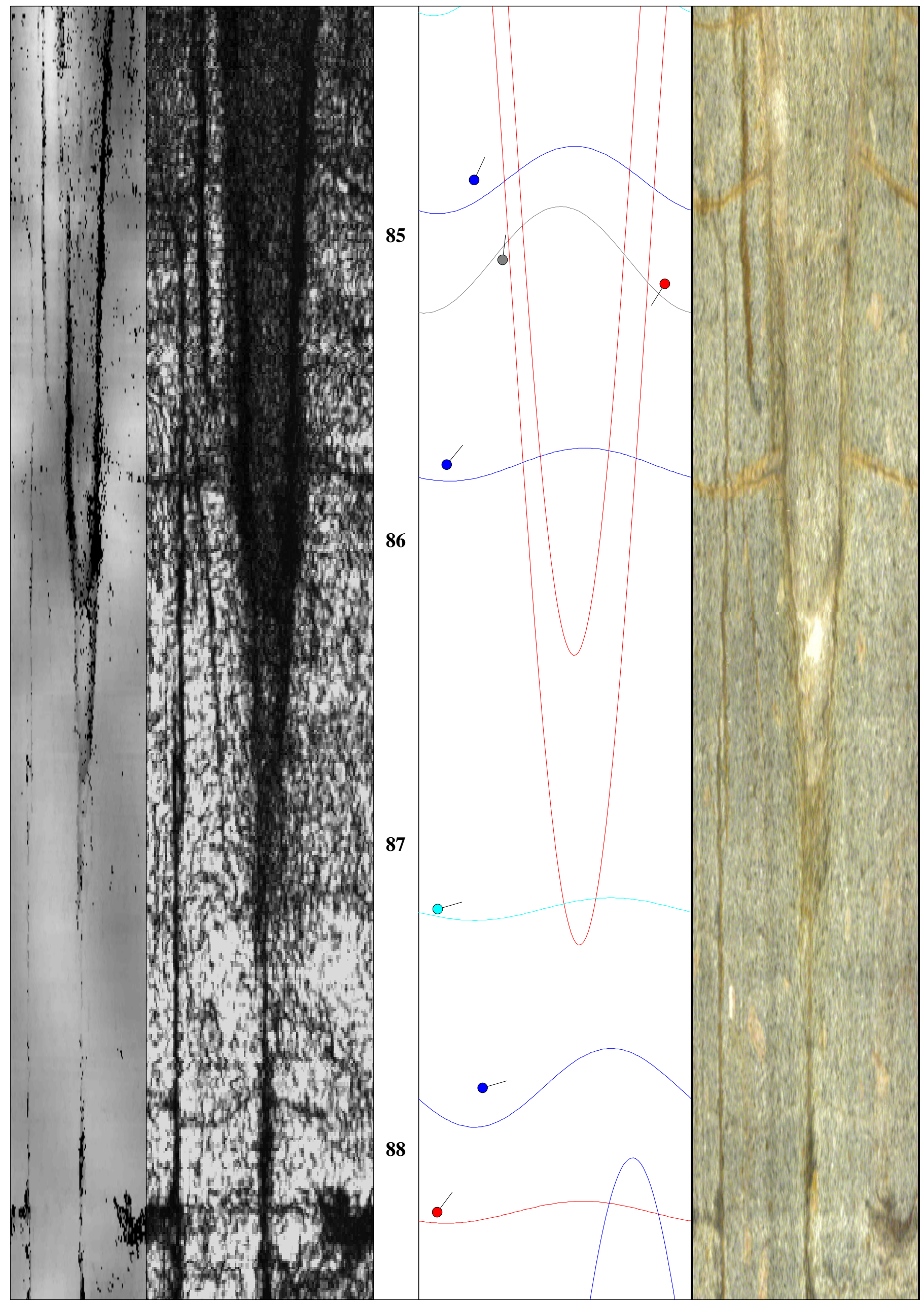




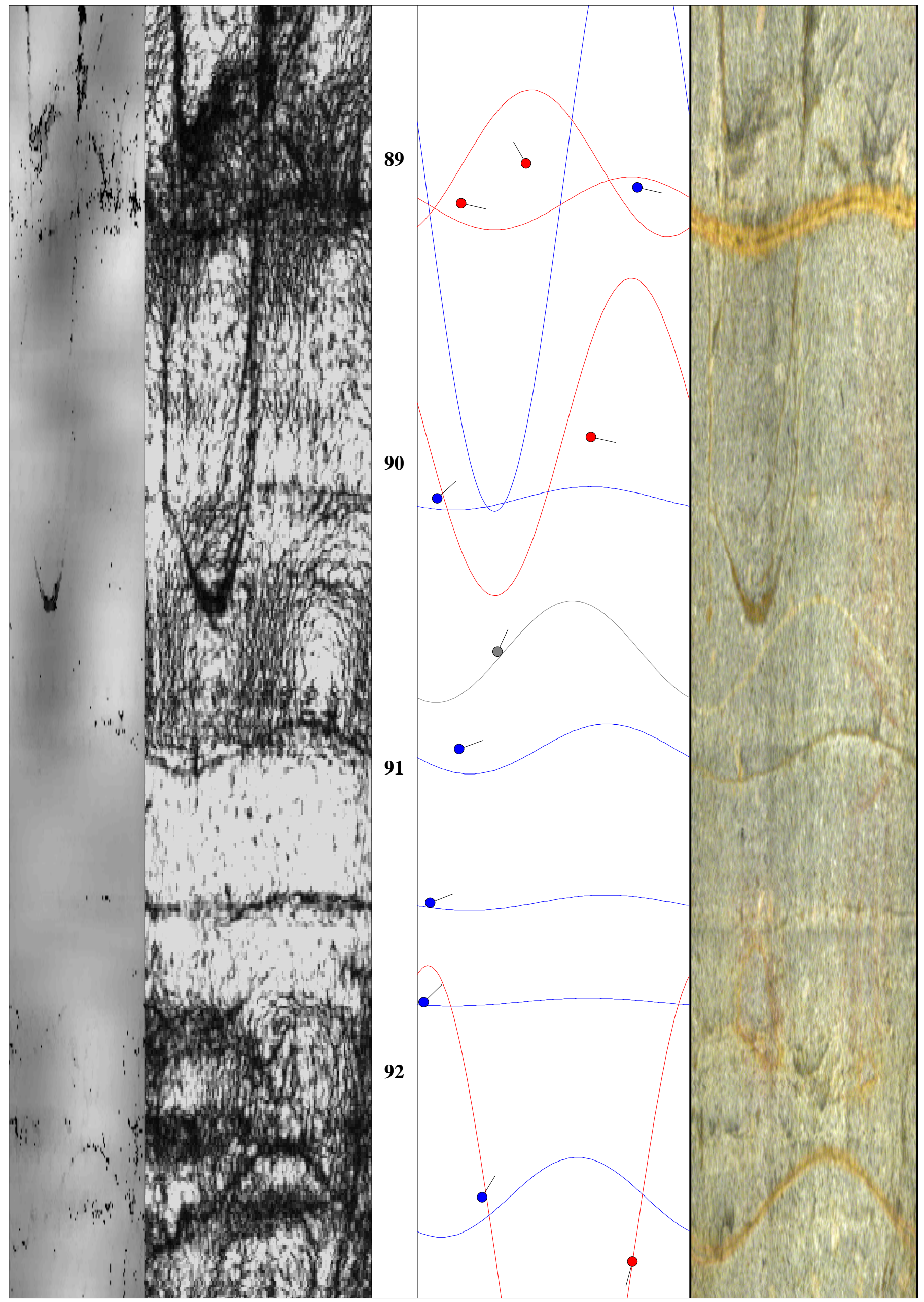




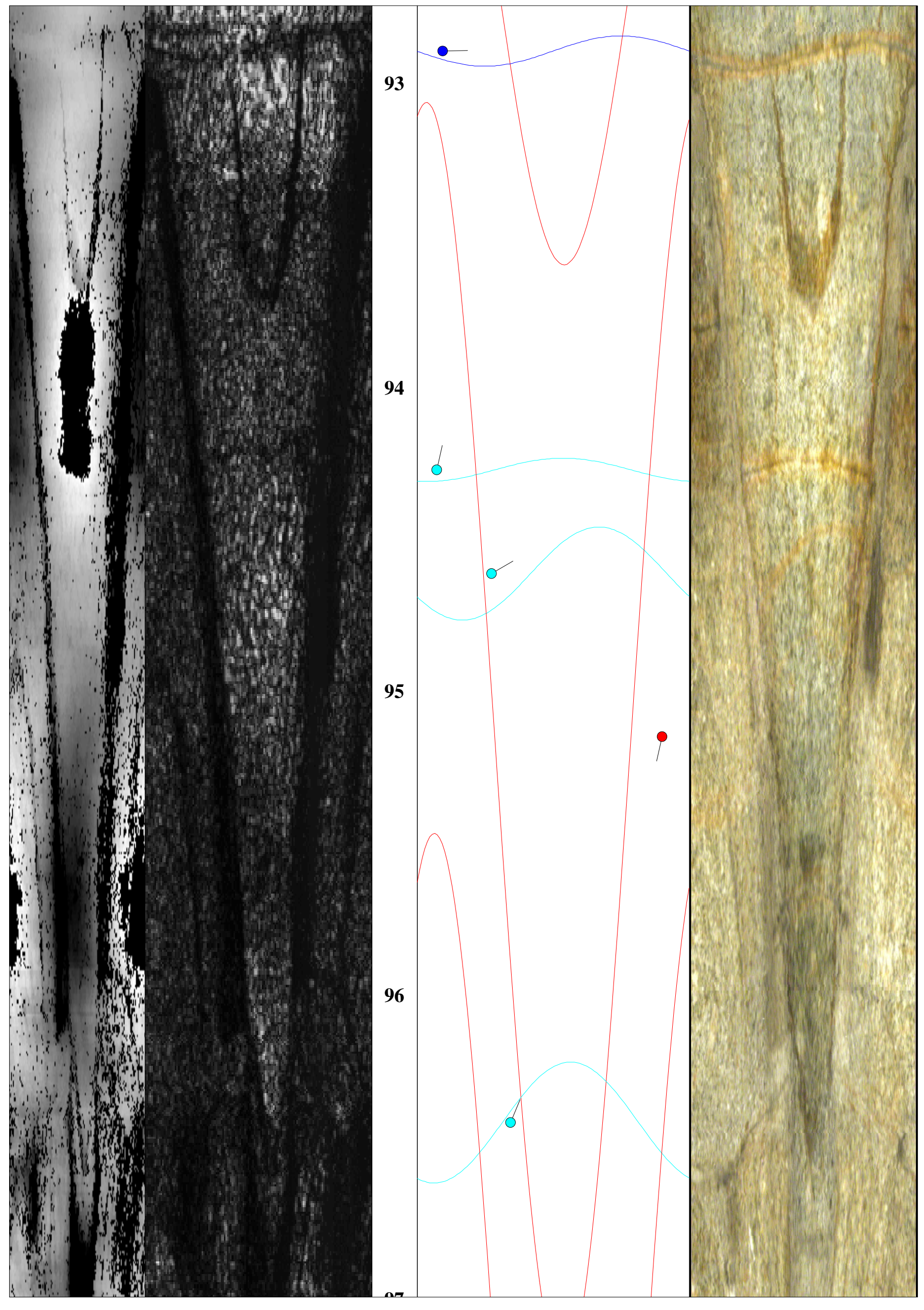




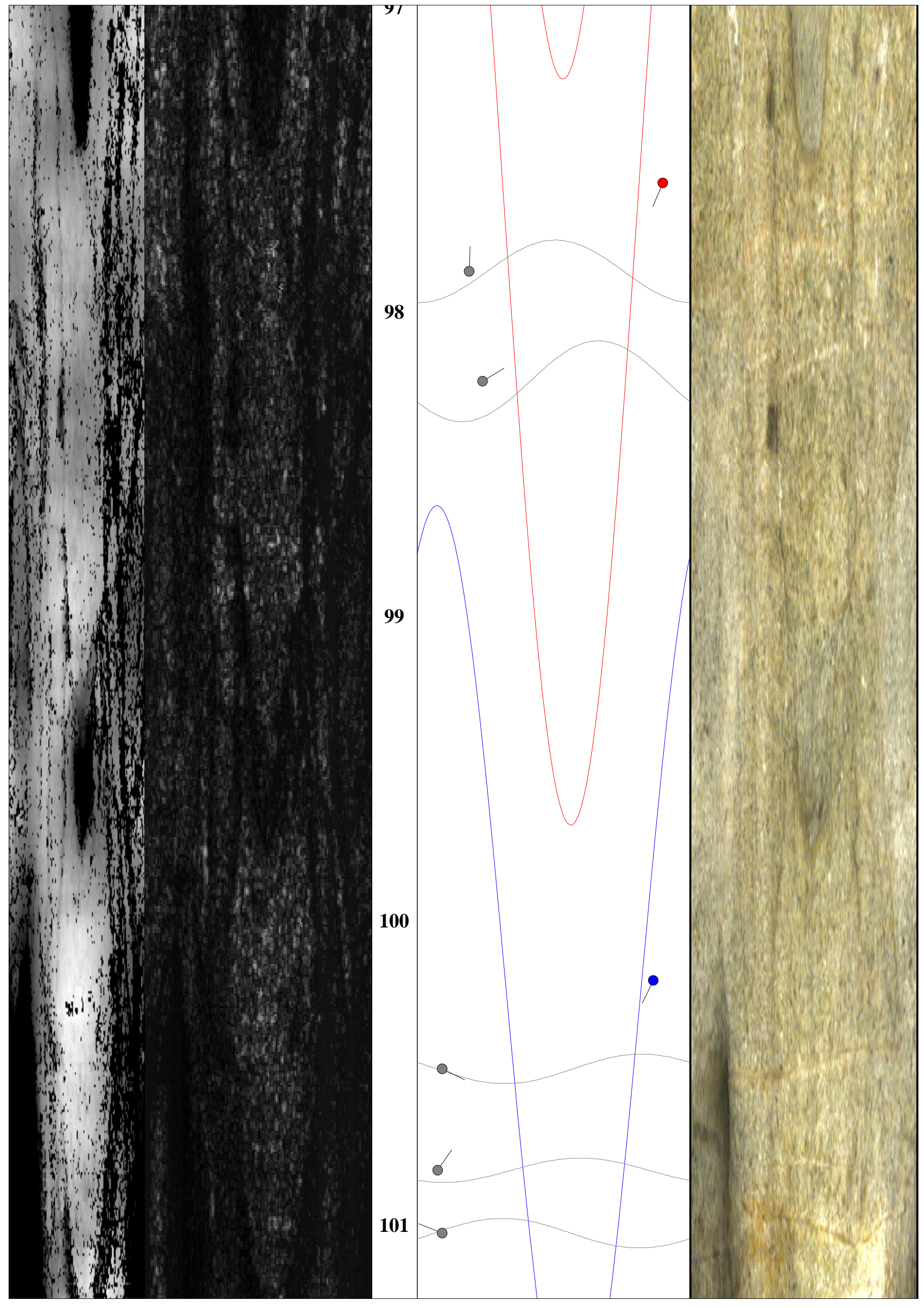




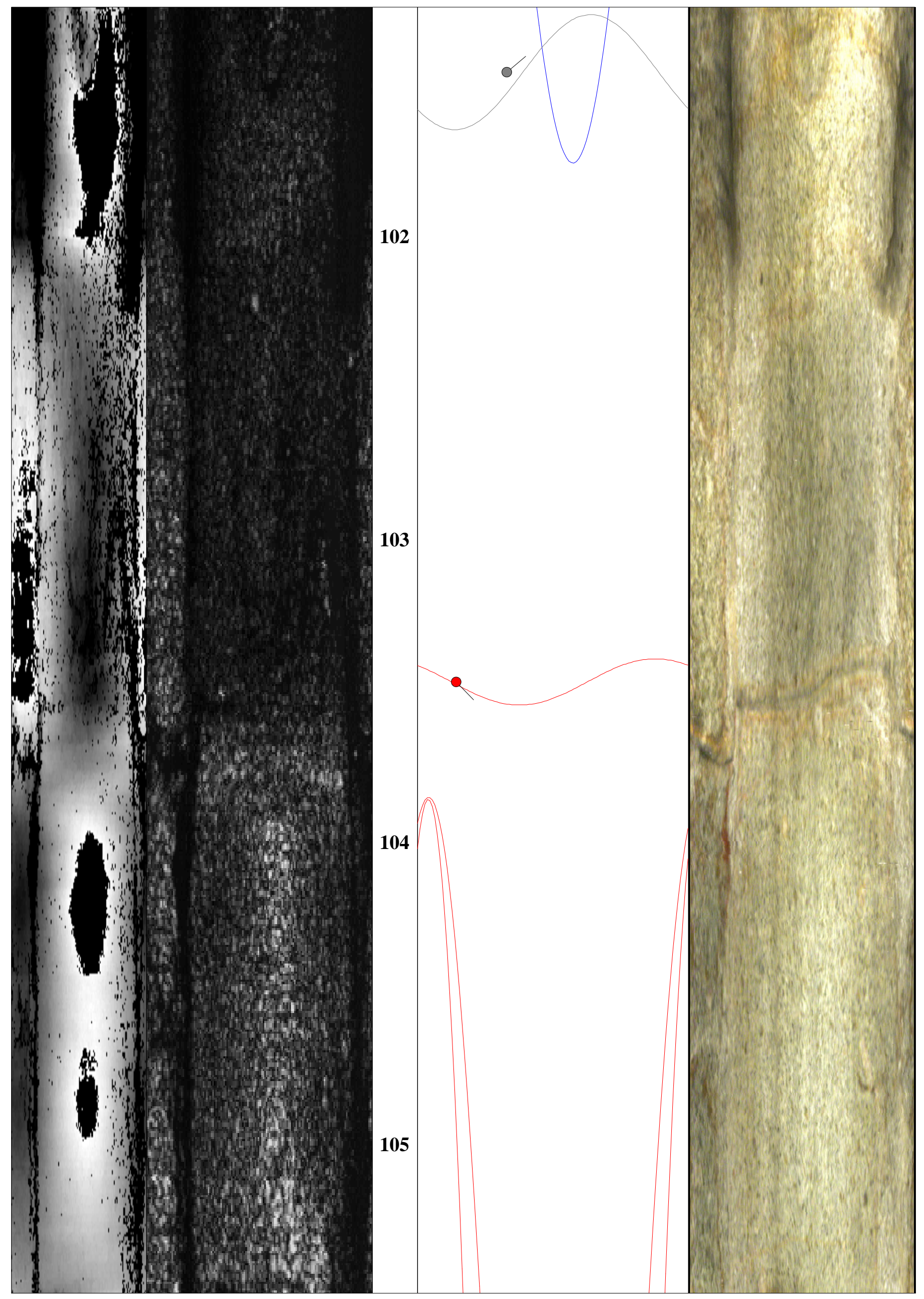




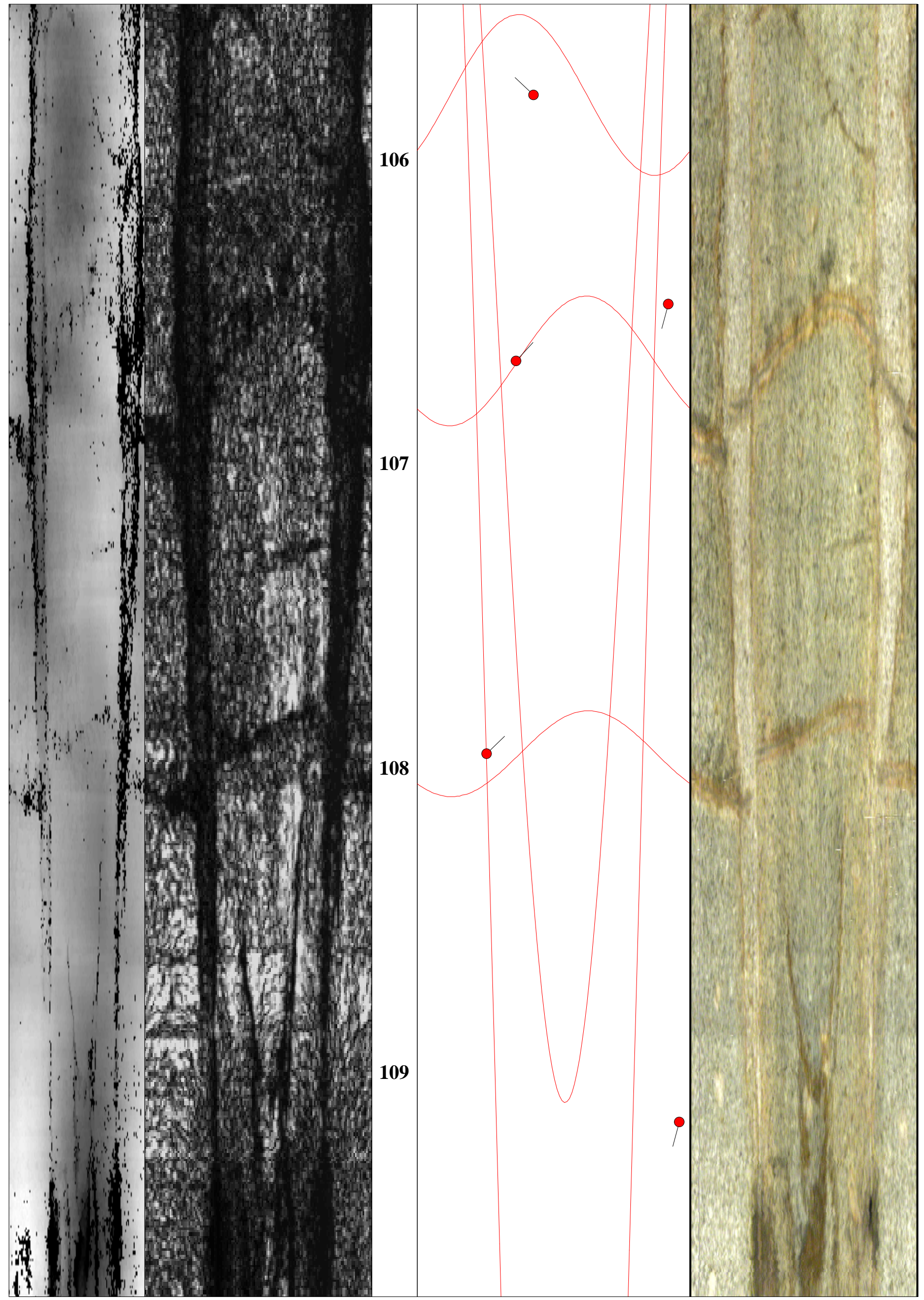




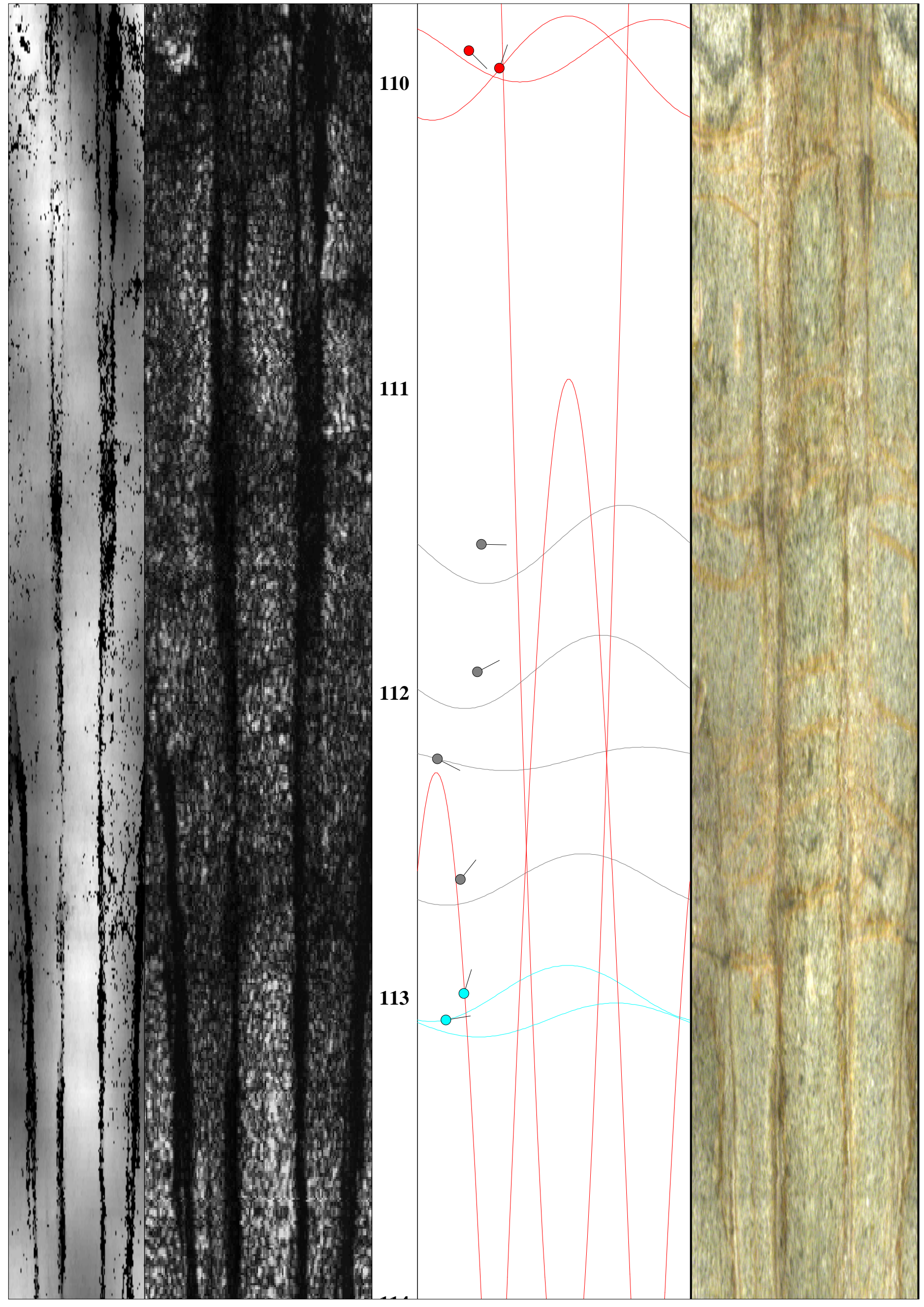




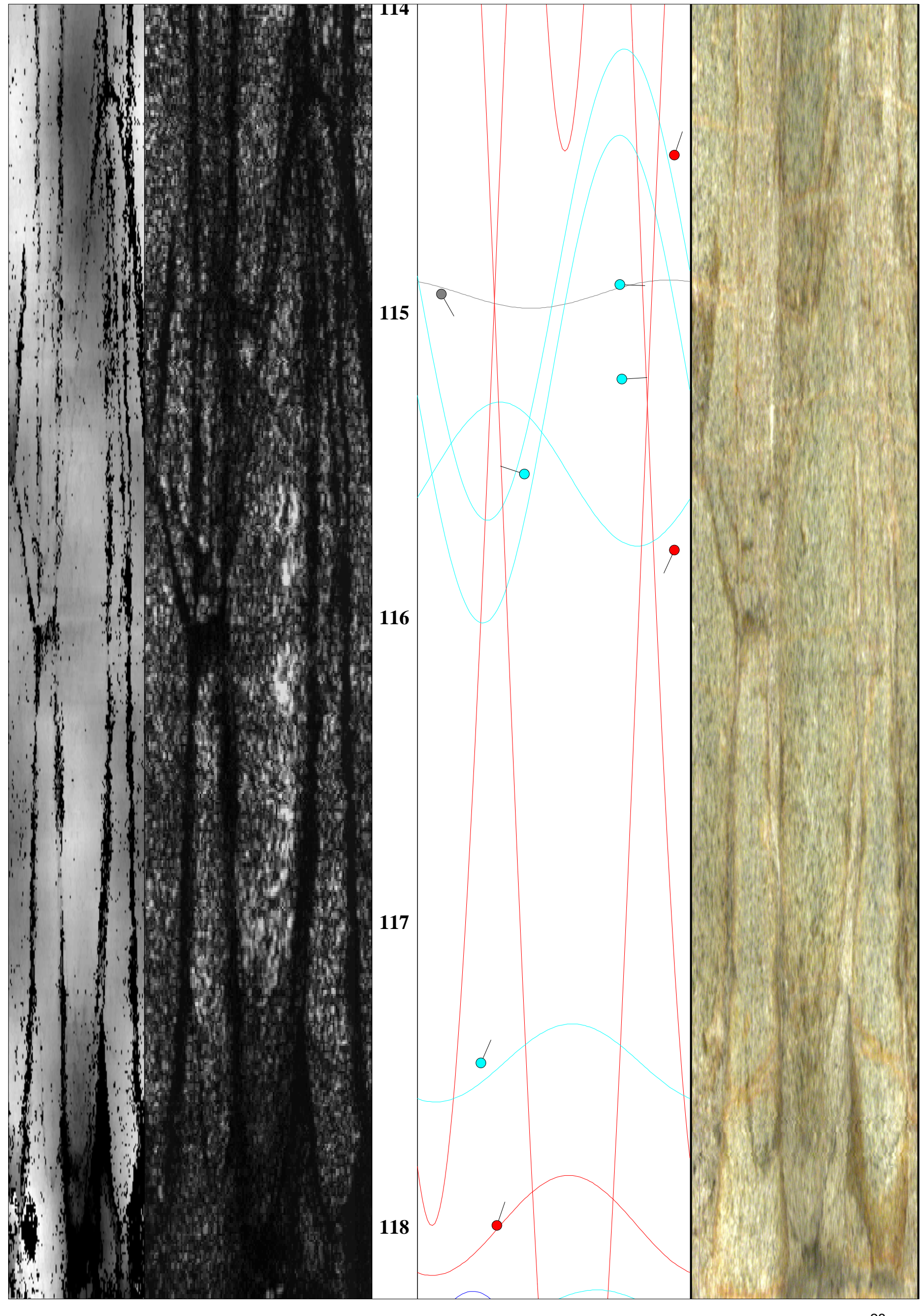




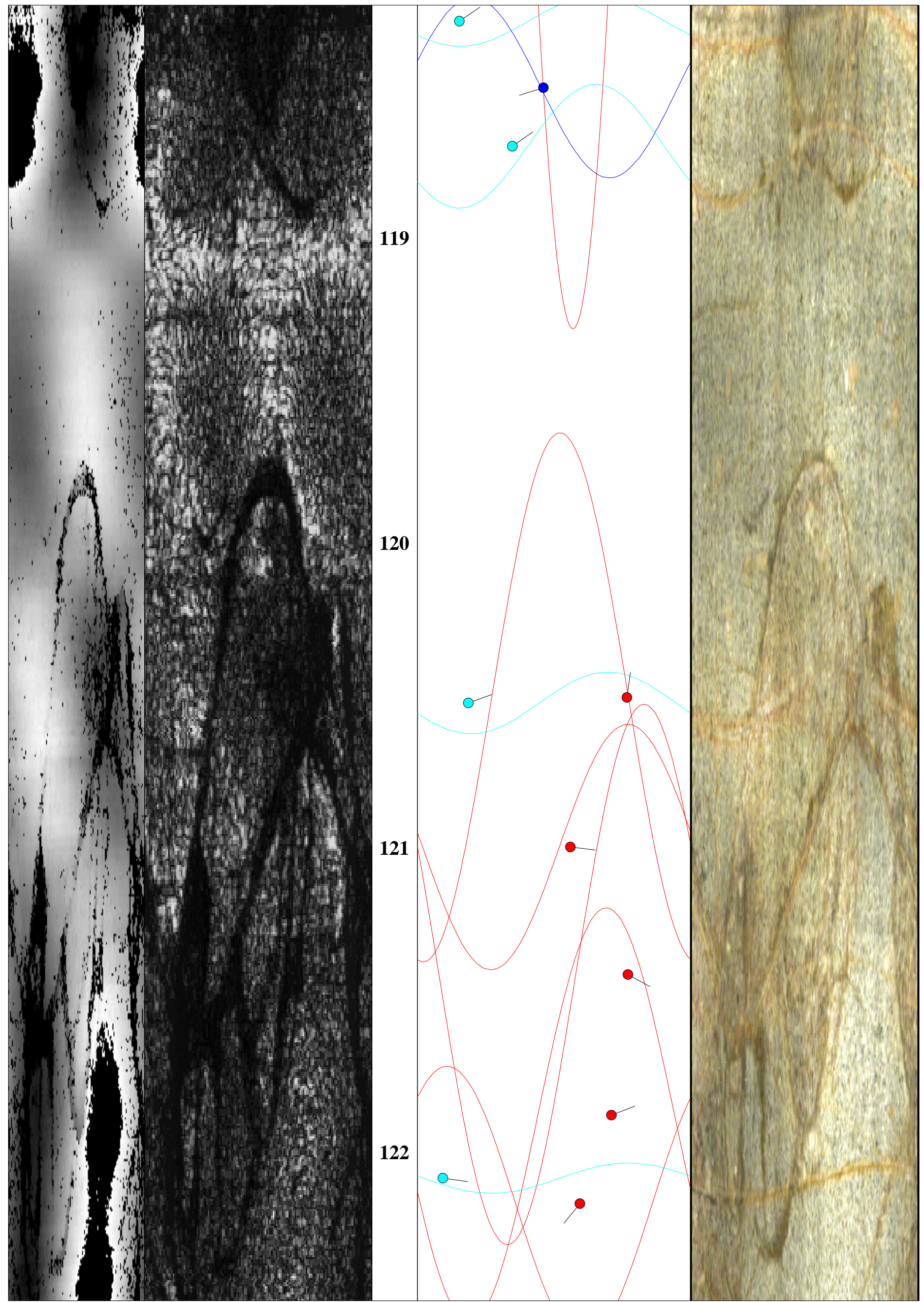




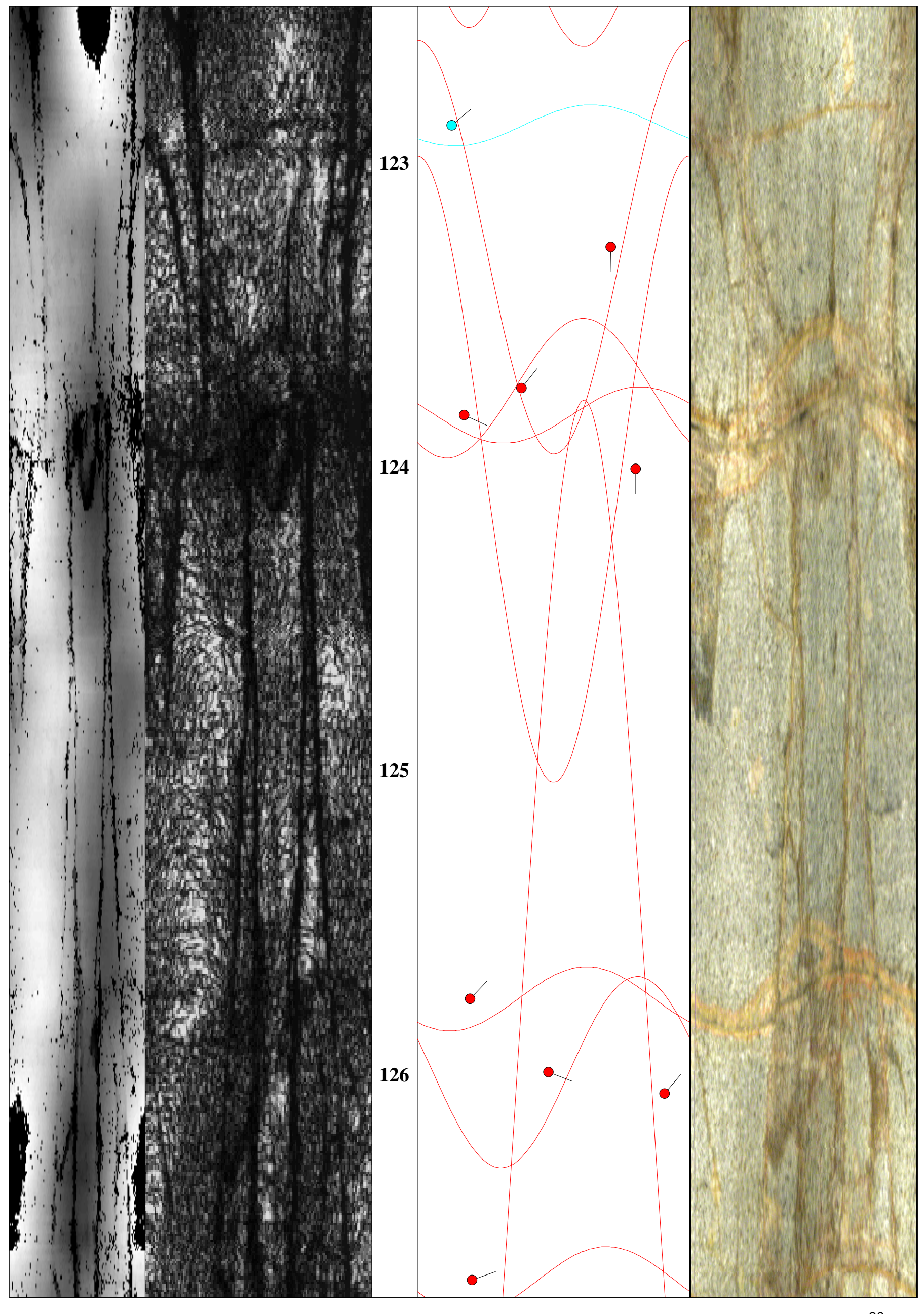




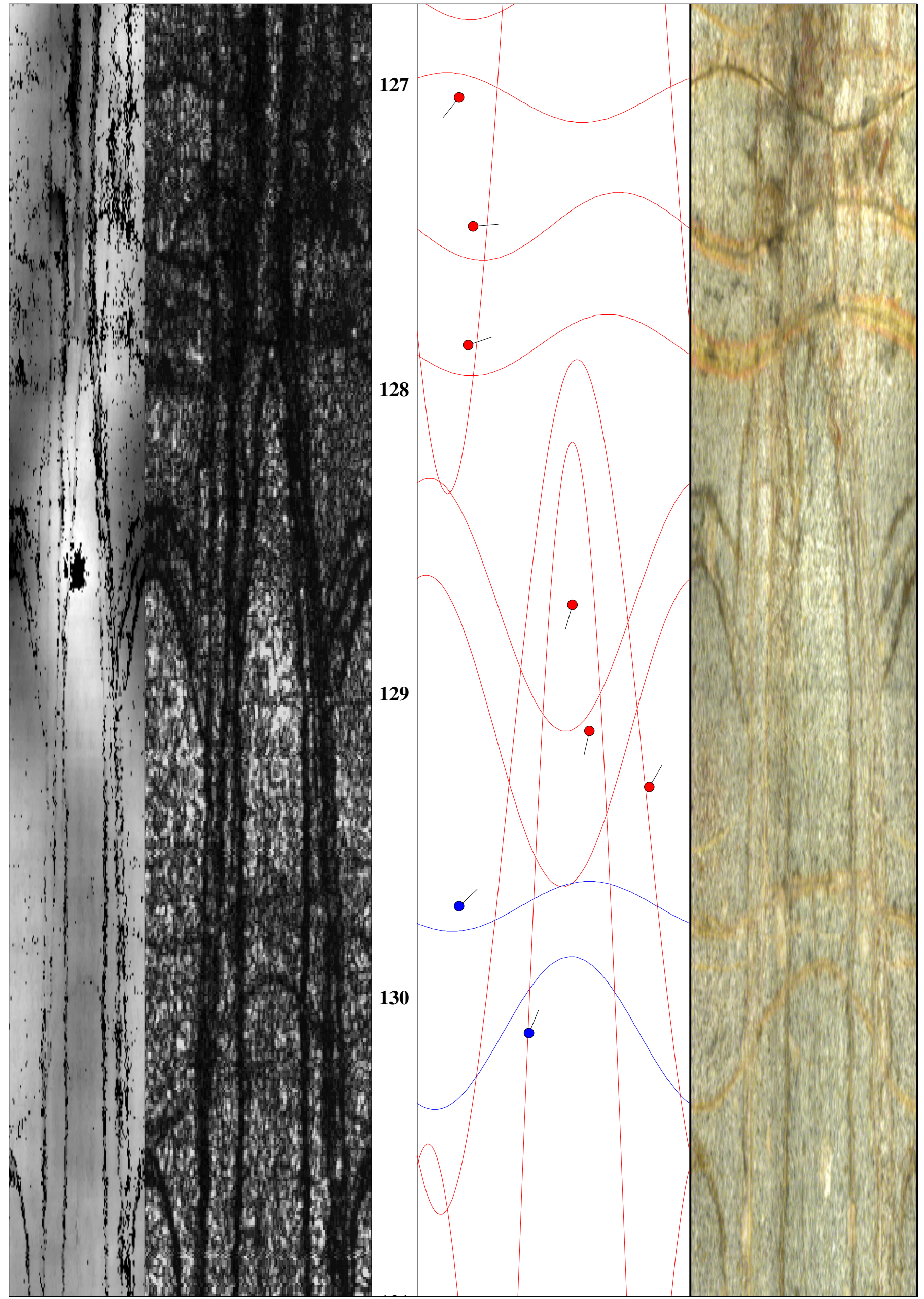




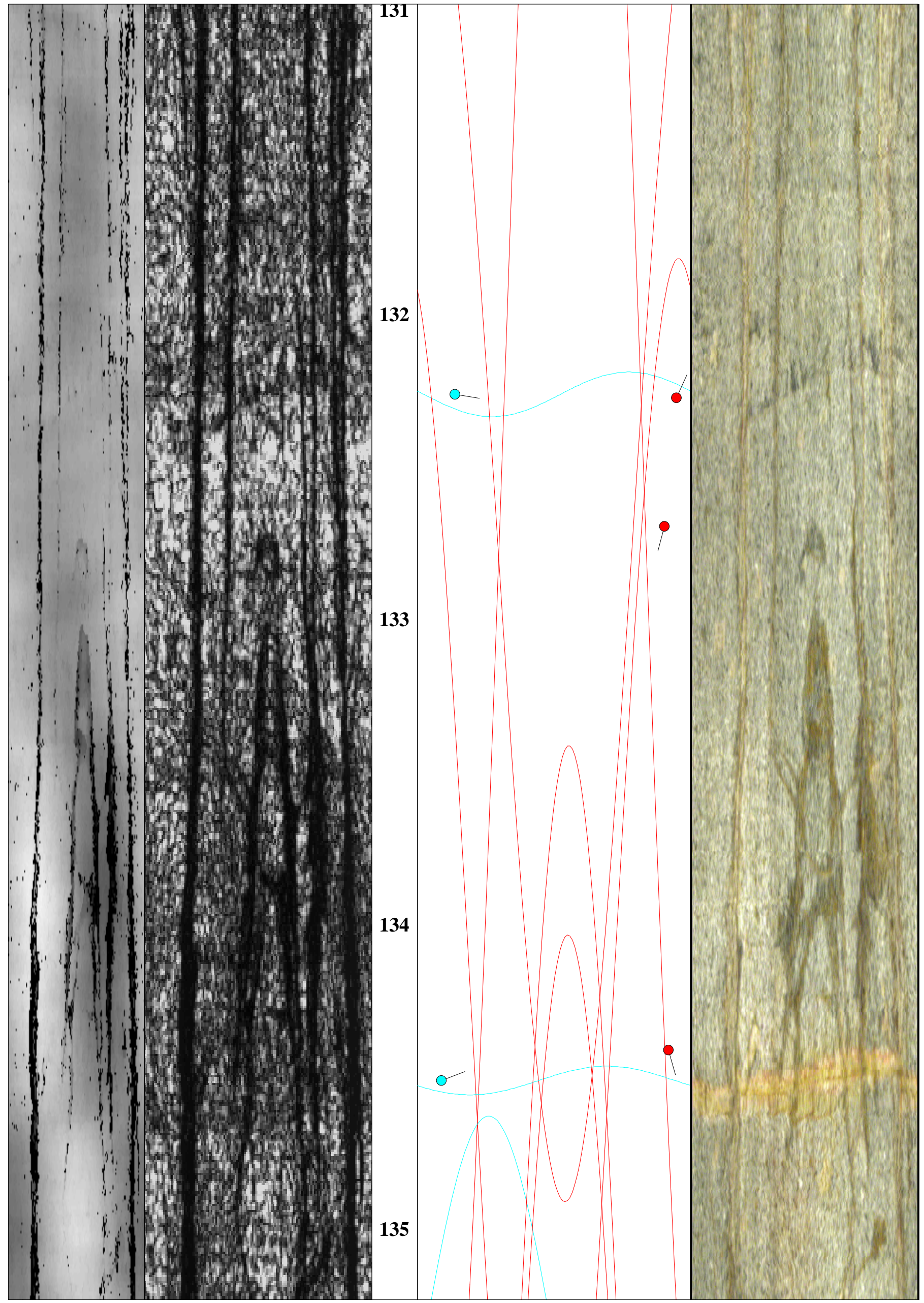




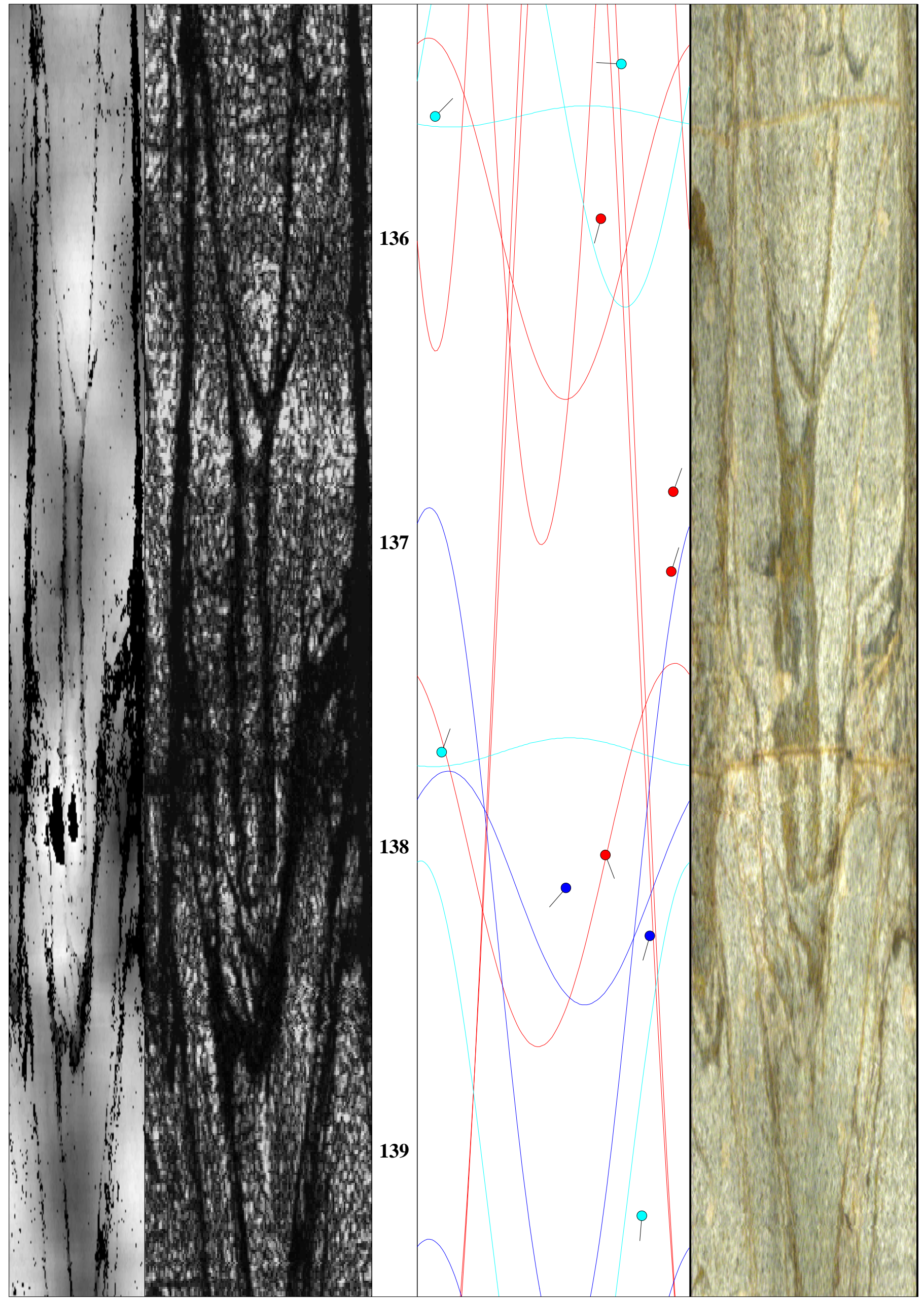




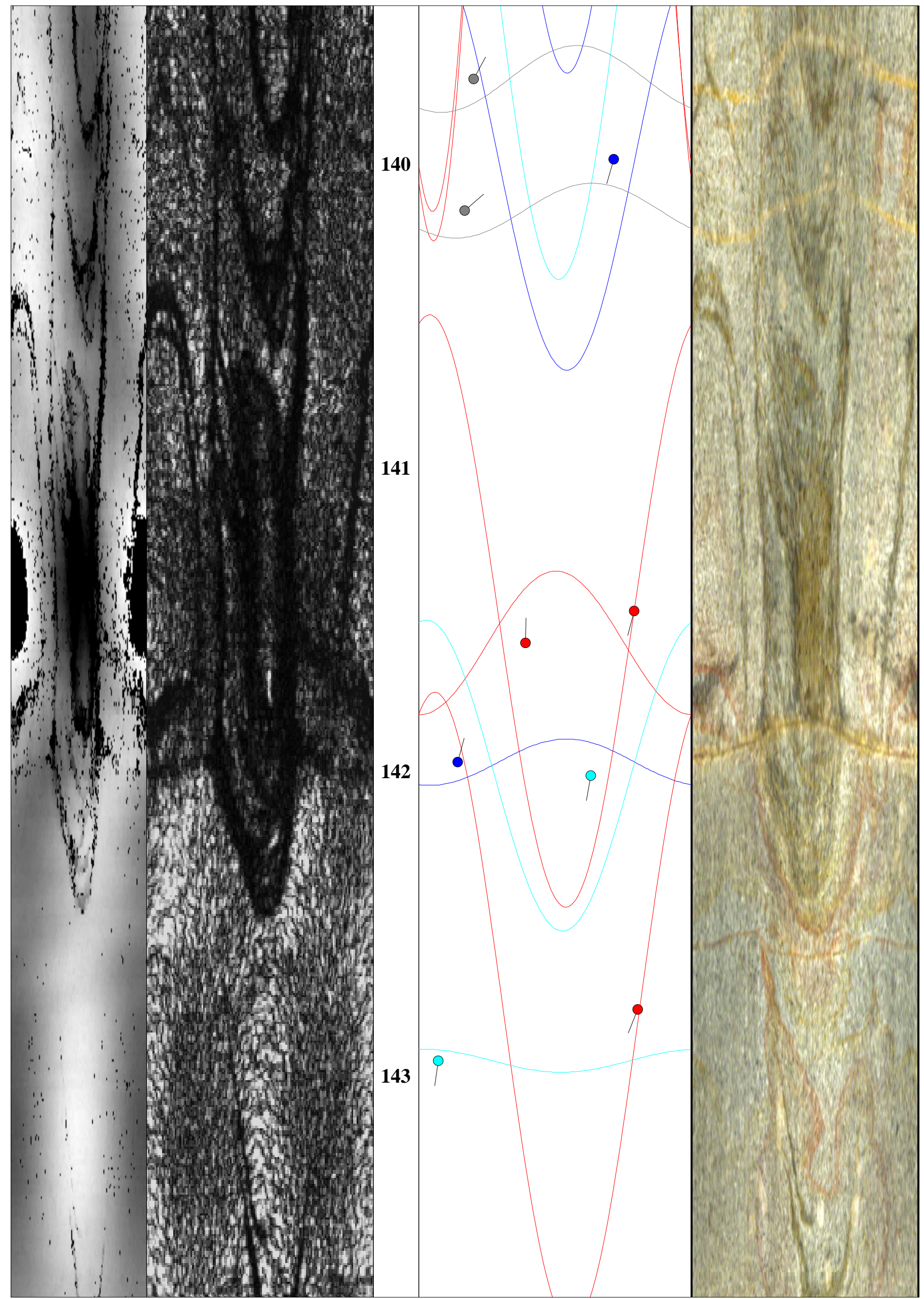




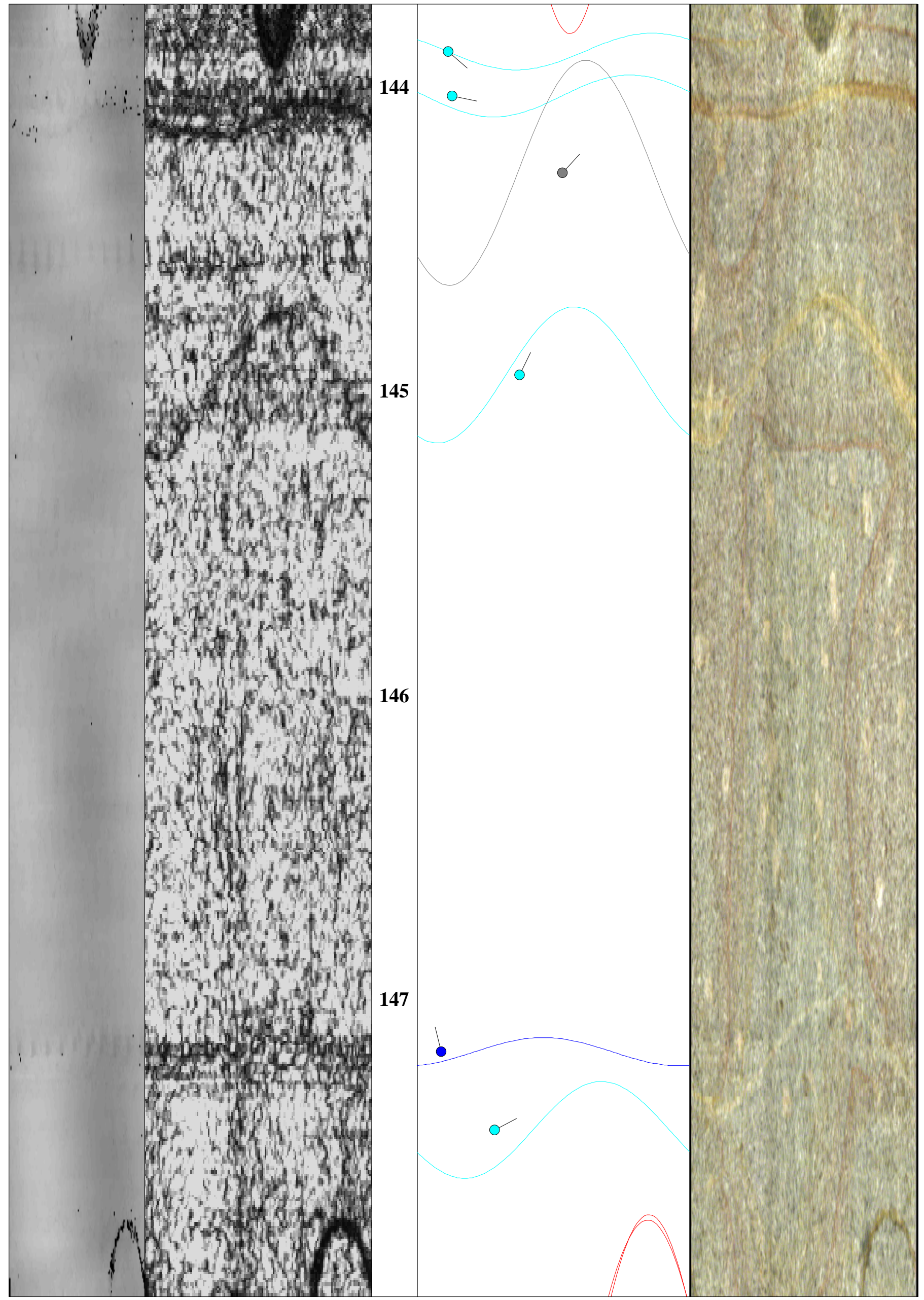




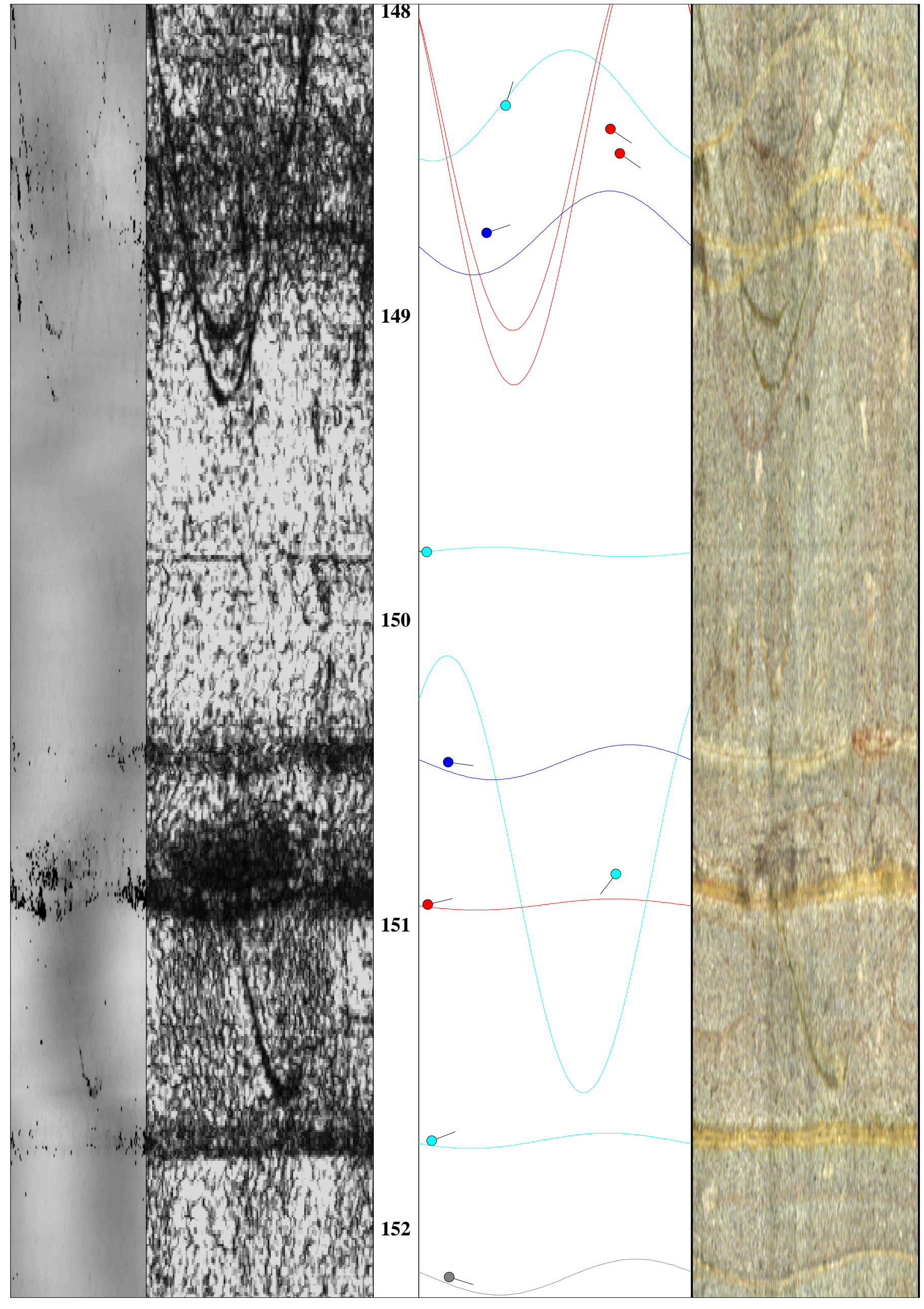




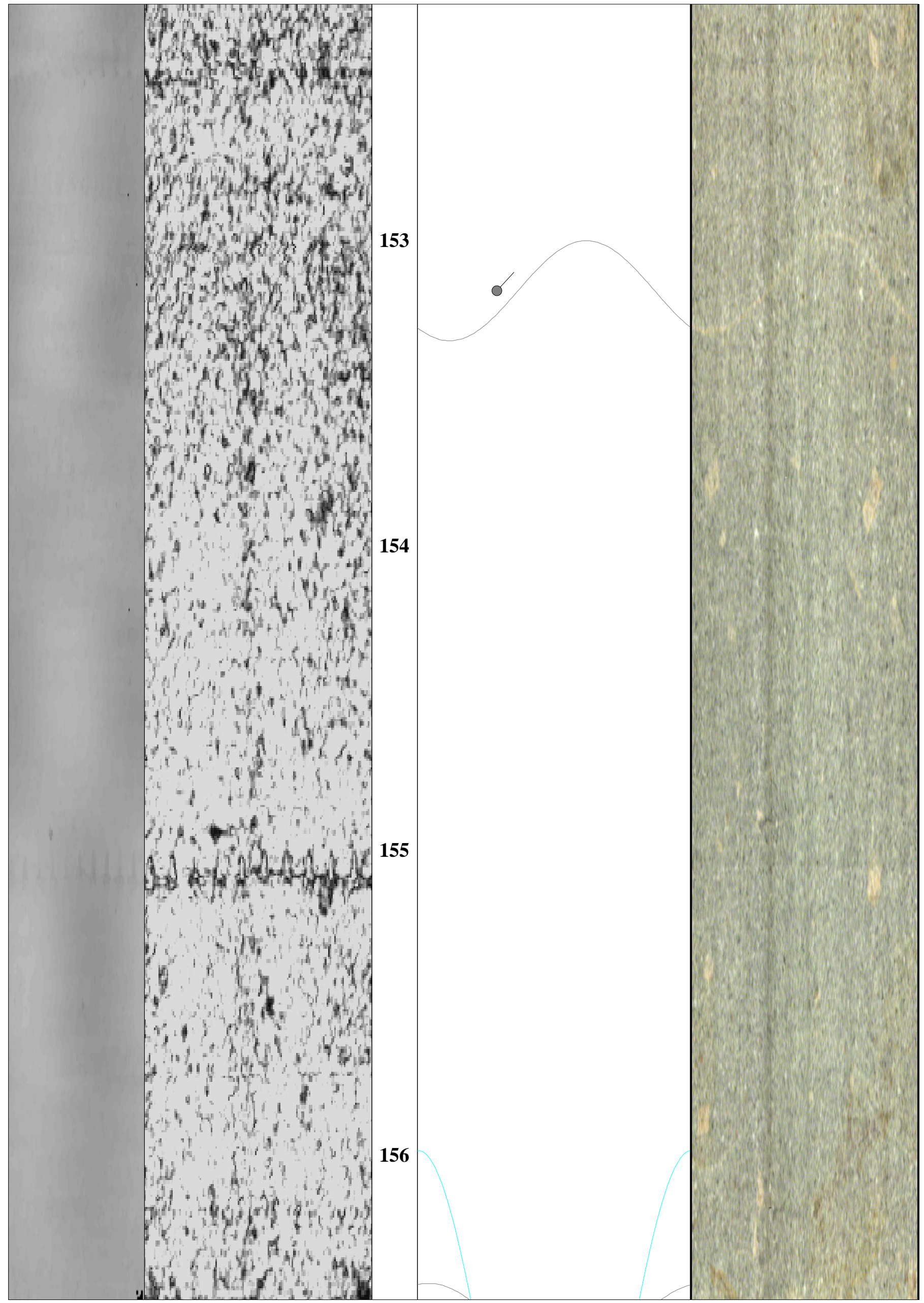




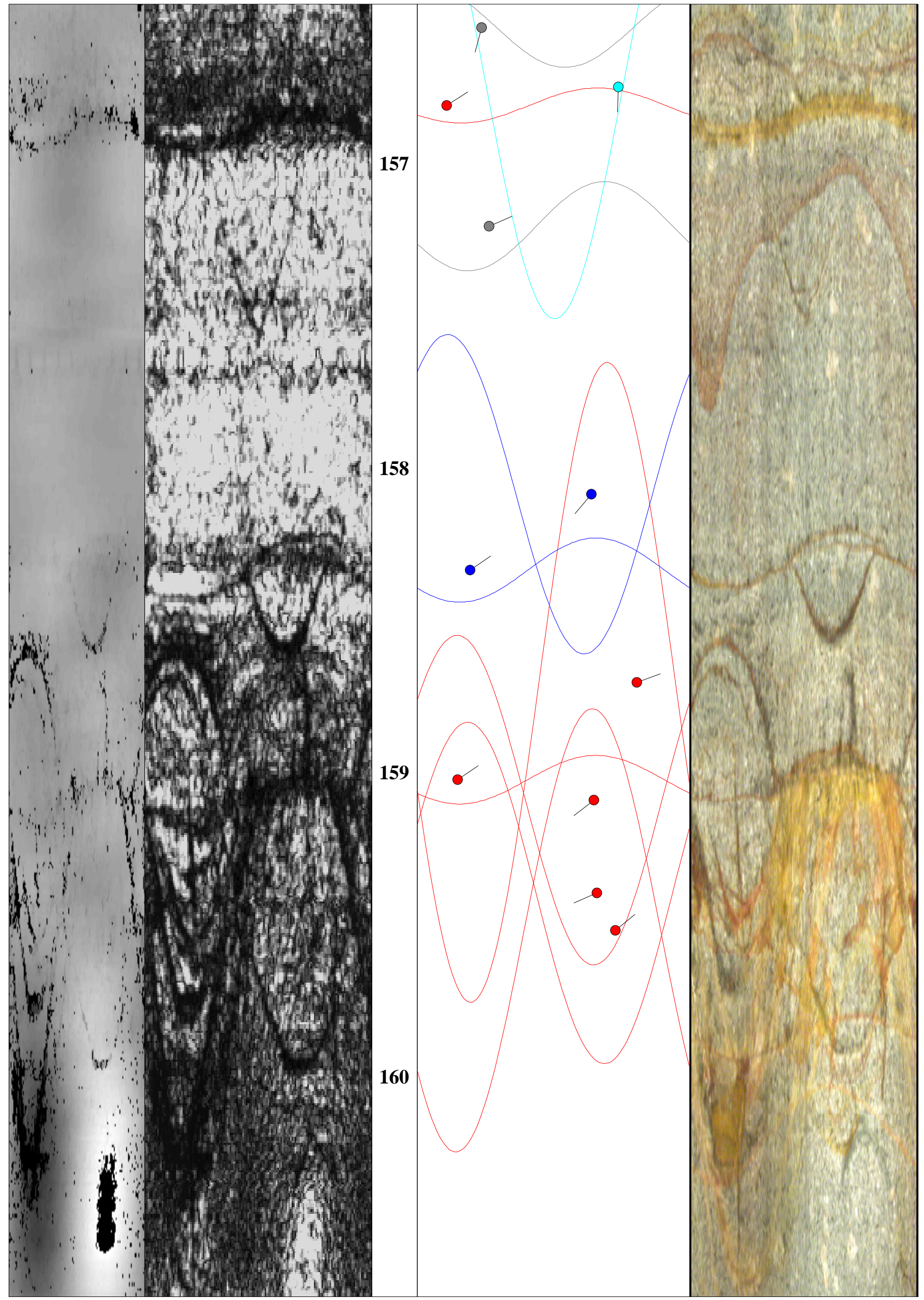




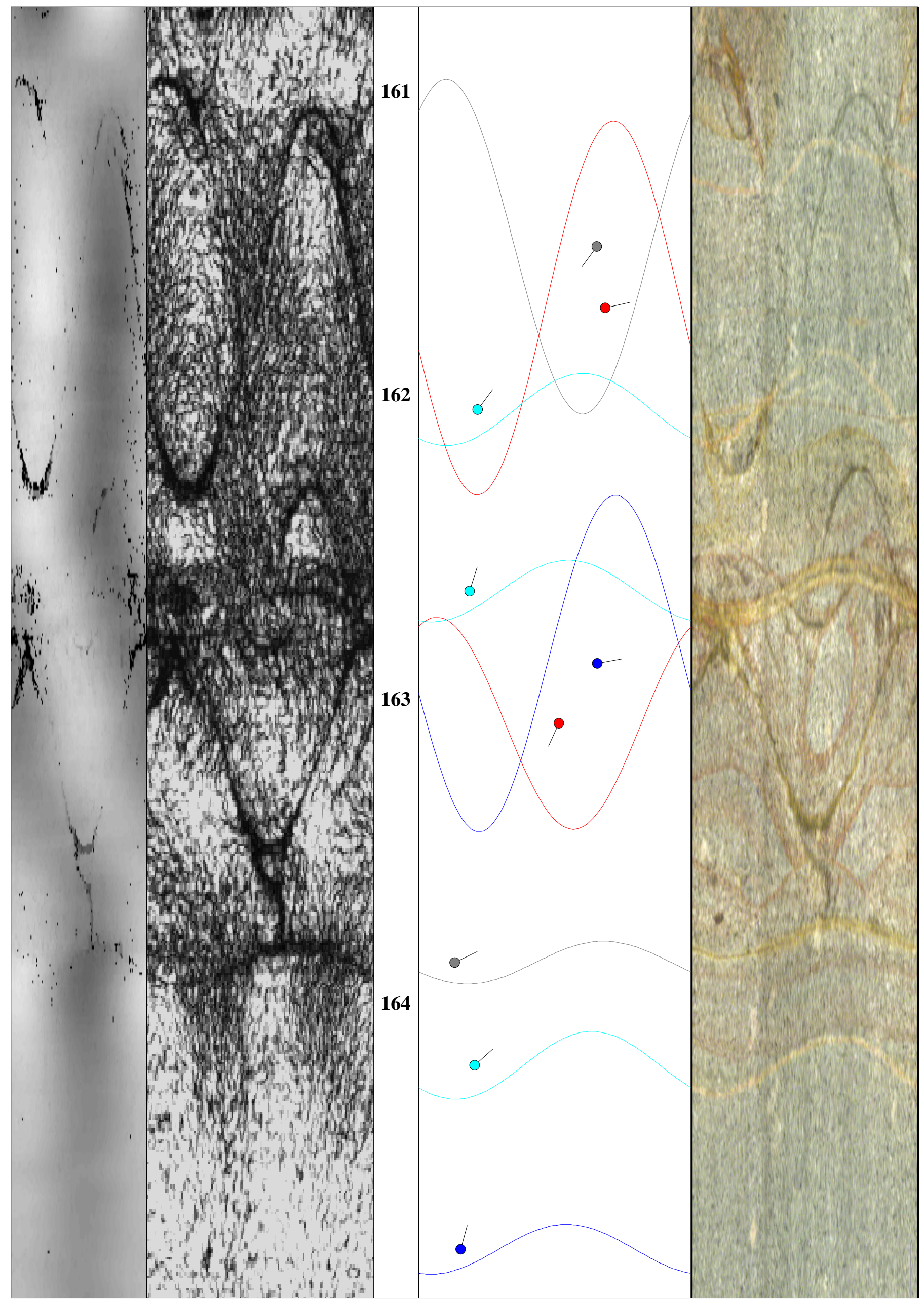




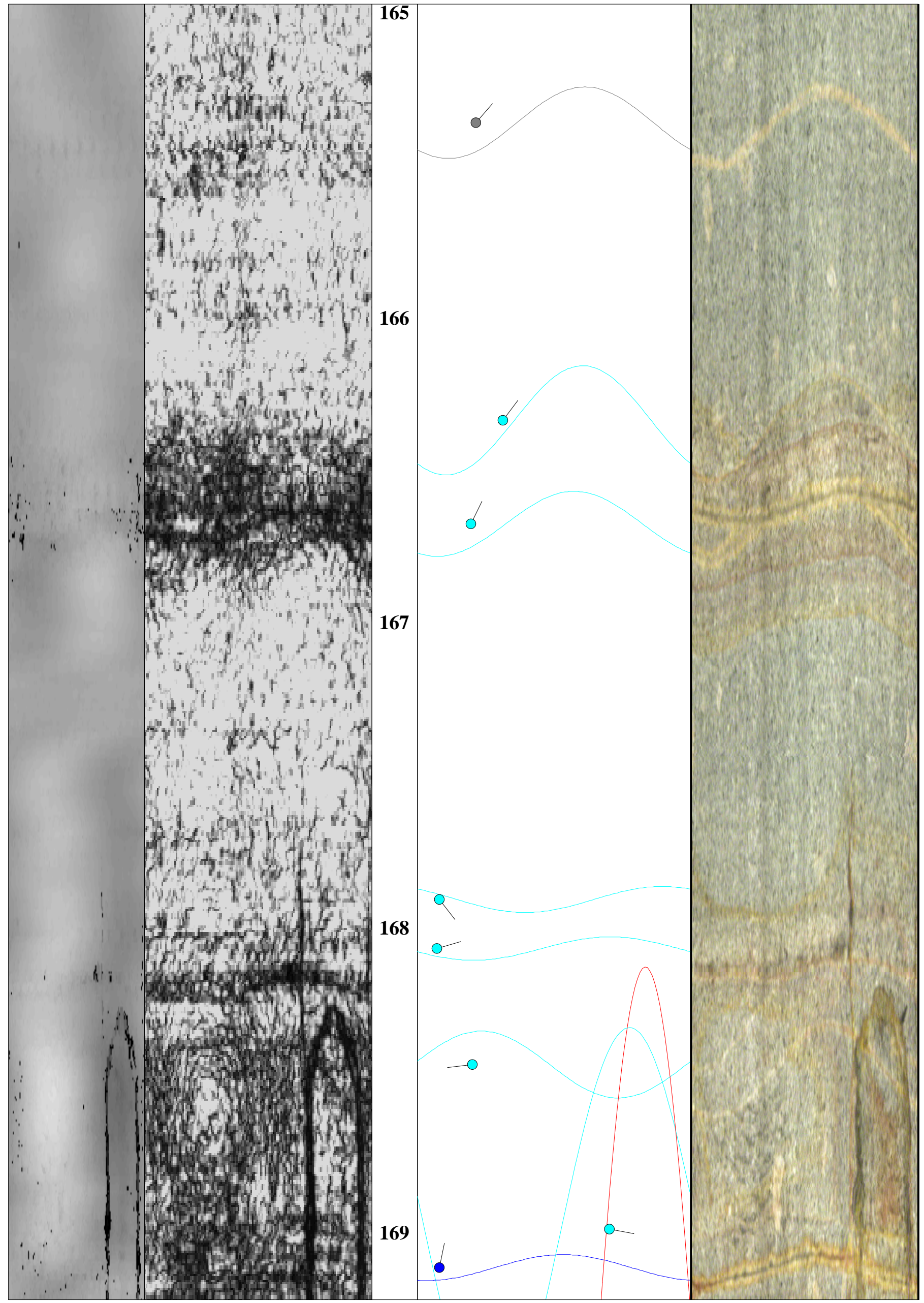




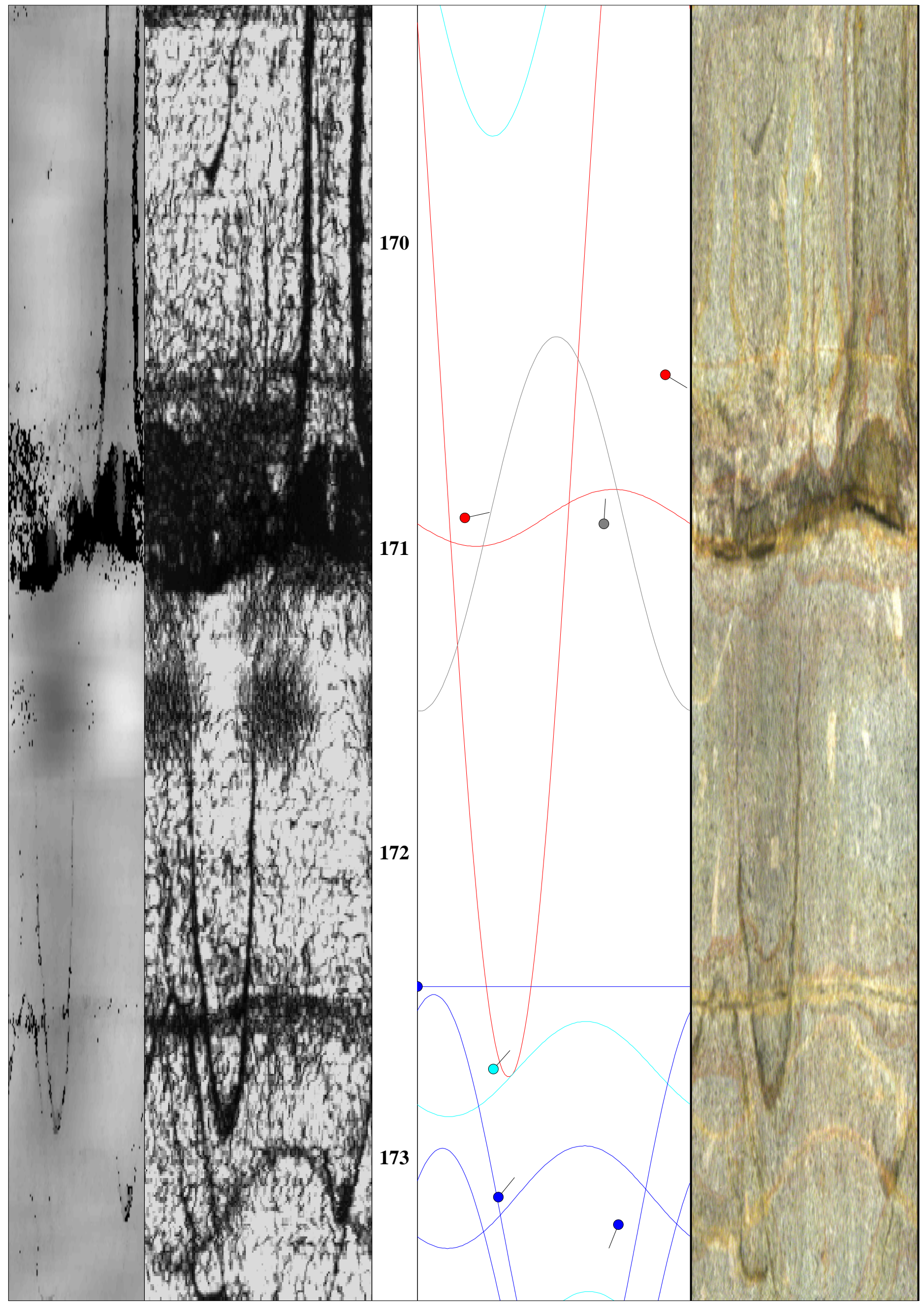




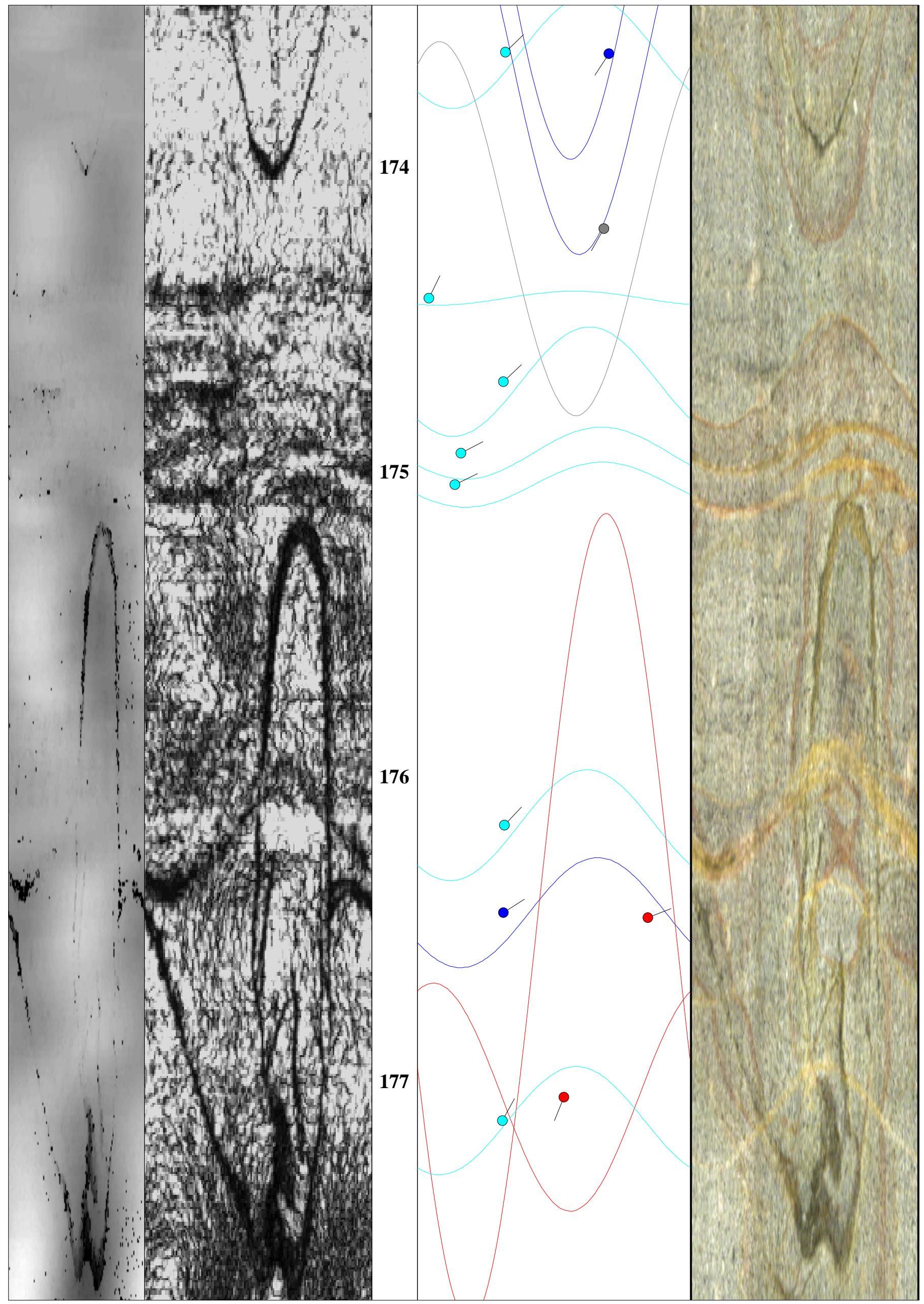




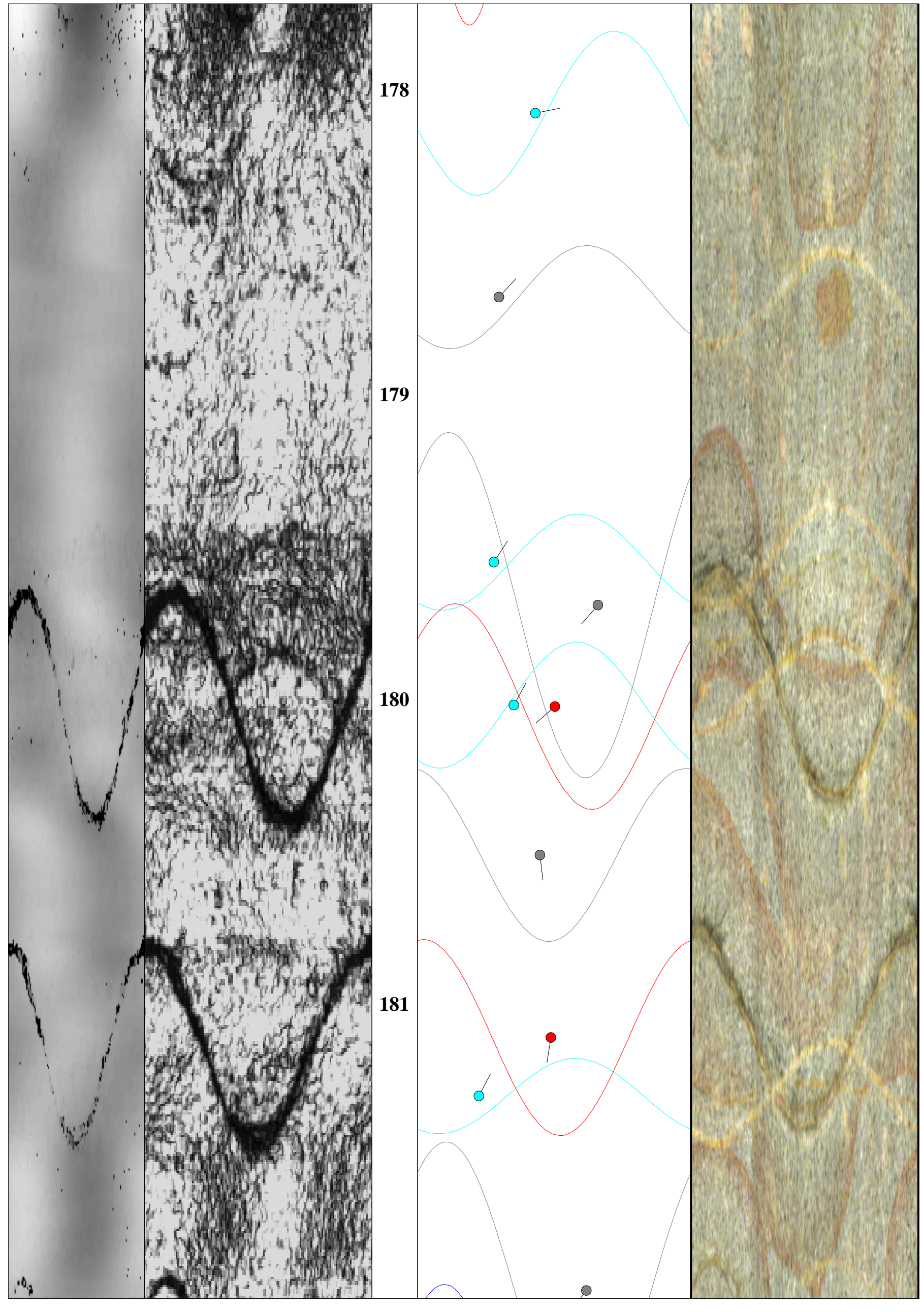




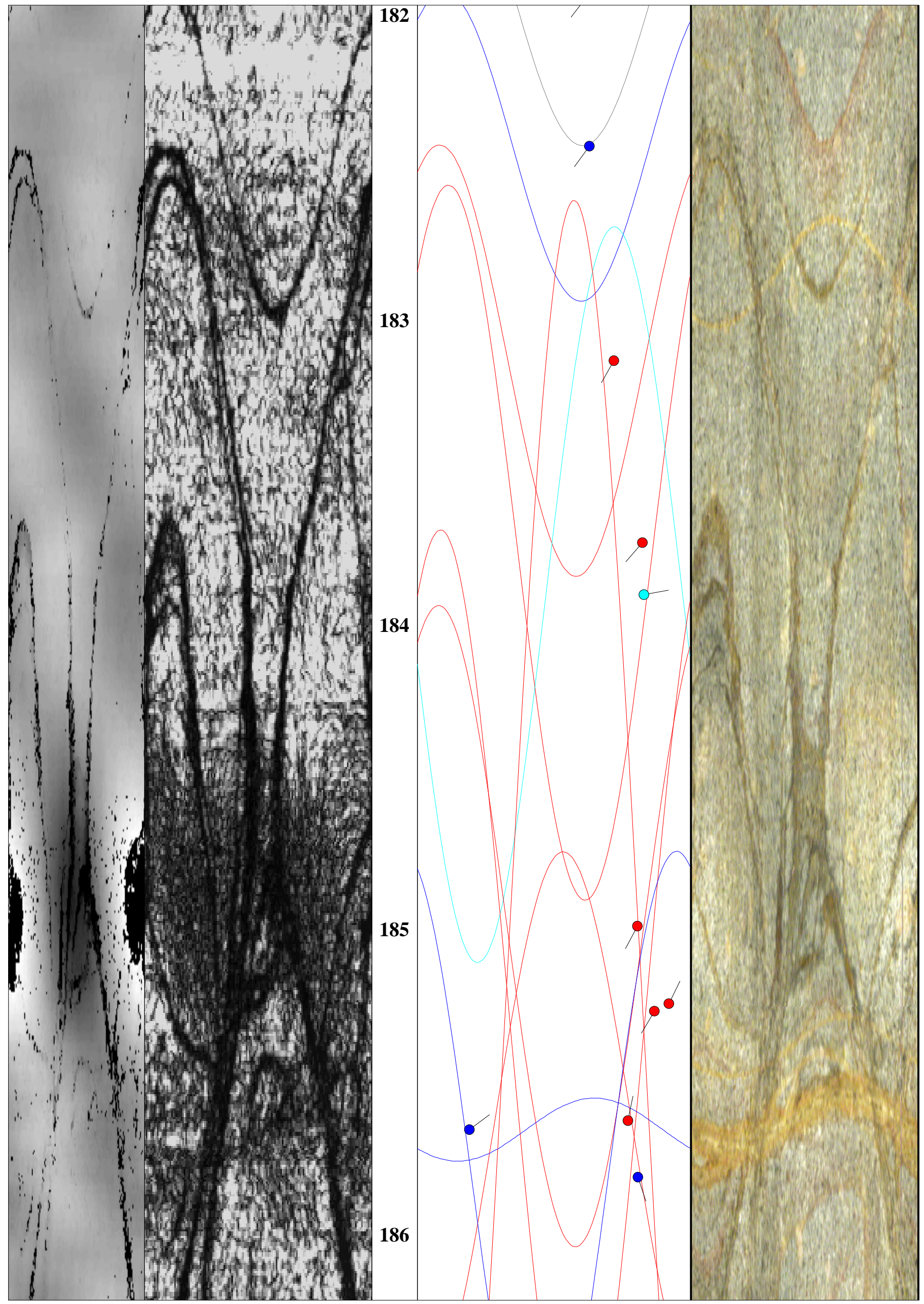




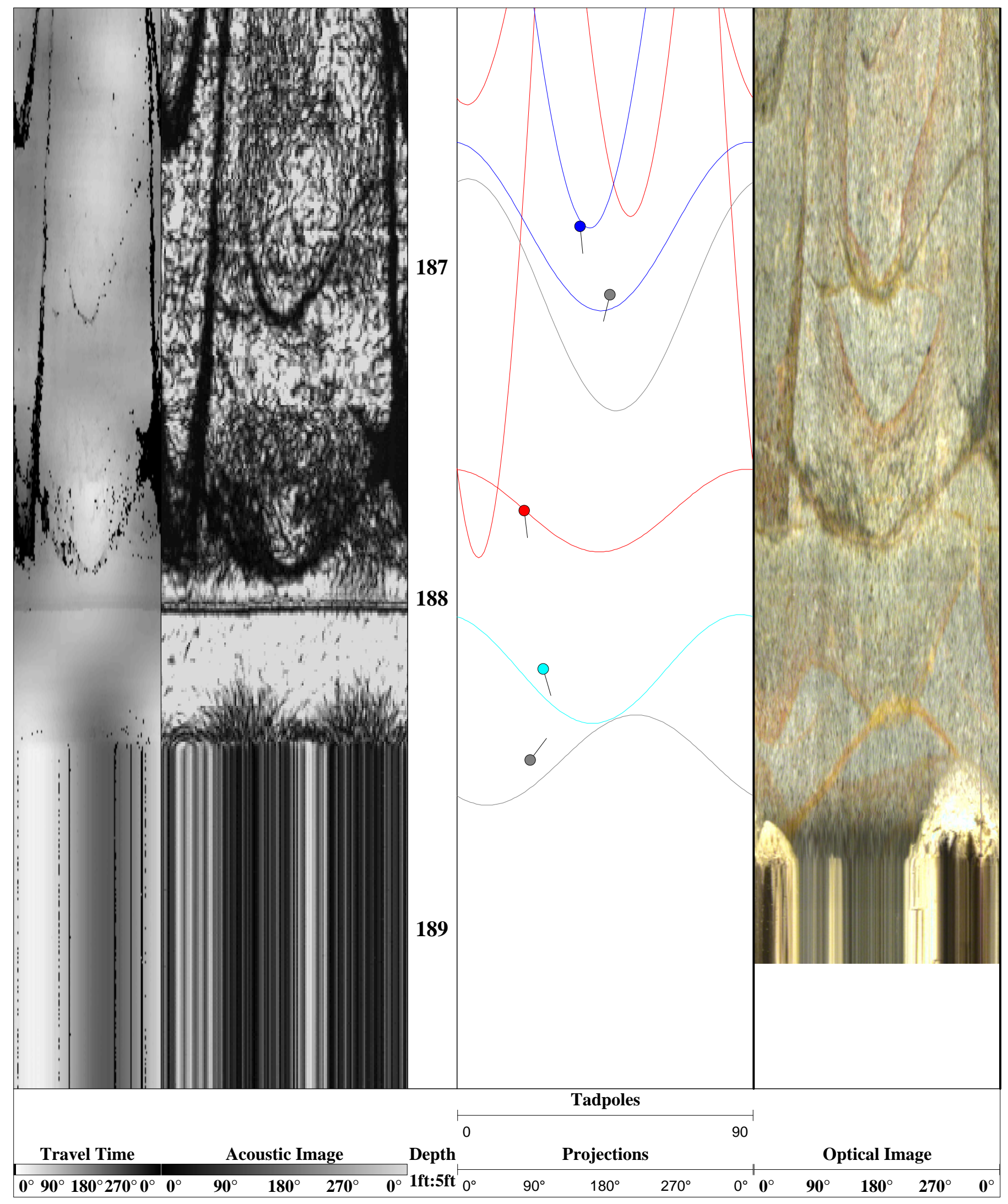




\section{Stereonet Diagram - Schmidt Projection}

Acoustic Televiewer Features

Nevada Test Site

Source Physics Experiment

U-15n6

NNSA/NSO

20 Sept 2010

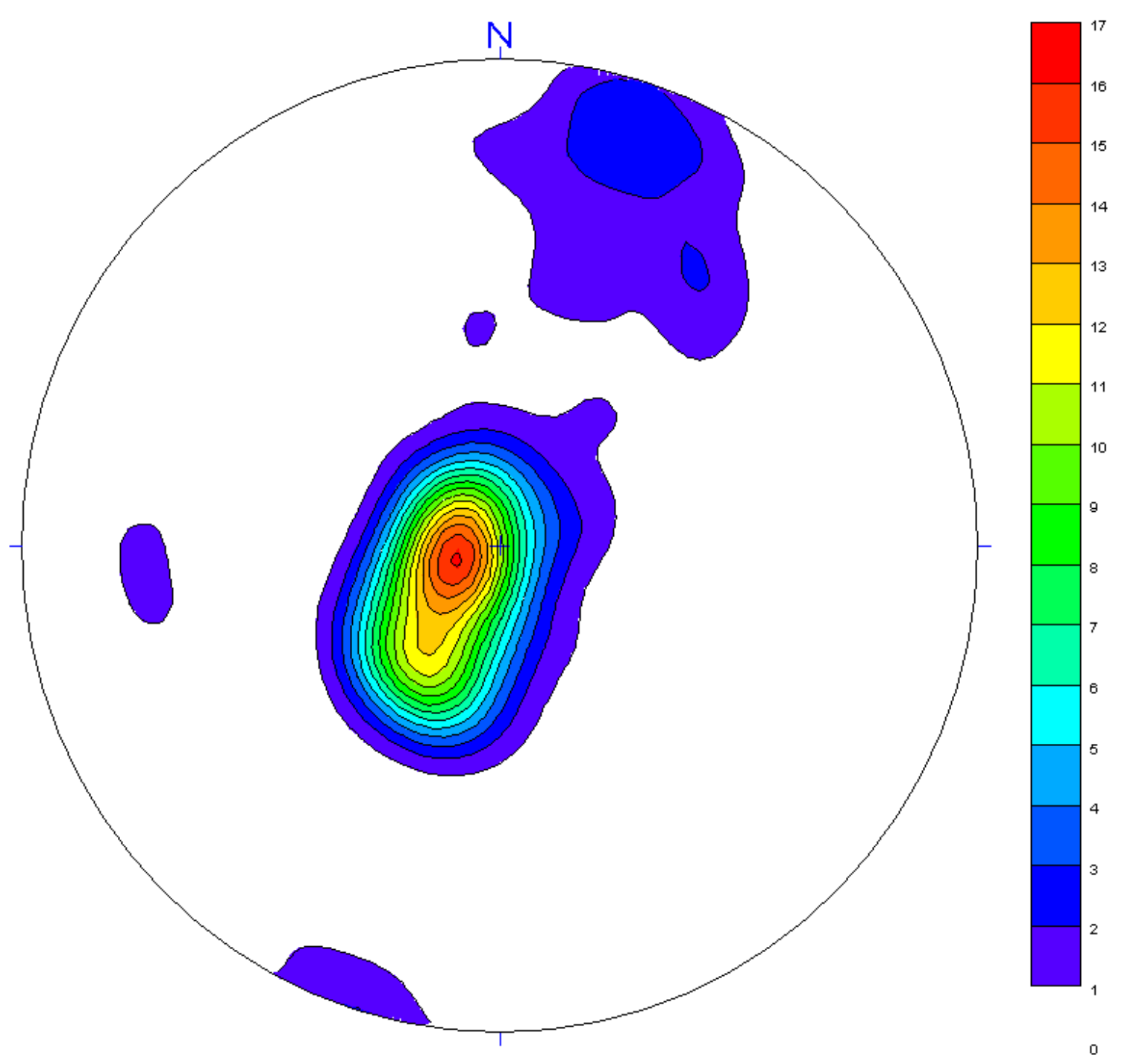

All directions are with respect to True North. 


\section{Stereonet Diagram - Schmidt Projection}

Acoustic Televiewer Features

Nevada Test Site

Source Physics Experiment

U-15n6

NNSA/NSO

20 Sept 2010

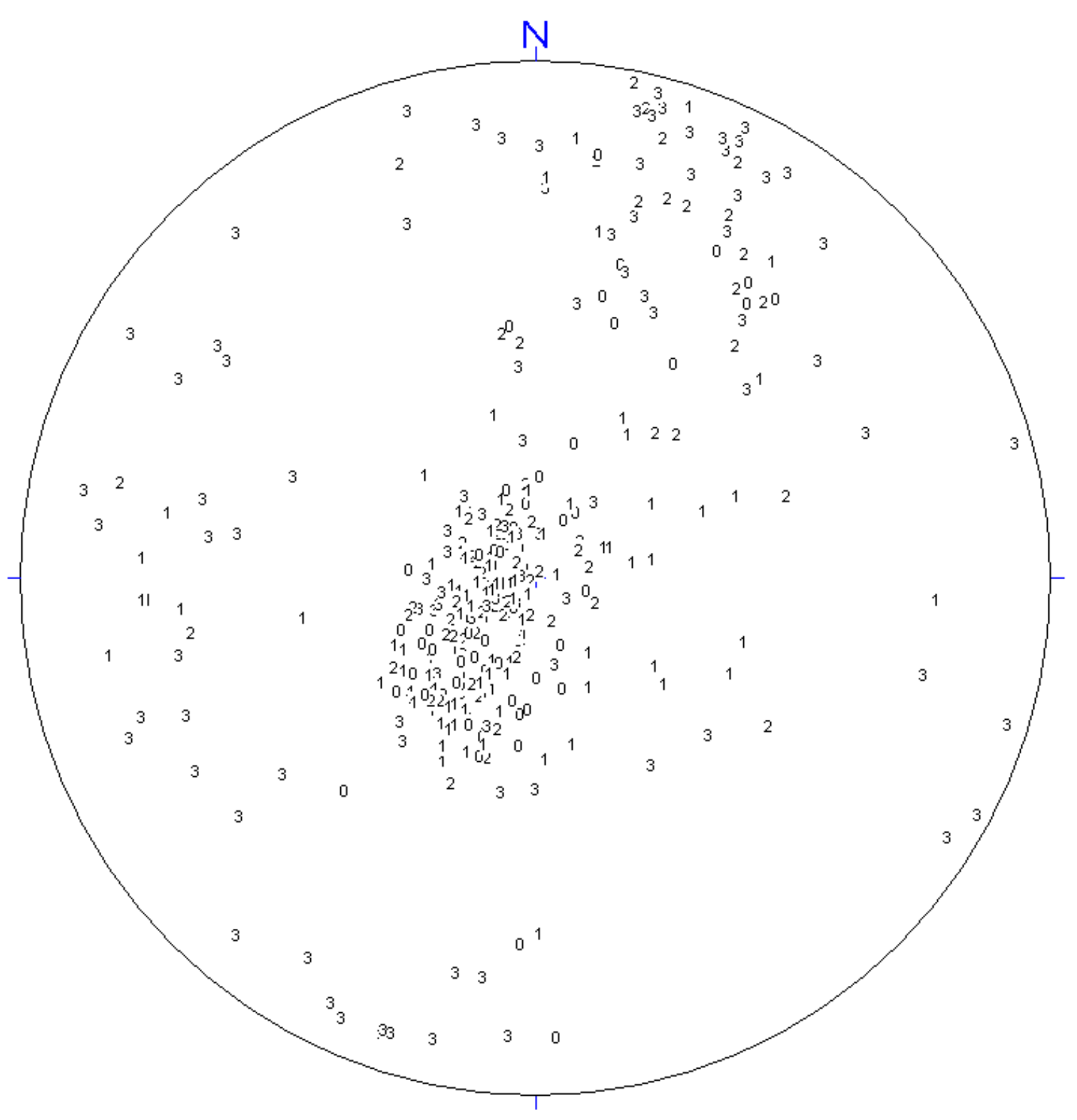

All directions are with respect to True North. 


\section{Rose Diagram - Dip Directions \\ Acoustic Televiewer Features \\ Nevada Test Site \\ Source Physics Experiment \\ U-15n6 \\ NNSA/NSO \\ 20 Sept 2010}

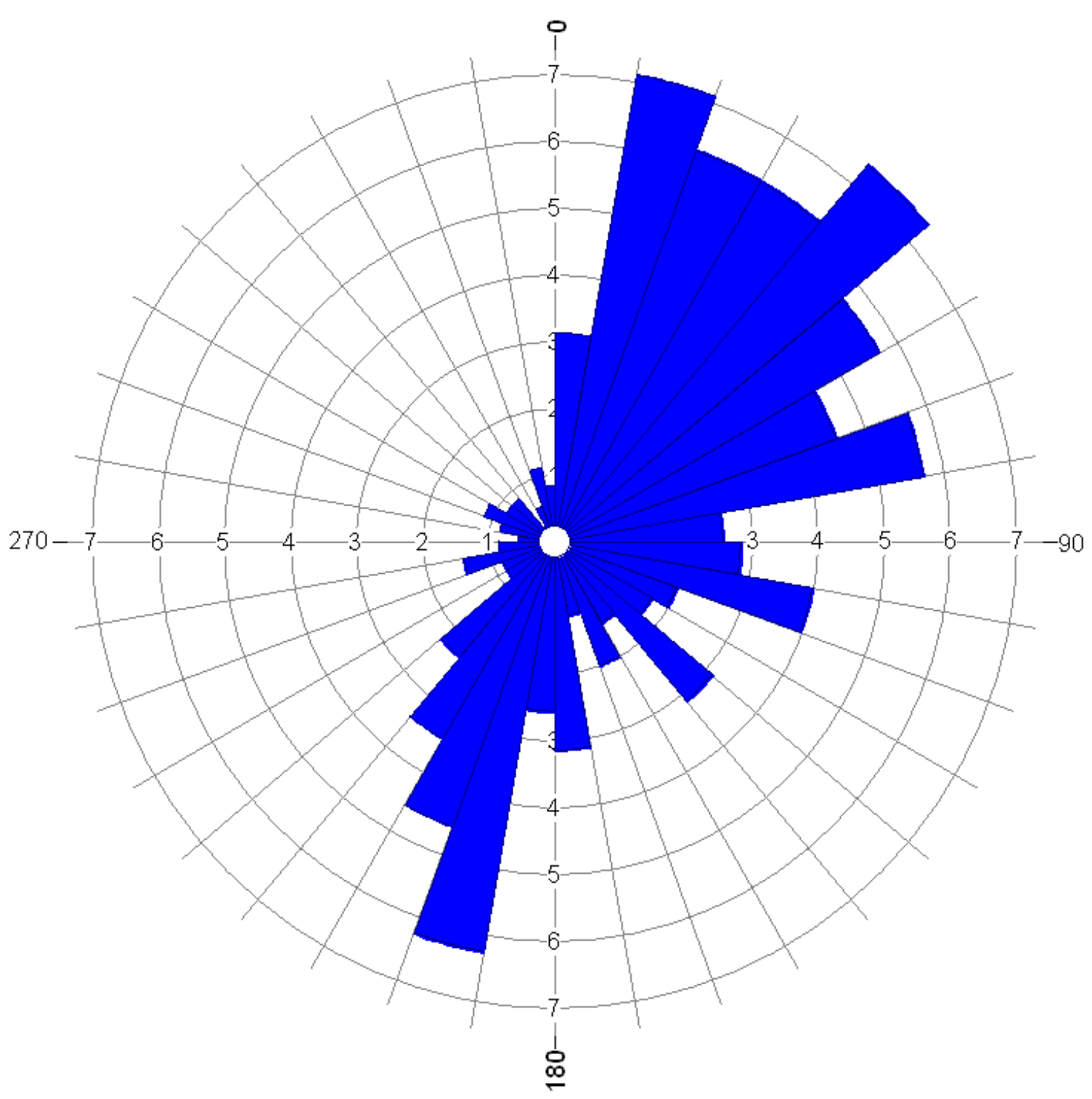




\section{Rose Diagram - Dip Angles \\ Acoustic Televiewer Features \\ Nevada Test Site \\ Source Physics Experiment \\ U-15n6 \\ NNSA/NSO \\ 20 Sept 2010}

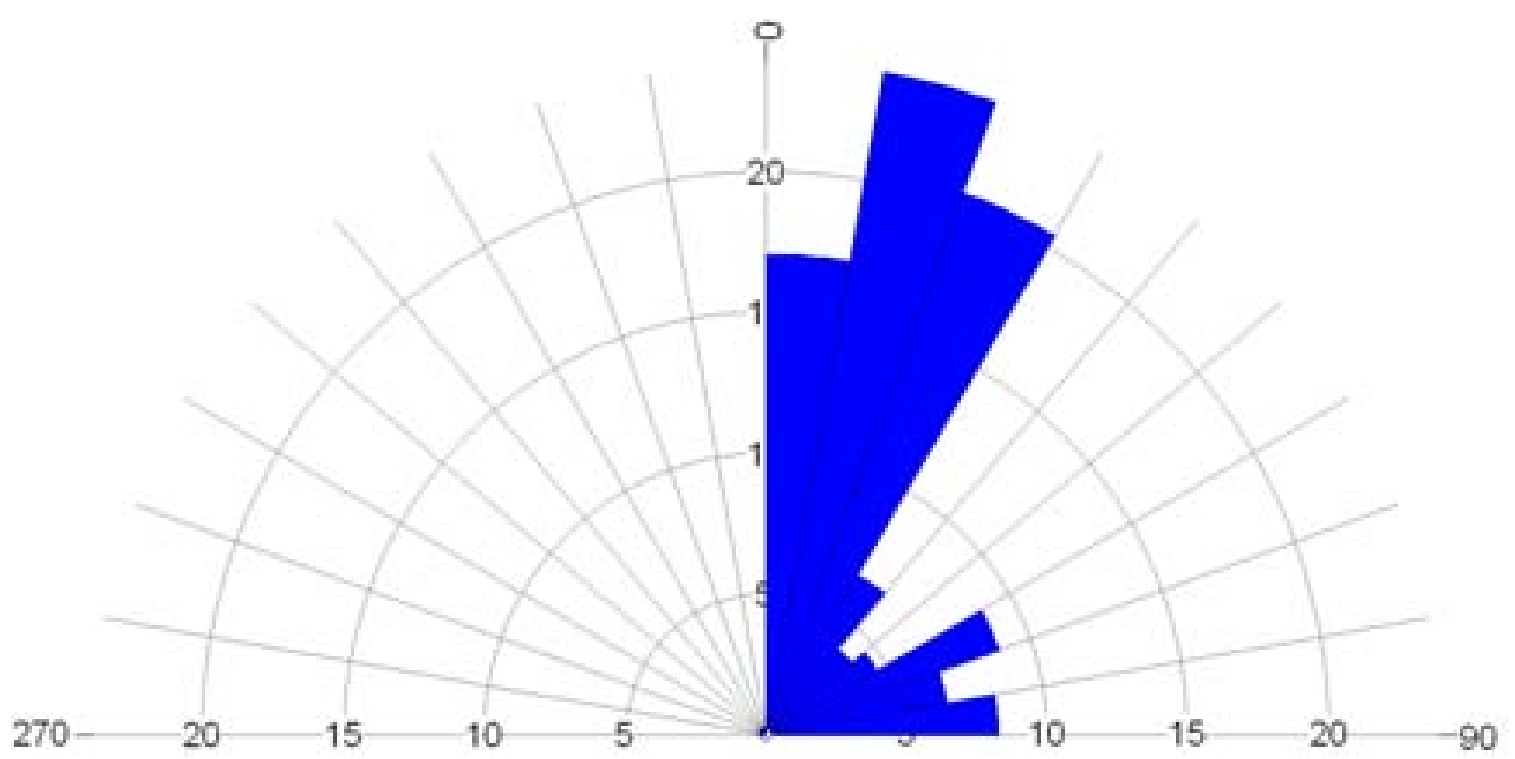




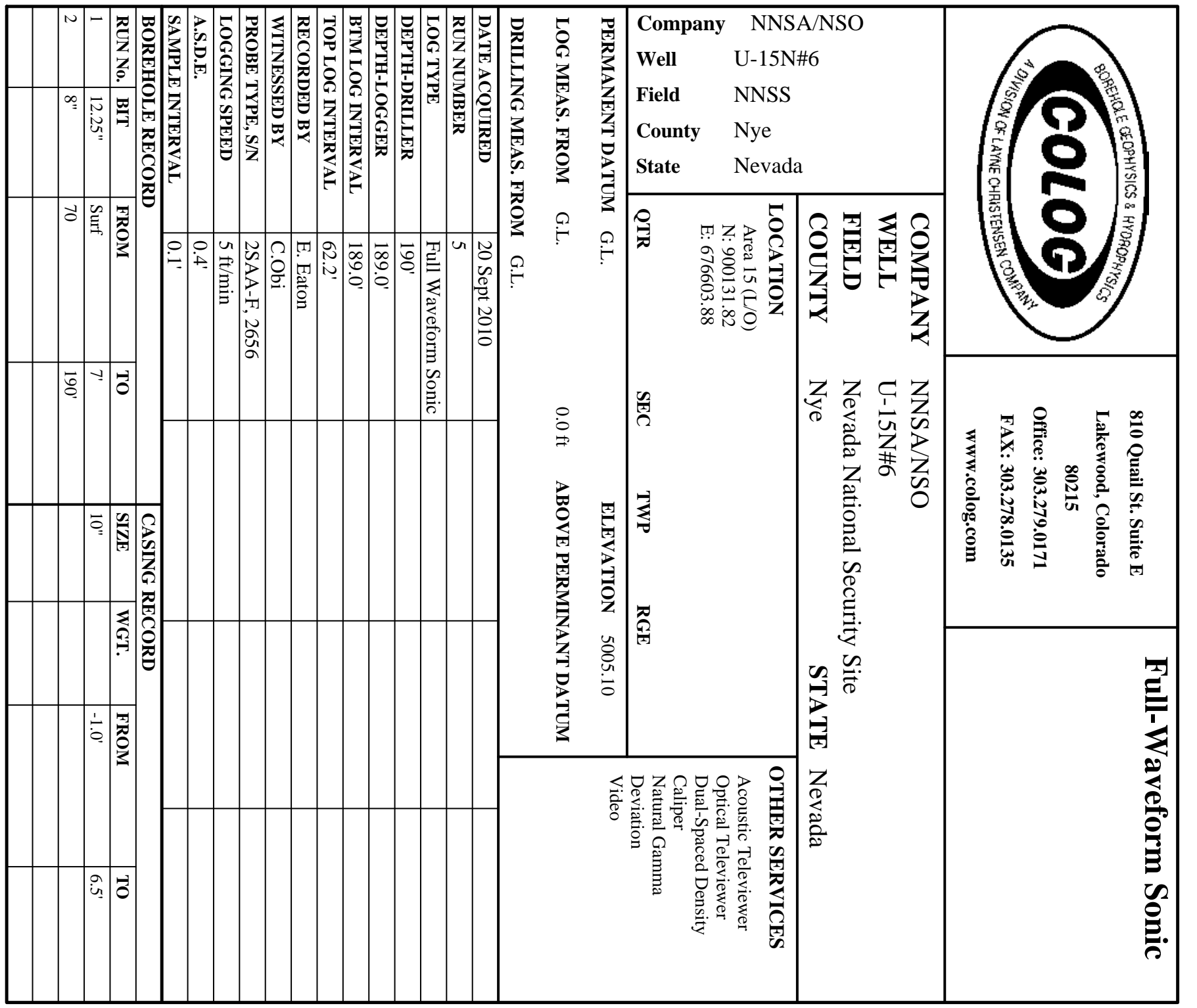




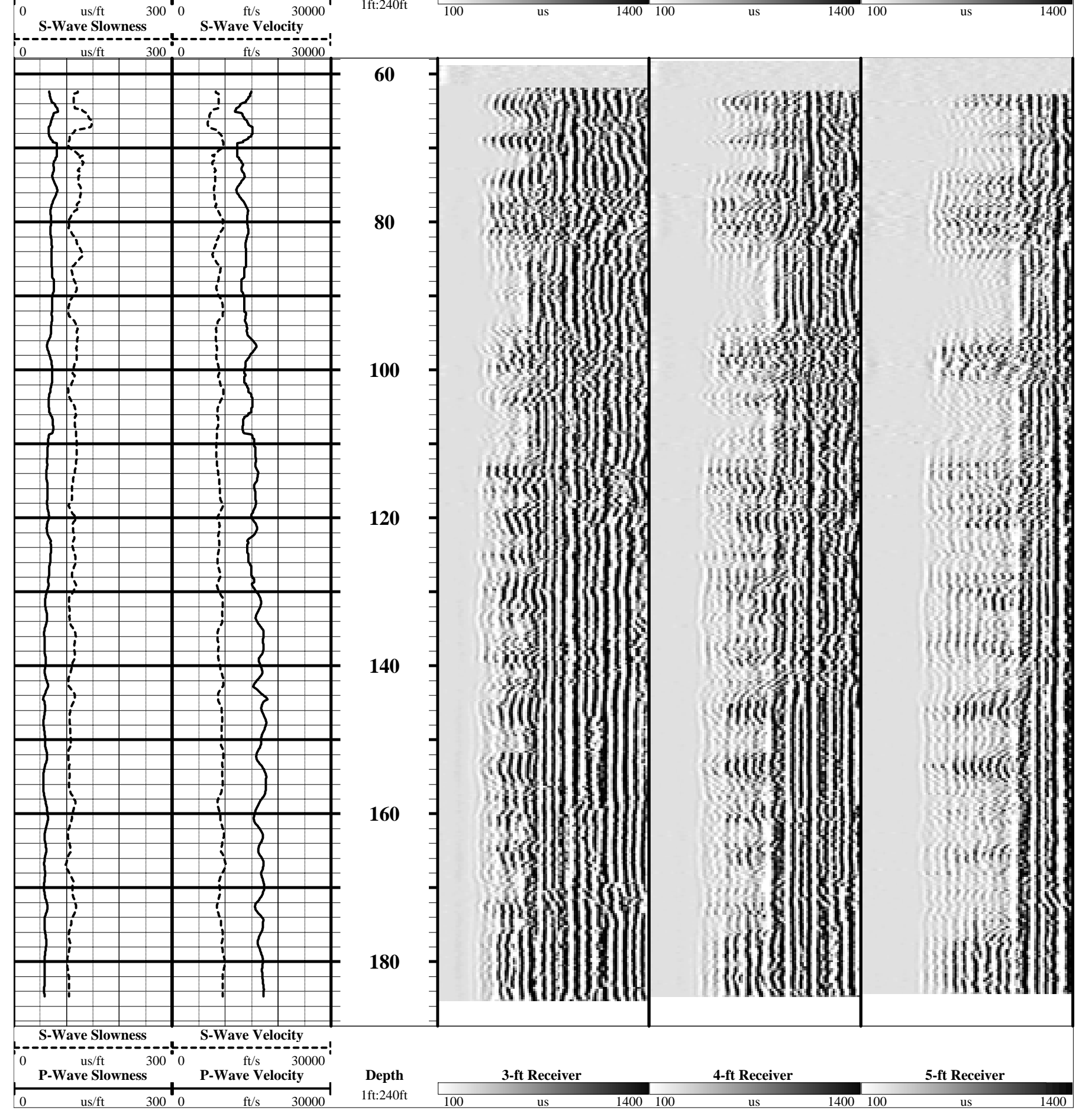




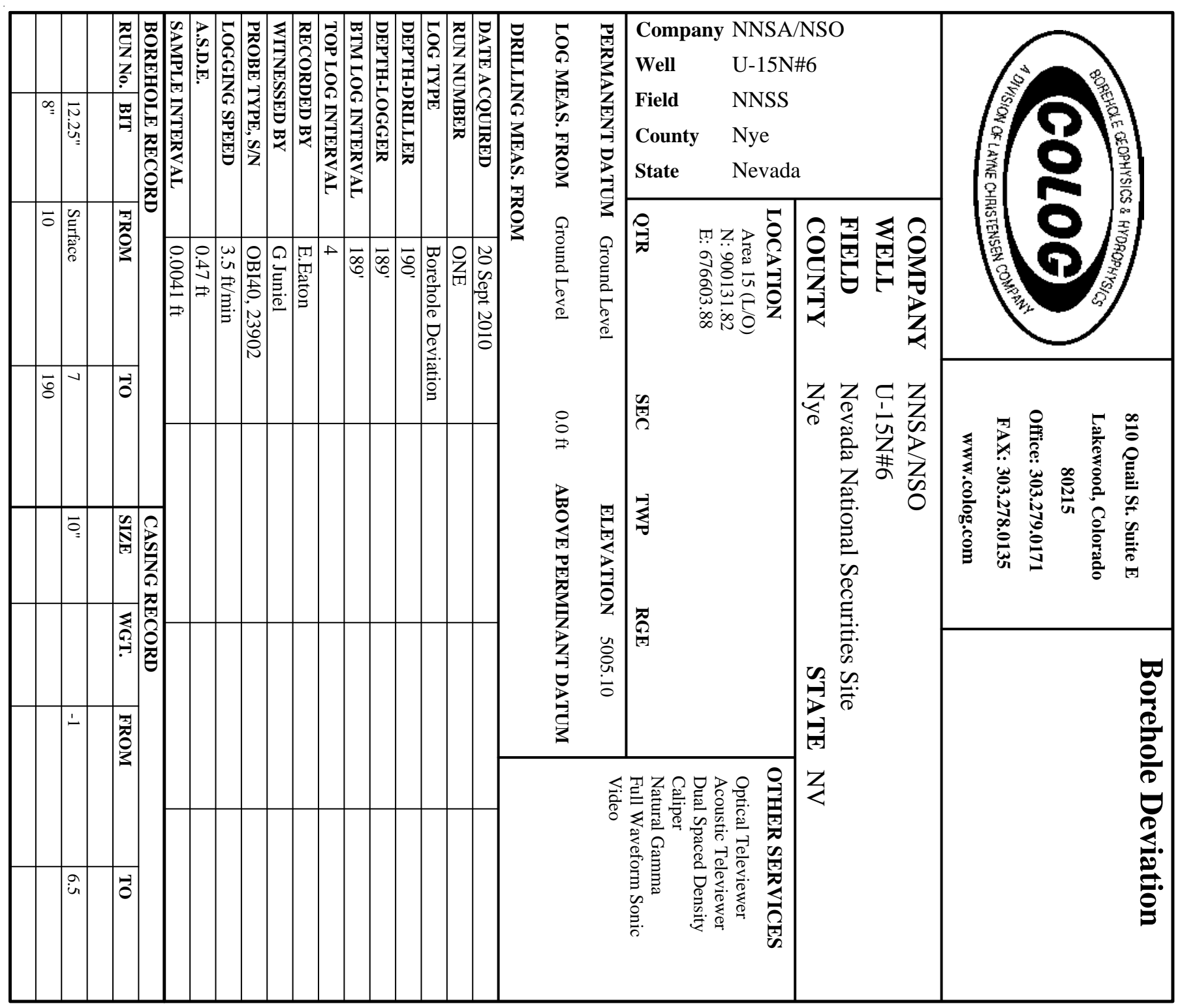

COMMENTS

NA - Not Available, N/A - Not Applicable 

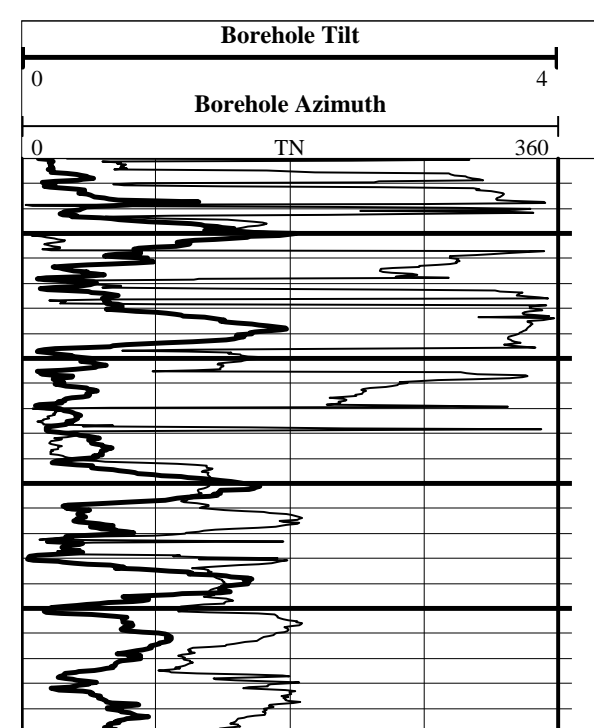

$<$

$\sum$

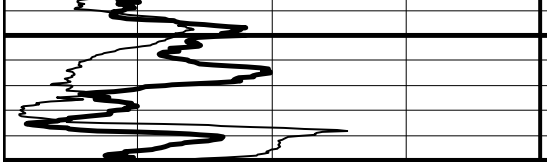

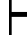

35

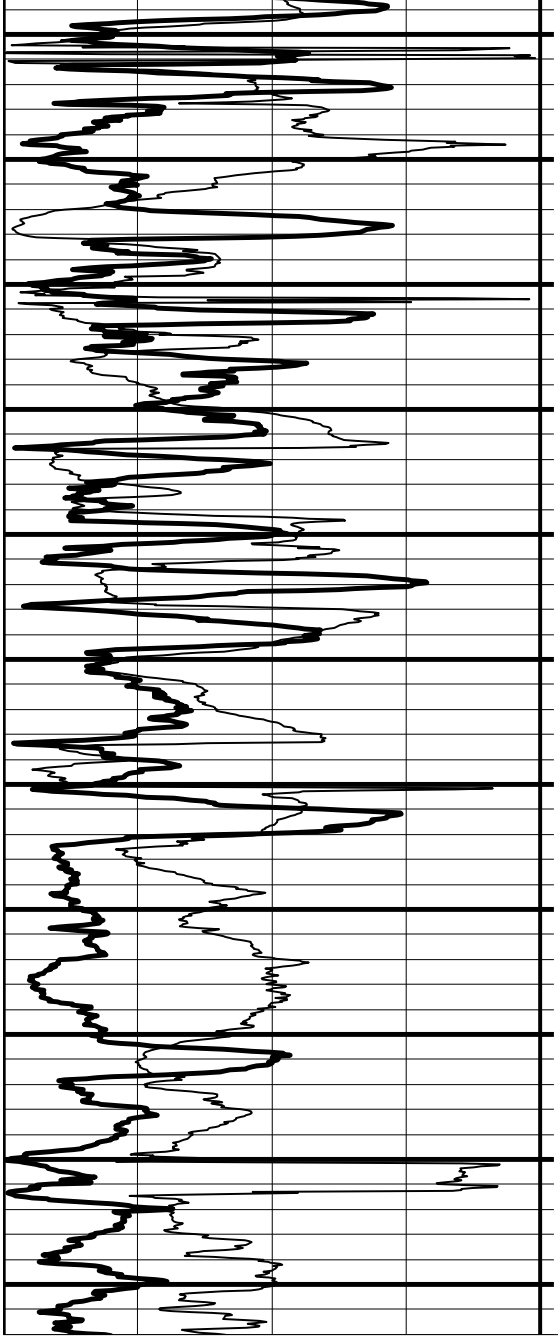

Depth

1ft:240ft

$\vdash_{-2}$

Northing

True Vertical Depth

20

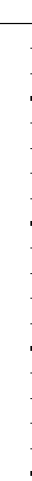

40

60

80

100
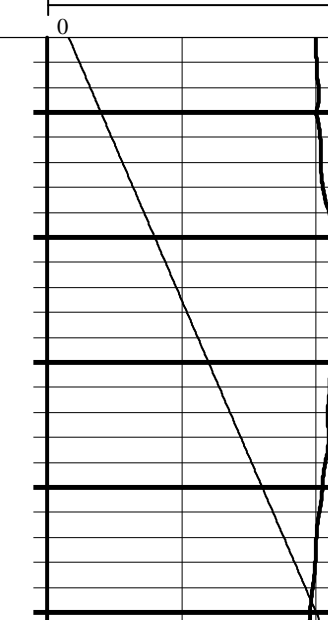

(2)

\begin{tabular}{|l|l|}
\hline & 200 \\
\hline
\end{tabular}

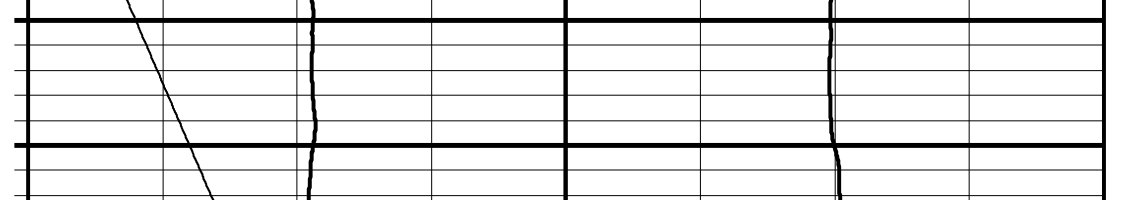

-

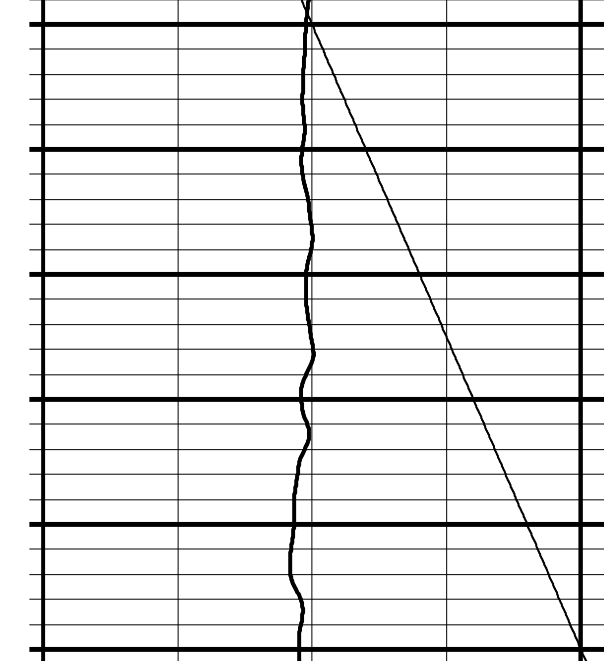

120

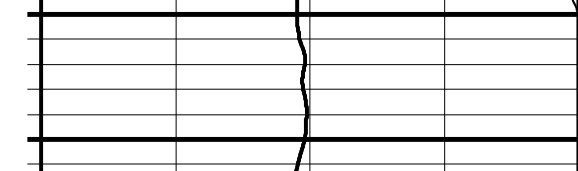

140
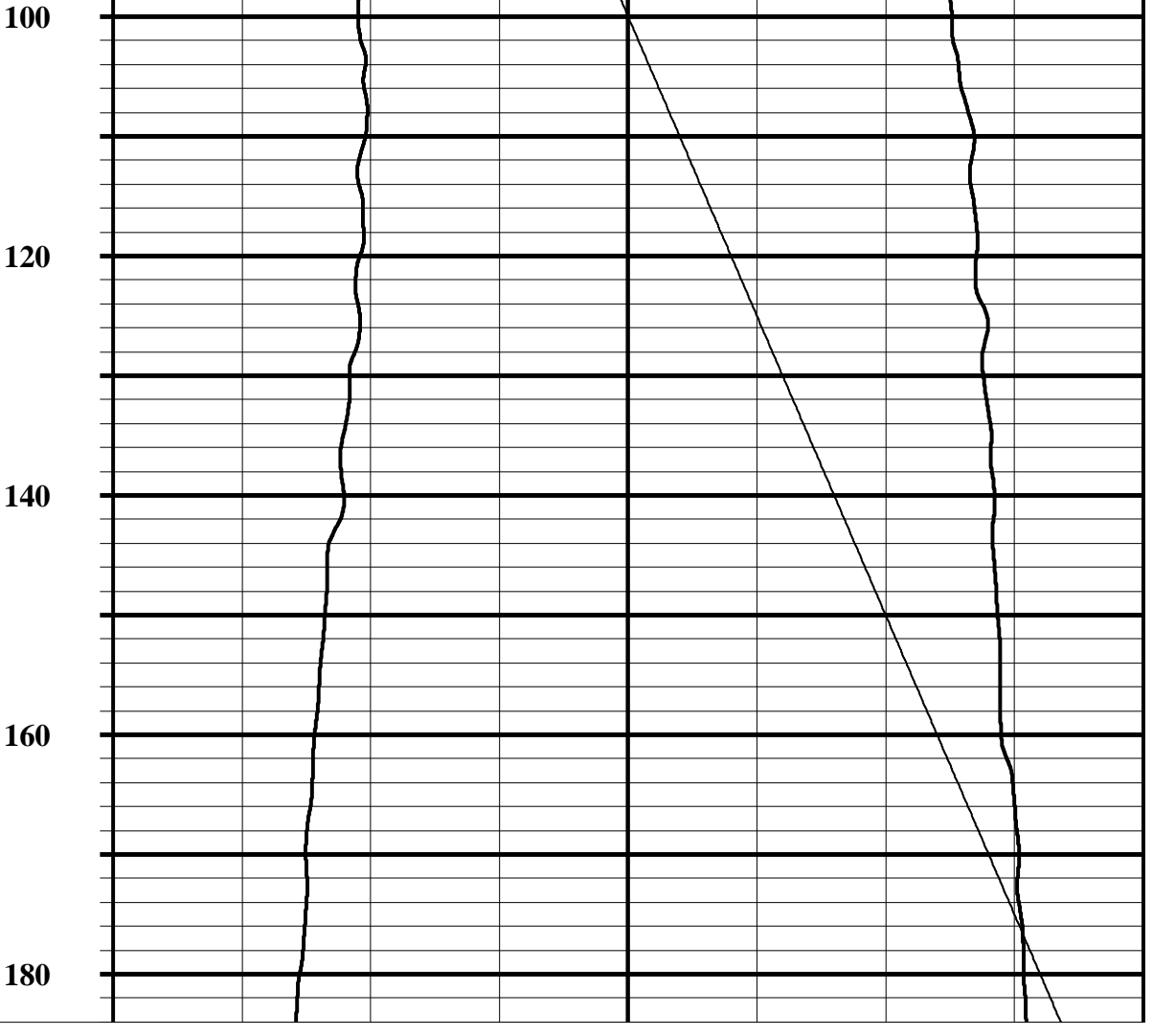


\begin{tabular}{|l|l|l|l|l|l|l|l|l|l|l|}
\hline$\rightleftharpoons 2$ & & & & & & & & & & \\
\hline
\end{tabular}

Page 3 


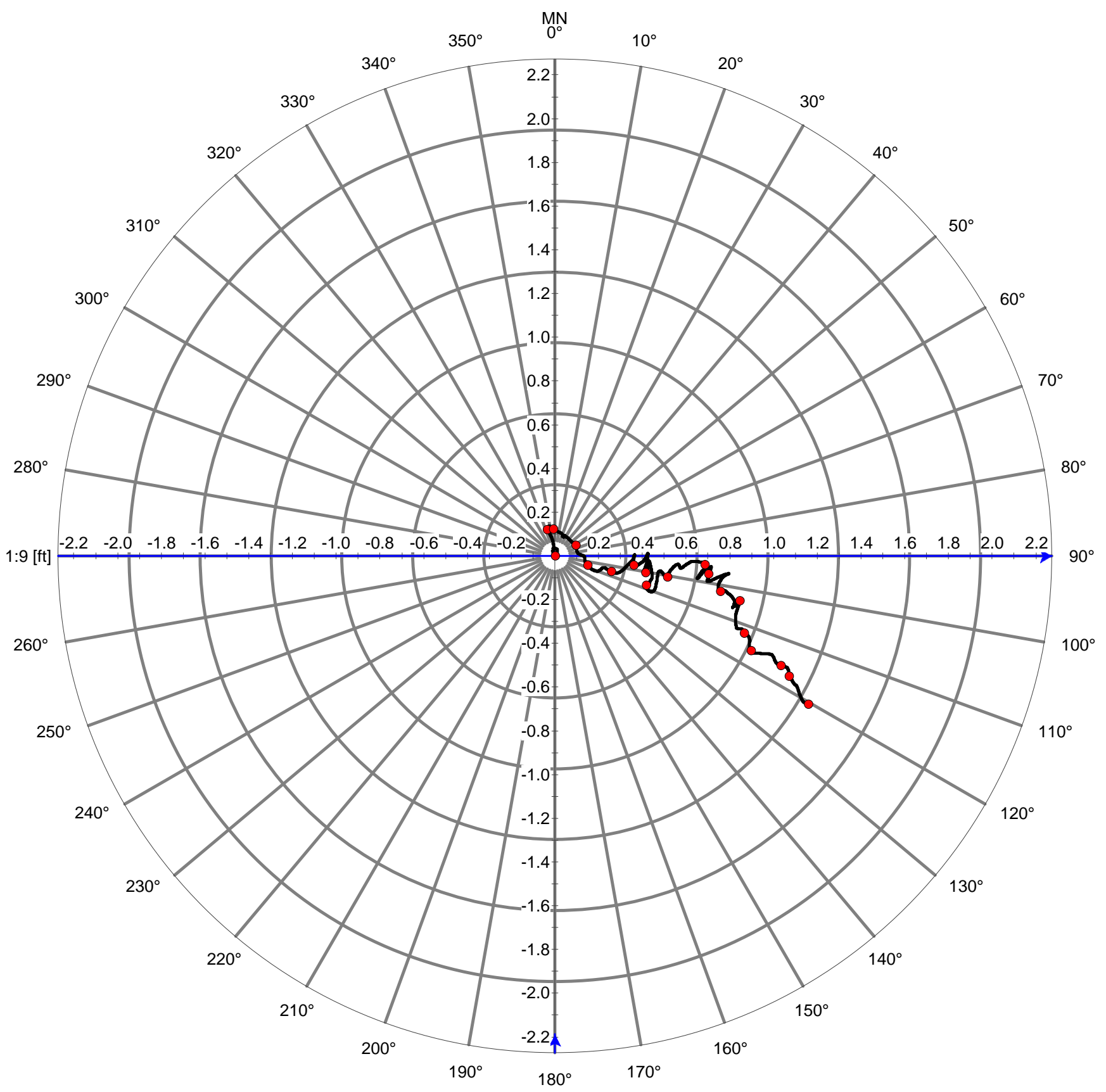




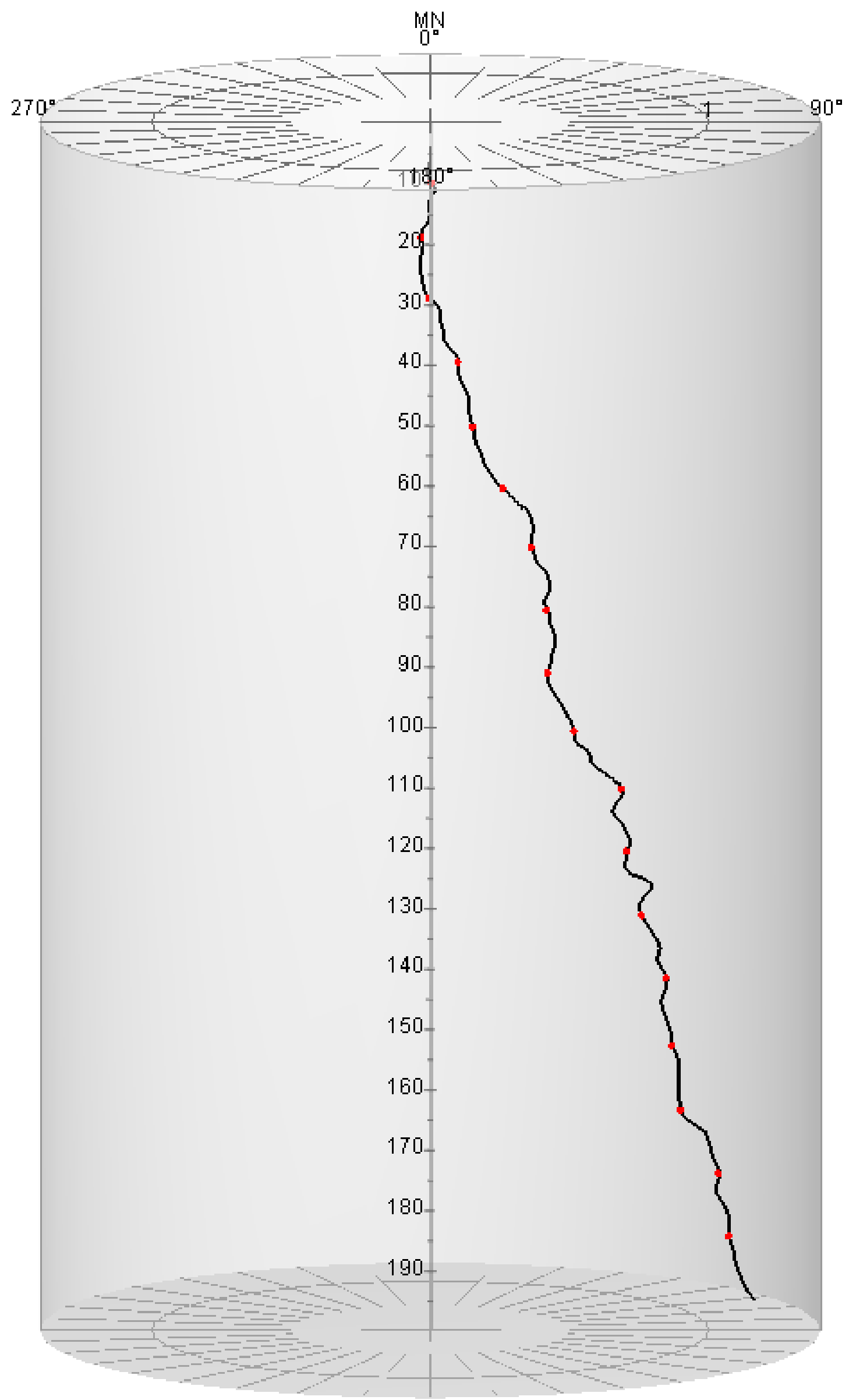




\begin{abstract}
APPENDIX G
Phase 1 Mechanical Testing Results on Core from Borehole U-15n, Nevada National Security Site, in Support of NCNS Source Physics Experiment

By

Scott Broome and Tom Pfeifle

Sandia National Laboratories
\end{abstract}

June 8, 2011 


\section{Scott T. Broome}

Member of the Technical Staff

Geomechanics Department 6914

\section{Sandia National Laboratories}

Abuquerque, NM 87185-1033

Phone: (505) 845-0541

Fax $(505)$ 284-5756

e-mailstbroom Bsandia.gov

date: June 8, 2011

to. Aviva Sussman, Christopher Bradley, Wendee Brunish (LANL), Tarabay Antoun (LLNL), Margaret Townsend (NSTec), Dennis Barker (NSTec)

from:

Scott Broome, Tom Pfeifle

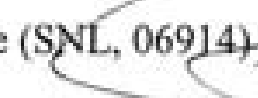

Subject:

Phase 1 mechanical testing results on core

Security Site, in support of NCNS Source Physics Experiment

\section{Background}

The Nevada National Security Site (NNSS) will serve as the geologic setting for a Source Physics Experiment (SPE) program. The SPE will provide ground truth data to create and improve strong ground motion and seismic S-wave generation and propagation models. The NNSS was chosen as the test bed because it provides a variety of geologic settings ranging from relatively simple to very complex.

Each series of SPE testing will comprise the setting and firing of explosive charges (source) placed in a central bore hole at varying depths and recording ground motions in instrumented bore holes located in two rings around the source positioned at different radii. Modeling using advanced simulation codes will be performed both a priori and after each test to predict ground response and to improve models based on acquired field data, respectively.

A key component in the predictive capability and ultimate validation of the models is the full understanding of the intervening geology between the source and the instrumented bore holes including the geomechanical behavior of the site rock/structural features. This memorandum reports on a limited scope of work for an initial phase of primarily unconfined compression testing.

Samples tested came from the U-15n core hole, which was drilled in granitic rock (quartz monzonite). The core hole was drilled at the location of the central SPE borehole, and thus represents material in which the explosive charges will be detonated. The U-15n location is the site of the first SPE, in Area 15 of the NNSS.

\section{Sample Preparation and Experimental Methods}

Specimen Preparation: Test specimens (right circular cylinders) were prepared from the 2.5 -india field core by cutting them to approximate length using a standard rock saw and then grinding 
the ends flat and parallel to final length such that the length-to-diameter ratio, L:D, on each test specimen is 2:1. Both the sawing and the grinding used standard tap water for cooling. All specimen dimensions were sized to provide representative results given the maximum grain size of this granite ranges from $0.5-6.35 \mathrm{~mm}(0.02-0.25 \mathrm{in})$. Phenocrysts in small quantities were observed along the core length and are as large as $\sim 25.4 \mathrm{~mm}$ across. The dimensions and mass of each specimen were accurately measured. Field cores used in preparing the test specimens were selected from approximately every 20 -foot interval of U-15n and had a useable length of approximately 6-7 inches so that the 5-inch-long specimens were prepared with sufficient material available near one end of each core to obtain thin sections and/or thicker billets of untested rock.

Calibration: Annual calibration of the load cell used to calculate unconfined compressive strength (UCS) is traceable to the U.S. National Institute of Standards and Technology. For all UCS tests, two strain gages were bonded at sample mid-height $180^{\circ}$ apart. A shakedown test was performed with a right circular steel specimen ( 4340 steel) instrumented with the same strain gages as those used on the SPE granite samples prior to any SPE UCS testing. The shake down test verified that all components of the test system were functioning correctly by ensuring measured properties (Young's modulus and Poisson's ratio) matched those published for 4340 steel.

Bulk Density Determination: The bulk density of each UCS test specimen was determined from its mass and volume where volume is calculated using dimensional measurements assuming a right-circular-cylindrical geometry.

Unconfined Compressive Strength (UCS) Testing: UCS tests were performed on granite specimens prepared from field cores recovered from approximately every 20 -foot interval of U$15 \mathrm{n}$. Using this strategy, tests were run on what is thought to be both weathered and fresh granite to determine if there are differences in mechanical properties over the entire core hole depth $(-200 \mathrm{ft})$. All specimens were instrumented to measure axial stress and axial and radial strains and were loaded quasi-statically in compression (axial strain rate of $\sim 1 \times 10^{-4} / \mathrm{sec}$ ) under ambient pressure and temperature conditions. Loading continued until the peak axial stress (i.e., the UCS strength) was observed. All samples were loaded to failure. However during loading, unload/reload cycles were performed at various axial stress levels to acquire data to estimate the compressive elastic properties - Young's modulus, $E_{\mathrm{c}}$ and Poisson's ratio, $v_{\mathrm{c}}$

Compressional and Shear Wave Velocity Measurements: Ultrasonic compressional and shear wave velocity measurements, $V_{p}$ and $V_{w}$ were performed on each UCS specimen under ambient conditions prior to UCS testing. Wave speed measurements were made coincident with each specimen axis and also orthogonal to the axis across two diameters separated by $90^{\circ}$.

\section{Experimental Results}

Table 1 lists the results from the unconfined compressive strength tests for borehole U-15n. Included in Table 1 are the sample number, depth, density, maximum axial stress (i.e., UCS 
strength), Young's modulus, Poisson's ratio and failure mode. Elastic properties were determined from the average of the unload portion of two unload/reload loops performed while the sample was loaded at a constant axial strain rate of $\sim 1 E-04$. Elastic properties for Sample SPE-UCS-5 were averaged from the slope during initial loading and one unload/reload cycle. Only one strain gage was used for the unload/reload cycle for this sample because the other strain gage had started to fail producing erratic data. This sample failed at the lowest stress and was from a highly altered zone adjacent to a fault. The failure mode for all samples was intact except for SPE-UCS-10. The failure mode for this sample was primarily along a pre existing weakness plane with a failure surface angle of $\sim 79^{\circ}$ where $0^{\circ}$ is perpendicular to the core axis. Samples with an intact failure mode nominally failed at angles between $70^{\circ}$ to $80^{\circ}$ resulting in a fairly intact cone on either end of the sample.

Table 1. Sample \#, Depth, Density, UCS Strength, Young's modulus, Poisson's Ratio and Failure Mode for U-15n

\begin{tabular}{|c|c|c|c|c|c|c|}
\hline Sample & Depth (ft) & Density $(\mathrm{g} / \mathrm{cc})$ & $\sigma_{\text {AX } \max }(\mathrm{MPa})$ & $E(\mathrm{GPa})$ & $v$ & Failure Mode $^{2}$ \\
\hline SPE-UCS-1 & 14 & 2.65 & 235.6 & 75.94 & 0.254 & Intact \\
\hline SPE-UCS-2* & 29 & 2.61 & 121.1 & 56.28 & 0.248 & Intact \\
\hline SPE-UCS-3 & 50 & 2.64 & 226.5 & 77.63 & 0.236 & Intact \\
\hline SPE-UCS-4 & 70 & 2.63 & 184.3 & 64.26 & 0.245 & Intact \\
\hline SPE-UCS-5 $* *$ & 87 & 2.55 & 41.6 & 35.07 & 0.16 & Intact \\
\hline SPE-UCS-6 & 108 & 2.64 & 210.2 & 70.28 & 0.218 & Intact \\
\hline SPE-UCS-7 & 132 & 2.63 & 205.4 & 76.4 & 0.201 & Intact \\
\hline SPE-UCS-8 & 154 & 2.64 & 192.8 & 75.67 & 0.232 & Intact \\
\hline SPE-UCS-9 & 177 & 2.64 & 227.8 & 77.79 & 0.24 & Intact \\
\hline SPE-UCS-10 & 192 & 2.65 & 165.8 & 76.38 & 0.22 & Intact/Fracture \\
\hline
\end{tabular}

${ }^{1}$ Intact failure mode indicates failure through intact material rather than along planes of weakness - Sample designated as weathered granite

*Sample from a highly altered zone adjacent to a fault. Elastic properties determined from initial loading and one unload/reload loop from one strain gage near failure

Sample SPE-UCS-9 had a chip on the top edge (Figure 1). It was decided to test the sample with the chip rather than cut it shorter and violate the 2:1 length-to-diameter ratio criterion. This sample failed at the highest stress and thus the chip was not likely to have significantly altered the UCS strength. Figure 2 shows a typical sample, complete with strain gages, mounted in the 5 $\mathrm{MN}$ load frame. The plastic curtain surrounding the loading platens ensured most tested pieces of the sample could be retained in the event of catastrophic failure. Plots of Engineering Axial Stress versus Axial, Lateral, and Volume strain for all ten UCS tests are presented at the end of this report. For these plots, volumetric strain is calculated from the axial and radial strains, i.e., $\varepsilon_{\mathrm{s}}=\varepsilon_{\mathrm{ax}}+2 \varepsilon_{\text {rad. }}$

Tables 2, 3 and 4 list the results from ultrasonic compressional and shear wave velocity measurements taken coincident with each specimen axis and also orthogonal to the axis across two diameters separated by $90^{\circ}$ respectively. The S Wave parallel to the core axis for sample 
SPE-UCS-3 was ambiguous and $v$ dynamic is not reported. Figure 3 shows a typical voltage versus time plot used to determine $\mathrm{P}$ and $\mathrm{S}$ wave velocities.

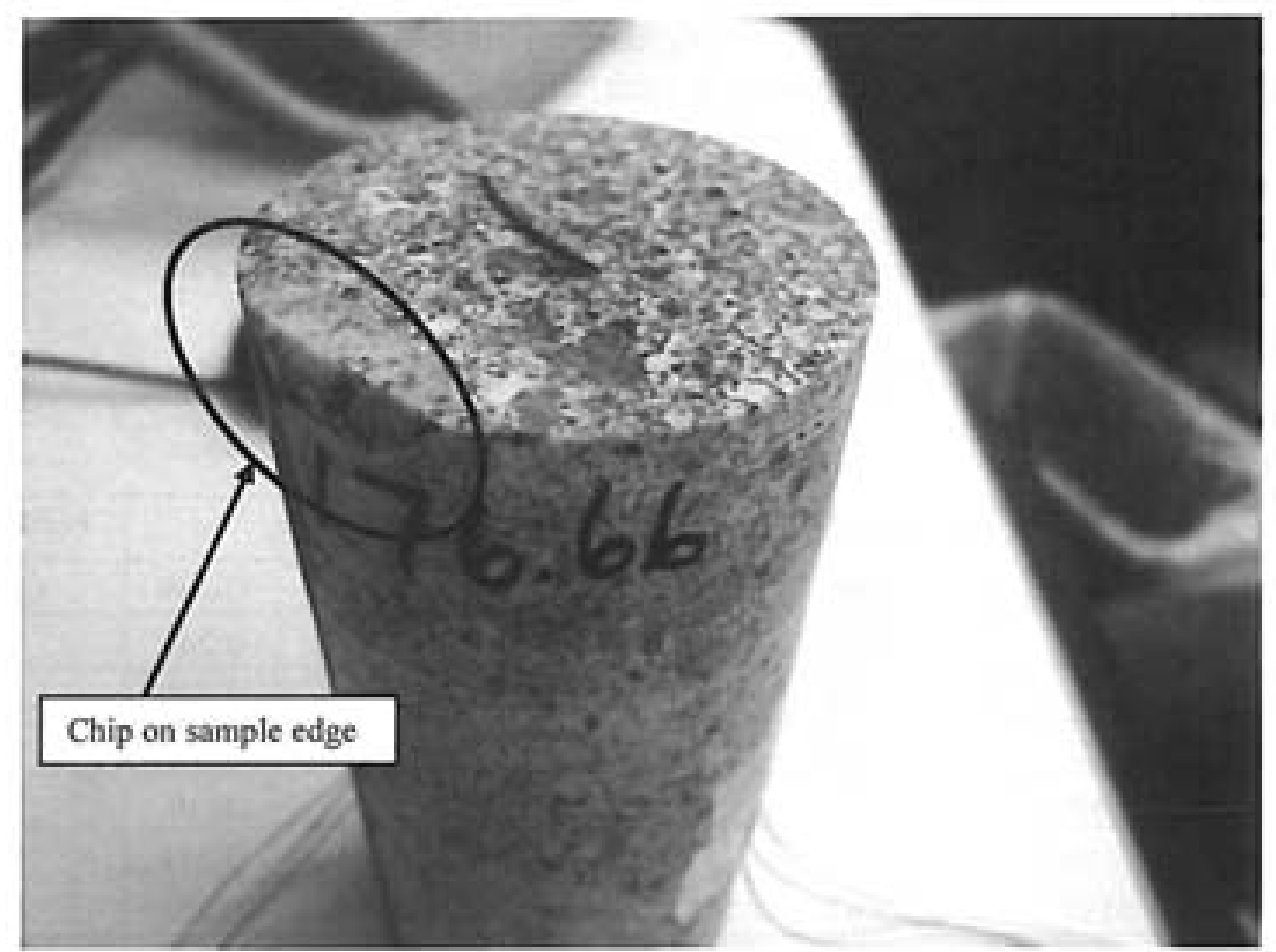

Figure 1. Sample SPE-UCS-9 with a chip on the top edge. 


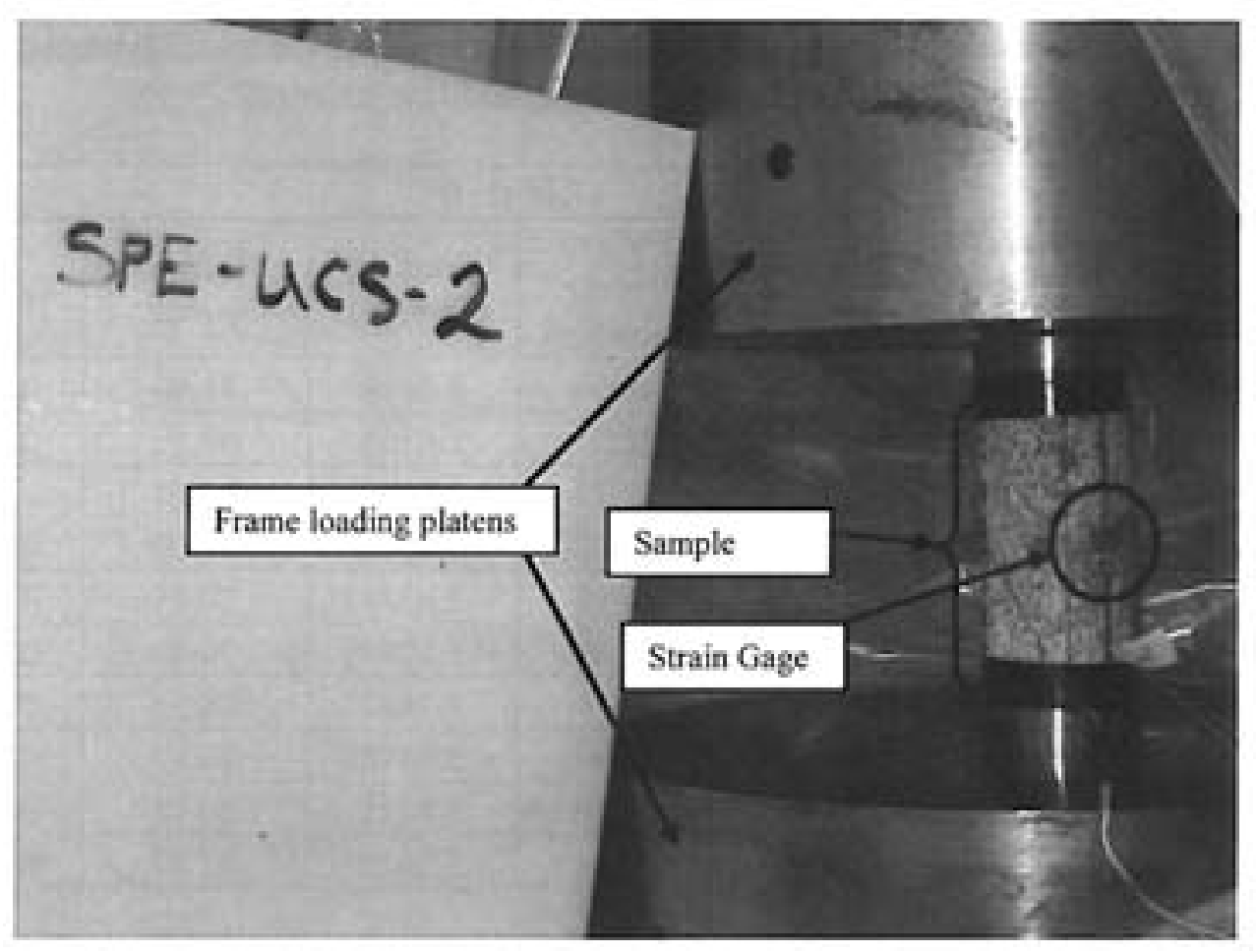

Figure 2. Sample SPE-UCS-2 mounted in load frame.

Table 2. P-and S-wave travel time and velocity and calculated values of dynamic $E$ and $v$ along core axis

\begin{tabular}{|c|c|c|c|c|c|c|}
\hline \multirow[b]{2}{*}{ Sample \# } & \multicolumn{6}{|c|}{ Axial } \\
\hline & $\begin{array}{c}\text { P Wave } \\
\text { Travel } \\
\text { Time ( } \mu s)\end{array}$ & $\begin{array}{c}\text { P-Velocity } \\
\text { (mm/ } \mathrm{ms} \text { ) }\end{array}$ & $\begin{array}{c}\text { S-Wave } \\
\text { Travel } \\
\text { Time ( } \mu \text { s) }\end{array}$ & $\begin{array}{c}\text { S-Velocity } \\
\text { (mm/ } \mathrm{ms} \text { ) }\end{array}$ & $\begin{array}{l}\text { EDramik } \\
\text { (GPa) }\end{array}$ & Voynamie \\
\hline SPE-UCS-1 & 22.02 & 5.8344 & 37.24 & 3.4325 & 77.01 & 0.235 \\
\hline SPE-UCS-2 & 27.44 & 4.6883 & 43.36 & 2.9562 & 53.40 & 0.170 \\
\hline SPE-UCS-3* & 21.19 & 6.1132 & 29.01 & 4.4499 & 97.94 & $N / A^{*}$ \\
\hline SPE-UCS-4 & 22.55 & 5.7025 & 36.55 & 3.5020 & 77.22 & 0.197 \\
\hline SPE-UCS-5 & 26.44 & 4.8752 & 40.59 & 3.1643 & 58.11 & 0.136 \\
\hline SPE-UCS- 6 & 22.20 & 5.8016 & 36.36 & 3.5253 & 79.23 & 0.207 \\
\hline SPE-UCS-7 & 22.08 & 5.8195 & 36.53 & 3.5004 & 78.41 & 0.217 \\
\hline SPE-UCS- 8 & 21.79 & 5.9275 & 37.26 & 3.4485 & 78.25 & 0.244 \\
\hline SPE-UCS-9 & 22.09 & 5.8879 & 38.43 & 3.3667 & 75.33 & 0.257 \\
\hline SPE-UCS-10 & 21.90 & 5.9079 & 36.03 & 3.5735 & 81.86 & 0.212 \\
\hline
\end{tabular}

•For Axial direction on sample SPE-UCS-3, S Wave was ambiguous 
Table 3. P-and S-wave travel time and velocity and calculated values of dynamic $E$ and $v$ orthogonal to core axis (along red line on core)

\begin{tabular}{|c|c|c|c|c|c|c|}
\hline \multirow[b]{2}{*}{ Sample \# } & \multicolumn{6}{|c|}{ Radial - $0^{\circ}$} \\
\hline & $\begin{array}{c}\text { P-Wave } \\
\text { Travel } \\
\text { Time ( } \mu \text { s) }\end{array}$ & $\begin{array}{l}\text { P-Velocity } \\
\text { (mm/ } / \mu \mathrm{s} \text { ) }\end{array}$ & $\begin{array}{c}\text { S-Wave } \\
\text { Travel } \\
\text { Time ( } \mu s)\end{array}$ & $\begin{array}{l}\text { S-Velocity } \\
\text { (mm/us) }\end{array}$ & $\begin{array}{l}\text { EOmamic } \\
(\mathrm{GPa})\end{array}$ & $V_{\text {Dynamic }}$ \\
\hline SPE-UCS-1 & 11.64 & 5.5804 & 18.96 & 3.3948 & 73.56 & 0.206 \\
\hline SPE-UCS-2 & 14.19 & 4.5381 & 22.54 & 2.8365 & 49.56 & 0.179 \\
\hline SPE-UCS-3 & 10.47 & 6.1757 & 17.73 & 3.6078 & 85.31 & 0.241 \\
\hline SPE-UCS-4 & 11.43 & 5.6718 & 18.32 & 3.5067 & 77.00 & 0.191 \\
\hline SPE-UCS-5 & 14.16 & 4.5552 & 21.81 & 2.9374 & 50.43 & 0.144 \\
\hline SPE-UCS-6 & 11.04 & 5.8819 & 18.35 & 3.5037 & 79.41 & 0.225 \\
\hline SPE-UCS-7 & 10.95 & 5.9386 & 17.2 & 3.7462 & 86.33 & 0.170 \\
\hline SPE-UCS-8 & 11.18 & 5.8110 & 18.14 & 3.5478 & 80.07 & 0.203 \\
\hline SPE-UCS-9 & 10.82 & 6.0165 & 16.88 & 3.8215 & 89.71 & 0.162 \\
\hline SPE-UCS-10 & 11.04 & 5.8960 & 18 & 3.5815 & 81.97 & 0.208 \\
\hline
\end{tabular}

Table 4. P- and S-wave travel time and velocity and calculated values of dynamic $E$ and $v$ orthogonal to core axis (perpendicular to red line on core)

Radial - $90^{\circ}$

\begin{tabular}{|c|c|c|c|c|c|c|}
\hline Sample \# & $\begin{array}{c}\text { P-Wave } \\
\text { Travel } \\
\text { Time ( } \mu \mathrm{s})\end{array}$ & $\begin{array}{c}\text { P-Velocity } \\
\text { (mm/ } \mu \mathrm{s})\end{array}$ & $\begin{array}{c}\text { S-Wave } \\
\text { Travel } \\
\text { Time }(\mu \mathrm{s})\end{array}$ & $\begin{array}{c}\text { S-Velocity } \\
(\mathrm{mm} / \mu \mathrm{s})\end{array}$ & $\begin{array}{c}E_{\text {Dmamic }} \\
(\mathrm{GPa})\end{array}$ & $\mathrm{V}_{\text {Dramic }}$ \\
\hline SPE-UCS-1 & 11.56 & 5.6199 & 18.56 & 3.4691 & 75.91 & 0.192 \\
\hline SPE-UCS-2 & 14.53 & 4.4299 & 22.8 & 2.8038 & 47.87 & 0.166 \\
\hline SPE-UCS-3 & 10.42 & 6.2061 & 17.6 & 3.6349 & 86.45 & 0.239 \\
\hline SPE-UCS-4 & 11.42 & 5.6768 & 18.78 & 3.4196 & 74.74 & 0.215 \\
\hline SPE-UCS-5 & 13.77 & 4.6868 & 21.3 & 3.0086 & 53.15 & 0.150 \\
\hline SPE-UCS-6 & 11.22 & 5.7852 & 18.74 & 3.4298 & 76.34 & 0.229 \\
\hline SPE-UCS-7 & 10.91 & 5.9609 & 18.46 & 3.4867 & 79.29 & 0.240 \\
\hline SPE-UCS-8 & 11.16 & 5.8217 & 18.51 & 3.4758 & 78.14 & 0.223 \\
\hline SPE-UCS-9 & 10.95 & 5.9433 & 17.14 & 3.7626 & 87.24 & 0.166 \\
\hline SPE-UCS-10 & 11.01 & 5.9125 & 17.25 & 3.7397 & 86.33 & 0.167 \\
\hline
\end{tabular}




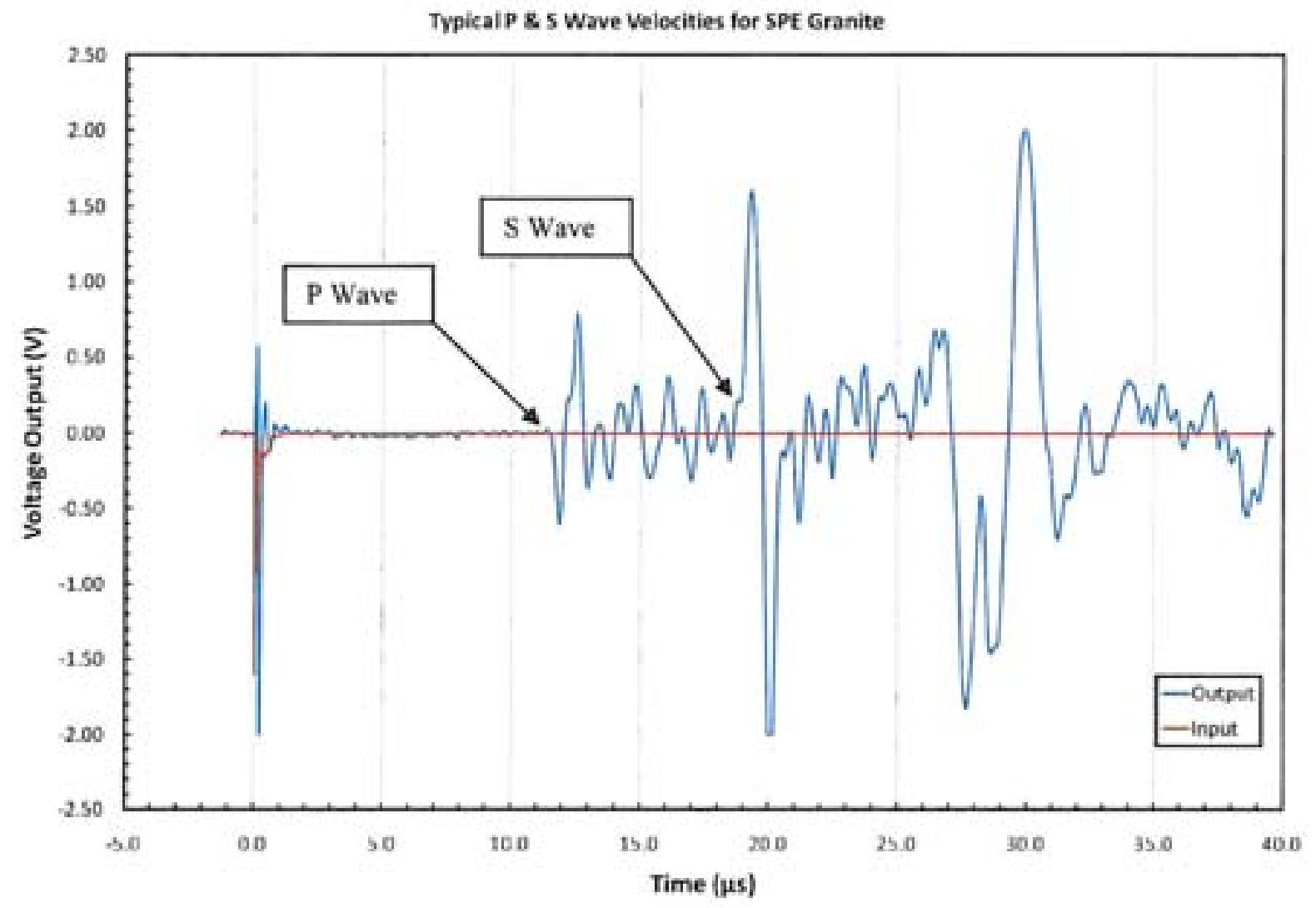

Figure 3. Typical velocity profile for determination of $\mathrm{P} \& \mathrm{~S}$ wave speed.

The dynamic elastic Young's modulus, $\mathrm{E}_{\text {dynamic }}$ was determined directly from:

$$
E_{\text {dymamic }}=\frac{\rho V_{s}^{2}\left(3 V_{p}^{2}-4 V_{s}^{2}\right)}{\left(V_{p}^{2}-V_{s}^{2}\right)}
$$

Where $\rho$ is the sample density and $\mathrm{V}_{\mathrm{P}}$ and $\mathrm{V}_{\mathrm{S}}$ are the compressional and shear wave velocities, respectively. Values of dynamic elastic Poisson's ratio, $v_{d \text { mmamic }}$, were calculated from:

$$
v_{d y m a m i c}=\frac{\left(V_{P}^{2}-2 V_{s}^{2}\right)}{2\left(V_{P}^{2}-V_{s}^{2}\right)}
$$

Dynamic Young's modulus ranges from approximately 47.9 to $97.9 \mathrm{GPa}$ and Poisson's ratio ranges from approximately 0.14 to 0.26 for all samples measured in the axial direction. 


\section{Analysis of Results}

Figure 4 plots density, unconfined compressive strength, Young's modulus and Poisson's ratio as functions of depth. Density is reasonably uniform over the cored interval, i.e., $-2.63 \mathrm{~g} / \mathrm{cc}$, with the exception of two depths, $-29 \mathrm{ft}$ and $-87 \mathrm{ft}$ where it decreases slightly to $2.61 \mathrm{~g} / \mathrm{cc}$ and somewhat more to $2.55 \mathrm{~g} / \mathrm{cc}$. Unconfined compressive strength, Young's modulus and Poisson's ratio follow this trend. The unconfined compressive strength is nominally $200 \mathrm{MPa}$ or greater over the cored depth; however, at depths of $-29 \mathrm{ft},-87 \mathrm{ft}$ and $-192 \mathrm{ft}$, the strength drops off to 121,42 and $166 \mathrm{MPa}$, respectively.

As discussed above, Young's modulus was determined using two methods: 1) directly from stress-strain data acquired during quasi-static unload/reload cycles and 2) indirectly calculated from density and compressional and shear wave velocity measurements. The values of Young's Modulus determined from the quasi-static testing were nominally $76 \mathrm{GPa}$ with lower values found from cores recovered at depths of $-29 \mathrm{ft}(56 \mathrm{GPa})$ and $-87 \mathrm{ft}(35 \mathrm{GPa})$. The values determined indirectly (dynamic methods) were consistently higher than the quasi-static values as expected except for cores recovered from near the surface $(-14 \mathrm{ft}$ and $-29 \mathrm{ft})$. For the deeper cores, the dynamic moduli were about 5 to $20 \%$ higher than the quasi-static values except at a depth of $-87 \mathrm{ft}$ where the dynamic modulus was about $50 \%$ higher. There was no observable difference in Poisson's ratio using either the quasi-static or dynamic methods. In general, the values of Poisson's ratio (both measured quasi-statically and dynamically) ranged from about 0.15 to 0.25 .

Compressional and shear wave velocities are plotted as a function of depth for measurements made parallel (axial) and normal (radial) to the specimen central axis in Figure 5. With the exception of measurements made at depths of $-29 \mathrm{ft}$ and $-87 \mathrm{ft}$, compressional wave velocities are $-5,900 \mathrm{~m} / \mathrm{sec}$. At $-29 \mathrm{ft}$ and $-87 \mathrm{ft}$, the compressional wave velocities are $-4,500 \mathrm{~m} / \mathrm{sec}$ and $-4,700 \mathrm{~m} / \mathrm{sec}$, respectively. The shear wave velocities are $\sim 3,600 \mathrm{~m} / \mathrm{sec}$ but drop somewhat at $-29 \mathrm{ft}$ and $-87 \mathrm{ft}$ to $-2,900 \mathrm{~m} / \mathrm{sec}$ and $-3,000 \mathrm{~m} / \mathrm{sec}$, respectively. Within the variability of the measurements, it appears there is no significant difference in velocities when measured parallel or normal to the specimen axis implying the recovered cores are reasonably isotropic (from a mechanical point of view). 

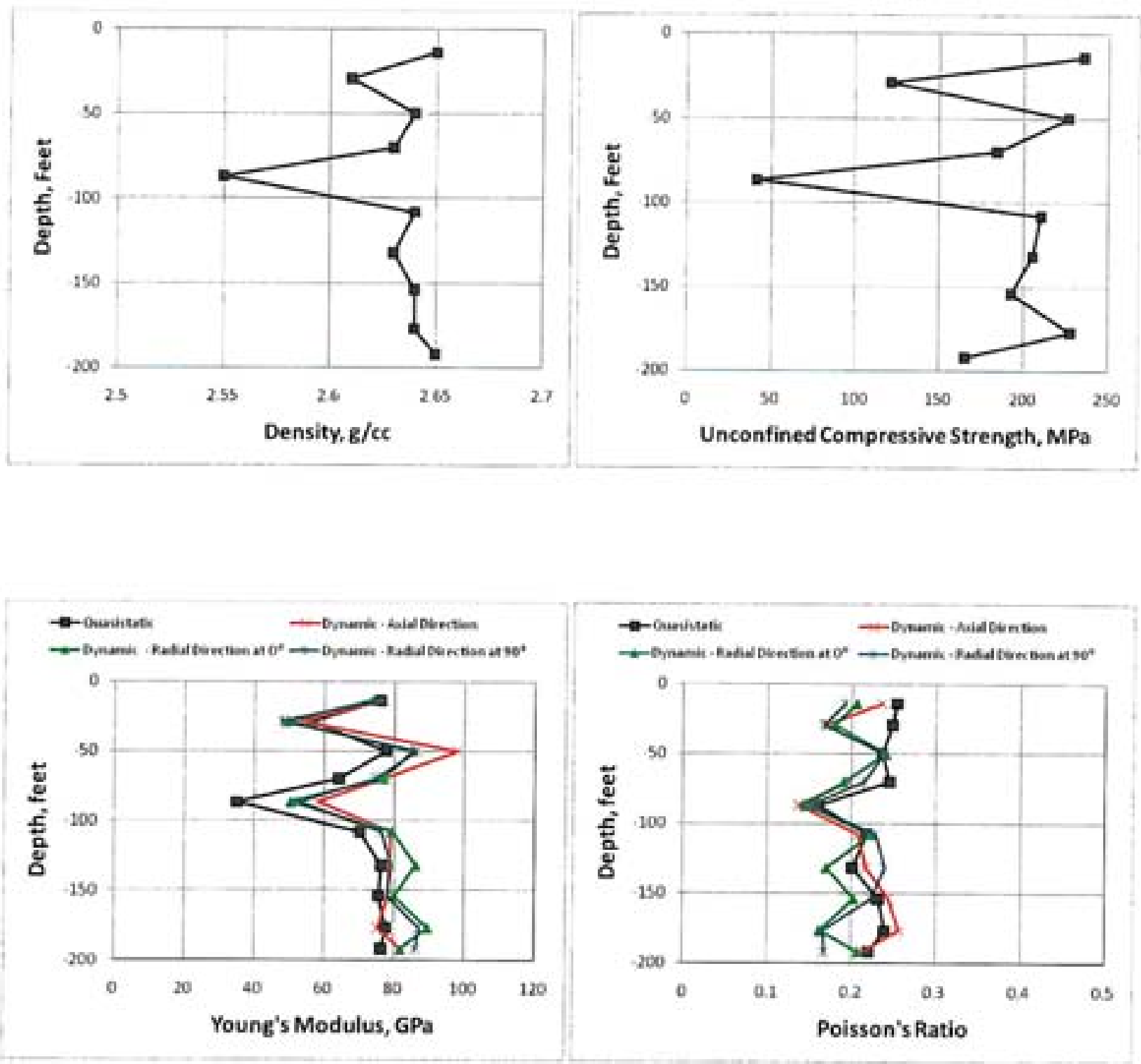

Figure 4. Density, UCS strength, Young's modulus and Poisson's ratio as functions of depth for Borehole U15-n. 

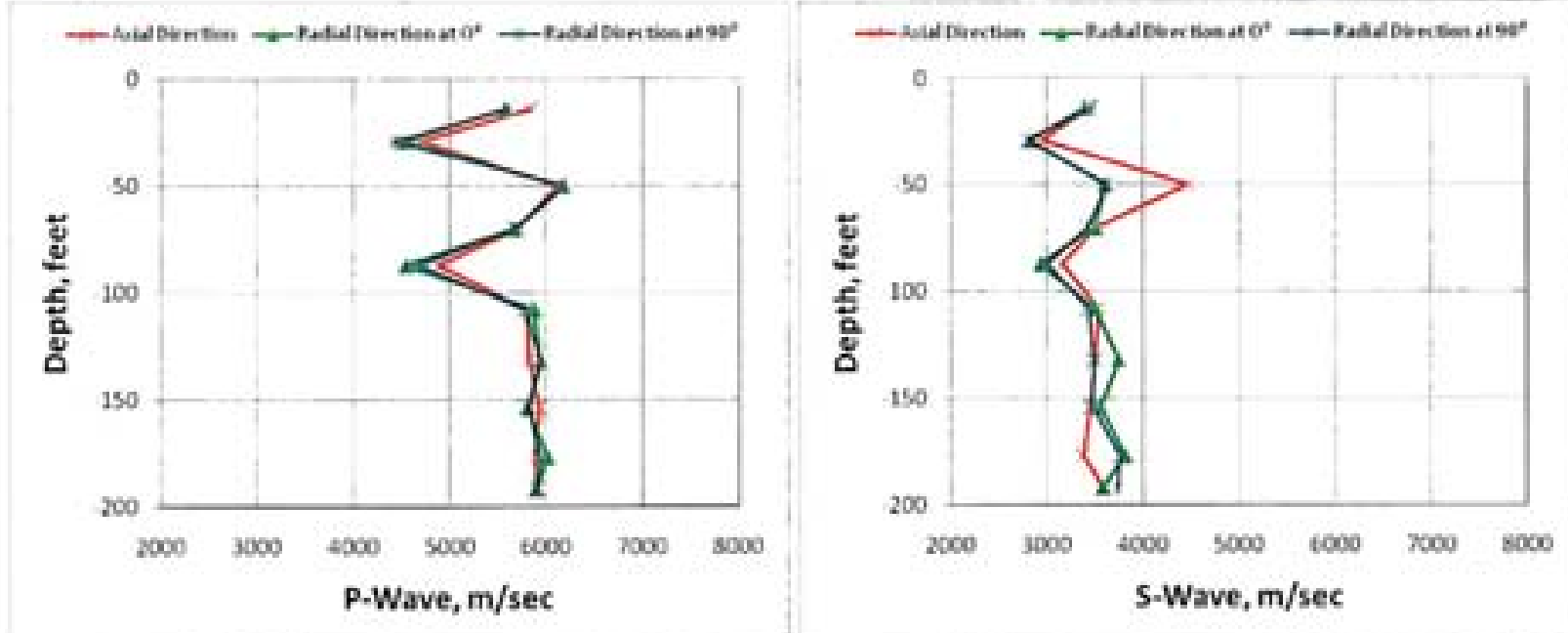

Figure 5. Compressional and shear wave velocities as functions of depth for Borehole U15-n.

A limited literature search was conducted to find relevant data sets that could be used for comparison with data acquired under this testing program. Schock et al (1973)' published data from quasi-static tests conducted on granodiorite samples recovered from the Climax stock, Area 15, Nevada National Security Site, Nye County, Nevada. Tests included hydrostatic compression to $4 \mathrm{GPa}$, triaxial compression at various confining pressures up to $700 \mathrm{MPa}$ and uniaxial strain. The granodiorite tested in their study had a material density of $2.67 \mathrm{~g} / \mathrm{cc}$ and a porosity of $\sim 0.7 \%$. Although Schock et al did not conduct any unconfined tests, they did perform one test at a confining pressure of 1 bar $(0.1 \mathrm{MPa})$. From plots presented in their paper, estimates of compressive strength, Young's modulus and Poisson's ratio were determined to be $-220 \mathrm{MPa}, 60 \mathrm{GPa}$ and $0.2-0.3$, respectively. These values are in reasonably good agreement with those determined from the current study if values from depths of $-29 \mathrm{ft}$ and $-87 \mathrm{ft}$ are not used in the comparison. Wilder and Yow $(1987)^{2}$ presented data acquired from tests on Climax stock samples comprising granodiorite and quartz monzonite and also summarized data from Pratt el al. The quartz monzonite tested in this second study had a density of $2.635 \mathrm{~g} / \mathrm{cc}$ and a porosity of $3.2 \%$. Properties reported in this study for UCS strength, Young's modulus and Poisson's ratio were $200 \mathrm{MPa}, 48 \mathrm{GPa}$, and 0.21 . With the exception of Young's modulus which is somewhat lower than in the current study, these properties compare favorably with those measured in the current study, again assuming the values obtained at depths of $-29 \mathrm{ft}$ and $-87 \mathrm{ft}$ are not used in the comparison. Wilder and Yow also reported a dynamic Young's modulus of $82.8 \mathrm{GPa}$, and compressional and shear wave velocities of $6,058 \mathrm{~m} / \mathrm{sec}$ and $3,541 \mathrm{~m} / \mathrm{sec}$, respectively, all of which are in very good agreement with the current study (with the exception of properties measured at depths of $-29 \mathrm{ft}$ and $-87 \mathrm{ft}$ ). Both data sets presented in the referenced reports are from depths of $942 \mathrm{ft}$ (HARD HAT) to $1519 \mathrm{ft}$ (PILE DRIVER) below ground surface; deeper than the current tested range of $14 \mathrm{ft}$ to $192 \mathrm{ft}$.

\footnotetext{
' Schock, R.N., H.C. Heard, and D.R. Stephens, 1973. "Stress-Strain Behavior of a Granodiorite and Two Graywackes on Compression to 20 Kilobars," $J$, of Geophysical Research, Vol 78, No. 26, September.

"Wilder, D.G. and J.L. Yow, Jr., 1987. "Geomechanics of the Spent Fuel Test - Climax," UCRL.-53767, prepared by Lawrence Livermore National Laboratory, Livermore, CA, July.
} 


\section{Recommendations for Additional Studies}

Split Hopkinson Pressure Bar: As an option, additional UCS tests could be performed at higher strain rates (500-2000/sec) using the Split Hopkinson Pressure Bar (SHPB) technique to evaluate the effects of strain rate on such mechanical properties as strength and elastic moduli. By combining the quasi-static and SHPB test results, strain rate effects over 6 to 7 orders of magnitude could be examined.

Two waxed samples (to preserve in situ moisture content), also from bore hole U-15n with depths of 50 and $157 \mathrm{ft}$, may be tested pending discussion of the results from this Phase 1 testing program. With the limited funding available, SHPB tests may be of higher priority than in situ moisture quasi-static UCS tests.

Optical Microscopy Thin Sections: Three polished dye-impregnated thin sections (mounted on $24 \times 46 \mathrm{~mm}$ slides) were prepared both from the untested end pieces of core saved during specimen preparation and from each of the tested UCS specimens. The thin sections for each end piece and tested specimen were oriented to coincide with three orthogonal directions. It is assumed that examination of the sections through optical microscopy will be performed by LANL under separate funding. As an option, thicker billet sections could also be fabricated using the same impregnation procedure as the thin sections. These billets could then be imaged using other techniques such as laser scanning confocal microscopy and/or focused ion beam/scanning electron beam microscopy (FIB/SEM) to obtain three-dimensional images of the pore/microfracture network. This option includes only the preparation of the thicker billets and not the actual imaging. 
Plots of Engineering Axial Stress versus Axial, Lateral, and Volume strain for all UCS tests

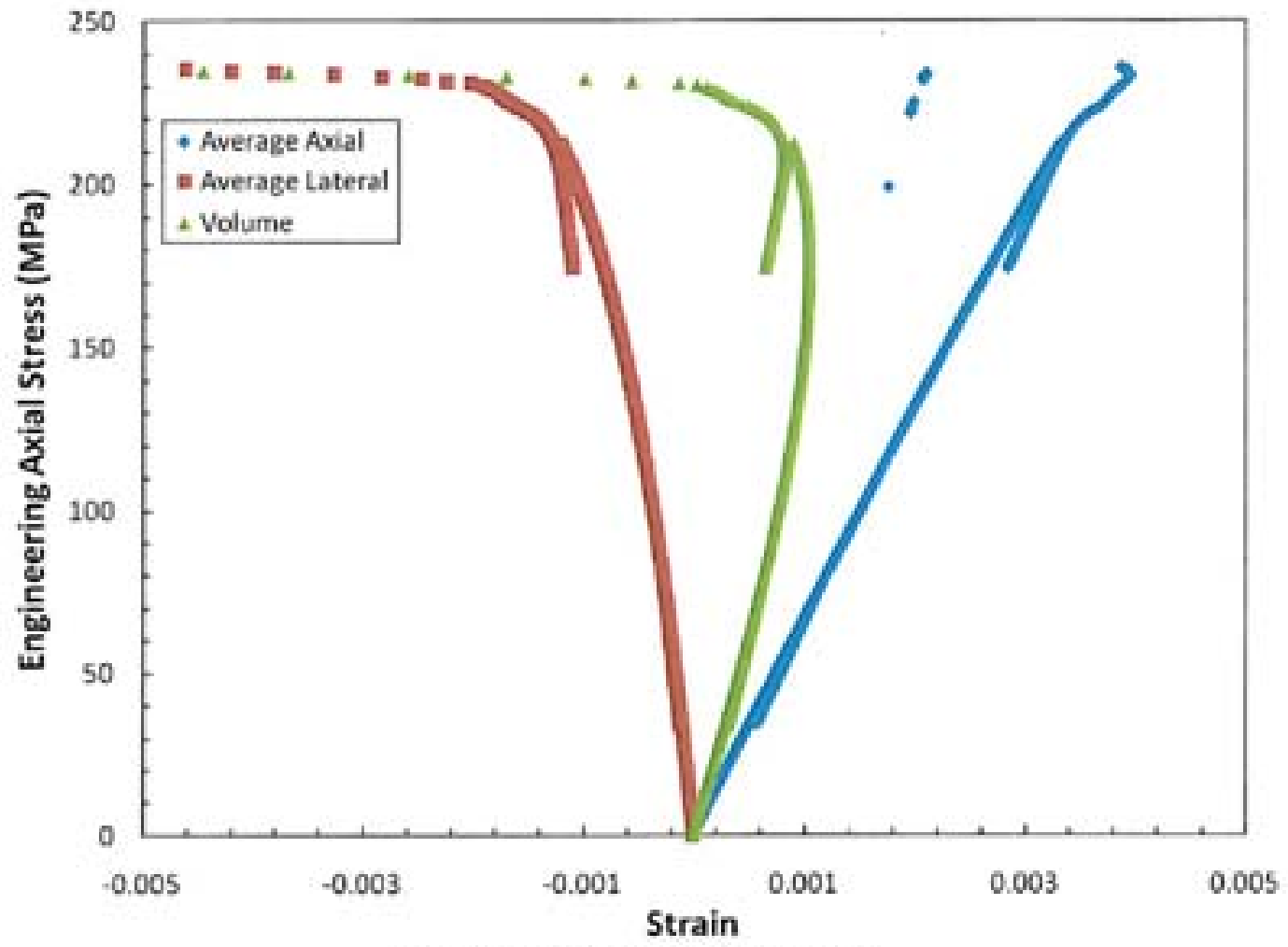

Figure 6. Sample SPE-UCS-1

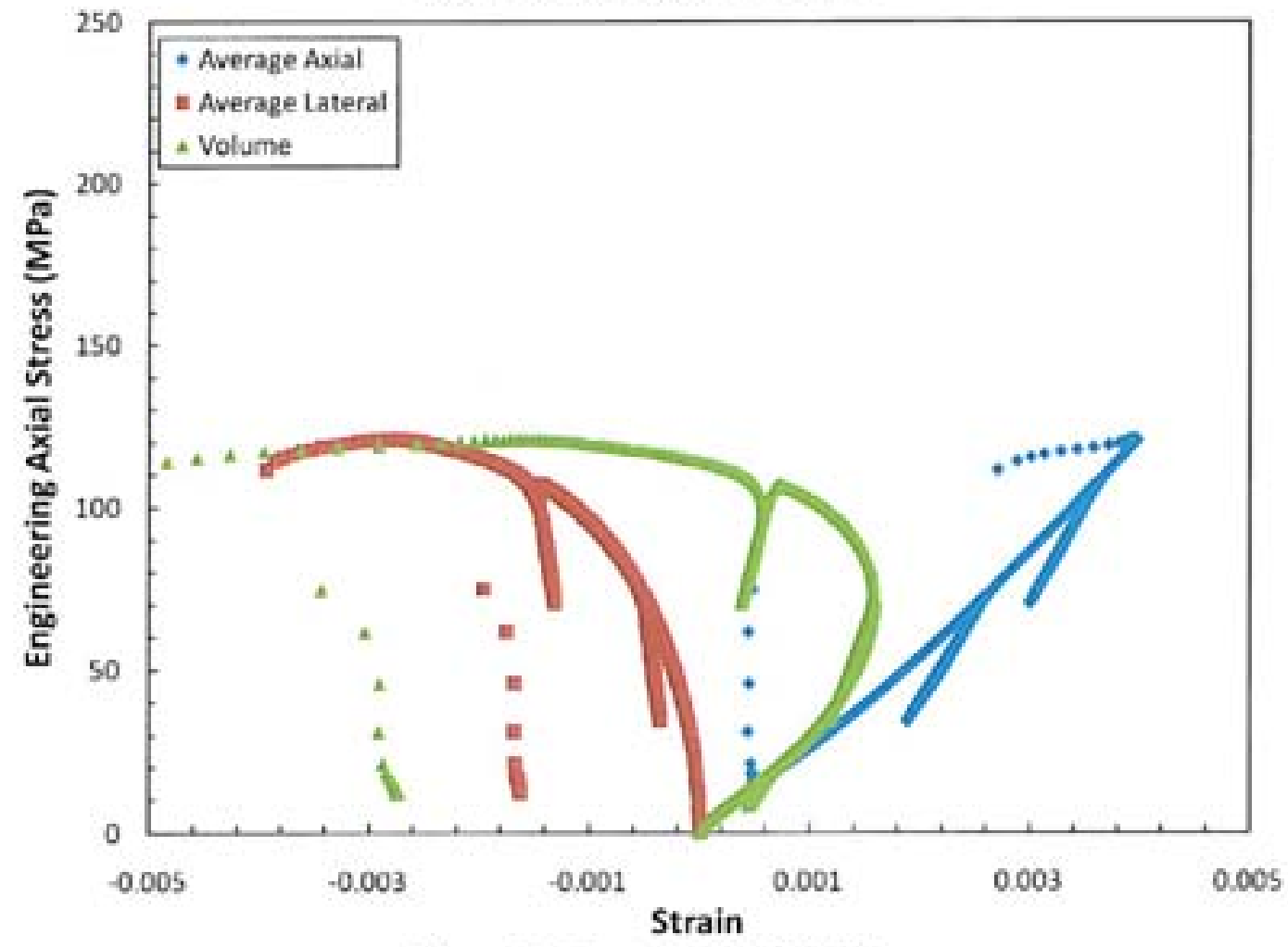

Figure 7. Sample SPE-UCS-2 


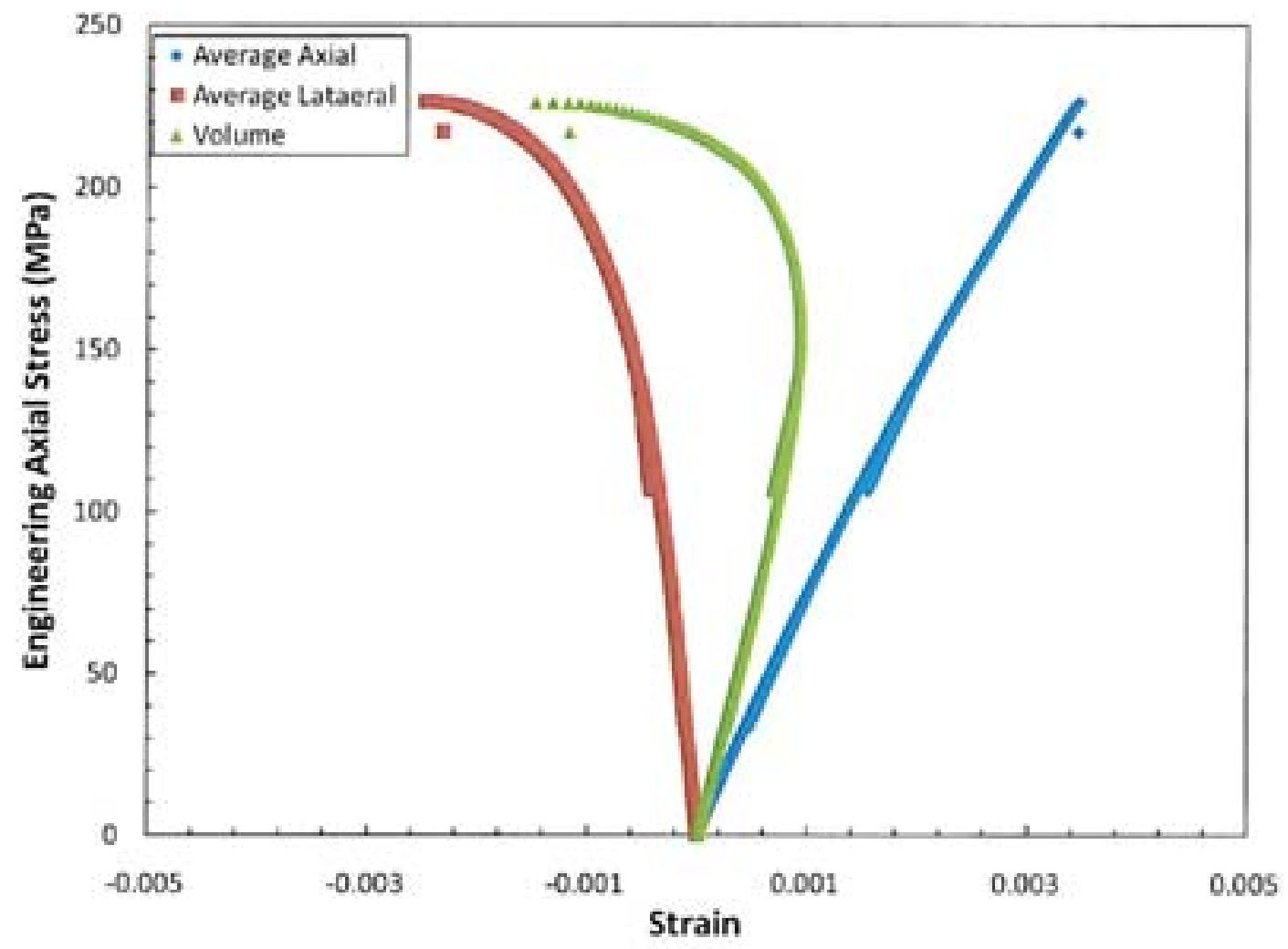

Figure 8. Sample SPE-UCS-3

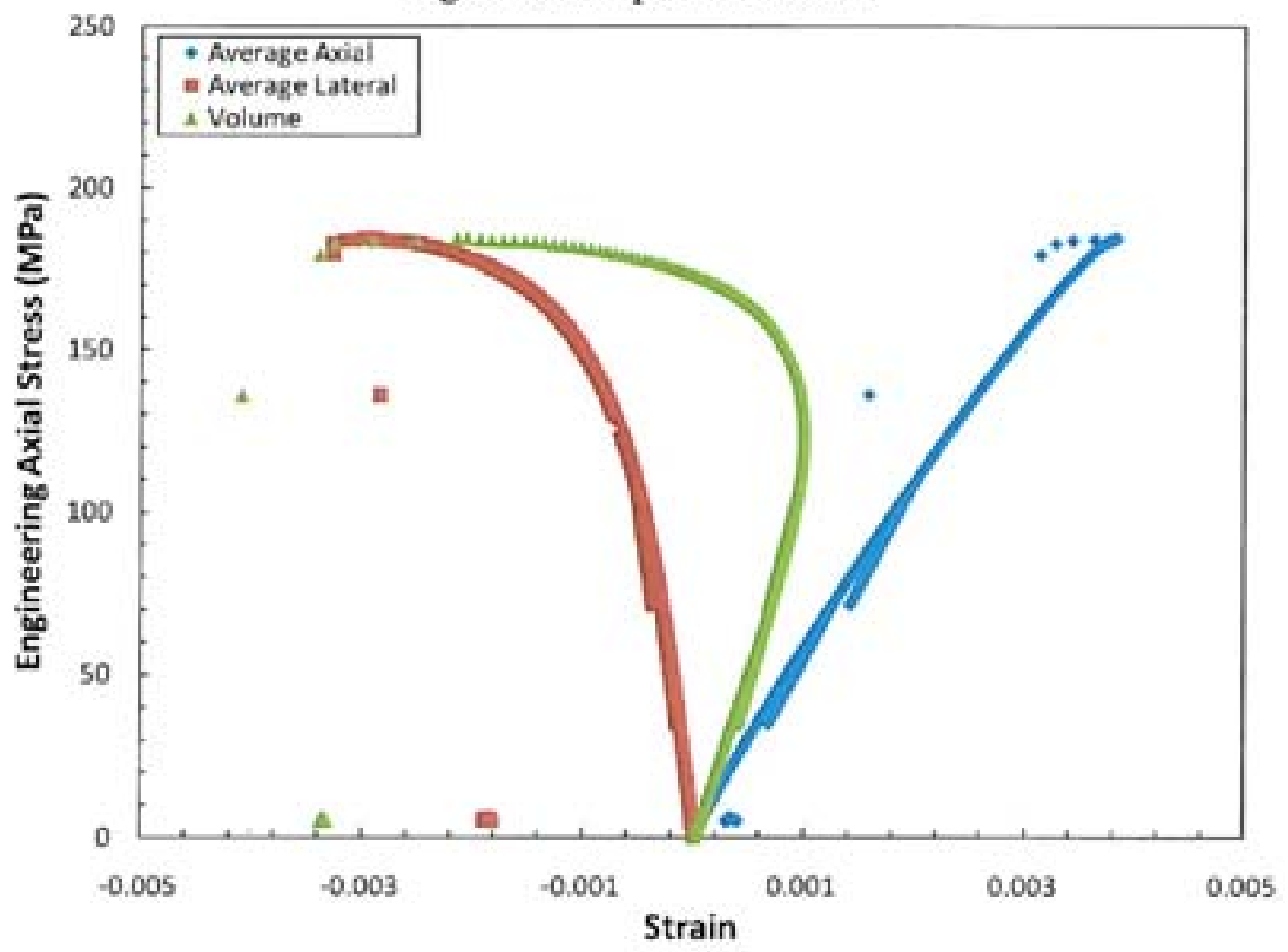

Figure 9. Sample SPE-UCS-4

13 


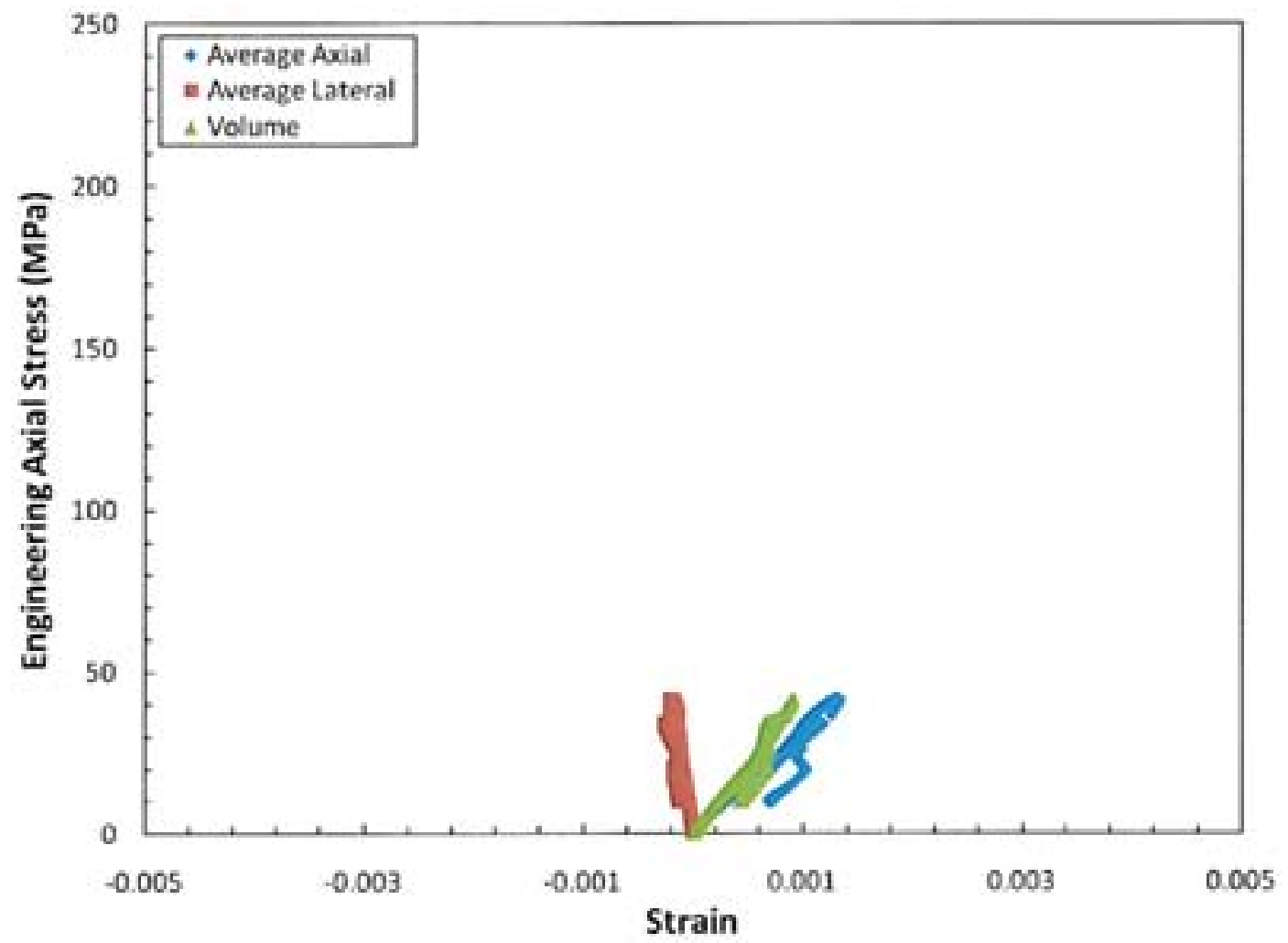

Figure 10. Sample SPE-UCS-5

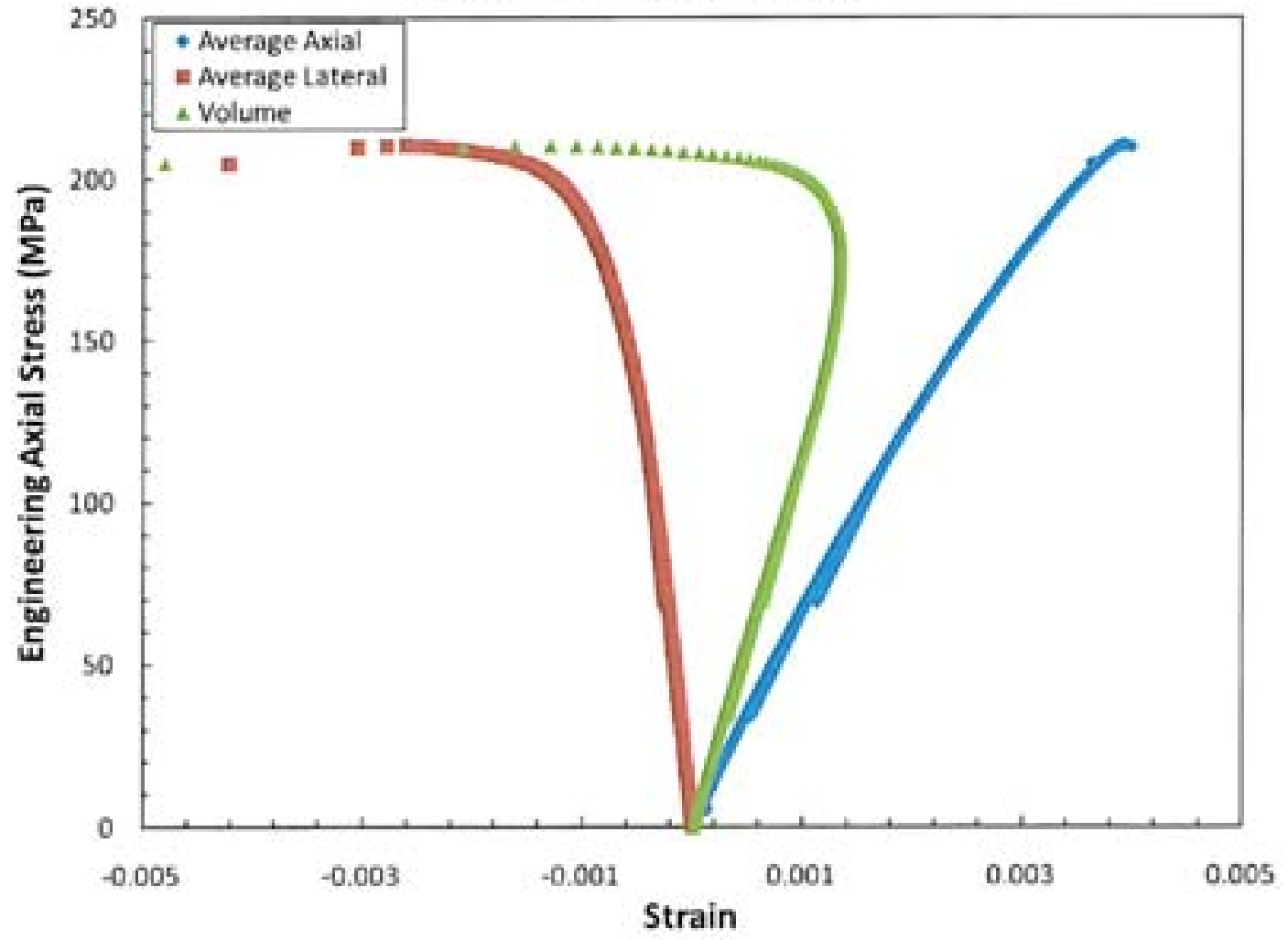

Figure 11. Sample SPE-UCS-6 


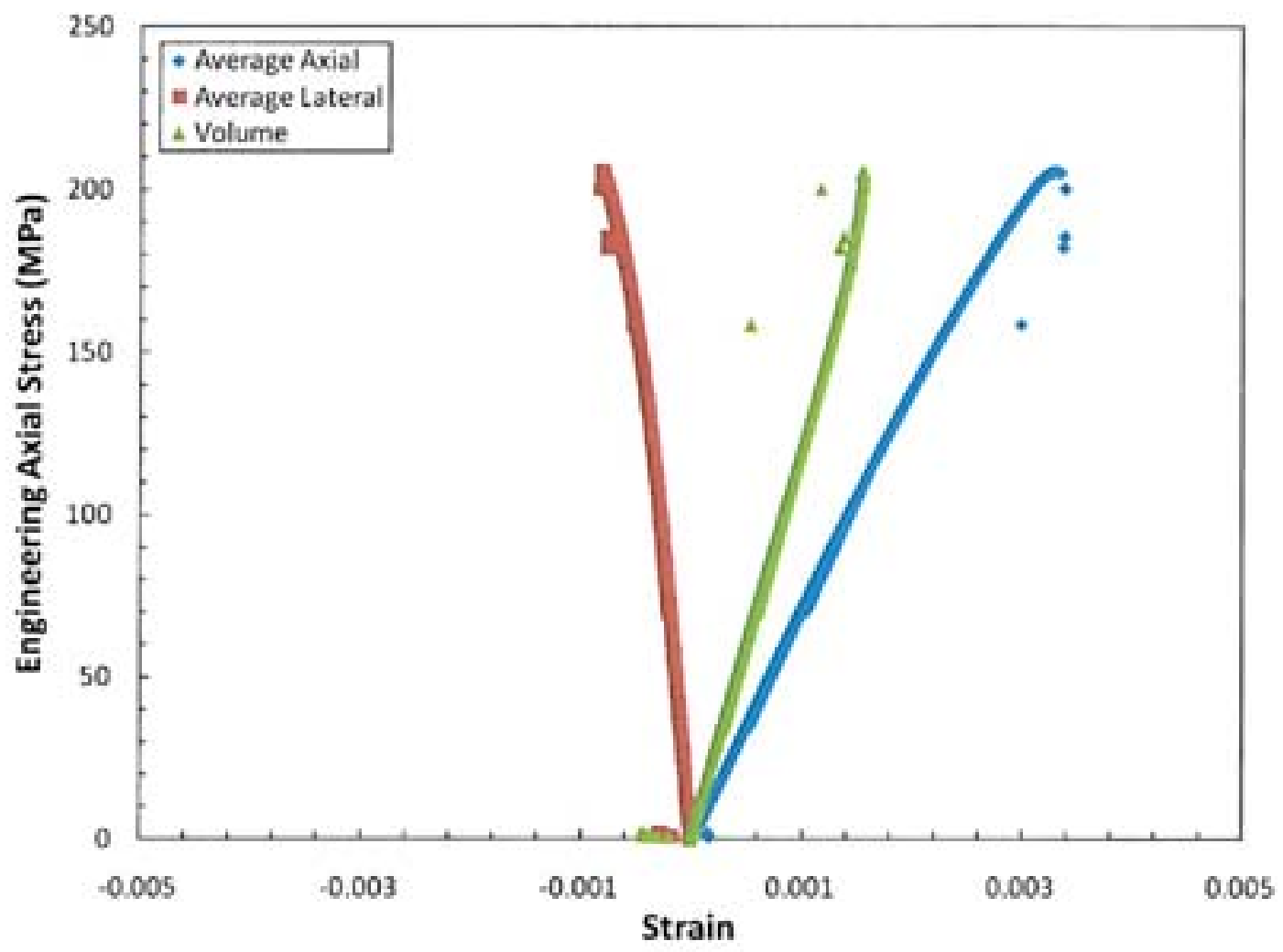

Figure 12. Sample SPE-UCS-7

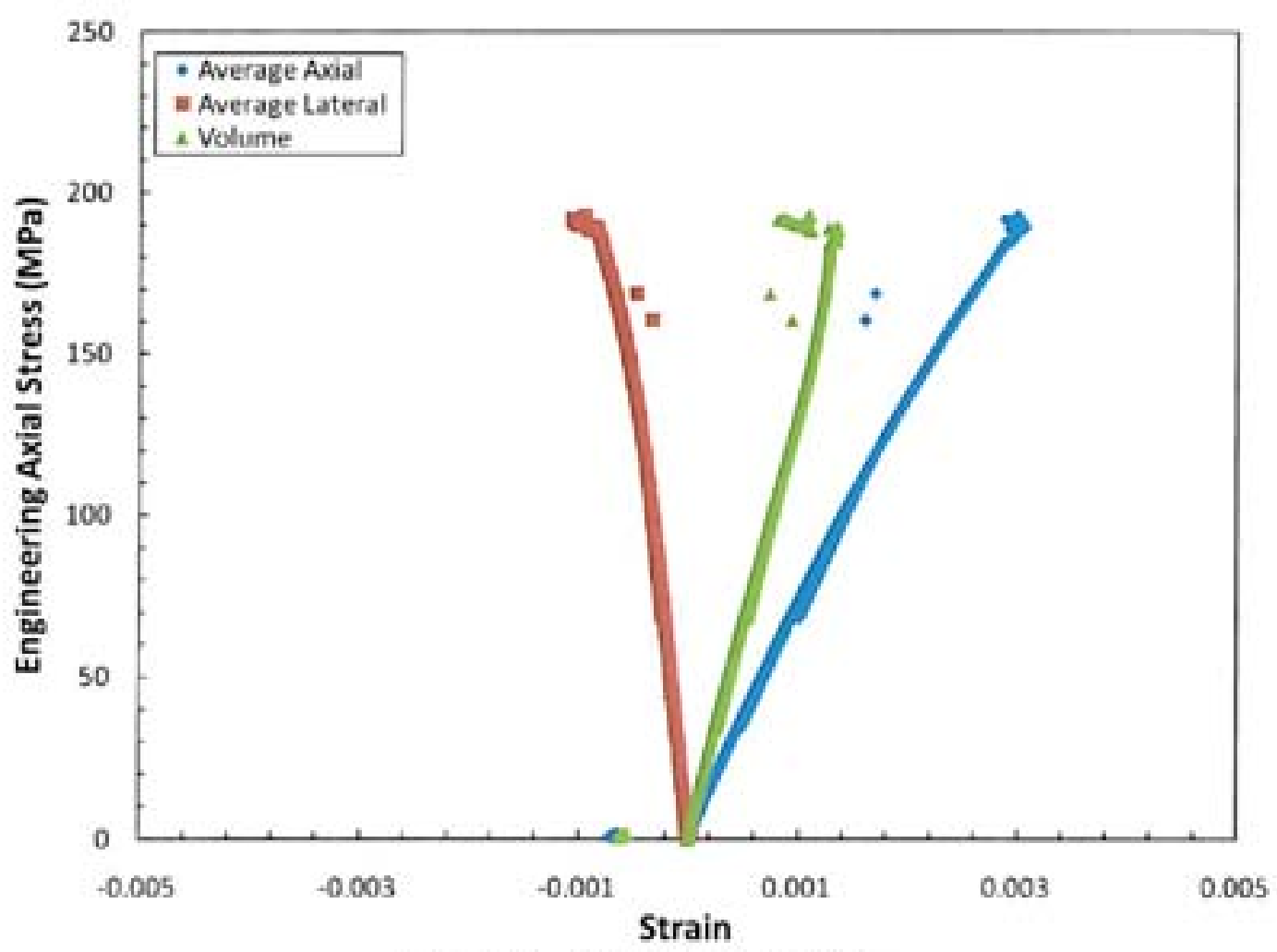

Figure 13. Sample SPE-UCS-8

15 


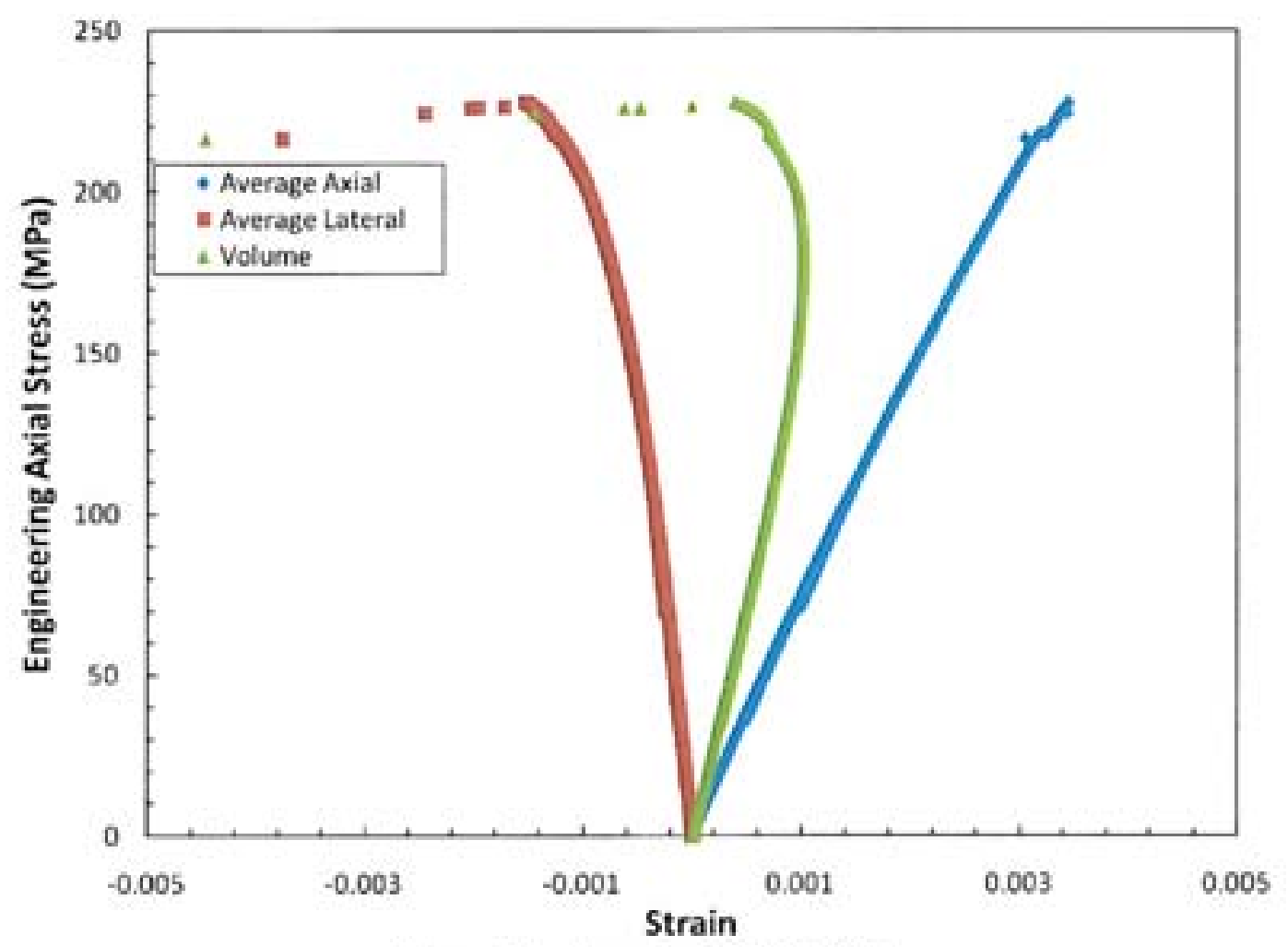

Figure 14. Sample SPE-UCS-9

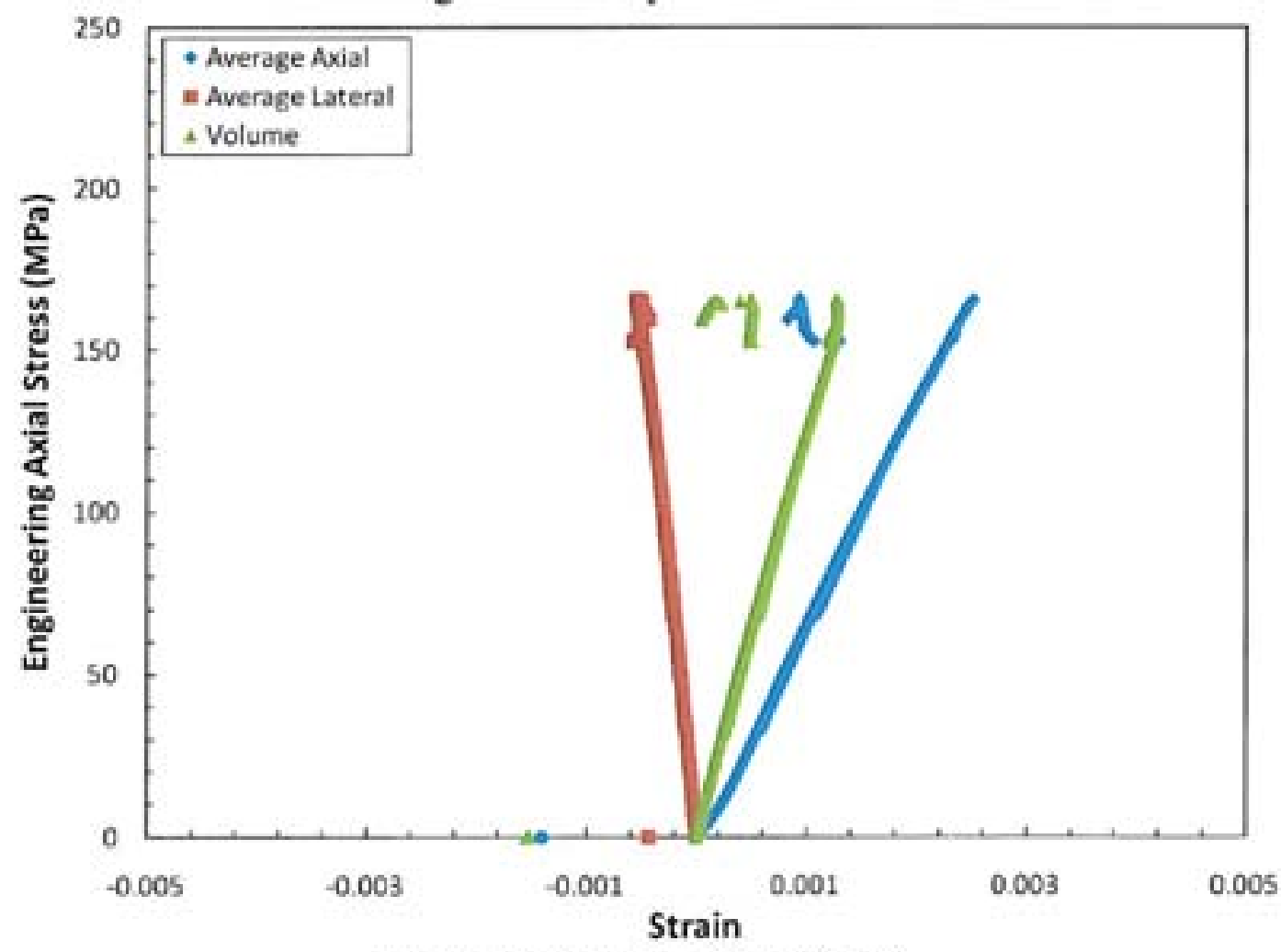

Figure 15. Sample SPE-UCS-10

16 


\section{APPENDIX H}

Measurements of Compressional Velocity Made on Behalf of the Defense Threat Reduction Agency Interagency Geotechnical Assessment Team (IGAT) on Samples from the U-15n Core Hole At the U.S. Geological Survey Core Library, Mercury, Nevada

November 21, 2011 
Table H-1

Measurements of Compressional Velocity (Radial Direction) Made on Behalf of the Defense Threat Reduction Agency Interagency Geotechnical Assessment Team (IGAT) on Samples from the U-15n Core Hole

Note: Measurements made on "HQ" (2.5 inch diameter) core stored at the U.S. Geological Survey Core Library in Mercury Nevada, November 21, 2011.

\begin{tabular}{|c|c|c|c|c|}
\hline $\begin{array}{l}\text { Measurement } \\
\text { Depth } \\
\text { (feet) }\end{array}$ & $\begin{array}{c}\text { Path Length } \\
\text { (millimeters) }\end{array}$ & $\begin{array}{c}\text { Time } \\
\text { (micro } \\
\text { seconds) }\end{array}$ & $\begin{array}{l}\text { Wavespeed } \\
\text { (kilometers/ } \\
\text { second) }\end{array}$ & Comments \\
\hline 7.5 & 63.17 & 14.97 & 4.94 & \\
\hline 8.5 & 63.52 & 14.38 & 4.42 & \\
\hline 11.5 & 63.29 & 14.50 & 4.36 & \\
\hline 12.5 & 63.40 & 14.50 & 4.37 & \\
\hline 13.5 & 63.42 & 14.25 & 4.45 & \\
\hline 15.5 & 63.32 & 16.50 & 3.84 & \\
\hline 16.3 & 63.65 & 14.08 & 4.52 & \\
\hline 17.6 & 48.12 & 12.73 & 3.78 & \\
\hline 18.5 & 63.47 & 15.02 & 4.23 & \\
\hline 19.5 & 63.37 & 14.09 & 4.50 & \\
\hline 20.5 & 63.39 & 19.59 & 3.24 & \\
\hline 21.2 & 63.57 & 16.88 & 3.77 & \\
\hline 25.0 & 63.50 & 13.66 & 4.65 & \\
\hline 26.2 & 63.31 & 21.36 & 2.96 & \\
\hline 27.2 & 63.43 & 16.11 & 3.94 & \\
\hline 28.1 & 63.40 & 18.14 & 3.50 & \\
\hline 28.9 & 63.00 & 19.66 & 3.20 & \\
\hline 30.1 & 63.30 & 17.29 & 3.66 & \\
\hline 31.3 & 63.38 & 19.91 & 3.18 & \\
\hline 32.0 & 63.35 & 19.91 & 3.18 & \\
\hline 33.0 & 63.44 & 19.03 & 3.33 & \\
\hline 34.5 & 63.32 & 18.98 & 3.34 & \\
\hline 35.5 & 63.35 & 20.05 & 3.16 & \\
\hline 36.9 & 63.40 & 18.72 & 3.39 & \\
\hline 37.5 & 63.35 & 14.40 & 4.40 & \\
\hline 38.5 & 63.33 & 16.35 & 3.87 & \\
\hline 39.3 & 63.38 & 14.91 & 4.25 & \\
\hline 41.5 & 63.37 & 14.74 & 4.30 & \\
\hline 42.7 & 63.35 & 14.66 & 4.32 & \\
\hline 43.5 & 63.27 & 13.64 & 4.64 & \\
\hline 44.3 & 63.41 & 13.64 & 4.65 & \\
\hline 45.0 & 63.46 & 13.47 & 4.71 & \\
\hline
\end{tabular}


Table H-1

Measurements of Compressional Velocity (Radial Direction) made on Behalf of the Defense Threat Reduction Agency Interagency Geotechnical Assessment Team (IGAT) on Samples from the U-15n Core Hole (continued)

\begin{tabular}{|c|c|c|c|c|}
\hline $\begin{array}{l}\text { Measurement } \\
\text { Depth } \\
\text { (feet) }\end{array}$ & $\begin{array}{c}\text { Path Length } \\
\text { (millimeters) }\end{array}$ & $\begin{array}{c}\text { Time } \\
\text { (micro } \\
\text { seconds) }\end{array}$ & $\begin{array}{c}\text { Wavespeed } \\
\text { (kilometers/ } \\
\text { second) }\end{array}$ & Comments \\
\hline 46.3 & 63.40 & 13.22 & 4.80 & \\
\hline 47.0 & 63.04 & 13.89 & 4.54 & \\
\hline 48.0 & 62.95 & 13.21 & 4.77 & \\
\hline 49.0 & 63.00 & 12.87 & 4.90 & \\
\hline 51.4 & 62.99 & 13.00 & 4.85 & \\
\hline 52.5 & 63.05 & 12.95 & 4.87 & \\
\hline 53.7 & 63.07 & 13.54 & 4.66 & \\
\hline 54.7 & 63.10 & 13.54 & 4.66 & \\
\hline 56.8 & 63.11 & 13.54 & 4.66 & \\
\hline 57.8 & 63.27 & 13.20 & 4.79 & \\
\hline 58.8 & 63.40 & 13.03 & 4.87 & \\
\hline 59.9 & 63.24 & 13.11 & 4.82 & \\
\hline 61.1 & 63.22 & 13.58 & 4.66 & \\
\hline 61.8 & 63.25 & 13.50 & 4.69 & \\
\hline 62.7 & 36.14 & 8.46 & 4.27 & \\
\hline 64.7 & 28.20 & 7.95 & 3.55 & \\
\hline 65.7 & 63.23 & 12.77 & 4.95 & \\
\hline 66.7 & 63.10 & 13.02 & 4.85 & \\
\hline 67.7 & 63.41 & 13.87 & 4.57 & \\
\hline 69.7 & 63.34 & 13.53 & 4.68 & \\
\hline 71.1 & 63.38 & 13.53 & 4.68 & \\
\hline 72.0 & 63.26 & 13.36 & 4.74 & \\
\hline 73.0 & 63.30 & 13.39 & 4.73 & \\
\hline 75.0 & 63.37 & 14.93 & 4.24 & \\
\hline 78.0 & 44.42 & 14.37 & 3.09 & \\
\hline 79.0 & 63.22 & 22.07 & 2.86 & \\
\hline 80.0 & 64.88 & 48.64 & 1.33 & \\
\hline 82.7 & 31.45 & 11.99 & 2.62 & \\
\hline 88.8 & 51.42 & 18.68 & 2.75 & \\
\hline 89.5 & 63.30 & 13.35 & 4.74 & \\
\hline 90.5 & 63.33 & 13.01 & 4.87 & \\
\hline 92.5 & 63.33 & 12.67 & 5.00 & \\
\hline 93.5 & 63.43 & 13.09 & 4.85 & \\
\hline 94.5 & 63.40 & 12.67 & 5.00 & \\
\hline 97.0 & 63.41 & 12.67 & 5.00 & \\
\hline
\end{tabular}


Table H-1

Measurements of Compressional Velocity (Radial Direction) made on Behalf of the Defense Threat Reduction Agency Interagency Geotechnical Assessment Team (IGAT) on Samples from the U-15n Core Hole (continued)

\begin{tabular}{|c|c|c|c|c|}
\hline $\begin{array}{l}\text { Measurement } \\
\text { Depth } \\
\text { (feet) }\end{array}$ & $\begin{array}{c}\text { Path Length } \\
\text { (millimeters) }\end{array}$ & $\begin{array}{c}\text { Time } \\
\text { (micro } \\
\text { seconds) }\end{array}$ & $\begin{array}{c}\text { Wavespeed } \\
\text { (kilometers/ } \\
\text { second) }\end{array}$ & Comments \\
\hline 98.0 & 63.41 & 13.60 & 4.66 & \\
\hline 99.5 & 63.36 & 12.75 & 4.97 & \\
\hline 100.5 & 63.33 & 12.75 & 4.97 & \\
\hline 101.5 & 63.40 & 12.75 & 4.97 & \\
\hline 103.5 & 63.36 & 13.93 & 4.55 & \\
\hline 117.4 & 42.59 & 12.24 & 3.48 & \\
\hline 109.8 & 63.42 & 12.58 & 5.04 & \\
\hline 110.8 & 63.00 & 13.76 & 4.58 & \\
\hline 112.8 & 63.52 & 13.34 & 4.76 & \\
\hline 114.5 & 63.50 & 13.17 & 4.82 & \\
\hline 115.5 & 63.51 & 12.58 & 5.05 & \\
\hline 116.4 & 63.53 & 13.09 & 4.85 & \\
\hline 117.3 & 63.37 & 13.09 & 4.84 & \\
\hline 118.9 & 63.44 & 12.75 & 4.98 & \\
\hline 119.9 & 63.40 & 12.75 & 4.97 & \\
\hline 121.7 & 63.52 & 12.92 & 4.92 & \\
\hline 122.7 & 63.46 & 12.92 & 4.91 & \\
\hline 123.5 & 63.49 & 14.27 & 4.45 & \\
\hline 124.1 & 63.50 & 16.72 & 3.80 & \\
\hline 124.7 & 63.53 & 15.62 & 4.07 & \\
\hline 126.0 & 63.47 & 13.00 & 4.88 & \\
\hline 127.0 & 63.42 & 12.75 & 4.97 & \\
\hline 129.0 & 63.52 & 15.57 & 4.08 & across healed joint \\
\hline 129.0 & 63.54 & 13.00 & 4.89 & $\begin{array}{l}\text { not through joint } \\
\text { (perpendicular) }\end{array}$ \\
\hline 130.0 & 63.55 & 14.77 & 4.30 & \\
\hline 132.6 & 63.52 & 14.18 & 4.48 & \\
\hline 133.7 & 63.41 & 13.16 & 4.82 & \\
\hline 134.7 & 63.43 & 12.57 & 5.05 & \\
\hline 135.7 & 63.33 & 12.57 & 5.04 & \\
\hline 136.6 & 63.37 & 12.99 & 4.88 & \\
\hline 140.0 & 63.37 & 12.40 & 5.11 & \\
\hline 141.6 & 63.47 & 12.40 & 5.12 & \\
\hline 143.0 & 63.42 & 12.40 & 5.11 & \\
\hline 144.2 & 63.47 & 12.65 & 5.02 & \\
\hline
\end{tabular}


Table H-1

Measurements of Compressional Velocity (Radial Direction) made on Behalf of the Defense Threat Reduction Agency Interagency Geotechnical Assessment Team (IGAT) on Samples from the U-15n Core Hole (continued)

\begin{tabular}{|c|c|c|c|c|}
\hline $\begin{array}{l}\text { Measurement } \\
\text { Depth } \\
\text { (feet) }\end{array}$ & $\begin{array}{c}\text { Path Length } \\
\text { (millimeters) }\end{array}$ & $\begin{array}{c}\text { Time } \\
\text { (micro } \\
\text { seconds) }\end{array}$ & $\begin{array}{c}\text { Wavespeed } \\
\text { (kilometers/ } \\
\text { second) }\end{array}$ & Comments \\
\hline 145.0 & 63.41 & 12.40 & 5.11 & \\
\hline 146.0 & 63.42 & 12.40 & 5.11 & \\
\hline 147.0 & 63.37 & 12.40 & 5.11 & \\
\hline 149.5 & 63.43 & 14.09 & 4.50 & \\
\hline 154.6 & 63.45 & 13.07 & 4.85 & \\
\hline 156.2 & 63.44 & 18.66 & 3.40 & \\
\hline 157.7 & 63.36 & 13.24 & 4.79 & \\
\hline 158.7 & 63.44 & 14.34 & 4.42 & \\
\hline 159.2 & 63.38 & 15.86 & 4.00 & \\
\hline 160.2 & 63.44 & 13.41 & 4.73 & \\
\hline 161.2 & 63.42 & 12.39 & 5.12 & \\
\hline 162.1 & 63.40 & 12.80 & 4.95 & \\
\hline 163.7 & 63.44 & 12.80 & 4.96 & \\
\hline 165.0 & 63.39 & 12.80 & 4.95 & \\
\hline 167.0 & 63.49 & 12.80 & 4.96 & \\
\hline 168.5 & 63.40 & 15.51 & 4.09 & \\
\hline 170.0 & 63.51 & 15.70 & 4.05 & \\
\hline 171.0 & 63.44 & 13.30 & 4.77 & \\
\hline 172.0 & 63.47 & 13.30 & 4.77 & \\
\hline 174.8 & 63.45 & 12.97 & 4.89 & \\
\hline 174.8 & 63.50 & 13.22 & 4.80 & \\
\hline 180.7 & 63.48 & 13.22 & 4.80 & \\
\hline 183.0 & 63.46 & 13.30 & 4.77 & \\
\hline 184.0 & 63.47 & 13.30 & 4.77 & \\
\hline 185.0 & 63.51 & 13.30 & 4.78 & \\
\hline 185.7 & 63.47 & 13.30 & 4.77 & \\
\hline 187.0 & 63.49 & 12.96 & 4.90 & \\
\hline 189.0 & 63.50 & 13.00 & 4.88 & \\
\hline 190.0 & 63.49 & 12.62 & 5.03 & \\
\hline 191.0 & 63.47 & 13.21 & 4.80 & \\
\hline 192.0 & 63.52 & 14.82 & 4.29 & \\
\hline 193.0 & 63.48 & 13.30 & 4.77 & \\
\hline 194.0 & 63.48 & 12.71 & 4.99 & \\
\hline 195.0 & 63.49 & 16.69 & 3.80 & \\
\hline 195.6 & 63.48 & 17.62 & 3.60 & \\
\hline
\end{tabular}


Table H-2

Measurements of Compressional Velocity (Axial Direction) made on Behalf of the Defense Threat Reduction Agency Interagency Geotechnical Assessment Team (IGAT) on Samples from the U-15n Core Hole

Note: Measurements made on "HQ" (2.5 inch diameter) core stored at the U.S. Geological Survey Core Library in Mercury Nevada, November 21, 2011.

\begin{tabular}{|c|c|c|c|}
\hline $\begin{array}{c}\text { Measurement Depth } \\
\text { (feet) }\end{array}$ & $\begin{array}{c}\text { Path Length } \\
\text { (millimeters) }\end{array}$ & $\begin{array}{c}\text { Time } \\
\text { (micro } \\
\text { seconds) }\end{array}$ & $\begin{array}{c}\text { Wavespeed } \\
\text { (kilometers/ } \\
\text { second) }\end{array}$ \\
\hline 7.5 & 182.90 & 45.60 & 4.01 \\
\hline 13.4 & 144.50 & 29.42 & 4.91 \\
\hline 15.0 & 94.41 & 28.70 & 3.29 \\
\hline 20.8 & 125.20 & 36.42 & 3.44 \\
\hline 26.1 & 122.30 & 47.62 & 2.57 \\
\hline 31.4 & 148.50 & 59.40 & 2.50 \\
\hline 35.4 & 74.30 & 28.10 & 2.64 \\
\hline 36.9 & 130.00 & 43.22 & 3.01 \\
\hline 45.0 & 120.90 & 31.72 & 3.81 \\
\hline 59.4 & 107.00 & 26.62 & 4.02 \\
\hline 126.1 & 149.00 & 31.72 & 4.70 \\
\hline 135.5 & 94.00 & 30.92 & 3.04 \\
\hline 118.9 & 146.00 & 38.50 & 3.79 \\
\hline 121.7 & 73.00 & 19.50 & 3.74 \\
\hline 135.5 & 94.00 & 30.92 & 3.04 \\
\hline 135.5 & 63.49 & 13.32 & 4.77 \\
\hline
\end{tabular}




\begin{abstract}
APPENDIX I
Projected Extent of Two Faults Encountered in Core Hole U-15n

By

UGTA/Boreholes Geology Group

National Security Technologies, LLC
\end{abstract}

March 8, 2011 


\section{Projected Extent of Two Faults Encountered in Core Hole U-15n \\ NSTec UGTA/Boreholes Geology Group March 8, 2011}

We have constructed a map and three vertical sections (attached) to illustrate the possible extents and orientations of the two main faults encountered in the U-15n core hole.

We made several simplifying assumptions to construct these drawings:

- We treated both faults as single dipping planes with strike and dip that do not change along the fault trace. We know that both faults are really zones of several fractures where encountered in the core hole, and used an average orientation of these planes. It is likely that both faults do change orientation slightly away from the core hole intercept (see discussions below), but we have very little to inform us as to what types of variation to expect.

- We call these structures "faults" mainly because they both consist of multiple fracture planes separated by gouge/fill material, and because slickensides were observed on some of the fracture surfaces. We do not have any information (or guesses) about amount or sense of displacement along the faults, because no "marker beds" are present in this massive granite body that could be use to determine offset.

- Our fracture orientation data came from Colog's tables, which they derived from their acoustic and optical televiewer logs (previously transmitted). We used our best judgment to select representative orientations from the Colog fracture tables.

- We treated all holes as vertical and straight. Most of the measured borehole deviations were less than a couple of feet, so we do not think this is a problem, given the uncertainty in the fault orientations. Holes U-15n\#1, \#2, and \#4 experienced the greatest deviation, of up to $6 \mathrm{ft}$ at TD. The other three instrument holes and the core hole showed less than $2 \mathrm{ft}$ deviation at TD.

One thing to keep in mind is that the length of exposure of an angular feature in a borehole is a function of hole diameter. That is, the apparent linear exposure interval of a high-angle feature will be greater in a large hole than in a small hole. The linear extent of these features in the 36-inch hole will be greater than in the core hole, which was 3.8 inches in diameter.

A previous report by our group (Preliminary Analysis of Fractures Identified on Borehole Image Logs from the SPE Drill Holes by Lance Prothro, January 2011) described the orientations of fractures encountered in the SPE holes and subdivided them into four sets based on orientation. The two faults described here are interpreted to belong to Sets 1 and 2, which are a conjugate set (similar strikes but opposite dips). Both faults strike generally parallel to the present-day minimum horizontal stress direction, and normal to the strike of Basin-and-Range normal faults in the area. Thus, they are likely small faults that are not regionally significant.

Brief descriptions of the two faults addressed in this report are given below, followed by short discussions of the cross sections, the map, and other fractures encountered. 


\section{Fault \#1 Characteristics (Fracture Set 1)}

- Depth $=83 \mathrm{ft}$

- $\quad$ Dip magnitude $=80$ degrees
- $\quad$ Dip direction $=15$ degrees azimuth

- Strike $=105$ degrees azimuth

- Description from core: The fault zone is exposed from the depth of 77.7 to $84 \mathrm{ft}$, and consists of several planes that range in dip magnitude from about 70 degrees to nearly vertical. The fault/fracture planes have thin gouge coats and slickensides in places. The granite is lighter in color, soft, and altered adjacent to fault/fracture planes. Little gouge is associated with zone, similar to Fault \#2. Significantly decomposed, soft rock is only seen near center of zone (around 80 to $81 \mathrm{ft}$ ).

\section{Fault \#2 Characteristics (Fracture Set 2)}

- $\quad$ Depth $=106 \mathrm{ft}$

- $\quad$ Dip magnitude $=79$ degrees
- $\quad$ Dip direction $=205$ degrees azimuth

- Strike $=295$ degrees azimuth

- Description from core: Exposed between the depths of 104 and $108 \mathrm{ft}$. The fault zone is bounded by high-angle (approximately 80 degrees) planes at top and bottom of interval. The rocks are fractured and weathered (buff colored) between the bounding fractures. Alteration is confined to the region between uppermost and lowermost planes of the zone. This fault zone appears not to be as highly fractured as Fault \#1. As in Fault \#1, there is little gouge. Decomposed, soft rock is limited to the interval between 105 and $106.8 \mathrm{ft}$.

\section{$\underline{\text { Cross Sections }}$}

Three cross sections were constructed (listed below). All instrument holes are marked with the proposed depths of the gage packages, and the core hole is marked with the proposed depths of the explosive packages. The map and cross sections were constructed at the scale of 1 inch $=20$ feet and can be plotted to scale on B-size paper (11 by 17 inches).

- A-A' through U-15n\#4, U-15n, and U-15n\#1 (NE-SW)

- B-B' through U-15n\#3, U-15n, and U-15n\#6 (NW-SE)

- C-C' through U-15n\#2, U-15n, and U-15n\#5 (W-E)

After these cross sections were constructed, we reexamined the acoustic and optical logs for all the holes to determine whether there were any candidate fractures that could be interpreted to correlate with the projections of the two faults. Where such fractures were logged, we added a purple triangle to the section to indicate their depth. We also looked for high-rank (Rank 4 or 5) highangle fractures in the instrument holes that could indicate faults that did not cross the core hole, and found a few, which are discussed at the end of this report (see Table 1 for fracture ranking criteria).

The relationship of the faults where they are projected to cross each other is unknown. On the cross sections we show them as if they both extend past each other, mainly to find the projected possible surface traces. It is likely, however, that one of the faults terminates against the other, though we do not know their relationship at this time.

Discussion of Cross Section A-A'

Neither fault is projected to cross $U-15 \mathrm{n} \# 1$ or $\# 4$. 


\section{Discussion of Cross Section B-B'}

Neither fault is projected to cross U-15n\#6, but Fault \#2 may cross U-15n\#3. In the acoustic and optical logs for U-15n\#3, we found that several sets of high-angle fractures were logged near the bottom of the hole. Two of these are marked on the cross section with purple triangles and a brief description of the fractures. If the dip of Fault \#2 decreases with depth, the upper of these two fractures (depth of $167.5 \mathrm{ft}$ ) could be interpreted to be its intercept. None of the high-angle fractures logged near the bottom of U-15n\#3 ranks higher than Rank 3.

\section{Discussion of Cross Section C-C'}

Fault \#1 may cross both U-15n\#2 and U-15n\#5. In U-15n\#2, a series of fractures was logged between the depths of 29 and $41 \mathrm{ft}$, including a Set \#1 fracture at $35.4 \mathrm{ft}$. If the dip of Fault \#1 decreases upward, this interval could be interpreted to be the intercept of Fault \#1. A Rank-3 fracture of Set \#1 was logged in U-15n\#5 at the depth of $183.8 \mathrm{ft}$. If the dip of Fault \#1 decreases downward, this fracture could be interpreted to be the intercept of Fault \#1. A Set \#2 fracture was logged near the bottom of U-15n\#2 (depth of $179.6 \mathrm{ft}$ ) that could be interpreted to be the intercept of Fault \#2 with only a slight decrease in the fault's dip.

\section{$\underline{\text { Map }}$}

The attached map shows the locations of all seven holes, the cross section locations, and the projected traces of both faults based on their interpreted orientations. The solid lines represent the traces at their subsurface locations. The dashed lines represent the projected surface traces of the faults, constructed from the surface intercepts from the three cross sections. By extending the surface traces of the faults along their strikes to the southeast, they are projected to meet approximately $200 \mathrm{ft}$ from the $\mathrm{U}-15 \mathrm{n}$ core hole on an azimuth of about 110 degrees. There is no visible evidence of the trace of either fault or their intersection at the surface.

No faults were mapped within 1,000 ft of the SPE site on the 1:4800 geologic by the U.S. Geological Survey (Map I-328, Preliminary Geologic Map of the Climax Stock and Vicinity, Nye County, Nevada, by F. N. Houser and F. G. Poole, 1960) or on the geologic quadrangle map for the area at 1:24,000 (GQ-214, Geologic Quadrangle Map of the Oak Spring Butte Quadrangle, Nye County Nevada, by H. Barnes, F. N. Houser, and F. B. Poole, 1963). In fact, neither map shows any surface faults on the granitic body. The more detailed 1960 map shows numerous locations where joint patterns were mapped, the closest being on the hillock northeast of the SPE site.

\section{Other Fractures}

- U-15n Core Hole. Both faults have several Rank 4 and Rank 5 fractures associated with them. There are also a few Rank 4 fractures among fractures in the low-angle set. Three other isolated high-angle fractures were also noted in the core hole at Rank 4 or 5 , which are listed below. None of these fractures have the associated severe breakouts and altered zones seen at the two fault zones described above.

o 117 feet depth: Rank 4, Set 2, dip magnitude $=74$ degrees; thin gouge $(<1 \mathrm{~mm}$ thick $)$ noted in core, but no slickensides

o 155 feet depth: Rank 5; Set 2, dip magnitude $=60$ degrees; thin clayey gouge $(<1 \mathrm{~mm})$ noted in core, but no slickensides

o 168-170 feet depth: Rank 4, Set 2, dip magnitude - 64-66 degrees; thin clayey gouge $(<1 \mathrm{~mm})$ noted in core, but no slickensides 
- Hole U-15n\#1 has one Rank 4 fracture, which is in the low-angle fracture set.

- Hole U-15n\#2 has seven Rank 4 fractures, which are all in the low-angle fracture set.

- Hole U-15n\#3 has a Rank 4 fracture at the depth of $81.9 \mathrm{ft}$, which belongs to Set 2 and has a dip of 82 degrees. This fracture caused a small breakout in the borehole wall (as seen on the caliper log), but appears not to be associated with a highly altered zone as seen in the two faults in the core hole.

- Holes U-15n\#4, \#5, and \#6 have no fractures ranked 4 or 5.

\section{Table 1}

Colog Feature Rankings

\begin{tabular}{|c|l|l|}
\hline Rank & \multicolumn{1}{|c|}{ Observation } & \multicolumn{1}{|c|}{ Flow Rating System $^{\text {a }}$} \\
\hline 0 & $\begin{array}{l}\text { No-Flow Feature } \\
\text { (bedding, healed fractures, vein, etc.) }\end{array}$ & Sealed, no flow \\
\hline 1 & $\begin{array}{l}\text { Weak Feature } \\
\text { (not continuous around the borehole) }\end{array}$ & Partial open crack \\
\hline 2 & Clear, Distinct Feature & Continuous open crack \\
\hline 3 & $\begin{array}{l}\text { Distinct Feature with Apparent Aperture } \\
\text { (visible on amplitude and travel-time images) }\end{array}$ & Wide open crack or cracks \\
\hline 4 & $\begin{array}{l}\text { Very Distinct, Wide, Possibly Interconnected } \\
\text { Fracture } \\
\text { (visible on amplitude and travel-time images) }\end{array}$ & $\begin{array}{l}\text { Very wide crack or multiple interconnected } \\
\text { fractures }\end{array}$ \\
\hline 5 & $\begin{array}{l}\text { Major Fracture Zone or Wash Out Zone } \\
\text { (visible on amplitude and travel-time images) }\end{array}$ & $\begin{array}{l}\text { Major fracture with large openings or } \\
\text { breakouts }\end{array}$ \\
\hline
\end{tabular}

a Primarily referring to potential for fluid flow. 


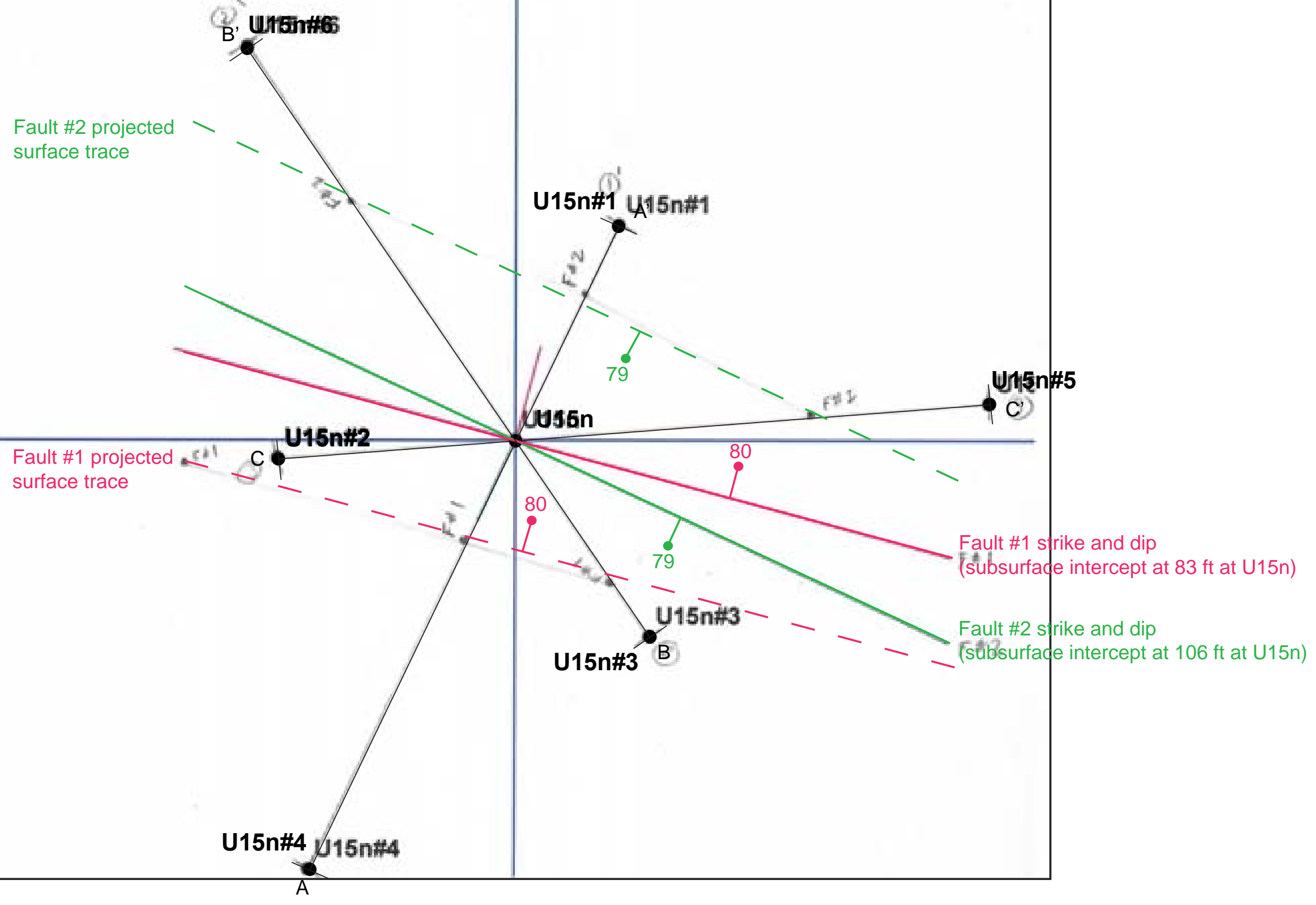


A

Southwest

Elevation
$\mathrm{m} \quad \mathrm{ft}$

1527 T 5010

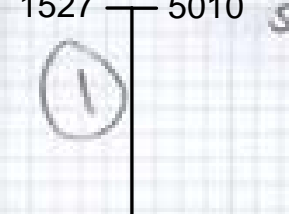

U15n\#4

$\mathrm{m}$

$1517-4990$

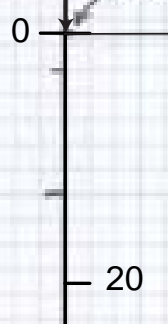

$-4970$

$-$

1507

$-4950$

(5)

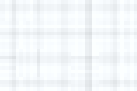

$-$

$-4930$

1497

$-4910$

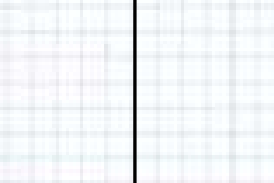

30

$-40$

$1487-4890$

4870

4

147

$-4850$

$1467-4810$

$-4830$

4790

Northeast

U15n\#1

$\mathrm{m} \mid \mathrm{ft}$

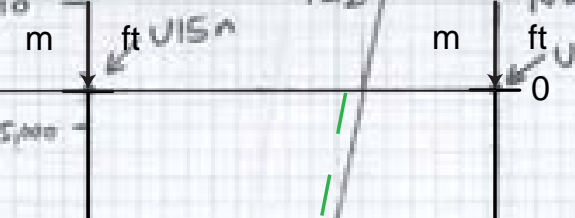

$-20$

$-60$

$20-$

$-80$

30

100

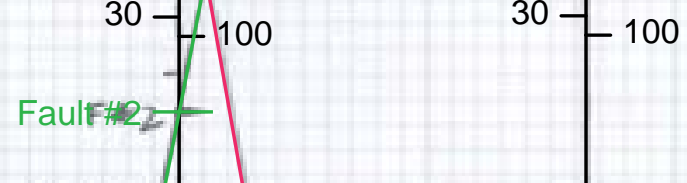

$-120$

$-140$

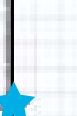

$-160$

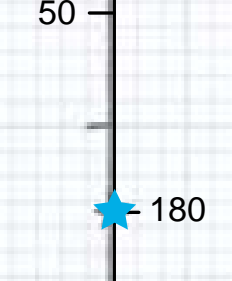

60<smiles>O=C(O)C1CC1</smiles>

No vertical exaggeration

Gage package

- Explosive package

_ Fault \#1, dashed where inferred

TD $=$ total depth of hole

$\mathrm{m}=$ meters

$\mathrm{ft}=$ feet

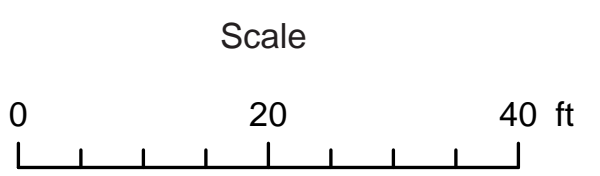



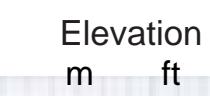

1527 T 5010

\section{U15n\#3}

U15n

U15n\#6

$\prod^{5010}$

$\mathrm{m}$

$\mathrm{m} \mid \mathrm{ft}$

$\mathrm{m} \quad \mathrm{ft}$

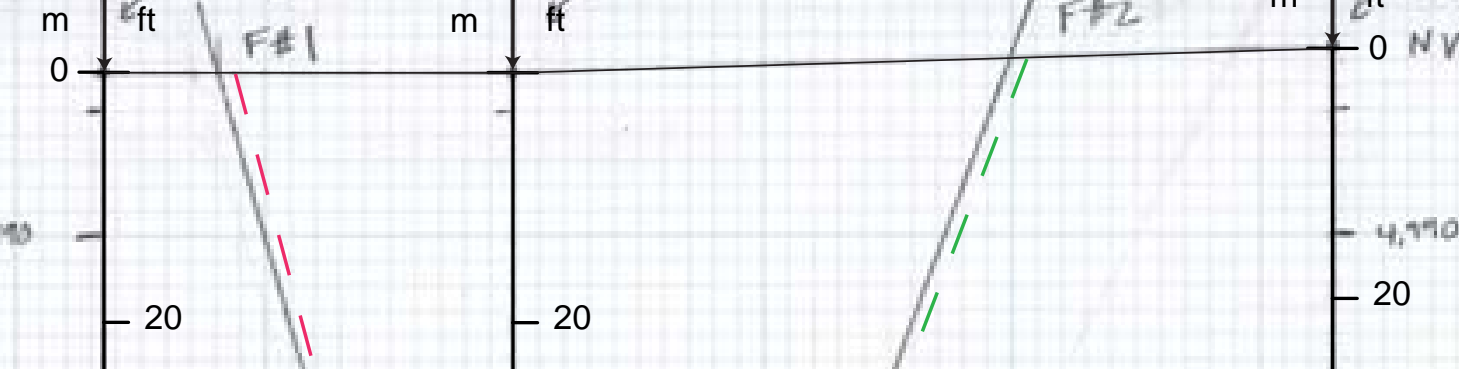

$-4970$

\begin{tabular}{|}
-4970 \\
-4950
\end{tabular}

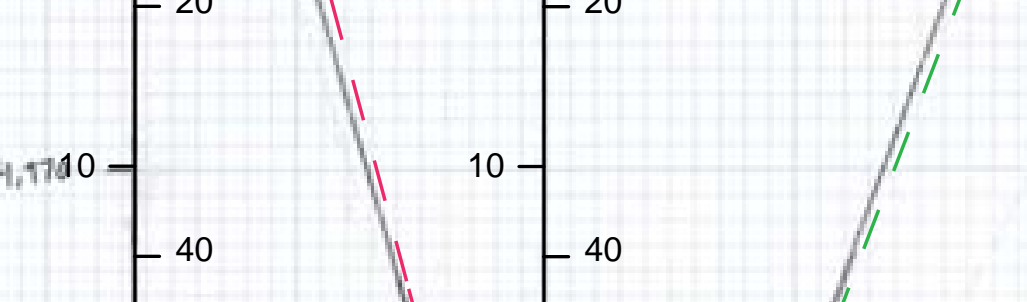

$\mid$\begin{tabular}{l|l}
-4930 \\
-4910
\end{tabular}

-4890

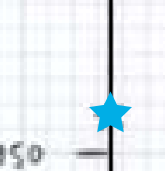

-4870

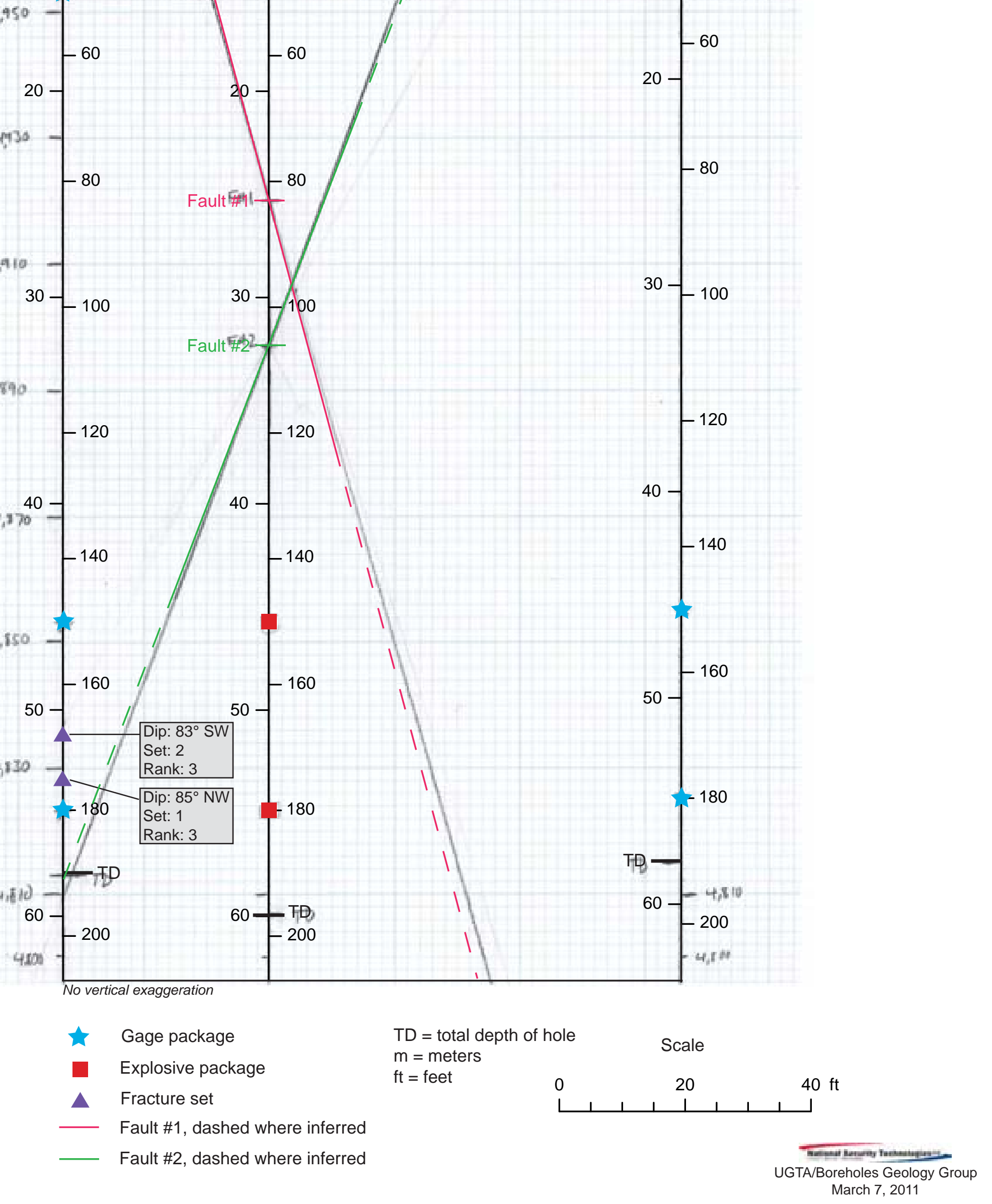




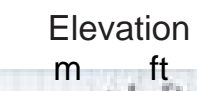

$\mathrm{m} \mathrm{ft}$

1527

U15n\#2

U15n

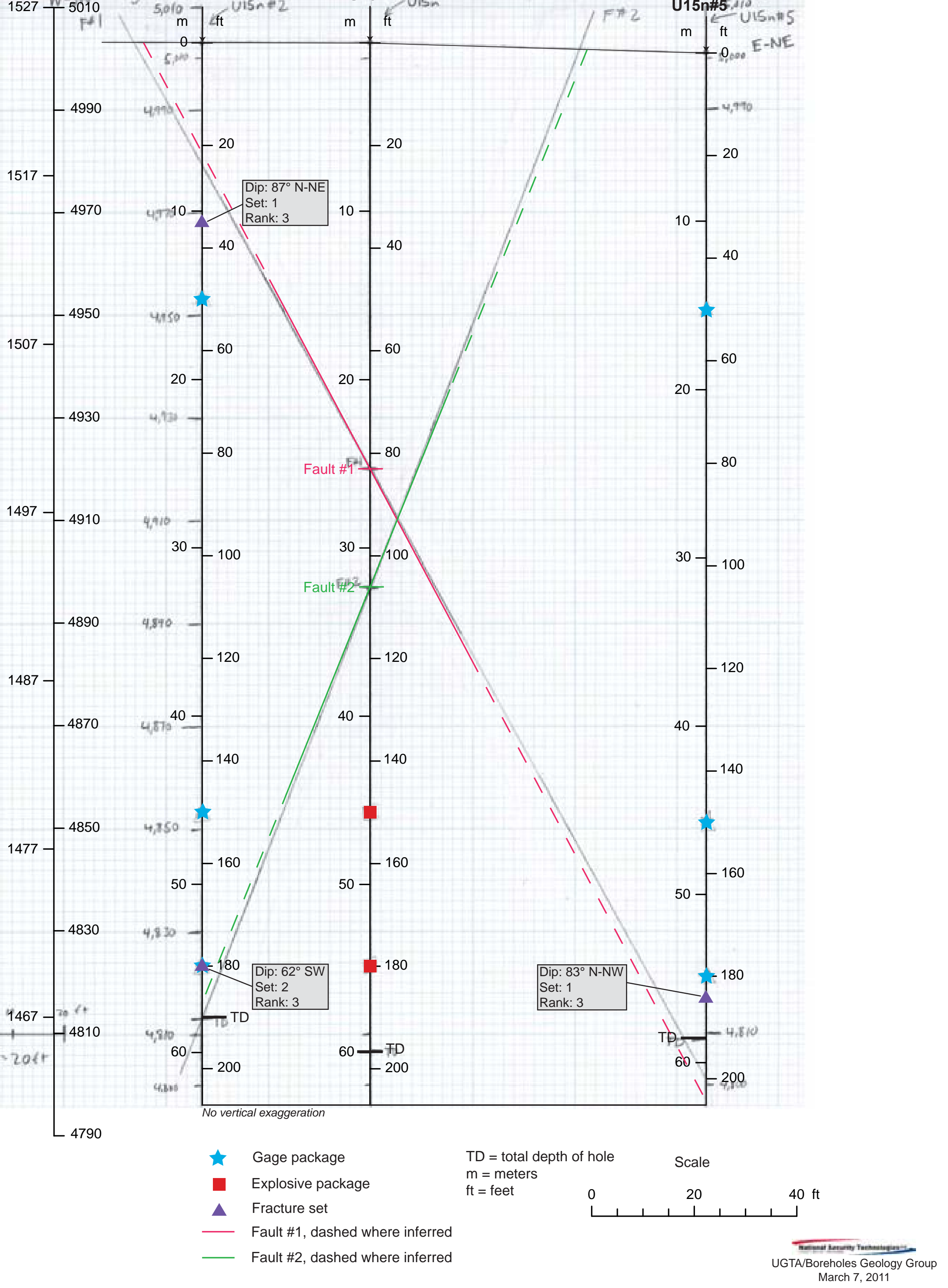




\author{
APPENDIX J \\ Fracture Data Tabulated from Borehole Image Logs by Colog, Inc. \\ U-15n Source Physics Experiment Holes \\ Appendix J-1: U-15n Core Hole \\ Appendix J-2: Instrument Hole U-15n\#1 \\ Appendix J-3: Instrument Hole U-15n\#2 \\ Appendix J-4: Instrument Hole U-15n\#3 \\ Appendix J-5: Instrument Hole U-15n\#4 \\ Appendix J-6: Instrument Hole U-15n\#5 \\ Appendix J-7: Instrument Hole U-15n\#6
}


Appendix J-1

Fracture Data Tabulated from Borehole Image Logs by Colog, Inc. For the U-15n Core Hole 
Orientation Summary Table

Acoustic Televiewer Features

Nevada Test Site

Source Physics Experiment

U-15N

NNSA/NSO

31 July 2010

\begin{tabular}{|c|c|c|c|c|c|c|}
\hline $\begin{array}{c}\text { Feature } \\
\text { No. }\end{array}$ & $\begin{array}{c}\text { Depth } \\
\text { (meters) } \\
\end{array}$ & $\begin{array}{l}\text { Depth } \\
\text { (feet) } \\
\end{array}$ & $\begin{array}{c}\text { Dip } \\
\text { Direction } \\
\text { (deg. } \mathrm{MN})\end{array}$ & $\begin{array}{c}\text { Dip } \\
\text { Direction } \\
\text { (deg. TN) }\end{array}$ & $\begin{array}{c}\text { Dip } \\
\text { Angle } \\
\text { (degrees) } \\
\end{array}$ & $\begin{array}{c}\text { Feature } \\
\text { Rank } \\
(0 \text { to } 5)\end{array}$ \\
\hline 1 & 4.56 & 15.0 & 88 & 101 & 8 & 4 \\
\hline 2 & 4.79 & 15.7 & 139 & 152 & 19 & 3 \\
\hline 3 & 4.83 & 15.8 & 157 & 170 & 11 & 3 \\
\hline 4 & 5.27 & 17.3 & 111 & 124 & 86 & 3 \\
\hline 5 & 5.88 & 19.3 & 148 & 161 & 16 & 1 \\
\hline 6 & 5.96 & 19.6 & 19 & 32 & 25 & 1 \\
\hline 7 & 5.98 & 19.6 & 255 & 268 & 1 & 3 \\
\hline 8 & 6.01 & 19.7 & 105 & 118 & 8 & 2 \\
\hline 9 & 6.26 & 20.6 & 18 & 30 & 24 & 1 \\
\hline 10 & 6.32 & 20.7 & 86 & 99 & 9 & 3 \\
\hline 11 & 6.34 & 20.8 & 60 & 73 & 10 & 1 \\
\hline 12 & 6.36 & 20.9 & 91 & 104 & 14 & 3 \\
\hline 13 & 6.41 & 21.0 & 36 & 49 & 14 & 1 \\
\hline 14 & 6.43 & 21.1 & 46 & 59 & 16 & 1 \\
\hline 15 & 6.64 & 21.8 & 51 & 64 & 14 & 3 \\
\hline 16 & 7.19 & 23.6 & 70 & 83 & 3 & 2 \\
\hline 17 & 7.21 & 23.6 & 98 & 110 & 14 & 2 \\
\hline 18 & 7.71 & 25.3 & 55 & 68 & 57 & 2 \\
\hline 19 & 7.73 & 25.4 & 256 & 269 & 24 & 1 \\
\hline 20 & 7.75 & 25.4 & 53 & 66 & 59 & 3 \\
\hline 21 & 7.80 & 25.6 & 54 & 67 & 8 & 4 \\
\hline 22 & 7.83 & 25.7 & 135 & 148 & 8 & 2 \\
\hline 23 & 7.85 & 25.8 & 54 & 66 & 64 & 1 \\
\hline 24 & 7.90 & 25.9 & 113 & 126 & 4 & 3 \\
\hline 25 & 7.92 & 26.0 & 73 & 85 & 3 & 1 \\
\hline 26 & 7.95 & 26.1 & 102 & 115 & 6 & 3 \\
\hline 27 & 8.49 & 27.8 & 108 & 121 & 80 & 1 \\
\hline 28 & 8.53 & 28.0 & 33 & 46 & 2 & 2 \\
\hline 29 & 8.54 & 28.0 & 117 & 130 & 88 & 1 \\
\hline 30 & 8.56 & 28.1 & 63 & 76 & 10 & 1 \\
\hline 31 & 8.58 & 28.2 & 95 & 108 & 8 & 2 \\
\hline 32 & 8.62 & 28.3 & 85 & 98 & 14 & 3 \\
\hline 33 & 9.10 & 29.9 & 275 & 288 & 16 & 2 \\
\hline 34 & 9.31 & 30.6 & 79 & 92 & 68 & 2 \\
\hline 35 & 9.40 & 30.8 & 73 & 86 & 71 & 1 \\
\hline 36 & 9.49 & 31.1 & 80 & 93 & 66 & 3 \\
\hline 37 & 9.53 & 31.3 & 95 & 108 & 8 & 2 \\
\hline 38 & 9.56 & 31.4 & 94 & 106 & 4 & 2 \\
\hline 39 & 9.59 & 31.5 & 29 & 42 & 6 & 1 \\
\hline 40 & 9.80 & 32.2 & 79 & 92 & 75 & 3 \\
\hline 41 & 9.83 & 32.3 & 80 & 93 & 7 & 2 \\
\hline 42 & 9.87 & 32.4 & 69 & 82 & 12 & 2 \\
\hline 43 & 10.01 & 32.9 & 114 & 127 & 14 & 3 \\
\hline 44 & 10.10 & 33.1 & 89 & 102 & 8 & 2 \\
\hline 45 & 10.16 & 33.3 & 117 & 130 & 8 & 2 \\
\hline
\end{tabular}

All directions have been corrected for borehole deviation, and are with respect to true north. 
Orientation Summary Table

Acoustic Televiewer Features

Nevada Test Site

Source Physics Experiment

U-15N

NNSA/NSO

31 July 2010

\begin{tabular}{|c|c|c|c|c|c|c|}
\hline $\begin{array}{c}\text { Feature } \\
\text { No. }\end{array}$ & $\begin{array}{c}\text { Depth } \\
\text { (meters) }\end{array}$ & $\begin{array}{l}\text { Depth } \\
\text { (feet) }\end{array}$ & $\begin{array}{c}\text { Dip } \\
\text { Direction } \\
\text { (deg. MN) }\end{array}$ & $\begin{array}{c}\text { Dip } \\
\text { Direction } \\
\text { (deg. TN) }\end{array}$ & $\begin{array}{c}\text { Dip } \\
\text { Angle } \\
\text { (degrees) }\end{array}$ & $\begin{array}{c}\text { Feature } \\
\text { Rank } \\
\text { (0 to 5) }\end{array}$ \\
\hline 46 & 10.35 & 34.0 & 242 & 255 & 3 & 2 \\
\hline 47 & 10.38 & 34.1 & 244 & 256 & 1 & 3 \\
\hline 48 & 10.63 & 34.9 & 117 & 130 & 77 & 1 \\
\hline 49 & 10.74 & 35.3 & 90 & 103 & 10 & 1 \\
\hline 50 & 10.98 & 36.0 & 13 & 26 & 27 & 1 \\
\hline 51 & 11.03 & 36.2 & 89 & 102 & 8 & 1 \\
\hline 52 & 11.06 & 36.3 & 199 & 212 & 5 & 1 \\
\hline 53 & 11.08 & 36.4 & 133 & 146 & 17 & 2 \\
\hline 54 & 11.27 & 37.0 & 56 & 69 & 12 & 1 \\
\hline 55 & 11.51 & 37.8 & 58 & 71 & 3 & 2 \\
\hline 56 & 11.55 & 37.9 & 69 & 82 & 10 & 3 \\
\hline 57 & 11.75 & 38.6 & 160 & 173 & 9 & 1 \\
\hline 58 & 11.86 & 38.9 & 109 & 122 & 8 & 2 \\
\hline 59 & 12.18 & 40.0 & 80 & 93 & 12 & 2 \\
\hline 60 & 12.50 & 41.0 & 344 & 356 & 6 & 1 \\
\hline 61 & 12.53 & 41.1 & 105 & 117 & 55 & 2 \\
\hline 62 & 12.80 & 42.0 & 142 & 155 & 51 & 1 \\
\hline 63 & 12.80 & 42.0 & 11 & 24 & 11 & 1 \\
\hline 64 & 12.89 & 42.3 & 77 & 90 & 14 & 2 \\
\hline 65 & 12.91 & 42.4 & 83 & 96 & 19 & 1 \\
\hline 66 & 13.08 & 42.9 & 132 & 144 & 69 & 1 \\
\hline 67 & 13.12 & 43.0 & 77 & 90 & 36 & 1 \\
\hline 68 & 13.31 & 43.7 & 64 & 77 & 6 & 2 \\
\hline 69 & 13.35 & 43.8 & 47 & 60 & 6 & 2 \\
\hline 70 & 13.39 & 43.9 & 63 & 76 & 7 & 2 \\
\hline 71 & 13.52 & 44.4 & 70 & 83 & 14 & 2 \\
\hline 72 & 13.57 & 44.5 & 43 & 56 & 1 & 2 \\
\hline 73 & 13.60 & 44.6 & 42 & 55 & 10 & 3 \\
\hline 74 & 13.62 & 44.7 & 166 & 179 & 2 & 1 \\
\hline 75 & 14.22 & 46.6 & 56 & 68 & 5 & 2 \\
\hline 76 & 14.34 & 47.1 & 75 & 88 & 5 & 2 \\
\hline 77 & 14.37 & 47.1 & 82 & 95 & 8 & 2 \\
\hline 78 & 14.74 & 48.4 & 28 & 41 & 27 & 1 \\
\hline 79 & 15.02 & 49.3 & 85 & 98 & 20 & 2 \\
\hline 80 & 15.28 & 50.1 & 123 & 135 & 11 & 1 \\
\hline 81 & 15.30 & 50.2 & 120 & 132 & 13 & 2 \\
\hline 82 & 15.51 & 50.9 & 177 & 190 & 82 & 1 \\
\hline 83 & 15.87 & 52.1 & 149 & 162 & 2 & 2 \\
\hline 84 & 15.89 & 52.1 & 70 & 82 & 12 & 2 \\
\hline 85 & 15.93 & 52.3 & 99 & 111 & 10 & 1 \\
\hline 86 & 16.28 & 53.4 & 81 & 94 & 12 & 2 \\
\hline 87 & 16.31 & 53.5 & 96 & 109 & 16 & 3 \\
\hline 88 & 16.34 & 53.6 & 112 & 125 & 10 & 1 \\
\hline 89 & 16.43 & 53.9 & 101 & 114 & 24 & 1 \\
\hline 90 & 16.60 & 54.5 & 348 & 0 & 84 & 3 \\
\hline
\end{tabular}

All directions have been corrected for borehole deviation, and are with respect to true north.

Page 2 
Orientation Summary Table

Acoustic Televiewer Features

Nevada Test Site

Source Physics Experiment

U-15N

NNSA/NSO

31 July 2010

\begin{tabular}{|c|c|c|c|c|c|c|}
\hline $\begin{array}{c}\text { Feature } \\
\text { No. }\end{array}$ & $\begin{array}{c}\text { Depth } \\
\text { (meters) }\end{array}$ & $\begin{array}{l}\text { Depth } \\
\text { (feet) } \\
\end{array}$ & $\begin{array}{c}\text { Dip } \\
\text { Direction } \\
\text { (deg. MN) }\end{array}$ & $\begin{array}{c}\text { Dip } \\
\text { Direction } \\
\text { (deg. TN) }\end{array}$ & $\begin{array}{c}\text { Dip } \\
\text { Angle } \\
\text { (degrees) } \\
\end{array}$ & $\begin{array}{c}\text { Feature } \\
\text { Rank } \\
\text { (0 to 5) } \\
\end{array}$ \\
\hline 91 & 16.74 & 54.9 & 360 & 13 & 26 & 1 \\
\hline 92 & 16.87 & 55.4 & 105 & 118 & 4 & 2 \\
\hline 93 & 16.89 & 55.4 & 251 & 264 & 67 & 2 \\
\hline 94 & 16.90 & 55.4 & 91 & 104 & 10 & 2 \\
\hline 95 & 17.12 & 56.2 & 32 & 44 & 27 & 1 \\
\hline 96 & 17.17 & 56.3 & 38 & 51 & 30 & 1 \\
\hline 97 & 17.34 & 56.9 & 80 & 93 & 3 & 2 \\
\hline 98 & 17.36 & 57.0 & 80 & 93 & 10 & 2 \\
\hline 99 & 17.47 & 57.3 & 121 & 134 & 10 & 2 \\
\hline 100 & 17.50 & 57.4 & 136 & 149 & 6 & 1 \\
\hline 101 & 18.13 & 59.5 & 62 & 75 & 71 & 2 \\
\hline 102 & 18.20 & 59.7 & 7 & 20 & 23 & 2 \\
\hline 103 & 18.31 & 60.1 & 45 & 58 & 3 & 2 \\
\hline 104 & 18.98 & 62.3 & 113 & 126 & 78 & 3 \\
\hline 105 & 19.25 & 63.2 & 232 & 245 & 27 & 1 \\
\hline 106 & 19.50 & 64.0 & 119 & 132 & 80 & 3 \\
\hline 107 & 20.39 & 66.9 & 14 & 26 & 8 & 1 \\
\hline 108 & 20.42 & 67.0 & 14 & 27 & 8 & 2 \\
\hline 109 & 20.49 & 67.2 & 48 & 61 & 7 & 2 \\
\hline 110 & 20.51 & 67.3 & 61 & 74 & 7 & 2 \\
\hline 111 & 20.74 & 68.1 & 51 & 64 & 3 & 1 \\
\hline 112 & 20.77 & 68.1 & 60 & 73 & 8 & 2 \\
\hline 113 & 21.58 & 70.8 & 84 & 97 & 1 & 1 \\
\hline 114 & 22.81 & 74.9 & 12 & 25 & 68 & 3 \\
\hline 115 & 22.83 & 74.9 & 33 & 46 & 6 & 2 \\
\hline 116 & 23.43 & 76.9 & 30 & 43 & 83 & 1 \\
\hline 117 & 23.50 & 77.1 & 7 & 20 & 86 & 2 \\
\hline 118 & 24.21 & 79.4 & 355 & 7 & 81 & 5 \\
\hline 119 & 24.65 & 80.9 & 358 & 11 & 76 & 5 \\
\hline 120 & 25.31 & 83.1 & 13 & 26 & 83 & 4 \\
\hline 121 & 25.38 & 83.3 & 257 & 270 & 73 & 3 \\
\hline 122 & 25.51 & 83.7 & 259 & 272 & 64 & 4 \\
\hline 123 & 25.75 & 84.5 & 268 & 281 & 72 & 2 \\
\hline 124 & 25.92 & 85.0 & 275 & 288 & 72 & 4 \\
\hline 125 & 26.09 & 85.6 & 273 & 286 & 81 & 1 \\
\hline 126 & 26.54 & 87.1 & 261 & 274 & 80 & 1 \\
\hline 127 & 26.94 & 88.4 & 74 & 87 & 14 & 2 \\
\hline 128 & 26.94 & 88.4 & 5 & 18 & 77 & 4 \\
\hline 129 & 27.09 & 88.9 & 3 & 16 & 84 & 1 \\
\hline 130 & 27.20 & 89.3 & 81 & 94 & 12 & 3 \\
\hline 131 & 27.35 & 89.7 & 56 & 69 & 8 & 1 \\
\hline 132 & 27.80 & 91.2 & 20 & 33 & 10 & 2 \\
\hline 133 & 27.99 & 91.8 & 121 & 134 & 8 & 2 \\
\hline 134 & 28.02 & 91.9 & 106 & 119 & 10 & 2 \\
\hline 135 & 28.38 & 93.1 & 75 & 88 & 8 & 1 \\
\hline
\end{tabular}

All directions have been corrected for borehole deviation, and are with respect to true north.

Page 3 
Orientation Summary Table

Acoustic Televiewer Features

Nevada Test Site

Source Physics Experiment

U-15N

NNSA/NSO

31 July 2010

\begin{tabular}{|c|c|c|c|c|c|c|}
\hline $\begin{array}{c}\text { Feature } \\
\text { No. }\end{array}$ & $\begin{array}{c}\text { Depth } \\
\text { (meters) }\end{array}$ & $\begin{array}{l}\text { Depth } \\
\text { (feet) }\end{array}$ & $\begin{array}{c}\text { Dip } \\
\text { Direction } \\
\text { (deg. MN) }\end{array}$ & $\begin{array}{c}\text { Dip } \\
\text { Direction } \\
\text { (deg. TN) }\end{array}$ & $\begin{array}{c}\text { Dip } \\
\text { Angle } \\
\text { (degrees) }\end{array}$ & $\begin{array}{c}\text { Feature } \\
\text { Rank } \\
\text { (0 to 5) }\end{array}$ \\
\hline 136 & 28.69 & 94.1 & 48 & 61 & 8 & 1 \\
\hline 137 & 29.85 & 97.9 & 29 & 42 & 24 & 1 \\
\hline 138 & 30.15 & 98.9 & 41 & 53 & 10 & 1 \\
\hline 139 & 30.36 & 99.6 & 27 & 40 & 26 & 1 \\
\hline 140 & 30.52 & 100.1 & 35 & 48 & 10 & 1 \\
\hline 141 & 31.03 & 101.8 & 52 & 65 & 4 & 2 \\
\hline 142 & 31.05 & 101.9 & 64 & 77 & 10 & 3 \\
\hline 143 & 31.14 & 102.2 & 59 & 72 & 10 & 1 \\
\hline 144 & 31.32 & 102.8 & 66 & 79 & 18 & 3 \\
\hline 145 & 31.42 & 103.1 & 194 & 207 & 81 & 3 \\
\hline 146 & 31.89 & 104.6 & 189 & 201 & 83 & 4 \\
\hline 147 & 32.10 & 105.3 & 193 & 205 & 80 & 4 \\
\hline 148 & 32.34 & 106.1 & 200 & 213 & 64 & 5 \\
\hline 149 & 32.55 & 106.8 & 62 & 75 & 9 & 2 \\
\hline 150 & 32.56 & 106.8 & 191 & 204 & 70 & 1 \\
\hline 151 & 32.65 & 107.1 & 202 & 215 & 74 & 2 \\
\hline 152 & 32.81 & 107.6 & 188 & 201 & 74 & 1 \\
\hline 153 & 32.83 & 107.7 & 194 & 207 & 73 & 2 \\
\hline 154 & 33.21 & 109.0 & 66 & 79 & 18 & 1 \\
\hline 155 & 33.75 & 110.7 & 14 & 26 & 26 & 1 \\
\hline 156 & 34.00 & 111.6 & 124 & 137 & 75 & 3 \\
\hline 157 & 34.08 & 111.8 & 118 & 130 & 76 & 3 \\
\hline 158 & 34.49 & 113.2 & 50 & 63 & 12 & 2 \\
\hline 159 & 34.74 & 114.0 & 195 & 208 & 85 & 1 \\
\hline 160 & 35.01 & 114.9 & 54 & 66 & 4 & 1 \\
\hline 161 & 35.03 & 114.9 & 15 & 27 & 6 & 2 \\
\hline 162 & 35.08 & 115.1 & 342 & 355 & 70 & 1 \\
\hline 163 & 35.64 & 116.9 & 208 & 221 & 74 & 4 \\
\hline 164 & 35.74 & 117.3 & 206 & 219 & 78 & 1 \\
\hline 165 & 35.83 & 117.6 & 103 & 115 & 10 & 2 \\
\hline 166 & 35.85 & 117.6 & 108 & 121 & 16 & 2 \\
\hline 167 & 35.91 & 117.8 & 22 & 35 & 12 & 1 \\
\hline 168 & 36.28 & 119.0 & 36 & 49 & 13 & 2 \\
\hline 169 & 36.42 & 119.5 & 55 & 68 & 12 & 1 \\
\hline 170 & 36.64 & 120.2 & 37 & 50 & 20 & 1 \\
\hline 171 & 36.76 & 120.6 & 63 & 76 & 18 & 1 \\
\hline 172 & 36.82 & 120.8 & 111 & 124 & 80 & 2 \\
\hline 173 & 36.94 & 121.2 & 82 & 95 & 10 & 1 \\
\hline 174 & 37.14 & 121.9 & 46 & 59 & 22 & 1 \\
\hline 175 & 37.57 & 123.3 & 62 & 75 & 19 & 1 \\
\hline 176 & 37.61 & 123.4 & 93 & 106 & 78 & 1 \\
\hline 177 & 37.64 & 123.5 & 66 & 79 & 24 & 2 \\
\hline 178 & 37.68 & 123.6 & 68 & 81 & 22 & 3 \\
\hline 179 & 37.69 & 123.7 & 197 & 210 & 73 & 1 \\
\hline 180 & 37.80 & 124.0 & 25 & 38 & 79 & 2 \\
\hline
\end{tabular}

All directions have been corrected for borehole deviation, and are with respect to true north. 
Orientation Summary Table

Acoustic Televiewer Features

Nevada Test Site

Source Physics Experiment

U-15N

NNSA/NSO

31 July 2010

\begin{tabular}{|c|c|c|c|c|c|c|}
\hline $\begin{array}{c}\text { Feature } \\
\text { No. }\end{array}$ & $\begin{array}{c}\text { Depth } \\
\text { (meters) }\end{array}$ & $\begin{array}{l}\text { Depth } \\
\text { (feet) } \\
\end{array}$ & $\begin{array}{c}\text { Dip } \\
\text { Direction } \\
\text { (deg. MN) }\end{array}$ & $\begin{array}{c}\text { Dip } \\
\text { Direction } \\
\text { (deg. } \mathbf{T N}) \\
\end{array}$ & $\begin{array}{c}\text { Dip } \\
\text { Angle } \\
\text { (degrees) } \\
\end{array}$ & $\begin{array}{c}\text { Feature } \\
\text { Rank } \\
\text { (0 to 5) } \\
\end{array}$ \\
\hline 181 & 37.84 & 124.1 & 84 & 97 & 18 & 1 \\
\hline 182 & 37.93 & 124.4 & 74 & 87 & 18 & 2 \\
\hline 183 & 38.23 & 125.4 & 60 & 73 & 25 & 2 \\
\hline 184 & 38.31 & 125.7 & 183 & 195 & 7 & 2 \\
\hline 185 & 38.80 & 127.3 & 269 & 282 & 3 & 1 \\
\hline 186 & 38.82 & 127.4 & 82 & 95 & 14 & 2 \\
\hline 187 & 38.93 & 127.7 & 110 & 123 & 3 & 1 \\
\hline 188 & 38.95 & 127.8 & 77 & 90 & 10 & 2 \\
\hline 189 & 38.95 & 127.8 & 220 & 233 & 62 & 2 \\
\hline 190 & 39.61 & 129.9 & 115 & 128 & 86 & 2 \\
\hline 191 & 39.80 & 130.6 & 37 & 50 & 29 & 1 \\
\hline 192 & 40.05 & 131.4 & 99 & 112 & 12 & 2 \\
\hline 193 & 40.11 & 131.6 & 55 & 68 & 22 & 1 \\
\hline 194 & 40.20 & 131.9 & 256 & 268 & 3 & 1 \\
\hline 195 & 40.41 & 132.6 & 41 & 54 & 15 & 2 \\
\hline 196 & 40.69 & 133.5 & 161 & 174 & 56 & 3 \\
\hline 197 & 40.87 & 134.1 & 198 & 211 & 37 & 3 \\
\hline 198 & 41.05 & 134.7 & 68 & 80 & 25 & 2 \\
\hline 199 & 41.18 & 135.1 & 65 & 78 & 6 & 1 \\
\hline 200 & 41.20 & 135.2 & 73 & 86 & 12 & 3 \\
\hline 201 & 41.23 & 135.3 & 62 & 75 & 20 & 1 \\
\hline 202 & 41.29 & 135.5 & 26 & 39 & 20 & 2 \\
\hline 203 & 41.80 & 137.1 & 204 & 217 & 60 & 2 \\
\hline 204 & 42.06 & 138.0 & 61 & 73 & 19 & 1 \\
\hline 205 & 42.33 & 138.9 & 52 & 65 & 18 & 2 \\
\hline 206 & 42.43 & 139.2 & 207 & 220 & 73 & 1 \\
\hline 207 & 42.45 & 139.3 & 76 & 89 & 20 & 2 \\
\hline 208 & 42.89 & 140.7 & 246 & 259 & 3 & 1 \\
\hline 209 & 43.65 & 143.2 & 236 & 249 & 20 & 1 \\
\hline 210 & 45.11 & 148.0 & 212 & 225 & 43 & 1 \\
\hline 211 & 45.32 & 148.7 & 214 & 227 & 41 & 2 \\
\hline 212 & 45.41 & 149.0 & 211 & 224 & 59 & 3 \\
\hline 213 & 45.44 & 149.1 & 314 & 327 & 71 & 2 \\
\hline 214 & 45.57 & 149.5 & 275 & 288 & 69 & 1 \\
\hline 215 & 45.88 & 150.5 & 260 & 273 & 52 & 3 \\
\hline 216 & 45.93 & 150.7 & 237 & 250 & 60 & 2 \\
\hline 217 & 46.45 & 152.4 & 109 & 122 & 10 & 2 \\
\hline 218 & 46.66 & 153.1 & 313 & 325 & 3 & 1 \\
\hline 219 & 47.34 & 155.3 & 184 & 197 & 60 & 5 \\
\hline 220 & 47.50 & 155.9 & 99 & 112 & 79 & 1 \\
\hline 221 & 47.62 & 156.2 & 50 & 63 & 12 & 2 \\
\hline 222 & 47.75 & 156.7 & 89 & 102 & 78 & 3 \\
\hline 223 & 47.82 & 156.9 & 9 & 22 & 59 & 1 \\
\hline 224 & 47.93 & 157.3 & 6 & 19 & 75 & 1 \\
\hline 225 & 47.96 & 157.3 & 202 & 215 & 52 & 3 \\
\hline
\end{tabular}

All directions have been corrected for borehole deviation, and are with respect to true north.

Page 5 
Orientation Summary Table

Acoustic Televiewer Features

Nevada Test Site

Source Physics Experiment

U-15N

NNSA/NSO

31 July 2010

\begin{tabular}{|c|c|c|c|c|c|c|}
\hline $\begin{array}{c}\text { Feature } \\
\text { No. }\end{array}$ & $\begin{array}{c}\text { Depth } \\
\text { (meters) }\end{array}$ & $\begin{array}{l}\text { Depth } \\
\text { (feet) }\end{array}$ & $\begin{array}{c}\text { Dip } \\
\text { Direction } \\
\text { (deg. MN) }\end{array}$ & $\begin{array}{c}\text { Dip } \\
\text { Direction } \\
\text { (deg. TN) }\end{array}$ & $\begin{array}{c}\text { Dip } \\
\text { Angle } \\
\text { (degrees) }\end{array}$ & $\begin{array}{c}\text { Feature } \\
\text { Rank } \\
\text { (0 to 5) }\end{array}$ \\
\hline 226 & 47.98 & 157.4 & 341 & 354 & 72 & 1 \\
\hline 227 & 48.07 & 157.7 & 5 & 18 & 15 & 2 \\
\hline 228 & 48.26 & 158.3 & 159 & 171 & 50 & 3 \\
\hline 229 & 48.28 & 158.4 & 187 & 200 & 59 & 2 \\
\hline 230 & 48.41 & 158.8 & 70 & 83 & 12 & 1 \\
\hline 231 & 48.51 & 159.2 & 61 & 74 & 10 & 1 \\
\hline 232 & 48.58 & 159.4 & 247 & 260 & 77 & 2 \\
\hline 233 & 48.58 & 159.4 & 191 & 204 & 54 & 3 \\
\hline 234 & 48.81 & 160.1 & 340 & 353 & 7 & 1 \\
\hline 235 & 48.82 & 160.2 & 340 & 353 & 8 & 1 \\
\hline 236 & 49.31 & 161.8 & 105 & 117 & 6 & 1 \\
\hline 237 & 49.41 & 162.1 & 68 & 81 & 4 & 3 \\
\hline 238 & 49.53 & 162.5 & 206 & 219 & 58 & 2 \\
\hline 239 & 49.54 & 162.5 & 188 & 201 & 42 & 1 \\
\hline 240 & 49.59 & 162.7 & 292 & 305 & 75 & 1 \\
\hline 241 & 49.65 & 162.9 & 309 & 322 & 9 & 1 \\
\hline 242 & 49.89 & 163.7 & 107 & 120 & 10 & 2 \\
\hline 243 & 49.94 & 163.9 & 107 & 120 & 73 & 1 \\
\hline 244 & 50.28 & 165.0 & 51 & 64 & 16 & 1 \\
\hline 245 & 50.35 & 165.2 & 27 & 40 & 8 & 2 \\
\hline 246 & 50.46 & 165.5 & 59 & 72 & 8 & 1 \\
\hline 247 & 50.48 & 165.6 & 71 & 84 & 16 & 1 \\
\hline 248 & 50.56 & 165.9 & 66 & 79 & 7 & 1 \\
\hline 249 & 50.67 & 166.2 & 64 & 77 & 10 & 3 \\
\hline 250 & 50.99 & 167.3 & 69 & 81 & 1 & 2 \\
\hline 251 & 51.01 & 167.4 & 213 & 226 & 23 & 1 \\
\hline 252 & 51.07 & 167.6 & 196 & 209 & 31 & 3 \\
\hline 253 & 51.10 & 167.7 & 21 & 34 & 29 & 1 \\
\hline 254 & 51.18 & 167.9 & 200 & 213 & 74 & 4 \\
\hline 255 & 51.23 & 168.1 & 282 & 294 & 30 & 1 \\
\hline 256 & 51.39 & 168.6 & 188 & 201 & 65 & 4 \\
\hline 257 & 51.49 & 168.9 & 35 & 48 & 22 & 1 \\
\hline 258 & 51.51 & 169.0 & 69 & 81 & 12 & 3 \\
\hline 259 & 51.55 & 169.1 & 24 & 37 & 80 & 1 \\
\hline 260 & 51.65 & 169.5 & 215 & 228 & 67 & 2 \\
\hline 261 & 51.74 & 169.8 & 216 & 229 & 63 & 1 \\
\hline 262 & 51.91 & 170.3 & 38 & 51 & 22 & 2 \\
\hline 263 & 51.95 & 170.4 & 195 & 208 & 66 & 4 \\
\hline 264 & 52.01 & 170.7 & 61 & 74 & 20 & 2 \\
\hline 265 & 52.23 & 171.4 & 41 & 54 & 23 & 1 \\
\hline 266 & 52.25 & 171.4 & 209 & 222 & 73 & 1 \\
\hline 267 & 52.26 & 171.5 & 144 & 157 & 11 & 1 \\
\hline 268 & 52.33 & 171.7 & 109 & 122 & 20 & 2 \\
\hline 269 & 52.68 & 172.8 & 114 & 127 & 81 & 3 \\
\hline 270 & 52.70 & 172.9 & 95 & 108 & 10 & 2 \\
\hline
\end{tabular}

All directions have been corrected for borehole deviation, and are with respect to true north. 
Orientation Summary Table

Acoustic Televiewer Features

Nevada Test Site

Source Physics Experiment

$\mathrm{U}-15 \mathrm{~N}$

NNSA/NSO

31 July 2010

\begin{tabular}{|c|c|c|c|c|c|c|}
\hline $\begin{array}{c}\text { Feature } \\
\text { No. }\end{array}$ & $\begin{array}{c}\text { Depth } \\
\text { (meters) }\end{array}$ & $\begin{array}{l}\text { Depth } \\
\text { (feet) }\end{array}$ & $\begin{array}{c}\text { Dip } \\
\text { Direction } \\
\text { (deg. } \mathrm{MN} \text { ) }\end{array}$ & $\begin{array}{c}\text { Dip } \\
\text { Direction } \\
(\text { deg. } T N)\end{array}$ & $\begin{array}{c}\text { Dip } \\
\text { Angle } \\
\text { (degrees) }\end{array}$ & $\begin{array}{c}\text { Feature } \\
\text { Rank } \\
(0 \text { to } 5)\end{array}$ \\
\hline 271 & 52.73 & 173.0 & 67 & 80 & 12 & 3 \\
\hline 272 & 52.82 & 173.3 & 116 & 129 & 81 & 2 \\
\hline 273 & 53.13 & 174.3 & 116 & 129 & 83 & 1 \\
\hline 274 & 53.15 & 174.4 & 12 & 25 & 13 & 3 \\
\hline 275 & 53.18 & 174.5 & 39 & 52 & 18 & 3 \\
\hline 276 & 53.45 & 175.4 & 199 & 211 & 74 & 3 \\
\hline 277 & 53.46 & 175.4 & 61 & 74 & 18 & 2 \\
\hline 278 & 53.50 & 175.5 & 37 & 49 & 80 & 1 \\
\hline 279 & 53.69 & 176.1 & 114 & 127 & 79 & 1 \\
\hline 280 & 53.74 & 176.3 & 68 & 81 & 10 & 3 \\
\hline 281 & 54.57 & 179.0 & 88 & 101 & 15 & 3 \\
\hline 282 & 54.68 & 179.4 & 189 & 202 & 85 & 1 \\
\hline 283 & 54.70 & 179.5 & 75 & 88 & 4 & 2 \\
\hline 284 & 54.82 & 179.8 & 239 & 252 & 43 & 3 \\
\hline 285 & 54.83 & 179.9 & 279 & 292 & 56 & 1 \\
\hline 286 & 55.19 & 181.1 & 49 & 62 & 8 & 1 \\
\hline 287 & 55.29 & 181.4 & 67 & 80 & 12 & 1 \\
\hline 288 & 55.44 & 181.9 & 182 & 194 & 35 & 2 \\
\hline 289 & 55.60 & 182.4 & 6 & 19 & 84 & 2 \\
\hline 290 & 55.61 & 182.5 & 42 & 55 & 22 & 2 \\
\hline 291 & 55.83 & 183.2 & 20 & 33 & 77 & 1 \\
\hline 292 & 55.87 & 183.3 & 6 & 19 & 14 & 2 \\
\hline 293 & 56.49 & 185.3 & 153 & 166 & 2 & 1 \\
\hline 294 & 56.51 & 185.4 & 43 & 56 & 14 & 3 \\
\hline 295 & 57.20 & 187.7 & 67 & 80 & 20 & 1 \\
\hline 296 & 57.27 & 187.9 & 270 & 283 & 33 & 1 \\
\hline 297 & 57.32 & 188.1 & 247 & 260 & 43 & 2 \\
\hline 298 & 57.49 & 188.6 & 34 & 47 & 8 & 2 \\
\hline 299 & 57.52 & 188.7 & 249 & 262 & 57 & 2 \\
\hline 300 & 57.56 & 188.9 & 251 & 264 & 53 & 2 \\
\hline
\end{tabular}

All directions have been corrected for borehole deviation, and are with respect to true north. 
Appendix J-2

Fracture Data Tabulated from Borehole Image Logs by Colog, Inc. for Instrument Hole U-15n\#1 
Orientation Summary Table - Image Features

Nevada Test Site

Source Physics Experiment

U-15N \#1

NNSA/NSO

21 Sept 2010

\begin{tabular}{|c|c|c|c|c|c|c|}
\hline $\begin{array}{c}\text { Feature } \\
\text { No. }\end{array}$ & $\begin{array}{c}\text { Depth } \\
\text { (meters) }\end{array}$ & $\begin{array}{l}\text { Depth } \\
\text { (feet) }\end{array}$ & $\begin{array}{c}\text { Dip } \\
\text { Direction } \\
\text { (degrees) }\end{array}$ & $\begin{array}{c}\text { Dip } \\
\text { Direction } \\
(\text { deg. } T N)\end{array}$ & $\begin{array}{c}\text { Dip } \\
\text { Angle } \\
\text { (degrees) }\end{array}$ & $\begin{array}{c}\text { Feature } \\
\text { Rank } \\
\text { (0 to 5) }\end{array}$ \\
\hline 1 & 2.17 & 7.1 & 120 & 133 & 75 & 3 \\
\hline 2 & 2.20 & 7.2 & 178 & 190 & 38 & 4 \\
\hline 3 & 2.29 & 7.5 & 181 & 194 & 7 & 0 \\
\hline 4 & 2.66 & 8.7 & 64 & 77 & 25 & 0 \\
\hline 5 & 2.76 & 9.1 & 52 & 65 & 21 & 0 \\
\hline 6 & 2.94 & 9.6 & 49 & 62 & 6 & 0 \\
\hline 7 & 3.00 & 9.8 & 47 & 60 & 10 & 0 \\
\hline 8 & 3.27 & 10.7 & 231 & 244 & 19 & 0 \\
\hline 9 & 3.29 & 10.8 & 29 & 42 & 34 & 0 \\
\hline 10 & 3.64 & 12.0 & 82 & 94 & 18 & 1 \\
\hline 11 & 3.81 & 12.5 & 28 & 41 & 15 & 1 \\
\hline 12 & 3.84 & 12.6 & 27 & 40 & 8 & 2 \\
\hline 13 & 3.88 & 12.7 & 346 & 358 & 14 & 0 \\
\hline 14 & 3.89 & 12.8 & 104 & 117 & 66 & 1 \\
\hline 15 & 3.97 & 13.0 & 318 & 330 & 27 & 1 \\
\hline 16 & 3.98 & 13.1 & 32 & 44 & 32 & 1 \\
\hline 17 & 4.03 & 13.2 & 26 & 39 & 22 & 1 \\
\hline 18 & 4.15 & 13.6 & 41 & 54 & 24 & 2 \\
\hline 19 & 4.33 & 14.2 & 8 & 21 & 24 & 2 \\
\hline 20 & 4.33 & 14.2 & 19 & 32 & 35 & 3 \\
\hline 21 & 4.54 & 14.9 & 95 & 108 & 8 & 0 \\
\hline 22 & 4.72 & 15.5 & 7 & 20 & 77 & 2 \\
\hline 23 & 4.91 & 16.1 & 92 & 105 & 49 & 1 \\
\hline 24 & 4.99 & 16.4 & 149 & 162 & 59 & 1 \\
\hline 25 & 5.16 & 16.9 & 9 & 22 & 80 & 1 \\
\hline 26 & 5.87 & 19.3 & 54 & 67 & 7 & 2 \\
\hline 27 & 6.46 & 21.2 & 5 & 18 & 25 & 1 \\
\hline 28 & 6.54 & 21.5 & 175 & 187 & 13 & 1 \\
\hline 29 & 6.61 & 21.7 & 188 & 201 & 24 & 1 \\
\hline 30 & 6.62 & 21.7 & 354 & 7 & 27 & 1 \\
\hline 31 & 7.26 & 23.8 & 189 & 202 & 80 & 1 \\
\hline 32 & 7.51 & 24.6 & 114 & 127 & 9 & 2 \\
\hline 33 & 7.76 & 25.5 & 33 & 46 & 21 & 1 \\
\hline 34 & 8.04 & 26.4 & 21 & 33 & 22 & 0 \\
\hline 35 & 8.06 & 26.5 & 145 & 158 & 6 & 3 \\
\hline 36 & 8.11 & 26.6 & 70 & 83 & 13 & 1 \\
\hline 37 & 8.12 & 26.7 & 176 & 189 & 10 & 3 \\
\hline 38 & 8.18 & 26.9 & 123 & 135 & 7 & 2 \\
\hline 39 & 8.28 & 27.2 & 280 & 293 & 9 & 1 \\
\hline 40 & 8.41 & 27.6 & 195 & 208 & 84 & 2 \\
\hline 41 & 8.56 & 28.1 & 127 & 140 & 11 & 0 \\
\hline 42 & 8.62 & 28.3 & 118 & 130 & 10 & 2 \\
\hline 43 & 8.71 & 28.6 & 171 & 184 & 9 & 3 \\
\hline 44 & 8.72 & 28.6 & 343 & 356 & 17 & 3 \\
\hline 45 & 8.80 & 28.9 & 113 & 126 & 10 & 2 \\
\hline
\end{tabular}

All directions have been corrected for borehole deviation, and are with respect to true north.

Page 1 
Orientation Summary Table - Image Features

Nevada Test Site

Source Physics Experiment

U-15N \#1

NNSA/NSO

21 Sept 2010

\begin{tabular}{|c|c|c|c|c|c|c|}
\hline $\begin{array}{c}\text { Feature } \\
\text { No. }\end{array}$ & $\begin{array}{c}\text { Depth } \\
\text { (meters) }\end{array}$ & $\begin{array}{l}\text { Depth } \\
\text { (feet) }\end{array}$ & $\begin{array}{c}\text { Dip } \\
\text { Direction } \\
\text { (degrees) }\end{array}$ & $\begin{array}{c}\text { Dip } \\
\text { Direction } \\
(\text { deg. } T N)\end{array}$ & $\begin{array}{c}\text { Dip } \\
\text { Angle } \\
\text { (degrees) }\end{array}$ & $\begin{array}{c}\text { Feature } \\
\text { Rank } \\
\text { (0 to 5) }\end{array}$ \\
\hline 46 & 8.85 & 29.0 & 249 & 262 & 16 & 1 \\
\hline 47 & 9.08 & 29.8 & 49 & 61 & 15 & 3 \\
\hline 48 & 9.10 & 29.9 & 286 & 299 & 15 & 3 \\
\hline 49 & 9.21 & 30.2 & 10 & 23 & 25 & 0 \\
\hline 50 & 9.25 & 30.3 & 199 & 212 & 51 & 2 \\
\hline 51 & 9.26 & 30.4 & 109 & 122 & 8 & 1 \\
\hline 52 & 9.59 & 31.5 & 20 & 32 & 21 & 2 \\
\hline 53 & 9.71 & 31.9 & 76 & 89 & 6 & 0 \\
\hline 54 & 9.75 & 32.0 & 178 & 191 & 19 & 0 \\
\hline 55 & 9.86 & 32.3 & 31 & 43 & 12 & 1 \\
\hline 56 & 9.92 & 32.5 & 69 & 82 & 3 & 0 \\
\hline 57 & 9.96 & 32.7 & 91 & 104 & 12 & 2 \\
\hline 58 & 10.05 & 33.0 & 109 & 122 & 6 & 0 \\
\hline 59 & 10.14 & 33.3 & 110 & 123 & 8 & 0 \\
\hline 60 & 10.17 & 33.4 & 128 & 141 & 7 & 2 \\
\hline 61 & 10.19 & 33.4 & 99 & 112 & 5 & 0 \\
\hline 62 & 10.21 & 33.5 & 48 & 61 & 6 & 0 \\
\hline 63 & 10.28 & 33.7 & 115 & 128 & 9 & 2 \\
\hline 64 & 10.47 & 34.4 & 28 & 41 & 16 & 2 \\
\hline 65 & 10.53 & 34.6 & 111 & 124 & 9 & 1 \\
\hline 66 & 10.57 & 34.7 & 108 & 120 & 9 & 1 \\
\hline 67 & 10.68 & 35.1 & 53 & 66 & 6 & 2 \\
\hline 68 & 10.73 & 35.2 & 30 & 43 & 6 & 0 \\
\hline 69 & 10.77 & 35.3 & 111 & 124 & 9 & 0 \\
\hline 70 & 10.80 & 35.4 & 93 & 106 & 5 & 0 \\
\hline 71 & 10.91 & 35.8 & 257 & 270 & 14 & 1 \\
\hline 72 & 10.97 & 36.0 & 61 & 74 & 7 & 1 \\
\hline 73 & 10.99 & 36.1 & 196 & 209 & 15 & 0 \\
\hline 74 & 11.04 & 36.2 & 152 & 165 & 10 & 2 \\
\hline 75 & 11.13 & 36.5 & 85 & 98 & 9 & 0 \\
\hline 76 & 11.14 & 36.6 & 162 & 175 & 8 & 2 \\
\hline 77 & 11.23 & 36.8 & 1 & 14 & 21 & 2 \\
\hline 78 & 11.24 & 36.9 & 50 & 62 & 15 & 1 \\
\hline 79 & 11.28 & 37.0 & 120 & 133 & 7 & 0 \\
\hline 80 & 11.32 & 37.1 & 89 & 102 & 12 & 1 \\
\hline 81 & 11.35 & 37.2 & 79 & 92 & 16 & 1 \\
\hline 82 & 11.39 & 37.4 & 70 & 83 & 9 & 1 \\
\hline 83 & 11.45 & 37.6 & 124 & 137 & 7 & 0 \\
\hline 84 & 11.49 & 37.7 & 22 & 35 & 6 & 0 \\
\hline 85 & 11.51 & 37.8 & 112 & 125 & 35 & 0 \\
\hline 86 & 11.53 & 37.8 & 38 & 51 & 31 & 0 \\
\hline 87 & 11.57 & 38.0 & 143 & 156 & 7 & 3 \\
\hline 88 & 11.60 & 38.1 & 136 & 148 & 9 & 3 \\
\hline 89 & 11.61 & 38.1 & 184 & 196 & 81 & 2 \\
\hline 90 & 11.68 & 38.3 & 113 & 125 & 7 & 2 \\
\hline
\end{tabular}

All directions have been corrected for borehole deviation, and are with respect to true north.

Page 2 
Orientation Summary Table - Image Features

Nevada Test Site

Source Physics Experiment

U-15N \#1

NNSA/NSO

21 Sept 2010

\begin{tabular}{|c|c|c|c|c|c|c|}
\hline $\begin{array}{c}\text { Feature } \\
\text { No. }\end{array}$ & $\begin{array}{c}\text { Depth } \\
\text { (meters) }\end{array}$ & $\begin{array}{l}\text { Depth } \\
\text { (feet) }\end{array}$ & $\begin{array}{c}\text { Dip } \\
\text { Direction } \\
\text { (degrees) }\end{array}$ & $\begin{array}{c}\text { Dip } \\
\text { Direction } \\
(\text { deg. } T N)\end{array}$ & $\begin{array}{c}\text { Dip } \\
\text { Angle } \\
\text { (degrees) }\end{array}$ & $\begin{array}{c}\text { Feature } \\
\text { Rank } \\
\text { (0 to 5) }\end{array}$ \\
\hline 91 & 11.80 & 38.7 & 354 & 7 & 4 & 1 \\
\hline 92 & 11.99 & 39.4 & 143 & 156 & 11 & 2 \\
\hline 93 & 12.13 & 39.8 & 115 & 128 & 8 & 1 \\
\hline 94 & 12.27 & 40.2 & 28 & 41 & 19 & 1 \\
\hline 95 & 12.30 & 40.3 & 157 & 170 & 13 & 1 \\
\hline 96 & 12.38 & 40.6 & 43 & 56 & 82 & 1 \\
\hline 97 & 12.48 & 41.0 & 35 & 47 & 25 & 0 \\
\hline 98 & 12.57 & 41.3 & 74 & 87 & 9 & 0 \\
\hline 99 & 12.71 & 41.7 & 47 & 60 & 6 & 2 \\
\hline 100 & 12.77 & 41.9 & 68 & 81 & 21 & 0 \\
\hline 101 & 12.91 & 42.3 & 13 & 26 & 64 & 3 \\
\hline 102 & 13.47 & 44.2 & 185 & 198 & 45 & 2 \\
\hline 103 & 13.51 & 44.3 & 88 & 101 & 5 & 0 \\
\hline 104 & 13.66 & 44.8 & 108 & 121 & 11 & 0 \\
\hline 105 & 13.94 & 45.7 & 20 & 33 & 33 & 0 \\
\hline 106 & 14.10 & 46.3 & 340 & 353 & 9 & 1 \\
\hline 107 & 14.14 & 46.4 & 331 & 344 & 63 & 1 \\
\hline 108 & 14.35 & 47.1 & 147 & 160 & 8 & 0 \\
\hline 109 & 14.69 & 48.2 & 132 & 144 & 13 & 1 \\
\hline 110 & 15.10 & 49.5 & 60 & 73 & 17 & 1 \\
\hline 111 & 15.12 & 49.6 & 283 & 296 & 18 & 1 \\
\hline 112 & 15.15 & 49.7 & 148 & 161 & 10 & 1 \\
\hline 113 & 15.26 & 50.1 & 117 & 130 & 21 & 0 \\
\hline 114 & 15.51 & 50.9 & 98 & 111 & 8 & 1 \\
\hline 115 & 16.48 & 54.1 & 104 & 117 & 72 & 2 \\
\hline 116 & 16.65 & 54.6 & 24 & 37 & 9 & 1 \\
\hline 117 & 16.72 & 54.9 & 48 & 61 & 16 & 1 \\
\hline 118 & 16.90 & 55.4 & 120 & 133 & 10 & 2 \\
\hline 119 & 17.00 & 55.8 & 103 & 115 & 10 & 2 \\
\hline 120 & 17.31 & 56.8 & 30 & 43 & 27 & 0 \\
\hline 121 & 17.88 & 58.7 & 125 & 138 & 9 & 2 \\
\hline 122 & 18.10 & 59.4 & 19 & 32 & 25 & 0 \\
\hline 123 & 18.61 & 61.1 & 141 & 154 & 4 & 3 \\
\hline 124 & 18.67 & 61.3 & 125 & 137 & 6 & 3 \\
\hline 125 & 18.77 & 61.6 & 10 & 22 & 27 & 0 \\
\hline 126 & 19.12 & 62.7 & 29 & 42 & 28 & 3 \\
\hline 127 & 19.26 & 63.2 & 66 & 79 & 9 & 0 \\
\hline 128 & 19.36 & 63.5 & 104 & 117 & 78 & 3 \\
\hline 129 & 19.58 & 64.2 & 97 & 110 & 69 & 3 \\
\hline 130 & 19.64 & 64.5 & 224 & 236 & 13 & 1 \\
\hline 131 & 19.71 & 64.7 & 285 & 298 & 75 & 3 \\
\hline 132 & 19.77 & 64.9 & 41 & 53 & 4 & 2 \\
\hline 133 & 20.05 & 65.8 & 88 & 101 & 10 & 1 \\
\hline 134 & 20.06 & 65.8 & 29 & 42 & 27 & 1 \\
\hline 135 & 20.18 & 66.2 & 111 & 124 & 7 & 2 \\
\hline
\end{tabular}

All directions have been corrected for borehole deviation, and are with respect to true north.

Page 3 
Orientation Summary Table - Image Features

Nevada Test Site

Source Physics Experiment

U-15N \#1

NNSA/NSO

21 Sept 2010

\begin{tabular}{|c|c|c|c|c|c|c|}
\hline $\begin{array}{c}\text { Feature } \\
\text { No. }\end{array}$ & $\begin{array}{c}\text { Depth } \\
\text { (meters) }\end{array}$ & $\begin{array}{l}\text { Depth } \\
\text { (feet) }\end{array}$ & $\begin{array}{c}\text { Dip } \\
\text { Direction } \\
\text { (degrees) }\end{array}$ & $\begin{array}{c}\text { Dip } \\
\text { Direction } \\
(\text { deg. } T N)\end{array}$ & $\begin{array}{c}\text { Dip } \\
\text { Angle } \\
\text { (degrees) }\end{array}$ & $\begin{array}{c}\text { Feature } \\
\text { Rank } \\
\text { (0 to 5) }\end{array}$ \\
\hline 136 & 20.24 & 66.4 & 84 & 96 & 6 & 1 \\
\hline 137 & 20.58 & 67.5 & 97 & 110 & 13 & 1 \\
\hline 138 & 20.99 & 68.9 & 132 & 145 & 65 & 3 \\
\hline 139 & 21.31 & 69.9 & 64 & 76 & 11 & 2 \\
\hline 140 & 21.37 & 70.1 & 20 & 32 & 84 & 3 \\
\hline 141 & 21.39 & 70.2 & 208 & 221 & 77 & 3 \\
\hline 142 & 21.44 & 70.3 & 119 & 132 & 6 & 2 \\
\hline 143 & 21.51 & 70.6 & 100 & 113 & 5 & 3 \\
\hline 144 & 21.61 & 70.9 & 39 & 51 & 6 & 2 \\
\hline 145 & 21.64 & 71.0 & 53 & 66 & 83 & 3 \\
\hline 146 & 21.75 & 71.4 & 69 & 82 & 68 & 3 \\
\hline 147 & 21.86 & 71.7 & 46 & 59 & 84 & 3 \\
\hline 148 & 21.99 & 72.2 & 207 & 219 & 79 & 3 \\
\hline 149 & 22.14 & 72.6 & 33 & 46 & 28 & 3 \\
\hline 150 & 22.17 & 72.7 & 201 & 214 & 13 & 1 \\
\hline 151 & 22.33 & 73.3 & 34 & 47 & 8 & 1 \\
\hline 152 & 22.49 & 73.8 & 39 & 52 & 6 & 2 \\
\hline 153 & 22.80 & 74.8 & 213 & 226 & 17 & 1 \\
\hline 154 & 22.82 & 74.9 & 27 & 40 & 29 & 1 \\
\hline 155 & 23.25 & 76.3 & 225 & 238 & 19 & 0 \\
\hline 156 & 23.28 & 76.4 & 36 & 49 & 55 & 0 \\
\hline 157 & 23.66 & 77.6 & 44 & 56 & 11 & 3 \\
\hline 158 & 23.69 & 77.7 & 37 & 50 & 27 & 3 \\
\hline 159 & 24.10 & 79.1 & 0 & 13 & 3 & 2 \\
\hline 160 & 24.12 & 79.1 & 42 & 55 & 10 & 2 \\
\hline 161 & 24.13 & 79.2 & 7 & 20 & 33 & 0 \\
\hline 162 & 24.24 & 79.5 & 27 & 40 & 82 & 3 \\
\hline 163 & 24.42 & 80.1 & 92 & 105 & 7 & 3 \\
\hline 164 & 24.73 & 81.2 & 38 & 50 & 10 & 3 \\
\hline 165 & 24.82 & 81.4 & 49 & 62 & 11 & 3 \\
\hline 166 & 24.91 & 81.7 & 261 & 274 & 51 & 3 \\
\hline 167 & 24.96 & 81.9 & 33 & 46 & 14 & 0 \\
\hline 168 & 24.99 & 82.0 & 28 & 41 & 22 & 0 \\
\hline 169 & 25.04 & 82.1 & 193 & 206 & 45 & 0 \\
\hline 170 & 25.22 & 82.7 & 29 & 42 & 30 & 3 \\
\hline 171 & 25.26 & 82.9 & 43 & 56 & 11 & 3 \\
\hline 172 & 25.53 & 83.8 & 103 & 116 & 9 & 0 \\
\hline 173 & 25.54 & 83.8 & 201 & 214 & 89 & 3 \\
\hline 174 & 25.63 & 84.1 & 213 & 226 & 70 & 3 \\
\hline 175 & 25.64 & 84.1 & 34 & 47 & 13 & 3 \\
\hline 176 & 25.72 & 84.4 & 27 & 40 & 9 & 3 \\
\hline 177 & 25.99 & 85.3 & 274 & 287 & 45 & 0 \\
\hline 178 & 26.44 & 86.7 & 3 & 16 & 67 & 3 \\
\hline 179 & 26.72 & 87.7 & 141 & 153 & 31 & 0 \\
\hline 180 & 26.72 & 87.7 & 42 & 55 & 8 & 1 \\
\hline
\end{tabular}

All directions have been corrected for borehole deviation, and are with respect to true north. 
Orientation Summary Table - Image Features

Nevada Test Site

Source Physics Experiment

U-15N \#1

NNSA/NSO

21 Sept 2010

\begin{tabular}{|c|c|c|c|c|c|c|}
\hline $\begin{array}{c}\text { Feature } \\
\text { No. }\end{array}$ & $\begin{array}{c}\text { Depth } \\
\text { (meters) }\end{array}$ & $\begin{array}{l}\text { Depth } \\
\text { (feet) }\end{array}$ & $\begin{array}{c}\text { Dip } \\
\text { Direction } \\
\text { (degrees) }\end{array}$ & $\begin{array}{c}\text { Dip } \\
\text { Direction } \\
(\text { deg. } T N)\end{array}$ & $\begin{array}{c}\text { Dip } \\
\text { Angle } \\
\text { (degrees) }\end{array}$ & $\begin{array}{c}\text { Feature } \\
\text { Rank } \\
\text { (0 to 5) }\end{array}$ \\
\hline 181 & 26.96 & 88.5 & 86 & 99 & 37 & 3 \\
\hline 182 & 27.00 & 88.6 & 73 & 86 & 22 & 1 \\
\hline 183 & 27.06 & 88.8 & 78 & 91 & 65 & 3 \\
\hline 184 & 27.16 & 89.1 & 58 & 71 & 14 & 3 \\
\hline 185 & 27.37 & 89.8 & 151 & 164 & 9 & 3 \\
\hline 186 & 27.51 & 90.3 & 41 & 54 & 23 & 2 \\
\hline 187 & 27.67 & 90.8 & 300 & 313 & 1 & 3 \\
\hline 188 & 27.76 & 91.1 & 224 & 237 & 18 & 1 \\
\hline 189 & 27.81 & 91.3 & 36 & 49 & 24 & 1 \\
\hline 190 & 27.84 & 91.3 & 195 & 207 & 81 & 3 \\
\hline 191 & 27.88 & 91.5 & 1 & 14 & 12 & 3 \\
\hline 192 & 27.95 & 91.7 & 88 & 101 & 15 & 3 \\
\hline 193 & 28.01 & 91.9 & 90 & 103 & 9 & 3 \\
\hline 194 & 28.07 & 92.1 & 109 & 121 & 78 & 2 \\
\hline 195 & 28.14 & 92.3 & 29 & 42 & 24 & 0 \\
\hline 196 & 28.62 & 93.9 & 14 & 27 & 88 & 3 \\
\hline 197 & 28.66 & 94.0 & 100 & 113 & 9 & 2 \\
\hline 198 & 29.00 & 95.2 & 67 & 80 & 13 & 0 \\
\hline 199 & 29.26 & 96.0 & 69 & 82 & 7 & 0 \\
\hline 200 & 29.30 & 96.1 & 40 & 53 & 20 & 1 \\
\hline 201 & 29.41 & 96.5 & 16 & 29 & 17 & 0 \\
\hline 202 & 29.47 & 96.7 & 14 & 27 & 85 & 3 \\
\hline 203 & 29.59 & 97.1 & 81 & 93 & 16 & 1 \\
\hline 204 & 29.64 & 97.2 & 78 & 90 & 15 & 1 \\
\hline 205 & 29.72 & 97.5 & 280 & 293 & 37 & 2 \\
\hline 206 & 29.89 & 98.1 & 61 & 74 & 18 & 0 \\
\hline 207 & 29.92 & 98.2 & 218 & 231 & 73 & 3 \\
\hline 208 & 30.05 & 98.6 & 88 & 101 & 17 & 0 \\
\hline 209 & 30.09 & 98.7 & 72 & 85 & 15 & 0 \\
\hline 210 & 30.15 & 98.9 & 157 & 169 & 23 & 0 \\
\hline 211 & 30.34 & 99.5 & 334 & 347 & 38 & 3 \\
\hline 212 & 30.40 & 99.8 & 281 & 294 & 14 & 0 \\
\hline 213 & 30.50 & 100.1 & 24 & 37 & 15 & 1 \\
\hline 214 & 30.72 & 100.8 & 93 & 106 & 10 & 0 \\
\hline 215 & 30.87 & 101.3 & 30 & 43 & 10 & 1 \\
\hline 216 & 31.43 & 103.1 & 69 & 82 & 14 & 2 \\
\hline 217 & 31.57 & 103.6 & 42 & 55 & 16 & 1 \\
\hline 218 & 31.73 & 104.1 & 12 & 24 & 79 & 3 \\
\hline 219 & 31.75 & 104.2 & 191 & 204 & 11 & 0 \\
\hline 220 & 31.87 & 104.6 & 62 & 75 & 11 & 0 \\
\hline 221 & 31.93 & 104.8 & 198 & 211 & 51 & 3 \\
\hline 222 & 31.97 & 104.9 & 204 & 216 & 59 & 2 \\
\hline 223 & 32.17 & 105.6 & 36 & 48 & 25 & 0 \\
\hline 224 & 32.42 & 106.4 & 9 & 22 & 86 & 3 \\
\hline 225 & 32.53 & 106.7 & 150 & 163 & 13 & 0 \\
\hline
\end{tabular}

All directions have been corrected for borehole deviation, and are with respect to true north.

Page 5 
Orientation Summary Table - Image Features

Nevada Test Site

Source Physics Experiment

U-15N \#1

NNSA/NSO

21 Sept 2010

\begin{tabular}{|c|c|c|c|c|c|c|}
\hline $\begin{array}{c}\text { Feature } \\
\text { No. }\end{array}$ & $\begin{array}{c}\text { Depth } \\
\text { (meters) }\end{array}$ & $\begin{array}{l}\text { Depth } \\
\text { (feet) }\end{array}$ & $\begin{array}{c}\text { Dip } \\
\text { Direction } \\
\text { (degrees) }\end{array}$ & $\begin{array}{c}\text { Dip } \\
\text { Direction } \\
(\text { deg. } T N)\end{array}$ & $\begin{array}{c}\text { Dip } \\
\text { Angle } \\
\text { (degrees) }\end{array}$ & $\begin{array}{c}\text { Feature } \\
\text { Rank } \\
\text { (0 to 5) }\end{array}$ \\
\hline 226 & 32.58 & 106.9 & 44 & 57 & 12 & 1 \\
\hline 227 & 32.71 & 107.3 & 91 & 104 & 13 & 1 \\
\hline 228 & 32.77 & 107.5 & 186 & 199 & 62 & 3 \\
\hline 229 & 32.78 & 107.6 & 67 & 80 & 11 & 1 \\
\hline 230 & 32.82 & 107.7 & 43 & 56 & 20 & 0 \\
\hline 231 & 33.02 & 108.3 & 219 & 232 & 45 & 3 \\
\hline 232 & 33.31 & 109.3 & 31 & 44 & 23 & 0 \\
\hline 233 & 33.37 & 109.5 & 271 & 284 & 57 & 3 \\
\hline 234 & 33.40 & 109.6 & 10 & 23 & 81 & 3 \\
\hline 235 & 33.86 & 111.1 & 33 & 46 & 16 & 0 \\
\hline 236 & 33.95 & 111.4 & 188 & 201 & 70 & 1 \\
\hline 237 & 34.41 & 112.9 & 28 & 41 & 33 & 1 \\
\hline 238 & 34.55 & 113.4 & 42 & 55 & 32 & 0 \\
\hline 239 & 34.56 & 113.4 & 39 & 52 & 14 & 0 \\
\hline 240 & 34.60 & 113.5 & 50 & 63 & 11 & 0 \\
\hline 241 & 34.78 & 114.1 & 56 & 69 & 17 & 1 \\
\hline 242 & 34.83 & 114.3 & 68 & 81 & 20 & 1 \\
\hline 243 & 34.98 & 114.8 & 43 & 56 & 26 & 2 \\
\hline 244 & 35.11 & 115.2 & 17 & 30 & 89 & 3 \\
\hline 245 & 35.28 & 115.8 & 36 & 49 & 19 & 0 \\
\hline 246 & 35.35 & 116.0 & 34 & 46 & 22 & 0 \\
\hline 247 & 35.42 & 116.2 & 109 & 121 & 77 & 3 \\
\hline 248 & 35.69 & 117.1 & 11 & 24 & 22 & 1 \\
\hline 249 & 35.73 & 117.2 & 27 & 40 & 9 & 1 \\
\hline 250 & 35.79 & 117.4 & 22 & 35 & 11 & 1 \\
\hline 251 & 35.93 & 117.9 & 60 & 73 & 4 & 0 \\
\hline 252 & 36.02 & 118.2 & 96 & 109 & 8 & 0 \\
\hline 253 & 36.09 & 118.4 & 37 & 50 & 11 & 0 \\
\hline 254 & 36.42 & 119.5 & 31 & 44 & 13 & 3 \\
\hline 255 & 36.59 & 120.0 & 244 & 257 & 67 & 3 \\
\hline 256 & 36.61 & 120.1 & 217 & 230 & 58 & 3 \\
\hline 257 & 36.62 & 120.2 & 95 & 108 & 63 & 3 \\
\hline 258 & 36.67 & 120.3 & 93 & 106 & 59 & 1 \\
\hline 259 & 36.79 & 120.7 & 237 & 250 & 56 & 3 \\
\hline 260 & 36.82 & 120.8 & 50 & 63 & 26 & 1 \\
\hline 261 & 37.16 & 121.9 & 104 & 117 & 19 & 4 \\
\hline 262 & 37.18 & 122.0 & 16 & 28 & 84 & 3 \\
\hline 263 & 37.34 & 122.5 & 51 & 64 & 16 & 1 \\
\hline 264 & 37.38 & 122.6 & 28 & 41 & 11 & 3 \\
\hline 265 & 37.43 & 122.8 & 55 & 68 & 10 & 1 \\
\hline 266 & 37.59 & 123.3 & 233 & 246 & 69 & 3 \\
\hline 267 & 37.62 & 123.4 & 40 & 53 & 10 & 1 \\
\hline 268 & 37.64 & 123.5 & 16 & 28 & 46 & 0 \\
\hline 269 & 37.73 & 123.8 & 36 & 49 & 9 & 2 \\
\hline 270 & 37.80 & 124.0 & 1 & 14 & 20 & 1 \\
\hline
\end{tabular}

All directions have been corrected for borehole deviation, and are with respect to true north.

Page 6 
Orientation Summary Table - Image Features

Nevada Test Site

Source Physics Experiment

U-15N \#1

NNSA/NSO

21 Sept 2010

\begin{tabular}{|c|c|c|c|c|c|c|}
\hline $\begin{array}{c}\text { Feature } \\
\text { No. }\end{array}$ & $\begin{array}{c}\text { Depth } \\
\text { (meters) }\end{array}$ & $\begin{array}{l}\text { Depth } \\
\text { (feet) }\end{array}$ & $\begin{array}{c}\text { Dip } \\
\text { Direction } \\
\text { (degrees) }\end{array}$ & $\begin{array}{c}\text { Dip } \\
\text { Direction } \\
(\text { deg. } T N)\end{array}$ & $\begin{array}{c}\text { Dip } \\
\text { Angle } \\
\text { (degrees) }\end{array}$ & $\begin{array}{c}\text { Feature } \\
\text { Rank } \\
\text { (0 to 5) }\end{array}$ \\
\hline 271 & 37.82 & 124.1 & 356 & 9 & 10 & 1 \\
\hline 272 & 37.98 & 124.6 & 234 & 247 & 2 & 1 \\
\hline 273 & 38.04 & 124.8 & 301 & 314 & 2 & 1 \\
\hline 274 & 38.09 & 125.0 & 51 & 64 & 17 & 1 \\
\hline 275 & 38.27 & 125.6 & 358 & 11 & 52 & 0 \\
\hline 276 & 38.28 & 125.6 & 99 & 112 & 17 & 0 \\
\hline 277 & 38.71 & 127.0 & 118 & 130 & 36 & 1 \\
\hline 278 & 38.75 & 127.1 & 349 & 2 & 19 & 3 \\
\hline 279 & 38.77 & 127.2 & 109 & 122 & 41 & 1 \\
\hline 280 & 38.83 & 127.4 & 114 & 127 & 39 & 3 \\
\hline 281 & 38.96 & 127.8 & 59 & 72 & 14 & 1 \\
\hline 282 & 38.97 & 127.9 & 53 & 66 & 49 & 3 \\
\hline 283 & 38.99 & 127.9 & 196 & 209 & 77 & 3 \\
\hline 284 & 39.14 & 128.4 & 217 & 230 & 50 & 3 \\
\hline 285 & 39.53 & 129.7 & 244 & 257 & 53 & 3 \\
\hline 286 & 39.65 & 130.1 & 222 & 235 & 46 & 2 \\
\hline 287 & 39.79 & 130.6 & 222 & 234 & 51 & 3 \\
\hline 288 & 39.83 & 130.7 & 46 & 58 & 25 & 1 \\
\hline 289 & 39.95 & 131.1 & 222 & 234 & 49 & 3 \\
\hline 290 & 40.03 & 131.3 & 41 & 54 & 36 & 2 \\
\hline 291 & 40.11 & 131.6 & 53 & 65 & 21 & 1 \\
\hline 292 & 40.41 & 132.6 & 206 & 219 & 71 & 3 \\
\hline 293 & 40.82 & 133.9 & 13 & 25 & 84 & 3 \\
\hline 294 & 40.83 & 134.0 & 15 & 28 & 81 & 3 \\
\hline 295 & 41.02 & 134.6 & 186 & 198 & 65 & 3 \\
\hline 296 & 41.06 & 134.7 & 180 & 192 & 78 & 3 \\
\hline 297 & 41.13 & 134.9 & 187 & 200 & 73 & 3 \\
\hline 298 & 41.19 & 135.1 & 45 & 58 & 20 & 0 \\
\hline 299 & 41.29 & 135.5 & 32 & 45 & 29 & 3 \\
\hline 300 & 41.38 & 135.8 & 34 & 47 & 28 & 0 \\
\hline 301 & 41.38 & 135.8 & 201 & 214 & 75 & 3 \\
\hline 302 & 41.57 & 136.4 & 190 & 203 & 80 & 3 \\
\hline 303 & 41.97 & 137.7 & 33 & 46 & 22 & 2 \\
\hline 304 & 42.07 & 138.0 & 35 & 48 & 23 & 0 \\
\hline 305 & 42.20 & 138.4 & 169 & 182 & 63 & 3 \\
\hline 306 & 42.31 & 138.8 & 193 & 206 & 72 & 3 \\
\hline 307 & 42.37 & 139.0 & 47 & 60 & 18 & 0 \\
\hline 308 & 42.38 & 139.1 & 181 & 194 & 57 & 3 \\
\hline 309 & 42.51 & 139.5 & 249 & 261 & 27 & 0 \\
\hline 310 & 42.52 & 139.5 & 186 & 199 & 69 & 3 \\
\hline 311 & 42.66 & 140.0 & 70 & 83 & 18 & 0 \\
\hline 312 & 42.71 & 140.1 & 91 & 104 & 17 & 3 \\
\hline 313 & 43.08 & 141.4 & 206 & 219 & 72 & 3 \\
\hline 314 & 43.27 & 142.0 & 31 & 44 & 10 & 0 \\
\hline 315 & 43.38 & 142.3 & 55 & 68 & 15 & 0 \\
\hline
\end{tabular}

All directions have been corrected for borehole deviation, and are with respect to true north. 
Orientation Summary Table - Image Features

Nevada Test Site

Source Physics Experiment

U-15N \#1

NNSA/NSO

21 Sept 2010

\begin{tabular}{|c|c|c|c|c|c|c|}
\hline $\begin{array}{c}\text { Feature } \\
\text { No. }\end{array}$ & $\begin{array}{c}\text { Depth } \\
\text { (meters) }\end{array}$ & $\begin{array}{l}\text { Depth } \\
\text { (feet) }\end{array}$ & $\begin{array}{c}\text { Dip } \\
\text { Direction } \\
\text { (degrees) }\end{array}$ & $\begin{array}{c}\text { Dip } \\
\text { Direction } \\
(\text { deg. } T N)\end{array}$ & $\begin{array}{c}\text { Dip } \\
\text { Angle } \\
\text { (degrees) }\end{array}$ & $\begin{array}{c}\text { Feature } \\
\text { Rank } \\
\text { (0 to 5) }\end{array}$ \\
\hline 316 & 43.39 & 142.4 & 196 & 208 & 77 & 3 \\
\hline 317 & 43.71 & 143.4 & 62 & 75 & 13 & 0 \\
\hline 318 & 43.82 & 143.8 & 73 & 85 & 16 & 0 \\
\hline 319 & 43.85 & 143.9 & 25 & 38 & 84 & 3 \\
\hline 320 & 44.01 & 144.4 & 59 & 72 & 17 & 0 \\
\hline 321 & 44.07 & 144.6 & 259 & 272 & 14 & 0 \\
\hline 322 & 44.10 & 144.7 & 76 & 89 & 15 & 0 \\
\hline 323 & 44.25 & 145.2 & 127 & 140 & 81 & 2 \\
\hline 324 & 44.27 & 145.3 & 75 & 87 & 14 & 0 \\
\hline 325 & 44.37 & 145.6 & 79 & 92 & 14 & 0 \\
\hline 326 & 44.74 & 146.8 & 200 & 213 & 81 & 2 \\
\hline 327 & 45.02 & 147.7 & 16 & 28 & 28 & 0 \\
\hline 328 & 45.05 & 147.8 & 14 & 27 & 17 & 0 \\
\hline 329 & 45.16 & 148.2 & 78 & 91 & 10 & 3 \\
\hline 330 & 45.24 & 148.4 & 76 & 89 & 15 & 0 \\
\hline 331 & 45.34 & 148.8 & 40 & 52 & 29 & 0 \\
\hline 332 & 45.44 & 149.1 & 79 & 92 & 13 & 0 \\
\hline 333 & 45.66 & 149.8 & 190 & 203 & 70 & 0 \\
\hline 334 & 45.74 & 150.1 & 124 & 137 & 23 & 0 \\
\hline 335 & 45.81 & 150.3 & 59 & 72 & 9 & 0 \\
\hline 336 & 45.83 & 150.4 & 74 & 86 & 9 & 0 \\
\hline 337 & 45.85 & 150.4 & 202 & 214 & 74 & 3 \\
\hline 338 & 45.86 & 150.5 & 72 & 85 & 9 & 0 \\
\hline 339 & 45.86 & 150.5 & 196 & 209 & 67 & 0 \\
\hline 340 & 45.92 & 150.7 & 165 & 178 & 55 & 3 \\
\hline 341 & 46.00 & 150.9 & 148 & 161 & 61 & 3 \\
\hline 342 & 46.02 & 151.0 & 209 & 222 & 73 & 3 \\
\hline 343 & 46.08 & 151.2 & 204 & 217 & 76 & 3 \\
\hline 344 & 46.20 & 151.6 & 186 & 199 & 48 & 3 \\
\hline 345 & 46.74 & 153.4 & 203 & 216 & 53 & 3 \\
\hline 346 & 46.74 & 153.4 & 208 & 221 & 45 & 3 \\
\hline 347 & 46.79 & 153.5 & 218 & 231 & 59 & 3 \\
\hline 348 & 46.81 & 153.6 & 46 & 59 & 13 & 0 \\
\hline 349 & 46.84 & 153.7 & 195 & 208 & 80 & 3 \\
\hline 350 & 47.02 & 154.3 & 206 & 219 & 66 & 3 \\
\hline 351 & 47.22 & 154.9 & 208 & 221 & 74 & 1 \\
\hline 352 & 47.28 & 155.1 & 203 & 216 & 71 & 3 \\
\hline 353 & 47.37 & 155.4 & 59 & 72 & 22 & 1 \\
\hline 354 & 47.38 & 155.5 & 199 & 212 & 67 & 3 \\
\hline 355 & 47.56 & 156.1 & 196 & 209 & 74 & 3 \\
\hline 356 & 47.66 & 156.4 & 206 & 219 & 72 & 3 \\
\hline 357 & 47.70 & 156.5 & 70 & 83 & 13 & 1 \\
\hline 358 & 47.74 & 156.6 & 211 & 223 & 74 & 3 \\
\hline 359 & 47.92 & 157.2 & 47 & 60 & 15 & 1 \\
\hline 360 & 48.00 & 157.5 & 45 & 58 & 8 & 1 \\
\hline
\end{tabular}

All directions have been corrected for borehole deviation, and are with respect to true north. 
Orientation Summary Table - Image Features

Nevada Test Site

Source Physics Experiment

U-15N \#1

NNSA/NSO

21 Sept 2010

\begin{tabular}{|c|c|c|c|c|c|c|}
\hline $\begin{array}{c}\text { Feature } \\
\text { No. }\end{array}$ & $\begin{array}{c}\text { Depth } \\
\text { (meters) }\end{array}$ & $\begin{array}{l}\text { Depth } \\
\text { (feet) }\end{array}$ & $\begin{array}{c}\text { Dip } \\
\text { Direction } \\
\text { (degrees) }\end{array}$ & $\begin{array}{c}\text { Dip } \\
\text { Direction } \\
(\text { deg. } T N)\end{array}$ & $\begin{array}{c}\text { Dip } \\
\text { Angle } \\
\text { (degrees) }\end{array}$ & $\begin{array}{c}\text { Feature } \\
\text { Rank } \\
\text { (0 to 5) }\end{array}$ \\
\hline 361 & 48.02 & 157.6 & 45 & 58 & 11 & 1 \\
\hline 362 & 48.05 & 157.7 & 14 & 26 & 81 & 3 \\
\hline 363 & 48.11 & 157.8 & 189 & 202 & 2 & 1 \\
\hline 364 & 48.13 & 157.9 & 65 & 78 & 15 & 1 \\
\hline 365 & 48.25 & 158.3 & 204 & 217 & 62 & 3 \\
\hline 366 & 48.41 & 158.8 & 168 & 181 & 68 & 3 \\
\hline 367 & 48.46 & 159.0 & 54 & 67 & 16 & 0 \\
\hline 368 & 48.53 & 159.2 & 189 & 202 & 73 & 3 \\
\hline 369 & 48.75 & 159.9 & 52 & 65 & 12 & 3 \\
\hline 370 & 48.91 & 160.5 & 68 & 81 & 21 & 3 \\
\hline 371 & 49.03 & 160.9 & 65 & 78 & 19 & 1 \\
\hline 372 & 49.21 & 161.5 & 116 & 129 & 80 & 3 \\
\hline 373 & 49.42 & 162.2 & 81 & 94 & 15 & 1 \\
\hline 374 & 49.49 & 162.4 & 110 & 123 & 78 & 3 \\
\hline 375 & 49.52 & 162.5 & 56 & 68 & 19 & 1 \\
\hline 376 & 49.83 & 163.5 & 63 & 75 & 11 & 1 \\
\hline 377 & 49.89 & 163.7 & 65 & 77 & 16 & 3 \\
\hline 378 & 49.90 & 163.7 & 227 & 240 & 51 & 1 \\
\hline 379 & 49.99 & 164.0 & 105 & 118 & 80 & 3 \\
\hline 380 & 50.01 & 164.1 & 205 & 218 & 48 & 3 \\
\hline 381 & 50.01 & 164.1 & 60 & 73 & 11 & 1 \\
\hline 382 & 50.28 & 165.0 & 76 & 89 & 12 & 1 \\
\hline 383 & 50.54 & 165.8 & 65 & 78 & 6 & 1 \\
\hline 384 & 50.70 & 166.3 & 239 & 252 & 65 & 3 \\
\hline 385 & 50.95 & 167.2 & 57 & 70 & 17 & 1 \\
\hline 386 & 51.02 & 167.4 & 59 & 72 & 29 & 1 \\
\hline 387 & 51.28 & 168.2 & 55 & 68 & 6 & 2 \\
\hline 388 & 51.45 & 168.8 & 68 & 81 & 14 & 2 \\
\hline 389 & 51.52 & 169.0 & 50 & 63 & 2 & 1 \\
\hline 390 & 51.56 & 169.2 & 78 & 91 & 25 & 1 \\
\hline 391 & 51.68 & 169.6 & 66 & 79 & 30 & 1 \\
\hline 392 & 52.10 & 170.9 & 69 & 82 & 15 & 1 \\
\hline 393 & 52.22 & 171.3 & 70 & 83 & 21 & 1 \\
\hline 394 & 52.30 & 171.6 & 17 & 30 & 71 & 2 \\
\hline 395 & 52.39 & 171.9 & 188 & 201 & 60 & 3 \\
\hline 396 & 52.39 & 171.9 & 51 & 64 & 7 & 1 \\
\hline 397 & 52.48 & 172.2 & 66 & 79 & 16 & 1 \\
\hline 398 & 52.67 & 172.8 & 67 & 79 & 9 & 1 \\
\hline 399 & 52.75 & 173.1 & 67 & 80 & 19 & 2 \\
\hline 400 & 52.82 & 173.3 & 78 & 90 & 64 & 3 \\
\hline 401 & 52.89 & 173.5 & 77 & 90 & 40 & 3 \\
\hline 402 & 52.97 & 173.8 & 135 & 148 & 78 & 3 \\
\hline 403 & 53.26 & 174.7 & 62 & 74 & 17 & 1 \\
\hline 404 & 53.38 & 175.1 & 67 & 79 & 20 & 2 \\
\hline 405 & 53.66 & 176.1 & 232 & 245 & 56 & 1 \\
\hline
\end{tabular}

All directions have been corrected for borehole deviation, and are with respect to true north.

Page 9 
Orientation Summary Table - Image Features

Nevada Test Site

Source Physics Experiment

U-15N \#1

NNSA/NSO

21 Sept 2010

\begin{tabular}{|c|c|c|c|c|c|c|}
\hline $\begin{array}{c}\text { Feature } \\
\text { No. }\end{array}$ & $\begin{array}{c}\text { Depth } \\
\text { (meters) }\end{array}$ & $\begin{array}{l}\text { Depth } \\
\text { (feet) }\end{array}$ & $\begin{array}{c}\text { Dip } \\
\text { Direction } \\
\text { (degrees) }\end{array}$ & $\begin{array}{c}\text { Dip } \\
\text { Direction } \\
\text { (deg. TN) }\end{array}$ & $\begin{array}{c}\text { Dip } \\
\text { Angle } \\
\text { (degrees) }\end{array}$ & $\begin{array}{c}\text { Feature } \\
\text { Rank } \\
\text { (0 to 5) }\end{array}$ \\
\hline 406 & 53.67 & 176.1 & 66 & 79 & 20 & 2 \\
\hline 407 & 53.69 & 176.2 & 216 & 229 & 58 & 1 \\
\hline 408 & 53.79 & 176.5 & 50 & 63 & 22 & 2 \\
\hline 409 & 53.81 & 176.5 & 127 & 140 & 79 & 3 \\
\hline 410 & 53.97 & 177.1 & 63 & 76 & 44 & 3 \\
\hline 411 & 54.03 & 177.3 & 216 & 229 & 69 & 3 \\
\hline 412 & 54.15 & 177.7 & 73 & 86 & 23 & 2 \\
\hline 413 & 54.39 & 178.5 & 65 & 78 & 12 & 1 \\
\hline 414 & 54.44 & 178.6 & 346 & 358 & 63 & 3 \\
\hline 415 & 54.49 & 178.8 & 260 & 273 & 10 & 1 \\
\hline 416 & 54.72 & 179.5 & 85 & 98 & 13 & 1 \\
\hline 417 & 54.81 & 179.8 & 74 & 87 & 14 & 1 \\
\hline 418 & 54.93 & 180.2 & 348 & 1 & 13 & 1 \\
\hline 419 & 55.08 & 180.7 & 103 & 115 & 79 & 3 \\
\hline 420 & 55.48 & 182.0 & 54 & 67 & 14 & 1 \\
\hline 421 & 55.61 & 182.4 & 109 & 121 & 81 & 3 \\
\hline 422 & 55.71 & 182.8 & 73 & 86 & 11 & 1 \\
\hline 423 & 55.76 & 182.9 & 13 & 26 & 83 & 3 \\
\hline 424 & 56.02 & 183.8 & 98 & 111 & 21 & 1 \\
\hline 425 & 56.15 & 184.2 & 69 & 82 & 9 & $\overline{1}$ \\
\hline 426 & 56.23 & 184.5 & 206 & 219 & 13 & 1 \\
\hline 427 & 56.42 & 185.1 & 187 & 200 & 43 & 3 \\
\hline 428 & 56.58 & 185.6 & 174 & 187 & 24 & 1 \\
\hline 429 & 56.65 & 185.9 & 68 & 81 & 10 & 1 \\
\hline 430 & 56.88 & 186.6 & 205 & 218 & 27 & $\overline{1}$ \\
\hline
\end{tabular}

All directions have been corrected for borehole deviation, and are with respect to true north.

Page 10 
Appendix J-3

Fracture Data Tabulated from Borehole Image Logs by Colog, Inc. For Instrument Hole U-15n\#2 
Orientation Summary Table - Image Features

Nevada Test Site

Source Physics Experiment

U-15N \#2

NNSA/NSO

21 Sept 2010

\begin{tabular}{|c|c|c|c|c|c|c|}
\hline $\begin{array}{c}\text { Feature } \\
\text { No. }\end{array}$ & $\begin{array}{c}\text { Depth } \\
\text { (meters) }\end{array}$ & $\begin{array}{l}\text { Depth } \\
\text { (feet) }\end{array}$ & $\begin{array}{c}\text { Dip } \\
\text { Direction } \\
\text { (degrees) }\end{array}$ & $\begin{array}{c}\text { Dip } \\
\text { Direction } \\
(\text { deg. } T N)\end{array}$ & $\begin{array}{c}\text { Dip } \\
\text { Angle } \\
\text { (degrees) }\end{array}$ & $\begin{array}{c}\text { Feature } \\
\text { Rank } \\
\text { (0 to 5) }\end{array}$ \\
\hline 1 & 4.07 & 13.4 & 77 & 90 & 10 & 0 \\
\hline 2 & 4.23 & 13.9 & 82 & 95 & 11 & 0 \\
\hline 3 & 4.43 & 14.6 & 108 & 121 & 14 & 3 \\
\hline 4 & 4.53 & 14.9 & 186 & 199 & 6 & 0 \\
\hline 5 & 4.82 & 15.8 & 140 & 153 & 15 & 1 \\
\hline 6 & 5.08 & 16.7 & 27 & 40 & 18 & 1 \\
\hline 7 & 5.69 & 18.7 & 55 & 68 & 7 & 2 \\
\hline 8 & 5.78 & 19.0 & 162 & 174 & 7 & 1 \\
\hline 9 & 6.02 & 19.8 & 134 & 147 & 11 & 1 \\
\hline 10 & 6.25 & 20.5 & 57 & 70 & 13 & 1 \\
\hline 11 & 6.30 & 20.7 & 39 & 52 & 25 & 2 \\
\hline 12 & 6.33 & 20.8 & 71 & 84 & 19 & 1 \\
\hline 13 & 6.41 & 21.0 & 75 & 88 & 12 & 1 \\
\hline 14 & 6.54 & 21.5 & 61 & 74 & 22 & 1 \\
\hline 15 & 6.75 & 22.1 & 138 & 151 & 16 & 1 \\
\hline 16 & 6.79 & 22.3 & 127 & 140 & 18 & 1 \\
\hline 17 & 6.80 & 22.3 & 180 & 193 & 14 & 1 \\
\hline 18 & 6.88 & 22.6 & 90 & 103 & 13 & 1 \\
\hline 19 & 6.97 & 22.9 & 135 & 148 & 20 & 1 \\
\hline 20 & 7.03 & 23.1 & 94 & 107 & 15 & 0 \\
\hline 21 & 7.05 & 23.1 & 78 & 90 & 18 & 0 \\
\hline 22 & 7.32 & 24.0 & 177 & 190 & 11 & 1 \\
\hline 23 & 7.39 & 24.2 & 147 & 160 & 33 & 1 \\
\hline 24 & 7.45 & 24.4 & 145 & 157 & 25 & 1 \\
\hline 25 & 7.55 & 24.8 & 71 & 84 & 16 & 0 \\
\hline 26 & 7.71 & 25.3 & 22 & 34 & 3 & 0 \\
\hline 27 & 8.04 & 26.4 & 88 & 101 & 34 & 1 \\
\hline 28 & 8.22 & 27.0 & 327 & 340 & 4 & 2 \\
\hline 29 & 8.25 & 27.1 & 135 & 148 & 26 & 1 \\
\hline 30 & 8.41 & 27.6 & 91 & 104 & 15 & 2 \\
\hline 31 & 8.44 & 27.7 & 93 & 106 & 13 & 1 \\
\hline 32 & 8.56 & 28.1 & 96 & 109 & 15 & 2 \\
\hline 33 & 8.58 & 28.2 & 282 & 295 & 7 & 2 \\
\hline 34 & 8.72 & 28.6 & 96 & 109 & 7 & 1 \\
\hline 35 & 8.88 & 29.1 & 119 & 132 & 8 & 0 \\
\hline 36 & 9.02 & 29.6 & 101 & 113 & 4 & 1 \\
\hline 37 & 9.09 & 29.8 & 83 & 95 & 12 & 0 \\
\hline 38 & 9.21 & 30.2 & 54 & 67 & 13 & 1 \\
\hline 39 & 9.34 & 30.6 & 16 & 28 & 5 & 1 \\
\hline 40 & 9.41 & 30.9 & 168 & 181 & 8 & 0 \\
\hline 41 & 9.48 & 31.1 & 283 & 296 & 7 & 1 \\
\hline 42 & 9.55 & 31.3 & 93 & 106 & 15 & 1 \\
\hline 43 & 9.68 & 31.8 & 40 & 53 & 15 & 0 \\
\hline 44 & 9.74 & 32.0 & 51 & 64 & 10 & 1 \\
\hline 45 & 9.86 & 32.4 & 104 & 117 & 11 & 1 \\
\hline
\end{tabular}

All directions have been corrected for borehole deviation, and are with respect to true north.

Page 1 
Orientation Summary Table - Image Features

Nevada Test Site

Source Physics Experiment

U-15N \#2

NNSA/NSO

21 Sept 2010

\begin{tabular}{|c|c|c|c|c|c|c|}
\hline $\begin{array}{c}\text { Feature } \\
\text { No. }\end{array}$ & $\begin{array}{c}\text { Depth } \\
\text { (meters) }\end{array}$ & $\begin{array}{l}\text { Depth } \\
\text { (feet) }\end{array}$ & $\begin{array}{c}\text { Dip } \\
\text { Direction } \\
\text { (degrees) }\end{array}$ & $\begin{array}{c}\text { Dip } \\
\text { Direction } \\
(\text { deg. } T N)\end{array}$ & $\begin{array}{c}\text { Dip } \\
\text { Angle } \\
\text { (degrees) }\end{array}$ & $\begin{array}{c}\text { Feature } \\
\text { Rank } \\
\text { (0 to 5) }\end{array}$ \\
\hline 46 & 9.94 & 32.6 & 32 & 45 & 23 & 0 \\
\hline 47 & 10.06 & 33.0 & 89 & 102 & 11 & 0 \\
\hline 48 & 10.13 & 33.3 & 113 & 126 & 8 & 0 \\
\hline 49 & 10.26 & 33.7 & 26 & 39 & 30 & 1 \\
\hline 50 & 10.44 & 34.3 & 7 & 20 & 19 & 1 \\
\hline 51 & 10.52 & 34.5 & 23 & 35 & 22 & 1 \\
\hline 52 & 10.55 & 34.6 & 44 & 57 & 10 & 0 \\
\hline 53 & 10.63 & 34.9 & 59 & 72 & 16 & 0 \\
\hline 54 & 10.77 & 35.4 & 12 & 25 & 87 & 3 \\
\hline 55 & 10.90 & 35.8 & 89 & 102 & 11 & 0 \\
\hline 56 & 10.98 & 36.0 & 117 & 130 & 20 & 1 \\
\hline 57 & 11.04 & 36.2 & 148 & 160 & 9 & 1 \\
\hline 58 & 11.16 & 36.6 & 112 & 125 & 12 & 1 \\
\hline 59 & 11.43 & 37.5 & 96 & 109 & 4 & 1 \\
\hline 60 & 11.60 & 38.1 & 43 & 56 & 24 & 0 \\
\hline 61 & 11.66 & 38.3 & 80 & 92 & 12 & 0 \\
\hline 62 & 12.12 & 39.8 & 169 & 182 & 15 & 1 \\
\hline 63 & 12.27 & 40.3 & 138 & 151 & 22 & 1 \\
\hline 64 & 12.44 & 40.8 & 133 & 146 & 7 & 1 \\
\hline 65 & 12.54 & 41.2 & 158 & 171 & 7 & 1 \\
\hline 66 & 12.62 & 41.4 & 55 & 68 & 29 & 1 \\
\hline 67 & 12.69 & 41.6 & 80 & 93 & 8 & 1 \\
\hline 68 & 12.73 & 41.8 & 84 & 96 & 12 & 1 \\
\hline 69 & 12.87 & 42.2 & 293 & 306 & 54 & 1 \\
\hline 70 & 12.91 & 42.3 & 105 & 118 & 10 & 1 \\
\hline 71 & 13.16 & 43.2 & 52 & 65 & 16 & 1 \\
\hline 72 & 13.18 & 43.3 & 291 & 304 & 75 & 1 \\
\hline 73 & 13.70 & 45.0 & 34 & 47 & 30 & 1 \\
\hline 74 & 13.78 & 45.2 & 116 & 129 & 46 & 1 \\
\hline 75 & 13.82 & 45.3 & 250 & 262 & 6 & 1 \\
\hline 76 & 13.98 & 45.9 & 103 & 116 & 8 & 2 \\
\hline 77 & 14.04 & 46.1 & 97 & 109 & 5 & 1 \\
\hline 78 & 14.05 & 46.1 & 70 & 82 & 26 & 0 \\
\hline 79 & 14.07 & 46.2 & 80 & 93 & 82 & 3 \\
\hline 80 & 14.07 & 46.2 & 32 & 45 & 24 & 0 \\
\hline 81 & 14.13 & 46.4 & 221 & 233 & 5 & 2 \\
\hline 82 & 14.22 & 46.7 & 146 & 159 & 7 & 2 \\
\hline 83 & 14.30 & 46.9 & 105 & 118 & 8 & 2 \\
\hline 84 & 14.36 & 47.1 & 139 & 152 & 5 & 1 \\
\hline 85 & 14.40 & 47.3 & 137 & 150 & 7 & 1 \\
\hline 86 & 14.48 & 47.5 & 38 & 50 & 2 & 2 \\
\hline 87 & 14.59 & 47.9 & 113 & 126 & 10 & 2 \\
\hline 88 & 14.69 & 48.2 & 90 & 103 & 8 & 1 \\
\hline 89 & 14.78 & 48.5 & 102 & 115 & 17 & 1 \\
\hline 90 & 14.84 & 48.7 & 201 & 214 & 72 & 3 \\
\hline
\end{tabular}

All directions have been corrected for borehole deviation, and are with respect to true north.

Page 2 
Orientation Summary Table - Image Features

Nevada Test Site

Source Physics Experiment

U-15N \#2

NNSA/NSO

21 Sept 2010

\begin{tabular}{|c|c|c|c|c|c|c|}
\hline $\begin{array}{c}\text { Feature } \\
\text { No. }\end{array}$ & $\begin{array}{l}\text { Depth } \\
\text { (meters) }\end{array}$ & $\begin{array}{l}\text { Depth } \\
\text { (feet) }\end{array}$ & $\begin{array}{c}\text { Dip } \\
\text { Direction } \\
\text { (degrees) }\end{array}$ & $\begin{array}{c}\text { Dip } \\
\text { Direction } \\
\text { (deg. TN) }\end{array}$ & $\begin{array}{c}\text { Dip } \\
\text { Angle } \\
\text { (degrees) }\end{array}$ & $\begin{array}{c}\text { Feature } \\
\text { Rank } \\
\text { (0 to 5) }\end{array}$ \\
\hline 91 & 14.85 & 48.7 & 196 & 209 & 7 & 2 \\
\hline 92 & 14.93 & 49.0 & 129 & 142 & 15 & 1 \\
\hline 93 & 14.95 & 49.1 & 181 & 194 & 14 & 1 \\
\hline 94 & 15.08 & 49.5 & 77 & 90 & 8 & 1 \\
\hline 95 & 15.32 & 50.3 & 51 & 64 & 17 & 0 \\
\hline 96 & 15.34 & 50.3 & 38 & 51 & 19 & 0 \\
\hline 97 & 15.39 & 50.5 & 58 & 71 & 12 & 0 \\
\hline 98 & 15.53 & 51.0 & 224 & 237 & 9 & 1 \\
\hline 99 & 15.68 & 51.4 & 25 & 38 & 87 & 3 \\
\hline 100 & 15.71 & 51.5 & 90 & 103 & 45 & 2 \\
\hline 101 & 15.83 & 52.0 & 67 & 80 & 15 & 0 \\
\hline 102 & 15.86 & 52.1 & 109 & 122 & 13 & 0 \\
\hline 103 & 15.96 & 52.4 & 38 & 51 & 14 & 1 \\
\hline 104 & 16.08 & 52.8 & 66 & 78 & 13 & 0 \\
\hline 105 & 16.16 & 53.0 & 15 & 28 & 29 & 0 \\
\hline 106 & 16.22 & 53.2 & 87 & 99 & 31 & 1 \\
\hline 107 & 16.26 & 53.3 & 201 & 214 & 18 & 1 \\
\hline 108 & 16.45 & 54.0 & 99 & 112 & 12 & 0 \\
\hline 109 & 16.56 & 54.3 & 41 & 54 & 21 & 0 \\
\hline 110 & 16.65 & 54.6 & 54 & 67 & 21 & 0 \\
\hline 111 & 16.79 & 55.1 & 196 & 209 & 60 & 0 \\
\hline 112 & 17.67 & 58.0 & 63 & 76 & 19 & 1 \\
\hline 113 & 17.79 & 58.4 & 52 & 65 & 15 & 0 \\
\hline 114 & 18.14 & 59.5 & 166 & 179 & 26 & 0 \\
\hline 115 & 18.31 & 60.1 & 80 & 93 & 14 & 2 \\
\hline 116 & 18.58 & 61.0 & 24 & 37 & 55 & 0 \\
\hline 117 & 18.81 & 61.7 & 75 & 88 & 17 & 1 \\
\hline 118 & 18.85 & 61.8 & 118 & 131 & 11 & 2 \\
\hline 119 & 19.03 & 62.4 & 224 & 237 & 3 & 3 \\
\hline 120 & 19.11 & 62.7 & 21 & 34 & 3 & 3 \\
\hline 121 & 19.21 & 63.0 & 294 & 307 & 28 & 1 \\
\hline 122 & 19.30 & 63.3 & 98 & 111 & 11 & 1 \\
\hline 123 & 19.34 & 63.4 & 222 & 234 & 21 & 1 \\
\hline 124 & 19.38 & 63.6 & 29 & 42 & 59 & 0 \\
\hline 125 & 20.29 & 66.6 & 102 & 115 & 3 & 1 \\
\hline 126 & 20.29 & 66.6 & 40 & 53 & 20 & 1 \\
\hline 127 & 20.55 & 67.4 & 98 & 111 & 17 & 0 \\
\hline 128 & 20.62 & 67.7 & 47 & 60 & 22 & 1 \\
\hline 129 & 20.69 & 67.9 & 4 & 17 & 29 & 1 \\
\hline 130 & 20.75 & 68.1 & 327 & 340 & 19 & 2 \\
\hline 131 & 20.78 & 68.2 & 121 & 134 & 19 & 3 \\
\hline 132 & 20.91 & 68.6 & 85 & 98 & 20 & 3 \\
\hline 133 & 20.96 & 68.8 & 254 & 267 & 11 & 1 \\
\hline 134 & 20.99 & 68.9 & 139 & 152 & 63 & 3 \\
\hline 135 & 21.00 & 68.9 & 235 & 247 & 19 & 2 \\
\hline
\end{tabular}

All directions have been corrected for borehole deviation, and are with respect to true north.

Page 3 
Orientation Summary Table - Image Features

Nevada Test Site

Source Physics Experiment

U-15N \#2

NNSA/NSO

21 Sept 2010

\begin{tabular}{|c|c|c|c|c|c|c|}
\hline $\begin{array}{c}\text { Feature } \\
\text { No. }\end{array}$ & $\begin{array}{c}\text { Depth } \\
\text { (meters) }\end{array}$ & $\begin{array}{l}\text { Depth } \\
\text { (feet) }\end{array}$ & $\begin{array}{c}\text { Dip } \\
\text { Direction } \\
\text { (degrees) }\end{array}$ & $\begin{array}{c}\text { Dip } \\
\text { Direction } \\
(\text { deg. } T N)\end{array}$ & $\begin{array}{c}\text { Dip } \\
\text { Angle } \\
\text { (degrees) }\end{array}$ & $\begin{array}{c}\text { Feature } \\
\text { Rank } \\
\text { (0 to 5) }\end{array}$ \\
\hline 136 & 21.05 & 69.1 & 311 & 324 & 61 & 2 \\
\hline 137 & 21.06 & 69.1 & 234 & 247 & 31 & 3 \\
\hline 138 & 21.13 & 69.3 & 107 & 120 & 9 & 1 \\
\hline 139 & 21.27 & 69.8 & 33 & 45 & 51 & 3 \\
\hline 140 & 21.28 & 69.8 & 131 & 144 & 25 & 0 \\
\hline 141 & 21.30 & 69.9 & 194 & 207 & 58 & 1 \\
\hline 142 & 21.42 & 70.3 & 14 & 27 & 15 & 2 \\
\hline 143 & 21.44 & 70.4 & 3 & 16 & 20 & 2 \\
\hline 144 & 21.48 & 70.5 & 132 & 145 & 44 & 3 \\
\hline 145 & 21.51 & 70.6 & 102 & 115 & 7 & 2 \\
\hline 146 & 21.52 & 70.6 & 224 & 237 & 16 & 1 \\
\hline 147 & 21.71 & 71.2 & 331 & 344 & 48 & 3 \\
\hline 148 & 21.76 & 71.4 & 86 & 99 & 56 & 3 \\
\hline 149 & 21.92 & 71.9 & 21 & 34 & 42 & 1 \\
\hline 150 & 22.05 & 72.3 & 339 & 352 & 17 & 0 \\
\hline 151 & 22.05 & 72.4 & 305 & 318 & 3 & 1 \\
\hline 152 & 22.12 & 72.6 & 224 & 237 & 7 & 0 \\
\hline 153 & 22.20 & 72.8 & 293 & 306 & 6 & 2 \\
\hline 154 & 22.20 & 72.9 & 17 & 29 & 10 & 2 \\
\hline 155 & 22.26 & 73.0 & 45 & 58 & 22 & 2 \\
\hline 156 & 22.41 & 73.5 & 43 & 56 & 28 & 0 \\
\hline 157 & 22.54 & 74.0 & 250 & 263 & 1 & 2 \\
\hline 158 & 22.60 & 74.1 & 40 & 53 & 23 & 3 \\
\hline 159 & 22.74 & 74.6 & 119 & 132 & 5 & 4 \\
\hline 160 & 22.75 & 74.6 & 318 & 331 & 52 & 3 \\
\hline 161 & 22.84 & 75.0 & 94 & 107 & 6 & 3 \\
\hline 162 & 23.40 & 76.8 & 186 & 199 & 17 & 1 \\
\hline 163 & 23.40 & 76.8 & 69 & 82 & 9 & 1 \\
\hline 164 & 23.51 & 77.1 & 53 & 66 & 25 & 2 \\
\hline 165 & 23.66 & 77.6 & 55 & 68 & 56 & 1 \\
\hline 166 & 23.88 & 78.4 & 58 & 71 & 20 & 0 \\
\hline 167 & 24.06 & 78.9 & 202 & 215 & 54 & 0 \\
\hline 168 & 24.10 & 79.1 & 50 & 63 & 17 & 0 \\
\hline 169 & 24.24 & 79.5 & 119 & 132 & 8 & 2 \\
\hline 170 & 24.37 & 80.0 & 80 & 93 & 6 & 3 \\
\hline 171 & 24.45 & 80.2 & 101 & 113 & 3 & 4 \\
\hline 172 & 24.55 & 80.6 & 116 & 129 & 14 & 3 \\
\hline 173 & 24.65 & 80.9 & 205 & 218 & 7 & 0 \\
\hline 174 & 24.87 & 81.6 & 75 & 88 & 6 & 3 \\
\hline 175 & 24.91 & 81.7 & 234 & 247 & 68 & 0 \\
\hline 176 & 24.91 & 81.7 & 64 & 76 & 3 & 4 \\
\hline 177 & 24.98 & 81.9 & 149 & 162 & 3 & 4 \\
\hline 178 & 25.07 & 82.3 & 76 & 89 & 9 & 3 \\
\hline 179 & 25.47 & 83.6 & 242 & 255 & 58 & 1 \\
\hline 180 & 25.60 & 84.0 & 36 & 49 & 17 & 3 \\
\hline
\end{tabular}

All directions have been corrected for borehole deviation, and are with respect to true north. 
Orientation Summary Table - Image Features

Nevada Test Site

Source Physics Experiment

U-15N \#2

NNSA/NSO

21 Sept 2010

\begin{tabular}{|c|c|c|c|c|c|c|}
\hline $\begin{array}{c}\text { Feature } \\
\text { No. }\end{array}$ & $\begin{array}{l}\text { Depth } \\
\text { (meters) }\end{array}$ & $\begin{array}{l}\text { Depth } \\
\text { (feet) }\end{array}$ & $\begin{array}{c}\text { Dip } \\
\text { Direction } \\
\text { (degrees) }\end{array}$ & $\begin{array}{c}\text { Dip } \\
\text { Direction } \\
\text { (deg. TN) }\end{array}$ & $\begin{array}{c}\text { Dip } \\
\text { Angle } \\
\text { (degrees) }\end{array}$ & $\begin{array}{c}\text { Feature } \\
\text { Rank } \\
\text { (0 to 5) }\end{array}$ \\
\hline 181 & 25.65 & 84.2 & 83 & 96 & 5 & 3 \\
\hline 182 & 25.70 & 84.3 & 65 & 78 & 41 & 3 \\
\hline 183 & 25.78 & 84.6 & 52 & 65 & 16 & 0 \\
\hline 184 & 25.90 & 85.0 & 51 & 64 & 29 & 0 \\
\hline 185 & 26.01 & 85.3 & 7 & 20 & 37 & 0 \\
\hline 186 & 26.09 & 85.6 & 54 & 67 & 69 & 3 \\
\hline 187 & 26.20 & 86.0 & 108 & 121 & 12 & 1 \\
\hline 188 & 26.30 & 86.3 & 42 & 55 & 30 & 1 \\
\hline 189 & 26.49 & 86.9 & 239 & 251 & 27 & 1 \\
\hline 190 & 26.51 & 87.0 & 37 & 50 & 34 & 2 \\
\hline 191 & 26.67 & 87.5 & 27 & 39 & 9 & 2 \\
\hline 192 & 26.70 & 87.6 & 141 & 153 & 22 & 2 \\
\hline 193 & 27.23 & 89.3 & 92 & 104 & 14 & 0 \\
\hline 194 & 27.97 & 91.8 & 53 & 66 & 14 & 3 \\
\hline 195 & 28.03 & 92.0 & 62 & 74 & 6 & 3 \\
\hline 196 & 28.09 & 92.2 & 32 & 45 & 15 & 1 \\
\hline 197 & 28.15 & 92.4 & 36 & 49 & 46 & 1 \\
\hline 198 & 28.81 & 94.5 & 70 & 83 & 15 & 1 \\
\hline 199 & 28.89 & 94.8 & 87 & 100 & 72 & 3 \\
\hline 200 & 29.15 & 95.6 & 47 & 59 & 23 & 1 \\
\hline 201 & 29.39 & 96.4 & 43 & 56 & 24 & 1 \\
\hline 202 & 29.51 & 96.8 & 67 & 79 & 12 & 1 \\
\hline 203 & 29.57 & 97.0 & 163 & 176 & 10 & 3 \\
\hline 204 & 29.69 & 97.4 & 251 & 263 & 11 & 2 \\
\hline 205 & 29.81 & 97.8 & 66 & 79 & 29 & 4 \\
\hline 206 & 29.98 & 98.4 & 96 & 109 & 16 & 0 \\
\hline 207 & 30.13 & 98.9 & 70 & 83 & 10 & 0 \\
\hline 208 & 30.31 & 99.4 & 115 & 127 & 9 & 1 \\
\hline 209 & 30.44 & 99.9 & 305 & 318 & 80 & 3 \\
\hline 210 & 30.50 & 100.1 & 40 & 53 & 9 & 3 \\
\hline 211 & 30.65 & 100.6 & 86 & 99 & 15 & 3 \\
\hline 212 & 30.74 & 100.9 & 318 & 330 & 78 & 3 \\
\hline 213 & 30.77 & 100.9 & 302 & 315 & 85 & 2 \\
\hline 214 & 30.90 & 101.4 & 121 & 134 & 22 & 3 \\
\hline 215 & 31.03 & 101.8 & 66 & 79 & 20 & 1 \\
\hline 216 & 31.15 & 102.2 & 111 & 124 & 35 & 3 \\
\hline 217 & 31.32 & 102.8 & 198 & 211 & 15 & 1 \\
\hline 218 & 31.76 & 104.2 & 153 & 166 & 17 & 3 \\
\hline 219 & 31.76 & 104.2 & 58 & 71 & 28 & 1 \\
\hline 220 & 31.86 & 104.5 & 208 & 220 & 11 & 1 \\
\hline 221 & 32.03 & 105.1 & 219 & 232 & 21 & 1 \\
\hline 222 & 32.77 & 107.5 & 42 & 55 & 19 & 0 \\
\hline 223 & 32.88 & 107.9 & 58 & 71 & 19 & 0 \\
\hline 224 & 33.10 & 108.6 & 17 & 30 & 5 & $\overline{1}$ \\
\hline 225 & 33.14 & 108.7 & 70 & 83 & 9 & 3 \\
\hline
\end{tabular}

All directions have been corrected for borehole deviation, and are with respect to true north.

Page 5 
Orientation Summary Table - Image Features

Nevada Test Site

Source Physics Experiment

U-15N \#2

NNSA/NSO

21 Sept 2010

\begin{tabular}{|c|c|c|c|c|c|c|}
\hline $\begin{array}{c}\text { Feature } \\
\text { No. }\end{array}$ & $\begin{array}{l}\text { Depth } \\
\text { (meters) }\end{array}$ & $\begin{array}{l}\text { Depth } \\
\text { (feet) }\end{array}$ & $\begin{array}{c}\text { Dip } \\
\text { Direction } \\
\text { (degrees) }\end{array}$ & $\begin{array}{c}\text { Dip } \\
\text { Direction } \\
\text { (deg. TN) }\end{array}$ & $\begin{array}{c}\text { Dip } \\
\text { Angle } \\
\text { (degrees) }\end{array}$ & $\begin{array}{c}\text { Feature } \\
\text { Rank } \\
\text { (0 to 5) }\end{array}$ \\
\hline 226 & 33.24 & 109.1 & 68 & 81 & 13 & 3 \\
\hline 227 & 33.36 & 109.4 & 126 & 138 & 18 & 1 \\
\hline 228 & 33.40 & 109.6 & 41 & 54 & 27 & 1 \\
\hline 229 & 33.49 & 109.9 & 57 & 70 & 16 & 0 \\
\hline 230 & 33.52 & 110.0 & 357 & 9 & 76 & 3 \\
\hline 231 & 33.63 & 110.3 & 38 & 50 & 23 & 0 \\
\hline 232 & 33.64 & 110.4 & 347 & 0 & 75 & 2 \\
\hline 233 & 33.76 & 110.8 & 23 & 35 & 28 & 0 \\
\hline 234 & 33.93 & 111.3 & 17 & 29 & 53 & 0 \\
\hline 235 & 34.02 & 111.6 & 88 & 101 & 15 & 0 \\
\hline 236 & 34.14 & 112.0 & 27 & 40 & 31 & 0 \\
\hline 237 & 34.34 & 112.7 & 33 & 45 & 29 & 0 \\
\hline 238 & 34.34 & 112.7 & 118 & 131 & 28 & 3 \\
\hline 239 & 34.47 & 113.1 & 105 & 118 & 7 & 4 \\
\hline 240 & 34.59 & 113.5 & 129 & 142 & 18 & 3 \\
\hline 241 & 34.62 & 113.6 & 104 & 117 & 9 & 0 \\
\hline 242 & 34.69 & 113.8 & 101 & 114 & 9 & 0 \\
\hline 243 & 35.51 & 116.5 & 276 & 288 & 13 & 2 \\
\hline 244 & 35.52 & 116.5 & 112 & 125 & 12 & 2 \\
\hline 245 & 35.59 & 116.8 & 30 & 42 & 25 & 1 \\
\hline 246 & 35.75 & 117.3 & 197 & 210 & 2 & 2 \\
\hline 247 & 35.92 & 117.9 & 113 & 126 & 10 & 0 \\
\hline 248 & 36.20 & 118.8 & 118 & 131 & 13 & 3 \\
\hline 249 & 36.37 & 119.3 & 45 & 58 & 26 & 1 \\
\hline 250 & 36.51 & 119.8 & 69 & 82 & 3 & 1 \\
\hline 251 & 36.53 & 119.9 & 76 & 89 & 14 & 1 \\
\hline 252 & 36.70 & 120.4 & 120 & 133 & 81 & 3 \\
\hline 253 & 36.71 & 120.5 & 123 & 136 & 73 & 3 \\
\hline 254 & 36.79 & 120.7 & 163 & 176 & 42 & 1 \\
\hline 255 & 36.88 & 121.0 & 105 & 118 & 16 & 3 \\
\hline 256 & 37.00 & 121.4 & 74 & 87 & 12 & 4 \\
\hline 257 & 37.11 & 121.8 & 125 & 138 & 29 & 3 \\
\hline 258 & 37.27 & 122.3 & 117 & 130 & 51 & 3 \\
\hline 259 & 37.43 & 122.8 & 74 & 87 & 29 & 3 \\
\hline 260 & 37.65 & 123.5 & 27 & 39 & 70 & 3 \\
\hline 261 & 37.80 & 124.0 & 66 & 79 & 18 & 2 \\
\hline 262 & 37.91 & 124.4 & 58 & 71 & 73 & 3 \\
\hline 263 & 38.64 & 126.8 & 17 & 30 & 76 & 3 \\
\hline 264 & 38.79 & 127.3 & 33 & 46 & 74 & 1 \\
\hline 265 & 39.06 & 128.1 & 8 & 21 & 78 & 1 \\
\hline 266 & 39.06 & 128.2 & 6 & 19 & 78 & 3 \\
\hline 267 & 39.13 & 128.4 & 16 & 29 & 46 & 3 \\
\hline 268 & 39.17 & 128.5 & 13 & 26 & 83 & 1 \\
\hline 269 & 39.26 & 128.8 & 11 & 24 & 9 & 3 \\
\hline 270 & 39.36 & 129.1 & 19 & 32 & 81 & 3 \\
\hline
\end{tabular}

All directions have been corrected for borehole deviation, and are with respect to true north.

Page 6 
Orientation Summary Table - Image Features

Nevada Test Site

Source Physics Experiment

U-15N \#2

NNSA/NSO

21 Sept 2010

\begin{tabular}{|c|c|c|c|c|c|c|}
\hline $\begin{array}{c}\text { Feature } \\
\text { No. }\end{array}$ & $\begin{array}{l}\text { Depth } \\
\text { (meters) }\end{array}$ & $\begin{array}{l}\text { Depth } \\
\text { (feet) }\end{array}$ & $\begin{array}{c}\text { Dip } \\
\text { Direction } \\
\text { (degrees) }\end{array}$ & $\begin{array}{c}\text { Dip } \\
\text { Direction } \\
\text { (deg. TN) }\end{array}$ & $\begin{array}{c}\text { Dip } \\
\text { Angle } \\
\text { (degrees) }\end{array}$ & $\begin{array}{c}\text { Feature } \\
\text { Rank } \\
(0 \text { to } 5) \\
\end{array}$ \\
\hline 271 & 39.40 & 129.3 & 60 & 73 & 15 & 1 \\
\hline 272 & 39.48 & 129.5 & 71 & 84 & 16 & 2 \\
\hline 273 & 39.54 & 129.7 & 59 & 72 & 23 & 1 \\
\hline 274 & 39.64 & 130.1 & 33 & 46 & 28 & 2 \\
\hline 275 & 39.69 & 130.2 & 43 & 56 & 18 & 1 \\
\hline 276 & 39.71 & 130.3 & 121 & 134 & 83 & 3 \\
\hline 277 & 39.83 & 130.7 & 147 & 160 & 7 & 2 \\
\hline 278 & 39.88 & 130.8 & 37 & 49 & 15 & 1 \\
\hline 279 & 40.15 & 131.7 & 72 & 85 & 10 & 3 \\
\hline 280 & 40.20 & 131.9 & 83 & 96 & 13 & 0 \\
\hline 281 & 40.27 & 132.1 & 132 & 145 & 16 & 1 \\
\hline 282 & 40.45 & 132.7 & 215 & 228 & 7 & 1 \\
\hline 283 & 40.50 & 132.9 & 190 & 203 & 3 & 1 \\
\hline 284 & 40.77 & 133.8 & 68 & 81 & 18 & 0 \\
\hline 285 & 40.93 & 134.3 & 27 & 40 & 72 & 0 \\
\hline 286 & 41.02 & 134.6 & 238 & 251 & 14 & 0 \\
\hline 287 & 41.03 & 134.6 & 210 & 222 & 5 & 3 \\
\hline 288 & 41.08 & 134.8 & 64 & 76 & 8 & 0 \\
\hline 289 & 41.86 & 137.3 & 6 & 19 & 81 & 3 \\
\hline 290 & 42.12 & 138.2 & 59 & 71 & 25 & 2 \\
\hline 291 & 42.16 & 138.3 & 11 & 24 & 83 & 3 \\
\hline 292 & 42.23 & 138.6 & 186 & 199 & 48 & 3 \\
\hline 293 & 42.30 & 138.8 & 16 & 29 & 83 & 3 \\
\hline 294 & 42.42 & 139.2 & 46 & 59 & 13 & 1 \\
\hline 295 & 42.63 & 139.9 & 197 & 210 & 52 & 1 \\
\hline 296 & 43.00 & 141.1 & 182 & 195 & 52 & 3 \\
\hline 297 & 43.31 & 142.1 & 59 & 72 & 14 & 1 \\
\hline 298 & 43.35 & 142.2 & 203 & 215 & 35 & 3 \\
\hline 299 & 43.46 & 142.6 & 204 & 216 & 34 & 3 \\
\hline 300 & 43.50 & 142.7 & 115 & 128 & 73 & 3 \\
\hline 301 & 43.53 & 142.8 & 216 & 229 & 35 & 0 \\
\hline 302 & 43.56 & 142.9 & 117 & 130 & 72 & 3 \\
\hline 303 & 43.57 & 142.9 & 118 & 131 & 67 & 3 \\
\hline 304 & 43.91 & 144.1 & 123 & 136 & 76 & 3 \\
\hline 305 & 43.93 & 144.1 & 126 & 138 & 70 & 1 \\
\hline 306 & 44.02 & 144.4 & 212 & 225 & 32 & 2 \\
\hline 307 & 44.11 & 144.7 & 98 & 111 & 7 & 1 \\
\hline 308 & 44.21 & 145.1 & 101 & 114 & 65 & 1 \\
\hline 309 & 44.47 & 145.9 & 115 & 127 & 80 & 3 \\
\hline 310 & 44.53 & 146.1 & 31 & 44 & 20 & 1 \\
\hline 311 & 44.66 & 146.5 & 112 & 125 & 10 & 2 \\
\hline 312 & 44.72 & 146.7 & 71 & 84 & 8 & 1 \\
\hline 313 & 45.07 & 147.9 & 69 & 82 & 11 & 0 \\
\hline 314 & 45.37 & 148.9 & 120 & 133 & 62 & 3 \\
\hline 315 & 45.62 & 149.7 & 83 & 96 & 69 & 3 \\
\hline
\end{tabular}

All directions have been corrected for borehole deviation, and are with respect to true north. 
Orientation Summary Table - Image Features

Nevada Test Site

Source Physics Experiment

U-15N \#2

NNSA/NSO

21 Sept 2010

\begin{tabular}{|c|c|c|c|c|c|c|}
\hline $\begin{array}{c}\text { Feature } \\
\text { No. }\end{array}$ & $\begin{array}{l}\text { Depth } \\
\text { (meters) }\end{array}$ & $\begin{array}{l}\text { Depth } \\
\text { (feet) }\end{array}$ & $\begin{array}{c}\text { Dip } \\
\text { Direction } \\
\text { (degrees) }\end{array}$ & $\begin{array}{c}\text { Dip } \\
\text { Direction } \\
\text { (deg. TN) }\end{array}$ & $\begin{array}{c}\text { Dip } \\
\text { Angle } \\
\text { (degrees) }\end{array}$ & $\begin{array}{c}\text { Feature } \\
\text { Rank } \\
(0 \text { to } 5) \\
\end{array}$ \\
\hline 316 & 45.63 & 149.7 & 54 & 67 & 24 & 1 \\
\hline 317 & 45.66 & 149.8 & 102 & 115 & 12 & 1 \\
\hline 318 & 45.97 & 150.8 & 7 & 20 & 78 & 1 \\
\hline 319 & 46.00 & 150.9 & 27 & 40 & 22 & 0 \\
\hline 320 & 46.05 & 151.1 & 60 & 73 & 22 & 0 \\
\hline 321 & 46.11 & 151.3 & 23 & 36 & 79 & 3 \\
\hline 322 & 46.37 & 152.1 & 211 & 224 & 65 & 3 \\
\hline 323 & 46.71 & 153.3 & 213 & 226 & 10 & 3 \\
\hline 324 & 46.80 & 153.6 & 7 & 20 & 5 & 2 \\
\hline 325 & 46.92 & 153.9 & 183 & 196 & 68 & 3 \\
\hline 326 & 47.19 & 154.8 & 356 & 9 & 10 & 3 \\
\hline 327 & 47.30 & 155.2 & 9 & 22 & 33 & 1 \\
\hline 328 & 47.36 & 155.4 & 233 & 246 & 74 & 3 \\
\hline 329 & 47.50 & 155.8 & 223 & 235 & 29 & 2 \\
\hline 330 & 47.94 & 157.3 & 217 & 230 & 35 & 1 \\
\hline 331 & 47.96 & 157.4 & 213 & 226 & 69 & 3 \\
\hline 332 & 48.04 & 157.6 & 227 & 240 & 21 & 0 \\
\hline 333 & 48.20 & 158.1 & 88 & 101 & 16 & 0 \\
\hline 334 & 48.23 & 158.2 & 212 & 225 & 87 & 3 \\
\hline 335 & 48.54 & 159.3 & 45 & 58 & 10 & 0 \\
\hline 336 & 48.69 & 159.7 & 35 & 48 & 69 & 3 \\
\hline 337 & 48.83 & 160.2 & 210 & 223 & 24 & 0 \\
\hline 338 & 48.90 & 160.4 & 54 & 67 & 15 & 0 \\
\hline 339 & 48.99 & 160.7 & 11 & 23 & 42 & 0 \\
\hline 340 & 49.10 & 161.1 & 245 & 258 & 63 & 3 \\
\hline 341 & 49.10 & 161.1 & 97 & 110 & 2 & 3 \\
\hline 342 & 49.16 & 161.3 & 22 & 35 & 80 & 3 \\
\hline 343 & 49.19 & 161.4 & 202 & 215 & 8 & 0 \\
\hline 344 & 49.41 & 162.1 & 20 & 33 & 44 & 3 \\
\hline 345 & 49.43 & 162.2 & 20 & 33 & 81 & 3 \\
\hline 346 & 49.77 & 163.3 & 56 & 69 & 21 & 0 \\
\hline 347 & 49.80 & 163.4 & 219 & 231 & 11 & 0 \\
\hline 348 & 49.87 & 163.6 & 27 & 40 & 63 & 3 \\
\hline 349 & 49.91 & 163.7 & 77 & 90 & 10 & 3 \\
\hline 350 & 49.98 & 164.0 & 71 & 84 & 27 & 1 \\
\hline 351 & 50.25 & 164.9 & 48 & 61 & 13 & 0 \\
\hline 352 & 50.29 & 165.0 & 57 & 70 & 12 & 0 \\
\hline 353 & 50.53 & 165.8 & 282 & 295 & 83 & 3 \\
\hline 354 & 50.74 & 166.5 & 64 & 77 & 26 & 0 \\
\hline 355 & 50.83 & 166.8 & 70 & 83 & 18 & 0 \\
\hline 356 & 51.13 & 167.8 & 70 & 83 & 72 & 3 \\
\hline 357 & 51.18 & 167.9 & 81 & 94 & 72 & 3 \\
\hline 358 & 51.44 & 168.8 & 112 & 124 & 84 & 3 \\
\hline 359 & 51.64 & 169.4 & 70 & 83 & 12 & $\overline{1}$ \\
\hline 360 & 51.89 & 170.3 & 81 & 93 & 23 & 2 \\
\hline
\end{tabular}

All directions have been corrected for borehole deviation, and are with respect to true north. 
Orientation Summary Table - Image Features

Nevada Test Site

Source Physics Experiment

U-15N \#2

NNSA/NSO

21 Sept 2010

\begin{tabular}{|c|c|c|c|c|c|c|}
\hline $\begin{array}{c}\text { Feature } \\
\text { No. }\end{array}$ & $\begin{array}{c}\text { Depth } \\
\text { (meters) }\end{array}$ & $\begin{array}{l}\text { Depth } \\
\text { (feet) }\end{array}$ & $\begin{array}{c}\text { Dip } \\
\text { Direction } \\
\text { (degrees) }\end{array}$ & $\begin{array}{c}\text { Dip } \\
\text { Direction } \\
\text { (deg. TN) }\end{array}$ & $\begin{array}{c}\text { Dip } \\
\text { Angle } \\
\text { (degrees) }\end{array}$ & $\begin{array}{c}\text { Feature } \\
\text { Rank } \\
\text { (0 to 5) }\end{array}$ \\
\hline 361 & 51.96 & 170.5 & 15 & 28 & 81 & 3 \\
\hline 362 & 51.96 & 170.5 & 49 & 62 & 21 & 0 \\
\hline 363 & 52.02 & 170.7 & 270 & 283 & 8 & 0 \\
\hline 364 & 52.28 & 171.5 & 355 & 8 & 6 & 2 \\
\hline 365 & 52.62 & 172.7 & 203 & 216 & 72 & 3 \\
\hline 366 & 52.72 & 173.0 & 23 & 36 & 10 & 2 \\
\hline 367 & 52.78 & 173.2 & 34 & 47 & 7 & 0 \\
\hline 368 & 52.85 & 173.4 & 212 & 225 & 65 & 3 \\
\hline 369 & 53.01 & 173.9 & 53 & 66 & 11 & 2 \\
\hline 370 & 53.16 & 174.4 & 133 & 146 & 32 & 3 \\
\hline 371 & 53.67 & 176.1 & 12 & 25 & 68 & 3 \\
\hline 372 & 54.07 & 177.4 & 168 & 181 & 38 & 3 \\
\hline 373 & 54.48 & 178.7 & 196 & 209 & 69 & 3 \\
\hline 374 & 54.75 & 179.6 & 215 & 228 & 64 & 3 \\
\hline 375 & 55.78 & 183.0 & 98 & 111 & 76 & 3 \\
\hline 376 & 55.84 & 183.2 & 113 & 126 & 84 & 3 \\
\hline 377 & 56.46 & 185.3 & 99 & 112 & 74 & 1 \\
\hline 378 & 56.93 & 186.8 & 103 & 116 & 74 & 3 \\
\hline 379 & 57.87 & 189.9 & 14 & 27 & 79 & 3 \\
\hline 380 & 57.89 & 189.9 & 100 & 113 & 6 & 1 \\
\hline 381 & 57.94 & 190.1 & 346 & 359 & 81 & 3 \\
\hline 382 & 58.62 & 192.3 & 93 & 106 & 23 & 1 \\
\hline
\end{tabular}

All directions have been corrected for borehole deviation, and are with respect to true north.

Page 9 
Appendix J-4

Fracture Data Tabulated from Borehole Image Logs by Colog, Inc. For Instrument Hole U-15n\#3 
Orientation Summary Table - Image Features

Nevada Test Site

Source Physics Experiment

U-15N \#3

NNSA/NSO

21 and 22 Sept 2010

\begin{tabular}{|c|c|c|c|c|c|c|}
\hline $\begin{array}{c}\text { Feature } \\
\text { No. }\end{array}$ & $\begin{array}{c}\text { Depth } \\
\text { (meters) }\end{array}$ & $\begin{array}{l}\text { Depth } \\
\text { (feet) }\end{array}$ & $\begin{array}{c}\text { Dip } \\
\text { Direction } \\
\text { (degrees) }\end{array}$ & $\begin{array}{c}\text { Dip } \\
\text { Direction } \\
(\text { deg. } T N)\end{array}$ & $\begin{array}{c}\text { Dip } \\
\text { Angle } \\
\text { (degrees) }\end{array}$ & $\begin{array}{c}\text { Feature } \\
\text { Rank } \\
\text { (0 to 5) }\end{array}$ \\
\hline 1 & 4.86 & 15.9 & 59 & 72 & 26 & 1 \\
\hline 2 & 5.17 & 17.0 & 26 & 38 & 16 & 0 \\
\hline 3 & 5.69 & 18.7 & 51 & 64 & 18 & 1 \\
\hline 4 & 5.82 & 19.1 & 48 & 60 & 22 & 2 \\
\hline 5 & 5.84 & 19.2 & 264 & 277 & 2 & 3 \\
\hline 6 & 5.98 & 19.6 & 57 & 69 & 16 & 1 \\
\hline 7 & 6.18 & 20.3 & 85 & 98 & 20 & 1 \\
\hline 8 & 6.22 & 20.4 & 149 & 162 & 21 & 0 \\
\hline 9 & 6.27 & 20.6 & 270 & 283 & 58 & 0 \\
\hline 10 & 6.71 & 22.0 & 65 & 78 & 22 & 3 \\
\hline 11 & 6.74 & 22.1 & 253 & 266 & 73 & 3 \\
\hline 12 & 6.97 & 22.9 & 68 & 81 & 21 & 3 \\
\hline 13 & 7.08 & 23.2 & 90 & 103 & 78 & 3 \\
\hline 14 & 7.18 & 23.6 & 273 & 286 & 11 & 3 \\
\hline 15 & 7.23 & 23.7 & 322 & 335 & 10 & 0 \\
\hline 16 & 7.51 & 24.6 & 85 & 98 & 30 & 0 \\
\hline 17 & 7.51 & 24.6 & 210 & 223 & 86 & 3 \\
\hline 18 & 7.74 & 25.4 & 25 & 38 & 84 & 3 \\
\hline 19 & 7.75 & 25.4 & 22 & 35 & 4 & 0 \\
\hline 20 & 7.84 & 25.7 & 55 & 68 & 8 & 0 \\
\hline 21 & 8.01 & 26.3 & 198 & 211 & 45 & 0 \\
\hline 22 & 8.03 & 26.3 & 7 & 19 & 28 & 2 \\
\hline 23 & 8.17 & 26.8 & 180 & 192 & 77 & 3 \\
\hline 24 & 8.21 & 26.9 & 230 & 243 & 52 & 3 \\
\hline 25 & 8.51 & 27.9 & 38 & 51 & 32 & 0 \\
\hline 26 & 8.64 & 28.4 & 104 & 117 & 1 & 2 \\
\hline 27 & 8.72 & 28.6 & 191 & 204 & 6 & 3 \\
\hline 28 & 8.83 & 29.0 & 50 & 62 & 24 & 3 \\
\hline 29 & 8.93 & 29.3 & 75 & 88 & 21 & 2 \\
\hline 30 & 9.18 & 30.1 & 120 & 133 & 81 & 3 \\
\hline 31 & 9.19 & 30.2 & 43 & 56 & 13 & 2 \\
\hline 32 & 9.23 & 30.3 & 220 & 233 & 67 & 3 \\
\hline 33 & 9.46 & 31.0 & 41 & 54 & 23 & 3 \\
\hline 34 & 9.53 & 31.3 & 195 & 208 & 78 & 3 \\
\hline 35 & 9.70 & 31.8 & 116 & 129 & 79 & 3 \\
\hline 36 & 10.10 & 33.1 & 187 & 200 & 74 & 3 \\
\hline 37 & 10.18 & 33.4 & 186 & 199 & 52 & 3 \\
\hline 38 & 10.21 & 33.5 & 56 & 69 & 23 & 1 \\
\hline 39 & 10.35 & 34.0 & 38 & 51 & 9 & 1 \\
\hline 40 & 10.41 & 34.2 & 121 & 134 & 71 & 3 \\
\hline 41 & 10.66 & 35.0 & 138 & 151 & 70 & 3 \\
\hline 42 & 10.72 & 35.2 & 109 & 122 & 71 & 3 \\
\hline 43 & 10.90 & 35.8 & 50 & 63 & 16 & 3 \\
\hline 44 & 10.93 & 35.9 & 62 & 75 & 12 & 0 \\
\hline 45 & 11.15 & 36.6 & 36 & 49 & 17 & 1 \\
\hline
\end{tabular}

All directions have been corrected for borehole deviation, and are with respect to true north.

Page 1 
Orientation Summary Table - Image Features

Nevada Test Site

Source Physics Experiment

U-15N \#3

NNSA/NSO

21 and 22 Sept 2010

\begin{tabular}{|c|c|c|c|c|c|c|}
\hline $\begin{array}{c}\text { Feature } \\
\text { No. }\end{array}$ & $\begin{array}{c}\text { Depth } \\
\text { (meters) }\end{array}$ & $\begin{array}{l}\text { Depth } \\
\text { (feet) }\end{array}$ & $\begin{array}{c}\text { Dip } \\
\text { Direction } \\
\text { (degrees) }\end{array}$ & $\begin{array}{c}\text { Dip } \\
\text { Direction } \\
\text { (deg. TN) }\end{array}$ & $\begin{array}{c}\text { Dip } \\
\text { Angle } \\
\text { (degrees) }\end{array}$ & $\begin{array}{c}\text { Feature } \\
\text { Rank } \\
\text { (0 to 5) }\end{array}$ \\
\hline 46 & 11.22 & 36.8 & 88 & 101 & 8 & 0 \\
\hline 47 & 11.25 & 36.9 & 128 & 141 & 76 & 3 \\
\hline 48 & 11.35 & 37.3 & 115 & 128 & 71 & 3 \\
\hline 49 & 11.38 & 37.4 & 358 & 11 & 8 & 3 \\
\hline 50 & 11.52 & 37.8 & 96 & 109 & 58 & 3 \\
\hline 51 & 11.62 & 38.1 & 122 & 135 & 80 & 3 \\
\hline 52 & 11.88 & 39.0 & 47 & 60 & 10 & 1 \\
\hline 53 & 11.90 & 39.0 & 71 & 84 & 11 & 1 \\
\hline 54 & 12.04 & 39.5 & 62 & 75 & 26 & 0 \\
\hline 55 & 12.07 & 39.6 & 73 & 86 & 17 & 3 \\
\hline 56 & 12.42 & 40.7 & 139 & 152 & 8 & 3 \\
\hline 57 & 12.49 & 41.0 & 99 & 111 & 5 & 0 \\
\hline 58 & 12.66 & 41.6 & 127 & 140 & 89 & 3 \\
\hline 59 & 12.80 & 42.0 & 189 & 202 & 72 & 3 \\
\hline 60 & 12.81 & 42.0 & 103 & 116 & 10 & 2 \\
\hline 61 & 12.86 & 42.2 & 102 & 115 & 57 & 1 \\
\hline 62 & 12.92 & 42.4 & 185 & 197 & 8 & 3 \\
\hline 63 & 12.93 & 42.4 & 191 & 204 & 71 & 3 \\
\hline 64 & 13.02 & 42.7 & 250 & 263 & 1 & 3 \\
\hline 65 & 13.08 & 42.9 & 69 & 82 & 13 & 2 \\
\hline 66 & 13.12 & 43.1 & 75 & 88 & 9 & 1 \\
\hline 67 & 13.18 & 43.2 & 89 & 102 & 14 & 0 \\
\hline 68 & 13.33 & 43.7 & 342 & 355 & 31 & 0 \\
\hline 69 & 13.34 & 43.8 & 308 & 321 & 13 & 3 \\
\hline 70 & 13.35 & 43.8 & 94 & 107 & 19 & 3 \\
\hline 71 & 13.43 & 44.1 & 45 & 57 & 14 & 3 \\
\hline 72 & 13.74 & 45.1 & 133 & 146 & 10 & 3 \\
\hline 73 & 13.77 & 45.2 & 162 & 175 & 14 & 3 \\
\hline 74 & 13.91 & 45.7 & 122 & 135 & 48 & 3 \\
\hline 75 & 13.94 & 45.8 & 315 & 328 & 40 & 0 \\
\hline 76 & 14.05 & 46.1 & 86 & 99 & 19 & 1 \\
\hline 77 & 14.08 & 46.2 & 117 & 130 & 18 & 3 \\
\hline 78 & 14.38 & 47.2 & 321 & 334 & 77 & 3 \\
\hline 79 & 14.50 & 47.6 & 27 & 40 & 17 & 0 \\
\hline 80 & 14.57 & 47.8 & 319 & 332 & 13 & 3 \\
\hline 81 & 14.66 & 48.1 & 312 & 325 & 74 & 0 \\
\hline 82 & 14.73 & 48.3 & 150 & 163 & 42 & 1 \\
\hline 83 & 14.93 & 49.0 & 153 & 166 & 55 & 3 \\
\hline 84 & 15.38 & 50.5 & 319 & 332 & 7 & 0 \\
\hline 85 & 15.52 & 50.9 & 77 & 90 & 5 & 1 \\
\hline 86 & 15.57 & 51.1 & 68 & 81 & 5 & 1 \\
\hline 87 & 15.63 & 51.3 & 79 & 92 & 26 & 3 \\
\hline 88 & 15.69 & 51.5 & 89 & 102 & 42 & 3 \\
\hline 89 & 15.86 & 52.1 & 39 & 52 & 10 & 3 \\
\hline 90 & 15.87 & 52.1 & 98 & 111 & 63 & 3 \\
\hline
\end{tabular}

All directions have been corrected for borehole deviation, and are with respect to true north.

Page 2 
Orientation Summary Table - Image Features

Nevada Test Site

Source Physics Experiment

U-15N \#3

NNSA/NSO

21 and 22 Sept 2010

\begin{tabular}{|c|c|c|c|c|c|c|}
\hline $\begin{array}{c}\text { Feature } \\
\text { No. }\end{array}$ & $\begin{array}{c}\text { Depth } \\
\text { (meters) }\end{array}$ & $\begin{array}{l}\text { Depth } \\
\text { (feet) }\end{array}$ & $\begin{array}{c}\text { Dip } \\
\text { Direction } \\
\text { (degrees) }\end{array}$ & $\begin{array}{c}\text { Dip } \\
\text { Direction } \\
\text { (deg. TN) }\end{array}$ & $\begin{array}{c}\text { Dip } \\
\text { Angle } \\
\text { (degrees) }\end{array}$ & $\begin{array}{c}\text { Feature } \\
\text { Rank } \\
\text { (0 to 5) }\end{array}$ \\
\hline 91 & 15.93 & 52.3 & 62 & 75 & 7 & 3 \\
\hline 92 & 16.04 & 52.6 & 274 & 287 & 73 & 3 \\
\hline 93 & 16.08 & 52.8 & 79 & 92 & 12 & 3 \\
\hline 94 & 16.27 & 53.4 & 31 & 44 & 14 & 2 \\
\hline 95 & 16.45 & 54.0 & 118 & 131 & 4 & 0 \\
\hline 96 & 16.49 & 54.1 & 311 & 323 & 40 & 1 \\
\hline 97 & 16.74 & 54.9 & 121 & 134 & 80 & 3 \\
\hline 98 & 16.98 & 55.7 & 237 & 250 & 11 & 3 \\
\hline 99 & 17.13 & 56.2 & 315 & 328 & 11 & 3 \\
\hline 100 & 17.22 & 56.5 & 41 & 54 & 4 & 3 \\
\hline 101 & 17.27 & 56.7 & 58 & 70 & 12 & 3 \\
\hline 102 & 17.28 & 56.7 & 194 & 207 & 81 & 3 \\
\hline 103 & 17.41 & 57.1 & 17 & 30 & 5 & 3 \\
\hline 104 & 17.68 & 58.0 & 72 & 85 & 6 & 2 \\
\hline 105 & 18.03 & 59.1 & 169 & 182 & 80 & 3 \\
\hline 106 & 18.09 & 59.4 & 51 & 64 & 7 & 0 \\
\hline 107 & 18.64 & 61.1 & 33 & 46 & 15 & 0 \\
\hline 108 & 19.14 & 62.8 & 234 & 247 & 75 & 1 \\
\hline 109 & 19.20 & 63.0 & 188 & 201 & 76 & 3 \\
\hline 110 & 19.40 & 63.7 & 182 & 194 & 80 & 3 \\
\hline 111 & 19.92 & 65.4 & 57 & 70 & 18 & 1 \\
\hline 112 & 20.04 & 65.8 & 208 & 221 & 79 & 3 \\
\hline 113 & 20.28 & 66.5 & 26 & 39 & 16 & 1 \\
\hline 114 & 20.31 & 66.7 & 38 & 51 & 13 & 1 \\
\hline 115 & 20.41 & 67.0 & 72 & 85 & 13 & 1 \\
\hline 116 & 20.53 & 67.4 & 73 & 86 & 12 & 0 \\
\hline 117 & 20.55 & 67.4 & 176 & 189 & 73 & 3 \\
\hline 118 & 20.59 & 67.5 & 63 & 76 & 9 & 0 \\
\hline 119 & 20.61 & 67.6 & 187 & 200 & 61 & 3 \\
\hline 120 & 20.62 & 67.7 & 89 & 102 & 69 & 3 \\
\hline 121 & 20.68 & 67.9 & 105 & 118 & 7 & 1 \\
\hline 122 & 21.16 & 69.4 & 67 & 80 & 12 & 0 \\
\hline 123 & 21.21 & 69.6 & 46 & 59 & 19 & 0 \\
\hline 124 & 21.47 & 70.4 & 66 & 79 & 20 & 0 \\
\hline 125 & 21.53 & 70.7 & 72 & 85 & 11 & 0 \\
\hline 126 & 21.69 & 71.2 & 39 & 52 & 16 & 0 \\
\hline 127 & 21.88 & 71.8 & 24 & 37 & 73 & 2 \\
\hline 128 & 21.99 & 72.1 & 3 & 16 & 20 & 0 \\
\hline 129 & 22.14 & 72.6 & 10 & 22 & 26 & 1 \\
\hline 130 & 22.30 & 73.2 & 16 & 29 & 77 & 2 \\
\hline 131 & 22.31 & 73.2 & 78 & 91 & 11 & 0 \\
\hline 132 & 22.50 & 73.8 & 10 & 23 & 68 & 2 \\
\hline 133 & 22.76 & 74.7 & 66 & 79 & 16 & 0 \\
\hline 134 & 23.46 & 77.0 & 33 & 45 & 14 & 0 \\
\hline 135 & 23.57 & 77.3 & 33 & 46 & 28 & 0 \\
\hline
\end{tabular}

All directions have been corrected for borehole deviation, and are with respect to true north.

Page 3 
Orientation Summary Table - Image Features

Nevada Test Site

Source Physics Experiment

U-15N \#3

NNSA/NSO

21 and 22 Sept 2010

\begin{tabular}{|c|c|c|c|c|c|c|}
\hline $\begin{array}{c}\text { Feature } \\
\text { No. }\end{array}$ & $\begin{array}{c}\text { Depth } \\
\text { (meters) }\end{array}$ & $\begin{array}{l}\text { Depth } \\
\text { (feet) }\end{array}$ & $\begin{array}{c}\text { Dip } \\
\text { Direction } \\
\text { (degrees) }\end{array}$ & $\begin{array}{c}\text { Dip } \\
\text { Direction } \\
\text { (deg. TN) }\end{array}$ & $\begin{array}{c}\text { Dip } \\
\text { Angle } \\
\text { (degrees) }\end{array}$ & $\begin{array}{c}\text { Feature } \\
\text { Rank } \\
\text { (0 to 5) }\end{array}$ \\
\hline 136 & 23.67 & 77.7 & 34 & 47 & 24 & 0 \\
\hline 137 & 23.86 & 78.3 & 180 & 192 & 87 & 3 \\
\hline 138 & 23.91 & 78.4 & 26 & 39 & 21 & 1 \\
\hline 139 & 24.06 & 78.9 & 40 & 53 & 20 & 0 \\
\hline 140 & 24.28 & 79.7 & 29 & 42 & 25 & 0 \\
\hline 141 & 24.76 & 81.2 & 14 & 27 & 57 & 2 \\
\hline 142 & 24.77 & 81.3 & 19 & 32 & 37 & 0 \\
\hline 143 & 24.97 & 81.9 & 196 & 209 & 83 & 4 \\
\hline 144 & 25.12 & 82.4 & 25 & 38 & 40 & 1 \\
\hline 145 & 25.75 & 84.5 & 188 & 200 & 71 & 0 \\
\hline 146 & 26.14 & 85.8 & 55 & 68 & 20 & 0 \\
\hline 147 & 26.66 & 87.5 & 191 & 204 & 86 & 3 \\
\hline 148 & 26.72 & 87.7 & 64 & 77 & 13 & 1 \\
\hline 149 & 26.77 & 87.8 & 58 & 70 & 20 & 1 \\
\hline 150 & 26.80 & 87.9 & 73 & 86 & 18 & 0 \\
\hline 151 & 26.90 & 88.2 & 58 & 71 & 12 & 0 \\
\hline 152 & 26.98 & 88.5 & 31 & 44 & 9 & 0 \\
\hline 153 & 27.08 & 88.8 & 84 & 97 & 10 & 0 \\
\hline 154 & 27.67 & 90.8 & 75 & 88 & 73 & 3 \\
\hline 155 & 27.78 & 91.2 & 191 & 204 & 78 & 3 \\
\hline 156 & 27.84 & 91.4 & 65 & 78 & 81 & 3 \\
\hline 157 & 27.90 & 91.5 & 195 & 208 & 85 & 3 \\
\hline 158 & 27.91 & 91.6 & 86 & 99 & 64 & 3 \\
\hline 159 & 28.51 & 93.5 & 196 & 209 & 80 & 3 \\
\hline 160 & 28.69 & 94.1 & 127 & 140 & 74 & 3 \\
\hline 161 & 28.96 & 95.0 & 194 & 206 & 78 & 3 \\
\hline 162 & 28.97 & 95.1 & 94 & 107 & 20 & 3 \\
\hline 163 & 29.14 & 95.6 & 63 & 76 & 11 & 3 \\
\hline 164 & 29.34 & 96.3 & 151 & 164 & 33 & 3 \\
\hline 165 & 29.39 & 96.4 & 63 & 76 & 16 & 2 \\
\hline 166 & 29.55 & 96.9 & 140 & 153 & 70 & 0 \\
\hline 167 & 29.78 & 97.7 & 140 & 152 & 77 & 3 \\
\hline 168 & 29.97 & 98.3 & 185 & 198 & 80 & 3 \\
\hline 169 & 30.04 & 98.6 & 48 & 61 & 77 & 3 \\
\hline 170 & 30.05 & 98.6 & 150 & 163 & 79 & 3 \\
\hline 171 & 30.33 & 99.5 & 77 & 90 & 19 & 2 \\
\hline 172 & 30.64 & 100.5 & 70 & 83 & 10 & 2 \\
\hline 173 & 30.64 & 100.5 & 105 & 118 & 56 & 1 \\
\hline 174 & 30.81 & 101.1 & 55 & 67 & 11 & 2 \\
\hline 175 & 30.82 & 101.1 & 104 & 116 & 60 & 1 \\
\hline 176 & 31.39 & 103.0 & 197 & 210 & 79 & 1 \\
\hline 177 & 31.40 & 103.0 & 114 & 127 & 14 & 0 \\
\hline 178 & 31.52 & 103.4 & 69 & 82 & 18 & 2 \\
\hline 179 & 31.63 & 103.8 & 77 & 90 & 10 & 2 \\
\hline 180 & 31.65 & 103.9 & 184 & 197 & 85 & 3 \\
\hline
\end{tabular}

All directions have been corrected for borehole deviation, and are with respect to true north.

Page 4 
Orientation Summary Table - Image Features

Nevada Test Site

Source Physics Experiment

U-15N \#3

NNSA/NSO

21 and 22 Sept 2010

\begin{tabular}{|c|c|c|c|c|c|c|}
\hline $\begin{array}{c}\text { Feature } \\
\text { No. }\end{array}$ & $\begin{array}{c}\text { Depth } \\
\text { (meters) }\end{array}$ & $\begin{array}{l}\text { Depth } \\
\text { (feet) }\end{array}$ & $\begin{array}{c}\text { Dip } \\
\text { Direction } \\
\text { (degrees) }\end{array}$ & $\begin{array}{c}\text { Dip } \\
\text { Direction } \\
\text { (deg. TN) }\end{array}$ & $\begin{array}{c}\text { Dip } \\
\text { Angle } \\
\text { (degrees) }\end{array}$ & $\begin{array}{c}\text { Feature } \\
\text { Rank } \\
\text { (0 to 5) }\end{array}$ \\
\hline 181 & 31.79 & 104.3 & 72 & 85 & 13 & 2 \\
\hline 182 & 32.01 & 105.0 & 312 & 325 & 13 & 0 \\
\hline 183 & 32.30 & 106.0 & 32 & 44 & 2 & 0 \\
\hline 184 & 32.47 & 106.5 & 67 & 80 & 19 & 0 \\
\hline 185 & 32.60 & 107.0 & 7 & 19 & 2 & 0 \\
\hline 186 & 32.75 & 107.5 & 60 & 73 & 15 & 0 \\
\hline 187 & 33.09 & 108.6 & 179 & 192 & 66 & 0 \\
\hline 188 & 33.24 & 109.1 & 45 & 58 & 22 & 3 \\
\hline 189 & 33.30 & 109.2 & 84 & 97 & 8 & 3 \\
\hline 190 & 33.51 & 110.0 & 316 & 329 & 67 & 3 \\
\hline 191 & 33.51 & 110.0 & 182 & 195 & 72 & 3 \\
\hline 192 & 33.60 & 110.3 & 42 & 54 & 33 & 3 \\
\hline 193 & 33.72 & 110.6 & 49 & 62 & 21 & 3 \\
\hline 194 & 33.89 & 111.2 & 59 & 72 & 6 & 1 \\
\hline 195 & 34.01 & 111.6 & 67 & 80 & 19 & 1 \\
\hline 196 & 34.08 & 111.8 & 59 & 72 & 14 & 1 \\
\hline 197 & 34.34 & 112.7 & 53 & 66 & 27 & 0 \\
\hline 198 & 34.77 & 114.1 & 38 & 51 & 32 & 0 \\
\hline 199 & 34.79 & 114.1 & 33 & 46 & 27 & 0 \\
\hline 200 & 35.00 & 114.8 & 69 & 81 & 18 & 2 \\
\hline 201 & 35.07 & 115.1 & 61 & 73 & 19 & 2 \\
\hline 202 & 35.15 & 115.3 & 75 & 88 & 18 & 2 \\
\hline 203 & 35.23 & 115.6 & 109 & 122 & 8 & 1 \\
\hline 204 & 35.36 & 116.0 & 66 & 79 & 7 & 0 \\
\hline 205 & 35.73 & 117.2 & 69 & 82 & 12 & 0 \\
\hline 206 & 35.84 & 117.6 & 16 & 29 & 7 & 0 \\
\hline 207 & 35.98 & 118.0 & 60 & 73 & 14 & 0 \\
\hline 208 & 36.09 & 118.4 & 62 & 75 & 9 & 0 \\
\hline 209 & 36.28 & 119.0 & 11 & 24 & 9 & 0 \\
\hline 210 & 36.41 & 119.5 & 35 & 48 & 6 & 0 \\
\hline 211 & 36.45 & 119.6 & 79 & 91 & 44 & 0 \\
\hline 212 & 36.47 & 119.6 & 99 & 112 & 83 & 3 \\
\hline 213 & 36.53 & 119.8 & 69 & 82 & 16 & 3 \\
\hline 214 & 36.59 & 120.0 & 55 & 68 & 19 & 3 \\
\hline 215 & 36.82 & 120.8 & 28 & 41 & 24 & 0 \\
\hline 216 & 36.89 & 121.0 & 357 & 10 & 12 & 0 \\
\hline 217 & 37.22 & 122.1 & 75 & 88 & 19 & 2 \\
\hline 218 & 37.33 & 122.5 & 59 & 72 & 77 & 3 \\
\hline 219 & 37.54 & 123.2 & 139 & 151 & 10 & 3 \\
\hline 220 & 37.80 & 124.0 & 89 & 102 & 14 & 2 \\
\hline 221 & 37.93 & 124.4 & 79 & 92 & 56 & 3 \\
\hline 222 & 38.01 & 124.7 & 76 & 89 & 56 & 1 \\
\hline 223 & 38.04 & 124.8 & 49 & 62 & 21 & 0 \\
\hline 224 & 38.26 & 125.5 & 13 & 25 & 29 & 0 \\
\hline 225 & 38.33 & 125.8 & 71 & 84 & 71 & 1 \\
\hline
\end{tabular}

All directions have been corrected for borehole deviation, and are with respect to true north.

Page 5 
Orientation Summary Table - Image Features

Nevada Test Site

Source Physics Experiment

U-15N \#3

NNSA/NSO

21 and 22 Sept 2010

\begin{tabular}{|c|c|c|c|c|c|c|}
\hline $\begin{array}{c}\text { Feature } \\
\text { No. }\end{array}$ & $\begin{array}{c}\text { Depth } \\
\text { (meters) }\end{array}$ & $\begin{array}{l}\text { Depth } \\
\text { (feet) }\end{array}$ & $\begin{array}{c}\text { Dip } \\
\text { Direction } \\
\text { (degrees) }\end{array}$ & $\begin{array}{c}\text { Dip } \\
\text { Direction } \\
\text { (deg. TN) }\end{array}$ & $\begin{array}{c}\text { Dip } \\
\text { Angle } \\
\text { (degrees) }\end{array}$ & $\begin{array}{c}\text { Feature } \\
\text { Rank } \\
\text { (0 to 5) }\end{array}$ \\
\hline 226 & 38.44 & 126.1 & 50 & 63 & 73 & 1 \\
\hline 227 & 38.77 & 127.2 & 98 & 111 & 68 & 3 \\
\hline 228 & 38.77 & 127.2 & 96 & 109 & 73 & 3 \\
\hline 229 & 38.80 & 127.3 & 52 & 65 & 28 & 0 \\
\hline 230 & 38.89 & 127.6 & 83 & 96 & 73 & 3 \\
\hline 231 & 38.95 & 127.8 & 67 & 80 & 13 & 3 \\
\hline 232 & 39.30 & 128.9 & 73 & 86 & 10 & 1 \\
\hline 233 & 39.38 & 129.2 & 63 & 76 & 76 & 3 \\
\hline 234 & 39.51 & 129.6 & 12 & 25 & 9 & 0 \\
\hline 235 & 39.58 & 129.9 & 67 & 80 & 77 & 3 \\
\hline 236 & 39.81 & 130.6 & 23 & 36 & 79 & 1 \\
\hline 237 & 39.84 & 130.7 & 23 & 36 & 83 & 3 \\
\hline 238 & 39.86 & 130.8 & 30 & 43 & 18 & 0 \\
\hline 239 & 40.02 & 131.3 & 56 & 69 & 18 & 0 \\
\hline 240 & 40.17 & 131.8 & 46 & 58 & 16 & 0 \\
\hline 241 & 40.60 & 133.2 & 169 & 182 & 87 & 3 \\
\hline 242 & 40.81 & 133.9 & 358 & 11 & 14 & 0 \\
\hline 243 & 40.86 & 134.1 & 2 & 15 & 23 & 0 \\
\hline 244 & 40.94 & 134.3 & 21 & 34 & 42 & 3 \\
\hline 245 & 40.96 & 134.4 & 145 & 158 & 22 & 3 \\
\hline 246 & 41.01 & 134.5 & 21 & 34 & 84 & 3 \\
\hline 247 & 41.07 & 134.8 & 39 & 52 & 74 & 3 \\
\hline 248 & 41.13 & 134.9 & 121 & 134 & 75 & 3 \\
\hline 249 & 41.31 & 135.5 & 84 & 97 & 7 & 0 \\
\hline 250 & 41.53 & 136.3 & 14 & 27 & 80 & 3 \\
\hline 251 & 41.54 & 136.3 & 37 & 50 & 24 & 0 \\
\hline 252 & 41.70 & 136.8 & 163 & 176 & 80 & 3 \\
\hline 253 & 41.93 & 137.6 & 80 & 92 & 82 & 2 \\
\hline 254 & 42.24 & 138.6 & 72 & 85 & 19 & 0 \\
\hline 255 & 42.26 & 138.7 & 91 & 104 & 17 & 2 \\
\hline 256 & 42.72 & 140.2 & 54 & 67 & 23 & 0 \\
\hline 257 & 42.99 & 141.0 & 60 & 73 & 16 & 0 \\
\hline 258 & 43.22 & 141.8 & 73 & 86 & 16 & 0 \\
\hline 259 & 43.32 & 142.1 & 77 & 90 & 17 & 3 \\
\hline 260 & 43.33 & 142.2 & 64 & 77 & 30 & 3 \\
\hline 261 & 43.67 & 143.3 & 29 & 42 & 37 & 0 \\
\hline 262 & 43.74 & 143.5 & 69 & 82 & 23 & 0 \\
\hline 263 & 43.77 & 143.6 & 193 & 206 & 2 & 2 \\
\hline 264 & 44.09 & 144.6 & 41 & 54 & 30 & 0 \\
\hline 265 & 44.16 & 144.9 & 53 & 66 & 17 & 0 \\
\hline 266 & 44.17 & 144.9 & 91 & 104 & 20 & 2 \\
\hline 267 & 44.47 & 145.9 & 80 & 93 & 17 & 1 \\
\hline 268 & 44.50 & 146.0 & 86 & 99 & 17 & 3 \\
\hline 269 & 44.56 & 146.2 & 190 & 203 & 73 & 1 \\
\hline 270 & 44.62 & 146.4 & 50 & 63 & 13 & 0 \\
\hline
\end{tabular}

All directions have been corrected for borehole deviation, and are with respect to true north.

Page 6 
Orientation Summary Table - Image Features

Nevada Test Site

Source Physics Experiment

U-15N \#3

NNSA/NSO

21 and 22 Sept 2010

\begin{tabular}{|c|c|c|c|c|c|c|}
\hline $\begin{array}{c}\text { Feature } \\
\text { No. }\end{array}$ & $\begin{array}{c}\text { Depth } \\
\text { (meters) }\end{array}$ & $\begin{array}{l}\text { Depth } \\
\text { (feet) }\end{array}$ & $\begin{array}{c}\text { Dip } \\
\text { Direction } \\
\text { (degrees) }\end{array}$ & $\begin{array}{c}\text { Dip } \\
\text { Direction } \\
\text { (deg. TN) }\end{array}$ & $\begin{array}{c}\text { Dip } \\
\text { Angle } \\
\text { (degrees) }\end{array}$ & $\begin{array}{c}\text { Feature } \\
\text { Rank } \\
\text { (0 to 5) }\end{array}$ \\
\hline 271 & 44.70 & 146.7 & 292 & 305 & 5 & 2 \\
\hline 272 & 44.85 & 147.2 & 56 & 69 & 10 & 0 \\
\hline 273 & 45.25 & 148.5 & 66 & 79 & 17 & 0 \\
\hline 274 & 45.54 & 149.4 & 46 & 58 & 24 & 0 \\
\hline 275 & 45.89 & 150.6 & 21 & 34 & 22 & 0 \\
\hline 276 & 46.22 & 151.6 & 11 & 24 & 26 & 0 \\
\hline 277 & 46.28 & 151.8 & 141 & 154 & 67 & 3 \\
\hline 278 & 46.41 & 152.3 & 139 & 152 & 69 & 3 \\
\hline 279 & 46.73 & 153.3 & 80 & 93 & 15 & 2 \\
\hline 280 & 46.89 & 153.9 & 75 & 87 & 14 & 0 \\
\hline 281 & 47.02 & 154.3 & 61 & 74 & 17 & 0 \\
\hline 282 & 47.28 & 155.1 & 328 & 341 & 3 & 1 \\
\hline 283 & 47.61 & 156.2 & 15 & 28 & 28 & 0 \\
\hline 284 & 47.83 & 156.9 & 40 & 53 & 15 & 0 \\
\hline 285 & 47.89 & 157.1 & 59 & 72 & 18 & 0 \\
\hline 286 & 48.05 & 157.7 & 100 & 113 & 26 & 0 \\
\hline 287 & 48.11 & 157.9 & 243 & 256 & 88 & 1 \\
\hline 288 & 48.42 & 158.9 & 74 & 87 & 6 & 0 \\
\hline 289 & 48.58 & 159.4 & 331 & 344 & 11 & 0 \\
\hline 290 & 49.02 & 160.8 & 74 & 87 & 8 & 0 \\
\hline 291 & 49.03 & 160.9 & 32 & 45 & 11 & 1 \\
\hline 292 & 49.13 & 161.2 & 56 & 69 & 17 & 3 \\
\hline 293 & 49.33 & 161.9 & 73 & 86 & 20 & 0 \\
\hline 294 & 49.37 & 162.0 & 64 & 77 & 17 & 3 \\
\hline 295 & 49.74 & 163.2 & 39 & 52 & 17 & 0 \\
\hline 296 & 49.85 & 163.6 & 273 & 286 & 1 & 3 \\
\hline 297 & 50.02 & 164.1 & 51 & 63 & 20 & 2 \\
\hline 298 & 50.18 & 164.6 & 40 & 52 & 15 & 0 \\
\hline 299 & 50.32 & 165.1 & 219 & 231 & 83 & 3 \\
\hline 300 & 50.60 & 166.0 & 50 & 63 & 22 & 0 \\
\hline 301 & 50.68 & 166.3 & 68 & 81 & 9 & 3 \\
\hline 302 & 51.05 & 167.5 & 194 & 207 & 84 & 3 \\
\hline 303 & 51.08 & 167.6 & 353 & 6 & 20 & 0 \\
\hline 304 & 51.76 & 169.8 & 63 & 76 & 9 & 2 \\
\hline 305 & 52.14 & 171.1 & 73 & 86 & 4 & 2 \\
\hline 306 & 52.33 & 171.7 & 113 & 126 & 79 & 2 \\
\hline 307 & 52.46 & 172.1 & 64 & 77 & 13 & 2 \\
\hline 308 & 52.64 & 172.7 & 30 & 43 & 26 & 1 \\
\hline 309 & 52.82 & 173.3 & 135 & 147 & 85 & 2 \\
\hline 310 & 53.05 & 174.1 & 140 & 153 & 67 & 3 \\
\hline 311 & 53.22 & 174.6 & 89 & 102 & 9 & 1 \\
\hline 312 & 53.23 & 174.6 & 303 & 316 & 86 & 3 \\
\hline 313 & 53.33 & 175.0 & 151 & 164 & 50 & 1 \\
\hline 314 & 53.56 & 175.7 & 91 & 104 & 49 & 1 \\
\hline 315 & 53.69 & 176.1 & 139 & 152 & 70 & 3 \\
\hline
\end{tabular}

All directions have been corrected for borehole deviation, and are with respect to true north. 
Orientation Summary Table - Image Features

Nevada Test Site

Source Physics Experiment

U-15N \#3

NNSA/NSO

21 and 22 Sept 2010

\begin{tabular}{|c|c|c|c|c|c|c|}
\hline $\begin{array}{c}\text { Feature } \\
\text { No. }\end{array}$ & $\begin{array}{l}\text { Depth } \\
\text { (meters) }\end{array}$ & $\begin{array}{l}\text { Depth } \\
\text { (feet) }\end{array}$ & $\begin{array}{c}\text { Dip } \\
\text { Direction } \\
\text { (degrees) }\end{array}$ & $\begin{array}{c}\text { Dip } \\
\text { Direction } \\
\text { (deg. TN) }\end{array}$ & $\begin{array}{c}\text { Dip } \\
\text { Angle } \\
\text { (degrees) }\end{array}$ & $\begin{array}{c}\text { Feature } \\
\text { Rank } \\
\text { (0 to 5) }\end{array}$ \\
\hline 316 & 53.71 & 176.2 & 55 & 67 & 10 & 2 \\
\hline 317 & 53.84 & 176.6 & 147 & 160 & 63 & 3 \\
\hline 318 & 53.85 & 176.7 & 134 & 147 & 10 & 2 \\
\hline 319 & 53.91 & 176.9 & 151 & 164 & 58 & 3 \\
\hline 320 & 54.11 & 177.5 & 7 & 20 & 11 & 2 \\
\hline 321 & 54.32 & 178.2 & 19 & 32 & 32 & 0 \\
\hline 322 & 54.43 & 178.6 & 43 & 56 & 30 & 2 \\
\hline 323 & 54.54 & 178.9 & 40 & 53 & 26 & 0 \\
\hline 324 & 54.72 & 179.5 & 144 & 157 & 62 & 2 \\
\hline
\end{tabular}

All directions have been corrected for borehole deviation, and are with respect to true north. 
Appendix J-5

Fracture Data Tabulated from Borehole Image Logs by Colog, Inc. For Instrument Hole U-15n\#4 
Orientation Summary Table - Image Features

Nevada Test Site

Source Physics Experiment

U-15N \#4

NNSA/NSO

22 Sept 2010

\begin{tabular}{|c|c|c|c|c|c|c|}
\hline $\begin{array}{c}\text { Feature } \\
\text { No. }\end{array}$ & $\begin{array}{c}\text { Depth } \\
\text { (meters) }\end{array}$ & $\begin{array}{l}\text { Depth } \\
\text { (feet) }\end{array}$ & $\begin{array}{c}\text { Dip } \\
\text { Direction } \\
\text { (degrees) }\end{array}$ & $\begin{array}{c}\text { Dip } \\
\text { Direction } \\
(\text { deg. } T N)\end{array}$ & $\begin{array}{c}\text { Dip } \\
\text { Angle } \\
\text { (degrees) }\end{array}$ & $\begin{array}{c}\text { Feature } \\
\text { Rank } \\
(0 \text { to } 5)\end{array}$ \\
\hline 1 & 4.85 & 15.9 & 90 & 102 & 44 & 0 \\
\hline 2 & 5.23 & 17.2 & 140 & 152 & 9 & 0 \\
\hline 3 & 5.25 & 17.2 & 60 & 73 & 25 & 0 \\
\hline 4 & 5.39 & 17.7 & 226 & 239 & 5 & 1 \\
\hline 5 & 5.52 & 18.1 & 64 & 76 & 7 & 1 \\
\hline 6 & 5.57 & 18.3 & 67 & 79 & 28 & 1 \\
\hline 7 & 5.68 & 18.6 & 72 & 85 & 9 & 1 \\
\hline 8 & 6.45 & 21.2 & 209 & 222 & 13 & 1 \\
\hline 9 & 6.51 & 21.4 & 43 & 56 & 20 & 1 \\
\hline 10 & 6.79 & 22.3 & 73 & 86 & 23 & 0 \\
\hline 11 & 6.93 & 22.8 & 22 & 35 & 3 & 1 \\
\hline 12 & 6.96 & 22.9 & 80 & 93 & 4 & 1 \\
\hline 13 & 7.05 & 23.1 & 72 & 85 & 10 & 1 \\
\hline 14 & 7.07 & 23.2 & 83 & 96 & 28 & 1 \\
\hline 15 & 7.14 & 23.4 & 30 & 43 & 17 & 1 \\
\hline 16 & 7.23 & 23.7 & 32 & 45 & 16 & 1 \\
\hline 17 & 7.50 & 24.6 & 71 & 84 & 35 & 1 \\
\hline 18 & 7.70 & 25.3 & 48 & 61 & 27 & 1 \\
\hline 19 & 7.83 & 25.7 & 40 & 53 & 10 & 1 \\
\hline 20 & 7.91 & 26.0 & 117 & 130 & 17 & 1 \\
\hline 21 & 8.08 & 26.5 & 115 & 128 & 21 & 1 \\
\hline 22 & 8.29 & 27.2 & 47 & 60 & 22 & 1 \\
\hline 23 & 8.44 & 27.7 & 68 & 81 & 26 & 0 \\
\hline 24 & 8.52 & 28.0 & 55 & 67 & 49 & 0 \\
\hline 25 & 8.63 & 28.3 & 40 & 53 & 12 & 1 \\
\hline 26 & 8.80 & 28.9 & 86 & 99 & 9 & 0 \\
\hline 27 & 8.99 & 29.5 & 42 & 55 & 11 & 0 \\
\hline 28 & 9.13 & 30.0 & 109 & 122 & 46 & 1 \\
\hline 29 & 9.30 & 30.5 & 26 & 38 & 12 & 1 \\
\hline 30 & 9.63 & 31.6 & 116 & 129 & 52 & 1 \\
\hline 31 & 9.73 & 31.9 & 103 & 116 & 58 & 1 \\
\hline 32 & 9.94 & 32.6 & 71 & 84 & 62 & 1 \\
\hline 33 & 10.24 & 33.6 & 60 & 73 & 14 & 2 \\
\hline 34 & 10.30 & 33.8 & 175 & 188 & 83 & 1 \\
\hline 35 & 10.36 & 34.0 & 46 & 59 & 12 & 0 \\
\hline 36 & 10.59 & 34.7 & 59 & 72 & 8 & 1 \\
\hline 37 & 10.67 & 35.0 & 54 & 67 & 9 & 1 \\
\hline 38 & 10.80 & 35.4 & 97 & 110 & 15 & 1 \\
\hline 39 & 11.12 & 36.5 & 299 & 312 & 56 & 0 \\
\hline 40 & 11.13 & 36.5 & 86 & 98 & 15 & 1 \\
\hline 41 & 11.20 & 36.8 & 196 & 209 & 83 & 1 \\
\hline 42 & 11.73 & 38.5 & 307 & 320 & 77 & 1 \\
\hline 43 & 11.78 & 38.6 & 55 & 68 & 6 & 1 \\
\hline 44 & 12.12 & 39.8 & 22 & 35 & 11 & 1 \\
\hline 45 & 12.40 & 40.7 & 196 & 209 & 84 & 1 \\
\hline
\end{tabular}

All directions have been corrected for borehole deviation, and are with respect to true north.

Page 1 
Orientation Summary Table - Image Features

Nevada Test Site

Source Physics Experiment

U-15N \#4

NNSA/NSO

22 Sept 2010

\begin{tabular}{|c|c|c|c|c|c|c|}
\hline $\begin{array}{c}\text { Feature } \\
\text { No. }\end{array}$ & $\begin{array}{c}\text { Depth } \\
\text { (meters) }\end{array}$ & $\begin{array}{l}\text { Depth } \\
\text { (feet) }\end{array}$ & $\begin{array}{c}\text { Dip } \\
\text { Direction } \\
\text { (degrees) }\end{array}$ & $\begin{array}{c}\text { Dip } \\
\text { Direction } \\
(\text { deg. } T N)\end{array}$ & $\begin{array}{c}\text { Dip } \\
\text { Angle } \\
\text { (degrees) }\end{array}$ & $\begin{array}{c}\text { Feature } \\
\text { Rank } \\
\text { (0 to 5) }\end{array}$ \\
\hline 46 & 12.41 & 40.7 & 51 & 64 & 10 & 0 \\
\hline 47 & 12.58 & 41.3 & 203 & 216 & 71 & 1 \\
\hline 48 & 12.65 & 41.5 & 50 & 63 & 13 & 1 \\
\hline 49 & 12.80 & 42.0 & 54 & 67 & 9 & 1 \\
\hline 50 & 13.19 & 43.3 & 52 & 65 & 9 & 0 \\
\hline 51 & 13.25 & 43.5 & 193 & 206 & 85 & 1 \\
\hline 52 & 13.41 & 44.0 & 93 & 106 & 6 & 0 \\
\hline 53 & 13.54 & 44.4 & 187 & 200 & 86 & 1 \\
\hline 54 & 13.68 & 44.9 & 102 & 115 & 10 & 1 \\
\hline 55 & 13.93 & 45.7 & 26 & 39 & 9 & 2 \\
\hline 56 & 14.07 & 46.2 & 68 & 81 & 17 & 0 \\
\hline 57 & 14.34 & 47.1 & 81 & 94 & 6 & 0 \\
\hline 58 & 14.68 & 48.2 & 61 & 74 & 11 & 0 \\
\hline 59 & 14.79 & 48.5 & 41 & 54 & 32 & 0 \\
\hline 60 & 14.96 & 49.1 & 88 & 101 & 5 & 0 \\
\hline 61 & 15.23 & 50.0 & 79 & 92 & 8 & 1 \\
\hline 62 & 15.25 & 50.0 & 70 & 82 & 45 & 1 \\
\hline 63 & 15.32 & 50.3 & 84 & 97 & 13 & 0 \\
\hline 64 & 15.41 & 50.6 & 73 & 85 & 15 & 0 \\
\hline 65 & 15.56 & 51.1 & 73 & 85 & 24 & 0 \\
\hline 66 & 15.62 & 51.3 & 111 & 124 & 72 & 1 \\
\hline 67 & 15.73 & 51.6 & 98 & 111 & 13 & 2 \\
\hline 68 & 15.91 & 52.2 & 42 & 55 & 15 & 2 \\
\hline 69 & 16.00 & 52.5 & 114 & 127 & 77 & 2 \\
\hline 70 & 16.03 & 52.6 & 45 & 58 & 9 & 1 \\
\hline 71 & 16.07 & 52.7 & 110 & 123 & 9 & 2 \\
\hline 72 & 16.13 & 52.9 & 119 & 132 & 73 & 2 \\
\hline 73 & 16.25 & 53.3 & 34 & 47 & 13 & 0 \\
\hline 74 & 16.36 & 53.7 & 105 & 118 & 70 & 1 \\
\hline 75 & 16.49 & 54.1 & 55 & 68 & 13 & 0 \\
\hline 76 & 16.79 & 55.1 & 105 & 117 & 70 & 1 \\
\hline 77 & 16.89 & 55.4 & 108 & 121 & 66 & 1 \\
\hline 78 & 17.10 & 56.1 & 84 & 97 & 17 & 0 \\
\hline 79 & 17.21 & 56.5 & 126 & 139 & 8 & 1 \\
\hline 80 & 17.46 & 57.3 & 63 & 75 & 19 & 1 \\
\hline 81 & 17.52 & 57.5 & 52 & 65 & 5 & 3 \\
\hline 82 & 17.61 & 57.8 & 185 & 198 & 4 & 0 \\
\hline 83 & 17.72 & 58.1 & 77 & 90 & 19 & 3 \\
\hline 84 & 17.78 & 58.3 & 47 & 60 & 17 & 1 \\
\hline 85 & 17.85 & 58.6 & 78 & 91 & 14 & 2 \\
\hline 86 & 17.99 & 59.0 & 53 & 66 & 21 & 1 \\
\hline 87 & 18.24 & 59.9 & 103 & 116 & 76 & 0 \\
\hline 88 & 18.26 & 59.9 & 7 & 20 & 25 & 1 \\
\hline 89 & 18.32 & 60.1 & 126 & 139 & 75 & 3 \\
\hline 90 & 18.38 & 60.3 & 62 & 75 & 20 & 0 \\
\hline
\end{tabular}

All directions have been corrected for borehole deviation, and are with respect to true north.

Page 2 
Orientation Summary Table - Image Features

Nevada Test Site

Source Physics Experiment

U-15N \#4

NNSA/NSO

22 Sept 2010

\begin{tabular}{|c|c|c|c|c|c|c|}
\hline $\begin{array}{c}\text { Feature } \\
\text { No. }\end{array}$ & $\begin{array}{c}\text { Depth } \\
\text { (meters) }\end{array}$ & $\begin{array}{l}\text { Depth } \\
\text { (feet) }\end{array}$ & $\begin{array}{c}\text { Dip } \\
\text { Direction } \\
\text { (degrees) }\end{array}$ & $\begin{array}{c}\text { Dip } \\
\text { Direction } \\
(\text { deg. } T N)\end{array}$ & $\begin{array}{c}\text { Dip } \\
\text { Angle } \\
\text { (degrees) }\end{array}$ & $\begin{array}{c}\text { Feature } \\
\text { Rank } \\
\text { (0 to 5) }\end{array}$ \\
\hline 91 & 18.39 & 60.3 & 97 & 110 & 78 & 3 \\
\hline 92 & 18.43 & 60.5 & 144 & 157 & 80 & 3 \\
\hline 93 & 18.47 & 60.6 & 57 & 70 & 5 & 1 \\
\hline 94 & 19.14 & 62.8 & 34 & 47 & 14 & 3 \\
\hline 95 & 19.32 & 63.4 & 209 & 222 & 33 & 0 \\
\hline 96 & 19.40 & 63.7 & 15 & 28 & 15 & 0 \\
\hline 97 & 19.43 & 63.8 & 65 & 78 & 20 & 0 \\
\hline 98 & 19.56 & 64.2 & 112 & 125 & 63 & 0 \\
\hline 99 & 19.66 & 64.5 & 28 & 41 & 45 & 1 \\
\hline 100 & 19.90 & 65.3 & 83 & 96 & 13 & 3 \\
\hline 101 & 19.97 & 65.5 & 358 & 11 & 40 & 1 \\
\hline 102 & 20.00 & 65.6 & 157 & 170 & 36 & 3 \\
\hline 103 & 20.10 & 66.0 & 142 & 155 & 37 & 3 \\
\hline 104 & 20.63 & 67.7 & 34 & 47 & 22 & 1 \\
\hline 105 & 20.69 & 67.9 & 27 & 40 & 13 & 1 \\
\hline 106 & 21.05 & 69.1 & 190 & 203 & 66 & 0 \\
\hline 107 & 21.05 & 69.1 & 36 & 49 & 24 & 3 \\
\hline 108 & 21.12 & 69.3 & 58 & 71 & 21 & 3 \\
\hline 109 & 21.16 & 69.4 & 98 & 110 & 12 & 3 \\
\hline 110 & 21.39 & 70.2 & 61 & 74 & 16 & 0 \\
\hline 111 & 21.45 & 70.4 & 54 & 66 & 16 & 1 \\
\hline 112 & 21.48 & 70.5 & 0 & 13 & 65 & 3 \\
\hline 113 & 21.60 & 70.9 & 13 & 26 & 87 & 3 \\
\hline 114 & 21.88 & 71.8 & 32 & 45 & 14 & 0 \\
\hline 115 & 22.21 & 72.9 & 10 & 23 & 80 & 3 \\
\hline 116 & 22.47 & 73.7 & 10 & 23 & 22 & 1 \\
\hline 117 & 22.66 & 74.4 & 16 & 29 & 20 & 1 \\
\hline 118 & 22.84 & 74.9 & 360 & 12 & 84 & 3 \\
\hline 119 & 23.64 & 77.6 & 0 & 13 & 52 & 1 \\
\hline 120 & 23.80 & 78.1 & 351 & 4 & 82 & 3 \\
\hline 121 & 24.44 & 80.2 & 106 & 119 & 65 & 3 \\
\hline 122 & 24.58 & 80.6 & 51 & 64 & 63 & 3 \\
\hline 123 & 25.02 & 82.1 & 37 & 50 & 17 & 1 \\
\hline 124 & 25.37 & 83.2 & 104 & 117 & 16 & 1 \\
\hline 125 & 25.43 & 83.4 & 89 & 102 & 84 & 3 \\
\hline 126 & 26.42 & 86.7 & 97 & 110 & 13 & 0 \\
\hline 127 & 26.76 & 87.8 & 36 & 49 & 22 & 0 \\
\hline 128 & 26.89 & 88.2 & 134 & 147 & 69 & 3 \\
\hline 129 & 27.01 & 88.6 & 17 & 30 & 87 & 3 \\
\hline 130 & 27.14 & 89.0 & 178 & 191 & 83 & 3 \\
\hline 131 & 27.97 & 91.8 & 7 & 20 & 85 & 3 \\
\hline 132 & 28.18 & 92.5 & 345 & 357 & 64 & 1 \\
\hline 133 & 28.22 & 92.6 & 359 & 12 & 78 & 3 \\
\hline 134 & 28.63 & 93.9 & 34 & 47 & 28 & 1 \\
\hline 135 & 28.89 & 94.8 & 39 & 52 & 17 & 1 \\
\hline
\end{tabular}

All directions have been corrected for borehole deviation, and are with respect to true north.

Page 3 
Orientation Summary Table - Image Features

Nevada Test Site

Source Physics Experiment

U-15N \#4

NNSA/NSO

22 Sept 2010

\begin{tabular}{|c|c|c|c|c|c|c|}
\hline $\begin{array}{c}\text { Feature } \\
\text { No. }\end{array}$ & $\begin{array}{c}\text { Depth } \\
\text { (meters) }\end{array}$ & $\begin{array}{l}\text { Depth } \\
\text { (feet) }\end{array}$ & $\begin{array}{c}\text { Dip } \\
\text { Direction } \\
\text { (degrees) }\end{array}$ & $\begin{array}{c}\text { Dip } \\
\text { Direction } \\
(\text { deg. } T N)\end{array}$ & $\begin{array}{c}\text { Dip } \\
\text { Angle } \\
\text { (degrees) }\end{array}$ & $\begin{array}{c}\text { Feature } \\
\text { Rank } \\
\text { (0 to 5) }\end{array}$ \\
\hline 136 & 29.09 & 95.5 & 13 & 26 & 74 & 3 \\
\hline 137 & 29.19 & 95.8 & 356 & 9 & 67 & 3 \\
\hline 138 & 29.27 & 96.0 & 339 & 352 & 78 & 3 \\
\hline 139 & 29.49 & 96.8 & 110 & 123 & 74 & 3 \\
\hline 140 & 29.49 & 96.8 & 34 & 46 & 26 & 1 \\
\hline 141 & 29.51 & 96.8 & 345 & 358 & 60 & 1 \\
\hline 142 & 29.96 & 98.3 & 68 & 81 & 9 & 1 \\
\hline 143 & 29.98 & 98.4 & 44 & 57 & 37 & 2 \\
\hline 144 & 30.12 & 98.8 & 3 & 16 & 38 & 1 \\
\hline 145 & 30.21 & 99.1 & 34 & 47 & 26 & 1 \\
\hline 146 & 30.30 & 99.4 & 93 & 106 & 74 & 3 \\
\hline 147 & 30.37 & 99.7 & 9 & 22 & 25 & 1 \\
\hline 148 & 30.53 & 100.2 & 39 & 52 & 25 & 1 \\
\hline 149 & 30.61 & 100.4 & 46 & 59 & 5 & 3 \\
\hline 150 & 30.67 & 100.6 & 130 & 143 & 72 & 3 \\
\hline 151 & 30.68 & 100.6 & 27 & 40 & 12 & 1 \\
\hline 152 & 30.91 & 101.4 & 177 & 190 & 57 & 1 \\
\hline 153 & 30.92 & 101.4 & 49 & 62 & 17 & 1 \\
\hline 154 & 31.01 & 101.7 & 106 & 119 & 80 & 3 \\
\hline 155 & 31.31 & 102.7 & 135 & 148 & 10 & 1 \\
\hline 156 & 31.37 & 102.9 & 44 & 57 & 19 & 3 \\
\hline 157 & 31.42 & 103.1 & 36 & 49 & 18 & 1 \\
\hline 158 & 31.79 & 104.3 & 37 & 50 & 19 & 0 \\
\hline 159 & 32.17 & 105.5 & 107 & 120 & 42 & 2 \\
\hline 160 & 32.38 & 106.2 & 115 & 127 & 9 & 2 \\
\hline 161 & 32.50 & 106.6 & 63 & 76 & 15 & 1 \\
\hline 162 & 32.53 & 106.7 & 17 & 30 & 86 & 3 \\
\hline 163 & 32.70 & 107.3 & 26 & 39 & 86 & 3 \\
\hline 164 & 32.90 & 107.9 & 21 & 34 & 60 & 0 \\
\hline 165 & 33.17 & 108.8 & 30 & 43 & 20 & 0 \\
\hline 166 & 33.24 & 109.1 & 124 & 137 & 77 & 3 \\
\hline 167 & 33.30 & 109.3 & 14 & 27 & 28 & 0 \\
\hline 168 & 33.46 & 109.8 & 339 & 352 & 41 & 2 \\
\hline 169 & 33.55 & 110.1 & 109 & 122 & 84 & 3 \\
\hline 170 & 33.55 & 110.1 & 95 & 108 & 14 & 1 \\
\hline 171 & 33.60 & 110.2 & 125 & 138 & 68 & 3 \\
\hline 172 & 33.87 & 111.1 & 66 & 79 & 7 & 2 \\
\hline 173 & 34.34 & 112.7 & 29 & 42 & 4 & 3 \\
\hline 174 & 34.44 & 113.0 & 44 & 57 & 34 & 2 \\
\hline 175 & 34.51 & 113.2 & 60 & 73 & 15 & 1 \\
\hline 176 & 35.32 & 115.9 & 288 & 301 & 69 & 3 \\
\hline 177 & 35.64 & 116.9 & 69 & 82 & 17 & 3 \\
\hline 178 & 35.73 & 117.2 & 27 & 40 & 39 & 1 \\
\hline 179 & 35.88 & 117.7 & 99 & 112 & 5 & 2 \\
\hline 180 & 36.24 & 118.9 & 18 & 31 & 27 & 0 \\
\hline
\end{tabular}

All directions have been corrected for borehole deviation, and are with respect to true north. 
Orientation Summary Table - Image Features

Nevada Test Site

Source Physics Experiment

U-15N \#4

NNSA/NSO

22 Sept 2010

\begin{tabular}{|c|c|c|c|c|c|c|}
\hline $\begin{array}{c}\text { Feature } \\
\text { No. }\end{array}$ & $\begin{array}{c}\text { Depth } \\
\text { (meters) }\end{array}$ & $\begin{array}{l}\text { Depth } \\
\text { (feet) }\end{array}$ & $\begin{array}{c}\text { Dip } \\
\text { Direction } \\
\text { (degrees) }\end{array}$ & $\begin{array}{c}\text { Dip } \\
\text { Direction } \\
(\text { deg. } T N)\end{array}$ & $\begin{array}{c}\text { Dip } \\
\text { Angle } \\
\text { (degrees) }\end{array}$ & $\begin{array}{c}\text { Feature } \\
\text { Rank } \\
\text { (0 to 5) }\end{array}$ \\
\hline 181 & 36.34 & 119.2 & 30 & 43 & 20 & 0 \\
\hline 182 & 36.42 & 119.5 & 345 & 358 & 13 & 1 \\
\hline 183 & 36.46 & 119.6 & 44 & 57 & 19 & 3 \\
\hline 184 & 36.51 & 119.8 & 18 & 31 & 63 & 0 \\
\hline 185 & 36.74 & 120.5 & 345 & 358 & 36 & 2 \\
\hline 186 & 36.90 & 121.1 & 13 & 26 & 78 & 3 \\
\hline 187 & 36.91 & 121.1 & 24 & 37 & 14 & 2 \\
\hline 188 & 37.05 & 121.5 & 59 & 72 & 17 & 3 \\
\hline 189 & 37.12 & 121.8 & 10 & 23 & 80 & 3 \\
\hline 190 & 37.21 & 122.1 & 45 & 58 & 14 & 2 \\
\hline 191 & 37.34 & 122.5 & 20 & 33 & 24 & 1 \\
\hline 192 & 37.51 & 123.1 & 22 & 35 & 21 & 0 \\
\hline 193 & 37.58 & 123.3 & 54 & 67 & 18 & 1 \\
\hline 194 & 37.85 & 124.2 & 47 & 60 & 19 & 0 \\
\hline 195 & 37.90 & 124.3 & 31 & 43 & 25 & 1 \\
\hline 196 & 37.98 & 124.6 & 19 & 32 & 24 & 0 \\
\hline 197 & 38.13 & 125.1 & 35 & 48 & 38 & 0 \\
\hline 198 & 38.18 & 125.3 & 16 & 29 & 25 & 0 \\
\hline 199 & 38.60 & 126.6 & 35 & 48 & 10 & 1 \\
\hline 200 & 38.87 & 127.5 & 185 & 198 & 50 & 0 \\
\hline 201 & 39.04 & 128.1 & 45 & 58 & 10 & 3 \\
\hline 202 & 39.16 & 128.5 & 31 & 44 & 3 & 1 \\
\hline 203 & 39.19 & 128.6 & 59 & 72 & 23 & 1 \\
\hline 204 & 39.33 & 129.0 & 87 & 100 & 28 & 0 \\
\hline 205 & 39.48 & 129.5 & 98 & 111 & 21 & 3 \\
\hline 206 & 39.70 & 130.3 & 10 & 23 & 85 & 3 \\
\hline 207 & 39.80 & 130.6 & 97 & 110 & 56 & 3 \\
\hline 208 & 40.00 & 131.2 & 23 & 36 & 19 & 3 \\
\hline 209 & 40.53 & 133.0 & 22 & 35 & 85 & 3 \\
\hline 210 & 40.69 & 133.5 & 196 & 209 & 85 & 3 \\
\hline 211 & 41.32 & 135.6 & 212 & 225 & 13 & 3 \\
\hline 212 & 41.43 & 135.9 & 10 & 23 & 9 & 3 \\
\hline 213 & 41.84 & 137.3 & 176 & 189 & 56 & 3 \\
\hline 214 & 41.92 & 137.5 & 55 & 68 & 29 & 2 \\
\hline 215 & 42.40 & 139.1 & 97 & 109 & 54 & 2 \\
\hline 216 & 42.41 & 139.1 & 103 & 116 & 10 & 2 \\
\hline 217 & 42.93 & 140.9 & 73 & 86 & 2 & 1 \\
\hline 218 & 43.35 & 142.2 & 87 & 99 & 11 & 0 \\
\hline 219 & 44.04 & 144.5 & 124 & 137 & 70 & 2 \\
\hline 220 & 44.32 & 145.4 & 15 & 28 & 88 & 3 \\
\hline 221 & 44.46 & 145.9 & 24 & 36 & 84 & 3 \\
\hline 222 & 44.74 & 146.8 & 162 & 174 & 80 & 0 \\
\hline 223 & 44.93 & 147.4 & 18 & 31 & 80 & 3 \\
\hline 224 & 45.39 & 148.9 & 118 & 131 & 44 & 3 \\
\hline 225 & 46.10 & 151.2 & 188 & 201 & 12 & 1 \\
\hline
\end{tabular}

All directions have been corrected for borehole deviation, and are with respect to true north.

Page 5 
Orientation Summary Table - Image Features

Nevada Test Site

Source Physics Experiment

U-15N \#4

NNSA/NSO

22 Sept 2010

\begin{tabular}{|c|c|c|c|c|c|c|}
\hline $\begin{array}{c}\text { Feature } \\
\text { No. }\end{array}$ & $\begin{array}{c}\text { Depth } \\
\text { (meters) }\end{array}$ & $\begin{array}{l}\text { Depth } \\
\text { (feet) }\end{array}$ & $\begin{array}{c}\text { Dip } \\
\text { Direction } \\
\text { (degrees) }\end{array}$ & $\begin{array}{c}\text { Dip } \\
\text { Direction } \\
(\text { deg. } T N)\end{array}$ & $\begin{array}{c}\text { Dip } \\
\text { Angle } \\
\text { (degrees) }\end{array}$ & $\begin{array}{c}\text { Feature } \\
\text { Rank } \\
\text { (0 to 5) }\end{array}$ \\
\hline 226 & 46.20 & 151.6 & 38 & 50 & 13 & 3 \\
\hline 227 & 46.54 & 152.7 & 26 & 39 & 82 & 3 \\
\hline 228 & 46.85 & 153.7 & 126 & 139 & 79 & 3 \\
\hline 229 & 46.87 & 153.8 & 125 & 138 & 65 & 3 \\
\hline 230 & 46.96 & 154.1 & 226 & 239 & 21 & 2 \\
\hline 231 & 47.11 & 154.6 & 66 & 79 & 16 & 3 \\
\hline 232 & 47.30 & 155.2 & 31 & 44 & 54 & 1 \\
\hline 233 & 47.35 & 155.4 & 91 & 104 & 5 & 1 \\
\hline 234 & 47.45 & 155.7 & 186 & 199 & 23 & 1 \\
\hline 235 & 47.63 & 156.3 & 30 & 43 & 5 & 3 \\
\hline 236 & 47.70 & 156.5 & 51 & 64 & 20 & 1 \\
\hline 237 & 47.85 & 157.0 & 23 & 36 & 6 & 3 \\
\hline 238 & 48.16 & 158.0 & 10 & 23 & 1 & 2 \\
\hline 239 & 48.38 & 158.7 & 45 & 58 & 9 & 2 \\
\hline 240 & 48.48 & 159.0 & 20 & 33 & 13 & 1 \\
\hline 241 & 48.54 & 159.3 & 44 & 57 & 7 & 2 \\
\hline 242 & 48.60 & 159.5 & 55 & 68 & 18 & 1 \\
\hline 243 & 48.87 & 160.3 & 336 & 348 & 32 & 3 \\
\hline 244 & 48.90 & 160.4 & 81 & 94 & 47 & 1 \\
\hline 245 & 48.92 & 160.5 & 209 & 222 & 78 & 3 \\
\hline 246 & 48.96 & 160.6 & 42 & 55 & 15 & 3 \\
\hline 247 & 49.01 & 160.8 & 15 & 28 & 67 & 3 \\
\hline 248 & 49.24 & 161.5 & 83 & 96 & 8 & 2 \\
\hline 249 & 49.70 & 163.1 & 323 & 336 & 5 & 2 \\
\hline 250 & 49.71 & 163.1 & 85 & 98 & 15 & 1 \\
\hline 251 & 49.91 & 163.7 & 46 & 59 & 26 & 0 \\
\hline 252 & 49.96 & 163.9 & 85 & 98 & 8 & 1 \\
\hline 253 & 50.03 & 164.2 & 69 & 82 & 5 & 1 \\
\hline 254 & 50.18 & 164.6 & 42 & 54 & 24 & 0 \\
\hline 255 & 50.26 & 164.9 & 123 & 136 & 68 & 3 \\
\hline 256 & 50.37 & 165.2 & 57 & 70 & 17 & 3 \\
\hline 257 & 50.37 & 165.3 & 114 & 126 & 68 & 3 \\
\hline 258 & 50.55 & 165.8 & 331 & 344 & 18 & 2 \\
\hline 259 & 50.59 & 166.0 & 43 & 55 & 17 & 2 \\
\hline 260 & 50.68 & 166.3 & 56 & 69 & 31 & 1 \\
\hline 261 & 50.73 & 166.5 & 75 & 88 & 32 & 1 \\
\hline 262 & 50.81 & 166.7 & 71 & 84 & 29 & 1 \\
\hline 263 & 50.94 & 167.1 & 59 & 72 & 18 & 1 \\
\hline 264 & 51.07 & 167.6 & 55 & 67 & 14 & 1 \\
\hline 265 & 51.15 & 167.8 & 151 & 164 & 80 & 3 \\
\hline 266 & 51.21 & 168.0 & 54 & 67 & 11 & 1 \\
\hline 267 & 51.23 & 168.1 & 310 & 323 & 78 & 3 \\
\hline 268 & 51.24 & 168.1 & 86 & 99 & 29 & 2 \\
\hline 269 & 51.24 & 168.1 & 213 & 226 & 75 & 3 \\
\hline 270 & 51.36 & 168.5 & 200 & 213 & 75 & 3 \\
\hline
\end{tabular}

All directions have been corrected for borehole deviation, and are with respect to true north.

Page 6 
Orientation Summary Table - Image Features

Nevada Test Site

Source Physics Experiment

U-15N \#4

NNSA/NSO

22 Sept 2010

\begin{tabular}{|c|c|c|c|c|c|c|}
\hline $\begin{array}{c}\text { Feature } \\
\text { No. }\end{array}$ & $\begin{array}{c}\text { Depth } \\
\text { (meters) }\end{array}$ & $\begin{array}{l}\text { Depth } \\
\text { (feet) }\end{array}$ & $\begin{array}{c}\text { Dip } \\
\text { Direction } \\
\text { (degrees) }\end{array}$ & $\begin{array}{c}\text { Dip } \\
\text { Direction } \\
(\text { deg. } T N)\end{array}$ & $\begin{array}{c}\text { Dip } \\
\text { Angle } \\
\text { (degrees) }\end{array}$ & $\begin{array}{c}\text { Feature } \\
\text { Rank } \\
\text { (0 to 5) }\end{array}$ \\
\hline 271 & 51.51 & 169.0 & 57 & 70 & 11 & 3 \\
\hline 272 & 51.68 & 169.6 & 187 & 200 & 76 & 3 \\
\hline 273 & 51.74 & 169.8 & 196 & 209 & 37 & 1 \\
\hline 274 & 52.00 & 170.6 & 12 & 25 & 17 & 0 \\
\hline 275 & 52.06 & 170.8 & 119 & 132 & 8 & 1 \\
\hline 276 & 52.21 & 171.3 & 74 & 87 & 18 & 0 \\
\hline 277 & 52.26 & 171.5 & 87 & 100 & 11 & 0 \\
\hline 278 & 52.41 & 172.0 & 65 & 78 & 12 & 2 \\
\hline 279 & 53.03 & 174.0 & 49 & 62 & 14 & 2 \\
\hline 280 & 53.61 & 175.9 & 13 & 25 & 6 & 2 \\
\hline 281 & 53.75 & 176.3 & 238 & 251 & 13 & 2 \\
\hline 282 & 53.94 & 177.0 & 201 & 214 & 82 & 3 \\
\hline 283 & 54.34 & 178.3 & 311 & 324 & 7 & 3 \\
\hline 284 & 54.52 & 178.9 & 262 & 275 & 50 & 1 \\
\hline 285 & 54.78 & 179.7 & 65 & 78 & 34 & 3 \\
\hline 286 & 54.86 & 180.0 & 71 & 84 & 39 & 3 \\
\hline 287 & 54.93 & 180.2 & 79 & 92 & 40 & 3 \\
\hline 288 & 55.28 & 181.4 & 74 & 87 & 28 & 3 \\
\hline 289 & 55.34 & 181.6 & 71 & 84 & 17 & 1 \\
\hline 290 & 55.41 & 181.8 & 69 & 82 & 32 & 1 \\
\hline 291 & 55.47 & 182.0 & 299 & 312 & 79 & 3 \\
\hline 292 & 55.52 & 182.2 & 132 & 145 & 21 & 1 \\
\hline 293 & 55.66 & 182.6 & 70 & 82 & 13 & 1 \\
\hline 294 & 55.70 & 182.7 & 10 & 23 & 84 & 3 \\
\hline 295 & 55.82 & 183.1 & 62 & 74 & 14 & 1 \\
\hline 296 & 55.82 & 183.2 & 89 & 102 & 36 & 1 \\
\hline 297 & 56.11 & 184.1 & 57 & 70 & 20 & 0 \\
\hline 298 & 56.18 & 184.3 & 68 & 81 & 26 & 0 \\
\hline 299 & 56.22 & 184.5 & 184 & 197 & 59 & 0 \\
\hline 300 & 56.41 & 185.1 & 199 & 212 & 75 & 3 \\
\hline 301 & 56.48 & 185.3 & 207 & 220 & 67 & 3 \\
\hline 302 & 57.06 & 187.2 & 203 & 216 & 84 & 3 \\
\hline 303 & 57.17 & 187.6 & 105 & 118 & 22 & 2 \\
\hline 304 & 57.30 & 188.0 & 72 & 85 & 16 & 3 \\
\hline 305 & 57.42 & 188.4 & 340 & 353 & 72 & 3 \\
\hline 306 & 58.37 & 191.5 & 25 & 38 & 85 & 3 \\
\hline 307 & 58.52 & 192.0 & 14 & 27 & 79 & 3 \\
\hline 308 & 58.56 & 192.1 & 207 & 220 & 77 & 3 \\
\hline 309 & 58.77 & 192.8 & 200 & 213 & 79 & 3 \\
\hline 310 & 58.78 & 192.9 & 109 & 122 & 82 & 3 \\
\hline 311 & 58.96 & 193.5 & 56 & 69 & 22 & 3 \\
\hline 312 & 59.01 & 193.6 & 230 & 243 & 1 & 3 \\
\hline 313 & 59.24 & 194.4 & 50 & 63 & 2 & 2 \\
\hline 314 & 59.34 & 194.7 & 212 & 225 & 73 & 3 \\
\hline 315 & 59.47 & 195.1 & 171 & 184 & 48 & 0 \\
\hline
\end{tabular}

All directions have been corrected for borehole deviation, and are with respect to true north.

Page 7 
Appendix J-6

Fracture Data Tabulated from Borehole Image Logs by Colog, Inc. For Instrument Hole U-15n\#5 
Orientation Summary Table - Image Features

Nevada Test Site

Source Physics Experiment

U-15N \#5

NNSA/NSO

21 Sept 2010

\begin{tabular}{|c|c|c|c|c|c|c|}
\hline $\begin{array}{c}\text { Feature } \\
\text { No. }\end{array}$ & $\begin{array}{c}\text { Depth } \\
\text { (meters) }\end{array}$ & $\begin{array}{l}\text { Depth } \\
\text { (feet) }\end{array}$ & $\begin{array}{c}\text { Dip } \\
\text { Direction } \\
\text { (degrees) }\end{array}$ & $\begin{array}{c}\text { Dip } \\
\text { Direction } \\
(\text { deg. } T N)\end{array}$ & $\begin{array}{c}\text { Dip } \\
\text { Angle } \\
\text { (degrees) }\end{array}$ & $\begin{array}{c}\text { Feature } \\
\text { Rank } \\
\text { (0 to 5) }\end{array}$ \\
\hline 1 & 3.72 & 12.2 & 199 & 212 & 85 & 3 \\
\hline 2 & 4.56 & 15.0 & 33 & 45 & 14 & 0 \\
\hline 3 & 4.92 & 16.1 & 51 & 64 & 10 & 2 \\
\hline 4 & 5.11 & 16.8 & 49 & 62 & 12 & 0 \\
\hline 5 & 5.31 & 17.4 & 33 & 46 & 11 & 1 \\
\hline 6 & 5.89 & 19.3 & 24 & 37 & 32 & 1 \\
\hline 7 & 6.05 & 19.8 & 34 & 46 & 24 & 1 \\
\hline 8 & 6.10 & 20.0 & 189 & 202 & 76 & 1 \\
\hline 9 & 6.31 & 20.7 & 57 & 70 & 21 & 0 \\
\hline 10 & 6.66 & 21.9 & 275 & 288 & 85 & 3 \\
\hline 11 & 6.89 & 22.6 & 34 & 47 & 9 & 0 \\
\hline 12 & 6.90 & 22.6 & 7 & 19 & 83 & 3 \\
\hline 13 & 7.04 & 23.1 & 54 & 67 & 5 & 1 \\
\hline 14 & 7.11 & 23.3 & 25 & 38 & 43 & 1 \\
\hline 15 & 7.12 & 23.4 & 57 & 70 & 13 & 0 \\
\hline 16 & 7.21 & 23.6 & 76 & 89 & 14 & 0 \\
\hline 17 & 7.27 & 23.9 & 184 & 197 & 75 & 0 \\
\hline 18 & 7.78 & 25.5 & 48 & 61 & 7 & 0 \\
\hline 19 & 7.86 & 25.8 & 67 & 80 & 16 & 0 \\
\hline 20 & 7.97 & 26.2 & 79 & 92 & 15 & 0 \\
\hline 21 & 8.04 & 26.4 & 169 & 182 & 69 & 0 \\
\hline 22 & 8.05 & 26.4 & 71 & 84 & 14 & 0 \\
\hline 23 & 8.17 & 26.8 & 64 & 77 & 17 & 0 \\
\hline 24 & 8.20 & 26.9 & 86 & 99 & 13 & 0 \\
\hline 25 & 8.60 & 28.2 & 58 & 71 & 11 & 0 \\
\hline 26 & 8.95 & 29.4 & 92 & 105 & 8 & 0 \\
\hline 27 & 9.26 & 30.4 & 14 & 26 & 11 & 0 \\
\hline 28 & 9.28 & 30.4 & 359 & 12 & 83 & 3 \\
\hline 29 & 9.33 & 30.6 & 178 & 191 & 81 & 1 \\
\hline 30 & 9.39 & 30.8 & 95 & 108 & 4 & 1 \\
\hline 31 & 9.62 & 31.6 & 43 & 56 & 58 & 1 \\
\hline 32 & 9.78 & 32.1 & 53 & 66 & 20 & 0 \\
\hline 33 & 9.83 & 32.2 & 68 & 80 & 13 & 1 \\
\hline 34 & 9.95 & 32.6 & 3 & 16 & 80 & 1 \\
\hline 35 & 9.99 & 32.8 & 185 & 198 & 78 & 3 \\
\hline 36 & 10.13 & 33.3 & 24 & 37 & 26 & 1 \\
\hline 37 & 10.31 & 33.8 & 13 & 26 & 17 & 0 \\
\hline 38 & 10.81 & 35.5 & 229 & 242 & 26 & 1 \\
\hline 39 & 10.91 & 35.8 & 75 & 88 & 73 & 3 \\
\hline 40 & 10.98 & 36.0 & 279 & 292 & 79 & 3 \\
\hline 41 & 11.36 & 37.3 & 90 & 103 & 65 & 3 \\
\hline 42 & 11.42 & 37.5 & 254 & 267 & 46 & 1 \\
\hline 43 & 11.47 & 37.6 & 50 & 63 & 17 & 1 \\
\hline 44 & 11.55 & 37.9 & 97 & 110 & 72 & 3 \\
\hline 45 & 11.86 & 38.9 & 27 & 40 & 14 & 0 \\
\hline
\end{tabular}

All directions have been corrected for borehole deviation, and are with respect to true north.

Page 1 
Orientation Summary Table - Image Features

Nevada Test Site

Source Physics Experiment

U-15N \#5

NNSA/NSO

21 Sept 2010

\begin{tabular}{|c|c|c|c|c|c|c|}
\hline $\begin{array}{c}\text { Feature } \\
\text { No. }\end{array}$ & $\begin{array}{c}\text { Depth } \\
\text { (meters) }\end{array}$ & $\begin{array}{l}\text { Depth } \\
\text { (feet) }\end{array}$ & $\begin{array}{c}\text { Dip } \\
\text { Direction } \\
\text { (degrees) }\end{array}$ & $\begin{array}{c}\text { Dip } \\
\text { Direction } \\
(\text { deg. } T N)\end{array}$ & $\begin{array}{c}\text { Dip } \\
\text { Angle } \\
\text { (degrees) }\end{array}$ & $\begin{array}{c}\text { Feature } \\
\text { Rank } \\
\text { (0 to 5) }\end{array}$ \\
\hline 46 & 11.89 & 39.0 & 13 & 26 & 15 & 0 \\
\hline 47 & 12.02 & 39.4 & 61 & 74 & 16 & 1 \\
\hline 48 & 12.08 & 39.6 & 59 & 72 & 78 & 3 \\
\hline 49 & 12.31 & 40.4 & 63 & 75 & 21 & 1 \\
\hline 50 & 12.55 & 41.2 & 27 & 39 & 10 & 1 \\
\hline 51 & 12.74 & 41.8 & 20 & 33 & 14 & 1 \\
\hline 52 & 12.83 & 42.1 & 347 & 0 & 82 & 1 \\
\hline 53 & 12.84 & 42.1 & 42 & 55 & 32 & 1 \\
\hline 54 & 13.14 & 43.1 & 82 & 95 & 55 & 1 \\
\hline 55 & 13.69 & 44.9 & 97 & 110 & 12 & 0 \\
\hline 56 & 13.91 & 45.6 & 185 & 198 & 14 & 0 \\
\hline 57 & 14.09 & 46.2 & 6 & 19 & 9 & 0 \\
\hline 58 & 14.28 & 46.9 & 39 & 52 & 13 & 0 \\
\hline 59 & 14.33 & 47.0 & 229 & 242 & 69 & 2 \\
\hline 60 & 14.47 & 47.5 & 218 & 231 & 74 & 3 \\
\hline 61 & 14.55 & 47.7 & 67 & 80 & 16 & 0 \\
\hline 62 & 14.57 & 47.8 & 51 & 64 & 50 & 1 \\
\hline 63 & 14.59 & 47.9 & 209 & 222 & 77 & 3 \\
\hline 64 & 14.88 & 48.8 & 173 & 186 & 19 & 1 \\
\hline 65 & 14.89 & 48.9 & 198 & 210 & 79 & 3 \\
\hline 66 & 15.08 & 49.5 & 47 & 60 & 7 & 1 \\
\hline 67 & 15.18 & 49.8 & 73 & 85 & 16 & 1 \\
\hline 68 & 15.24 & 50.0 & 120 & 133 & 17 & 1 \\
\hline 69 & 15.48 & 50.8 & 55 & 68 & 15 & 2 \\
\hline 70 & 15.59 & 51.1 & 86 & 99 & 15 & 1 \\
\hline 71 & 15.71 & 51.5 & 70 & 83 & 17 & 1 \\
\hline 72 & 15.76 & 51.7 & 49 & 62 & 15 & 1 \\
\hline 73 & 16.05 & 52.7 & 190 & 203 & 65 & 3 \\
\hline 74 & 16.08 & 52.8 & 144 & 157 & 68 & 3 \\
\hline 75 & 16.13 & 52.9 & 219 & 232 & 37 & 3 \\
\hline 76 & 16.21 & 53.2 & 33 & 46 & 20 & 0 \\
\hline 77 & 16.24 & 53.3 & 264 & 277 & 68 & 3 \\
\hline 78 & 16.25 & 53.3 & 48 & 61 & 25 & 1 \\
\hline 79 & 16.50 & 54.1 & 141 & 154 & 69 & 3 \\
\hline 80 & 16.57 & 54.4 & 216 & 229 & 15 & 1 \\
\hline 81 & 16.63 & 54.6 & 174 & 187 & 24 & 1 \\
\hline 82 & 16.67 & 54.7 & 356 & 8 & 86 & 3 \\
\hline 83 & 16.74 & 54.9 & 325 & 337 & 5 & 2 \\
\hline 84 & 16.84 & 55.3 & 50 & 63 & 9 & 1 \\
\hline 85 & 16.90 & 55.5 & 172 & 185 & 47 & 1 \\
\hline 86 & 17.01 & 55.8 & 187 & 199 & 59 & 1 \\
\hline 87 & 17.03 & 55.9 & 204 & 216 & 33 & 1 \\
\hline 88 & 17.14 & 56.2 & 55 & 68 & 4 & 0 \\
\hline 89 & 17.32 & 56.8 & 55 & 68 & 11 & 0 \\
\hline 90 & 17.42 & 57.2 & 59 & 72 & 23 & 0 \\
\hline
\end{tabular}

All directions have been corrected for borehole deviation, and are with respect to true north.

Page 2 
Orientation Summary Table - Image Features

Nevada Test Site

Source Physics Experiment

U-15N \#5

NNSA/NSO

21 Sept 2010

\begin{tabular}{|c|c|c|c|c|c|c|}
\hline $\begin{array}{c}\text { Feature } \\
\text { No. }\end{array}$ & $\begin{array}{c}\text { Depth } \\
\text { (meters) }\end{array}$ & $\begin{array}{l}\text { Depth } \\
\text { (feet) }\end{array}$ & $\begin{array}{c}\text { Dip } \\
\text { Direction } \\
\text { (degrees) }\end{array}$ & $\begin{array}{c}\text { Dip } \\
\text { Direction } \\
(\text { deg. } T N)\end{array}$ & $\begin{array}{c}\text { Dip } \\
\text { Angle } \\
\text { (degrees) }\end{array}$ & $\begin{array}{c}\text { Feature } \\
\text { Rank } \\
\text { (0 to 5) }\end{array}$ \\
\hline 91 & 17.44 & 57.2 & 335 & 348 & 70 & 3 \\
\hline 92 & 17.66 & 57.9 & 317 & 330 & 22 & 2 \\
\hline 93 & 18.07 & 59.3 & 16 & 29 & 9 & 2 \\
\hline 94 & 18.65 & 61.2 & 265 & 278 & 15 & 2 \\
\hline 95 & 18.87 & 61.9 & 98 & 111 & 81 & 3 \\
\hline 96 & 18.91 & 62.0 & 105 & 118 & 77 & 3 \\
\hline 97 & 18.91 & 62.1 & 5 & 18 & 10 & 1 \\
\hline 98 & 19.03 & 62.4 & 299 & 312 & 85 & 3 \\
\hline 99 & 19.04 & 62.5 & 66 & 79 & 9 & 1 \\
\hline 100 & 19.15 & 62.8 & 94 & 107 & 10 & 1 \\
\hline 101 & 19.44 & 63.8 & 89 & 101 & 67 & 1 \\
\hline 102 & 19.46 & 63.9 & 39 & 52 & 21 & 0 \\
\hline 103 & 19.54 & 64.1 & 89 & 102 & 55 & 2 \\
\hline 104 & 19.79 & 64.9 & 158 & 171 & 33 & 1 \\
\hline 105 & 19.82 & 65.0 & 105 & 117 & 76 & 3 \\
\hline 106 & 19.82 & 65.0 & 42 & 55 & 19 & 0 \\
\hline 107 & 19.89 & 65.3 & 51 & 64 & 18 & 0 \\
\hline 108 & 20.13 & 66.0 & 51 & 64 & 18 & 3 \\
\hline 109 & 20.20 & 66.3 & 60 & 73 & 17 & 2 \\
\hline 110 & 20.24 & 66.4 & 92 & 105 & 21 & 3 \\
\hline 111 & 20.36 & 66.8 & 78 & 91 & 12 & 1 \\
\hline 112 & 20.52 & 67.3 & 86 & 99 & 74 & 3 \\
\hline 113 & 20.61 & 67.6 & 92 & 104 & 48 & 3 \\
\hline 114 & 20.74 & 68.0 & 100 & 112 & 56 & 3 \\
\hline 115 & 20.82 & 68.3 & 105 & 118 & 61 & 3 \\
\hline 116 & 20.99 & 68.9 & 66 & 79 & 14 & 3 \\
\hline 117 & 21.01 & 68.9 & 269 & 282 & 80 & 3 \\
\hline 118 & 21.05 & 69.1 & 314 & 326 & 55 & 3 \\
\hline 119 & 21.15 & 69.4 & 61 & 73 & 10 & 1 \\
\hline 120 & 21.28 & 69.8 & 222 & 235 & 68 & 3 \\
\hline 121 & 21.49 & 70.5 & 56 & 69 & 14 & 0 \\
\hline 122 & 21.67 & 71.1 & 88 & 101 & 17 & 2 \\
\hline 123 & 21.73 & 71.3 & 190 & 203 & 59 & 0 \\
\hline 124 & 21.83 & 71.6 & 92 & 105 & 79 & 3 \\
\hline 125 & 21.87 & 71.8 & 150 & 163 & 13 & 0 \\
\hline 126 & 21.96 & 72.0 & 9 & 22 & 7 & 3 \\
\hline 127 & 22.10 & 72.5 & 279 & 292 & 31 & 3 \\
\hline 128 & 22.19 & 72.8 & 168 & 181 & 31 & 1 \\
\hline 129 & 22.28 & 73.1 & 84 & 97 & 72 & 3 \\
\hline 130 & 22.34 & 73.3 & 105 & 117 & 28 & 2 \\
\hline 131 & 22.47 & 73.7 & 115 & 128 & 72 & 3 \\
\hline 132 & 22.72 & 74.5 & 213 & 226 & 19 & 3 \\
\hline 133 & 22.79 & 74.8 & 356 & 9 & 71 & 3 \\
\hline 134 & 22.97 & 75.4 & 8 & 21 & 43 & 0 \\
\hline 135 & 23.00 & 75.5 & 354 & 6 & 78 & 3 \\
\hline
\end{tabular}

All directions have been corrected for borehole deviation, and are with respect to true north.

Page 3 
Orientation Summary Table - Image Features

Nevada Test Site

Source Physics Experiment

U-15N \#5

NNSA/NSO

21 Sept 2010

\begin{tabular}{|c|c|c|c|c|c|c|}
\hline $\begin{array}{c}\text { Feature } \\
\text { No. }\end{array}$ & $\begin{array}{c}\text { Depth } \\
\text { (meters) }\end{array}$ & $\begin{array}{l}\text { Depth } \\
\text { (feet) }\end{array}$ & $\begin{array}{c}\text { Dip } \\
\text { Direction } \\
\text { (degrees) }\end{array}$ & $\begin{array}{c}\text { Dip } \\
\text { Direction } \\
(\text { deg. } T N)\end{array}$ & $\begin{array}{c}\text { Dip } \\
\text { Angle } \\
\text { (degrees) }\end{array}$ & $\begin{array}{c}\text { Feature } \\
\text { Rank } \\
\text { (0 to 5) }\end{array}$ \\
\hline 136 & 23.04 & 75.6 & 245 & 258 & 36 & 1 \\
\hline 137 & 23.11 & 75.8 & 70 & 82 & 30 & 3 \\
\hline 138 & 23.21 & 76.1 & 82 & 95 & 22 & 2 \\
\hline 139 & 23.36 & 76.7 & 62 & 74 & 15 & 1 \\
\hline 140 & 23.38 & 76.7 & 116 & 128 & 79 & 3 \\
\hline 141 & 23.39 & 76.8 & 47 & 60 & 16 & 1 \\
\hline 142 & 23.45 & 76.9 & 51 & 64 & 15 & 0 \\
\hline 143 & 23.57 & 77.3 & 121 & 134 & 12 & 1 \\
\hline 144 & 23.65 & 77.6 & 62 & 75 & 11 & 0 \\
\hline 145 & 23.78 & 78.0 & 21 & 34 & 75 & 3 \\
\hline 146 & 23.84 & 78.2 & 256 & 268 & 7 & 3 \\
\hline 147 & 23.98 & 78.7 & 100 & 113 & 7 & 2 \\
\hline 148 & 24.34 & 79.9 & 239 & 252 & 59 & 3 \\
\hline 149 & 24.54 & 80.5 & 163 & 176 & 45 & 3 \\
\hline 150 & 24.60 & 80.7 & 123 & 136 & 85 & 3 \\
\hline 151 & 24.66 & 80.9 & 204 & 216 & 47 & 3 \\
\hline 152 & 24.67 & 80.9 & 66 & 79 & 17 & 1 \\
\hline 153 & 24.77 & 81.3 & 156 & 168 & 30 & 1 \\
\hline 154 & 24.98 & 82.0 & 82 & 94 & 22 & 3 \\
\hline 155 & 25.22 & 82.7 & 52 & 65 & 25 & 3 \\
\hline 156 & 25.25 & 82.8 & 329 & 342 & 65 & 3 \\
\hline 157 & 25.40 & 83.3 & 17 & 30 & 18 & 2 \\
\hline 158 & 25.50 & 83.7 & 318 & 330 & 56 & 1 \\
\hline 159 & 25.64 & 84.1 & 115 & 128 & 75 & 3 \\
\hline 160 & 25.66 & 84.2 & 123 & 136 & 85 & 3 \\
\hline 161 & 25.72 & 84.4 & 48 & 61 & 10 & 1 \\
\hline 162 & 25.93 & 85.1 & 18 & 31 & 10 & 0 \\
\hline 163 & 25.94 & 85.1 & 118 & 130 & 87 & 3 \\
\hline 164 & 26.50 & 86.9 & 52 & 65 & 16 & 1 \\
\hline 165 & 26.67 & 87.5 & 71 & 84 & 22 & 1 \\
\hline 166 & 26.79 & 87.9 & 40 & 53 & 25 & 0 \\
\hline 167 & 26.99 & 88.5 & 54 & 67 & 17 & 3 \\
\hline 168 & 27.07 & 88.8 & 117 & 130 & 86 & 3 \\
\hline 169 & 27.08 & 88.9 & 52 & 65 & 17 & 2 \\
\hline 170 & 27.32 & 89.6 & 77 & 90 & 13 & 3 \\
\hline 171 & 27.34 & 89.7 & 72 & 84 & 12 & 2 \\
\hline 172 & 27.45 & 90.1 & 83 & 96 & 20 & 0 \\
\hline 173 & 27.62 & 90.6 & 39 & 52 & 12 & 0 \\
\hline 174 & 27.70 & 90.9 & 93 & 106 & 11 & 0 \\
\hline 175 & 27.89 & 91.5 & 75 & 88 & 19 & 3 \\
\hline 176 & 27.94 & 91.7 & 67 & 80 & 13 & 2 \\
\hline 177 & 27.98 & 91.8 & 75 & 88 & 11 & 0 \\
\hline 178 & 28.11 & 92.2 & 106 & 118 & 4 & 2 \\
\hline 179 & 28.29 & 92.8 & 52 & 65 & 20 & 0 \\
\hline 180 & 28.41 & 93.2 & 50 & 63 & 15 & 3 \\
\hline
\end{tabular}

All directions have been corrected for borehole deviation, and are with respect to true north. 
Orientation Summary Table - Image Features

Nevada Test Site

Source Physics Experiment

U-15N \#5

NNSA/NSO

21 Sept 2010

\begin{tabular}{|c|c|c|c|c|c|c|}
\hline $\begin{array}{c}\text { Feature } \\
\text { No. }\end{array}$ & $\begin{array}{c}\text { Depth } \\
\text { (meters) }\end{array}$ & $\begin{array}{l}\text { Depth } \\
\text { (feet) }\end{array}$ & $\begin{array}{c}\text { Dip } \\
\text { Direction } \\
\text { (degrees) }\end{array}$ & $\begin{array}{c}\text { Dip } \\
\text { Direction } \\
(\text { deg. } T N)\end{array}$ & $\begin{array}{c}\text { Dip } \\
\text { Angle } \\
\text { (degrees) }\end{array}$ & $\begin{array}{c}\text { Feature } \\
\text { Rank } \\
\text { (0 to 5) }\end{array}$ \\
\hline 181 & 28.46 & 93.4 & 64 & 77 & 14 & 2 \\
\hline 182 & 28.74 & 94.3 & 65 & 78 & 20 & 3 \\
\hline 183 & 28.81 & 94.5 & 70 & 82 & 16 & 0 \\
\hline 184 & 29.01 & 95.2 & 71 & 84 & 13 & 0 \\
\hline 185 & 29.11 & 95.5 & 62 & 75 & 11 & 0 \\
\hline 186 & 29.26 & 96.0 & 72 & 84 & 11 & 1 \\
\hline 187 & 29.34 & 96.3 & 59 & 72 & 20 & 0 \\
\hline 188 & 29.43 & 96.5 & 34 & 47 & 37 & 1 \\
\hline 189 & 29.57 & 97.0 & 271 & 284 & 14 & 1 \\
\hline 190 & 29.67 & 97.4 & 273 & 286 & 16 & 3 \\
\hline 191 & 29.77 & 97.7 & 122 & 135 & 87 & 3 \\
\hline 192 & 29.83 & 97.9 & 308 & 321 & 7 & 3 \\
\hline 193 & 29.91 & 98.1 & 323 & 336 & 25 & 3 \\
\hline 194 & 29.97 & 98.3 & 342 & 355 & 21 & 1 \\
\hline 195 & 30.06 & 98.6 & 58 & 70 & 14 & 3 \\
\hline 196 & 30.09 & 98.7 & 51 & 64 & 8 & 1 \\
\hline 197 & 30.18 & 99.0 & 48 & 61 & 19 & 0 \\
\hline 198 & 30.42 & 99.8 & 30 & 43 & 23 & 0 \\
\hline 199 & 30.78 & 101.0 & 278 & 291 & 24 & 3 \\
\hline 200 & 30.78 & 101.0 & 78 & 90 & 13 & 3 \\
\hline 201 & 30.78 & 101.0 & 271 & 284 & 52 & 0 \\
\hline 202 & 30.90 & 101.4 & 304 & 316 & 26 & 3 \\
\hline 203 & 30.99 & 101.7 & 75 & 88 & 14 & 3 \\
\hline 204 & 31.07 & 101.9 & 56 & 69 & 19 & 0 \\
\hline 205 & 31.10 & 102.0 & 53 & 66 & 17 & 0 \\
\hline 206 & 31.22 & 102.4 & 36 & 48 & 12 & 3 \\
\hline 207 & 31.34 & 102.8 & 48 & 61 & 17 & 3 \\
\hline 208 & 31.46 & 103.2 & 69 & 82 & 17 & 2 \\
\hline 209 & 31.54 & 103.5 & 253 & 266 & 58 & 3 \\
\hline 210 & 31.67 & 103.9 & 254 & 267 & 48 & 3 \\
\hline 211 & 31.81 & 104.4 & 73 & 85 & 11 & 2 \\
\hline 212 & 31.83 & 104.4 & 255 & 267 & 57 & 0 \\
\hline 213 & 31.85 & 104.5 & 93 & 106 & 18 & 1 \\
\hline 214 & 31.97 & 104.9 & 295 & 308 & 17 & 0 \\
\hline 215 & 32.20 & 105.7 & 52 & 65 & 20 & 0 \\
\hline 216 & 32.24 & 105.8 & 68 & 81 & 19 & 3 \\
\hline 217 & 32.30 & 106.0 & 249 & 262 & 54 & 0 \\
\hline 218 & 32.31 & 106.0 & 46 & 59 & 18 & 1 \\
\hline 219 & 32.43 & 106.4 & 249 & 262 & 43 & 3 \\
\hline 220 & 32.49 & 106.6 & 258 & 271 & 49 & 3 \\
\hline 221 & 32.68 & 107.2 & 217 & 230 & 47 & 3 \\
\hline 222 & 32.70 & 107.3 & 76 & 88 & 13 & 3 \\
\hline 223 & 32.71 & 107.3 & 236 & 249 & 62 & 1 \\
\hline 224 & 32.86 & 107.8 & 69 & 82 & 13 & 1 \\
\hline 225 & 32.93 & 108.0 & 59 & 72 & 10 & 1 \\
\hline
\end{tabular}

All directions have been corrected for borehole deviation, and are with respect to true north. 
Orientation Summary Table - Image Features

Nevada Test Site

Source Physics Experiment

U-15N \#5

NNSA/NSO

21 Sept 2010

\begin{tabular}{|c|c|c|c|c|c|c|}
\hline $\begin{array}{c}\text { Feature } \\
\text { No. }\end{array}$ & $\begin{array}{c}\text { Depth } \\
\text { (meters) }\end{array}$ & $\begin{array}{l}\text { Depth } \\
\text { (feet) }\end{array}$ & $\begin{array}{c}\text { Dip } \\
\text { Direction } \\
\text { (degrees) }\end{array}$ & $\begin{array}{c}\text { Dip } \\
\text { Direction } \\
(\text { deg. } T N)\end{array}$ & $\begin{array}{c}\text { Dip } \\
\text { Angle } \\
\text { (degrees) }\end{array}$ & $\begin{array}{c}\text { Feature } \\
\text { Rank } \\
\text { (0 to 5) }\end{array}$ \\
\hline 226 & 32.93 & 108.0 & 119 & 132 & 86 & 3 \\
\hline 227 & 32.98 & 108.2 & 53 & 66 & 18 & 1 \\
\hline 228 & 33.03 & 108.4 & 47 & 60 & 15 & 0 \\
\hline 229 & 33.22 & 109.0 & 61 & 74 & 10 & 0 \\
\hline 230 & 33.45 & 109.7 & 101 & 114 & 2 & 3 \\
\hline 231 & 33.47 & 109.8 & 8 & 21 & 12 & 2 \\
\hline 232 & 33.70 & 110.6 & 286 & 299 & 4 & 1 \\
\hline 233 & 33.81 & 110.9 & 50 & 63 & 8 & 3 \\
\hline 234 & 33.83 & 111.0 & 121 & 134 & 87 & 3 \\
\hline 235 & 33.87 & 111.1 & 291 & 304 & 15 & 1 \\
\hline 236 & 33.97 & 111.5 & 65 & 78 & 23 & 1 \\
\hline 237 & 34.19 & 112.2 & 27 & 40 & 31 & 1 \\
\hline 238 & 34.26 & 112.4 & 47 & 59 & 11 & 2 \\
\hline 239 & 34.35 & 112.7 & 61 & 74 & 16 & 0 \\
\hline 240 & 34.50 & 113.2 & 24 & 37 & 8 & 1 \\
\hline 241 & 34.62 & 113.6 & 67 & 80 & 19 & 3 \\
\hline 242 & 34.69 & 113.8 & 303 & 316 & 78 & 3 \\
\hline 243 & 34.75 & 114.0 & 65 & 77 & 12 & 3 \\
\hline 244 & 34.80 & 114.2 & 48 & 61 & 6 & 1 \\
\hline 245 & 35.05 & 115.0 & 119 & 132 & 85 & 3 \\
\hline 246 & 35.26 & 115.7 & 172 & 185 & 14 & 1 \\
\hline 247 & 35.34 & 116.0 & 220 & 233 & 3 & 1 \\
\hline 248 & 35.42 & 116.2 & 77 & 90 & 9 & 3 \\
\hline 249 & 35.48 & 116.4 & 87 & 100 & 11 & 1 \\
\hline 250 & 35.52 & 116.5 & 206 & 218 & 15 & 1 \\
\hline 251 & 35.66 & 117.0 & 221 & 233 & 24 & 0 \\
\hline 252 & 35.88 & 117.7 & 99 & 112 & 36 & 1 \\
\hline 253 & 35.94 & 117.9 & 53 & 66 & 17 & 1 \\
\hline 254 & 35.99 & 118.1 & 60 & 73 & 13 & 1 \\
\hline 255 & 35.99 & 118.1 & 112 & 125 & 49 & 1 \\
\hline 256 & 36.18 & 118.7 & 65 & 78 & 15 & 2 \\
\hline 257 & 36.27 & 119.0 & 53 & 66 & 26 & 1 \\
\hline 258 & 36.29 & 119.1 & 79 & 92 & 78 & 3 \\
\hline 259 & 36.47 & 119.7 & 38 & 51 & 17 & 2 \\
\hline 260 & 36.66 & 120.3 & 181 & 194 & 86 & 3 \\
\hline 261 & 36.67 & 120.3 & 185 & 198 & 74 & 1 \\
\hline 262 & 36.91 & 121.1 & 194 & 207 & 66 & 1 \\
\hline 263 & 36.91 & 121.1 & 72 & 85 & 21 & 2 \\
\hline 264 & 37.23 & 122.1 & 14 & 27 & 29 & 3 \\
\hline 265 & 37.36 & 122.6 & 308 & 320 & 22 & 3 \\
\hline 266 & 37.45 & 122.9 & 172 & 185 & 16 & 1 \\
\hline 267 & 37.48 & 123.0 & 194 & 207 & 84 & 3 \\
\hline 268 & 37.56 & 123.2 & 355 & 8 & 13 & 1 \\
\hline 269 & 37.74 & 123.8 & 234 & 247 & 19 & 2 \\
\hline 270 & 37.79 & 124.0 & 305 & 318 & 12 & 1 \\
\hline
\end{tabular}

All directions have been corrected for borehole deviation, and are with respect to true north. 
Orientation Summary Table - Image Features

Nevada Test Site

Source Physics Experiment

U-15N \#5

NNSA/NSO

21 Sept 2010

\begin{tabular}{|c|c|c|c|c|c|c|}
\hline $\begin{array}{c}\text { Feature } \\
\text { No. }\end{array}$ & $\begin{array}{c}\text { Depth } \\
\text { (meters) }\end{array}$ & $\begin{array}{l}\text { Depth } \\
\text { (feet) }\end{array}$ & $\begin{array}{c}\text { Dip } \\
\text { Direction } \\
\text { (degrees) }\end{array}$ & $\begin{array}{c}\text { Dip } \\
\text { Direction } \\
(\text { deg. } T N)\end{array}$ & $\begin{array}{c}\text { Dip } \\
\text { Angle } \\
\text { (degrees) }\end{array}$ & $\begin{array}{c}\text { Feature } \\
\text { Rank } \\
\text { (0 to 5) }\end{array}$ \\
\hline 271 & 38.05 & 124.9 & 53 & 66 & 20 & 2 \\
\hline 272 & 38.12 & 125.1 & 193 & 206 & 84 & 3 \\
\hline 273 & 38.51 & 126.4 & 82 & 95 & 18 & 2 \\
\hline 274 & 38.55 & 126.5 & 213 & 225 & 33 & 3 \\
\hline 275 & 38.62 & 126.7 & 115 & 128 & 81 & 3 \\
\hline 276 & 38.69 & 126.9 & 73 & 86 & 13 & 1 \\
\hline 277 & 39.03 & 128.1 & 110 & 123 & 75 & 1 \\
\hline 278 & 39.04 & 128.1 & 52 & 65 & 22 & 1 \\
\hline 279 & 39.26 & 128.8 & 176 & 189 & 4 & 3 \\
\hline 280 & 39.54 & 129.7 & 30 & 43 & 20 & 1 \\
\hline 281 & 39.64 & 130.1 & 53 & 66 & 21 & 3 \\
\hline 282 & 39.68 & 130.2 & 28 & 41 & 10 & 1 \\
\hline 283 & 39.75 & 130.4 & 113 & 126 & 82 & 3 \\
\hline 284 & 39.76 & 130.5 & 239 & 252 & 14 & 1 \\
\hline 285 & 39.97 & 131.2 & 180 & 193 & 51 & 1 \\
\hline 286 & 39.98 & 131.2 & 353 & 6 & 20 & 1 \\
\hline 287 & 40.26 & 132.1 & 29 & 41 & 12 & 2 \\
\hline 288 & 40.35 & 132.4 & 109 & 122 & 64 & 3 \\
\hline 289 & 40.36 & 132.4 & 38 & 51 & 15 & 3 \\
\hline 290 & 40.43 & 132.7 & 133 & 146 & 51 & 3 \\
\hline 291 & 41.04 & 134.6 & 40 & 52 & 11 & 2 \\
\hline 292 & 41.59 & 136.5 & 62 & 74 & 17 & 2 \\
\hline 293 & 41.73 & 136.9 & 195 & 207 & 82 & 3 \\
\hline 294 & 41.79 & 137.1 & 29 & 42 & 21 & 0 \\
\hline 295 & 41.90 & 137.5 & 89 & 102 & 8 & 1 \\
\hline 296 & 42.21 & 138.5 & 68 & 80 & 8 & 0 \\
\hline 297 & 42.36 & 139.0 & 130 & 143 & 69 & 1 \\
\hline 298 & 42.65 & 139.9 & 48 & 61 & 17 & 2 \\
\hline 299 & 42.74 & 140.2 & 69 & 82 & 11 & 0 \\
\hline 300 & 43.02 & 141.2 & 125 & 138 & 77 & 3 \\
\hline 301 & 43.16 & 141.6 & 75 & 87 & 5 & 1 \\
\hline 302 & 43.21 & 141.8 & 105 & 117 & 13 & 3 \\
\hline 303 & 43.29 & 142.0 & 77 & 90 & 12 & 3 \\
\hline 304 & 43.35 & 142.2 & 54 & 67 & 14 & 3 \\
\hline 305 & 43.53 & 142.8 & 60 & 73 & 11 & 1 \\
\hline 306 & 43.60 & 143.1 & 25 & 37 & 12 & 1 \\
\hline 307 & 43.82 & 143.8 & 131 & 144 & 66 & 3 \\
\hline 308 & 43.86 & 143.9 & 128 & 141 & 76 & 3 \\
\hline 309 & 43.93 & 144.1 & 35 & 48 & 15 & 1 \\
\hline 310 & 43.97 & 144.3 & 64 & 77 & 28 & 3 \\
\hline 311 & 44.04 & 144.5 & 51 & 64 & 9 & 2 \\
\hline 312 & 44.23 & 145.1 & 145 & 158 & 57 & 3 \\
\hline 313 & 44.45 & 145.8 & 31 & 44 & 7 & 3 \\
\hline 314 & 44.53 & 146.1 & 95 & 108 & 8 & 1 \\
\hline 315 & 44.66 & 146.5 & 119 & 132 & 76 & 3 \\
\hline
\end{tabular}

All directions have been corrected for borehole deviation, and are with respect to true north. 
Orientation Summary Table - Image Features

Nevada Test Site

Source Physics Experiment

U-15N \#5

NNSA/NSO

21 Sept 2010

\begin{tabular}{|c|c|c|c|c|c|c|}
\hline $\begin{array}{c}\text { Feature } \\
\text { No. }\end{array}$ & $\begin{array}{c}\text { Depth } \\
\text { (meters) }\end{array}$ & $\begin{array}{l}\text { Depth } \\
\text { (feet) }\end{array}$ & $\begin{array}{c}\text { Dip } \\
\text { Direction } \\
\text { (degrees) }\end{array}$ & $\begin{array}{c}\text { Dip } \\
\text { Direction } \\
(\text { deg. } T N)\end{array}$ & $\begin{array}{c}\text { Dip } \\
\text { Angle } \\
\text { (degrees) }\end{array}$ & $\begin{array}{c}\text { Feature } \\
\text { Rank } \\
\text { (0 to 5) }\end{array}$ \\
\hline 316 & 44.71 & 146.7 & 108 & 121 & 57 & 3 \\
\hline 317 & 44.73 & 146.8 & 92 & 104 & 10 & 1 \\
\hline 318 & 44.89 & 147.3 & 55 & 68 & 8 & 1 \\
\hline 319 & 44.92 & 147.4 & 40 & 53 & 12 & 1 \\
\hline 320 & 45.12 & 148.0 & 79 & 91 & 12 & 2 \\
\hline 321 & 45.37 & 148.9 & 161 & 173 & 73 & 1 \\
\hline 322 & 45.38 & 148.9 & 63 & 76 & 20 & 1 \\
\hline 323 & 45.57 & 149.5 & 72 & 85 & 15 & 3 \\
\hline 324 & 45.95 & 150.8 & 112 & 125 & 82 & 3 \\
\hline 325 & 46.36 & 152.1 & 68 & 81 & 13 & 1 \\
\hline 326 & 46.40 & 152.2 & 21 & 34 & 10 & 0 \\
\hline 327 & 46.43 & 152.3 & 11 & 24 & 13 & 1 \\
\hline 328 & 46.54 & 152.7 & 350 & 3 & 22 & 0 \\
\hline 329 & 46.92 & 153.9 & 126 & 139 & 9 & 3 \\
\hline 330 & 47.03 & 154.3 & 131 & 144 & 32 & 1 \\
\hline 331 & 47.62 & 156.2 & 44 & 57 & 22 & 2 \\
\hline 332 & 47.66 & 156.4 & 57 & 69 & 17 & 3 \\
\hline 333 & 47.72 & 156.6 & 154 & 167 & 39 & 2 \\
\hline 334 & 48.15 & 158.0 & 52 & 65 & 17 & 3 \\
\hline 335 & 48.20 & 158.2 & 63 & 76 & 14 & 3 \\
\hline 336 & 48.63 & 159.6 & 52 & 65 & 19 & 0 \\
\hline 337 & 48.87 & 160.3 & 61 & 74 & 19 & 2 \\
\hline 338 & 48.99 & 160.7 & 98 & 111 & 84 & 3 \\
\hline 339 & 49.04 & 160.9 & 73 & 86 & 12 & 3 \\
\hline 340 & 49.14 & 161.2 & 31 & 44 & 28 & 0 \\
\hline 341 & 49.69 & 163.0 & 25 & 38 & 25 & 0 \\
\hline 342 & 49.83 & 163.5 & 39 & 51 & 24 & 3 \\
\hline 343 & 49.87 & 163.6 & 148 & 161 & 19 & 3 \\
\hline 344 & 49.94 & 163.9 & 61 & 74 & 12 & 0 \\
\hline 345 & 50.73 & 166.4 & 58 & 70 & 22 & 3 \\
\hline 346 & 51.89 & 170.2 & 52 & 65 & 18 & 2 \\
\hline 347 & 52.05 & 170.8 & 268 & 281 & 57 & 3 \\
\hline 348 & 52.24 & 171.4 & 308 & 321 & 9 & 0 \\
\hline 349 & 52.27 & 171.5 & 54 & 66 & 18 & 0 \\
\hline 350 & 52.38 & 171.9 & 58 & 70 & 17 & 0 \\
\hline 351 & 52.60 & 172.6 & 63 & 76 & 17 & 2 \\
\hline 352 & 52.86 & 173.4 & 67 & 80 & 14 & 2 \\
\hline 353 & 52.89 & 173.5 & 55 & 67 & 12 & 2 \\
\hline 354 & 53.21 & 174.6 & 124 & 136 & 86 & 3 \\
\hline 355 & 53.45 & 175.4 & 35 & 48 & 10 & 2 \\
\hline 356 & 53.67 & 176.1 & 57 & 70 & 8 & 3 \\
\hline 357 & 53.68 & 176.1 & 224 & 237 & 71 & 2 \\
\hline 358 & 53.81 & 176.6 & 39 & 52 & 13 & 0 \\
\hline 359 & 54.54 & 179.0 & 15 & 28 & 14 & 3 \\
\hline 360 & 54.88 & 180.1 & 54 & 66 & 19 & 1 \\
\hline
\end{tabular}

All directions have been corrected for borehole deviation, and are with respect to true north. 
Orientation Summary Table - Image Features

Nevada Test Site

Source Physics Experiment

U-15N \#5

NNSA/NSO

21 Sept 2010

\begin{tabular}{|c|c|c|c|c|c|c|}
\hline $\begin{array}{c}\text { Feature } \\
\text { No. }\end{array}$ & $\begin{array}{c}\text { Depth } \\
\text { (meters) }\end{array}$ & $\begin{array}{l}\text { Depth } \\
\text { (feet) }\end{array}$ & $\begin{array}{c}\text { Dip } \\
\text { Direction } \\
\text { (degrees) }\end{array}$ & $\begin{array}{c}\text { Dip } \\
\text { Direction } \\
\text { (deg. TN) }\end{array}$ & $\begin{array}{c}\text { Dip } \\
\text { Angle } \\
\text { (degrees) }\end{array}$ & $\begin{array}{c}\text { Feature } \\
\text { Rank } \\
\text { (0 to 5) }\end{array}$ \\
\hline 361 & 55.16 & 181.0 & 10 & 23 & 22 & 0 \\
\hline 362 & 55.59 & 182.4 & 304 & 317 & 67 & 3 \\
\hline 363 & 55.64 & 182.6 & 345 & 358 & 18 & 3 \\
\hline 364 & 55.72 & 182.8 & 25 & 38 & 15 & 0 \\
\hline 365 & 55.78 & 183.0 & 48 & 61 & 18 & 0 \\
\hline 366 & 56.02 & 183.8 & 295 & 308 & 83 & 3 \\
\hline 367 & 56.67 & 185.9 & 43 & 55 & 19 & 3 \\
\hline 368 & 56.67 & 185.9 & 231 & 244 & 76 & 3 \\
\hline 369 & 56.88 & 186.6 & 56 & 69 & 21 & 0 \\
\hline 370 & 57.11 & 187.4 & 34 & 47 & 25 & 1 \\
\hline 371 & 57.39 & 188.3 & 23 & 36 & 20 & 1 \\
\hline 372 & 57.51 & 188.7 & 60 & 73 & 17 & 1 \\
\hline 373 & 57.77 & 189.5 & 356 & 8 & 18 & 0 \\
\hline 374 & 57.91 & 190.0 & 354 & 7 & 18 & 0 \\
\hline 375 & 58.03 & 190.4 & 63 & 76 & 24 & 3 \\
\hline 376 & 58.06 & 190.5 & 41 & 54 & 6 & 3 \\
\hline 377 & 58.07 & 190.5 & 132 & 144 & 21 & 3 \\
\hline 378 & 58.11 & 190.7 & 217 & 230 & 80 & 3 \\
\hline 379 & 58.18 & 190.9 & 52 & 65 & 19 & 3 \\
\hline 380 & 58.18 & 190.9 & 286 & 299 & 7 & 2 \\
\hline 381 & 58.23 & 191.0 & 30 & 43 & 20 & 1 \\
\hline 382 & 58.28 & 191.2 & 350 & 3 & 7 & 2 \\
\hline 383 & 58.35 & 191.4 & 358 & 11 & 16 & 1 \\
\hline 384 & 58.78 & 192.9 & 35 & 47 & 22 & 0 \\
\hline 385 & 59.19 & 194.2 & 123 & 136 & 87 & 3 \\
\hline
\end{tabular}

All directions have been corrected for borehole deviation, and are with respect to true north.

Page 9 
Appendix J-7

Fracture Data Tabulated from Borehole Image Logs by Colog, Inc. For Instrument Hole U-15n\#6 
Orientation Summary Table - Image Features

Nevada Test Site

Source Physics Experiment

U-15N \#6

NNSA/NSO

20 Sept 2010

\begin{tabular}{|c|c|c|c|c|c|c|}
\hline $\begin{array}{c}\text { Feature } \\
\text { No. }\end{array}$ & $\begin{array}{c}\text { Depth } \\
\text { (meters) }\end{array}$ & $\begin{array}{l}\text { Depth } \\
\text { (feet) }\end{array}$ & $\begin{array}{c}\text { Dip } \\
\text { Direction } \\
\text { (degrees) }\end{array}$ & $\begin{array}{c}\text { Dip } \\
\text { Direction } \\
(\text { deg. } T N)\end{array}$ & $\begin{array}{c}\text { Dip } \\
\text { Angle } \\
\text { (degrees) }\end{array}$ & $\begin{array}{c}\text { Feature } \\
\text { Rank } \\
\text { (0 to 5) }\end{array}$ \\
\hline 1 & 1.50 & 4.9 & 138 & 151 & 78 & 3 \\
\hline 2 & 2.03 & 6.7 & 233 & 246 & 8 & 2 \\
\hline 3 & 2.09 & 6.9 & 358 & 11 & 30 & 1 \\
\hline 4 & 2.69 & 8.8 & 337 & 350 & 20 & 1 \\
\hline 5 & 3.08 & 10.1 & 349 & 2 & 28 & 1 \\
\hline 6 & 3.56 & 11.7 & 172 & 185 & 77 & 3 \\
\hline 7 & 3.74 & 12.3 & 100 & 113 & 80 & 3 \\
\hline 8 & 4.00 & 13.1 & 10 & 23 & 36 & 3 \\
\hline 9 & 4.08 & 13.4 & 33 & 46 & 23 & 3 \\
\hline 10 & 4.11 & 13.5 & 255 & 268 & 86 & 3 \\
\hline 11 & 4.18 & 13.7 & 15 & 28 & 26 & 2 \\
\hline 12 & 4.33 & 14.2 & 103 & 116 & 11 & 2 \\
\hline 13 & 4.34 & 14.2 & 18 & 31 & 29 & 1 \\
\hline 14 & 4.41 & 14.5 & 25 & 38 & 27 & 0 \\
\hline 15 & 4.67 & 15.3 & 53 & 66 & 6 & 0 \\
\hline 16 & 4.91 & 16.1 & 13 & 26 & 83 & 3 \\
\hline 17 & 5.00 & 16.4 & 344 & 357 & 12 & 0 \\
\hline 18 & 5.40 & 17.7 & 209 & 222 & 28 & 1 \\
\hline 19 & 5.52 & 18.1 & 48 & 61 & 23 & 1 \\
\hline 20 & 5.58 & 18.3 & 73 & 86 & 20 & 3 \\
\hline 21 & 5.68 & 18.6 & 76 & 89 & 8 & 2 \\
\hline 22 & 5.71 & 18.7 & 264 & 277 & 8 & 2 \\
\hline 23 & 5.88 & 19.3 & 180 & 193 & 15 & 0 \\
\hline 24 & 5.92 & 19.4 & 51 & 64 & 26 & 0 \\
\hline 25 & 5.98 & 19.6 & 49 & 62 & 7 & 0 \\
\hline 26 & 6.08 & 19.9 & 169 & 182 & 11 & 0 \\
\hline 27 & 6.22 & 20.4 & 171 & 184 & 14 & 2 \\
\hline 28 & 6.25 & 20.5 & 52 & 65 & 22 & 1 \\
\hline 29 & 6.29 & 20.7 & 211 & 224 & 11 & 0 \\
\hline 30 & 6.44 & 21.1 & 49 & 62 & 7 & 0 \\
\hline 31 & 6.53 & 21.4 & 68 & 81 & 5 & 1 \\
\hline 32 & 6.77 & 22.2 & 197 & 210 & 42 & 0 \\
\hline 33 & 7.04 & 23.1 & 229 & 242 & 48 & 1 \\
\hline 34 & 7.11 & 23.3 & 213 & 226 & 26 & 1 \\
\hline 35 & 7.22 & 23.7 & 250 & 263 & 11 & 1 \\
\hline 36 & 7.36 & 24.1 & 205 & 218 & 9 & 0 \\
\hline 37 & 7.50 & 24.6 & 349 & 2 & 19 & 0 \\
\hline 38 & 7.55 & 24.8 & 8 & 21 & 23 & 0 \\
\hline 39 & 7.58 & 24.9 & 84 & 97 & 60 & 1 \\
\hline 40 & 7.68 & 25.2 & 26 & 39 & 22 & 2 \\
\hline 41 & 7.80 & 25.6 & 37 & 50 & 17 & 0 \\
\hline 42 & 7.92 & 26.0 & 94 & 107 & 17 & 1 \\
\hline 43 & 8.13 & 26.7 & 86 & 99 & 66 & 1 \\
\hline 44 & 8.63 & 28.3 & 47 & 60 & 24 & 1 \\
\hline 45 & 9.16 & 30.0 & 242 & 254 & 7 & 2 \\
\hline
\end{tabular}

All directions have been corrected for borehole deviation, and are with respect to true north.

Page 1 
Orientation Summary Table - Image Features

Nevada Test Site

Source Physics Experiment

U-15N \#6

NNSA/NSO

20 Sept 2010

\begin{tabular}{|c|c|c|c|c|c|c|}
\hline $\begin{array}{c}\text { Feature } \\
\text { No. }\end{array}$ & $\begin{array}{c}\text { Depth } \\
\text { (meters) }\end{array}$ & $\begin{array}{l}\text { Depth } \\
\text { (feet) }\end{array}$ & $\begin{array}{c}\text { Dip } \\
\text { Direction } \\
\text { (degrees) }\end{array}$ & $\begin{array}{c}\text { Dip } \\
\text { Direction } \\
(\text { deg. } T N)\end{array}$ & $\begin{array}{c}\text { Dip } \\
\text { Angle } \\
\text { (degrees) }\end{array}$ & $\begin{array}{c}\text { Feature } \\
\text { Rank } \\
\text { (0 to 5) }\end{array}$ \\
\hline 46 & 9.28 & 30.4 & 38 & 51 & 25 & 2 \\
\hline 47 & 9.38 & 30.8 & 31 & 44 & 26 & 1 \\
\hline 48 & 9.43 & 30.9 & 171 & 184 & 39 & 2 \\
\hline 49 & 9.55 & 31.3 & 142 & 155 & 10 & 2 \\
\hline 50 & 9.62 & 31.6 & 78 & 90 & 10 & 2 \\
\hline 51 & 9.77 & 32.1 & 129 & 141 & 7 & 2 \\
\hline 52 & 9.77 & 32.1 & 199 & 212 & 66 & 2 \\
\hline 53 & 9.81 & 32.2 & 208 & 221 & 68 & 2 \\
\hline 54 & 10.04 & 32.9 & 100 & 113 & 2 & 1 \\
\hline 55 & 10.10 & 33.1 & 84 & 97 & 8 & 1 \\
\hline 56 & 10.16 & 33.3 & 106 & 119 & 7 & 2 \\
\hline 57 & 10.17 & 33.4 & 288 & 301 & 86 & 3 \\
\hline 58 & 10.20 & 33.5 & 225 & 238 & 31 & 2 \\
\hline 59 & 10.24 & 33.6 & 154 & 167 & 10 & 1 \\
\hline 60 & 10.33 & 33.9 & 249 & 261 & 34 & 1 \\
\hline 61 & 10.38 & 34.1 & 62 & 75 & 16 & 2 \\
\hline 62 & 10.40 & 34.1 & 251 & 264 & 12 & 1 \\
\hline 63 & 10.63 & 34.9 & 264 & 276 & 15 & 1 \\
\hline 64 & 10.64 & 34.9 & 81 & 94 & 14 & 1 \\
\hline 65 & 10.88 & 35.7 & 130 & 143 & 15 & 2 \\
\hline 66 & 10.99 & 36.1 & 315 & 328 & 6 & 3 \\
\hline 67 & 11.03 & 36.2 & 299 & 311 & 10 & 2 \\
\hline 68 & 11.10 & 36.4 & 38 & 51 & 26 & 2 \\
\hline 69 & 11.21 & 36.8 & 100 & 113 & 12 & 3 \\
\hline 70 & 11.52 & 37.8 & 5 & 18 & 22 & 0 \\
\hline 71 & 11.84 & 38.9 & 175 & 188 & 74 & 3 \\
\hline 72 & 12.03 & 39.5 & 188 & 200 & 70 & 2 \\
\hline 73 & 12.24 & 40.2 & 1 & 14 & 17 & 1 \\
\hline 74 & 12.36 & 40.6 & 213 & 226 & 40 & 0 \\
\hline 75 & 12.53 & 41.1 & 250 & 263 & 28 & 1 \\
\hline 76 & 12.93 & 42.4 & 298 & 311 & 35 & 1 \\
\hline 77 & 12.96 & 42.5 & 14 & 27 & 11 & 3 \\
\hline 78 & 13.01 & 42.7 & 36 & 49 & 8 & 3 \\
\hline 79 & 13.07 & 42.9 & 199 & 212 & 80 & 3 \\
\hline 80 & 13.08 & 42.9 & 49 & 62 & 7 & 2 \\
\hline 81 & 13.13 & 43.1 & 72 & 85 & 12 & 1 \\
\hline 82 & 13.17 & 43.2 & 53 & 66 & 9 & 2 \\
\hline 83 & 13.23 & 43.4 & 138 & 151 & 7 & 1 \\
\hline 84 & 13.30 & 43.7 & 132 & 145 & 9 & 2 \\
\hline 85 & 13.35 & 43.8 & 16 & 29 & 23 & 1 \\
\hline 86 & 13.48 & 44.2 & 299 & 311 & 88 & 3 \\
\hline 87 & 13.69 & 44.9 & 328 & 341 & 15 & 1 \\
\hline 88 & 13.77 & 45.2 & 220 & 233 & 29 & 2 \\
\hline 89 & 13.94 & 45.7 & 16 & 29 & 31 & 2 \\
\hline 90 & 14.02 & 46.0 & 154 & 167 & 11 & 2 \\
\hline
\end{tabular}

All directions have been corrected for borehole deviation, and are with respect to true north.

Page 2 
Orientation Summary Table - Image Features

Nevada Test Site

Source Physics Experiment

U-15N \#6

NNSA/NSO

20 Sept 2010

\begin{tabular}{|c|c|c|c|c|c|c|}
\hline $\begin{array}{c}\text { Feature } \\
\text { No. }\end{array}$ & $\begin{array}{c}\text { Depth } \\
\text { (meters) }\end{array}$ & $\begin{array}{l}\text { Depth } \\
\text { (feet) }\end{array}$ & $\begin{array}{c}\text { Dip } \\
\text { Direction } \\
\text { (degrees) }\end{array}$ & $\begin{array}{c}\text { Dip } \\
\text { Direction } \\
(\text { deg. } T N)\end{array}$ & $\begin{array}{c}\text { Dip } \\
\text { Angle } \\
\text { (degrees) }\end{array}$ & $\begin{array}{c}\text { Feature } \\
\text { Rank } \\
\text { (0 to 5) }\end{array}$ \\
\hline 91 & 14.14 & 46.4 & 28 & 41 & 16 & 1 \\
\hline 92 & 14.15 & 46.4 & 153 & 166 & 13 & 1 \\
\hline 93 & 14.32 & 47.0 & 14 & 27 & 10 & 1 \\
\hline 94 & 14.39 & 47.2 & 139 & 152 & 7 & 3 \\
\hline 95 & 14.44 & 47.4 & 309 & 322 & 24 & 1 \\
\hline 96 & 14.48 & 47.5 & 145 & 158 & 8 & 1 \\
\hline 97 & 14.55 & 47.7 & 74 & 87 & 8 & 2 \\
\hline 98 & 14.60 & 47.9 & 54 & 67 & 21 & 0 \\
\hline 99 & 14.85 & 48.7 & 158 & 171 & 14 & 0 \\
\hline 100 & 15.31 & 50.2 & 130 & 143 & 24 & 1 \\
\hline 101 & 15.51 & 50.9 & 106 & 118 & 8 & 2 \\
\hline 102 & 15.58 & 51.1 & 137 & 150 & 13 & 2 \\
\hline 103 & 15.65 & 51.3 & 111 & 124 & 13 & 2 \\
\hline 104 & 15.83 & 51.9 & 104 & 117 & 12 & 2 \\
\hline 105 & 15.93 & 52.3 & 100 & 113 & 10 & 1 \\
\hline 106 & 16.08 & 52.8 & 188 & 201 & 71 & 0 \\
\hline 107 & 16.18 & 53.1 & 19 & 32 & 28 & 0 \\
\hline 108 & 16.80 & 55.1 & 24 & 37 & 16 & 0 \\
\hline 109 & 17.11 & 56.1 & 55 & 68 & 11 & 2 \\
\hline 110 & 17.14 & 56.2 & 198 & 211 & 85 & 1 \\
\hline 111 & 17.20 & 56.4 & 358 & 11 & 80 & 0 \\
\hline 112 & 17.24 & 56.6 & 351 & 4 & 15 & 3 \\
\hline 113 & 17.29 & 56.7 & 48 & 61 & 16 & 2 \\
\hline 114 & 17.30 & 56.8 & 239 & 252 & 21 & 1 \\
\hline 115 & 17.50 & 57.4 & 138 & 151 & 10 & 2 \\
\hline 116 & 17.78 & 58.3 & 33 & 46 & 29 & 1 \\
\hline 117 & 17.87 & 58.6 & 195 & 208 & 83 & 3 \\
\hline 118 & 17.88 & 58.7 & 18 & 31 & 31 & 0 \\
\hline 119 & 18.01 & 59.1 & 68 & 80 & 9 & 1 \\
\hline 120 & 18.08 & 59.3 & 173 & 186 & 13 & 1 \\
\hline 121 & 18.17 & 59.6 & 127 & 140 & 14 & 2 \\
\hline 122 & 18.68 & 61.3 & 26 & 39 & 24 & 1 \\
\hline 123 & 18.78 & 61.6 & 131 & 144 & 15 & 1 \\
\hline 124 & 18.92 & 62.1 & 303 & 316 & 85 & 3 \\
\hline 125 & 18.93 & 62.1 & 309 & 322 & 27 & 1 \\
\hline 126 & 18.95 & 62.2 & 29 & 42 & 28 & 1 \\
\hline 127 & 18.96 & 62.2 & 110 & 123 & 7 & 1 \\
\hline 128 & 19.18 & 62.9 & 24 & 36 & 24 & 1 \\
\hline 129 & 19.27 & 63.2 & 359 & 12 & 58 & 1 \\
\hline 130 & 19.33 & 63.4 & 66 & 79 & 7 & 3 \\
\hline 131 & 19.57 & 64.2 & 56 & 68 & 26 & 1 \\
\hline 132 & 19.65 & 64.5 & 35 & 48 & 21 & 2 \\
\hline 133 & 19.66 & 64.5 & 284 & 297 & 67 & 3 \\
\hline 134 & 20.27 & 66.5 & 22 & 35 & 19 & 1 \\
\hline 135 & 20.36 & 66.8 & 151 & 164 & 5 & 1 \\
\hline
\end{tabular}

All directions have been corrected for borehole deviation, and are with respect to true north.

Page 3 
Orientation Summary Table - Image Features

Nevada Test Site

Source Physics Experiment

U-15N \#6

NNSA/NSO

20 Sept 2010

\begin{tabular}{|c|c|c|c|c|c|c|}
\hline $\begin{array}{c}\text { Feature } \\
\text { No. }\end{array}$ & $\begin{array}{c}\text { Depth } \\
\text { (meters) }\end{array}$ & $\begin{array}{l}\text { Depth } \\
\text { (feet) }\end{array}$ & $\begin{array}{c}\text { Dip } \\
\text { Direction } \\
\text { (degrees) }\end{array}$ & $\begin{array}{c}\text { Dip } \\
\text { Direction } \\
(\text { deg. } T N)\end{array}$ & $\begin{array}{c}\text { Dip } \\
\text { Angle } \\
\text { (degrees) }\end{array}$ & $\begin{array}{c}\text { Feature } \\
\text { Rank } \\
\text { (0 to 5) }\end{array}$ \\
\hline 136 & 20.46 & 67.1 & 174 & 187 & 33 & 3 \\
\hline 137 & 20.60 & 67.6 & 107 & 120 & 4 & 2 \\
\hline 138 & 20.85 & 68.4 & 195 & 208 & 51 & 0 \\
\hline 139 & 21.24 & 69.7 & 10 & 22 & 21 & 0 \\
\hline 140 & 21.74 & 71.3 & 35 & 48 & 7 & 3 \\
\hline 141 & 21.77 & 71.4 & 192 & 204 & 87 & 2 \\
\hline 142 & 21.81 & 71.5 & 181 & 194 & 6 & 3 \\
\hline 143 & 21.94 & 72.0 & 145 & 158 & 9 & 3 \\
\hline 144 & 22.03 & 72.3 & 160 & 173 & 7 & 3 \\
\hline 145 & 22.34 & 73.3 & 97 & 109 & 54 & 3 \\
\hline 146 & 22.35 & 73.3 & 53 & 65 & 52 & 3 \\
\hline 147 & 22.56 & 74.0 & 60 & 73 & 66 & 3 \\
\hline 148 & 22.64 & 74.3 & 96 & 109 & 76 & 3 \\
\hline 149 & 23.04 & 75.6 & 303 & 316 & 44 & 2 \\
\hline 150 & 23.42 & 76.8 & 34 & 47 & 23 & 0 \\
\hline 151 & 23.62 & 77.5 & 162 & 175 & 6 & 2 \\
\hline 152 & 23.77 & 78.0 & 4 & 17 & 83 & 3 \\
\hline 153 & 23.85 & 78.3 & 204 & 217 & 77 & 3 \\
\hline 154 & 24.58 & 80.6 & 193 & 206 & 83 & 2 \\
\hline 155 & 24.62 & 80.8 & 81 & 94 & 13 & 1 \\
\hline 156 & 24.88 & 81.6 & 204 & 217 & 14 & 1 \\
\hline 157 & 25.44 & 83.5 & 31 & 43 & 27 & 1 \\
\hline 158 & 25.64 & 84.1 & 17 & 30 & 29 & 1 \\
\hline 159 & 25.65 & 84.1 & 205 & 218 & 80 & 3 \\
\hline 160 & 25.85 & 84.8 & 24 & 37 & 19 & 2 \\
\hline 161 & 25.93 & 85.1 & 7 & 20 & 28 & 0 \\
\hline 162 & 25.96 & 85.2 & 212 & 225 & 81 & 3 \\
\hline 163 & 26.14 & 85.8 & 41 & 53 & 10 & 2 \\
\hline 164 & 26.58 & 87.2 & 70 & 83 & 7 & 1 \\
\hline 165 & 26.76 & 87.8 & 73 & 86 & 21 & 2 \\
\hline 166 & 26.89 & 88.2 & 40 & 53 & 6 & 3 \\
\hline 167 & 27.13 & 89.0 & 330 & 343 & 35 & 3 \\
\hline 168 & 27.16 & 89.1 & 102 & 115 & 73 & 2 \\
\hline 169 & 27.17 & 89.2 & 104 & 117 & 15 & 3 \\
\hline 170 & 27.41 & 89.9 & 103 & 115 & 57 & 3 \\
\hline 171 & 27.47 & 90.1 & 47 & 60 & 7 & 2 \\
\hline 172 & 27.62 & 90.6 & 25 & 38 & 27 & 0 \\
\hline 173 & 27.72 & 90.9 & 68 & 81 & 14 & 2 \\
\hline 174 & 27.87 & 91.5 & 60 & 73 & 4 & 2 \\
\hline 175 & 27.97 & 91.8 & 27 & 40 & 2 & 2 \\
\hline 176 & 28.17 & 92.4 & 29 & 42 & 21 & 2 \\
\hline 177 & 28.23 & 92.6 & 194 & 207 & 71 & 3 \\
\hline 178 & 28.32 & 92.9 & 90 & 103 & 8 & 2 \\
\hline 179 & 28.73 & 94.3 & 7 & 20 & 5 & 1 \\
\hline 180 & 28.84 & 94.6 & 64 & 77 & 23 & 1 \\
\hline
\end{tabular}

All directions have been corrected for borehole deviation, and are with respect to true north.

Page 4 
Orientation Summary Table - Image Features

Nevada Test Site

Source Physics Experiment

U-15N \#6

NNSA/NSO

20 Sept 2010

\begin{tabular}{|c|c|c|c|c|c|c|}
\hline $\begin{array}{c}\text { Feature } \\
\text { No. }\end{array}$ & $\begin{array}{c}\text { Depth } \\
\text { (meters) }\end{array}$ & $\begin{array}{l}\text { Depth } \\
\text { (feet) }\end{array}$ & $\begin{array}{c}\text { Dip } \\
\text { Direction } \\
\text { (degrees) }\end{array}$ & $\begin{array}{c}\text { Dip } \\
\text { Direction } \\
(\text { deg. } T N)\end{array}$ & $\begin{array}{c}\text { Dip } \\
\text { Angle } \\
\text { (degrees) }\end{array}$ & $\begin{array}{c}\text { Feature } \\
\text { Rank } \\
\text { (0 to 5) }\end{array}$ \\
\hline 181 & 29.00 & 95.2 & 192 & 205 & 84 & 3 \\
\hline 182 & 29.39 & 96.4 & 21 & 33 & 30 & 1 \\
\hline 183 & 29.74 & 97.6 & 203 & 216 & 81 & 3 \\
\hline 184 & 29.83 & 97.9 & 360 & 12 & 18 & 0 \\
\hline 185 & 29.94 & 98.2 & 58 & 70 & 21 & 0 \\
\hline 186 & 30.54 & 100.2 & 206 & 219 & 78 & 2 \\
\hline 187 & 30.63 & 100.5 & 118 & 131 & 8 & 0 \\
\hline 188 & 30.73 & 100.8 & 38 & 51 & 6 & 0 \\
\hline 189 & 30.79 & 101.0 & 286 & 299 & 8 & 0 \\
\hline 190 & 30.93 & 101.5 & 50 & 63 & 29 & 0 \\
\hline 191 & 31.54 & 103.5 & 139 & 152 & 13 & 3 \\
\hline 192 & 32.24 & 105.8 & 311 & 324 & 38 & 3 \\
\hline 193 & 32.46 & 106.5 & 195 & 208 & 84 & 3 \\
\hline 194 & 32.51 & 106.7 & 43 & 56 & 31 & 3 \\
\hline 195 & 32.91 & 108.0 & 43 & 56 & 22 & 3 \\
\hline 196 & 33.28 & 109.2 & 194 & 207 & 87 & 3 \\
\hline 197 & 33.50 & 109.9 & 135 & 147 & 16 & 3 \\
\hline 198 & 33.51 & 110.0 & 18 & 30 & 28 & 3 \\
\hline 199 & 33.99 & 111.5 & 88 & 101 & 22 & 0 \\
\hline 200 & 34.12 & 111.9 & 62 & 74 & 21 & 0 \\
\hline 201 & 34.20 & 112.2 & 112 & 125 & 7 & 0 \\
\hline 202 & 34.32 & 112.6 & 39 & 52 & 14 & 0 \\
\hline 203 & 34.44 & 113.0 & 17 & 30 & 15 & 1 \\
\hline 204 & 34.46 & 113.1 & 84 & 97 & 9 & 1 \\
\hline 205 & 34.89 & 114.5 & 19 & 32 & 83 & 3 \\
\hline 206 & 35.02 & 114.9 & 93 & 105 & 66 & 1 \\
\hline 207 & 35.03 & 114.9 & 160 & 173 & 8 & 0 \\
\hline 208 & 35.12 & 115.2 & 86 & 99 & 66 & 1 \\
\hline 209 & 35.21 & 115.5 & 289 & 301 & 36 & 1 \\
\hline 210 & 35.29 & 115.8 & 205 & 218 & 85 & 3 \\
\hline 211 & 35.80 & 117.5 & 23 & 36 & 20 & 1 \\
\hline 212 & 35.97 & 118.0 & 18 & 31 & 26 & 3 \\
\hline 213 & 36.05 & 118.3 & 55 & 68 & 13 & 1 \\
\hline 214 & 36.12 & 118.5 & 253 & 266 & 42 & 2 \\
\hline 215 & 36.18 & 118.7 & 55 & 68 & 31 & 1 \\
\hline 216 & 36.73 & 120.5 & 8 & 20 & 70 & 3 \\
\hline 217 & 36.74 & 120.5 & 68 & 80 & 17 & 1 \\
\hline 218 & 36.88 & 121.0 & 97 & 109 & 50 & 3 \\
\hline 219 & 37.01 & 121.4 & 118 & 131 & 69 & 3 \\
\hline 220 & 37.15 & 121.9 & 68 & 81 & 64 & 3 \\
\hline 221 & 37.21 & 122.1 & 97 & 110 & 8 & 1 \\
\hline 222 & 37.24 & 122.2 & 219 & 232 & 54 & 3 \\
\hline 223 & 37.45 & 122.9 & 48 & 61 & 9 & 1 \\
\hline 224 & 37.58 & 123.3 & 182 & 195 & 65 & 3 \\
\hline 225 & 37.72 & 123.7 & 38 & 51 & 32 & 3 \\
\hline
\end{tabular}

All directions have been corrected for borehole deviation, and are with respect to true north.

Page 5 
Orientation Summary Table - Image Features

Nevada Test Site

Source Physics Experiment

U-15N \#6

NNSA/NSO

20 Sept 2010

\begin{tabular}{|c|c|c|c|c|c|c|}
\hline $\begin{array}{c}\text { Feature } \\
\text { No. }\end{array}$ & $\begin{array}{c}\text { Depth } \\
\text { (meters) }\end{array}$ & $\begin{array}{l}\text { Depth } \\
\text { (feet) }\end{array}$ & $\begin{array}{c}\text { Dip } \\
\text { Direction } \\
\text { (degrees) }\end{array}$ & $\begin{array}{c}\text { Dip } \\
\text { Direction } \\
(\text { deg. } T N)\end{array}$ & $\begin{array}{c}\text { Dip } \\
\text { Angle } \\
\text { (degrees) }\end{array}$ & $\begin{array}{c}\text { Feature } \\
\text { Rank } \\
\text { (0 to 5) }\end{array}$ \\
\hline 226 & 37.74 & 123.8 & 121 & 134 & 15 & 3 \\
\hline 227 & 37.80 & 124.0 & 181 & 193 & 74 & 3 \\
\hline 228 & 38.33 & 125.8 & 43 & 56 & 18 & 3 \\
\hline 229 & 38.40 & 126.0 & 110 & 123 & 44 & 3 \\
\hline 230 & 38.43 & 126.1 & 40 & 53 & 82 & 3 \\
\hline 231 & 38.61 & 126.7 & 69 & 82 & 19 & 3 \\
\hline 232 & 38.72 & 127.0 & 219 & 232 & 12 & 3 \\
\hline 233 & 38.85 & 127.5 & 81 & 94 & 20 & 3 \\
\hline 234 & 38.97 & 127.9 & 67 & 80 & 18 & 3 \\
\hline 235 & 39.23 & 128.7 & 197 & 209 & 51 & 3 \\
\hline 236 & 39.36 & 129.1 & 192 & 205 & 57 & 3 \\
\hline 237 & 39.41 & 129.3 & 30 & 43 & 76 & 3 \\
\hline 238 & 39.53 & 129.7 & 45 & 58 & 13 & 2 \\
\hline 239 & 39.66 & 130.1 & 22 & 35 & 36 & 2 \\
\hline 240 & 40.31 & 132.3 & 98 & 111 & 11 & 1 \\
\hline 241 & 40.32 & 132.3 & 24 & 37 & 85 & 3 \\
\hline 242 & 40.45 & 132.7 & 194 & 207 & 81 & 3 \\
\hline 243 & 40.97 & 134.4 & 164 & 177 & 82 & 3 \\
\hline 244 & 41.00 & 134.5 & 63 & 76 & 8 & 1 \\
\hline 245 & 41.28 & 135.4 & 274 & 287 & 67 & 1 \\
\hline 246 & 41.33 & 135.6 & 41 & 54 & 7 & 1 \\
\hline 247 & 41.43 & 135.9 & 195 & 208 & 60 & 3 \\
\hline 248 & 41.71 & 136.8 & 19 & 32 & 83 & 3 \\
\hline 249 & 41.79 & 137.1 & 18 & 31 & 83 & 3 \\
\hline 250 & 41.97 & 137.7 & 13 & 26 & 7 & 1 \\
\hline 251 & 42.07 & 138.0 & 160 & 173 & 62 & 3 \\
\hline 252 & 42.11 & 138.1 & 221 & 234 & 51 & 2 \\
\hline 253 & 42.15 & 138.3 & 196 & 209 & 78 & 2 \\
\hline 254 & 42.43 & 139.2 & 185 & 198 & 75 & 1 \\
\hline 255 & 42.59 & 139.7 & 29 & 42 & 17 & 0 \\
\hline 256 & 42.67 & 140.0 & 195 & 208 & 65 & 2 \\
\hline 257 & 42.72 & 140.2 & 48 & 60 & 15 & 0 \\
\hline 258 & 43.12 & 141.5 & 194 & 207 & 70 & 3 \\
\hline 259 & 43.15 & 141.6 & 2 & 15 & 37 & 3 \\
\hline 260 & 43.27 & 142.0 & 15 & 28 & 15 & 2 \\
\hline 261 & 43.28 & 142.0 & 190 & 203 & 55 & 1 \\
\hline 262 & 43.52 & 142.8 & 202 & 215 & 70 & 3 \\
\hline 263 & 43.57 & 143.0 & 198 & 211 & 4 & 1 \\
\hline 264 & 43.86 & 143.9 & 132 & 145 & 10 & 1 \\
\hline 265 & 43.90 & 144.0 & 101 & 114 & 11 & 1 \\
\hline 266 & 43.98 & 144.3 & 42 & 55 & 47 & 0 \\
\hline 267 & 44.18 & 145.0 & 26 & 39 & 33 & 1 \\
\hline 268 & 44.86 & 147.2 & 342 & 355 & 8 & 2 \\
\hline 269 & 44.94 & 147.4 & 62 & 74 & 25 & 1 \\
\hline 270 & 45.20 & 148.3 & 17 & 30 & 29 & 1 \\
\hline
\end{tabular}

All directions have been corrected for borehole deviation, and are with respect to true north. 
Orientation Summary Table - Image Features

Nevada Test Site

Source Physics Experiment

U-15N \#6

NNSA/NSO

20 Sept 2010

\begin{tabular}{|c|c|c|c|c|c|c|}
\hline $\begin{array}{c}\text { Feature } \\
\text { No. }\end{array}$ & $\begin{array}{c}\text { Depth } \\
\text { (meters) }\end{array}$ & $\begin{array}{l}\text { Depth } \\
\text { (feet) }\end{array}$ & $\begin{array}{c}\text { Dip } \\
\text { Direction } \\
\text { (degrees) }\end{array}$ & $\begin{array}{c}\text { Dip } \\
\text { Direction } \\
(\text { deg. } T N)\end{array}$ & $\begin{array}{c}\text { Dip } \\
\text { Angle } \\
\text { (degrees) }\end{array}$ & $\begin{array}{c}\text { Feature } \\
\text { Rank } \\
\text { (0 to 5) }\end{array}$ \\
\hline 271 & 45.23 & 148.4 & 124 & 137 & 63 & 3 \\
\hline 272 & 45.25 & 148.5 & 125 & 138 & 66 & 3 \\
\hline 273 & 45.33 & 148.7 & 71 & 84 & 22 & 2 \\
\hline 274 & 45.65 & 149.8 & 276 & 289 & 4 & 1 \\
\hline 275 & 45.86 & 150.5 & 97 & 110 & 9 & 2 \\
\hline 276 & 45.98 & 150.8 & 217 & 230 & 66 & 1 \\
\hline 277 & 46.01 & 150.9 & 74 & 87 & 2 & 3 \\
\hline 278 & 46.24 & 151.7 & 61 & 73 & 4 & 1 \\
\hline 279 & 46.38 & 152.2 & 105 & 118 & 9 & 0 \\
\hline 280 & 46.69 & 153.2 & 41 & 54 & 26 & 0 \\
\hline 281 & 47.72 & 156.6 & 196 & 208 & 21 & 0 \\
\hline 282 & 47.78 & 156.8 & 181 & 194 & 66 & 1 \\
\hline 283 & 47.80 & 156.8 & 56 & 69 & 10 & 3 \\
\hline 284 & 47.92 & 157.2 & 66 & 79 & 24 & 0 \\
\hline 285 & 48.19 & 158.1 & 221 & 233 & 58 & 2 \\
\hline 286 & 48.26 & 158.3 & 54 & 67 & 17 & 2 \\
\hline 287 & 48.37 & 158.7 & 70 & 83 & 72 & 3 \\
\hline 288 & 48.47 & 159.0 & 53 & 66 & 13 & 3 \\
\hline 289 & 48.49 & 159.1 & 233 & 246 & 59 & 3 \\
\hline 290 & 48.59 & 159.4 & 247 & 260 & 60 & 3 \\
\hline 291 & 48.62 & 159.5 & 51 & 63 & 65 & 3 \\
\hline 292 & 49.23 & 161.5 & 217 & 230 & 61 & 0 \\
\hline 293 & 49.29 & 161.7 & 77 & 90 & 59 & 3 \\
\hline 294 & 49.39 & 162.1 & 32 & 45 & 18 & 1 \\
\hline 295 & 49.58 & 162.7 & 13 & 26 & 17 & 1 \\
\hline 296 & 49.65 & 162.9 & 80 & 92 & 58 & 2 \\
\hline 297 & 49.71 & 163.1 & 205 & 217 & 46 & 3 \\
\hline 298 & 49.95 & 163.9 & 63 & 76 & 11 & 0 \\
\hline 299 & 50.05 & 164.2 & 47 & 60 & 18 & 1 \\
\hline 300 & 50.23 & 164.8 & 12 & 25 & 14 & 2 \\
\hline 301 & 50.40 & 165.4 & 38 & 51 & 19 & 0 \\
\hline 302 & 50.70 & 166.3 & 36 & 49 & 28 & 1 \\
\hline 303 & 50.80 & 166.7 & 23 & 36 & 18 & 1 \\
\hline 304 & 51.18 & 167.9 & 148 & 161 & 7 & 1 \\
\hline 305 & 51.23 & 168.1 & 70 & 83 & 6 & 1 \\
\hline 306 & 51.34 & 168.5 & 264 & 277 & 19 & 1 \\
\hline 307 & 51.51 & 169.0 & 99 & 112 & 63 & 1 \\
\hline 308 & 51.55 & 169.1 & 9 & 22 & 7 & 2 \\
\hline 309 & 51.95 & 170.4 & 120 & 133 & 82 & 3 \\
\hline 310 & 52.09 & 170.9 & 80 & 93 & 16 & 3 \\
\hline 311 & 52.10 & 170.9 & 3 & 16 & 61 & 0 \\
\hline 312 & 52.56 & 172.4 & 242 & 255 & 0 & 2 \\
\hline 313 & 52.64 & 172.7 & 41 & 54 & 25 & 1 \\
\hline 314 & 52.77 & 173.1 & 38 & 51 & 26 & 2 \\
\hline 315 & 52.80 & 173.2 & 202 & 215 & 66 & 2 \\
\hline
\end{tabular}

All directions have been corrected for borehole deviation, and are with respect to true north.

Page 7 
Orientation Summary Table - Image Features

Nevada Test Site

Source Physics Experiment

U-15N \#6

NNSA/NSO

20 Sept 2010

\begin{tabular}{|c|c|c|c|c|c|c|}
\hline $\begin{array}{c}\text { Feature } \\
\text { No. }\end{array}$ & $\begin{array}{c}\text { Depth } \\
\text { (meters) }\end{array}$ & $\begin{array}{l}\text { Depth } \\
\text { (feet) }\end{array}$ & $\begin{array}{c}\text { Dip } \\
\text { Direction } \\
\text { (degrees) }\end{array}$ & $\begin{array}{c}\text { Dip } \\
\text { Direction } \\
\text { (deg. TN) }\end{array}$ & $\begin{array}{c}\text { Dip } \\
\text { Angle } \\
\text { (degrees) }\end{array}$ & $\begin{array}{c}\text { Feature } \\
\text { Rank } \\
\text { (0 to 5) }\end{array}$ \\
\hline 316 & 52.92 & 173.6 & 45 & 58 & 28 & 1 \\
\hline 317 & 52.92 & 173.6 & 213 & 226 & 64 & 2 \\
\hline 318 & 53.10 & 174.2 & 209 & 222 & 62 & 0 \\
\hline 319 & 53.17 & 174.4 & 11 & 24 & 4 & 1 \\
\hline 320 & 53.25 & 174.7 & 45 & 58 & 28 & 1 \\
\hline 321 & 53.32 & 174.9 & 61 & 74 & 14 & 1 \\
\hline 322 & 53.35 & 175.0 & 62 & 75 & 12 & 1 \\
\hline 323 & 53.69 & 176.2 & 43 & 56 & 29 & 1 \\
\hline 324 & 53.78 & 176.5 & 56 & 69 & 29 & 2 \\
\hline 325 & 53.79 & 176.5 & 68 & 81 & 76 & 3 \\
\hline 326 & 53.96 & 177.1 & 202 & 214 & 49 & 3 \\
\hline 327 & 53.99 & 177.1 & 28 & 41 & 28 & 1 \\
\hline 328 & 54.28 & 178.1 & 79 & 91 & 39 & 1 \\
\hline 329 & 54.46 & 178.7 & 42 & 55 & 27 & 0 \\
\hline 330 & 54.73 & 179.6 & 31 & 44 & 26 & 1 \\
\hline 331 & 54.77 & 179.7 & 222 & 235 & 59 & 0 \\
\hline 332 & 54.87 & 180.0 & 28 & 41 & 32 & 1 \\
\hline 333 & 54.87 & 180.0 & 230 & 243 & 46 & 3 \\
\hline 334 & 55.02 & 180.5 & 174 & 187 & 40 & 0 \\
\hline 335 & 55.20 & 181.1 & 189 & 202 & 44 & 3 \\
\hline 336 & 55.26 & 181.3 & 27 & 40 & 20 & 1 \\
\hline 337 & 55.46 & 181.9 & 218 & 231 & 56 & 0 \\
\hline 338 & 55.60 & 182.4 & 216 & 228 & 57 & 2 \\
\hline 339 & 55.82 & 183.1 & 209 & 222 & 65 & 3 \\
\hline 340 & 56.00 & 183.7 & 221 & 234 & 74 & 3 \\
\hline 341 & 56.05 & 183.9 & 79 & 92 & 74 & 1 \\
\hline 342 & 56.38 & 185.0 & 208 & 221 & 73 & 3 \\
\hline 343 & 56.46 & 185.2 & 26 & 39 & 83 & 3 \\
\hline 344 & 56.47 & 185.3 & 211 & 224 & 78 & 3 \\
\hline 345 & 56.58 & 185.6 & 12 & 24 & 70 & 3 \\
\hline 346 & 56.59 & 185.7 & 49 & 62 & 17 & 2 \\
\hline 347 & 56.63 & 185.8 & 161 & 174 & 71 & 2 \\
\hline 348 & 56.96 & 186.9 & 176 & 189 & 36 & 2 \\
\hline 349 & 57.02 & 187.1 & 194 & 207 & 45 & 0 \\
\hline 350 & 57.22 & 187.7 & 175 & 188 & 20 & 3 \\
\hline 351 & 57.37 & 188.2 & 167 & 180 & 26 & 1 \\
\hline 352 & 57.45 & 188.5 & 34 & 47 & 21 & 0 \\
\hline
\end{tabular}

All directions have been corrected for borehole deviation, and are with respect to true north. 


\section{APPENDIX K \\ Information Regarding Weathering at the U15n Source Physics Experiment Site}

Table K-1: Visual Weathering Characteristics of U-15n Core Table K-2: U.S. Bureau of Reclamation Weathering Categories

Table K-3: International Society of Rock Mechanics Weathering Classification 
Table K-1

\section{Visual Weathering Characteristics of U-15n Core}

\begin{tabular}{|c|c|l||}
\hline Depth (feet) & $\begin{array}{c}\text { USBR } \\
\text { Weathering } \\
\text { Category }\end{array}$ & \multicolumn{1}{c|}{ Comment } \\
\hline $7-20$ & W3 & $\begin{array}{l}\text { About 90\% of observable core is relatively unweathered (W3) quartz } \\
\text { monzonite and 10\% is relatively weathered (W4) }\end{array}$ \\
\hline $20-45$ & W4 & $\begin{array}{l}\text { About 65\% of observable core is relatively weathered (W4); 35\% } \\
\text { (minor zones) is relatively unweathered (W3). }\end{array}$ \\
\hline $45-75$ & W3 & $\begin{array}{l}\text { Core is mostly hard, stained granodiorite (USBR category W3, } \\
\text { slightly weathered) }\end{array}$ \\
\hline $75-88.5$ & Fault zone & $\begin{array}{l}\text { Shows low resistivity and low density on logs. Feldspars are altered } \\
\text { to clay, and biotite is surrounded by alteration holes of bronze } \\
\text { biotite. This sheared material is not considered in the determination } \\
\text { of weathering and alteration categories by USBR procedure. }\end{array}$ \\
\hline $88.5-104$ & W3 & Core is mostly hard, stained quartz monzonite (W3). \\
\hline $104-107$ & Fault zone & Fault zone, similar to fault zone at 75-88.5 ft. \\
\hline $107-138$ & W3 & Core is mostly hard, stained quartz monzonite (W3). \\
\hline $138-148$ & W3 & $\begin{array}{l}\text { Relatively unweathered quartz monzonite with little staining and few } \\
\text { fractures (W3) }\end{array}$ \\
\hline $148-196.5$ & W3 & $\begin{array}{l}\text { Core is mostly hard, stained quartz monzonite (W3), with minor } \\
\text { areas of W4 adjacent to faults or fractures at 155.5-156.5, 168-171, } \\
\text { and 194.8-196.5 ft. }\end{array}$ \\
\hline \hline
\end{tabular}

a U.S. Bureau of Reclamation Weathering Categories. See Table K-2. Information about the International Society of Rock Mechanics (ISRM) Weathering Classification system is provided in Table K-3 for comparison. 


\section{Table K-2 \\ U.S. Bureau of Reclamation Weathering Categories}

\begin{tabular}{|c|c|c|}
\hline Name Sy & mbol & Description \\
\hline Decomposed & w9 & $\begin{array}{l}\text { Body of rock is discolored or oxidized throughout, but resistant } \\
\text { minerals such as quartz may be unaltered; all feldspars and } \\
\text { ferromagnesian minerals are completely altered to clay; } \\
\text { complete separation of grain boundaries (disaggregated), partial } \\
\text { or complete remnant rock structure may be preserved, but } \\
\text { resembles a soil. }\end{array}$ \\
\hline $\begin{array}{l}\text { Very Intensely } \\
\text { Weathered }^{\mathrm{a}}\end{array}$ & W8 & \\
\hline Intensely Weathered & W7 & $\begin{array}{l}\text { Body of rock is discolored or oxidized throughout; all feldspars } \\
\text { and ferromagnesian minerals are altered to clay to some extent. } \\
\text { All fracture surfaces are discolored or oxidized, surfaces friable; } \\
\text { partial separation of grain boundaries, rock is friable; in situ } \\
\text { disaggregation of grantics common in semi-arid regions; texture } \\
\text { altered and leaching of soluble minerals may be complete. } \\
\text { Rock has dull sound when struck with hammer; rock is } \\
\text { weakened, usually can be broken with moderate to heavy } \\
\text { manual pressure or by light hammer blow without reference to } \\
\text { planes of weakness. }\end{array}$ \\
\hline $\begin{array}{l}\text { Intensely to Moderately } \\
\text { Weathered }^{\text {a }}\end{array}$ & W6 & \\
\hline Moderately Weathered & W5 & $\begin{array}{l}\text { Discoloration or oxidation extends from fractures, usually } \\
\text { throughout body of rock; ferromagnesian minerals are "rusty," } \\
\text { feldspar crystals area "cloudy"' all fracture surfaces are } \\
\text { discolored or oxidized; partial opening of grain boundaries } \\
\text { visible; texture generally preserved by soluble minerals may be } \\
\text { mostly leached. Hammer does not ring when rock is struck; } \\
\text { body of rock is slightly weakened. }\end{array}$ \\
\hline $\begin{array}{l}\text { Moderately to Slightly } \\
\text { Weathered }^{\text {a }}\end{array}$ & W4 & \\
\hline Slightly Weathered & W3 & $\begin{array}{l}\text { Discoloration or oxidation is limited to surface of, or short } \\
\text { distance from fractures; some feldspar crystals are dull; fracture } \\
\text { surfaces have minor to complete discoloration or oxidation; no } \\
\text { visible separation of grain boundaries; texture preserved and } \\
\text { minor leaching of soluble minerals may be present. Hammer } \\
\text { rings when crystalline rocks are struck; body of rock is not } \\
\text { weakened by weathering. }\end{array}$ \\
\hline $\begin{array}{l}\text { Slightly Weathered to } \\
\text { Fresh }{ }^{\text {a }}\end{array}$ & W2 & \\
\hline Fresh & W1 & $\begin{array}{l}\text { Body of rock is not oxidized or discolored; fracture surface are } \\
\text { not oxidized or discolored }{ }^{\text {b. }} \text {; no separation of grain boundaries; } \\
\text { no change of texture and no solutioning. Hammer rings when } \\
\text { crystalline rocks are struck. }\end{array}$ \\
\hline
\end{tabular}

Taken from U.S. Bureau of Reclamation, 2007. Engineering Geology Field Manual, Figure 4-6, page 67. www.usbr.gov/pmts/geology/geolman/. Accessed on October 17, 2011.

a. Combination of descriptors is used where equal distribution of both weathering characteristics are present over significant intervals or where characteristics noted are "in between" the diagnostic characteristics.

b. Characteristics of fractures surfaces do not include directional weathering along shears or faults and their associated fracture zones. For example, a shear that carries weathering to great depths in a fresh rock mass would not require the whole rock mass to be classified as weathered. 


\section{Table K-3}

\section{International Society of Rock Mechanics Weathering Classification}

\begin{tabular}{|c|c|c|}
\hline Term G & rade & Description \\
\hline Residual Soil & & $\begin{array}{l}\text { All rock material is converted to soil; the mass structure } \\
\text { and material fabric are destroyed; there is a large change } \\
\text { in volume but the soil has not been significantly } \\
\text { transported. }\end{array}$ \\
\hline Completely Weathered & W5 & $\begin{array}{l}\text { All rock material is decomposed and/or disintegrated to } \\
\text { soil; the original mass structure is still largely intact. }\end{array}$ \\
\hline Highly Weathered & W4 & $\begin{array}{l}\text { More than half of the rock material is decomposed and/or } \\
\text { disintegrated to soil; fresh or discolored rock is present } \\
\text { either as a discontinuous framework or as core stones. }\end{array}$ \\
\hline Moderately Weathered & W3 & $\begin{array}{l}\text { Less than half of the rock material is decomposed and/or } \\
\text { disintegrated to soil; fresh or discolored rock is present } \\
\text { either as a discontinuous framework or as core stones. }\end{array}$ \\
\hline Slightly Weathered & W2 & $\begin{array}{l}\text { Discoloration indicates weathering of rock material and } \\
\text { discontinuity surfaces; weathering may discolor all the } \\
\text { rock material. }\end{array}$ \\
\hline Fresh Rock & W1 & $\begin{array}{l}\text { No visible sign of rock material weathering; perhaps slight } \\
\text { discoloration on major discontinuity surfaces. }\end{array}$ \\
\hline
\end{tabular}

International Society for Rock Mechanics, 1981. "Basic Geotechnical Description of Rock Masses." International Journal of Rock Mechanics, Mining Sciences, and Geomechanics Abstracts, vol. 18, pp. 85-110. 


\begin{abstract}
APPENDIX L
Water in the SPE Holes

Email from Margaret Townsend, UGTA/Boreholes Geology Group, National Security Technologies, LLC
\end{abstract}

To Source Physics Experiment Subject Matter Experts

December 29, 2010 


\begin{tabular}{ll}
$\begin{array}{ll}\text { From: } \\
\text { To: }\end{array}$ & Townsend, Margaret \\
& Barker, Dennis; Ortego, Paul; Schuette, Robert; Snelson-Gerlicher, Catherine; Graves, Tom; "Antoun, Tarabay \\
Cc: & H."; "lomov1@llnl.gov"; "Wendee Brunish"; "Chris Bradley"; "Aviva Sussman"; "reabbott@sandia.gov"; "Corbell, \\
Subject: & Lee, Ping; Drellack, Sigmund \\
Date: & water in the SPE holes \\
Attachments: & Wednesday, December 29, 2010 4:54:38 PM \\
& $\underline{\text { U-15n\#5 water chem.pdf }}$ \\
& $\underline{U}$ \\
\hline
\end{tabular}

SPE Team,

As you know, we have found that the holes drilled at the $U-15 n$ site contain water. This was a surprise to me, and at first I thought this must be water from the drilling operation seeping back into the open holes after being forced into natural fractures during drilling. However, subsequent investigations indicate that it is natural groundwater. Here is an update, first the chemistry analysis, then the water levels.

\section{Water Chemistry}

On October 21, 2010, the NSTec Ecological and Environmental Monitoring Group collected one water sample from hole $\mathrm{U}-15 \mathrm{n} \# 5$ and one from the water truck that delivered water for making up the foam used as a drilling fluid (source is Water Well 8 in Area 18). The samples were analyzed at a commercial laboratory for metals (Calcium, Magnesium, Potassium, Silica [Silicon], Sodium) and four other routinely monitored stable chemistry parameters:

- Alkalinity, Bicarbonate ( $\mathrm{HCO}$ ) as $\mathrm{CaCO} 3$

- Alkalinity, Carbonate (CO3) as $\mathrm{CaCO} 3$

- Chloride, Fluoride, Sulfate as SO4

- Total Dissolved Solids (TDS)

The sampling crew also used a meter to measure $\mathrm{pH}$, temperature, specific conductance, and turbidity of the borehole water at the time of sampling.

The lab data package is about an inch thick, but I scanned the summary sheet and attached it to this message (I wrote the borehole meter readings at the bottom). The results indicate that only bicarbonate alkalinity and total dissolved solids were detectable in the sample from the water truck, while in the sample from the borehole they also measured chloride, fluoride, and sulfate. The lab also reported that due to very high sodium levels in the truck sample they had to dilute the sample 12-fold.

It is hard to make a definitive statement about the source of the borehole water based on only these two samples, but the significant difference between the two samples seems to indicate that they are from two different sources. Given the composition of the granite, and some mineralization not far away, the presence of chloride, fluoride and sulfate appears to indicate that the sample from $\mathrm{U}-15 \mathrm{n} \# 5$ is formation water.

\section{Water Levels}

Water level depths tagged during geophysical logging (September 20, 2010) ranged from 57.3 to 77 
$\mathrm{ft}$, as reported on the daily drilling report:

- Hole \#1 Fluid at 58.3'

- Hole \#2 Fluid at 77'

- Hole \#3 Fluid at 58'

- Hole \#4 Fluid at 61'

- Hole \#5 Fluid at 57.3'

- Hole \#6 Fluid at $61.5^{\prime}$

On the same day that they collected the water sample from U-15n\#5 (October 21, 2010), the Ecological Monitoring folks measured recharge of water in hole \#5 during pumping: while pumping at $1.3 \mathrm{GPM}$, they measured the recharge rate at approximately $1.306 \mathrm{gal} / \mathrm{ft}$ every 10 minutes.

An NSTec crew measured the water levels on December 9, 2010, and reported a fluid level depth of $58 \mathrm{ft}$ in all five open instrument holes and the 36 -in. hole, which was $112 \mathrm{ft}$ deep at the time. This seemed to indicate that the holes are communicating through the fracture system, allowing the fluid levels to equilibrate in all holes.

NSTec geologists measured the water levels in all six open holes twice on December 23 and twice on December 28, 2010. The measured water level depths below ground surface were very similar to those measured two weeks before, ranging from about 57 to $60 \mathrm{ft}$. I've attached an Excel spreadsheet that lists these latest measurements and shows a graphical plot of the data. We plan to measure the water levels again next week, to try to determine if the slight rise seen in some of the holes continues, following the rains we've been having.

I hope to send out next week some preliminary interpretations of the fracture data from the instrument holes.

Let me know if there are any questions.

Maggie

Margaret Townsend

702-295-6521

NSTec Environmental Restoration

Contractor to the United States Department of Energy 
264 Welsh Pool Road

Exton, PA 19341

Phone: 610-280-3000

Fax: $610-250-3041$

National Security Technologies, LLC

2621 Losee Road, Mail Stop NTS273

North Las Vegas NV, 89030
Project: BOA

Project Number: V3513

Project Manager: Ted Redding
Reported:

$11 / 16 / 201017: 22$

\section{Wet Chemistry}

Lionville Laboratory

\begin{tabular}{|c|c|c|c|c|c|c|c|c|}
\hline Analyte & Result and Qualifier & $\begin{array}{l}\text { Reporting } \\
\text { Limit }\end{array}$ & Units & Dilution & Batch & Propased & Analyred & Method \\
\hline \multicolumn{9}{|c|}{ U-15N-5 (1010109-01) Water } \\
\hline Carbonate Alkalinity & $2.0 \mathrm{U}$ & 2.0 & met. & 1 & 1.011059 & $10 / 29 / 2010$ & $1029 / 2010$ & SM 23208 \\
\hline Bicarboaate Alkalinity & 245 & 2.0 & mel & 1 & L011059 & $10 / 29 / 2010$ & $10 / 29 / 2010$ & SM 23201 \\
\hline Total Dissolved Solids & 383 & 5.0 & meth & 1 & 1.010402 & $10 / 27 / 2010$ & $1027 / 2010$ & $5 \mathrm{M} 2540 \mathrm{C}$ \\
\hline Chloride & 10.6 & 2.50 & mel & 10 & L.011245 & $11 / 202010$ & $11 / 112010$ & $\begin{array}{c}\text { EPA } 300.0 \\
\text { (1993) }\end{array}$ \\
\hline Fluoride & 0.52 & 0.25 & $\mathrm{mgl}$ & 1 & L.011245 & $11 / 10 / 2010$ & $11 / 11 / 2010$ & $\begin{array}{c}\text { EPA } 300.0 \\
\text { (1993) }\end{array}$ \\
\hline Sulfate & 42.3 & 2.50 & mel & 10 & 1.011245 & $11 / 10 / 2010$ & $11 / 12010$ & EPA 300.0 \\
\hline
\end{tabular}

U-15N-T (1010109-02) Water

\begin{tabular}{|c|c|c|c|c|c|c|c|c|c|}
\hline Carbonate Alkalinity & 10.0 & $\mathrm{u}$ & 10.0 & mpl & 1 & L0110s9 & $1029 / 2010$ & 10292010 & SM 23203 \\
\hline Bicarbonate Alkalinity & 202 & & 10.0 & $\mathrm{mgl}$ & 1 & 1.011059 & $10 / 29 / 2010$ & $10 / 29 / 2010$ & SM 23208 \\
\hline Total Dissolved Solids & 15.0 & & 5.0 & mpl. & 1 & L010402 & $1027 / 2010$ & $10 / 27 / 2010$ & SM 2540C \\
\hline Chloride & 1250 & $\mathrm{U}$ & 1250 & mol & 5000 & L.011245 & $11 / 102010$ & $11 / 11 / 2010$ & $\begin{array}{c}\text { EPA } 300.0 \\
(1993)\end{array}$ \\
\hline Fluoride & 1250 & $\mathrm{u}$ & 1250 & mgl & 5000 & to11245 & $11 / 102010$ & $11 / 11 / 2010$ & $\begin{array}{l}\text { EPA } 300.0 \\
\text { (1993) }\end{array}$ \\
\hline Sulfate & 1250 & $\mathrm{U}$ & 1250 & $\mathrm{mg} / \mathrm{L}$ & 5000 & L.011245 & II/Tan2010 & $11 / 112010$ & $\begin{array}{c}\text { EPA } 3000 \\
(1993)\end{array}$ \\
\hline
\end{tabular}

$$
\begin{aligned}
& \text { Measured in } 4.15 n=5 \text { by ETS, } 21 \text { Oot } 2010 \\
& \text { P1t }=7.25 \\
& \text { Temp }=17.4^{\circ} \mathrm{C} \\
& \text { Spr. Conductance }=566 \mu \mathrm{s} / \mathrm{cm} \\
& \text { Turbidity }=1.03 \text { (NTa) }
\end{aligned}
$$


U15n Borehole Groundwater Elevations

\begin{tabular}{|c|c|c|c|c|c|c|c|c|c|c|c|c|c|c|c|c|c|c|c|c|}
\hline \multirow{3}{*}{ Date } & \multirow{3}{*}{ Time } & \multirow{3}{*}{ Baro } & \multicolumn{3}{|c|}{ U-15n (36") } & \multicolumn{3}{|c|}{ U-15n \#1 } & \multicolumn{3}{|c|}{ U-15n \#2 } & \multicolumn{3}{|c|}{ U-15n \#3 } & \multicolumn{3}{|c|}{ U-15n \#4 } & \multicolumn{3}{|c|}{ U-15n \#5 } \\
\hline & & & \multicolumn{2}{|c|}{$\begin{array}{l}\text { GS Elevation: } \\
\text { TOC Stickup AGS: }\end{array}$} & \multirow{2}{*}{\begin{tabular}{|c|}
$\begin{array}{c}5003.12 \\
2.56\end{array}$ \\
GW Elev \\
\end{tabular}} & \multicolumn{2}{|c|}{\begin{tabular}{|l|} 
GS Elevation: \\
TOC Stickup AGS:
\end{tabular}} & \multirow{2}{*}{\begin{tabular}{|c|}
$\begin{array}{c}5003.19 \\
0.60\end{array}$ \\
GW Elev \\
\end{tabular}} & \multicolumn{2}{|c|}{$\begin{array}{l}\text { GS Elevation: } \\
\text { TOC Stickup AGS: }\end{array}$} & \multirow{2}{*}{\begin{tabular}{|c|}
$\begin{array}{c}5003.28 \\
0.65\end{array}$ \\
GW Elev \\
\end{tabular}} & \multicolumn{2}{|c|}{\begin{tabular}{|l|} 
GS Elevation: \\
TOC Stickup AGS:
\end{tabular}} & \multirow{2}{*}{\begin{tabular}{|c|}
5003.85 \\
0.60 \\
GW Elev \\
\end{tabular}} & \multicolumn{2}{|c|}{\begin{tabular}{|l|} 
GS Elevation: \\
TOC Stickup AGS:
\end{tabular}} & \multirow{2}{*}{\begin{tabular}{|c|}
$\begin{array}{c}5003.79 \\
0.75\end{array}$ \\
GW Elev \\
\end{tabular}} & \multicolumn{2}{|c|}{\begin{tabular}{|l} 
GS Elevation: \\
TOC Stickup AGS:
\end{tabular}} & \multirow{2}{*}{\begin{tabular}{|c|}
$\begin{array}{c}5003.27 \\
0.65\end{array}$ \\
GW Elev \\
\end{tabular}} \\
\hline & & & \begin{tabular}{|l} 
Time \\
\end{tabular} & DTW & & Time & DTW & & Time & DTW & & Time & DTW & & Time & DTW & & Time & DTW & \\
\hline $12 / 23 / 2010$ & $7: 15$ & \begin{tabular}{|c||}
867.6 \\
-20
\end{tabular} & $9: 10$ & 59.89 & 4945.79 & 9:05 & 58.05 & 4945.74 & 9:00 & 57.69 & 4946.24 & $8: 50$ & 57.57 & 4946.88 & $8: 55$ & 58.77 & 4945.77 & $8: 41$ & 57.35 & 4946.57 \\
\hline & & & $15: 25$ & 59.89 & & $15: 20$ & & & $15: 19$ & & 4946.21 & 15: & & & $15: 17$ & & & $15: 10$ & 57.37 & 4946.55 \\
\hline $12 / 28 / 2010$ & & & $8: 29$ & 59.89 & 4945.79 & $8: 17$ & 57.78 & 4946.01 & $8: 27$ & 57.69 & 4946.24 & $8: 22$ & 57.42 & 4947.03 & $8: 24$ & 58.76 & 4945.78 & $8: 20$ & 57.17 & 4946.75 \\
\hline $12 / 28 / 2010$ & 15:45 & | 862.9|| & 16:06 & 59.87 & 4945.81 & $15: 45$ & 57.76 & 4946.03 & $15: 59$ & 57.78 & 4946.15 & 15:54 & 57.38 & 4947.07 & 15:57 & 58.75 & 4945.79 & $15: 39$ & 57.10 & 4946.82 \\
\hline
\end{tabular}

AGS = Above Ground Surface, stickup height of TOC in feet, approximate due to uneven ground surface

Baro = Barometric Pressure, in millibars, at Station 2, reported from the NOAA ARL SORD MEDA Data website

DTW = Depth To Water, in feet measured with electronic sounding tape from top of casing

GS = Ground Surface, elevation in feet, approximate due to uneven ground surface

$\mathrm{GW}=$ Ground Water, elevation in feet, approximate due to uneven ground surface

$\mathrm{TOC}=$ Top Of Casing, measurement point

Measurements made by NSTec UGTA/Boreholes geologists

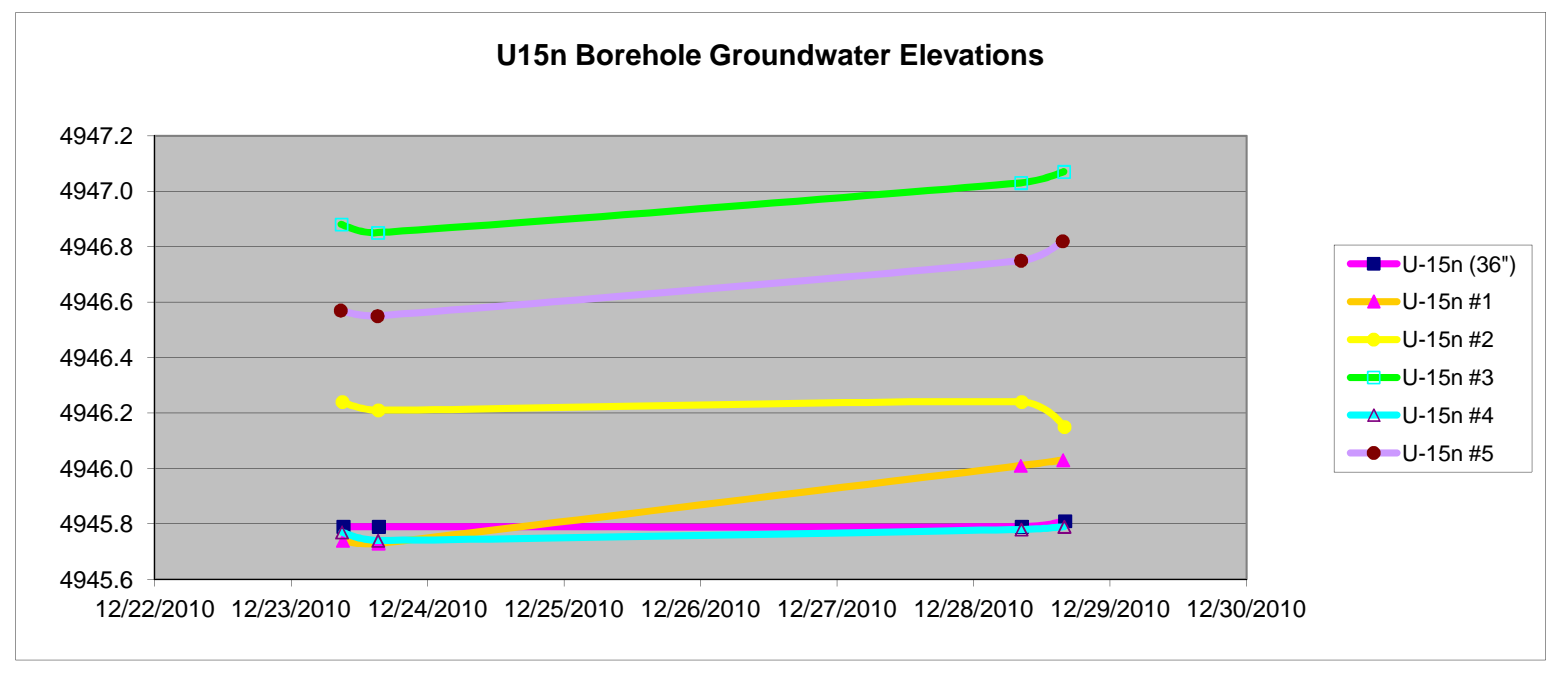




\section{Plate 1}

Houser, F. N., and F. G. Poole, 1960. Preliminary Geologic Map of the Climax Stock and Vicinity, Nye County, Nevada. U.S. Geological Survey, Miscellaneous Geologic Investigations

Map I-328 


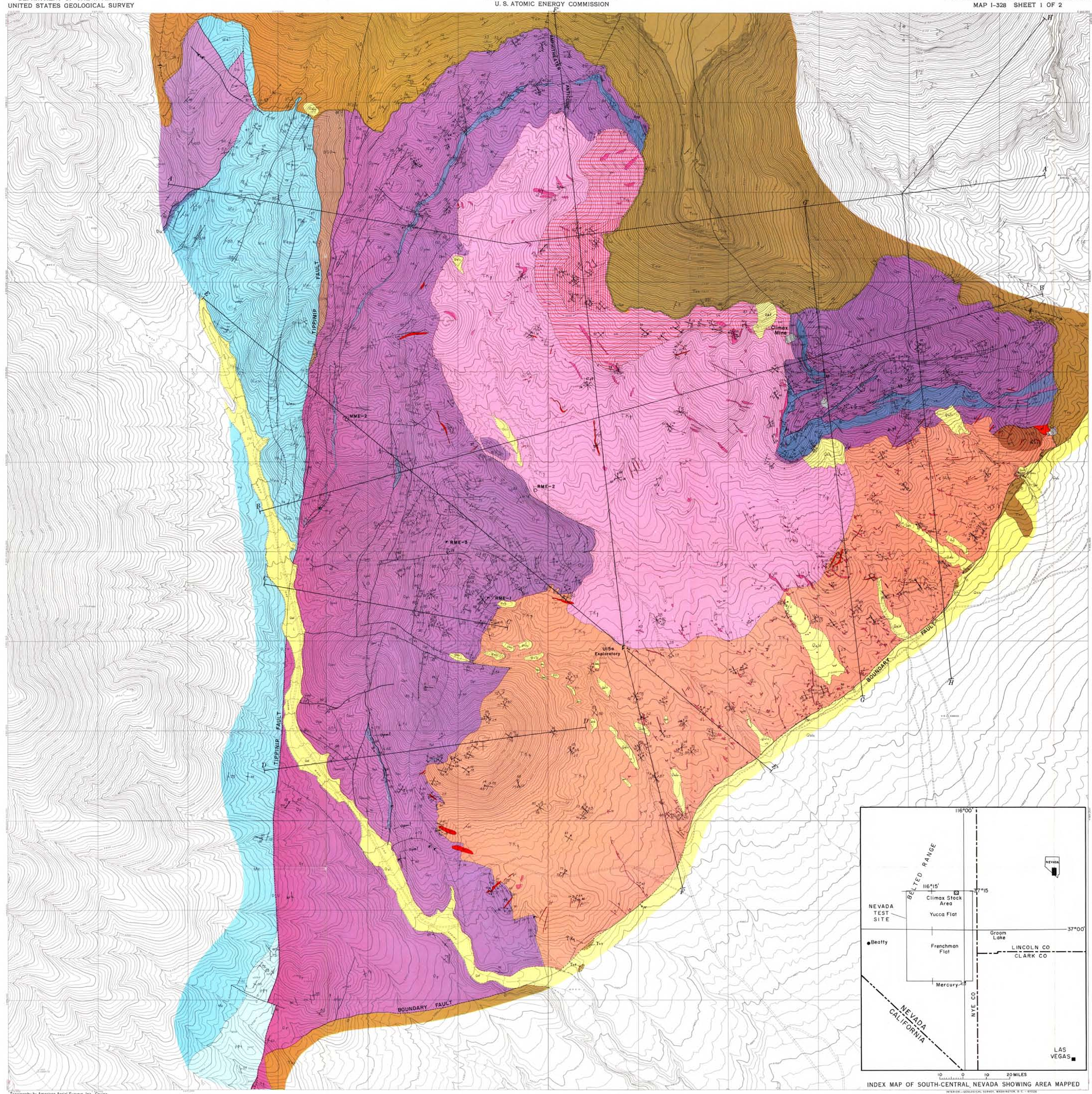

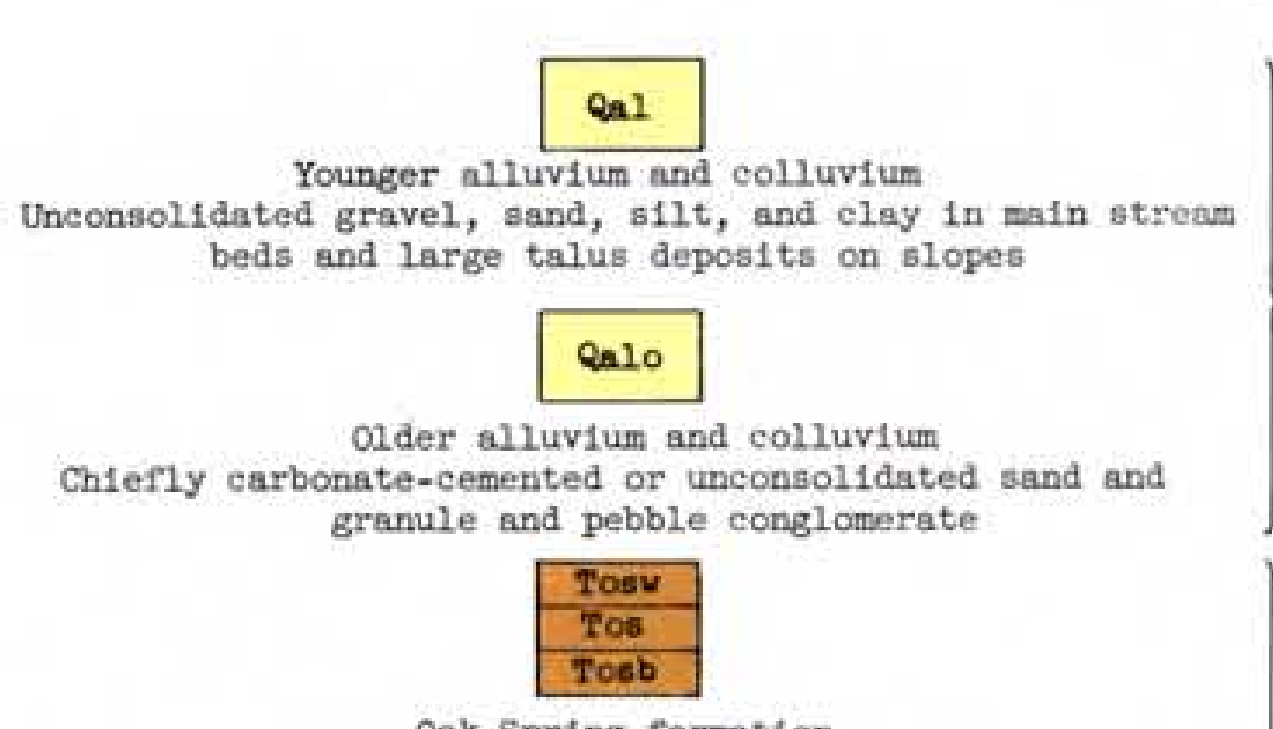

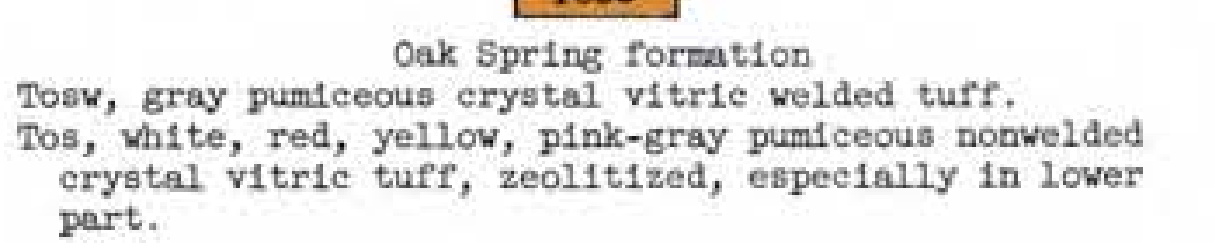

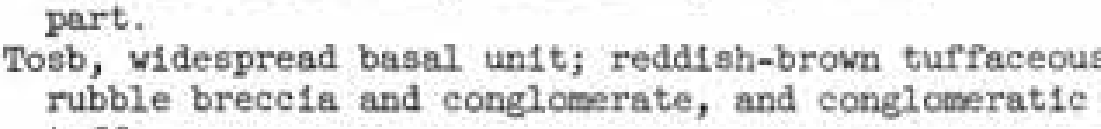

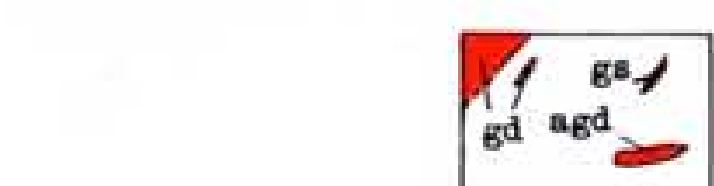

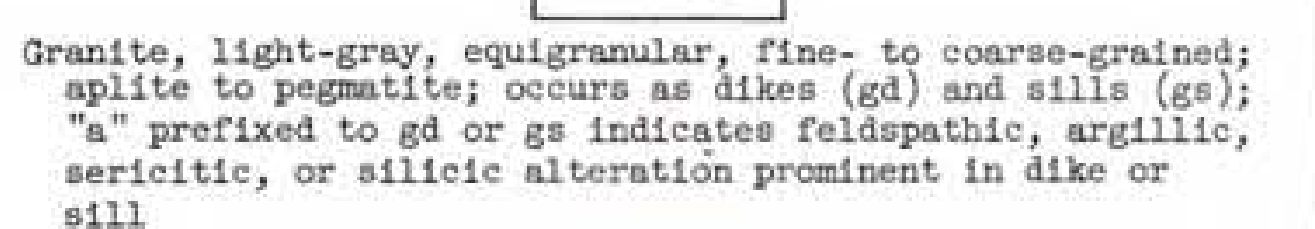
$\pi \times s$

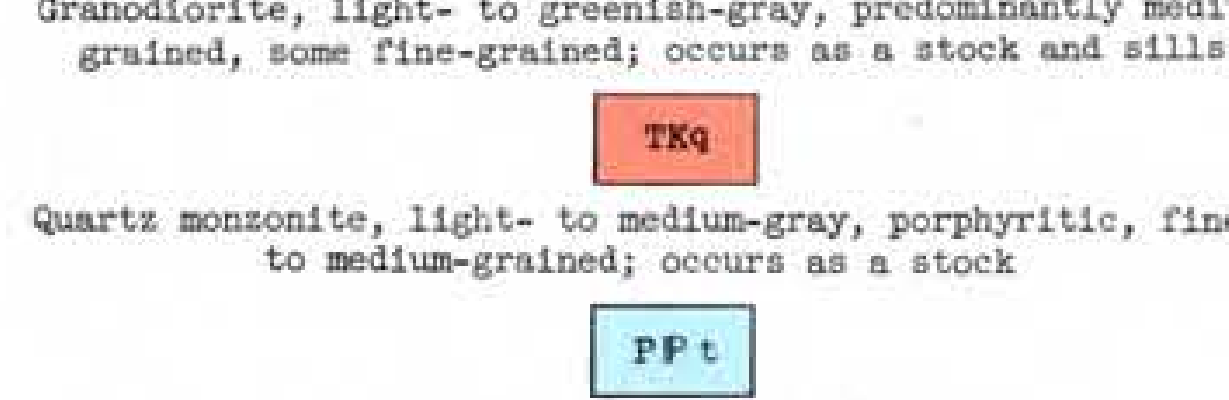

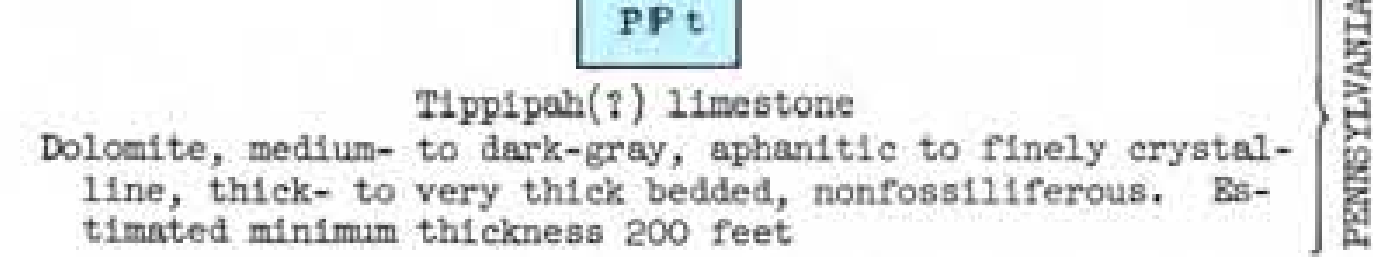

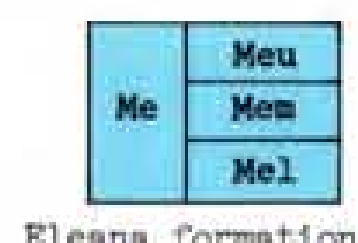

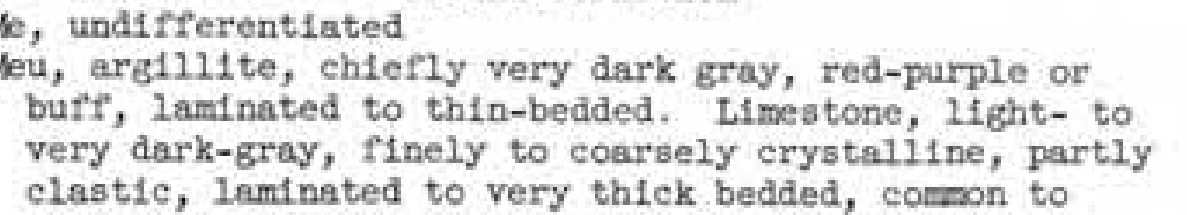

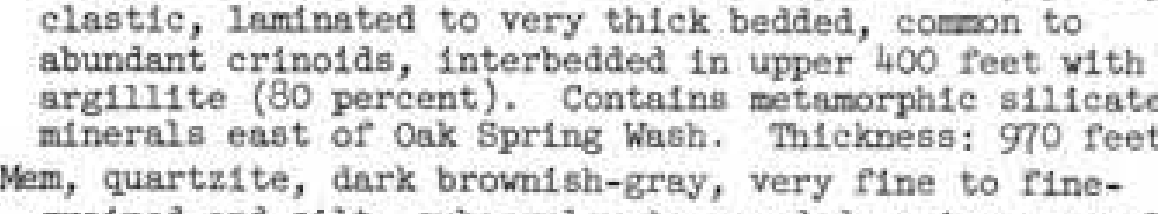

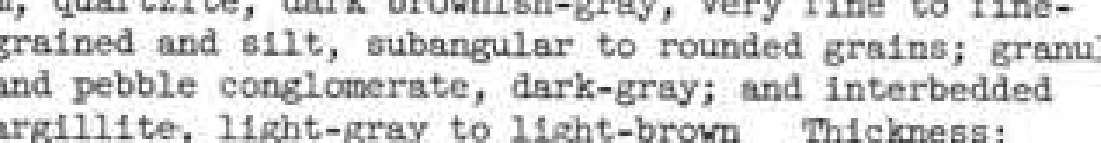

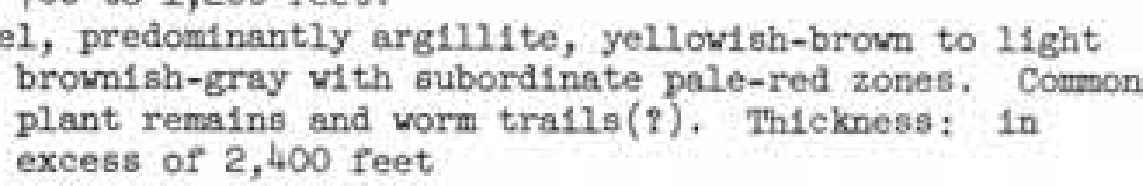

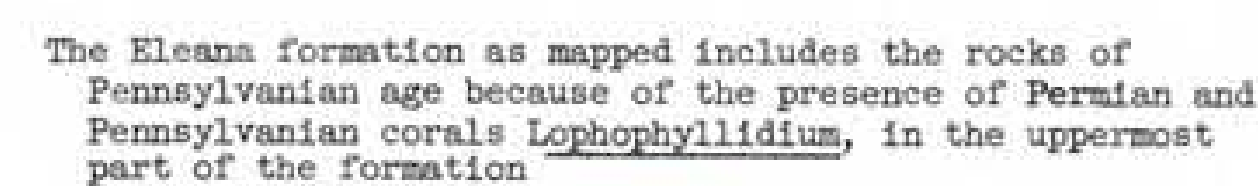
(D)

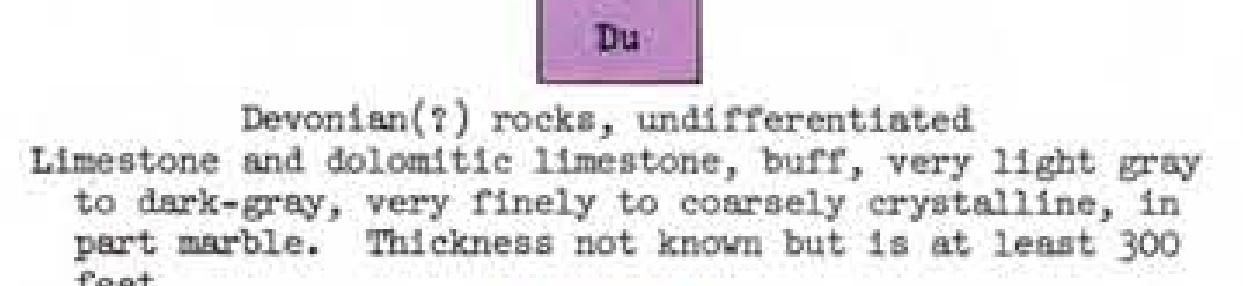

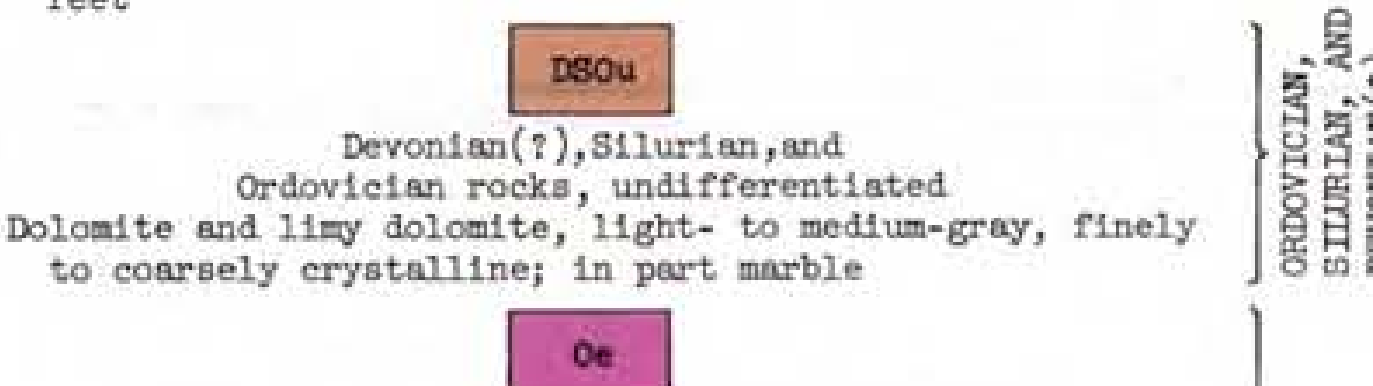

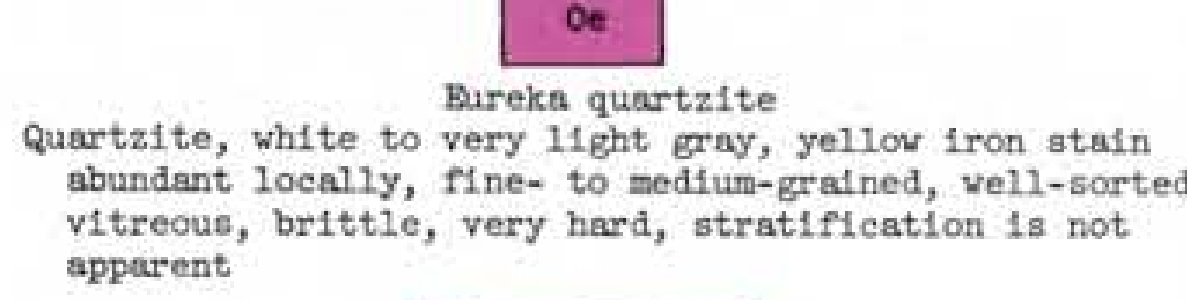

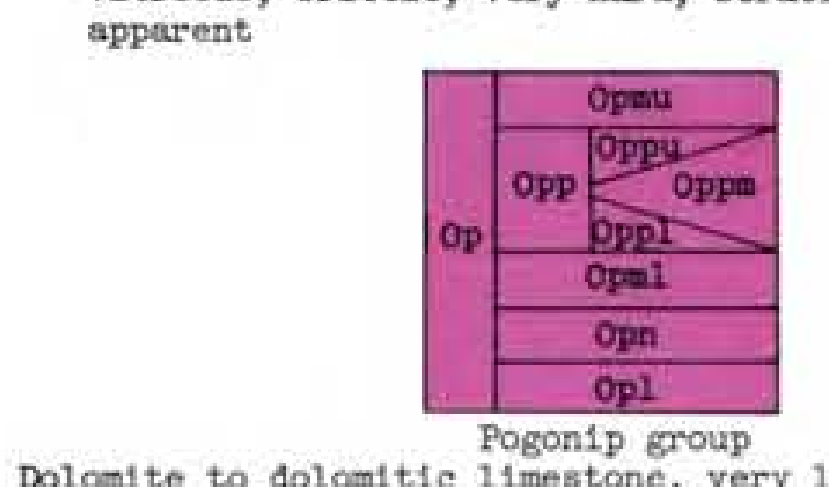

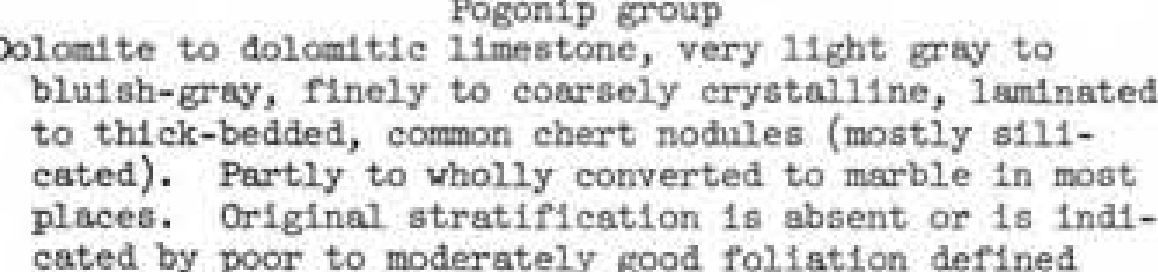

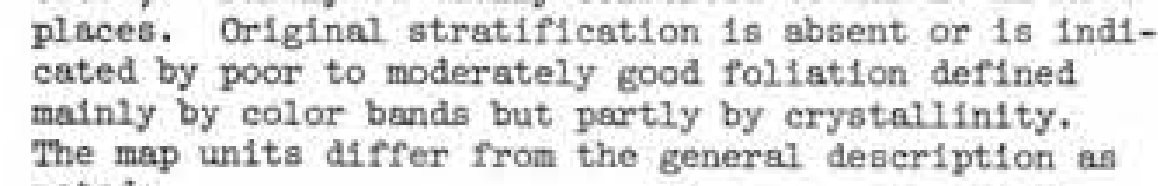

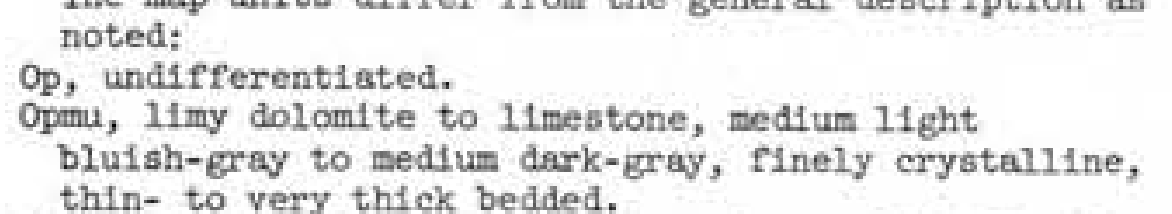

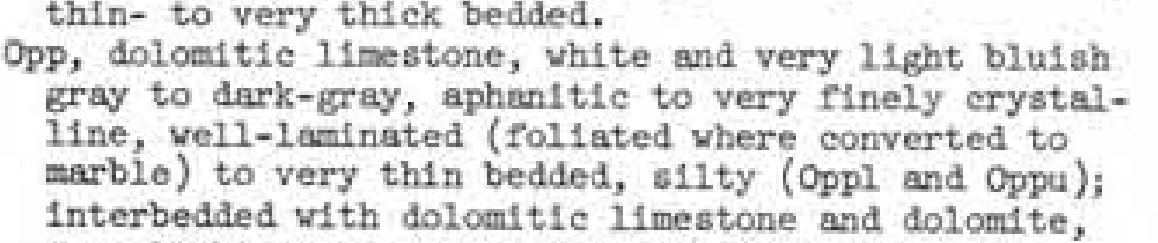

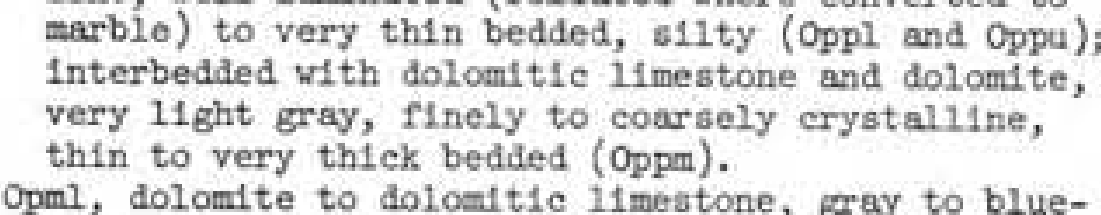

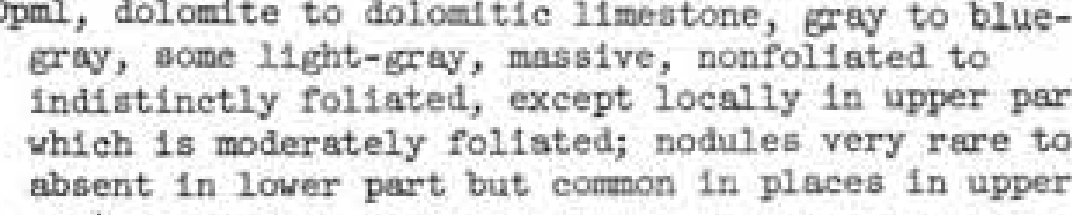

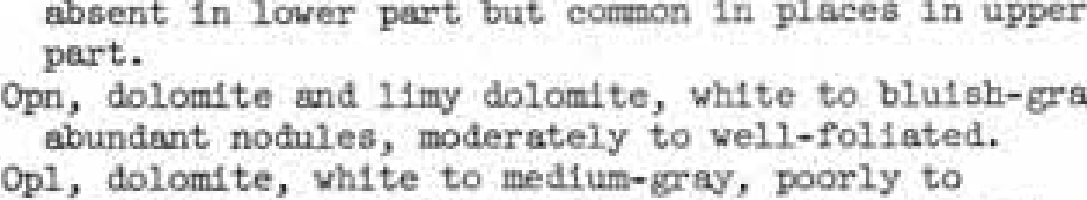

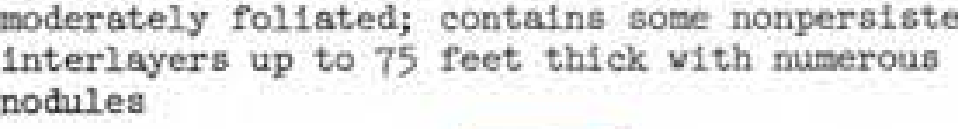

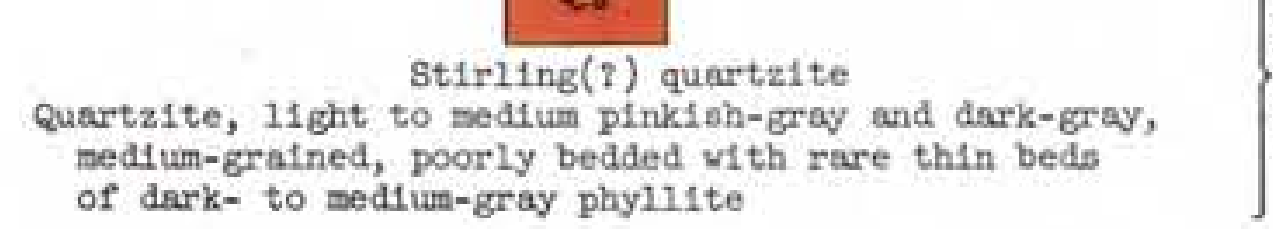

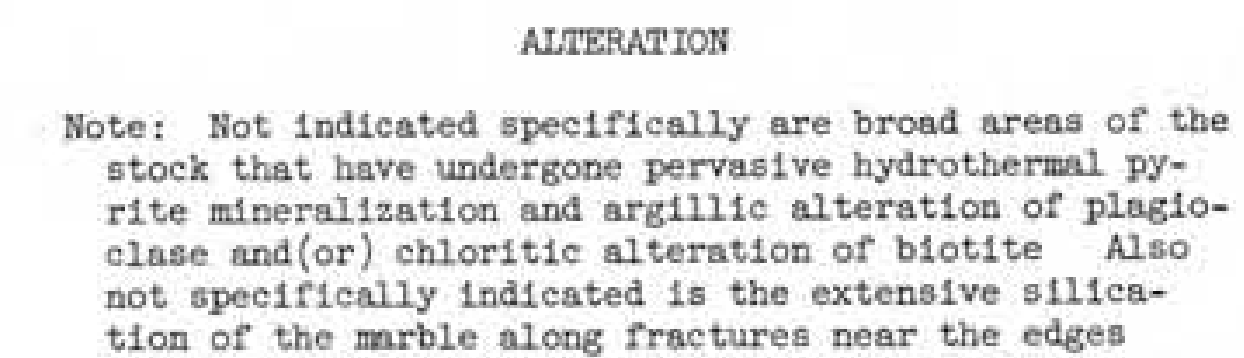

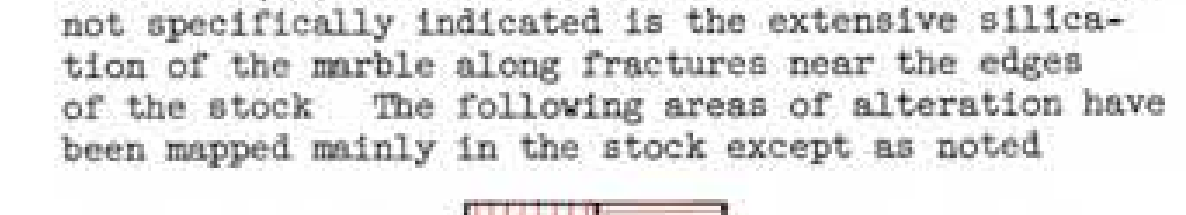

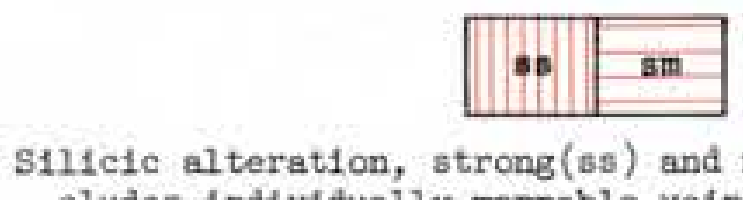

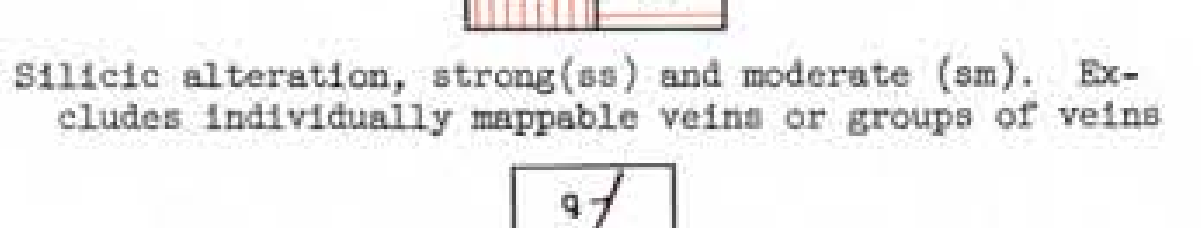

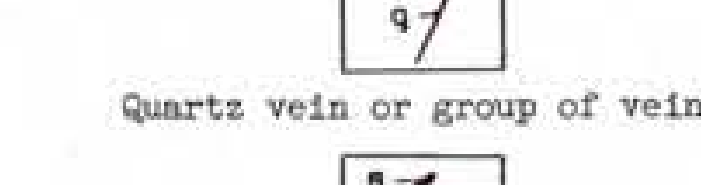

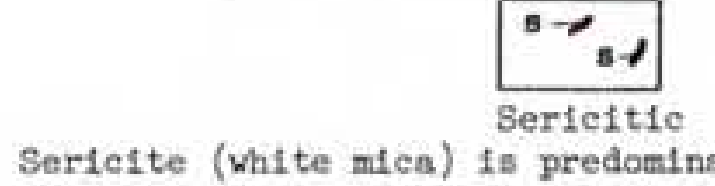
b/

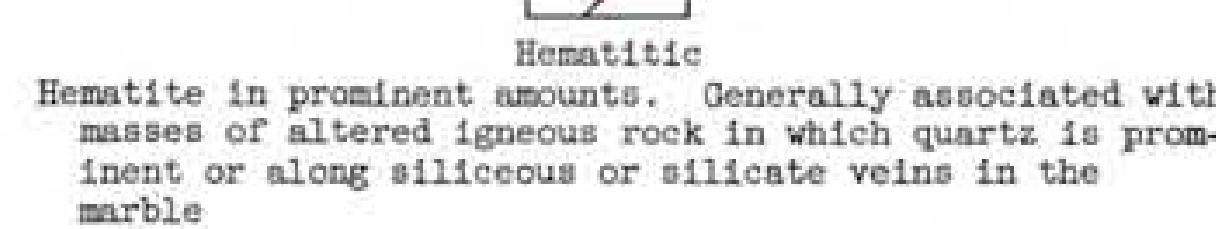

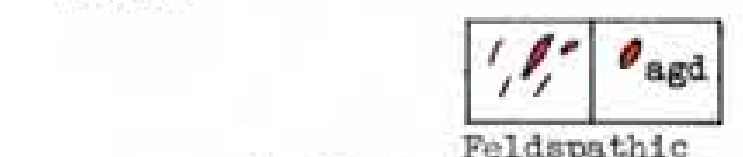

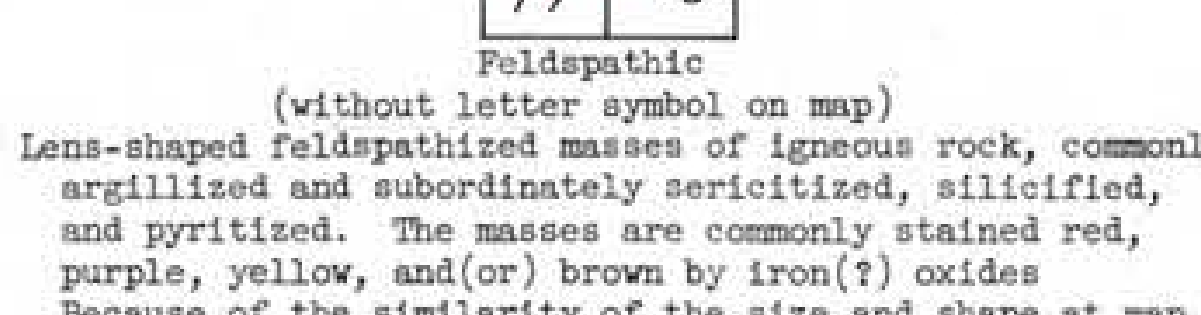

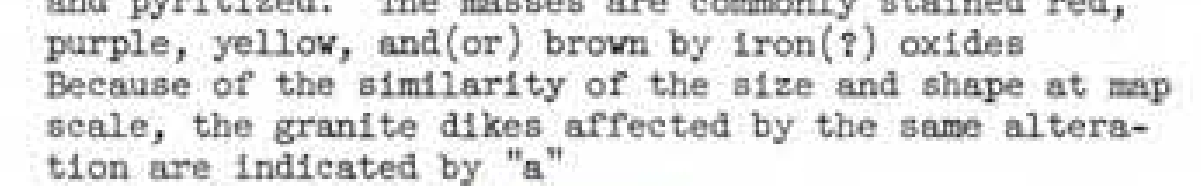
'十

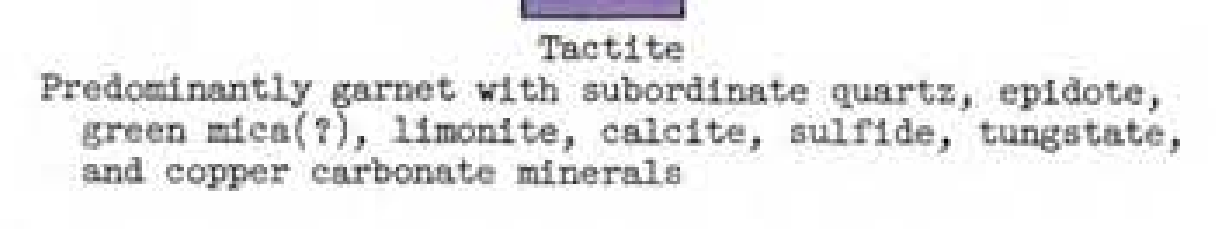

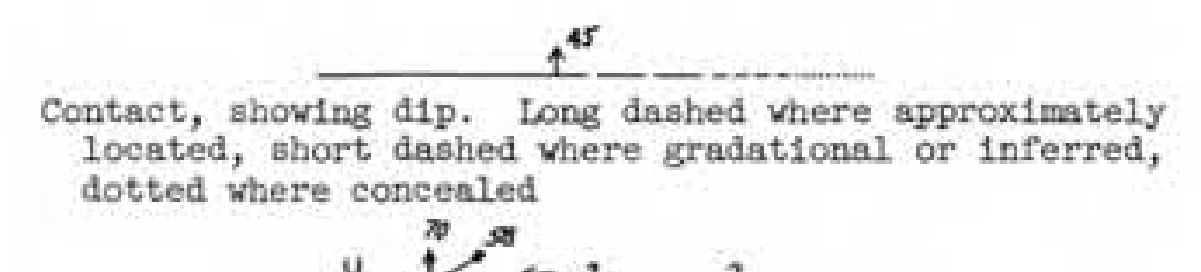

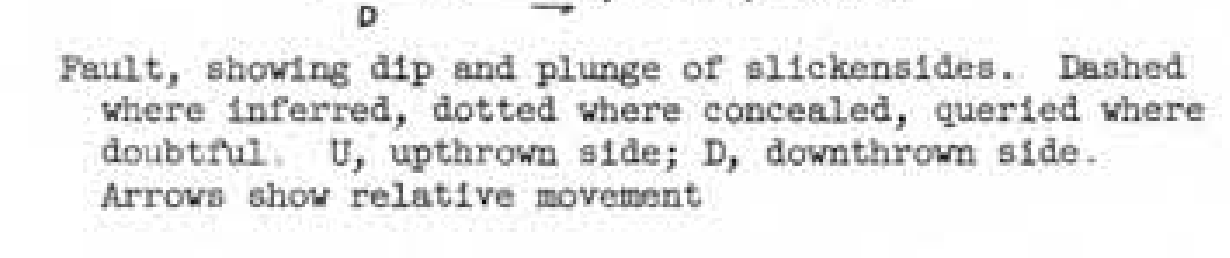

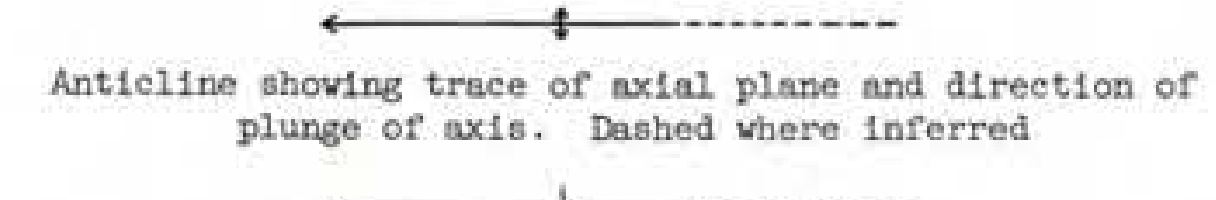

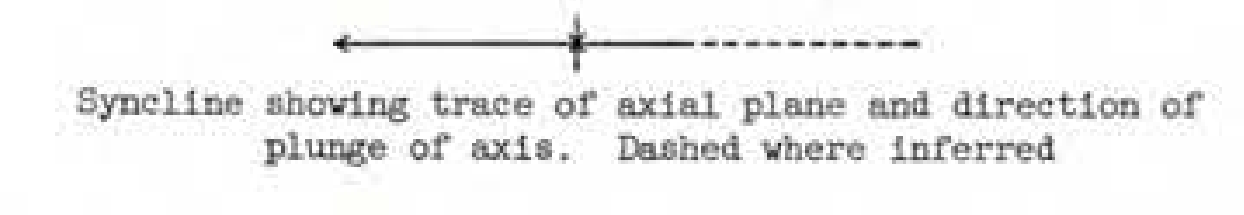

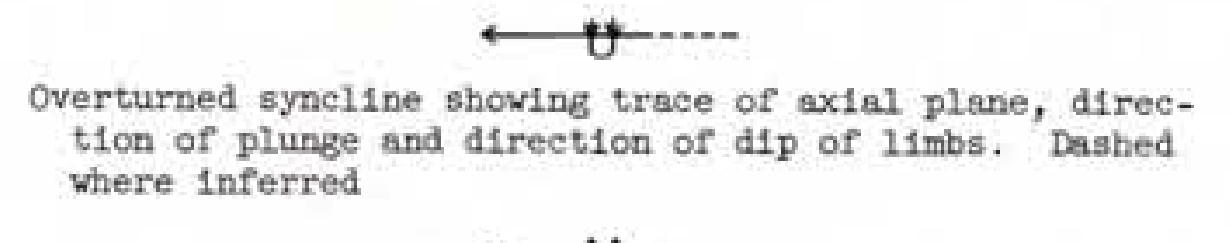

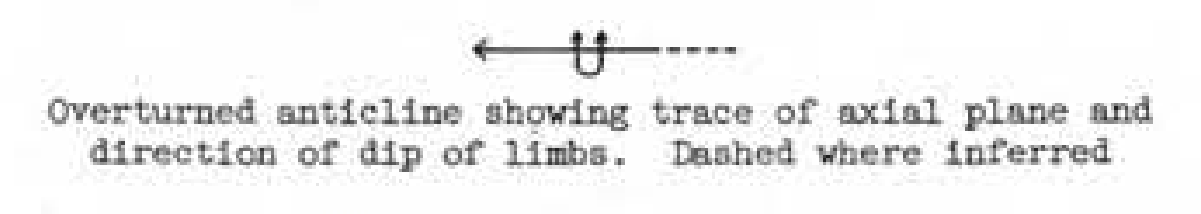

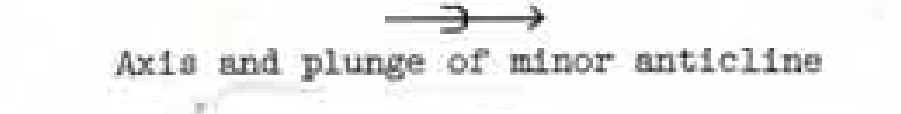

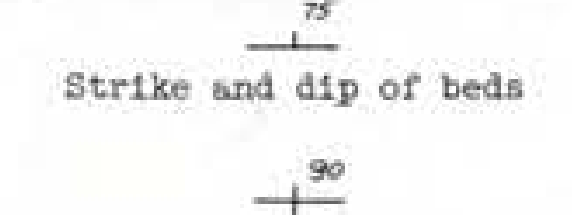
strithe of vertical bods

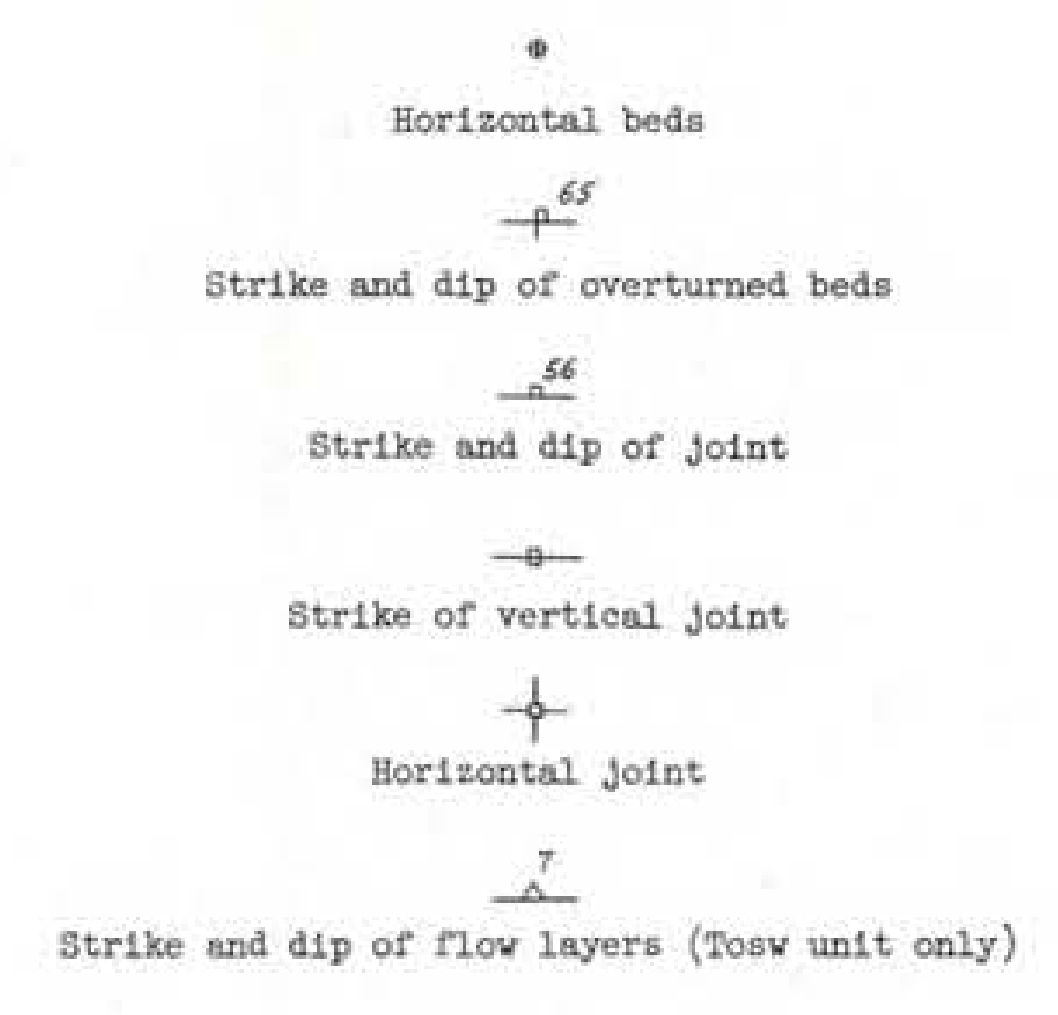
serrite and atip of clearage

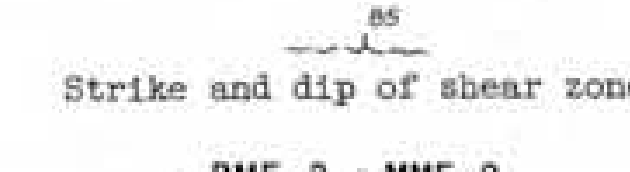

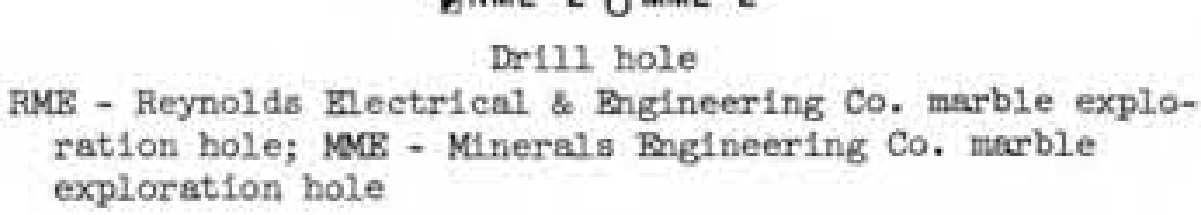
sist พxine dump

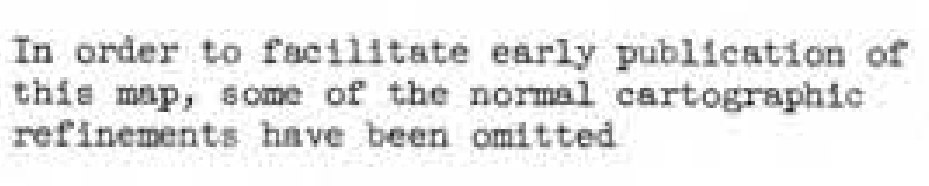

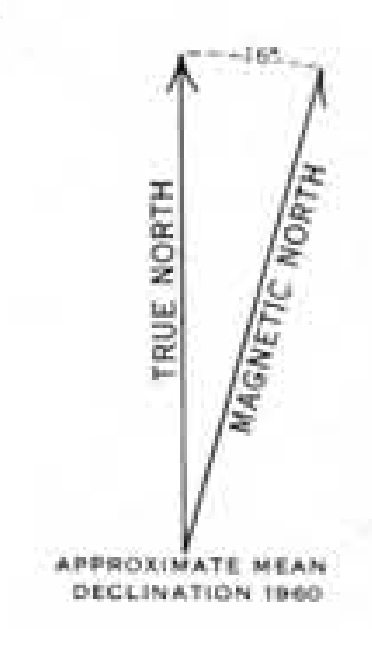




\section{Plate 2}

Barnes, H., F. N. Houser, and F. G. Poole, 1963. Geologic Map of the Oak Spring Quadrangle, Nye County, Nevada.

U.S. Geological Survey Map GQ-214 


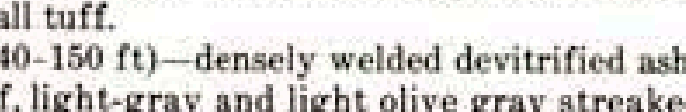

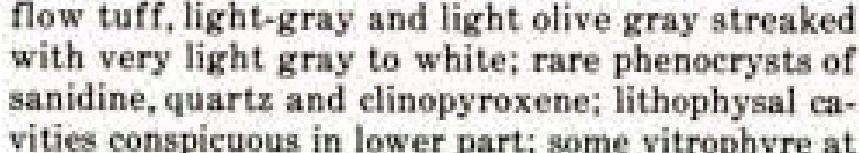

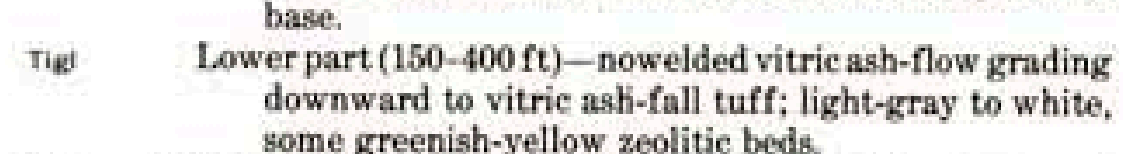

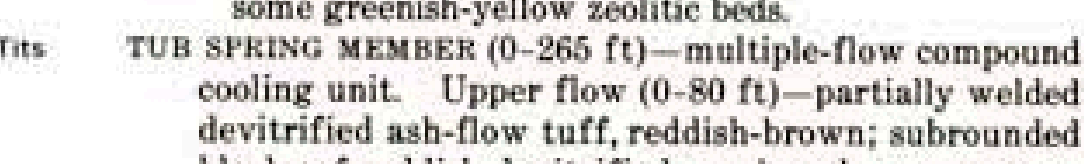

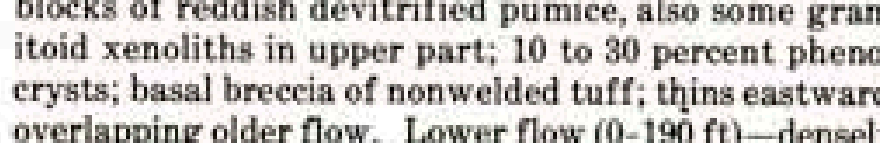

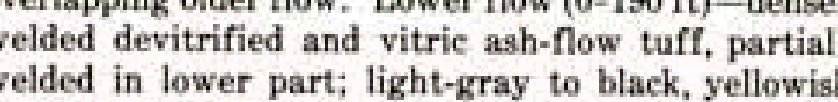

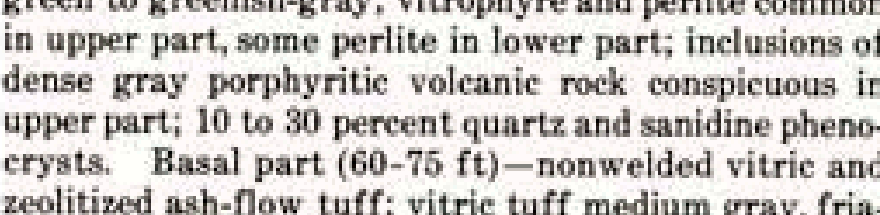

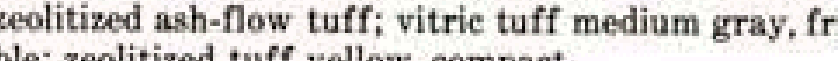

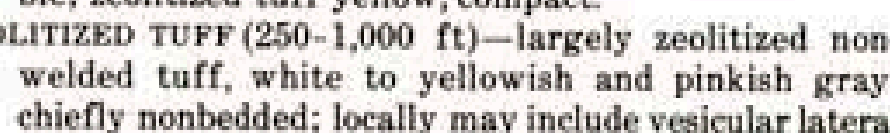

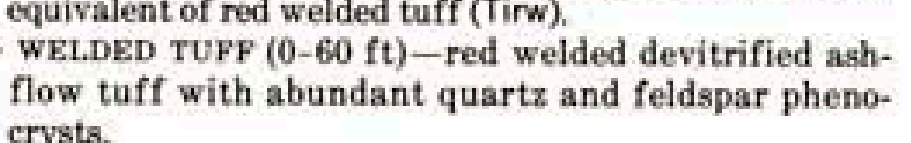

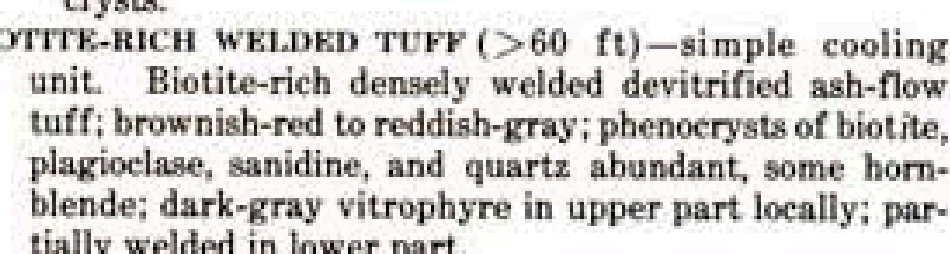

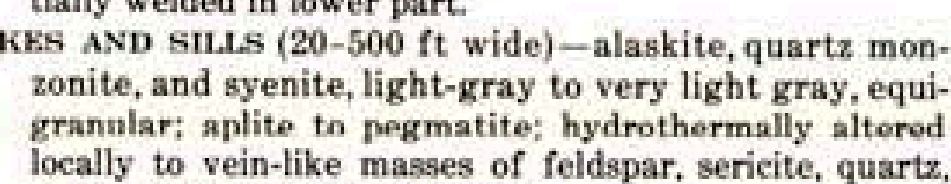

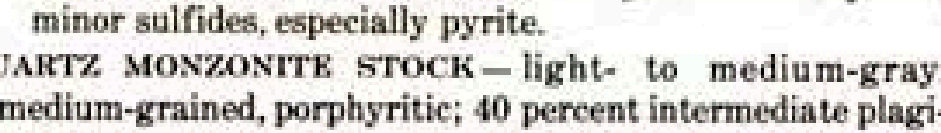

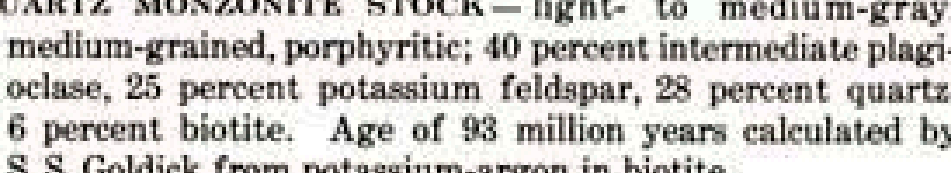

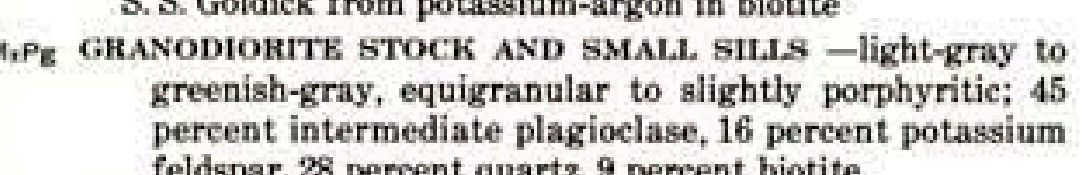

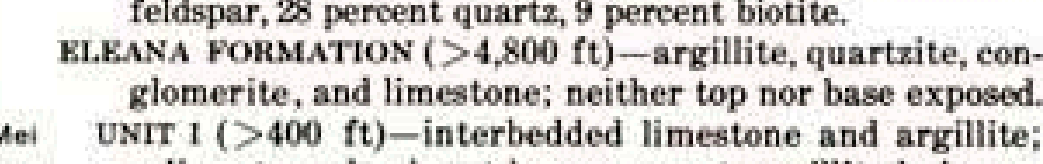

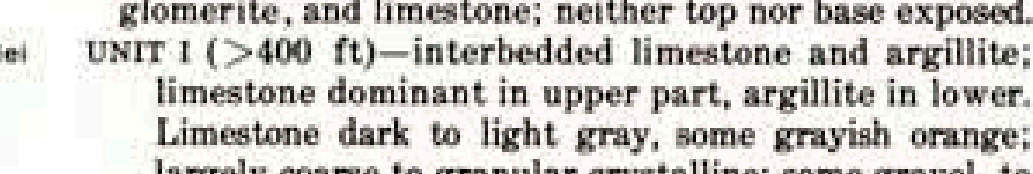

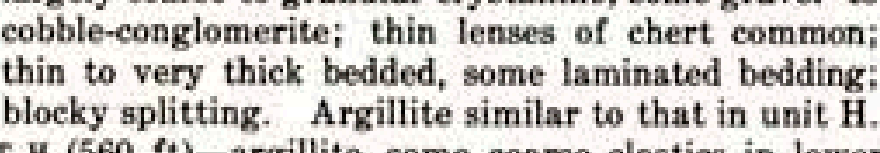

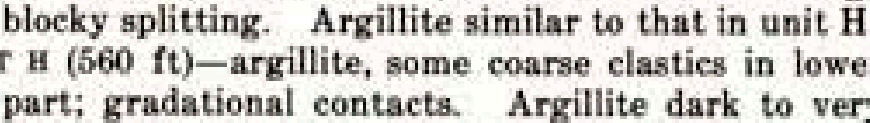

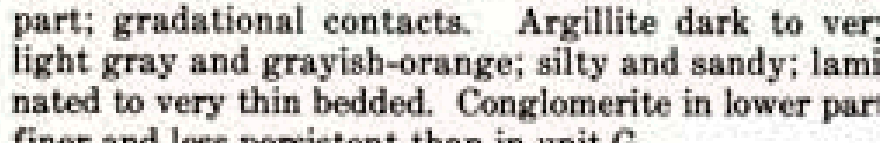

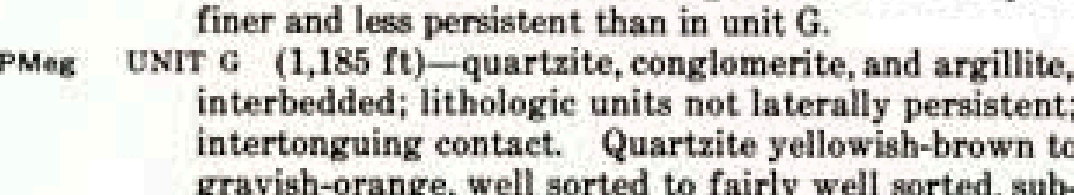

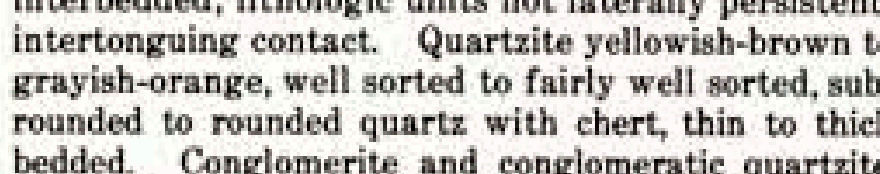

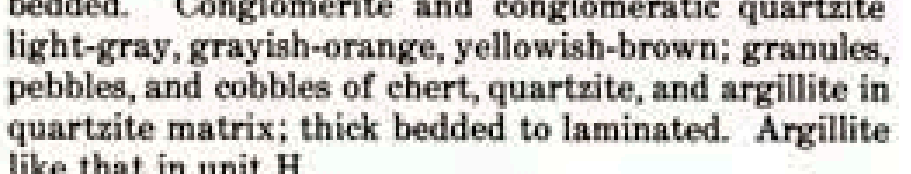

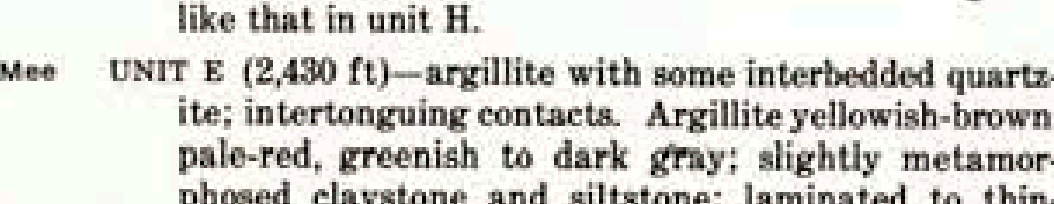

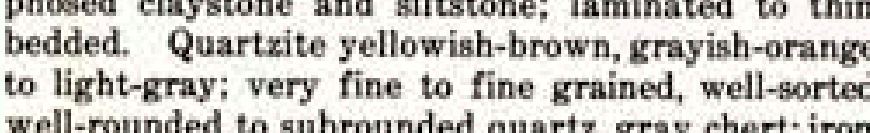

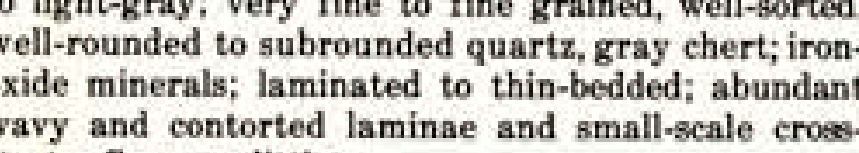

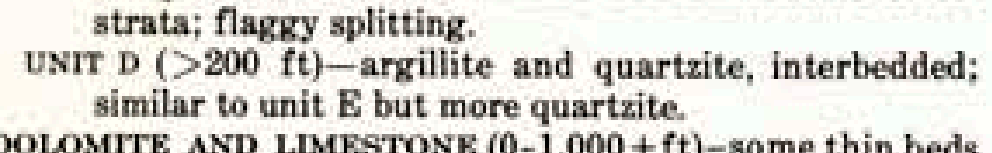

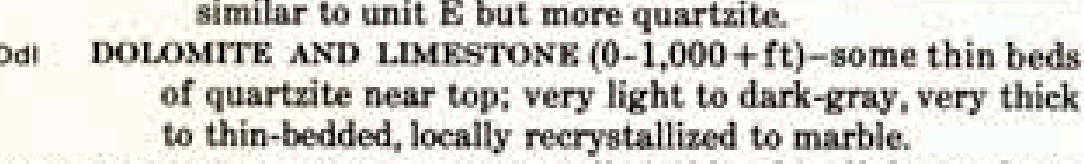

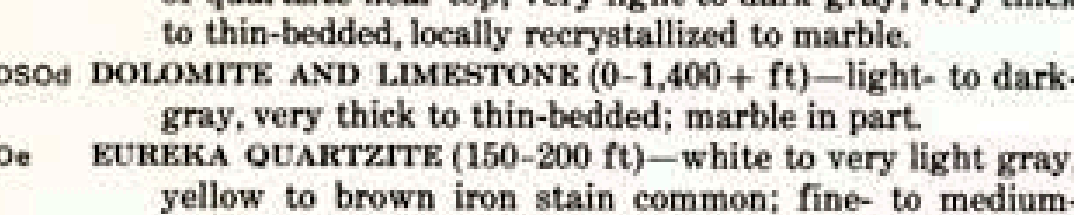

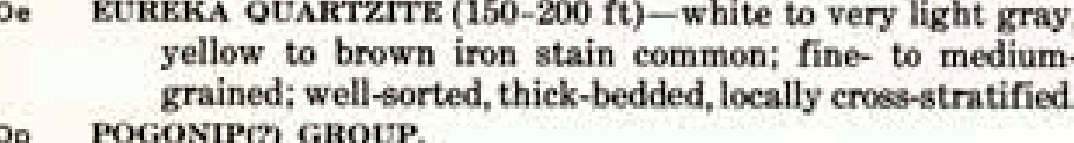

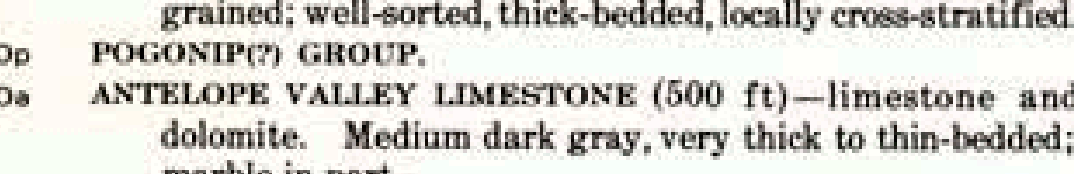

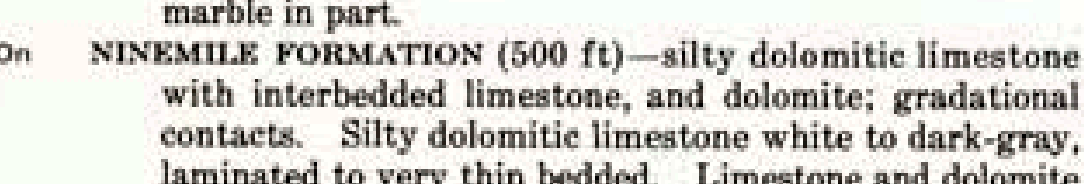

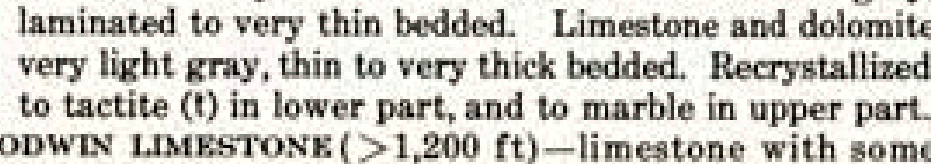

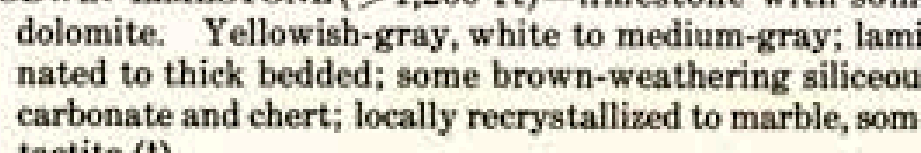

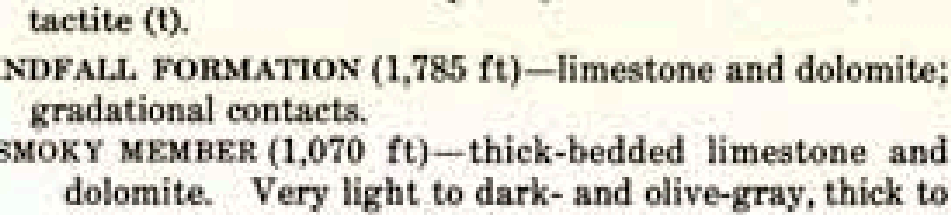

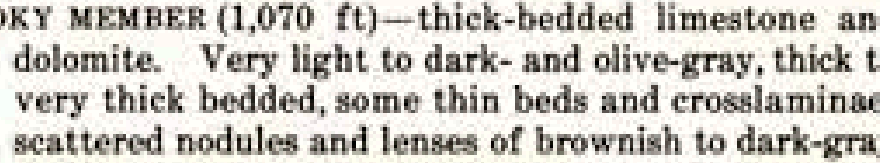

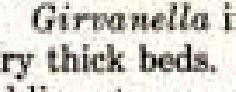

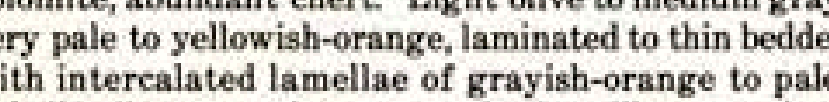

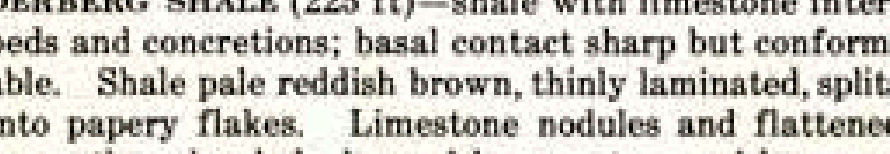

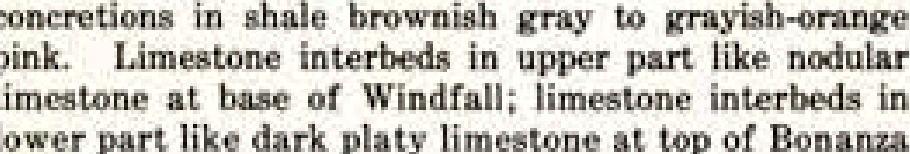

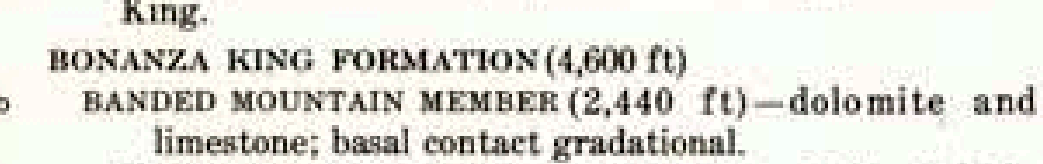

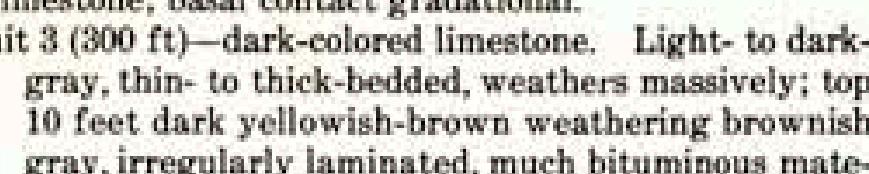

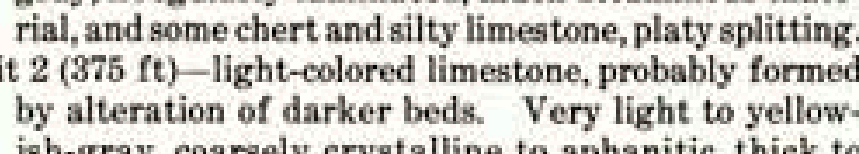

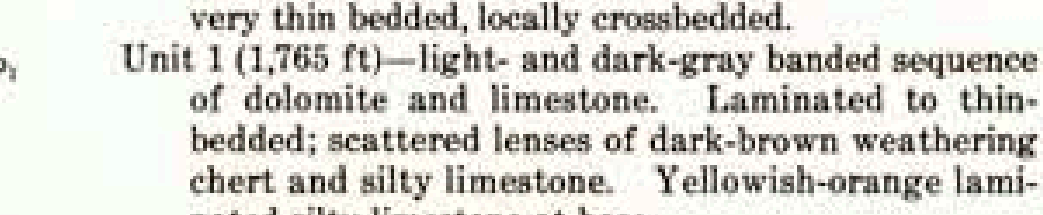

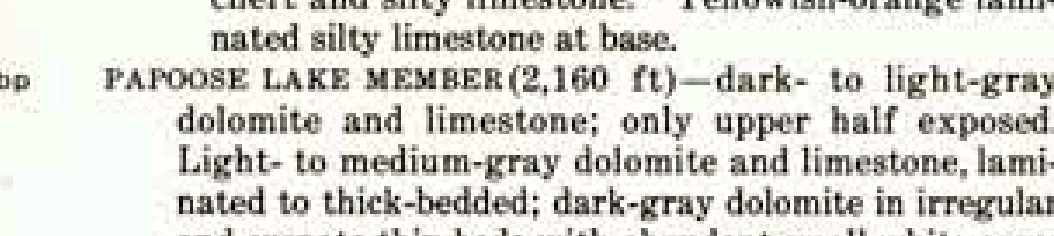

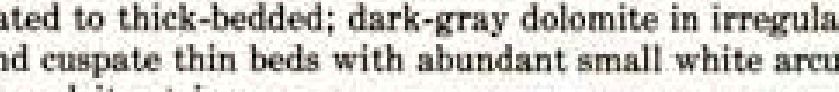

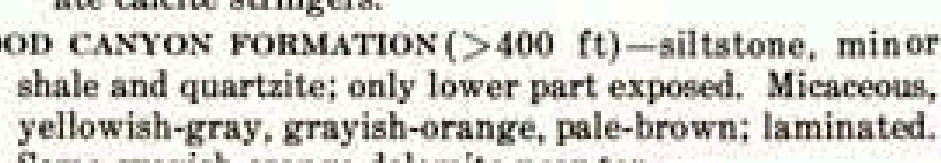

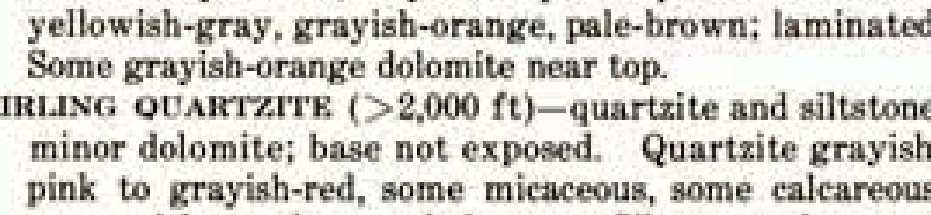
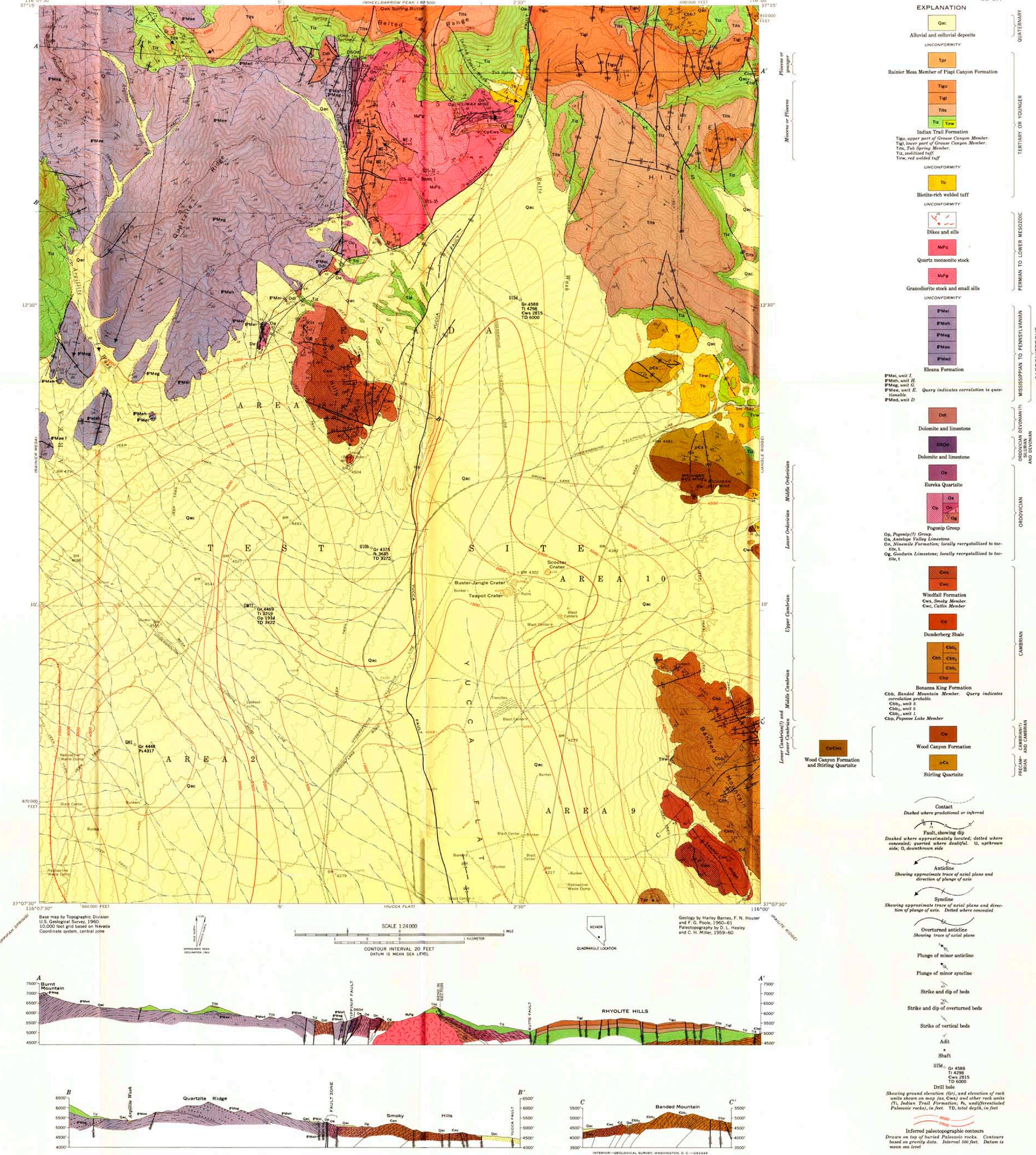